\title{
"MODELO DE DISEÑO DE LA LONGITUD DE LOS CARRILES DE DECELERACIÓN PARALELOS, BASADO EN EL DESARROLLO Y LA APLICACIÓN DE UN INDICADOR DE LA CONFLICTIVIDAD DE LAS MANIOBRAS DE SALIDA"
}

\section{TESIS DOCTORAL}

Presentada por:

MARIO ALFONSO ROMERO ROJAS

Dirigida por:

Prof. Doctor ALFREDO GARCÍA GARCÍA 

El desarrollo de este trabajo titulado "MODELO DE DISEÑO DE LA LONGITUD DE LOS CARRILES DE DECELERACIÓN PARALELOS, BASADO EN EL DESARROLLO Y LA APLICACIÓN DE UN INDICADOR DE LA CONFLICTIVIDAD DE LAS MANIOBRAS DE SALIDA" ha sido posible gracias a la colaboración de la Conselleria de Infraestructuras y Transporte de la Generalitat Valenciana, por su subvención de la fase experimental. En esta fase ha colaborado también la empresa FCC Construcción, S.A.

La Dirección General de Tráfico ha colaborado en la fase de toma de datos permitiendo hacer grabaciones de vídeo desde su Centro de Gestión de Tráfico de Valencia.

El Servicio de Estadística del Observatorio Nacional de Seguridad Vial ha suministrado la información de accidentalidad necesaria para la validación del indicador propuesto.

El autor quiere expresar su agradecimiento al profesor Doctor Alfredo García García por su colaboración en el desarrollo del trabajo.

Asimismo a D. Alfredo Cavaliere y D. Rosario Cavarra, estudiantes Erasmus de Ingeniería Civil, quienes han colaborado durante diferentes fases del trabajo de campo y del procesamiento de datos.

Finalmente, agradecer a todas aquellas personas que de una u otra forma han colaborado con la realización de este trabajo.

El autor: Mario Alfonso Romero Rojas 


\section{RESUMEN}

La presente tesis doctoral tiene como objetivo principal el desarrollo de un nuevo modelo de diseño de la longitud de carriles de deceleración, basado en la evaluación del diseño y la funcionalidad de los carriles de deceleración del tipo paralelo, en función de su longitud, mediante el desarrollo y la aplicación de un nuevo indicador de conflictividad para las maniobras de salida. Dicho objetivo ha surgido a partir del estudio del estado del arte en el que se destaca como las observaciones experimentales realizadas por diversos investigadores no se corresponden con los modelos cinemáticos de deceleración uniforme que suelen adoptarse para el cálculo de la longitud del carril de deceleración, lo que conlleva la necesidad de un nuevo modelo.

La investigación se ha basado en la hipótesis fundamental de que el comportamiento de los conductores que toman un carril de deceleración varía en función de la longitud del carril. Este cambio de comportamiento afecta tanto a la operación como a la funcionalidad de los carriles de deceleración y por consiguiente influye sobre la seguridad vial.

En el desarrollo del trabajo se distinguen dos fases. La primera consiste en una fase experimental en un carril de deceleración paralelo variando su longitud, aprovechando una obra de mejora de la autovía CV-35. En la segunda fase se lleva a cabo la validación de los resultados observando 10 carriles de deceleración adicionales. En ambas, se realizó un análisis cualitativo por observación directa en videos y un análisis cuantitativo en el que se pretendía medir las características de la evolución de los vehículos.

Para lograrlo, se desarrolló un programa informático de restitución de perspectivas cónicas a partir de videos, que permitiera hacer un seguimiento individualizado de los vehículos y conocer en cada momento su posición, velocidad y aceleración.

Con el fin de poder valorar adecuadamente las diferentes maniobras encontradas se decidió utilizar, en la evaluación cuantitativa, las Técnicas de Conflictos de Tráfico. Dichas técnicas permiten evaluar la seguridad del tráfico a partir de medidas espaciotemporales entre los vehículos y la utilización de indicadores de conflictividad. Para ello, fue necesario desarrollar y validar una nueva familia de indicadores de conflictividad aplicable a las maniobras de salida denominada TiPCLA (Tiempo Potencial de Colisión Lateral o Alcance) que ha permitido evaluar cuantitativamente la conflictividad de los carriles de deceleración del estudio.

A partir del análisis se confirma la hipótesis de trabajo y se concluye que los carriles muy largos o muy cortos son los menos seguros por lo que las longitudes intermedias son las óptimas.

Finalmente, se propone un nuevo modelo de diseño de la longitud de carriles de deceleración paralelos que tiene en cuenta, tanto, la dinámica de la maniobra de salida, como, el comportamiento de los conductores y la seguridad vial. 


\section{ABSTRACT}

This thesis has been developed with the aim of the development of a new design model of the deceleration lanes length, based on evaluation of the design and operation of the parallel deceleration lanes, depending on its length, by development and implementation of a new conflict indicator for exiting maneuvers. This aim has emerged from the study of the state of the art which stands out that Kinematic models of uniform deceleration, which are usually adopted for designing deceleration lanes, do not correspond with experimental observations carried out by various researchers.

The research was based on the fundamental assumption that the behavior of drivers who take a deceleration lane varies depending on the deceleration lane length. This behavior change affects the operation of deceleration lanes and therefore influences road safety.

The research development has two phases. The first is a experimental phase in a parallel deceleration lane changing its length. In the second phase was carried out to validate results by observing 10 additional deceleration lanes. In both, a qualitative analysis was performed by video observation and a quantitative analysis which sought to measure the characteristics of the vehicles evolution.

To achieve this, a computer software for restitution of conical perspective from videos was developed. It allows us to tracking individual vehicles at all frames and know their position, speed and acceleration rates.

In order to properly assess the various maneuvers found, it was decided to use for the quantitative evaluation, the Traffic Conflict Techniques. Such techniques allow us to assess road safety based on time-space measures between vehicles and with the use of conflict indicators. To do this, it was necessary to developed and validate a new conflict indicator applicable on exit maneuvers. Indicator called TiPCLA (Potential Time to Rear end or Lateral Collision) was developed. It has allowed a quantitative assessment of the conflict of deceleration lanes of the study.

Based on the results analysis, the working hypothesis was confirmed. It was possible to conclude that too long or too short deceleration lanes are less safer. The optimal are intermediate length.

Finally, a new design model for parallel deceleration lane length was developed. This model takes into account both the dynamics of the exit maneuver, as the drivers behavior and road safety. 


\section{RESUM}

La present tesi doctoral té com a objectiu principal el desenvolupament d'un nou model de disseny de la longitud de carrils de desacceleració, basat en l'avaluació del disseny i la funcionalitat dels carrils de desacceleració del tipus paral'lel, en funció de la seua longitud, per mitjà del desenvolupament i l'aplicació d'un nou indicador de conflictivitat per a les maniobres d'eixida. Aquest objectiu ha sorgit a partir de l'estudi de l'estat de l'art en que es destaca com les observacions experimentals realitzades per diversos investigadors no es corresponen amb els models cinematics de desacceleració uniforme que solen adoptar-se per al càlcul de la longitud del carril de desacceleració, la qual cosa comporta la necessitat d'un nou model.

La investigació s'ha basat en la hipòtesi fonamental de que el comportament dels conductors que prenen un carril de desacceleració varia en funció de la longitud del carril. Este canvi de comportament afecta tant l'operació com a la funcionalitat dels carrils de desacceleració i per consegüent influïx sobre la seguretat viària.

En el desenvolupament del treball es destingixen dos fases. La primera consistix en una fase experimental en un carril de desacceleració paral'lel variant la seua longitud, aprofitant una obra de millora de l'autovia CV-35. En la segona fase es du a terme la validació dels resultats observant 10 carrils de desacceleració addicionals. En les dues, es va realitzar una anàlisi qualitativa per observació directa en vídeos $i$ una anàlisi quantitativa en que es pretenia mesurar les característiques de l'evolució dels vehicles.

Per a aconseguir-ho, es va desenvolupar un programa informàtic de restitució de perspectives còniques a partir de vídeos, que permetrà fer un seguiment individualitzat dels vehicles i conéixer en cada moment la seua posició, velocitat i acceleració.

A fi de poder valorar adequadament les diferents maniobres trobades es va decidir utilitzar, en I'avaluació quantitativa, les Tècniques de Conflictes de Tràfic. Dites tècniques permeten avaluar la seguretat del tràfic a partir de mesures espai-temporals entre els vehicles i la utilització d'indicadors de conflictivitat. Per a això, va ser necessari desenvolupar i validar una nova família d'indicadors de conflictivitat aplicable a les maniobres d'eixida denominada TiPCLA (Temps Potencial de Col'lisió Lateral o Alcans) que ha permès avaluar quantitativament la conflictivitat dels carrils de desacceleració de l'estudi.

A partir de l'anàlisi es confirma la hipòtesi de treball i es conclou que els carrils molt llargs o molt curts són els menys segurs pel que les longituds intermèdies són les òptimes.

Finalment, es proposa un nou model de disseny de la longitud de carrils de desacceleració paral'lels que té en compte, tant la dinàmica de la maniobra d'eixida, com el comportament dels conductors i la seguretat viària. 


\section{ÍNDICE}

$\begin{array}{lll}\text { RESUMEN II } & \text { II }\end{array}$

$\begin{array}{ll}\text { ABSTRACT III } & \text { III }\end{array}$

RESUM IV IV

1 INTRODUCCIÓN 1

2 ANTECEDENTES 3

3 ESTADO DEL ARTE: INVESTIGACIONES PREVIAS 5

3.1 INVESTIGACIONES ANTERIORES 5

3.1.1 Velocidades 5

$\begin{array}{lll}3.1 .2 & \text { Trayectorias } & 10\end{array}$

$\begin{array}{lll}3.1 .3 & \text { Deceleraciones } & 21\end{array}$

$\begin{array}{lll}3.1 .4 & \text { Seguridad vial } & 36\end{array}$

3.2 MODELOS CINEMÁTICOS 49

3.2.1 Recomendaciones para el proyecto de intersecciones. 49

3.2.2 Recomendaciones para el proyecto de enlaces 50

3.2.3 Modelo de Babkov 52

3.2.4 Norma técnica CNR 52

3.2.5 Modelo AASHTO 53

3.3 MODELOS DINÁMICOS

$\begin{array}{lll}\text { 3.3.1 Modelo de Fukutome } & 67\end{array}$

3.3.2 Modelo de Rocci 69

$\begin{array}{lll}\text { 3.3.3 Modelo de Fazio y Michael } & 72\end{array}$

3.3.4 Instrucción de Trazado 3.1-IC 88

3.4 TÉCNICAS DE CONFLICTOS DE TRÁFICO 98

3.4.1 Problemas iniciales de las TCT y discusión sobre su validez 99

$\begin{array}{lll}3.4 .2 & \text { Indicadores de TCT } & 100\end{array}$

3.4.3 Selección de indicadores de conflicto aplicables en carriles de deceleración 110 
$\begin{array}{lll}\text { 3.5.1 Definición geométrica } & 111\end{array}$

3.5.2 La vista humana y los aparatos de fotografía 113

$\begin{array}{ll}\text { 3.5.3 Expresiones algebraicas } & 113\end{array}$

$\begin{array}{ll}\text { 3.5.4 Transformación inversa a la perspectiva } & 120\end{array}$

$\begin{array}{ll}3.5 .5 & \text { La homología plana } \\ & 122\end{array}$

$\begin{array}{ll}3.5 .6 & \text { Homología inversa } \\ 3.5 .7 & 127\end{array}$

$\begin{array}{lll}3.5 .7 & \text { La doble homología } & 131\end{array}$

4 OBJETIVOS DE LA INVESTIGACIÓN 133

$\begin{array}{lll}4.1 & \text { OBJETIVO PRINCIPAL } & 133\end{array}$

$\begin{array}{lll}4.2 & \text { OBJETIVOS ESPECÍFICOS } & 133\end{array}$

5 MÉTODO 135

$\begin{array}{lll}5.1 & \text { HIPÓTESIS } & 135\end{array}$

5.2 METODOLOGÍA 135

5.2.1 Diseño experimental 136

5.2.2 Ejecución experimental 136

$\begin{array}{lll}\text { 5.2.3 Toma de datos } & 136\end{array}$

$\begin{array}{lll}\text { 5.2.4 Reducción de datos } & 137\end{array}$

6 DESARROLLO 139

$\begin{array}{llr}6.1 & \text { EJECUCIÓN EXPERIMENTAL } & 139\end{array}$

$\begin{array}{lll}\text { 6.1.1 Diseño experimental } & 139\end{array}$

6.1.2 Instalación de las configuraciones fase experimental 149

$\begin{array}{ll}\text { 6.1.3 Toma de datos de campo } & 152\end{array}$

6.2 REDUCCIÓN DE DATOS 155

$\begin{array}{lll}6.2 .1 & \text { Evaluación cualitativa } & 155\end{array}$

$\begin{array}{lll}6.2 .2 & \text { Evaluación cuantitativa } & 157\end{array}$

$\begin{array}{lll}\text { 6.2.3 } & \text { Restitución de maniobras } & 158\end{array}$

6.2.4 Descripción de la aplicación de restitución de maniobras 163

$\begin{array}{lll}\text { 6.3 DISEÑO DE INDICADORES DE CONFLICTIVIDAD } & 173\end{array}$

$\begin{array}{lll}\text { 6.3.1 Tiempo máximo de reacción (TMR) } & 173\end{array}$

6.3.2 Tiempo potencial para colisión lateral o alcance (TiPCLA) 174

$\begin{array}{lll}6.3 .3 & \text { Aplicación } & 181\end{array}$ 
6.4 RESULTADOS

6.4.1 Velocidades

6.4.2 Trayectorias

6.4.3 Punto de salida

6.4.4 Aceleraciones y deceleraciones

6.4.5 Maniobras conflictivas

6.4.6 Indicadores de conflictividad

6.4.7 Accidentalidad

7.1 EVALUACIÓN CUALITATIVA

7.1.1 Punto de salida

7.1.2 Maniobras conflictivas

7.2 EVALUACIÓN CUANTITATIVA

7.2.1 Velocidad

7.2.2 Aceleraciones y deceleraciones

7.2.3 Trayectorias

7.2.4 Accidentalidad

7.2.5 Indicadores de conflictividad

8.1 LONGITUD DE LA CUÑA PARA CARRILES DE DECELERACIÓN

8.2 MODELO PARA EL CÁLCULO DE LA LONGITUD DEL CARRIL DE DECELERACIÓN 259

8.2.1 Longitud de la maniobra de cambio de carril 260

8.2.2 Longitud de la maniobra de frenado 263

8.2.3 Selección de tasas de deceleración y punto de inicio de la maniobra de cambio de carril

8.2.4 Límite mínimo para la longitud del carril de deceleración 265

8.3 LONGITUDES RESULTANTES DE LA APLICACIÓN DEL MODELO 266

$\begin{array}{lll}8.4 & \text { EVALUACIÓN DEL MODELO } & 267\end{array}$ 
9 DISCUSIÓN

9.1 APLICACIÓN DEL MODELO 273

9.2 APLICACIÓN DE LOS INDICADORES DE CONFLICTIVIDAD TIPCLA 274

9.3 APLICACIÓN DE LAS HERRAMIENTAS DESARROLLADAS EN LA INVESTIGACIÓN 274

10 APLICACIÓNES PRÁCTICAS

10.1 MODELO DE DISEÑO PROPUESTO 277

10.2 MODELOS DE EVALUACIÓN 277

10.3 INDICADORES DE CONFLICTIVIDAD DE LA FAMILIA TIPCLA 277

10.4 PROGRAMA DE RESTITUCIÓN DE MANIOBRAS 278

11 FUTURAS LINEAS DE INVESTIGACIÓN 279

12 CONCLUSIONES 281

$\begin{array}{ll}\text { REFERENCIAS } & 287\end{array}$

ANEXOS

ANEXO NO. 1. INVENTARIO DE MANIOBRAS EN LOS CARRILES DE DECELERACIÓN

ANEXO NO 2. CARACTERISTICAS DE LOS CARRILES DE DECELERACIÓN

ANEXO NO. 3. CODIGO FUENTE DE LA APLICACIÓN DESARROLLADOA

ANEXO NO. 4. DATOS DE ACCIDENTALIDAD

ANEXO NO. 5. RESULTADOS DE LA APLICACIÓN DE LOS INDICADORES TIPCLA PARA LOS CARRILES DE DECELERACIÓN ESTUDIADOS

ANEXO NO. 6. PUBLICACIONES PROPIAS Y SUS REFERENCIAS 


\section{ÍNDICE DE FIGURAS}

Figura 1: Distribución de la velocidad al inicio del carril de deceleración (Canale et al 1998).

Figura 2: Área de influencia de una vía de deceleración considerando la velocidad de los vehículos que divergen frente a los que continúan por la vía principal (Jouzy 1963) 8

Figura 3: Vía de deceleración. Sandiacre A52. (Ackroyd et al. 1975) 9

Figura 4: Trayectorias de incorporación 10

Figura 5: Porcentaje de vehículos que divergen en diferentes secciones de un carril de deceleración. Yanai, Israel. (Livneh 1988)

Figura 6: Puntos de incorporación y velocidades a lo largo de un carril de deceleración. Indiana. (Jouzy 1963)

Figura 7: Maniobras de divergencia en una vía de deceleración paralela en recta. (Canale et al. 1998).

Figura 8: Envolvente de las trayectorias. (Canale et al. 1998).

Figura 9: Maniobras de divergencia en una vía de deceleración paralela en la que la curvatura del tronco es de signo opuesto a la del ramal de salida. (Colonna et al. 1997).

Figura 10: Frecuencia acumulada de la longitud de divergencia. (Colonna et al 1997) 14

Figura 11: Frecuencia de la longitud de divergencia. (Colonna et al. 1997) 14

Figura 12: Maniobra de diversos tipos de vehículos y situaciones. (Colonna 1997) 15

Figura 13: Posición de la rueda delantera izquierda de los vehículos, respecto del borde exterior del pavimento, cuando termina la cuña. (Fukutome 1963)

Figura 14: Puntos de incorporación y velocidades a lo largo de un carril de deceleración. Indiana (1). (Jouzy 1963)

Figura 15: Puntos de incorporación y velocidades a lo largo de un carril de deceleración. Indiana (2). (Jouzy 1963)

Figura 16: Puntos de incorporación y velocidades a lo largo de un carril de deceleración. Indiana (3). (Jouzy 1963)

Figura 17: Puntos de incorporación y velocidades a lo largo de un carril de deceleración. Indiana (4). (Jouzy 1963) 20

Figura 18: Trayectoria de cambio de carril (Rioux 1977) 21

Figura 19: Variación del coeficiente de deslizamiento longitudinal y transversal. 24

$\begin{array}{ll}\text { Figura 20: Curva típica de deceleración durante el frenado } & 27\end{array}$

Figura 21: Influencia en la distancia de parada de la velocidad, humedad del $\begin{array}{ll}\text { pavimento y ABS } & 28\end{array}$ 
Figura 22: Deceleración por retención con el motor (AASHO 1954)

Figura 23: Distancia recorrida reteniendo con el motor.(AASHO 1954)

Figura 24: Deceleración al frenar.(AASHO 1954)

Figura 25: Distancia recorrida mientras se frena (AASHTO 1994)

Figura 26: Distancia recorrida mientras se frena. (AASHTO 1994)

Figura 27: Deceleración frenando y reteniendo con el motor. (Livneh 1988)

Figura 28: Evolución de la aceleración transversal a lo largo de una vía de deceleración en curva de signo opuesto a la del tronco. (Colonna et al. 1997).

Figura 29: Número de accidentes de camión en el área de divergencia, respecto a la nariz. (Janson, 1998)

Figura 30: Tasas de accidentes según el tipo de ramal de salida. (Lundy 1967)

Figura 31: Las cuatro áreas de conflicto dentro de la zona de influencia. (Janson 1998).

Figura 32: Tasas de accidentes: Carril de deceleración vs tronco de salida. (Lundy 1967)

Figura 33: Tasas de accidentes al variar el radio y el ángulo de la primera curva del ramal, y la longitud del carril de deceleración. (Lundy 1967)

Figura 34: Tasa de accidentes en función de la longitud del carril de deceleración. (Cirillo 1970).

Figura 35: relación B/C vs longitud del carril de deceleración en función de la longitud original del carril 46

Figura 36: Configuración de los cuatro tipos de salidas

Figura 37: Esquemas de los carriles de deceleración. "Recomendaciones para el Proyecto de Enlaces" (1968)

Figura 38: Carril de deceleración según Norme Tecniche CNR. 15 abril 1983. N. 9053

Figura 39: Tipos de carriles de deceleración $\quad 55$

Figura 40: Longitudes de los carriles de deceleración según los casos I, II y III. $\quad 59$

Figura 41: Ramal de salida sugerido por Fukutome (1963).

Figura 42: Comparación de la longitud de carril de deceleración Fukutome, AASHTO e Instrucción de Trazado 3.1-IC

Figura 43: Aceleraciones y deceleraciones medias en vías de cambio de velocidad. (Rocci, 1986).

Figura 44: Posición del punto $P$

Figura 45: Posición del punto Q calidad imagen 76

Figura 46: Inicio del frenado, punto $\mathrm{R}$ 78 
Figura 47 Longitud del carril de deceleración según el modelo de Fazio et al. (1990) 82

Figura 48 Comparación modelo AASHTO vs. modelo de comportamiento

Figura 49: Comparación modelo de la Instrucción de Trazado 3.1-IC vs. modelo de comportamiento

Figura 50: Carriles de deceleración, secciones características. Norma 3.1-IC "Trazado" (1999)

Figura 51: Longitud de los carriles de deceleración para algunos calores de velocidad y pendiente. Instrucción de Trazado 3.1-IC (1999)

Figura 52: Equilibrio de fuerzas en un vehículo de peso P.

Figura 53: Comparación entre el modelo AASHTO (2001) y la Instrucción de Trazado 3.1-IC (1999)

Figura 54: Comparación entre el modelo de Rocci (1988) y la Instrucción de Trazado 3.1-IC (1999)

Figura 55: Pirámide de seguridad según Hydén (1987)

Figura 56: Determinación de la severidad del conflicto

Figura 57: Tiempo de exposición a umbral bajo de TTC e Integral de TTC bajo umbral

Figura 58: Ejemplo de cálculo de PET

Figura 59: Situación que se presenta en el cálculo de DST 107

Figura 60: Representación del tiempo potencial a colisión

Figura 61: Homología

Figura 62: Perspectiva cónica

Figura 63: Otros elementos de la perspectiva cónica

Figura 64: Perspectiva cónica canónica

Figura 65: La transformación inversa a la perspectiva tiene múltiples soluciones

Figura 66: Perspectiva de un triángulo

Figura 67: Abatimiento del plano horizontal sobre el plano de cuadro

Figura 68: Abatimiento del vértice sobre el plano de cuadro

Figura 69: Perspectiva cónica reducida a transformación plana

Figura 70: Los puntos de fuga en una homología plana

Figura 71: Transformación homológica de un cuadrilátero. Paso 1

Figura 72: Transformación homológica de un cuadrilátero. Paso 2

Figura 73: Transformación homológica de un cuadrilátero. Paso 3

Figura 74: Transformación homológica de un cuadrilátero. Paso 4 
Figura 75: Ejemplo de rectángulo de referencia

Figura 76: Situación inicial $\quad 139$

Figura 77: Utilización de cinta para la señalización provisional 140

Figura 78: Carril de deceleración tipo paralelo 140

Figura 79: Fotografía configuración inicial 142

Figura 80: Línea discontinua antes de la nariz 142

Figura 81: Configuración 1 carril de deceleración de longitud máxima 143

Figura 82: Fotografía configuración $1 \quad 143$

Figura 83: Configuración 2 - carril de deceleración de longitud 285 m 144

Figura 84: Fotografía configuración 2

Figura 85: Configuración 3 - carril de deceleración de longitud 187 m 145

Figura 86: Fotografía configuración $3 \quad 145$

Figura 87: Configuración 4 - carril de deceleración de longitud 107 m 146

Figura 88: Fotografía configuración $4 \quad 146$

Figura 89: Colocación de bionda 147

Figura 90: Fotografía configuración final $\quad 147$

Figura 91: Plano de situación de los carriles de deceleración 149

Figura 92: Utilización de cinta para la señalización provisional 150

Figura 93: Colocación de la barrera de seguridad 150

Figura 94: Fresado de la señalización existente $\quad 151$

Figura 95: Línea continua antes de llegar a la nariz 151

Figura 96: Ubicación de cámaras en el pórtico 152

Figura 97: Ubicación de cámaras en el puente 153

Figura 98: Ubicación de la cámara en la nariz 154

Figura 99 Cámaras de la DGT $\quad 154$

Figura 100 Imagen de una de las cámaras de la DGT 155

Figura 101: Tipos de maniobras de salida con adelantamiento 156

Figura 102: Homologías utilizadas en el programa 159

Figura 103 Restitución Gráfica $\quad 161$

Figura 104: Homologías para cambio de pendiente de la vía 161

Figura 105: Sistema de referencia para los vídeos 162

Figura 106: Proceso de estabilización de la imágen 166 
Figura 107: Imagen de fondo

Figura 108:Resta imagen actual y fondo

Figura 109: Bordes de la Imagen

Figura 110: Líneas de referencia de zona

Figura 111: Referencias de la perspectiva cónica

Figura 112: Detectores de vehículos en la imagen

Figura 113: Seguimiento de vehículos

Figura 114: Familia de indicadores TiPCLA

Figura 115: Variación del indicador de conflictividad en el tiempo para un conflicto específica

Figura 116: TiPCLA para una Maniobra Específica

Figura 117: Variación de los Indicadores en función del umbral

Figura 118: Velocidades libres en la sección transversal del punto medio del carril de deceleración en la configuración inicial

Figura 119: Velocidad carril 1 y al abandonar la vía principal

Figura 120: Velocidad limitada, media y percentil 85 en la nariz

Figura 121: Percentil 85 de la velocidad antes de salir; en el momento de abandonar el carril y en la nariz

Figura 122: Variación del percentil 85 de la velocidad al abandonar la vía principal en función de la relación $L / L_{0}$

Figura 123: Percentiles 85 y 50 de la velocidad transversal de la maniobra de cambio de carril

Figura 124: Nube de puntos de trayectorias restituidas en cada configuración

Figura 125: Nube de puntos de trayectorias restituidas en los carriles de comprobación

Figura 126: Nube de puntos de trayectorias restituidas en los carriles de comprobación

Figura 127: Distancia de inicio de la maniobra de cambio de carril respecto al inicio de la cuña

Figura 128: Tiempo de inicio de la maniobra de cambio de carril respecto al inicio de la cuña

Figura 129: Proporción entre la longitud de la maniobra de salida y la longitud de la cuña

Figura 130: Distribución de la salida

Figura 131: Porcentaje de vehículos que aceleran en cada configuración 
Figura 132: Porcentaje de vehículos que aceleran

Figura 133: Deceleraciones en los carriles de deceleración

Figura 134: Salidas anticipadas en función de la longitud del carril

Figura 135: Porcentaje de Salidas tardías en función de la longitud del carril

Figura 136: Porcentaje de Salidas tardías en función de la intensidad del tráfico

Figura 137: Porcentaje de reincorporaciones en función de la longitud del carril

Figura 138: Porcentaje de salidas cuyo origen es uno de los carriles rápidos en función de la longitud

Figura 139: Porcentaje de salidas cuyo origen es uno de los carriles rápidos en función de la intensidad

Figura 140: Porcentaje de adelantamientos por tipo en cada configuración

Figura 141: Variación del valor medio de la integral de TiPCLA en función del valor umbral, IM_TiPCLA

Figura 142: Variación del valor medio del tiempo bajo un umbral de TiPCLA en función del valor umbral, TM_TiPCLA

Figura 143: Indicador de conflictividad para cada carril bajo un umbral de 1,5 s 201

Figura 144: Indicador de conflictividad en función de la longitud

Figura 145: Indicador de conflictividad en función del la relación $L / L_{0}$

Figura 146: Índice de accidentalidad y de peligrosidad en función de la relación $L / L_{0} 207$

Figura 147: Accidentes en función de la relación $L / L_{0}$

Figura 148: Maniobras analizadas por carril de deceleración

Figura 149: Regresión polinómica de la Relación $L / L_{0}(R L)$ y salida en la cuña

Figura 150: Regresión polinómica de la Relación $L / L_{0}(R L)$ y salida en la zona media213

Figura 151: Efecto del componente relación $L / L_{0}(R L)$ sobre el porcentaje de salida Anticipada

Figura 152: Porcentaje de Salidas tardías en función del número de carriles de la vía principal

Figura 153: Efecto del componente relación $L / L_{0}(R L)$ sobre el porcentaje de salidas desde uno de los carriles rápidos

Figura 154: Modelo ajustado de la transformación del porcentaje de origen en carril rápido y la longitud del carril de deceleración

Figura 155: Disminución de velocidad entre la vía principal y al abandonar el carril 227 Figura 156: Diferencia entre el percentil 85 de la velocidad en la nariz y el límite de velocidad en ese punto 
Figura 157: Distribución de la velocidad transversal media en las maniobras de cambio de carril

Figura 158: Efecto del componente longitud en la variación del \% de vehículos que aceleran en el carril de deceleración

Figura 159: Distribución de frecuencia de tasa de deceleración subconsciente

Figura 160: Distribución de frecuencia de tasa de deceleración

Figura 161: Efecto de la longitud en la variación del número de accidentes con víctimas para diferentes intervalos de confianza

Figura 162: Variación del número de accidentes al año por cada $100 \mathrm{M}$ de vehículos en función de $L$ y de $L_{0}$

Figura 163: Variación del coeficiente de correlación $\mathrm{R}^{2}$ en función del umbral para IM_TiPCLA

Figura 164: Variación del coeficiente de correlación $\mathrm{R}^{2}$ en función del umbral para TM_TiPCLA

Figura 165: Secciones características del carril de deceleración paralelo

Figura 166: Evaluación del Indicador IM_TiPCLA $A_{1,5}$ en función del percentil de deceleración seleccionado

Figura 167: Evaluación del índice de peligrosidad en función del percentil de deceleración seleccionado

Figura 168: Comparación de longitudes de diseño de los carriles de deceleración para $\mathrm{V}_{0}=80 \mathrm{~km} / \mathrm{h}$ (referencia ajustada)

Figura 169: Comparación de longitudes de diseño de los carriles de deceleración para $\mathrm{V}_{0}=100 \mathrm{~km} / \mathrm{h}$ (referencia ajustada)

Figura 170: Comparación de longitudes de diseño de los carriles de deceleración para $\mathrm{V}_{0}=120 \mathrm{~km} / \mathrm{h}$ (referencia ajustada)

Figura 171: Porcentaje de carriles que mejoran de acuerdo con cada criterio

Figura 172: Porcentaje de criterios que mejoran en cada carril estudiado

Figura 173: Laboratorio Móvil de Tráfico desarrollado 


\section{ÍNDICE DE TABLAS}

Tabla 1: Velocidad en la vía principal y en la de deceleración (Livneh et al 1988) ....... 6

Tabla 2: Trayectorias (De la Iglesia y García 2000) .......................................... 16

Tabla 3: Porcentaje de vehículos que divergen en distintas secciones de 3 carriles de deceleración de Israel. (Livneh et al., 1988) ...................................................18

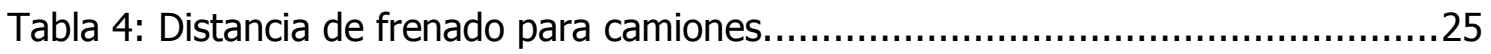

Tabla 5: Distancia de frenado con pavimento húmedo, para vehículos con o sin ABS. (NHTSA 1991).

Tabla 6: Influencia de la velocidad, el estado de los neumáticos y el espesor de la película de agua en el CRL y el CRT. (Vigueras et al. 1992) ................................. 26

Tabla 7: Deceleración considerada por la AASHTO(1954) . .................................. 27

Tabla 8: Deceleración admitida por los conductores ante un objeto inesperado. Estudio 1 NCHRP (1997) "Determination of Stopping Sight Distances" Report 400................29

Tabla 9: Deceleraciones admitidas por los conductores ante un objeto inesperado. Estudio 2. NCHRP (1997) "Determination of Stopping Sight Distances" Report 400 ....29

Tabla 10: Deceleraciones admitidas por los conductores ante un objeto esperado. Estudio 3. NCHRP (1997) "Determination of Stopping Sight Distancies" Report 400. ..30

Tabla 11: Aceleraciones en la vía de deceleración y en el ramal de salida de tres enlaces del Reino Unido. (Ackroyd, 1975)......................................................34

Tabla 12: Deceleraciones en 3 vías de deceleración de Israel. (Livneh et al., 1988). ..35

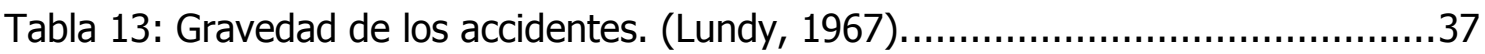

Tabla 14: Vehículos involucrados en los accidentes. (Lundy, 1967) .........................38

Tabla 15: Distribución de los accidentes según la iluminación. (Lundy 1967) .............39

Tabla 16: Tasa de accidentes nocturnos y diurnos. (Lundy 1967) ...........................39

Tabla 17: Índice de accidentes en la proximidad de los ramales de salida. (Cirillo 1967)

Tabla 18: Índice de accidentes de camión según el área de influencia de un ramal de salida (Janson 1998).

Tabla 19: Longitudes recomendadas para las vías de deceleración en intersecciones. (Rasantes suaves, $\pm 2 \% 0$ inferiores). ("Recomendaciones para el proyecto de intersecciones", 1968) 50

Tabla 20: Longitud de los carriles de deceleración según las "Recomendaciones para el Proyecto de Enlaces" (1968) ................................................................... 51

Tabla 21: Longitud de la cuña, pendiente 0\%. NORME TECNICHE CNR. Italia ...........53

Tabla 22: Longitud de los carriles de deceleración. AASHTO 2001 .........................54 
Tabla 23: Factores de ajuste en función de la pendiente

Tabla 24: Relación entre la velocidad de diseño y la velocidad media en autopistas con un volumen de tráfico bajo

Tabla 25: Velocidad media en curva. AASHTO 1954

Tabla 26: Longitud del carril de deceleración, (pies). AASHTO 1954

Tabla 27: Longitud de los carriles de deceleración. AASHTO 1954

Tabla 28: Relación entre la velocidad de diseño y la velocidad media en una autopista con volumen bajo de tráfico

Tabla 29: Longitud de los carriles de deceleración. AASHO 1965.

Tabla 30: Comparación entre la longitud que necesitan los conductores para decelerar, basado en su comportamiento real, y el valor que aconseja la AASHTO. (Livneh et al. 1988).

Tabla 31: Comparación de las longitudes del carril de deceleración propuestas por Livneh vs las de la AASHTO.

Tabla 32: Valores del carril de deceleración. Rocci (1986). .71

Tabla 33: Distancia entre la nariz y el punto en el que se inicia la divergencia, $L_{\text {det1 }}$. (Fazio et al. 1990)

Tabla 34: Longitud necesaria para incorporarse al carril de deceleración, Lsc. (Fazio et al. 1990)

Tabla 35: Longitud entre la nariz y un punto, $Q$, en el que el vehículo ya se encuentra en el carril de deceleración, $L_{\text {Det2 }}$. (Fazio et al. 1990).

Tabla 36: Longitud máxima necesaria para incorporarse a una vía de deceleración. (Fazio et al. 1990)

Tabla 37: Distancia de frenado en un ramal curvo, $L_{B C}$. (Fazio et al. 1990)..... .79

Tabla 38: Distancia de frenado en un ramal recto, $\mathrm{L}_{\mathrm{Bd}}$. (Fazio et al. 1990). .80

Tabla 39: Longitud del carril de deceleración según el modelo de Fazio et al. (1990) .81

Tabla 40: Longitudes de la cuña según la norma 3.1-IC, (1999). .89

Tabla 41: Longitud del carril de deceleración para algunos valores discretos de $\mathrm{i}, \mathrm{V}_{\text {do }} \mathrm{Y}$

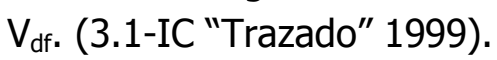
.90

Tabla 42: Longitud ( $m$ ) de la Cuña Triangular de Transición 141

Tabla 43: Longitud del Carril de Deceleración 141

Tabla 44: Carriles de deceleración seleccionados para la fase de comprobación 148

Tabla 45: Restitución de puntos 160

Tabla 46: Acciones de los vehículos en conflicto. 174

Tabla 47: Acciones del vehículo líder para el TiPCLA. 175 
Tabla 48: Accidentes reportados en los carriles estudiados 204

Tabla 49: Índices con el total de accidentes 205

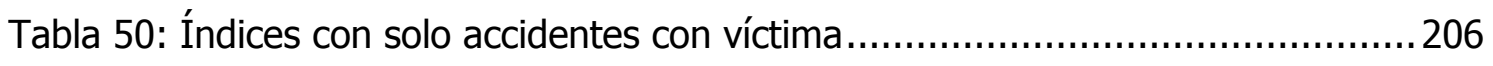

Tabla 51: Análisis de regresión entre el punto de salida y la longitud. 210

Tabla 52: Análisis varianza entre el punto de salida y la longitud del carril de deceleración 211

Tabla 53: Análisis de regresión polinomial entre el porcentaje de salidas en la cuña y la relación $L / L_{0}(R L)$.

Tabla 54: Análisis de varianza de la regresión polinomial entre el porcentaje de salidas en la cuña y la relación $L / L_{0}(R L)$.

Tabla 55: Análisis de regresión lineal múltiple para el porcentaje de salidas anticipadas 214

Tabla 56: Análisis de varianza para el porcentaje de salidas anticipadas. .214

Tabla 57: Análisis de regresión lineal entre el porcentaje de salidas tardías y las maniobras cuyo origen es uno de los carriles rápidos

Tabla 58: Análisis de varianza entre el porcentaje de salidas tardías y las maniobras cuyo origen es uno de los carriles rápidos

Tabla 59: Análisis de regresión lineal entre el porcentaje de reincorporaciones y la Longitud del carril de deceleración.

Tabla 60: Análisis de varianza entre el porcentaje de reincorporaciones y la Longitud del carril de deceleración .....

Tabla 61: Análisis de regresión lineal múltiple para el porcentaje de salidas con origen rápido 218

Tabla 62: Análisis de varianza para el porcentaje de salidas con origen rápido

Tabla 63: Análisis de regresión entre porcentaje de origen rápido transformado y Longitud del carril de deceleración

Tabla 64: Análisis de varianza de origen rápido transformado y Longitud del carril de deceleración

Tabla 65: Análisis de regresión lineal múltiple para el porcentaje de adelantamiento exterior ..... 223

Tabla 66: Análisis de varianza para el porcentaje de adelantamiento exterior ......

Tabla 67: Análisis de regresión lineal entre el porcentaje de adelantamiento exterior y la longitud del carril.

Tabla 68: Análisis de varianza de la relación entre el porcentaje de adelantamiento exterior y la longitud del carril. .224

Tabla 69: Análisis de regresión lineal entre el diferencial del percentil 85 de la velocidad en la vía principal y al abandonarla respecto a la relación $L / L_{0}(R L)$. 225 
Tabla 70: Análisis de varianza para el diferencial del percentil 85 de la velocidad en la vía principal y al abandonarla respecto a la relación $L / L_{0}(R L)$

Tabla 71: Análisis de regresión lineal para el percentil 85 del diferencial de la velocidad en la vía principal y al abandonarla en \% 226

Tabla 72: Análisis de varianza para el percentil 85 del diferencial de la velocidad en la vía principal y al abandonarla en \% 226

Tabla 73: Análisis de regresión polinómica entre la velocidad en la nariz y a relación $\mathrm{L} / \mathrm{L}_{0}(\mathrm{RL})$ 228

Tabla 74: Análisis de varianza para la relación entre la velocidad en la nariz y a relación $\mathrm{L} / \mathrm{L}_{0}(\mathrm{RL})$

Tabla 75: Análisis de regresión lineal múltiple para el porcentaje de vehículos que aceleran en el carril de deceleración 231

Tabla 76: Análisis de varianza para el porcentaje de vehículos que aceleran en el carril de deceleración.

Tabla 77: Análisis de regresión múltiple para el valor medio del número de accidentes en la zona de influencia del carril de deceleración 235

Tabla 78: Análisis de varianza para el valor medio del número de accidentes en la zona de influencia del carril de deceleración 235

Tabla 79: Análisis de regresión polinomial para el valor medio del número de accidentes con víctimas en la zona de influencia del carril de deceleración 236

Tabla 80: Análisis de varianza para el valor medio del número de accidentes con víctimas en la zona de influencia del carril de deceleración

Tabla 81: Análisis de regresión múltiple para el número medio de accidentes totales al año por cada 100 millones de vehículos en la zona de influencia del carril de deceleración

Tabla 82: Análisis de regresión múltiple para el número medio de accidentes totales al año por cada 100 millones de vehículos en la zona de influencia del carril de deceleración 239

Tabla 83: Análisis de regresión múltiple para el número medio de accidentes con víctimas al año por cada $100 \mathrm{M}$ de vehículos

Tabla 84: Análisis varianza para el número medio de accidentes con víctimas al año por cada $100 \mathrm{M}$ de vehículos.

Tabla 85: Análisis de regresión polinomial para el número medio de accidentes con víctimas al año por cada 100 millones de vehículos (simplificado).

Tabla 86: Análisis de varianza para el número medio de accidentes con víctimas al año por cada 100 millones de vehículos (simplificado) 242 
Tabla 87: Análisis de regresión múltiple para el número medio de accidentes totales al año por cada 100 millones de vehículos $\mathrm{km}$ en la zona de influencia del carril de deceleración

Tabla 88: Análisis de varianza para el número medio de accidentes totales al año por cada 100 millones de vehículos km en la zona de influencia del carril de deceleración

Tabla 89: Análisis de regresión múltiple para el índice de peligrosidad 244

Tabla 90: Análisis de varianza para el índice de peligrosidad 244

Tabla 91: Análisis de regresión polinomial para el índice de peligrosidad (simplificado) 245

Tabla 92: Análisis de varianza para el índice de peligrosidad (simplificado). 245

Tabla 93: Análisis de regresión polinómica para el índice de peligrosidad y a relación $\mathrm{L} / \mathrm{L}_{0}(\mathrm{RL})$ 246

Tabla 94: Análisis de varianza para el índice de peligrosidad y a relación $L / L_{0}(R L)$.. 246 Tabla 95: Análisis de regresión lineal múltiple para el valor medio de la integral de TiPCLA $_{1,5}$ 250

Tabla 96: Análisis de varianza para el valor medio de la integral de TiPCLA 1,5 250

Tabla 97: Análisis de regresión polinomial para IM_TiPCLA $A_{1,5}$ en función de la Longitud 251

Tabla 98: Análisis de varianza para IM_TiPCLA ${ }_{1,5}$ en función de la Longitud. 251

Tabla 99: Análisis de regresión polinomial para IM_TiPCLA $A_{1,5}$ en función de la relación $\mathrm{L} / \mathrm{L}_{0}$ 252

Tabla 100: Análisis de varianza para IM_TiPCLA $A_{1,5}$ en función de la relación $L / L_{0} \ldots . . .252$ Tabla 101: Análisis de regresión lineal múltiple para el valor medio de tiempo bajo el umbral $1,5 \mathrm{~s}$ de TiPCLA 253

Tabla 102: Análisis de varianza para el valor medio de tiempo bajo el umbral 1,5 s de TiPCLA 253

Tabla 103: Análisis de regresión polinomial para TM_TiPCLA ${ }_{1,5}$ en función de la relación $\mathrm{L} / \mathrm{L}_{0}$ 254

Tabla 104: Análisis de varianza para TM_TiPCLA $A_{1,5}$ en función de la relación $L / L_{0} \ldots . .254$

Tabla 105: Resumen de valores óptimos para los diferentes factores estudiados ..... 257

Tabla 106: Longitud de los carriles de deceleración a partir del modelo 266

Tabla 107: Longitud de los carriles de deceleración a partir del modelo 267 


\section{INTRODUCCIÓN}

Teniendo en cuenta que las observaciones experimentales realizadas por diversos investigadores no se corresponden con los modelos cinemáticos de deceleración uniforme que suelen adoptarse para el cálculo de la longitud del carril de deceleración, se planteó la realización de esta tesis doctoral, con el fin de evaluar el diseño y la funcionalidad de los carriles de deceleración del tipo paralelo, en función de su longitud, mediante el desarrollo y la aplicación de un nuevo indicador de conflictividad para las maniobras de salida

Aprovechando que la Consellería de Infraestructuras y Transporte construyó una vía de servicio exterior que permite la accesibilidad a unas instalaciones deportivas y a una estación de servicio en la autovía CV-35, en el PK 7, se ha analizado el comportamiento de los vehículos en un carril de deceleración con diferentes configuraciones. De igual manera, y con el fin de poder comparar los resultados experimentales, se ha analizado el comportamiento de los vehículos en 10 carriles de deceleración seleccionados para la etapa de comprobación.

Por otra parte, los estudios de seguridad vial se hacen, usualmente, mediante el estudio estadístico de la accidentalidad y de sus consecuencias, como pérdidas de vidas, heridos graves, daños materiales, entre otros. No obstante, este tipo de análisis no se puede aplicar a toda la red vial, pues en muchos lugares el tamaño de la muestra no es suficiente para tener validez estadística, ya sea por no contar con la información histórica necesaria, debido a la poca frecuencia de accidentes o, simplemente, porque los accidentes con solo daños materiales no quedan reflejados en las estadísticas.

Como alternativa a esta situación, se han utilizado las técnicas de conflictos de tráfico que, a partir de indicadores de proximidad al accidente basados en medidas espaciotemporales de la cercanía de los usuarios de las vías, permiten hacer una evaluación cuantitativa de la peligrosidad.

Hasta ahora, se han desarrollado diversos indicadores de conflictividad para analizar la peligrosidad asociada a maniobras de cruce. En cambio, las maniobras de seguimiento, donde no está determinada claramente la zona de conflicto, están muy poco estudiadas. Por ello, se ha diseñado un nuevo indicador de conflictividad, denominado TiPCLA (Tiempo Potencial de Colisión Lateral o Alcance), aplicable a las maniobras de seguimiento y de cambio de carril que ocurren en los carriles de deceleración.

Los resultados de la aplicación del indicador TiPCLA, fueron contrastados con los datos de accidentalidad suministrados por el Servicio de Estadística del Observatorio Nacional de Seguridad Vial, con el fin de hacer una validación y calibrar sus parámetros.

Para la evaluación de los indicadores de conflictividad se ha desarrollado una aplicación informática que, a partir de grabaciones de vídeo, permite obtener en cada momento, la posición, velocidad y aceleración adoptadas por los vehículos involucrados, gracias a la utilización de las técnicas de restitución de perspectivas cónicas. 
Se ha encontrado en la investigación, no solo que un carril de deceleración demasiado largo no elimina la afectación al flujo principal, sino que adicionalmente facilita la ejecución de maniobras peligrosas por parte de los conductores, y en carriles demasiado cortos se disminuye la frecuencia de las maniobras peligrosas dentro del carril de deceleración pero se aumenta la afección a la vía principal, planteando la necesidad de una solución de compromiso que minimice ambas situaciones.

A partir de los resultados obtenidos y teniendo en cuenta el comportamiento observado de los conductores, se propone un nuevo modelo de diseño para la longitud de los carriles de deceleración tipo paralelo.

A continuación, se presentan los antecedentes de la investigación, el estado del arte en investigaciones anteriores, la metodología empleada para la restitución de maniobras, una descripción de las características de la aplicación desarrollada, los objetivos, el diseño y la metodología experimental, el diseño del indicador de conflictividad, los resultados experimentales, su análisis, el nuevo modelo de diseño, las conclusiones y su correspondiente discusión, así como las posibles líneas de investigación derivadas de esta tesis. 


\section{ANTECEDENTES}

En el Departamento de Ingeniería e Infraestructura de los Transportes, Grupo de Investigación en Ingeniería de Carreteras, se realizó la investigación "Estudio del Diseño y Funcionalidad de las Vías de Deceleración", durante los años 1997 a 1999, que fue presentada en junio de 1999 como ejercicio final de carrera por la alumna Dña. Ana María de la Iglesia Montoliu, y tutorado por el Prof. Alfredo García García, en donde se encontró, entre otras conclusiones, que es necesario analizar en mayor profundidad el comportamiento del conductor en las vías de deceleración, ya que los modelos cinemáticos de deceleración uniforme que se suelen adoptar no se ajustaban a las observaciones experimentales que se realizaron. De este Estudio se presentó una ponencia en el IV Congreso de Ingeniería del Transporte en 2000.

En junio de 2003, la Autovía Valencia-Lliria CV-35, en el P.K. 7, contaba con un carril de trenzado de unos $580 \mathrm{~m}$ de longitud que servía como incorporación para los vehículos provenientes de unas instalaciones deportivas y de una estación de servicio, y como salida de la autovía hacia el barrio de La Coma y Campolivar.

La Conselleria de Infraestructuras y Transporte construyó una vía de servicio exterior que permite la accesibilidad indirecta de las instalaciones mencionadas, por lo cual fue cerrado el acceso a la autovía en este punto, convirtiendo el carril de trenzado en un carril de deceleración paralelo.

Al cerrar dicha incorporación, la longitud del carril de deceleración se debía acomodar de acuerdo con la normativa existente (Instrucción de Trazado de Carreteras, 3.1-IC), situación que se aprovechó para realizar un estudio experimental, pues era un escenario idóneo y único que permitió, durante el año 2004, hacer experimentos con diferentes longitudes del carril de deceleración, sin variar ninguno de los demás condicionantes del tráfico.

Posteriormente, como parte del convenio de colaboración suscrito entre la Conselleria de Infraestructuras y Transporte de la Generalitat Valenciana y la Universidad Politécnica de Valencia, en el año 2007, se realizó el estudio de la influencia de la capacidad y comportamiento de los conductores en el diseño de carriles de deceleración, en el que se evidenciaba la necesidad de un nuevo modelo de diseño para la longitud de carriles de deceleración paralelos. 


\section{ESTADO DEL ARTE: INVESTIGACIONES PREVIAS}

A continuación se recogen las principales conclusiones de investigaciones anteriores respecto a: los carriles de deceleración en donde se tiene en cuenta las trayectorias, velocidades, deceleraciones, seguridad vial y los modelos más representativos para su diseño; las técnicas de análisis de conflictos de tráfico; y la restitución de perspectivas cónicas. Todo ello sirve como base fundamental para la ejecución de la presente investigación.

\subsection{INVESTIGACIONES ANTERIORES}

A continuación se recogen las principales conclusiones de investigaciones anteriores respecto a los carriles de deceleración, en referencia a las velocidades de los vehículos, las trayectorias que describen, la deceleración y la seguridad vial.

\subsubsection{Velocidades}

La velocidad de los vehículos que circulan por el carril de deceleración está determinada por la combinación de varios factores:

- La velocidad de los vehículos en la vía principal, que influye en la velocidad con que se entra en el carril de deceleración.

- La longitud de carril de deceleración.

- La curva del ramal, que determina la velocidad a la que deben llegar.

- La pendiente longitudinal, tanto del carril de deceleración como del ramal.

- El volumen de tráfico.

- La composición del tráfico, debido a que los vehículos pesados ralentizan la circulación.

- Las condiciones de visibilidad.

- La señalización, ya que una señalización incorrecta puede provocar deceleraciones indeseables en el tronco y en el ramal.

A continuación se presentan los resultados de las investigaciones relacionadas con la velocidad de los vehículos en diferentes puntos de los carriles de deceleración.

\subsubsection{Velocidad al inicio del carril de deceleración}

La velocidad de los vehículos al inicio del carril de deceleración es siempre menor a la del resto de vehículos de la vía principal, lo que indica que deceleran en el tronco y con esta deceleración se interfiere en el tráfico del mismo. De la Iglesia y García (2000), encontraron que los vehículos que continuaban por la vía principal, circulaban a una velocidad un $14 \%$ superior a los que divergían. 
La Tabla 1 resume los resultados del estudio realizado por Livneh et al (1988) en tres vías de deceleración de Israel, respecto al volumen y velocidad medios. Se puede observar que la velocidad de los vehículos que van a incorporarse al carril de deceleración es inferior a la velocidad de los vehículos en la vía principal (Ver Figura 14 y Figura 15.)

Tabla 1: Velocidad en la vía principal y en la de deceleración (Livneh et al 1988)

\begin{tabular}{|c|c|c|c|c|c|c|c|c|c|c|c|}
\hline \multirow{3}{*}{ LUGAR } & \multirow{3}{*}{ TIPO } & \multirow{3}{*}{$\begin{array}{c}L \\
(\mathbf{m})\end{array}$} & \multicolumn{3}{|c|}{ VIA PRINCIPAL } & \multicolumn{6}{|c|}{ VÍA DE DECELERACIÓN } \\
\hline & & & \multicolumn{2}{|c|}{$\begin{array}{l}\text { Volumen } \\
\text { (veh./h) }\end{array}$} & \multirow{2}{*}{$\begin{array}{c}\begin{array}{c}\text { Velocidad } \\
(\mathbf{k m} / \mathbf{h})\end{array} \\
\mathrm{TV}\end{array}$} & \multicolumn{2}{|c|}{$\begin{array}{l}\text { Volumen } \\
\text { (veh./h) }\end{array}$} & \multicolumn{2}{|c|}{$\begin{array}{c}\text { Velocidad } \\
\text { inicial } \\
(\mathbf{k m} / \mathbf{h})\end{array}$} & \multicolumn{2}{|c|}{$\begin{array}{c}\text { Velocidad } \\
\text { final } \\
(\mathbf{k m} / \mathbf{h})\end{array}$} \\
\hline & & & C & VP & & C & VP & C & VP & C & VP \\
\hline Netania & Directo & 240 & 246 & 106 & 84.4 & 193 & 29 & 79.3 & 79.0 & 44.5 & 42.2 \\
\hline Yanai & Paralelo & 100 & 418 & 119 & 76.9 & 11 & 7 & 58.4 & 42.7 & 20.2 & 15.7 \\
\hline Gan-Shmuel & Directo & 175 & 396 & 78 & 59.8 & 20 & 12 & 56.1 & 51.3 & 29.0 & 28.7 \\
\hline
\end{tabular}

$\mathrm{C}=$ Coches; $\mathrm{VP}=$ Vehículos pesados; TV = Todos los vehículos

De igual manera, se puede observar en la Figura 16 y en la Figura 17 esta diferencia de velocidad encontrada por Jouzy et al (1963) en los Estados Unidos.

En el estudio realizado por Canale (1998), en una vía de deceleración paralela, también se aprecia que la velocidad de los vehículos al inicio de la vía de deceleración es menor a la velocidad de los vehículos del tronco, ya que la velocidad de proyecto de la autopista, por ser de tipo II (según la clasificación Italiana de las carreteras), se encontraba entre 90 y $120 \mathrm{~km} / \mathrm{h}$, pero el $75 \%$ de los vehículos divergían con una velocidad entre $80 \mathrm{~km} / \mathrm{h}$ y $110 \mathrm{~km} / \mathrm{h}$ y el valor medio estaba próximo a los $90 \mathrm{~km} / \mathrm{h}$, como se aprecia en la Figura 1. 


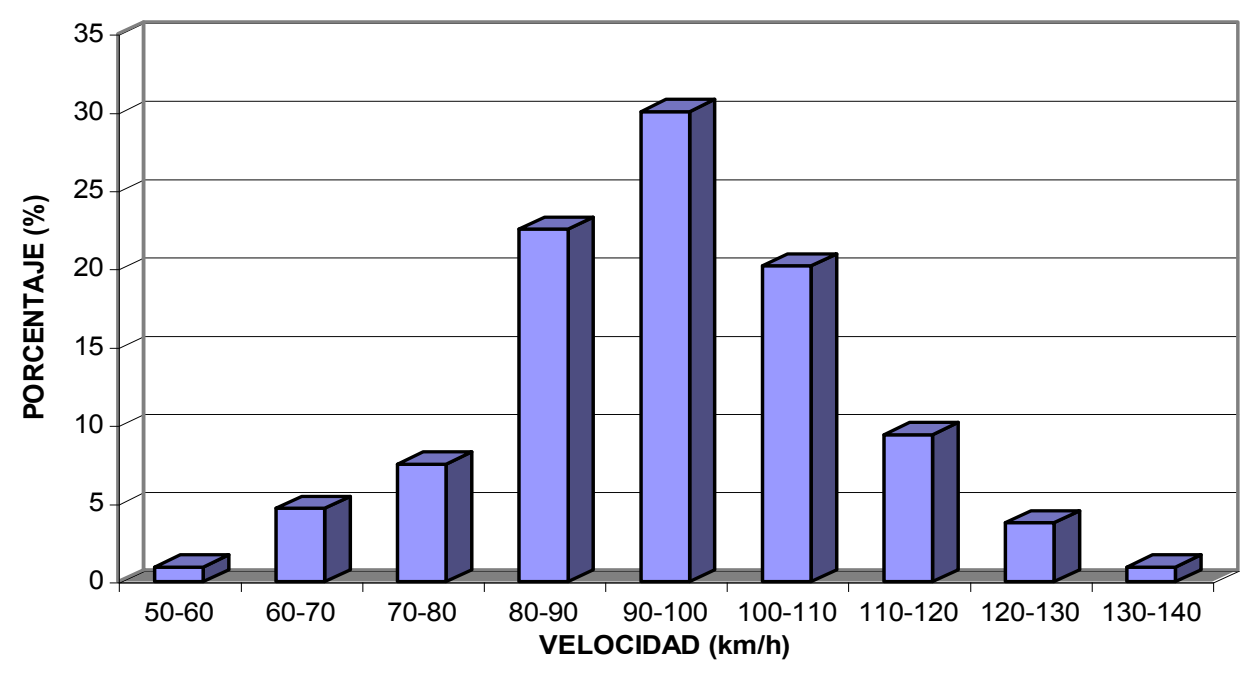

Figura 1: Distribución de la velocidad al inicio del carril de deceleración (Canale et al 1998).

Algunos investigadores afirman que los conductores que divergen, generalmente, deceleran hasta lograr una velocidad de alrededor de $50 \mathrm{mph}(80 \mathrm{~km} / \mathrm{h})$ antes de abandonar la autopista. Tal afirmación fue hecha por primera vez por Miller (1951), cuando esta velocidad era ligeramente inferior a la de la vía principal y no implicaba que hubiera grandes deceleraciones en el tronco.

Posteriormente, Fukutome y Moskowitz (1963) llegaron a una afirmación similar, pero entonces las velocidades en la vía principal habían aumentado. Ningún otro investigador ha llegado a esta conclusión ya que, por ejemplo, la velocidad en las vías principales que analizó Livneh (1988) era igual o inferior a $80 \mathrm{~km} / \mathrm{h}$, y si se examinan todos los carriles de deceleración que estudió Jouzy (1963) se observa que en algunos casos se diverge a $60 \mathrm{mph}(96 \mathrm{~km} / \mathrm{h})$.

La prueba más rotunda de que tal afirmación no es cierta se encuentra en los resultados del estudio de Canale (1998), ya que como se observa en la Figura 1 los vehículos divergen con velocidades superiores a $80 \mathrm{~km} / \mathrm{h}$.

Teniendo en cuenta lo anterior, se debería profundizar en este tema e intentar encontrar una relación entre la velocidad a la que circulan los vehículos en la vía principal, la velocidad con la que divergen y la longitud del carril de deceleración, porque las deceleraciones bruscas en la vía principal resultan peligrosas y si se prevé que se van a producir se deben intentar evitar o reducir al máximo con medidas tales como señalización o modificación de la geometría. 


\subsubsection{Zona de influencia de la disminución de la velocidad en el flujo principal}

Como los vehículos que van a divergir frenan en la vía principal e interfieren en el resto de vehículos, se ha querido determinar el punto del tronco en que empiezan a frenar.

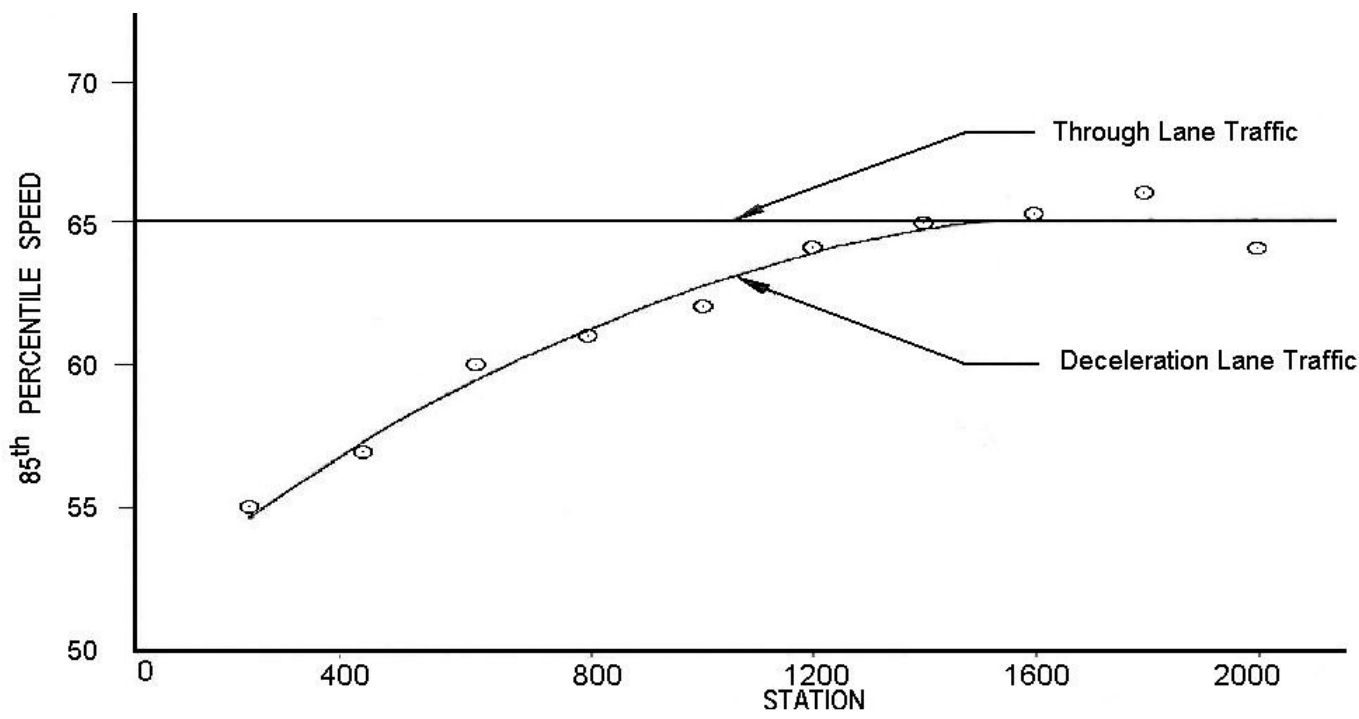

Figura 2: Área de influencia de una vía de deceleración considerando la velocidad de los vehículos que divergen frente a los que continúan por la vía principal (Jouzy 1963)

Los estudios que se han hecho (Jouzy et al.1963) apuntan a que el área de influencia se extiende 480 m corriente arriba de la nariz, (Figura 2), pero en este estudio no se ha tenido en cuenta la influencia de la longitud del carril sobre este fenómeno.

\subsubsection{Velocidad de los vehículos ligeros vs. vehículos pesados}

A lo largo de toda la vía de deceleración, la velocidad de los vehículos pesados es inferior a la de los ligeros, como se observa en la Figura 3 (Ackroyd et al. 1975 en el análisis que hicieron de las velocidades de los vehículos en los enlaces en diamante rurales de Gran Bretaña). 


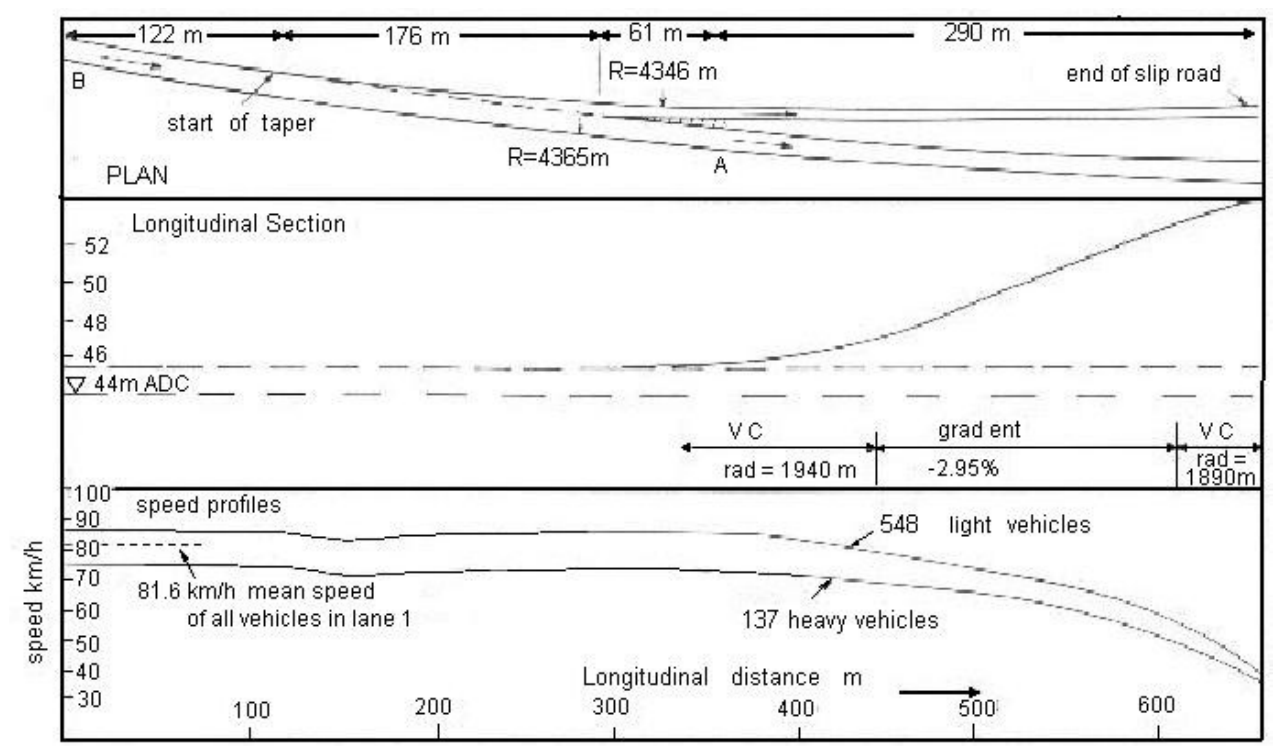

Figura 3: Vía de deceleración. Sandiacre A52. (Ackroyd et al. 1975)

\subsubsection{Velocidad a lo largo del carril de deceleración}

Fukutome et al. (1963) consideran que existe una velocidad máxima psicológica que no es rebasada, aunque las características de la vía de deceleración lo permitan, que se cifra en $46 \mathrm{mph}$ (74 km/h). Si bien esta idea puede ser acertada y existe una velocidad psicológica que no rebasan los conductores cuando se encuentran en una vía de deceleración, las investigaciones de Jouzy (1963), llevadas a cabo 2 años después también en los Estados Unidos y en carriles directos muestran velocidades de $70 \mathrm{mph}$ $(112 \mathrm{~km} / \mathrm{h})$ en carriles de deceleración. Por tanto es evidente que si se quiere conocer la velocidad máxima se deben realizar nuevas investigaciones y tener en consideración factores como la velocidad inicial y la longitud del carril, sin olvidar que el hecho en sí de que en una vía de deceleración se acelere hasta una velocidad máxima es una señal inequívoca de un mal diseño.

En las vías de deceleración con una longitud excesiva, los vehículos inicialmente no deceleran, llegando en algunos casos a acelerar y rebasar al vehículo que les precedía en la calzada principal, con el riesgo importante de colisión si este último decide también salir, pero en una posición más avanzada del carril de deceleración. Este comportamiento está muy documentado, como se observa en la Figura 14 (Jouzy et al.1963) y en la Figura 3 (Ackroyd et al. 1975) y Fukutome et al. (1963).

\subsubsection{Velocidad en la nariz}

La observación hecha por Jouzy (1963) de que muchos vehículos no obedecían la señalización que regulaba la velocidad y alcanzan el ramal de salida con una velocidad mayor a la indicada (en la Figura 17 en la nariz hay una señal que indica que la velocidad de salida es $40 \mathrm{mph}$ y el $15 \%$ de los conductores llegan con una velocidad superior a $54 \mathrm{mph}$ ) plantea que gran parte de la deceleración tiene lugar en el ramal de salida lo que puede ser la causa de que parte de los accidentes tengan lugar en este tramo. 


\subsubsection{Trayectorias}

De acuerdo con la AASHTO (1965) los conductores cuando tienen libertad para elegir la trayectoria con que se desplazan al carril de deceleración prefieren una trayectoria directa a una inversa aunque el carril sea de tipo paralelo. En un estudio realizado por Miller (1951) se había observado esta tendencia en un carril de deceleración tipo paralelo, de $360 \mathrm{~m}$. En él se analizaron las trayectorias que seguían los conductores, como se muestra en la Figura 4, observando que el $45 \%$ utilizaban una trayectoria directa, el $30 \%$ empleaban el carril tal y como había sido diseñado y realizaban una curva inversa y el $25 \%$ tardaban en salirse. Sin embargo, también se observó, al aumentar el tráfico en algunas autopistas, que con volúmenes de tráfico elevados hay una tendencia de más conductores a emplear una longitud mayor del carril tipo paralelo y a realizar una curva inversa. Por otra parte, en investigaciones recientes, De la Iglesia y García (2000), se encontró, por el contrario, que cuando los conductores tienen libertad para elegir la trayectoria de incorporación a una vía de deceleración se incorporan preferentemente con una curva y contra curva suave.

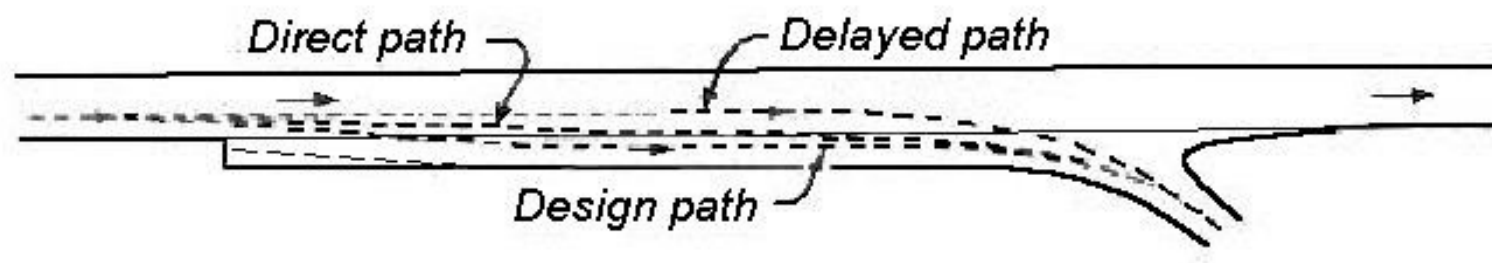

Figura 4: Trayectorias de incorporación

De acuerdo con Koepke F.J. (1993), investigaciones realizadas en la década de los 60 indican que casi todos los vehículos que salen (el 95\%) tienden a incorporarse con una trayectoria directa al carril de deceleración aunque sea de tipo paralelo y que los vehículos circulan por el carril principal y no terminan de abandonarlo hasta que se encuentran entre 15 y $60 \mathrm{~m}$ de la nariz del carril de deceleración.

Un estudio más reciente es el realizado en los ochenta por Livneh (1988). En él, entre otras cosas, se analizaba el punto en el que los vehículos divergían de la vía principal y se incorporaban al carril de deceleración. A continuación se comparan estos resultados con investigaciones anteriores para estudiar si se han producido cambios en el comportamiento de los conductores.

Si se comparan los porcentajes de los vehículos que divergen a lo largo de un carril de deceleración paralelo de 100 m, en Yanai, Israel, (Livneh et al. 1988), Figura 5, con lo los que se obtuvieron por Jouzy et al. (1963) en carriles que, aunque no se ajustan al tipo paralelo, son similares (cuña y un tramo casi paralelo de ancho $3,6 \mathrm{~m}$ o superior) y con una longitud disponible para la deceleración de $111 \mathrm{~m}$, se observa, en la Figura 6, que en el primer tramo el $83,64 \%$ de los vehículos divergen en la cuña, que se puede interpretar como que un porcentaje alto se incorpora con una curva inversa, es decir utilizan el carril tal y como fue diseñado aprovechando al máximo su longitud. Por contra, al analizar los puntos y porcentajes con los que los vehículos del segundo carril divergen, se observa que, como otros estudios afirman, los conductores no aprovechan toda la longitud del carril. Teniendo en cuenta las secciones en las que divergen la 
mayoría de los vehículos, cercanas a la cuña, se podría interpretar que los conductores utilizan mayoritariamente una trayectoria directa, (Jouzy 1963) concluye que los conductores prefieren una trayectoria directa pero en ninguno de los carriles que analiza indica las trayectorias que han seguido los vehículos).

Tras esta comparación se observa que ha aumentado el número de conductores que se incorporan a una vía de deceleración paralela con una maniobra de curva y contra curva, pero no se puede afirmar que sea la tendencia mayoritaria ya que la longitud del carril de deceleración, $100 \mathrm{~m}$ incluida la cuña, es $20 \mathrm{~m}$ menor que la recomendada por la AASHTO (1984) y una longitud tan corta puede inducir al conductor a divergir antes.

Tampoco se puede afirmar que el comportamiento de los conductores ha cambiado rotundamente porque el carril de Yanai se ha comparado con otro que en realidad no es paralelo, tiene una longitud mayor, $111 \mathrm{~m}$ disponibles para la deceleración frente a los 100 totales de Yanai y las velocidades iniciales y finales son diferentes.

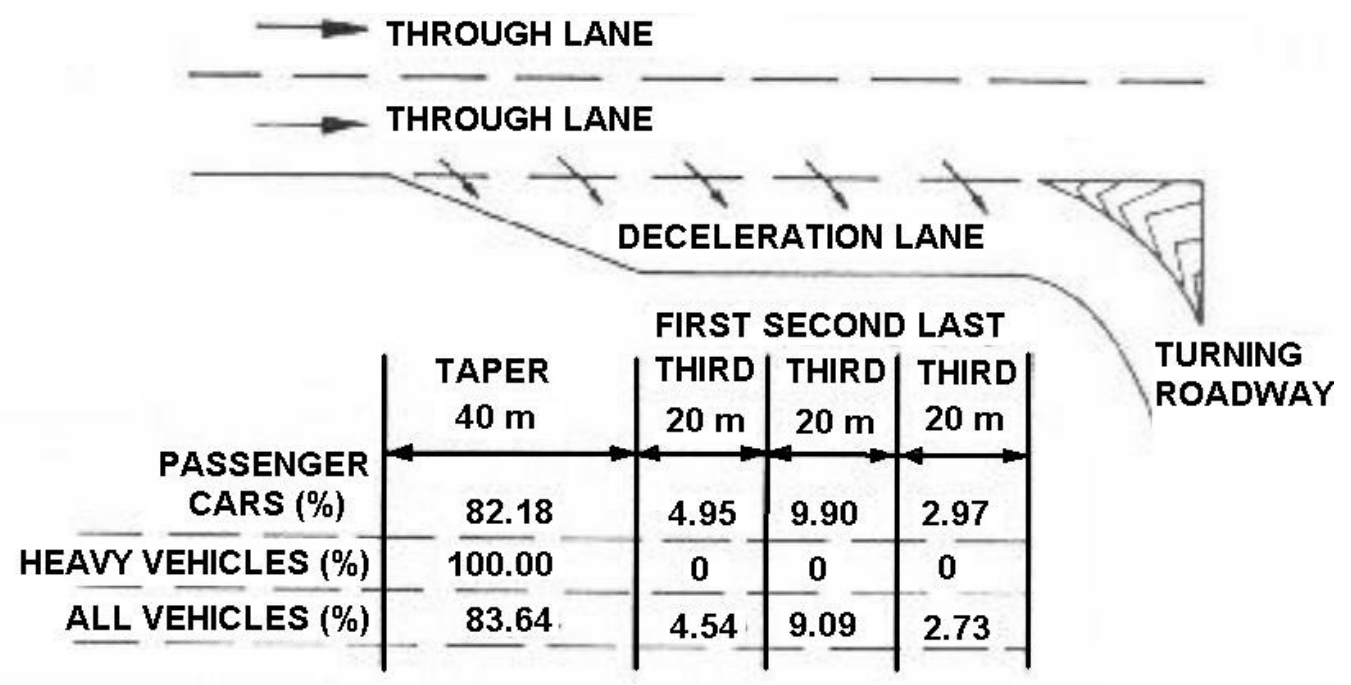

Figura 5: Porcentaje de vehículos que divergen en diferentes secciones de un carril de deceleración. Yanai, Israel. (Livneh 1988) 


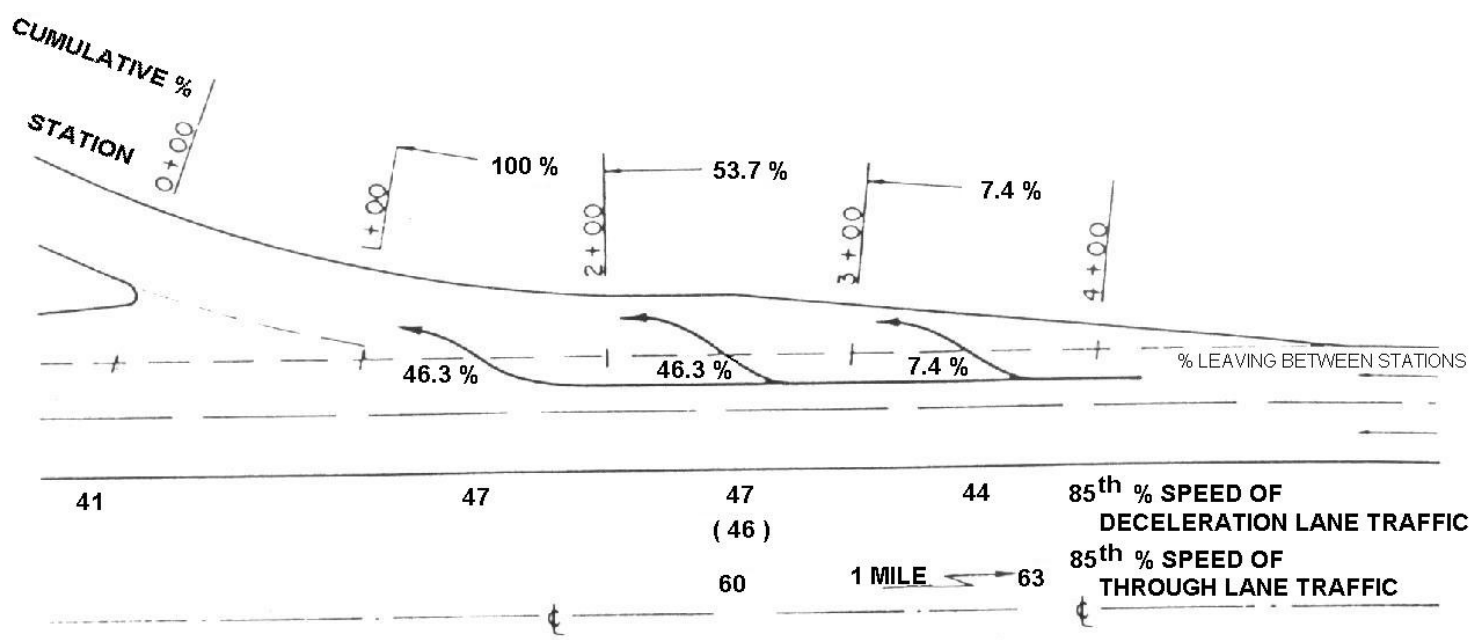

Las estaciones están cada 100 pies; 1 pie $=0,3048 \mathrm{~m} ; 1 \mathrm{mph}=1,6093 \mathrm{~km} / \mathrm{h}$

Figura 6: Puntos de incorporación y velocidades a lo largo de un carril de deceleración. Indiana. (Jouzy 1963)

Para poder extraer conclusiones fiables es necesario disponer de datos de vías de deceleración representativas de las diferentes geometrías, pero son escasos. Probablemente esta escasez se deba a que en EEUU se admite desde hace más de 40 años que los carriles tipo directo se adaptan mejor al comportamiento del conductor y no analizan otras posibilidades, quedando limitada la investigación a la realizada en otros países como Israel, Gran Bretaña, España e Italia ,donde cabe destacar los estudios realizados en los últimos años por distintos investigadores a raíz de la publicación de su normativa de trazado: C.N.R. "Norme sulle caratteristiche geometriche e di traffico delle intersizioni stradali urbane" Bollettino Ufficiale N.901983, (B.U. 90/83).

En investigaciones realizadas en Italia, en las que se han analizado las vías de deceleración paralelas, en recta, (Canale et al. 1998) y en curva (Colonna et al. 1997). Del análisis de resultados obtenidos por Canale (1998), se observa que para afrontar la salida del tronco en una vía de deceleración paralela que se encuentra en recta los conductores emplean una de las maniobras que se muestran en la Figura 7.

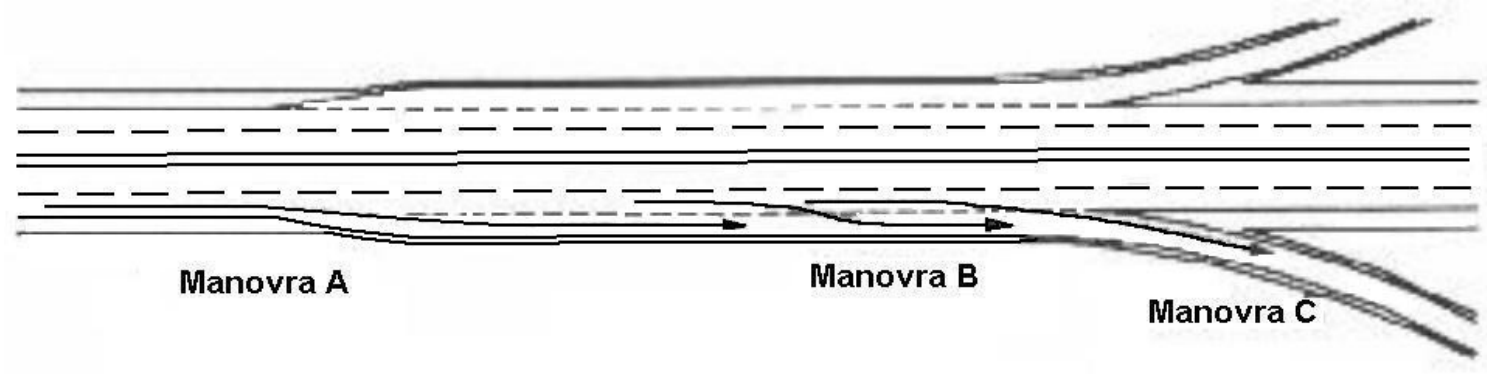

Figura 7: Maniobras de divergencia en una vía de deceleración paralela en recta. (Canale et al. 1998). 
Para definir la trayectoria que describen los vehículos en una vía de deceleración paralela en recta se trazó la envolvente del $75 \%$ de todas las trayectorias analizadas y como se observa en la Figura 8 los conductores prefieren una maniobra de salida en la que se varíe de forma gradual la dirección, lo que supone una maniobra directa.

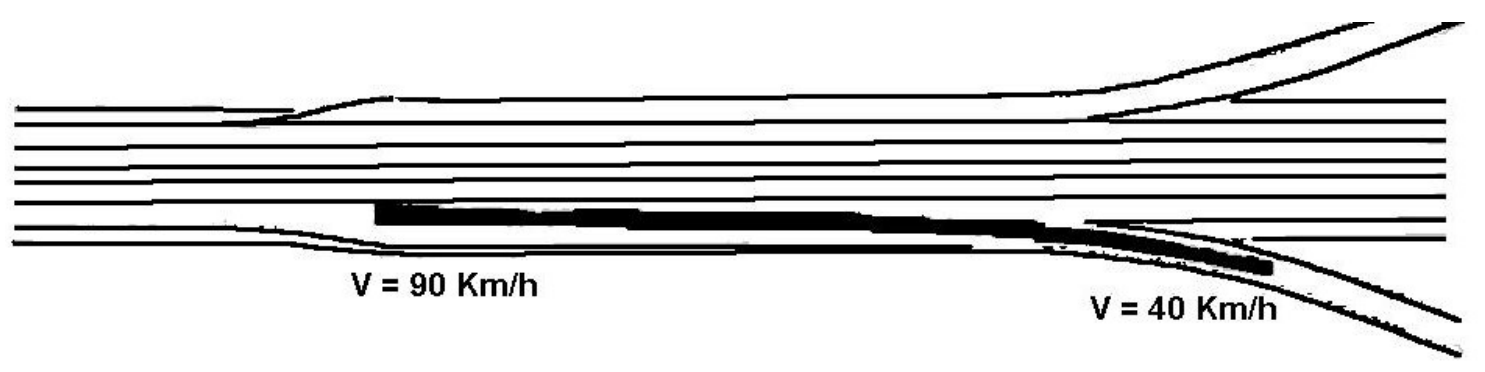

Figura 8: Envolvente de las trayectorias. (Canale et al. 1998).

Del estudio que ha realizado Colonna (1997) en una vía de deceleración paralela en la que la curvatura del tronco es de signo opuesto a la del ramal de salida se deduce que hay tres maniobras posibles que se muestran en la Figura 9.

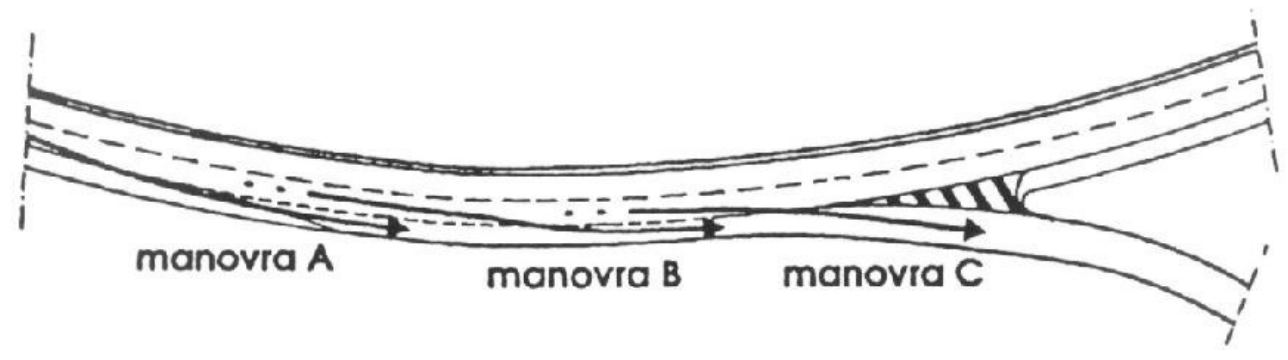

Figura 9: Maniobras de divergencia en una vía de deceleración paralela en la que la curvatura del tronco es de signo opuesto a la del ramal de salida. (Colonna et al. 1997).

Para analizar la longitud de la maniobra de divergencia en una vía de deceleración paralela en la que la curvatura del tronco es de signo opuesto a la del ramal de salida, se utilizó como parámetro la distancia entre el punto en que comienza el carril de deceleración y el punto en el que el vehículo atraviesa la marca vial que delimita el carril y el tronco. Examinando la Figura 10 y Figura 11 se observa la elevada concentración de maniobras muy largas, es decir, la fuerte tendencia de los automovilistas a retrasar al máximo el cambio de carril, lo que induce a pensar que los conductores, cuando el tráfico lo permite, tienden a retrasar la salida para rectificar al máximo la trayectoria y así atenuar el efecto de la curvatura. De hecho, casi la mitad de los vehículos cruzaban la línea de separación entre la vía principal y el carril de deceleración una vez superado el $80 \%$ del carril de deceleración, y el otro $80 \%$ de los vehículos lo hacían más allá de la mitad del carril de deceleración. Como ningún vehículo de los filmados siguió una maniobra de tipo $A$, se deduce que alrededor del $57 \%$ de los vehículos siguió una maniobra de tipo $B$ y el resto una de tipo $C$. 


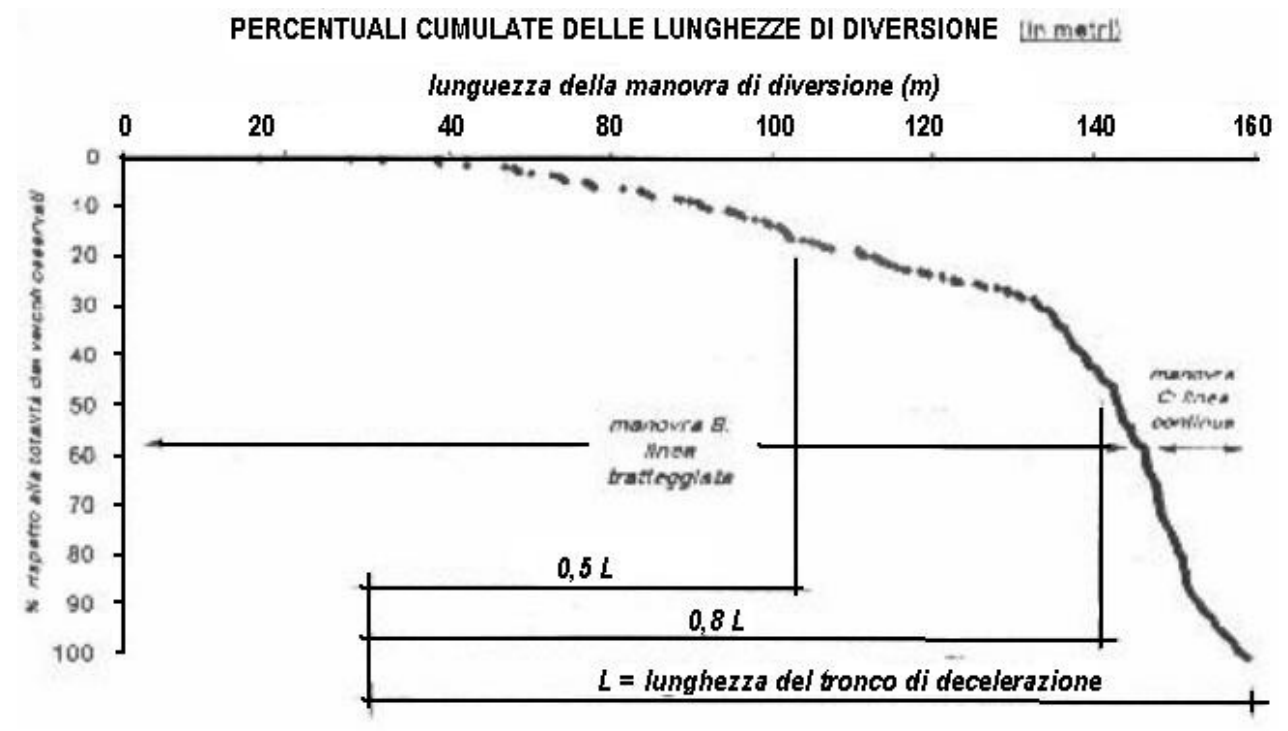

Figura 10: Frecuencia acumulada de la longitud de divergencia. (Colonna et al 1997)

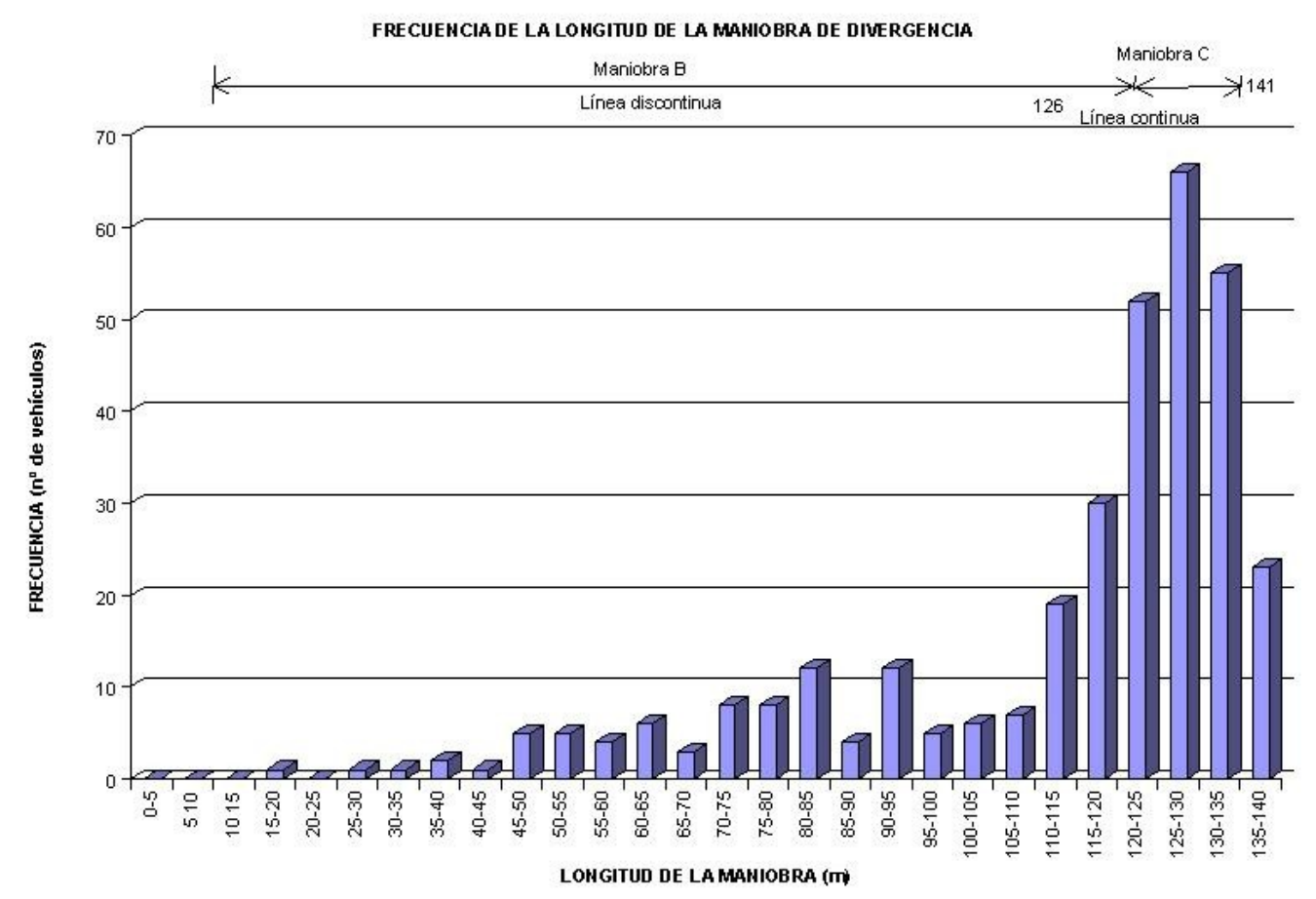

Figura 11: Frecuencia de la longitud de divergencia. (Colonna et al. 1997)

Analizando los resultados del estudio de Colonna (1997) según los diversos tipos de vehículos (Figura 12), se aprecia un incremento respecto a la media de las maniobras de tipo $B$ en vehículos pesados, articulados y furgonetas, ya que a causa de la mayor cota de su baricentro no pueden seguir con comodidad maniobras que se caracterizan 
por un incremento excesivo de la fuerza centrípeta, causado por un repentino aumento de la curvatura de la trayectoria, por lo que es de esperar que estos vehículos tiendan a separarse rápidamente de la vía principal. También se ha estudiado el efecto de las caravanas, y se ha alcanzado la conclusión de que la maniobra que se emplea es sensible a que el vehículo se encuentre a la cabeza de la caravana o en ella,; en el segundo caso prevalece la maniobra $B$.

Al trazar la banda que engloba todas las trayectorias en una vía de deceleración paralela en la que la curvatura del tronco es de signo opuesto a la del ramal de salida se obtiene que en la parte inicial, hasta casi $30 \mathrm{~m}$ de la nariz, su anchura es de casi 4 $\mathrm{m}$ que pasa a $6 \mathrm{~m}$ si se consideran los vehículos pesados ya que algunos vehículos emplean el carril de adelantamiento. Al final de la vía de deceleración el ancho es de 2 $\mathrm{m}$, y no está centrado respecto al eje del ramal, sino escorado hacia el cebreado de la nariz.
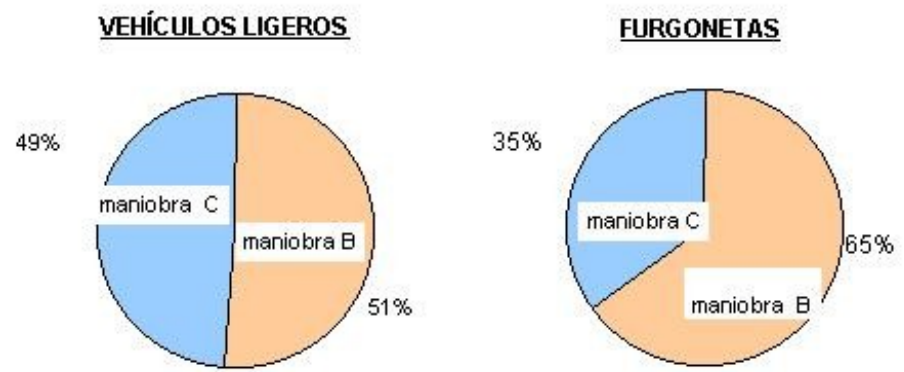

\section{VEHICULOS PESADOS}
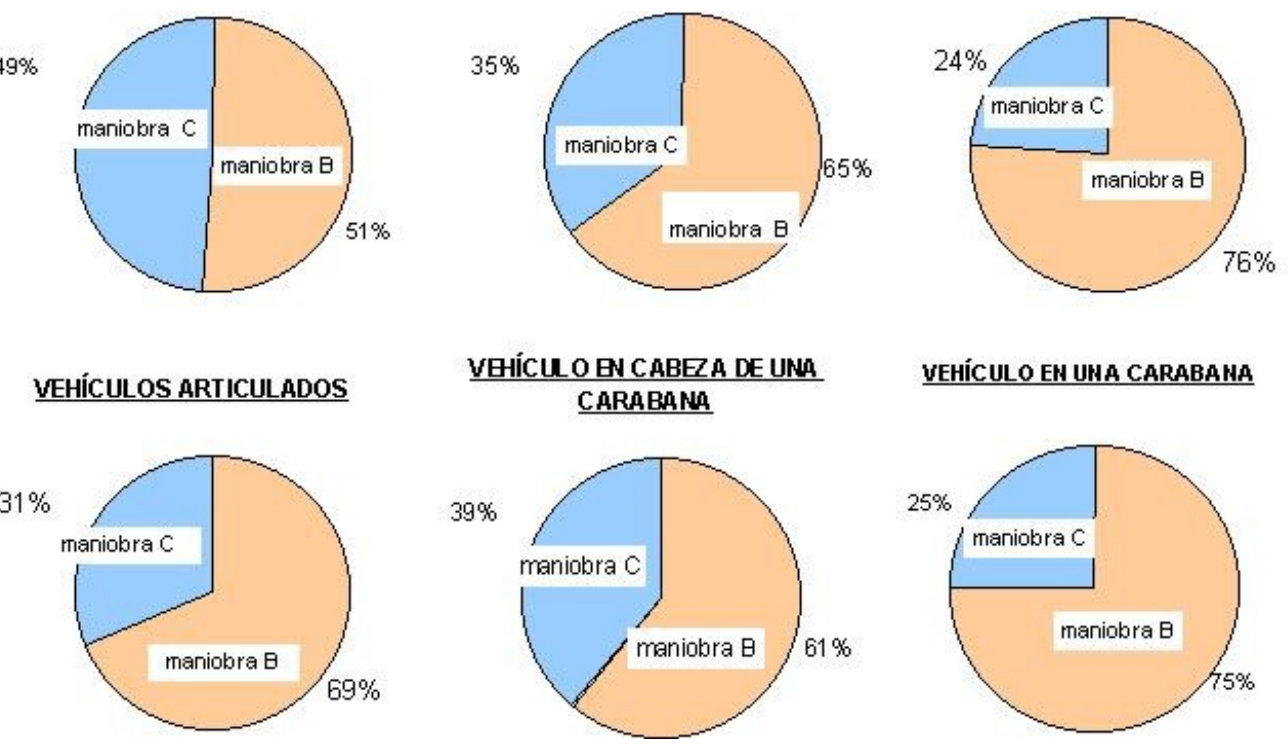

Figura 12: Maniobra de diversos tipos de vehículos y situaciones. (Colonna 1997)

Analizando la trayectoria en una vía de deceleración paralela en la que la curvatura del tronco es de signo opuesto a la del ramal de salida se observa que es posible dividirla en 4 zonas de distintas características:

- La zona I, en la que el desarrollo de la curvatura parece que no se ajusta a ninguna regla; sin embargo, se aprecia que algunos conductores efectúan una primera maniobra en " $\mathrm{S}$ ", durante una treintena de metros, para pasar de la vía principal al carril de deceleración sin tener en cuenta la curvatura del tronco.

- En la zona II los conductores describen una trayectoria caracterizada por una curvatura poco variable, próxima a la del tronco. A continuación un punto de inflexión marca la transición a la zona III, con él se pasa de la curvatura similar a la de la vía principal a la del ramal y difiere de un vehículo a otro, pero para todos los 
vehículos observados, excepto uno, se encuentra en un tramo corto, menor a 20 m.

- En la zona III el conductor no se encuentra condicionado por la curvatura del tronco y durante unos treinta metros sigue una maniobra bastante libre que por lo tanto se parece a la de los carriles de deceleración que se encuentran en recta.

- La última zona, la IV, se inicia en el punto en el que los radios de los vehículos son casi idénticos al del ramal de salida.

De la Iglesia y García al (2000), concluyen a partir del análisis de las grabaciones que los vehículos se incorporan a una vía de deceleración con una maniobra de curva y contra-curva, (maniobra A), sobre todo si se trata de vehículos pesados. También se observa que en las vías de deceleración muy cortas aumentan las maniobras directas, llegando a ser las mayoritarias en los vehículos ligeros. Del estudio se deduce que los giros directos, maniobra $C$, sólo son significativos en las vías de deceleración cortas. Los resultados se muestran en la Tabla 2.

Tabla 2: Trayectorias (De la Iglesia y García 2000)

\begin{tabular}{|c|c|c|c|c|c|c|}
\hline \multirow{2}{*}{} & \multicolumn{2}{|c|}{ N-221 - PK 14 } & \multicolumn{2}{c|}{ CV - 35 PK 5 } & \multicolumn{2}{c|}{ N 332 PK 280,5 } \\
\cline { 2 - 7 } & LIGEROS & PESADOS & LIGEROS & PESADOS & LIGEROS & PESADOS \\
\hline A & $62,5 \%$ & $86,1 \%$ & $45,2 \%$ & $72,4 \%$ & $86,5 \%$ & $92,9 \%$ \\
\hline B & $35,7 \%$ & $13,9 \%$ & $51,6 \%$ & $24,2 \%$ & $13,5 \%$ & $9,1 \%$ \\
\hline C & $1,8 \%$ & - & $3,2 \%$ & $3,4 \%$ & - & - \\
\hline
\end{tabular}

Como ya se ha visto, la mayoría de los conductores, (alrededor del $80 \%$ ), se incorpora al carril de deceleración en la cuña, aprovechando así la mayor parte del carril. Son muchos los estudios que lo demuestran: Jouzy et al. (1965), Livneh et al. (1988), o por ejemplo Fukutome y Moskowitz, (1963) analizaron 8 ramales de salida directos y en la Figura 13 se muestra la posición que ocupaban el $90 \%$ de las ruedas delanteras izquierdas de los vehículos, respecto del borde exterior del pavimento de la vía principal, al terminar la cuña. Como se observa la mayoría de los vehículos ya se han incorporado al carril de deceleración. Sin embargo, alrededor del 3\% de los vehículos que se incorporan lo hacen cerca o incluso cruzando el área cebreada de la nariz, lo que causa un grave peligro a otros vehículos que están decelerando.

En los estudios que se han realizado en las vías de deceleración paralelas se ha observado que los vehículos tienden a retrasar el punto de incorporación a la vía de deceleración por lo que el porcentaje de vehículos que se incorpora cuando la marca vial es continua es mayor, por ejemplo, en la investigación de Colonna et al. (1997) el $43 \%$ de los vehículos siguieron una maniobra C, es decir, se incorporaban a la vía de deceleración cruzando la línea continua que separa el tronco de la vía de deceleración, (Figura 10). Para intentar corregir esta actitud se debería hacer un estudio en el que se analizara si los conductores ante la señalización actual comprenden que se aproximan 
a un carril de deceleración, si sería más adecuada otra señalización o si ese porcentaje corresponde a conductores temerarios que prefieren este tipo de maniobras.

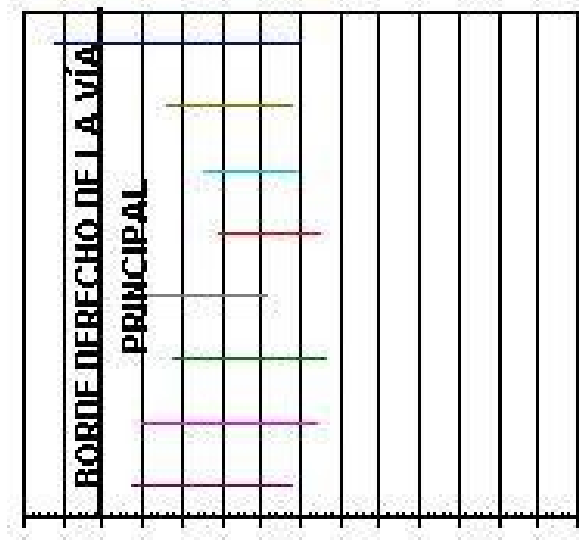

14131211109876543210

DISTAHCIA AL BORDE

DERECHO DE LA víA

PRIMCIPAL, (pies)

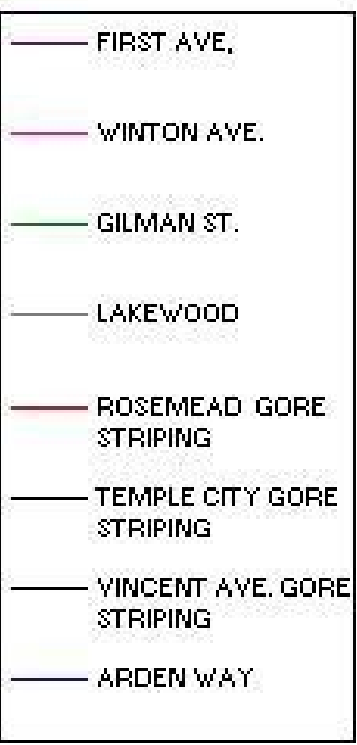

Figura 13: Posición de la rueda delantera izquierda de los vehículos, respecto del borde exterior del pavimento, cuando termina la cuña. (Fukutome 1963)

De los distintos estudios se deduce que el punto en que se incorporan los vehículos a la vía de deceleración se ve influido por su longitud. Cuando las vías de deceleración son extremadamente largas se observa que disminuye el porcentaje de los vehículos que se incorporan en la cuña (p.e. el 71.9\% en Netania, Tabla 3, Livneh et al. 1988), pero aunque la longitud en la que se producen las divergencias es mayor, en la investigación de Jouzy (1963) se concluye que en un tramo de entre 90 y $120 \mathrm{~m}$ divergen aproximadamente el $90 \%$ de los vehículos, como se observa en la Figura 14.

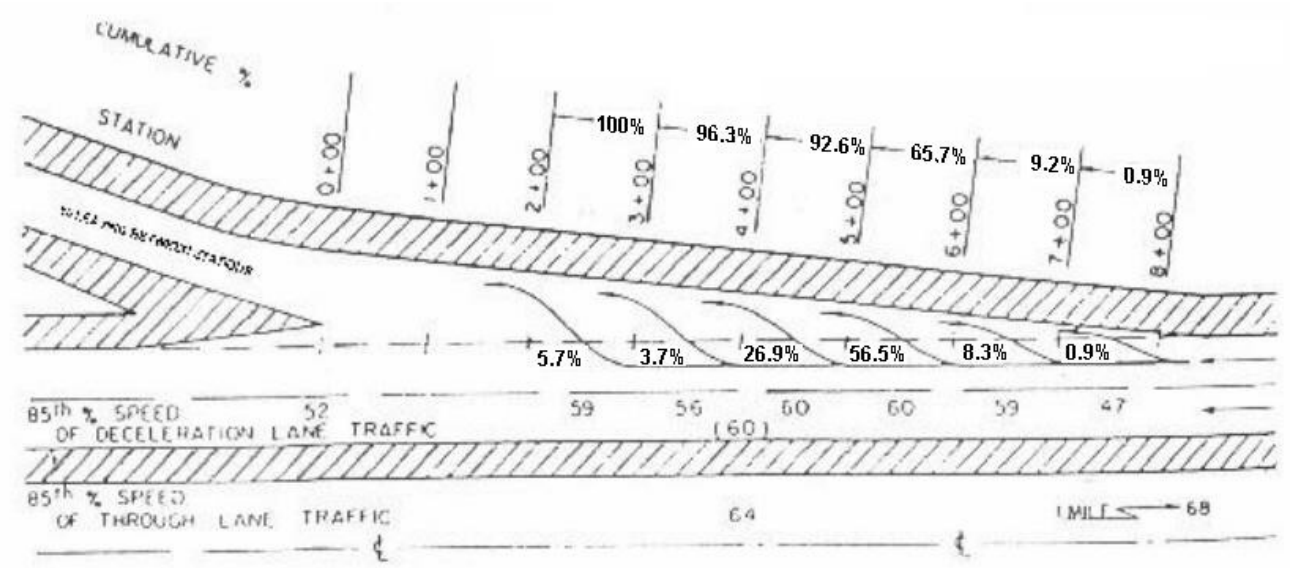

Figura 14: Puntos de incorporación y velocidades a lo largo de un carril de deceleración. Indiana (1). (Jouzy 1963) 
Tabla 3: Porcentaje de vehículos que divergen en distintas secciones de 3 carriles de deceleración de Israel. (Livneh et al., 1988)

\begin{tabular}{|c|c|c|c|c|c|c|c|}
\hline \multirow[t]{2}{*}{ LUGAR } & \multirow[t]{2}{*}{ TIPO } & \multirow{2}{*}{$\begin{array}{c}\text { TIPO DE } \\
\text { VEHÍCULO }\end{array}$} & \multicolumn{5}{|c|}{ PUNTOS DE INCORPORACIÓN (\%) } \\
\hline & & & CUÑA & $\begin{array}{c}1^{0} \\
\text { TERCI } \\
0\end{array}$ & $\begin{array}{c}2^{\circ} \\
\text { TERCI } \\
\mathbf{0}\end{array}$ & $\begin{array}{c}\mathbf{3}^{\mathbf{0}} \\
\text { TERCI } \\
\mathbf{0}\end{array}$ & NARIZ \\
\hline \multirow[t]{3}{*}{ Netania } & \multirow{3}{*}{$\begin{array}{l}\text { Directo } \\
L=240 \mathrm{~m}\end{array}$} & Coches & 71,90 & 20,20 & 4,40 & 3,50 & 0 \\
\hline & & Veh. pesados & 88,90 & 11,10 & 0 & 0 & 0 \\
\hline & & Total Vehículos & 74,24 & 18,94 & 3,79 & 3,03 & 0 \\
\hline \multirow[t]{3}{*}{ Yanai } & \multirow{3}{*}{$\begin{array}{l}\text { Paralelo } \\
\mathrm{L}=100 \mathrm{~m}\end{array}$} & Coches & 82,18 & 4,95 & 9,90 & 0 & 0 \\
\hline & & Veh. pesados & 100,0 & 0 & 0 & 0 & 0 \\
\hline & & Total vehículos & 83,64 & 4,45 & 9,09 & 2,73 & 0 \\
\hline \multirow{3}{*}{$\begin{array}{c}\text { Gan- } \\
\text { Shmuel }\end{array}$} & \multirow{3}{*}{$\begin{array}{l}\text { Directo } \\
\mathrm{L}=175 \mathrm{~m}\end{array}$} & Coches & 83,05 & 3,40 & 8,47 & 5,08 & 0 \\
\hline & & Veh. pesados & 88,24 & 2,94 & 2,94 & 5,88 & 0 \\
\hline & & Total vehículos & 84,94 & 3,23 & $6 ., 45$ & 8,38 & 0 \\
\hline
\end{tabular}

Cuando un carril de deceleración es corto los vehículos se incorporan al inicio y lo usan en toda su longitud, como se puede observar en la Figura 15 y en la Figura 16, (Jouzy et al.1963), de 45 y 72 m respectivamente, desde donde el carril tiene un ancho de 1,8 $m$ hasta el inicio de la curva del ramal de salida.

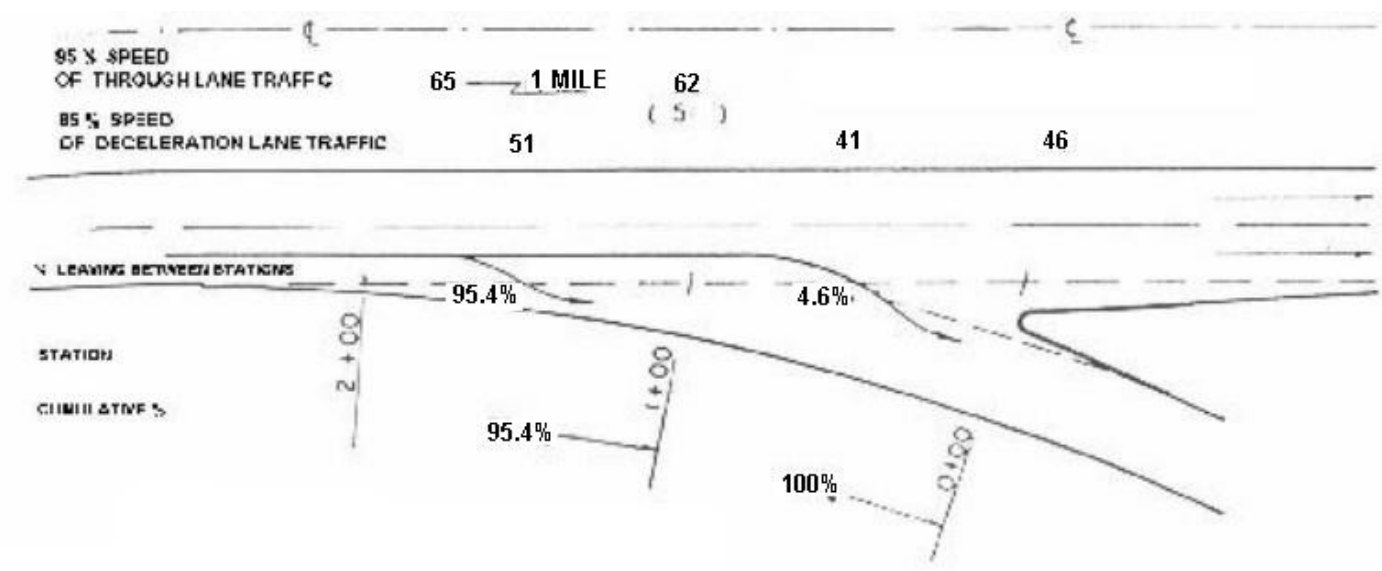

Figura 15: Puntos de incorporación y velocidades a lo largo de un carril de deceleración. Indiana (2). (Jouzy 1963)

Hay una notable diferencia entre el comportamiento de los vehículos ligeros y los pesados (camiones y autobuses) y es que estos últimos se incorporan antes y usan una gran porción de la vía de deceleración. Esta diferencia puede atribuirse a que los conductores están familiarizados con la forma de abordar el carril para, al utilizar toda la longitud, conseguir mayor confort y seguridad en la maniobra de incorporación. Esto se observa en el estudio de Livneh (1988), en el que en las tres vías de deceleración 
analizadas, de distintos tipos y longitudes, siempre divergen antes los vehículos pesados, Tabla 3, y en el estudio de Colonna (1997) donde el porcentaje de vehículos pesados que se incorporan con una maniobra $B$, atravesando la línea discontinua, es mayor que el de ligeros, Figura 12.

La alineación en planta condiciona donde se incorporan los vehículos, ya que si el carril de deceleración está en una curva a la izquierda con mucha curvatura, tienden a salir antes, incluso puede provocar la duda en los vehículos que circulan por la autopista sobre la trayectoria que deben seguir y hacerles decelerar de forma peligrosa en el carril principal. Este problema surge cuando la velocidad de diseño es de $80 \mathrm{~km} / \mathrm{h}$ o menor ya que a velocidades mayores la curvatura de muchas autopistas es despreciable y no afecta a los carriles de deceleración que están en una curva a la izquierda. Una muestra de que los radios amplios en el tronco no afectan al comportamiento de los conductores en la vía de deceleración es una vía de unos $90 \mathrm{~m}$, Figura 17, estudiado por Jouzy (1963), en una autopista en la que los vehículos circulaban a más de $95 \mathrm{~km} / \mathrm{h}$, en la que los conductores retrasaban la incorporación si se compara con el comportamiento de los conductores del carril de la Figura 15 que está en un tramo recto. Otro ejemplo es la vía de deceleración estudiada por Colonna (1997) donde la velocidad en el tronco era de $120 \mathrm{~km} / \mathrm{h}$ y como se observa en la Figura 11 la mayor parte de los vehículos retrasaban el momento en que se incorporaban a la vía de deceleración.

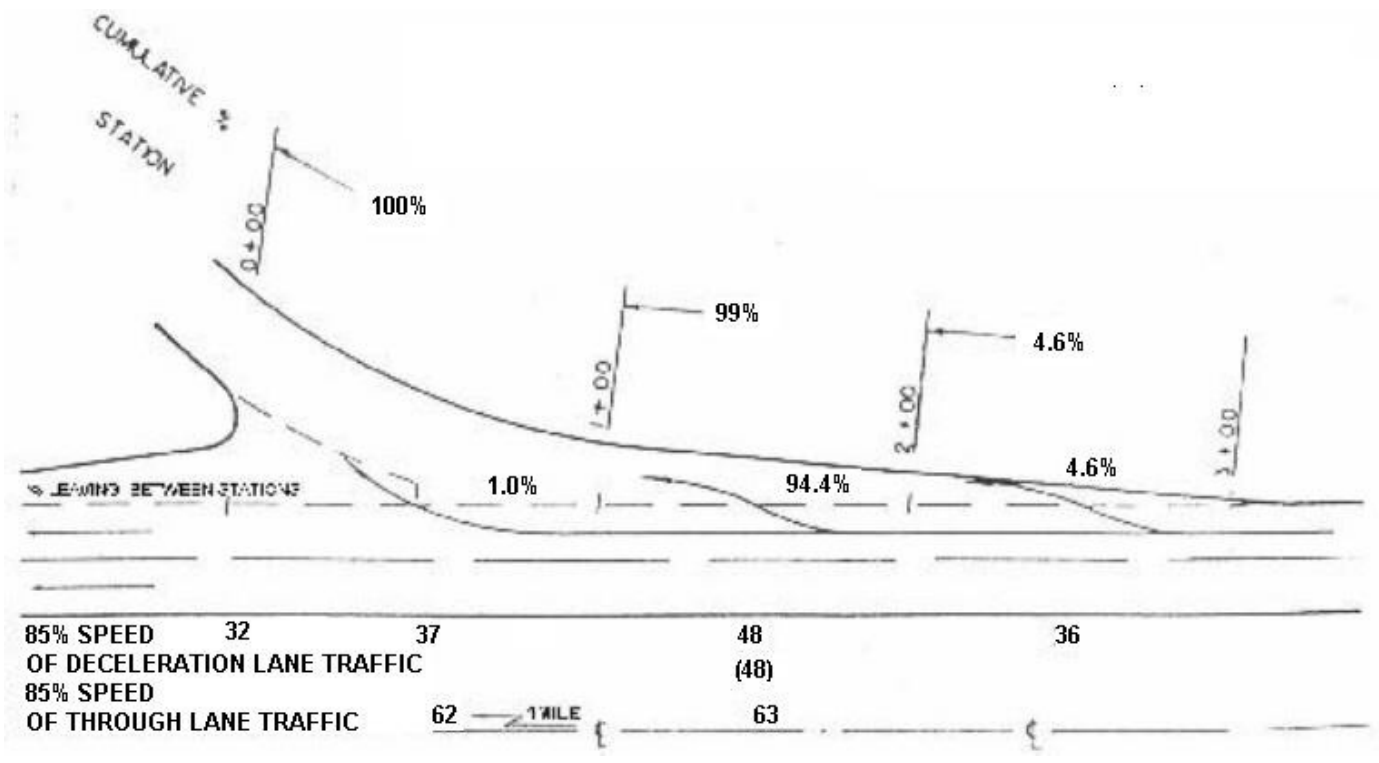

Figura 16: Puntos de incorporación y velocidades a lo largo de un carril de deceleración. Indiana (3). (Jouzy 1963) 


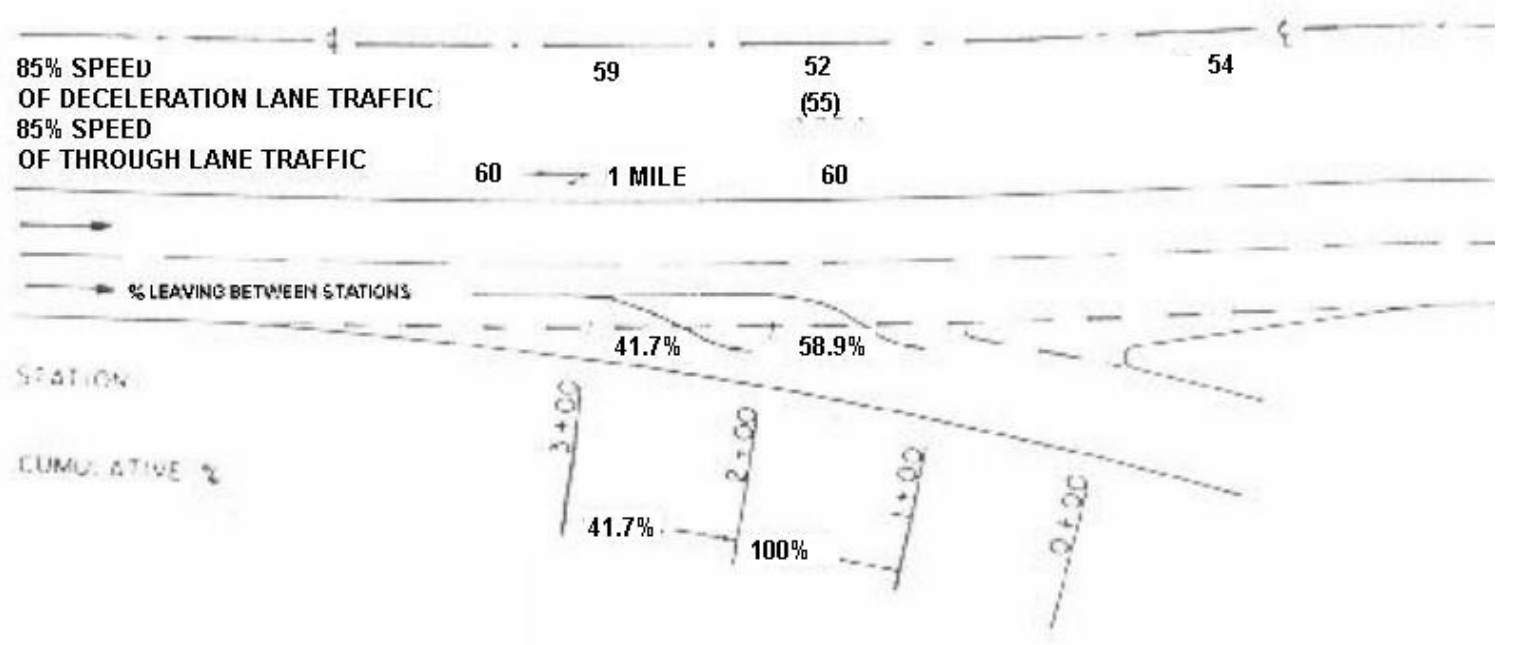

Figura 17: Puntos de incorporación y velocidades a lo largo de un carril de deceleración. Indiana (4). (Jouzy 1963)

En el estudio realizado por Bella, García y Gómez (2009) en el que se analiza el comportamiento del conductor en tres tipologías de salida: una directa, una paralela y una de altas prestaciones, para distintas situaciones de tráfico en un simulador de conducción, se llega a las siguientes conclusiones: que independientemente de la situación de tráfico, en la tipología directa el conductor realiza la maniobra de inserción en el carril de deceleración de manera más brusca que en la tipología paralela, y que la maniobra de inserción realizada en la tipología de alta prestación es una maniobra intermedia entre las dos mencionadas anteriormente. Cabe también señalar que la configuración directa se encuentra caracterizada por un menor número de trayectorias anómalas, ello se produce por el hecho de que el conductor tiene menos opciones de elegir el tipo de maniobra que quiere efectuar, además de que es menor el espacio por el cual se puede introducir en el carril de deceleración y por esto tiene un comportamiento más homogéneo.

Rioux (1977) estudió las maniobras de cambio de carril, utilizando fotografías a intervalos regulares de tiempo. En su investigación encontró que el tiempo empleado para realizar la maniobra de cambio de carril variaba, en función de la velocidad del vehículo, entre 3 y 4 segundos, a mayor velocidad mayor tiempo de maniobra. Se adoptó un tiempo medio de 3,5 segundos.

Rioux (1977) encontró que la trayectoria descrita por la evolución de los vehículos al cambiar de carril, sigue la forma de la función coseno si la velocidad del vehículo permanece constante, de lo contrario, la función coseno sufre una deformación por el efecto de acelerar o decelerar (Figura 18). 

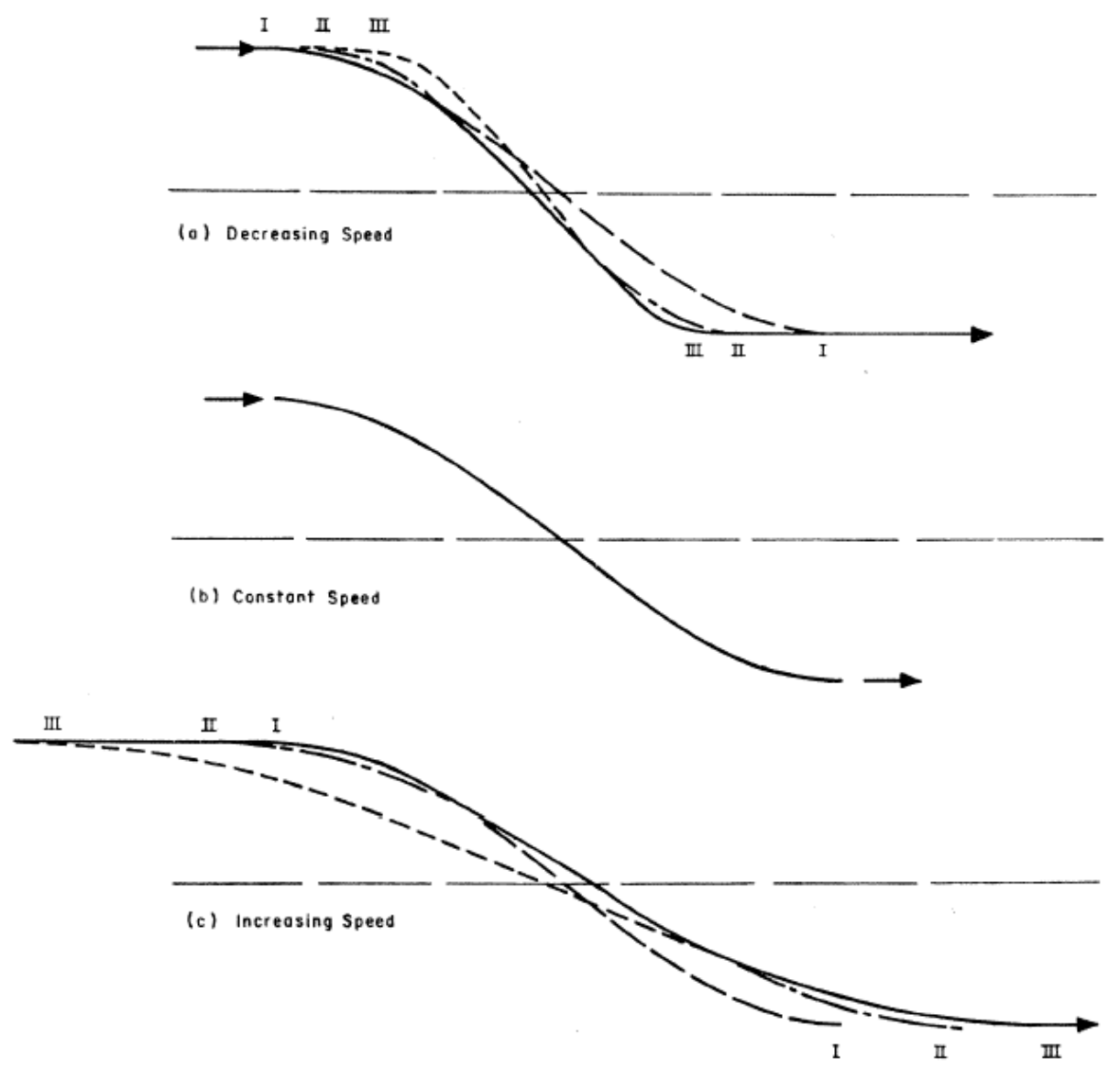

Figura 18: Trayectoria de cambio de carril (Rioux 1977)

\subsubsection{Deceleraciones}

En las vías de deceleración hay dos formas de decelerar: dejar de presionar el acelerador y retener con el motor, que son las llamadas maniobras subconscientes, en las que se obtienen deceleraciones del orden de los $5 \mathrm{~km} / \mathrm{h} / \mathrm{s}\left(1,39 \mathrm{~m} / \mathrm{s}^{2}\right)$, y decelerar con una suave aplicación de los frenos, que son las maniobras deliberadas, en las que se alcanzan deceleraciones de hasta $10 \mathrm{~km} / \mathrm{h} / \mathrm{s}\left(2,78 \mathrm{~m} / \mathrm{s}^{2}\right)$.

De las deceleraciones obtenidas en distintos estudios hay que destacar las que proponen Livneh (1988) (Figura 22), Colonna (1997) y Canale (1998), valores sensiblemente inferiores a los valores confortables que emplea la AASHTO (2001), que para una velocidad de $88 \mathrm{Km} / \mathrm{h}$ corresponde a $2,49 \mathrm{~m} / \mathrm{s}^{2}$, ya que mientras estos últimos se obtuvieron en 1938 en la aproximación a un STOP, los restantes estudios se han realizado en vías de deceleración. En concreto, Colonna (1997) obtuvo deceleraciones en el intervalo de 1,25 a 2,25 m/s ${ }^{2}$, con un valor medio de 1,6 m/s .

El tiempo máximo que se decelera por retención del motor según De la Iglesia y García (2000), fue de 6,4 segundos para el $80 \%$ de los vehículos ligeros, mientras que AASHTO (1965) propone 3 segundos y Livneh (1988) estableció 10 segundos. 


\subsubsection{Modelos de variación de velocidad}

Tras percibir el conductor la necesidad de decelerar (curva, obstáculo, etc.), transcurre un intervalo de evaluación y reacción, sin que durante él se modifique la marcha del vehículo: a partir de entonces se decelera hasta reducir la velocidad al valor deseado no más allá del punto en que éste resulta necesario.

Algunos de los parámetros que intervienen en la deceleración son:

\subsection{La velocidad inicial}

Puede ser constante e igual a la máxima alcanzable, si ha tenido oportunidad de desarrollarse porque la alineación recta anterior haya tenido suficiente longitud; o incluso puede, en casos extremos, que durante el periodo de evaluación y reacción se haya seguido acelerando.

\subsection{La reducción necesaria de la velocidad}

Hay que distinguir varios tipos de maniobra: las maniobras de emergencia que pueden deberse a un obstáculo inesperado que obligue a detenerse, las maniobras deliberadas, como la aproximación a una divergencia, en las que no se exceden los rozamientos movilizables mediante una suave aplicación de los frenos y las maniobras subconscientes o semiautomáticas, como ajustar la velocidad para tomar una curva, en las que se deja de acelerar y se retiene con el motor. En esta última maniobra parece que no se puede superar una reducción de unos $20 \mathrm{~km} / \mathrm{h}$ sin que la maniobra necesite pasar a ser deliberada, para lo cual se necesita que el conductor llegue a darse cuenta de esta necesidad.

\subsection{La máxima deceleración admisible}

Se encuentra muy por debajo del coeficiente de rozamiento longitudinal entre vehículo y pavimento (que sólo se necesita en caso de emergencia). En las maniobras de emergencia el conductor admite una deceleración máxima. En las maniobras deliberadas, según Rocci (1988), no debe sobrepasarse los $10 \mathrm{~km} / \mathrm{h} / \mathrm{s}\left(2,78 \mathrm{~m} / \mathrm{s}^{2}\right)$, con lo que, en una rasante horizontal, se movilizaría un rozamiento de 0,28. En las maniobras subconscientes, según Rocci (1988), no deben rebasarse los $5 \mathrm{~km} / \mathrm{h} / \mathrm{s}$ (1,38 $\mathrm{m} / \mathrm{s}^{2}$ ), con lo que se movilizaría un rozamiento de 0,14 .

\subsection{El modelo de deceleración}

La variación de la velocidad con el recorrido depende de si la maniobra es de emergencia, deliberada o subconsciente. A las primeras se ajusta bien un modelo cuadrático (deceleración constante e igual a la media), según la ecuación (1):

$$
\frac{V}{V_{C}}=\sqrt{\left.N^{2}-N^{2}-\right) \frac{s}{d}}
$$

Siendo: 
- $\mathrm{V}_{\mathrm{c}}=$ Velocidad final

- $\quad \mathrm{V}=$ Velocidad en un punto genérico

- $\mathrm{s}=$ Distancia de ese punto al inicial

- $\quad \mathrm{N}=$ Razón entre la velocidad inicial y final

- $\mathrm{d}=$ Distancia necesaria para decelerar.

La deceleración A es constante, según la ecuación (2):

$$
A=\frac{V^{2}-}{7.2 \cdot d} \cdot V_{C}
$$

A en $\mathrm{m} / \mathrm{s}, \mathrm{V}_{\mathrm{c}}$ en $\mathrm{km} / \mathrm{h}$ y $\mathrm{d}$ en $\mathrm{m}$

A las maniobras subconscientes se ajusta mejor un modelo cúbico, según la ecuación (3):

$$
\frac{V}{V_{C}}=\sqrt{N^{2}-\left(N^{2}-1\right) \cdot\left(\frac{s}{d}\right)^{2} \cdot\left(3-2 \cdot \frac{s}{d}\right)}
$$

Rocci (1988) recomienda tomar la velocidad inicial igual a $\mathrm{V}_{85}$, (velocidad no superada por el $85 \%$ de los conductores), para las maniobras en que la condición determinante es la comodidad, como la aproximación a una divergencia o a una curva circular, e igual a $\mathrm{V}_{99}$ si se trata de maniobras relacionadas con la seguridad, como es en el caso de las maniobras de emergencia.

Para los valores límite de deceleración señalados, y si la relación entre la velocidad inicial y final no es muy grande (no superior a 2) los modelos anteriores pueden aproximarse con la ecuación (4):

$$
d=\bullet \cdot V_{0} \cdot \Delta
$$

Siendo:

- $\quad \mathrm{d}=$ Distancia necesaria para decelerar $(\mathrm{m})$.

- $\mathrm{V}_{0}=$ Velocidad inicial $(\mathrm{km} / \mathrm{h})$

- $\Delta \mathrm{V}=$ Pérdida de velocidad $(\mathrm{km} / \mathrm{h})$

- $\mathrm{K}=$ Un coeficiente igual a $1 / 45$ si la maniobra es deliberada y la deceleración máxima de $10 \mathrm{~km} / \mathrm{h} / \mathrm{s}$, e igual a $3 / 40$ para maniobras subconscientes y deceleración máxima de $5 \mathrm{~km} / \mathrm{h} / \mathrm{s}$.

\subsubsection{El frenado}

En el frenado interviene varios aspectos que es necesario analizar:

\subsection{Capacidad de frenado de los vehículos:}

Las maniobras de frenado pueden describirse con dos modelos generales: frenado con ruedas bloqueadas y frenado controlado 
En el primer caso el vehículo desliza con las ruedas bloqueadas, movilizando el coeficiente de deslizamiento longitudinal, $f_{\mathrm{S}}$, pero en este punto el rozamiento transversal es mínimo (Figura 19) con lo que se puede producir la pérdida de control del vehículo. Con un frenado controlado se aplican los frenos de forma que las ruedas continúan rodando sin bloquearse mientras el vehículo decelera. La distancia recorrida con este frenado está gobernada por un rozamiento longitudinal a la izquierda del máximo rozamiento disponible, que se alcanza con un deslizamiento entre el 10 y el $15 \%$, pero por la pendiente abrupta de la curva de rozamiento longitudinal a la izquierda del máximo y por los métodos de frenado usados por los conductores para evitar el bloqueo de las ruedas, el coeficiente de rozamiento es generalmente menor al rozamiento longitudinal de deslizamiento, con lo que la distancia necesaria para detenerse cuando se controla el frenado es mayor que cuando se frena con las ruedas bloqueadas. A pesar de esto, los conductores normalmente prefieren realizar un frenado controlado, modulando el pedal de frenado para variar la fuerza de frenado y evitar el bloqueo de las ruedas.
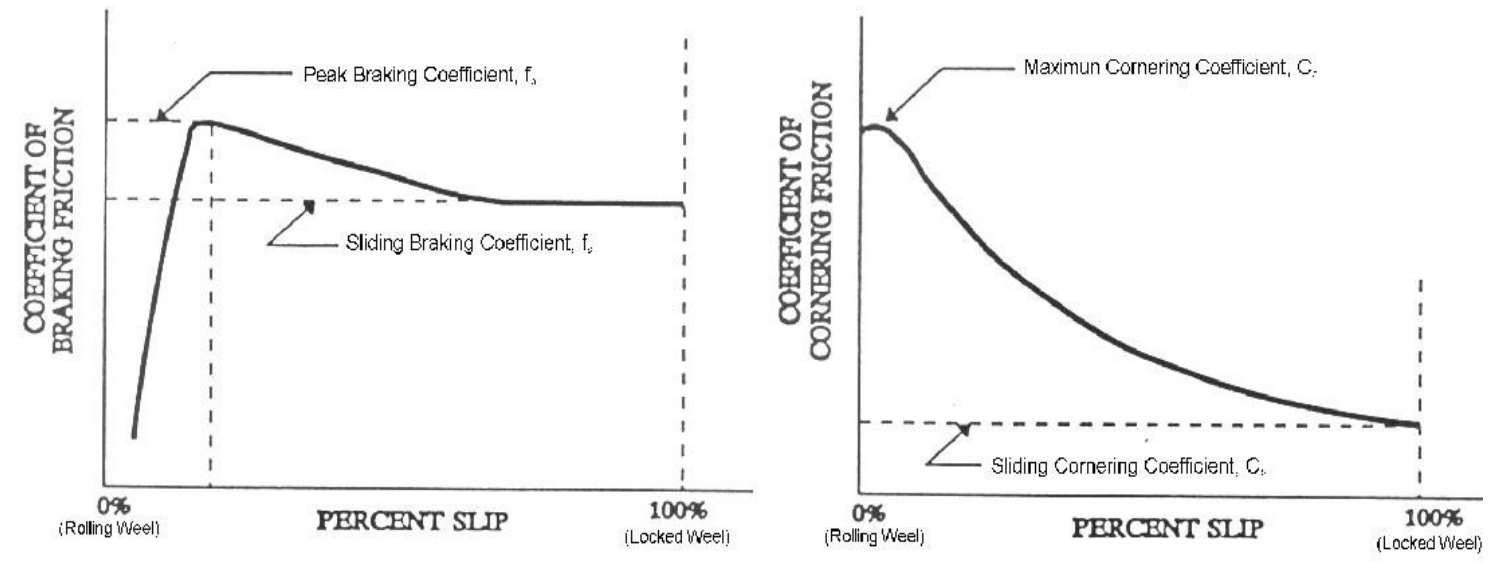

Figura 19: Variación del coeficiente de deslizamiento longitudinal y transversal.

El hecho de que para el diseño se empleen los vehículos de pasajeros ha llevado a investigar la validez de la distancia de parada para los vehículos pesados, ya que, como documentó Olson (1984) la eficiencia de frenado de un vehículo de pasajeros de 1982, era aproximadamente el $91 \%$ del rozamiento longitudinal máximo y entre el 55 y el $59 \%$ en los vehículos pesados. Pero estudios de campo muestran que muchos vehículos pesados son capaces de detenerse en la distancia de frenado de la AASHTO (TRB 1997) si el pavimento está seco, y si poseen un sistema de frenado antibloqueo, $A B S$, pueden detenerse con el pavimento húmedo en la distancia de frenado de la AASHTO (TRB 1997), como se demuestra en los estudios de campo realizados por Harwood et al.(TRB 1997) en los que se evaluaba la distancia de frenado en pavimentos húmedos de camiones vacíos en tres supuestos: camión con sistema convencional de frenos y un conductor sin experiencia, el mismo camión con un conductor experto y el mismo camión con ABS y un conductor habitual. Los resultados se muestran en la Tabla 4. 
Tabla 4: Distancia de frenado para camiones.

\begin{tabular}{|c|c|c|c|c|}
\hline \multirow{2}{*}{$\begin{array}{c}\text { VELOCIDAD } \\
\text { DE DISEÑO } \\
(\mathbf{m p h})\end{array}$} & $\begin{array}{c}\text { AASHTO } \\
\text { (Vehículos de } \\
\text { pasajeros) } \\
\text { (pies) }\end{array}$ & \multicolumn{3}{|c|}{$\begin{array}{c}\text { DISTANCIA DE FRENADO PARA CAMIONES } \\
\text { (pies) }\end{array}$} \\
\cline { 3 - 5 } & $\begin{array}{c}\text { CONDUCT. SIN } \\
\text { EXPERIENCIA }\end{array}$ & $\begin{array}{c}\text { CONDUCT. CON } \\
\text { EXPERIENCIA }\end{array}$ & ABS \\
\hline 20 & 33 & 77 & 48 & 37 \\
\hline 30 & 86 & 186 & 115 & 88 \\
\hline 40 & 167 & 344 & 213 & 172 \\
\hline 50 & 278 & 538 & 333 & 267 \\
\hline 60 & 414 & 744 & 462 & 375 \\
\hline 70 & 583 & 1013 & 628 & 510 \\
\hline
\end{tabular}

También se ha demostrado que disminuye la distancia de frenado de los vehículos ligeros con ABS, pudiendo lograrse mejoras del 50\% en pavimentos asfálticos húmedos y del $25 \%$ en pavimentos de hormigón, pulidos y húmedos, como lo demuestran los test de frenado realizados por el NHTSA en 1991. En la Tabla 5 se muestran los resultados en el caso de frenado con ruedas bloqueadas en un pavimento de hormigón húmedo y pulido en un tramo recto con $A B S$ en todas las ruedas y sin ABS.

Tabla 5: Distancia de frenado con pavimento húmedo, para vehículos con o sin ABS.

(NHTSA 1991).

\begin{tabular}{|c|c|c|c|c|}
\hline \multirow{2}{*}{ VEHÍcULO } & $\begin{array}{c}\text { VELOCIDAD } \\
\text { (mph) }\end{array}$ & \multicolumn{2}{|c|}{$\begin{array}{c}\text { DISTANCIA DE FRENADO } \\
\text { (pies) }\end{array}$} & $\begin{array}{c}\text { Porcentaje } \\
\text { de mejora }\end{array}$ \\
\cline { 3 - 4 } & & CON ABS & SIN ABS & \\
\hline Toyota Supra & 35 & 63 & 79 & 20,3 \\
& 50 & 131 & 198 & 33,8 \\
\hline Acura Legend & 35 & 75 & 84 & 10,7 \\
& 50 & 152 & 196 & 22,4 \\
\hline Cadillac Brougham & 35 & 72 & 98 & 26,5 \\
& 50 & 144 & 244 & 41,0 \\
\hline Chrysler Imperial & 35 & 78 & 98 & 20,4 \\
& 50 & 164 & 221 & 25,8 \\
\hline
\end{tabular}

Características de frenado: en recta, rueda bloqueada, pav. hormigón pulido y húmedo $(f=0,28)$

Con lo expuesto se concluye que cuando hay problemas de deslizamiento, como sucede en un pavimento húmedo, el uso extensivo del ABS puede resolver la cuestión 
de frenado controlado o frenado con las ruedas bloqueada, ya que el conductor mantiene el control del vehículo mientras usa un coeficiente de rozamiento longitudinal próximo al máximo. Pero cuando no hay problemas de deslizamiento un vehículo con el sistema de frenado ABS necesita mayores longitudes de frenado que otro igual sin ABS.

Otro factor que afecta a la capacidad de frenado de los vehículos es el estado de los neumáticos ya que con los neumáticos desgastados los coeficientes de rozamiento longitudinal y transversal decrecen. Dijks (NHTSA 1991) observó que si los pavimentos tenían una macrotextura rugosa el estado de los neumáticos tenía un efecto pequeño en los coeficientes de fricción, pero que en pavimentos con macrotextura lisa y neumáticos desgastados el coeficiente de rozamiento disminuía substancialmente. El CRL y el CRT apenas disminuyen con el incremento de la velocidad sobre pavimento seco, pero se aprecia una fuerte disminución cuanto más gruesa es la película de agua sobre la calzada. La Tabla 6, constata lo expuesto.

Tabla 6: Influencia de la velocidad, el estado de los neumáticos y el espesor de la película de agua en el CRL y el CRT. (Vigueras et al. 1992)

\begin{tabular}{|c|c|c|c|c|c|c|c|}
\hline \multirow{2}{*}{$\begin{array}{c}\text { ESPESOR DE } \\
\text { LAE PEÍCULA }\end{array}$} & \multirow{2}{*}{$\begin{array}{c}\text { ESTADO DE LOS } \\
\text { NEUMATICOS }\end{array}$} & \multicolumn{3}{|c|}{ VELOCIDAD DEL VEHÍCULO (km/h) } \\
\cline { 3 - 7 } & & \multicolumn{2}{|c|}{$\mathbf{3 0}$} & \multicolumn{2}{|c|}{$\mathbf{6 0}$} & \multicolumn{2}{|c|}{$\mathbf{9 0}$} \\
\cline { 3 - 8 } & & CRL & CRT & CRL & CRT & CRL & CRT \\
\hline \multirow{2}{*}{$0,2 \mathrm{~mm}$} & BUENO (con dibujo) & 0,80 & 0,60 & 0,75 & 0,40 & 0,68 & 0,30 \\
\cline { 2 - 8 } & DESGASTADOS (sin dibujo) & 0,80 & 0,35 & 0,50 & 0,20 & 0,38 & 0,10 \\
\hline \multirow{2}{*}{$2,0 \mathrm{~mm}$} & BUENO (con dibujo) & 0,80 & 0,55 & 0,70 & 0,25 & 0,40 & 0,12 \\
\cline { 2 - 8 } & DESGASTADOS (sin dibujo) & 0,75 & 0,30 & 0,40 & 0,12 & 0,20 & 0,05 \\
\hline
\end{tabular}

CRL: Coeficiente de rozamiento longitudinal. CRT: Coeficiente de rozamiento transversal.

\subsection{Estado de las carreteras.}

El análisis de los datos de la fricción del pavimento, obtenidos de la base de datos de California, Texas y del SHRP, muestra que la fricción de la mayoría de las autopistas excede los valores asumidos por la AASHTO (1990) para la distancia de visibilidad de parada, lo que proporciona un factor adicional de seguridad en condiciones de pavimento húmedo. En principio se asume que estos resultados se pueden extrapolar a todas las carreteras.

\subsection{Comportamiento del conductor.}

El interés se centra en conocer que deceleración consideran los conductores confortable porque será la que utilicen al frenar. El Institute of Transportation Engineer (ITE) establece en el "Handbook of Highway Engineering", (1975), que son confortables deceleraciones de hasta 10 pies/s $\mathrm{s}^{2}(0,32 \mathrm{~g})$, valores que como se observa en la Figura 24 y la Tabla 7 son mayores que los considerados por la AASHTO (1954). 
Tabla 7: Deceleración considerada por la AASHTO(1954).

\begin{tabular}{|c|c|c|c|c|}
\hline $\begin{array}{c}\text { Tipo de } \\
\text { Deceleración }\end{array}$ & $\begin{array}{c}\text { Velocidad } \\
\text { mph } \\
(\mathrm{km} / \mathrm{h})\end{array}$ & $\begin{array}{c}\text { Distancia de } \\
\text { frenado: p } \\
\text { (m) }\end{array}$ & Fricción & $\begin{array}{c}\text { Deceleración } \\
\left(\mathrm{m} / \mathrm{s}^{2}\right)\end{array}$ \\
\hline Deceleración & $60(88)$ & 475 (145) & 0,25 & 2,49 \\
\hline Confortable & $30(44)$ & $180(55)$ & 0,17 & 1,64 \\
\hline Deceleración max. & $60(88)$ & $210(64)$ & 0,57 & 5,61 \\
\hline Pavimento seco & $30(44)$ & $50(15)$ & 0,60 & 5,88 \\
\hline Deceleración máxima & $60(88)$ & $295(90)$ & 0,41 & 3,99 \\
\hline Pavimento húmedo & $30(44)$ & $70(21)$ & 0,43 & 4,21 \\
\hline
\end{tabular}

Para conocer el comportamiento de los conductores al decelerar el NCHRP realizó una serie de estudios de campo (T.R.B. (1997): "Determination of Stopping Sight Distances", NCHRP Report 400). En ellos se observó que la deceleración durante el frenado no es constante y que la máxima deceleración se alcanza al final, como se refleja en la Figura 20, una curva típica de deceleración. Como se esperaba el estado del pavimento, la velocidad inicial y el uso o no del ABS dieron lugar a diferencias en la distancia de frenado. Como se observa en la Figura 21, conforme aumenta la velocidad inicial aumenta la distancia de frenado, la distancia es mayor cuando el pavimento está húmedo y el $A B S$ produce mayores beneficios con altas velocidades y pavimentos húmedos. Otro dato es que las distancias de frenado observadas en recta fueron similares a las observadas en curva.

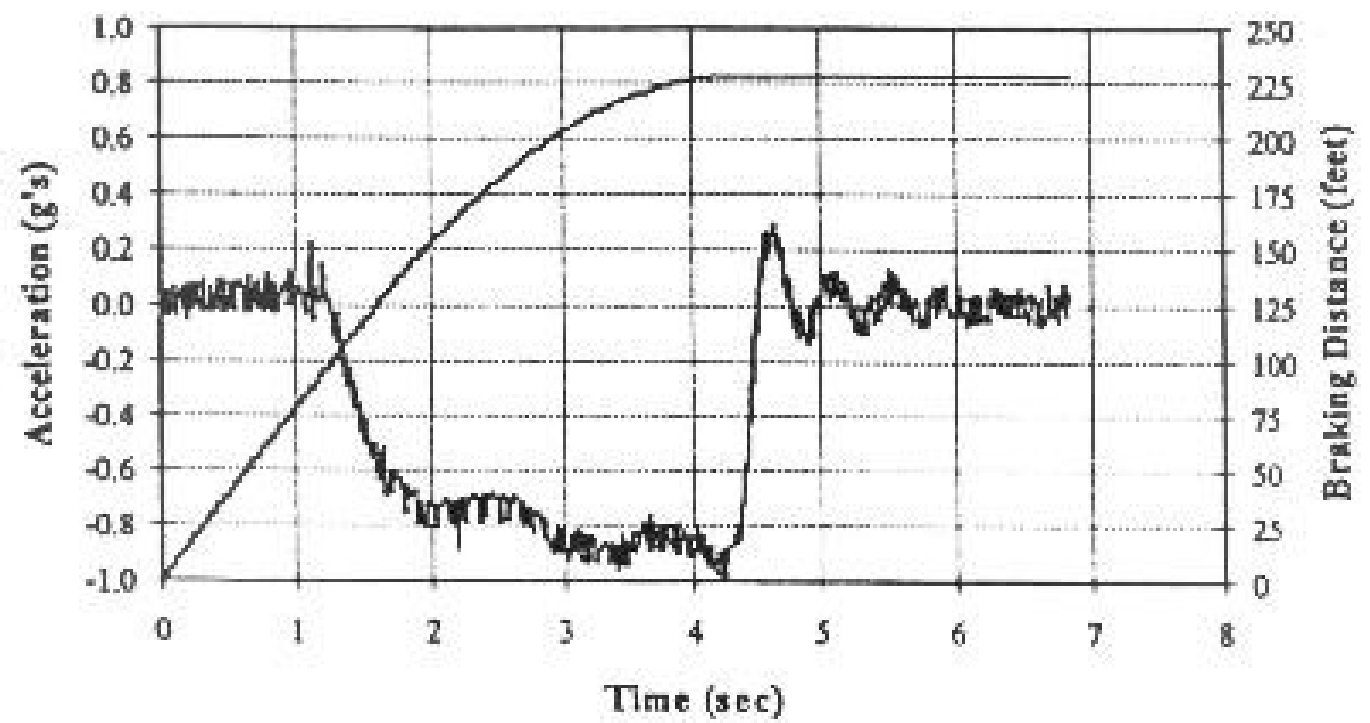

Figura 20: Curva típica de deceleración durante el frenado 


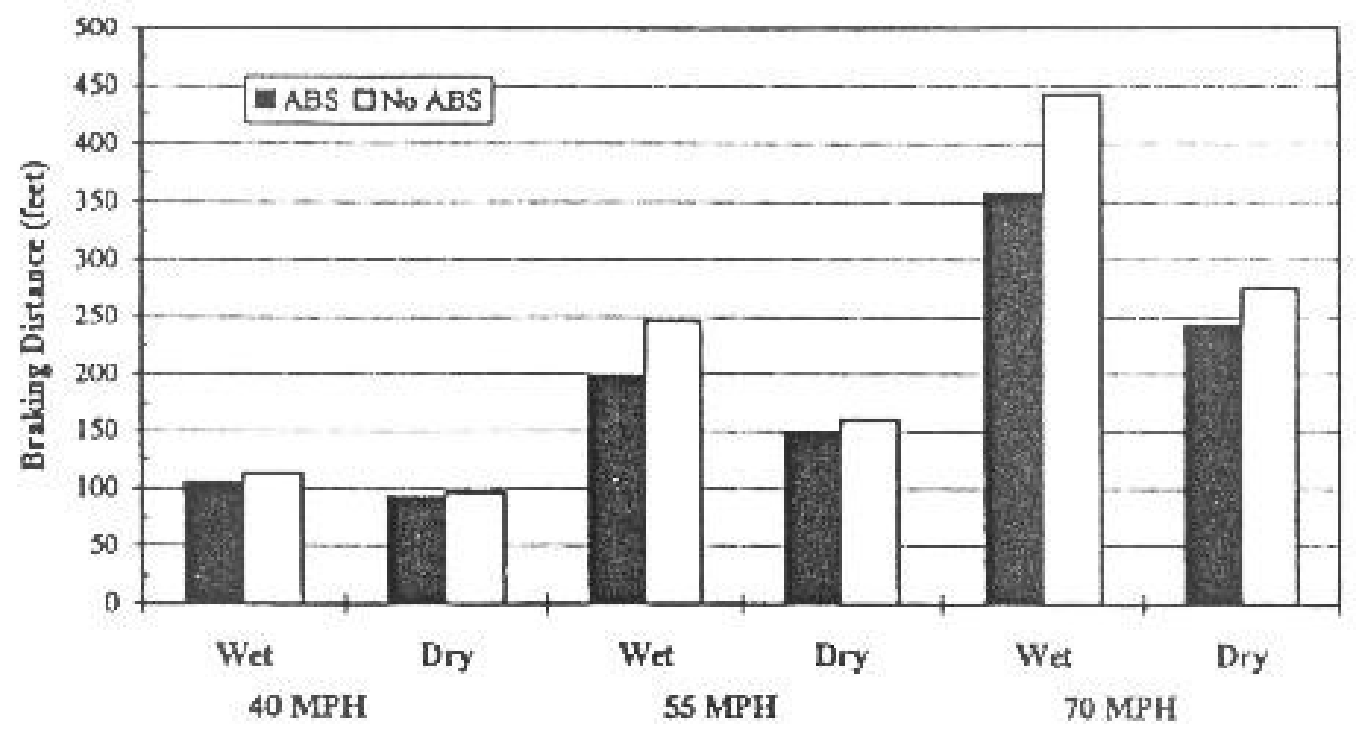

Figura 21: Influencia en la distancia de parada de la velocidad, humedad del pavimento y ABS

Respecto a la deceleración admitida por los conductores como confortable ante la necesidad de frenar por la presencia de un objeto inesperado se debe considerar la que elijan la mayoría de los conductores; por ello se opta por $3,4 \mathrm{~m} / \mathrm{s}^{2}$ ya que aproximadamente el $90 \%$ de los conductores eligieron deceleraciones superiores (AASHTO 2001). Cuando se espera un objeto, como puede ser el caso de un carril de deceleración, la deceleración es menor y por ello parece apropiada, observando la Tabla 10, una deceleración de $3,2 \mathrm{~m} / \mathrm{s}^{2}$, que coincide con el valor propuesto por la ITE. Estos valores pueden justificarse con la Tabla 8, la Tabla 9 y la Tabla 10, donde se resumen los resultados de los estudios de campo 1, 2 y 3 respectivamente, realizados en un circuito cerrado. Como se observa los conductores admiten deceleraciones mayores a las que se aceptan como confortables. Cuando un conductor circula con un vehículo que no le es familiar admite deceleraciones mayores que cuando circula con su vehículo como se observa en las diferentes deceleraciones del estudio 2, (conducen un vehículo al que no están habituados), y el estudio 3 (conducen su propio vehículo).

AASHTO (2001) utiliza en el diseño de la distancia de visibilidad de parada una deceleración constante, $3,4 \mathrm{~m} / \mathrm{s}^{2}$ en vez de un coeficiente de rozamiento en función de la velocidad de diseño. 
Tabla 8: Deceleración admitida por los conductores ante un objeto inesperado. Estudio 1 NCHRP (1997) "Determination of Stopping Sight Distances" Report 400

\begin{tabular}{|c|c|c|c|c|c|c|c|c|}
\hline $\begin{array}{c}\text { VELOCIDAD } \\
\text { (mph) }\end{array}$ & Pavimento & ABS & No & Media & STD & $\mathbf{8 5 \%}$ & $\mathbf{9 0 \%}$ & $\mathbf{9 5 \%}$ \\
\hline 40 & Seco & No & 191 & 0,60 & 0,122 & 0,47 & 0,44 & 0,4 \\
\hline 40 & Seco & Si & 176 & 0,62 & 0,134 & 0,48 & 0,45 & 0,4 \\
\hline 40 & Húmedo & No & 203 & 0,49 & 0,067 & 0,42 & 0,4 & 0,38 \\
\hline 40 & Húmedo & Si & 186 & 0,54 & 0,071 & 0,47 & 0,45 & 0,42 \\
\hline 55 & Seco & No & 216 & 0,65 & 0,135 & 0,51 & 0,48 & 0,43 \\
\hline 55 & Seco & Si & 203 & 0,71 & 0,163 & 0,54 & 0,50 & 0,44 \\
\hline 55 & Húmedo & No & 146 & 0,42 & 0,074 & 0,34 & 0,33 & 0,3 \\
\hline 55 & Húmedo & Si & 171 & 0,53 & 0,206 & 0,32 & 0,26 & 0,19 \\
\hline
\end{tabular}

Tabla 9: Deceleraciones admitidas por los conductores ante un objeto inesperado. Estudio 2. NCHRP (1997) "Determination of Stopping Sight Distances" Report 400

\begin{tabular}{|c|c|c|c|}
\hline \multirow{2}{*}{} & \multicolumn{3}{|c|}{ DECELERACIÓN (g) } \\
\cline { 2 - 4 } & $\begin{array}{c}\text { Estudio 2 } \\
\text { ABS }\end{array}$ & $\begin{array}{c}\text { Estudio 2 } \\
\text { Sin ABS }\end{array}$ & $\begin{array}{c}\text { Estudio 3 } \\
\text { Sin ABS }\end{array}$ \\
\hline Media & 0,63 & 0,62 & 0,55 \\
\hline $75 \%$ & 0,50 & 0,49 & 0,43 \\
\hline $90 \%$ & 0,42 & 0,42 & 0,37 \\
\hline $95 \%$ & 0,38 & 0,38 & 0,32 \\
\hline $99 \%$ & 0,28 & 0,29 & 0,24 \\
\hline AASHTO & 0,30 & 0,30 & 0,30 \\
\hline
\end{tabular}


Tabla 10: Deceleraciones admitidas por los conductores ante un objeto esperado. Estudio 3. NCHRP (1997) "Determination of Stopping Sight Distancies" Report 400.

\begin{tabular}{|c|c|c|c|}
\hline \multirow{2}{*}{} & \multicolumn{3}{|c|}{ DECELERACIÓN (g) } \\
\cline { 2 - 4 } & $\begin{array}{c}\text { Estudio 2 } \\
\text { ABS }\end{array}$ & $\begin{array}{c}\text { Estudio 2 } \\
\text { Sin ABS }\end{array}$ & $\begin{array}{c}\text { Estudio 3 } \\
\text { Sin ABS }\end{array}$ \\
\hline Media & 0,55 & 0,49 & 0,45 \\
\hline $75 \%$ & 0,46 & 0,44 & 0,36 \\
\hline $90 \%$ & 0,40 & 0,41 & 0,31 \\
\hline $95 \%$ & 0,37 & 0,39 & 0,27 \\
\hline $99 \%$ & 0,30 & 0,35 & 0,21 \\
\hline AASHTO & 0,30 & 0,30 & 0,30 \\
\hline
\end{tabular}

\subsubsection{La deceleración en los carriles de deceleración}

En EE.UU. se determinaron las características de los distintos tipos de deceleración, a principios de la década de los 40, analizando el comportamiento del conductor, y los resultados se representaron en gráficas y tablas que siguen empleándose en la actualidad con algunas pequeñas variaciones como considerar ahora velocidades mayores.

Los índices de deceleración por retención con el motor para vehículos ligeros, se determinaron a partir de una serie de trayectos en prueba, (Loutzenheiser 1938), y se muestran en la Figura 23. En otros estudios se obtuvieron valores similares (Wilson, 1940 y Beakey, 1938). Las tasas de deceleración total de la Figura 23 están expresadas de forma más cómoda en la Figura 23 que muestra, la distancia recorrida y la velocidad alcanzada durante un período de tiempo para cualquier velocidad inicial.

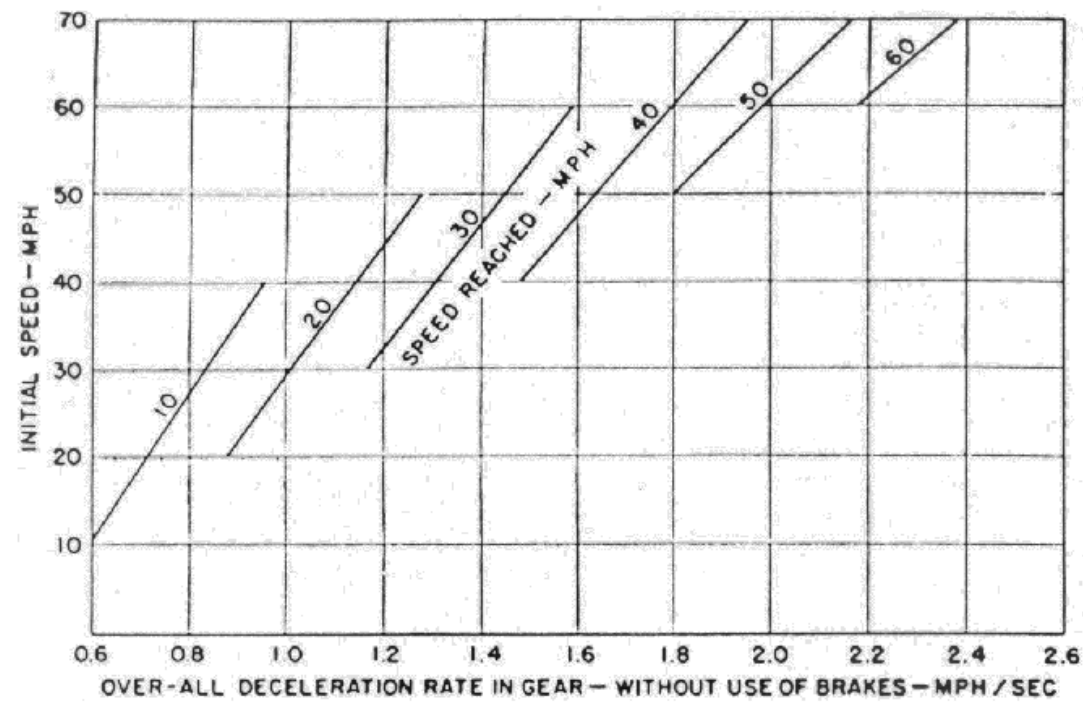

Figura 22: Deceleración por retención con el motor (AASHO 1954) 


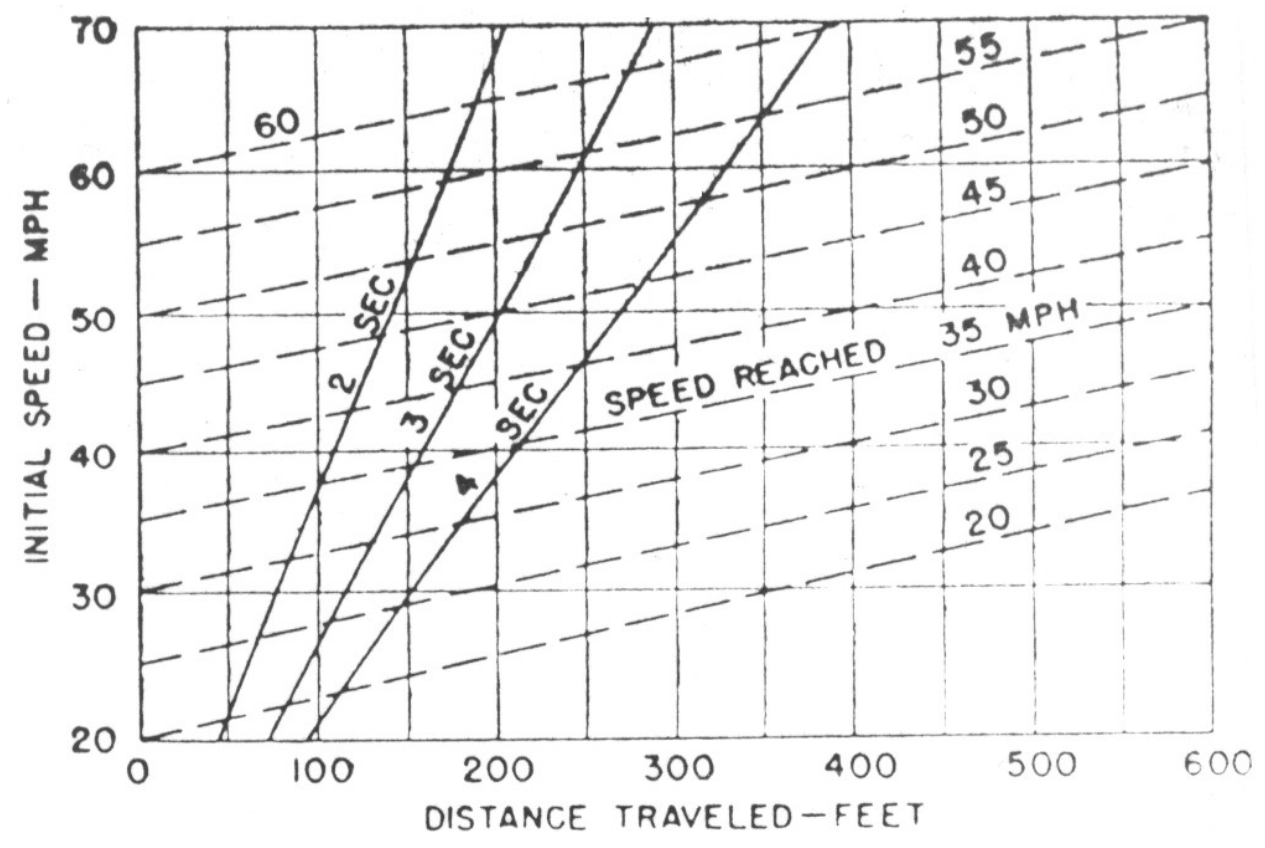

Figura 23: Distancia recorrida reteniendo con el motor.(AASHO 1954)

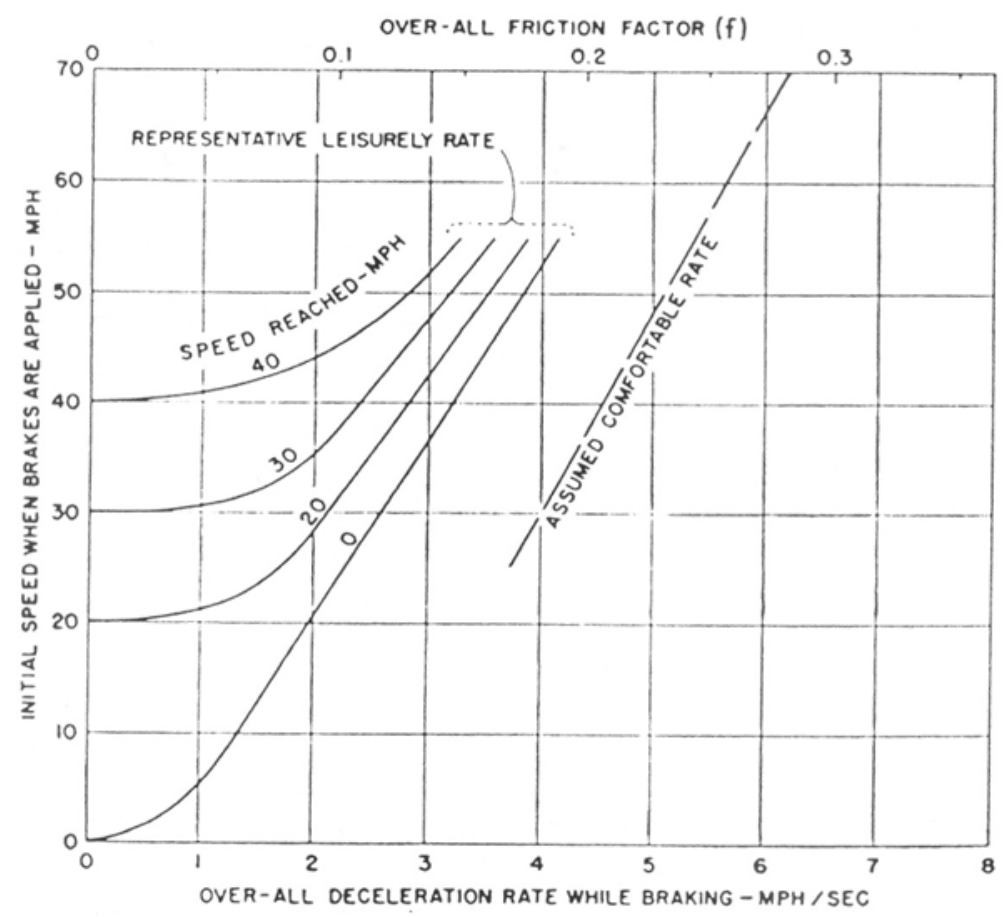

Figura 24: Deceleración al frenar.(AASHO 1954) 


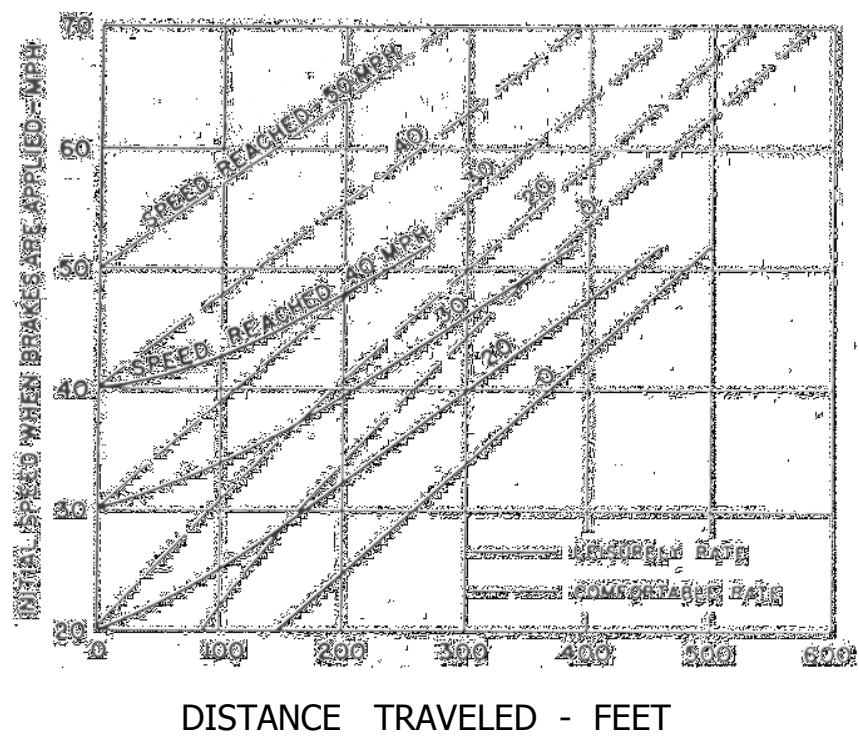

Figura 25: Distancia recorrida mientras se frena (AASHTO 1994)

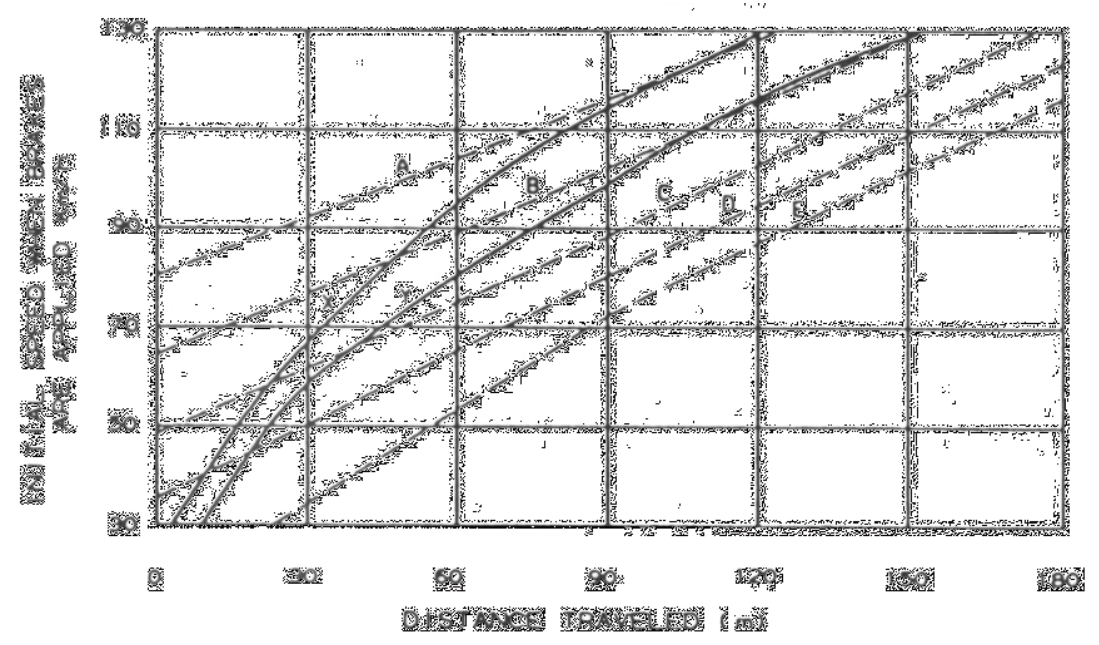

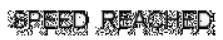

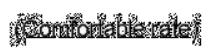

潾

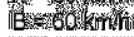

(1)

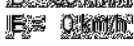

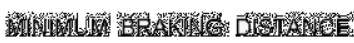

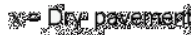

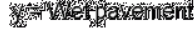

Figura 26: Distancia recorrida mientras se frena. (AASHTO 1994)

Para conocer las características de deceleración del vehículo mientras frena se observaron vehículos aproximándose a una intersección regulada por una señal de stop (J. Beakey, 1938). Al ser esta una acción predeterminada, se supuso que los vehículos que se aproximan a la curva del ramal de salida siguen un comportamiento similar. Los resultados de este estudio se expresan de forma que se muestra la deceleración dada la velocidad inicial y final, estas curvas aparecen en la Figura 24. Los índices, con una deceleración "relajada" son obviamente mucho menores que los llamados índices "confortables". Estos datos se exponen de una forma más útil en la Figura 25, que muestra la distancia recorrida mientras se frena entre dos velocidades cualesquiera. En la actualidad la AASHTO (1994) sólo utiliza el concepto de deceleración confortable y ha convertido la gráfica a las unidades del Sistema Internacional, (Figura 26). 
En las últimas décadas se han llevado a cabo estudios de campo en vías de deceleración en los que se ha analizado la deceleración que han necesitado los conductores para divergir de la autopista. En todos ellos para obtener la deceleración entre dos puntos, j y j+1 se aplicó la ecuación (5).

$$
D_{i j}=\frac{1}{n} \sum_{i=1}^{n} \frac{v^{2}}{2 \cdot d_{j j+1}}
$$

siendo:

- $\quad D_{i j}=$ La deceleración media entre la sección j y j+1, $\left(\mathrm{m} / \mathrm{s}^{2}\right)$

- $v_{i j}=$ La velocidad del vehículo i en el punto j, $(\mathrm{m} / \mathrm{s})$.

- $v_{\mathrm{ij}+1}=$ La velocidad del vehículo i en el punto $\mathrm{j}+1,(\mathrm{~m} / \mathrm{s})$.

- $\mathrm{d}_{\mathrm{j}, \mathrm{j}+1}=\mathrm{La}$ distancia entre los puntos $\mathrm{j}$ y $\mathrm{j}+1,(\mathrm{~m})$

Por lo que salvo cuando se conocía que se estaban aplicando los frenos, (porque se encendían las luces traseras), la deceleración que se obtenía era fruto de la retención con el motor y de aplicar los frenos.

En el ramal de salida se obtuvieron deceleraciones máximas del orden de $1 \mathrm{~m} / \mathrm{s}^{2}$ (Fukutome y Moskowitz (1963), obtuvieron 0,94 m/s y Ackroyd (1975), 0,97 m/s $\mathrm{s}^{2}$ Tabla 11). Cuando la terminción del ramal era un Stop, los conductores frenaban como máximo hasta $1,75 \mathrm{~m} / \mathrm{s}^{2}$ (Fukutome (1963) obtuvo 1,72 m/s ${ }^{2}$ y Ackroyd (1975) 1,61 $\left.\mathrm{m} / \mathrm{s}^{2}\right)$.

En las vías de deceleración, la deceleración depende de:

- La velocidad en el ramal; ya que velocidades menores producen mayores deceleraciones en el tramo final, (Gan-Shmuel).

- La velocidad en la vía principal; en principio mayores velocidades iniciales dan lugar a mayores deceleraciones iniciales, salvo que la longitud del carril de deceleración sea excesiva.

- La longitud de la vía; algunos investigadores afirman que vías más cortas dan lugar a mayores deceleraciones iniciales, (Yanai, en Israel, Tabla 12). En el caso de que la longitud de las vías de deceleración sea excesiva los conductores mantienen la velocidad o incluso la aumentan, (es decir, deceleración nula o incluso aceleración), como lo demuestran los estudios de Ackroyd, (1975). 
Tabla 11: Aceleraciones en la vía de deceleración y en el ramal de salida de tres enlaces del Reino Unido. (Ackroyd, 1975)

\begin{tabular}{|c|c|c|c|c|c|}
\hline \multirow{2}{*}{ LOCALIZACIÓN } & \multicolumn{2}{|c|}{$\begin{array}{c}\text { VÍA DE } \\
\text { DECELERACIÓN }\end{array}$} & \multicolumn{2}{c|}{ RAMAL } & $\begin{array}{c}\text { AL APLICAR } \\
\text { LOS FRENOS }\end{array}$ \\
\cline { 2 - 6 } & LIGEROS & PESADOS & LIGEROS & PESADOS & LIGEROS \\
\hline Sandiacre & 0 & 0 & $-0,97$ & $-0,69$ & $-1,58$ \\
\hline Annesley & $+0,07$ & 0 & $-0,89$ & $-0,78$ & $-1,61$ \\
\hline Nuthall & $-0,19$ & $-0,15$ & $-0,89$ & $-0,67$ & $-1,5$ \\
\hline
\end{tabular}

Al recopilar las deceleraciones que se han obtenido en distintas vías de deceleración se observa que en la actualidad el valor ha aumentado. Colonna (1997), establece que la aceleración está comprendida entre $-2.25 \mathrm{~m} / \mathrm{s}^{2}$ y $-1,25 \mathrm{~m} / \mathrm{s}^{2}$, con un valor medio de cerca de $-1,6 \mathrm{~m} / \mathrm{s}^{2}$, este valor medio coincide con el obtenido por Canale (1998), y corresponde a la deceleración típica de una maniobra en la que sólo se retiene con el motor. Si se comparan estos valores con los obtenidos por Livneh (1988), en la Tabla 12 , se observa que son superiores, al igual que los obtenidos por Ackroyd (1975), en la Tabla 11, si bien estos últimos no son representativos de todas las vías de deceleración ya que analizó vías con una longitud superior a lo normal.

Si se comparan las deceleraciones que se han obtenido con los valores asumidos como confortables por la AASHTO (1954), Tabla 7, se observa que a lo largo de toda la vía de deceleración y del ramal de salida son inferiores, ya que en las vías de deceleración analizadas por Colonna (1997) y Canale (1998) la velocidad inicial era superior a 90 $\mathrm{km} / \mathrm{h}$, y sólo se supera en un caso: en la terminal de un ramal que estudió Fukutome (1963) en la que se frenaba completamente desde $28 \mathrm{mph}$ con una deceleración de $1,72 \mathrm{~m} / \mathrm{s}^{2}$, pero esta deceleración es muy inferior a la que las investigaciones del NCHRP demostraron que asumen los conductores como confortable, $3,4 \mathrm{~m} / \mathrm{s}^{2}$, o la deceleración que asigna Rocci (1993) a las maniobras deliberadas, 2,78 m/s .

Los vehículos pesados deceleran menos que los ligeros como muestran los estudios de Ackroyd (1975) y Livneh (1988), pero también se observa que en las vías de deceleración que están correctamente diseñadas (Netania) o son relativamente largas (los estudiados por Ackroyd 1975) la deceleración de los vehículos ligeros y pesados es similar; por contra, carriles muy corto, (Yanai), acentúan la diferencia. 
Tabla 12: Deceleraciones en 3 vías de deceleración de Israel. (Livneh et al., 1988).

\begin{tabular}{|c|c|c|c|c|c|c|}
\hline \multirow{2}{*}{ LOCALIZACIÓN } & \multicolumn{3}{|c|}{ DECELERACIÓN DE LOS } & \multicolumn{3}{c|}{$\begin{array}{c}\text { DECELERACIÓN DE LOS } \\
\text { VEHÍCULOS PESADOS(m/s }\end{array}$} \\
\cline { 2 - 7 } & $\begin{array}{c}\mathbf{1 0}^{\mathbf{0}} \\
\text { TERCIO }\end{array}$ & $\begin{array}{c}\mathbf{2}^{\mathbf{0}} \\
\text { TERCIO }\end{array}$ & FINAL & $\begin{array}{c}\mathbf{1 0}^{\mathbf{0}} \\
\text { TERCIO }\end{array}$ & $\begin{array}{c}\mathbf{2}^{\mathbf{0}} \\
\text { TERCIO }\end{array}$ & FINAL \\
\hline Netania & 0,45 & 0,51 & 0,79 & 0,46 & 0,55 & 0,74 \\
\hline Yanai & 1,02 & 1,24 & 0,93 & 0,58 & 0,83 & 0,31 \\
\hline Gan-Shmuel & 0,81 & 0,56 & 1,48 & 0,40 & 0,58 & 1,03 \\
\hline
\end{tabular}

Se decelera más al final de la vía de deceleración, cerca del ramal, salvo si la vía es muy corta en cuyo caso las mayores deceleraciones tienen lugar antes, como se observa en el estudio de Livneh (1988). Con esto se corrobora que en las vías de deceleración los conductores se comportan como se indicó en la Figura 20.

En el carril de Netania, que se ajusta a los criterios de diseño de la AASHTO (2001), se separó la deceleración que se alcanzaba con la retención del motor y la que se obtenía frenando. A cada tipo de deceleración se le ajustó una recta. La recta que determinaba la deceleración al frenar resultó tener una pendiente similar a la de la recta que según la AASHTO (2001) proporciona una deceleración confortable. Los valores de la retención con el motor recomendado por la AASHTO (2001), son considerablemente superiores a los obtenidos en Netania. Por ejemplo, para una velocidad de $80 \mathrm{~km} / \mathrm{h}$, el valor recomendado es de $0,77 \mathrm{~m} / \mathrm{s}^{2}$, mientras que la ecuación de la recta obtenida por Livneh (1988) sugiere un valor de $0,42 \mathrm{~m} / \mathrm{s}^{2}$, una diferencia del $45 \%$. Los resultados se muestran en la Figura 27.

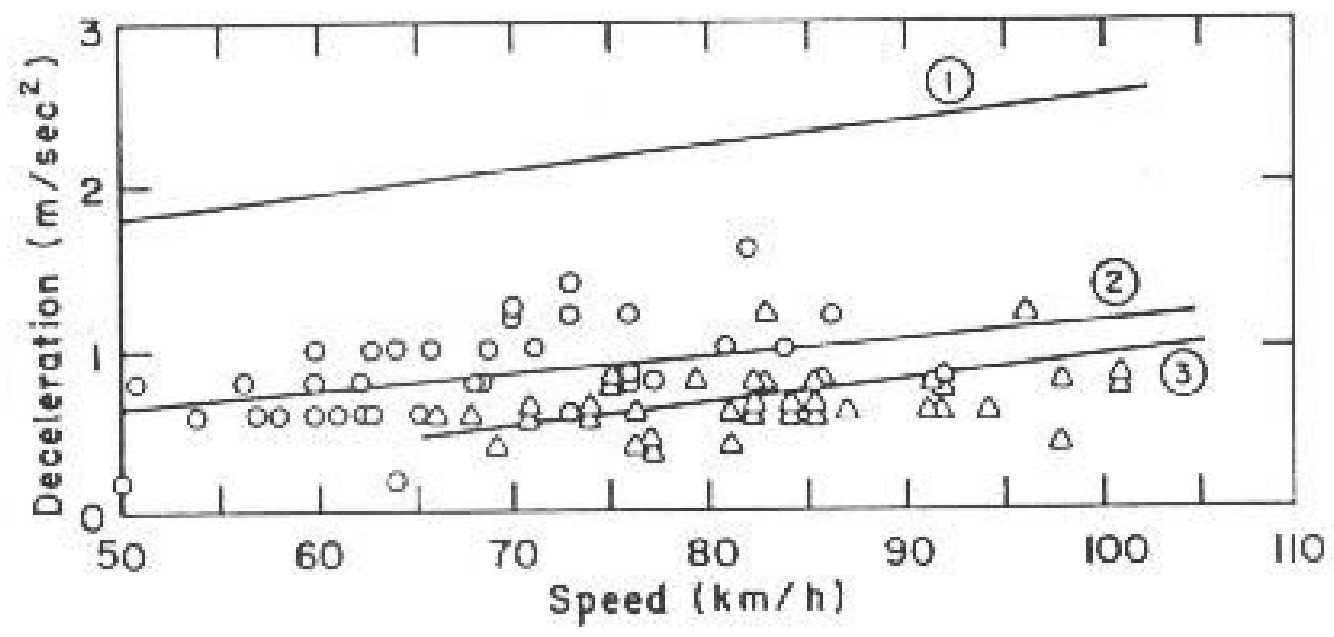

1 Deceleración propuesta por la AASHTO mientras se frena

2 Deceleración frenando. $\mathrm{DB}=0,05447+0,0113 \cdot \mathrm{SB}$ (SB Velocidad al comenzar a frenar)

3 Retención del motor DG $=-0,77305+0,01495 \cdot S G$ (SG Velocidad al inicio del carril de deceleración)

Figura 27: Deceleración frenando y reteniendo con el motor. (Livneh 1988) 
Todo lo tratado hasta ahora se refiere a la aceleración longitudinal pero cuando un vehículo se incorpora a una vía de deceleración se desplaza lateralmente y aparece una aceleración transversal. De todos los estudios que se han llevado a cabo sólo se ha tenido en cuenta en el realizado por Colonna (1997), por eso a continuación se adjunta la Figura 28 en la que se observa la variación de la aceleración transversal a lo largo de la coordenada curvilínea ya que aunque no de forma clara si sirve para dar un orden de magnitud y observar su evolución, a la vez que es un documento único.

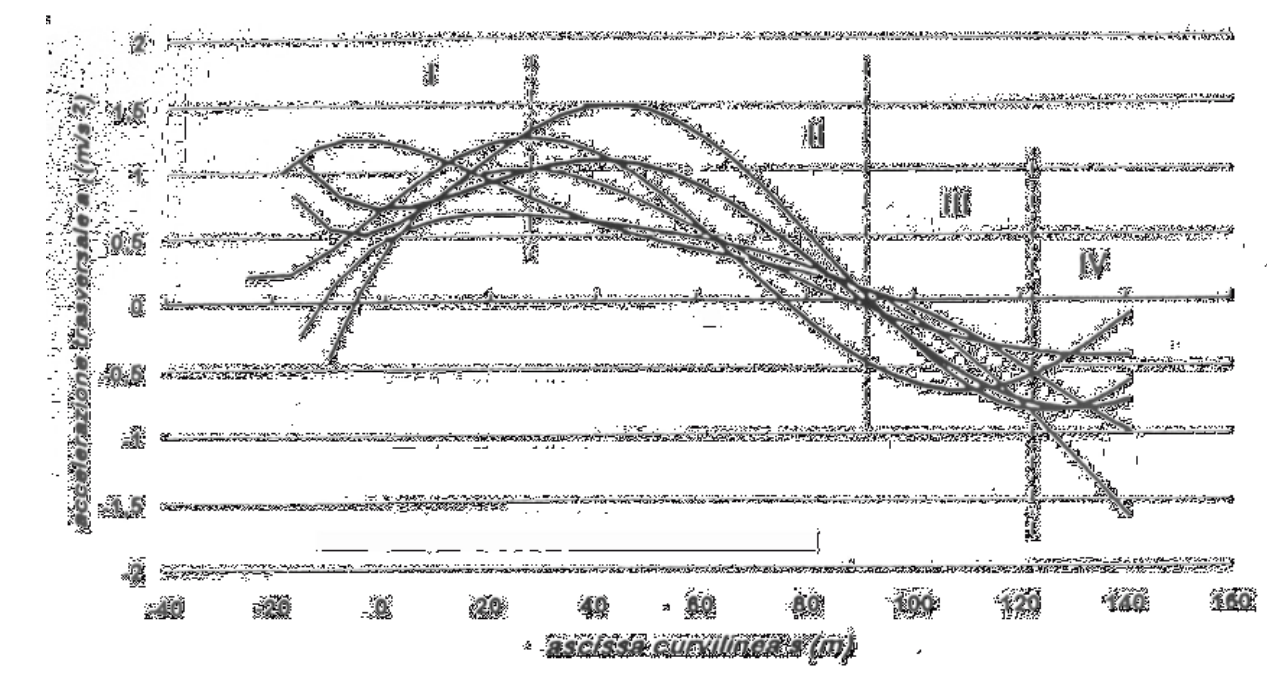

Figura 28: Evolución de la aceleración transversal a lo largo de una vía de deceleración en curva de signo opuesto a la del tronco. (Colonna et al. 1997).

\subsubsection{Seguridad vial}

En una carretera se pretende que la circulación sea segura, y por tanto sin accidentes, pero por desgracia los accidentes son un fenómeno cotidiano. De acuerdo con la Dirección General de Energía y Transportes (2009) durante el año 2007en la Unión Europea-27, perdieron la vida, en accidentes de tráfico, 42.448 personas, y ocurrieron 1.276.800 accidentes con víctimas. En el "Programa de acción europeo de seguridad vial 2003-2010", la Comisión persigue un objetivo global: reducir a la mitad el número de personas que fallecen anualmente en la carretera.

Esta siniestralidad representa el aspecto negativo de mayor importancia de los relacionados con la circulación por carretera, y por tanto es imprescindible reducirlos al máximo. Por ello se debe estudiar donde se producen, cómo ocurren y los factores que han influido en los mismos, para luego extraer unas conclusiones que lleven a reducir su número y gravedad.

Al analizar los puntos en los que se han producido accidentes se observa que los enlaces son puntos conflictivos: en EEUU, entre el $20 \%$ y el $30 \%$ de los accidentes de camión en las autopistas suceden en o cerca de los enlaces, (excluyendo las intersecciones), a pesar de que suponen menos de un $5 \%$ de todos los kilómetros de 
carril en las autopistas. Asimismo, las estadísticas reflejan que los accidentes por vehículo y distancia recorrida son más frecuentes en las secciones de las autopistas con puentes o enlaces que en las secciones sin ellos.

En las vías de deceleración los accidentes se caracterizan porque en más de la mitad de los accidentes interviene un único vehículo, en el $42 \%$ de los accidentes intervienen objetos fijos y los accidentes más habituales son los raspados.

Lo anterior justifica el considerable interés y esfuerzo que se ha empleado en investigaciones para relacionar la seguridad con el diseño geométrico y las operaciones características de los ramales de los enlaces de las autopistas.

A continuación se resumen las conclusiones a las que se han llegado en las distintas investigaciones, (Lundy, 1967; Cirillo, 1970; Twomey et al. 1993, Janson et al. 1998, Bared et al. 1999, Chen et al 2008, Byung et al. 2010, Chen 2010), que han analizado la seguridad vial en los ramales de salida (si no se indica lo contrario incluye al carril de deceleración). Los valores numéricos son los obtenidos en los ramales analizados y no se pueden extrapolar a todos pero sirven para indicar correlaciones y dan un orden de magnitud.

Los datos de los accidentes se pueden analizar bajo distintos puntos de vista:

\subsubsection{Aspectos no geométricos.}

\subsection{Gravedad del accidente.}

No se observan diferencias significativas a la hora de clasificar los accidentes por su gravedad entre los porcentajes del ramal de salida (incluido el carril de deceleración) y de la vía principal, (Tabla 13). Se aprecia que en el ramal de salida hay más accidentes en los que sólo se producen daños materiales que en las secciones de la autopista, cuando podría esperarse una proporción mayor de accidentes con heridos o muertos que en la vía principal porque tienen un gran número de elementos fijos adyacentes; sin embargo, esto no sucede, y es muy probable que se deba a que las velocidades son menores.

Tabla 13: Gravedad de los accidentes. (Lundy, 1967).

\begin{tabular}{|c|c|c|}
\hline \multirow{2}{*}{ GRAVEDAD DEL ACCIDENTE } & \multicolumn{2}{|c|}{ PORCENTAJE TOTAL DE ACCIDENTES } \\
\cline { 2 - 3 } & RAMAL DE SALIDA & AUTOPISTA \\
\hline CON MUERTOS & 1,5 & 1,8 \\
\hline CON HERIDOS & 41,5 & 42,9 \\
\hline SÓLO CON DAÑOS MATERIALES & 57,0 & 55,3 \\
\hline TOTAL & 100,0 & 100,0 \\
\hline No DE HERIDOS POR ACCIDENTE & 0,58 & 0,74 \\
\hline
\end{tabular}




\subsection{Accidentes simples o múltiples.}

En los ramales de salida el porcentaje de accidentes en los que se ve involucrado un solo vehículo es mayor que en las autopistas pero se ve contrarrestado por el descenso de los accidentes de 3 o más vehículos (Tabla 14). La causa puede ser que muchos accidentes se deben a vehículos que se salen del ramal porque circulan a una velocidad superior a la que fue diseñado.

Tabla 14: Vehículos involucrados en los accidentes. (Lundy, 1967)

\begin{tabular}{|c|c|c|c|}
\hline \multirow{2}{*}{ TIPO } & \multicolumn{2}{|c|}{$\begin{array}{c}\text { ACCIDENTES TOTALES } \\
\text { (Porcentaje) }\end{array}$} & $\begin{array}{c}\text { ÍNDICE DE } \\
\text { ACCIDENTES } \\
\text { (ACC/MV) }\end{array}$ \\
\cline { 2 - 4 } & RAMAL DE SALIDA & AUTOPISTA & RAMAL DE SALIDA \\
\hline UN VEHÍCULO & 51 & 28 & 0,48 \\
\hline DOS VEHÍCULO & 43 & 53 & 0,41 \\
\hline TRES O MÁS VEHÍCULOS & 6 & 19 & 0,06 \\
\hline TOTAL & 100 & 100 & 0,95 \\
\hline
\end{tabular}

Con los datos de los accidentes de los camiones de más de 1000 libras en el estado de Washington analizados por Janson et al. (1998) se obtiene que los roces laterales, son, con un porcentaje similar, los más frecuentes en cualquier tipo de ramal, y que el mayor número de vuelcos se produce en los enlaces tipo lazo. Si se analiza la zona en que se producen se obtiene que los roces laterales son los más frecuentes en cualquier zona, especialmente en el área de divergencia y en la zona corriente abajo de la cuña. En el ramal de salida se produce el mayor número de vuelcos y el menor de colisiones traseras.

\subsection{Objetos fijos}

Los objetos fijos se ven involucrados en alrededor del $42 \%$ del total de los accidentes del ramal de salida. No sorprende un porcentaje tan alto porque las áreas de los ramales de salida contienen alrededor del $36 \%$ del total de los objetos fijos de las autopistas y estos se concentran en puntos como la nariz, que es extremadamente vulnerable a los conductores que interpretan mal el carril de deceleración.

\subsection{Iluminación del ramal}

En la Tabla 15 se muestra el porcentaje total de accidentes producidos bajo varias condiciones de iluminación en los ramales de salida y en las autopistas. Esta información presentada así es poco útil pero permite obtener la tasa de accidentes diurnos y nocturnos. Lógicamente el mayor porcentaje de accidentes se produce de día porque es el periodo más largo y circulan más vehículos y el menor porcentaje al 
amanecer y anochecer porque es el periodo más pequeño con diferencia. La razón que justifica que en los ramales sean menos los accidentes de noche sin alumbrado que los alumbrados, es porque son menos los enlaces no alumbrados.

Tabla 15: Distribución de los accidentes según la iluminación. (Lundy 1967)

\begin{tabular}{|c|c|c|}
\hline \multirow{2}{*}{$\begin{array}{c}\text { CONDICIONES DE } \\
\text { ILUMINACIÓN }\end{array}$} & \multicolumn{2}{|c|}{ PORCENTAJE DE ACCIDENTES } \\
\cline { 2 - 3 } & RAMAL DE SALIDA & AUTOPISTA \\
\hline DE DÍA & 57 & 52 \\
\hline AMANECER-ANOCHECER & 3 & 3 \\
\hline DE NOCHE SIN ALUMBRADO & 8 & 25 \\
\hline DE NOCHE CON ALUMBRADO & 32 & 21 \\
\hline TOTAL & 100 & 100 \\
\hline
\end{tabular}

Para calcular la tasa de accidentes diurnos y nocturnos, (Tabla 16) se emplea la hipótesis de que el $70 \%$ de los trayectos se producen de día y el $30 \%$ durante el alba, el ocaso y de noche, y se aplica ecuación (6):

$$
\text { Tasa de Accidentes diurnos }=\text { Tasa de accidentes }-\frac{\% \text { acidentes diurnos }}{\text { exposición diurna }}
$$

La tasa de accidentes nocturnos es superior a la diurna, y se observa que la de los ramales de salida es significativamente menor a la de las autopistas, pero es difícil determinar si este descenso se debe al alumbrado de los enlaces.

Tabla 16: Tasa de accidentes nocturnos y diurnos. (Lundy 1967)

\begin{tabular}{|c|c|c|c|c|}
\hline TIPO & $\begin{array}{c}\text { TASA DE } \\
\text { ACCIDENTES TOTAL } \\
\text { (Acc/MV) }\end{array}$ & $\begin{array}{c}\text { TASA } \\
\text { DIURNA }\end{array}$ & $\begin{array}{c}\text { TASA } \\
\text { NOCTURNA }\end{array}$ & $\begin{array}{c}\text { PORCENTAJE } \\
\text { DE AUMENTO }\end{array}$ \\
\hline RAMAL DE SALIDA & 0,95 & 0,77 & 1,36 & 77 \\
\hline AUTOPISTA & 1,29 & 0,96 & 2,06 & 115 \\
\hline
\end{tabular}

\subsection{Efecto de los volúmenes de tráfico}

Cuando el volumen tráfico es pequeño son frecuentes los accidentes en la salida de la autopista hacia los ramales, debido a que los vehículos salen fuera de la calzada con un exceso de velocidad para iniciar la maniobra. 
En los ramales con mayor volumen de tráfico disminuyen los accidentes, esto puede deberse a una combinación de dos factores: generalmente los criterios de diseño son mejores para volúmenes mayores y los volúmenes altos impiden que se desarrollen velocidades muy elevadas lo que lleva a que la velocidad se aproxime a la prevista en el ramal.

\subsubsection{6 Área de influencia}

Analizando el número de accidentes que se producen corriente arriba de la nariz de un carril de deceleración se puede determinar el área en la que influye. Sin embargo con los datos de Cirillo (1967) es difícil determinarla con exactitud porque utiliza intervalos muy amplios, pero se observa que en zonas urbanas el área de influencia es mayor. Esto puede deberse a que la intensidad es mayor y como se observó los conductores acostumbran a decelerar en el carril principal y perturban más la circulación.

Tabla 17: Índice de accidentes en la proximidad de los ramales de salida. (Cirillo 1967)

\begin{tabular}{|c|c|c|}
\hline $\begin{array}{c}\text { DISTANCIA A LA NARIZ } \\
\text { (Corriente arriba) }\end{array}$ & $\begin{array}{c}\text { TASA }^{\text {a }} \text { DE ACCIDENTES } \\
\text { URBANOS }\end{array}$ & $\begin{array}{c}\text { TASA }^{\mathrm{a}} \text { DE ACCIDENTES } \\
\text { INTERURBANOS }\end{array}$ \\
\hline menos de 0,2 millas & 131 & 76 \\
\hline $0,2-0,5$ millas & 127 & 75 \\
\hline $0,5-1$ millas & 110 & 69 \\
\hline 1-2 millas & 75 & 69 \\
\hline 2-4 millas & 63 & 68 \\
\hline 4-8 millas & 69 & 62 \\
\hline
\end{tabular}

${ }^{\text {a } A c c / 100 ~ M V ~ M i l l a s ~}$

Pero con los datos de los accidentes de los camiones de más de 1000 libras en el estado de Washington sí se puede determinar la zona de influencia del ramal de salida. Los resultados se muestran en la Figura 29, donde aparecen los accidentes de camión corriente arriba y abajo de la cuña y donde se observa que el área de influencia se extiende 0,25 millas $(400 \mathrm{~m})$ corriente arriba de la cuña y 0,2 millas (320 m) corriente abajo de la cuña. 


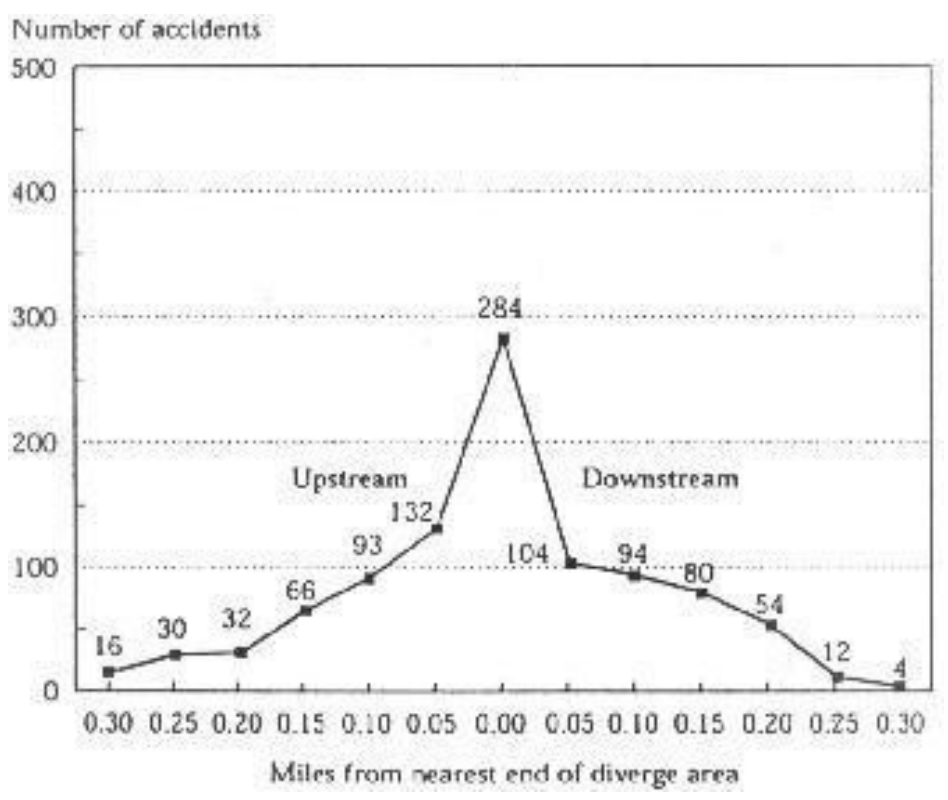

Longitud media del carril de deceleración: 0,107 millas =172 m; 1 milla =1609 m

Figura 29: Número de accidentes de camión en el área de divergencia, respecto a la nariz. (Janson, 1998)

\subsubsection{Aspectos geométricos}

\subsection{Tipo de ramal}

En la Figura 30 se muestran las tasas de accidentes para los tipos básicos de ramales de salida. En ella se observa que los ramales con mayor tasa de accidentes son los de salida por la izquierda y las tijeras, (ramal que conecta con una vía de doble sentido en un punto en el que éstos se han separado; cruza primero el sentido opuesto y luego confluye con el otro a un sólo carril), ya que requieren maniobras complejas o inesperadas que aparentemente causan la confusión. Los ramales en enlaces tipo diamante, que son rectos, son los de menor tasa de accidentes. El resto tienen índices similares. Las tasas son tasas medias y no reflejan necesariamente la seguridad de los distintos tipos de enlace porque no incluyen los accidentes en los cruces ni en el carril principal contiguo al carril de deceleración. 


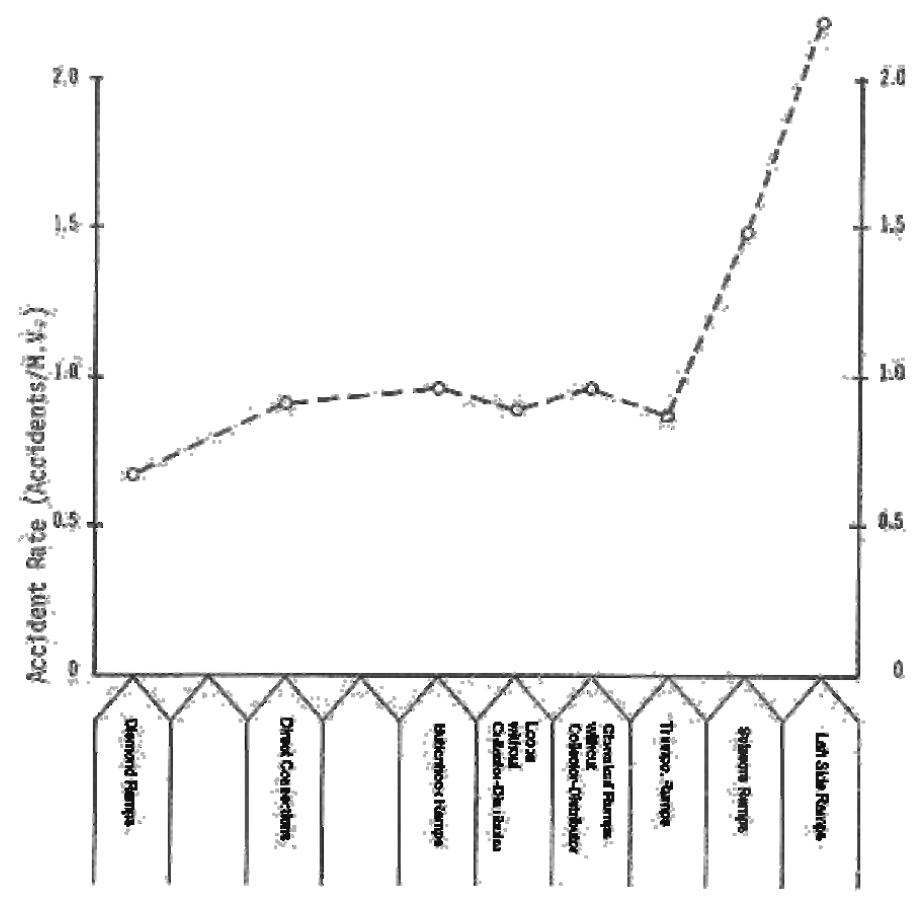

Figura 30: Tasas de accidentes según el tipo de ramal de salida. (Lundy 1967)

Los estudios indican que deben evitarse siempre que sean posibles las salidas por la izquierda y los ramales en tijera y que deben usarse vías colectoras cuando el volumen de tráfico es alto, especialmente cuando se utilizan lazos y tréboles.

\subsection{Ramal en rampa o en pendiente}

Los ramales de salida en rampa tienen una tasa de 0,89 Acc/MV en comparación con los 1,07 Acc/MV si está en pendiente. Esta diferencia puede deberse a que la gravedad facilita la deceleración en los casos en rampa y a que dificulta la deceleración cuando se encuentra en pendiente.

\subsection{Localización de los accidentes en los ramales de salida}

De los accidentes que se producen en un ramal de salida, el porcentaje mayor tiene lugar en el carril de deceleración. Esto puede deberse a que, como se observó al estudiar la velocidad, en el carril de deceleración no se frena tanto como se había previsto al diseñarlo.

Si se analizan los accidentes por vehículo y longitud se observa que hay diferencia según la zona de conflicto ya que la frecuencia de accidentes en el carril de deceleración es mucho mayor, seguida, por este orden, de la zona corriente abajo de la nariz, la zona corriente arriba de la cuña y el ramal de salida. A este resultado llegó Janson (1998) al analizar los ramales en los que habían sucedido accidentes dividiendo la zona de influencia de la divergencia en cuatro áreas, (consecuencia de la Figura 29), que se muestran en la Figura 31. Los resultados aparecen en la Tabla 18 y sirven de orientación pero no son extrapolables porque se analizan sólo los ramales con 
accidentes, en el área de divergencia se incluye la vía de deceleración y el carril exterior de la autopista y se estudian sólo los camiones.

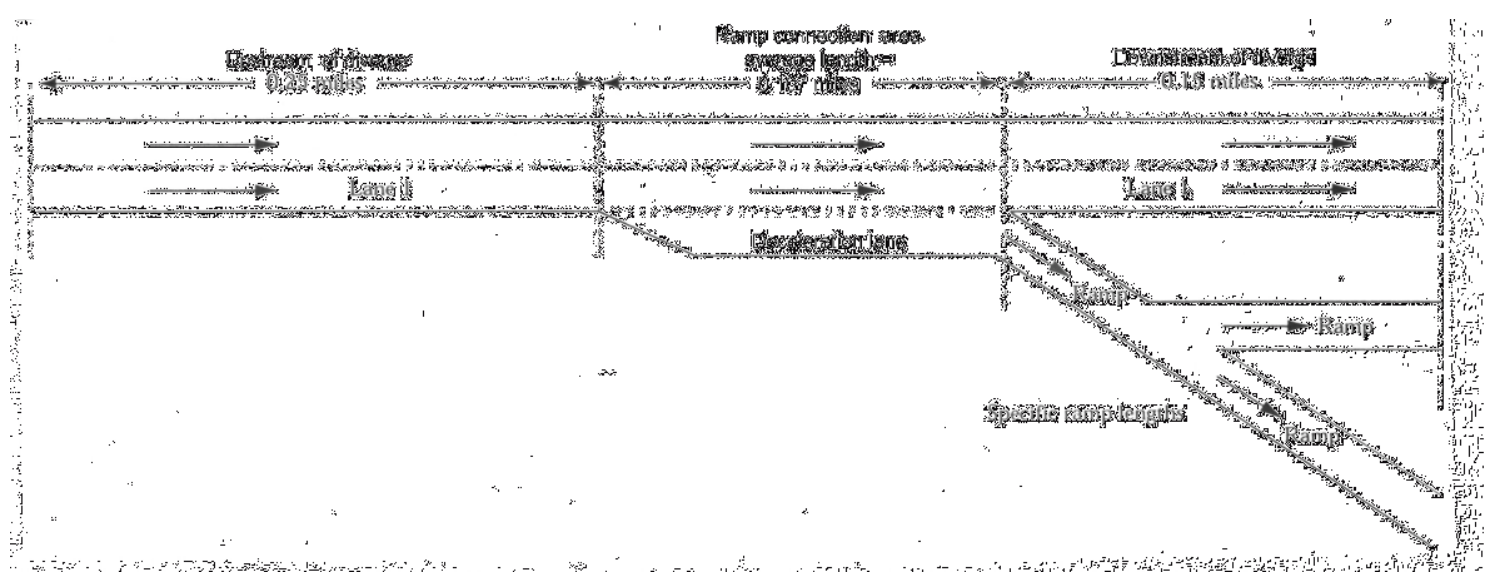

Figura 31: Las cuatro áreas de conflicto dentro de la zona de influencia. (Janson 1998).

Tabla 18: Índice de accidentes de camión según el área de influencia de un ramal de salida (Janson 1998).

\begin{tabular}{|c|c|c|c|}
\hline & $\begin{array}{c}\text { No DE } \\
\text { ACCIDENTES }\end{array}$ & $\begin{array}{c}\text { CAMIONES EN EL RAMAL Y } \\
\text { MILLA RECORRIDA. CRD } \\
\text { (Millón) }\end{array}$ & Acc/CRD \\
\hline CORRIENTE ARRIBA & 119 & 29,7 & 4,0 \\
\hline ÁREA DE DIVERGENCIA & 131 & 14,6 & 9,0 \\
\hline RAMAL & 91 & 52,1 & 1,7 \\
\hline CORRIENTE ABAJO & 122 & 23,8 & 5,1 \\
\hline TOTAL & 463 & 120,3 & 3,8 \\
\hline
\end{tabular}

En la Figura 32 se representan los índices de accidentes, para los distintos tipos de ramal, según se hayan producido en el carril de deceleración o en el área del ramal de salida. Los datos muestran que, si se excluyen las salidas por la izquierda, no hay diferencias significativas entre las tasas de accidentes en los carriles de deceleración de los distintos tipos de ramales. El ramal "gancho" (ramal compuesto por una alineación recta y en la terminal una curva de radio pequeño que lo conecta perpendicularmente con una vía de doble sentido de circulación), y el de salida por la izquierda experimentan la tasa de accidentes mayor, (no hay datos que permitan localizar en qué punto del ramal en tijera se produce el accidente). 


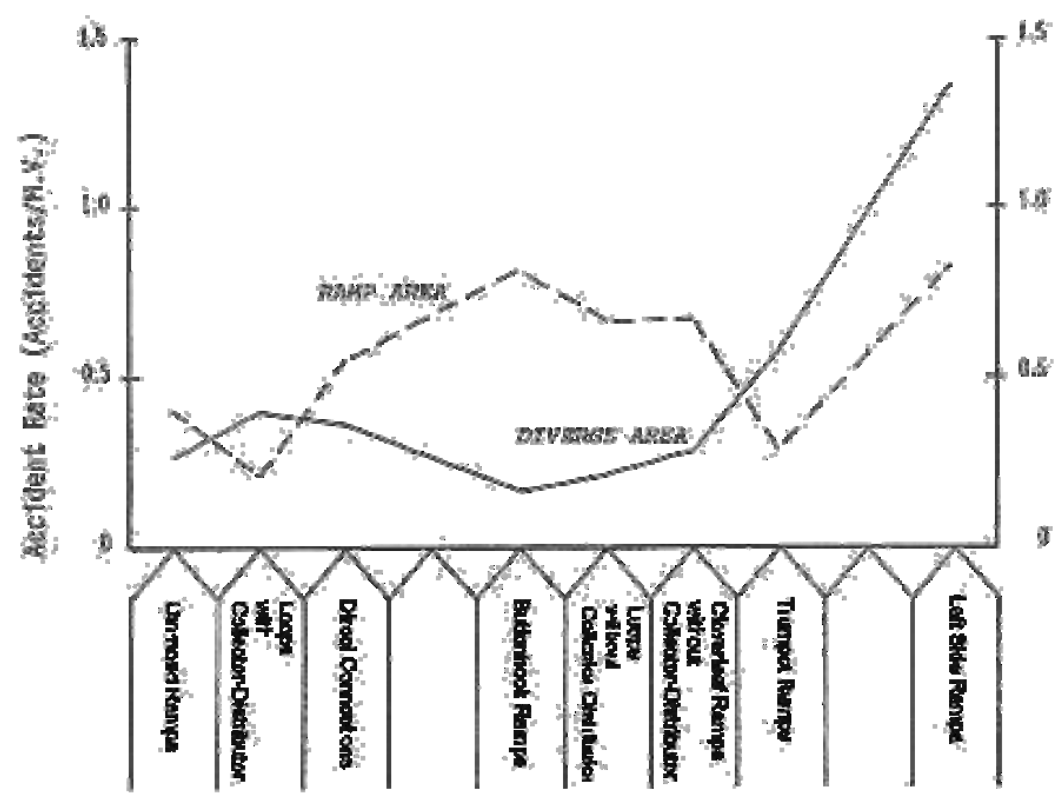

Figura 32: Tasas de accidentes: Carril de deceleración vs tronco de salida. (Lundy 1967)

En la Figura 32 se representan los índices de accidentes, para los distintos tipos de ramal, según se hayan producido en el carril de deceleración o en el área del ramal de salida. Los datos muestran que, si se excluyen las salidas por la izquierda, no hay diferencias significativas entre las tasas de accidentes en los carriles de deceleración de los distintos tipos de ramales. El ramal "gancho", (ramal compuesto por una alineación recta y en la terminal una curva de radio pequeño que lo conecta perpendicularmente con una vía de doble sentido de circulación), y el de salida por la izquierda experimentan la tasa de accidentes mayor, (no hay datos que permitan localizar en qué punto del ramal en tijera se produce el accidente).

\subsection{Geometría de los ramales de salida}

Lundy (1967) para analizar la influencia de la geometría se ordenaron los ramales de salida según diferentes variables: longitud, radio, ángulo, y se obtuvo la tasa de accidentes, resultando la Figura 33. En ella se observa que los ramales de salida con longitudes del carril de deceleración elevadas ( $270 \mathrm{~m}$ o más), tienen tasas menores que los ramales con longitudes de deceleración menores. Los ramales con radios pequeños y ángulos de la primera curva elevados tienen tasas menores que si el radio y el ángulo son medios, y ello es debido posiblemente a que los conductores toman mayores precauciones en el primer caso mientras que no perciben como peligrosos los ramales de radio y ángulo medio. Los ramales rectos, (radio infinito y ángulo cero), tienen tasas menores que cualquiera de los ramales curvos.

El hecho de que la tasa de accidentes sea menor a mayor longitud del carril de deceleración podría llevar a incrementar su longitud, pero los estudios demuestran que se obtiene un beneficio relativamente pequeño si el porcentaje de vehículos que 
divergen es menor que el $6 \%$ del volumen de la vía principal, (Figura 32) Cuando se supera el $6 \%$, la longitud adicional aporta cierto beneficio en términos de descenso de la tasa de accidentes.

\section{TASA DE ACCIDENTES}

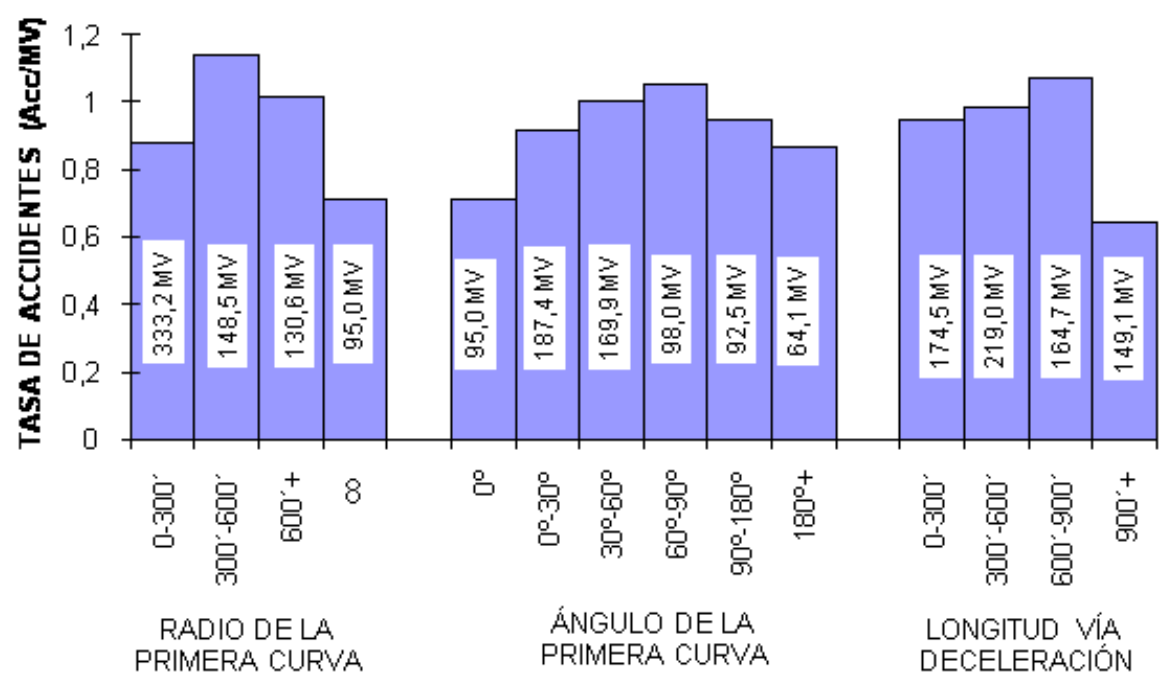

Figura 33: Tasas de accidentes al variar el radio y el ángulo de la primera curva del ramal, y la longitud del carril de deceleración. (Lundy 1967)

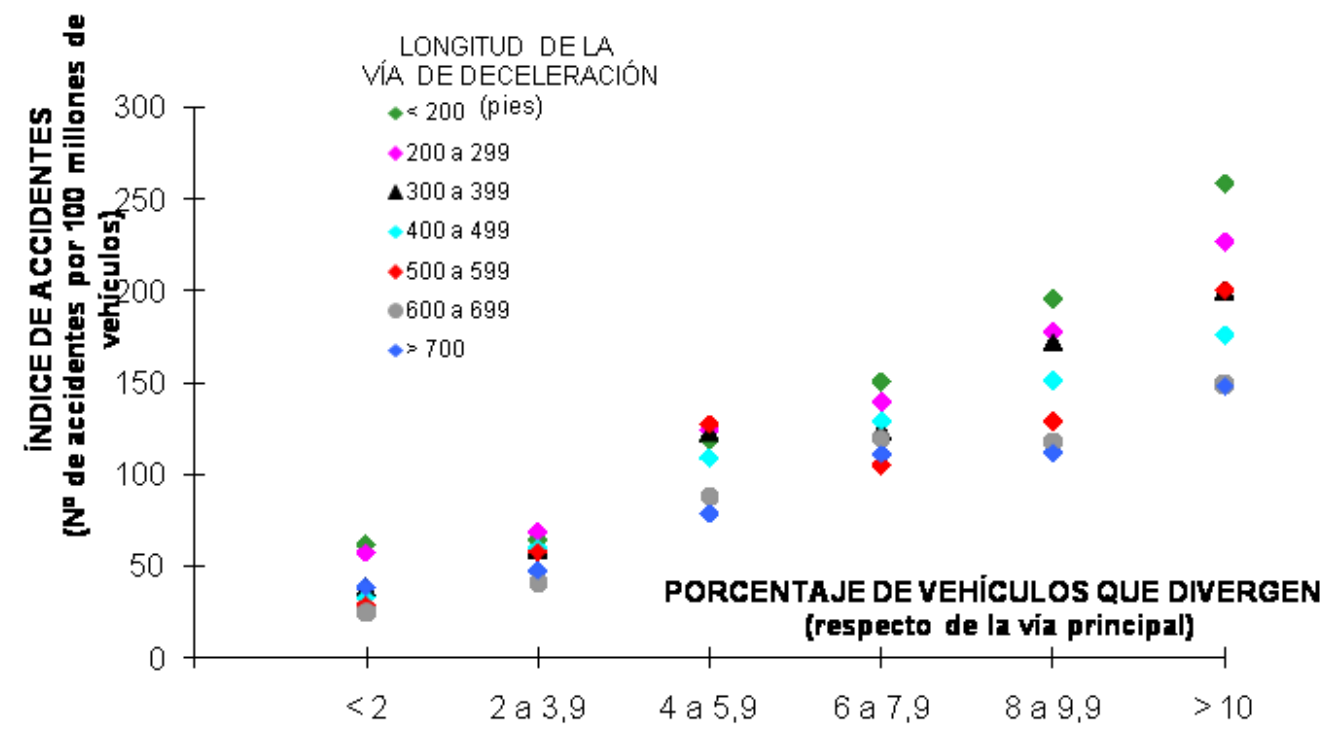

Figura 34: Tasa de accidentes en función de la longitud del carril de deceleración. (Cirillo 1970). 
Bared et al (1999), basado en la variación de la accidentalidad en función de la longitud, encontrada por Cirillo (1970), resalta la importancia de tener longitudes mayores en los carril de cambio de velocidad, pero limita su longitud basado en un análisis coste beneficio, (Figura 35).

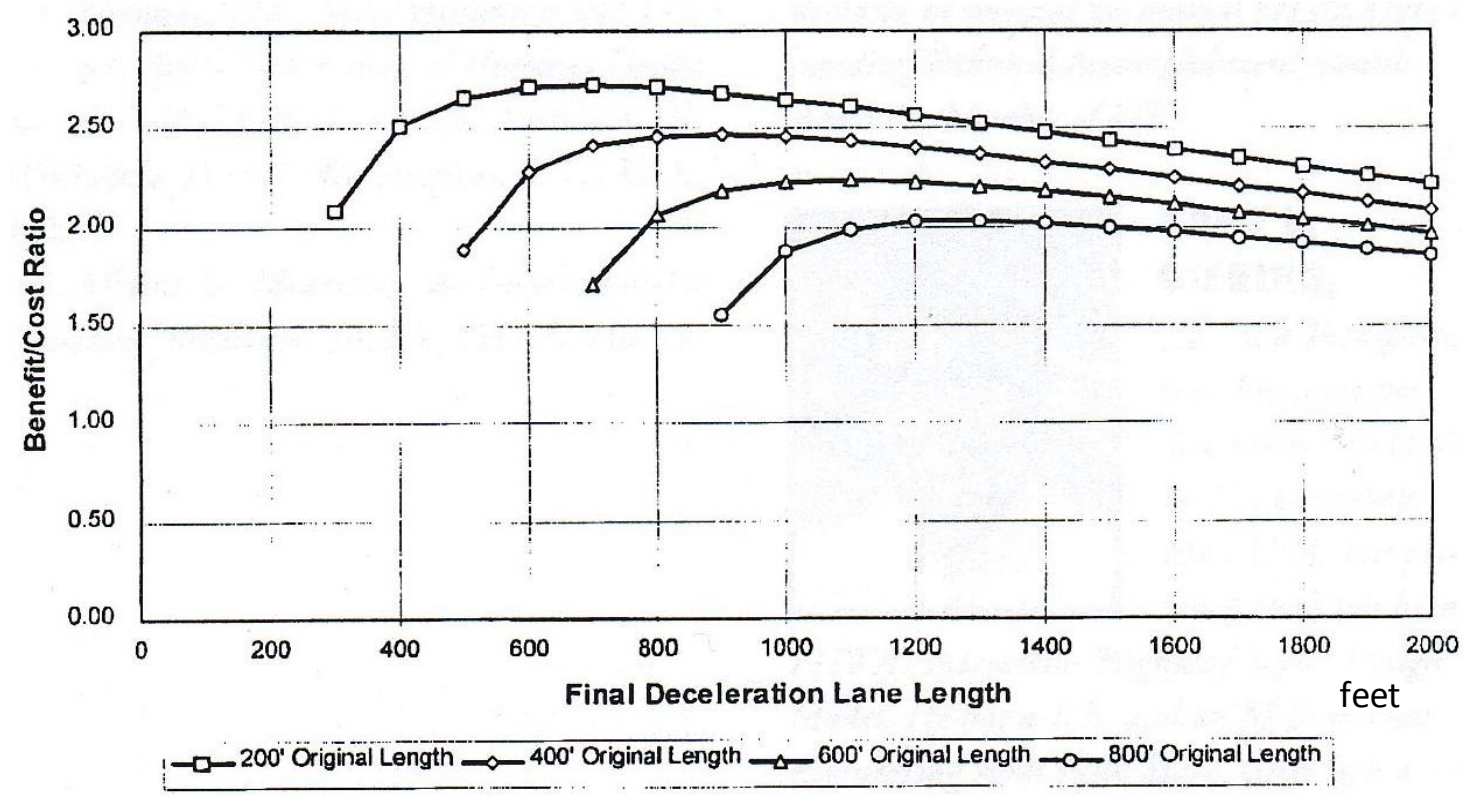

Figura 35: relación B/C vs longitud del carril de deceleración en función de la longitud original del carril

Uno de los últimos estudios que se han realizado para analizar la influencia que tiene en la seguridad el tipo de configuración de salida y el número de carriles en la misma es el presentado en el octogésimo séptimo congreso anual del TRB por parte de Chen et al. (2008). Hasta el momento los estudios realizados no habían tenido en cuenta la importancia que podría tener dicho aspecto en la seguridad; por tanto, con esta investigación se trató de verificar cuál sería la configuración óptima de los carriles para que la siniestralidad fuese mínima.

En el estudio se plantearon cuatro tipologías de salidas (Ver Figura 36) sobre las que se llevó a cabo el análisis, que son las siguientes:

La salida tipo 1 se trataba de un único carril nuevo de salida, con la configuración habitual de cierta longitud para la deceleración y una cuña inicial de transición. La salida tipo 2 consistía en un carril de salida perdido, es decir, que el número de carriles de la vía principal disminuía en uno, pasando el carril situado más a la derecha en la autopista a ser el ramal de salida. La salida tipo 3 correspondía con un ramal de salida de dos carriles, al que se llegaba con un carril derecho perdido y un carril bífido que permitía optar por la continuidad en la calzada principal o la salida hacia el carril 2 del ramal. La salida tipo 4 englobaba también un ramal de salida de dos carriles, pero en este caso se perdía un carril de la calzada principal y se ganaba otro nuevo por la derecha. 

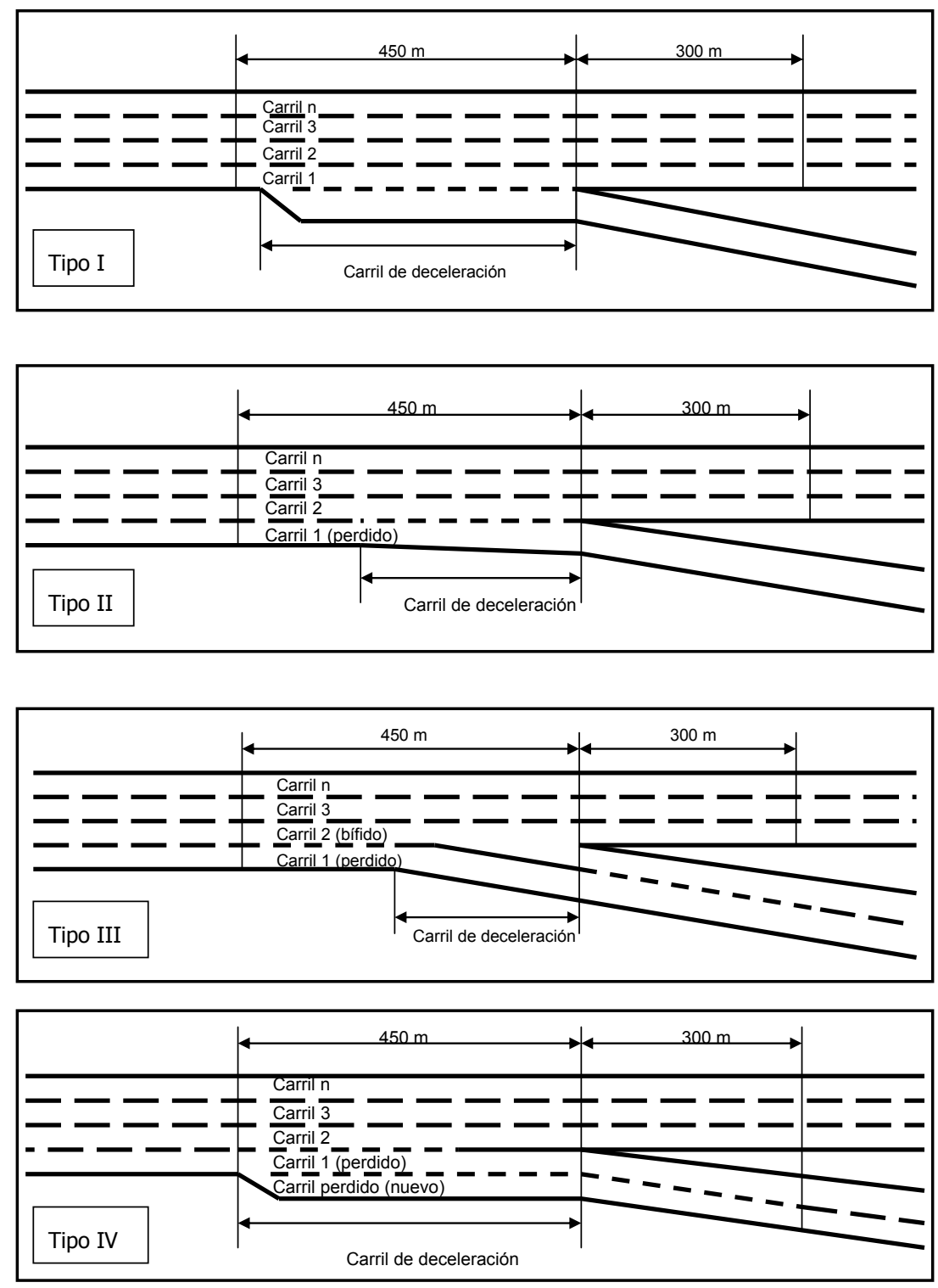

Figura 36: Configuración de los cuatro tipos de salidas

Los estudios realizados hasta el momento respecto al funcionamiento de las salidas en autopistas se habían centrado fundamentalmente en un aspecto, que era la longitud del carril de deceleración, pero nunca se había tenido en cuenta la influencia que podía tener el número de carriles del ramal de salida en la siniestralidad.

En este estudio se han utilizado datos de accidentes de 424 tramos de autopista de Florida. Para cada tramo de autopista se han analizado dos secciones: la primera sección a 450 m antes de la salida y la segunda 300 m después de la sección de salida; en total una longitud para cada tramo de $750 \mathrm{~m}$. Dentro de los datos de accidentes se ha hecho la distinción entre accidentes con sólo daños materiales, accidentes con víctimas y accidentes con víctimas mortales. 
Además hay que tener en cuenta que el estudio se centra en los efectos sobre la seguridad de salidas por la derecha; no se tiene en cuenta en este caso la posibilidad de salidas por la izquierda. Los datos de accidentes se corresponden con 3 años, de 2004 a 2006.

Sobre la base de datos recogidos, se ha llevado a cabo un análisis estadístico para evaluar la influencia sobre la seguridad de las distintas tipologías de salida. En las comparaciones transversales se han analizado las siguientes variables: frecuencia de accidentes, tasa de accidentes (medido en número de accidentes por millón de vehículos y por milla), y la gravedad de los accidentes.

En esta caso se ha tomado como modelo estadístico el de Poisson, ya que la variable número de accidentes es aleatoria y discreta, frente a lo que sería el modelo clásico de regresión lineal donde la variable es continua y de varianza constante.

También puede ser de aplicación el modelo binomial, donde se asume que la variable $\mathrm{n}^{0}$ de accidentes se distribuye según una función Poisson-Gamma.

La salida tipo 1 es la que mejor funcionamiento presenta desde el punto de vista de la frecuencia y tasa de accidentes, es decir, presenta el menor número de accidentes. La salida tipo 2 es la que presenta una mayor frecuencia y tasa de accidentes y, por tanto, un mayor número de accidentes. La salida tipo 3 presenta unos valores bajos de frecuencia y tasa de accidentes frente a la salida tipo 4, la cual presenta unos valores tanto mayores pero que no superan en ningún caso los de tipo 2 .

Desde el punto de vista de la gravedad de los accidentes se puede decir que los porcentajes de accidentes que son mortales y accidentes con víctimas son similares para los 4 tipos: siendo ligeramente superior en el tipo 2 y un poco inferior en el tipo 1 respecto al resto.

Según los resultados del análisis realizado para las distintas tipologías de salida, se ha visto que la más segura es la de tipo 1 . Si se comparan las 2 tipologías de salida que disponen de un solo carril (tipos 1 y 2 ) se ve cómo al pasar de la tipología 1 a la 2 se incrementa el número de accidentes en un $12,8 \%$. Si se comparan las dos tipologías de salida que disponen dos carriles (tipos 3 y 4) se ve como la tipología 3 es la más segura que la 4 , con un número de accidentes un $11,7 \%$, superior en el tipo 4.

Por tanto, se concluye que para un único carril de salida la más segura es la tipología 1: y que para dos carriles de salida la tipología más segura es la de tipo 3. Esto se debe a que tanto en la tipología 2 como en la 4 no se da la posibilidad de continuar por la autopista y, por tanto, cuando los conductores que no quieren desviarse se dan cuenta de que realmente han entrado en un carril de salida, intentan hacer maniobras para incorporarse de nuevo al carril que les permita continuar por la vía principal, efectuando una maniobra de cambio carril apresurada, siempre conflictiva y que, en muchos casos, puede tener un riesgo importante de accidente.

Chen et al. (2010) evalúa la seguridad en carriles de salida por la izquierda por medio de observaciones y grabaciones en vídeo en cuatro carriles de salida. Han utilizado Técnicas de Conflictos de Tráfico y han tomado datos de geometría, velocidad de los vehículos, intensidad de tráfico y señalización. Los estudios de campo los han 
complementado con estadísticas de accidentes de 11 carriles de salida por la izquierda y 16 por la derecha.

Los análisis revelan que los carriles de salida por la izquierda tienen un mayor número medio de accidentes, así como un mayor índice de accidentalidad y un mayor porcentaje de accidentes graves.

El modelo de predicción de la frecuencia de accidentes tiene como variables explicativas: la intensidad del tráfico de la vía principal y del carril de salida, la longitud del carril de deceleración y el indicador de salida por la izquierda.

Otro aspecto importante en la seguridad de los carriles de deceleración es el relacionado con la funcionalidad del mismo. Huaguo et al. (2010) han observado una diferencia de velocidad entre los vehículos que salen y los que continúan por la vía principal de $10 \mathrm{mph}$. Asimismo, han observado que, en los carriles de salida por la izquierda, cerca de un $5 \%$ de los vehículos realizaban un cambio de carril, de los cuales el $15 \%$ lo hacían de manera brusca.

Byung et al (2010) evaluaron los efectos que tienen sobre la seguridad vial la presencia de diferentes elementos en las autovías. Han encontrado que la densidad de carriles de deceleración no es una variable significativa en la accidentalidad. Por el contrario la densidad de carriles de entrada en tramos curvos tiene un impacto negativo en la accidentalidad.

\subsection{MODELOS CINEMÁTICOS}

De los distintos modelos empleados para describir la divergencia de una vía principal a través de un carril de deceleración el cinemático es el más empleado, y es por tanto el utilizado por algunas normativas o recomendaciones, como la de la AASHTO, como base para determinar su longitud. Mientras que la norma española, Instrucción de Trazado 3.1-IC (1999), sigue un modelo dinámico ya que la fórmula que proporciona la longitud del carril de deceleración se deduce, como se verá al tratar esta norma, de aplicar la "Ecuación Fundamental de la Dinámica", la segunda Ley de Newton.

A continuación se recogen los principales modelo cinemáticos utilizados para el cálculo de la longitud de los carriles de deceleración.

\subsubsection{Recomendaciones para el proyecto de intersecciones.}

En la antigua Instrucción de Carreteras, 3.1-IC "Trazado" (1964), no se hacía referencia a los carriles de deceleración. Fue en las posteriores "Recomendaciones para el proyecto de intersecciones" y en "Recomendaciones para el proyecto de enlaces" de 1968 , en las que apareció la figura de las vías de cambio de velocidad, pero se diferenciaba según fuera el ramal de un enlace o de una intersección.

La longitud propuesta para las vías de deceleración en las "Recomendaciones para el proyecto de intersecciones" es, como se observa en la Tabla 19, una conversión a las unidades del Sistema Internacional de las longitudes que proponía la AASHO en el 
"Green Book" (1954), Tabla 27, y el "Blue Book" (1965), Tabla 29. Por tanto, en las "Recomendaciones para el proyecto de intersecciones" se sigue un modelo cinemático.

Tabla 19: Longitudes recomendadas para las vías de deceleración en intersecciones. (Rasantes suaves, $\pm 2 \%$ inferiores). ("Recomendaciones para el proyecto de intersecciones", 1968)

\begin{tabular}{|c|c|c|c|c|c|c|c|c|}
\hline \multicolumn{2}{|c|}{$\begin{array}{c}\text { Velocidad específica del ramal } \\
\text { de giro, km/h }\end{array}$} & STOP & $\mathbf{2 5}$ & $\mathbf{3 0}$ & $\mathbf{4 0}$ & $\mathbf{5 0}$ & $\mathbf{6 0}$ & $\mathbf{8 0}$ \\
\hline \multicolumn{2}{|c|}{ Radio mínimo de la curva, m. } & & $\mathbf{1 5}$ & $\mathbf{2 5}$ & $\mathbf{4 5}$ & $\mathbf{7 5}$ & $\mathbf{1 2 0}$ & $\mathbf{2 5 0}$ \\
\hline $\begin{array}{c}\text { Velocidad } \\
\text { específica de la } \\
\text { carretera, } \\
\mathbf{k m} / \mathbf{h}\end{array}$ & $\begin{array}{c}\text { Longitud de la } \\
\text { Transición, } \mathbf{m}\end{array}$ & \multicolumn{7}{|c|}{ LONGITUD DE LA VÍA DE DECELERACIÓN. } \\
Incluida la cuña, m \\
\hline 50 & 45 & 70 & 50 & 45 & 45 & - & - & - \\
\hline 60 & 55 & 90 & 70 & 70 & 55 & 55 & - & - \\
\hline 70 & 60 & 105 & 90 & 90 & 75 & 60 & 60 & - \\
\hline 80 & 65 & 120 & 105 & 105 & 90 & 75 & 65 & - \\
\hline 100 & 75 & 140 & 125 & 125 & 110 & 95 & 80 & 75 \\
\hline 120 & 90 & 160 & 145 & 145 & 130 & 130 & 110 & 90 \\
\hline
\end{tabular}

\subsubsection{Recomendaciones para el proyecto de enlaces}

En la segunda norma que apareció en España sobre el trazado de carreteras, la 3.1-IC "Trazado"(1964), no se hacía referencia a los carriles de deceleración, fue en las "Recomendaciones para el proyecto de Enlaces" y en las "Recomendaciones para el proyecto de intersecciones", de 1968, cuando por primera vez aparece esta figura que se definió como: "Vía auxiliar de una carretera de circulación rápida destinada especialmente a reducir la velocidad de los vehículos que salen de la misma".

En las "Recomendaciones para el proyecto de enlaces" se establece la longitud de la vía de deceleración en función del nivel de servicio de la autopista (Tabla 20) Estos valores se complementan con las transiciones indicadas en los esquemas adjuntos (Figura 37). 


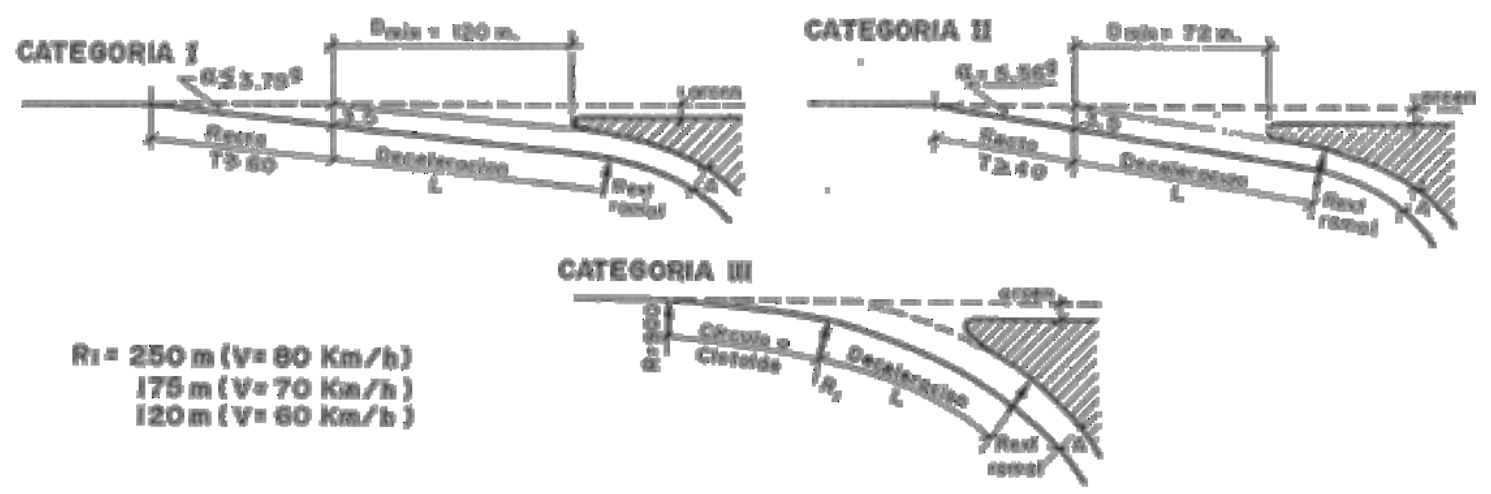

Figura 37: Esquemas de los carriles de deceleración. "Recomendaciones para el Proyecto de Enlaces" (1968)

Tabla 20: Longitud de los carriles de deceleración según las "Recomendaciones para el Proyecto de Enlaces" (1968)

\begin{tabular}{|c|c|c|c|c|c|c|c|c|}
\hline $\mathbf{V}_{\text {esp }}$ & $\mathbf{R}_{\text {ext }}$ & Ancho & \multicolumn{6}{|c|}{ LONGITUD DECELERACIÓN, L. (m) } \\
\hline Ramal & Ramal & Ramal & I & \multicolumn{2}{|c|}{ II } & \multicolumn{3}{|c|}{ III } \\
\hline $\begin{array}{c}\mathbf{( k m / h} \\
\mathbf{)}\end{array}$ & $\mathbf{( m )}$ & $\mathbf{( m )}$ & & $\begin{array}{c}\mathbf{8 0} \\
\mathbf{k m} / \mathbf{h}\end{array}$ & $\begin{array}{c}\mathbf{7 0} \\
\mathbf{~ k m / h}\end{array}$ & $\begin{array}{c}\mathbf{8 0} \\
\mathbf{k m} / \mathbf{h}\end{array}$ & $\begin{array}{c}\mathbf{7 0} \\
\mathbf{~ k m / h}\end{array}$ & $\begin{array}{c}\mathbf{6 0} \\
\mathbf{~ k m / h}\end{array}$ \\
\hline Stop & - & 5 & 240 & 120 & 105 & 120 & 105 & 90 \\
\hline 25 & 20 & 5 & 210 & 105 & 90 & 105 & 90 & 70 \\
\hline 30 & 30 & 4,75 & 200 & 105 & 90 & 105 & 90 & 70 \\
\hline 35 & 40 & 4,75 & 192 & 90 & 85 & 90 & 75 & 60 \\
\hline 40 & 50 & 4,5 & 185 & 90 & 85 & 90 & 75 & 55 \\
\hline 45 & 60 & 4,2 & 180 & 85 & 85 & 90 & 75 & 55 \\
\hline 50 & 75 & 4,2 & 175 & 85 & 85 & 75 & 60 & 55 \\
\hline 55 & 90 & 4,2 & 170 & 85 & 85 & 75 & 60 & 55 \\
\hline 60 & 120 & 4,0 & 160 & 85 & 85 & 75 & 60 & - \\
\hline 70 & 180 & 4,0 & 148 & 85 & 85 & 60 & - & - \\
\hline 80 & 250 & 4,0 & 140 & 85 & - & - & - & - \\
\hline
\end{tabular}

En las Recomendaciones no se justifica como se obtienen estos valores, pero si se observa la Tabla 22, (son los mismos valores que los propuestos por el "Libro Azul" de 1965 pero convertidos al S.I.), se comprueba que los valores, para velocidades iguales o menores a $80 \mathrm{~km} / \mathrm{h}$, son muy similares ya que las diferencias máximas son de $15 \mathrm{~m}$. Esto implica que estas recomendaciones están inspiradas en el "Libro Azul" (1965), y por tanto en el "Green Book" de 1954, lo que supone que se aplica un modelo cinemático. Los valores recomendados para la categoría I también son, excepto para la condición de parada, parecidos a los propuestos por la AASHTO (1965) para una velocidad inicial de $120 \mathrm{~km} / \mathrm{h}$. La salvedad es que en las longitudes de las recomendaciones no se incluye la cuña mientras que en el "Green Book" de 1954 si se hacía, lo que hace que estén del lado de la seguridad, sobre todo cuando la diferencia 
entre la velocidad inicial y final es pequeña pues existe un valor mínimo, superior al de la AASHTO (1965), que incluso se aplica en la categoría II cuando la velocidad inicial y final son la misma. Otra razón que justifica que estas recomendaciones están inspiradas en el "Green Book" de 1954, es que estas longitudes se aplican en terreno llano con pendiente de hasta $\pm 2 \%$ y que los coeficientes correctores según la pendiente son iguales a los que recomienda la AASHTO (1965) (Tabla 23).

\subsubsection{Modelo de Babkov}

Para obtener la longitud de los carriles de deceleración, Babkov (1985) propone:

$$
L=\frac{r^{2}-r^{2}}{26 d}
$$

Siendo:

- $\quad \mathrm{L}=$ Longitud del carril de deceleración, incluida la cuña, $\mathrm{m}$.

- $\mathrm{V}_{1}=$ Velocidad en la autopista $(\mathrm{km} / \mathrm{h})$

- $\mathrm{V}_{2}=$ Velocidad en el ramal $(\mathrm{km} / \mathrm{h})$

- $\quad \mathrm{d}=$ Deceleración del vehículo $\left(\mathrm{m} / \mathrm{s}^{2}\right)$. Según lo observado en el rango de $-1,75$ $\mathrm{m} / \mathrm{s}^{2}-2,5 \mathrm{~m} / \mathrm{s}^{2}$.

Obtener la ecuación (7) es muy sencillo, basta suponer un movimiento rectilíneo uniformemente variado con $\mathrm{V}$ en $\mathrm{m} / \mathrm{s}$ que se observa en la ecuación (8)

$$
L=\frac{r^{2}-r^{2}}{2 d}
$$

Al pasar $\mathrm{V}$ a km/h se obtiene la ecuación (9):

$$
L=\frac{V_{1}^{2}-r_{2}^{2}}{2 \cdot 3.6^{2} \cdot d}=>L=\frac{V^{2}-r_{2}^{2}}{26 d}
$$

\subsubsection{Norma técnica CNR}

En la "Norme sulle Caratteristiche Geometriche e di Traffico delle Intersezioni Stradali Urbane" (1983), el carril de deceleración (Figura 38) está constituido por:

- $\quad$ El tramo necesario para el cambio de carril, la cuña. (La traducción literal sería tronco de maniobra)

- El tramo en que se efectúa la mayor parte de la deceleración. (Tronco de deceleración) 


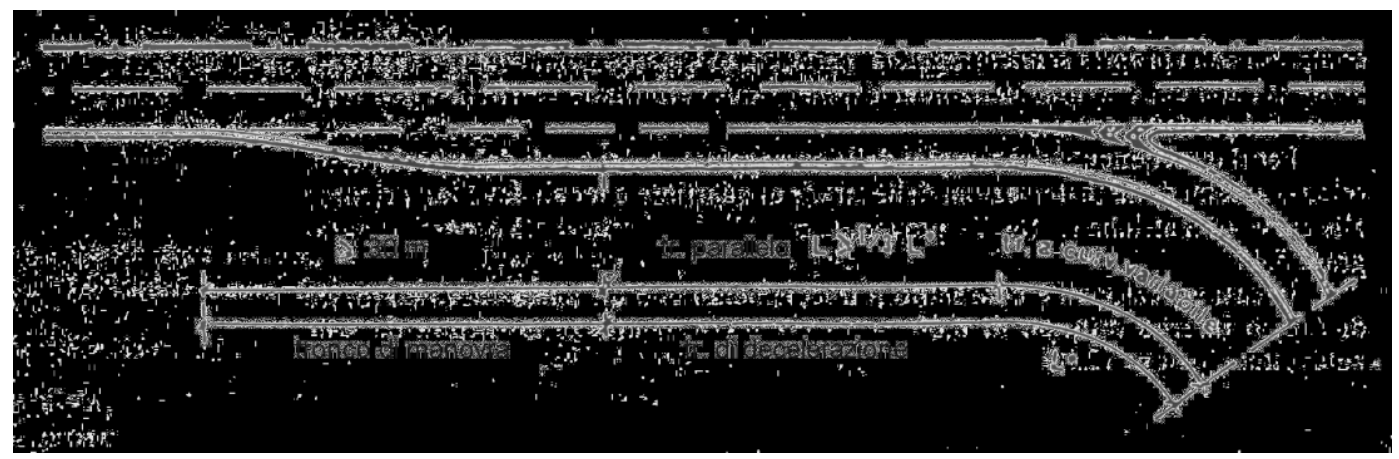

Figura 38: Carril de deceleración según Norme Tecniche CNR. 15 abril 1983. N. 90

El tronco de maniobra se dimensiona en función de la velocidad. Esta longitud no debe ser menor a $30 \mathrm{~m}$.

Tabla 21: Longitud de la cuña, pendiente 0\%. NORME TECNICHE CNR. Italia

\begin{tabular}{|c|l|l|l|l|}
\hline $\mathrm{V}(\mathrm{km} / \mathrm{h})$ & 60 & 70 & 80 & 90 \\
\hline $\mathrm{L}(\mathrm{m})$ & 30 & 35 & 40 & 45 \\
\hline
\end{tabular}

$\mathrm{V}=$ Velocidad en la autopista $(\mathrm{km} / \mathrm{h})$.

$\mathrm{L}=$ Longitud de la cuña $(m)$.

El tronco de deceleración, comienza al final del tronco de maniobra y finaliza al inicio del ramal de salida. Debe tener su longitud relacionada con la disminución de la velocidad de la vía principal y del ramal de salida. La deceleración es de $2 \mathrm{~m} / \mathrm{s}^{2}$. La parte inicial del tronco de deceleración debe permanecer paralela a la vía principal en una longitud no menor a 1/3. En el caso de que la parte inicial del ramal de salida fuera de curvatura creciente, la misma se puede considerar parte integrante del tronco de deceleración.

\subsubsection{Modelo AASHTO}

Las recomendaciones de la AASHTO (American Association of State Highways and Transportation Officials) para el diseño de autopistas se recogen en sucesivas ediciones bajo el nombre de: "A Policy on Geometric Design of Rural Highways", hasta la edición de 1965 y posteriormente en "A Policy on Geometric Design of Highways and Streets". Estas publicaciones, se conocen por el color de sus tapas "Green Book", en castellano "Libro Verde", excepto la edición de 1965 que tenía las tapas azules y es conocida como el "Blue Book" o "Libro Azul".

La edición del "Libro Verde" de 1994 es la primera en la que adoptan las unidades del Sistema Métrico Internacional y se mantienen en las ediciones posteriores.

En relación a los carriles de deceleración distingue entre los carriles de tipo directo y los de tipo paralelo. En lo referente a la longitud, aunque en ambos casos es igual, hay alguna variación en cuanto a cuáles son los puntos entre los cuales se mide la longitud y al ángulo de la cuña. 
Para el carril tipo directo, la longitud disponible para decelerar se asume que se extiende desde el punto donde el borde derecho de la cuña está a 3,6 m del borde derecho del tronco, hasta el punto que determina la velocidad segura en el ramal de salida. La longitud entre estos puntos debe ser por lo menos mayor que la distancia para llevar a cabo la deceleración necesaria, que está determinada por la velocidad del tráfico en el carril principal y la velocidad del ramal. La deceleración puede estar impuesta por una condición de parada (una detención completa), como en el caso de un cruce al final de un enlace en diamante, o por la curvatura del ramal de salida que determina la velocidad crítica. Las longitudes mínimas de deceleración para distintas combinaciones de velocidades en la vía principal y en el ramal se dan en la Tabla 22.

Para el carril tipo paralelo, la longitud de los carriles de deceleración tipo paralelo se mide desde el punto donde alcanzan el ancho de 3,6 $\mathrm{m}$ hasta el punto donde el ramal se separa de la autopista, es decir, en el inicio de la curva. Cuando el ramal es curvo, se recomienda que exista una transición al final del carril de deceleración con una sucesión de curvas, siendo el radio de la primera de $300 \mathrm{~m}$ o más. También se aconseja utilizar una transición o una curva de amplio radio si el carril de deceleración conecta con un ramal relativamente recto. En estos casos se puede considerar una porción del ramal como parte de la longitud de deceleración y de este modo se podría acortar un poco la longitud necesaria en los carriles de deceleración paralelos. Las longitudes mínimas se muestran en la Tabla 22.

Tabla 22: Longitud de los carriles de deceleración. AASHTO 2001

\begin{tabular}{|c|c|c|c|c|c|c|c|c|c|}
\hline \multicolumn{10}{|c|}{ LONGITUD DEL CARRIL DE DECELERACIÓN, L (m) } \\
\hline \multirow{3}{*}{$\begin{array}{c}\text { VELOCIDAD } \\
\text { DE DISEÑO } \\
\text { EN LA } \\
\text { AUTOPISTA, } \\
\text { V }\end{array}$} & \multirow{3}{*}{$\begin{array}{l}\text { VELOCIDAD } \\
\text { MEDIA, } \mathbf{v}_{\mathrm{a}}\end{array}$} & \multicolumn{8}{|c|}{$\begin{array}{l}\text { VELOCIDAD DE DISEÑO EN LA CURVA V' a } \\
\qquad(\mathrm{km} / \mathrm{h})\end{array}$} \\
\hline & & $\mathbf{0}$ & 20 & 30 & 40 & 50 & 60 & 70 & 80 \\
\hline & & \multicolumn{8}{|c|}{ VELOCIDAD MEDIA EN LA CURVA V" a $(\mathrm{km} / \mathrm{h})$} \\
\hline$(\mathrm{km} / \mathrm{h})$ & $(\mathrm{km} / \mathrm{h})$ & 0 & 20 & 28 & 35 & 42 & 51 & 63 & 70 \\
\hline 50 & 47 & 75 & 70 & 60 & 45 & & & & \\
\hline 60 & 55 & 95 & 90 & 80 & 65 & 55 & & & \\
\hline 70 & 63 & 110 & 105 & 95 & 85 & 70 & 55 & & \\
\hline 80 & 70 & 130 & 125 & 115 & 100 & 90 & 80 & 55 & \\
\hline 90 & 77 & 145 & 140 & 135 & 120 & 110 & 100 & 75 & 60 \\
\hline 100 & 85 & 170 & 165 & 155 & 145 & 135 & 120 & 100 & 85 \\
\hline 110 & 91 & 180 & 180 & 170 & 160 & 150 & 140 & 120 & 105 \\
\hline 120 & 98 & 200 & 195 & 185 & 175 & 170 & 155 & 140 & 120 \\
\hline
\end{tabular}

(Pendiente entre el 0 y el $\pm 2 \%$ ). 


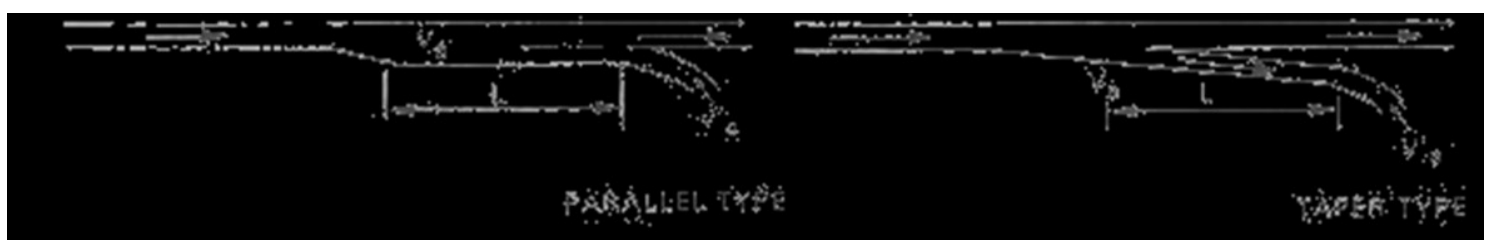

Figura 39: Tipos de carriles de deceleración

Como se observa, en esta edición se da una tabla con los valores de la longitud del carril de deceleración para algunas velocidades de diseño puntuales en la vía principal y el ramal de salida, y como no se indica el criterio o la fórmula seguidos para obtenerlas el único método para determinar la longitud en otros casos será interpolar.

Las longitudes de los carriles de deceleración de la Tabla 22 se basan en:

- Una pendiente entre el 0 y el $\pm 2 \%$.

- La suposición de que se puede habilitar un peralte adecuado en la curva del ramal.

- Los volúmenes de tráfico no son de tal intensidad que causen interferencias importantes con el movimiento del tráfico principal.

Cuando no se cumplen las condiciones anteriores es necesario ajustar las longitudes de los carriles de deceleración dados en la Tabla 22. Los ajustes por la pendiente aparecen en la Tabla 23, pues como la longitud se determina con un modelo cinemático se obtiene la longitud del carril de deceleración en llano por lo que se debe corregir según la magnitud de la pendiente. La corrección de la longitud según la pendiente se determinó en la edición de 1954 y en la actualidad se siguen empleando los mismos índices. Como no se disponían de los datos del comportamiento del conductor mientras deceleraba en pendientes se aproximó aplicando los principios de la mecánica a los índices de deceleración en llano. Los cálculos dieron como resultado unas longitudes de los carriles de deceleración que divididas por las correspondientes a llano daban como resultado los ratios de la Tabla 23 que son los que se siguen empleando en la actualidad. Los ratios de esta tabla multiplicados por las longitudes de la Tabla 22 proporcionan las longitudes recomendadas por la AASHTO cuando el carril de deceleración tiene una pendiente que no está entre $\pm 2 \%$.

Tabla 23: Factores de ajuste en función de la pendiente

\begin{tabular}{|c|c|c|}
\hline $\begin{array}{c}\text { VELOCIDAD DE } \\
\text { DISEÑO }\end{array}$ & $\begin{array}{c}\text { ÍNDICE POR EL QUE SE MULTIPLICA LA LONGITUD } \\
\text { EN LLANO }\end{array}$ \\
\hline & RAMPA DEL 3 AL 4 \% & PENDIENTE DEL 3 AL 4 \% \\
\hline TODAS & 0,9 & 1,2 \\
\hline & RAMPA DEL 5 AL 6 \% & PENDIENTE DEL 5 AL 6\% \\
\hline TODAS & 0,8 & 1,35 \\
\hline
\end{tabular}


Para conocer el origen de estas longitudes hay que recurrir a ediciones anteriores de la AASHTO.

El manual de la AASHO de 1954 "A Policy on Geometric Desing of Rural Highways", permite entender cómo se obtienen las longitudes de los carriles de deceleración recomendadas actualmente, ya que estos valores son fruto de evoluciones sucesivas de las longitudes propuestas en esta edición.

A continuación se resume el contenido del Green Book de 1954 relativo a la longitud del carril de deceleración:

La longitud de un carril de deceleración se basa en la combinación de tres factores:

- La velocidad con la que los conductores penetran en el carril de deceleración.

- La velocidad al inicio del ramal de salida.

- La forma de decelerar o los factores de deceleración.

La mayoría de los conductores, cuando se introducen en los carriles de deceleración, circulan a una velocidad igual o menor a la velocidad media de la carretera (velocidad a volúmenes relativamente bajos), como mostraba un estudio de aquella época, (J. V. Miller Jr, 1951), en carriles de deceleración en Pennsylvania en el que se revelaba que alrededor de dos tercios de los conductores que divergían al inicio del carril circulaban a velocidades menores de $50 \mathrm{mph}(80 \mathrm{~km} / \mathrm{h})$, lo que entonces suponía una velocidad inferior a la de la vía principal pero sin diferir de ésta mucho.

Basándose en lo anterior se asume, por motivos de diseño, que los conductores que entran en el carril de deceleración circulan a la velocidad media de la autopista de acuerdo con la relación entre la velocidad de diseño y la velocidad media de la Tabla 24, y para guiar al pequeño porcentaje de conductores que circula a una velocidad mayor se deben colocar, a una distancia suficiente antes del inicio del carril de deceleración, las señalizaciones que indiquen la divergencia para permitir que esos conductores aminoren la marcha.

Tabla 24: Relación entre la velocidad de diseño y la velocidad media en autopistas con un volumen de tráfico bajo

\begin{tabular}{|c|c|c|}
\hline & \multicolumn{2}{|c|}{ VELOCIDAD MEDIA } \\
\hline $\begin{array}{c}\text { VELOCIDAD DE DISEÑo } \\
\text { (mph) }\end{array}$ & $\begin{array}{c}\text { Porcentaje de la } \\
\text { velocidad de diseño }\end{array}$ & Mph \\
\hline 30 & 90 & 27 \\
\hline 40 & 85 & 34 \\
\hline 50 & 80 & 40 \\
\hline 60 & 75 & 45 \\
\hline 70 & 70 & 49 \\
\hline
\end{tabular}


La velocidad media en el ramal depende del radio de la curva del ramal y se obtiene de la Tabla 25. De la diferencia entre la velocidad media en la autopista y al inicio de la curva del ramal de salida se determina la longitud del carril de deceleración.

Tabla 25: Velocidad media en curva. AASHTO 1954

\begin{tabular}{|c|c|c|c|c|c|}
\hline $\begin{array}{c}\text { Velocidad } \\
\text { de diseño } \\
\text { en curva } \\
\text { (mph) }\end{array}$ & $\begin{array}{c}\text { Factor de } \\
\text { rozamiento } \\
\text { transversal. f }\end{array}$ & $\begin{array}{c}\text { PERALTE } \\
\text { e }\end{array}$ & $\begin{array}{c}\text { Radio } \\
\text { calculado. } \\
\text { (pie) }\end{array}$ & $\begin{array}{c}\text { Radio } \\
\text { redondead } \\
\text { o (pie) }\end{array}$ & $\begin{array}{c}\text { Velocidad } \\
\text { media, } \\
\text { (mph) }\end{array}$ \\
\hline 15 & 0,32 & 0,00 & 47 & 50 & 14 \\
\hline 20 & 0,27 & 0,02 & 92 & 90 & 18 \\
\hline 25 & 0,23 & 0,04 & 154 & 150 & 22 \\
\hline 30 & 0,2 & 0,06 & 231 & 230 & 26 \\
\hline 35 & 0,18 & 0,08 & 314 & 310 & 30 \\
\hline 40 & 0,16 & 0,09 & 426 & 430 & 34 \\
\hline
\end{tabular}

El tercer factor que determina la longitud del carril de deceleración es, como ya se indicó; la forma de decelerar o los factores de deceleración. La deceleración de un vehículo al aproximarse a una divergencia generalmente está compuesta de dos etapas:

1.- Se levanta gradualmente el pedal del acelerador y el vehículo va aminorando la velocidad por retención del motor, sin usar los frenos.

2.- Se aplican los frenos.

Los índices de deceleración por retención del motor y las características de deceleración del vehículo mientras frena al aproximarse a la curva del ramal de salida que se utilizan para determinar la longitud del carril de deceleración son los que se determinaron al inicio de la década de los 40 y que ya se expusieron en el apartado de deceleración.

Los factores de las páginas anteriores, combinados, permiten la determinación de las longitudes de los carriles de deceleración para cualquier suposición o hipótesis de la manera en la que los conductores operan. Dado que esta forma varía, se consideran tres tipos de posibles operaciones, los casos I, II, y III, que producen longitudes lógicas y no excesivamente largas.

Caso I. Asume que los conductores:

- Circulan a la velocidad media de la vía al inicio del carril de deceleración.

- Deceleran por retención del motor durante 3 segundos a partir de la entrada en el carril de deceleración. 
- $\quad$ Frenan con un índice confortable en el carril hasta que alcanzan la velocidad media de la curva inicial del ramal de salida.

Las longitudes basadas en estas hipótesis permiten al conductor decelerar de forma confortable y segura cuando se aproxima al carril de deceleración con la velocidad media de la vía.

Caso II: Asume que los conductores:

- Circulan a la velocidad media de la vía antes de llegar al carril de deceleración.

- Deceleran con retención del motor en la autopista durante 3 segundos antes de llegar al inicio del carril de deceleración.

- Continúan decelerando con retención del motor durante 2 segundos más una vez han entrado en el carril de deceleración.

- $\quad$ Frenan con un índice relajado hasta que alcanzan la velocidad media de la curva inicial del ramal de salida.

Esto representa una aproximación relajada de bastantes conductores. Este índice de deceleración se usa cuando los conductores reducen un poco la velocidad en la vía principal porque así frenan más gradualmente.

Caso III. Asume que los conductores:

- Viajan a la velocidad de diseño de la vía antes de llegar al carril de deceleración.

- Deceleran por la retención del motor en la vía durante tres segundos antes de alcanzar el inicio del carril de deceleración.

- Desde que entran en el carril de deceleración y hasta que alcanzan la velocidad de diseño de la curva inicial del ramal de salida frenan con un índice confortable si la velocidad de diseño de la autopista es elevada y relajado si la velocidad de diseño es inferior.

Esta operación es menos común porque incluso los conductores que circulan a alta velocidad y van a abandonar la carretera habitualmente reducen su velocidad bastante antes de la salida. Cuando los conductores se aproximan a altas velocidades, son capaces de reaccionar antes de alcanzar el carril de deceleración y aplican los frenos en el carril principal antes de, o, en el inicio del carril de deceleración, cuya longitud debería ser suficiente para permitir un frenado confortable hasta la velocidad de diseño de la curva del ramal de salida. 
Tabla 26: Longitud del carril de deceleración, (pies). AASHTO 1954

\begin{tabular}{|c|c|c|c|c|c|c|c|c|c|c|}
\hline \multirow{2}{*}{$\begin{array}{l}\text { Vd } \\
\text { Aut. } \\
\text { Mph }\end{array}$} & \multicolumn{10}{|c|}{ VELOCIDAD DE DISEÑO EN EL RAMAL (mph) } \\
\hline & Caso & $\mathbf{S}$ & 15 & 20 & 25 & 30 & 35 & 40 & 45 & 50 \\
\hline \multirow{3}{*}{30} & I & 210 & 170 & 140 & 110 & - & - & - & - & - \\
\hline & II & 230 & 150 & 130 & - & - & - & - & - & - \\
\hline & III & 220 & 160 & 130 & - & - & - & - & - & - \\
\hline \multirow{3}{*}{40} & I & 300 & 260 & 240 & 210 & 180 & 140 & - & - & - \\
\hline & II & 330 & 270 & 250 & 210 & 150 & - & - & - & - \\
\hline & III & 320 & 280 & 250 & 200 & 140 & - & - & - & - \\
\hline \multirow{3}{*}{50} & I & 380 & 340 & 320 & 290 & 260 & 230 & 180 & 110 & - \\
\hline & II & 400 & 350 & 330 & 290 & 240 & 190 & 100 & - & - \\
\hline & III & 370 & 340 & 310 & 270 & 230 & 170 & 110 & - & - \\
\hline \multirow{3}{*}{60} & I & 440 & 400 & 380 & 360 & 330 & 290 & 250 & 220 & 180 \\
\hline & II & 440 & 400 & 380 & 350 & 310 & 270 & 200 & 150 & - \\
\hline & III & 400 & 370 & 350 & 310 & 280 & 240 & 180 & 120 & - \\
\hline \multirow{3}{*}{70} & I & 550 & 460 & 440 & 420 & 390 & 360 & 320 & 280 & 250 \\
\hline & II & 500 & 460 & 440 & 410 & 380 & 340 & 290 & 240 & 170 \\
\hline & III & 500 & 470 & 450 & 420 & 390 & 340 & 300 & 240 & 190 \\
\hline
\end{tabular}

$\mathrm{S}=$ Condición de parada; 1 pie $=0,3048 \mathrm{~m} .1 \mathrm{mph}=1,609 \mathrm{~km} / \mathrm{h}$

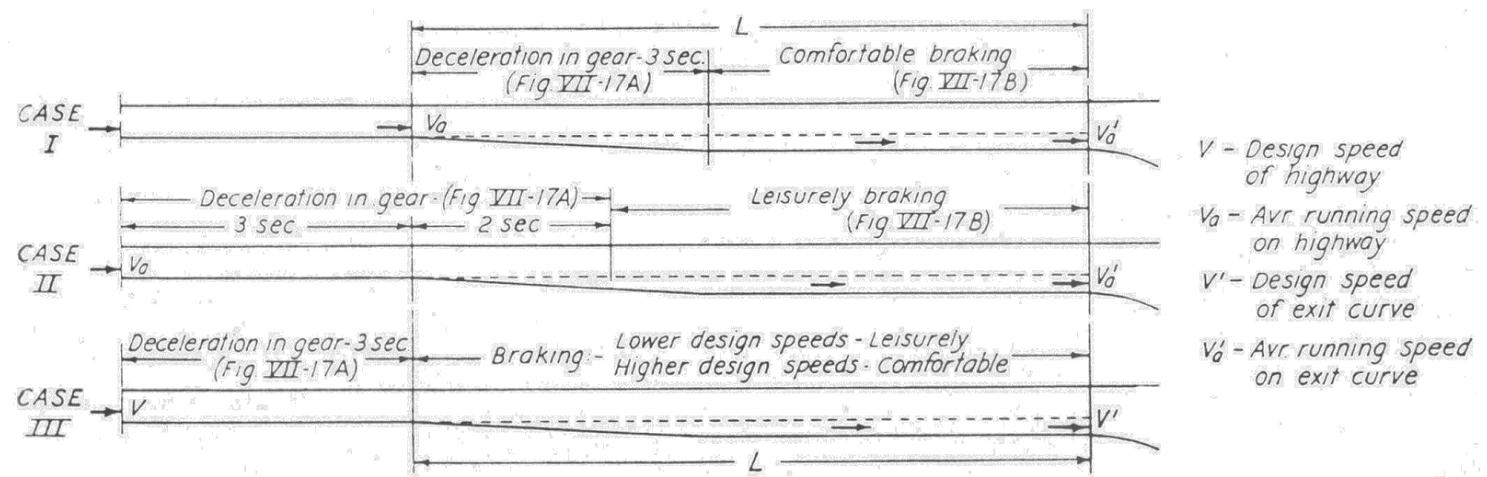

Figura 40: Longitudes de los carriles de deceleración según los casos I, II y III.

Los casos I y II se cree que son representativos de las condiciones en las que deberían basarse las longitudes mínimas de los carriles de deceleración. El caso III se incluye para comparar las longitudes de los casos I y II con las longitudes para los vehículos 
que se aproximan a la divergencia a la velocidad de diseño. Basándose en las relaciones de velocidad previamente establecidas en la Tabla 24 y en la Tabla 25, se obtienen las longitudes de los carriles de deceleración para cada caso que están tabuladas en la Figura 40. Las longitudes derivadas son aproximadamente las mismas en cada caso, están redondeadas y resumidas en la Tabla 27, y son las que esta edición sugiere para el diseño:

Tabla 27: Longitud de los carriles de deceleración. AASHTO 1954

\begin{tabular}{|c|c|c|c|c|c|c|c|c|c|c|}
\hline \multirow{2}{*}{\multicolumn{2}{|c|}{$\begin{array}{c}\text { Velocidad de diseño en } \\
\text { la curva del ramal } \\
\text { (mph) }\end{array}$}} & \multirow[t]{2}{*}{$\begin{array}{l}\text { Parad } \\
\text { a }\end{array}$} & 15 & 20 & 25 & 30 & 35 & 40 & 45 & 50 \\
\hline & & & 50 & 90 & 150 & 230 & 310 & 430 & 550 & 690 \\
\hline $\begin{array}{c}\text { Velocidad } \\
\text { de diseño } \\
\text { de la } \\
\text { autopista } \\
\text { (mph) }\end{array}$ & $\begin{array}{c}\text { Longitud } \\
\text { de la cuña } \\
\text { (pies) }\end{array}$ & \multicolumn{9}{|c|}{$\begin{array}{c}\text { LONGITUD DEL CARRIL DE DECELERACIÓN. } \\
\text { Incluida la cuña (pies) }\end{array}$} \\
\hline 40 & 175 & 300 & 250 & 250 & 200 & 175 & $*$ & - & - & - \\
\hline 50 & 200 & 400 & 350 & 350 & 300 & 250 & 250 & 200 & $*$ & - \\
\hline 60 & 225 & 450 & 400 & 400 & 350 & 350 & 300 & 250 & 225 & $*$ \\
\hline 70 & 250 & 500 & 450 & 450 & 400 & 400 & 350 & 350 & 300 & 250 \\
\hline
\end{tabular}

1 pie $=0,3048$ m.; $1 \mathrm{mph}=1,609 \mathrm{~km} / \mathrm{h} ; *$ Longitud menor a la cuña.

Como se observa tras el redondeo, en algunos casos para una misma velocidad de diseño en la autopista y distintas velocidades en el ramal se proponen las mismas longitudes, lo que muestra la ausencia de un criterio ya que unas veces se ha redondeado al alza y otras a la baja, pero esto último no implica una disminución de la seguridad porque:

- Las longitudes están en pies por lo que una diferencia de 10 pies, que podría parecer grande, al pasarla a metros (unidad del S.I. utilizada en España) son $3 \mathrm{~m}$ y esta diferencia en un carril de deceleración no es grande.

- $\quad$ Las longitudes se han obtenido para las velocidades medias cuando el volumen es bajo con lo que son mayores que si el volumen fuera alto y se quedaría del lado de la seguridad.

Estas longitudes están basadas en el comportamiento de los vehículos ligeros. Pese a que los camiones requieren mayores distancias para decelerar para las mismas diferencias de velocidades, no se justifican carriles más largos dado que las velocidades medias son menores que las de los vehículos ligeros. 
En la Tabla 27 los valores de la tercera columna muestran las longitudes necesarias de deceleración hasta un stop y se aplican también en intersecciones controladas por semáforos y carriles en los que se prevea que va a existir almacenamiento.

Teóricamente, las longitudes de los carriles de deceleración deberían medirse desde el punto en el que alcanzan el ancho total, 3,6 m, pero pese a ser deseable, esta forma de medirlo puede proporcionar longitudes elevadas y difíciles de alcanzar. Como puede asumirse que los conductores se preparan para abandonar la autopista antes de alcanzar el carril de deceleración (divergen a velocidades menores que las de la vía principal) y que cierta deceleración, como la deceleración con el motor, se lleva a cabo en la longitud de la cuña, se asume que la longitud de la cuña (o parte de ella) se incluye en la longitud total del carril de deceleración.

Cuando el carril de deceleración es de tipo paralelo, su longitud se mide desde el extremo más estrecho de la cuña hasta el inicio de la curva del ramal de salida. Los carriles de deceleración que comienzan abruptamente con un ancho total o parcial, se miden desde el inicio del carril auxiliar.

En los carriles de deceleración directos la longitud puede medirse desde el punto donde la cuña tiene un ancho de unos 3 o 4 pies $(0,9-1,2 \mathrm{~m})$, pero es preferible que sea de 5 o 6 pies $(1,5 \circ 1,8 \mathrm{~m})$. En casos especiales, como las vías en las que se puedan alcanzar altas velocidades, los carriles de deceleración pueden medirse a partir de donde el ensanchamiento tiene el ancho total, esto da como resultado una longitud total igual a la mostrada en la Tabla 27 más la longitud de la cuña. Este incremento de longitud en llano puede permitir velocidades en la autopista de unas $5 \mathrm{mph}(8 \mathrm{~km} / \mathrm{h})$ mayores que la media o permitir más libertad para los valores de deceleración que los asumidos.

De todo lo expuesto hay que destacar tres aspectos que serían utilizados en posteriores ediciones:

- El proceso seguido para obtener la longitud del carril de deceleración. Se suponen unas hipótesis sobre la forma en que operan los conductores y se obtiene la longitud según curvas en las que en función de la velocidad inicial y del tiempo de deceleración por retención del motor se obtiene la distancia recorrida y la velocidad alcanzada, y con esta velocidad se entra en otra gráfica y se determina la distancia recorrida al frenar según la velocidad que se alcanza en el ramal.

- Las longitudes obtenidas para cada una de las tres hipótesis sobre la forma de operar de los conductores son aproximadamente las mismas, por lo que estos valores se redondean a un valor único.

- $\quad$ En vías en las que se pueden alcanzar velocidades elevadas, los carriles de deceleración pueden medirse a partir del punto en el que la cuña tiene el ancho total; esto da como resultado una longitud total igual a la mostrada en la Tabla 27 más la longitud de la cuña. 
Para obtener la longitud del carril de deceleración con la edición de AASHO (1965), se sigue el mismo proceso que en la edición anterior pero con dos diferencias:

- Sólo hay una hipótesis sobre la forma de operar de los conductores, el caso I de la edición anterior. El motivo de esta variación, aunque no se indica explícitamente, parece ser que las longitudes obtenidas en cada hipótesis eran similares.

- Dada una velocidad de diseño, la velocidad media con la que circulan los vehículos es mayor a la de la edición anterior (Tabla 28), ya que en los últimos 15 años se había observado un ligero aumento que llevó a corregir los valores, por lo que aunque las gráficas con las que se obtiene la distancia de deceleración para los vehículos de ligeros son iguales a las de la edición anterior, las longitudes son mayores a las de 1954 (Tabla 29):

Tabla 28: Relación entre la velocidad de diseño y la velocidad media en una autopista con volumen bajo de tráfico

\begin{tabular}{|c|c|c|c|c|c|c|c|c|}
\hline $\begin{array}{c}\text { VELOCIDAD DE DISEÑO } \\
\text { (mph) }\end{array}$ & 30 & 40 & 50 & 60 & 65 & 70 & 75 & 80 \\
\hline VELOCIDAD MEDIA (mph) & 28 & 36 & 44 & 52 & 55 & 58 & 61 & 64 \\
\hline
\end{tabular}

Tabla 29: Longitud de los carriles de deceleración. AASHO 1965.

\begin{tabular}{|c|c|c|c|c|c|c|c|c|c|c|}
\hline \multicolumn{2}{|c|}{$\begin{array}{c}\text { Velocidad de diseño } \\
\text { en la curva del ramal } \\
\text { (mph) }\end{array}$} & & 15 & 20 & 25 & 30 & 35 & 40 & 45 & 50 \\
\hline \multicolumn{2}{|c|}{$\begin{array}{l}\text { Radio mínimo de la } \\
\text { curva (pies) }\end{array}$} & STOP & 50 & 90 & 150 & 230 & 310 & 430 & 550 & 690 \\
\hline $\begin{array}{c}\text { Velocidad } \\
\text { de diseño } \\
\text { de la } \\
\text { autopista } \\
\text { (mph) }\end{array}$ & $\begin{array}{l}\text { Longitud } \\
\text { de la } \\
\text { cuña } \\
\text { (pies) }\end{array}$ & \multicolumn{9}{|c|}{$\begin{array}{l}\text { LONGITUD DEL CARRIL DE DECELERACIÓN. } \\
\text { Incluida la cuña (pies) }\end{array}$} \\
\hline 30 & 150 & 235 & 185 & 160 & 140 & - & - & - & - & - \\
\hline 40 & 190 & 315 & 295 & 265 & 235 & 185 & 155 & - & - & - \\
\hline 50 & 230 & 435 & 405 & 385 & 355 & 315 & 285 & 225 & 175 & - \\
\hline 60 & 270 & 535 & 500 & 490 & 460 & 430 & 410 & 340 & 300 & 240 \\
\hline 65 & 290 & 570 & 540 & 530 & 490 & 480 & 430 & 380 & 330 & 280 \\
\hline 70 & 300 & 615 & 590 & 570 & 550 & 510 & 490 & 430 & 390 & 340 \\
\hline 75 & 315 & 660 & 630 & 610 & 590 & 560 & 530 & 470 & 440 & 390 \\
\hline 80 & 330 & 700 & 680 & 660 & 640 & 610 & 480 & 530 & 490 & 450 \\
\hline
\end{tabular}

1 pie $=0,3048 \mathrm{~m} . ; 1 \mathrm{mph}=1,609 \mathrm{~km} / \mathrm{h}$

Las longitudes en la edición del "Green Book" (AASHTO, 1990), son las mismas que en la edición de 1965 pero ahora no se incluye la cuña, con lo que se recoge la idea expresada en la edición de 1954 en el caso de vías en las que los vehículos circulan a 
alta velocidad. La mejora de las prestaciones de los vehículos y de las infraestructuras hace que se puedan considerar las autopistas actuales como vías de alta velocidad.

Los valores de la longitud de los carriles de deceleración de la edición de 1994 son una conversión a las unidades del Sistema Internacional de los de la edición de 1990, y en la edición 2001 se mantienen.

Si se analiza el procedimiento propuesto por la AASHTO para obtener la longitud del carril de deceleración surgen una serie de objeciones simplemente por el método expuesto, no por los resultados:

- Las maniobras que en el "Libro Verde" de 1954 se asumió que representaban el comportamiento de los conductores en los carriles de deceleración no se basan en ninguna observación empírica, simplemente se plantearon distintas hipótesis. Esta conclusión se alcanza por el hecho de que la edición de 1954 remite a los estudios que justifican los datos que aporta y cuando plantea los tres casos que representan el comportamiento de los conductores en un carril de deceleración simplemente dice que se suponen tres hipótesis.

- Se considera la deceleración por retención con el motor como un movimiento rectilíneo uniformemente decelerado (un modelo cuadrático), pero al ser lo que Rocci (1993) considera una maniobra subconsciente se debería considerar un modelo cúbico.

- $\quad$ Fitzpatrick (2010) cuestiona si los conductores actuales se comportan en los carriles de deceleración igual a como se supuso que lo hacían en los años 50. ..

- $\quad$ Se debe cuestionar si sigue siendo válida la recomendación de hace más de 50 años de que la longitud de las vías de alta velocidad se obtiene no incluyendo en la longitud recomendada la cuña (el espacio recorrido por un vehículo que circula a la velocidad media de la autopista durante 3,5 segundos).

- $\quad$ Y sobre todo, es muy cuestionable obtener las longitudes utilizando unas gráficas que se obtuvieron basándose en estudios de finales de los años treinta y principios de los cuarenta.

- La velocidad media en el carril principal obtenida según la velocidad de diseño para condiciones de bajo volumen de tráfico puede no coincidir con la real; por ejemplo en el estudio de Livneh (1988) era menor que la supuesta por la AASHTO, y lo atribuía a que el porcentaje de vehículos pesados era muy alto.

- La velocidad media de los vehículos que divergen, en el inicio del carril de deceleración, es menor que la velocidad media de la vía principal.

- Los valores de la deceleración obtenidos en las observaciones empíricas de los carriles de deceleración son menores que los recomendados como confortables por la AASHTO. 
- $\quad$ El tiempo en que se retiene con el motor en los carriles correctamente diseñados y largos, es mayor a lo supuesto por la AASHTO. Livneh (1988), basado en las observaciones en los carriles que analizó, estableció que la deceleración por retención del motor se producía, como media, durante 10 segundos.

Basado en los resultados obtenidos en los estudios de campo que se llevaron a cabo en Netania, Livneh et al. (1988) determinaron cual debía ser la longitud de los carriles de deceleración según el comportamiento de los conductores, los cuales proceden del siguiente modo:

- $\quad$ Divergen a una velocidad inferior a la velocidad media de la vía principal.

- Deceleran por retención del motor durante $10 \mathrm{~s}$, con una deceleración menor a la asumida por la AASHTO, obtenida basado en observaciones empíricas a las que se les puede ajustar la ecuación (10):

$$
D_{R}=-0,77305+0,01495 \cdot V_{0}
$$

siendo:

$D_{R}=$ Deceleración por retención del motor, $\left(\mathrm{m} / \mathrm{s}^{2}\right)$.

$\mathrm{V}_{0}=$ Velocidad de divergencia, $(\mathrm{km} / \mathrm{h})$.

- $\quad$ Frenan con una deceleración que obtuvieron basándose en los estudios de campo que habían realizado, y que seguía la ecuación (11):

$$
D_{F}=0,05447+0,0113 \cdot V_{0}
$$

siendo:

$D_{\mathrm{F}}=$ Deceleración por aplicación de los frenos, $\left(\mathrm{m} / \mathrm{s}^{2}\right)$.

$\mathrm{V}_{0}=$ Velocidad de divergencia, $(\mathrm{km} / \mathrm{h})$.

Siguiendo este proceso la longitud que se obtiene es la que se muestra en la Tabla 30; en ella también aparece la que recomienda la AASHTO (1990)

Tabla 30: Comparación entre la longitud que necesitan los conductores para decelerar, basado en su comportamiento real, y el valor que aconseja la AASHTO.

\begin{tabular}{|c|c|c|c|c|c|c|c|c|}
\hline \multirow[b]{2}{*}{ MODELO } & \multicolumn{4}{|c|}{ VELOCIDADES (km/h) } & \multicolumn{4}{|c|}{ LONGITUDES (m) } \\
\hline & $V_{\text {DISEÑO }}$ & $\mathrm{V}_{\text {MEDIA }}$ & $\begin{array}{l}\mathrm{V}_{\text {MEDIA }} \\
\text { INICIO } \\
\text { CUÑA }\end{array}$ & $\begin{array}{l}\mathrm{V}_{\mathrm{A}} \quad 3 \mathrm{~s} \\
\text { RETENER } \\
\text { MOTOR }\end{array}$ & $\begin{array}{l}\mathrm{L}_{\text {CUÑA }} \\
\text { (V=cts, } 3.5 \\
\text { s) }\end{array}$ & $\begin{array}{l}\text { L } \\
\text { RETENCIÓN }\end{array}$ & $\begin{array}{l}\mathrm{L} \\
\text { FRENADO }\end{array}$ & $\begin{array}{l}\text { L } \\
\text { TOTAL }\end{array}$ \\
\hline AASHTO & 112 & 93 & 93 & 83 & 90 & 73 & 88 & 251 \\
\hline $\begin{array}{c}\text { Comportamiento } \\
\text { real }\end{array}$ & 112 & 85 & 79 & 75 & - & 200 & 40 & 240 \\
\hline
\end{tabular}

(Livneh et al. 1988) 
Si bien los datos en los que se basa el estudio son limitados si reflejan dos hechos constatados: la deceleración es menor a la recomendada por la AASHTO (2001) y el periodo en que se decelera por retención del motor es superior a lo supuesto. Por tanto, es interesante analizar los resultados. En primer lugar se observa que se obtiene una longitud similar a la propuesta por la AASHTO (2001). También se aprecia que la velocidad después de $3 \mathrm{~s}$ de decelerar por retención del motor es menor a la propuesta por la AASHTO (2001), probablemente porque la velocidad de los vehículos que divergen es inferior a la supuesta.

Lo más destacado es que la longitud que se recorre durante la deceleración por retención del motor es mucho mayor a lo previsto, por tanto es imprescindible conocer con exactitud la capacidad de deceleración por retención del motor, ya que el propio Livneh (1988) reconoce que sus datos son limitados. Por ejemplo, si se supone que en Netania los vehículos utilizaban la deceleración máxima que propone Rocci (1993) para las maniobras subconscientes, $5 \mathrm{~km} / \mathrm{h} / \mathrm{s}$, hasta la máxima disminución de la velocidad que se puede lograr con una maniobra inconsciente $\Delta V=20 \mathrm{~km} / \mathrm{h}$, se hubiera necesitado, aplicando la ecuación $\mathrm{d}=\mathrm{K} \cdot \mathrm{V}_{0}{ }^{*} \Delta \mathrm{V}$, una distancia $\mathrm{d}=119 \mathrm{~m}$ (81 m menor a lo obtenido), si el resto del proceso fuera igual al propuesto por Livneh (1988), la distancia de frenado sería $80 \mathrm{~m}$, por lo que la longitud total sería $199 \mathrm{~m}$ (41 m menos de lo que obtiene Livneh (1988)). He aquí la importancia de conocer con exactitud: primero, cuánto tiempo deceleran reteniendo con el motor; y segundo, la capacidad de retención del motor de los vehículos. También se deben analizar las diferencias que provoca en la longitud final representar las maniobras subconscientes con un modelo cuadrático en vez de con uno cúbico.

Livneh (1988) propuso una ecuación, para determinar la longitud del carril de deceleración en función de la velocidad media de los vehículos en la vía principal y en el ramal de salida y del frenado, que supone una aproximación numérica al comportamiento real del tráfico (ecuación(12)). Pero como él mismo reconoció, la falta de datos le obligaba a tener que utilizar el frenado y la velocidad media que recomienda la AASHTO.

$$
L={ }^{\prime}, 75 \cdot V_{0}+\frac{\left(\left[, 667 \cdot V_{0}\right)^{2}-V_{f}\right)^{2}}{2 \cdot d}-
$$

Siendo:

- $\mathrm{L}=$ Longitud del carril de deceleración $(\mathrm{m})$

- $\mathrm{V}_{0}=$ Velocidad media en el carril principal $(\mathrm{m} / \mathrm{s})$

- $V_{f}=$ Velocidad media de los vehículos en el ramal $(\mathrm{m} / \mathrm{s})$

- $\quad d=$ Deceleración mientras se frena $\left(\mathrm{m} / \mathrm{s}^{2}\right)$

Como se observa en la Tabla 31, proporciona longitudes similares a las de la AASHTO, esto puede deberse a que en realidad la menor deceleración se ve compensada porque se comienza a decelerar desde un principio. Pero el hecho de que la AASHTO proporcione unas longitudes similares a las que se obtendrían si se adaptara al nuevo 
comportamiento de los conductores no es razón para que no se produzca esta modificación.

Tabla 31: Comparación de las longitudes del carril de deceleración propuestas por Livneh vs las de la AASHTO

\begin{tabular}{|c|c|c|c|c|c|c|c|c|c|}
\hline \multicolumn{2}{|c|}{ AUTOPISTA } & \multicolumn{8}{|c|}{ LONGIUD DEL CARRIL DE DECELERACIÓN (m) } \\
\hline & & \multicolumn{2}{|c|}{$\begin{array}{l}\mathbf{V}_{\text {DISEÑO RAMAL }} \\
24 \mathrm{~km} / \mathrm{h}\end{array}$} & \multicolumn{2}{|c|}{$\begin{array}{l}\mathbf{V}_{\text {DISEÑO RAMAL }} \\
32 \mathrm{~km} / \mathrm{h}\end{array}$} & \multicolumn{2}{|c|}{$\begin{array}{c}V_{\text {DISEÑO RAMAL }} \\
48 \mathrm{~km} / \mathrm{h}\end{array}$} & \multicolumn{2}{|c|}{$\begin{array}{c}\text { V DISEÑO RAMAL } \\
64 \mathrm{~km} / \mathrm{h}\end{array}$} \\
\hline \multirow[t]{2}{*}{$\begin{array}{l}\mathbf{V}_{\text {DISEÑO }} \\
\mathbf{K m} / \mathbf{h}\end{array}$} & \multirow[t]{2}{*}{$\begin{array}{l}\mathbf{V}_{\text {MEDIA }} \\
\mathbf{k m} / \mathbf{h}\end{array}$} & \multicolumn{2}{|c|}{$\begin{array}{c}\mathbf{V}_{\text {MEDIA RAMAL }} \\
22 \mathrm{~km} / \mathrm{h}\end{array}$} & \multicolumn{2}{|c|}{$\begin{array}{c}V_{\text {MEDIA RAMAL }} \\
29 \mathrm{~km} / \mathrm{h}\end{array}$} & \multicolumn{2}{|c|}{$\begin{array}{c}V_{\text {MEDIA RAMAL }} \\
45 \mathrm{~km} / \mathrm{h}\end{array}$} & \multicolumn{2}{|c|}{$\begin{array}{c}V_{\text {MEDIA RAMAL }} \\
54 \mathrm{~km} / \mathrm{h}\end{array}$} \\
\hline & & $\begin{array}{c}\text { AASHT } \\
0\end{array}$ & Ec (3) & $\begin{array}{c}\text { AASHT } \\
0\end{array}$ & Ec (3) & $\begin{array}{c}\text { AASHT } \\
0\end{array}$ & Ec (3) & $\begin{array}{c}\text { AASHT } \\
0\end{array}$ & Ec (3) \\
\hline 80 & 70 & 188 & 191 & 181 & 183 & 166 & 156 & - & - \\
\hline 96 & 83 & 231 & 235 & 224 & 227 & 209 & 202 & 179 & 182 \\
\hline 112 & 93 & 263 & 268 & 255 & 261 & 248 & 237 & 218 & 219 \\
\hline 120 & 97 & 283 & 284 & 275 & 277 & 268 & 254 & 238 & 236 \\
\hline 128 & 102 & 303 & 301 & 295 & 294 & 280 & 271 & 258 & 254 \\
\hline
\end{tabular}

Son necesarias investigaciones en que se analice dada la velocidad de diseño de la vía principal, cual es la velocidad media y a qué velocidad se produce la divergencia, ya que se ha observado que la velocidad media que recomienda la AASHTO no coincide con la que en realidad existe y que los vehículos no divergen a la velocidad media sino que deceleran en la vía principal y salen a menor velocidad.

En los carriles de deceleración los conductores frenan con una deceleración menor a la que supone la AASHTO (2001), que a su vez es inferior a las propuestas por muchos investigadores como las que los conductores consideran confortables. A este hecho se une que los conductores deceleran con retención del motor durante más tiempo de lo previsto, sobre todo en los carriles que se diseñan siguiendo los criterios de la AASHTO (2001). Por tanto se considera que es necesario seguir investigando qué deceleraciones se producen en el carril de deceleración y que sucede si se obliga al conductor a emplear deceleraciones más próximas a las que se consideran como las máximas que admite como confortables.

De los diferentes modelos cinemáticos el de la AASHTO es el más extendido, no por la sencillez, sino por ser la AASHTO uno de los primeros organismo que proporcionó unos criterios de diseño de las autopistas que han ido adoptando otros organismos. Pero existen otros modelos cinemáticos mucho más sencillos que se obtienen de suponer que los vehículos en un carril de deceleración tienen un movimiento rectilíneo 
uniformemente variado, y la única diferencia es la deceleración que se propone y entre qué puntos se mide la longitud.

\subsection{MODELOS DINÁMICOS}

A continuación se describen los principales modelos para el cálculo de la longitud del carril de deceleración resultantes de aplicar la "Ecuación Fundamental de la Dinámica", la segunda Ley de Newton, como el que propone la norma española, 3.1-IC de 1999.

\subsubsection{Modelo de Fukutome}

Como conclusión del estudio hecho por Fukutome y Moskowitz en 1963 en 8 ramales de salida donde se analizaban las velocidades de los conductores a lo largo del ramal se propuso un carril de deceleración estándar en un intento de eliminar dudas en los conductores y simplificar la ingeniería. Esto supone un enfoque diferente, ya que en los modelos anteriores primero se propuso el modelo y luego se analizó el comportamiento de los conductores en los carriles de deceleración para observar si ellos con su actitud satisfacían el modelo. En este caso primero se analiza el comportamiento de los conductores y basado en él se determina el modelo. Es, por tanto, un modelo empírico, es decir, basado en la experiencia que proporcionaban todos los datos de que disponían por la observación que habían realizado en los ramales.

Los datos de campo mostraban que cuando el carril de deceleración tenía una longitud excesiva los vehículos mantenían en él una velocidad constante e incluso aceleraban, por lo que analizando las longitudes que usaban los conductores para decelerar y la velocidad se observó que cuando la curva tenía un radio de 400 pies (120 m), la longitud del carril de deceleración debía ser como mínimo de 450 pies, ya que distancias menores daban lugar a velocidades significativamente bajas en la nariz, lo que interfería en la vía principal, y producían deceleraciones mayores. Si en el ramal había una condición de parada se necesitaban 750 pies y cuando el radio de la curva era de 1000 pies era necesaria una longitud mínima para permitir la transición al ramal de salida sin interferir en el tráfico principal de 315 pies.

En la Figura 41 se define la geometría del carril propuesto, la longitud que se mide a partir de que la anchura del carril es 3,6 m, se obtiene de una gráfica en que se representan: el punto A (la distancia necesaria para detenerse), el punto B (la distancia necesaria para decelerar cuando el radio de la curva es de 400 pies), y el punto $C$ (cuando sólo se necesita una distancia mínima). Al unir esto puntos se obtiene una curva que permite obtener la longitud del carril de deceleración $D$, para cualquier radio, $\mathrm{R}$. 


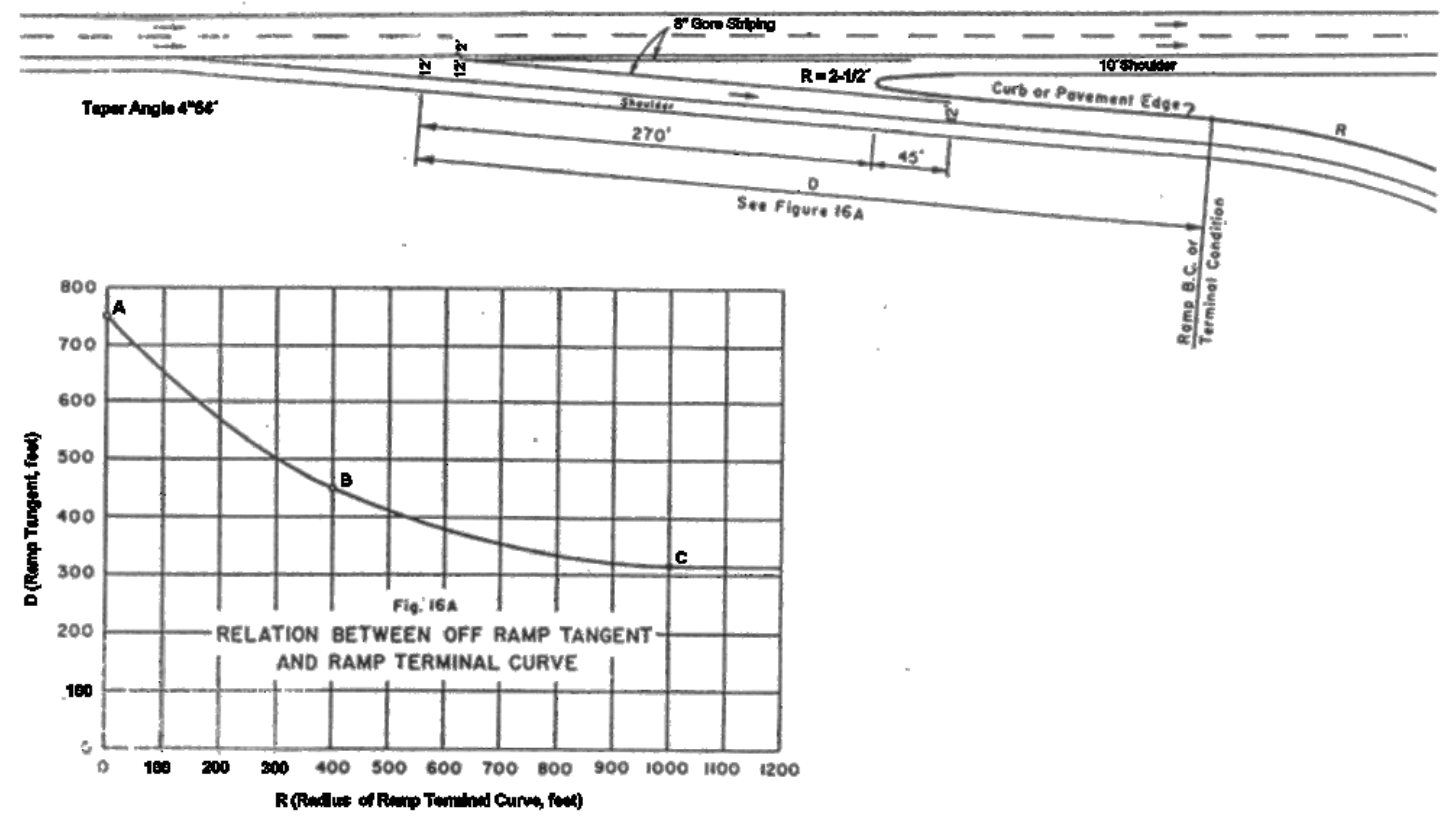

Figura 41: Ramal de salida sugerido por Fukutome (1963).

Basándose en las observaciones de campo, los autores recomiendan que se mantenga un radio de 400 pies como mínimo para todos los ramales, también se aconseja que los radios menores de 130 pies sean considerados una situación de parada.

Para analizar el modelo se han representado en la Figura 42 los valores propuestos por Fukutome y Moskowitz (1963) junto a los que recomienda la AASHTO (2001) y la Instrucción de Trazado 3.1-I.C. (1999) española. Como en la AASHTO (2001) y la norma Española la longitud depende directamente de la velocidad en la vía principal y en el ramal de salida, para realizar la gráfica ha sido necesario representar la longitud de la vía de deceleración en función del radio del ramal de salida y de las velocidades en la autopista, en este caso de 120 y $90 \mathrm{~km} / \mathrm{h}$.

Fukutome et al. (1963) no tienen en cuenta la velocidad en la vía principal ya que según sus observaciones cuando los vehículos divergen generalmente deceleran hasta velocidades de $80 \mathrm{~km} / \mathrm{h}$ antes de abandonar la autopista. Como el carril de deceleración, tanto en el modelo propuesto por Fukutome (1963) como en el de la AASHTO (2001), tiene un ancho de 3,6 m, para poder compararlo con la norma española se han restado a las longitudes propuestas por esta la parte de cuña que incluían. 


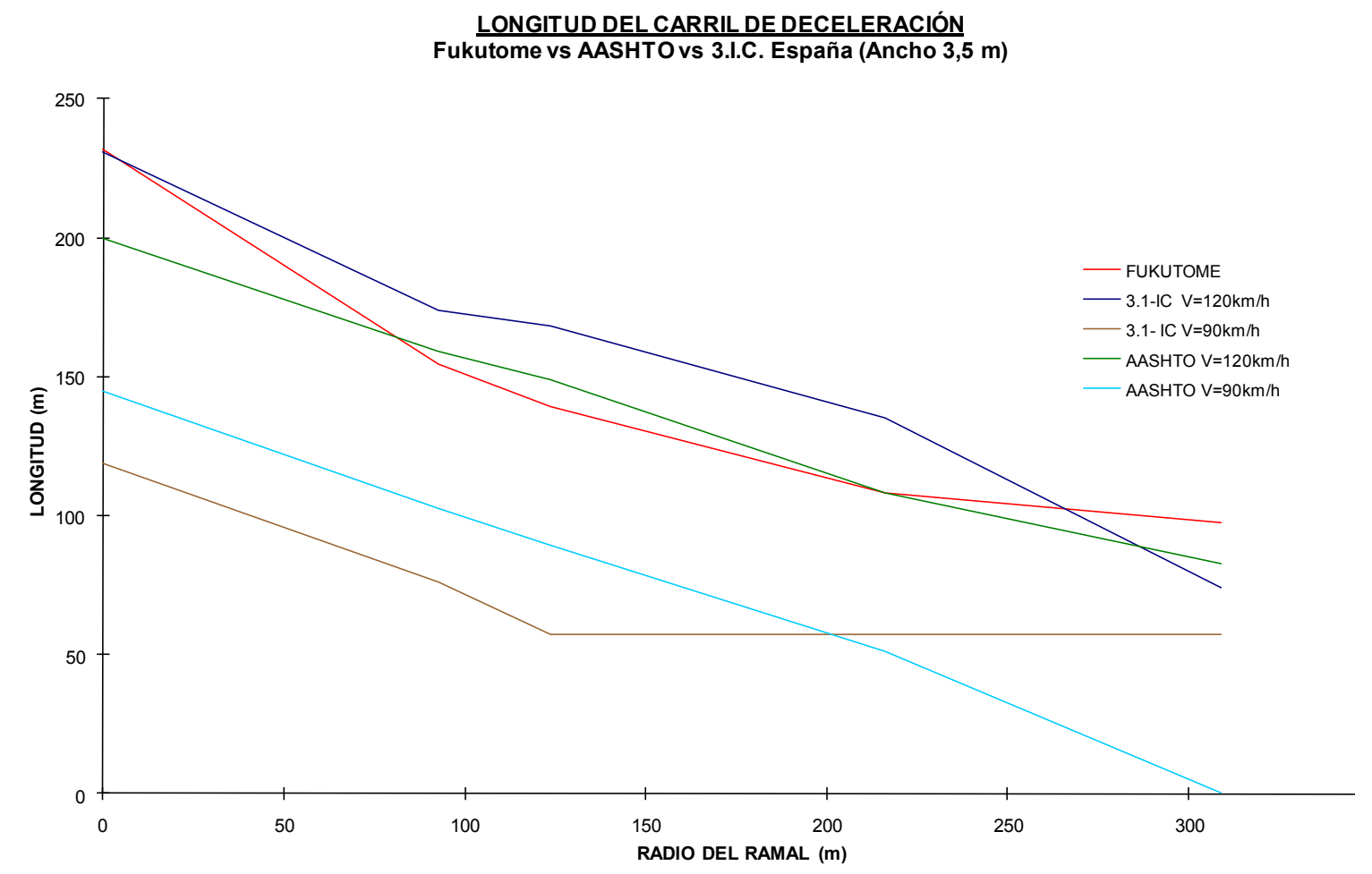

Figura 42: Comparación de la longitud de carril de deceleración Fukutome, AASHTO e Instrucción de Trazado 3.1-IC

En la Figura 41 se observa que con este modelo se sobredimensionan los carriles de deceleración cuando la velocidad en la vía principal es media o baja. Sólo cuando la velocidad es alta el modelo propone longitudes semejantes a las de la AASHTO (2001) y a la norma española, con diferencias del orden de $30 \mathrm{~m}$. La norma española para velocidades en el ramal del orden de 60 a $75 \mathrm{~km} / \mathrm{h}$ recomienda longitudes del carril de deceleración unos $30 \mathrm{~m}$ mayores a las propuestas por los demás modelos.

\subsubsection{Modelo de Rocci}

Rocci en el libro "Trazado de Carreteras" (1986), recoge un modelo dinámico para determinar la longitud de la vía de deceleración, en el que se calcula la longitud utilizando la ecuación (13):

$$
L=\frac{V_{f}^{2}-{ }^{2}{ }_{o}}{254 \cdot(a-}
$$

Siendo:

- L: Longitud de la vía de deceleración, (m), definida desde el punto en que el borde exterior de dicha vía está a $1,5 \mathrm{~m}$ del tronco, hasta el punto en que el borde interior de la vía está a $1 \mathrm{~m}$ del tronco.

- $\mathrm{V}_{\mathrm{f}}$ : Velocidad final de la maniobra $(\mathrm{km} / \mathrm{h})$.

- $\mathrm{V}_{0}$ : Velocidad inicial de la maniobra $(\mathrm{km} / \mathrm{h})$ 
- a: Deceleración media (unidades " $g$ ") con su signo. Valores máximos según Figura 43.

- i: Inclinación longitudinal de la rasante (tanto por uno), con su signo.

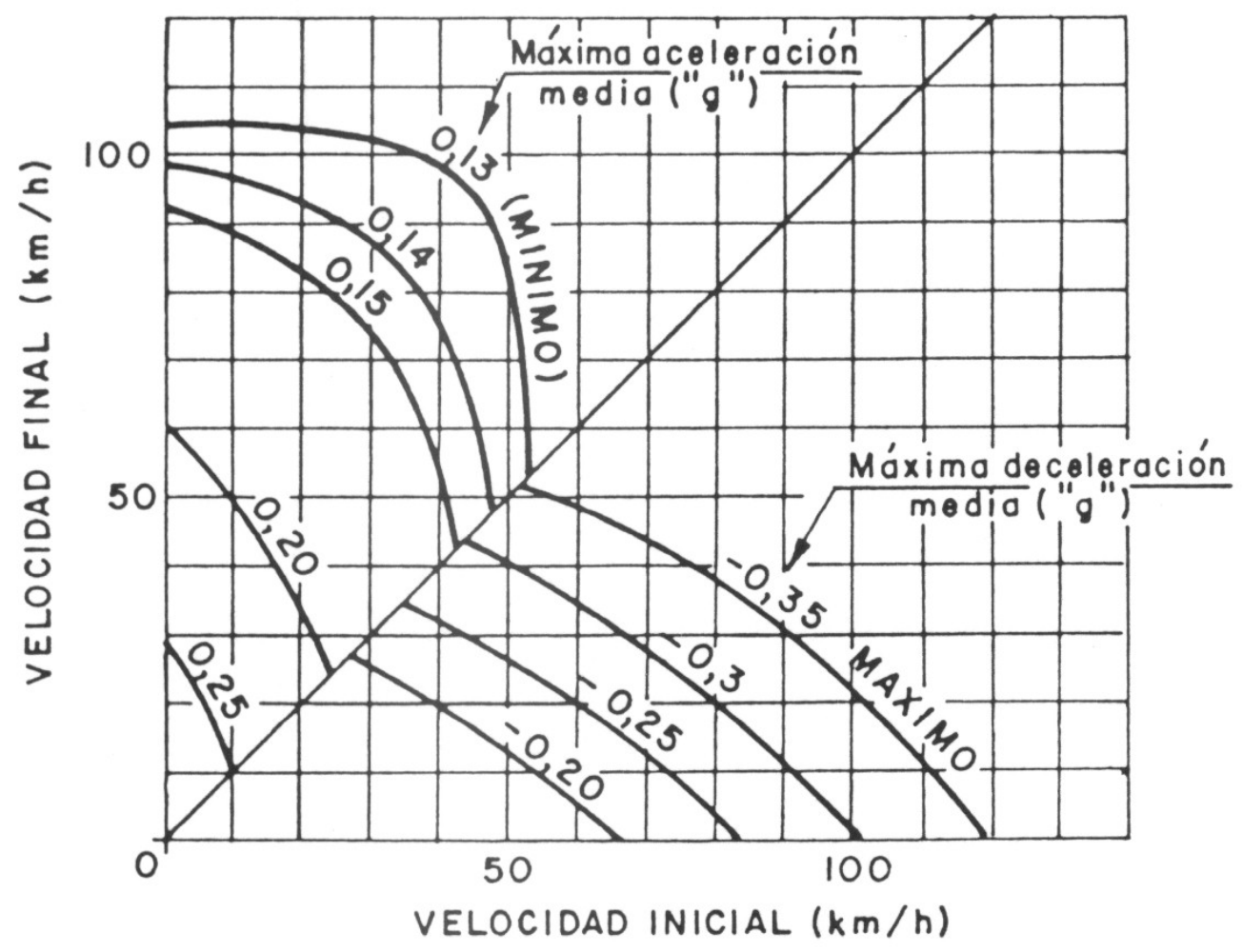

Figura 43: Aceleraciones y deceleraciones medias en vías de cambio de velocidad. (Rocci, 1986).

Las longitudes de la vía de deceleración según el modelo de Rocci (1986) se muestran en Tabla 32 y la Figura 43. Es importante resaltar cómo el modelo propuesto por Rocci (1986) supone una maniobra con deceleración uniforme cuyo valor varía en función de la velocidad inicial y la velocidad final. Esto hace que las longitudes de los carriles de deceleración calculadas con este modelo sean menores que las calculadas con el modelo de la Instrucción de trazado 3.1-IC (1999). Asimismo, se puede observar como la deceleración máxima considerada coincide con los valores de deceleración considerados como confortables por la AASHTO (2001). 
Tabla 32: Valores del carril de deceleración. Rocci (1986).

\begin{tabular}{|c|c|c|c|c|c|c|c|c|c|c|c|c|c|c|c|}
\hline \multicolumn{16}{|c|}{ VELOCIDAD $V_{d 0}=60 \mathrm{~km} / \mathrm{h}$} \\
\hline $\mathbf{V}_{\text {df }}$ & \multicolumn{15}{|c|}{ INCLINACIÓN DE LA RASANTE (\%) } \\
\hline $\mathbf{K m} / \mathbf{h}$ & -7 & -6 & -5 & -4 & -3 & -2 & -1 & 0 & 1 & 2 & 3 & 4 & 5 & 6 & 7 \\
\hline 0 & 129 & 118 & 109 & 101 & 94 & 89 & 83 & 79 & 75 & 71 & 67 & 64 & 62 & 59 & 57 \\
\hline 10 & 92 & 86 & 81 & 77 & 73 & 69 & 66 & 63 & 60 & 57 & 55 & 53 & 51 & 49 & 48 \\
\hline 20 & 70 & 66 & 63 & 60 & 57 & 55 & 52 & 50 & 48 & 47 & 45 & 43 & 42 & 41 & 39 \\
\hline 30 & 49 & 47 & 45 & 43 & 42 & 40 & 39 & 37 & 36 & 35 & 34 & 33 & 32 & 31 & 30 \\
\hline 40 & 31 & 30 & 29 & 28 & 27 & 26 & 25 & 25 & 24 & 23 & 22 & 22 & 21 & 21 & 20 \\
\hline 50 & 15 & 15 & $1<$ & 14 & 14 & 13 & 13 & 12 & 12 & 12 & 1 & 11 & 1 & 11 & 10 \\
\hline \multicolumn{16}{|c|}{ VELOCIDAD $V_{d 0}=80 \mathrm{~km} / \mathrm{h}$} \\
\hline $\mathbf{V}_{\text {df }}$ & \multicolumn{15}{|c|}{ INCLINACIÓN DE LA RASANTE (\%) } \\
\hline $\mathrm{km} / \mathrm{h}$ & -7 & -6 & -5 & -4 & -3 & 2 & -1 & 0 & 1 & 2 & 3 & 4 & 5 & 6 & 7 \\
\hline $\mathbf{0}$ & 148 & 140 & 133 & 126 & 120 & 115 & 110 & 105 & 101 & 97 & 93 & 90 & 87 & 84 & 81 \\
\hline 10 & 126 & 120 & 114 & 109 & 105 & 100 & 97 & 93 & 90 & 86 & 84 & 81 & 78 & 76 & 74 \\
\hline 20 & 103 & 98 & 94 & 91 & 87 & 84 & 81 & 79 & 76 & 74 & 72 & 69 & 67 & 66 & 64 \\
\hline 30 & 85 & 82 & 79 & 76 & 73 & 71 & 69 & 67 & 65 & 63 & 61 & 59 & 58 & 56 & 55 \\
\hline 40 & 67 & 65 & 63 & 61 & 59 & 57 & 56 & 54 & 52 & 51 & 50 & 48 & 47 & 46 & 45 \\
\hline 50 & 55 & 53 & 51 & 50 & 48 & 47 & 45 & 44 & 43 & 41 & 40 & 39 & 38 & 37 & 37 \\
\hline 60 & 39 & 38 & 37 & 36 & 34 & 33 & 32 & 31 & 31 & 30 & 29 & 28 & 28 & 27 & 26 \\
\hline \multicolumn{16}{|c|}{ VELOCIDAD $V_{\mathrm{d} 0}=100 \mathrm{~km} / \mathrm{h}$} \\
\hline $\mathbf{V}_{\mathrm{df}}$ & \multicolumn{15}{|c|}{ INCLINACIÓN DE LA RASANTE (\%) } \\
\hline $\mathbf{k m} / \mathbf{h}$ & -7 & -6 & -5 & -4 & -3 & -2 & -1 & 0 & 1 & 2 & 3 & 4 & 5 & 6 & 7 \\
\hline 0 & 175 & 168 & 161 & 154 & 149 & 143 & 138 & 133 & 129 & 125 & 121 & 118 & 114 & 111 & 108 \\
\hline 10 & 156 & 150 & 144 & 139 & 134 & 130 & 126 & 122 & 118 & 115 & 111 & 108 & 105 & 103 & 100 \\
\hline 20 & 137 & 133 & 128 & 124 & 120 & 116 & 113 & 110 & 106 & 104 & 101 & 98 & 96 & 93 & 91 \\
\hline 30 & 128 & 124 & 119 & 116 & 112 & 109 & 105 & 102 & 100 & 97 & 94 & 92 & 90 & 87 & 85 \\
\hline 40 & 118 & 114 & 110 & 107 & 103 & 100 & 97 & 94 & 92 & 89 & 87 & 85 & 83 & 81 & 79 \\
\hline 50 & 105 & 102 & 98 & 95 & 92 & 89 & 87 & 84 & 82 & 80 & 78 & 76 & 74 & 72 & 70 \\
\hline 60 & 90 & 87 & 84 & 81 & 79 & 10 & 74 & 72 & 70 & 68 & 66 & 65 & 63 & 61 & 60 \\
\hline
\end{tabular}




\begin{tabular}{|c|c|c|c|c|c|c|c|c|c|c|c|c|c|}
\hline \multicolumn{10}{|c|}{ VELOCIDAD $_{\mathbf{d} \mathbf{0}}=\mathbf{1 2 0} \mathbf{~ k m / h}$} \\
\hline $\mathbf{V}_{\mathbf{d f}}$ & \multicolumn{10}{|c|}{ INCLINACIÓN DE LA RASANTE (\%) } \\
\hline $\mathbf{~ k m / h}$ & $\mathbf{- 6}$ & $\mathbf{- 5}$ & $\mathbf{- 4}$ & $\mathbf{- 3}$ & $\mathbf{- 2}$ & $\mathbf{- 1}$ & $\mathbf{0}$ & $\mathbf{1}$ & $\mathbf{2}$ & $\mathbf{3}$ & $\mathbf{4}$ & $\mathbf{5}$ & $\mathbf{6}$ \\
\hline $\mathbf{0}$ & 195 & 189 & 183 & 177 & 172 & 167 & 162 & 157 & 153 & 149 & 145 & 138 & 135 \\
\hline $\mathbf{1 0}$ & 194 & 188 & 182 & 176 & 171 & 166 & 161 & 156 & 152 & 148 & 141 & 137 & 134 \\
\hline $\mathbf{2 0}$ & 190 & 184 & 178 & 172 & 167 & 162 & 157 & 153 & 149 & 145 & 138 & 134 & 131 \\
\hline $\mathbf{3 0}$ & 183 & 177 & 171 & 166 & 161 & 156 & 152 & 148 & 144 & 140 & 133 & 130 & 127 \\
\hline $\mathbf{4 0}$ & 174 & 168 & 163 & 157 & 153 & 148 & 144 & 140 & 136 & 133 & 126 & 123 & 120 \\
\hline $\mathbf{5 0}$ & 162 & 156 & 151 & 146 & 142 & 138 & 134 & 130 & 127 & 123 & 117 & 114 & 112 \\
\hline $\mathbf{6 0}$ & 147 & 142 & 137 & 133 & 129 & 125 & 121 & 118 & 115 & 112 & 106 & 104 & 101 \\
\hline
\end{tabular}

\subsubsection{Modelo de Fazio y Michael}

A finales de la década de los ochenta se desarrolló un modelo basado en el comportamiento de los conductores que fue publicado en 1990 y cuyos autores son: Joseph Fazio, Richard Michaels, William Reilly, James Schoen y Abishai Polus. El modelo propone tres elementos de respuesta consecutivos que juntos definen la longitud del carril de deceleración. El primer elemento es el punto en el que empieza la divergencia que depende del criterio del conductor quien se basa en la velocidad angular con la que percibe que se desplaza un punto de la cuña, foco, (aunque es él el que se desplaza). El segundo elemento es la distancia que necesitan los conductores para reorientar el vehículo una vez que se encuentran en el carril de deceleración. El tercer elemento es la distancia a la cual los conductores empiezan a frenar para pasar del carril de deceleración al ramal de salida. Para cada uno de estos elementos se desarrolló una definición matemática y estas definiciones permitieron el análisis de longitudes críticas del carril de deceleración. Para validar el modelo se compararon las distancias previstas con el comportamiento observado en ramales de salida en curva y en recta.

Para salir de una autopista el conductor debe realizar como mínimo 4 tareas:

1.- Detectar la existencia del carril de deceleración.

2.- Divergir desde el flujo principal de tráfico al carril de deceleración, es decir, iniciar la maniobra de cambio de dirección.

3.- Terminar la maniobra y reorientar el vehículo.

4.- Frenar para tener controlada la trayectoria en el punto que impone la velocidad del ramal de salida. 
El primer punto establece que el conductor cuando circula por la autopista ve el carril de deceleración desde una distancia adecuada. El conductor es consciente de la salida antes de verla, bien por la información de las señales o por la experiencia previa. Este conocimiento hace que el conductor que pretende salir se dirija al carril de la derecha. En algún punto el carril de salida se hace visible, y debe ser percibido como una expansión del ángulo visual. Debido a la agudeza visual del hombre, esta percepción sucede mucho tiempo antes del inicio físico del carril de cambio de velocidad. Las señales y el carril sirven como un estímulo de alerta, pero no proporcionan un criterio para iniciar la maniobra de divergencia.

Cuando el vehículo circula con un movimiento lineal por la autopista, el campo de visión del conductor está en un continuo estado de cambio. Los elementos de la autopista a los que enfoca el conductor en la distancia parecen fijos, mientras que los puntos cercanos están en movimiento. Estos objetos cambian del estado estacionario al de movimiento y esta variación se define en términos de la velocidad angular de los elementos del campo visual. En la zona de transición de un estado a otro los elementos tienen una velocidad angular cercana a la velocidad angular umbral del conductor, $\omega_{\mathrm{t}}$. que en muchos conductores tiene un valor de 0,004 rad/s, según obtuvieron Michaels y Fazio en un estudio realizado en 1989 en vehículos que convergían. Cuando los elementos en el punto de mira del conductor tienen una velocidad angular $\omega$ que es menor que $\omega_{\mathrm{t}}$, los puntos parecen estacionarios. Sin embargo, cuando $\omega \geq \omega_{\mathrm{t}}$ se aprecia un movimiento lateral de esos elementos.

Cuando un conductor planea salir de la autopista, se asume que el vehículo se encuentra en el carril de la derecha de la autopista cierta distancia antes del carril de deceleración. Al aproximarse, los elementos de la salida aumentan su velocidad angular hasta que alcanzan la velocidad angular umbral del conductor. Cuando en algún punto, al inicio del ramal de salida se alcanza una velocidad angular superior a la umbral (es decir, el ramal cambia de un estado estacionario a otro en que se mueve), se asume que el conductor inicia la divergencia. Con esta hipótesis el conductor no responde al tamaño de la tangente o al ángulo por ellos mismos, sino a los cambios en el tamaño de la tangente y el ángulo (es decir, la velocidad angular).

Una vez que los conductores han reorientado el vehículo, se deben preparar para adaptarse a la trayectoria del ramal de salida. Para ramales en curva, se supone que se empieza a frenar cuando se observa el lado interior de la curva dominante con una velocidad angular frenando, $\omega_{\mathrm{b}}$, en el rango de 0,1 a $0,3 \mathrm{rad} / \mathrm{s}$. El valor de 0,1 rad/s se usa cuando no se conoce el valor de $\omega_{\mathrm{b}}$ porque este es el valor en el que la aceleración angular se aproxima al mínimo. Este valor fue determinado por Gordon y Michaels en 1963.

Para ramales de salida en recta, (ej. enlaces en diamante), se hace la hipótesis de que se empieza a frenar cuando el conductor observa los puntos cercanos al final del ramal con la velocidad angular umbral, $\omega_{t}$. Ejemplos de puntos cerca del final del ramal son: una señal de tráfico, o la parte trasera del último vehículo de una cola.

Con base a esta descripción del proceso de divergencia, se divide el carril de deceleración en tres segmentos longitudinales. El primer segmento es la longitud 
recorrida durante el cambio de carril, $\mathrm{L}_{\text {sc. }}$. El segundo segmento es la longitud recorrida durante la deceleración por retención del motor, $L_{G}, y$ el tercer segmento es la distancia recorrida mientras se frena $L_{B}$. La suma de estas tres longitudes es la longitud del carril de deceleración necesaria.

Cuando el conductor observa un punto de la nariz, el foco, con una velocidad angular mayor al umbral $\omega_{\mathrm{t}}$, inicia la maniobra de incorporación al carril de deceleración desde el punto $\mathrm{P}$ en el que se encuentra. A efectos de cálculo se considera que el foco está situado en el borde izquierdo del ramal, a unos 8 pies del borde exterior del tronco. En la Figura 44 se representa esta situación. La distancia, $L_{\text {det1, }}$ desde el punto $P$ hasta la nariz se define con la siguiente ecuación (14):

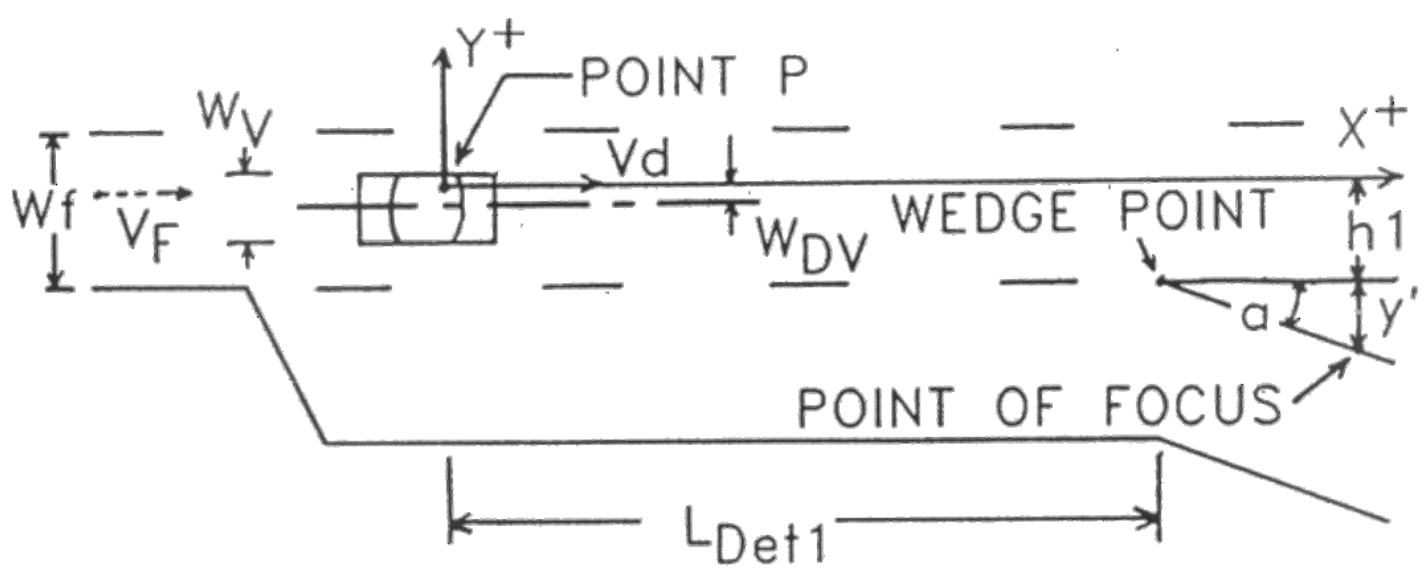

Figura 44: Posición del punto P

$$
\left.L_{D e t 1}=\left[\frac{V_{d}}{\left[D_{t}\right.} \cdot \mathbf{Q}_{1}+y_{-}^{\prime}-\boldsymbol{6}_{1}+y^{\prime 2}\right]^{2}\right]^{\frac{1}{\vdots}}-\frac{y^{\prime}}{\tan \alpha}
$$

Siendo:

- $\quad \mathrm{L}_{\text {det1 }}=$ Distancia de la nariz al punto en el que se inicia la divergencia.

- $\mathrm{V}_{\mathrm{d}}=$ Velocidad del vehículo en la divergencia, $\mathrm{V}_{\mathrm{d}} \approx \mathrm{V}_{\mathrm{f}}$ (velocidad de los vehículos en la autopista).

- $\omega_{\mathrm{t}}=$ Velocidad angular umbral, $\omega_{\mathrm{t}} \approx 0,004 \mathrm{rad} / \mathrm{s}$

- $\mathrm{h}_{1}=$ Distancia del punto medio de los ojos del conductor a un punto en el lado derecho del carril exterior de la autopista. $h_{1}=\left(\frac{V_{f}}{2}\right) \vdash V_{D V}$

- $\quad \mathrm{W}_{\mathrm{f}}=$ Ancho del carril de una autopista. $\mathrm{W}_{\mathrm{f}}=12$ pies

- $\mathrm{W}_{\mathrm{DV}}=$ Distancia del punto medio de los ojos al eje longitudinal del vehículo. $\mathrm{W}_{\mathrm{DV}} \approx 1,5$ pies.

- $y^{\prime}=$ Distancia entre el foco y el borde exterior de la autopista, $y^{\prime} \approx 8$ pies.

$\alpha=$ Ángulo de divergencia. Para ramales en recta $2^{\circ} \leq \alpha \leq 5^{\circ}$, y para ramales en curva $2^{\circ} \leq \alpha \leq 3^{\circ}$. 
Tabla 33: Distancia entre la nariz y el punto en el que se inicia la divergencia, $L_{\text {det1 }}$. (Fazio et al. 1990)

\begin{tabular}{|c|c|c|}
\hline $\begin{array}{c}\mathbf{V}_{\text {diseño }} \\
(\mathbf{k m} / \mathbf{h})\end{array}$ & $\mathbf{V}_{\text {autopista }}(\mathbf{k m} / \mathbf{h})$ & $\mathbf{L}_{\text {Det1 }} \mathbf{( m )}$ \\
\hline 50 & 47 & 140 \\
\hline 60 & 55 & 150 \\
\hline 70 & 63 & 159 \\
\hline 80 & 70 & 167 \\
\hline 90 & 77 & 174 \\
\hline 100 & 85 & 182 \\
\hline 110 & 91 & 188 \\
\hline 120 & 98 & 195 \\
\hline
\end{tabular}

La ecuación (14) se puede aplicar a ramales en curva o en recta. Dependiendo del diseño del ramal el punto de referencia, $\mathrm{y}^{\prime}$, varía considerablemente pero la distancia de detección no es sensible a y' si este está dentro de un rango razonable.

Conociéndose la velocidad de la autopista, se puede calcular la longitud necesitada por el conductor para completar la maniobra de desplazamiento al carril de deceleración con la siguiente ecuación (15):

$$
\mathrm{L}_{\mathrm{sc}}=\mathrm{V}_{\mathrm{d}} \times \mathrm{SC}_{\mathrm{t}} .
$$

Siendo:

- $\mathrm{SC}_{\mathrm{t}}=\mathrm{El}$ tiempo en el que se realiza la maniobra, 1,5 $\mathrm{s}$ según el estudio de McRuer y Klein, en 1975.

Tabla 34: Longitud necesaria para incorporarse al carril de deceleración, $L_{s c}$. (Fazio et al. 1990)

\begin{tabular}{|c|c|c|}
\hline $\begin{array}{c}\mathbf{V}_{\text {diseño }} \\
(\mathbf{k m} / \mathbf{h})\end{array}$ & $\mathbf{V}_{\text {autopista }}(\mathbf{k m} / \mathbf{h})$ & $\mathbf{L}_{\mathbf{s c}} \mathbf{( \mathbf { m } )}$ \\
\hline 50 & 47 & 20 \\
\hline 60 & 55 & 23 \\
\hline 70 & 63 & 26 \\
\hline 80 & 70 & 29 \\
\hline 90 & 77 & 32 \\
\hline 100 & 85 & 35 \\
\hline 110 & 91 & 38 \\
\hline 120 & 98 & 41 \\
\hline
\end{tabular}


Para tener un rango de la distancia que necesita un conductor para desplazarse al carril de deceleración es necesario conocer un punto en el que la maniobra ya haya terminado, $\mathrm{Q}$, dado que ya se conoce el punto en el que se inicia el desplazamiento, $\mathrm{P}$. La longitud entre $\mathrm{P}$ y $\mathrm{Q}$ proporciona la distancia máxima necesaria para trasladarse al carril de deceleración ya que en realidad el vehículo se incorpora en un punto entre $P$ y Q. El punto Q, representado en la Figura 45, es la posición en la que se encuentra el conductor, cuando está en el carril de deceleración y detecta que el foco alcanza una velocidad angular de aproximadamente 0,004 rad/s. La distancia entre el punto Q y la nariz se llama $L_{\text {det2 }}$ y se obtiene con la ecuación (16) que puede ser emplear en enlaces con ramales tipo diamante o curvas.

$$
L_{D e t_{2}}=\frac{\Gamma V_{d}}{\left\lfloor D_{t}\right.} \cdot \boldsymbol{Q}^{\prime}-h_{2}-\left(\boldsymbol{y}^{\prime}-h_{2}{ }^{2}\right]^{\frac{1}{\vdots}}-\frac{y^{\prime}}{\tan \alpha}
$$

Siendo:

- $\mathrm{h}_{2}=$ La distancia lateral desde un punto del lado izquierdo del carril de deceleración al punto medio entre los ojos del conductor, en pies.

$$
h_{2}=\left(\frac{W_{D}}{2}\right)-V_{D V}
$$

- $\mathrm{W}_{\mathrm{D}}=$ Anchura del carril de deceleración. $\mathrm{W}_{\mathrm{D}}=12$ pies

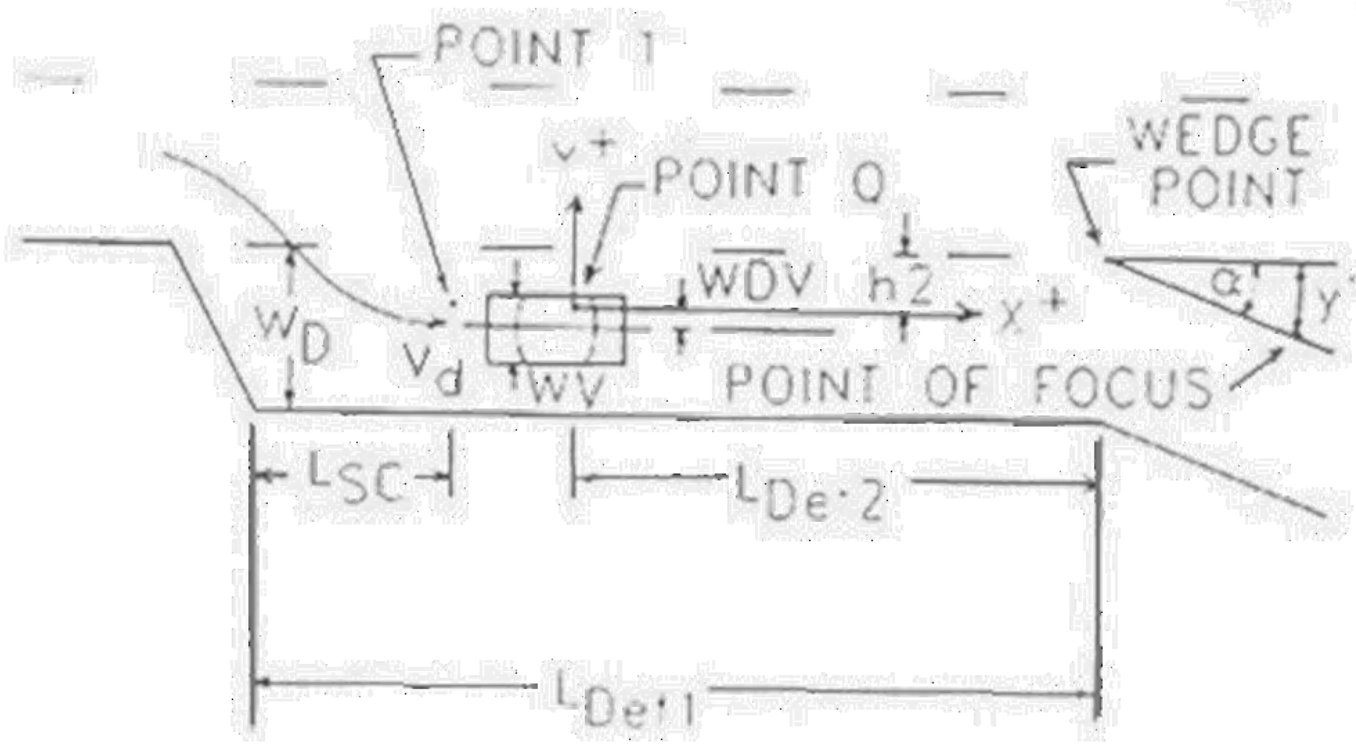

Figura 45: Posición del punto Q calidad imagen 
Tabla 35: Longitud entre la nariz y un punto, $Q$, en el que el vehículo ya se encuentra en el carril de deceleración, $L_{\text {Det2. (Fazio et al. 1990) }}$

\begin{tabular}{|c|c|c|}
\hline $\begin{array}{c}\mathbf{V}_{\text {diseño }} \\
\mathbf{( k m / h )}\end{array}$ & $\begin{array}{c}\mathbf{V}_{\text {autopista }} \\
(\mathbf{k m} / \mathbf{h})\end{array}$ & $\begin{array}{c}\mathbf{L}_{\text {Det2 }} \\
\mathbf{( m )}\end{array}$ \\
\hline 50 & 47 & 75 \\
\hline 60 & 55 & 80 \\
\hline 70 & 63 & 85 \\
\hline 80 & 70 & 88 \\
\hline 90 & 77 & 92 \\
\hline 100 & 85 & 96 \\
\hline 110 & 91 & 98 \\
\hline 120 & 98 & 101 \\
\hline
\end{tabular}

En $Q$ ya ha terminado la maniobra de divergencia, por lo que una vez obtenida la posición del punto $\mathrm{P}$ y $\mathrm{Q}$ respecto a la nariz, la máxima longitud de la zona de desplazamiento al carril de deceleración se obtiene restando la distancia entre el punto $Q$ y la nariz, $L_{\text {Det2, }}$ de la distancia entre el punto $P$ y la nariz, $L_{\text {Det1. }}$. Esta distancia máxima es la distancia entre el punto en el que el conductor detecta el inicio del movimiento del ramal de salida desde el carril exterior de la autopista y el lugar donde detecta el movimiento del ramal desde el carril de deceleración. La ecuación (18) es la que determina esta distancia máxima:

$$
L_{S C \max }=L_{\text {Det1 }}-L_{\text {Det2 }}
$$

Tabla 36: Longitud máxima necesaria para incorporarse a una vía de deceleración.

(Fazio et al. 1990)

\begin{tabular}{|c|c|c|}
\hline $\begin{array}{c}\mathbf{V}_{\text {diseño }} \\
(\mathbf{k m} / \mathbf{h})\end{array}$ & $\begin{array}{c}\mathbf{L}_{\mathbf{s c}} \\
\mathbf{( m )}\end{array}$ & $\begin{array}{c}\mathbf{L}_{\mathbf{s c} \text { máx }} \\
\mathbf{( m )}\end{array}$ \\
\hline 50 & 20 & 65 \\
\hline 60 & 23 & 70 \\
\hline 70 & 26 & 75 \\
\hline 80 & 29 & 79 \\
\hline 90 & 32 & 83 \\
\hline 100 & 35 & 87 \\
\hline 110 & 38 & 90 \\
\hline 120 & 41 & 93 \\
\hline
\end{tabular}


La posición del punto $\mathrm{R}$ depende de si el ramal de salida es curva (e.j. enlaces en trébol) o recta (e.j. enlaces en diamante), como se observa en la Figura 46. Para el ramal de salida en curva, el punto $\mathrm{R}$ representa el inicio de un periodo de transición: el conductor cambia de la trayectoria del carril de deceleración a la trayectoria curva del ramal. El punto $\mathrm{R}$ indica la posición del conductor cuando el foco, en el lado interior de la curva del ramal de salida, visible a una cierta distancia, $\mathrm{S}$, alcanza la velocidad angular umbral de frenado del conductor, 0,1 rad/s. La ecuación (19) para obtener $L_{B C}$ es:

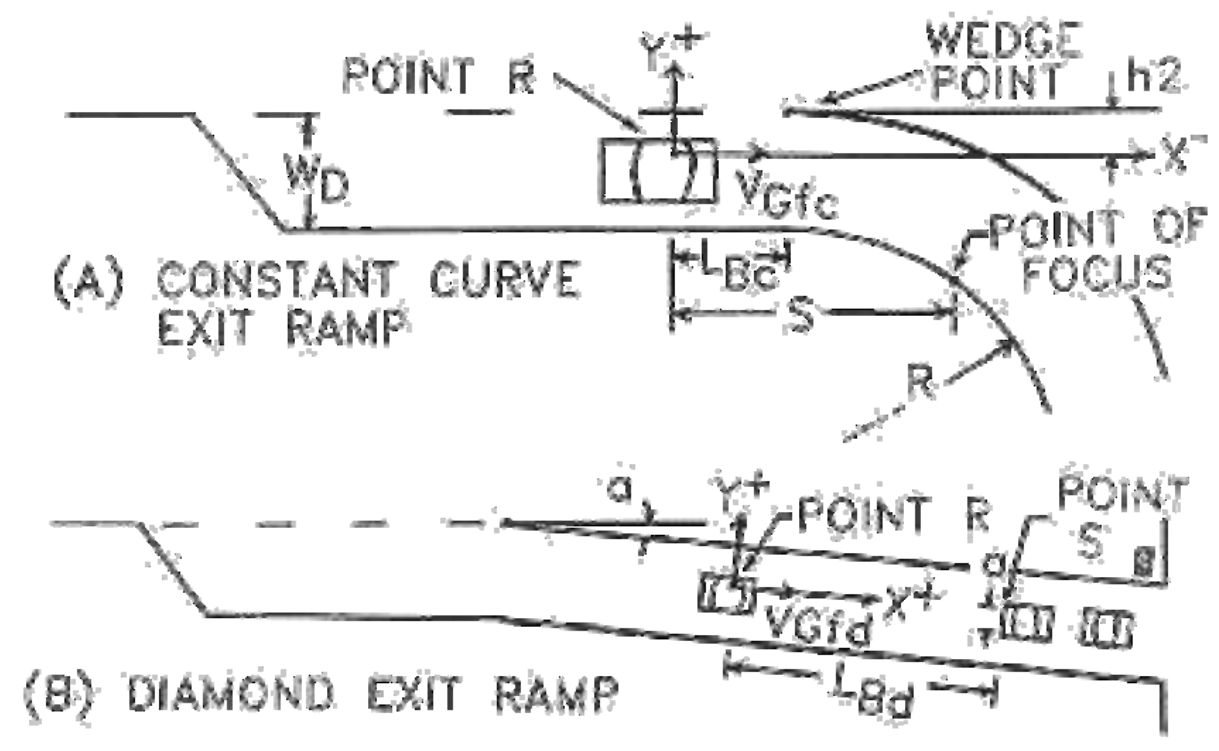

Figura 46: Inicio del frenado, punto $R$

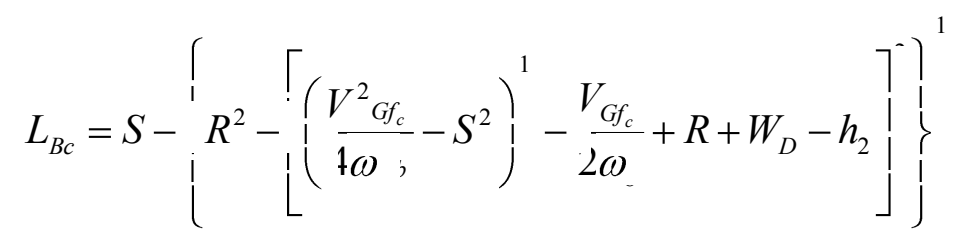

Siendo:

- $\mathrm{L}_{\mathrm{BC}}=$ Distancia de frenado cuando el ramal es curvo. La distancia desde el punto $\mathrm{R}$ a la nariz.

- $\mathrm{S}=$ Distancia de visibilidad al lado interior de la curva, que se determinó en un artículo sobre la percepción del conductor de Michaels y Cozan (1963): S =3,41 $\cdot \mathrm{V}_{\mathrm{GfC}}$

- $\mathrm{R}=$ Radio de curvatura mínimo, en pies, ecuación (20).

$$
R=\frac{V_{c}}{15 \cdot\left(++^{c}-\right.}
$$

- $\mathrm{V}_{\mathrm{c}}=$ Velocidad impuesta en la curva.

- $\mathrm{e}+\mathrm{f}=$ Peralte más coeficiente de fricción, $\mathrm{e}+\mathrm{f} \approx 0,2$ 
- $\quad \mathrm{V}_{\mathrm{Gfc}}=$ Velocidad del conductor al final de la deceleración por retención del motor, en pies/s. $\mathrm{V}_{\mathrm{Gfc}} \approx \mathrm{V}_{\mathrm{d}}$. La ecuación (21) es la exacta:

$$
V_{G f c}=\sqrt{\boldsymbol{(}_{d}^{2}-: L_{G c} \cdot d_{G}}
$$

- $\mathrm{L}_{\mathrm{Gc}}=$ Distancia en que se decelera por la retención del motor, en pies.

- $\mathrm{d}_{\mathrm{G}}=$ Deceleración con retención del motor, $\mathrm{d}_{\mathrm{G}} \approx 2$ pies $/ \mathrm{s}^{2}$

- $\omega_{\mathrm{b}}=$ Velocidad angular frenando, en rads/s Ecuación (22)

$$
\omega=\frac{V_{G f c} \cdot y}{s^{2}+,^{2}}
$$

El punto $\mathrm{R}$ es donde el conductor empezará a frenar respecto al punto de control punto S.

Tabla 37: Distancia de frenado en un ramal curvo, $L_{B C}$. (Fazio et al. 1990)

\begin{tabular}{|c|c|c|c|c|c|c|}
\hline & & $\begin{array}{c}\mathbf{V}_{\mathbf{c}} \\
\mathbf{( k m / h )}\end{array}$ & 21 & 30 & 40 & 50 \\
\hline $\mathbf{V}_{\mathbf{d}}$ & $\mathbf{V}_{\mathbf{G f c}}$ & $\mathbf{R}(\mathbf{m})$ & 17 & 35 & 63 & 98 \\
\hline $\mathbf{( k m / h )}$ & $\mathbf{( k m / h )}$ & $\mathbf{S}(\mathbf{m})$ & \multicolumn{4}{|c|}{$\mathbf{L}_{\mathbf{B C}} \mathbf{( m )}$} \\
\hline 50 & 47 & 40 & 23 & 12 & 1 & - \\
\hline 60 & 55 & 48 & 31 & 18 & 5 & - \\
\hline 70 & 63 & 56 & 39 & 24 & 10 & - \\
\hline 80 & 70 & 63 & 47 & 30 & 15 & 0 \\
\hline 90 & 77 & 70 & 55 & 36 & 20 & 4 \\
\hline 100 & 85 & 78 & 64 & 43 & 25 & 9 \\
\hline 110 & 91 & 84 & 73 & 49 & 30 & 12 \\
\hline 120 & 98 & 91 & 84 & 55 & 35 & 17 \\
\hline
\end{tabular}

En el caso de los ramales de salida rectas tipo diamante, el punto de control está normalmente próximo al final del ramal (e.j. señales de tráfico, señales de stop, vehículos en cola). En estos casos se asume que la deceleración por la aplicación de los frenos empieza en el punto $\mathrm{R}$ cuando los elementos críticos del término del ramal, como punto $S$, alcanzan la velocidad angular umbral $\left(\omega_{t}\right)$ como muestra la Figura 46. La distancia de frenado en un ramal en recta, $L_{B d}$, se puede calcular con la siguiente ecuación (23):

$$
L_{B d}=\left(\frac{V_{G f d} a}{\omega}-a^{2}\right)^{1}
$$

Siendo:

- $L_{B d}=$ La distancia de frenado en ramales en recta, distancia entre los puntos $R$ y $S$, en pies.

- $a=$ Ancho de un vehículo, en pies. $a \approx 6$ pies 
Tabla 38: Distancia de frenado en un ramal recto, $L_{B d .}$ (Fazio et al. 1990)

\begin{tabular}{|c|c|c|}
\hline $\mathbf{V}_{\mathbf{d}}$ & $\mathbf{V}_{\mathbf{G f c}}$ & $\mathbf{L}_{\mathbf{B d}}$ \\
\hline $\mathbf{( k m / h )}$ & $\mathbf{( k m / h )}$ & $\mathbf{( m )}$ \\
\hline 50 & 47 & 72 \\
\hline 60 & 55 & 79 \\
\hline 70 & 63 & 86 \\
\hline 80 & 70 & 91 \\
\hline 90 & 77 & 96 \\
\hline 100 & 85 & 101 \\
\hline 110 & 91 & 105 \\
\hline 120 & 98 & 109 \\
\hline
\end{tabular}

También se asume que el conductor decelerará con un ratio suficiente para mantener la velocidad angular de los elementos críticos en el umbral. Esta deceleración aplicando los frenos, $d_{B d}$, es función esencialmente de la velocidad del conductor al final de la deceleración sin aplicación de los frenos, $V_{\mathrm{Gfd}}$ y de la longitud, $\mathrm{L}_{\mathrm{Bd}}$. La ecuación (24), calcula la deceleración con frenos instantánea, necesaria para satisfacer este criterio:

$$
d_{B c}=\frac{0 \cdot V_{G f d}}{2 a} L_{B d}
$$

Una vez determinadas $L_{s c}$ y $L_{B}$, se conoce la longitud del carril de cambio de velocidad, asumiendo que no es necesaria una distancia de circulación por el carril de deceleración. Esta distancia de circulación es la distancia que no se necesita ni para la maniobra de desplazamiento lateral al carril de deceleración ni para frenar: este segmento proporciona el tiempo que emplea el conductor en reorientar el vehículo a una trayectoria rectilínea, tras haberse incorporado al carril, y en anticipar la respuesta a la necesidad de controlar la dirección y frenar antes del ramal (deceleración por retención del motor). Tanto para ramales de salida en curva y recta, la distancia necesaria para la deceleración por retención del motor, $L_{G c}$ y $L_{G d}$ está definida por la ecuación (25):

$$
\mathrm{L}_{\mathrm{Gc}}=\mathrm{L}_{\mathrm{Gd}}=50 \text { a } 100 \text { pies }
$$

Después de que se han determinado de forma individual las tres distancias necesarias que componen un carril de deceleración, tanto para los ramales en curva y en recta, se conoce la longitud total del carril de deceleración, $L_{D}$. Para los ramales en curva se define la ecuación (26):

$$
L_{D}=L_{S C}+L_{G C}+L_{B C}
$$

Para ramales en recta se define la ecuación (27): 


$$
L_{D}=L_{S C}+L_{G d}+L_{B d}
$$

El modelo se aplica a carriles de deceleración de tipo paralelo y también a los de tipo directo con tal de que cuando el conductor se encuentre en el punto $P$ la cuña tenga un ancho de 12 pies $(3,6 \mathrm{~m})$. En el caso de conductores no habituados con el ramal y ramales con un volumen bajo o moderado el modelo es conservador. Para conductores habituales probablemente proporciona una longitud del carril de deceleración mayor a la necesaria. El modelo se desarrolló suponiendo carriles de deceleración y ramales sin pendiente, por lo que se debe adaptar a estas condiciones.

A continuación se aplica la ecuación (24) para poder analizar las longitudes que se obtienen con este modelo, para ello se ha supuesto que:

- Las variables toman los valores recomendados por los autores.

- La longitud que se recorre mientras se deceleraba con retención del motor es de 30 m.

- Dada una velocidad de diseño, la velocidad a la que circulan los vehículos por la autopista es la que especifica la AASHTO (2001).

- La longitud necesaria para decelerar ante una condición de parada en un ramal en curva se asemeja a un ramal recto.

En la Tabla 39 se muestra el resultado, pero para facilitar el análisis se ha representado en Figura 47. En ella se observa:

Tabla 39: Longitud del carril de deceleración según el modelo de Fazio et al. (1990)

\begin{tabular}{|c|c|c|c|c|c|c|c|c|c|}
\hline $\mathbf{V}_{\text {proyecto }}$ & $\mathbf{V}_{\mathbf{d}}$ & LON & $\begin{array}{l}\text { TUD } \\
\text { DELC }\end{array}$ & $\begin{array}{l}\mathrm{LC} \\
\mathrm{EL} \mathrm{C}\end{array}$ & $\begin{array}{l}\text { IL D } \\
\text { IPOF }\end{array}$ & & $\begin{array}{l}\text { RAC } \\
\text { O DI }\end{array}$ & $\begin{array}{l}\text { SE } \\
\text { ZIC }\end{array}$ & EL \\
\hline \multirow[t]{2}{*}{$(\mathrm{km} / \mathrm{h})$} & $(\mathrm{km} / \mathrm{h})$ & \multicolumn{8}{|c|}{ Velocidad de diseño en la curva de salida $(\mathrm{km} / \mathrm{h})$} \\
\hline & & 0 & 21 & 30 & 40 & 50 & 60 & 70 & 80 \\
\hline 50 & 47 & 122 & 72 & 61 & 50 & - & - & - & - \\
\hline 60 & 55 & 132 & 83 & 71 & 58 & 53 & - & - & - \\
\hline 70 & 63 & 142 & 95 & 80 & 66 & 56 & 56 & - & - \\
\hline 80 & 70 & 150 & 106 & 89 & 74 & 59 & 59 & 59 & - \\
\hline 90 & 77 & 158 & 117 & 98 & 82 & 66 & 62 & 62 & 62 \\
\hline 100 & 85 & 167 & 130 & 109 & 91 & 74 & 65 & 65 & 65 \\
\hline 110 & 91 & 173 & 141 & 117 & 98 & 80 & 68 & 68 & 68 \\
\hline 120 & 98 & 180 & 155 & 126 & 106 & 87 & 71 & 71 & 71 \\
\hline
\end{tabular}




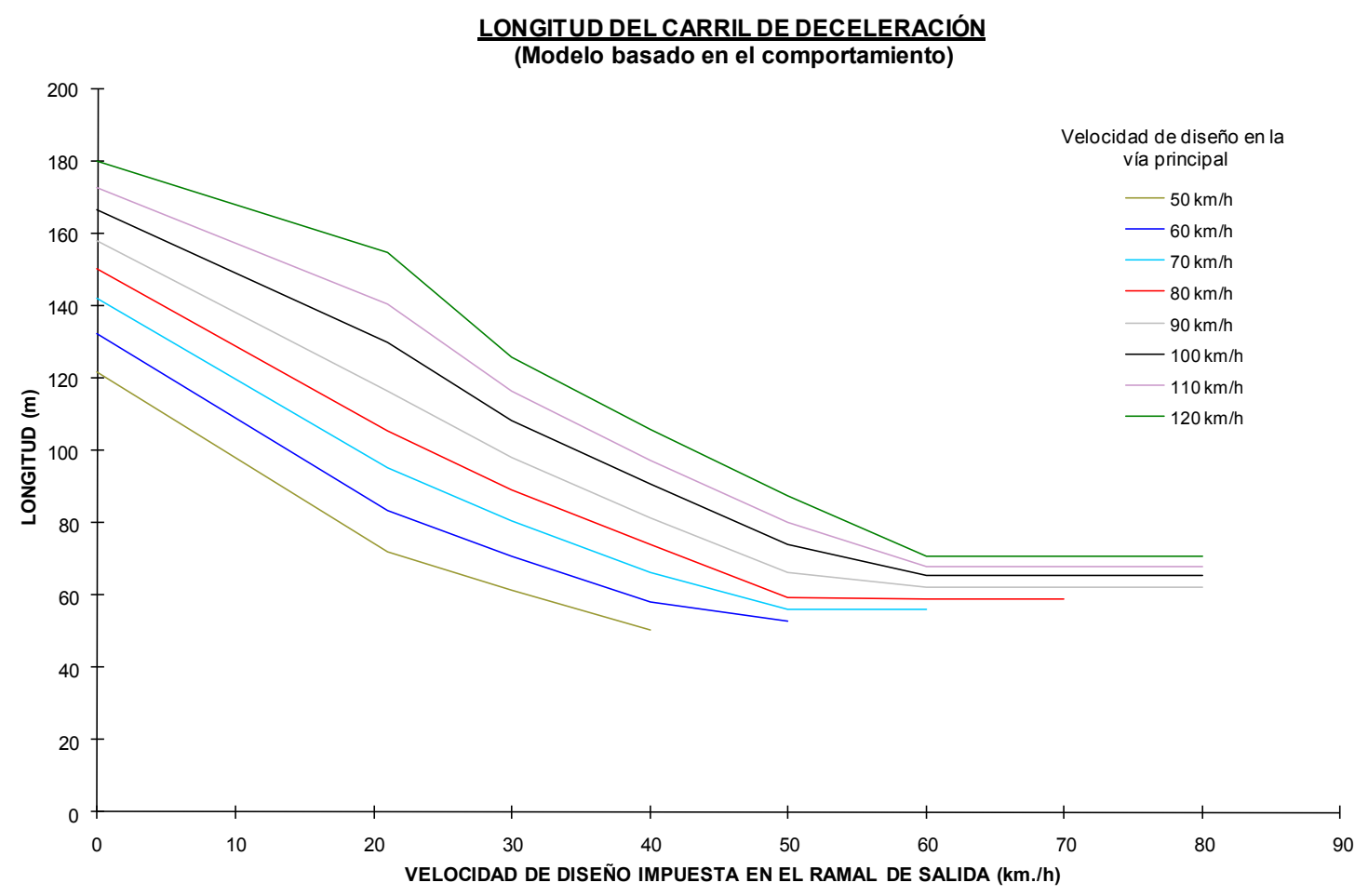

Figura 47 Longitud del carril de deceleración según el modelo de Fazio et al. (1990)

- Cuando la velocidad en la vía principal es elevada y el radio de la curva del ramal es grande, lo que implica que en el ramal se pueden desarrollar velocidades altas, la longitud del carril de deceleración no es sensible a la velocidad de la curva. Esto es debido a que la única longitud que necesitan los conductores es la necesaria para desplazarse al carril de deceleración y decelerar con la retención del motor ya que al tener la curva un radio amplio y por tanto una velocidad elevada empiezan a frenar en el propio ramal. Este hecho se refleja en el modelo cuando al determinar la longitud de frenado en curva se obtiene un valor negativo, que indica que no se frena en el carril de deceleración y que, por tanto, debe sustituirse por un cero.

- Cuando tanto en la vía principal como en el ramal las velocidades son elevadas apenas hay diferencia entre la longitud que se necesita para decelerar para diferentes velocidades en la autopista. Al ser esta diferencia de $3 \mathrm{~m}$ se puede afirmar que en todos estos casos se necesita la misma distancia. Estos resultados pueden explicarse basado en las observaciones hechas por Fukutome y Moskowitz (1963) que indicaban que los vehículos que divergen generalmente deceleran hasta una velocidad cercana a las $50 \mathrm{mph}(80 \mathrm{~km} / \mathrm{h})$ antes de abandonar la autopista, por lo tanto si para altas velocidades los vehículos frenan en la vía principal y entran al carril de deceleración con una velocidad similar todos necesitarán la misma longitud, si bien este hecho se aprecia mejor cuando la velocidad del ramal es elevada. Pero en el modelo nunca se considera que los vehículos que circulan a altas velocidades deceleran en la autopista y divergen a una velocidad similar por lo que las observaciones hechas por Fukutome (1963) sólo resultan útiles para no 
rechazar a primera vista los resultados del modelo. Como se observa en la gráfica para velocidades de $80 \mathrm{~km} / \mathrm{h}$ o superiores y velocidades en el ramal de $60 \mathrm{~km} / \mathrm{h}$ o mayores se necesita la misma longitud, que podría establecerse en $70 \mathrm{~m}$, teniendo toda esta distancia el mismo ancho que el carril de una autopista, 3,6 m según el modelo y la AASHTO (2001) y 3,5 m en España. Se propone esta longitud porque es un número redondo, fácil de recordar al ser el mismo para distintos casos y al ser prácticamente el mayor se evitan los problemas de seguridad que podría causar una distancia insuficiente.

- La hipótesis de que la condición de parada en un ramal en curva se asemeja a una detención en un ramal recto parece ser acertada cuando la velocidad en la autopista es elevada, mayor de $80 \mathrm{~km} / \mathrm{h}$, ya que todos los puntos parecen estar en una recta, mientras que para velocidades menores se observa un cambio de la pendiente que puede ser un indicio de que la hipótesis hecha no es aplicable en estos casos.

- En la Figura 47 se observa que en realidad las curvas son rectas por lo que se podría ajustar a los resultados de la ecuación (26) una ecuación lineal que es mucho más sencilla, aunque en este caso sus sumandos y coeficientes no tendrían significado físico, y hacer la longitud igual a $70 \mathrm{~m}$ cuando las velocidades tanto en la vía principal como en el ramal son elevadas.

Para profundizar en el análisis es necesario compararlo con los modelos ya existentes: el cinemático (AASHTO 2001) y dinámico (3.1-IC, España).

\section{LONGITUD DEL CARRIL DE DECELERACIÓN}

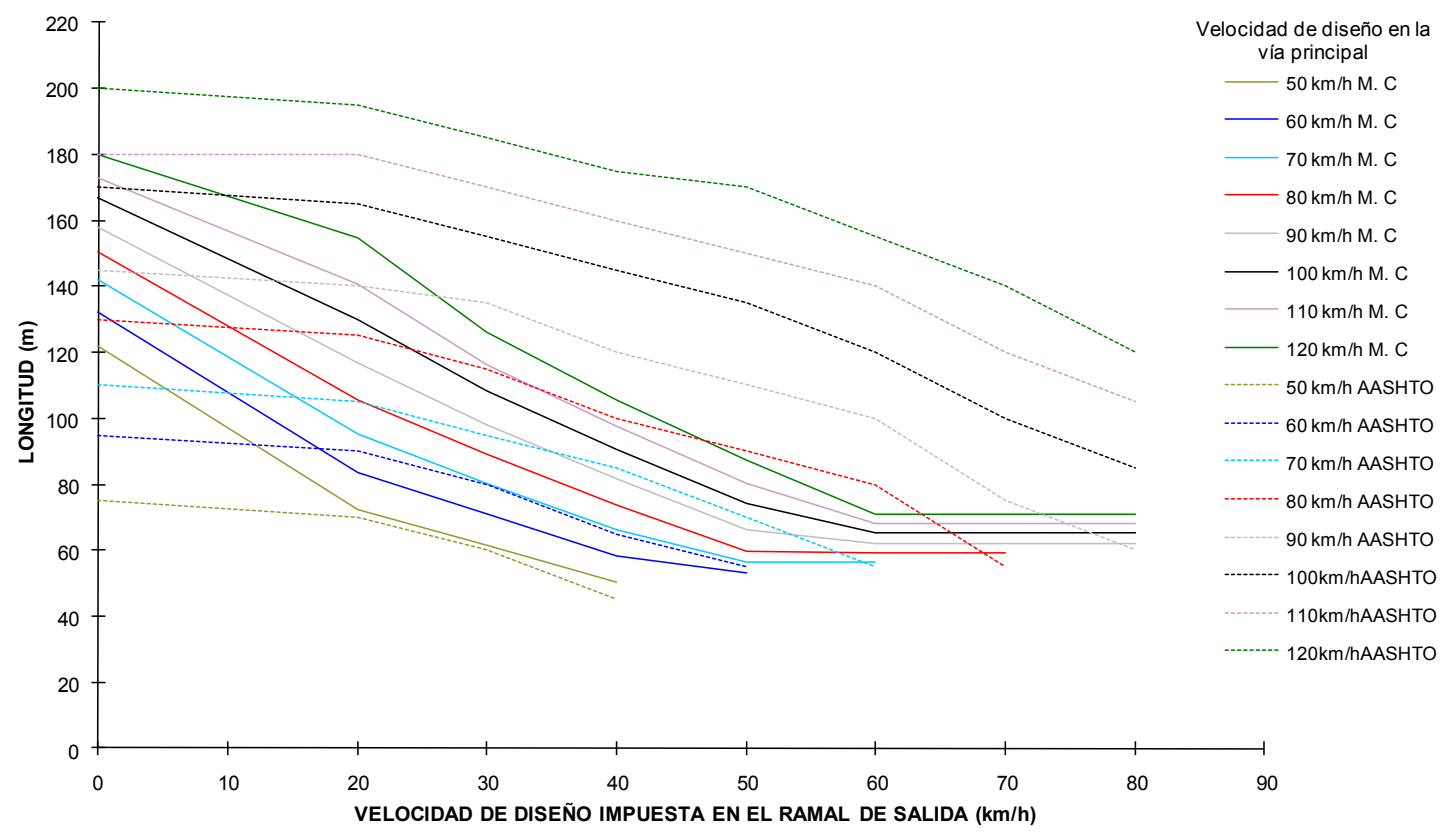

Figura 48 Comparación modelo AASHTO vs. modelo de comportamiento 
Al comparar las longitudes que recomienda la AASHTO con las que propone este modelo del comportamiento, Figura 48, se observa que:

- En contra de lo que cabría esperar este modelo proporciona longitudes del carril de deceleración mucho menores que las de la AASHTO (2001) (en algunos puntos la diferencia es de $84 \mathrm{~m}$ ). Estas diferencias están mucho más acentuadas cuando la velocidad en la vía principal es elevada mientras que para velocidades muy bajas (50 km/h y $60 \mathrm{~km} / \mathrm{h}$ ) se ajustan bastante bien. Otro aspecto es que cuando la diferencia entre la velocidad de la vía principal y el carril de deceleración es mínima $(10 \mathrm{~km} / \mathrm{h})$, la longitud se puede considerar que es en ambos casos igual, salvo cuando las velocidades en la autopista son muy elevadas (110 y $120 \mathrm{~km} / \mathrm{h}$ ), pero cuando la diferencia de velocidades es tan pequeña, aunque exista una solución matemática que nos defina la longitud, no tiene sentido una vía de deceleración.

- Con esta gráfica parece confirmarse lo inadecuado que resulta suponer, sobre todo cuando la velocidad en la vía principal es menor a $80 \mathrm{~km} / \mathrm{h}$, que la detención en un ramal curvo se puede asimilar a una detención en un ramal recto, ya que mientras que en la AASHTO (2001) se observa que la pendiente de la curva disminuye y tiende a cero en el modelo del comportamiento aumenta la pendiente. Por esto parece más adecuado calcular esta distancia manteniendo la pendiente de la recta que une los puntos que se obtienen con la ecuación (26) así se obtienen unos resultados más parecidos a los de la AASHTO (2001).

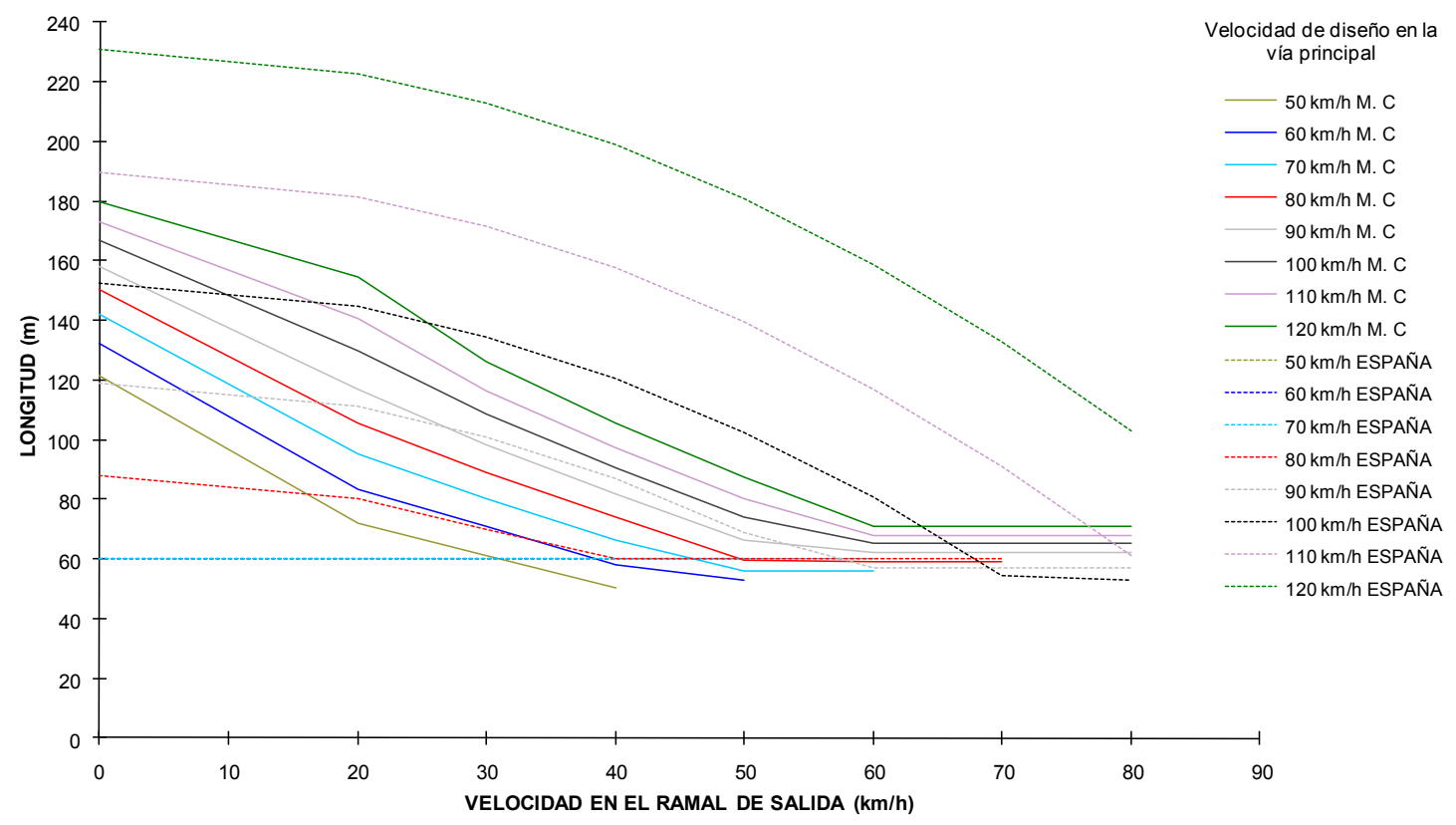

Figura 49: Comparación modelo de la Instrucción de Trazado 3.1-IC vs. modelo de comportamiento 
Para comparar las longitudes propuestas por el Modelo del Comportamiento con los que propone la norma 3.1-IC española, se ha considerado sólo la longitud del carril de deceleración que tiene un ancho de 3,5 m, Figura 49. Los resultados confirman que cuando la velocidad en la vía principal es elevada el Modelo del Comportamiento da valores significativamente menores. En este caso cuando la velocidad en la autopista es pequeña el modelo da longitudes mayores, y no similares como anteriormente. Ambos modelos proponen longitudes similares cuando la velocidad en la autopista es de $90 \mathrm{~km} / \mathrm{h}$. Cuando la velocidad del ramal es cero la pendiente de la curva de la norma española tiende a cero y no aumenta como llega a suceder en el Modelo del Comportamiento.

Para validar el modelo se evaluó con los datos recogidos en un estudio del NCHRP (Reilly et al. 1989) (datos no publicados) en siete ramales. La evaluación del modelo quería probar su aptitud para determinar: $L_{d e t 1}, L_{S C}, L_{G}$ y $L_{B}$, comparando las distancias previstas con el comportamiento de salida observado.

La distancia inicial de divergencia $L_{\text {det1 }}$, la longitud de desplazamiento $L_{s c}$ y la distancia de frenado en ramales $L_{B C}$ en curva observadas no fueron estadísticamente diferentes a las previstas por el modelo.

La comparación entre $L_{s c \max }$ del modelo, suponiendo $\omega_{\mathrm{t}}=0,004 \mathrm{rad} / \mathrm{s}$, y la medida $\mathrm{L}_{\mathrm{sc}}$, reveló que $\mathrm{L}_{\text {scmax }}$ era superior en todos los casos a $\mathrm{L}_{s c}$. El valor $\mathrm{L}_{s \mathrm{~s} \text { max }}$ es útil para prevenir el sobredimensionamiento de la longitud del carril de cambio de velocidad, ya que si $L_{s c}$ es mayor que $L_{s c \max }$, los conductores pueden usar la longitud extra para acelerar.

Para los ramales en curva los datos de campo fueron consistentes con los valores estimados por el modelo: las diferencias eran 7 y 15 pies. Para los ramales en recta las longitudes observadas eran significativamente diferentes de las predicciones del modelo, ya que el modelo proporcionaba longitudes mayores. Estas diferencias, según los autores, parecían ser causadas por la imposibilidad para determinar en los datos de campo donde empezaban a frenar los vehículos.

Este es un modelo relativamente reciente, se presentó en 1990, y por estar tan arraigado el modelo propuesto por la AASHTO, que básicamente no ha variado desde 1954 (Fitzpatrick 2010), no ha tenido una gran repercusión ya que ni siquiera ha servido para plantear la necesidad de modificar el criterio con que se diseñan los carriles de deceleración. Hasta tal punto ha tenido poco éxito que cuando se presentó se reconocía que como muchos ramales no tienen radio constante sino que son clotoides se debía modificar la ecuación (17) para reflejar este hecho y que posteriormente aparecería esta adaptación. Esta poca repercusión puede deberse a que propone un enfoque completamente distinto al empleado hasta ahora: los clásicos modelos dinámicos o cinemáticos, pero siempre es positivo ampliar el enfoque que se da a un tema y verlo bajo distintos puntos de vista.

Dejando de lado la repercusión que ha tenido el modelo, es importante analizar el procedimiento empleado: se grabó en vídeo a los vehículos, determinando el tiempo por el que figuraba en las cintas, y para las distancias se tomó como referencia conos 
fluorescentes situados cada 16-30 m. La deceleración se obtenía al observar una variación en la velocidad que se determinaba porque se conocía la distancia entre dos conos y el tiempo que el vehículo empleaba en recorrerla. Esto hace que no se pueda determinar con exactitud cuándo empieza a decelerar el vehículo. Pero lo más curioso es que cuando el modelo no predice con exactitud la distancia de frenado en los ramales en recta la justificación que se da es que en los datos de campo no se pudo determinar con exactitud cuando los conductores empiezan a frenar aplicando los frenos, siendo esto lo más sencillo, ya que como ya hicieran Livneh y Polus basta con tener situada una cámara detrás y observar cuando se encienden las luces traseras rojas porque se está pisando el freno. Otras cuestiones relacionadas con el procedimiento empleado es que si bien tienen en cuenta que el uso de conos puede influir en el conductor y los colocan a cierta distancia del carril de deceleración no se puede afirmar que donde los colocaron no afectaran al tráfico, otro aspecto es que el modelo se desarrolla para curvas de radio constante y se analizaron ramales que eran clotoides por lo que tuvieron que aproximarlos a curvas de un radio equivalente constante, con lo que el inicio del frenado sucede a velocidades angulares por debajo de $0,1 \mathrm{rad} / \mathrm{s}$, como los propios autores reconocen. Otro aspecto, pero que es de difícil solución, es que probablemente muchos de los conductores que emplearon esos ramales los conocían por lo que tenían un comportamiento sobreaprendido. Un aspecto positivo del procedimiento empleado es que como en el modelo se supone que el vehículo no se ve afectado por otros vehículos que estén circulando por el carril de deceleración, sólo se emplearon para el análisis los vehículos independientes, es decir, en flujo libre.

A priori parece que este modelo proporcionará longitudes excesivas porque la longitud del carril de deceleración empieza en el punto en que el vehículo, que se encuentra en el carril principal, comienza a divergir y en este punto ya se exige que el ancho del carril de deceleración sea de 3,6 m, anchura que sólo es necesaria cuando el vehículo ya se ha incorporado a la vía de deceleración.

El modelo es complicado ya que intervienen muchas variables que se deben suponer y que pueden llevar a errores en la distancia. De estas variables hay algunas muy importantes que están basadas en estudios anteriores de los propios autores y que se aceptan sin ser cuestionadas cuando son la base del modelo y fallos en ellas pueden provocar errores importantes; por ejemplo, si $\omega_{\mathrm{t}}<0,004 \mathrm{rad} / \mathrm{s}$, los conductores divergirán después de lo previsto, y si $\omega_{\mathrm{t}}>0,004 \mathrm{rad} / \mathrm{s}$, antes, o el tiempo en el que se desplazan al carril de deceleración que también varía según el conductor. $\mathrm{Si}_{\mathrm{SC}}>1,5$ $\mathrm{s}$, $\mathrm{L}_{s c}$ será mayor que el valor previsto por el modelo y $\mathrm{SC}_{\mathrm{t}}<1,5 \mathrm{~s}$, será menor, asumiendo en ambos casos una velocidad de divergencia constante. Como se vio al analizar la cuña algunos autores consideran que el tiempo que se emplea en la divergencia son $3,5 \mathrm{~s}$ en vez de $1,5 \mathrm{~s}$.

En ningún otro modelo se hace un análisis diferente según la geometría del ramal de salida y sólo influye la velocidad que el ramal impone al conductor. Sin embargo, al modelo le faltaría contemplar que sucede cuando en la curva hay impuesta una 
condición de parada, ya que como en este supuesto el radio es cero y se ha dado una definición matemática para obtener la longitud de frenado, ecuación (19), la ecuación no tiene solución ya que no hay raíz cuadrada de un número negativo. Al no contemplarse este supuesto se puede asemejar este caso a un ramal en recta, ecuación(23)). Tampoco se prevé que sucede cuando al calcular la distancia de frenado $y>\left\{+V_{D}-1_{2}\right.$, Aunque observando la Figura 46 se deduce que en este supuesto se debe aplicar la ecuación (29).

$$
\text { Siendo: } y=\frac{V_{G f_{c}}}{7,2 \cdot \omega}-\left(\frac{V^{2} G_{c}}{51,84 \cdot \omega ;}-S^{2}\right)^{1}
$$

(Con la longitud en metros y la velocidad en $\mathrm{km} / \mathrm{h}$ )

$$
\left.\left.L_{B c}=S-R_{i}^{2}-\frac{V_{G f_{c}}}{{ }^{\prime}, 2 \cdot \omega}-\left(\frac{V_{G f_{c}}^{2}}{\left(j, 84 \cdot \omega_{b}\right.}-S^{2}\right)^{1}-R-W_{D}+h_{2}\right)\right\}
$$

El uso de este modelo es complejo ya que hay que aplicar una serie de ecuaciones y son muchas las variables a considerar. Para que sea más cómodo su uso se deberían suponer algunas variables, aplicar las ecuaciones y representar los resultados en tablas o gráficos. Otro aspecto es que las unidades del modelo están en el sistema inglés por lo que a continuación se han convertido las ecuaciones para que entrando con las longitudes en metros y las velocidades en $\mathrm{km} / \mathrm{m}$ los cálculos sean más fáciles. Las ecuaciones (30), (31), (32) y (33) son las que se han empleado en las tablas que aparecen en este apartado:

$$
\begin{aligned}
& \left.L_{D e t 1}=\left\lceil\frac{V_{d}}{3,6 \cdot \omega_{t}} \cdot \mathbf{Q}_{1}+y^{\prime}-\mathbf{6}_{1}+y^{\prime}\right]^{2}\right]^{1}-\frac{y^{\prime}}{\tan \alpha} \\
& L_{S C}=\frac{\mathrm{V}}{3,6} \cdot S C_{t} \\
& \left.\left.L_{\text {Det }_{2}}=\Gamma \frac{V_{d}}{\left\lfloor, 6 \cdot \omega_{t}\right.} \cdot \boldsymbol{x}^{\prime}-h_{2}-\boldsymbol{x}^{\prime}-h_{2}\right]^{2}\right]^{\frac{1}{3}}-\frac{y^{\prime}}{\tan \alpha} \\
& \left.\left.L_{B c}=S-R_{i}^{2}-R_{1}^{\lceil}\left(\frac{V_{G f_{c}}^{2}}{i 1,84 \cdot \omega_{b}}-S^{2}\right)^{1}-\frac{V_{G f_{c}}}{1,2 \cdot \omega}+R+W_{D}-h_{2}\right\}^{-}\right\}^{1}
\end{aligned}
$$


Siendo:

$$
\begin{gathered}
\mathrm{S}=0,93 \cdot \mathrm{V}_{\mathrm{Gfc}} \\
R=\frac{V_{c}^{2}}{127 \cdot\left(e+{ }^{c}\right)} \\
L_{B d}=\left(\frac{V_{G f d} a}{3,6 \cdot \omega}-a^{2}\right)^{1} \\
d_{B c}=\frac{0 \cdot V_{G f d}}{7,2 \cdot a} L_{B d} \\
\mathrm{~L}_{\mathrm{Gc}}=\mathrm{L}_{\mathrm{Gd}}=16-30 \mathrm{~m}
\end{gathered}
$$

\subsubsection{Instrucción de Trazado 3.1-IC}

En la norma 3.1-IC "Trazado" (1999), para calcular la longitud de las vías de deceleración, se supone que la velocidad de un vehículo varía entre los siguientes valores:

- $\quad V_{d o}$, velocidad inicial, su valor es el menor entre la velocidad de proyecto $\left(V_{P}\right)$, y la velocidad máxima señalizada en la calzada principal, a la altura de la sección característica de $1,5 \mathrm{~m}$; aquélla donde la anchura del carril medida perpendicularmente al eje de la calzada principal desde el borde de ésta es de 1,5 m.

- $\quad V_{d f r}$ velocidad final, es el valor de la velocidad específica $\left(V_{e}\right)$ del elemento del carril de deceleración que contiene la sección característica de $1 \mathrm{~m}$; aquélla donde la separación entre el borde de la calzada del carril y el de la calzada principal, medida perpendicularmente al eje de ésta, es de $1 \mathrm{~m}$.

Para determinar la longitud $(L)$ de los carriles de deceleración entre las secciones indicadas (Figura 50), se aplica la ecuación (39), que se deduce de un modelo dinámico; como la longitud se obtiene con un equilibrio de fuerzas en la fórmula ya se considera la inclinación de la rasante, obteniendo que conforme aumenta la pendiente aumenta la longitud, pero no de manera lineal, sino que el aumento de la pendiente en una unidad produzca un aumento de la longitud mayor conforme crece la pendiente.

$$
L=\frac{V_{d o}^{2}-r^{2}}{254 \cdot i+0} \geq 00 m
$$

Siendo:

$L=$ longitud del carril de deceleración $(\mathrm{m})$ entre las secciones características.

$i=$ inclinación de la rasante en tanto por uno (positiva en rampa, negativa en pendiente) 
Un aspecto importante es que mientras la norma española 3.1-IC "Trazado" permite obtener longitudes del carril de deceleración para cualquier pendiente y de hecho en las tablas que la acompañan se calculan para pendientes de $\pm 7 \%$ (excepto si la velocidad inicial es de $120 \mathrm{~km} / \mathrm{h}$ ), la AASHTO sólo considera pendientes de hasta \pm $6 \%$.
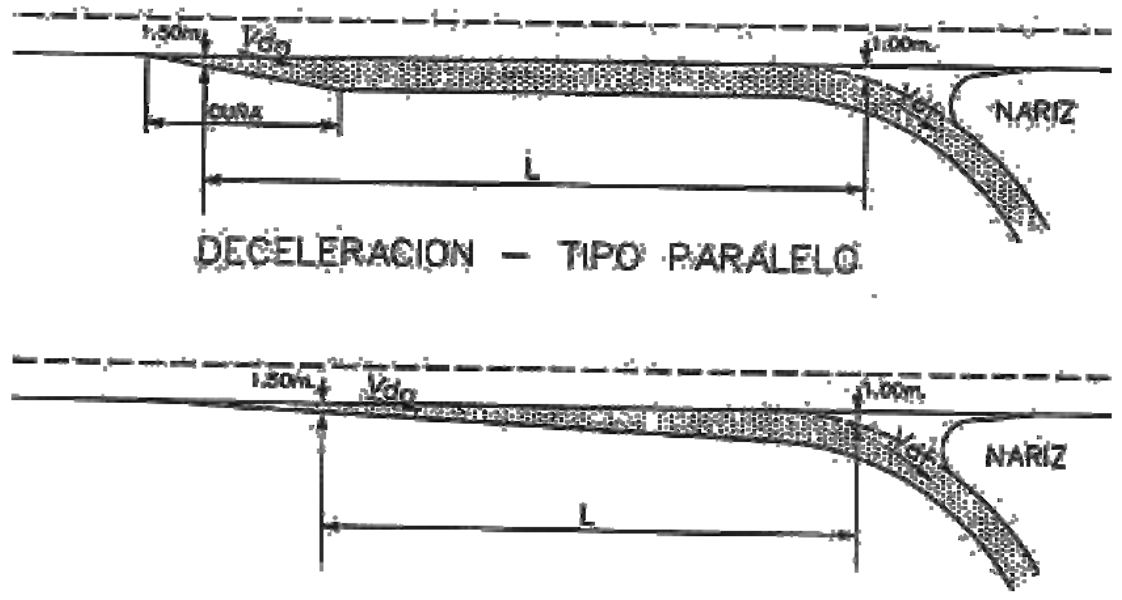

\section{DECEELERACION - TIRO DIRECTO}

Figura 50: Carriles de deceleración, secciones características. Norma 3.1-IC "Trazado" (1999)

En la norma 3.1-IC "Trazado" (1999) se establece que los carriles de deceleración serán, en general, de tipo paralelo, y excepcionalmente, previa expresa justificación, podrán ser de tipo directo, con curvaturas progresivamente crecientes, pero sólo cuando su longitud sea igual o menor a $180 \mathrm{~m}$.

En lo referente a la cuña, como ya se mencionó, la Norma 3.1-IC "Trazado" (1999), diferencia según el tipo de carril:

En los carriles de deceleración directos la cuña es tangente al borde de la calzada principal o forma con él un ángulo cuya cotangente se encuentra entre veinte y treinta y cinco (ambos incluidos).

Para los carriles de deceleración paralelos establece que la longitud de la cuña será el espacio que recorre un vehículo durante 3 segundos, con una velocidad igual a la mayor de los valores de la velocidad de proyecto y la máxima limitada a la altura de la sección característica de 1,5 m; siempre esta longitud sea mayor a la mínima de 70 m, y cuyos valores se recogen en la Tabla 40.

Tabla 40: Longitudes de la cuña según la norma 3.1-IC, (1999)

\begin{tabular}{|c|c|}
\hline MÁX. ( $\mathbf{p}$, limitada) $\mathbf{( k m} / \mathbf{h})$ & LONGITUD DE LA CUÑA (m) \\
\hline$\leq \mathbf{8 0}$ & 70 \\
\hline $\mathbf{1 0 0}$ & 83 \\
\hline $\mathbf{1 2 0}$ & 100 \\
\hline
\end{tabular}


En la Tabla 41 se indican las longitudes de los carriles de deceleración para valores discretos de $i, V_{d o}$ y $V_{d f}$ y en la Figura 51 se representan los valores continuos para algunas velocidades iniciales y pendientes.

Tabla 41: Longitud del carril de deceleración para algunos valores discretos de $\mathbf{i}, \mathbf{V}_{\mathrm{do}}$

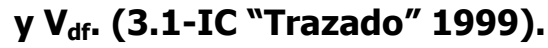

VELOCIDAD $V_{\mathrm{d} 0}=60 \mathrm{~km} / \mathrm{h}$

\begin{tabular}{|c|c|c|c|}
\hline $\mathbf{V}_{\mathbf{d f}}$ & \multicolumn{3}{|c|}{ INCLINACIÓN DE LA RASANTE (\%) } \\
\hline $\mathbf{( k m} / \mathbf{h})$ & -7 & -6 & $-5 \leq \mathrm{i} \leq 7$ \\
\hline $\mathbf{0}$ & 112 & 104 & 100 \\
\hline $\mathbf{1 0}$ & 109 & 101 & 100 \\
\hline $\mathbf{2 0} \leq \mathbf{V}_{\mathbf{d f}} \leq \mathbf{6 0}$ & 100 \\
\hline
\end{tabular}

VELOCIDAD $V_{\mathrm{d} 0}=80 \mathrm{~km} / \mathrm{h}$

\begin{tabular}{|c|c|c|c|c|c|c|c|c|c|c|c|c|c|c|c|}
\hline $\mathbf{V}_{\mathbf{d f}}$ & \multicolumn{10}{|c|}{ INCLINACIÓN DE LA RASANTE (\%) } \\
\hline $\mathbf{~ k m / h}$ & $\mathbf{- 7}$ & $\mathbf{- 6}$ & $\mathbf{- 5}$ & $\mathbf{- 4}$ & $\mathbf{- 3}$ & $\mathbf{- 2}$ & $\mathbf{- 1}$ & $\mathbf{0}$ & $\mathbf{1}$ & $\mathbf{2}$ & $\mathbf{3}$ & $\mathbf{4}$ & $\mathbf{5}$ & $\mathbf{6}$ & $\mathbf{7}$ \\
\hline $\mathbf{0}$ & 199 & 184 & 172 & 161 & 151 & 142 & 135 & 128 & 122 & 116 & 111 & 106 & 102 & 100 & 100 \\
\hline $\mathbf{1 0}$ & 196 & 181 & 169 & 158 & 149 & 140 & 133 & 126 & 120 & 114 & 109 & 105 & 100 & 100 & 100 \\
\hline $\mathbf{2 0}$ & 186 & 173 & 161 & 151 & 142 & 134 & 126 & 120 & 114 & 109 & 104 & 100 & 100 & 100 & 100 \\
\hline $\mathbf{3 0}$ & 171 & 158 & 147 & 138 & 130 & 122 & 116 & 110 & 105 & 100 & 100 & 100 & 100 & 100 & 100 \\
\hline $\mathbf{4 0}$ & 149 & 138 & 129 & 120 & 113 & 107 & 101 & 100 & 100 & 100 & 100 & 100 & 100 & 100 & 100 \\
\hline $\mathbf{5 0}$ & 121 & 112 & 105 & 100 & 100 & 100 & 100 & 100 & 100 & 100 & 100 & 100 & 100 & 100 & 100 \\
\hline $\mathbf{6 0}$ & 100 & 100 & 100 & 100 & 100 & 100 & 100 & 100 & 100 & 100 & 100 & 100 & 100 & 100 & 100 \\
\hline
\end{tabular}

VELOCIDAD $V_{\mathrm{d} 0}=100 \mathrm{~km} / \mathrm{h}$

\begin{tabular}{|c|c|c|c|c|c|c|c|c|c|c|c|c|c|c|c|}
\hline $\mathbf{V}_{\mathbf{d f}}$ & \multicolumn{10}{c|}{ INCLINACIÓN DE LA RASANTE (\%) } \\
\hline $\mathbf{~ k m / h}$ & $\mathbf{- 7}$ & $\mathbf{- 6}$ & $\mathbf{- 5}$ & $\mathbf{- 4}$ & $\mathbf{- 3}$ & $\mathbf{- 2}$ & $\mathbf{- 1}$ & $\mathbf{0}$ & $\mathbf{1}$ & $\mathbf{2}$ & $\mathbf{3}$ & $\mathbf{4}$ & $\mathbf{5}$ & $\mathbf{6}$ & $\mathbf{7}$ \\
\hline $\mathbf{0}$ & 310 & 288 & 268 & 251 & 236 & 223 & 211 & 200 & 190 & 182 & 174 & 166 & 159 & 153 & 148 \\
\hline $\mathbf{1 0}$ & 307 & 285 & 265 & 248 & 234 & 220 & 209 & 198 & 188 & 180 & 172 & 165 & 158 & 152 & 146 \\
\hline $\mathbf{2 0}$ & 298 & 276 & 257 & 241 & 227 & 214 & 202 & 192 & 183 & 174 & 167 & 160 & 153 & 147 & 142 \\
\hline $\mathbf{3 0}$ & 282 & 262 & 244 & 228 & 215 & 203 & 192 & 182 & 173 & 165 & 158 & 151 & 145 & 139 & 134 \\
\hline $\mathbf{4 0}$ & 261 & 242 & 225 & 211 & 198 & 187 & 177 & 168 & 160 & 153 & 146 & 140 & 134 & 129 & 124 \\
\hline $\mathbf{5 0}$ & 233 & 216 & 201 & 188 & 177 & 167 & 158 & 150 & 143 & 136 & 130 & 125 & 120 & 115 & 111 \\
\hline $\mathbf{6 0}$ & 199 & 184 & 172 & 161 & 151 & 142 & 135 & 128 & 122 & 116 & 111 & 106 & 102 & 100 & 100 \\
\hline
\end{tabular}


VELOCIDAD $V_{\mathrm{d} 0}=120 \mathrm{~km} / \mathrm{h}$

\begin{tabular}{|c|c|c|c|c|c|c|c|c|c|c|c|c|c|}
\hline $\mathbf{V}_{\mathbf{d f}}$ & \multicolumn{10}{|c|}{ INCLINACIÓN DE LA RASANTE (\%) } \\
\hline $\mathbf{~ k m / h}$ & $\mathbf{- 6}$ & $\mathbf{- 5}$ & $\mathbf{- 4}$ & $\mathbf{- 3}$ & $\mathbf{- 2}$ & $\mathbf{- 1}$ & $\mathbf{0}$ & $\mathbf{1}$ & $\mathbf{2}$ & $\mathbf{3}$ & $\mathbf{4}$ & $\mathbf{5}$ & $\mathbf{6}$ \\
\hline $\mathbf{0}$ & 414 & 386 & 361 & 340 & 321 & 303 & 288 & 274 & 261 & 250 & 239 & 230 & 221 \\
\hline $\mathbf{1 0}$ & 411 & 383 & 359 & 337 & 318 & 301 & 286 & 272 & 260 & 248 & 238 & 228 & 219 \\
\hline $\mathbf{2 0}$ & 403 & 375 & 351 & 330 & 312 & 295 & 280 & 266 & 254 & 243 & 233 & 223 & 215 \\
\hline $\mathbf{3 0}$ & 388 & 362 & 339 & 319 & 301 & 284 & 270 & 257 & 245 & 234 & 224 & 215 & 207 \\
\hline $\mathbf{4 0}$ & 368 & 343 & 321 & 302 & 285 & 270 & 256 & 244 & 232 & 222 & 213 & 204 & 196 \\
\hline $\mathbf{5 0}$ & 342 & 319 & 299 & 281 & 265 & 251 & 238 & 226 & 216 & 207 & 198 & 190 & 182 \\
\hline $\mathbf{6 0}$ & 311 & 290 & 271 & 255 & 240 & 228 & 216 & 206 & 196 & 187 & 180 & 172 & 166 \\
\hline
\end{tabular}

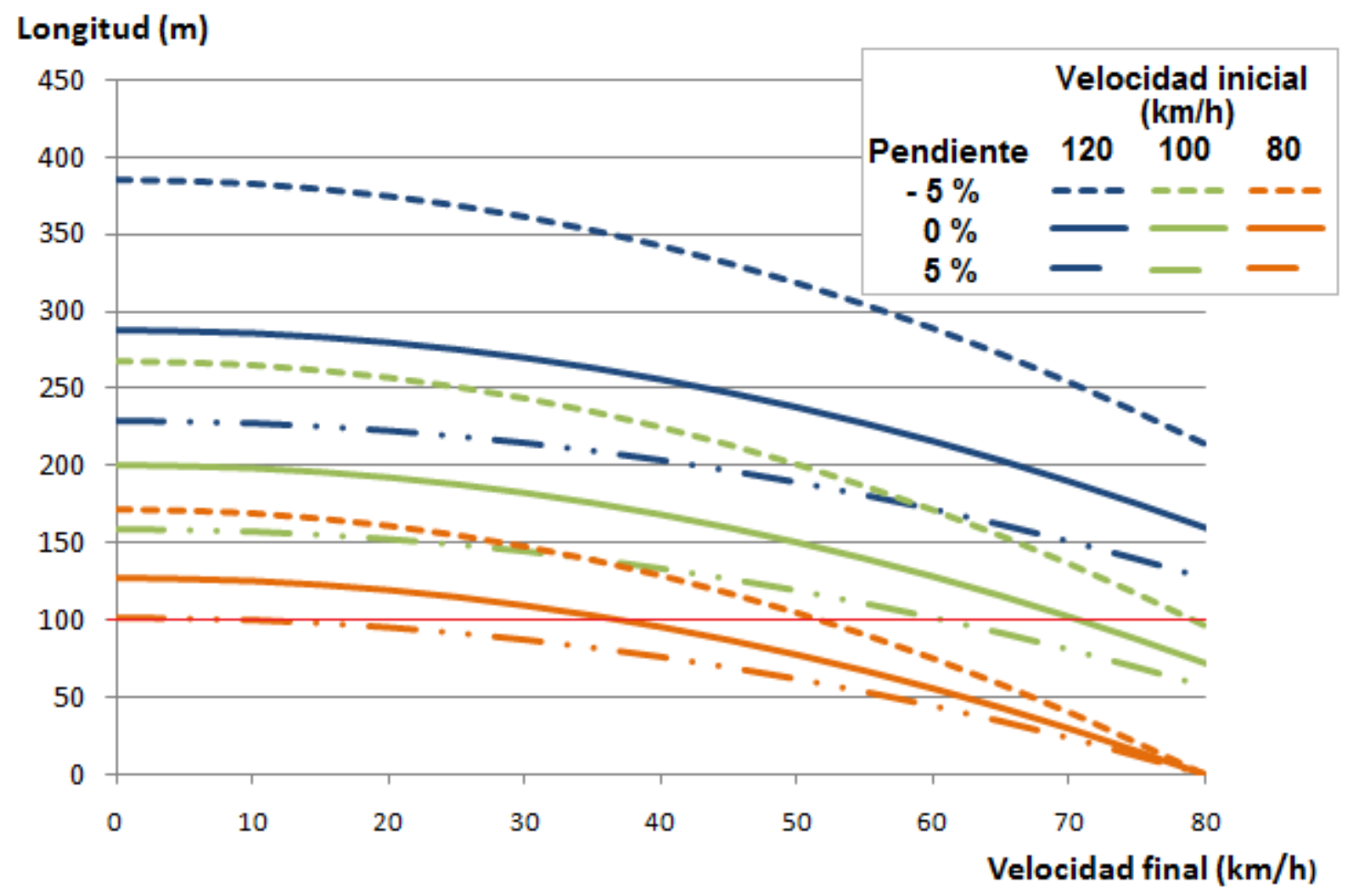

Figura 51: Longitud de los carriles de deceleración para algunos calores de velocidad y pendiente. Instrucción de Trazado 3.1-IC (1999)

La ecuación (39) se obtiene estableciendo el equilibrio de fuerzas en un vehículo de peso $\mathrm{P}$, que circula por una carretera de pendiente $\mathrm{i}=\tan \alpha$ a una velocidad $\mathrm{V}(\mathrm{km} / \mathrm{h})$, que se detiene con un movimiento uniformemente decelerado a la distancia $L_{D}$, (Figura 52). 
Aplicando la Segunda Ley de Newton:

$$
\Sigma \vec{i}=\mathrm{n} \cdot \overrightarrow{\mathrm{a}}
$$

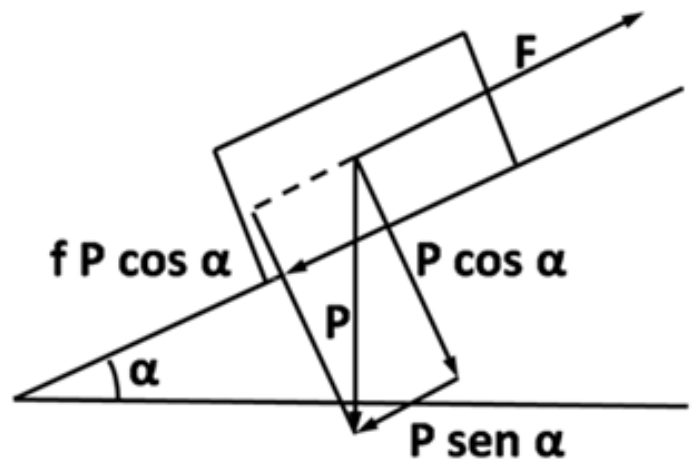

Figura 52: Equilibrio de fuerzas en un vehículo de peso $P$.

$$
P \cdot f \cdot \operatorname{Cos} \alpha:{ }^{\supset} \cdot \operatorname{Sen} \alpha=n \cdot d=\frac{D}{g} \cdot d
$$

(siendo d la deceleración del vehículo en $\mathrm{m} / \mathrm{s}^{2}$ )

$$
\begin{gathered}
-\frac{P}{g} \cdot d+P \cdot f \cdot \operatorname{Cos} \alpha: P \cdot \operatorname{Sen} \alpha=1 \\
-\frac{d}{g}+f \cdot \operatorname{Cos} \alpha: \text { Sen } \alpha=1
\end{gathered}
$$

Para valores pequeños de $\alpha$ :

$$
\begin{gathered}
\begin{array}{c}
\cos \alpha=1 \\
\tan \alpha=
\end{array} \quad-\frac{d}{g}+f \pm i=1 \\
\text { Si } d=\frac{V_{0}^{2}-r_{f}^{2}}{2 \cdot L_{D}} \quad(\operatorname{con} \mathrm{V} \text { en } \mathrm{m} / \mathrm{s}) \rightarrow \\
\rightarrow-\frac{V_{0}^{2}-V_{f}^{2}}{2 \cdot L_{D} \cdot g}+f \pm i=1 \quad \rightarrow \quad \frac{V_{0}^{2}-r_{f}^{2}}{2 \cdot g \cdot \mathbb{f} \pm}=i_{D}
\end{gathered}
$$

Si expresamos $V$ en $\mathrm{km} / \mathrm{h}$ tenemos:

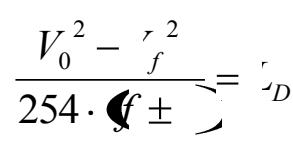


Sí $f=0,2$, es decir, si se considera una deceleración media uniforme de 0,2 g, que equivale a $-1,96 \mathrm{~m} / \mathrm{s}^{2}$ :

$$
\frac{V_{o}^{2}-l_{f}^{2}}{254 \cdot i+i 0}=-D
$$

Una vez expuesto el criterio que sigue la Norma 3.1-IC"Trazado" (1999) para determinar la longitud de las vías de deceleración se pueden analizar distintos aspectos.

La Norma considera que comienza cuando el ancho de la sección es de 1,5 m y resulta lógico porque basándonos en las observaciones empíricas se observa que:

- Los conductores comienzan a decelerar en la vía principal por lo que divergen a una velocidad menor a la que circulan los vehículos que continúan por el flujo principal.

- Desde que se inicia la divergencia los conductores comienzan a decelerar reteniendo con el motor, como observó Livneh (1988).

Por todo esto es obvio que la hipótesis de que los vehículos divergen durante 3,5 segundos con la velocidad del flujo principal es errónea ya que divergen a una velocidad menor a la del flujo principal y emplean la cuña para decelerar. Por lo tanto lo lógico es incluir la cuña como parte del carril de deceleración. Elegir la sección en la que el ancho es de 1,5 m como el inicio de la vía de deceleración parece arbitrario porque podía haberse elegido otro ancho, entre 0 y 3,5, pero puede justificarse sobre la base de que con esa anchura una parte del vehículo ya se puede encontrar en la vía de deceleración y, sin buscar un criterio físico, por ser un número fácil de recordar por acabar en cinco.

Lo que no parece lógico es fijar la sección característica de $1 \mathrm{~m}$ como el final de la deceleración. Las investigaciones muestran que los conductores toman el ramal a una velocidad superior a lo recomendado, lo que indica que utilizan parte del ramal para decelerar. Como se observó esto podría ser la causa de algunos accidentes, pero sería necesario saber el trazado de esos ramales, si la razón de esos accidentes fue el exceso de velocidad y si ese exceso era fruto de la tendencia observada a superar la velocidad indicada o se trataba de una velocidad temeraria. Debería plantearse, como sucede en la Norma italiana y como aconseja la AASHTO (2001), el considerar que una parte del ramal se emplea para decelerar. Como es lógico depende del trazado y no se podría hacer en los casos en que la curvatura inicial fuera muy grande. En la Norma italiana y en el "Libro Verde" de la AASHTO (2001) se tiene en cuenta esta posibilidad pero no la concretan: en Italia se establece que si la curvatura es creciente se puede considerar como máximo dos tercios de la longitud de deceleración dentro del ramal pero no fija el valor de la curvatura inicial, mientras el "Green Book"(2001) recomienda que si el radio de la curva inicial es igual o superior a $300 \mathrm{~m}$ (1000 pies) se puede considerar una parte del ramal como vía de deceleración, pero no ponen un límite a esa longitud ni indican las características geométricas que debe tener el tramo de ramal que sigue a esa curva. En las "Recomendaciones para el Proyecto de Enlaces" 
(1968) también se consideraba y como se observa en la Figura 37 se incluía una parte del ramal como vía de deceleración.

Se debe estudiar el hecho de poder considerar una parte del ramal como vía de deceleración, es decir, incluir parte de la clotoide inicial, con la que se materializa la transición hasta la curva de radio constante, en la longitud de la vía de deceleración. También se debería seguir investigando en la línea que propone Canale, según el cual la curva de transición al ramal de salida es una hiperclotoide de parámetro $n=2$ que se emplea para decelerar Esto supondría un ahorro importante, por tanto se deberían dirigir las investigaciones a analizar cómo se decelera en las curvas para tratar de encontrar una relación entre el radio y la longitud de la curva que utilizan los conductores en la deceleración.

En lo relativo a las velocidades que condicionan la longitud de la vía de deceleración, en realidad la velocidad inicial que se debía utilizar es la velocidad a la que operan los conductores, pero es muy difícil determinar esta velocidad. Por un lado el trazado anterior a la vía de deceleración puede hacer que los vehículos circulen a una velocidad superior a la de proyecto, por ejemplo, una recta de gran longitud puede hacer que algunos vehículos desarrollen velocidades superiores a $140 \mathrm{~km} / \mathrm{h}$, y por otro, como lo demuestran los estudios de campo, los vehículos divergen a una velocidad inferior a la que circulan los vehículos del flujo principal.

El problema radica en cómo obtener la velocidad de operación. Se podría tratar de determinar a que velocidad se circulará en función del trazado pero siempre habrá conductores temerarios que superen este valor, lo que sí se conoce es que los conductores que divergen no se comportan igual que los que continúan por la vía principal y esto debe ser la base del diseño.

En el supuesto de que exista una limitación de velocidad, si bien es cierto que hay una tendencia a no respetarlas, la actitud observada en el conductor que diverge puede llevarnos a afirmar que, si no hasta el límite indicado, sí moderará la velocidad. Las objeciones que se podrían hacer es, en primer lugar, que sucede si el conductor no conoce con la suficiente antelación que debe divergir; y en segundo lugar, no se debería calcular la longitud del carril en función de un valor arbitrario de límite de velocidad en la sección de 1,5 m de anchura sino en función del límite de velocidad de la vía.

En lo relativo a la deceleración, el coeficiente de rozamiento que la norma considera que se moviliza en las vías de deceleración es inferior al que utilizan otros autores, y también es menor si se compara con el que se utiliza en otras normas españolas, incluso en la misma 3.1-IC, por ejemplo:

- Cuando la pendiente es del $0 \%$ la Norma 3.1-IC "Trazado" supone una deceleración media de $0,2 \mathrm{~g}\left(1.96 \mathrm{~m} / \mathrm{s}^{2}\right)$, valor que está cercano a los $2 \mathrm{~m} / \mathrm{s}^{2}$ recomendados por la norma italiana y en la parte inferior del rango propuesto por Babkov $\left(1,75 \mathrm{~m} / \mathrm{s}^{2}-2,5 \mathrm{~m} / \mathrm{s}^{2}\right)$. Si se compara esta deceleración con la que propone Rocci (1993) (Figura 43), se observa que cuando la velocidad inicial es superior a 
$60 \mathrm{~km} / \mathrm{h}$ (el ámbito de aplicación de la norma 3.1-IC), la deceleración de Rocci es superior a los $0,2 \mathrm{~g}$ de la 3.1-IC.

- En la Norma 3.1-IC se considera que en las vías de deceleración se moviliza siempre un coeficiente de rozamiento longitudinal de 0,2 , pero cuando calcula la distancia que necesita un conductor para detenerse ante un objeto inesperado a $150 \mathrm{~km} / \mathrm{h}$ considera un rozamiento de 0,249. En la "Orden del 16 de Diciembre de 1997 por la que se Regulan los Accesos a las Carreteras del Estado, las Vías de Servicio y la Construcción de Instalaciones de Servicio" se establece que en los accesos a instalaciones de servicio, la longitud del carril central de deceleración se obtiene utilizando un coeficiente de rozamiento longitudinal de 0,3. En la Norma 8.3-IC "Señalización de Obras" (1987) se considera que el valor de la deceleración media puede tomarse desde unos $5 \mathrm{~km} / \mathrm{h} / \mathrm{s}$, correspondiente a retener el vehículo por medio del motor, hasta unos $10 \mathrm{~km} / \mathrm{h} / \mathrm{s}$, correspondientes a la aplicación de los frenos sin brusquedad, valores que como se observa son los propuestos por Rocci en: "Hacia una Norma de Trazado", Carreteras (1988). La equivalencia en unidades " $\mathrm{g}$ " es, respectivamente, de 0,14 y 0,28.

A lo anterior se une que las investigaciones muestran que los conductores asumen como confortables deceleraciones de $0,34 \mathrm{~g}$, aunque en los estudios de campo en las vías de deceleración se obtienen deceleraciones medias de $1,6 \mathrm{~m} / \mathrm{s}^{2}$ que se logran reteniendo con el motor.

A la vista de estos resultados se observa que la deceleración propuesta por la 3.1-IC $(0.2 \mathrm{~g})$, se encuentra en el rango de deceleraciones empleado por otras normas e investigadores en las vías de deceleración, aunque es menor a la que, según la norma, se emplearía en otras situaciones, por ejemplo: detenerse ante un objeto inesperado en vez de en una vía de deceleración. En lo referente a la relación entre la deceleración propuesta por la 3.1-IC y la medida en las vías de deceleración, la real, se aprecia que la primera es ligeramente superior, $\left(1,96 \mathrm{~m} / \mathrm{s}^{2}\right.$ frente a $\left.1,6 \mathrm{~m} / \mathrm{s}^{2}\right)$, lo que no plantea problemas de seguridad por varios motivos:

- El valor de la deceleración media en las vías de deceleración $\left(1,6 \mathrm{~m} / \mathrm{s}^{2}\right)$, no está suficientemente corroborado ya que si bien de los estudios de campo se deduce que la deceleración es menor a la supuesta por la AASHTO (2001), no se han realizado las suficientes investigaciones; una muestra de ello es que la cifra de 1,6 $\mathrm{m} / \mathrm{s}^{2}$ se extrae de las investigaciones realizadas en Italia, en 1997 y 1998, en dos vías de deceleración.

- Los estudios de campo muestran que los vehículos entran en la vía de deceleración con una velocidad menor a la del tronco. Dado que la diferencia entre la deceleración supuesta por la 3.1-IC y la real es pequeña, la longitud que se necesita para decelerar es similar, ya que en un caso se supone que la velocidad inicial es mayor pero también es mayor la deceleración, (Norma 3.1-IC), y en el otro es menor la velocidad inicial y la deceleración (la realidad). 
De lo anterior se deduce que si a la hora de proyectar se pretende satisfacer las expectativas del conductor, la Norma 3.1-IC "Trazado" (1999), en lo referente a la deceleración en las vías de deceleración lo hace de forma correcta. Pero dado que la deceleración es menor a valores que resultan razonables, ya que los estudios de campo muestran que los conductores asumen como confortables deceleraciones de $0,34 \mathrm{~g}$, cabe plantearse si se podría proyectar de forma que los conductores emplearan deceleraciones mayores, del orden de $0,28 \mathrm{~g}$ que se alcanza con una suave aplicación de los frenos, siempre que con esta deceleración no se interfiera en la circulación de la vía principal. De esta forma se reduciría la longitud de la vía de deceleración lo que implicaría un importante ahorro económico. Para ello son necesarias futuras investigaciones en las que se analice el efecto de diferentes elementos en la deceleración. Algunos de estos elementos son: la longitud y trazado de la vía de deceleración, la geometría de la cuña, la señalización y la distancia de visibilidad.

La longitud mínima de 100 m no está justificada porque si se supone que el modelo es válido no hay porque hacer excepciones. Ya en las "Recomendaciones para el Proyecto de Enlaces" (Tabla 20) se observa que hay unos valores mínimos y los actuales $100 \mathrm{~m}$ están muy próximos a aquellos (por ejemplo, para una carretera de categoría II y velocidad de $80 \mathrm{~km} / \mathrm{h}$ se propone una longitud mínima de $85 \mathrm{~m}$ y si se le añade la longitud de la cuña con un ancho superior a 1,5 m obtendríamos $105 \mathrm{~m}$ ). De todos modos no se puede aventurar si los actuales $100 \mathrm{~m}$ se fijaron sobre la base del uso establecido con las Recomendaciones de 1968 o se eligió por ser un número fácil de recordar, debió ser el resultado de ambas situaciones.

No se pueden comparar directamente unos valores con otros porque las longitudes propuestas por la AASHTO consideran el carril con ancho completo y en la Norma 3.1IC también se incluye parte de la cuña. Para poder compararlas se ha considerado sólo la longitud en la que el carril tiene un ancho de 3,5 m. Los resultados se muestran en la Figura 53. Como se observa sólo cuando la velocidad es superior a $120 \mathrm{~km} / \mathrm{h}$ la Norma española proporciona distancias superiores a las de la AASHTO (2001). Las máximas diferencias aparecen cuando las velocidades iníciales se encuentran entre 80 y $70 \mathrm{~km} / \mathrm{h}$ y la condición final es una condición de parada, y son del orden de 40 a 50 m. Sólo cuando las velocidades iníciales son muy bajas, y no hay necesidad de reducir mucho la velocidad, la AASHTO (2001) propone longitudes mayores. 


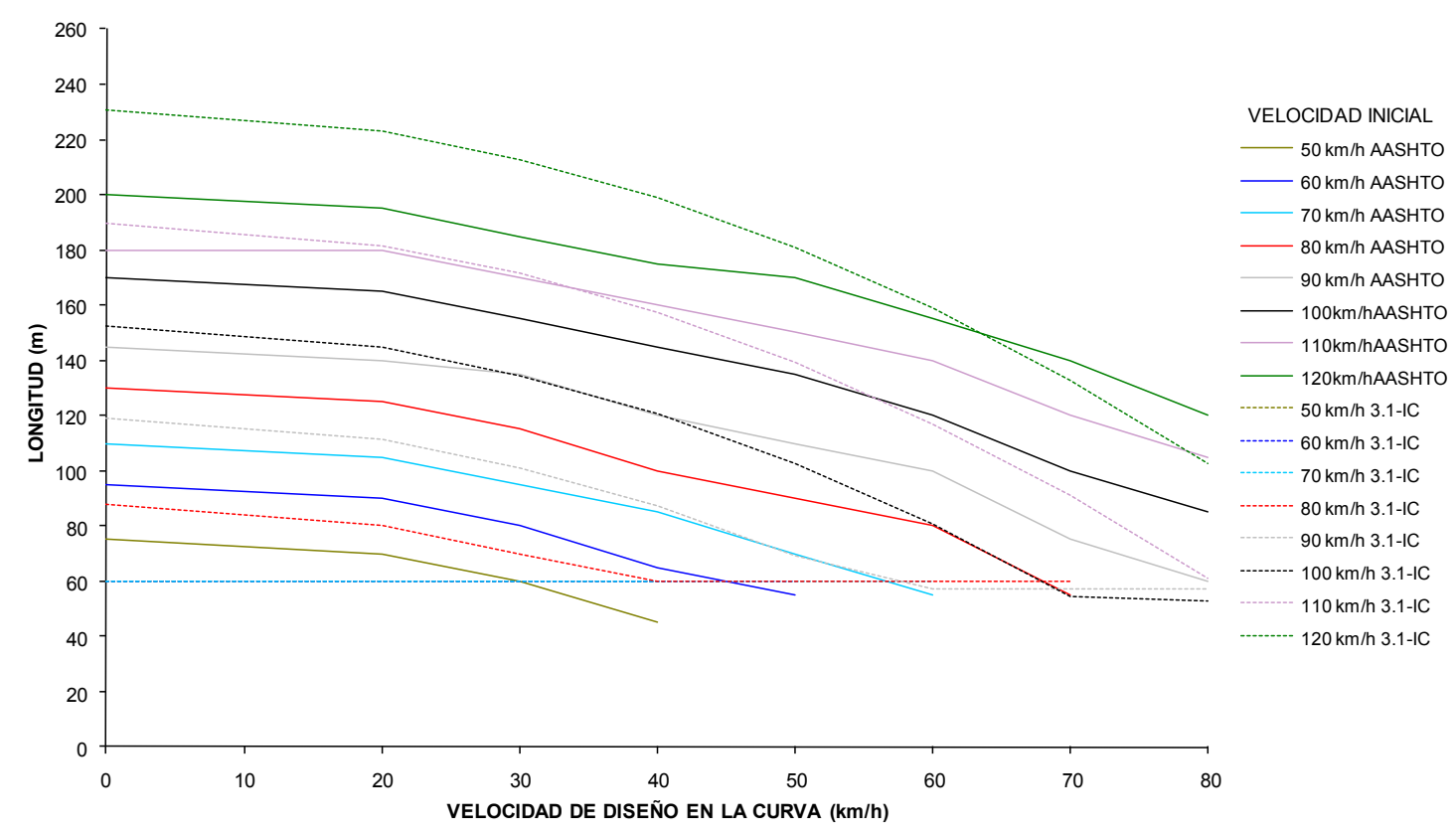

Figura 53: Comparación entre el modelo AASHTO (2001) y la Instrucción de Trazado 3.1-IC (1999)

Comparando con la longitud propuesta por Rocci (1988), se puede observar que la longitud de la Norma es siempre mayor, con las mayores diferencias cuando la velocidad inicial es elevada, como se aprecia en la Figura 54.

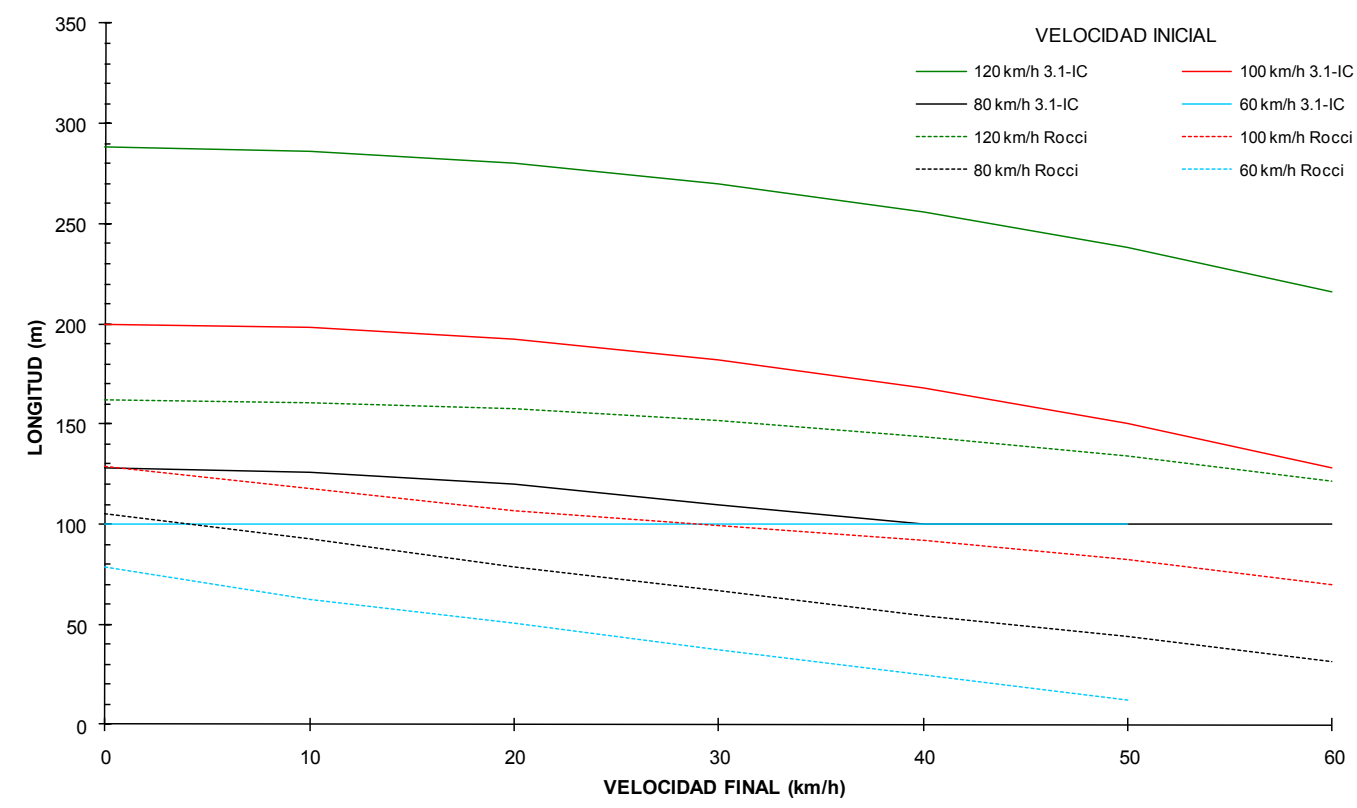

Figura 54: Comparación entre el modelo de Rocci (1988) y la Instrucción de Trazado 3.1-IC (1999) 


\subsection{TÉCNICAS DE CONFLICTOS DE TRÁFICO}

La seguridad del tráfico está relacionada con un conjunto complejo de factores, entre los que se incluyen los usuarios de las vías, y los vehículos. Cualquier cambio en el comportamiento de los vehículos o de los seres humanos, requiere soluciones de largo plazo, sin embargo mejoras en lo relacionado con el tráfico, cambios "de ingeniería" o de diseño, pueden hacerse relativamente rápido. Las técnicas de conflictos de tráfico (Traffic Conflict Techniques, TCT) posibilitan el estudio ágil y simple de los riesgos en el tráfico. Es posible determinar en qué medida un lugar es peligroso después de tres a cinco días de estudio de conflictos y de ser necesario, proponer soluciones apropiadas. Las TCT no requieren equipamiento complicado y los observadores están preparados para llevar a cabo estudios después de una semana de entrenamiento.

Generalmente, las medidas de seguridad en el tráfico se hacen en término de números de accidentes y de sus consecuencias, tales como: pérdidas de vidas, heridos graves y pérdidas materiales. Estadísticamente, los datos de accidentalidad han proporcionado información necesaria para identificar los "puntos negros" en la red viaria, al mismo tiempo que generan información acerca de deficiencias o necesidades de los usuarios de las vías.

Los datos de accidentalidad no se pueden aplicar a toda la red viaria para evaluar su grado de seguridad, ya que en muchos lugares no se cuenta con estos datos 0 simplemente nunca ha ocurrido un accidente. En el caso de la implementación de una nueva medida de seguridad en un tramo determinado, sería imposible aplicar los datos de accidentalidad, pues ésta sería una nueva configuración en la que no se cuenta con datos previos de accidentes. Así pues, factores como estos hacen imposible el uso de datos de accidentalidad en la evaluación de la seguridad en determinados lugares 0 momentos.

Es necesario, por tanto, evaluar la seguridad de otra forma. Por ello, se sugieren medidas de "proximidad al accidente", basadas en medidas espacio-temporales de la proximidad de los usuarios de la vía (o sus vehículos) al supuesto punto o zona de colisión.

Una ventaja de estas medidas es que situaciones en las que hay un cierto grado de peligrosidad suceden más frecuentemente que los accidentes como tal (Figura 55). También estos indicadores implican un adelanto en la seguridad del tráfico, pues identifican problemas de seguridad antes de que sucedan los accidentes, con lo cual se genera la necesidad de unos indicadores de conflictos en el tráfico (TCT). 


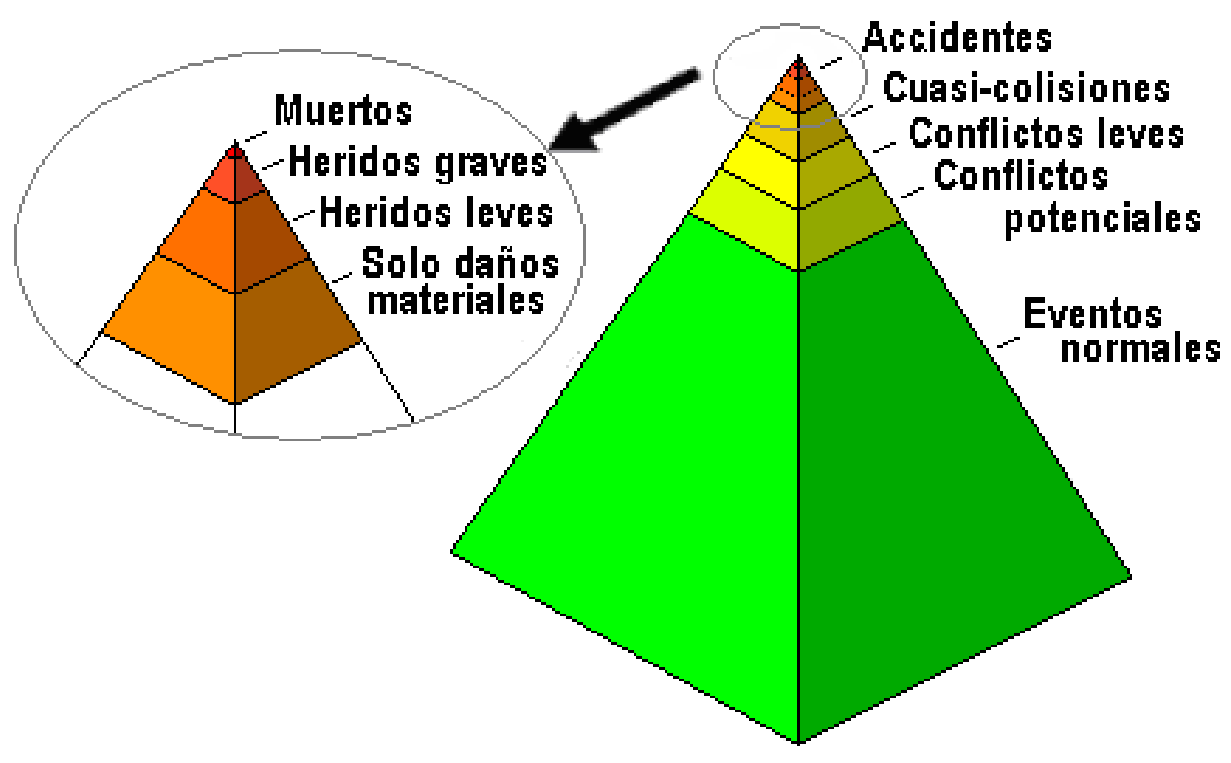

Figura 55: Pirámide de seguridad según Hydén (1987)

\subsubsection{Problemas iniciales de las TCT y discusión sobre su validez}

Las técnicas de conflicto de tráfico tuvieron sus inicios en una investigación dirigida por el laboratorio de General Motors de Detroit a finales de la década de los 60, para identificar los problemas de seguridad relacionados con la construcción del vehículo (Perkins y Harris 1967; 1968). El enfoque adoptado fue observar y registrar interacciones inseguras entre los vehículos, en función de la ocurrencia de maniobras evasivas para evitar colisiones potenciales. Los beneficios de esta técnica fueron aceptados con entusiasmo por investigadores en diferentes partes del mundo, que buscaban establecer la relación entre los conflictos y los accidentes. Sin embargo, la investigación reveló muy pronto un importante número de debilidades, las cuales proyectaban dudas y escepticismo en este enfoque del estudio de la seguridad en el tráfico (Cooper, 1977; Williams, 1981; Chin y Quek, 1997).

A pesar de los muchos problemas relacionados con la validez y medida de confiabilidad, otro grupo de investigadores continuó con los experimentos para establecer definiciones y métodos acerca de las técnicas de conflicto de tráfico (Grayson y otros, 1984).

La validez de las TCT es, a menudo, determinada por el nivel de correlación estadística entre los conflictos observados y los datos de accidentes. Esto fue considerado en los primeros años de desarrollo para establecer la técnica como una alternativa al empleo de datos de accidentes. Durante este tiempo, sin embargo, hubo estudios que indicaron niveles bajos de correlación y hubo estudios que sugirieron la existencia de niveles aceptables de correlación (Williams, 1981).

Chin y Quek (1997) sugieren que estos problemas de validez se debían, al menos parcialmente, a la calidad y cobertura de los datos de los accidentes. Para resolver los 
problemas de validez del método, se proponían dos soluciones distintas. La primera es que el método solo se estaba aplicando a aquellos casos donde los datos de los accidentes eran insuficientes para ser aplicados en el análisis, y la segunda propuesta es redefinir conceptos de conflicto y técnicas de medida para asegurar una mejor correlación (Amundsen y Hydén, 1977; Zimolong y otros, 1980; Hyden y otros, 1982).

Algunos estudios cuestionan temas fundamentales relacionados con la necesidad de la validez. Hauer (1979) se opuso a la idea de predecir accidentes, sugiriendo en cambio la gran necesidad de impedirlos en lugar de predecirlos. En un informe posterior propuesto por Hauer y Garder (1986) se argumenta que la validez de las TCT debería ser evaluada comparando los niveles de discrepancia entre las estimaciones de los conflictos y los índices de accidentalidad. Sugiere que el método que tenga menor discrepancia en los resultados será el método con mayor grado de validez.

Grayson y Hakker (1987) sugieren que la validez no solamente debería reducirse al establecimiento de una relación estadística entre accidentes y conflictos y proponen que la validez debería ser establecida como "un proceso de causalidad común" que puede conducir a resultados diferentes para conflictos y accidentes, en lugar de medidas de comparación entre estos dos juegos de datos. Oppe (1986), yendo más

lejos sugirió la necesidad de clasificar conflictos y accidentes según el tipo de maniobra y el nivel de severidad para hacer comparaciones relevantes a la validez.

Chin y Quek (1997) dicen que las TCT pueden ser utilizadas puesto que estas se emplean como un instrumento de diagnostico y de evaluación y no como un método de predicción. Migletz (1985) y Svensson (1992), han indicado que los estudios de conflicto pueden producir estimaciones de la ocurrencia de accidentes tan buenas 0 mejores como las basadas en estadísticas de accidentalidad, además estos estudios de conflicto requieren menos tiempo de toma de datos.

\subsubsection{Indicadores de TCT}

A continuación se hace una descripción de los indicadores de conflictividad desarrollados en las Técnicas de Conflictos de Tráfico.

\subsubsection{Tiempo hasta el accidente (Time to accident) - (TA)}

Perkins y Harri (1967) definieron TA como el tiempo restante para que ocurra un accidente, tomando como base el punto, en tiempo y espacio, en el cual un vehículo toma una acción evasiva. El TA se calcula usando valoraciones de velocidad y distancia realizadas por observadores entrenados. Al estar basada en el punto en el cual se toma una acción, esta medida no tiene en cuenta el tiempo de reacción. Para que esta medida sea válida, los vehículos deben tener curso de colisión basado en la estimación de velocidad y distancia.

Teniendo como base el valor de TA, se clasifican los conflictos como "serio" y "noserio", de acuerdo con una función no lineal, que se aprecia en la Figura 56, que tiene en cuenta la tasa media de desaceleración para evitar una colisión en velocidades diferentes y el coeficiente de fricción estándar (Hydén, 1987). 


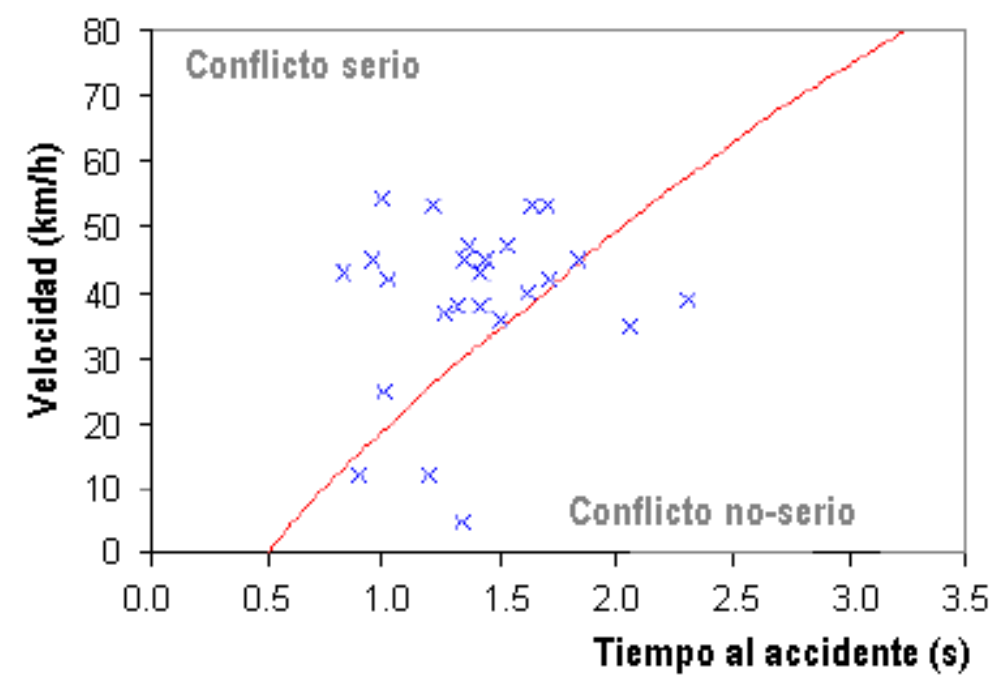

Figura 56: Determinación de la severidad del conflicto

Para determinar la severidad del conflicto se consideran: la diferencia de velocidades, la proximidad de tiempo y la capacidad de deceleración. Se debe resaltar que, para predicciones de accidentalidad, se emplean únicamente los conflictos serios.

El indicador TA es un indicador eficaz de seguridad pero el hecho de que se haga una estimación de la velocidad y de la distancia hace que se puedan obtener valores erróneos de TA. Además, en las situaciones que implican giro o incorporaciones de vehículos es necesario considerar la aceleración del vehículo para estimar el posible punto de colisión.

Asimismo, las situaciones más complejas deberían ser analizadas por medio de vídeos para determinar velocidades, aceleraciones, y distancias, con mayor exactitud.

\subsubsection{Tiempo hasta colisión (Time to collision ) - (TTC)}

Hayward (1972) describe este indicador como el tiempo restante para una colisión hipotética que ocurriría si los vehículos implicados mantuvieran su velocidad y trayectoria. Valores pequeños de TTC indican una alta probabilidad de colisión.

Cavallo y Laurent (1988) definen el TTC como el tiempo restante para alcanzar un obstáculo.

Es importante tener en cuenta que, cuando hay un curso de colisión, el valor TTC disminuye con el tiempo. La medida crítica en la estimación de la severidad de conflicto es por lo tanto el mínimo TTC durante el conflicto. El valor máximo es infinito y el mínimo es cero.

Adicionalmente, en situaciones críticas de seguridad, como en el caso de seguimiento entre dos vehículos, viajando a poca distancia y a la misma velocidad, el valor calculado para TTC es infinito. Así mismo, en el caso en que dos vehículos viajen en 
paralelo a poca distancia lateral, el TTC también es infinito puesto que no hay un punto de colisión. Estas situaciones hacen que el indicador TTC sea aplicable principalmente cuando existe una zona de conflicto claramente definida como en cruces de trayectorias.

\subsubsection{Tiempo de exposición a umbral bajo de TTC (Time exposed TTC) - (TET)}

Una nueva evolución de la medida de TTC ha sido propuesta por Minderhood y Bovy (2000), quienes sugieren este nuevo indicador de seguridad basado en TTC. Este indicador es útil para hacer un análisis comparativo de la seguridad vial. En contraste con el clásico TTC que es medido en una sección específica, este nuevo indicador utiliza la trayectoria del vehículo en un periodo de tiempo específico de un segmento de vía con el fin de calcular un indicador general de seguridad. Estos valores pueden ser analizados para determinar valores para vehículos específicos y probabilidades de seguridad crítica.

Este indicador mide la duración de la exposición del vehículo a un valor crítico de TTC. Este valor es sumado para todos los vehículos que pasan en un tramo de vía seleccionado durante un periodo de tiempo. El resultado es una medida del tiempo expuesto a situaciones críticas de TTC y se define según la ecuación (49):

$$
T E T=\sum_{i=1}^{N} \sum_{t=0}^{T} \partial_{i}(t) \cdot \tau
$$

donde:

$$
\partial(t)=\begin{aligned}
& 1, \quad \text { si } 0 \leq T T C_{i}(t) \leq \text { umbral } T T C \\
& \vdots 0, \quad \text { en caso contrario }
\end{aligned}
$$

$T T C_{i}(t)$ es el valor de $T T C$ del vehículo ien el instante $t$.

T es el intervalo de muestreo.

$\mathrm{N}$ es el total de vehículos en un periodo determinado de tiempo.

T es periodo de tiempo considerado.

El problema que surge con este indicador, para el caso de seguimiento, es la definición del valor umbral de TTC ya que se debe adoptar el valor umbral adecuado a cada caso. Aunque el TTC incorpora dos factores importantes en el comportamiento de los conductores, la velocidad relativa y la distancia relativa a un vehículo precedente, TTC no tiene en cuenta que a mayor velocidad absoluta, se requiere mayor tiempo y distancia para decelerar y parar. Sultán et al (2002) analizaron el comportamiento de 
los conductores durante el seguimiento normal, encontrando una disminución en el mínimo valor de TTC cuando disminuye la velocidad.

\subsubsection{Integral de TTC bajo umbral (Time integrated TTC) - (TIT)}

Minderhood y Bovy (2000) también desarrollaron otra evolución al TTC. Esta evolución es un indicador que utiliza la integral del perfil de TTC para expresar el nivel de seguridad, siendo esta medida equivalente a representar el área del perfil TTC por debajo de un umbral, según la ecuación (51), proveyendo información de la seriedad de una situación de conflicto.

$$
T I T=\sum_{i=1}^{N} \int_{0}^{T}\left(\text { Umbral } \quad T T C \quad-T T C_{i}(t)\right) \cdot \partial(t) \cdot d t
$$

donde:

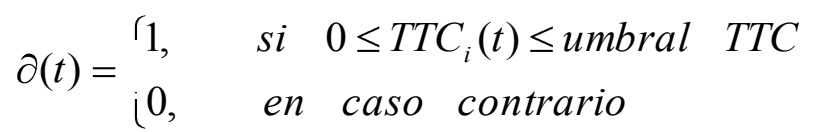

$\pi C_{i}(t)$ es el valor de $T T C$ del vehículo i en el instante $t$.

$\mathrm{N}$ es el total de vehículos en un periodo determinado de tiempo.

T es periodo de tiempo considerado

Al hacer el sumatorio de este valor para todos los vehículos que pasan por un tramo específico de la vía, es posible calcular el valor medio y así poder compararlo con otras situaciones. Esta medida de TTC es recomendada para ser utilizada, principalmente, en estudios de simulación.

La Figura 57 muestra gráficamente los valores de Tiempo de exposición a umbral bajo de TTC y de Integral de TTC bajo umbral.

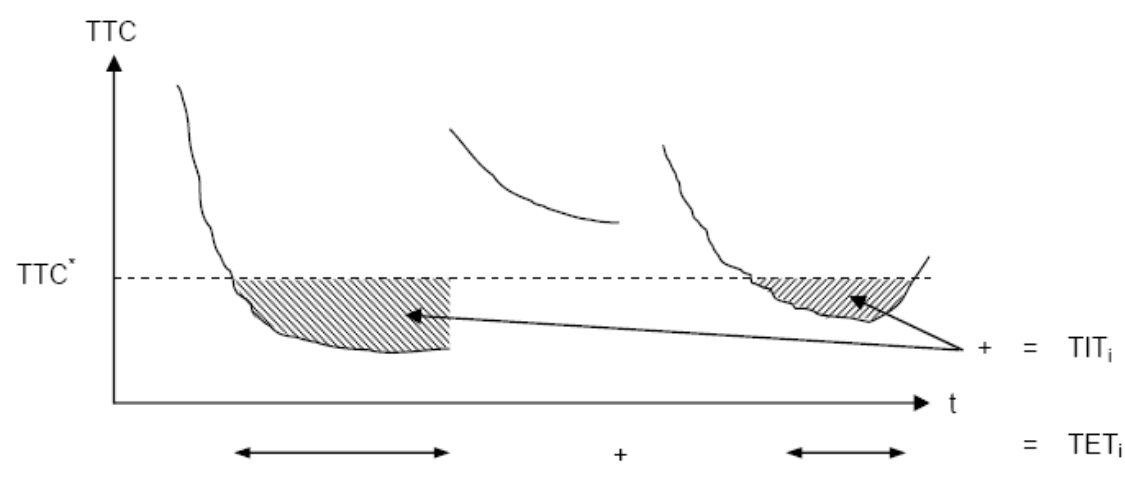

Figura 57: Tiempo de exposición a umbral bajo de TTC e Integral de TTC bajo umbral 
Al igual que en el indicador de Tiempo de exposición a umbral bajo de TTC, especialmente para el caso de seguimiento, se puede discutir la selección del valor umbral de TTC, puesto que este valor depende de la velocidad.

\subsubsection{TTC para aproximaciones (Approximate TTC) (a-TTC)}

Esta variación de $\pi T C$, se centra en el conflicto de seguimiento. Tiene en cuenta específicamente la reducción de la distancia relativa entre dos vehículos. Se calcula como la distancia entre los vehículos partido por la diferencia de velocidades entre ellos. (Minderhood y Bovy, 2000).

El indicador a-TTC tiene el problema que incluso en una situación en que un vehículo siga a otro a una distancia muy corta, pero a la misma velocidad, a-TTC toma un valor de infinito por lo que no representa adecuadamente la conflictividad asociada en esta situación.

\subsubsection{Tiempo hasta la cebra (Time to Zebra) - TTZ}

Otra variación del concepto del Tiempo para la Colisión se ha desarrollado para estimar la seguridad del tráfico en las travesías peatonales. El valor de TTZ se ha utilizado por varios investigadores, entre ellos Varhelyi (1996), para determinar la frecuencia y gravedad del encuentro crítico entre los vehículos que se acercaban a un paso de peatones y los peatones que cruzaban dicho paso. En este estudio, los intervalos críticos del tiempo y de la distancia fueron identificados según la velocidad de acercamiento de los vehículos.

Se desarrolló un esquema de clasificación para registrar los diversos resultados posibles entre los vehículos y los peatones. Este estudio concluye que muchos conductores no adaptan su velocidad al límite fijado en los pasos de peatones, y adicionalmente que los conductores no ven a los peatones que cruzan por los pasos de cebra como un riesgo potencial.

El estudio demostró que solamente uno de cada cuatro conductores paró o frenó para permitir que los peatones cruzaran. Los conductores que no pararon forzaron a los peatones, en muchos casos, a darle la prioridad al vehículo en el paso de cebra.

Es importante señalar que estos estudios fueron realizados antes de la reforma de la prioridad en cebras en Suecia, que en la actualidad obliga a los conductores a que paren para permitir el paso de peatones y ciclistas.

\subsubsection{Tiempo tras despejar la zona de conflicto (Post-Encroachment Time) (PET)}

Este indicador mide la diferencia de tiempo entre el momento en que el primer vehículo abandona la zona de conflicto y el momento en que el segundo vehículo entra a esta zona.

El concepto PET ha sido utilizado como una técnica de conflictos en Canadá y Holanda (Cooper (1983); van der Horst y Kraay (1986); Hydén (1987) y (1996); Topp (1998)). 
EI PET es obtenido más fácilmente con un análisis fotométrico, pues no requiere datos relativos a velocidades y distancias. La medida en P ET representa la diferencia en tiempo del paso de los vehículos implicados sobre una zona común, es decir, el área de colisión potencial. Esto hace que el PET sea una medida útil y objetiva, además de requerir menos trabajo que el $T T C$, pues no hay que calcular tiempos con cada acontecimiento crítico de seguridad.

En la Figura 58 se muestra un ejemplo del cálculo del PET. En la parte "a" de la figura se observa un vehículo abandonando una posible zona de conflicto y en la parte " $b$ " de la figura la entrada de otro vehículo a esta zona de conflicto. La diferencia de tiempo de estos dos eventos es la medida del PET.

Valores pequeños de PET indican una alta probabilidad de colisión.

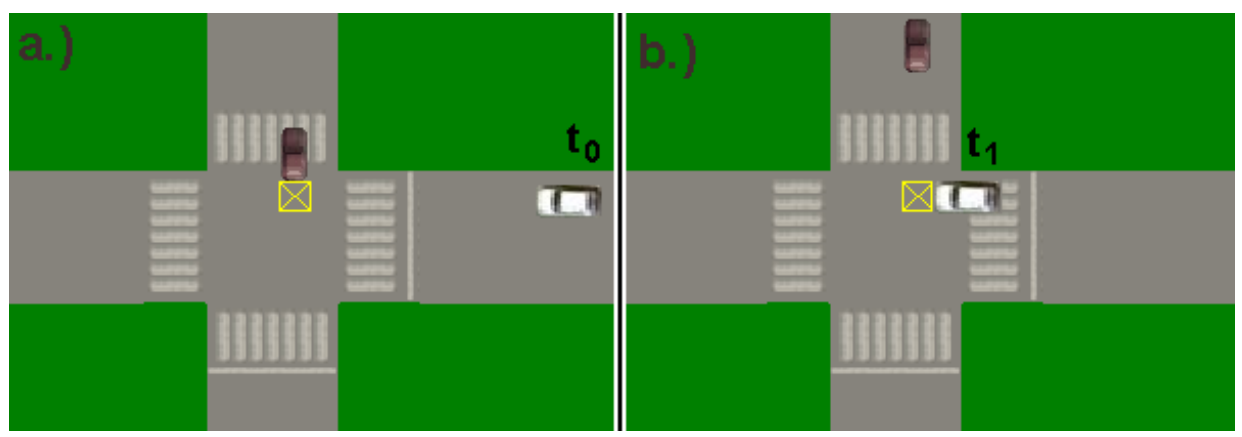

Figura 58: Ejemplo de cálculo de PET

El indicador PET deja de lado el efecto de frenado o la acción evasiva que pueda hacer el segundo vehículo antes de llegar a la zona de conflicto, además es necesario contar con una zona de conflicto claramente definida.

\subsubsection{Tiempo de invasión (Encroachment Time) (ET)}

ET se define como la duración de tiempo durante la cual un usuario sin prioridad está sobre la zona de conflicto (FHWA 2003).

El Time integrated TTC se asemeja al ET y puede ser útil como un método que proporciona más información con respecto a la gravedadde las situaciones de tráfico.

Aunque este concepto no se limita a maniobras de cruce transversal es difícil de aplicar cuando no existe una zona de conflicto claramente definida, pero tiene la ventaja de ser de fácil obtención en la toma de datos de campo.

\subsubsection{Tiempo tras despejar la zona de conflicto sin reacción (Initially attempted post encroachment time) (IAPT)}

IAPT se define como el lapso de tiempo calculado entre el momento en que el primer vehículo abandona la zona de conflicto y el momento en que el segundo vehículo 
entraría en ella si continúa circulando con la misma velocidad y trayectoria que llevaba en el instante en que el primero entra en dicha zona. (FHWA 2003)

Este indicador tiene las mismas ventajas y desventajas que el PET fundamental, aunque tiene en cuenta la acción evasiva que pueda hacer el segundo vehículo.

Para el caso de seguimiento, y en general para los casos en que no hay una zona de conflicto claramente definida, el indicador IAPT no es aplicable pues no se puede determinar claramente el momento en que el primer vehículo abandona la zona de conflicto ni tampoco el momento en que el segundo vehículo entra en ella.

\subsubsection{Intervalo (Gap time) (GT)}

Se define el GT como el tiempo transcurrido desde el momento en que un vehículo que realiza una maniobra de giro sale de la zona de conflicto y el momento en que un vehiculo que continua recto llega a la zona de conflicto.

El indicador GT se basa en estimar el tiempo de llegada a la zona de conflicto en lugar de medir la diferencia real.

\subsubsection{Tasa de deceleración (Deceleration rate) (DR)}

DR es la medida de la máxima tasa de deceleración que un vehículo debe hacer para evitar una colisión (FHWA, 2003). Hydén (1987) menciona la energía de deceleración como un aspecto importante en la determinación de la gravedad de un conflicto puesto que valores elevados de DR indican una alta probabilidad de colisión.

Medir la tasa real de deceleración resulta difícil y es necesario utilizar otros medios que requieren muchos recursos.

Es posible utilizar dos variaciones de esta medida, similares a las variaciones de $\Pi T C$, midiendo el tiempo de exposición a una tasa de deceleración umbral, como por ejemplo $-2,0 \mathrm{~m} / \mathrm{seg}^{2}$, e igualmente tomando el valor de la integral de la tasa de deceleración por debajo de ese umbral.

\subsubsection{Deceleración para tiempo tras despejar la zona de conflicto seguro (Deceleration-to-safety time) (DST)}

Este indicador es similar a DR y es definido como la deceleración necesaria (donde ésta es la primera acción evasiva) para alcanzar una medida de PET igual a cero segundos. Topp (1998) utilizó esta medida como complemento al indicador PET, mediante un análisis fotométrico, para determinar los niveles de seguridad en intersecciones de vehículos y peatones.

La Figura 59 muestra gráficamente la situación para el cálculo de DST. En la parte izquierda de la Figura 59 el vehículo se aproxima con una velocidad $V_{V}$ e inicia la acción evasiva, correspondiente a una deceleración, para evitar el accidente. Es ente instante se conoce también su posición y la del vehículo o el peatón en conflicto. A partir de 
estos datos se puede calcular la mínima deceleración necesaria para evitar el accidente (situación 2).

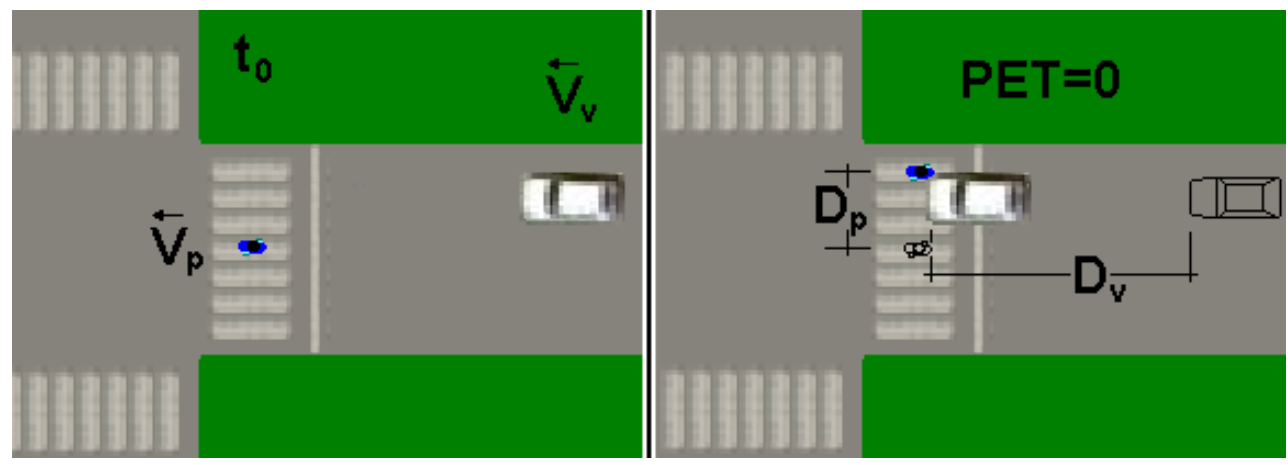

Figura 59: Situación que se presenta en el cálculo de DST

\subsubsection{Proporción de distancia de parada (Proportion of stopping distance) (PSD)}

Esta medida representa la proporción de distancia disponible para hacer una maniobra de frenado frente a la distancia de parada (FHWA, 2003). Valores de PSD mayores que 1 indican una situación segura.

\subsubsection{4 "jerks" (fuerza g compuesta y velocidad)}

Gully et al., (1995) identificó una relación entre la frecuencia de accidentes y la observación del comportamiento de conductores en cambios abruptos de carril conjuntamente con una fuerte deceleración.

Wåhlberg (2000) investigó la relación entre la frecuencia de accidentes para conductores de autobús durante diferentes períodos de tiempo y la velocidad media en conjunto con la aceleración compuesta.

Se observó que la aceleración compuesta junto con la velocidad constituye un indicador de la conflictividad de las maniobras individuales.

La aceleración compuesta corresponde a la suma vectorial de la aceleración producida por un giro o un cambio de carril, ya sea a izquierdas o derechas, y la aceleración longitudinal que puede ser aceleración o deceleración.

\subsubsection{Frecuencia de ondas de choque (Shock-wave frequency)}

Un estudio de Van Arem y DeVos (1997) en relación con los efectos de un carril especial para vehículos "inteligentes" sobre flujos de tráfico, mostró que la frecuencia de ondas de choque podría ser aplicada como un indicador útil de seguridad. 


\subsubsection{Tiempo hasta cruzar la línea (Time-to-line crossing) - (TLC)}

Esta medida es usada para determinar el TTC restante en una situación de conflicto antes de que un vehículo cruce la línea de borde o la de separación de carriles.

Este indicador pretende evaluar, principalmente, el desempeño de los conductores ante situaciones de somnolencia y por consiguiente la probabilidad de que ocurra un accidente por salida de la calzada.

Vogel (2003) dice que este indicador es muy útil para evaluarlo en estudios basados sobre simuladores, pero que, por el contrario, en situaciones reales es difícil de evaluar si no se cuenta con un vehículo dotado de instrumentación avanzada. Sin embargo, es posible evaluarlo en tramos cortos de carretera mediante filmaciones de vídeo.

\subsubsection{7 Índice potencial de colisión ante una deceleración de emergencia (Potential index for collision with urgent deceleration) - (PICUD)}

PICUD es un índice para evaluar la posibilidad que dos vehículos consecutivos puedan chocar asumiendo que el vehículo principal realiza una maniobra de parada de emergencia. (Uno et al 2002)

PICUD es definido como la distancia entre los dos vehículos considerados en el conflicto después de la parada de emergencia de los vehículos implicados. La situación que representa un PICUD de $0 \mathrm{~m}$ o menos representa una situación en la cual la colisión entre los vehículos no puede ser evitada, incluso si el vehículo que va detrás aplica una frenada de emergencia después de una deceleración rápida del vehículo principal.

La valoración de PICUD requiere dos parámetros predeterminados:

- Tiempo de reacción del conductor

- $\quad$ Tasa de desaceleración de los vehículos.

El índice PICUD es considerado como el índice para evaluar el peligro potencial de colisión de alcances.

Para calcularlo la ecuación (53) es:

$$
\operatorname{PICUD}(m)=\frac{\mathrm{V}^{2}-r_{2}^{2}}{2 \cdot \alpha}+i_{0}-r_{2} \cdot \Delta
$$

donde:

$\mathrm{S}_{0}:$ distancia libre entre los dos vehículos $(\mathrm{m})$.

$\mathrm{V}_{1}$ : velocidad del primer vehículo o vehículo líder $(\mathrm{m} / \mathrm{s})$.

$\mathrm{V}_{2}$ : velocidad del segundo vehículo $(\mathrm{m} / \mathrm{s})$.

$\Delta \mathrm{t}$ : tiempo de reacción del conductor (s)

$\mathrm{a}:$ tasa de deceleración $\left(\mathrm{m} / \mathrm{s}^{2}\right)$ 


\subsubsection{Tiempo potencial hasta colisión (Potential time to collision) - (PTTC)}

Wakabayashi y Renge (2003) proponen el indicador PTTC para evaluar la seguridad del tráfico en un entorno de alta velocidad y congestión.

PTTC es un indicador del tipo "si...entonces", es decir, evalúa lo que pasaría si se presentara el caso en que el vehículo principal realizara una maniobra evasiva o si disminuyera su velocidad y el vehículo que lo sigue no hiciera ningún tipo de maniobra evasiva Figura 60.

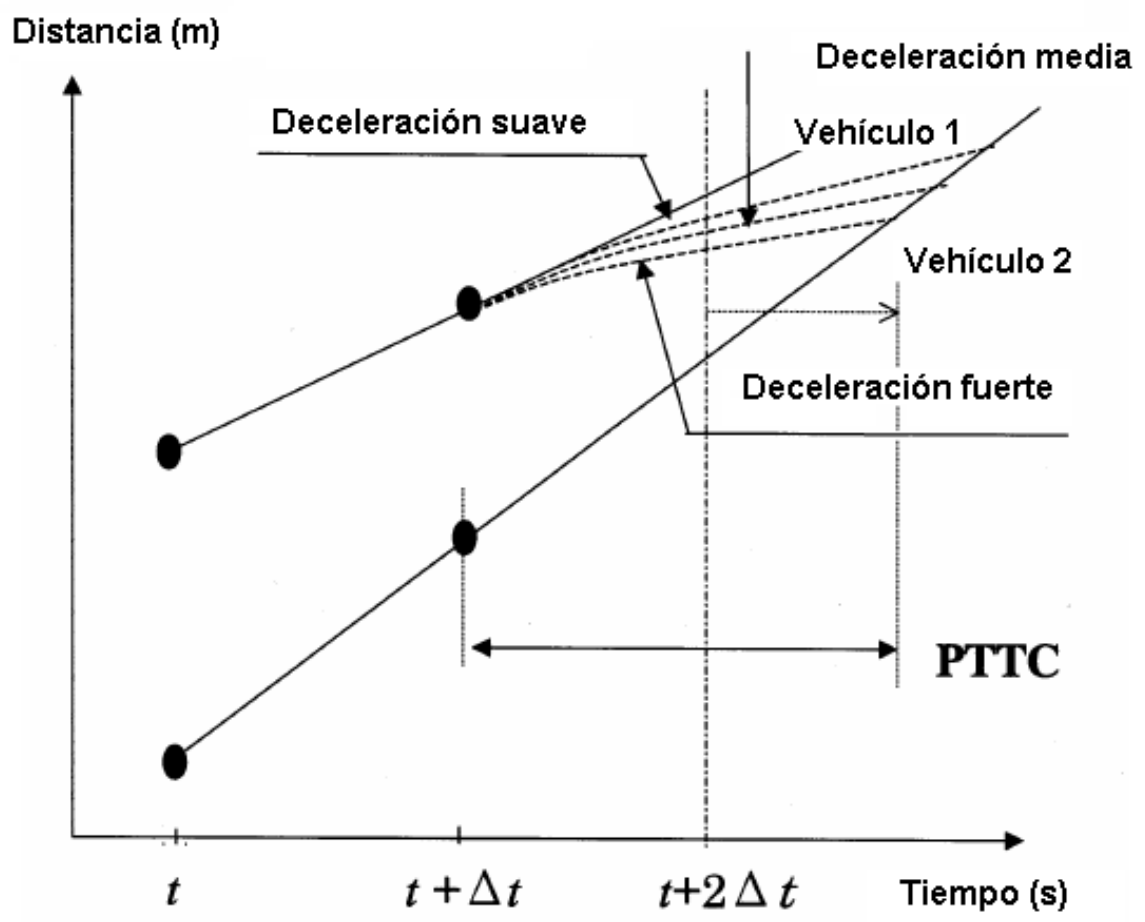

Figura 60: Representación del tiempo potencial a colisión

El valor de PTTC se obtiene solucionando la ecuación (54)

$$
D=1 \cdot P T T C+\frac{x \cdot P T T C^{2}}{2}
$$

donde:

$D$ : diferencia de distancias entre los vehículos $(\mathrm{m})$.

$\Delta V$ : diferencia de velocidades entre los vehículos $(\mathrm{m} / \mathrm{s})$.

$a$ : deceleración $\left(\mathrm{m} / \mathrm{s}^{2}\right)$ 
Los autores plantean la posibilidad de extender este indicador para tener en cuenta la diferencia de posición transversal, pero por el momento se puede utilizar, principalmente, en el conflicto de seguimiento.

\subsubsection{Selección de indicadores de conflicto aplicables en carriles de deceleración}

Hasta la fecha, dentro de las técnicas de análisis de conflictos de tráfico, se han desarrollado gran variedad de indicadores que pretenden reflejar la conflictividad en el tráfico.

Los indicadores desarrollados se han aplicado principalmente en intersecciones, pero son difíciles de aplicar en otras situaciones, pues requieren una zona de conflicto claramente definida.

Hasta ahora, se han definido algunos indicadores que se pueden utilizar en caso de no tener una zona de conflicto claramente definida. Estos son:

- $\quad$ TTC para aproximaciones (Approximate TTC) a-TTC

- $\quad$ Tiempo potencial hasta colisión (Potential Time to Collision) PTTC

- Índice potencial de colisión ante una deceleración de emergencia (Potential Index for Collision with Urgent Deceleration) - (PICUD)

Estos indicadores son aplicables en el caso de conflictos relacionados con el seguimiento. Sin embargo no se han tenido en cuenta los posibles conflictos transversales al eje de la vía, que son los que ocurren precisamente en las maniobras de salida.

En consecuencia, es necesario desarrollar un nuevo indicador de conflictividad que tenga en cuenta tanto el caso de seguimiento, conflicto paralelo al eje de la vía, como el cambio de carril, conflicto transversal.

\subsection{RESTITUCIÓN DE PERSPECTIVAS}

La restitución utilizando perspectiva cónica permite la reconstrucción a escala de la planta y el alzado de un objeto con la ayuda del conocimiento de su forma y de alguna de sus medidas, mediante las relaciones de homología existentes entre una figura plana y su perspectiva. (Albert 2002)

Esta técnica, conocida como restitución de trayectorias o restitución de perspectivas, ya se ha utilizado en otras ocasiones, por otros investigadores, con buenos resultados. (Ahmed (1999), Davis (2004), Wei y otros (2005)).

Las grabaciones de video, al igual que las fotografías, son representaciones gráficas de la realidad. La realidad es espacial o tridimensional, pero la representación gráfica es plana o bidimensional. El paso de una a otra se realiza mediante una transformación 
geométrica conocida como perspectiva cónica. A cada punto del espacio se le hace corresponder un punto en la imagen.

La restitución de perspectivas consiste en realizar el proceso inverso a esa transformación geométrica. Para cada punto de la imagen, se calcula el punto del espacio que le corresponde. A partir de las coordenadas de imagen, obtenemos las coordenadas en la realidad.

Con este proceso se puede conocer la posición real de los vehículos que aparecen en la imagen, para cada instante considerado. Si se realiza para diferentes instantes temporales, e consigue la trayectoria completa.

La velocidad o la aceleración se obtienen posteriormente, a partir de la variación temporal en la posición. Para su cálculo se parte de que la velocidad es la derivada de la posición respecto del tiempo, y la aceleración, la derivada de la velocidad.

\subsubsection{Definición geométrica}

La perspectiva cónica es un tipo de sistema de representación. Los sistemas de representación se definen como procesos geométricos reversibles entre el plano y el espacio (Gil Saurí, 1997). Su función es doble. Por un lado, dibujar sobre un plano las formas del espacio. Por el otro, reconstruir la forma espacial a partir del dibujo plano. Esta segunda función es la que interesa. Pero para entender el proceso inverso, es necesario estudiar también el directo.

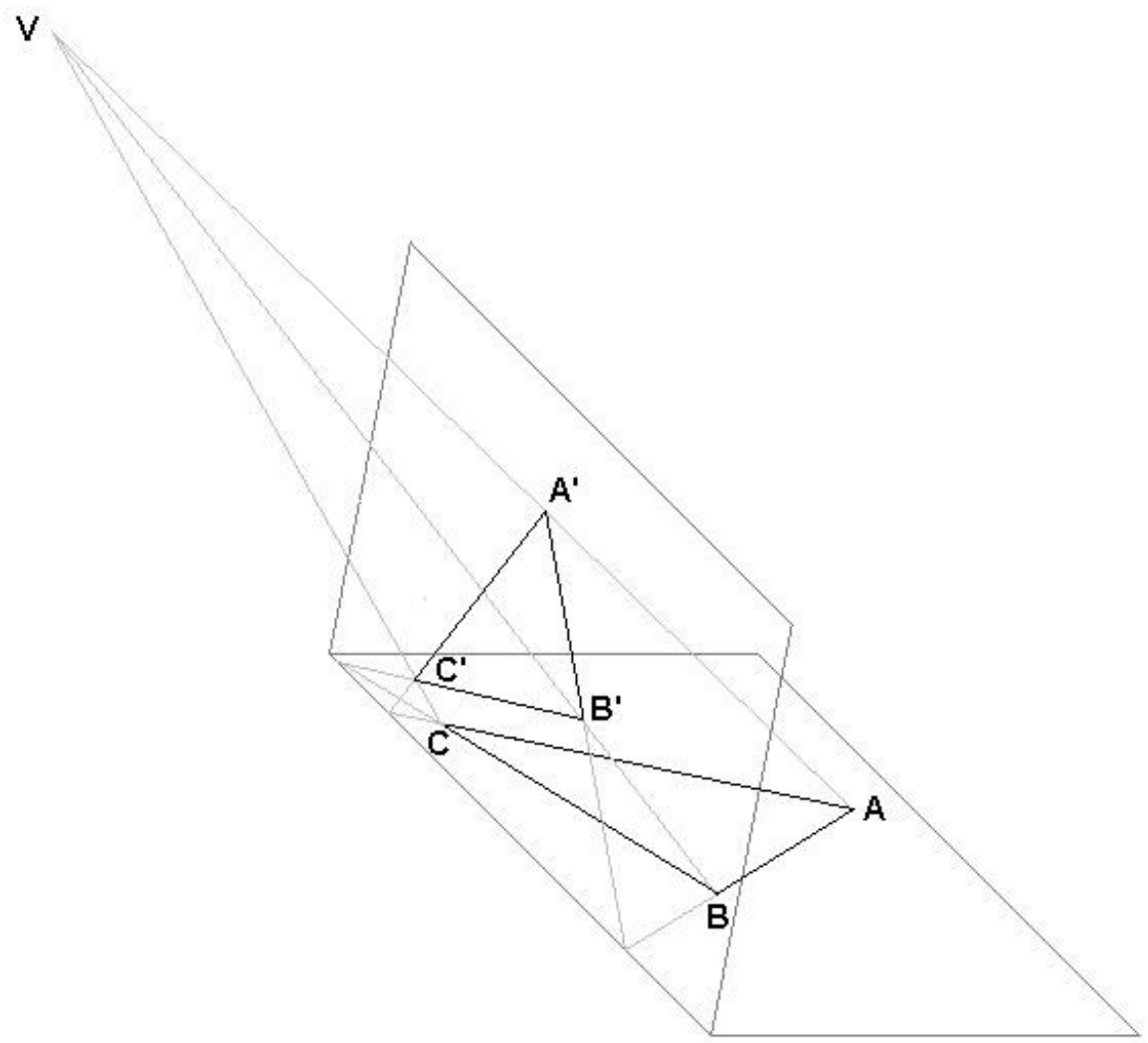

Figura 61: Homología 
Desde el punto de vista geométrico, dos figuras son homográficas, cuando son secciones planas de una misma radiación cónica, tal como se observa en la Figura 61.

El sistema cónico tiene como elementos fundamentales el vértice, punto de vista o centro de proyección ( $V$, y el plano del dibujo o plano de cuadro $(P C)$. Para obtener la representación cónica de un punto $(A)$ en el espacio, se traza una recta $(r)$ desde el vértice hasta el punto. La intersección de dicha recta con el plano de cuadro es la imagen del punto $(A)$. En la Figura 62, para una mayor claridad, se muestra el plano horizontal o geometral $(P H)$.

Entonces, para obtener la perspectiva de cualquier figura, sólo se tiene que crear un haz de rectas que salga de $V$ y pase por los puntos deseados. La intersección de ese haz con el plano del cuadro proporciona la imagen deseada.

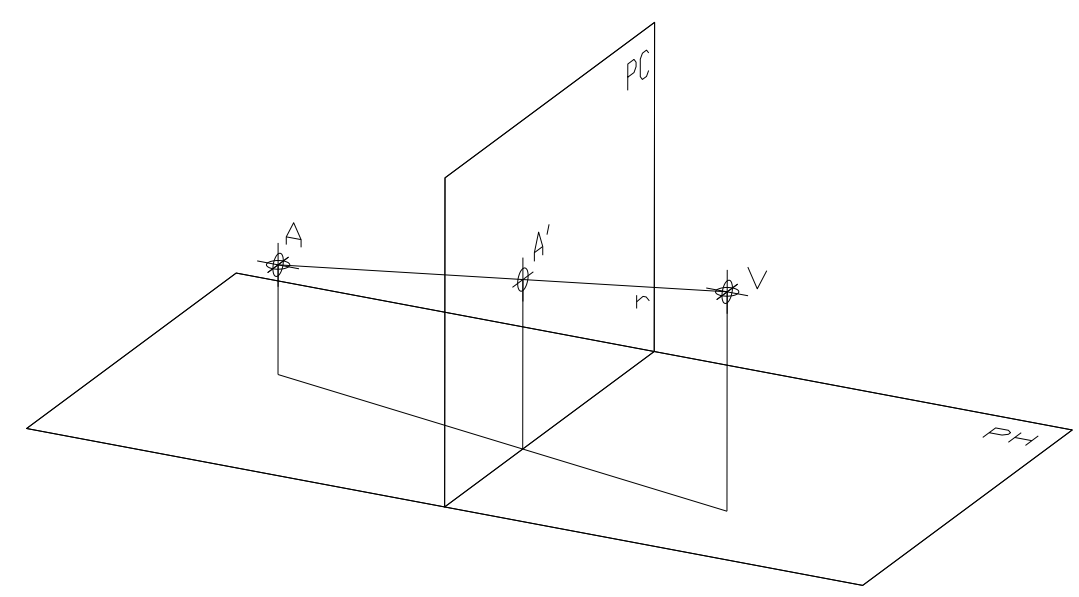

Figura 62: Perspectiva cónica

La intersección del plano horizontal $P H$ y el plano de cuadro $P C$ es la línea de tierra $L T$. El plano perpendicular al del cuadro, paralelo al plano horizontal, y pasando por el vértice, se denomina plano del horizonte. La intersección entre el plano del horizonte y el plano del cuadro es la línea de horizonte $L H$. En efecto, ningún punto perteneciente al plano horizontal tendrá su imagen más arriba que la línea de horizonte. Es una línea límite.

La proyección ortogonal del vértice $V$ sobre el plano del cuadro es el punto principal $P$. Está sobre la línea de horizonte. La recta que sale de $V$ y pasa por $P$ es la dirección de cámara o motivo.

El plano paralelo al del cuadro, pasando por el vértice es el plano de desvanecimiento $P D$. Los puntos pertenecientes a este plano no tienen imagen en el plano del cuadro. Los puntos en el semiespacio posterior al plano de desvanecimiento tienen una imagen virtual. Corresponden a puntos a las espaldas del observador. 


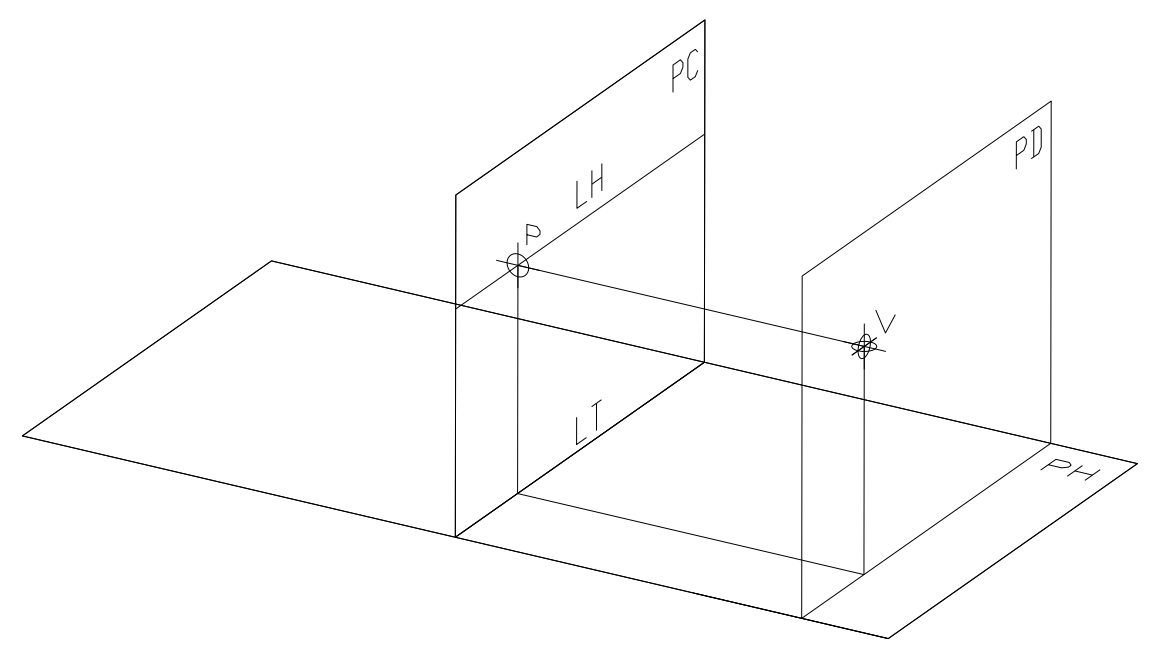

Figura 63: Otros elementos de la perspectiva cónica

\subsubsection{La vista humana y los aparatos de fotografía}

Las imágenes obtenidas mediante perspectiva cónica se parecen mucho a la percepción que se tiene de ellas mediante el ojo humano. La razón de ello es que el ojo tiene un funcionamiento similar. Los haces luminosos que llegan a la pupila son desviados por el cristalino hacia un punto, que es el equivalente al vértice o centro de proyección. Luego impactan sobre una superficie sensible, que es la equivalente al plano del cuadro, en la cual existen terminaciones nerviosas que recogen la información, llevándola al cerebro.

Las fotografías y videos también son perspectivas cónicas. Los haces luminosos que llegan al objetivo son desviados por las lentes hacia un punto denominado foco. Posteriormente, impactan sobre una superficie plana sensible a la luz, que es el negativo de la película fotográfica, en una cámara analógica, o los sensores fotoeléctricos de una cámara digital.

Un video es una sucesión de fotografías, por lo que cada fotograma del video se puede considerar como una perspectiva cónica de la realidad.

\subsubsection{Expresiones algebraicas}

En este desarrollo se utilizan coordenadas homogéneas, tal y como recomiendan Gil Saurí (1997) y Auñón (2000).

A partir de un punto $P$ de coordenadas absolutas $(a, b, c)$ con $a, b, c$ números reales cualesquiera. Cualquier grupo de 4 números reales $(x, y, z, \lambda)$ son coordenadas homogéneas de ese punto $P$ si cumplen la ecuación (55):

$$
a=\frac{x}{\lambda} \cdot b=\frac{v}{\lambda} \cdot c=\frac{z}{\lambda} .
$$


Si $\lambda=1$, se denominan coordenadas homogéneas normalizadas. Cualquier valor real de $\lambda$ es permisible, salvo el cero. Como se observa, a cada punto le corresponden infinitas coordenadas homogéneas posibles. Es un espacio vectorial de dimensión 1.

Este artificio matemático permite simplificar mucho las expresiones matemáticas de estas transformaciones geométricas.

Si se supone que el vértice de la perspectiva se encuentra en el origen de coordenadas, la dirección de cámara o motivo es el eje $O Z$, y el plano de cuadro está a una distancia $d$ de la cámara. Esta perspectiva se denomina perspectiva cónica canónica (Auñón, 2000).

En ese caso, se puede calcular la perspectiva de un punto mediante las expresiones (56), (57) y (58), que se obtienen simplemente por semejanza de triángulos.

$$
\begin{aligned}
& x_{\text {proyección }}=i_{\text {real }} \cdot \frac{d}{z_{\text {real }}} \\
& y_{\text {proyección }}=i_{\text {real }} \cdot \frac{d}{z_{\text {real }}} \\
& z_{\text {proyección }}=l
\end{aligned}
$$

Figura 64: Perspectiva cónica canónica 
Si se reordenan las anteriores expresiones, de forma matricial, en coordenadas homogéneas, se obtiene la ecuación(59):

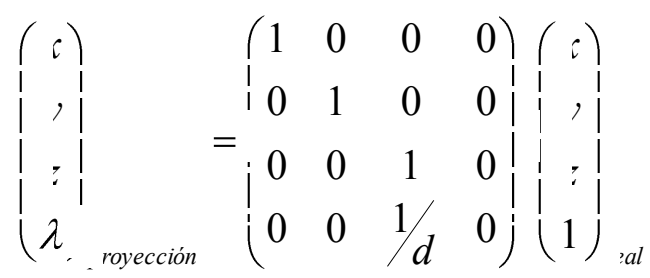

Esta forma matricial es común a todas las transformaciones geométricas de tipo lineal. Una perspectiva es una transformación lineal puesto que las formas proyectadas mantienen el orden correspondiente a sus originales: un punto se transforma en un punto, una recta en una recta, una curva en una curva, etc. La forma genérica de las transformaciones lineales se expresa de manera matricial según la ecuación (60):

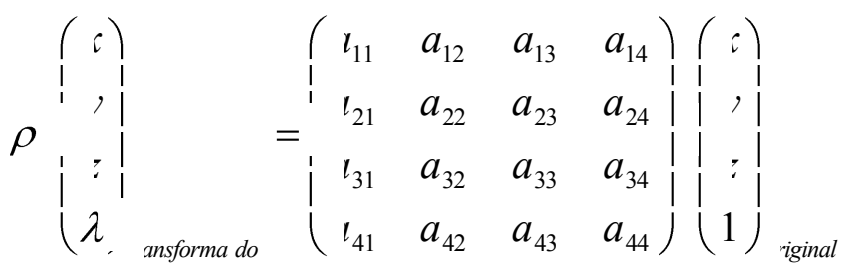

En el caso de no tratarse de la perspectiva canónica, es necesario realizar algunos cambios.

Si el vértice no se encuentra en el origen, se puede realizar una traslación de coordenadas, de manera que sí lo esté. Y luego deshacer la traslación, para obtener las coordenadas originales.

Una traslación de coordenadas, usando coordenadas homogéneas, se expresa matricialmente con la ecuación (61). Los valores $V_{x} V_{y}, V_{z \prime}$ son las coordenadas del vértice de proyección.

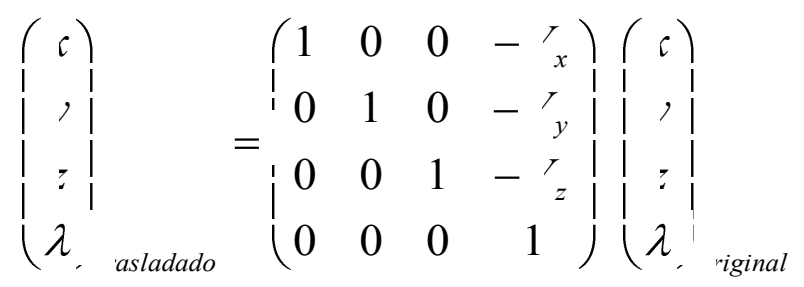

La perspectiva cónica de vértice $\left(V_{x}, V_{y}, V_{z}\right)$, y plano de cuadro $z=d$, se expresa con la ecuación (62): 


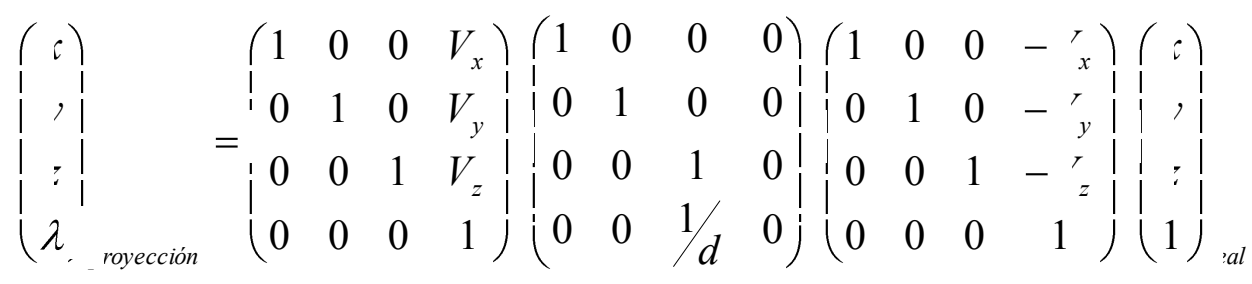

Si el motivo no es paralelo a la dirección $O Z$ (el plano de cuadro no es paralelo al $O X Y$ ), entonces habrá que realizar uno o varios giros de ejes coordenados. La expresión para un giro alrededor el eje $O X$, con un ángulo a, es la ecuación (63):

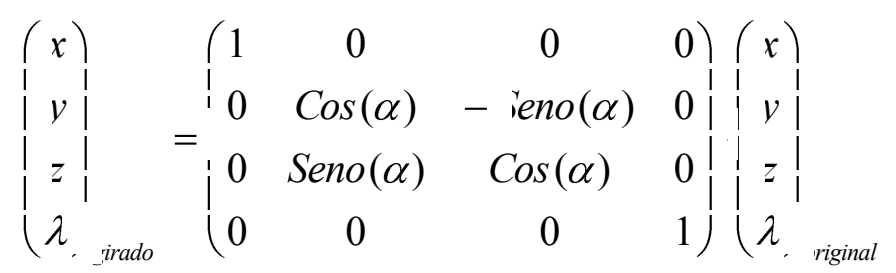

Análogas expresiones pueden obtenerse para giros alrededor del eje $O Y$. Es la ecuación(64):

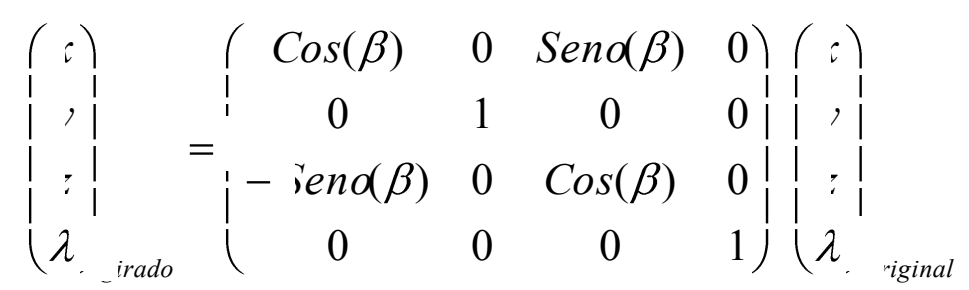

Y el eje OZ. En la ecuación(65):

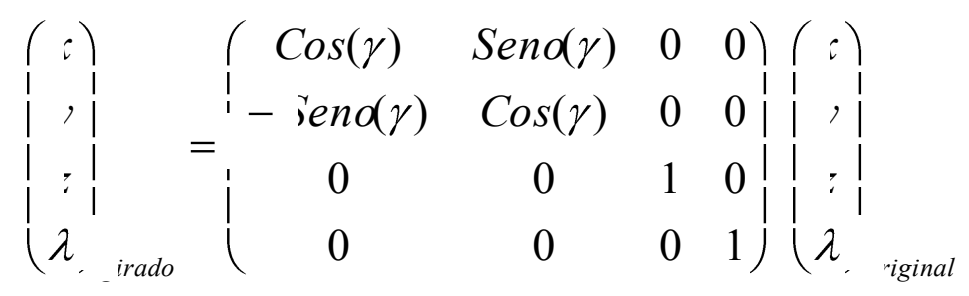

Esto sumado a la traslación, en caso de que el vértice no esté en el origen, da la ecuación (66), que proporciona el valor de una perspectiva cónica genérica. 


$$
\begin{aligned}
& \left(\begin{array}{l}
x \\
v \\
z \\
\lambda \text {, royección }
\end{array}=\left(\begin{array}{cccc}
1 & 0 & 0 & V_{x} \\
0 & 1 & 0 & V_{y} \\
0 & 0 & 1 & V_{z} \\
0 & 0 & 0 & 1
\end{array}\right)\left(\begin{array}{cccc}
1 & 0 & 0 & 0 \\
0 & \operatorname{Cos}(\alpha & -i e n o(\alpha & 0 \\
0 & \operatorname{Seno}(\alpha & \operatorname{Cos}(\alpha & 0 \\
0 & 0 & 0 & 1
\end{array}\right)\right.
\end{aligned}
$$

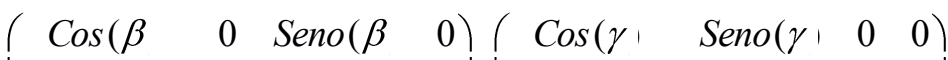

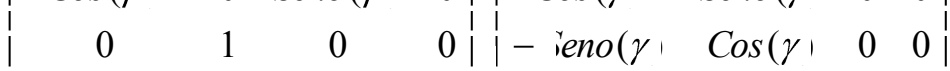

$$
\begin{aligned}
& \left|\begin{array}{llll|lll}
-\operatorname{ieno}(\beta & 0 & \operatorname{Cos}(\beta & 0
\end{array}\right| \begin{array}{llll}
0 & 0 & 1 & 0
\end{array} \mid \\
& \left(\begin{array}{llll}
0 & 0 & 0 & 1
\end{array}\right)\left(\begin{array}{llll}
0 & 0 & 0 & 1
\end{array}\right) \\
& \left(\begin{array}{cccc}
1 & 0 & 0 & 0 \\
0 & 1 & 0 & 0 \\
0 & 0 & 1 & 0 \\
0 & 0 & 1 / d & 0
\end{array}\right) \\
& \left(\begin{array}{cccc}
\operatorname{Cos}(\gamma, & -\operatorname{ieno}(\gamma, & 0 & 0 \\
\operatorname{Seno}(\gamma, & \operatorname{Cos}(\gamma, & 0 & 0 \\
0 & 0 & 1 & 0 \\
0 & 0 & 0 & 1
\end{array}\right)\left(\begin{array}{cccc}
\operatorname{Cos}(\beta & 0 & -\operatorname{ieno}(\beta & 0 \\
0 & 1 & 0 & 0 \\
\operatorname{Seno}(\beta & 0 & \operatorname{Cos}(\beta & 0 \\
0 & 0 & 0 & 1
\end{array}\right)
\end{aligned}
$$

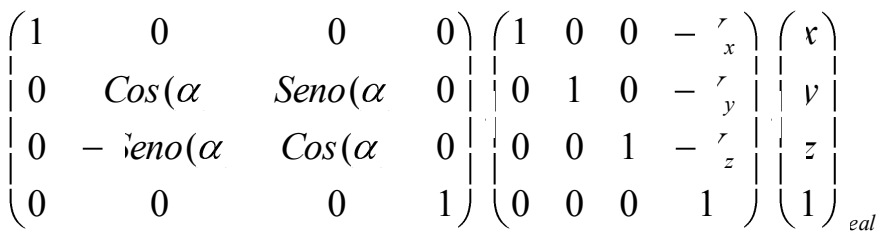

Si $T$ es la matriz de traslación, y $G$ la matriz de giros, se puede simplificar la ecuación (67):

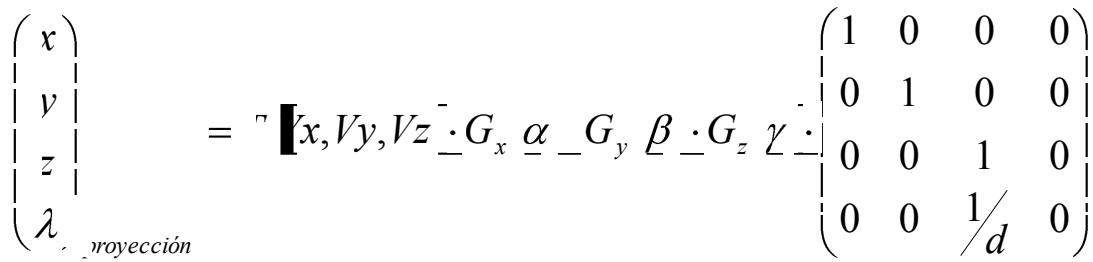

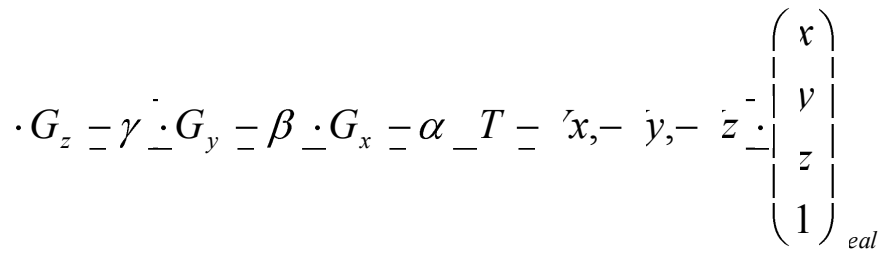

Por otro lado, no se desea conocer las coordenadas $(x, y, z)$ del punto de proyección, pues son puntos sobre un plano inclinado cualquiera. Interesa tomar las coordenadas $(x, y)$ locales en el plano. 
Para ello, no se deshará la traslación y los giros. El resultado es que la tercera ecuación resulta $z_{\text {proyección }}=d$, para todo $(x, y, z)_{\text {real }}$ La ecuación (68) para el cálculo de la perspectiva cónica se simplifica un poco:

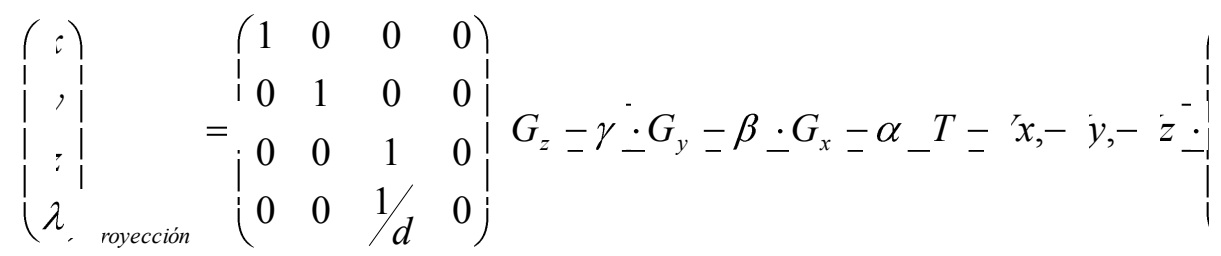

Desarrollando y simplificando esta expresión, se obtiene (69) y (70):

$$
\begin{aligned}
& x_{\text {proy }}=d \frac{(\mathrm{Vx}-\mathrm{x}) \operatorname{Cos}[\beta \operatorname{Cos}[\gamma+(\mathrm{Vy}-\mathrm{y})(\operatorname{Sin}[\alpha \sin [\beta \operatorname{Cos}[\gamma-\operatorname{Cos}[\alpha \operatorname{Sin}[\gamma)+(\mathrm{Vz}-\mathrm{z})(-\operatorname{Sin}[\alpha \sin [\gamma-\operatorname{Cos}[\alpha \sin [\beta \operatorname{Cos}[\gamma)}{(\mathrm{Vx}-\mathrm{x}) \operatorname{Sin}[\beta-(\mathrm{Vy}-\mathrm{y}) \operatorname{Sin}[\alpha \operatorname{Cos}[\beta+\mathrm{Vz}-\mathrm{z}) \operatorname{Cos}[\alpha \operatorname{Cos}[\beta} \\
& y_{\text {proy }}=d \frac{(\mathrm{Vx}-\mathrm{x}) \operatorname{Cos}[\beta \operatorname{Sin}[\gamma+(\mathrm{Vy}-\mathrm{y})(\operatorname{Sin}[\alpha \operatorname{Sin}[\beta \operatorname{Sin}[\gamma+\operatorname{Cos}[\alpha \operatorname{Cos}[\gamma)+(\mathrm{Vz}-\mathrm{z})(\operatorname{Sin}[\alpha \operatorname{Cos}[\gamma-\operatorname{Cos}[\alpha \sin [\beta \operatorname{Sin}[\gamma)}{(\mathrm{Vx}-\mathrm{x}) \operatorname{Sin}[\beta-(\mathrm{Vy}-\mathrm{y}) \operatorname{Sin}[\alpha \operatorname{Cos}[\beta+\mathrm{Vz}-\mathrm{z}) \operatorname{Cos}[\alpha \operatorname{Cos}[\beta}
\end{aligned}
$$

Se señala aquí que la distancia focal $d$ ha resultado funcionar como un factor de escala. Cuando el plano de cuadro se aleja del vértice, la imagen se agranda. Esto es precisamente lo que hacen algunos equipos fotográficos al realizar zoom óptico: aumentar la distancia entre la lente y el equipo sensible.

El denominador de ambas fracciones es idéntico y corresponde a la coordenada $z_{\text {real }}$ en los ejes girados y trasladados. El numerador de la primera expresión es $x_{\text {real }} Y$ el de la segunda, $y_{\text {realı }}$ ambos también en ejes girados y trasladados.

Los factores $V x, V y, V z$ aparecen modificando las coordenadas reales $x, y, z$, pues son las distancias de traslación.

En cuanto a los términos en $a, \beta, \gamma$, corresponden a la matriz de giro. Si la matriz de giro es $G$, se podría simplificar dando como resultado las ecuaciones (71) y (72).

$$
\begin{aligned}
& x_{\text {proy }}=l \frac{(\mathrm{Vx}-\mathrm{x}) G_{11}+(\mathrm{Vy}-\mathrm{y}) G_{12}}{(\mathrm{Vx}-\mathrm{x}) G_{31}}-\frac{(\mathrm{Vz}-\mathrm{z}) G_{13}}{\mathrm{Vy}-\mathrm{y}) G_{32}}+\frac{\mathrm{Vz}-\mathrm{z}) G_{33}}{\mathrm{~V}} \\
& y_{\text {proy }}=l \frac{(\mathrm{Vx}-\mathrm{x}) G_{21}+(\mathrm{Vy}-\mathrm{y}) G_{22}}{(\mathrm{Vx}-\mathrm{x}) G_{31}-(\mathrm{Vy}-\mathrm{y}) G_{32}}+\frac{(\mathrm{Vz}-\mathrm{z}) G_{23}}{\mathrm{Vz}-\mathrm{z}) G_{33}}
\end{aligned}
$$

Los elementos $G_{i j}$ son los elementos de la matriz de giro, que debe cumplir, para ser una matriz de ese tipo:

$$
\begin{gathered}
\operatorname{Det}[G]=1 \\
G^{1}=G
\end{gathered}
$$


Se podría simplificar aún más las expresiones, si se expresan matricialmente, en coordenadas homogéneas(75) y (76).

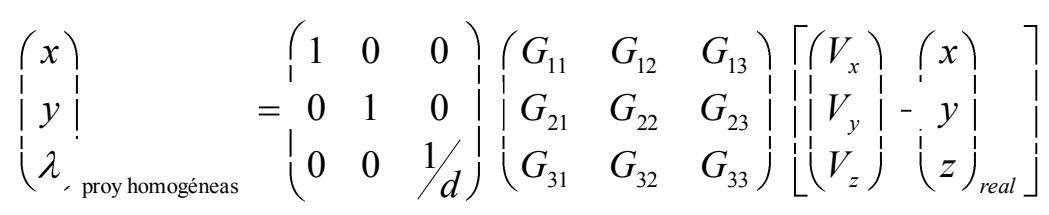

$$
\begin{aligned}
& x_{\text {proy }}=\frac{x_{\text {proyhomogénea }}}{\lambda} ; \quad y_{\text {proy }}=\frac{v_{\text {proyhomogénea }}}{\lambda_{\mathrm{x}} \text { oyhomogénénea }}
\end{aligned}
$$

Por último, el origen de coordenadas definido en el espacio real puede no tener nada que ver con el definido en el plano de imagen. En ese caso, se podría considerar que las coordenadas $(x, y)_{\text {proy }}$ han sufrido una traslación. Ecuaciones (77) y (78)

$$
\begin{aligned}
& x_{\text {proy }}=l \frac{(\mathrm{Vx}-\mathrm{x}) G_{11}+(\mathrm{Vy}-\mathrm{y}) G_{12}}{(\mathrm{Vx}-\mathrm{x}) G_{31}-(\mathrm{Vy}-\mathrm{y}) G_{32}}+\frac{(\mathrm{Vz}-\mathrm{z}) G_{13}}{(\mathrm{Vz}-\mathrm{z}) G_{33}}+i_{x} \\
& y_{\text {proy }}=l \frac{(\mathrm{Vx}-\mathrm{x}) G_{21}+(\mathrm{Vy}-\mathrm{y}) G_{22}}{(\mathrm{Vx}-\mathrm{x}) G_{31}-(\mathrm{Vy}-\mathrm{y}) G_{32}}+\left(\overline{\mathrm{Vz}-\mathrm{z}) G_{23}}+i_{y}\right.
\end{aligned}
$$

$\mathrm{Si}$, además de sufrir una traslación, hubieran sufrido un escalado, el factor de escala quedaría enmascarado con la distancia focal $d$, que es un amplificador.

Si además de traslación y escalado hubieran sufrido un giro, quedaría enmascarado con el giro $Y$, de eje $O Z$.

De manera genérica, las expresiones anteriores son de la forma (ecuaciones (79) y (80)):

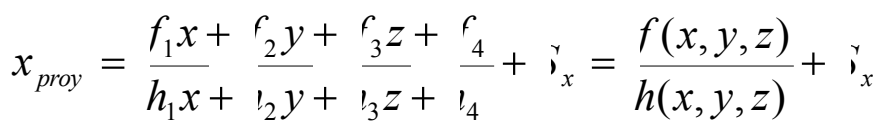

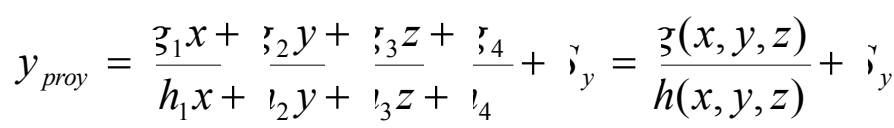

Donde las funciones $f, g, h$ son lineales. 
Se tienen 9 parámetros que caracterizan la perspectiva:

- $\quad$ por las coordenadas del vértice: $V_{x}, V_{y}, V_{z}$.

- $\quad$ por la dirección o motivo: $a, \beta, \gamma$.

- 1 por la distancia focal: $d$.

- 2 por la traslación en el plano imagen: $S_{x}, S_{y}$.

Las 3 de dirección y la distancia focal podrían sustituirse por 3 de la coordenada del punto principal $P$. Conocido el vértice $V$ y su proyección en el plano de cuadro $P$, la distancia entre ellos determina $d, y$ el plano de cuadro queda definido por ser perpendicular al vector $V P$.

Resultarían 8 parámetros, finalmente:

- $\quad$ por las coordenadas del vértice: $V x, V y, V z$.

- $\quad$ por las coordenadas del punto principal: Px, Py, Pz.

- $\quad$ por la traslación en el plano imagen: Sx, Sy.

\subsubsection{Transformación inversa a la perspectiva}

El problema de la restitución de perspectivas se puede plantear de la siguiente manera. Se conocen las coordenadas reales de una serie de puntos de referencia, así como las coordenadas planas de estos puntos en un sistema de referencia definido en la imagen.

No se conoce la posición del plano de cuadro, ni el origen o las direcciones principales del sistema de referencia definido en la imagen. Por tanto, lo único que se conoce de las referencias en la imagen es la posición relativa entre ellas (distancias y ángulos entre ellas).

Como se ha visto anteriormente, la perspectiva se caracteriza por 8 parámetros. Cada punto de referencia, de coordenadas conocidas tanto en la realidad como en la imagen, da 2 ecuaciones. Esto lleva a considerar que se necesitan 4 puntos.

Si se cuenta con 4 referencias, se es capaz de determinar los parámetros de la perspectiva: la posición del vértice y la posición del plano de cuadro.

El siguiente paso sería, dado un punto en el plano de cuadro, obtener la posición del punto en la realidad. Pero ese problema no tiene solución. Como se muestra en la Figura 65, existen infinitos puntos $A_{i}$ que tienen como punto imagen $A$ '. Todos esos puntos tienen en común que pertenecen a una recta que pasa por $V$. Por lo tanto, definen un espacio vectorial de dimensión 1.

Haría falta otro parámetro adicional para definir el problema completamente. Usualmente, se toma la cota del punto. Si se conoce la coordenada $z$ de los puntos representados en la imagen, se puede realizar la transformación inversa a la perspectiva cónica. 


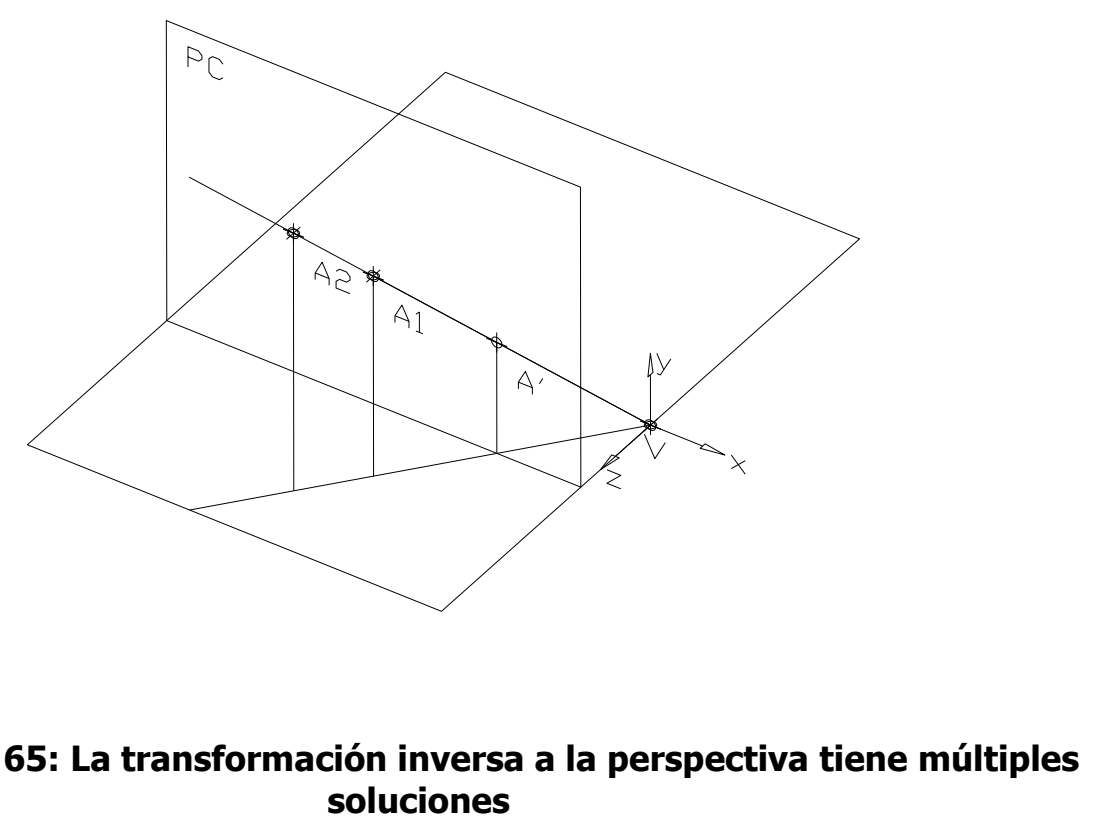

En restituciones de trayectorias de tráfico, lo que se suele hacer es restituir puntos sobre la superficie del pavimento. Si se restituye el punto de apoyo de las ruedas de un vehículo, se conoce perfectamente su posición.

Por tanto, la solución del problema está en la intersección de la recta $V A^{\prime}$ con la superficie del pavimento. Si se considera el pavimento como una superficie plana de cota $Z$, el problema es más sencillo. Pero también se puede considerar el pavimento como una superficie topográfica compleja, y calcular exactamente la posición de la rueda. Para ello haría falta conocer esa superficie topográfica.

\subsubsection{Resolución numérica}

Anteriormente se ha definido la perspectiva cónica mediante dos funciones de la siguiente forma (81) y (82):

$$
\begin{aligned}
& \left.x_{\text {provección }}=f_{1} \backslash x, y, z\right\}_{\text {real }},\left\{V_{x}, V_{y}, V_{z}\right\},\left\{P_{x}, P_{y}, P_{z}\right\},\left\{S_{x}, S_{y}\right\} \\
& \left.y_{\text {proyección }}=f_{2} \backslash \mathbf{|}, y, z\right\}_{\text {real }},\left\{V_{x}, V_{y}, V_{z}\right\},\left\{P_{x}, P_{y}, P_{z}\right\},\left\{S_{x}, S_{y}\right\} \text { - }
\end{aligned}
$$

Si se tiene 4 puntos de los que se conoce $\{x, y, z\}_{\text {real }}\{x, y\}_{\text {proyección }}$ se puede plantear un sistema de 8 ecuaciones no lineales, para calcular los 8 parámetros.

La resolución de sistemas de ecuaciones no lineales se realiza mediante métodos numéricos. El más conocido es el de Newton-Raphson.

Según este método, se parte de un valor inicial de las variables, y se van modificando éstos hasta conseguir que se satisfagan (aproximadamente) todas las ecuaciones.

Se plantea este sistema en el programa informático Mathematica ${ }^{\circledR}$, desarrollado por Wolfram Research. Se realizaron diferentes pruebas, planteando problemas sencillos de solución conocida. 
El resultado fue que la convergencia no siempre fue buena, dependiendo mucho de los valores iniciales dados a las variables. Una de las características del método de Newton-Raphson es que es un método sin garantía de éxito. Si los valores iniciales de las variables no son buenos, puede no converger nunca.

Si se indican valores cercanos a los que son solución, hay más posibilidades de convergencia, pero tampoco hay garantía. Además, a priori es difícil estimar cuáles son esos valores.

Podría crearse una rutina que generase puntos iniciales aleatorios, dentro de un rango predeterminado, para repetir el cálculo en el caso de superar un límite de iteraciones. Si hay solución dentro de ese rango, este método la encuentra, aunque puede que tarde mucho tiempo.

Aunque existen muchas estrategias orientadas a evitar la no convergencia del método, se decidió que era recomendable encontrar un método con garantía de éxito, aunque fuese más complicado de implementar. $\mathrm{Y}$, en efecto, ese método existe y se describe en las siguientes secciones.

\subsubsection{La homología plana}

\subsubsection{Definición geométrica}

Como se ha comentado anteriormente, el problema que se quiere resolver sólo tiene solución si los puntos a restituir se encuentran sobre una superficie conocida. Si se supone que dichos puntos están sobre el plano horizontal. En ese caso, la transformación geométrica de la perspectiva se convierte en una transformación de plano a plano. Esto simplifica muchísimo el desarrollo, como se expone a continuación.

Se retoma la definición de perspectiva cónica. Considerando el vértice $V$, desde el cual se proyecta el triángulo sobre el plano del dibujo.

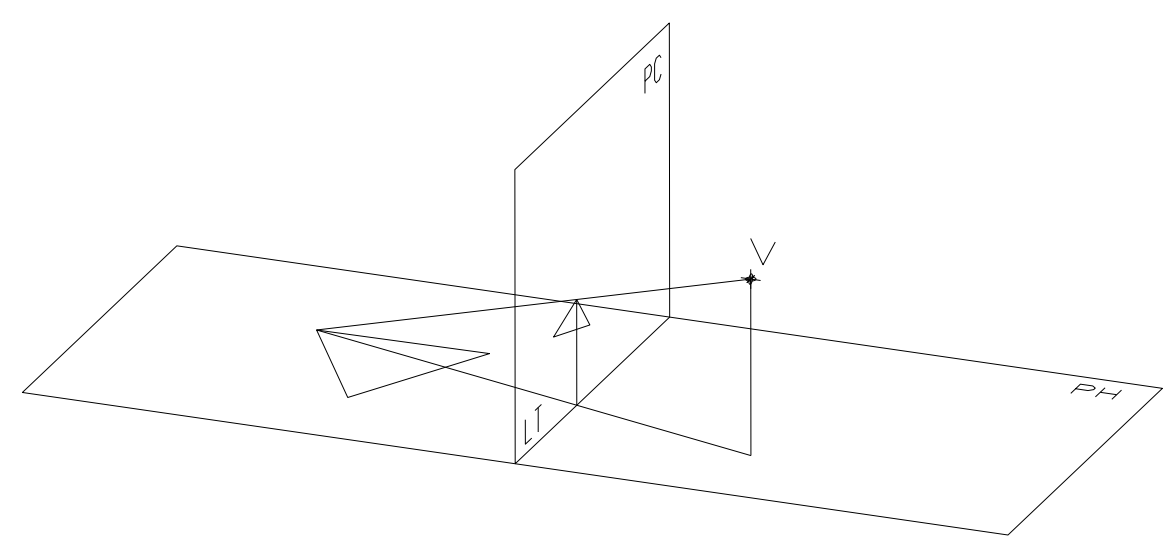

Figura 66: Perspectiva de un triángulo 
Si se abate el plano horizontal sobre el plano del cuadro, utilizando como eje de abatimiento la línea de tierra, se consigue que todas las construcciones estén en el mismo plano.

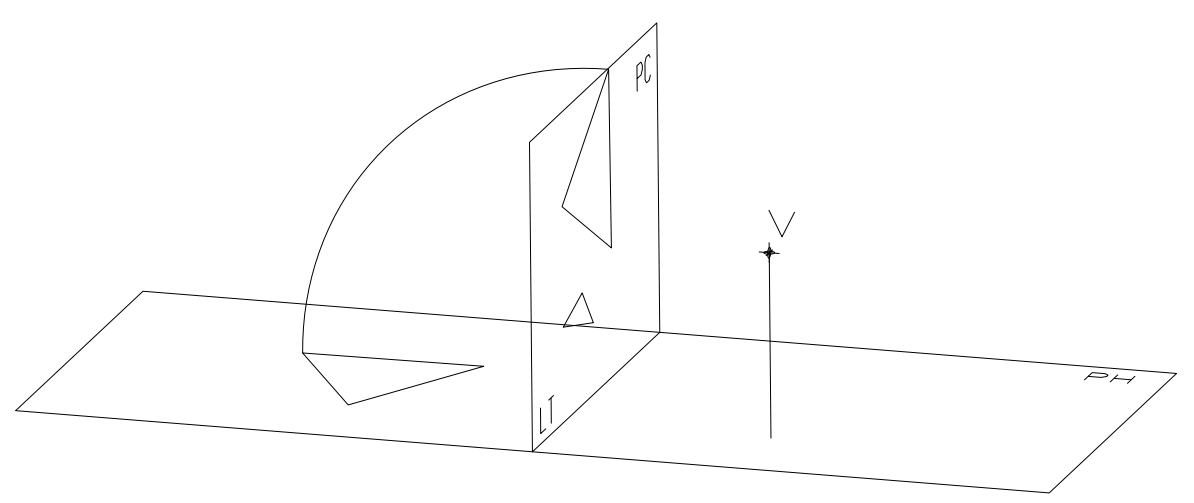

Figura 67: Abatimiento del plano horizontal sobre el plano de cuadro

Se aplica entonces el Teorema de Chasles-Steiner: "establecida una perspectividad entre dos formas planas, al girar un plano sobre el otro, se conserva la perspectividad. Su centro $V$, se mueve en un plano perpendicular al eje de giro, describiendo una circunferencia cuyo centro está en la recta límite". Este teorema garantiza que las relaciones entre la figura real y su imagen siguen manteniéndose, después del giro. Además, indica cómo se mueve el vértice $V$.

La recta límite es aquella en la que se sitúan las proyecciones de los puntos del plano horizontal que están en el infinito. En el límite, los puntos del plano horizontal infinitamente alejados de $V$, tienen su imagen sobre la línea de horizonte. Como se puede recordar, el punto principal $P$, o proyección ortogonal de $V$ sobre $P C$, pertenece a la línea de horizonte. Por lo tanto, el centro del giro de $V$, según el Teorema de Chasles-Steiner, se encuentra sobre el punto principal.

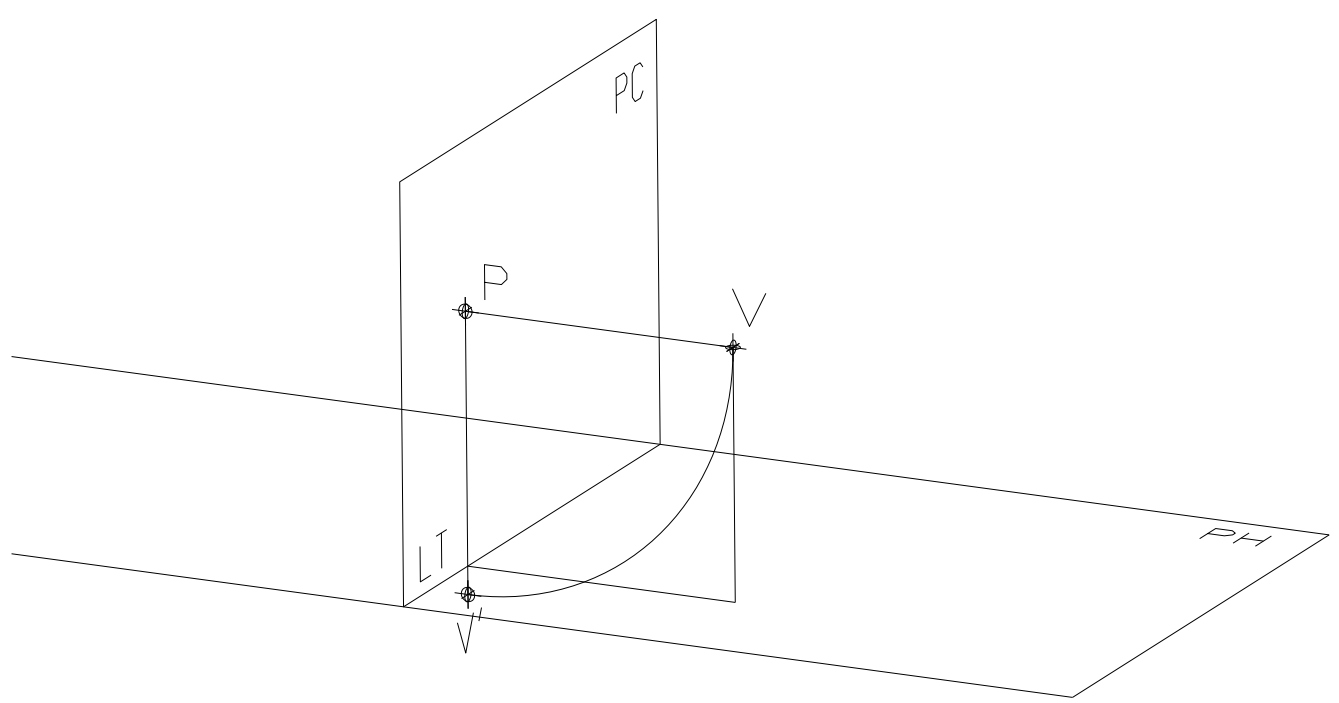

Figura 68: Abatimiento del vértice sobre el plano de cuadro 
Después de estas operaciones, se ha conseguido pasar de un problema tridimensional a un problema plano. La perspectiva es ahora una transformación plana, una relación entre figuras del mismo plano, el plano de cuadro.

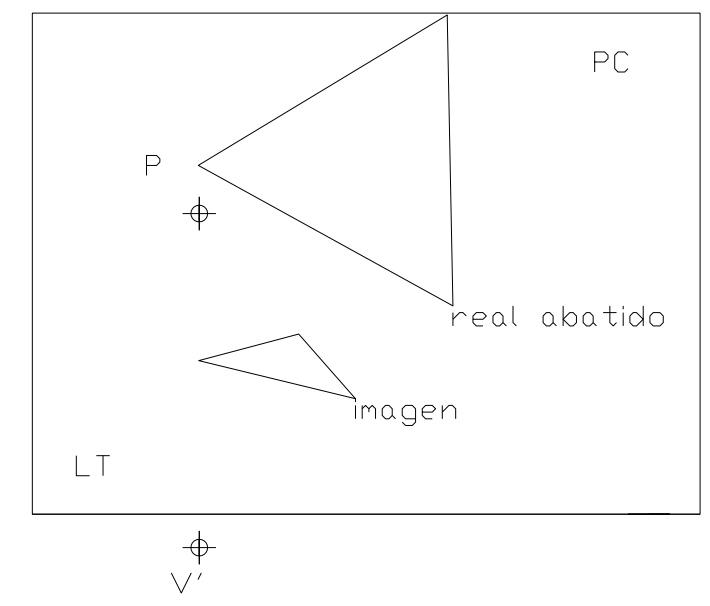

Figura 69: Perspectiva cónica reducida a transformación plana

Se descubrirán ahora las características de esta transformación:

Se trata de una transformación plana, pues relaciona elementos pertenecientes al mismo plano.

Se trata de una homografía o colinealidad, pues a cada punto se le hace corresponder otro punto, y a cada recta, otra recta.

Hay una serie rectilínea invariante, la línea de tierra. Esta recta pertenece al plano horizontal y al plano de cuadro, por lo tanto, la transformada de ella es ella misma.

Hay un haz de rectas invariante. Las rectas que parten del vértice son imágenes de sí mismas.

Por definición, se está ante una homología plana. Se enunciaran ahora algunas propiedades que resultarán útiles:

Un punto y su homólogo están alineados con V.

Una recta y su homóloga se cortan en el eje.

Las homólogas de dos rectas paralelas no son paralelas y se cortan en un punto de la recta límite.

Hay dos rectas límites, una para las figuras originales y otra para las imágenes. La recta límite correspondiente a las imágenes es la línea de horizonte.

En el siguiente dibujo se muestra una aplicación clásica de la perspectiva cónica. Se observa como la imagen en perspectiva del rectángulo verde, es un cuadrilátero rojo en el que los lados no son paralelos. Las intersecciones de las rectas homólogas con la recta límite son los llamados "puntos de fuga". 


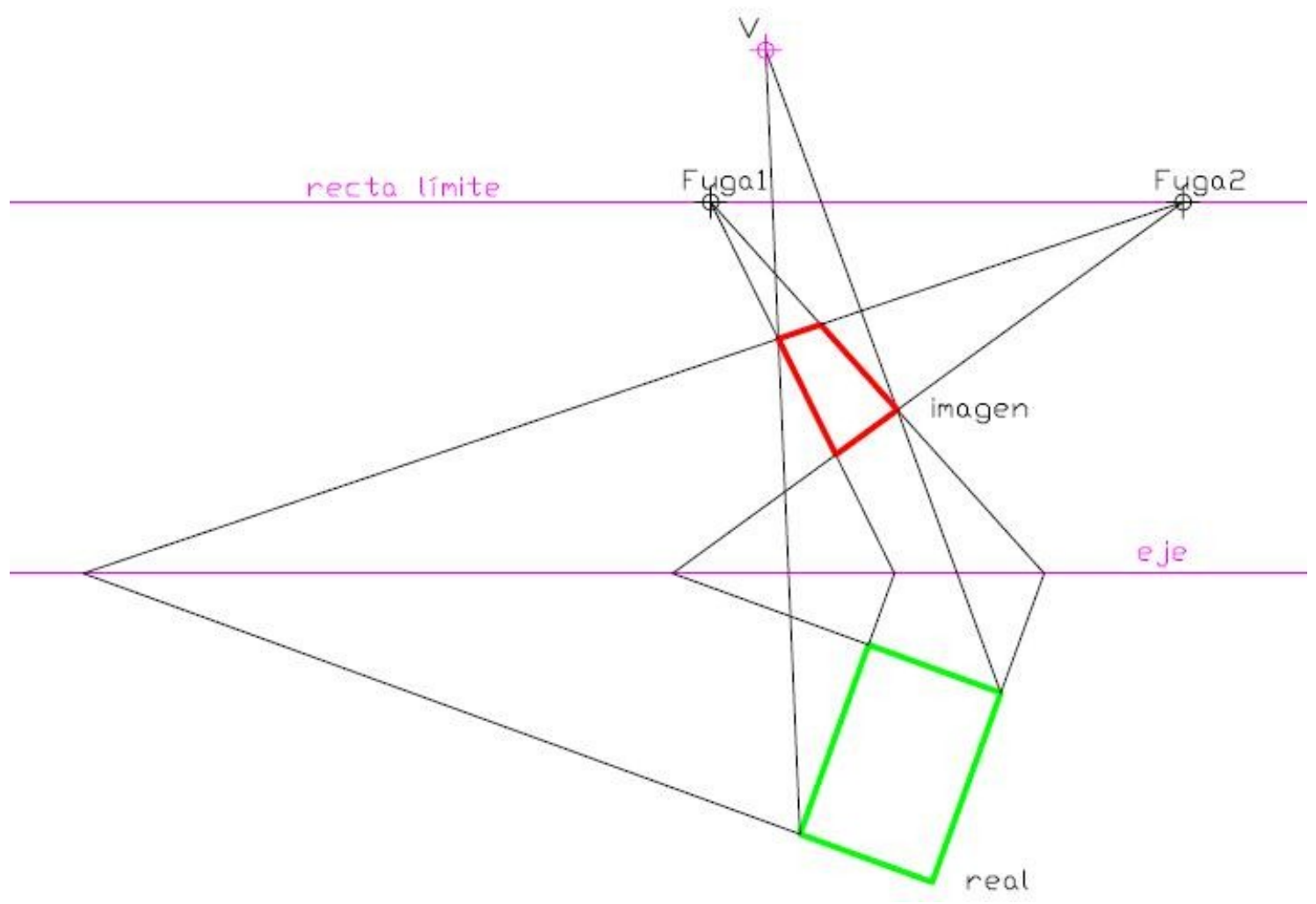

Figura 70: Los puntos de fuga en una homología plana

\subsubsection{Expresiones algebraicas}

Al igual que se descubre la perspectiva tridimensional en función de expresiones algebraicas, se mostraran las ecuaciones que sirven para describir una homología.

Una homografía plana, como es una transformación lineal, se puede describir mediante la ecuación lineal (83):

$$
\rho\left\{\begin{array}{l}
x \\
y \\
\lambda, \text { nagen }
\end{array}=\left(\begin{array}{lll}
x_{11} & a_{12} & a_{13} \\
x_{21} & a_{22} & a_{23} \\
x_{31} & a_{32} & a_{33}
\end{array}\right)\left(\begin{array}{l}
x \\
y
\end{array}\right)\left(\begin{array}{l}
x, \text { eal } \\
\lambda
\end{array}\right.\right.
$$

Debe cumplirse siempre que el determinante de la matriz $a_{i j}$ sea distinto de cero. Esto garantiza que exista función inversa, con lo que a partir de las coordenadas de la imagen, se pueden calcular las del punto real.

Una homología es un tipo particular de homografía. Si el vértice es el origen de coordenadas, e imponemos los invariantes, se llega fácilmente a la ecuación (84) (Gil Saurí, 1997): 


$$
\left(\begin{array}{l}
x \\
y \\
\lambda, \text { omológia }
\end{array}=\left(\begin{array}{ccc}
x_{11} & 0 & 0 \\
0 & a_{11} & 0 \\
x_{31} & a_{32} & a_{33}
\end{array}\right)\left(\begin{array}{l}
x \\
\lambda
\end{array}\right)\right.
$$

Si el vértice no es el origen, entonces hay que hacer previamente una traslación. La expresión matricial de una traslación, en coordenadas homogéneas en el plano (ecuación (85)):

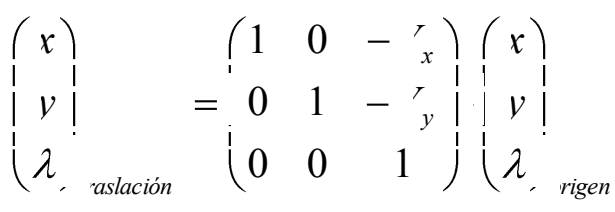

Si se componen ambas expresiones resulta la ecuación (86):

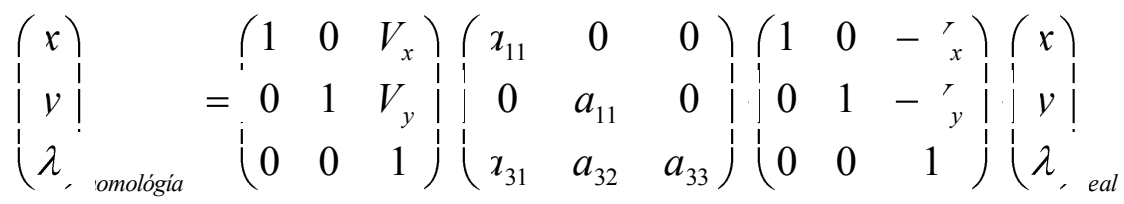

Que es una expresión de 6 parámetros. Se pueden obtener mediante el conocimiento de 3 puntos y sus homólogos. Efectivamente, conocer un triángulo y su homólogo permite determinar el vértice y el eje de homología fácilmente.

Operando, se llega a las ecuaciones (87) y (88):

$$
\begin{aligned}
& x_{\text {proy }}=\frac{\mathrm{q}_{11}\left(\mathrm{x}-\mathrm{V}_{\mathrm{x}}\right)+\mathrm{V}_{\mathrm{x}}\left(\mathrm{a}_{33}+\mathrm{a}_{31}\left(\mathrm{x}-\mathrm{V}_{\mathrm{x}}\right)+\mathrm{a}_{32}\left(\mathrm{y}-\mathrm{V}_{\mathrm{y}}\right)\right)}{\mathrm{a}_{33}+\mathrm{a}_{31}\left(\mathrm{x}-\mathrm{V}_{\mathrm{x}}\right)+\mathrm{a}_{32}\left(\mathrm{y}-\mathrm{V}_{\mathrm{y}}\right)} \\
& y_{\text {proy }}=\frac{\mathrm{q}_{11}\left(\mathrm{y}-\mathrm{V}_{\mathrm{y}}\right)+\mathrm{V}_{\mathrm{y}}\left(\mathrm{a}_{33}+\mathrm{a}_{31}\left(\mathrm{x}-\mathrm{V}_{\mathrm{x}}\right)+\mathrm{a}_{32}\left(\mathrm{y}-\mathrm{V}_{\mathrm{y}}\right)\right)}{\mathrm{a}_{33}+\mathrm{a}_{31}\left(\mathrm{x}-\mathrm{V}_{\mathrm{x}}\right)+\mathrm{a}_{32}\left(\mathrm{y}-\mathrm{V}_{\mathrm{y}}\right)}
\end{aligned}
$$

Si se considera que el origen de coordenadas del dibujo puede no coincidir con el del abatimiento del plano real, habría que considerar una traslación de coordenadas (ecuaciones (89).y (90)): 


$$
\begin{aligned}
& x_{\text {proy }}=\frac{\mathrm{a}_{11}\left(\mathrm{x}-\mathrm{V}_{\mathrm{x}}\right)+\mathrm{V}_{\mathrm{x}}\left(\mathrm{a}_{33}+\mathrm{a}_{31}\left(\mathrm{x}-\mathrm{V}_{\mathrm{x}}\right)+\mathrm{a}_{32}\left(\mathrm{y}-\mathrm{V}_{\mathrm{y}}\right)\right)}{\mathrm{a}_{33}+\mathrm{a}_{31}\left(\mathrm{x}-\mathrm{V}_{\mathrm{x}}\right)+\mathrm{a}_{32}\left(\mathrm{y}-\mathrm{V}_{\mathrm{y}}\right)}+i_{x} \\
& y_{\text {proy }}=\frac{\mathrm{a}_{11}\left(\mathrm{y}-\mathrm{V}_{\mathrm{y}}\right)+\mathrm{V}_{\mathrm{y}}\left(\mathrm{a}_{33}+\mathrm{a}_{31}\left(\mathrm{x}-\mathrm{V}_{\mathrm{x}}\right)+\mathrm{a}_{32}\left(\mathrm{y}-\mathrm{V}_{\mathrm{y}}\right)\right)}{\mathrm{a}_{33}+\mathrm{a}_{31}\left(\mathrm{x}-\mathrm{V}_{\mathrm{x}}\right)+\mathrm{a}_{32}\left(\mathrm{y}-\mathrm{V}_{\mathrm{y}}\right)}+i_{y}
\end{aligned}
$$

Estas dos expresiones, son de la forma, (ecuaciones (91) y (92)):

$$
\begin{aligned}
& x_{\text {proy }}=\frac{f_{1} x+\frac{f_{2} y}{h_{1} x}+\frac{f_{3}}{i_{2} y}+\frac{i_{3}}{i_{3}}+i_{x}=\frac{f(x, y)}{h(x, y)}+i_{x}}{y_{\text {proy }}=\frac{3_{1} x+\frac{r_{2} y}{h_{1} x}+\frac{r_{3}}{i_{2} y}+i_{3}}{i_{3}}=\frac{3(x, y)}{h(x, y)}+i_{y}}
\end{aligned}
$$

Es decir, análogas a las expresiones obtenidas para la perspectiva tridimensional, aunque más sencillas.

Este tipo de expresiones son las utilizadas por Davis (2004), que a su vez las extrae de Bleyl (1976).

\subsubsection{Homología inversa}

\subsubsection{Algebraicamente}

El proceso para resolver el problema inverso numéricamente es análogo al caso tridimensional. Se tienen unas expresiones no lineales con 8 parámetros a determinar para definir la homología.

Si se conocen 4 puntos en sus coordenadas reales y del dibujo, se puede resolver el sistema de ecuaciones, calculando los 8 parámetros. La resolución, una vez más, debe realizarse por métodos numéricos.

Son aplicables aquí los comentarios acerca de la convergencia de estos métodos. Al no ser métodos con garantía de éxito, la resolución del problema se puede complicar.

\subsubsection{Geométricamente}

El problema inverso de homología consiste en determinar una homología que transforme una figura dada, en otra.

Dadas las coordenadas de 3 puntos y sus homólogos, es posible determinar la homología. Trazando rectas desde cada uno de sus puntos hacia sus homólogos, se obtienen tres rectas que se cruzan en un único punto: el vértice. Si se extienden los 
lados de los triángulos real y homológico, los puntos de corte pertenecen al eje de homología.

Si no se conoce la posición de uno de los triángulos, sino sólo su forma y dimensiones, el problema está indeterminado. Por ejemplo, se puede encontrar una homología que transforme un triángulo cualquiera en otro equilátero (o de forma arbitraria), pero el problema tiene múltiples soluciones.

Si en lugar de 3 vértices conocidos, son 4, el problema sí queda determinado.

La siguiente construcción permite encontrar la homología que transforma un cuadrilátero cualquiera, en un rectángulo (Gil Saurí, 1997). El cuadrilátero rojo está en la imagen y se quiere que su homólogo real sea un rectángulo de dimensiones conocidas.

Como los lados opuestos del cuadrilátero, son paralelas en la realidad, se cortan en la recta límite. Los puntos $P, Q$ de intersección de esas rectas definen la recta límite, en color morado.

Como los lados contiguos del cuadrilátero, son perpendiculares en la realidad, el vértice estará en el arco capaz de $90^{\circ}$ del segmento $P Q$.

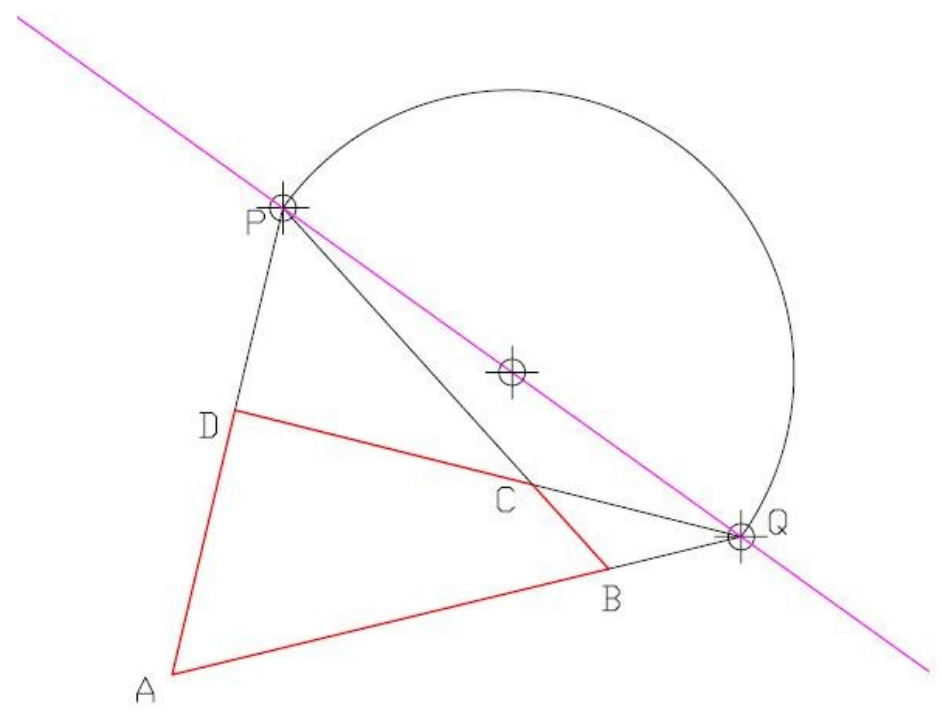

Figura 71: Transformación homológica de un cuadrilátero. Paso 1

Análogamente, las diagonales del rectángulo se cruzan con un ángulo que es conocido, pues se conoce su forma y dimensiones. En el caso de que el rectángulo sea cuadrado, ese ángulo es $90^{\circ}$. Así pues, el vértice debe estar en el arco capaz del segmento $M N$. 


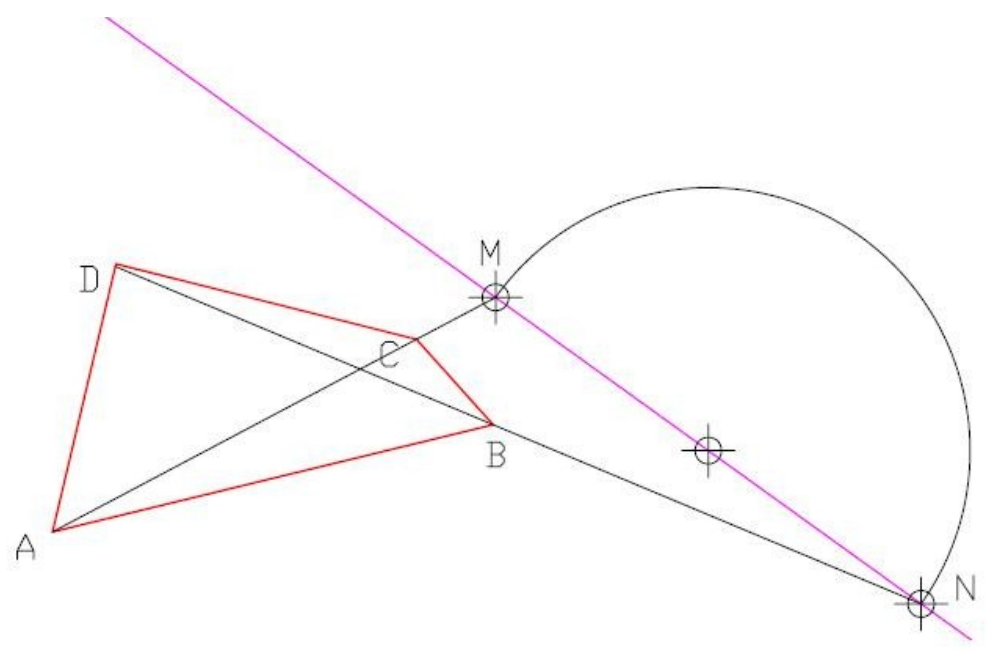

Figura 72: Transformación homológica de un cuadrilátero. Paso 2

Donde se corten los dos arcos capaces, tenemos la localización del vértice $V$. Trazando rectas desde $V$ hasta $A B C D$ se tienen las rectas sobre las que se sitúan los puntos homólogos $A^{\prime} B^{\prime} C^{\prime} D^{\prime}$. Se toma una de las dimensiones conocidas del rectángulo, por ejemplo, el lado $A^{\prime} B^{\prime}$. Como ese lado es paralelo a $V Q$, se puede trazar una paralela a $V A$, para encontrar la posición de $B$.

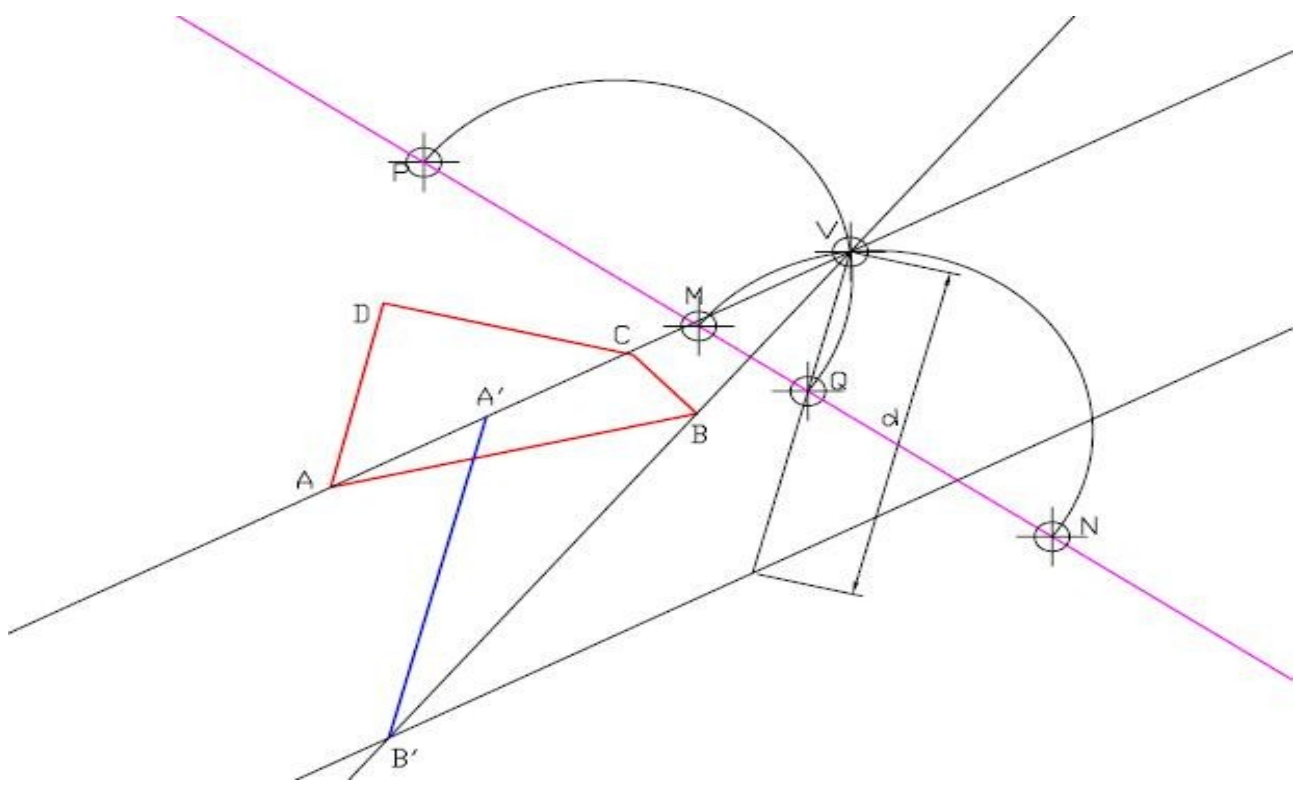

Figura 73: Transformación homológica de un cuadrilátero. Paso 3

El punto de corte de $A B$ con $A^{\prime} B^{\prime}$ es un punto del eje de homología. Como este eje es paralelo a la recta límite, queda perfectamente definido: es la línea verde.

Con el vértice y el eje de homología, ya se pueden calcular los demás puntos del rectángulo (en la figura, un cuadrado). 


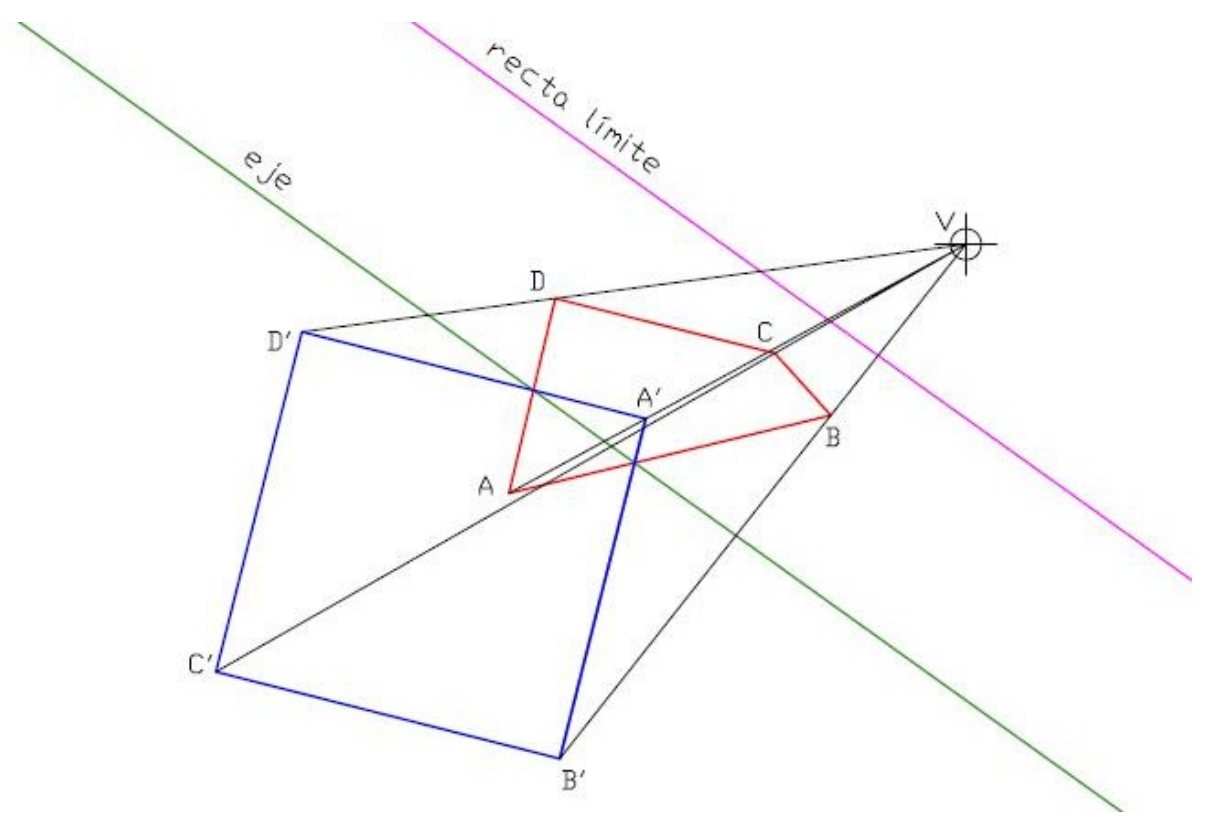

Figura 74: Transformación homológica de un cuadrilátero. Paso 4

Esta construcción es muy importante, pues permite definir la homología, si se reconoce en la imagen un rectángulo de dimensiones conocidas. En una carretera existen multitud de rectángulos que pueden servir de referencia. Por ejemplo, tomar un rectángulo definido por el ancho de un carril (en recta), y la distancia entre dos balizas consecutivas.

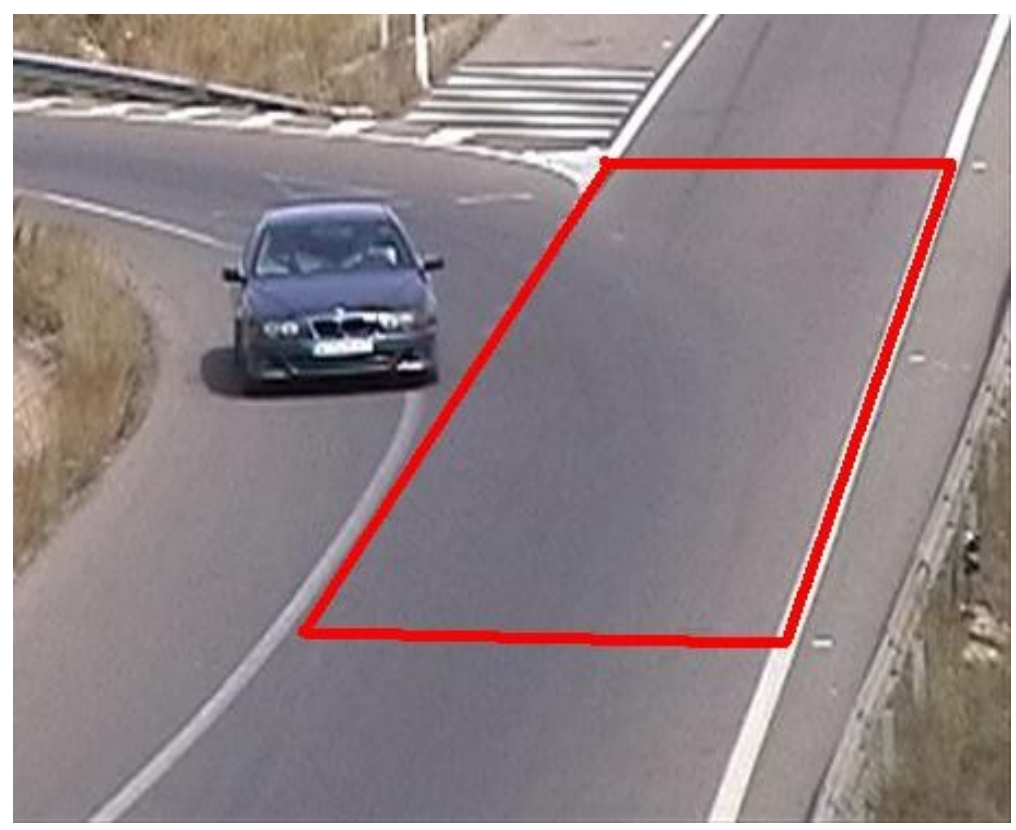

Figura 75: Ejemplo de rectángulo de referencia 


\subsubsection{Crítica del método}

El método anteriormente descrito es realmente útil en la mayoría de los casos. Pero también tiene sus inconvenientes.

En primer lugar, obliga a localizar un rectángulo en la imagen real y puede ser que no exista ninguno, como en una carretera con un trazado muy curvo.

En segundo lugar, habría que comprobar, in situ, si los lados del rectángulo son realmente perpendiculares.

Por último, puede que los vértices del rectángulo no sean fácilmente identificables sobre la imagen. En el ejemplo anterior puede verse cómo los vértices de la derecha están sobre la línea, junto a las balizas captafaros. Pero los vértices de la izquierda están en puntos difícilmente distinguibles. Esto se podría solventar colocando sobre el pavimento una marca claramente visible desde la videocámara (por ejemplo, una cruz de pintura).

El método anterior puede suavizar sus condiciones de manera que también sirve un paralelogramo cualquiera (no necesariamente rectángulo). Sólo hay que variar los ángulos de los arcos capaces para determinar $V$.

La determinación de la homología que transforma un cuadrilátero cualquiera en otro de forma arbitraria no puede realizarse con variantes del método anterior.

\subsubsection{La doble homología}

La doble homología permite resolver los problemas del método anterior, mediante la concatenación de dos homologías sucesivas. Se define un dibujo intermedio o auxiliar, entre el real y la perspectiva cónica (Albert 2002).

Al aumentar a dos el número de homologías se incremente el número de incógnitas del problema, pero partiendo del mismo número de datos (4 referencias), se produce una indeterminación. Existen múltiples soluciones para el problema. Esto da la libertad para escoger algunos de estos parámetros, simplificando el problema.

Hay que tener en cuenta que entre los puntos del espacio real y los del espacio imagen hay una relación lineal. Además que una homología es una transformación lineal, por lo que, la concatenación de dos homologías también lo es.

Si se tiene una traslación, que no es más que otra transformación lineal, la concatenación de dos homologías y una traslación también se constituye en otra transformación lineal.

La descripción detallada del método se presenta en el capítulo de Metodología Experimental. 


\section{OBJETIVOS DE LA INVESTIGACIÓN}

\subsection{OBJETIVO PRINCIPAL}

El objetivo principal de la investigación es desarrollar un nuevo modelo de diseño de la longitud de los carriles de deceleración tipo paralelo basado en el desarrollo y la aplicación de un indicador de la conflictividad para las maniobras de salida.

\subsection{OBJETIVOS ESPECÍFICOS}

Se plantean toda una serie de objetivos de la investigación, para llegar a desarrollar el objeto final de la Tesis:

- Estudiar experimentalmente, sobre un mismo escenario, la evolución de los vehículos en un carril de deceleración tipo paralelo para analizar el diseño y funcionalidad en función de su longitud, mediante el establecimiento de diferentes configuraciones experimentales.

- Contrastar los resultados experimentales mediante el estudio del diseño y funcionalidad de una muestra significativa de carriles de deceleración adicionales.

- Tanto para el estudio experimental como para el estudio de los carriles adicionales se analizan los siguientes aspectos:

- Trayectorias y puntos de incorporación al carril de deceleración.

- Las velocidades de los vehículos.

- Duración de las maniobras.

- Las situaciones de tráfico en la vía principal.

- Las deceleraciones y aceleraciones de los vehículos.

- La seguridad vial.

- Desarrollar un modelo de restitución de maniobras, que permita obtener la evolución de los vehículos a partir del procesamiento de vídeos digitalizados.

- Correlacionar la longitud de los carriles de deceleración con la evolución conflictiva de los vehículos en los mismos.

- Desarrollar un nuevo indicador de conflictividad, enmarcado en las técnicas de análisis de conflictos de tráfico, que pueda ser utilizado en maniobras de salida.

- Desarrollar y evaluar una metodología para la aplicación del indicador que se adopte.

- Desarrollar un modelo de diseño de la longitud de los carriles de deceleración tipo paralelo. 


\section{MÉTODO}

A continuación se presentan las hipótesis de la investigación y la metodología utilizada para la consecución de los objetivos propuestos.

\subsection{HIPÓTESIS}

La hipótesis fundamental de trabajo es que el comportamiento de los conductores que toman un carril de deceleración varía en función de la longitud del carril. Este cambio de comportamiento afecta tanto a la operación como a la funcionalidad de los carriles de deceleración y por consiguiente influye sobre la seguridad vial.

El cambio de comportamiento se fundamenta en que un carril muy corto provoca que los conductores realicen maniobras más bruscas. Estas maniobras conllevan una mayor afección a la vía principal debido a que los vehículos tendrán que iniciar su maniobra de deceleración antes de tomar el carril de deceleración. Todo esto supone un incremento en el riesgo de colisión.

En el otro extremo se encuentran los carriles muy largos que, en teoría, los vehículos que salen no deberían afectar al flujo de la vía principal. Sin embargo, la maniobra de salida inicia con un cambio de carril que afecta, en cierta medida, al flujo de la vía principal. Por otra parte, al disponer de más longitud, se espera una mayor dispersión en el punto de salida. Adicionalmente, aunque cabría esperar maniobras de deceleración más suaves, puede darse el caso de que algunos conductores inicialmente no deceleren, para ganar algo de tiempo, llegando incluso a acelerar y rebasar al vehículo que les preceda en la calzada principal. Esto genera una mayor dispersión en el comportamiento de los conductores e incrementa el riesgo de colisión.

Un carril de deceleración dimensionado adecuadamente para las condiciones locales, con una longitud intermedia, conseguiría a la vez tener poca afección a la vía principal y minimizar la frecuencia de comportamientos anómalos. Por consiguiente, esta solución supondría minimizar el riesgo de colisión en las maniobras de salida mejorando la seguridad vial.

\subsection{METODOLOGÍA}

Aprovechando que la Consellería de Infraestructuras y Transporte construyó una vía de servicio exterior que permite la accesibilidad a unas instalaciones deportivas y a una estación de servicio en el PK 7 de la autovía CV-35, y cerró la incorporación del carril de trenzado en ese punto, que contaba con unos $580 \mathrm{~m}$ de longitud, convirtiéndolo en un carril de deceleración tipo paralelo cuya longitud y señalización había que adecuarla a la normativa vigente (Instrucción de Trazado de Carreteras, 3.1-IC), se planteó hacer el estudio del diseño y funcionalidad de los carriles de deceleración en función de su longitud, pues era un escenario idóneo y único que permitía hacer experimentos con 
diferentes longitudes del carril de deceleración, sin variar ninguno de los demás condicionantes del tráfico.

A continuación se presenta el método seguido en la investigación, incluyendo una breve descripción de cada etapa del desarrollo de la misma.

\subsubsection{Diseño experimental}

La investigación se plantea en dos etapas claramente definidas. La primera, en la que se estudia el comportamiento de los conductores en un mismo carril de deceleración variando su longitud. La segunda, corresponde a una fase de comprobación mediante observaciones en diferentes carriles de deceleración existentes con el fin de validar los resultados.

En la primera fase, se estudia la situación inicial. Posteriormente se varía sucesivamente la longitud del carril de deceleración en cuatro etapas. La primera configuración corresponde a la máxima longitud posible de acuerdo con los condicionantes propios de la zona de estudio. La segunda configuración corresponde a la longitud especificada en la Instrucción de trazado 3.1 IC (1999). La tercera corresponde a una longitud intermedia y la cuarta corresponde a una configuración muy corta.

En la segunda fase, se selecciona una muestra de 10 carriles de deceleración existentes con longitudes largas, medias y cortas, que permiten contrastar los resultados experimentales sin necesidad de intervenir en los carriles de deceleración.

\subsubsection{Ejecución experimental}

Para una adecuada toma de datos es imprescindible evitar cualquier influencia perturbadora que modifique el comportamiento de los conductores. Debido a ello, para variar la longitud del carril de deceleración se utilizan marcas viales.

Asimismo, para evitar introducir una variable adicional se decidió adaptar la longitud de la línea continua al llegar a la nariz de modo que fuera apta para todas las configuraciones experimentales.

Finalmente, en los carriles de deceleración seleccionados en la fase de comprobación no se realizó ninguna modificación.

\subsubsection{Toma de datos}

Con el fin de registrar todas las maniobras de salida durante un periodo de tiempo específico de modo que permitiera estudiar adecuadamente el comportamiento de los vehículos en las maniobras de salida, se utilizan grabaciones de vídeo que cubran la totalidad del carril.

El periodo de toma de datos debe permitir evaluar, principalmente, situaciones de flujo libre y, adicionalmente, situaciones de alta densidad de tráfico. 


\subsubsection{Reducción de datos}

La reducción de datos está dividida en dos niveles. El primero, para una evaluación cualitativa y, el segundo, para una evaluación cuantitativa.

La evaluación cualitativa se realiza por observación directa de los vídeos, con el fin de hacer una clasificación de las maniobras que conllevan cierto riesgo asociado. A partir de la clasificación desarrollada, se realiza un inventario de maniobras y se analiza estadísticamente la relación existente entre el comportamiento observado y las características de los carriles de deceleración, mediante la utilización de modelos de regresión.

A su vez, la evaluación cuantitativa se realiza en dos niveles: evaluación de las maniobras libres para caracterizar la evolución de los vehículos y la evaluación de la conflictividad mediante la cuantificación del indicador de conflictividad desarrollado en esta investigación, para cada uno de los vehículos que salen en un periodo de tiempo determinado.

Para lograrlo, se desarrolló un programa informático de restitución de perspectivas cónicas a partir de vídeos, que permitiera hacer un seguimiento individualizado de los vehículos y conocer en cada momento su posición, su velocidad y su aceleración.

Con la ayuda de este programa se evaluó la velocidad de los vehículos en diferentes secciones del carril de deceleración, así como el porcentaje de vehículos que aceleran en el carril de deceleración, las tasas de deceleración y los indicadores de conflictividad mediante la utilización de las Técnicas de Conflictos de Tráfico.

Los datos de accidentalidad se han obtenido gracias al Servicio de Estadística del Observatorio Nacional de Seguridad Vial de la Dirección General de Tráfico, se han obtenido los datos de accidentalidad. Estos datos permiten, en primer lugar, evaluar la variación de la accidentalidad en función de las características geométricas de los carriles estudiados $y$, en segundo lugar, validar los resultados del indicador de conflictividad desarrollado. 


\section{DESARROLLO}

En este capítulo se presenta el desarrollo de la investigación incluyendo la ejecución experimental, la reducción y tratamiento de los datos, el diseño de los indicadores de conflictividad y los resultados.

\subsection{EJECUCIÓN EXPERIMENTAL}

En la ejecución experimental se presenta, en primer lugar, el diseño experimental para las dos fases de la investigación, seguido de la instalación de las configuraciones y la toma de datos.

\subsubsection{Diseño experimental}

A continuación se presenta el diseño experimental para la investigación, la cual ha sido desarrollada en dos fases. Una primera fase experimental en la que se estudia el comportamiento de los conductores en un mismo carril de deceleración variando su longitud; y una segunda fase de comprobación mediante de observaciones en la que se seleccionan 10 nuevos carriles de deceleración existentes con el fin de validar los resultados de la primera etapa experimental.

\subsubsection{Fase experimental}

Aprovechando las obras para mejorar un tramo de la autovía CV-35, próxima a la ciudad de Valencia se ha desarrollado la primera fase que consiste en evaluar el comportamiento de los conductores en función de la longitud del carril de deceleración.

\subsection{Condicionantes}

Debido a la existencia del carril paralelo de trenzado de aproximadamente $580 \mathrm{~m}$ de longitud, la longitud máxima del carril de deceleración estaba condicionada por esta distancia, y adicionalmente por la señalización existente, pues se contaba con una longitud de 440 metros desde el final de la línea continua actual hasta el inicio de la nariz de salida.

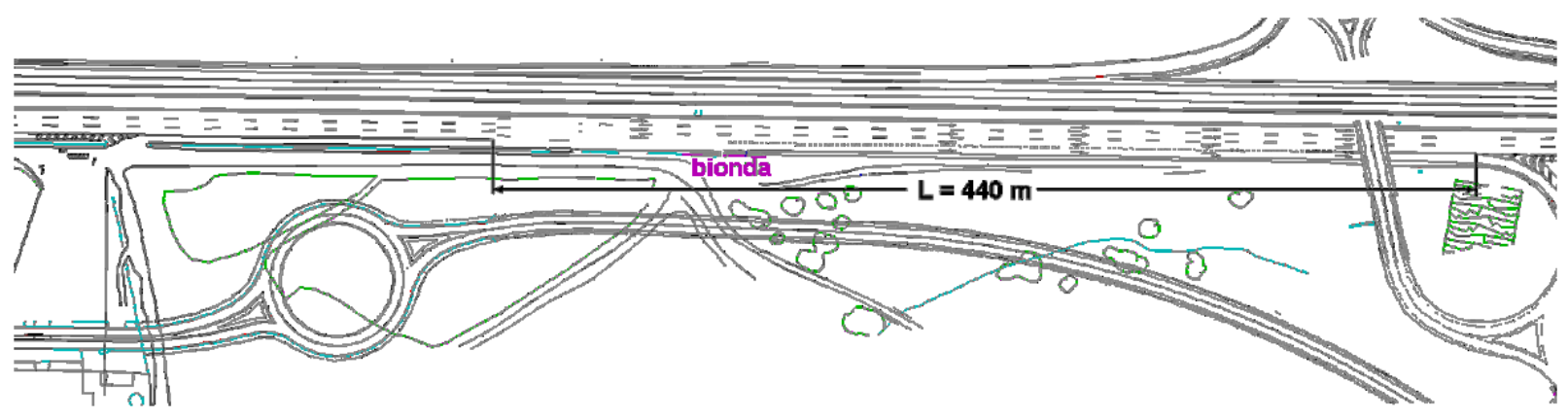

Figura 76: Situación inicial

Por otra parte, para evitar cualquier influencia perturbadora que modificara el comportamiento de los conductores, la materialización del carril de deceleración debía hacerse mediante señalización en el pavimento. 
Se decidió utilizar cinta adhesiva para variar la longitud del carril, con lo cual una vez concluida la fase experimental, se retiró y se procedió a la señalización definitiva.

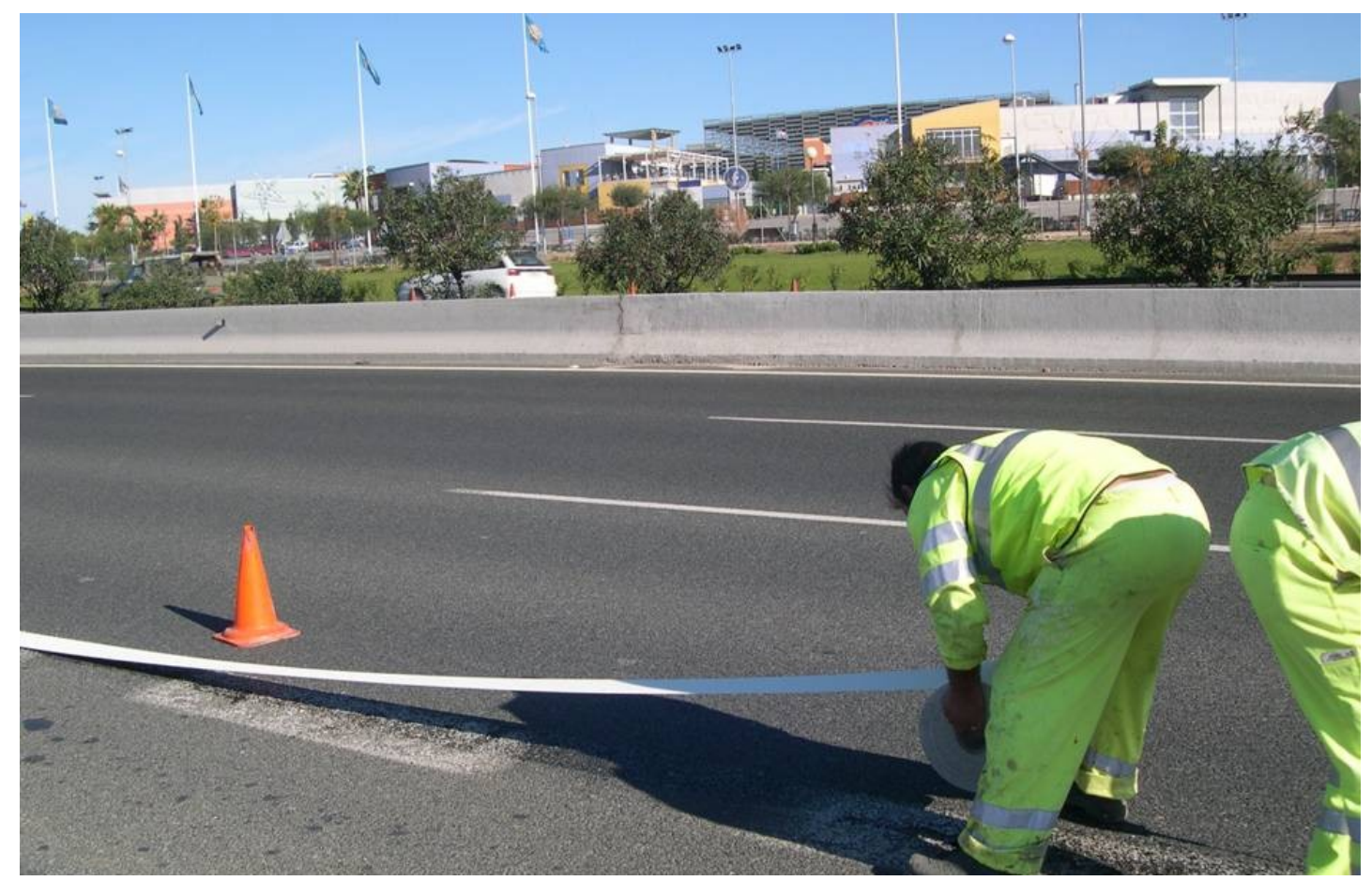

Figura 77: Utilización de cinta para la señalización provisional

Adicionalmente, la Instrucción de Carreteras en su apartado 7.4.4 establece las características de los carriles de deceleración, que para esta investigación serán de tipo paralelo.

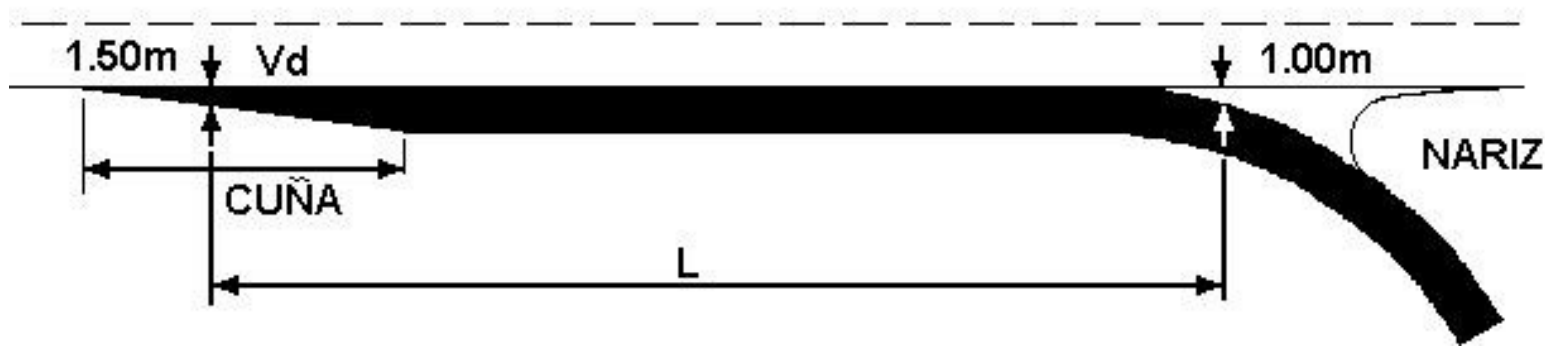

Fuente: Instrucción de Carreteras, 3.1-IC (1999)

Figura 78: Carril de deceleración tipo paralelo

En la Instrucción de Carreteras, se establece la longitud de la cuña de transición para carriles de deceleración paralelo, en función del menor de los valores de velocidad de proyecto $V_{p}$ y la máxima señalizada a la altura de la sección característica de 1,5 metros, de acuerdo con la Tabla 42. 
Tabla 42: Longitud (m) de la Cuña Triangular de Transición

\begin{tabular}{|c|c|}
\hline $\begin{array}{c}\text { Mínima }\left(\mathrm{V}_{\mathrm{p}} \text { limitada }\right) \\
(\mathrm{Km} / \mathrm{h})\end{array}$ & Deceleración \\
\hline$\leq 80$ & 70 \\
\hline 100 & 83 \\
\hline 120 & 100 \\
\hline
\end{tabular}

Fuente: Instrucción de Carreteras, 3.1-IC

La longitud del carril de deceleración está definida como la distancia entre las secciones características de $1.5 \mathrm{~m}$ de ancho en la cuña y $1,0 \mathrm{~m}$ de ancho en la nariz, en función de la inclinación de la rasante, la velocidad utilizada para determinar la longitud de la cuña y la velocidad específica en el ramal a la altura de la sección característica de $1,0 \mathrm{~m}$.

Para el tramo de vía de estudio, la inclinación de la rasante es $-2 \%$, la velocidad específica del ramal a la altura de la sección característica de 1,00 m, $V_{\mathrm{df}}=40 \mathrm{~km} / \mathrm{h}$, debido a que no se encuentra señalizada la velocidad a la altura de la sección característica de $1,5 \mathrm{~m}$, se utilizaron diferentes velocidades para el cálculo de la longitud del carril $V_{\text {do }}=120 \mathrm{Km} / \mathrm{h}, 100 \mathrm{~km} / \mathrm{h}$ y $80 \mathrm{~km} / \mathrm{h}$.

Tabla 43: Longitud del Carril de Deceleración

\begin{tabular}{|c|c|c|c|c|c|c|}
\hline & \multicolumn{2}{|c|}{$\begin{array}{c}\text { Velocidad } \\
\mathrm{V}_{\mathrm{do}}=80 \mathrm{Km} / \mathrm{h}\end{array}$} & \multicolumn{2}{c|}{$\begin{array}{c}\text { Velocidad } \\
\mathrm{V}_{\mathrm{do}}=100 \mathrm{Km} / \mathrm{h}\end{array}$} & \multicolumn{2}{c|}{$\begin{array}{c}\text { Velocidad } \\
\mathrm{V}_{\mathrm{do}}=120 \mathrm{Km} / \mathrm{h}\end{array}$} \\
\hline \multirow{2}{*}{$\mathrm{V}_{\mathrm{df}}(\mathrm{Km} / \mathrm{h})$} & $\begin{array}{c}\text { Inclinación de la } \\
\text { rasante }(\%)\end{array}$ & \multicolumn{2}{c|}{$\begin{array}{c}\text { Inclinación de la } \\
\text { rasante }(\%)\end{array}$} & \multicolumn{2}{c|}{$\begin{array}{c}\text { Inclinación de la } \\
\text { rasante }(\%)\end{array}$} \\
\cline { 2 - 7 } & -2 & 0 & -2 & 0 & -2 & 0 \\
\hline 40 & 107 & 100 & 187 & 168 & 285 & 256 \\
\hline
\end{tabular}

Fuente: Instrucción de Carreteras, 3.1-IC

\subsection{Configuraciones}

En primer lugar se evaluó una configuración inicial, para estudiar el comportamiento de los conductores en el estado inicial del carril. Se dejó el carril de trenzado original, aunque estaba siendo utilizado únicamente como salida ya que la entrada ya se encontraba cerrada. 


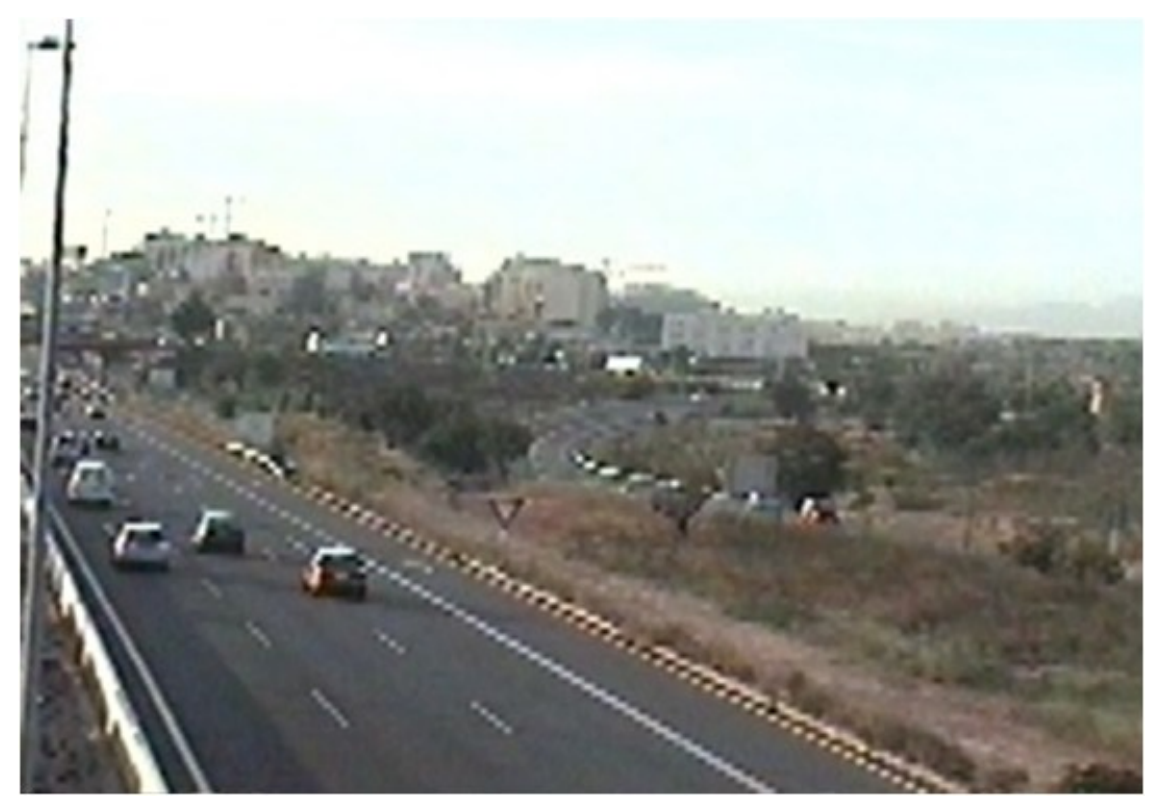

Figura 79: Fotografía configuración inicial

Posteriormente, durante la fase experimental se evaluaron cuatro configuraciones, variando la longitud del carril de deceleración desde los 395 metros, que era la máxima posible, hasta los 107 metros, para estudiar el comportamiento de los conductores en función de dicha longitud.

Debido a que originalmente la longitud de la línea continua de separación del carril de deceleración, antes de llegar a la nariz, era de 65 metros, que en la configuración 4 podría afectar el comportamiento de los conductores al salir, se decidió acortar su longitud en 35 metros, convirtiéndolos en discontinuos, para las 4 configuraciones y de esta manera evitar introducir una variable adicional en la fase de experimentación.

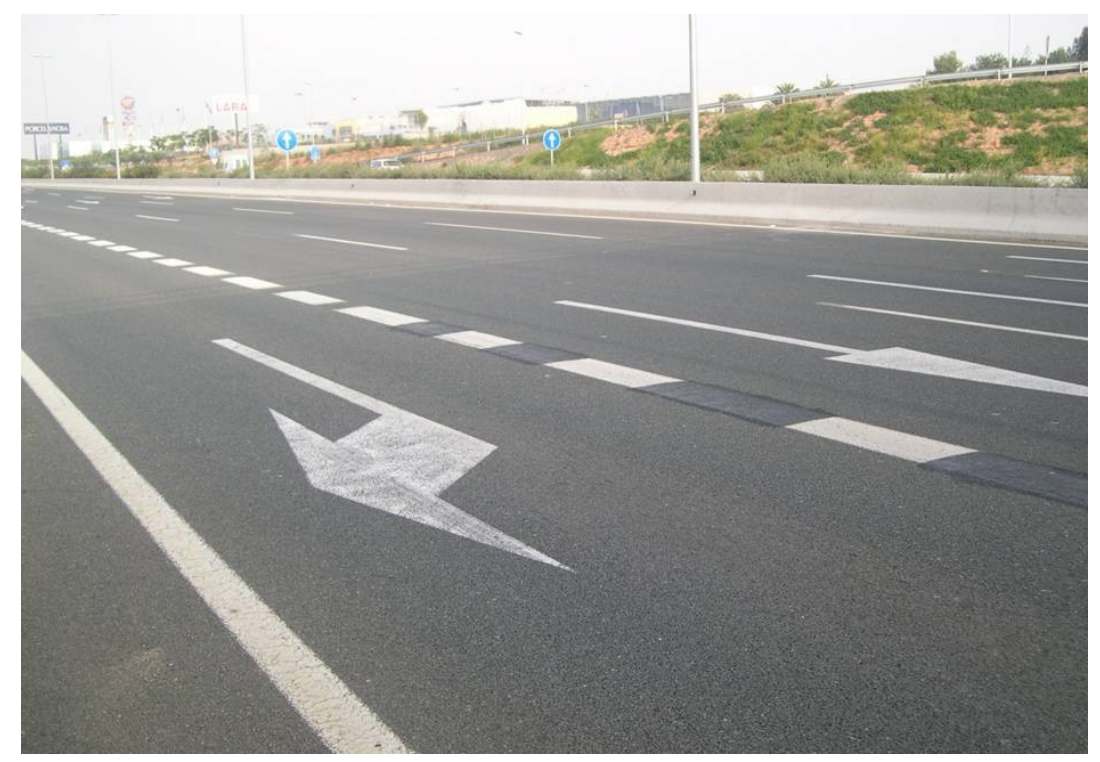

Figura 80: Línea discontinua antes de la nariz 
Con la configuración uno, se pretendía estudiar el comportamiento de los vehículos en longitudes superiores a las estipuladas en la Instrucción de Trazado (1999), por lo que se utilizó la longitud máxima que corresponde a 395 metros, medidos desde el punto en que la cuña tiene un ancho de 1,5 metros hasta el punto en que la nariz de la salida tiene una anchura de 1 metro, con una longitud de cuña de 100 metros, que equivaldría, según la norma mencionada, a que la menor velocidad entre la limitada a la altura de la sección característica de $1,5 \mathrm{~m}$ de ancho y la velocidad del proyecto fuese de $127 \mathrm{Km} / \mathrm{h}$.

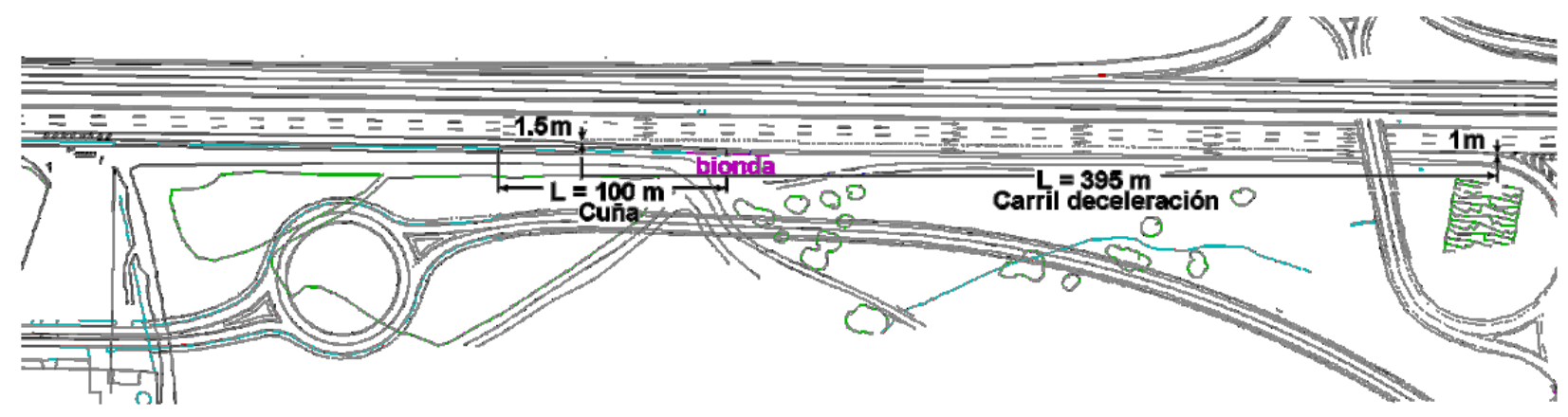

Figura 81: Configuración 1 carril de deceleración de longitud máxima

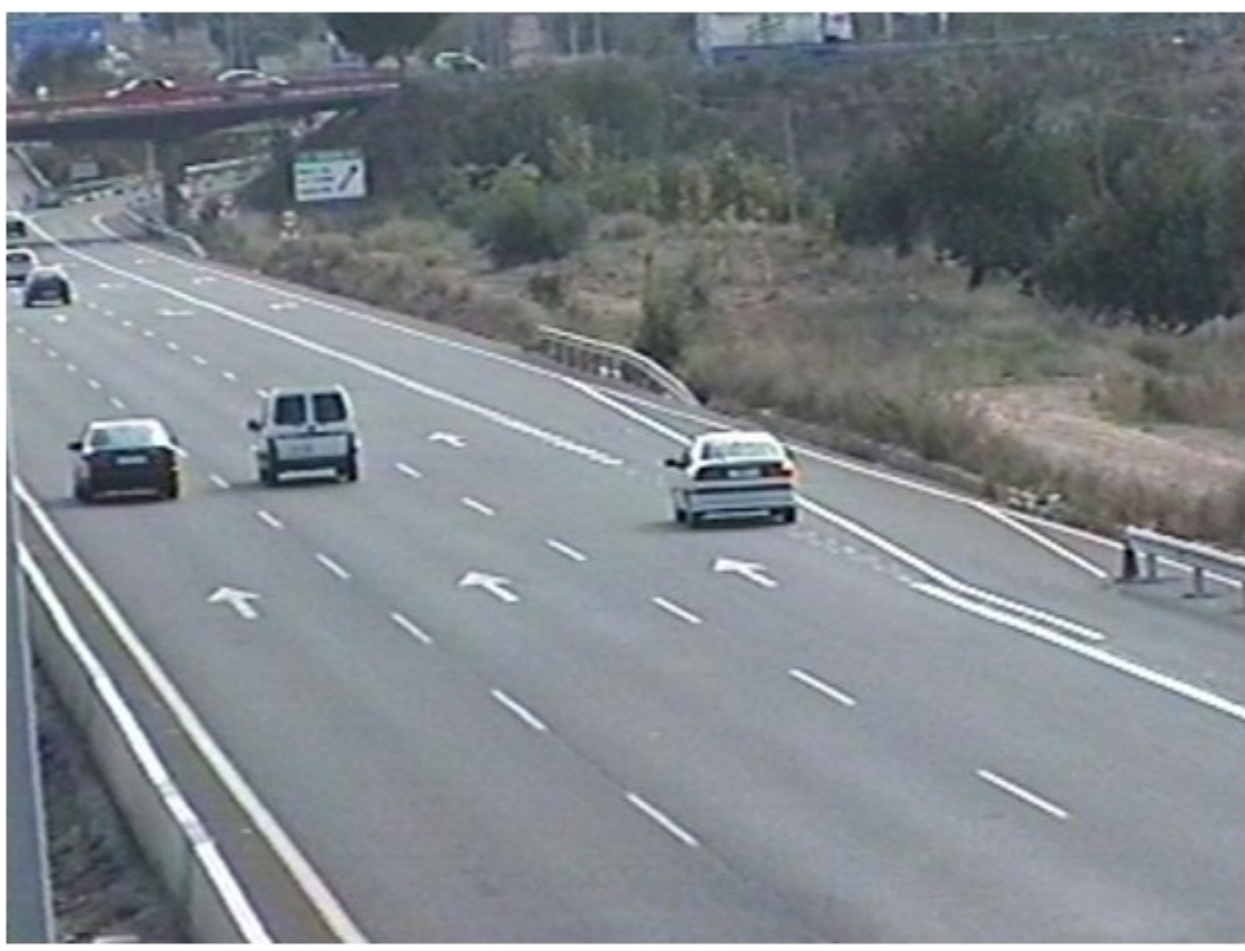

Figura 82: Fotografía configuración 1

Para la configuración 2, se tomó una longitud del carril correspondiente a $285 \mathrm{~m}$, calculada a partir de una velocidad de $120 \mathrm{Km} / \mathrm{h}$ y una salida a velocidad de $40 \mathrm{Km} / \mathrm{h}$ con un $-2 \%$ de pendiente y con una longitud de cuña de 100 metros. 


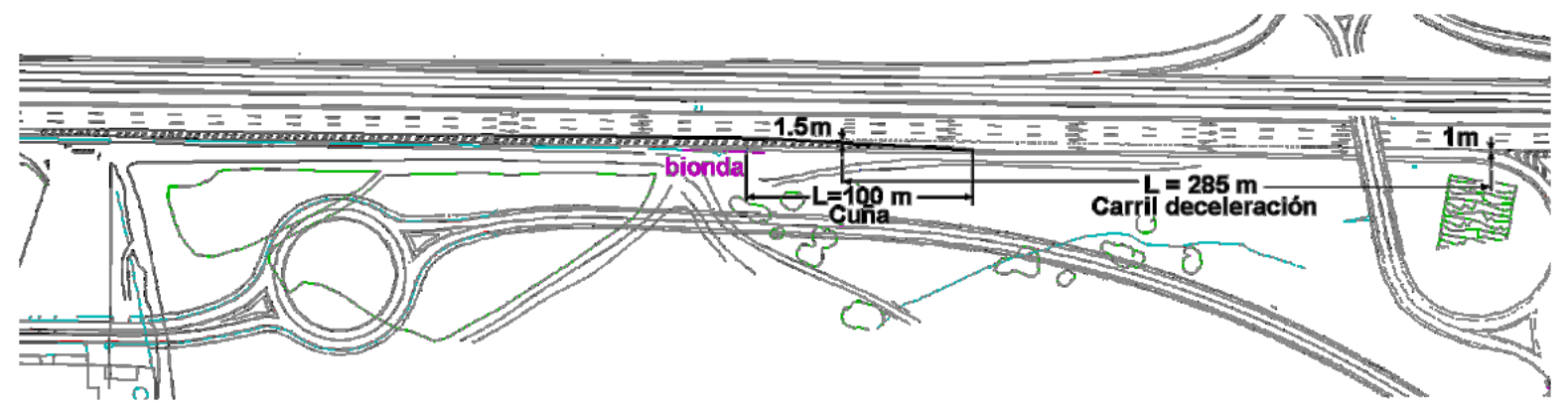

Figura 83: Configuración 2 - carril de deceleración de longitud 285 m

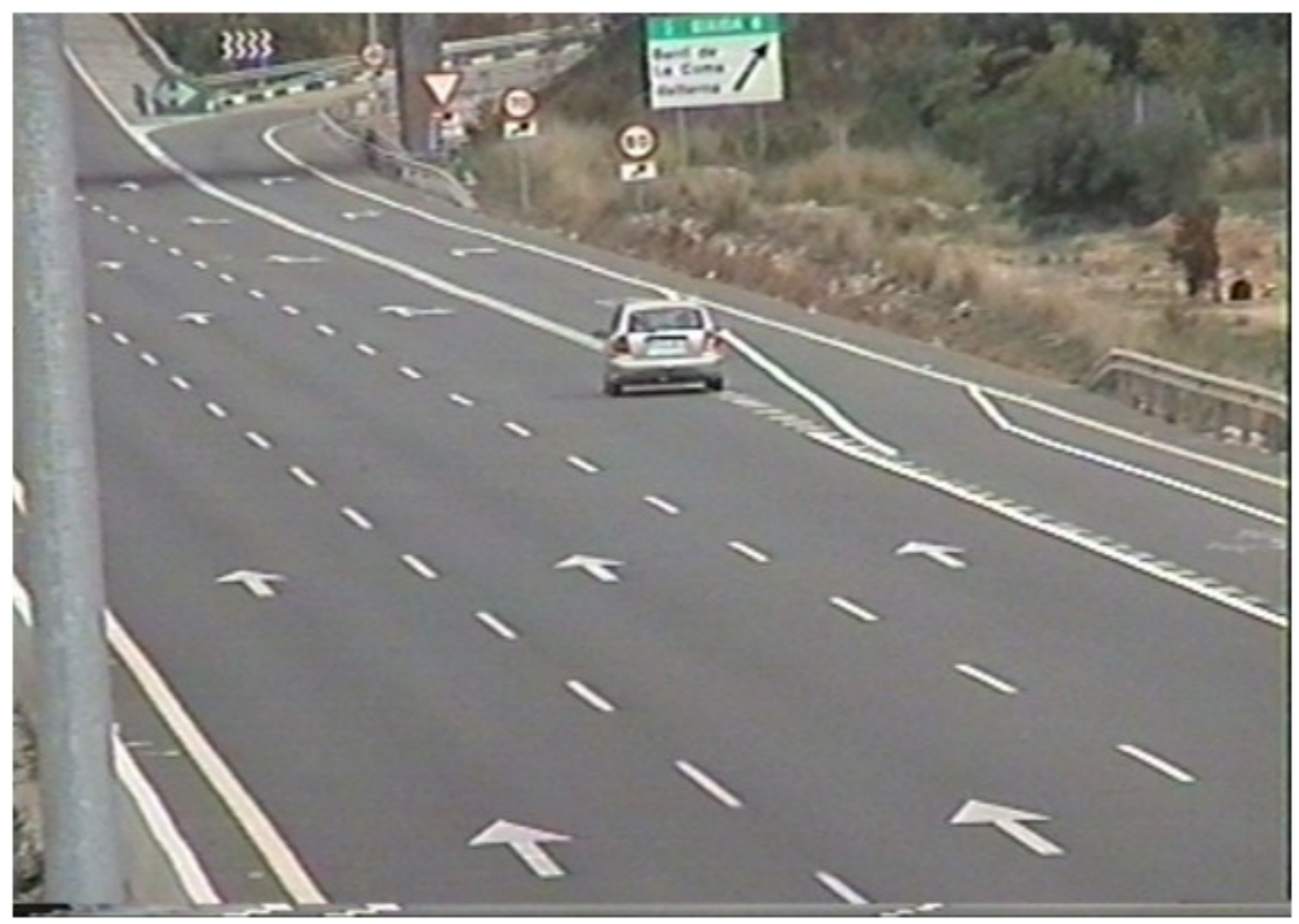

Figura 84: Fotografía configuración 2

Como configuración 3 se tomó una longitud del carril de $187 \mathrm{~m}$, calculada a partir de una velocidad de $100 \mathrm{Km} / \mathrm{h}$ y una salida a velocidad de $40 \mathrm{Km} / \mathrm{h}$ con la misma pendiente y con una longitud de cuña de 83 metros. 


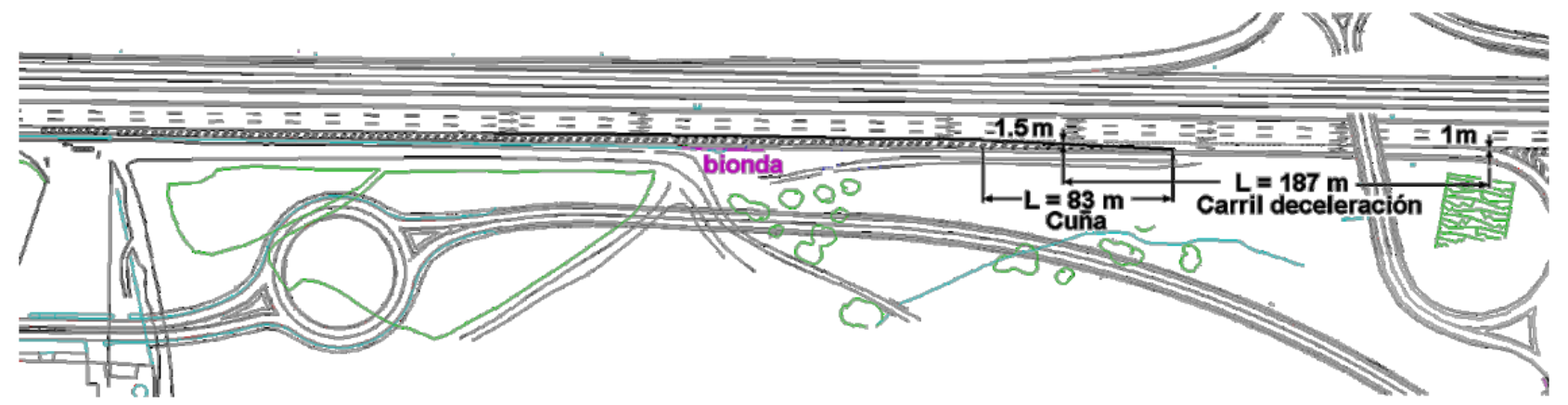

Figura 85: Configuración 3 - carril de deceleración de longitud 187 m

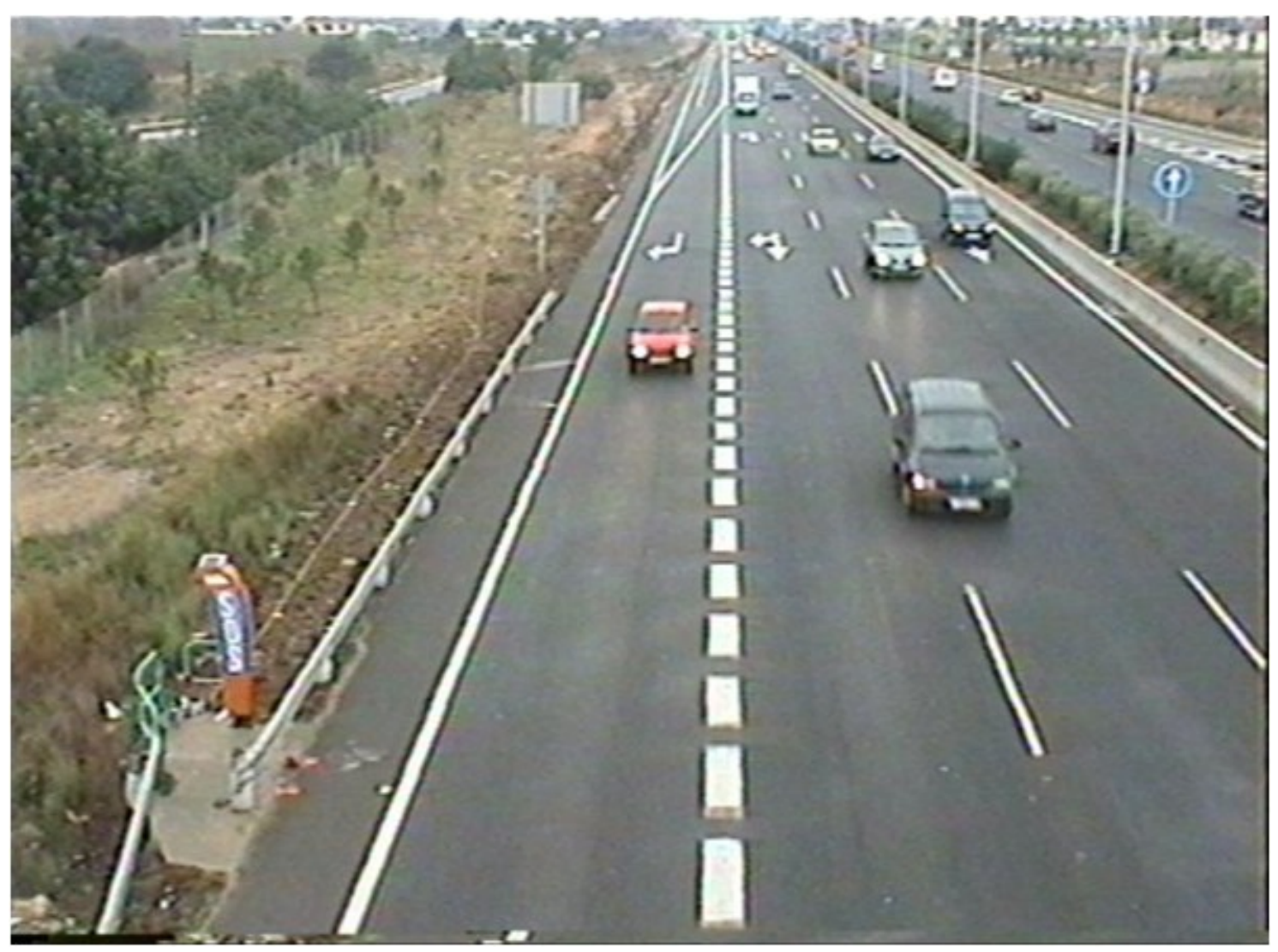

Figura 86: Fotografía configuración 3

Como configuración 4 se tomó una longitud del carril de a 107 m, calculada a partir de una velocidad de $80 \mathrm{Km} / \mathrm{h}$ y una salida a velocidad de $40 \mathrm{Km} / \mathrm{h}$ con la misma pendiente y una longitud de cuña de $70 \mathrm{~m}$. 


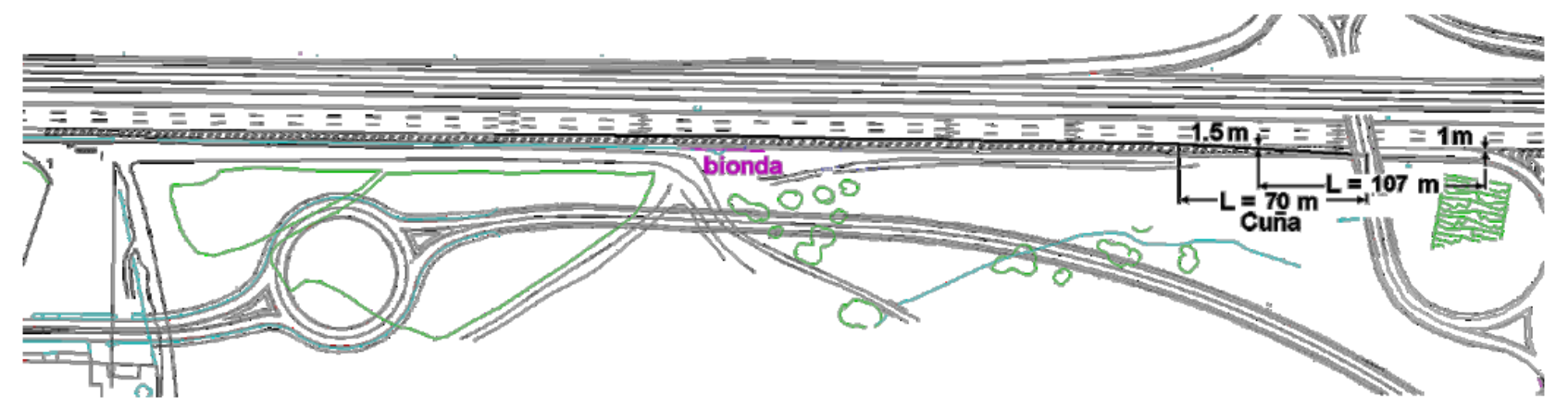

Figura 87: Configuración 4 - carril de deceleración de longitud 107 m

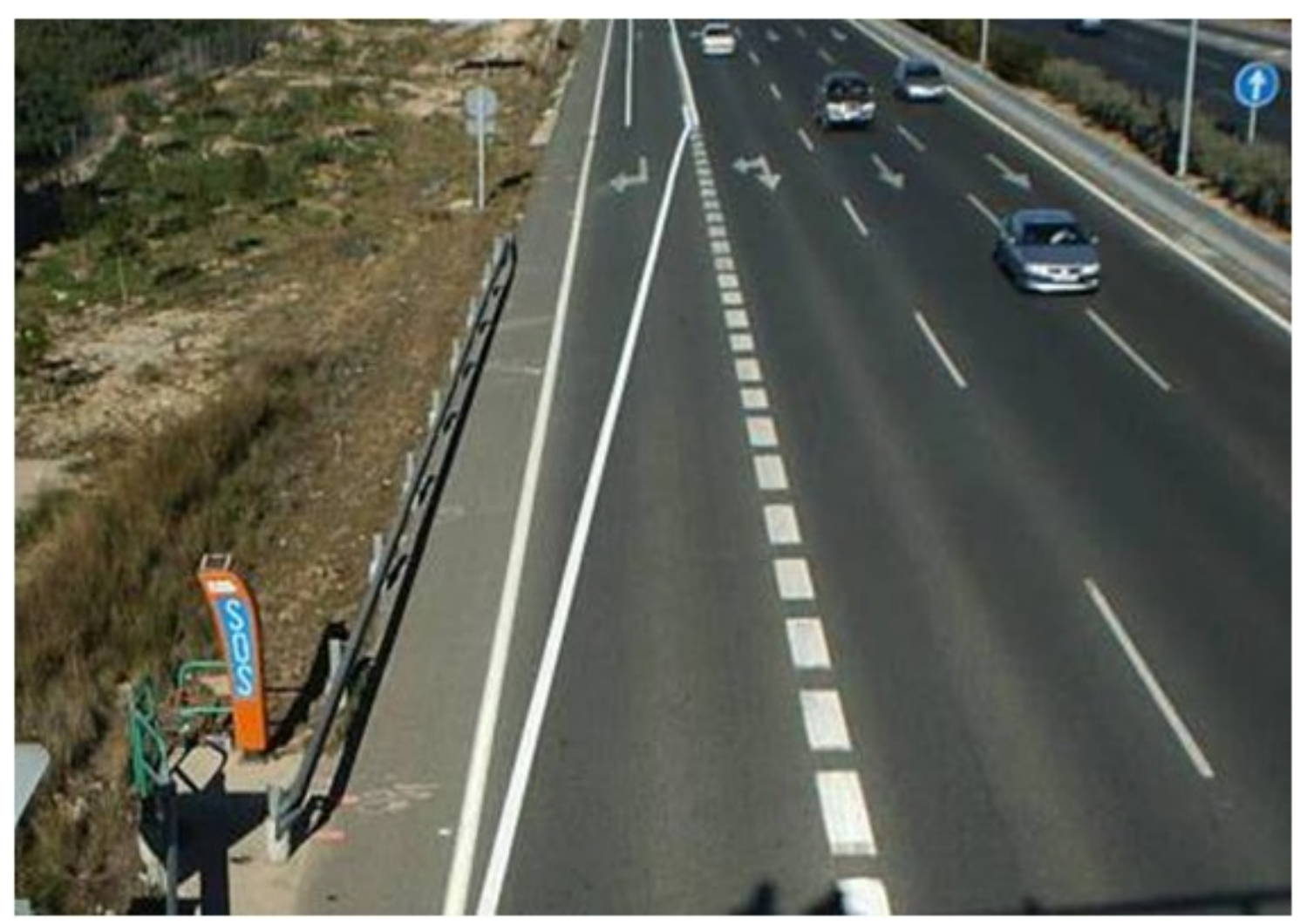

Figura 88: Fotografía configuración 4

Finalmente, se evaluó la configuración definitiva, equivalente a la primera configuración, pero adicionando una bionda para conformar el arcén a lo largo de la cuña, y de esa forma evaluar el efecto que tiene la colocación de la bionda frente a la demarcación provisional. 


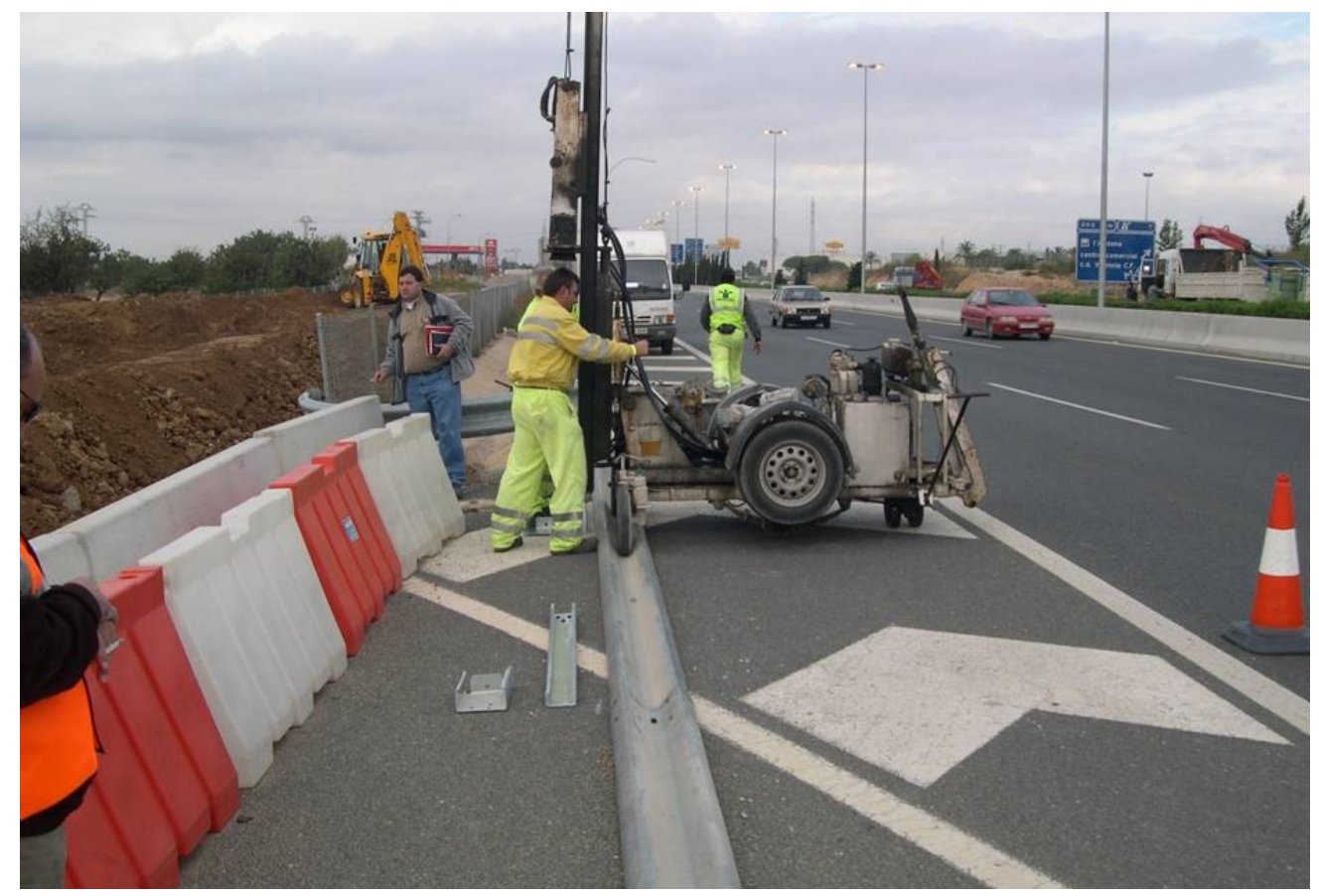

Figura 89: Colocación de bionda

Como configuración definitiva se toma una configuración equivalente a la primera configuración, pero adicionando una bionda para conformar el arcén a lo largo de la cuña.

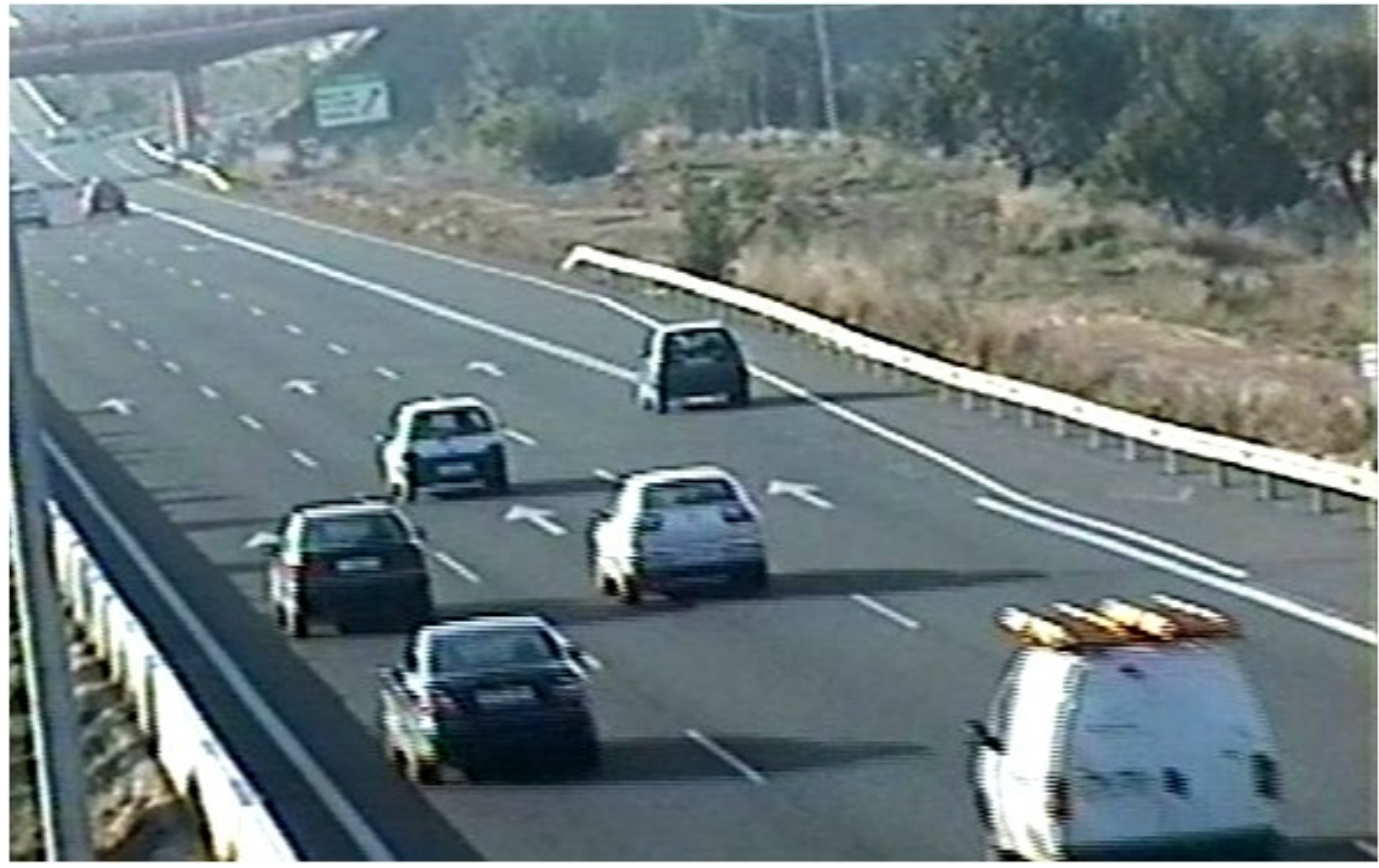

Figura 90: Fotografía configuración final 


\subsection{Fase de comprobación}

Aprovechando las cámaras con que cuenta la DGT en su Centro de Control de Valencia se ha desarrollado la segunda fase de toma de datos para evaluar el comportamiento de los vehículos en 10 carriles de deceleración existentes, cercanos a la ciudad de Valencia, con diversas longitudes cortas, medias y largas.

Las características de los carriles de deceleración que se han tenido en cuenta para el desarrollo de esta fase de comprobación son los siguientes:

- Debe existir una cámara del Centro de Gestión de Tráfico de Valencia que pueda enfocar la totalidad del carril.

- El volumen de tráfico debe ser tal que se pueda obtener un número razonable de maniobras de salida, tanto libres como condicionadas.

- El carril de deceleración debe estar, preferiblemente, en un tramo recto de la autovía.

De acuerdo con los requisitos antes mencionados, en la Tabla 44 se relacionan los carriles de deceleración seleccionados y sus características.

Tabla 44: Carriles de deceleración seleccionados para la fase de comprobación

\begin{tabular}{|l|c|c|c|c|}
\hline \multicolumn{1}{|c|}{ Carril } & $\begin{array}{c}\text { Longitud } \\
\mathbf{( m )}\end{array}$ & $\begin{array}{c}\text { Cuña } \\
\mathbf{( m )}\end{array}$ & $\begin{array}{c}\text { Radio de la } \\
\text { curva } \\
\mathbf{( m )}\end{array}$ & $\begin{array}{c}\text { V específica } \\
\text { del ramal } \\
\mathbf{( k m / h )}\end{array}$ \\
\hline A3 - 3,51 & 80 & 34 & 30 & 30 \\
\hline A7 - 484 & 217 & 100 & 40 & 40 \\
\hline V21 - 14,3 a & 215 & 100 & 120 & 60 \\
\hline V21 - 14,3 b & 184 & 100 & 82 & 50 \\
\hline V21 - 5,1 & 187 & 83 & 60 & 40 \\
\hline V21 - 8,95 & 209 & 83 & 100 & 55 \\
\hline V30 - 4,9 & 88 & 70 & 60 & 40 \\
\hline V31 - 6,8 & 137 & 70 & 32,5 & 40 \\
\hline V31 - 8,5 & 100 & 70 & 32,5 & 40 \\
\hline V31 -9,8 & 229 & 100 & 180 & \\
\hline
\end{tabular}

Para determinar la duración de las grabaciones en vídeo de cada carril de esta fase se ha tenido en cuenta que al menos 250 vehículos hagan la maniobra de salida y que como mínimo sea de 1 hora de duración.

Las características detalladas de los carriles de deceleración seleccionados pueden verse en el Anexo No. 2. 


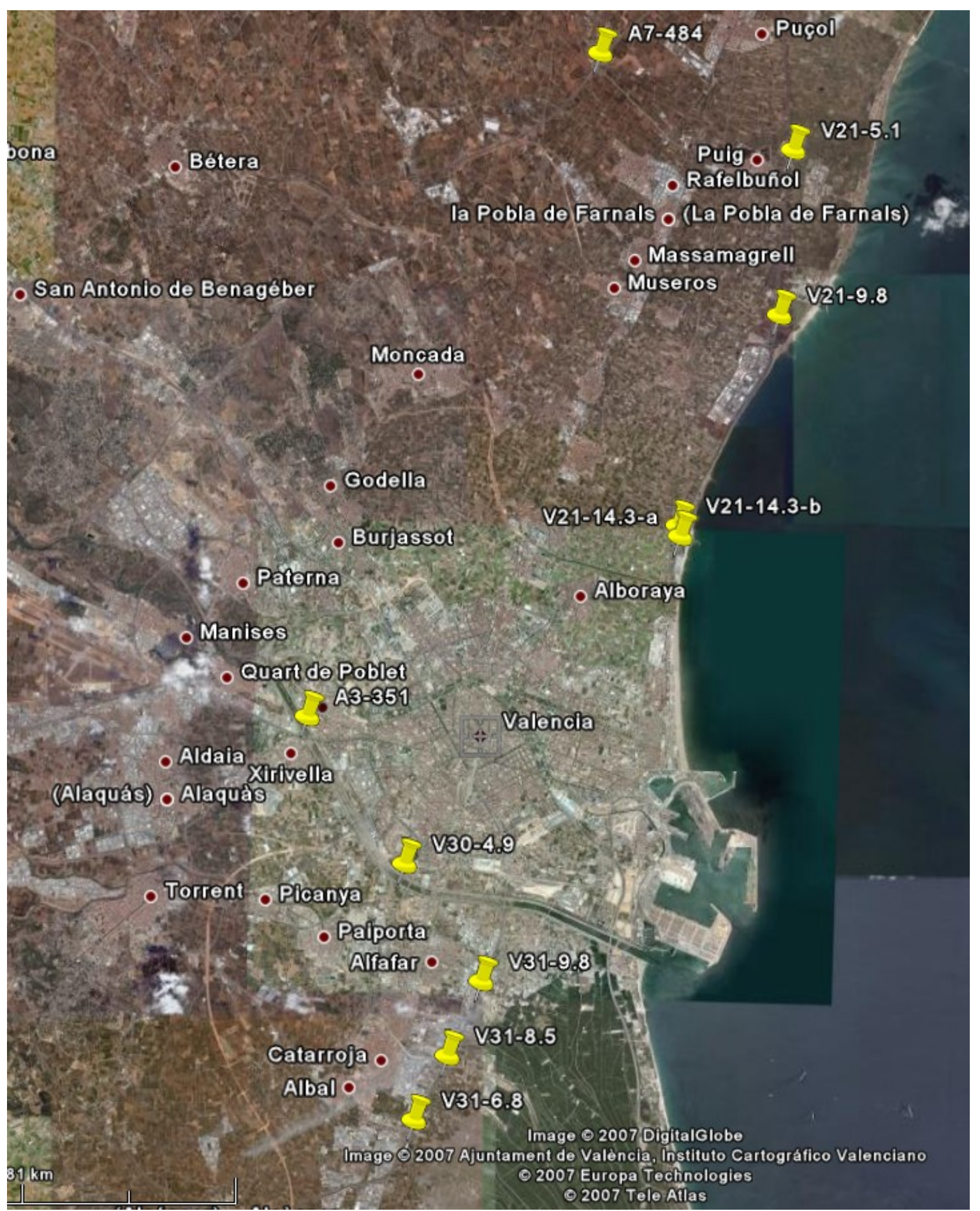

Figura 91: Plano de situación de los carriles de deceleración

\subsubsection{Instalación de las configuraciones fase experimental}

Para variar la longitud del carril de deceleración en cada configuración experimental se utilizó cinta adhesiva retirable, de color blanco. Se demarcó la línea de borde de calzada y la cuña. Una vez concluida la fase experimental, se retiró esta cinta y se procedió a la señalización definitiva. 


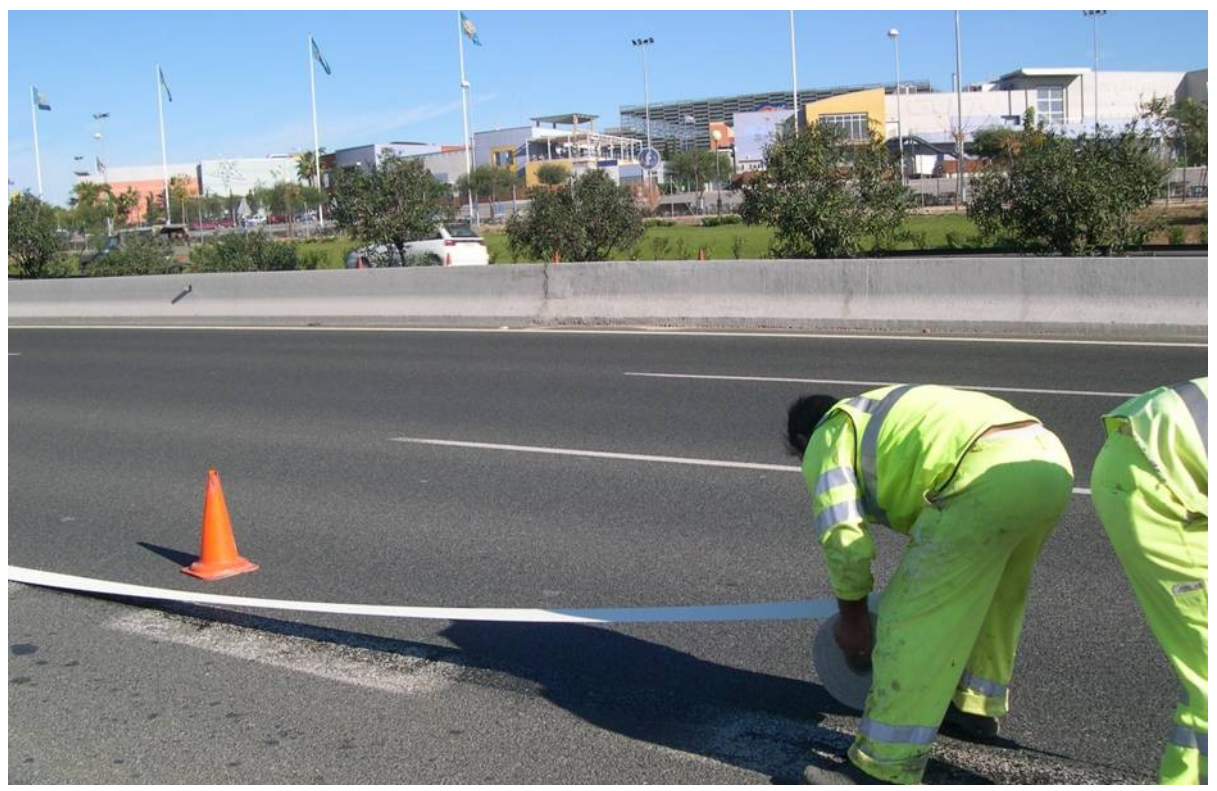

Figura 92: Utilización de cinta para la señalización provisional

Adicionalmente, para la configuración 1 y para la configuración final, se prolongó la barrera metálica de seguridad por el borde del arcén, como se puede observar en la Figura 93. Para las demás configuraciones el borde de arcén se demarcó con cinta adhesiva de $0,10 \mathrm{~m}$ de ancho.

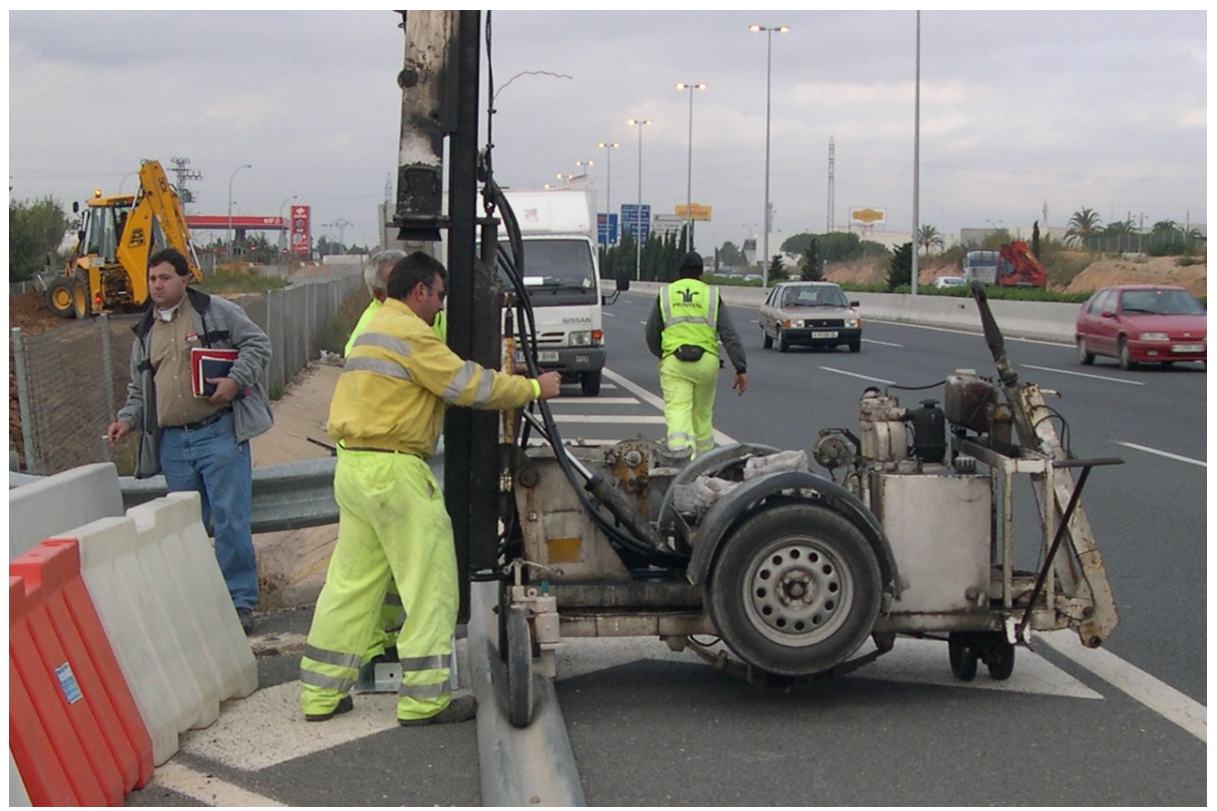

Figura 93: Colocación de la barrera de seguridad

De acuerdo con la Instrucción de Carreteras 8.2-IC, la línea de borde debe tener un ancho de $0,20 \mathrm{~m}$, de modo que fue necesario fresar la línea discontinua de $0,40 \mathrm{~m}$ de ancho y colocar cinta adhesiva para hacer esta señalización. Asimismo fue necesario fresar la señalización existente que pudiera condicionar el comportamiento de los conductores (Figura 94). 


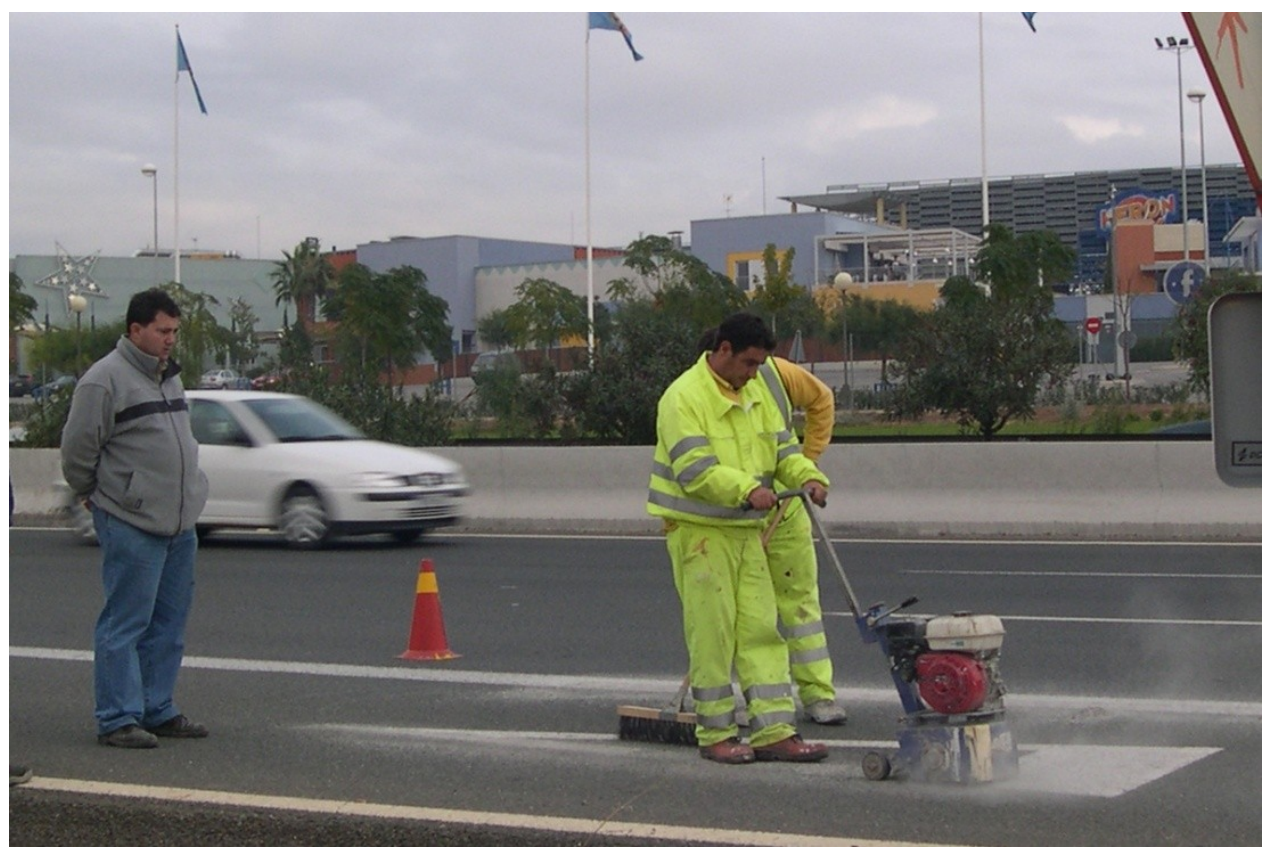

Figura 94: Fresado de la señalización existente

Teniendo en cuenta que la longitud de la línea continua de separación del carril de deceleración, antes de llegar a la nariz, podría afectar al comportamiento de los conductores en la configuración más corta, se decidió acortar su longitud dejando 30 $\mathrm{m}$ de línea continua y convirtiendo los $35 \mathrm{~m}$ restantes en discontinuos. De esta manera se evita introducir una variable adicional en la fase de experimentación.

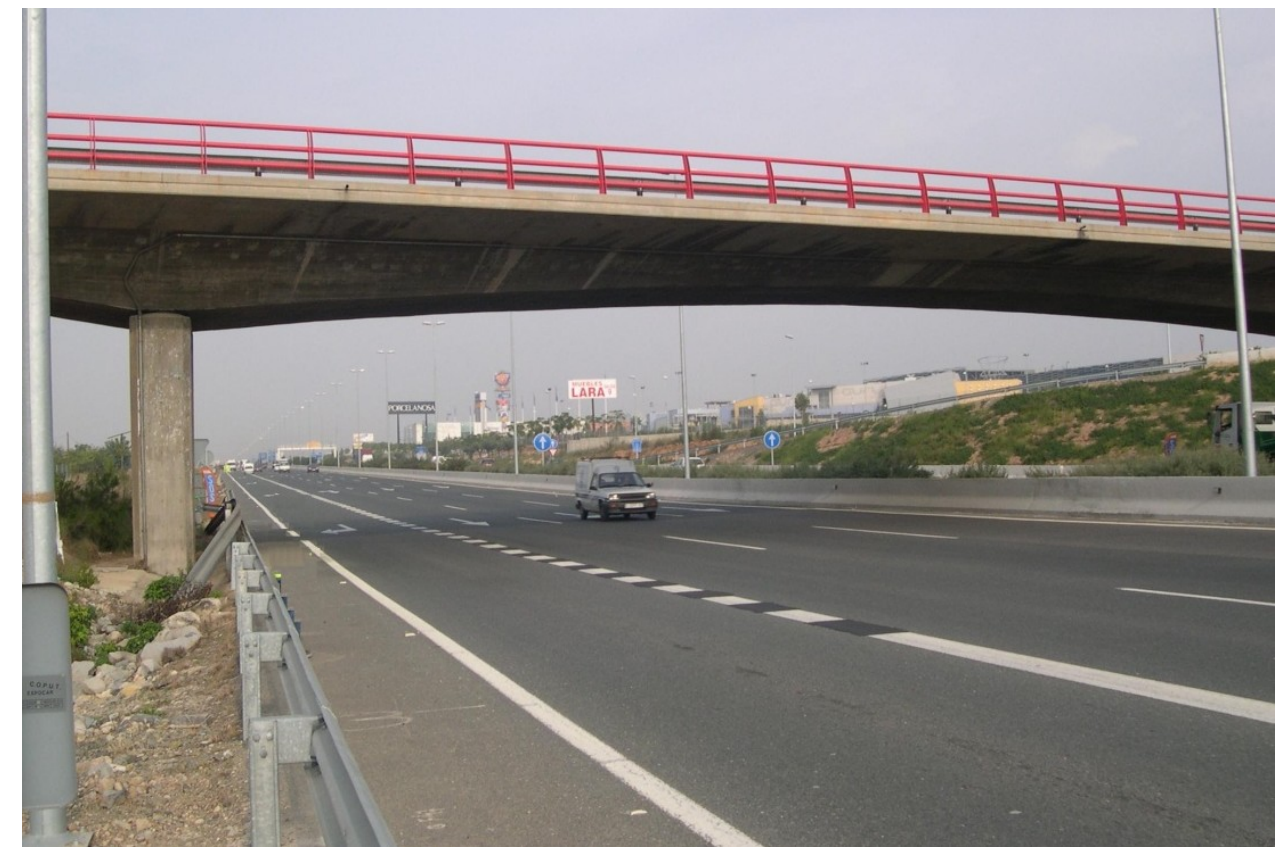

Figura 95: Línea continua antes de llegar a la nariz

Finalmente es importante señalar que durante la fase de comprobación no se realizó ninguna intervención en los carriles de deceleración seleccionados. 


\subsubsection{Toma de datos de campo}

A continuación se describe el procedimiento seguido para la toma de datos tanto en la fase experimental como en la fase de comprobación.

\subsubsection{Toma de datos fase experimental}

Durante esta fase, la recolección de información in situ se hizo mediante filmación en vídeo desde 4 puntos simultáneos para abarcar todo el tramo. Los vídeos fueron tomados entre las 8:30 a.m. y las 11:30 a.m. Durante este periodo se presentan las diferentes situaciones de tráfico, para cada una de las 6 configuraciones del carril de deceleración. Así, se pudo evaluar situaciones de alta densidad de tráfico al principio de las mañanas y situaciones de flujo libre posteriormente.

Las cámaras se ubicaron de manera distinta en función de la longitud del carril de deceleración, con el fin de lograr la completa restitución de la evolución de los vehículos.

En la configuración inicial y en la configuración 1, se ubicó una cámara en un pórtico de panel de señalización variable situado en la calzada de sentido contrario a $125 \mathrm{~m}$ del inicio de la cuña que grabó los vehículos desde atrás y una segunda cámara en el mismo sitio pero enfocando transversalmente con el fin de medir las velocidades puntuales de los vehículos en la vía. Las otras cámaras se ubicaron en un puente que precede la salida, cada una en un lateral distinto del puente, grabando una frontalmente los vehículos y la otra posteriormente, de manera que la superposición de la restitución posterior de las dos imágenes permita conocer la evolución completa del vehículo, integrando la evolución en la parte oculta posteriormente.

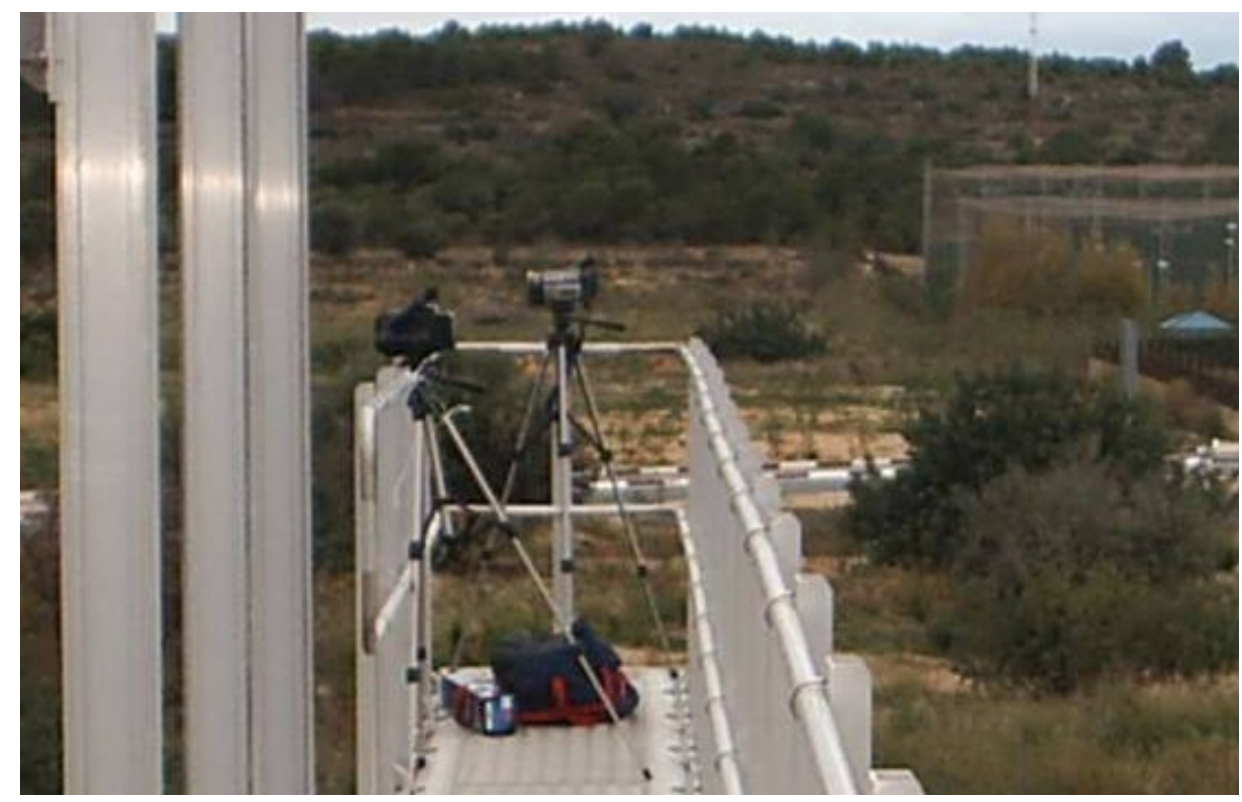

Figura 96: Ubicación de cámaras en el pórtico 


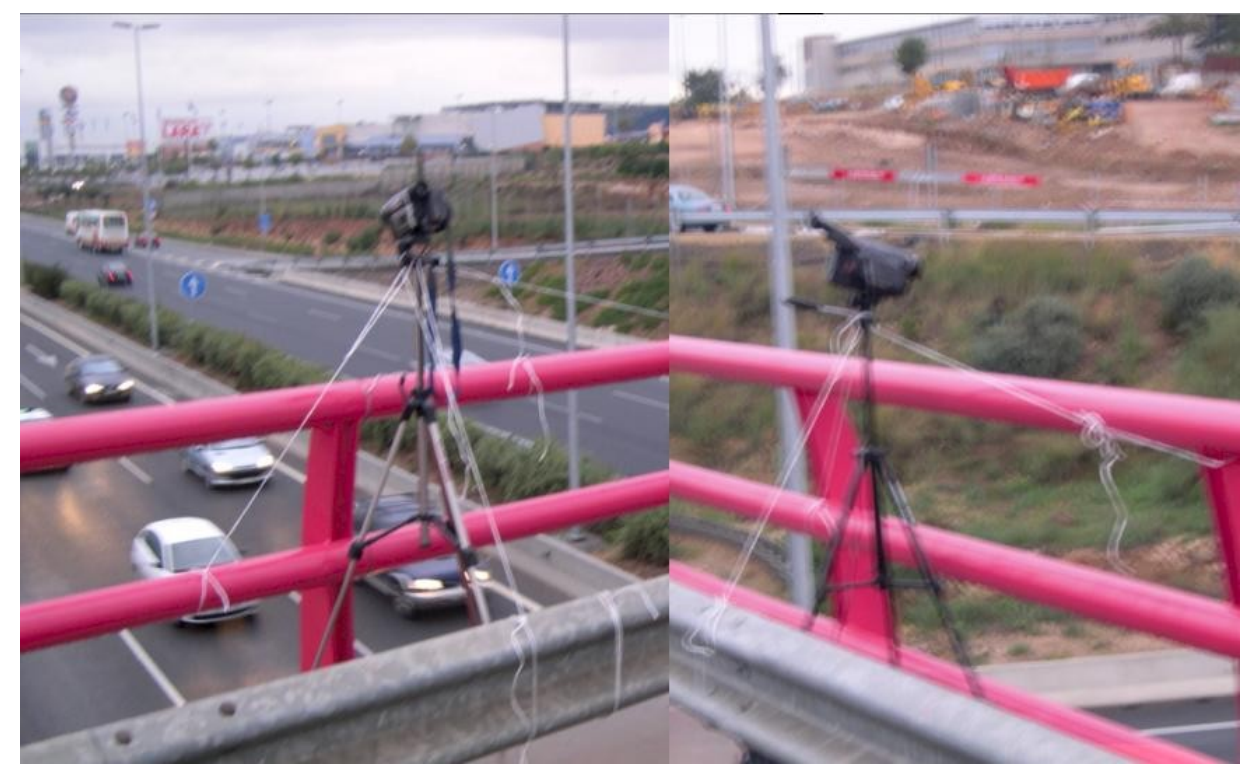

Figura 97: Ubicación de cámaras en el puente

En la segunda configuración la ubicación de las cámaras es la misma de la primera configuración, variando únicamente el punto de enfoque de la cámara 2 para tomar las velocidades puntuales en el punto ubicado $125 \mathrm{~m}$ antes del inicio de la cuña.

En la tercera configuración se modificó, con respecto a la configuración precedente, la ubicación de la cámara 1, que se colocó en la nariz de la salida siempre con el fin de conseguir la evolución completa del vehículo cubriendo la parte del escenario situado debajo del puente, y la ubicación de la cámara 2, que se colocó sobre el puente enfocando la vía en el punto situado a $125 \mathrm{~m}$ del inicio de la cuña, siempre con el fin de medir velocidades previas puntuales en la vía principal.

En la cuarta configuración, la ubicación de las cámaras fue similar a la de la tercera configuración, excepto que solo fue necesario utilizar una cámara enfocando frontalmente sobre el puente para obtener las velocidades puntuales y la evolución de los vehículos. 


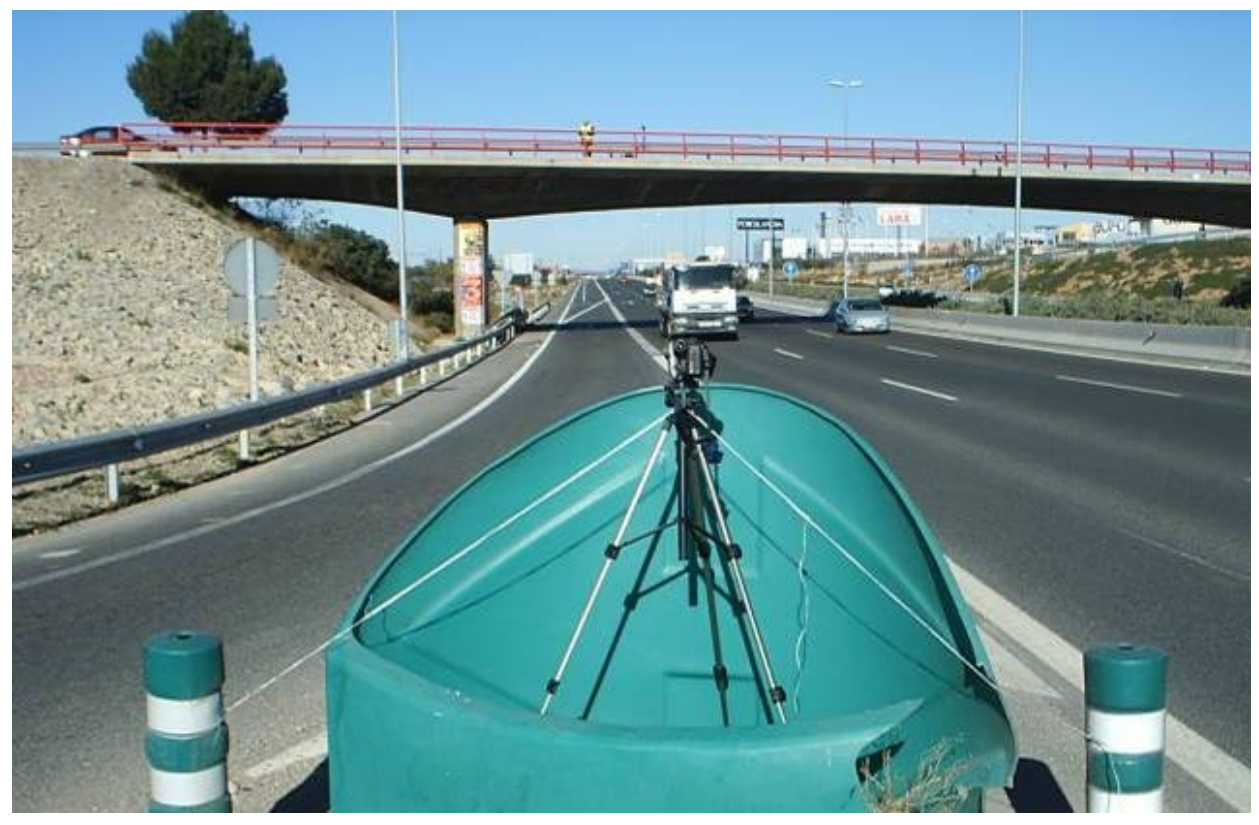

Figura 98: Ubicación de la cámara en la nariz

Para la determinación del punto donde frenan los vehículos, en la fase experimental, se colocó una señal luminosa activada a distancia, mediante un pulsador, cuando se encendían las luces del freno lo cual se puede apreciar en el vídeo y referenciar de esta forma la maniobra de frenado.

\subsubsection{Toma de datos fase de comprobación}

En la fase de comprobación, la recolección de información in situ se hizo mediante filmación en vídeo utilizando las cámaras del Centro de Control de Tráfico de Valencia, de la Dirección General de Tráfico. La Figura 99 muestra una de las cámaras utilizadas en la toma de datos.

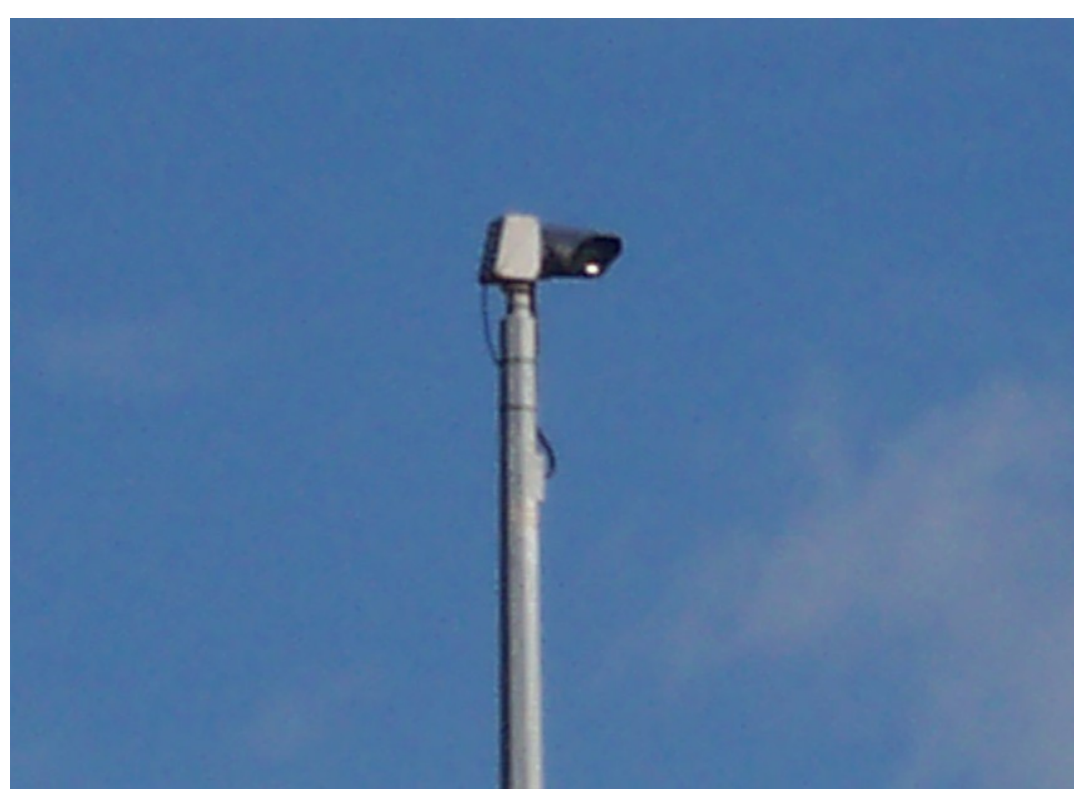

Figura 99 Cámaras de la DGT 
En cada una de los 10 carriles de deceleración seleccionados se realizo una filmación de vídeo de por lo menos 1 hora en la cual se garantizara que al menos se realizaran 250 maniobras de salida.

Se prestó especial atención a la selección de los carriles de modo que la cámara de la DGT pudiese enfocar la totalidad del carril para poder obtener la evolución completa de los vehículos, como se puede observar en la Figura 100.

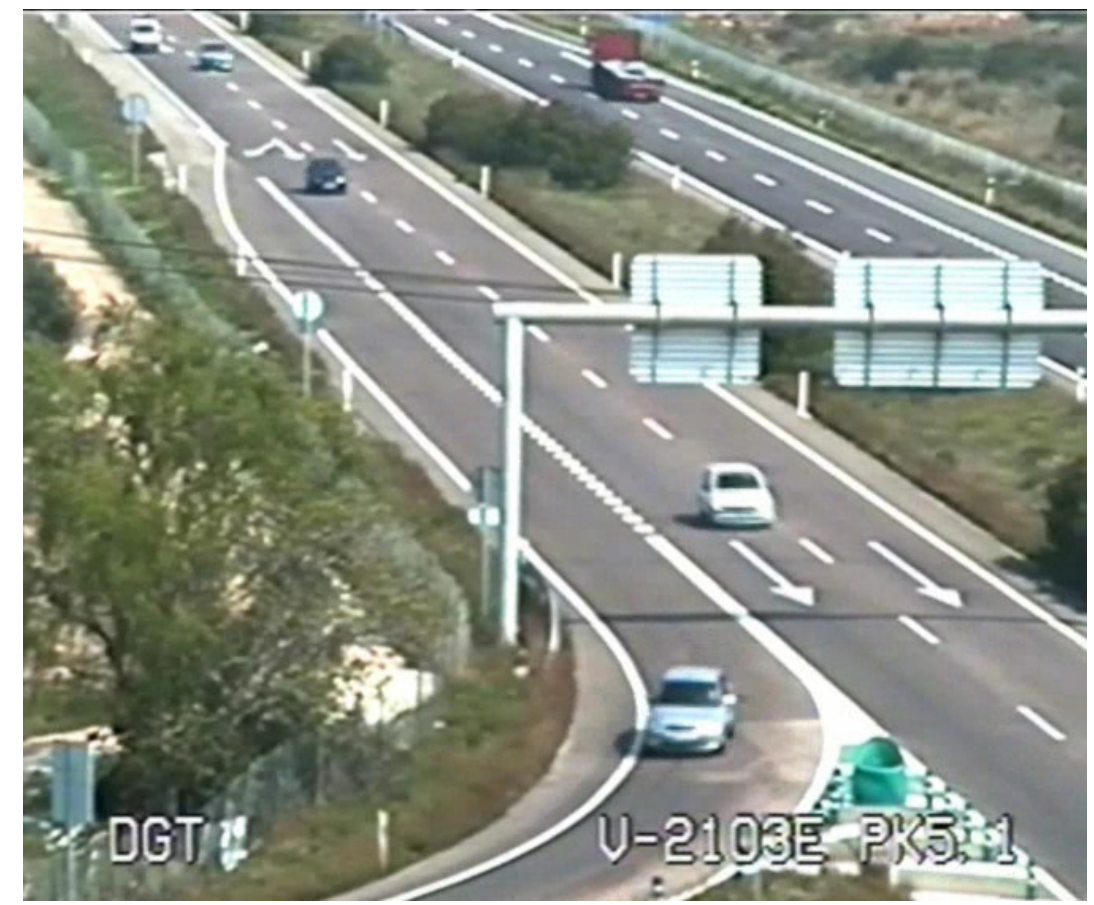

Figura 100 Imagen de una de las cámaras de la DGT

\subsection{REDUCCIÓN DE DATOS}

En la investigación, la reducción de datos está dividida en dos niveles. En primer lugar, la reducción de datos para la evaluación cualitativa y en segundo lugar la reducción de datos para la evaluación cuantitativa.

\subsubsection{Evaluación cualitativa}

En primer lugar, se realizó una evaluación cualitativa por observación directa de los vídeos con el fin de determinar las diferentes modalidades en el comportamiento de todos los vehículos que proceden a abandonar la vía por completo.

Las modalidades de maniobras encontradas que conllevan cierto riesgo de colisión se clasifican en los siguientes cinco tipos principales:

- Salida cuyo origen es uno de los carriles rápidos.

- Maniobras de adelantamiento durante la salida.

- Maniobras de reincorporación a la vía principal. 
- Salidas anticipadas.

- Salidas tardías.

En cuanto a los adelantamientos se han clasificado en tres tipos (Figura 101):

- Adelantamiento exterior, que corresponde a un vehículo que adelanta por la vía principal a otro que circula por la vía de deceleración y posteriormente sale.

- Adelantamiento interior no confluyente, que el vehículo que adelanta circula por el carril de deceleración y el que es adelantado continua por la vía principal.

- Adelantamiento interior confluyente, que se diferencia del anterior en que el vehículo que es adelantado sale.
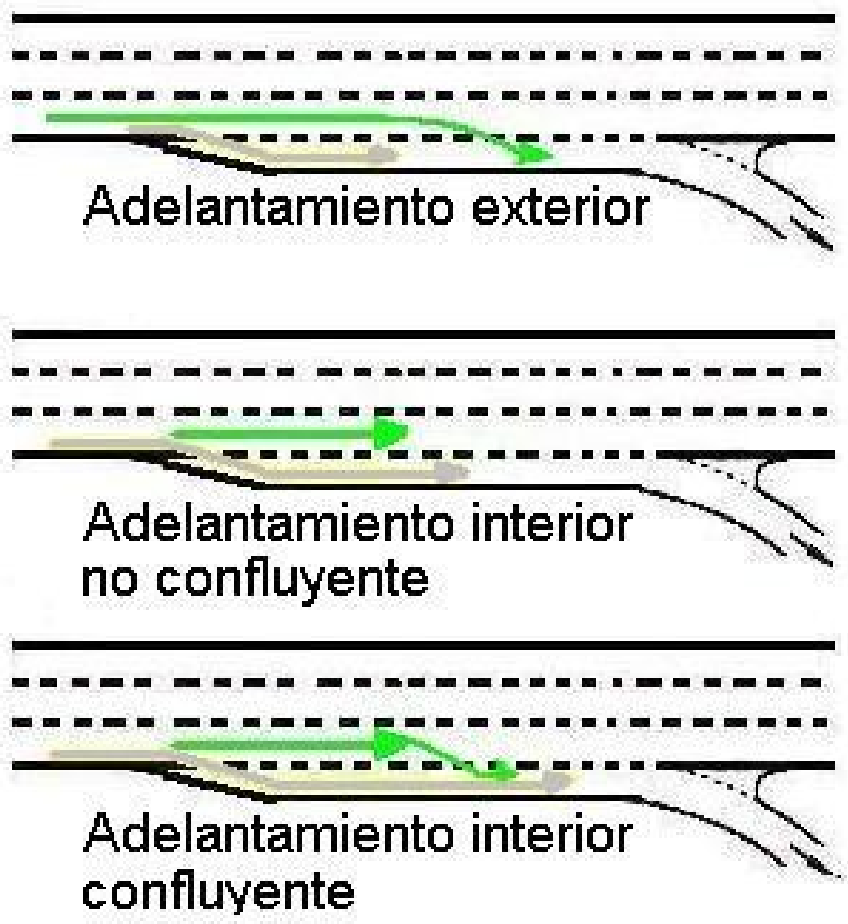

Figura 101: Tipos de maniobras de salida con adelantamiento

A partir de la clasificación desarrollada, se realizó un inventario de maniobras, tanto para cada configuración experimental, como para cada carril de la fase de comprobación.

Se diferenció el tipo de tráfico entre vehículos pesados y vehículos ligeros y se puso particular atención en el tratamiento de los datos al considerar aquellos vehículos cuyo comportamiento se encuentra condicionado por los vehículos que le preceden.

Asimismo, se localizó, para todas las maniobras de salida, el punto en el que el vehículo abandona la vía principal, diferenciando en los siguientes sectores:

- Salida anticipada

- Salida en la cuña

- Salida intermedia 
- Salida tardía.

Posteriormente, los resultados de la evaluación cualitativa se analizan estadísticamente para verificar la relación existente entre el comportamiento observado y las características del carril de deceleración mediante la utilización de modelos de regresión.

\subsubsection{Evaluación cuantitativa}

La evaluación cuantitativa se realizó en dos niveles: evaluación de las maniobras libres para caracterizar la evolución de los vehículos en función de la longitud del carril de deceleración y la evaluación de la conflictividad mediante la aplicación del indicador de conflictividad desarrollado, a todos los vehículos que salen en un periodo de tiempo determinado.

\subsubsection{Evaluación de las maniobras libres}

En la evaluación cuantitativa de las maniobras libres se pretende medir las características de la evolución de los vehículos en función de la longitud del carril de deceleración, en cuanto a la trayectoria, la velocidad en diferentes puntos, las aceleraciones y las deceleraciones.

Para ello se seleccionaron, de cada configuración y de cada carril de deceleración, 50 vehículos ligeros que estuviesen a flujo libre en el momento de la salida, seleccionando los vehículos cuyo intervalo con relación al vehículo precedente fuera superior a $5 \mathrm{~s}, \mathrm{y}$ que el carril de deceleración estuviese también libre para que la maniobra de salida no estuviese condicionada ni en la vía principal ni durante la maniobra de salida.

Para lograrlo, se desarrolló un programa informático de restitución de perspectivas cónicas que, a partir de los vídeos digitalizados, obtiene la posición de los vehículos en cada cuadro de la imagen. Con ello se obtienen las trayectorias y se calculan las velocidades y aceleraciones en dichos puntos utilizando derivadas numéricas.

En el apartado 6.2.3 se describe la técnica de restitución de maniobras utilizada y en el apartado 6.2.4 se presenta una descripción de la aplicación informática desarrollada.

\subsubsection{Evaluación de la conflictividad}

Con el fin de poder valorar adecuadamente la conflictividad de las maniobras, en los diferentes carriles de deceleración y en las configuraciones experimentales se utilizaron las Técnicas de Conflictos de Tráfico considerando todos los vehículos que salen durante un periodo de una hora junto con todos los vehículos de alrededor que pudieran entrar en conflicto con ellos.

Para este análisis se utilizó una nueva familia de indicadores de conflictividad denominada TiPCLA (Tiempo Potencial de Colisión Lateral o Alcance), que se presenta en el numeral 0 .

Este indicador permite comparar cuantitativamente la seguridad del tráfico en dos situaciones diferentes, sin embargo, al ser un nuevo indicador, fue necesario validar 
sus resultados comparándolos con las estadísticas de accidentalidad de tráfico de los años 2004 al 2007, en las mismas localizaciones estudiadas.

Posteriormente se procede a evaluar la correlación entre los resultados del indicador TiPCLA y las características de los carriles de deceleración evaluados mediante la utilización de modelos de regresión.

\subsubsection{Evaluación de la accidentalidad}

Gracias al Servicio de Estadística del Observatorio Nacional de Seguridad Vial de la Dirección General de Tráfico, se han obtenido los datos de accidentalidad, tanto los accidentes con solo daños materiales cómo los accidentes con víctimas, que incluyen heridos leves, heridos graves y muertos.

Es importante resaltar que se han tomado los accidentes ubicados en los puntos kilométricos correspondientes a los carriles de deceleración, entre los $400 \mathrm{~m}$ antes de la cuña y los 320 metros después de la nariz, tal como lo comprobó Cirilo (1967).

Estos datos permiten, en primer lugar, evaluar la accidentalidad en función de las características geométricas de los carriles estudiados y, en segundo lugar, validar los resultados del indicador de conflictividad desarrollado.

Los datos de accidentalidad se analizan estadísticamente para verificar la relación existente entre diferentes índices de accidentalidad y las características del carril de deceleración mediante la utilización de modelos de regresión.

\subsubsection{Restitución de maniobras}

Una vez realizadas y digitalizadas las filmaciones se han procesado por medio de una aplicación informática desarrollada empleando técnicas de restitución de perspectiva cónicas por medio de una doble homología.

A continuación se describen las técnicas utilizadas para restituir la posición de los vehículos, para calcular sus parámetros cinemáticos y las técnicas utilizadas para facilitar esta labor.

\subsubsection{Restitución de la posición de los vehículos}

La restitución utilizando perspectiva cónica permite la reconstrucción a escala de la planta y el alzado de un objeto con la ayuda del conocimiento de su forma y de alguna de sus medidas, mediante las relaciones de homología existentes entre una figura plana y su perspectiva.

Los fotogramas de la vía, obtenidos a partir del vídeo, serán perspectivas de cuadro inclinado, con tres direcciones principales de fuga, donde, para hacer la restitución, se convierte el trapezoide correspondiente al tramo de vía en un rectángulo, a través de dos homologías consecutivas, sin necesidad de calcular el centro de la homología, sino a partir de dos medidas de la planta (ancho y largo). 
Para realizar la restitución, mediante el empleo de esta técnica de doble homología, es necesario definir únicamente 4 puntos de referencia. No obstante, con el fin de aumentar la precisión es posible definir un número mayor de puntos, al igual que en el caso de realizar una restitución de una vía con cambio de pendiente.

Como sistema de referencia para la restitución se han utilizado las marcas viales, cuyas medidas y distancias se han determinado previamente in situ, lo que permite ubicar espacialmente las trayectorias de los vehículos en el procesamiento de los vídeos.

Como se observa en la Figura 102, en la primera homología se convierte el trapezoide de la imagen en un trapecio. En la segunda homología este trapecio se convierte en un rectángulo de dimensiones conocidas.

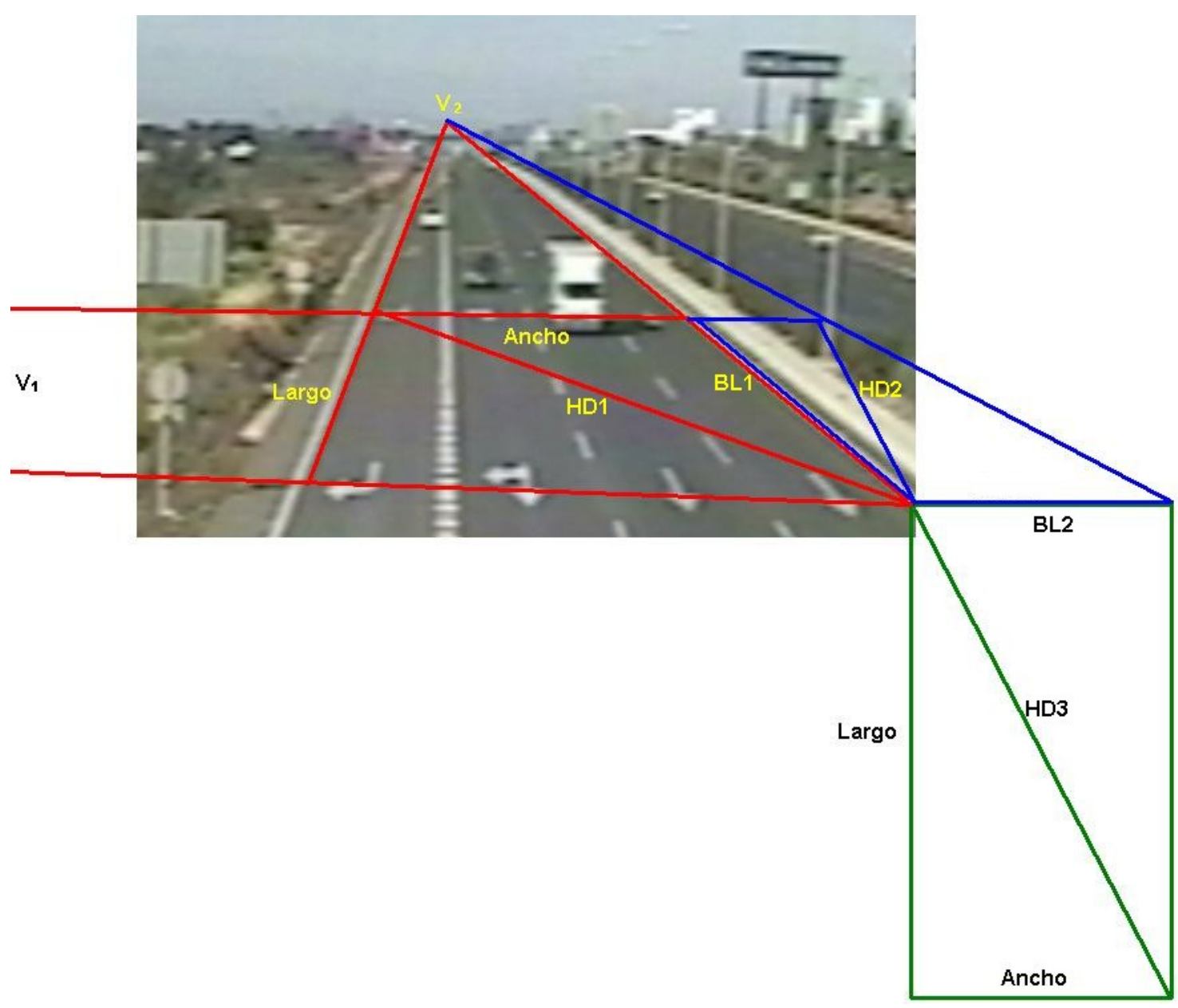

Figura 102: Homologías utilizadas en el programa

Para realizar el procedimiento de la doble homología, es necesario en primer lugar determinar los puntos de referencia. A continuación se determinan los puntos de fuga $\left(V_{1}\right.$ y $\left.V_{2}\right)$ encontrando la intersección de las líneas de referencia. 
Posteriormente, con las dimensiones de la vía, se construyen las líneas de base de las dos homologías (BL1 y BL2) así como las tres diagonales homológicas (HD1, HD2 y HD3) como se observa en la Figura 102.

El procedimiento para obtener las coordenadas reales de un punto en la imagen se resume en la Tabla 45 y la Figura 103.

Tabla 45: Restitución de puntos

\begin{tabular}{|c|c|c|c|c|c|}
\hline Línea & Desde & Hasta & Característica & $\begin{array}{c}\text { Encontrar } \\
\text { intersección con }\end{array}$ & $\begin{array}{c}\text { Define } \\
\text { nuevo punto }\end{array}$ \\
\hline L1 & V2 & P & & BL1 & P1 \\
\hline L2 & P1 & & Paralela a BL2 & HD2 & P2 \\
\hline L3 & V1 & P2 & & BL2 & P3 \\
\hline L4 & P3 & & Perpendicular a BL2 & HD3 & P4 \\
\hline L5 & V1 & P & & HD1 & P5 \\
\hline L6 & V2 & P5 & & BL1 & P6 \\
\hline L7 & P6 & & Paralela a BL2 & & P7 \\
\hline L8 & V1 & P7 & & BL2 & P8 \\
\hline
\end{tabular}




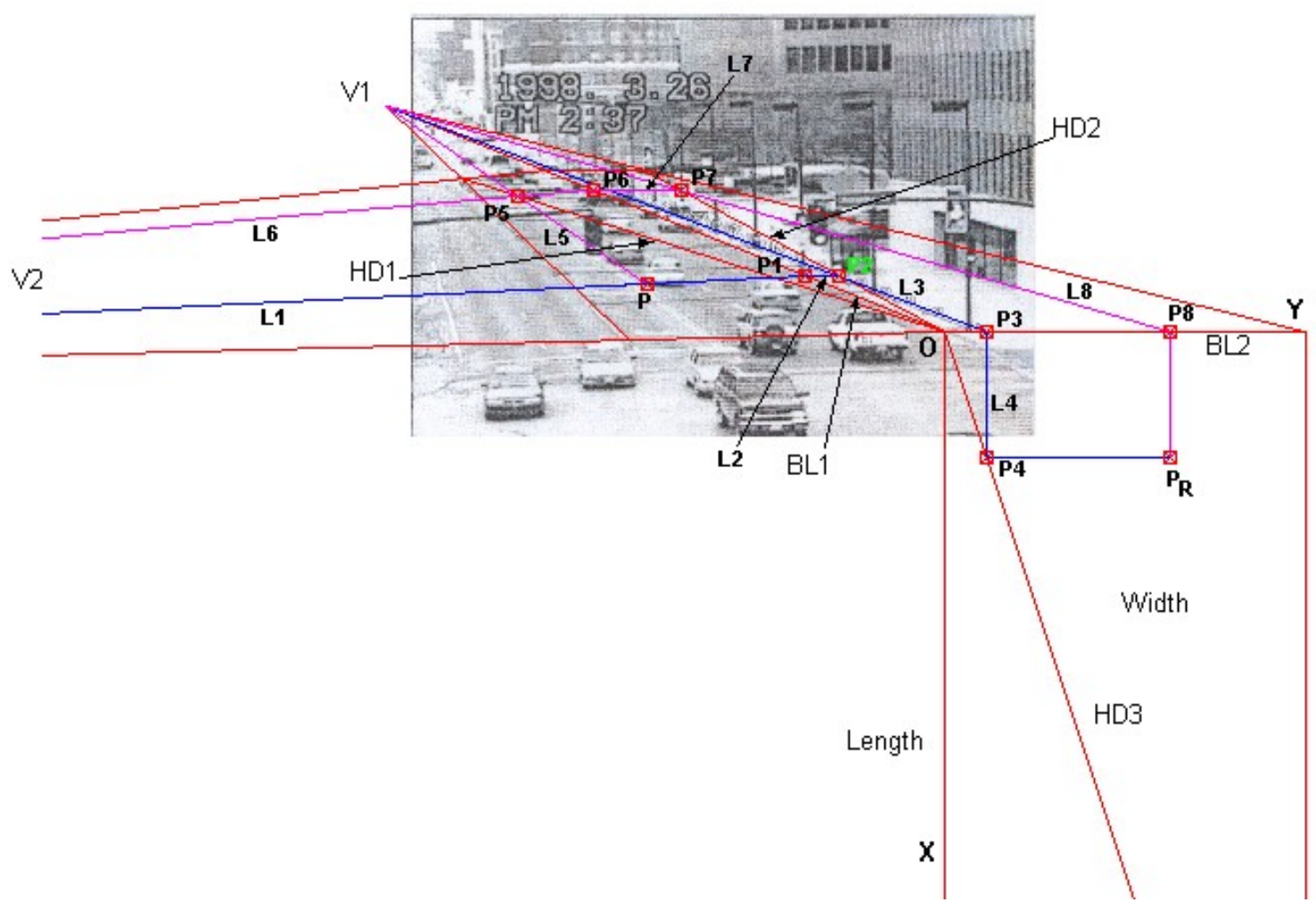

Figura 103 Restitución Gráfica

Para el caso en el que la vía tiene cambios de pendiente, y teniendo en cuenta que las homologías están dadas para una figura plana, se hace una aproximación de la sección de la vía a planos sucesivos, de forma que pueda aplicarse las homologías con el mínimo de error, como se muestra en la Figura 104.

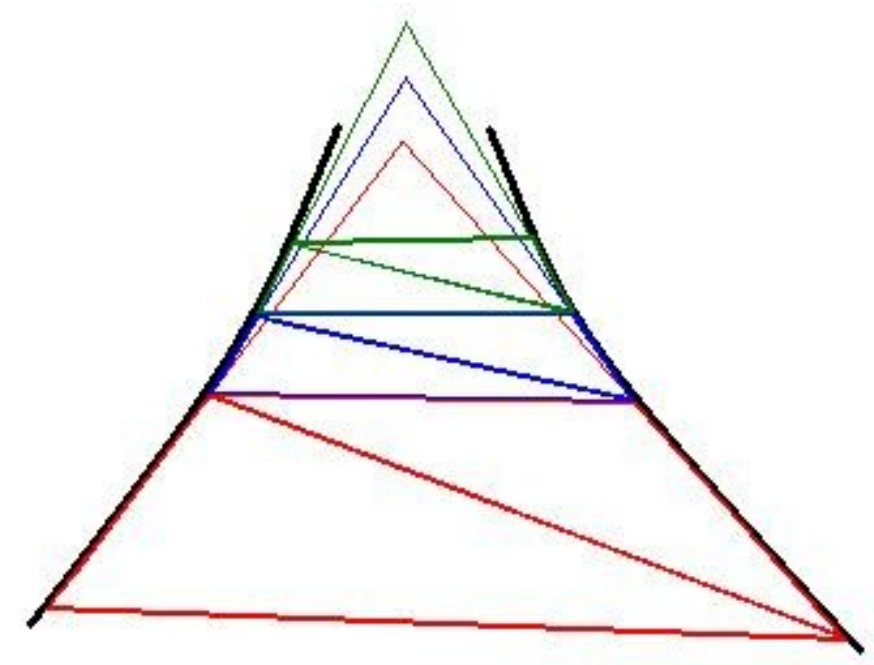

Figura 104: Homologías para cambio de pendiente de la vía 
El programa fue diseñado para permitir el trabajo con cuatro vídeos de manera simultánea, referenciando cada uno de ellos al mismo punto como eje de coordenadas (Figura 105).
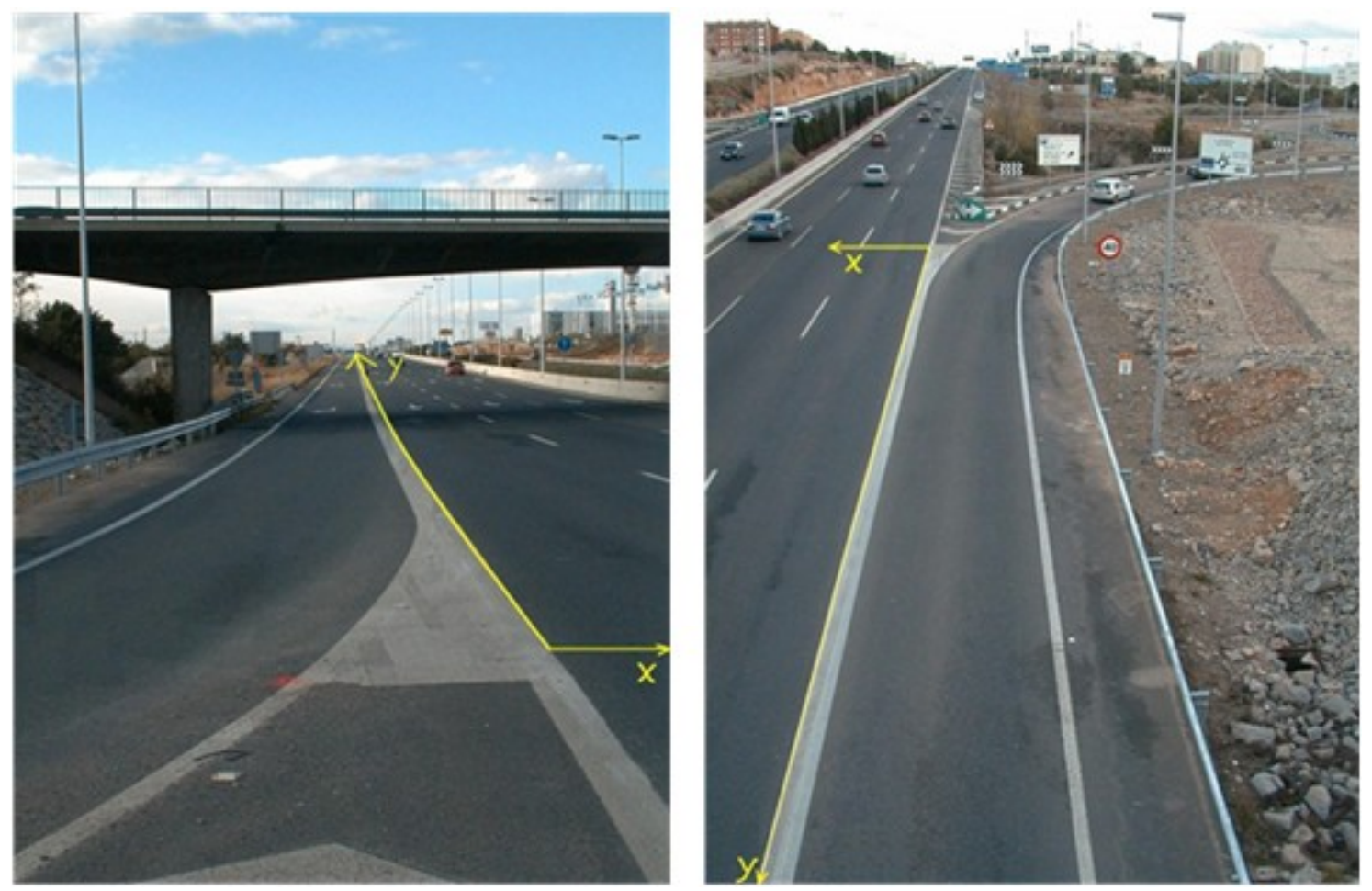

Figura 105: Sistema de referencia para los vídeos

\subsubsection{Cálculo de parámetros cinemáticos de los vehículos}

Las mediciones de tiempos se han tomado a partir del vídeo y con ellas se ha calculado la velocidad de los vehículos, sus aceleraciones y deceleraciones. Además, se ha calculado los indicadores de conflictividad que permiten hacer el análisis.

Una vez conocida la evolución de los vehículos, al restituir su posición en los diferentes cuadros del vídeo, se puede conocer su velocidad y su aceleración relacionando dichas posiciones con el tiempo transcurrido en el vídeo.

Se utilizan las siguientes ecuaciones para el cálculo de derivadas de la posición respecto al tiempo. Estas ecuaciones coinciden con el cálculo de la recta de mejor ajuste de tres puntos. La ecuación (93) corresponde al cálculo de la velocidad y la ecuación (94) a la aceleración.

$$
\begin{gathered}
f^{\prime}(x)=\frac{f(x+\Delta-(x-\Delta)}{2 \cdot \Delta} \\
f^{\prime \prime}(x)=\frac{f^{\prime}\left(x+\Delta-{ }^{\prime}(x-\Delta\right.}{2 \cdot \Delta}=\frac{f(x+2 \cdot \Delta-2 \cdot f(x)+(x-2 \cdot \Delta}{4 \cdot \Delta^{2}}
\end{gathered}
$$


Para la restitución de las trayectorias, se ha trabajado con vídeos digitalizados a 5 cuadros por segundo lo que permite conocer la ubicación de los vehículos a intervalos de tiempo de 0,2 segundos.

\subsubsection{Descripción de la aplicación de restitución de maniobras}

La aplicación para restitución de maniobras a partir de vídeos ha sido desarrollada utilizando Microsoft Visual Basic debido, en primer lugar, a la agilidad que aporta en la etapa de desarrollo y, en segundo lugar, a la facilidad de uso en el sistema Windows.

El código fuente de la aplicación informática desarrollada puede verse en el Anexo No. 3.

A continuación se hace un resumen de los aspectos generales del programa, que incluye su instalación, los requisitos del sistema y de hardware y algunas recomendaciones para mejorar su comportamiento. Además se presenta una breve descripción de la funcionalidad del programa.

\subsubsection{Aspectos generales}

A continuación se presentan los elementos básicos de la aplicación informática desarrollada.

\subsection{Requisitos del sistema}

La aplicación fue desarrollada para operar bajo Windows XP y sus requisitos son los que impone este sistema operativo.

Se recomiendan las siguientes características del ordenador:

- $1 \mathrm{~GB}$ de memoria RAM.

- $\quad$ Procesador de $2 \mathrm{GHz}$ o superior.

- Disco duro con espacio libre de $10 \mathrm{~GB}$

- $\quad$ Lector de CD ROM

- $\quad$ Tarjeta gráfica de 32 MB

\subsection{Instalación del programa}

La instalación es análoga a cualquier otra instalación convencional, por lo que los pasos a seguir son los siguientes: 
- Insertar el CD-ROM en la unidad correspondiente.

- $\quad$ Iniciar "Setup.exe".

- Seguir las instrucciones en pantalla para completar la instalación

\subsection{Recomendaciones}

Para obtener unos resultados óptimos con la utilización del programa informático hay que tener en cuenta, en primer lugar, la ubicación de la cámara de vídeo y, en segundo lugar, la digitalización de la imagen.

Es recomendable, para hacer las grabaciones, que la cámara se encuentre ubicada en una posición elevada y, en lo posible, alineada con el eje de la vía y centrada en el carril que se desea analizar.

La posición elevada permite tener un mejor ángulo de visión y garantiza una mejor precisión en el posicionamiento vertical. Por el contrario, si la cámara está muy baja un píxel de la imagen puede suponer algunos metros de diferencia en el posicionamiento, especialmente en lugares alejados de la misma.

El enfoque de la cámara debe ser fijo, para evitar movimientos de encuadre de la imagen que no son corregidos por el programa. De la misma manera se debe evitar que la cámara pueda girar o desplazarse.

Para la digitalización de la imagen hay que tener en cuenta el número de cuadros por segundo con el que se hace la grabación y que la digitalización coincida con un divisor entero de este número.

Asimismo, cuanta más resolución tenga la imagen, la precisión de la restitución será mayor.

\subsubsection{Descripción del programa}

Se han definido dentro de la aplicación 4 módulos funcionales: el manejo de vídeos, la visión artificial, el cálculo de los indicadores de conflictividad y, por último, el manejo de la base de datos.

\subsection{Manejo de vídeos}

Este módulo es el encargado del manejo simultáneo de varios vídeos, sincronizarlos, entregar a los demás módulos el fotograma que se debe analizar, estabilizar la imagen y calcular la imagen de fondo.

\subsection{Manejo simultáneo de vídeos}

En primer lugar, es importante resaltar que la aplicación desarrollada utiliza un componente de Windows que permite utilizar cualquier formato de vídeo soportado por este sistema. 
El módulo de manejo de vídeos es el encargado de manejar, obtener y entregar a los demás módulos la imagen que debe ser analizada en cada momento.

El programa permite manejar hasta 4 vídeos de forma simultánea. Para adicionar un vídeo basta con hacer clic sobre el botón de "abrir vídeo", el cual despliega una la ventana de búsqueda de ficheros. En caso de haberlo referenciado previamente, este se carga de forma automática.

Una vez adicionados uno o más vídeos se puede almacenar un proyecto que despliega nuevamente la ventana de manejo de ficheros estándar de Windows y almacena los datos relativos a los diferentes vídeos abiertos, con su correspondiente posición e incluso su desfase de sincronización.

Cuenta con los botones de "Abrir vídeo", "Guardar Vídeo", "Abrir Proyecto", "Guardar Proyecto", crear un "Nuevo Proyecto", "Activar" cada uno de los vídeos abiertos y de "Salir" de la aplicación.

Adicionalmente cuenta con botones para el movimiento del vídeo, "Adelante", "Atrás", "Primero", "Último", y una barra de desplazamiento para controlar el vídeo.

Otra de las funciones importantes del módulo de manejo de vídeos es la de sincronizar los diferentes vídeos abiertos en un proyecto, con el fin de unificar la referencia temporal y de esta forma poder evaluar la trayectoria de los vehículos en conjunto y no como una simple sucesión de trayectorias parciales.

Para sincronizar los vídeos se selecciona un conjunto de vehículos para los cuales se calcula por separado su velocidad y posición en cada uno de ellos. A continuación, conociendo la velocidad en función de la posición, por medio de una regresión polinómica, se obtiene la fórmula de velocidad en función de la posición que más se aproxime a cada vehículo estudiado.

Una vez obtenida la fórmula de regresión se evalúa por intervalos muy pequeños de posición, el tiempo que transcurre entre una posición conocida en un vídeo hasta otra posición conocida en el vídeo siguiente.

Este procedimiento se realiza para los distintos vehículos seleccionados y se obtiene el valor medio de desfase entre un vídeo y otro. Se hace un análisis de normalidad para descartar datos anómalos y así mejorar la precisión en la sincronización de los vídeos.

\subsection{Estabilización de la imagen}

Este módulo se encarga de detectar automáticamente los movimientos de la cámara, y calcular la magnitud de los mismos tanto para el eje x como para el eje y de la imagen $y$, de esta forma, evitar errores de restitución por este motivo.

La estabilización se lleva a cabo ubicando una zona de la imagen, que es definida por el usuario, obteniendo posteriormente la imagen de referencia y, con ella, se hace una búsqueda alrededor de un punto definido que permita minimizar el error absoluto entre la imagen actual y la de referencia. 


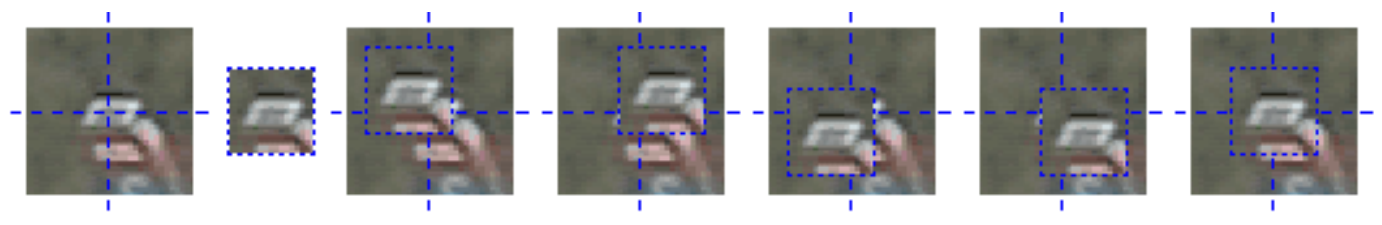

Figura 106: Proceso de estabilización de la imágen

El proceso de estabilización de la imagen se ejecuta de manera automática cada vez que se cambia de fotograma.

\subsection{Cálculo de imagen de fondo}

La imagen de fondo sirve tanto como referencia como para encontrar los pixeles que cambian en cada fotograma, tal y como se muestra en la Figura 108, restando las intensidades que definen cada pixel de la imagen actual con la imagen de fondo (Figura 107).

El procedimiento de cálculo de la imagen de fondo se realiza de manera automática una vez se ha referenciado el vídeo y la imagen de fondo queda almacenada para futuras ejecuciones del programa. Si ya se ha calculado el fondo para un vídeo determinado, no se vuelve a calcular (aunque existe la posibilidad de hacerlo mediante el comando "Calcular fondo").

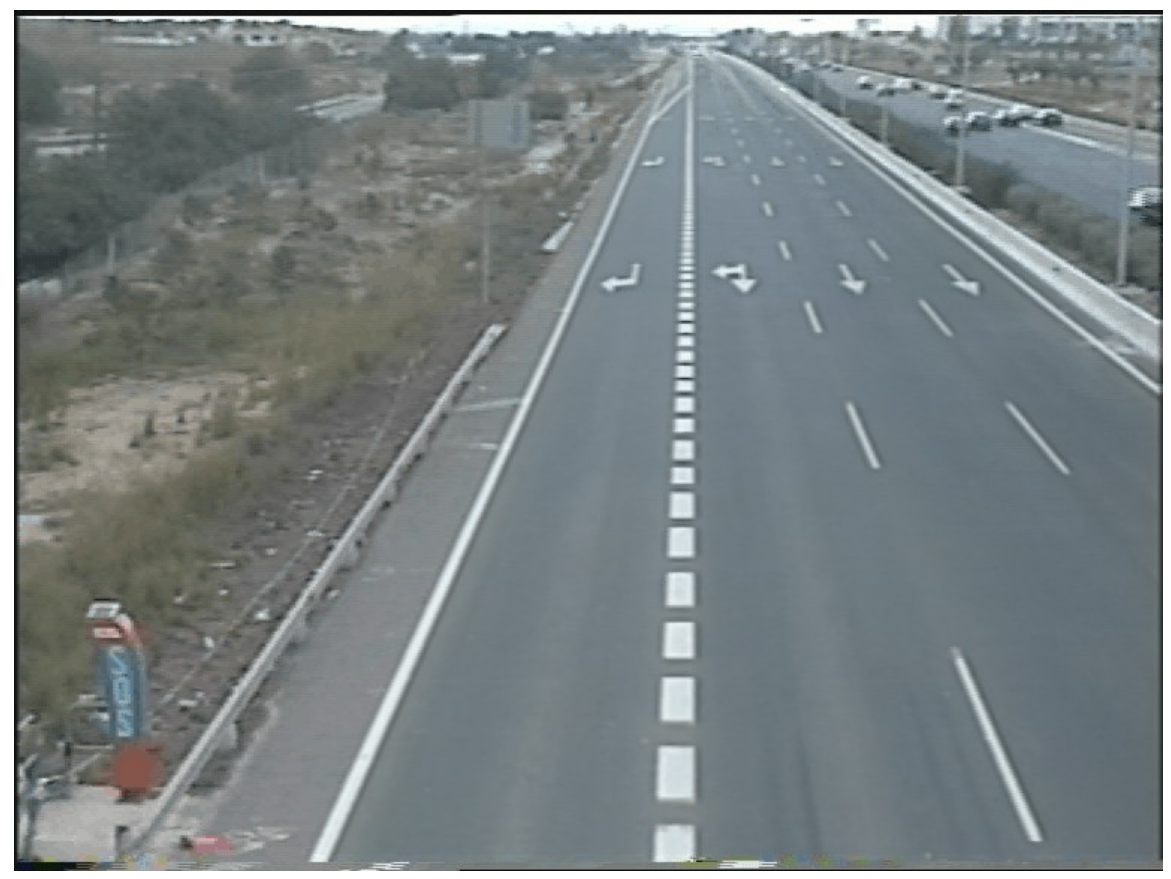

Figura 107: Imagen de fondo

Para calcular la imagen de fondo se hace un muestreo del vídeo y se calcula el color promedio de cada pixel. Este método es muy útil cuando se cuenta con tráfico fluido, pues la frecuencia de exposición del fondo es mayor que cuando hay congestión.

Para remediar en parte esta situación, se ha implementado un segundo nivel de muestreo en el cual se considera que un pixel está dentro de la media si no se desvía 
más de un porcentaje de la misma y, de esta forma, se disminuye el peso específico de lo que no es fondo dentro de la media.

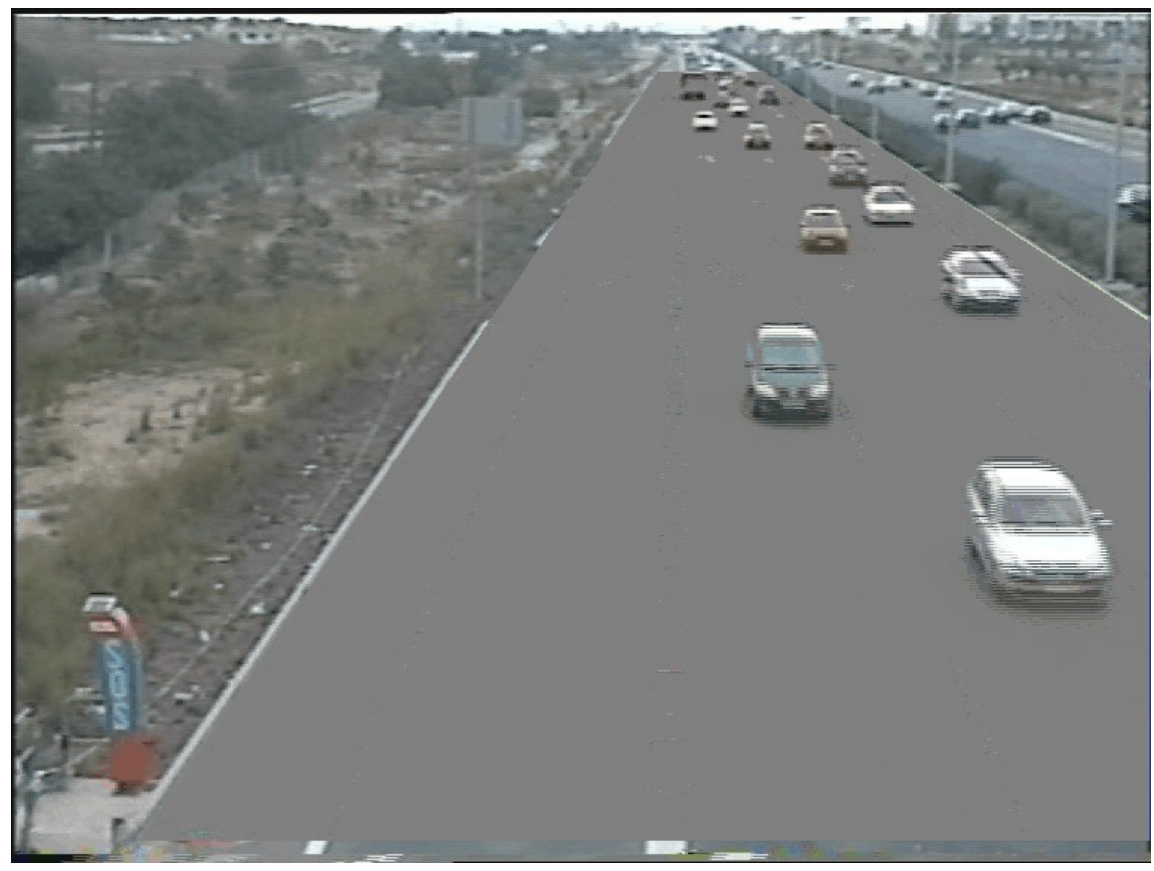

Figura 108:Resta imagen actual y fondo

Se cuenta con diferentes botones de utilidades para el manejo de la imagen que permiten por ejemplo restar a la imagen actual el fondo, de forma que se resalten los elementos que han cambiado en la imagen (Figura 108), o resaltar los bordes de una imagen determinada.

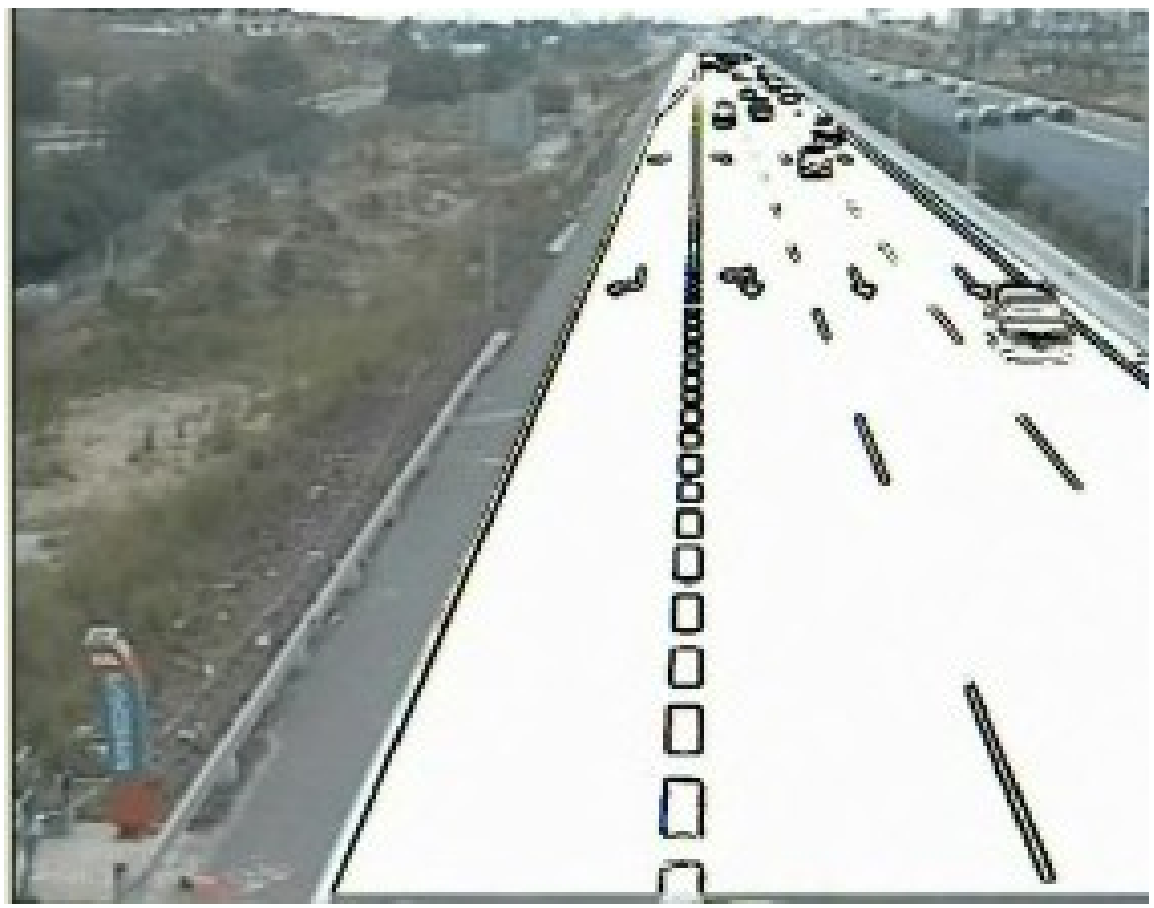

Figura 109: Bordes de la Imagen 


\subsection{Visión artificial y restitución de coordenadas}

Este módulo es el encargado de fijar las referencias, detectar vehículos, hacer la restitución de coordenadas y calcular la velocidad y la aceleración.

El módulo de visión artificial y restitución de coordenadas parte de la imagen estabilizada que recibe del módulo de manejo de vídeos y de la imagen de fondo que se ha calculado.

Para agilizar los cálculos se define una zona de trabajo evitando así tener que procesar gran cantidad de datos que no pertenezcan a la vía.

Al abrir un vídeo se lee la zona de trabajo especificada previamente. En caso de no haberse definido con anterioridad, el programa define una zona de trabajo por defecto, que al hacer click sobre el botón de "Rehacer zona de referencia" permite arrastrar sobre la imagen las líneas que delimitan dicha zona. Este proceso de edición de la zona de referencia termina al hacer clic sobre el botón de "Finalizar Zona de Referencia". En la Figura 110 se puede observar el manejo de las líneas de referencia.

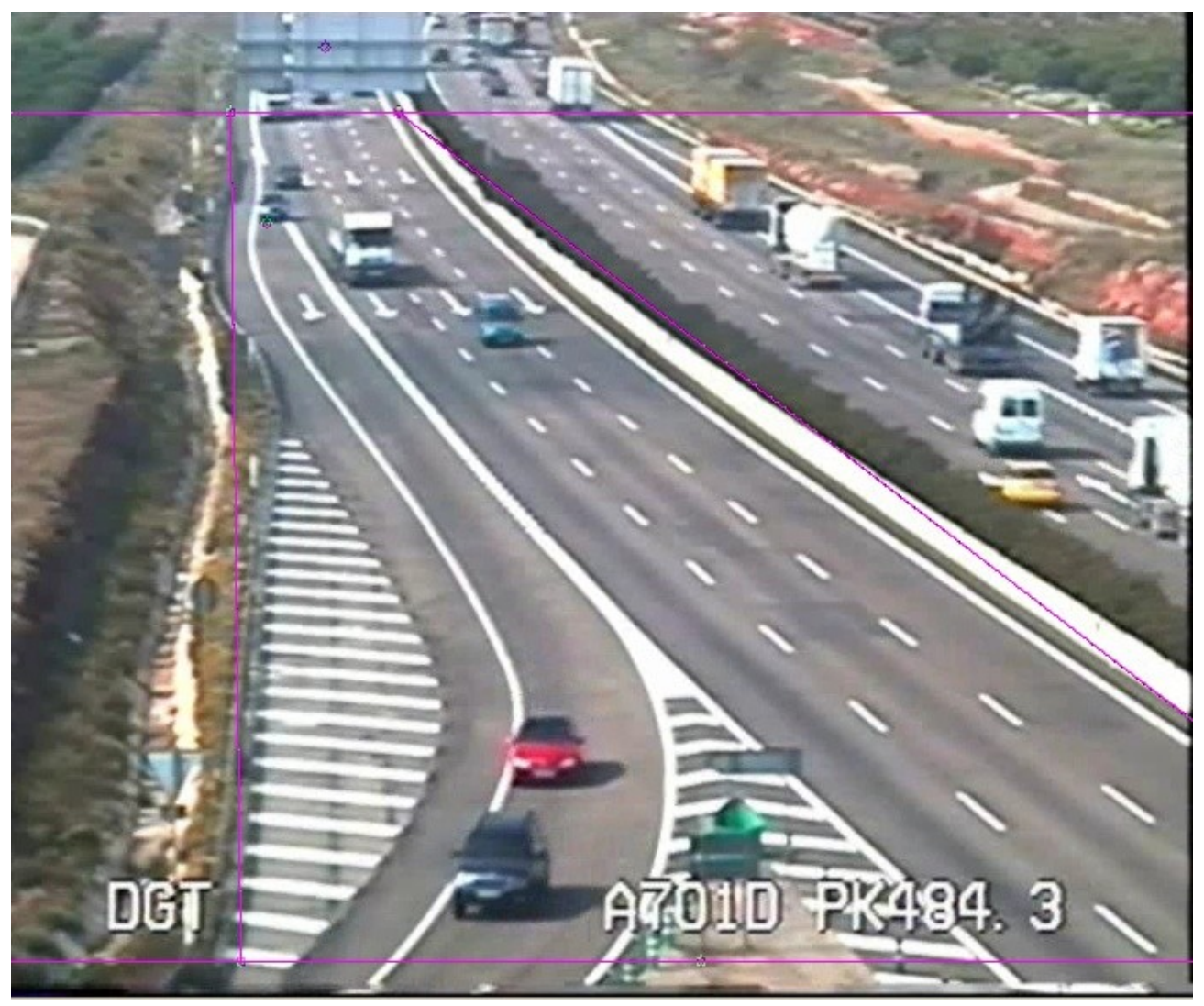

Figura 110: Líneas de referencia de zona

Adicionalmente, este módulo es el encargado del manejo de las referencias para la restitución de coordenadas y del cálculo de la posición real de los pixeles de la imagen 
siguiendo el procedimiento descrito en el apartado de restitución de maniobras (apartado 6.2.3).

El funcionamiento de las referencias para restitución de posiciones es similar al de las zonas de referencia. Se leen las referencias al abrir el vídeo, en caso de no tener referencias se generan unas por defecto que se editan arrastrando los puntos de referencia sobre la imagen una vez se activa el botón de "Modificar Referencias". Adicionalmente se permite la entrada de las dimensiones de los rectángulos referenciados (ancho y largo) y de su posición (Pk y Pt del borde izquierdo). Se termina el modo de edición de las referencias con el botón "Finalizar Referencias".

Se han creado dos botones adicionales que permiten crear referencias cercanas o referencias lejanas, con el fin de ubicar los nuevos puntos de referencia en caso de tener un cambio de pendiente o de curvatura.

Se puede observar en la Figura 111 la edición de las referencias con múltiples referencias para la imagen.

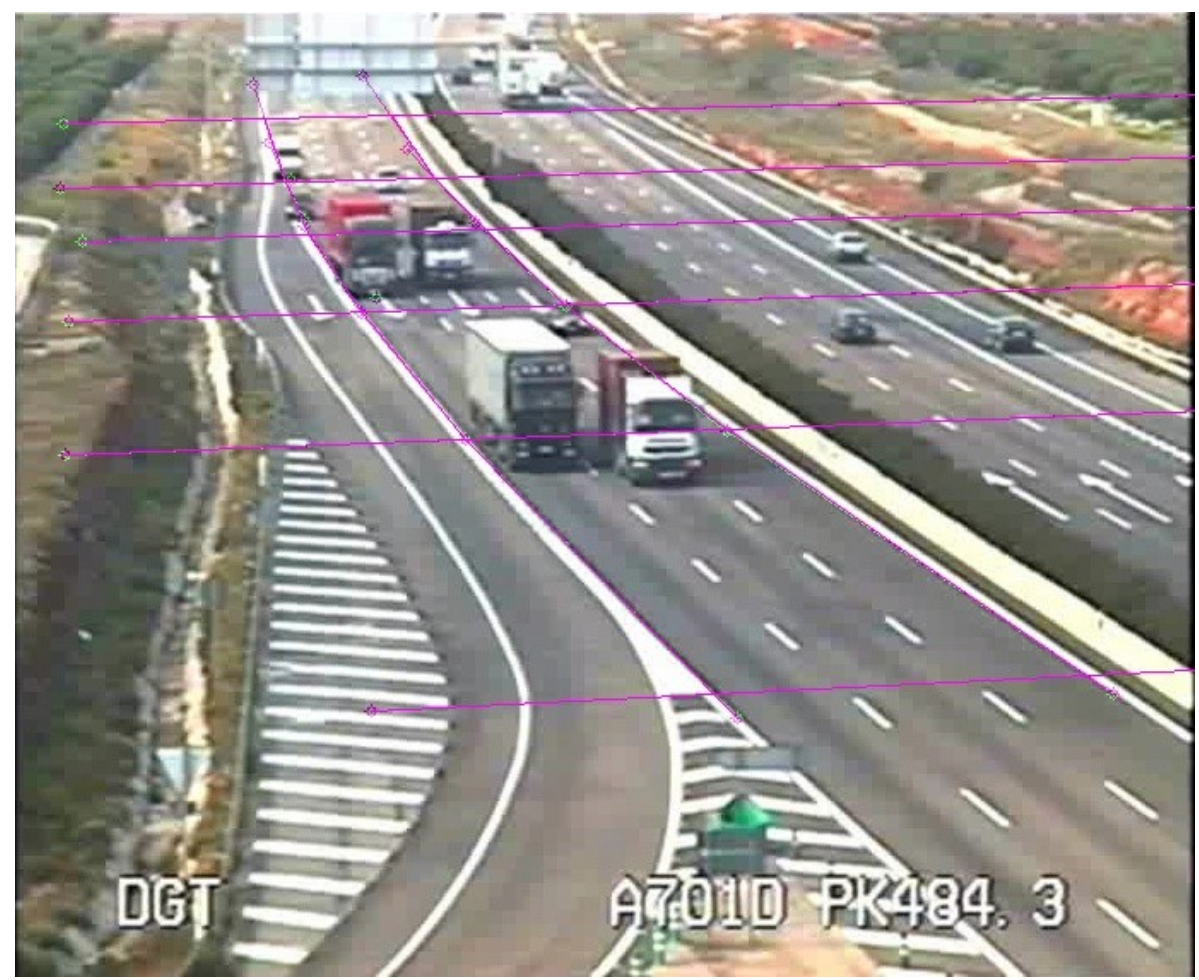

Figura 111: Referencias de la perspectiva cónica

Este módulo permite ubicar detectores en la imagen que operan mediante la comparación entre la imagen actual y la de fondo, cuando superan un porcentaje de pixeles que se desvían más de un cierto valor umbral en su composición de color, se considera que hay un vehículo sobre el detector, en caso contrario el detector está libre. 


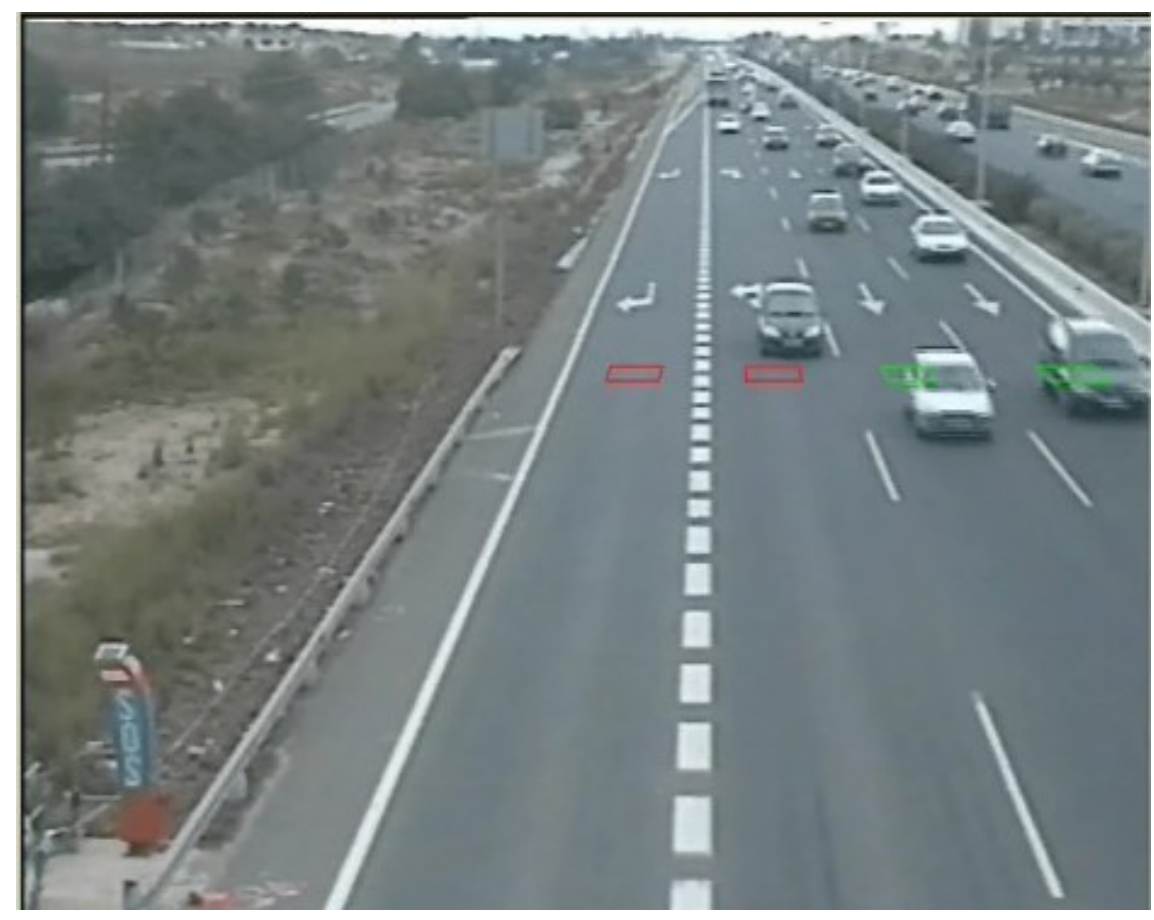

Figura 112: Detectores de vehículos en la imagen

Esta utilidad permite obtener la intensidad del tráfico, pero no permite diferenciar entre vehículos pesados y automóviles.

Para ubicar los detectores basta con hacer click en el botón "Adicionar detectores" y a continuación sobre cada uno de los laterales del detector que se desea ubicar, iniciando por el borde izquierdo, luego el derecho, a continuación el borde superior y finalmente el inferior. El programa asume una forma rectangular que se ve deformada por la perspectiva cónica.

Partiendo de esta detección se ha implementado un algoritmo de seguimiento de vehículos que, a partir de la detección de un vehículo, busca la trayectoria del vehículo ubicándolo en los fotogramas anteriores del vídeo en dirección al punto de fuga principal y a continuación busca el centro del vehículo para encontrar la posición del mismo cuadro a cuadro. 


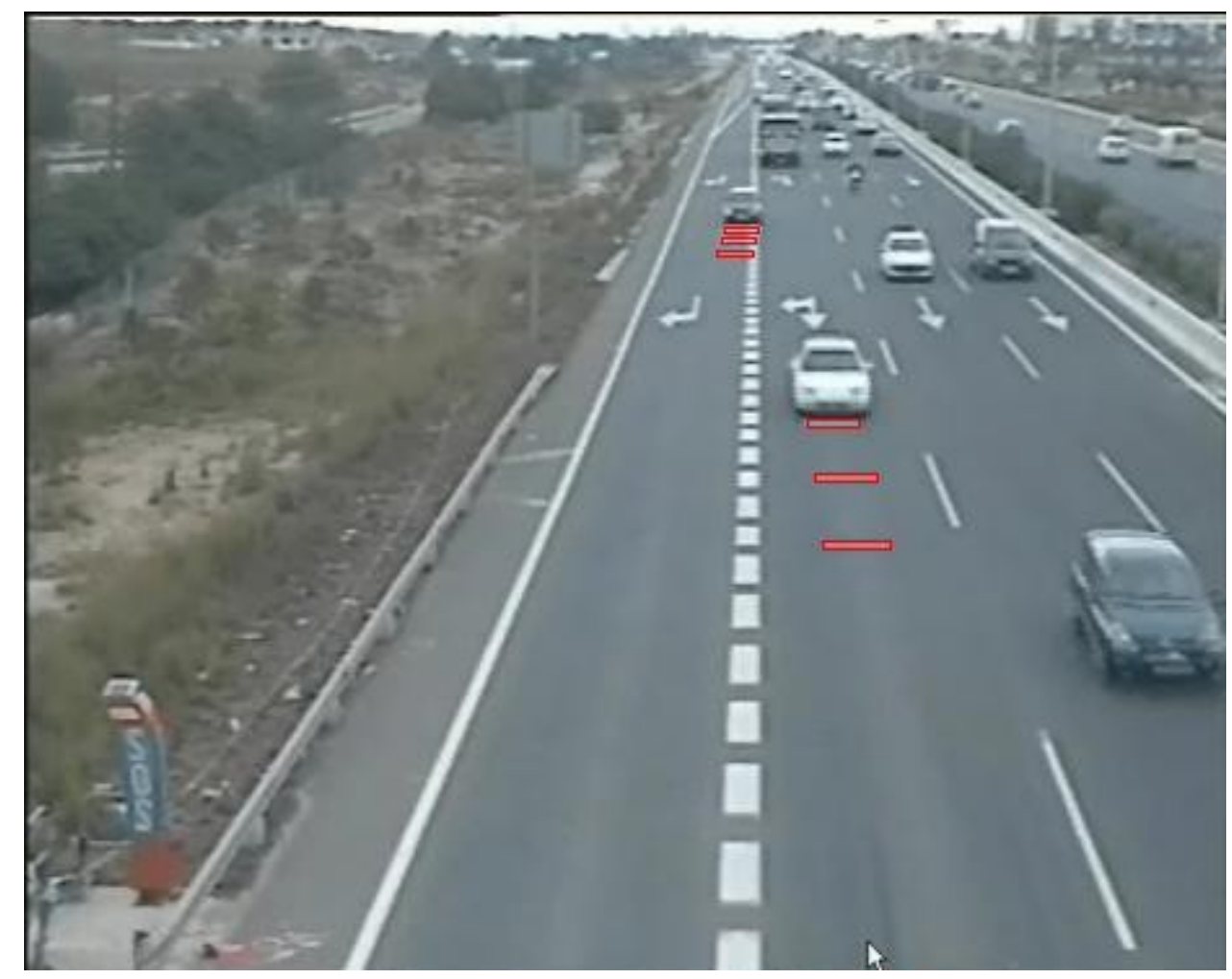

Figura 113: Seguimiento de vehículos

Es importante señalar que este algoritmo requiere que se pueda diferenciar claramente un vehículo de otro y además se ve afectado en cierta medida por las sombras que proyectan los vehículos. Por esta razón, el programa permite ubicar manualmente los vehículos y así garantizar una correcta ubicación de los vehículos en la imagen.

Para ubicar manualmente los vehículos se hace click sobre el botón de "Crear Vehículo", el cual le asigna un código, posteriormente al hacer click sobre la imagen se encuentra su posición y se almacena en la base de datos. Una vez hecho esto se puede mover el vídeo hacia adelante o hacia atrás y seguir almacenando ubicaciones de este mimo vehículo.

Una vez obtenidas las posiciones del vehículo en los distintos fotogramas se debe hacer click en el botón de "Calcular velocidades", el cual toma los datos de posicionamiento del vehículo y calcula la velocidad y la aceleración en cada momento de la trayectoria. Además este procedimiento interpola las posiciones ocultas del vehículo, en caso de que existan.

Todos estos datos son almacenados en la base de datos asociada al vídeo.

Aplicar las técnicas de visión artificial en el tratamiento de imágenes con el fin de tomar los datos necesarios para las Técnicas de Conflictos de Tráfico, supone una serie de ventajas que hacen que el proceso se agilice, aportándole mayor facilidad de operación y mayor precisión.

Con esta técnica se minimiza subjetividad que supone el trabajo realizado únicamente por personas, ya que una persona tras visualizar repetidamente una situación, que al 
principio catalogaba como peligrosa, puede llegar a considerarla normal, mientras que con la técnica de visión artificial los criterios se mantienen una situación tras otra.

Asimismo, cuando el trabajo es realizado por personas, éste puede resultar tedioso y provocar en el ingeniero o persona entrenada en seguridad vial una pérdida de atención por muy exhaustivo que haya sido su entrenamiento. Sin embargo, al emplear técnicas de visión artificial este problema desaparece.

Además de estas ventajas, la mencionada técnica tiene una ventaja adicional que consiste en el registro de los datos del conflicto que permite que éste sea estudiado nuevamente y los resultados obtenidos sean contrastados.

Como se ha citado en los párrafos anteriores, la visión artificial, aplicada a las TCT, tiene una serie de ventajas que instan a seguir con su desarrollo. En él hay que tener en cuenta una serie de dificultades que de obviarlas podrían distorsionar los resultados. Entre ellas pueden destacarse dos claramente diferenciadas: las sombras y la separación entre vehículos.

Al encontrarse con sombras, el sistema de visión artificial puede detectarlo como un vehículo de un tamaño diferente al real, bien detectándolo como un vehículo menor al eliminar parte de éste en el proceso de eliminación de sombras, o bien al considerar parte de éstas como parte integrante del vehículo. Del mismo modo, cuando aparecen dos vehículos consecutivos la sombra de uno de ellos puede llevar al sistema a considerarlos como uno solo. Con ello los resultados no serían los correctos.

Por otra parte, cuando la separación entre vehículos es mínima, como en el caso de altos volúmenes de tráfico, el sistema puede interpretar dos o más vehículos muy juntos como uno solo con lo que, de nuevo, los resultados estarían distorsionados.

Para disminuir el efecto que puede tener las dificultades mencionadas, se debe poner especial cuidado en la ubicación y enfoque de las cámaras.

Con la aplicación sucesiva de filtros, cada imagen es analizada y comparada con una imagen de fondo, que se ha calculado previamente y que se va corrigiendo a lo largo del tiempo, para encontrar la ubicación de los pixeles que cambian en una imagen y, posteriormente, ubicar los vehículos.

Debido a las dificultades mencionadas, la aplicación desarrollada no automatiza el proceso de detección de vehículos pero si ayuda al usuario a su ubicación de modo que le facilite su labor.

\subsection{Manejo de la base de datos}

El último modulo se encarga del almacenamiento, búsqueda y recuperación de datos para los demás módulos y de exportar los datos a Excel.

La aplicación utiliza Microsoft Access como motor de base de datos, debido a la facilidad de manejo y a la compatibilidad con otros componentes de Office, lo que facilita la portabilidad de los datos. 
El manejo de la base de datos es transparente al usuario, es decir el usuario no debe hacer ningún tipo de acción para su operación.

\subsection{Cálculo de indicadores de conflictividad}

Este módulo recibe, de la base de datos, las posiciones, velocidades y aceleraciones de cada vehículo a lo largo de su trayectoria, con lo que se calcula para cada maniobra los indicadores de conflictividad seleccionados y los acumula para todo el periodo estudiado.

Para calcular todos los valores de TiPCLA basta con hacer click sobre el botón "TCT" el cual genera una tabla con los resultados de los indicadores asociados al vídeo.

El proceso de cálculo del indicador se presenta en la sección 0 donde se describe el indicador utilizado.

\subsection{DISEÑO DE INDICADORES DE CONFLICTIVIDAD}

Hasta la fecha, dentro de las técnicas de conflictos de tráfico, se han desarrollado gran variedad de indicadores que pretenden reflejar la conflictividad en el tráfico. Dichos indicadores se han utilizado principalmente en intersecciones, pero son difíciles de aplicar en otras situaciones, pues requieren una zona de conflicto claramente definida.

Existen algunos indicadores que se pueden utilizar en caso de no tener una zona de conflicto acotada, aplicables en el caso de conflictos relacionados con el seguimiento. Estos son:

- TTC para aproximaciones (Approximate TTC) a-TTC

- Tiempo potencial hasta colisión (Potential Time to Collision) PTTC

- Índice potencial de colisión ante una deceleración de emergencia (Potential Index for Collision with Urgent Deceleration) - (PICUD)

Los indicadores mencionados no tienen en cuenta los conflictos transversales, que ocurren en las maniobras de trenzado, incorporación y salida.

Para tener en cuenta tanto los conflictos paralelos al eje de la vía como los transversales se ha desarrollado los siguientes indicadores de conflictividad como alternativas para reflejar la conflictividad en dichas maniobra.

\subsubsection{Tiempo máximo de reacción (TMR)}

Este nuevo indicador de conflictividad es del tipo condicional, pues evalúa lo que sucedería en caso de presentarse una situación determinada. Se calcula el tiempo máximo de reacción con el que contaría un conductor para evitar una colisión ante una eventual deceleración o cambio de carril del vehículo en conflicto.

Su principal ventaja es que permite evaluar la conflictividad tanto longitudinal como transversalmente y evita tener que introducir el tiempo de reacción como un parámetro adicional en su evaluación. 
Como el valor del tiempo máximo de reacción va variando con la evolución de los vehículos, se debe buscar la situación en la cual el valor sea el mínimo, caracterizando de esta forma el conflicto.

Debido a que tener solo un valor puntual puede llevar a interpretaciones erróneas, para tener una mejor caracterización del conflicto se plantea la utilización conjunta de este indicador con la integral del mismo bajo un valor umbral y con el intervalo de tiempo bajo este umbral. Estos dos nuevos valores indican no solo que tan serio es el conflicto sino que tanta exposición al conflicto hay.

Para obtener el valor del tiempo máximo de reacción (TMR) se debe conocer la posición inicial, la velocidad inicial, tanto longitudinal como transversal y la aceleración inicial, de cada vehículo involucrado en el conflicto.

Con estos datos se procede a calcular el tiempo máximo de reacción para evitar una colisión, tomando las posibles combinaciones de comportamiento entre los dos vehículos en conflicto que se muestran en la Tabla 46.

Tabla 46: Acciones de los vehículos en conflicto

\begin{tabular}{|c|l|c|c|}
\hline \multirow{1}{*}{ Vehículo } & \multicolumn{1}{|c|}{ Acción } & Deceleración & $\begin{array}{c}\text { Velocidad } \\
\text { Transversal }\end{array}$ \\
\hline \multirow{4}{*}{ Vehículo líder } & Frenado de emergencia & $-20 \mathrm{~km} / \mathrm{h} / \mathrm{s}$ & $0 \mathrm{~m} / \mathrm{s}$ \\
\cline { 2 - 4 } & Frenado medio & $-10 \mathrm{~km} / \mathrm{h} / \mathrm{s}$ & $0 \mathrm{~m} / \mathrm{s}$ \\
\cline { 2 - 4 } & Decelera & $-3,33 \mathrm{~km} / \mathrm{h} / \mathrm{s}$ & $0 \mathrm{~m} / \mathrm{s}$ \\
\cline { 2 - 4 } & Frena y cambia & $-10 \mathrm{~km} / \mathrm{h} / \mathrm{s}$ & $1 \mathrm{~m} / \mathrm{s}$ \\
\cline { 2 - 4 } & Decelera y cambia & $-3,33 \mathrm{~km} / \mathrm{h} / \mathrm{s}$ & $1 \mathrm{~m} / \mathrm{s}$ \\
\hline \multirow{3}{*}{ Otro vehículo } & Frenado & $-20 \mathrm{~km} / \mathrm{h} / \mathrm{s}$ & $0 \mathrm{~m} / \mathrm{s}$ \\
\cline { 2 - 4 } & Frena y cambia & $-10 \mathrm{~km} / \mathrm{h} / \mathrm{s}$ & $1 \mathrm{~m} / \mathrm{s}$ \\
\cline { 2 - 4 } & Decelera y cambia & $-3,33 \mathrm{~km} / \mathrm{h} / \mathrm{s}$ & $1 \mathrm{~m} / \mathrm{s}$ \\
\hline
\end{tabular}

Como resultado se pueden obtener tiempos de reacción negativos, lo que indica que de presentarse la maniobra del vehículo líder la colisión es inevitable, valores menores a 0,5 s donde la colisión es probable, entre 0,5 y $1 \mathrm{~s}$ donde es posiblemente evitable la colisión y mayores de $1 \mathrm{~s}$ donde la colisión es evitable.

Finalmente se puede calcular la peligrosidad mediante el cálculo de las velocidades en el momento de la colisión, si se tiene un tiempo de reacción de $1 \mathrm{~s}$.

\subsubsection{Tiempo potencial para colisión lateral o alcance (TiPCLA)}

Se plantea el indicador de conflictividad TiPCLA, que al igual que el TMR, es del tipo condicional, y pretende evaluar la conflictividad calculando el tiempo que transcurre entre el momento en que el vehículo líder realiza una maniobra y el momento en que se presenta la colisión en caso de que el vehículo que le sigue no hiciera ningún tipo de maniobra evasiva. 
En el caso de estar evaluando únicamente conflictos longitudinales, es decir, el caso de seguimiento, el indicador sería equivalente al PTTC propuesto por Wakabayashi y Renge (2003), aplicando las deceleraciones propuestas por ellos. Sin embargo, la diferencia radica en los tipos de maniobra que puede realizar el vehículo líder, relacionadas en la Tabla 47, pues se incluyen cambios de carril de acuerdo con la evolución transversal encontrada por Rioux (1977) que corresponde con la función coseno, que se contrae o expande si el vehículo acelera o decelera.

Tabla 47: Acciones del vehículo líder para el TiPCLA

\begin{tabular}{|l|l|c|c|c|}
\hline \multicolumn{1}{|c|}{ Acción } & \multicolumn{1}{|c|}{$\begin{array}{c}\text { Conflicto } \\
\text { evaluado }\end{array}$} & Sigla & Deceleración & $\begin{array}{c}\text { Velocidad } \\
\text { Transversal }\end{array}$ \\
\hline $\begin{array}{l}\text { Frenado de } \\
\text { emergencia }\end{array}$ & Seguimiento. & PTTC & $-20 \mathrm{~km} / \mathrm{h} / \mathrm{s}$ & $0 \mathrm{~m} / \mathrm{s}$ \\
\hline Cambia de carril & Lateral. & PTTLC & $0 \mathrm{~km} / \mathrm{h} / \mathrm{s}$ & $\pm 1 \mathrm{~m} / \mathrm{s}$ \\
\hline $\begin{array}{l}\text { Frena y cambia de } \\
\text { carril }\end{array}$ & $\begin{array}{l}\text { Seguimiento y } \\
\text { Lateral. }\end{array}$ & PTTCCf & $-10 \mathrm{~km} / \mathrm{h} / \mathrm{s}$ & $\pm 1 \mathrm{~m} / \mathrm{s}$ \\
\hline $\begin{array}{l}\text { Decelera y cambia } \\
\text { de carril }\end{array}$ & $\begin{array}{l}\text { Seguimiento y } \\
\text { Lateral. }\end{array}$ & PTTCCd & $-3,33 \mathrm{~km} / \mathrm{h} / \mathrm{s}$ & $\pm 1 \mathrm{~m} / \mathrm{s}$ \\
\hline
\end{tabular}

Su principal ventaja, al igual que el TMR, es que permite evaluar la conflictividad tanto longitudinal como transversalmente y evita tener que introducir el tiempo de reacción como un parámetro adicional en su evaluación, pero adicionalmente simplifica de manera importante los cálculos necesarios para obtener el valor del indicador del conflicto, pues el vehículo líder es el único que desarrolla algún tipo de maniobra.

Como el valor del TiPCLA va variando con la evolución de los vehículos, se debe buscar la situación en la cual se obtenga el valor mínimo, caracterizando de esta forma el conflicto.

Para el cálculo del indicador en cada instante de tiempo, se debe tomar el mínimo de los siguientes resultados de acuerdo con la ecuación (95).

$$
\text { TiPCLA }=\min (\text { PTTC, PTTLC, PTTCCF, PTTCCd })
$$

Los datos necesarios para obtener el valor TiPCLA son la velocidad inicial tanto longitudinal como transversal de los dos vehículos involucrados en el conflicto, así como su posición inicial.

El cálculo de la evolución de los vehículos para cada posible acción del líder, se basa en un proceso iterativo en el que se conocen las condiciones iniciales y se evalúan las siguientes. De esta forma se calcula el tiempo transcurrido entre la acción del líder y el momento en que se presentaría una colisión. Se toma el mínimo valor de los calculados por las diferentes acciones del líder.

Para medir el tiempo de exposición a valores peligrosos de conflicto se utiliza el tiempo durante el cual el valor TiPCLA es inferior a un valor umbral, llamado T_TiPCLA . 
Además del tiempo de exposición a valores peligrosos de TiPCLA, es importante conocer la seriedad de la exposición, por lo que se utiliza la integral de TiPCLA bajo un valor umbral, denominado I_TiPCLA . Finalmente, como medida de la peligrosidad media durante el periodo de exposición se calcula el valor R_TiPCLA $A_{U}$ como la diferencia entre el umbral y el cociente entre I_TiPCLA y T_TiPCLA.

Para calcular el valor total de tiempo bajo un valor umbral de TiPCLA se utiliza la ecuación (96).

$$
T_{-} T i P C L A_{U}=\sum_{i=1}^{N} \sum_{t=0}^{T} \partial_{i}(t) \cdot \tau
$$

donde:

$$
\begin{aligned}
& \text { 1, } \quad \operatorname{si~} \operatorname{TiPCLA}_{i}(t) \leq \text { Umbral } \quad \text { y } \quad \operatorname{TiPCLA}_{i-1}(t) \leq \text { Umbral }
\end{aligned}
$$

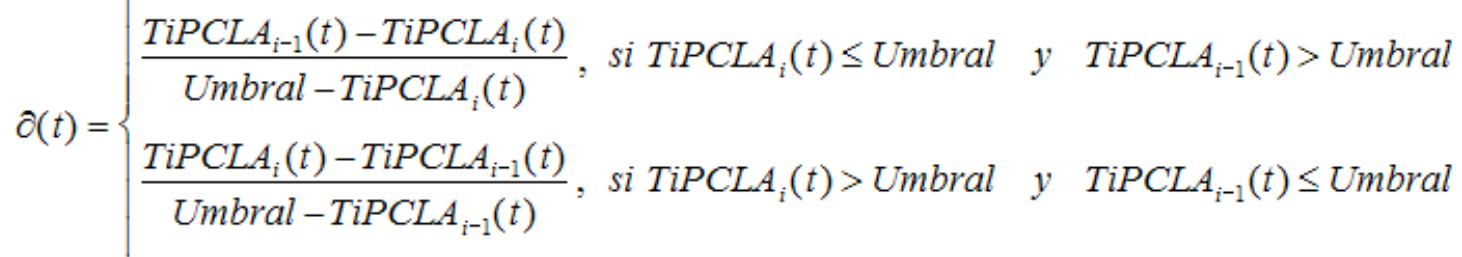

$$
\begin{aligned}
& \text { 0, en caso contrario }
\end{aligned}
$$

- $\quad \operatorname{TiPCLA}(t)$ es el valor de TiPCLA del vehículo $i$ que realiza una maniobra en el instante $t(\mathrm{~s})$.

- $\quad$ es el intervalo de muestreo (s).

- $\quad \mathrm{N}$ es el total de vehículos en un periodo determinado de tiempo.

- $\quad$ T es periodo de tiempo considerado para la maniobra (s).

Asimismo, con la ecuación (97) se calcula la integral de TiPCLA bajo un valor umbral U

$$
I_{-} T i P C L A=\sum_{i=1}^{N} \int_{0}^{T}\left(U-T i P C L A_{1}(t)\right) \cdot \partial(t) \cdot d t
$$

donde:

- U umbral considerado (s).

- $\quad \mathrm{N}$ el número de maniobras consideradas. 


$$
\partial(t)=\begin{array}{lll}
1, & \text { si } & \operatorname{TiPCLA}_{i}(t) \leq U \\
0, & \text { en } & \text { caso contrario }
\end{array}
$$

- $\quad \operatorname{TiPCL} A_{i}(t)$ es el valor de TiPCLA del vehículo $i$ que realiza una maniobra en el instante $t(\mathrm{~s})$.

- $\quad \mathrm{N}$ es el total de vehículos en un periodo determinado de tiempo.

Finalmente, con la ecuación (98) se calcula la relación R_TiPCLA entre los indicadores anteriores.

$$
R_{-} T i P C L A_{U}=J-\frac{I_{-} T i P C L A_{U}}{\Gamma \_T i P C L A_{U}}
$$

donde:

- U umbral considerado (s).

- I_TiPCLA ${ }_{U}$ : integral de TiPCLA bajo un valor umbral $U\left(\mathrm{~s}^{2}\right)$.

- T_TiPCLA : valor total de tiempo bajo un valor umbral de TiPCLA (s).

Para tener una mejor caracterización del conflicto se debe utilizar conjuntamente el indicador con la integral del mismo bajo un valor umbral y con el intervalo de tiempo bajo este umbral. Estos dos valores indican no solo que tan serio es el conflicto sino que tanta exposición al conflicto hay.

\subsubsection{Indicadores agregados TiPCLA}

Para poder comparar dos ubicaciones o dos situaciones de tráfico diferentes, se busca tener indicadores agregados de la conflictividad, por lo que se han desarrollado los siguientes indicadores derivados de TiPCLA:

En primer lugar el tiempo medio de TiPCLA bajo un valor umbral $U$ por unidad de tiempo, definido como se muestra en la ecuación (99).

$$
\text { Tt_TiPCLA }_{U}=\frac{\sum_{\equiv}^{*} \operatorname{TiPCLA}_{\mathrm{U}, \mathrm{i}}}{\text { periodo }}
$$

donde:

- Tt_TiPCLA $A_{u}$ : tiempo total de T_TiPCLA $A_{U}$ bajo el umbral $U$ por unidad de tiempo (s/h).

- T_TiPCLA Ti $_{\text {: }}$ tiempo en el que el valor TiPCLA es inferior al valor umbral U de la maniobra i (s). 
- Periodo: tiempo total de observación (h).

- $\mathrm{N}$ : número total de maniobras observadas.

En segundo lugar, el valor medio de las integrales de TiPCLA bajo un valor umbral $\mathrm{U}$ por unidad de tiempo, definido por la ecuación (100).

$$
\text { SI_TiPCLA }_{U}==\frac{\sum_{=}^{\prime \prime} \Gamma_{\text {piPCLA }}{ }_{\mathrm{U}, \mathrm{i}}}{\text { periodo }}
$$

donde:

- SI_ TiPCLA: suma de I_ TiPCLA $u$ bajo el umbral U por unidad de tiempo $\left(\mathrm{s}^{2} / \mathrm{h}\right)$.

- I_TiPCLAU:: Integral de TiPCLA bajo el valor umbral U de la maniobra i $\left(\mathrm{s}^{2}\right)$

- Periodo: tiempo total de observación (h).

- $\mathrm{N}$ : número total de maniobras observadas.

El tiempo medio de exposición a un valor de TiPCLA inferior a un umbral $U$ por maniobra, definido como se muestra en la ecuación (101).

$$
\mathrm{TM}_{-} \operatorname{TiPCLA}_{\mathrm{U}}=\frac{\sum_{\equiv}^{\prime} \operatorname{TiPCLA}_{\mathrm{U}, \mathrm{i}}}{\mathrm{N}}
$$

donde:

- TM_TiPCLAU: tiempo medio por maniobra de T_TiPCLA $A_{U}$ bajo un valor umbral U (s/veh).

- T_TiPCLAU: tiempo en el que el valor TiPCLA es inferior al valor umbral U de la maniobra i (s).

- $\mathrm{N}$ : número total de maniobras observadas.

Finalmente, el valor medio de la integral de TiPCLA bajo un umbral U por maniobra, definido en la ecuación (102).

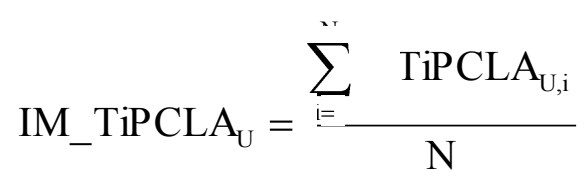

donde:

- IM_TiPCLAu: valor medio de I_TiPCLAu por maniobra $\left(\mathrm{s}^{2} / v e h\right)$. 
- I_TiPCLA Ai: Integral de TiPCLA bajo el valor umbral U de la maniobra i.

- $\mathrm{N}$ : número total de maniobras observadas.

Los dos primeros indicadores representan la frecuencia de exposición y la intensidad de los conflictos durante un periodo de tiempo determinado y los últimos representan el valor medio por maniobra. En la Figura 114 se puede observar gráficamente la representación de estos indicadores.

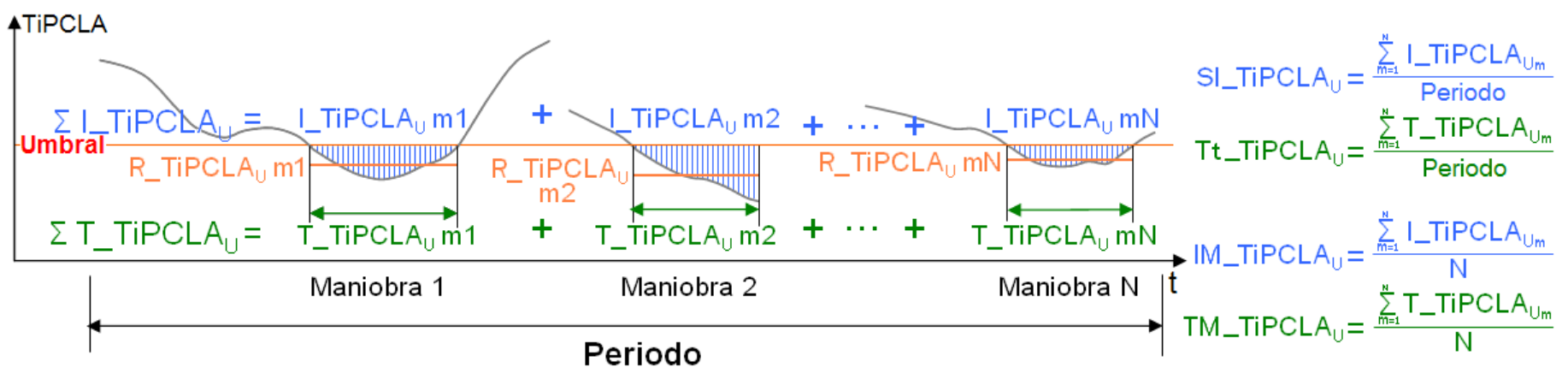

Figura 114: Familia de indicadores TiPCLA

Es importante resaltar que para medir la conflictividad de una maniobra determinada, en cada instante de tiempo $t$, se debe tomar el valor más desfavorable de conflictividad, lo que implica en cada momento evaluar la conflictividad del vehículo que realiza la maniobra con todos los vehículos aledaños y seleccionar el peor de los casos.

\subsubsection{TiPCLA para un conflicto específico}

Para aplicar el indicador TiPCLA en un conflicto específico se obtiene en primer lugar las posiciones, tanto transversal como longitudinal de los dos vehículos involucrados en el conflicto, y sus velocidades, longitudinales y transversales.

Con estos datos se calcula, para cada instante de tiempo, los diferentes valores que componen el indicador TiPCLA. Es importante resaltar que dicho cálculo se hace dos veces, es decir, primero se selecciona un vehículo como líder y se calcula para cada instante de tiempo y, a continuación, se hace el cálculo seleccionando el otro vehículo como el líder. Finalmente, en cada instante de tiempo i se selecciona el menor valor, como el valor TiPCLA $A_{i}$ para este momento. En la Figura 115 se muestra gráficamente la variación del indicador de conflictividad calculado en función del tiempo. 


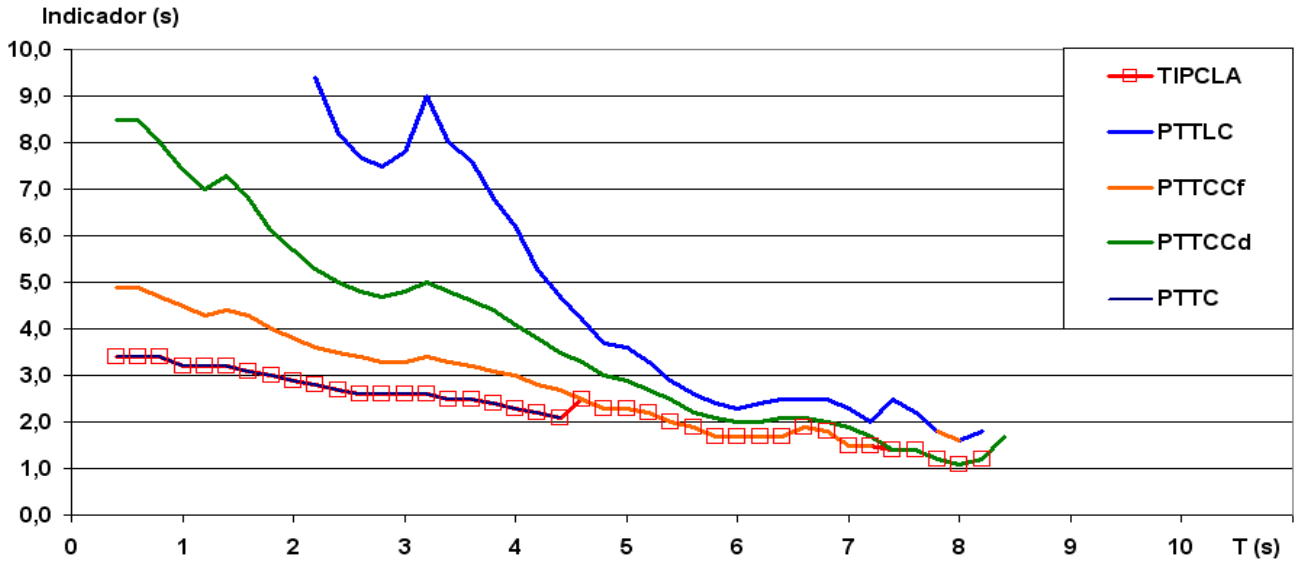

Figura 115: Variación del indicador de conflictividad en el tiempo para un conflicto específica

\subsubsection{TiPCLA para una maniobra específica}

El cálculo de TiPCLA de una maniobra específica se utiliza para conocer la conflictividad de la maniobra desarrollada por un vehículo. En consecuencia, se calcula la conflictividad de ese vehículo con cada uno de los vehículos de su entorno, siguiendo la metodología empleada para el cálculo de un conflicto específico, y seleccionando en cada instante el menor valor de TiPCLA, independiente del vehículo con el que entra en conflicto.

A continuación, en la Figura 116, se muestra gráficamente el cálculo descrito. Asimismo se puede observar los valores de I_TiPCLA 2.0, T_TiPCLA 2.0 y R_TiPCLA 2.0.

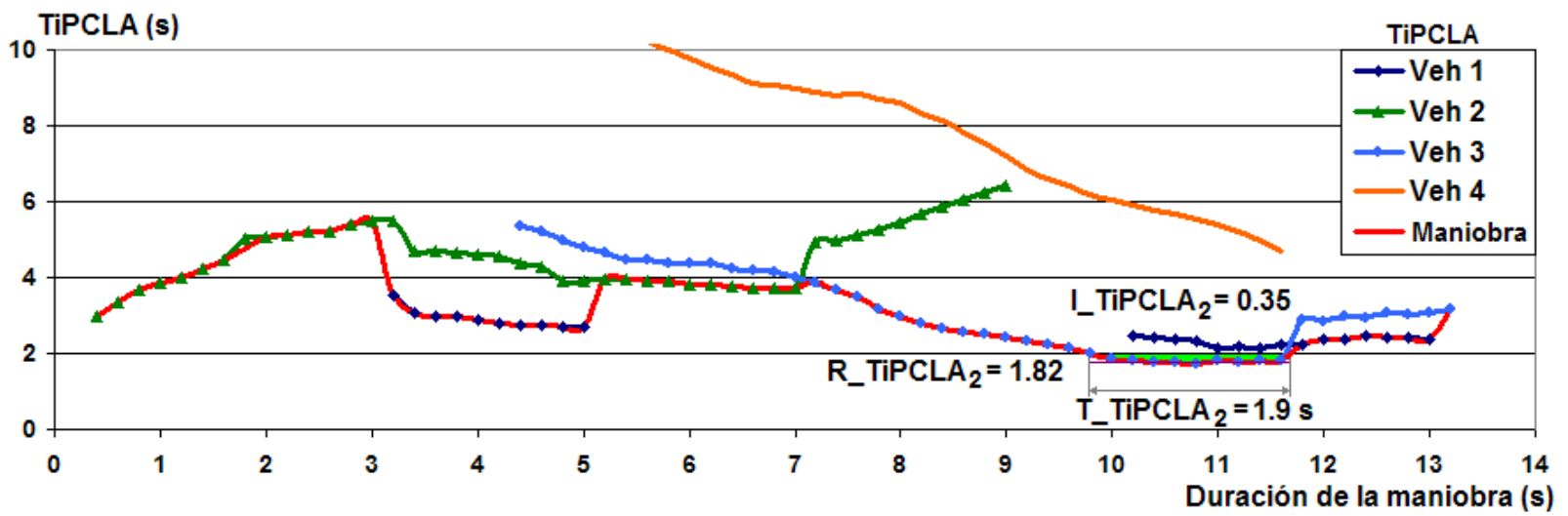

Figura 116: TiPCLA para una Maniobra Específica

Se puede observar la evolución del conflicto mientras se produce la maniobra y cómo a lo largo de la maniobra la mayor conflictividad se produce con distintos vehículos. 


\subsubsection{TiPCLA para múltiples maniobras}

Para el análisis de una ubicación específica se calculan los indicadores I_TiPCLA y $T_{\_}$TiPCLA $u$ para cada maniobra de una muestra continua, posteriormente se obtienen los valores de SI_TiPCLA ${ }_{U}$, Tt_TiPCLA, IM_TiPCLA $A_{u}$ y TM_TiPCLA

En la Figura 117 se puede observar la variación de estos indicadores en función del umbral.

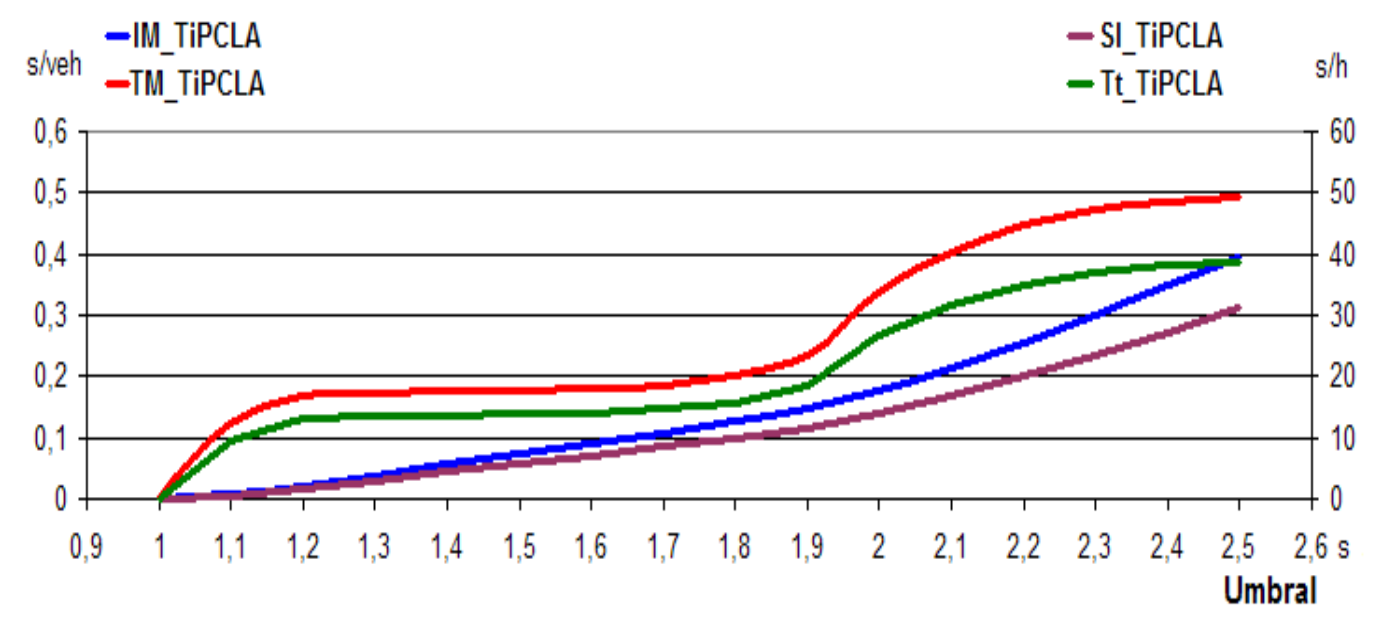

Figura 117: Variación de los Indicadores en función del umbral

Como se puede observar en la Figura 117, los valores relacionados con el tiempo de exposición, es decir los valores Tt_TiPCLA $\cup$, y TM_TiPCLA $A_{\cup}$ tienen un comportamiento muy estable para un umbral dentro del intervalo $(1,2-1,8)$ s y los valores relacionados con la integral de TiPCLA, tienen un crecimiento lineal.

Para valores inferiores a 1,2 s se observa un crecimiento acelerado del tiempo de exposición y un aumento en la pendiente de los indicadores relacionados con la integral de TiPCLA, lo que significa que para estos valores de umbral hay maniobras no se van teniendo en cuenta a medida que crece el umbral.

Finalmente, para umbrales superiores a $1,8 \mathrm{~s}$, se observa nuevamente un crecimiento debido a que se incluyen maniobras consideradas normales.

Para evaluar la conflictividad de diferentes emplazamientos es suficiente con obtener los valores bajo un umbral dentro del intervalo recomendado $(1,2-1,8)$ s y compararlos.

\subsubsection{Aplicación}

Para la aplicación de los indicadores de conflicto se plantean dos alternativas, la primera por visionado directo de los vídeos y la segunda haciendo uso del modelo de restitución de maniobras a partir de los vídeos digitalizados.

En el caso del visionado de los vídeos, se toman tiempos en secciones conocidas de la vía con la ayuda de una rejilla sobrepuesta. Adicionalmente se deben tomar los tiempos en secciones transversales específicas las cuales son: punto en que se aprecia el inicio de cambio de carril, momento en el que el vehículo pisa la línea de separación 
de carriles, momento en el que el vehículo abandona el carril, punto en que se centra en el carril o inicia a discurrir paralelo a él.

En el caso de que se utilice el modelo de restitución de maniobras, se obtiene la posición longitudinal y transversal de los vídeos en cada momento, asociado al tiempo del vídeo.

Con estos valores se obtiene la velocidad tanto longitudinal como transversal de los vehículos, su posición en un determinado instante de tiempo y su aceleración, que son los datos necesarios para el cálculo de los indicadores.

Se calcula el valor del indicador en cada instante de tiempo evaluado y se hace un seguimiento de los vehículos involucrados para determinar el valor mínimo del indicador que es el que caracteriza la maniobra. Igualmente se obtiene la integral del indicador bajo un valor umbral y la suma de tiempo bajo un valor umbral.

\subsubsection{Selección del indicador de conflictividad}

De los dos indicadores propuestos se utilizará el tiempo potencial para colisión lateral o alcance, TiPCLA, debido a que permite evaluar el conflicto de una manera que se simplifican los cálculos, además porque representa el proceso de una colisión cuando el conductor no percibe las maniobras de su predecesor y ocurre un accidente.

Teniendo en cuenta que para el análisis que nos ocupa en esta investigación se debe tomar un valor general para los distintos carriles de deceleración y no se puede utilizar un valor puntual para caracterizar la operación del carril de deceleración, se utilizarán los indicadores agregados IM_TiPCLA y TM_TiPCLA

Para la evaluación se debe tomar el valor umbral que, en el proceso de validación, mejor se ajuste a los datos de accidentalidad. A priori se puede inferir que el umbral seleccionado debe estar en el intervalo $(1,2-1,8)$, que es el intervalo en el que los valores TiPCLA permanecen estables.

\subsection{RESULTADOS}

A continuación se presentan los resultados experimentales para la evaluación cualitativa que se ha realizado por observación directa de los vídeos, como la evaluación cuantitativa realizada aplicando las Técnicas de conflictos de Tráfico y específicamente el indicador de conflictividad TiPCLA, diseñado específicamente para los conflictos que se presentan en los carriles de deceleración.

Para la evaluación se seleccionaron, de cada carril de deceleración, 50 vehículos ligeros que reunieran las siguientes condiciones: su intervalo con relación al vehículo precedente sea superior a $5 \mathrm{~s}$ y que el carril de deceleración se encontrara libre en el momento de la salida.

Adicionalmente se tomaron maniobras tanto libres como condicionadas durante un periodo continuo de una hora para calcular los índices de conflictividad. 


\subsubsection{Velocidades}

Antes del inicio del desarrollo experimental, se realizó una medición de velocidades a flujo libre de los vehículos en cada uno de los carriles en la situación inicial. En dicha medición se encontraron velocidades de operación $V_{85}$ muy altas en los tres carriles de la autovía, superiores a la velocidad del proyecto, especialmente en el carril izquierdo (carril 3).

Adicionalmente, se observa una gran dispersión de las velocidades en el carril derecho (carril 1), lo que hace que el riesgo de accidentalidad aumente.

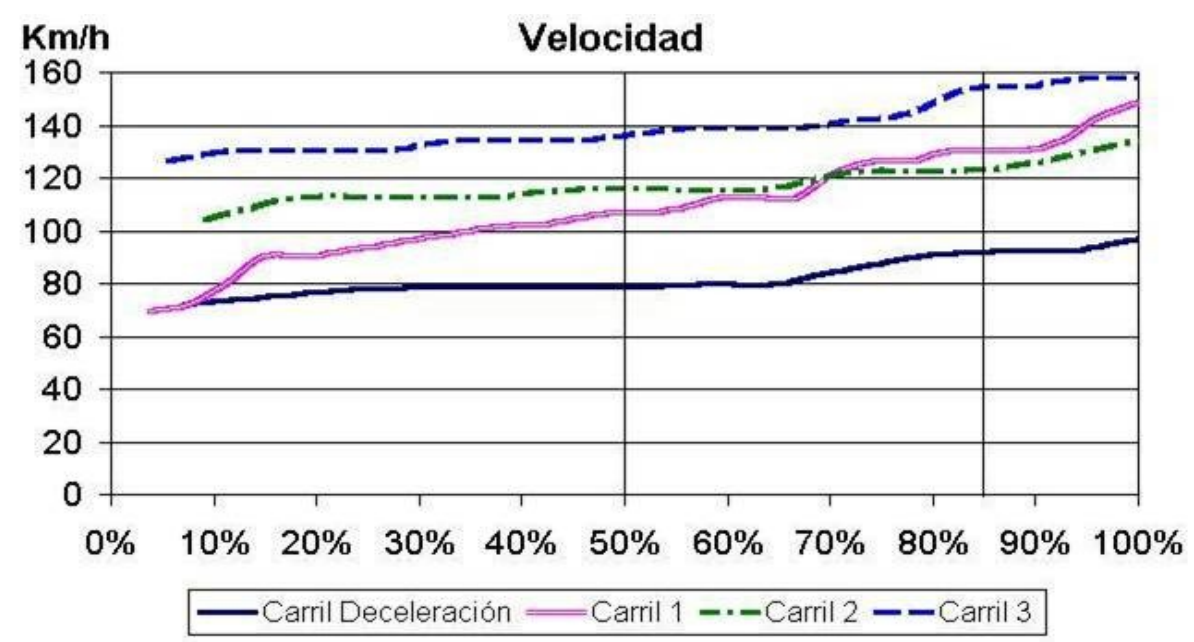

Figura 118: Velocidades libres en la sección transversal del punto medio del carril de deceleración en la configuración inicial

En la primera fase se evaluaron las velocidades de los vehículos ligeros antes de su salida en el carril derecho (carril 1) en el punto donde su velocidad no se viera afectada por la maniobra de salida como en el punto donde abandonan por completo la vía principal

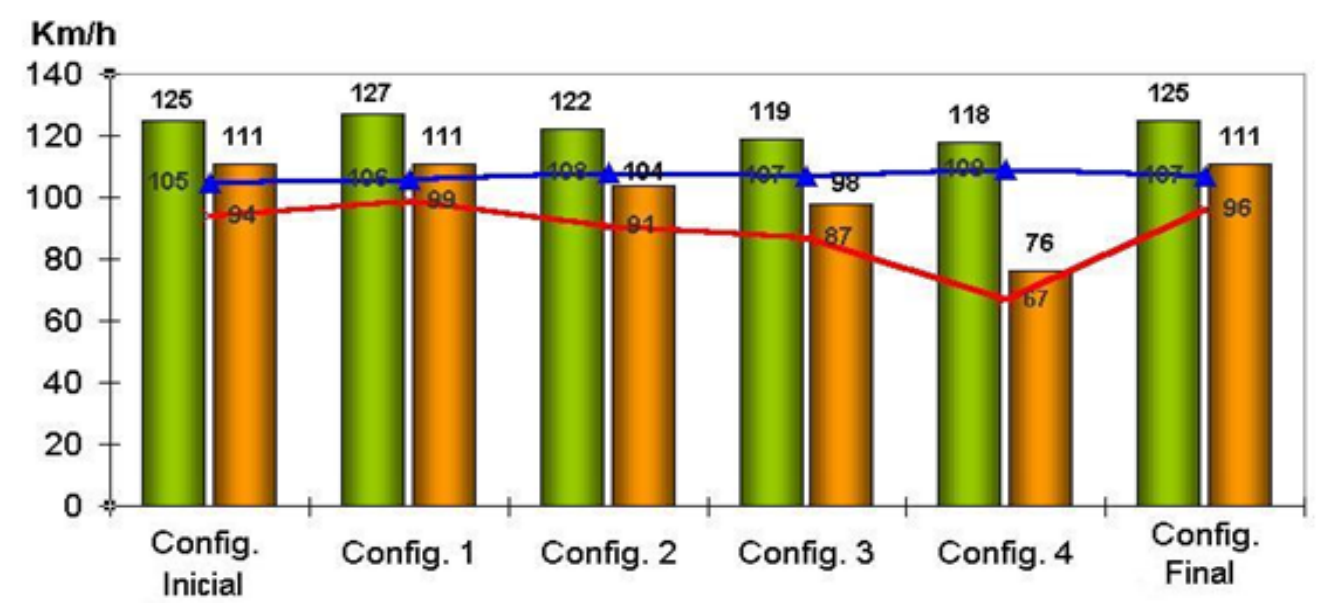

$\square$ V85L $\square$ V85i $₫$-Vmedia $L \multimap$ Vmedia i

Figura 119: Velocidad carril 1 y al abandonar la vía principal 
En las todas las configuraciones excepto en la configuración 4, se encuentra una disminución aproximada de $17 \mathrm{Km} / \mathrm{h}$ en el percentil 85 de la velocidad entre el punto donde no se encuentra afectada la velocidad en la vía principal y el punto donde el vehículo abandona completamente la vía principal, pero en la configuración 4, esta disminución es de $42 \mathrm{Km} / \mathrm{h}$.

Se realizó la medición de la velocidad en la nariz para observar su comportamiento en función de la longitud del carril, encontrando que en todos los casos el percentil 85 de dicha velocidad es superior a la velocidad limitada. Adicionalmente, si el carril es muy largo o muy corto esta velocidad es mayor que si se tiene una distancia intermedia.

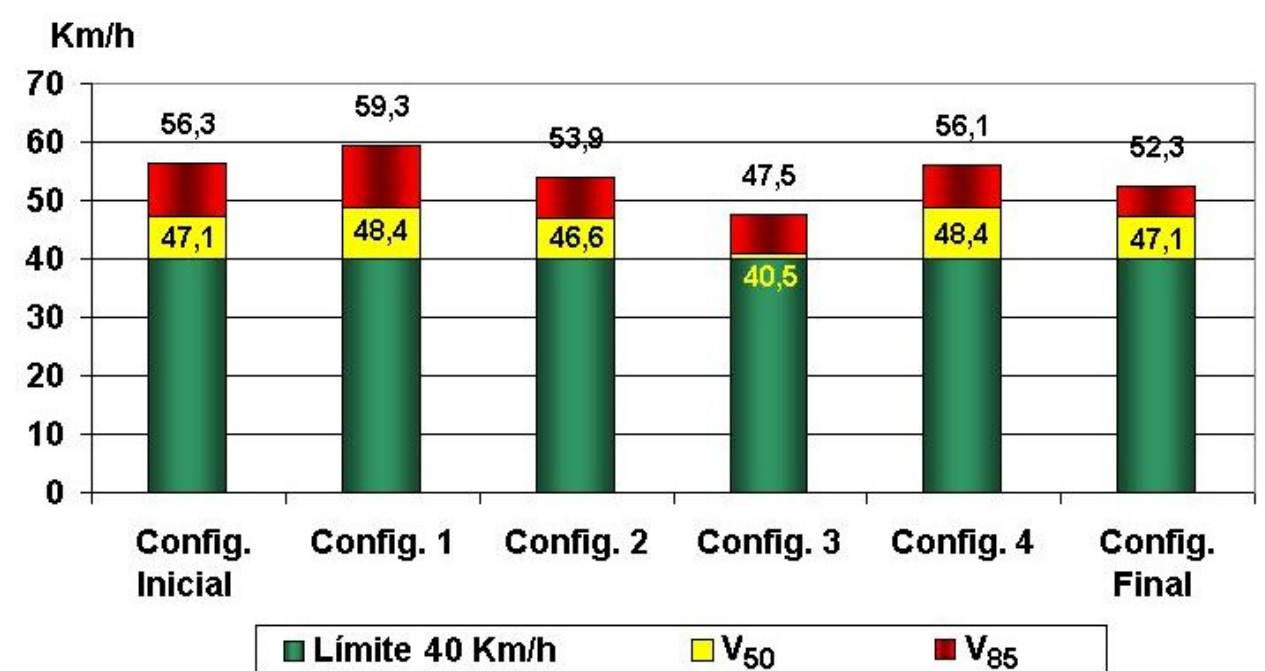

Figura 120: Velocidad limitada, media y percentil 85 en la nariz

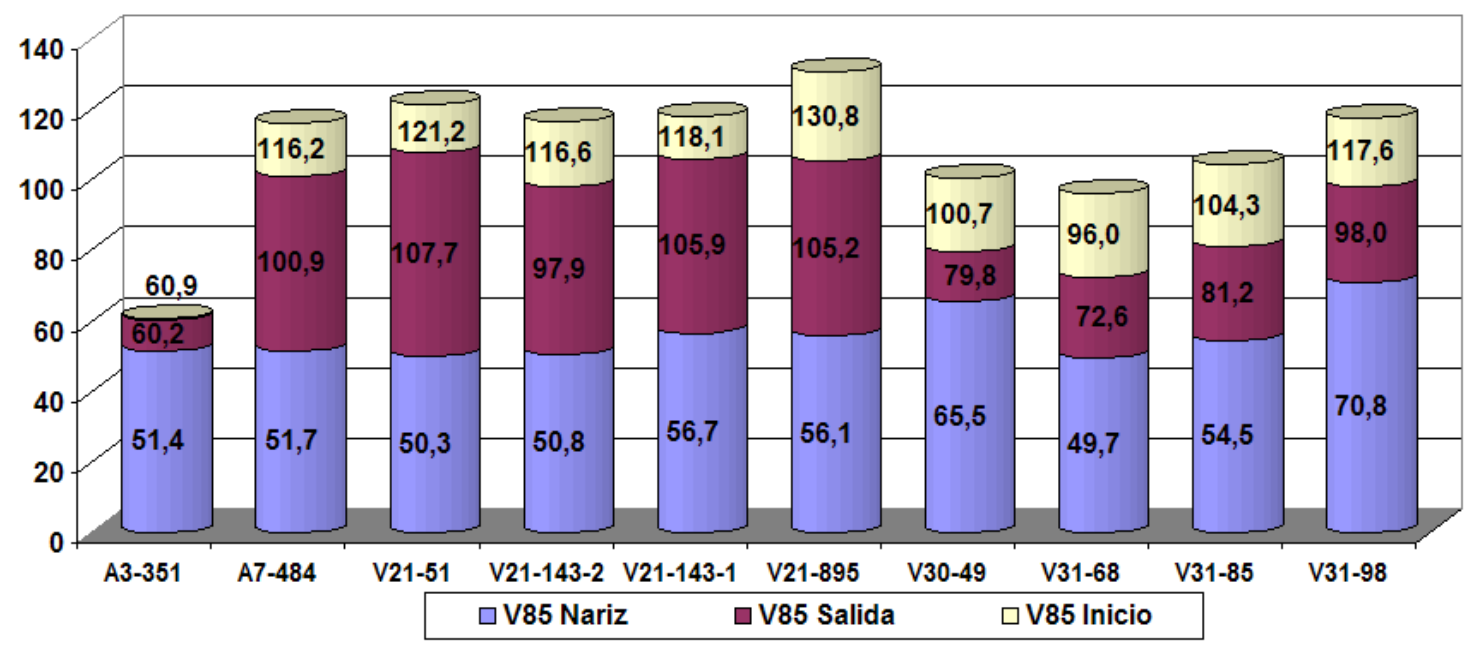

Figura 121: Percentil 85 de la velocidad antes de salir; en el momento de abandonar el carril y en la nariz 
Se realizó la misma medición en los carriles de deceleración de la segunda fase. Se ha encontrado que al igual que en las configuraciones experimentales, el percentil 85 de la velocidad en la nariz es superior al límite de velocidad.

De la misma manera la diferencia de velocidad entre el punto donde inicia el carril de deceleración y el punto donde el vehículo sale es de $17,3 \mathrm{~km} / \mathrm{h}$. Se encontró por el contrario que en el carril A3-351 dicha diferencia en casi nula, debido posiblemente a que ese punto coincide con la salida de la ciudad y la diferencia de velocidades entre la vía principal y la salida es muy baja.

Teniendo en cuenta que los carriles de deceleración seleccionados tienen características diferentes, con el fin de tener un valor de longitud que sea más homogéneo, se ha utilizado la relación entre la longitud real del carril de deceleración (L) y la longitud calculada según la Instrucción de Trazado 3.1-IC (1999) tomando el límite de velocidad de la vía y no la velocidad limitada en la sección de 1,5 m de anchura de la cuña $\left(L_{0}\right)$.

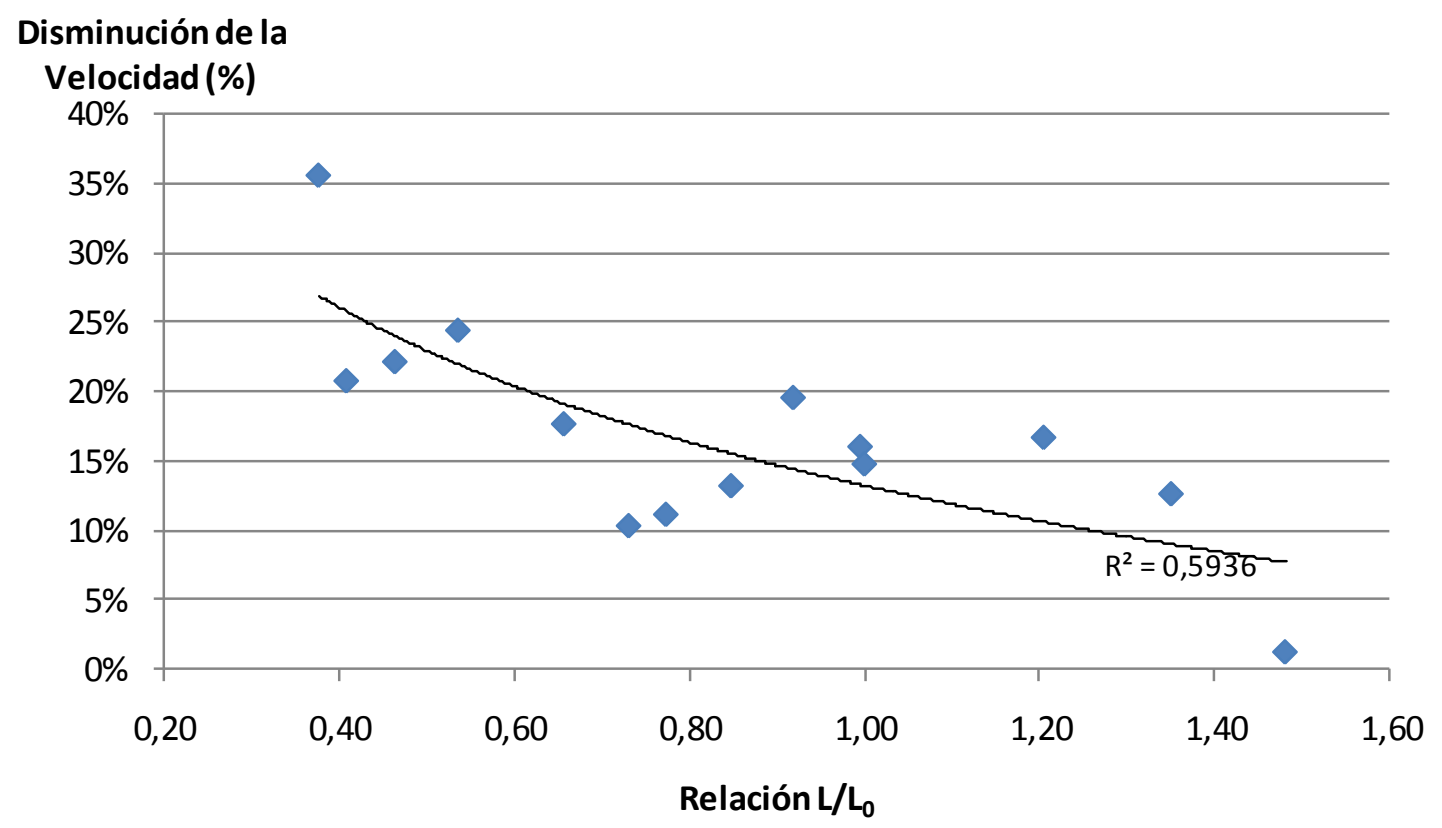

Figura 122: Variación del percentil 85 de la velocidad al abandonar la vía principal en función de la relación $L / L_{0}$

En la Figura 122 se puede observar la variación de la diferencia del percentil 85 de la velocidad en función de la relación $L / L_{0}$ en la que se confirma, en primer lugar, que los vehículos deceleran antes de tomar el carril de deceleración.

Asimismo, se observa que si el carril es muy corto respecto a su longitud de diseño, disminución de velocidad es mayor, afectando en mayor medida el flujo de la vía principal. Para una relación $L / L_{0}$ de 1 , la disminución de velocidad está alrededor del 14\%, lo que coincide con lo observado por De la Iglesia y García (2000). 
Adicionalmente se evidencia que los conductores deceleran durante la maniobra de cambio de carril, lo cual influye en la vía principal.

Para caracterizar la maniobra de cambio de carril se ha evaluado la velocidad transversal de los vehículos encontrando muy poca variación entre los carriles analizados.

En la Figura 123 se puede observar los percentiles 50 y 85 de la velocidad transversal para cada uno de los carriles analizados. Asimismo, puede observarse como el percentil 50 de la velocidad transversal varía entre 0,87 y 1,08 m/s, mientras que el percentil 85 de dicha velocidad varía entre 0,93 y $1,16 \mathrm{~m} / \mathrm{s}$.

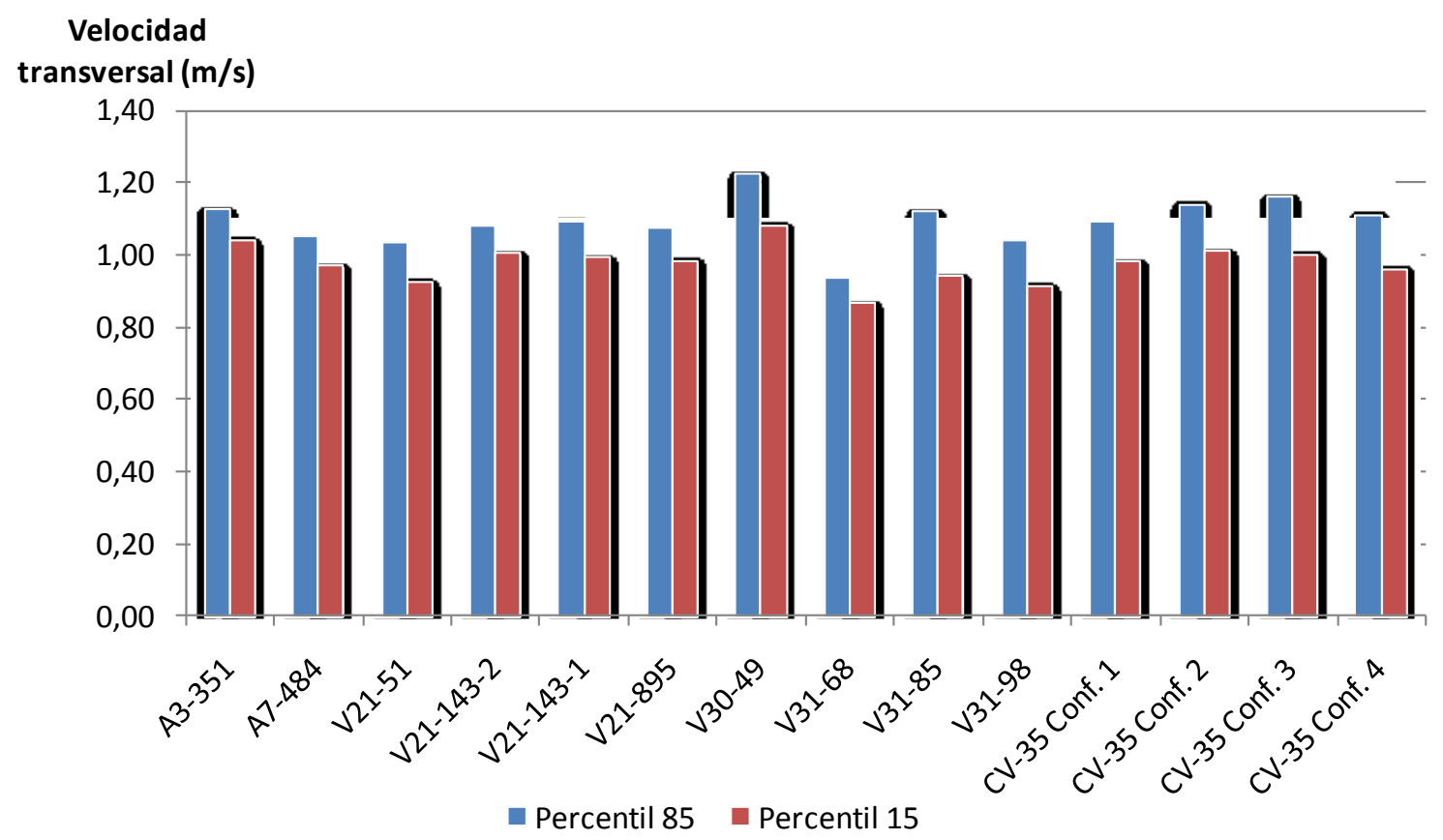

Figura 123: Percentiles 85 y 50 de la velocidad transversal de la maniobra de cambio de carril 


\subsubsection{Trayectorias}

A continuación se muestra la nube de puntos de las trayectorias seguidas por los vehículos en cada uno de los carriles de deceleración estudiados.
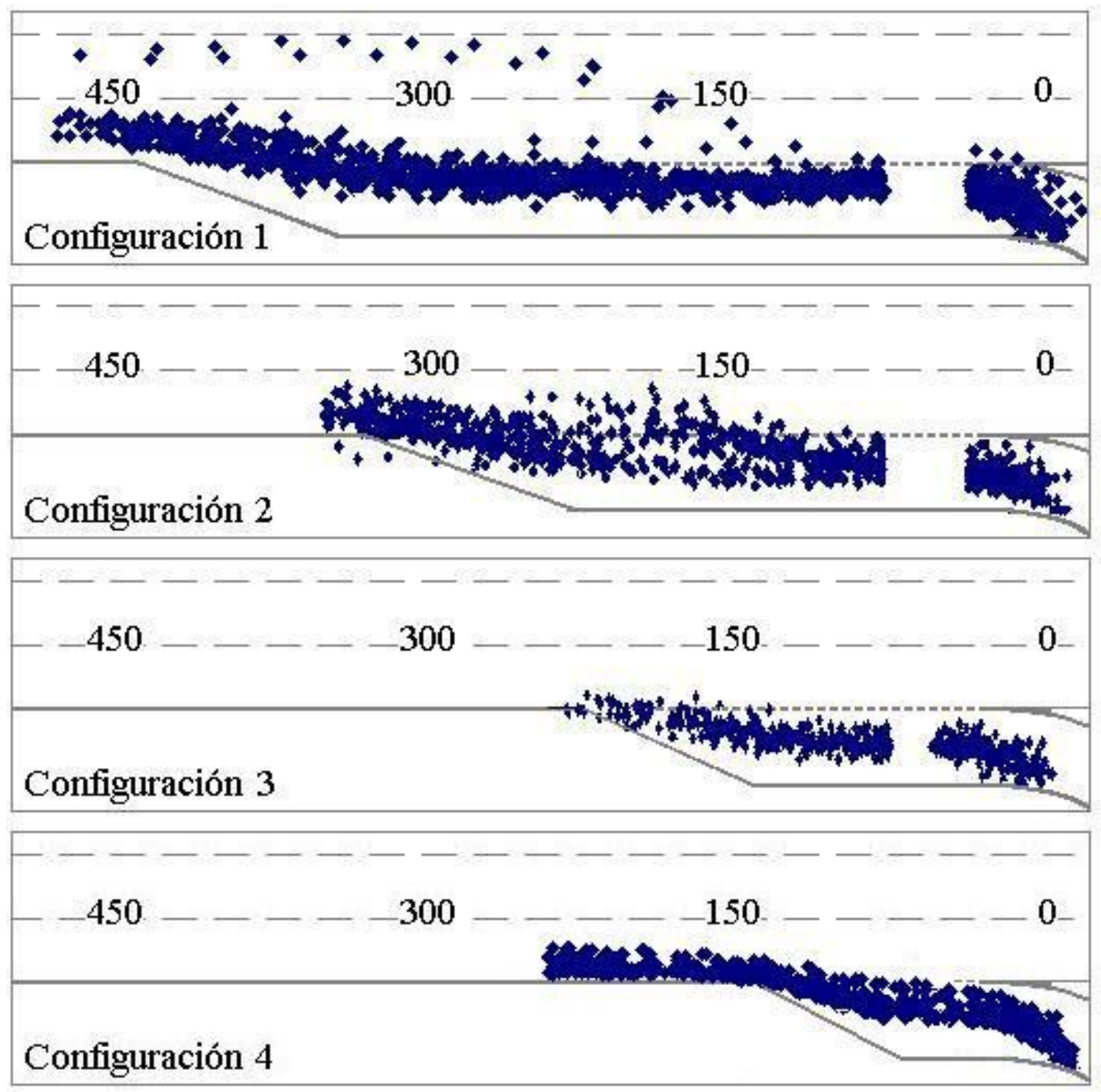

Figura 124: Nube de puntos de trayectorias restituidas en cada configuración

En los carriles experimentales se observa en la configuración 1 y en la 4, que los vehículos al llegar a la nariz modifican su trayectoria para maximizar el radio de la rampa de salida, confirmando el comportamiento de la velocidad de los vehículos en la nariz. 

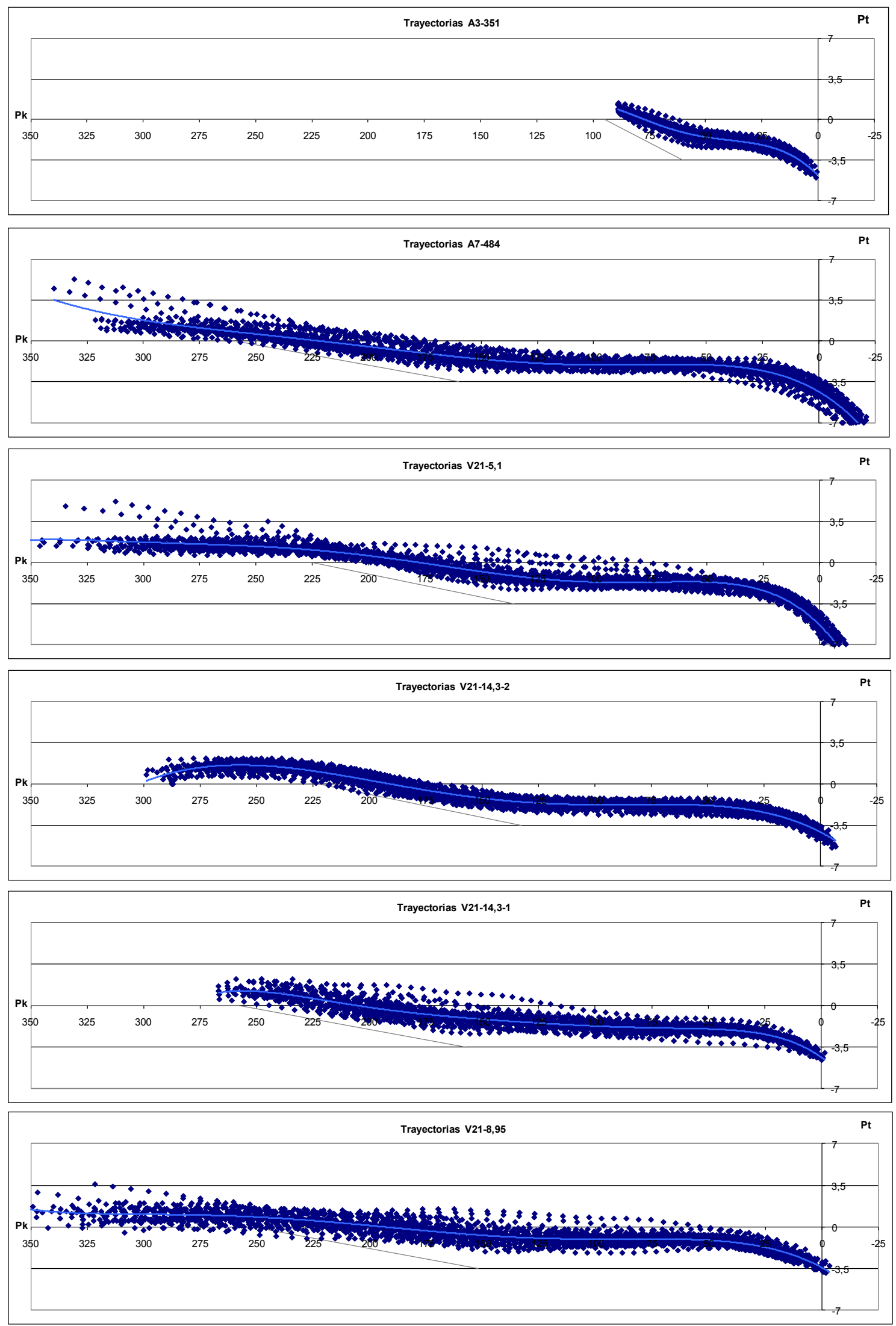

Figura 125: Nube de puntos de trayectorias restituidas en los carriles de comprobación 


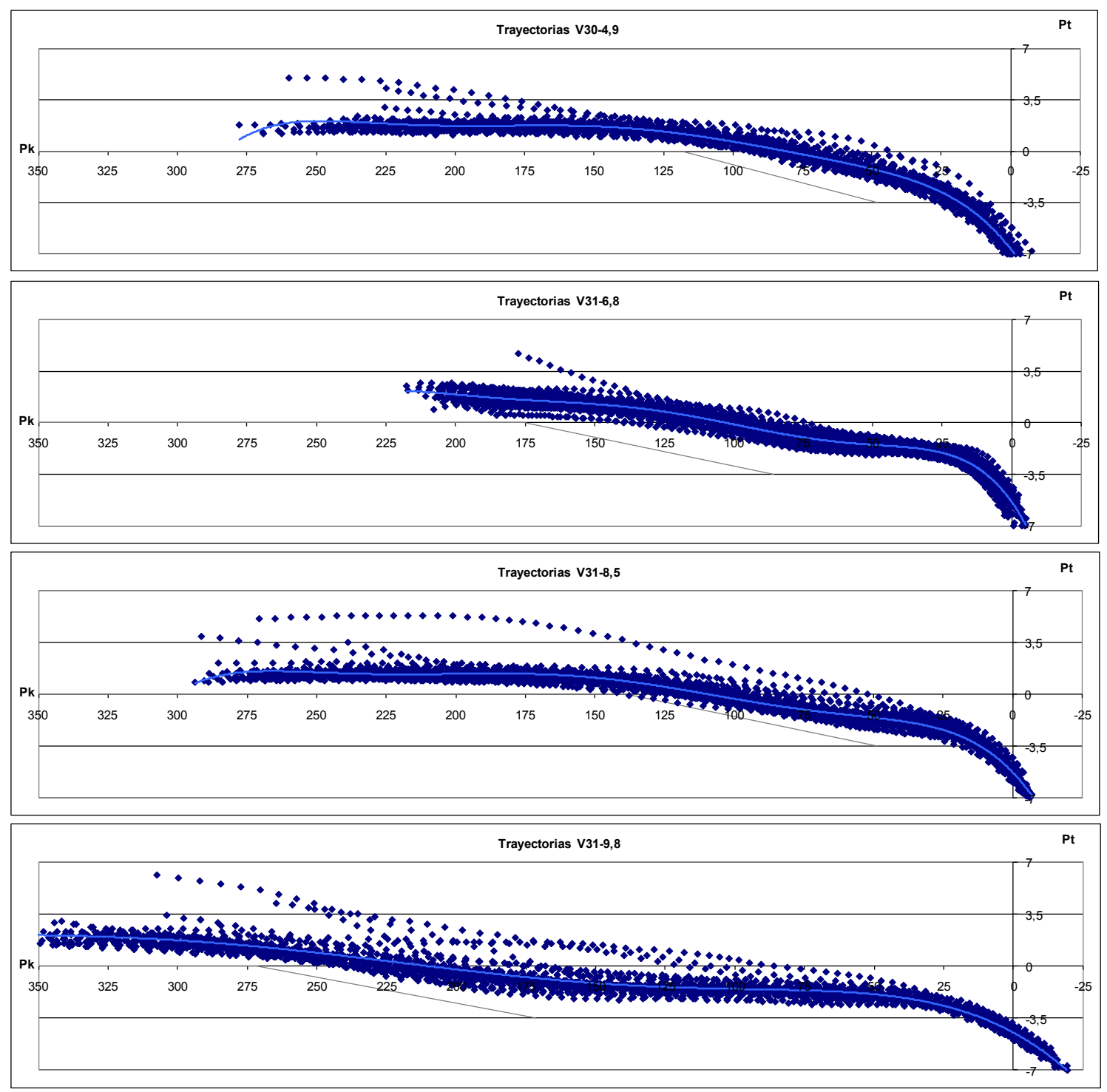

Figura 126: Nube de puntos de trayectorias restituidas en los carriles de comprobación

Se puede observar que los conductores prefieren una trayectoria compuesta por curva y contra curva en lugar de la maniobra directa, excepto en el carril de la V30-4,9 que, posiblemente por estar ubicado en una curva a izquierda de la autovía, los conductores modifican su comportamiento dando como resultado una maniobra más directa.

Asimismo, se observa cómo algunos conductores optimizan la trayectoria de cambio de carril iniciándola antes del inicio de la cuña mientras otros inician la maniobra pasado el inicio de la cuña por lo que se ha evaluado la distancia entre el inicio de la cuña y el inicio de la maniobra de cambio de carril. 
Se observa en la Figura 127 los percentiles 15, 50 y 85 de la distancia entre el inicio de la maniobra de cambio de carril y el inicio de la cuña para cada uno de los carriles estudiados.

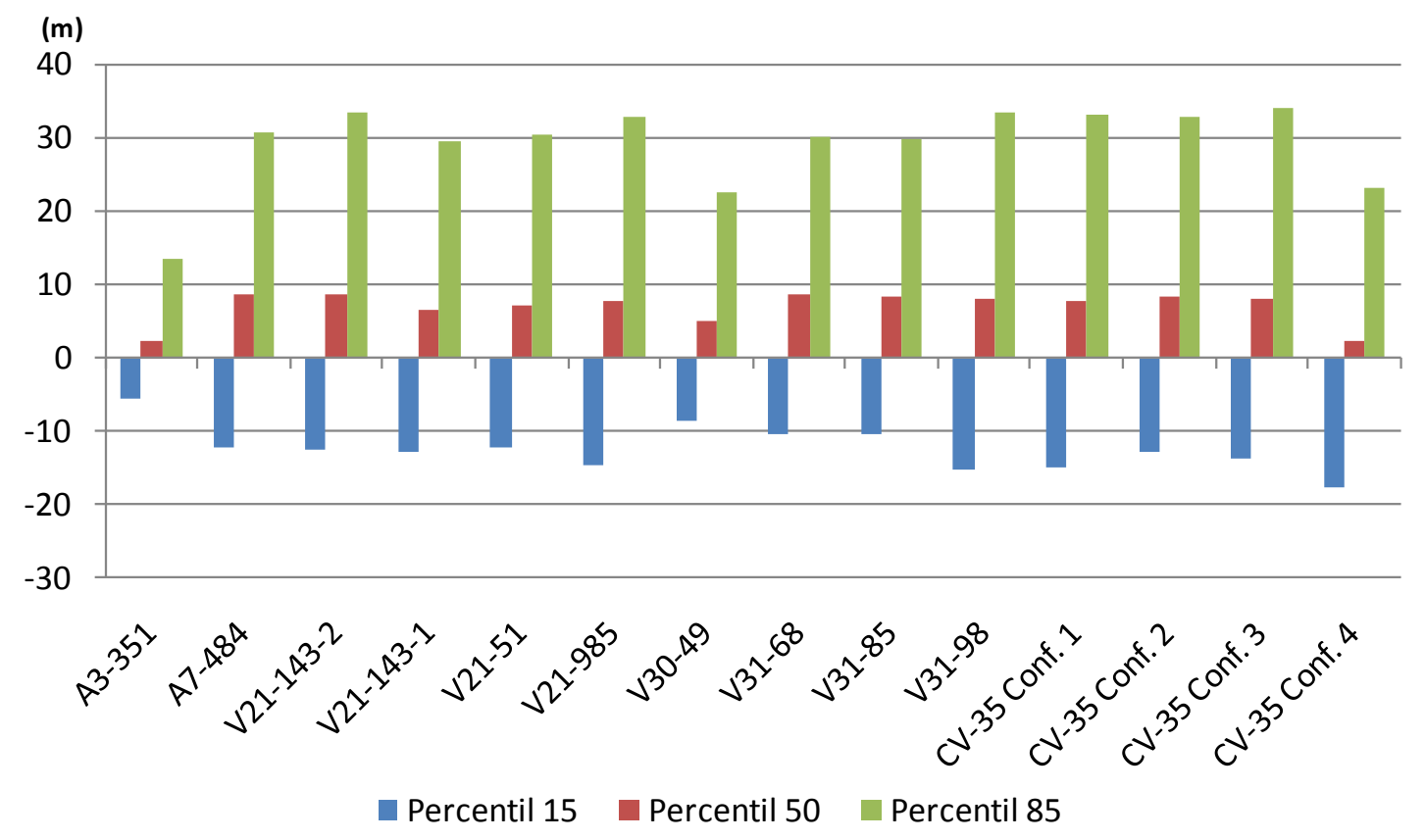

Figura 127: Distancia de inicio de la maniobra de cambio de carril respecto al inicio de la cuña

Se destaca la diferencia de distancia entre los carriles más cortos y los demás carriles, en especial el carril A3-351. Esta diferencia puede deberse posiblemente a que éste carril coincide con la salida de la ciudad por lo que la velocidad en la vía principal es muy baja en este punto, cercano a los $60 \mathrm{~km} / \mathrm{h}$. En el caso del carril de la CV-35 configuración 4 se observa como el punto de inicio de la maniobra está desplazado aguas arriba del carril debido al aumento en el porcentaje de maniobras anticipadas y a que el carril era muy corto.

Asimismo, se observa que la distancia de inicio de la maniobra de cambio de carril coincide con la sección característica en que la cuña tiene una anchura de $1 \mathrm{~m}$.

En la Figura 128 se observa el tiempo necesario para que un vehículo recorra la distancia entre el inicio de la maniobra de cambio de carril y el inicio de la cuña, suponiendo que viaja a una velocidad equivalente a la velocidad de la vía principal. Se observa que los conductores inician la maniobra de cambio de carril, aproximadamente entre $0,4 \mathrm{~s}$ antes de llegar al inicio de la cuña y $1 \mathrm{~s}$ después de pasar el inicio de la cuña, para los percentiles 15 y 85 , respectivamente. 


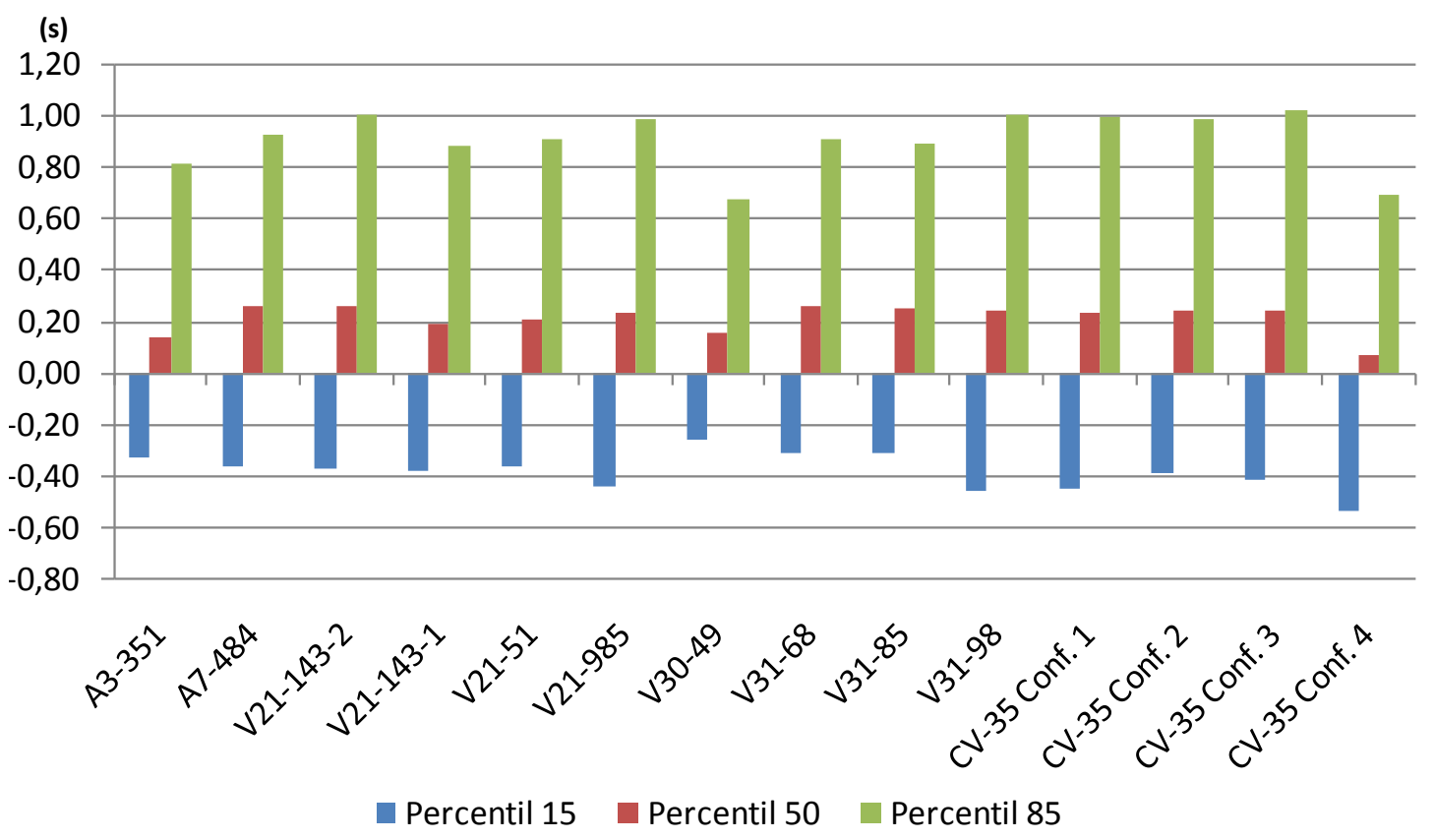

Figura 128: Tiempo de inicio de la maniobra de cambio de carril respecto al inicio de la cuña

Se ha evaluado la proporción entre la longitud de las maniobras de cambio de carril para cada uno de los carriles estudiados y la longitud de la cuña existente o la longitud de la cuña normalizada teniendo en cuenta el límite de velocidad genérico de la vía. (Figura 129)

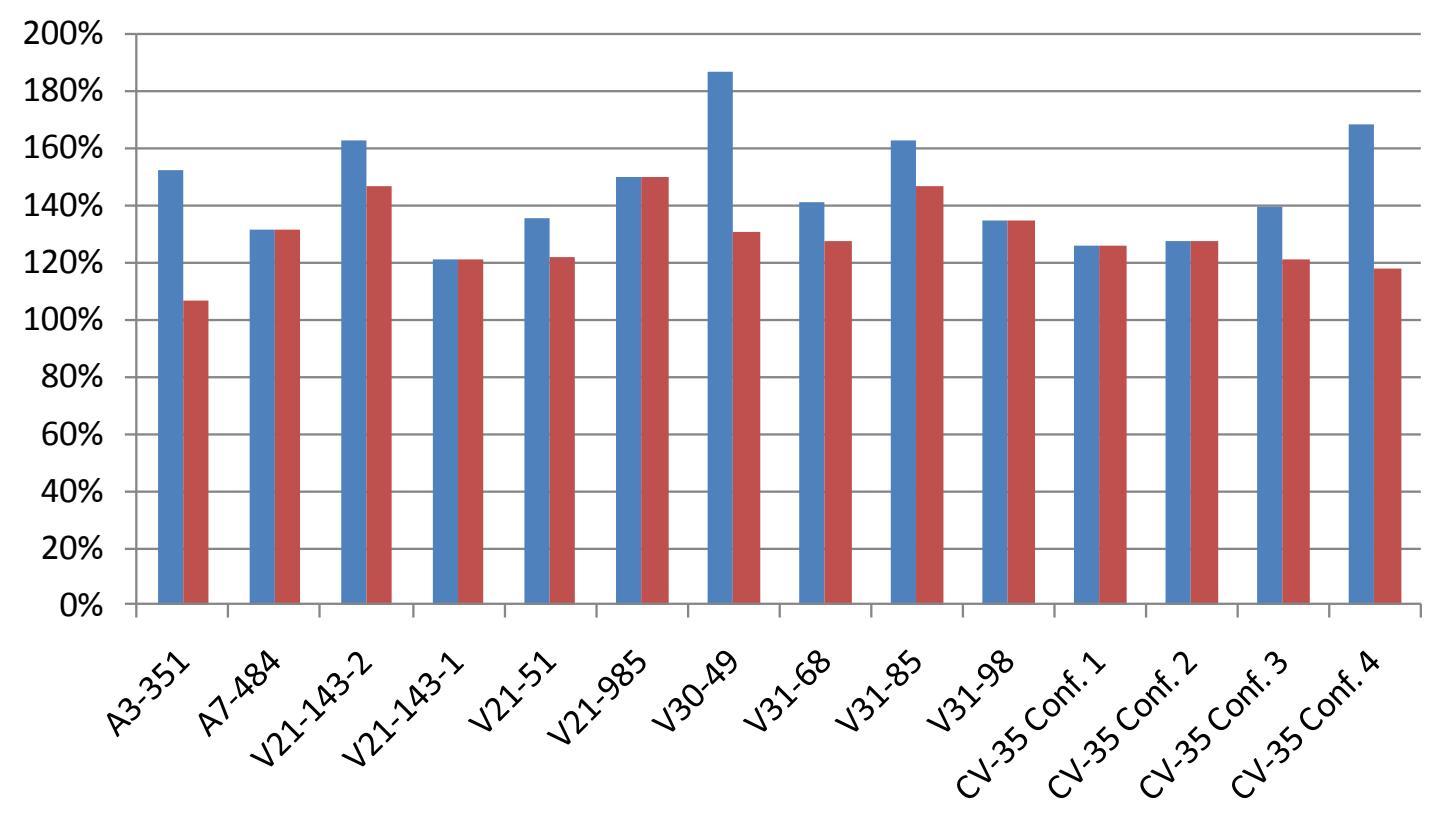

- Percentil 50 de la longitud maniobra de salida / Longitud de la cuña

- Percentil 50 de la longitud maniobra de salida / Longitud de la cuña normalizada

Figura 129: Proporción entre la longitud de la maniobra de salida y la longitud de la cuña 
Se puede observar que, para todos los carriles estudiados, la proporción entre el percentil 50 de la longitud de la maniobra de salida y la longitud de la cuña varía entre el $120 \%$ y el $185 \%$, con una alta variabilidad en este valor.

En cuanto a la proporción entre el percentil 50 de la longitud de las maniobras de salida y la longitud normalizada de la cuña considerando la el límite de velocidad genérico de la vía se puede observar, en la Figura 129, que disminuye la variabilidad de esta proporción, manteniéndose entre el $106 \%$ y el $149 \%$.

\subsubsection{Punto de salida}

Es importante resaltar que en la configuración inicial de la primera fase, la salida es muy dispersa a lo largo del carril de deceleración debido a que en ella no estaba señalizada la cuña, lo que confunde a un número apreciable de conductores al no poder localizar con suficiente antelación la posición exacta de la salida.

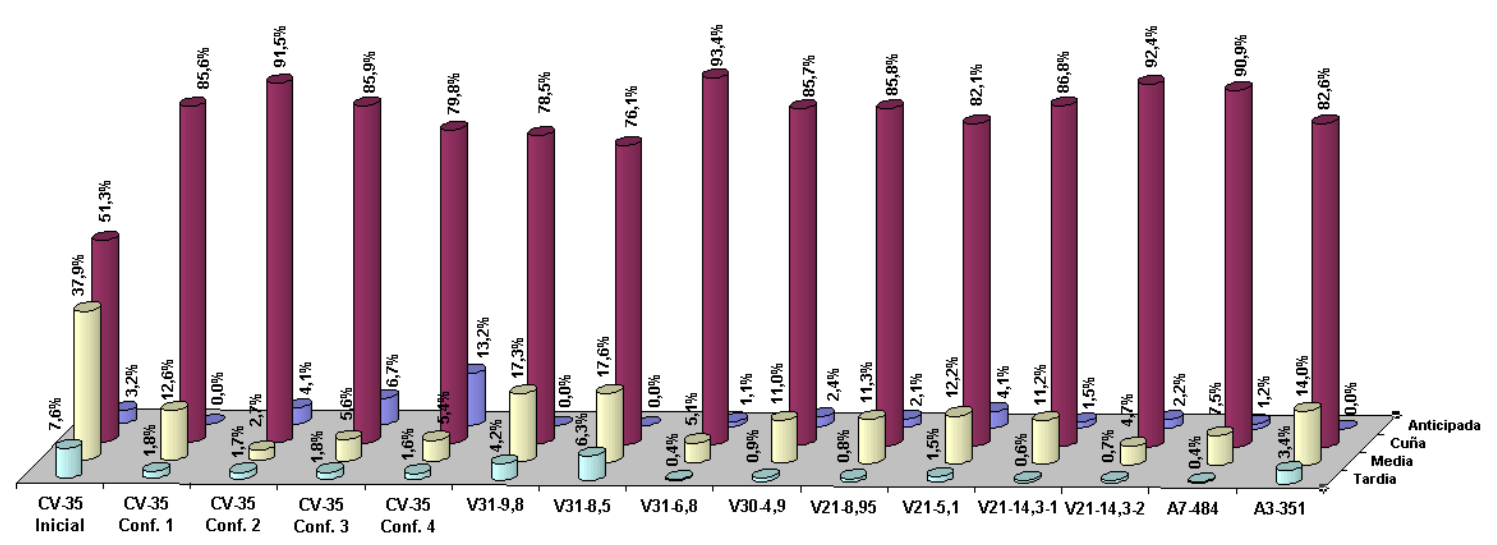

Figura 130: Distribución de la salida

En las demás configuraciones y carriles adicionales más del $76 \%$ de los vehículos salen en la cuña, lo que reafirma la importancia de la cuña. Asimismo se observa como existe un porcentaje de vehículos entre el $2,7 \%$ y el $17,3 \%$ que sale en la zona intermedia del carril.

\subsubsection{Aceleraciones y deceleraciones}

En primer lugar, se procedió a evaluar el porcentaje de los vehículos que aceleran en el carril de deceleración, como una medida de la funcionalidad del carril, pues si es demasiado largo, existe la posibilidad de acelerar y posteriormente decelerar para salir. 


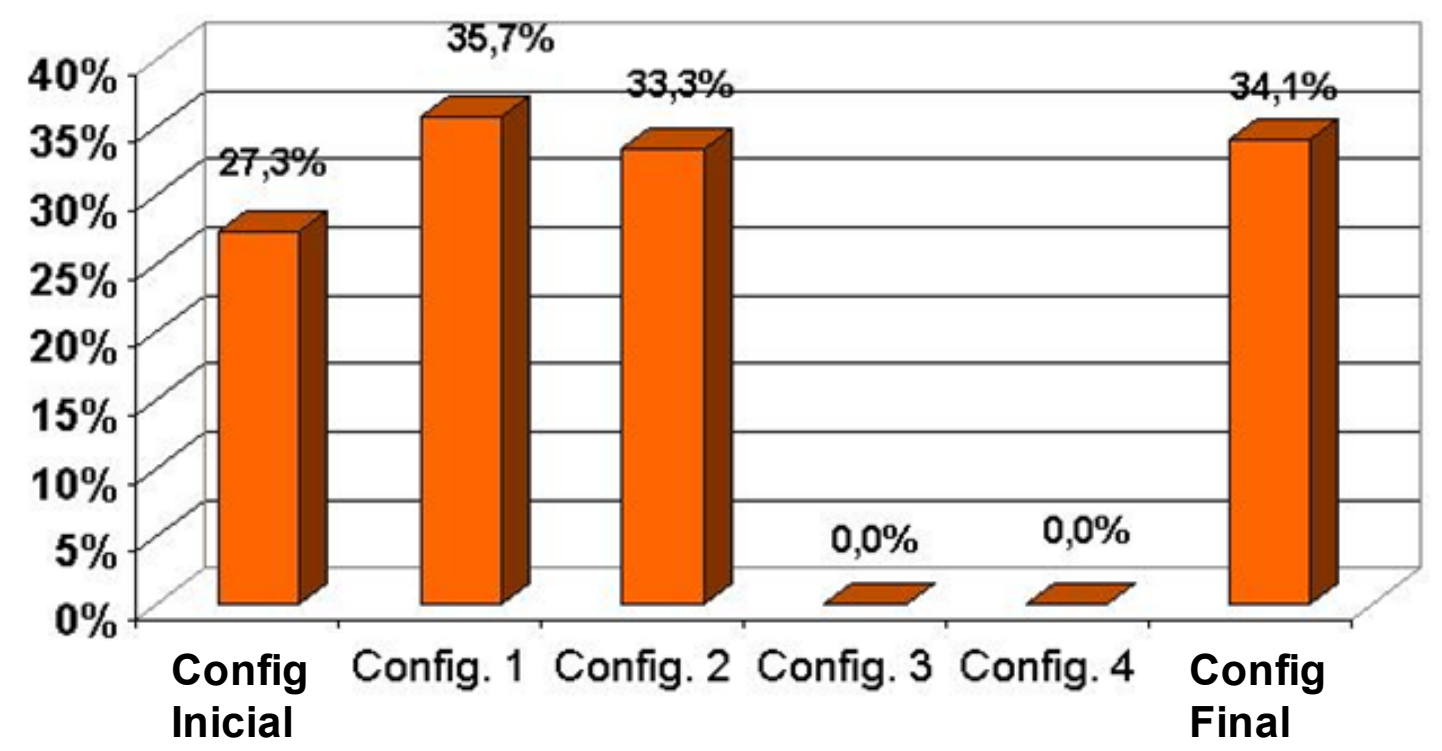

Figura 131: Porcentaje de vehículos que aceleran en cada configuración

Como se puede observar, en configuraciones cuya longitud es mayor, es decir las configuraciones experimentales inicial, 1, 2 y final, aproximadamente un tercio de los vehículos aceleran en el carril de deceleración, mostrando que la longitud es demasiado larga, mientras que en la configuraciones 3 y 4 , ningún vehículo acelera en el carril.

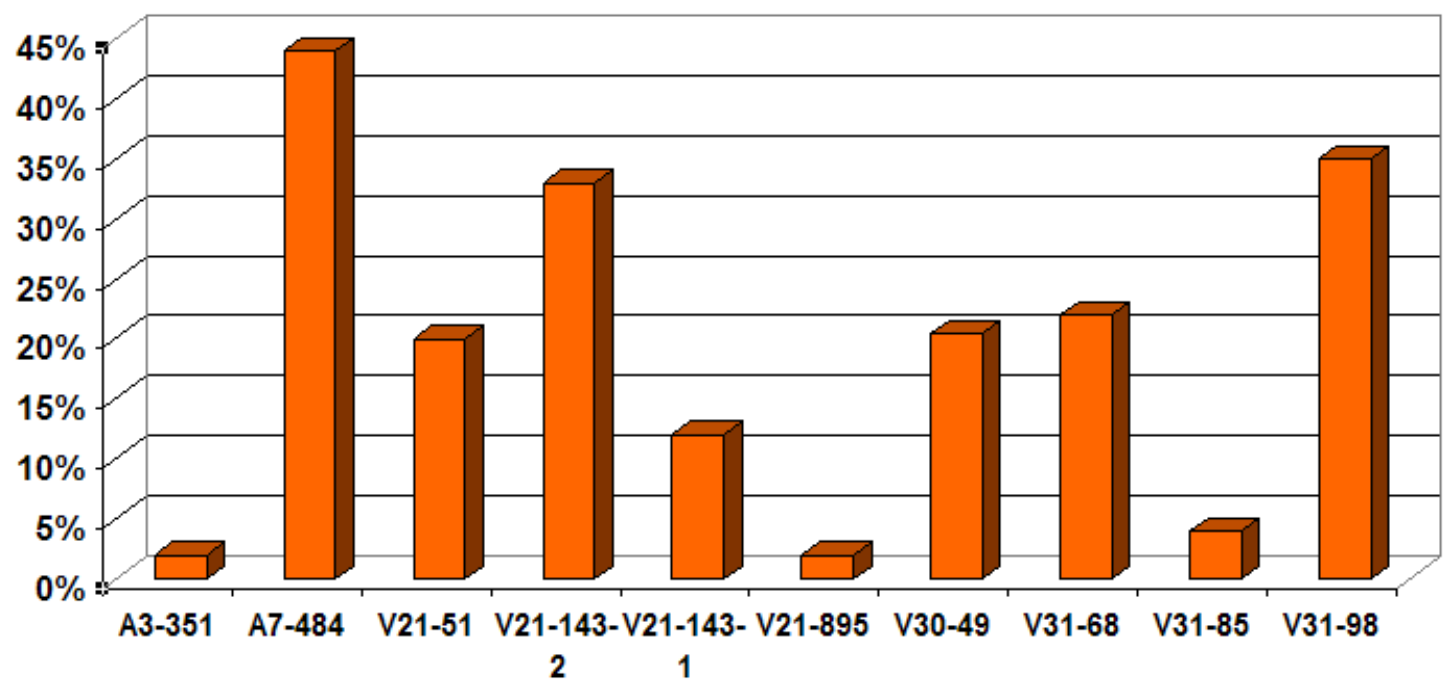

Figura 132: Porcentaje de vehículos que aceleran

Se puede observar que en el carril A7-484 se presenta un elevado número de vehículos que aceleran en el carril de deceleración, esta situación debe estudiarse pues puede ser debido no solo a la longitud del carril sino también al alto porcentaje de vehículos pesados que hay en ese punto. 
En los carriles experimentales se ha encontrado una tasa de deceleración por retención con el motor de $-0,76 \mathrm{~m} / \mathrm{s}^{2}$, más alto que el encontrado por Polus et al. (1985), pero más cerca al valor recomendado por la AASHTO. Se encontró una duración de la maniobra subconsciente que varía entre los 5,9 y los 7,4 s, que son valores cercanos al encontrado por de la Iglesia y García (2000) de 6,4 s y superior al de la AASHTO que es de 3,5 s.

Como se puede observar en la Figura 133, no se ha encontrado una variación apreciable entre los valores de deceleración en función de la longitud del carril de deceleración, lo que nos muestra que los conductores realizan la maniobra de deceleración, sin tener en cuenta la longitud del carril, sino dependiendo de su apreciación de la distancia a la salida.

Al tener en cuenta todos los carriles estudiados, se han encontrado que los percentiles 15,50 y 85 de la deceleración por retención del motor tienen un valor de $-0,95,-0,76$ y $-0,54 \mathrm{~m} / \mathrm{s}^{2}$, respectivamente.

Los percentiles 85,50 y 15 de la deceleración por frenado tienen un valor de -1,79, 2,44 y $-3,30 \mathrm{~m} / \mathrm{s}^{2}$, respectivamente, al considerar todos los carriles de deceleración. Estos valores de deceleración son considerados confortables en las maniobras de frenado.

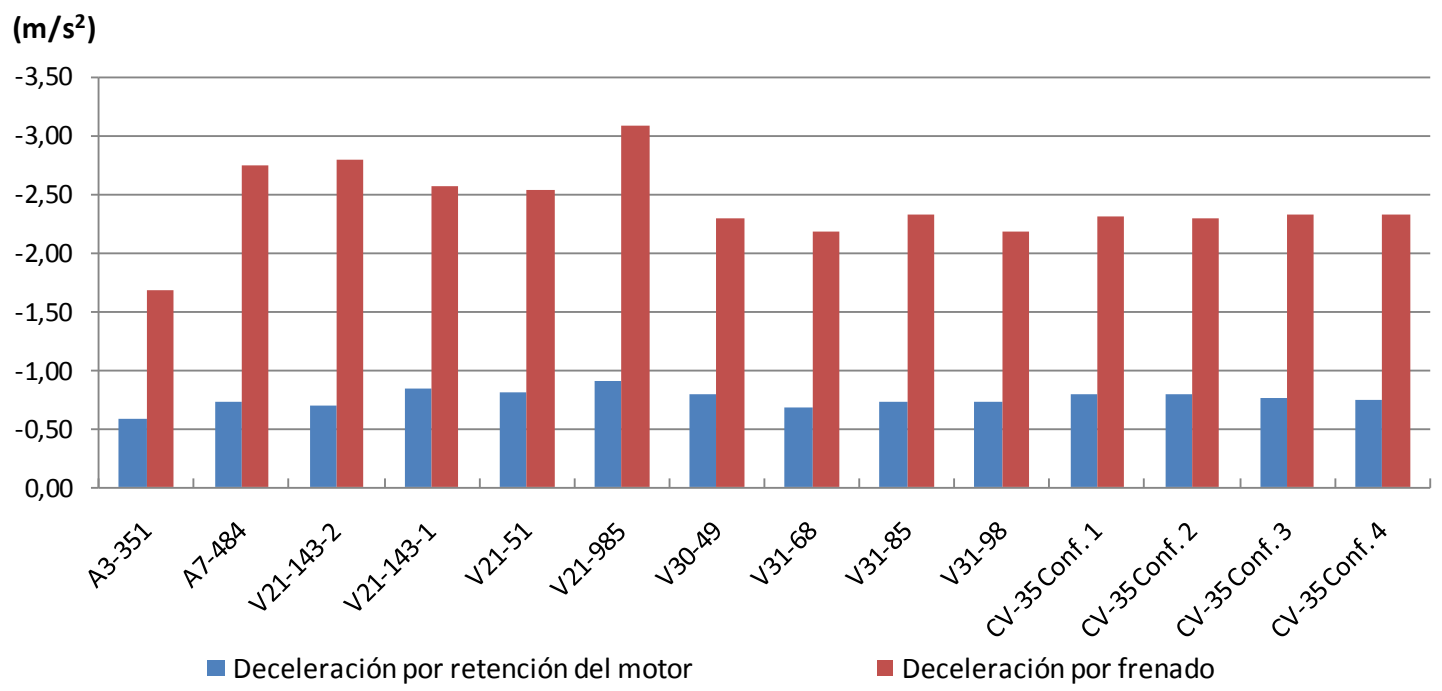

Figura 133: Deceleraciones en los carriles de deceleración

\subsubsection{Maniobras conflictivas}

Se procedió a realizar una evaluación cualitativa por observación directa de las imágenes para determinar las diferentes modalidades en el comportamiento de todos los vehículos que proceden a abandonar la vía por completo, muchos de ellos en situación de flujo condicionado. En el Anexo No. 1 se presenta el inventario de las maniobras de salida estudiadas. 


\subsubsection{Salidas anticipadas}

En la Figura 134 se observa como al parecer las maniobras de salida anticipada son mayores en los carriles más cortos y disminuyen al aumentar su longitud. Sin embargo si no se tiene en cuenta los carriles experimentales (resaltados en rojo) sino únicamente los carriles de control, no se puede observar esa tendencia, lo que lleva a pensar que esta situación fue inducida debida a la ejecución experimental y que en realidad depende de las condiciones locales de la salida.

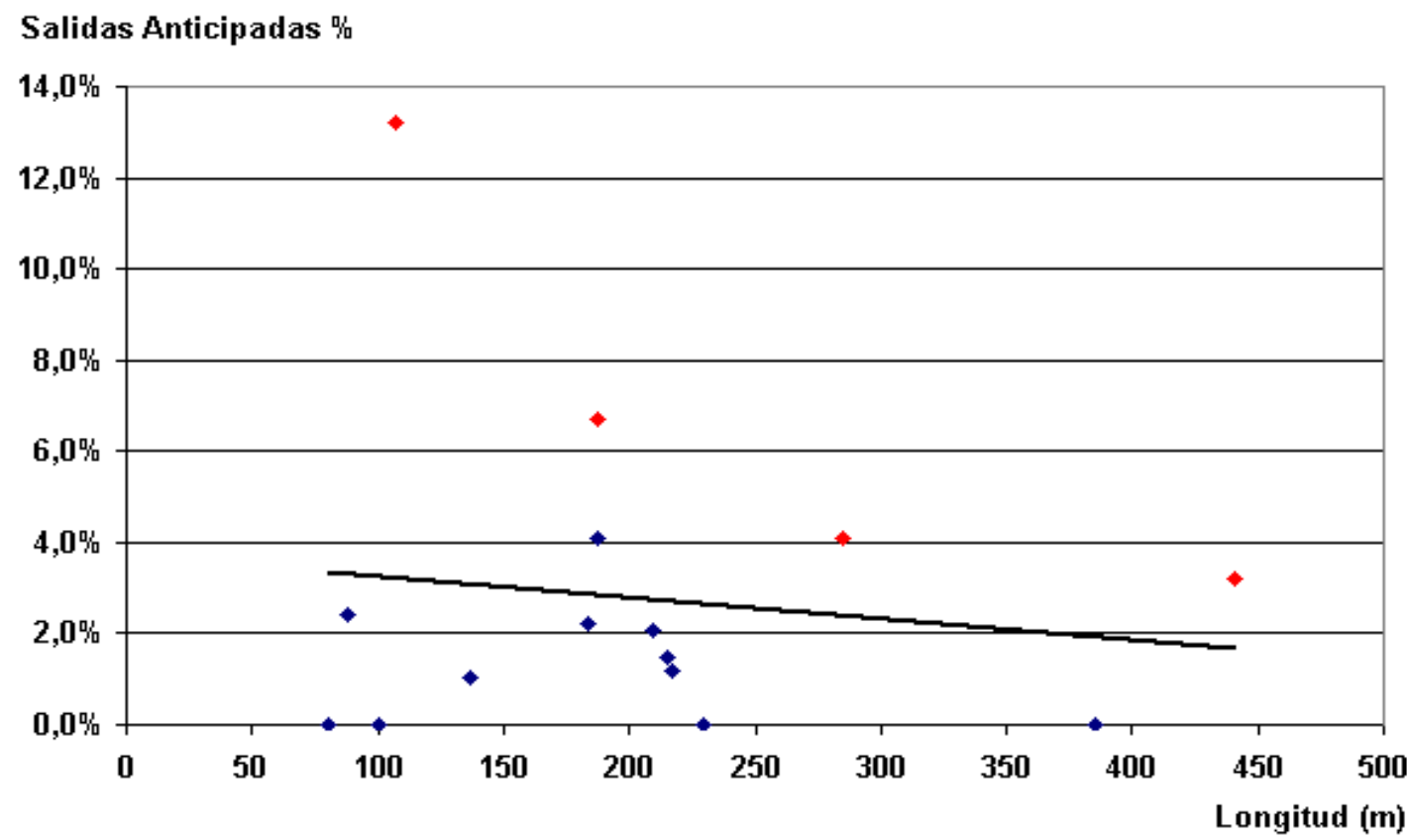

Figura 134: Salidas anticipadas en función de la longitud del carril

\subsubsection{Salidas tardías}

Como ya se ha mencionado el porcentaje de salidas tardías en la configuración inicial es muy elevado al no tener demarcada la cuña, por lo que no se ha tenido en cuenta para el análisis.

Se puede observar en la Figura 135 que, aunque los datos son dispersos, el porcentaje de salidas tardías disminuye al aumentar la longitud del carril. Esta dispersión es debida a que este mismo porcentaje aumenta con la intensidad del tráfico, tal y como se observa en la Figura 136. 
Salidas Tardías \%

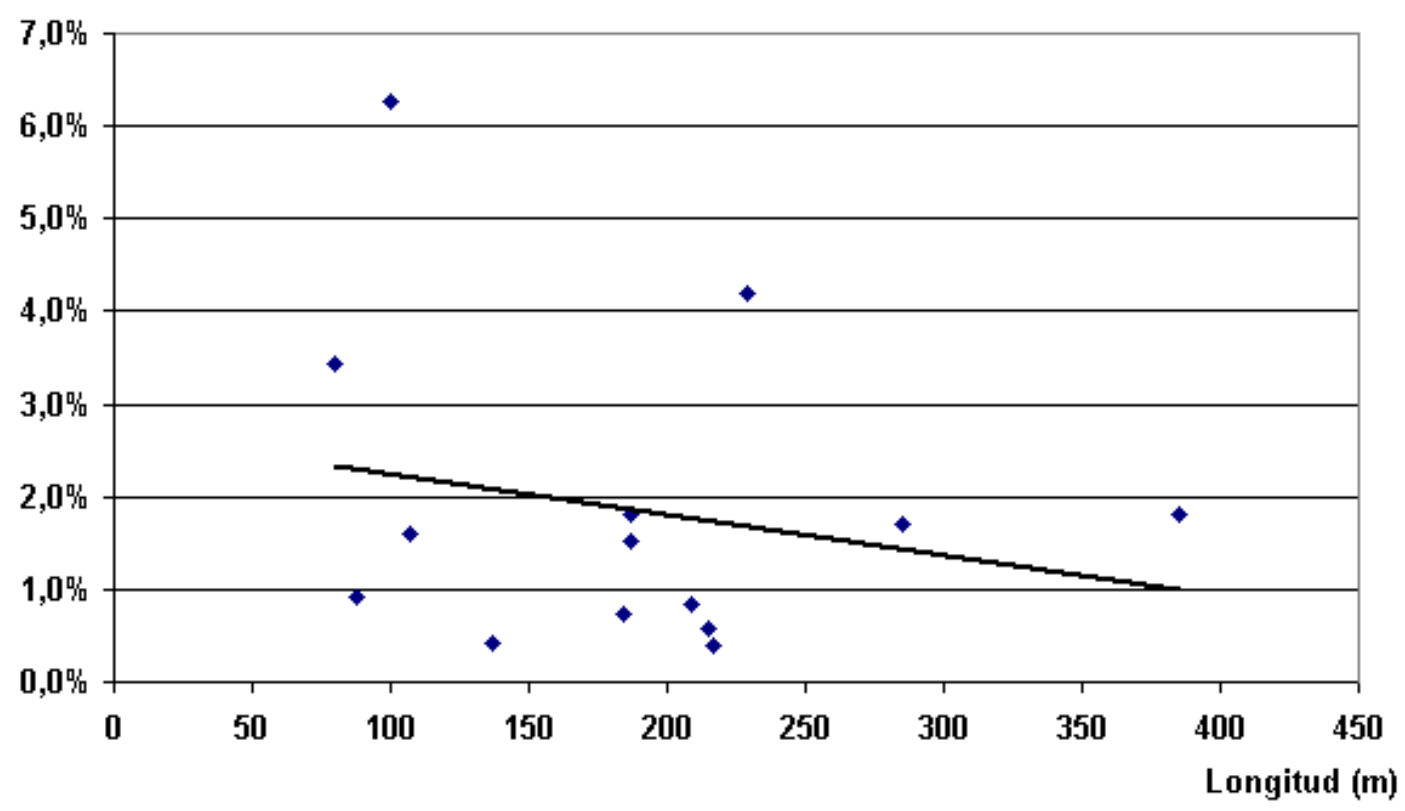

Figura 135: Porcentaje de Salidas tardías en función de la longitud del carril

Salidas Tardías \%

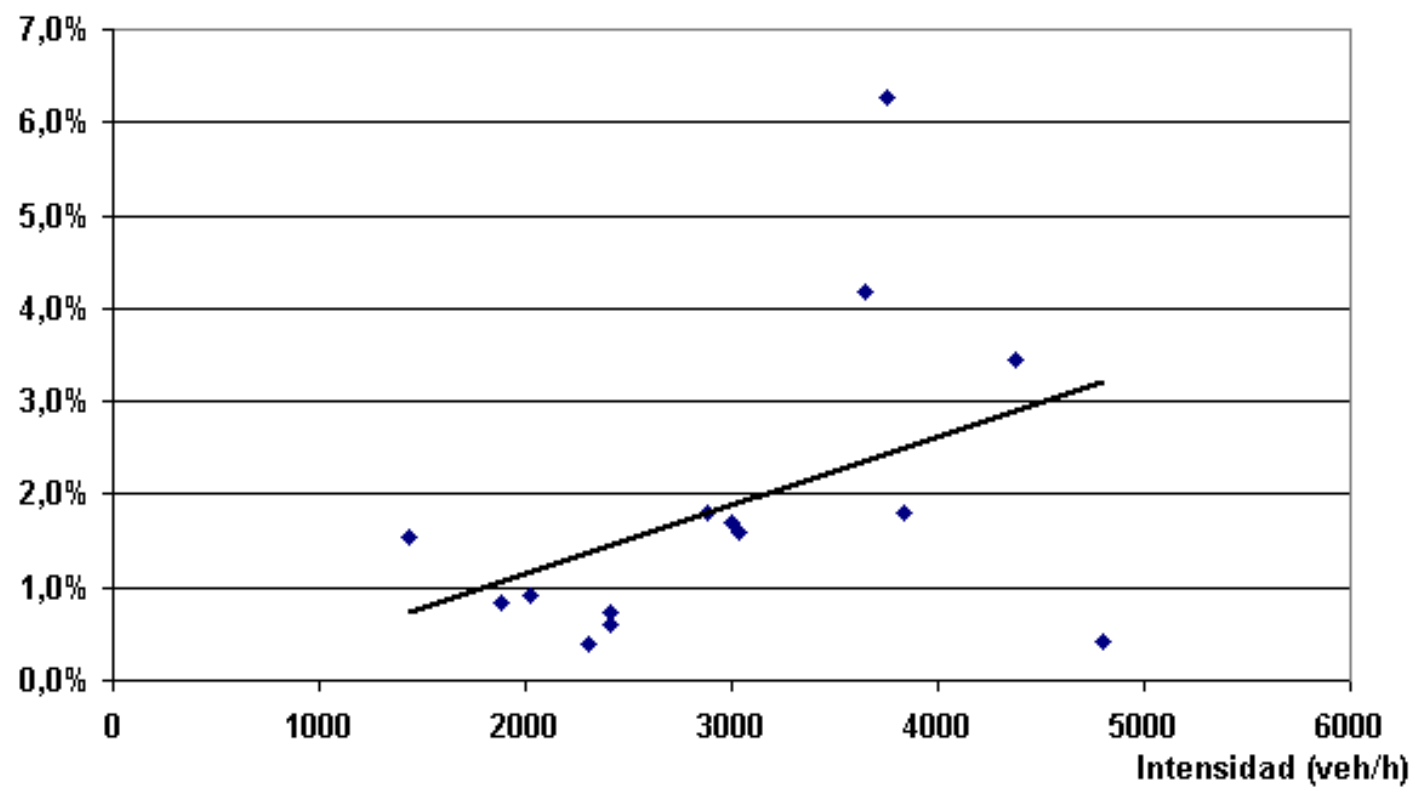

Figura 136: Porcentaje de Salidas tardías en función de la intensidad del tráfico 


\subsubsection{Reincorporaciones}

En la Figura 137 se muestra como al aumentar la longitud del carril se incrementa el porcentaje de reincorporaciones. Esto es debido en primer lugar a que en carriles demasiado largos los conductores pueden interpretar el carril como un carril adicional por no apreciar fácilmente la salida. Si adicionalmente no se tiene señalizada la cuña, este fenómeno se incrementa.

Adicionalmente, en carriles más cortos, los conductores no tienen tiempo de hacer la maniobra de reincorporación en caso de haberse percatado de que han equivocado la salida.

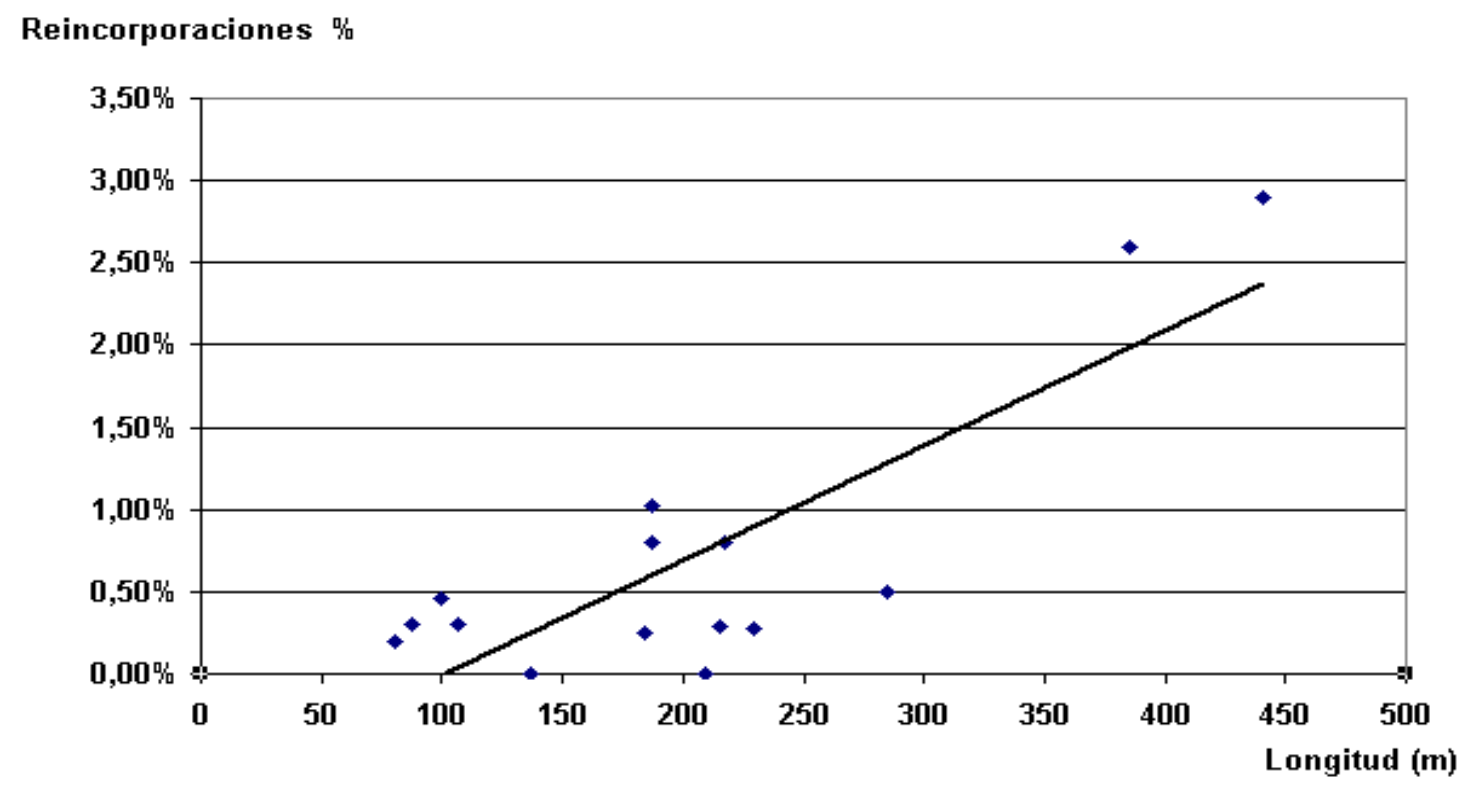

Figura 137: Porcentaje de reincorporaciones en función de la longitud del carril

\subsubsection{Origen de los carriles rápidos}

El porcentaje de maniobras cuyo origen es uno de los carriles rápidos se eleva al aumentar la longitud del carril de deceleración, debido, principalmente, a que los conductores aprovechan la maniobra de cambio de carril para enlazarla con la maniobra de salida.

Este tipo de maniobra está íntimamente relacionada con la maniobra tardía y como se puede observar en la Figura 139, también está relacionada con la intensidad del tráfico. El porcentaje de maniobras cuyo origen es uno de los carriles rápidos aumenta con la intensidad. 
Origen en carriles rápidos \%

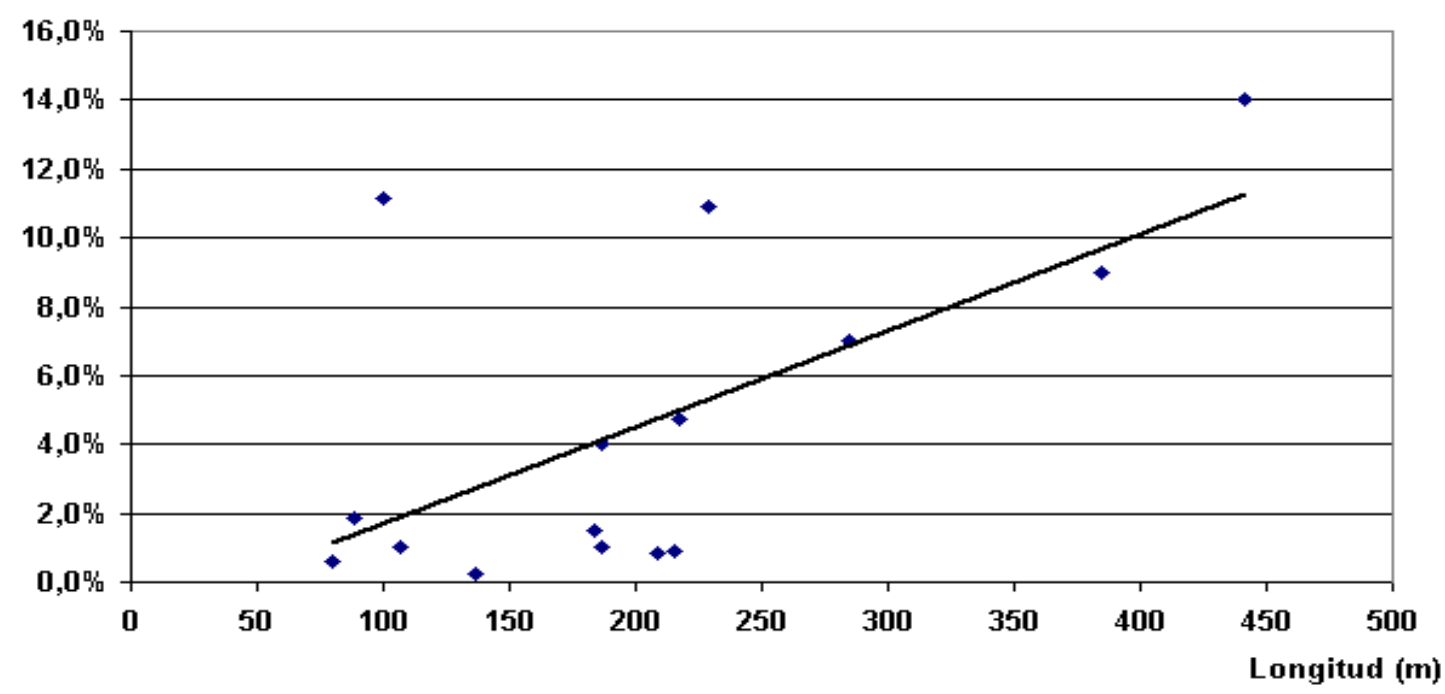

Figura 138: Porcentaje de salidas cuyo origen es uno de los carriles rápidos en función de la longitud

Origen en carriles rápidos $\%$

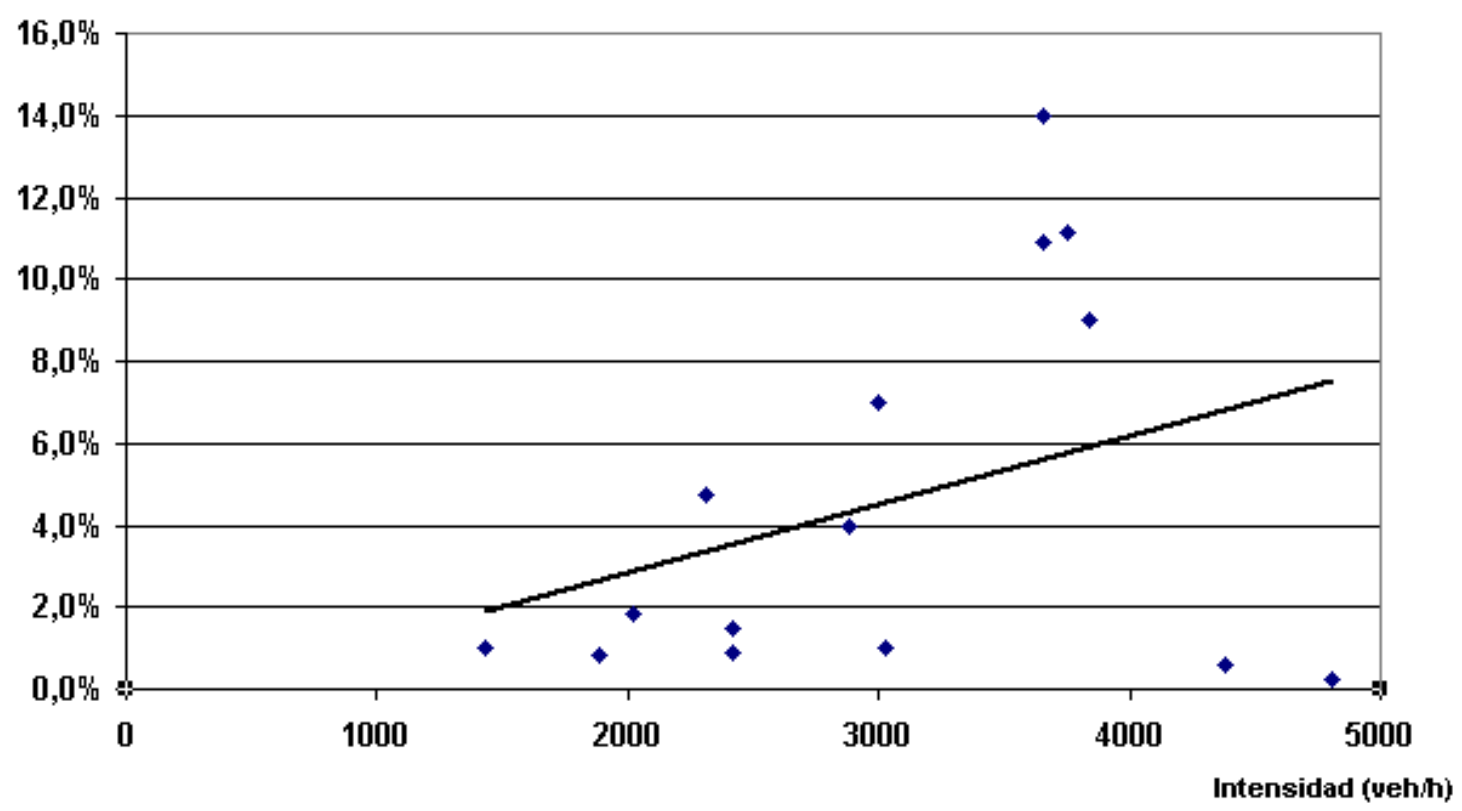

Figura 139: Porcentaje de salidas cuyo origen es uno de los carriles rápidos en función de la intensidad 


\subsubsection{Adelantamientos}

La Figura 140 muestra el porcentaje de maniobras en las que el vehículo que sale realiza un adelantamiento. Asimismo se muestra el tipo de adelantamiento que realiza.

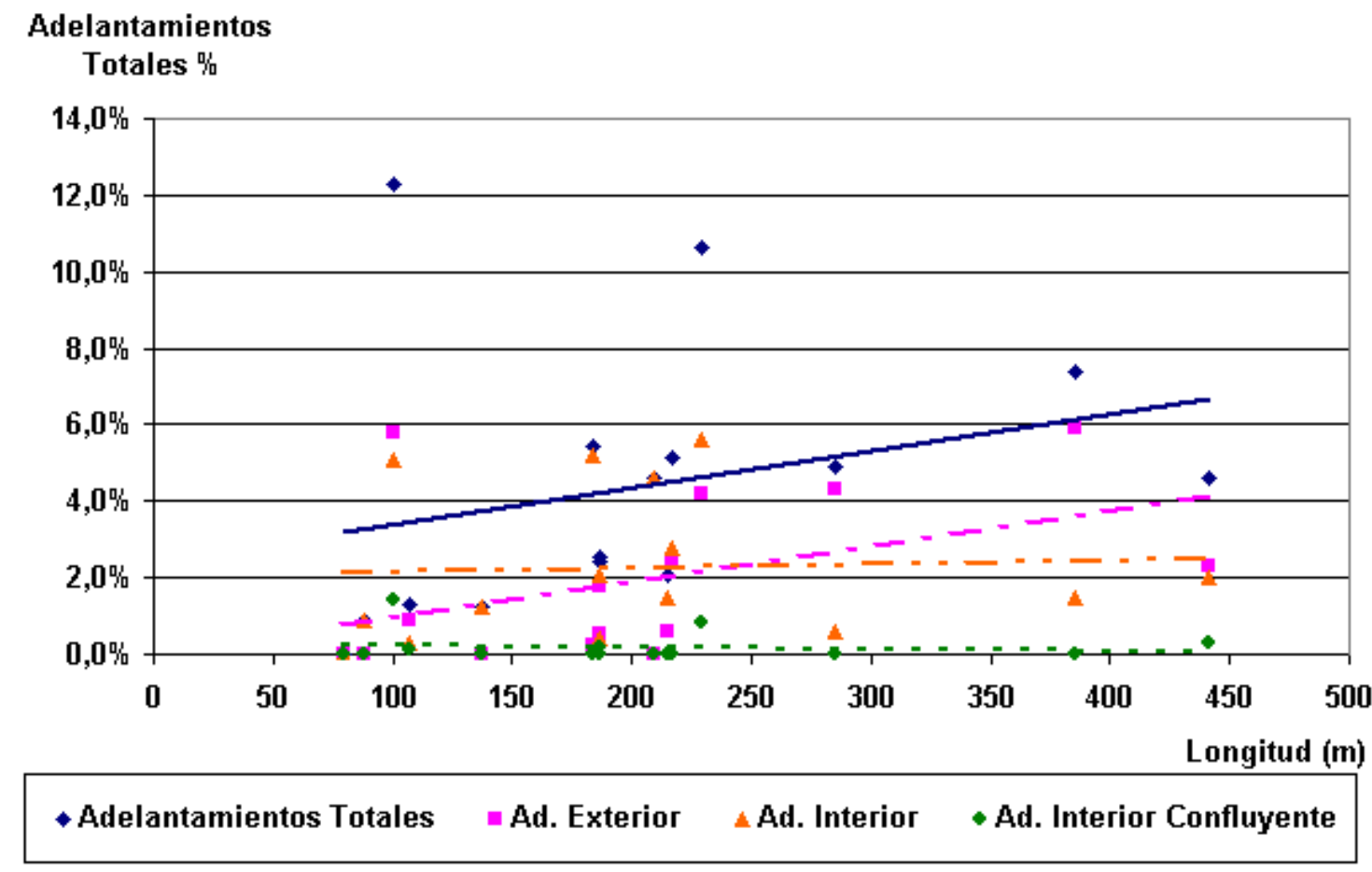

Figura 140: Porcentaje de adelantamientos por tipo en cada configuración

Se puede observar que los adelantamientos del tipo exterior aumentan con la longitud del carril, no obstante los otros tipos de adelantamientos no se ven afectados por la longitud del mismo.

\subsubsection{Indicadores de conflictividad}

Se ha calculado, en primer lugar, la variación del valor medio de la integral de TiPCLA en función del valor umbral, así como la variación del valor medio del tiempo en función del valor umbral.

Como se puede observar en la Figura 141 el valor medio de la integral de TiPCLA, tiene un crecimiento casi lineal cuando el umbral varía entre los 1,2 y los 1,7 s. Asimismo, en la Figura 142 se observa que en ese mismo intervalo, el valor medio del tiempo en función bajo un valor umbral de TiPCLA, tiene un comportamiento estable.

En el Anexo No.5 se presentan las tablas de los resultados de la aplicación de los indicadores TiPCLA en función del umbral. 
IM_TiPCLA $\left(s^{2} / v e h\right)$

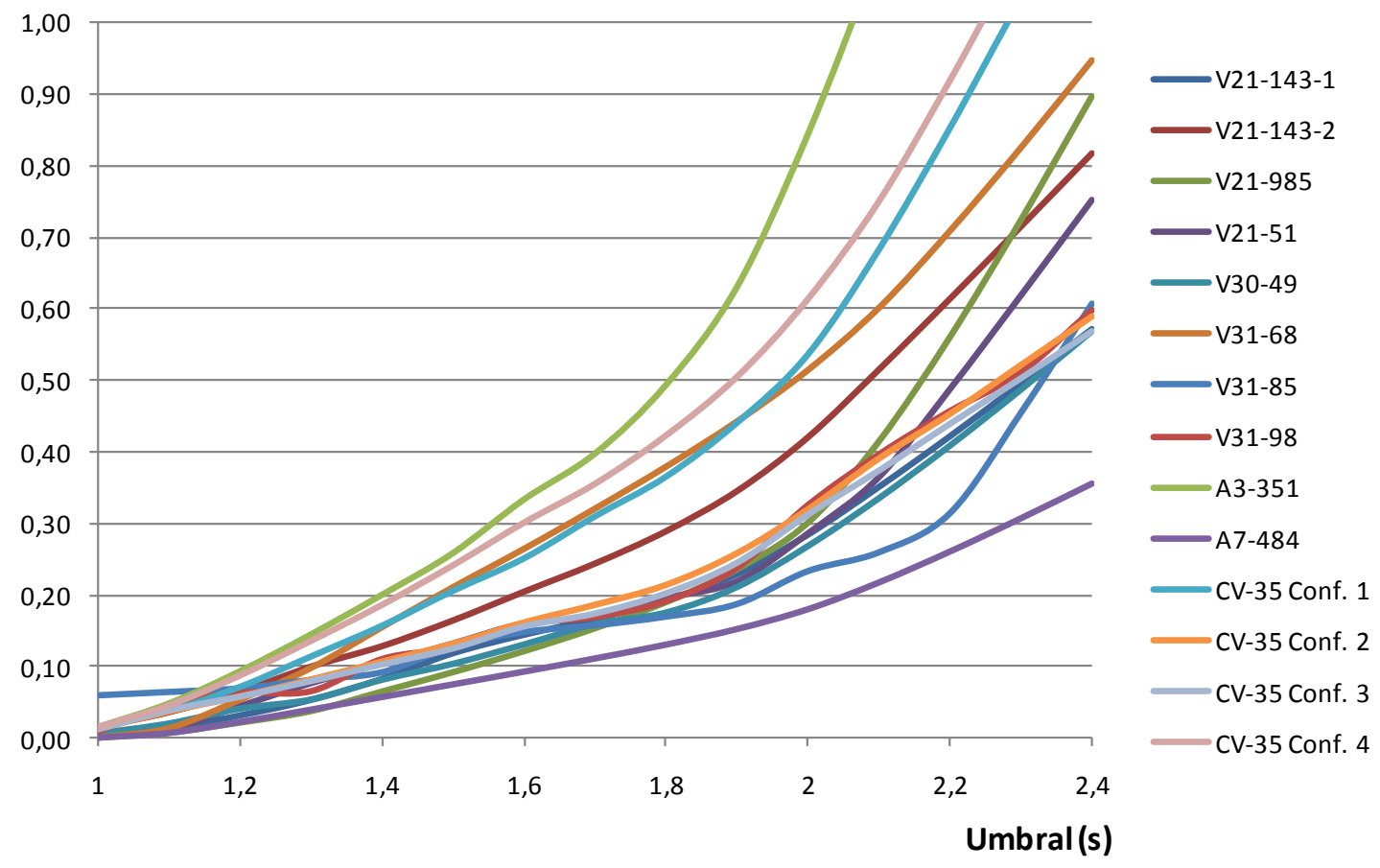

Figura 141: Variación del valor medio de la integral de TiPCLA en función del valor umbral, IM_TiPCLA
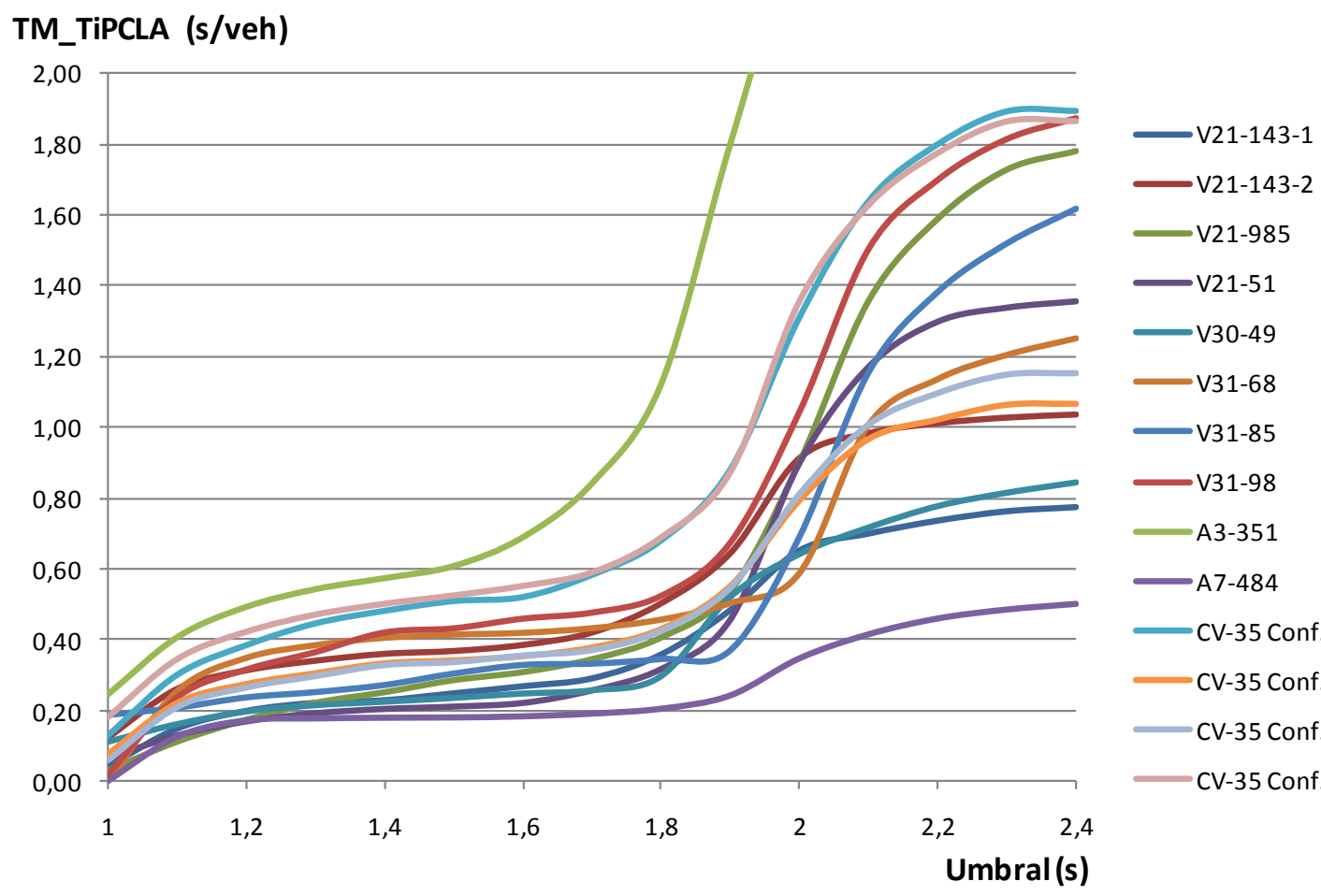

V21-143-2

V21-985

V30-49

V31-68

V31-85

V31-98

A3-351

A7-484

CV-35 Conf. 1

CV-35 Conf. 2

CV-35 Conf. 3

CV-35 Conf. 4

Figura 142: Variación del valor medio del tiempo bajo un umbral de TiPCLA en función del valor umbral, TM_TiPCLA 
Para poder comparar los valores en los diferentes carriles de deceleración, se ha tomado inicialmente el umbral de $1,5 \mathrm{~s}$, que está en un punto medio del intervalo estable de los valores los cuales se muestran en la Figura 143. Es necesario evaluar la sensibilidad del umbral para que represente adecuadamente la conflictividad. Dicho análisis se presenta en el capítulo de análisis.

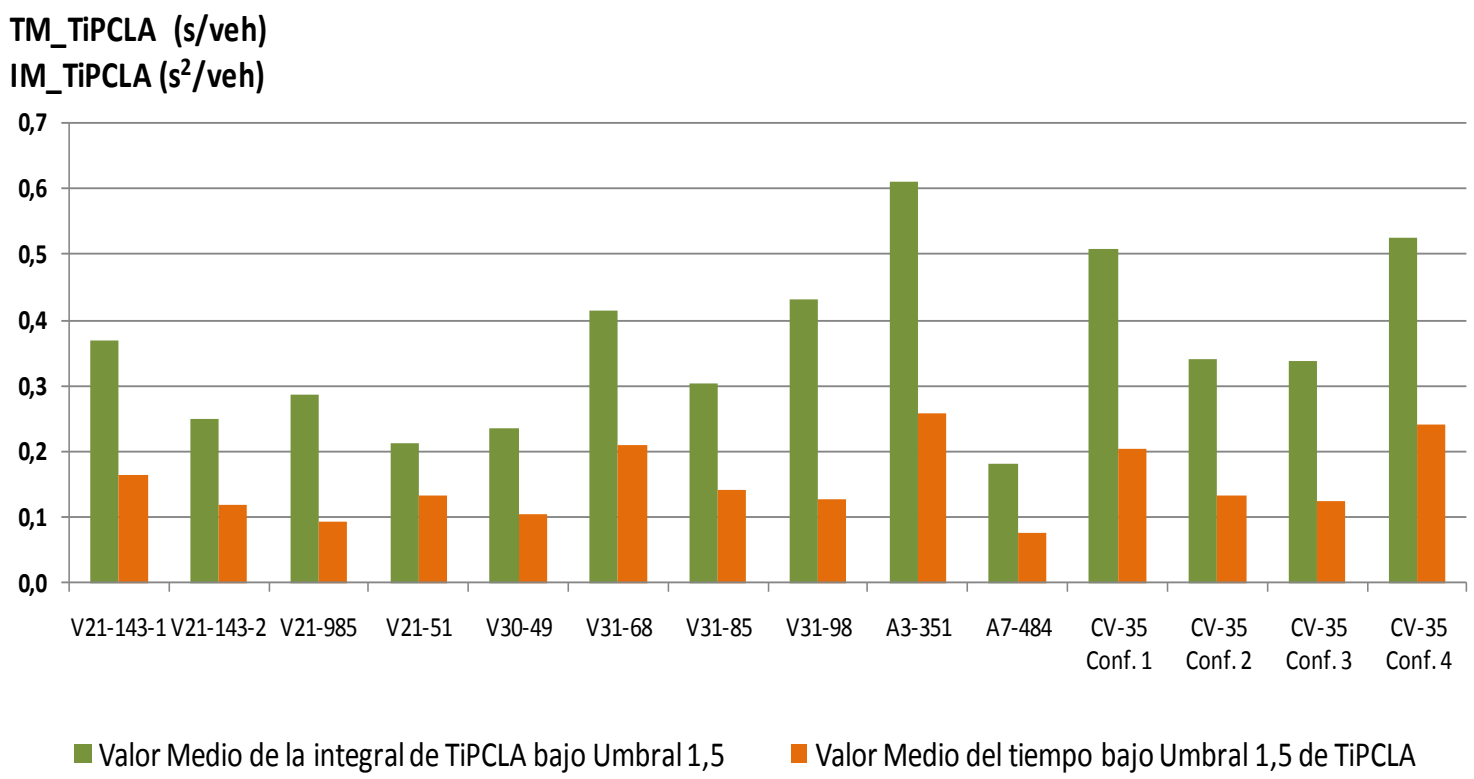

Figura 143: Indicador de conflictividad para cada carril bajo un umbral de 1,5 s

Como se puede observar en la Figura 144 y en la Figura 145 ambos valores presentan un comportamiento similar. Los valores más altos se encuentran en aquellas ubicaciones con menor longitud, debido a que, como se pudo observar en las diferencias de velocidades experimentales, los vehículos deceleran en la vía principal aumentando la exposición a un posible conflicto de alcance.

En los carriles más largos se observa un incremento de los indicadores debido, posiblemente, a la mayor exposición a conflictos laterales y en algunos casos a la mayor frecuencia de maniobras peligrosas y en los más cortos se observa un incremento por las maniobras de alcance.

Asimismo se puede observar cómo en los carriles más cortos hay una mayor dispersión en los valores con respecto a los carriles más largos. 


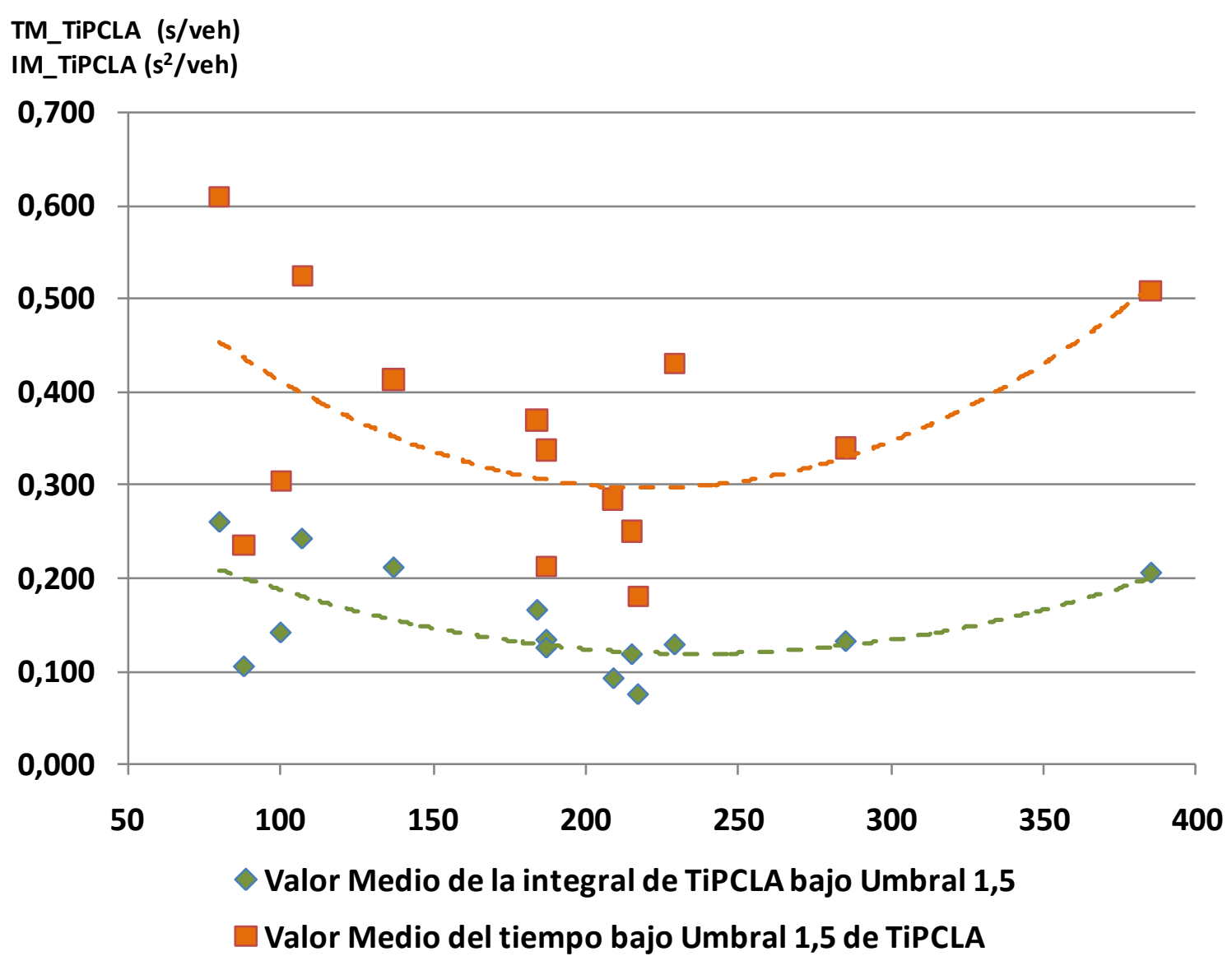

Figura 144: Indicador de conflictividad en función de la longitud

Sin embargo, teniendo en cuenta que los carriles de deceleración tienen diferentes características de diseño, para poder comparar los valores debe utilizarse, en lugar de la longitud absoluta, la relación entre la longitud real del carril y la longitud de diseño calculada con la velocidad inicial igual al límite genérico de velocidad de la vía.

Al igual que con las longitudes absolutas se puede verificar utilizando las longitudes relativas que los menores valores del indicador TiPCLA son los correspondientes a valores intermedios de esta relación, manteniéndose una alta dispersión para valores bajos de la relación. 


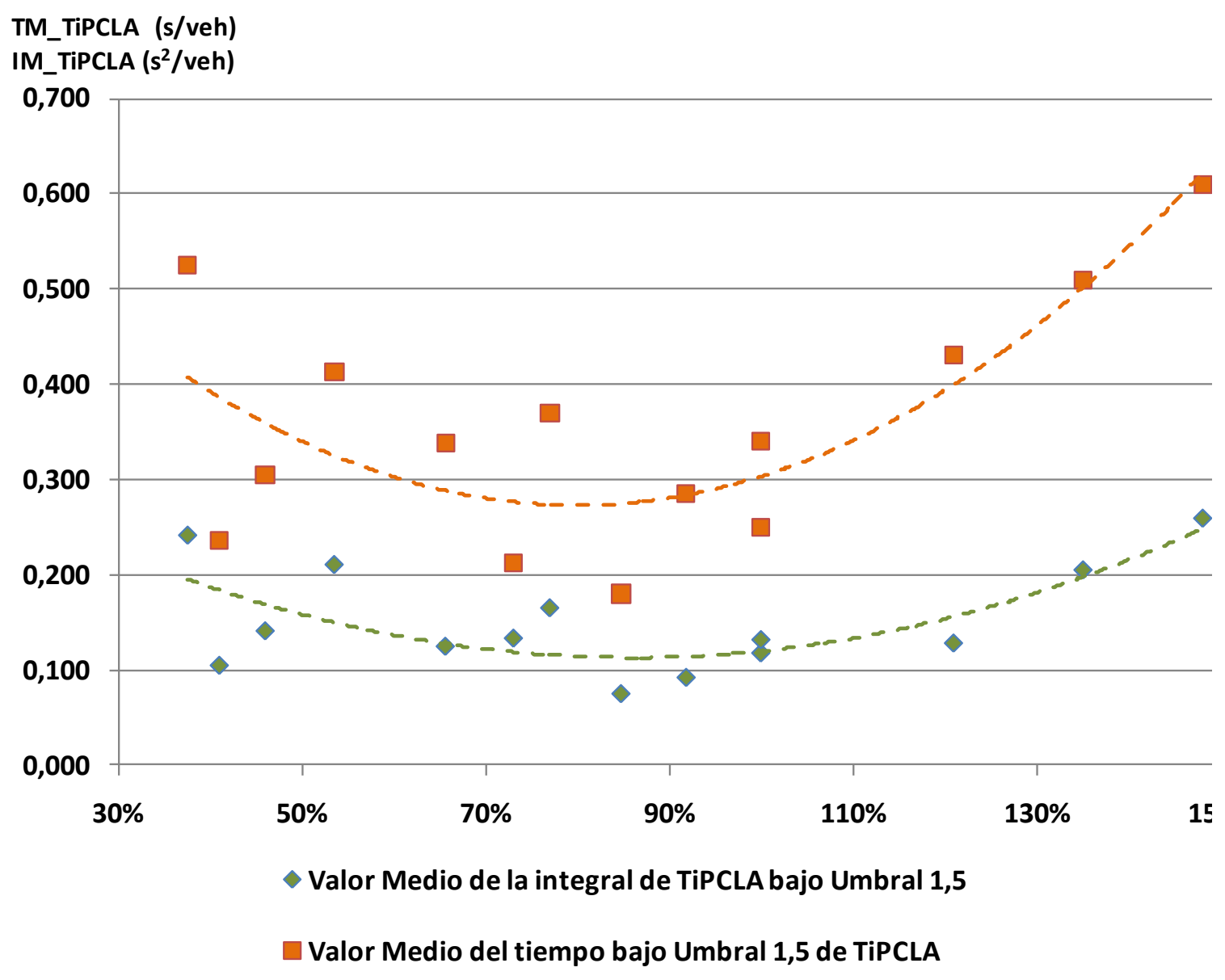

Figura 145: Indicador de conflictividad en función del la relación $L / L_{0}$

\subsubsection{Accidentalidad}

Gracias al Servicio de Estadística del Observatorio Nacional de Seguridad Vial de la Dirección General de Tráfico, se han obtenido los datos de accidentalidad en las vías estudiadas, en los puntos kilométricos correspondientes a los carriles de deceleración. Se han estudiado tanto la totalidad de los accidentes reportados en los tramos de estudio cómo los accidentes con víctimas, que incluyen heridos leves, heridos graves y muertos (Tabla 48). En el Anexo No. 4 se presentan los datos completos de accidentalidad.

Es importante resaltar que se han tomado los accidentes ubicados entre los $400 \mathrm{~m}$ antes de la cuña y los 320 metros después de la cuña, tal como lo comprobó Cirilo (1967).

Si bien es cierto que se incluye la totalidad de los accidentes, al no poder determinar con exactitud la causa, es importante señalan que aunque algunos accidentes no 
ocurrieran en el carril de deceleración, el accidente puede estar ligado a la existencia del carril de deceleración por la inestabilidad en el flujo que genera su presencia.

Tabla 48: Accidentes reportados en los carriles estudiados

\begin{tabular}{|c|c|c|c|c|c|c|c|c|c|c|}
\hline \multirow{2}{*}{ Carril } & \multicolumn{4}{|c|}{ Número total de accidentes } & \multicolumn{4}{c|}{ Número de accidentes con víctima } \\
\cline { 2 - 11 } & 2004 & 2005 & 2006 & 2007 & promedio & 2004 & 2005 & 2006 & 2007 & promedio \\
\hline V21-143-1 & 0 & 0 & 4 & 19 & 3,5 & 0 & 0 & 1 & 6 & 1,75 \\
\hline V21-143-2 & 0 & 0 & 3 & 1 & 1 & 0 & 0 & 1 & 1 & 0,5 \\
\hline V21-985 & 0 & 0 & 5 & 2 & 1,75 & 0 & 0 & 1 & 0 & 0,25 \\
\hline V21-51 & 0 & 1 & 2 & 0 & 0,75 & 0 & 1 & 1 & 0 & 0,5 \\
\hline V30-49 & 1 & 0 & 5 & 3 & 2,25 & 1 & 0 & 2 & 2 & 1,25 \\
\hline V31-68 & 3 & 0 & 2 & 5 & 2,5 & 2 & 0 & 1 & 2 & 1,25 \\
\hline V31-85 & 0 & 0 & 5 & 3 & 2 & 0 & 0 & 3 & 1 & 1 \\
\hline V31-98 & 0 & 0 & 3 & 5 & 2 & 0 & 0 & 1 & 0 & 0,25 \\
\hline A3-351 & 0 & 1 & 9 & 4 & 3,5 & 0 & 1 & 5 & 1 & 1,5 \\
\hline A7-484 & 0 & 1 & 1 & 1 & 0,75 & 0 & 1 & 0 & 1 & 1,75 \\
\hline CV35-7 & 0 & 0 & 3 & 8 & 2,75 & 0 & 0 & 3 & 3 & 0,5 \\
\hline
\end{tabular}

Es importante resaltar el aumento, tanto, en el número total de accidentes, cómo en el total de accidentes con víctima, en las inmediaciones del carril de la V21 en el Pk 14,3 sentido Valencia que ha ocurrido a partir de la segunda mitad del 2006 lo que coincide con el derribo del puente de entrada a la ciudad de Valencia en esta vía y su consiguiente aumento de colas.

Esta situación hace que para el análisis de los datos de accidentalidad no se tendrá en cuenta el carril V21-143-1.

A partir de los datos de accidentalidad y de la intensidad media diaria del tramo aguas arriba del carril de deceleración, se han calculado seis índices de accidentalidad:

- Número total de accidentes al año por cada 100 millones de vehículos

- Número total de accidentes al año por cada 100 millones de vehículos por km

- Número de accidentes con víctima al año por cada 100 millones de vehículos 
- Número de accidentes con víctima al año por cada 100 millones de vehículos por km. Este último se conoce cómo índice de peligrosidad.

Se presenta en la Tabla 49 los valores puntuales para los años 2004 al 2007, y el valor promedio para los últimos 3 o 4 años.

Tabla 49: Índices con el total de accidentes

\begin{tabular}{|c|c|c|c|c|c|c|c|c|c|c|}
\hline \multirow{2}{*}{ Carril } & \multicolumn{5}{|c|}{ Accidentes / 100 M Veh } & \multicolumn{5}{c|}{ Accidentes / 100 M Veh*km } \\
\cline { 2 - 10 } & $\mathbf{2 0 0 4}$ & $\mathbf{2 0 0 5}$ & $\mathbf{2 0 0 6}$ & $\mathbf{2 0 0 7}$ & Promedio & $\mathbf{2 0 0 4}$ & $\mathbf{2 0 0 5}$ & $\mathbf{2 0 0 6}$ & $\mathbf{2 0 0 7}$ & Promedio \\
\hline V21-143-1 & 0 & 0 & 29,69 & 75,7 & 26,35 & 0 & 0 & 31,75 & 80,97 & 28,18 \\
\hline V21-143-2 & 0 & 0 & 22,08 & 7,32 & 7,41 & 0 & 0 & 24,43 & 8,1 & 8,2 \\
\hline V21-985 & 0 & 0 & 54,48 & 20,65 & 18,93 & 0 & 0 & 58,64 & 22,23 & 20,38 \\
\hline V21-51 & 0 & 10,87 & 21,79 & 0 & 8,11 & 0 & 11,99 & 24,03 & 0 & 8,95 \\
\hline V30-49 & 6,49 & 0 & 37,57 & 22,18 & 16,20 & 8,03 & 0 & 46,49 & 27,45 & 20,05 \\
\hline V31-68 & 19,96 & 0 & 12,92 & 31,13 & 16,17 & 23,29 & 0 & 15,08 & 36,32 & 18,87 \\
\hline V31-85 & 0 & 0 & 32,31 & 18,68 & 12,93 & 0 & 0 & 39,4 & 22,78 & 15,77 \\
\hline V31-98 & 0 & 0 & 20,62 & 35,33 & 14,03 & 0 & 0 & 21,73 & 37,23 & 14,78 \\
\hline A3-351 & 0 & 8,08 & 73,72 & 32,65 & 28,74 & 0 & 10,1 & 92,15 & 40,82 & 35,92 \\
\hline A7-484 & 0 & 6,89 & 6,88 & 6,77 & 4,95 & 0 & 7,35 & 7,34 & 7,23 & 5,28 \\
\hline CV35-7 & 0 & 0 & 17,99 & 46,5 & 16,58 & 0 & 0 & 24,99 & 64,58 & 23,03 \\
\hline
\end{tabular}


Tabla 50: Índices con solo accidentes con víctima

\begin{tabular}{|c|c|c|c|c|c|c|c|c|c|c|}
\hline \multirow{2}{*}{ Carril } & \multicolumn{3}{|c|}{ Accidentes con víctima / 100 M Veh } & \multicolumn{4}{c|}{ Accidentes con víctima /100 M Veh*km } \\
\cline { 2 - 11 } & $\mathbf{2 0 0 4}$ & $\mathbf{2 0 0 5}$ & $\mathbf{2 0 0 6}$ & $\mathbf{2 0 0 7}$ & Promedio & $\mathbf{2 0 0 4}$ & $\mathbf{2 0 0 5}$ & $\mathbf{2 0 0 6}$ & $\mathbf{2 0 0 7}$ & Promedio \\
\hline V21-143-1 & 0 & 0 & 7,42 & 35,42 & 13,17 & 0 & 0 & 7,94 & 48,58 & 14,09 \\
\hline V21-143-2 & 0 & 0 & 7,36 & 7,32 & 3,71 & 0 & 0 & 8,14 & 8,1 & 4,1 \\
\hline V21-985 & 0 & 0 & 10,9 & 0 & 2,70 & 0 & 0 & 11,73 & 0 & 2,91 \\
\hline V21-51 & 0 & 10,87 & 10,9 & 0 & 5,41 & 0 & 11,99 & 12,01 & 0 & 5,96 \\
\hline V30-49 & 3,24 & 0 & 7,51 & 7,39 & 9,00 & 8,03 & 0 & 18,6 & 18,3 & 11,14 \\
\hline V31-68 & 13,31 & 0 & 6,46 & 12,45 & 8,08 & 15,53 & 0 & 7,54 & 14,53 & 9,43 \\
\hline V31-85 & 0 & 0 & 19,39 & 6,23 & 6,47 & 0 & 0 & 23,64 & 7,59 & 7,89 \\
\hline V31-98 & 0 & 0 & 6,87 & 0 & 1,75 & 0 & 0 & 7,24 & 0 & 1,85 \\
\hline A3-351 & 0 & 8,08 & 40,96 & 8,16 & 14,37 & 0 & 10,1 & 51,2 & 10,2 & 17,96 \\
\hline A7-484 & 0 & 6,89 & 0 & 6,77 & 3,30 & 0 & 7,35 & 0 & 7,23 & 12,56 \\
\hline CV35-7 & 0 & 0 & 17,99 & 17,44 & 9,04 & 0 & 0 & 24,99 & 24,22 & 3,52 \\
\hline
\end{tabular}

En la Figura 146 se presenta el índice de accidentalidad y el índice de peligrosidad medio de los últimos 3 o 4 años en función de la relación entre la longitud real del carril y la longitud de diseño calculada con la velocidad inicial igual al límite genérico de velocidad de la vía. 


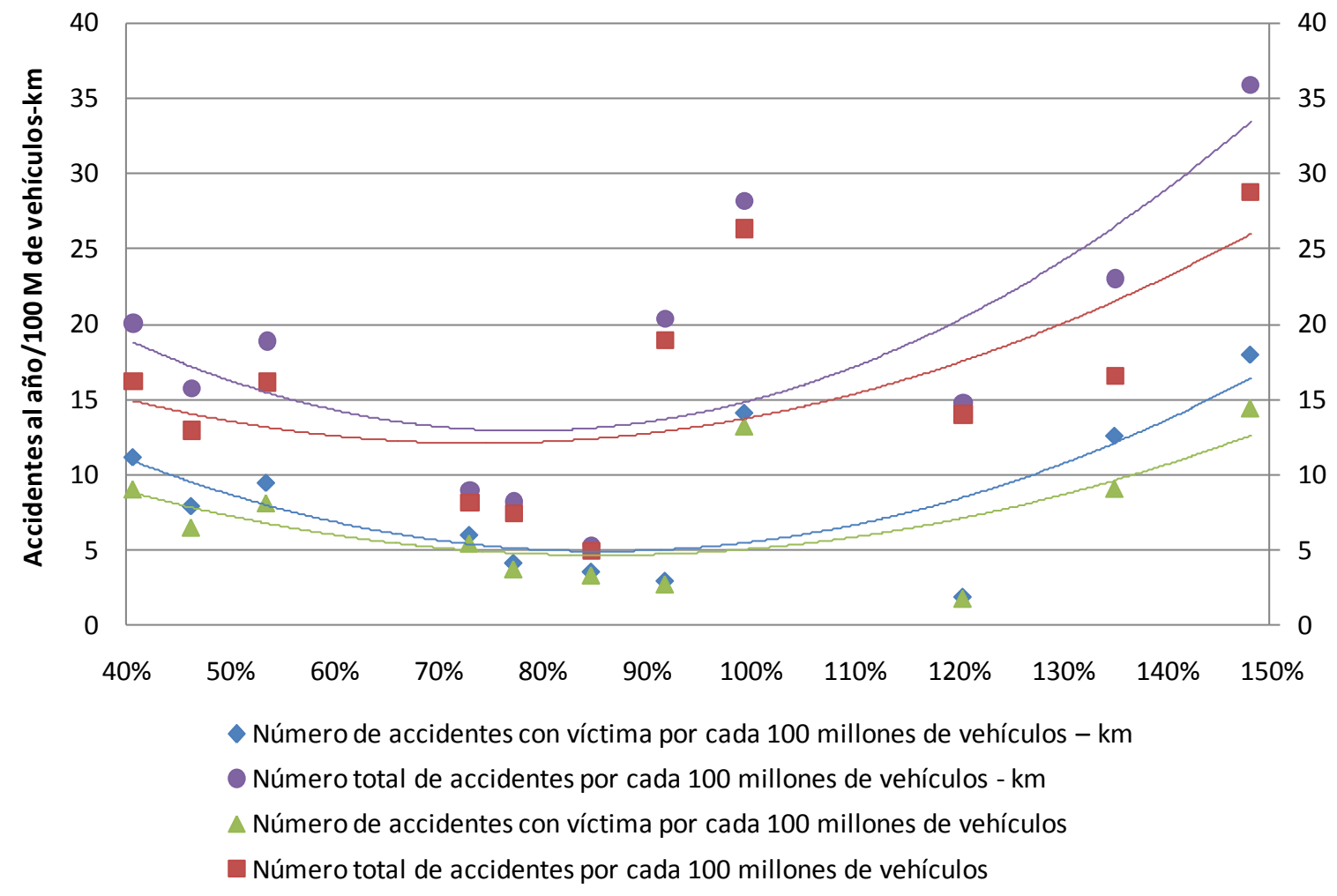

Figura 146: Índice de accidentalidad y de peligrosidad en función de la relación $L / L_{0}$

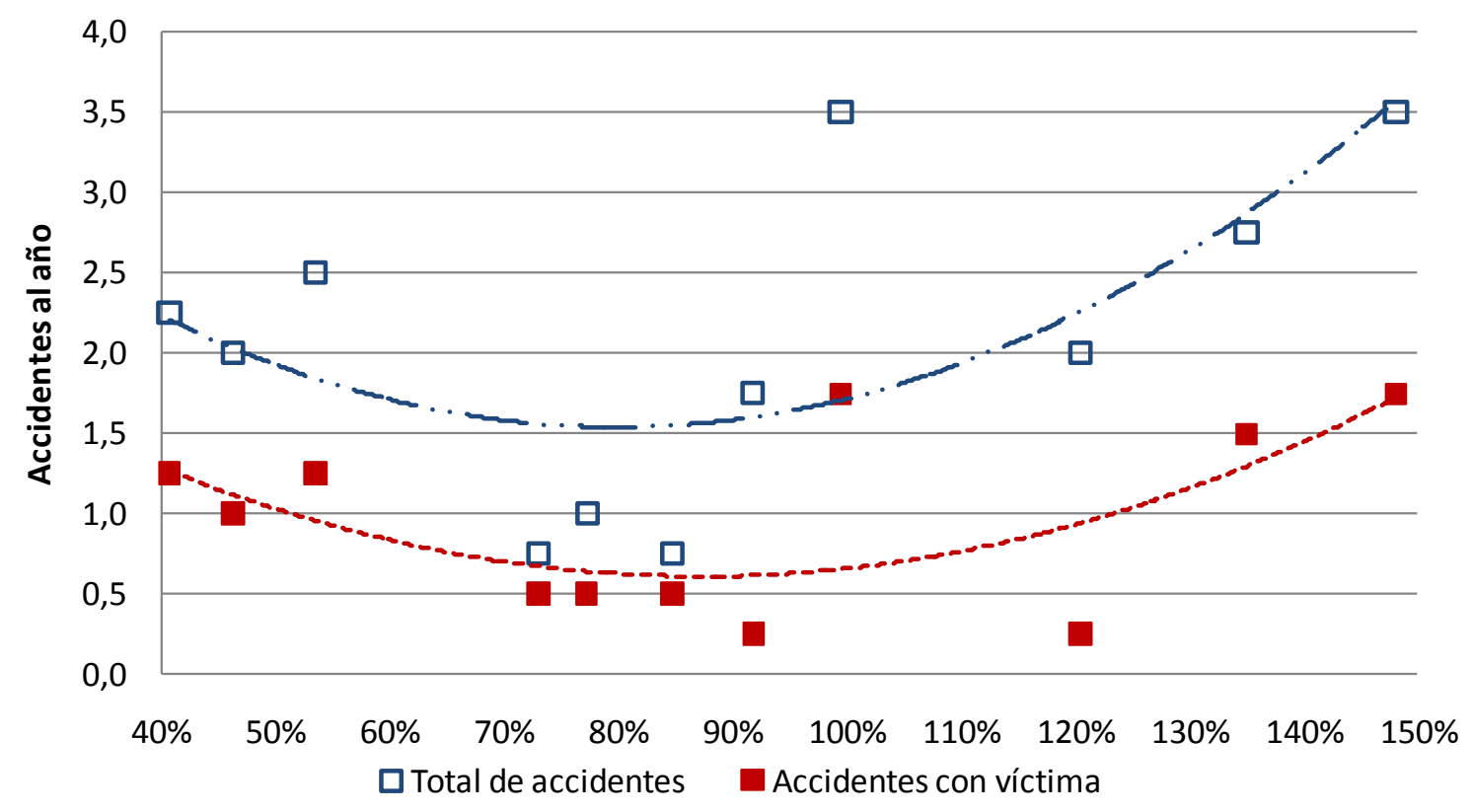

Figura 147: Accidentes en función de la relación $L / L_{0}$

Se puede observar en la Figura 146 y en la Figura 147, que los valores menores de accidentalidad, tanto para el número de accidentes con y sin víctima y para los índices de accidentes, corresponden a valores intermedios de longitud relativa del carril de 
deceleración. Los valores de ajuste y porcentajes óptimos se presentan en el capítulo de análisis.

Adicionalmente se confirma que el carril de la CV21-143-2 tiene un comportamiento que se sale de la tendencia de los demás carriles, debido a la congestión producida por las obras de construcción de la nueva entrada a Valencia. 


\section{ANÁLISIS}

Teniendo como base el estado del arte elaborado y los resultados experimentales de la evaluación, tanto cualitativa como cuantitativa, se presenta a continuación el análisis detallado de dichos resultados y su comparación con investigaciones anteriores, para así poder alcanzar las conclusiones finales de esta investigación.

Para la evaluación de la velocidad y la aceleración, se seleccionaron, de cada uno de los 10 carriles de deceleración y de las configuraciones experimentales, 50 vehículos ligeros, para un total de 800 vehículos, que reunieran las siguientes condiciones: su intervalo con relación al vehículo precedente sea superior a $5 \mathrm{~s}$ y que el carril de deceleración se encontrara libre en el momento de la salida, es decir, maniobras de salidas totalmente libres.

Adicionalmente se tomaron maniobras tanto libres como condicionadas durante un periodo continuo de 30 minutos en cada carril de deceleración para calcular los índices de conflictividad, para un total de 1143 maniobras de salida, distribuidas de acuerdo con la Figura 148.

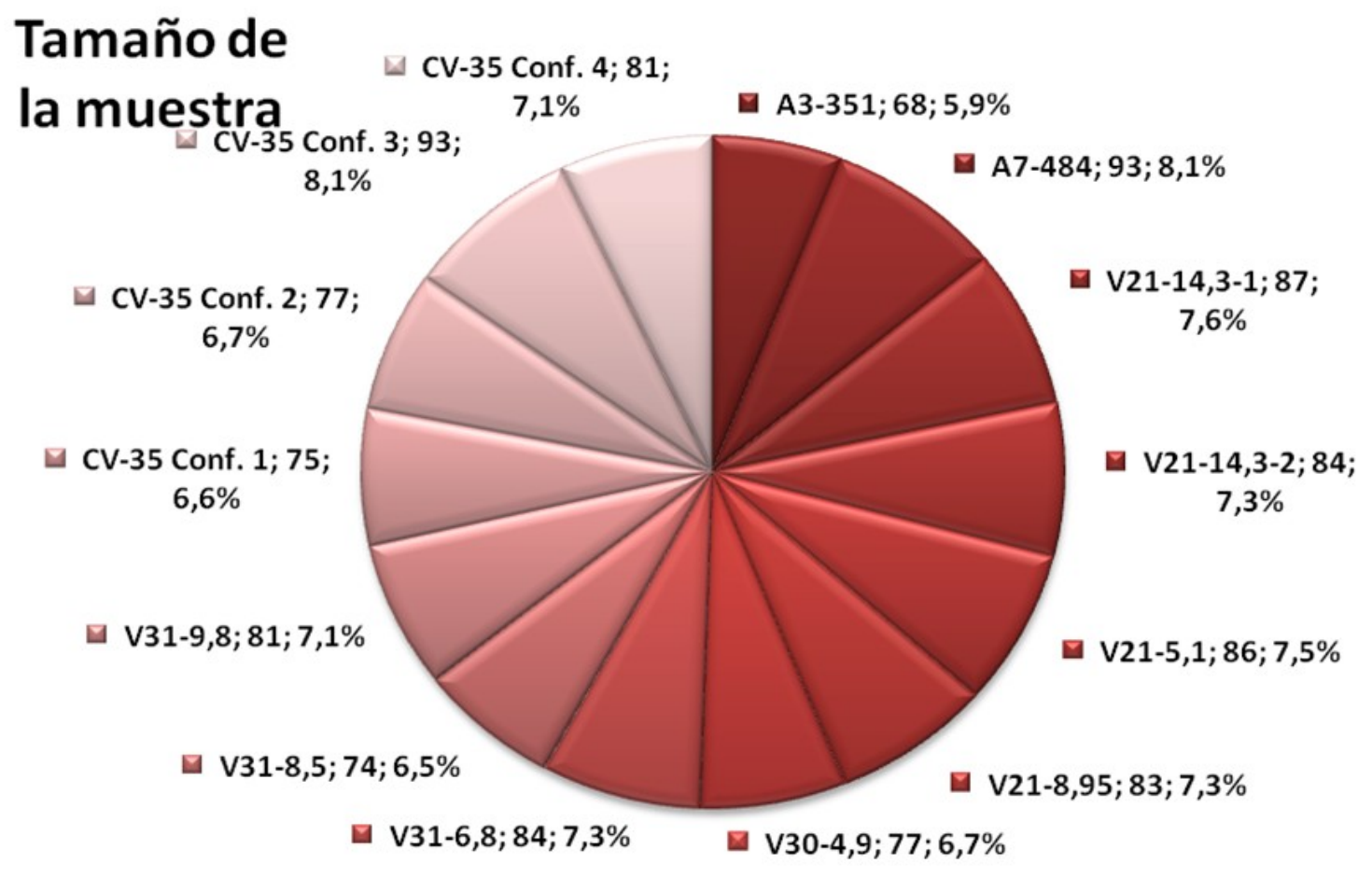

Figura 148: Maniobras analizadas por carril de deceleración 


\subsection{EVALUACIÓN CUALITATIVA}

\subsubsection{Punto de salida}

Se ha realizado el análisis del punto de salida para determinar si hay relación estadísticamente significativa entre el porcentaje de salidas en cada zona definida y la longitud.

Posteriormente se ha realizado el mismo análisis pero teniendo en cuenta no la longitud del carril sino la relación entre la longitud del carril y la longitud calculada teniendo en cuenta el límite de velocidad de la vía y no la velocidad limitada en la sección de $1,5 \mathrm{~m}$ de la cuña.

Es importante resaltar que no se ha tenido en cuenta los datos de la configuración experimental inicial debido a que en ella no estaba señalizada la cuña, lo que confunde a un número apreciable de conductores al no poder localizar con suficiente antelación la posición exacta de la salida.

Tabla 51: Análisis de regresión entre el punto de salida y la longitud

\begin{tabular}{|l|c|c|c|c|}
\hline \multicolumn{1}{|c|}{ Parámetro } & Estimación & $\begin{array}{c}\text { Error } \\
\text { Estándar }\end{array}$ & T Estadístico & P-Valor \\
\hline \multicolumn{5}{|c|}{ Anticipada } \\
\hline Punto de corte & 4,42397 & 2,45799 & 1,79983 & 0,0971 \\
\hline Longitud & $-0,00895999$ & 0,0121071 & $-0,740059$ & 0,4735 \\
\hline \multicolumn{5}{|c|}{ Cuña } \\
\hline Punto de corte & 82,0708 & 3,57311 & 22,969 & 0,0000 \\
\hline Longitud & 0,0184324 & 0,0175998 & 1,04731 & 0,3156 \\
\hline \multicolumn{5}{|c|}{ Media } \\
\hline Punto de corte & 10,8341 & 3,33138 & 3,25213 & 0,0069 \\
\hline Longitud & $-0,00516373$ & 0,0164091 & $-0,314687$ & 0,7584 \\
\hline \multicolumn{5}{|c|}{ Tardía } \\
\hline Ordenada & 2,68286 & 1,14948 & 2,33397 & 0,0378 \\
\hline Longitud & $-0,00434482$ & 0,0056619 & $-0,767378$ & 0,4577 \\
\hline
\end{tabular}


Tabla 52: Análisis varianza entre el punto de salida y la longitud del carril de deceleración

\begin{tabular}{|l|c|c|c|c|c|}
\hline Fuente & $\begin{array}{c}\text { Suma de } \\
\text { Cuadrados }\end{array}$ & GL & $\begin{array}{c}\text { Cuadrados } \\
\text { Medios }\end{array}$ & F-Ratio & P-Valor \\
\hline \multicolumn{7}{|c|}{ Anticipada } \\
\hline Modelo & 7,26253 & 1 & 7,26253 & 0,55 & 0,4735 \\
\hline Residuo & 159,124 & 12 & 13,2604 & & \\
\hline \multicolumn{7}{|c|}{ Cuña } \\
\hline Modelo & 30,7352 & 1 & 30,7352 & 1,10 & 0,3156 \\
\hline Residuo & 336,254 & 12 & 28,0212 & \\
\hline \multicolumn{7}{|c|}{ Media } \\
\hline Modelo & 2,41213 & 1 & 2,41213 & 0,10 & 0,7584 \\
\hline Residuo & 292,296 & 12 & 24,358 & \\
\hline \multicolumn{7}{|c|}{ Tardia } \\
\hline Modelo & 1,70772 & 1 & 1,70772 & 0,59 & 0,4577 \\
\hline Residuo & 34,8 & 12 & 2,9 & \\
\hline
\end{tabular}

Como se puede observar en la Tabla 52 el p-valor para todas las zonas de salida, es mayor a 0,10 . Se puede afirmar que no hay una relación estadísticamente significativa entre el punto de salida y la longitud sin transformar del carril de deceleración.

Como se había mencionado, con el fin de tener un valor de longitud que sea más homogéneo dada la diversidad de características de los carriles de deceleración seleccionados, se ha utilizado la relación $\mathrm{L} / \mathrm{L}_{0}$, siendo $\mathrm{L}$ la longitud real del carril de deceleración y Lo la longitud calculada según la Instrucción de Trazado 3.1-IC (1999) tomando el límite de velocidad de la vía y no la velocidad limitada en la sección de 1,5 $m$ de anchura de la cuña.

Tabla 53: Análisis de regresión polinomial entre el porcentaje de salidas en la cuña y la relación $L / L_{0}(R L)$

\begin{tabular}{|l|c|c|c|c|}
\hline \multicolumn{1}{|c|}{ Parámetro } & Estimación & $\begin{array}{c}\text { Error } \\
\text { Estándar }\end{array}$ & T Estadístico & P-Valor \\
\hline CONSTANTE & 68,8826 & 8,8545 & 7,77939 & 0,0000 \\
\hline Relación $\mathrm{L} / \mathrm{L}_{0}$ & 41,659 & 21,4404 & 1,94302 & 0,0780 \\
\hline$\left(\text { Relación } \mathrm{L} / \mathrm{L}_{0}\right)^{2}$ & $-22,3089$ & 11,7359 & $-1,90092$ & 0,0838 \\
\hline
\end{tabular}


Tabla 54: Análisis de varianza de la regresión polinomial entre el porcentaje de salidas en la cuña y la relación $L / L_{0}(R L)$

\begin{tabular}{|l|c|c|c|c|c|}
\hline Fuente & $\begin{array}{c}\text { Suma de } \\
\text { Cuadrados }\end{array}$ & GL & $\begin{array}{c}\text { Cuadrados } \\
\text { Medios }\end{array}$ & F-Ratio & P-Valor \\
\hline Modelo & 90,8084 & 2 & 45,4042 & 1,89 & 0,1971 \\
\hline Residuo & 264,406 & 11 & 24,0369 & & \\
\hline
\end{tabular}

La Tabla 53 muestra los resultados de ajuste al modelo polinomio de segundo orden para describir la relación entre el porcentaje de salida en la cuña y la relación $L / L_{0}$ $(\mathrm{RL})$. La ecuación (103) describe el modelo encontrado.

$$
\mathrm{PSC}=68,8826+41,659 * \mathrm{RL}-22,3089 * \mathrm{RL}^{2}
$$

donde:

- PSC: Porcentaje de salidas en la cuña (\%).

- RL: relación entre la Longitud real del carril $(L)$ y la calculada de acuerdo con la Instrucción de Trazado $\left(\mathrm{L}_{0}\right)$ (tanto por uno).

\section{Salida en la cuña}

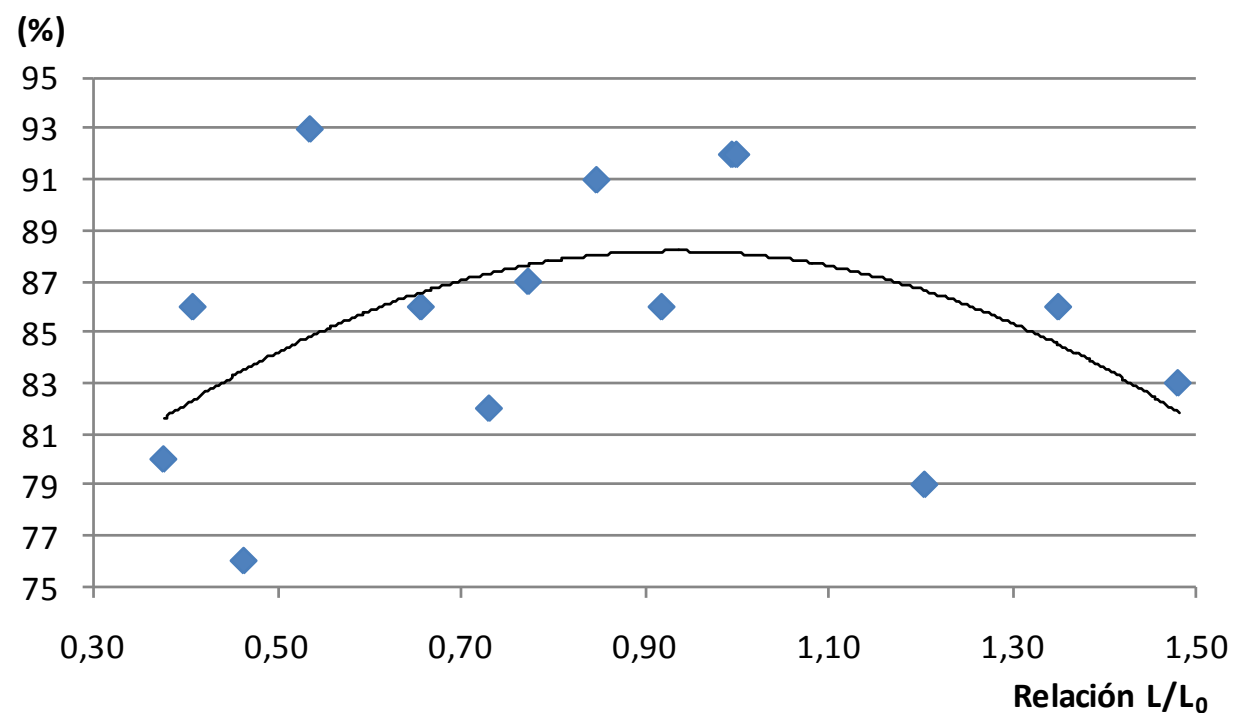

Figura 149: Regresión polinómica de la Relación $L / L_{0}(R L)$ y salida en la cuña

Como se observa en la Tabla 54 el p-valor es superior a 0,10, por lo que se puede afirmar que no existe una relación estadísticamente significativa entre el porcentaje de vehículos que salen en la cuña y la relación $L / L_{0}(R L)$ para un nivel de confianza del $90 \%$. Sin embargo, el p-valor individual de los elementos del modelo de regresión es 
inferior a 0,10 , lo que indica que aunque la correlación no es fuerte para el modelo total pero que depende de la variable independiente RL.

El valor del estadístico R-cuadrado indica que el modelo explica un $25,6 \%$ de la variabilidad en el porcentaje de salida en la cuña.

Asimismo es importante resaltar que el máximo de la regresión obtenida se encuentra cuando la relación $L / L_{0}(R L)$ es igual al 93,4\%.

Para el caso del porcentaje de salidas en la zona media, no se encontró una relación estadísticamente significativa entre la relación $L / L_{0}$ y dicho porcentaje. Sin embargo, a modo indicativo se presenta en la Figura 150 el ajuste al modelo polinomio de segundo orden para describir esta relación de acuerdo con la ecuación (104):

$$
\mathrm{PSM}=16,5849-21,3813 * \mathrm{RL}+13,8385 * \mathrm{RL}^{2}
$$

donde:

- PSM: Porcentaje de salidas en la zona media (\%).

- RL: relación entre la Longitud real del carril (L) y la calculada de acuerdo con la Instrucción de Trazado 3.1-IC (1999) $\left(L_{0}\right)$

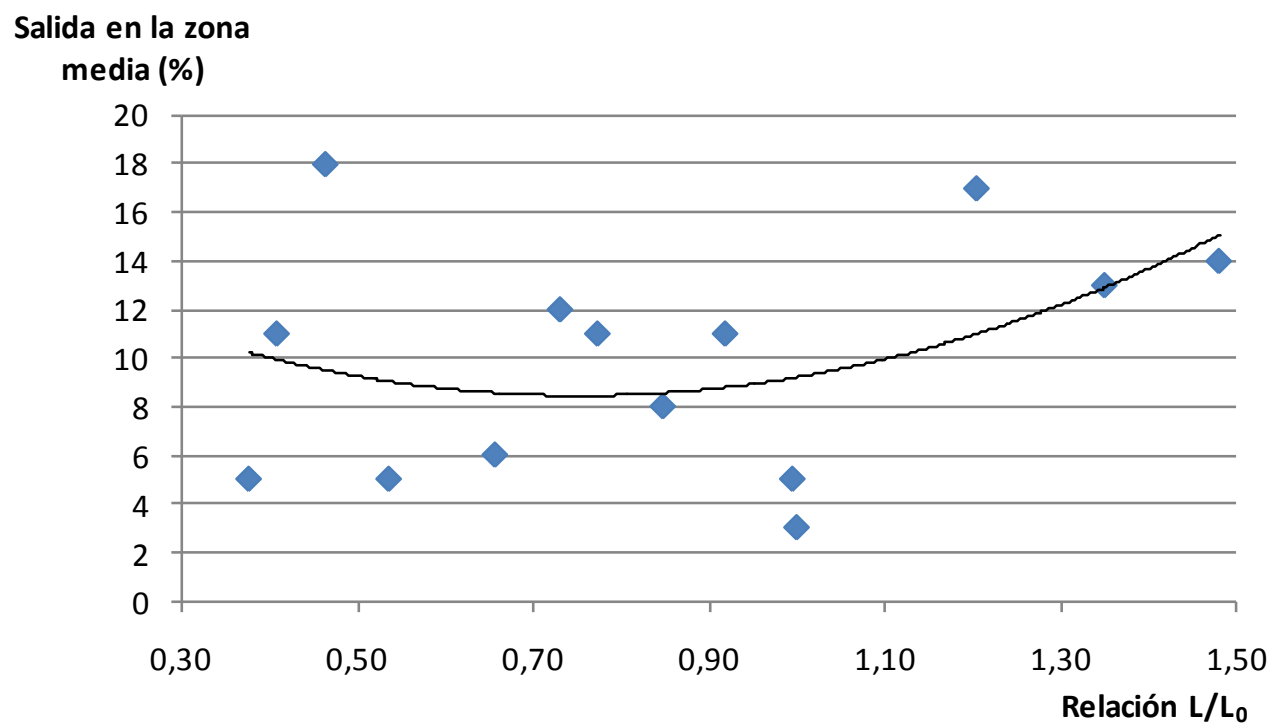

Figura 150: Regresión polinómica de la Relación $L / L_{0}(R L)$ y salida en la zona media

Es importante resaltar que el mínimo de la regresión obtenida se encuentra cuando la relación $L / L_{0}(R L)$ es igual al $78.8 \%$.

Desde el punto de vista cualitativo se ha puesto en evidencia la importancia de la cuña para guiar a los conductores en la maniobra de salida, pues se pasa del 51,3\% cuando no se tiene la cuña a valores superiores al $80 \%$, resultados similares a los que Livneh et al. (1988) encontraron en cada uno de los tres carriles de deceleración que el 
porcentaje de vehículos que divergen en la cuña es del $82 \%, 100 \%$ y $83 \%$, respectivamente.

\subsubsection{Maniobras conflictivas}

La evaluación cualitativa realizada por observación directa de las imágenes se ha centrado en determinar las diferentes modalidades en el comportamiento de todos los vehículos que salen y en medir el porcentaje de maniobras que realizan determinados comportamientos. A continuación se muestran el análisis estadístico de dichos resultados.

\subsubsection{Salidas anticipadas}

Como se ha mencionado en el análisis del punto de salida, no se ha encontrado una relación estadísticamente significativa entre la longitud del carril de deceleración y el porcentaje de salidas anticipadas. Sin embargo, se ha encontrado una relación entre este porcentaje y cuatro variables independientes: intensidad, número de carriles de la vía principal, porcentaje de vehículos pesados y la relación $L / L_{0}(R L)$.

Tabla 55: Análisis de regresión lineal múltiple para el porcentaje de salidas anticipadas

\begin{tabular}{|l|c|c|c|c|}
\hline \multicolumn{1}{|c|}{ Parámetro } & Estimación & $\begin{array}{c}\text { Error } \\
\text { Estándar }\end{array}$ & T Estadístico & P-Valor \\
\hline CONSTANTE & 9,9774 & 4,11101 & 2,42699 & 0,0382 \\
\hline Relación L/L $L_{0}$ & $-5,1766$ & 1,96226 & $-2,63808$ & 0,0270 \\
\hline Intensidad & $-0,0106227$ & 0,00328555 & $-3,23316$ & 0,0103 \\
\hline Carriles VP & 5,08342 & 1,73663 & 2,92717 & 0,0168 \\
\hline P_Pesados & $-0,331323$ & 0,107927 & $-3,06988$ & 0,0134 \\
\hline
\end{tabular}

Tabla 56: Análisis de varianza para el porcentaje de salidas anticipadas

\begin{tabular}{|l|c|c|c|c|c|}
\hline \multicolumn{1}{|c|}{ Fuente } & $\begin{array}{c}\text { Suma de } \\
\text { Cuadrados }\end{array}$ & GL & $\begin{array}{c}\text { Cuadrados } \\
\text { Medios }\end{array}$ & F-Ratio & P-Valor \\
\hline Modelo & 117,232 & 4 & 29,3079 & 5,37 & 0,0173 \\
\hline Residuo & 49,1554 & 9 & 5,46171 & & \\
\hline
\end{tabular}

En la Tabla 56 se muestran los resultados del ajuste a un modelo de regresión lineal múltiple para describir la relación entre el porcentaje de salidas anticipadas y 4 variables independientes: intensidad total, número de carriles de la vía principal, el porcentaje de vehículos pesados y la relación $L / L_{0}(R L)$. 
La ecuación (105) corresponde al modelo ajustado:

$$
A=9,9774-5,1766 * R L-0,0106227 * I+5,08342 * C-0,331323 * P
$$

donde:

- A: Porcentaje de salidas anticipadas

- RL: relación entre la longitud real del carril (L) y la calculada de acuerdo con la Instrucción de Trazado 3.1-IC (1999) $\left(L_{0}\right)$

- I: Intensidad total $(\mathrm{veh} / \mathrm{h})$

- C: Número de carriles de la vía principal

- P: Porcentaje de vehículos pesados (\%)

Como se observa en la Tabla 56, el p-valor es inferior a 0,05, por lo que se puede afirmar que existe una relación estadísticamente significativa entre porcentaje de salidas anticipadas y las 4 variables independientes mencionadas para un nivel de confianza del $95 \%$.

El valor del estadístico R-cuadrado indica que el modelo explica un $70,45 \%$ de la variabilidad en el porcentaje de salidas anticipadas.

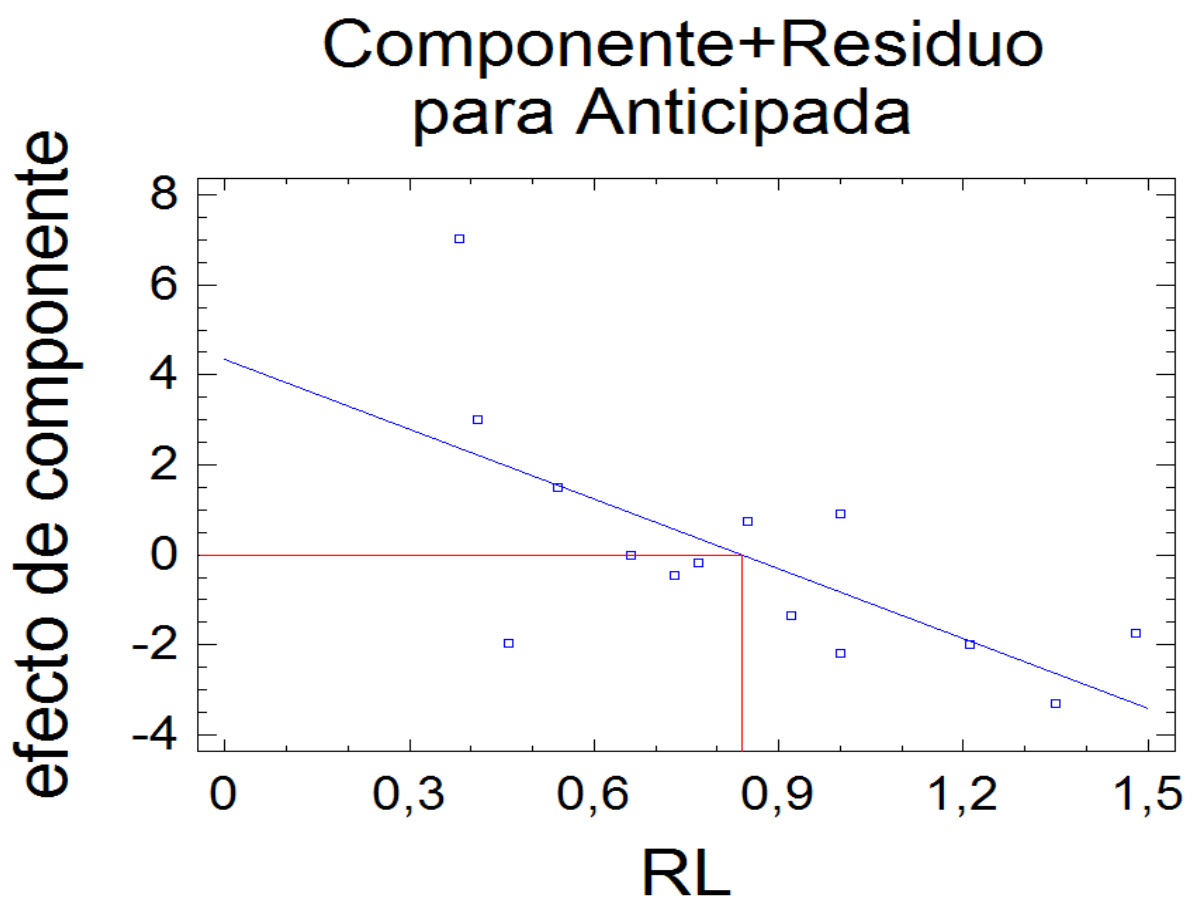

Figura 151: Efecto del componente relación $L / L_{0}(R L)$ sobre el porcentaje de salida Anticipada 
En la Figura 151 se observa como al aumentar la relación $L / L_{0}(R L)$ del carril de deceleración, disminuye el porcentaje de maniobras de salida anticipada. Asimismo se observa que dicha componente tiene un valor de 0 en su efecto cuando la relación $L / L_{0}$ $(R L)$ es 0,84 . Para longitudes superiores a este valor el porcentaje de maniobras de salida anticipada disminuye.

\subsubsection{Salidas tardías}

Como ya se ha mencionado no se ha encontrado una relación estadísticamente significativa entre el porcentaje de salidas tardías y la longitud del carril de deceleración para un nivel de confianza del $90 \%$. Tampoco se ha encontrado relación estadísticamente significativa, para ese mismo nivel de confianza, entre el porcentaje de maniobras tardías y ninguna de las otras variables estudiadas: longitud, intensidad, $\%$ de vehículos pesados, \% de vehículos que salen, densidad, relación $L / L_{0}(R L)$ y número de carriles de la vía principal.

No obstante a lo anterior se ha encontrado que el número de carriles de la vía principal influye en el porcentaje de salidas tardías como se puede observar en la Figura 152, pero también en la dispersión de los resultados. Esto es debido a que al aumentar el número de carriles de la vía principal, aumenta la probabilidad de que un conductor no tome con anticipación el carril adecuado para posteriormente salir y se vea obligado a hacer una maniobra tardía y por consiguiente también una maniobra cuyo origen sea uno de los carriles rápidos.

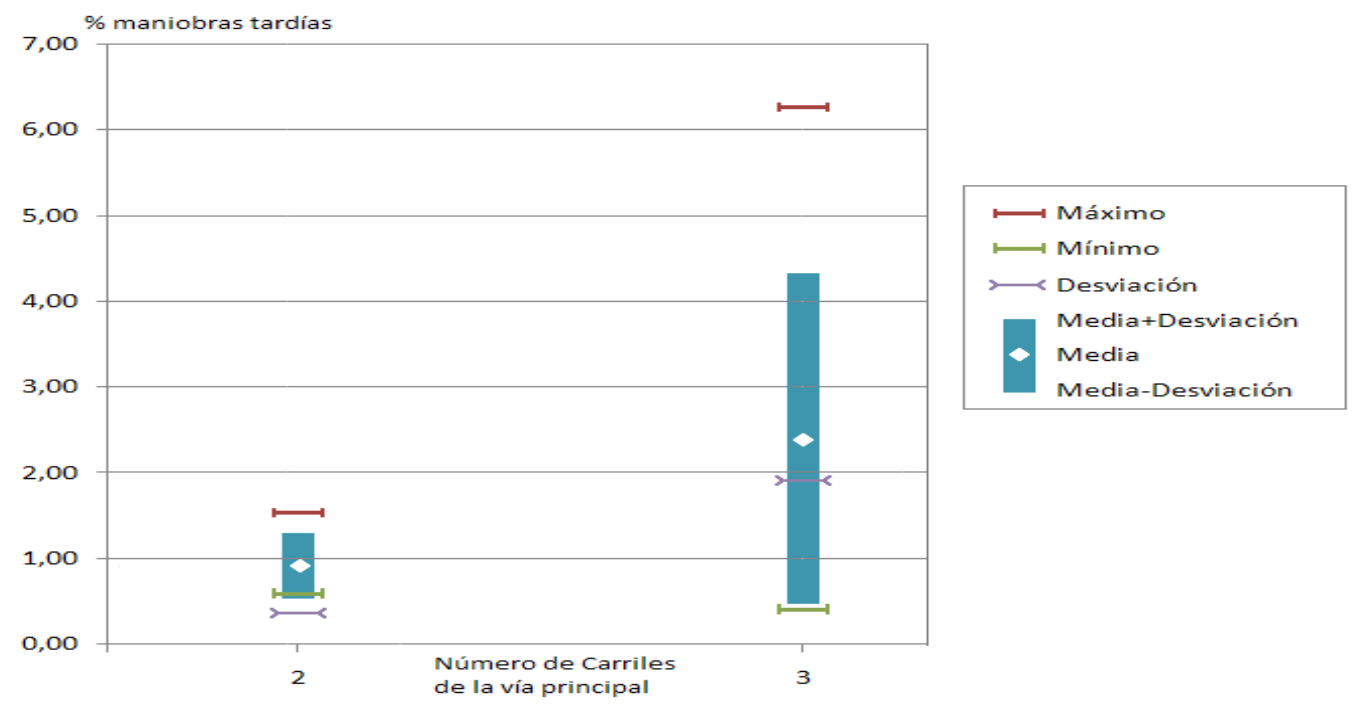

Figura 152: Porcentaje de Salidas tardías en función del número de carriles de la vía principal

De acuerdo con lo anterior se procedió a hacer el análisis de correlación entre maniobras tardías y maniobras cuyo origen es uno de los carriles rápidos, encontrando que existe relación estadísticamente significativa entre el porcentaje de maniobras tardías y maniobras cuyo origen es uno de los carriles rápidos, para un nivel de confianza del 99\%, dado que el p-valor en la Tabla 58 es inferior a 0,01. 
Tabla 57: Análisis de regresión lineal entre el porcentaje de salidas tardías y las maniobras cuyo origen es uno de los carriles rápidos

\begin{tabular}{|l|c|c|c|c|}
\hline \multicolumn{1}{|c|}{ Parámetro } & Estimación & $\begin{array}{c}\text { Error } \\
\text { Estándar }\end{array}$ & T Estadístico & P-Valor \\
\hline CONSTANTE & 0,755698 & 0,484681 & 1,55917 & 0,1449 \\
\hline Origen rápido & 0,286346 & 0,0884083 & 3,23891 & 0,0071 \\
\hline
\end{tabular}

Tabla 58: Análisis de varianza entre el porcentaje de salidas tardías y las maniobras cuyo origen es uno de los carriles rápidos

\begin{tabular}{|l|c|c|c|c|c|}
\hline \multicolumn{1}{|c|}{ Fuente } & $\begin{array}{c}\text { Suma de } \\
\text { Cuadrados }\end{array}$ & GL & $\begin{array}{c}\text { Cuadrados } \\
\text { Medios }\end{array}$ & F-Ratio & P-Valor \\
\hline Modelo & 17,0287 & 1 & 17,0287 & 10,49 & 0,0071 \\
\hline Residuo & 19,479 & 12 & 1,62325 & & \\
\hline
\end{tabular}

La ecuación (106) corresponde al modelo lineal para describir la relación entre el porcentaje de maniobras tardías y el porcentaje de maniobras cuyo origen es uno de los carriles rápidos es:

$$
\mathrm{T}=0,755698+0,286346^{*} \mathrm{OR}
$$

donde:

- T: Porcentaje de maniobras tardías (\%).

- OR: Porcentaje de salidas cuyo origen es uno de los carriles rápidos.

El valor del estadístico R-cuadrado indica que el modelo explica un 46,64\% de la variabilidad en el porcentaje de salidas tardías.

\subsubsection{Reincorporaciones}

En el análisis de correlación entre reincorporaciones y la longitud del carril de deceleración se ha encontrando que existe relación estadísticamente significativa entre las dos variables, para un nivel de confianza del $99 \%$, dado que el p-valor en la Tabla 60 es inferior a 0,01.

Tabla 59: Análisis de regresión lineal entre el porcentaje de reincorporaciones y la Longitud del carril de deceleración

\begin{tabular}{|l|c|c|c|c|}
\hline \multicolumn{1}{|c|}{ Parámetro } & Estimación & $\begin{array}{c}\text { Error } \\
\text { Estándar }\end{array}$ & T Estadístico & P-Valor \\
\hline CONSTANTE & $-0,468565$ & 0,332568 & $-1,40893$ & 0,1842 \\
\hline Longitud & 0,00549422 & 0,0016381 & 3,35401 & 0,0057 \\
\hline
\end{tabular}

Tabla 60: Análisis de varianza entre el porcentaje de reincorporaciones y la Longitud del carril de deceleración 


\begin{tabular}{|l|c|c|c|c|c|}
\hline Fuente & $\begin{array}{c}\text { Suma de } \\
\text { Cuadrados }\end{array}$ & GL & $\begin{array}{c}\text { Cuadrados } \\
\text { Medios }\end{array}$ & F-Ratio & P-Valor \\
\hline Modelo & 2,73077 & 1 & 2,73077 & 11,25 & 0,0057 \\
\hline Residuo & 2,91298 & 12 & 0,242748 & & \\
\hline
\end{tabular}

La ecuación (107) corresponde al modelo lineal para describir la relación entre el porcentaje de maniobras de reincorporación y la longitud del carril de deceleración es:

$$
R=-0,468565+0,00549422^{*} L
$$

donde:

- R: Porcentaje de maniobras de reincorporación (\%)

- L: Longitud real del carril (m)

El valor del estadístico R-cuadrado indica que el modelo explica un 48,39\% de la variabilidad en el porcentaje de reincorporaciones.

Al aumentar la longitud del carril se incrementa el porcentaje de reincorporaciones debido en primer lugar a que en carriles demasiado largos los conductores pueden interpretar el carril como un carril adicional por no apreciar fácilmente la salida y en carriles muy cortos, los conductores no tienen tiempo de hacer la maniobra de reincorporación en caso de haberse percatado de que han equivocado la salida.

\subsubsection{Origen de los carriles rápidos}

En el análisis del porcentaje de maniobras cuyo origen es uno de los carriles rápidos se ha encontrado una relación estadísticamente significativa, para un nivel de confianza del $90 \%$, entre este porcentaje y dos variables independientes: la relación $L / L_{0}(R L)$ y el porcentaje de vehículos que salen (PVS) de acuerdo con los resultados de la Tabla 62.

Tabla 61: Análisis de regresión lineal múltiple para el porcentaje de salidas con origen rápido

\begin{tabular}{|c|c|c|c|c|}
\hline Parámetro & Estimación & $\begin{array}{c}\text { Error } \\
\text { Estándar }\end{array}$ & T Estadístico & P-Valor \\
\hline CONSTANTE & 4,43661 & 2,42134 & 1,83229 & 0,0941 \\
\hline Relación L/L 0 & 6,05772 & 2,7364 & 2,21375 & 0,0489 \\
\hline PVS & $-37,9063$ & 12,3015 & $-3,08143$ & 0,0104 \\
\hline
\end{tabular}


Tabla 62: Análisis de varianza para el porcentaje de salidas con origen rápido

\begin{tabular}{|l|c|c|c|c|c|}
\hline Fuente & $\begin{array}{c}\text { Suma de } \\
\text { Cuadrados }\end{array}$ & GL & $\begin{array}{c}\text { Cuadrados } \\
\text { Medios }\end{array}$ & F-Ratio & P-Valor \\
\hline Modelo & 101,829 & 2 & 50,9144 & 5,29 & 0,0246 \\
\hline Residuo & 105,853 & 11 & 9,62301 & & \\
\hline
\end{tabular}

En la Tabla 61 se muestran los resultados del ajuste a un modelo de regresión lineal múltiple para describir la relación entre el porcentaje de salidas cuyo origen es uno de los carriles rápidos y dos variables independientes: relación $L / L_{0}(R L)$ y el porcentaje de vehículos que salen.

La ecuación (108) corresponde al modelo ajustado:

$$
\mathrm{OR}=4,43661+6,05772 * \mathrm{RL}-37,9063 * \mathrm{PVS}
$$

donde:

- OR: Porcentaje de maniobras cuyo origen es uno de los carriles rápidos (\%).

- RL: relación entre la Longitud real del carril (L) y la calculada de acuerdo con la Instrucción de Trazado 3.1-IC (1999) $\left(\mathrm{L}_{0}\right)$

- PVS: Porcentaje de vehículos que salen (\%)

En la ecuación se observa como al aumentar la relación L/Lo (RL) aumenta el porcentaje de maniobras desde los carriles rápidos. Asimismo, al aumentar el porcentaje de vehículos que salen disminuye este porcentaje de maniobras.

Como se observa en la Tabla 62, el p-valor es inferior a 0,05, por lo que se puede afirmar que existe una relación estadísticamente significativa entre el porcentaje de salidas cuyo origen es uno de los carriles rápidos y las dos variables independientes mencionadas para un nivel de confianza del 95\%.

El valor del estadístico R-cuadrado indica que el modelo explica un $49,03 \%$ de la variabilidad en el porcentaje de salidas cuyo origen es uno de los carriles rápidos. 


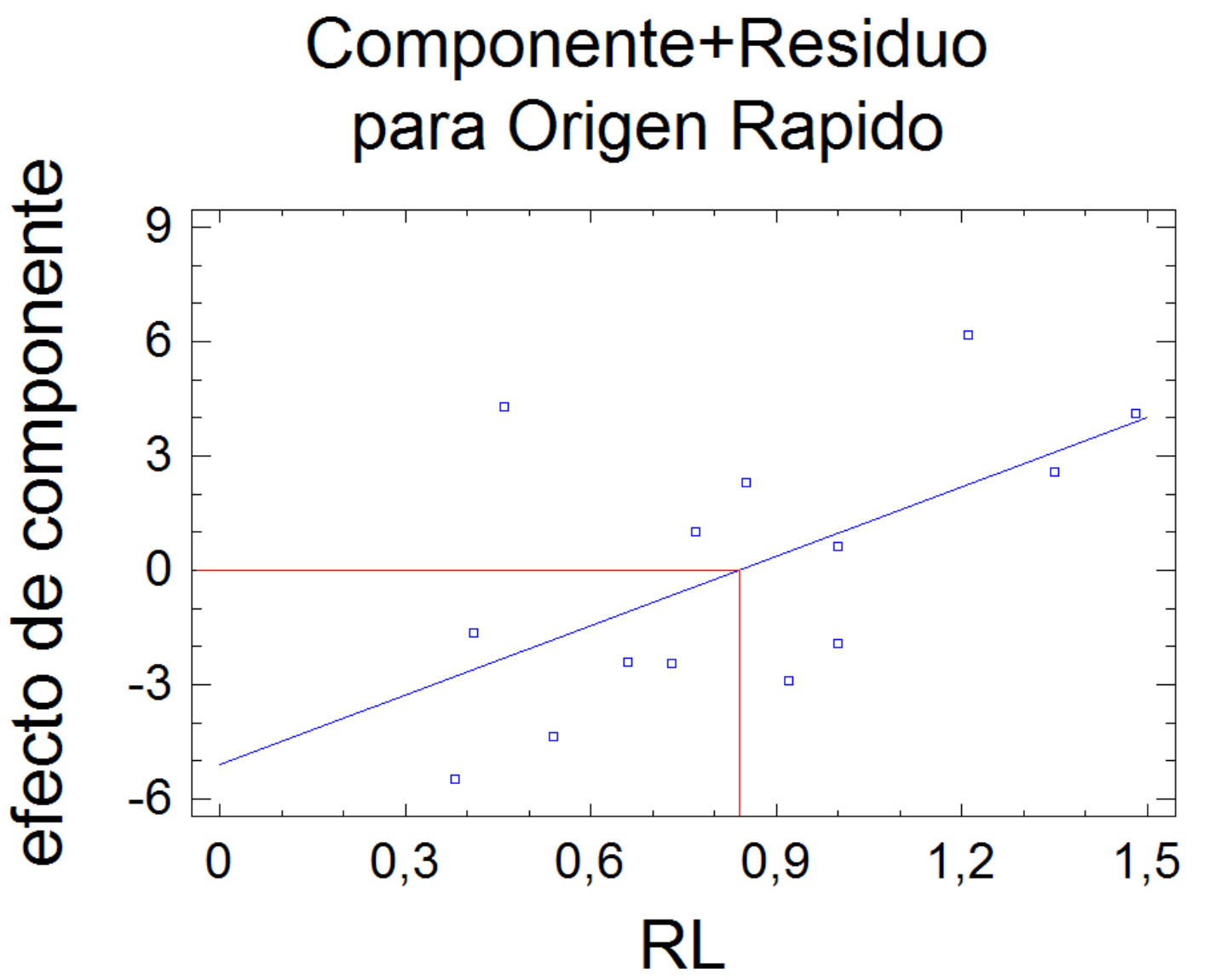

Figura 153: Efecto del componente relación $L / L_{0}(R L)$ sobre el porcentaje de salidas desde uno de los carriles rápidos

En la Figura 153 se observa como al aumentar la relación $L / L_{0}(R L)$ del carril de deceleración, aumenta también el porcentaje de maniobras de salida desde uno de los carriles rápidos. Asimismo se observa que dicha componente tiene un valor de 0 en su efecto cuando la relación $L / L_{0}(R L)$ es 0,84 . Para longitudes superiores a este valor el porcentaje de maniobras de salida con origen en uno de los carriles rápidos aumenta.

En el análisis de la correlación entre el porcentaje de maniobras cuyo origen es uno de los carriles rápidos y la longitud del carril de deceleración no se encontró una relación lineal ni polinómica estadísticamente significativa entre las dos variables para un nivel de confianza del $90 \%$, sin embargo se ha encontrado que al hacer una transformación Box-Cox que permite corregir problemas de normalidad y de heterocedasticidad, se encuentra que para dicho nivel de confianza si existe una relación estadísticamente significativa entre los valores transformados del porcentaje de maniobras cuyo origen es uno de los carriles rápidos y la longitud del carril de deceleración, ya que el p-valor en la Tabla 64 es inferior a 0,1. 
Tabla 63: Análisis de regresión entre porcentaje de origen rápido transformado y Longitud del carril de deceleración

\begin{tabular}{|l|c|c|c|c|}
\hline \multicolumn{1}{|c|}{ Parámetro } & Estimación & $\begin{array}{c}\text { Error } \\
\text { Estándar }\end{array}$ & T Estadístico & P-Valor \\
\hline CONSTANTE & $-0,153241$ & 1,61537 & $-0,0948642$ & 0,9260 \\
\hline Longitud & 0,0149472 & 0,0079567 & 1,87857 & 0,0848 \\
\hline
\end{tabular}

Tabla 64: Análisis de varianza de origen rápido transformado y Longitud del carril de deceleración

\begin{tabular}{|l|c|c|c|c|c|}
\hline Fuente & $\begin{array}{c}\text { Suma de } \\
\text { Cuadrados }\end{array}$ & GL & $\begin{array}{c}\text { Cuadrados } \\
\text { Medios }\end{array}$ & F-Ratio & P-Valor \\
\hline Modelo & 20,2112 & 1 & 20,2112 & 3,53 & 0,0848 \\
\hline Residuo & 68,7259 & 12 & 5,72715 & & \\
\hline
\end{tabular}

La ecuación (109) corresponde al modelo ajustado, mostrado como una línea continua, es:

$$
\operatorname{Box} \operatorname{Cox}(O R)=-0,153241+0,0149472^{*} \mathrm{~L}
$$

donde:

- $\quad \operatorname{Box} \operatorname{Cox}(O R)=\frac{\mathrm{OR}^{0,0554872}-1}{0,0554872 * 2,11387^{-0,944513}}$

- OR: Porcentaje de vehículos que salen cuyo origen es uno de los carriles rápidos.

- L: Longitud real del carril

El valor del estadístico R-cuadrado indica que el modelo explica un $22,73 \%$ de la variabilidad en el porcentaje de maniobras cuyo origen es uno de los carriles rápidos. Dicha relación puede considerarse muy débil por lo que se prefiere la relación con las tres variables independientes anteriores: relación $L / L_{0}(R L)$, intensidad y densidad. 


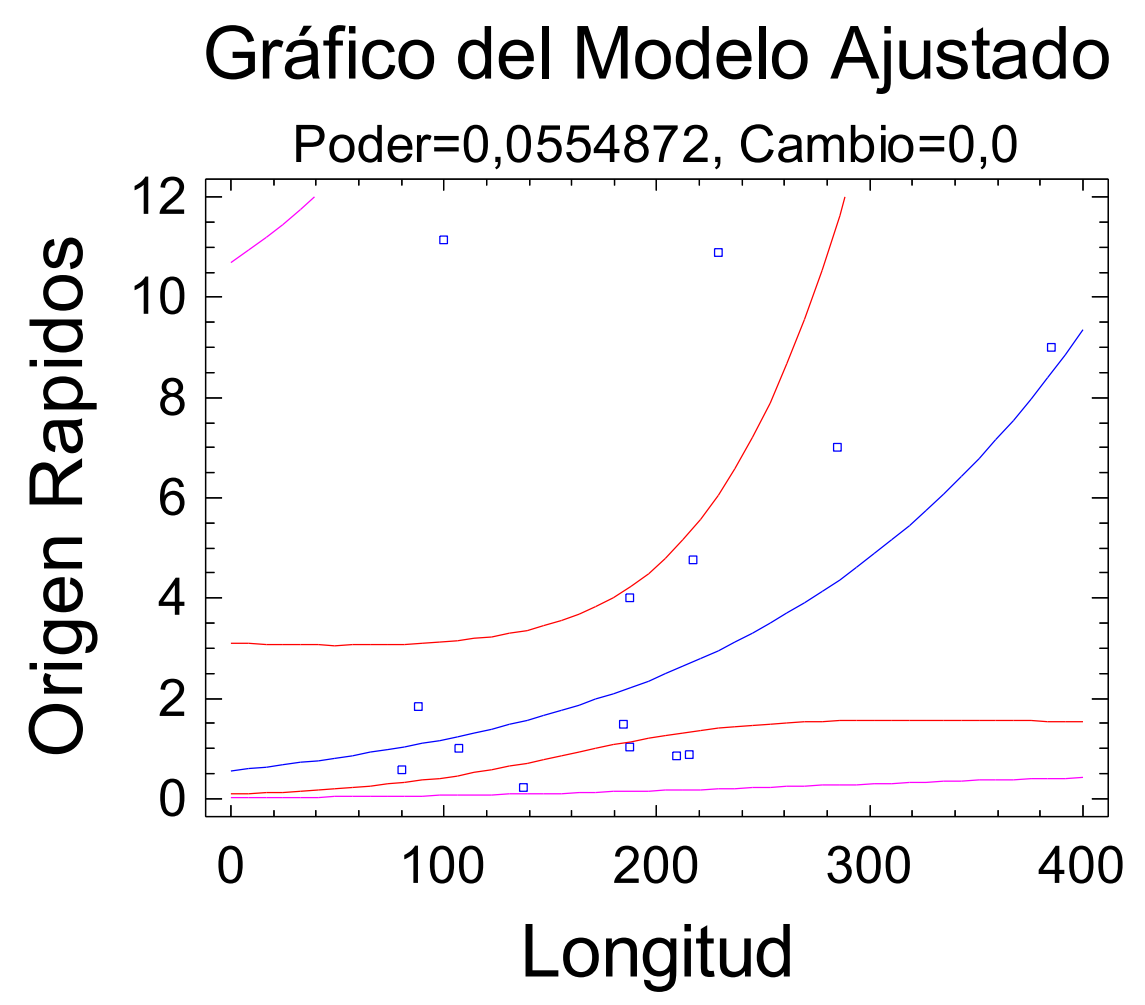

Figura 154: Modelo ajustado de la transformación del porcentaje de origen en carril rápido y la longitud del carril de deceleración

Al aumentar la longitud del carril de deceleración aumenta el porcentaje de maniobras cuyo origen es uno de los carriles rápidos, debido, principalmente, a que la mayor longitud del carril permite a los conductores enlazar la maniobra de cambio de carril con la maniobra de salida.

Como se ha mencionado anteriormente, este tipo de maniobra está íntimamente relacionada con la maniobra de salida tardía.

\subsubsection{Adelantamientos}

Se ha realizado un análisis estadístico de las maniobras de salida con adelantamiento teniendo en cuenta los 3 casos de adelantamientos y las 2 combinaciones adicionales. Los tres casos de adelantamientos son: el adelantamiento exterior, el adelantamiento interior no confluyente y el adelantamiento interior confluyente. Las dos combinaciones son los adelantamientos interiores totalizados que corresponde a la suma del adelantamiento interior confluyente con el no confluyente, y adicionalmente se ha tomado la suma de los tres tipos de adelantamientos.

Es importante señalar que salvo para el caso de adelantamiento exterior no se ha encontrado una relación estadísticamente significativa, con un nivel de confianza del 
$90 \%$, entre los otros 4 casos y ninguna de las variables explicativas del problema. Esto se puede deber a la poca frecuencia de ocurrencia de adelantamientos interiores.

Para el caso de adelantamiento exterior se ha encontrado una relación estadísticamente significativa entre este valor y dos variables independientes: la longitud del carril de deceleración y el número de carriles de la vía principal, con un nivel de confianza del 95\% puesto que el p-valor de la Tabla 66 es inferior a 0,05.

Tabla 65: Análisis de regresión lineal múltiple para el porcentaje de adelantamiento exterior

\begin{tabular}{|l|c|c|c|c|}
\hline \multicolumn{1}{|c|}{ Parámetro } & Estimación & $\begin{array}{c}\text { Error } \\
\text { Estándar }\end{array}$ & T Estadístico & P-Valor \\
\hline CONSTANTE & $-6,70448$ & 2,53115 & $-2,64879$ & 0,0226 \\
\hline Longitud & 0,0130044 & 0,00536391 & 2,42442 & 0,0337 \\
\hline Carriles VP & 2,33896 & 0,899861 & 2,59924 & 0,0247 \\
\hline
\end{tabular}

Tabla 66: Análisis de varianza para el porcentaje de adelantamiento exterior

\begin{tabular}{|l|c|c|c|c|c|}
\hline \multicolumn{1}{|c|}{ Fuente } & $\begin{array}{c}\text { Suma de } \\
\text { Cuadrados }\end{array}$ & GL & $\begin{array}{c}\text { Cuadrados } \\
\text { Medios }\end{array}$ & F-Ratio & P-Valor \\
\hline Modelo & 35,8725 & 2 & 17,9363 & 6,95 & 0,0112 \\
\hline Residuo & 28,3927 & 11 & 2,58115 & & \\
\hline
\end{tabular}

En la Tabla 65 se muestran los resultados del ajuste a un modelo de regresión lineal múltiple para describir la relación entre el porcentaje de maniobras con adelantamiento exterior y las 2 variables independientes mencionadas.

La ecuación (110) corresponde al modelo ajustado:

$$
\mathrm{Ae}=-6,70448+0,0130044 * \mathrm{~L}+2,33896 * \text { Cvp }
$$

donde:

- Ae: Porcentaje de maniobras con adelantamiento exterior (\%).

- L: Longitud del carril de deceleración (m)

- Cvp: Número de carriles de la vía principal.

El valor del estadístico R-cuadrado indica que el modelo explica un 55,82\% de la variabilidad en el porcentaje de salidas con adelantamiento exterior.

Con el fin de simplificar el modelo se ha buscado la relación entre el porcentaje de maniobras con adelantamiento exterior y la longitud del carril de deceleración. Se ha encontrado que existe una relación estadísticamente significativa entre estas dos variables con un nivel de confianza del $95 \%$ puesto que el p-valor de la Tabla 68 es inferior a 0,05. 
Tabla 67: Análisis de regresión lineal entre el porcentaje de adelantamiento exterior y la longitud del carril

\begin{tabular}{|l|c|c|c|c|}
\hline \multicolumn{1}{|c|}{ Parámetro } & Estimación & $\begin{array}{c}\text { Error } \\
\text { Estándar }\end{array}$ & T Estadístico & P-Valor \\
\hline CONSTANTE & $-0,759831$ & 1,31914 & $-0,576003$ & 0,5753 \\
\hline Longitud & 0,014275 & 0,0064976 & 2,19696 & 0,0484 \\
\hline
\end{tabular}

Tabla 68: Análisis de varianza de la relación entre el porcentaje de adelantamiento exterior y la longitud del carril

\begin{tabular}{|l|c|c|c|c|c|}
\hline Fuente & $\begin{array}{c}\text { Suma de } \\
\text { Cuadrados }\end{array}$ & GL & $\begin{array}{c}\text { Cuadrados } \\
\text { Medios }\end{array}$ & F-Ratio & P-Valor \\
\hline Modelo & 18,4341 & 1 & 18,4341 & 4,83 & 0,0484 \\
\hline Residuo & 45,831 & 12 & 3,81925 & & \\
\hline
\end{tabular}

La ecuación (111) corresponde al modelo ajustado:

$$
A E=-0,759831+0,014275^{*} \mathrm{~L}
$$

donde:

- AE: Porcentaje de maniobras con adelantamiento exterior (\%).

- L: Longitud real del carril ( $m)$.

El valor del estadístico R-cuadrado indica que el modelo explica un $28,68 \%$ de la variabilidad en el porcentaje de salidas con adelantamiento exterior.

Es importante resaltar que al aumentar la longitud del carril de deceleración aumenta el porcentaje de adelantamiento exterior, debido principalmente a que los conductores cuentan con tiempo suficiente para hacer la maniobra de adelantamiento antes de salir. Este comportamiento se ve incrementado igualmente al aumentar el número de carriles de la vía principal.

\subsection{EVALUACIÓN CUANTITATIVA}

\subsubsection{Velocidad}

El análisis de la velocidad se ha basado en dos elementos principales: en primer lugar se ha analizado el diferencial de velocidad entre la velocidad en la vía principal antes de verse afectado por la maniobra de salida y la velocidad en el momento de abandonar completamente la vía principal; y en segundo lugar la velocidad en la nariz.

En el primer caso se ha evaluado tanto el diferencial del percentil 85 de la velocidad entre la velocidad en la vía principal y la de abandono del carril como el percentil 85 del diferencial de la velocidad en estos mismos instantes. El primer caso no representa exactamente la afección de los vehículos a la vía principal puesto que puede 
amortiguar su efecto, sin embargo se ha evaluado para tener un punto de comparación con relación al segundo caso.

Para el análisis se ha tenido en cuenta la relación entre la longitud real del carril observado $(L)$ y la longitud calculada según la Instrucción de Trazado 3.1-IC (1999) tomando el límite de velocidad de la vía y no la velocidad limitada en la sección de 1,5 m de anchura de la cuña $\left(L_{0}\right)$.

\subsubsection{Diferencial de velocidad para abandonar la vía principal}

En cuanto al porcentaje de disminución del percentil 85 de la velocidad entre la vía principal y al abandonar el carril, se ha encontrado una relación estadísticamente representativa entre este valor y dos variables explicativas: la relación $L / L_{0}(R L)$ y el porcentaje de vehículos que salen. El nivel de confianza de esta relación es del 99\%, de acuerdo con la Tabla 70, ya que el p-valor es inferior a 0,01.

Tabla 69: Análisis de regresión lineal entre el diferencial del percentil 85 de la velocidad en la vía principal y al abandonarla respecto a la relación $L / L_{0}(R L)$

\begin{tabular}{|l|c|c|c|c|}
\hline \multicolumn{1}{|c|}{ Parámetro } & Estimación & $\begin{array}{c}\text { Error } \\
\text { Estándar }\end{array}$ & T Estadístico & P-Valor \\
\hline CONSTANTE & 20,7739 & 3,11932 & 6,65976 & 0,0000 \\
\hline Ln(Relación L/L $)$ & $-10,8836$ & 2,9945 & $-3,63454$ & 0,0039 \\
\hline PVS & $-45,3483$ & 16,9133 & $-2,68122$ & 0,0214 \\
\hline
\end{tabular}

Tabla 70: Análisis de varianza para el diferencial del percentil 85 de la velocidad en la vía principal y al abandonarla respecto a la relación $L / L_{0}(R L)$

\begin{tabular}{|l|c|c|c|c|c|}
\hline \multicolumn{1}{|c|}{ Fuente } & $\begin{array}{c}\text { Suma de } \\
\text { Cuadrados }\end{array}$ & GL & $\begin{array}{c}\text { Cuadrados } \\
\text { Medios }\end{array}$ & F-Ratio & P-Valor \\
\hline Modelo & 612,97 & 2 & 306,485 & 16,56 & 0,0005 \\
\hline Residuo & 203,565 & 11 & 18,5059 & & \\
\hline
\end{tabular}

La ecuación (112) corresponde al modelo lineal para describir la relación entre el diferencial del percentil 85 de la velocidad entre la vía principal y al abandonar el carril y la relación $L / L_{0}(R L)$ es:

$$
\Delta \mathrm{V}_{85}=20,7739-10,8836^{*} \operatorname{Ln}(\mathrm{RL})-45,3483^{*} \mathrm{PVS}
$$

donde:

- $\Delta \mathrm{V}_{85}$ : Porcentaje de disminución del percentil 85 de la velocidad entre la vía principal y al abandonar el carril (\%).

- RL: relación entre la longitud real del carril (L) y la calculada de acuerdo con la Instrucción de Trazado 3.1-IC (1999) $\left(L_{0}\right)$. 
- PVS: Porcentaje de vehículos que salen (\%).

El valor del estadístico R-cuadrado indica que el modelo explica un 75,07\% de la variabilidad en el diferencial, en porcentaje, del percentil 85 de la velocidad en la vía principal y al abandonarla.

Tabla 71: Análisis de regresión lineal para el percentil 85 del diferencial de la velocidad en la vía principal y al abandonarla en \%

\begin{tabular}{|l|c|c|c|c|}
\hline \multicolumn{1}{|c|}{ Parámetro } & Estimación & $\begin{array}{c}\text { Error } \\
\text { Estándar }\end{array}$ & T Estadístico & P-Valor \\
\hline CONSTANTE & 19,4413 & 3,51852 & 5,52542 & 0,0002 \\
\hline Ln(Relación L/L $)$ & $-12,8813$ & 3,37772 & $-3,8136$ & 0,0029 \\
\hline PVS & $-35,4531$ & 19,0778 & $-1,85834$ & 0,0901 \\
\hline
\end{tabular}

Tabla 72: Análisis de varianza para el percentil 85 del diferencial de la velocidad en la vía principal y al abandonarla en \%

\begin{tabular}{|l|c|c|c|c|c|}
\hline Fuente & $\begin{array}{c}\text { Suma de } \\
\text { Cuadrados }\end{array}$ & GL & $\begin{array}{c}\text { Cuadrados } \\
\text { Medios }\end{array}$ & F-Ratio & P-Valor \\
\hline Modelo & 655,138 & 2 & 327,569 & 13,91 & 0,0010 \\
\hline Residuo & 259,002 & 11 & 23,5457 & & \\
\hline
\end{tabular}

La ecuación (113) corresponde al modelo para describir la relación entre el percentil 85 del diferencial de la velocidad entre la vía principal y al abandonar el carril en porcentaje y las variables explicativas es:

$$
\text { Percentil } 85 \Delta V=19,4413-12,8813^{*} \operatorname{Ln}(R L)-35,4531^{*} P V S
$$

donde:

- Percentil $85 \Delta \mathrm{V}$ : Percentil 85 del porcentaje de disminución de la velocidad entre la vía principal y al abandonar el carril (\%).

- RL: relación entre la Longitud real del carril (L) y la calculada de acuerdo con la Instrucción de Trazado 3.1-IC (1999) $\left(\mathrm{L}_{0}\right)$.

- PVS: Porcentaje de vehículos que salen (\%).

El valor del estadístico R-cuadrado indica que el modelo explica un $71,67 \%$ de la variabilidad en el percentil 85 del diferencial de la velocidad en la vía principal y al abandonarla.

Aunque al valor R-cuadrado es superior para la regresión del diferencial del percentil 85 de la velocidad que para el percentil 85 del diferencial de la velocidad, el primer 
caso no representa exactamente la afección de los vehículos a la vía principal puesto que se amortigua el efecto de la reducción de la velocidad. Para ambos casos de regresión en el valor 1,0 de la relación $L / L_{0}(R L)$ se obtiene un diferencial alrededor del $14 \%$ que coincide con el valor encontrado por De la Iglesia y García (2000). En la Figura 155 se puede observar el ajuste de ambas regresiones a la nube de puntos.

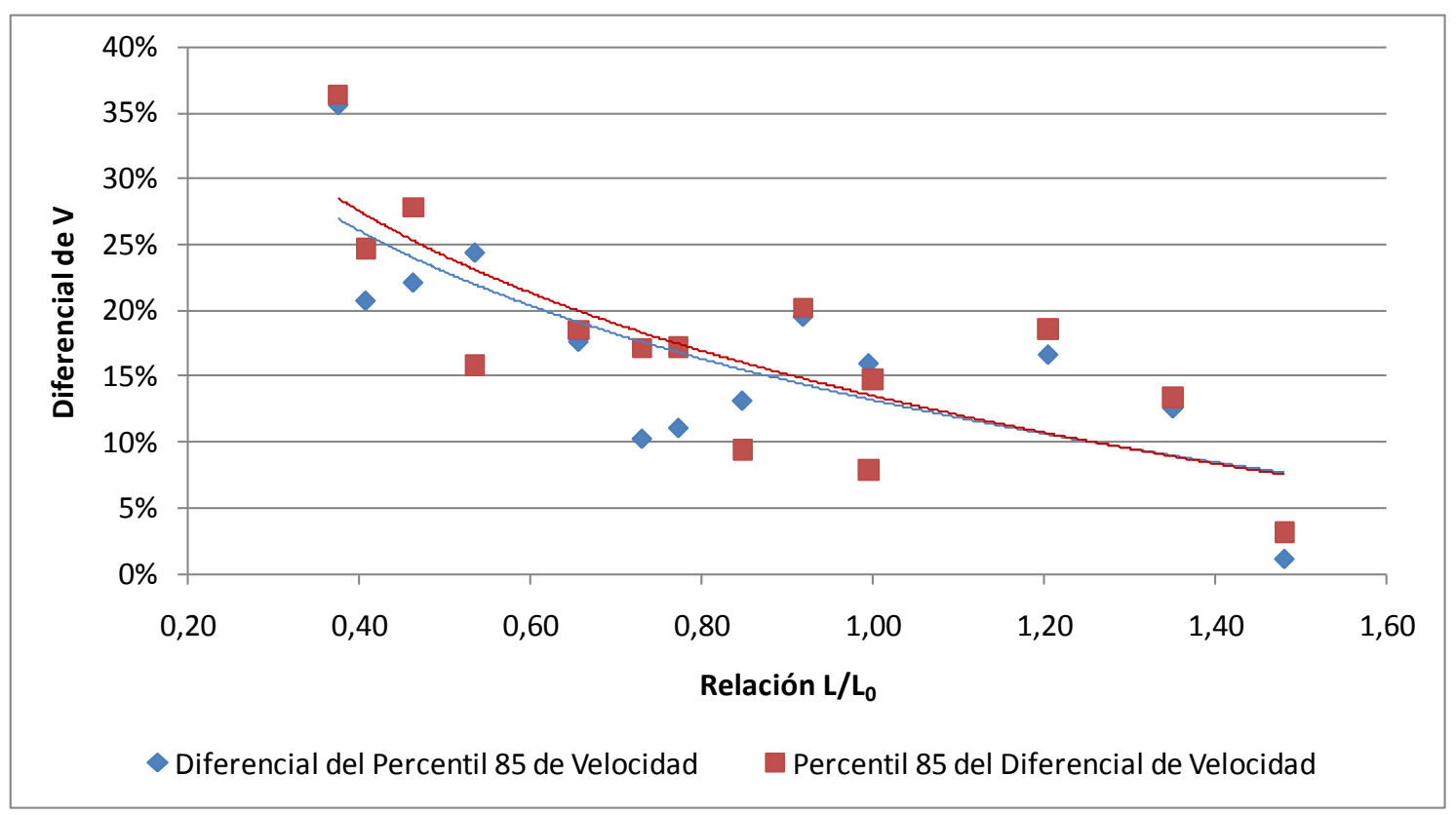

Figura 155: Disminución de velocidad entre la vía principal y al abandonar el carril

Estos resultados confirman, en primer lugar, que los vehículos deceleran antes de tomar el carril de deceleración. Se debe resaltar que si el carril de deceleración es muy corto esta disminución de velocidad afecta en mayor medida al flujo de la vía principal. Asimismo, se destaca que el percentil 85 del porcentaje de disminución de la velocidad entre la vía principal y al abandonar el carril depende del logaritmo de la relación $L / L_{0}$ $(\mathrm{RL})$ por lo que tiende a ser asintótica.

\subsubsection{Velocidad en la nariz}

En primer lugar, es importante resaltar que se ha encontrado que, para todos los carriles estudiados, el percentil 85 de la velocidad en la nariz es superior al límite de velocidad en ese punto.

Por otra parte, no se ha encontrado una relación estadísticamente representativa entre la velocidad en la nariz y ninguna de las variables explicativas para un nivel de confianza del $90 \%$. Esto es debido a que existe variabilidad en el límite de velocidad en cada ubicación. Por esta razón se ha buscado la relación entre la diferencia entre el percentil 85 de la velocidad en la nariz y el límite de velocidad en la misma y las diferentes variables explicativas. 
Cómo se observa en la Figura 156, se ha encontrado una relación polinómica estadísticamente representativa entre la velocidad en la nariz y la relación $L / L_{0}(R L)$ con un nivel de confianza del $99 \%$ de acuerdo con la Tabla 74 , ya que el p-valor es inferior a 0,01 .

Tabla 73: Análisis de regresión polinómica entre la velocidad en la nariz y a relación $\mathbf{L} / \mathbf{L}_{\mathbf{0}}(\mathbf{R L})$

\begin{tabular}{|c|c|c|c|c|}
\hline Parámetro & Estimación & $\begin{array}{c}\text { Error } \\
\text { Estándar }\end{array}$ & T Estadístico & P-Valor \\
\hline CONSTANTE & 28,7454 & 5,51759 & 5,20976 & 0,0003 \\
\hline Relación $L_{/} L_{0}$ & $-44,7499$ & 13,3604 & $-3,34946$ & 0,0065 \\
\hline$\left(\text { Relación } L / L_{0}\right)^{2}$ & 26,9381 & 7,31309 & 3,68355 & 0,0036 \\
\hline
\end{tabular}

Tabla 74: Análisis de varianza para la relación entre la velocidad en la nariz y a relación $L / L_{0}(R L)$

\begin{tabular}{|l|c|c|c|c|c|}
\hline \multicolumn{1}{|c|}{ Fuente } & $\begin{array}{c}\text { Suma de } \\
\text { Cuadrados }\end{array}$ & GL & $\begin{array}{c}\text { Cuadrados } \\
\text { Medios }\end{array}$ & F-Ratio & P-Valor \\
\hline Modelo & 147,222 & 2 & 73,6112 & 7,89 & 0,0075 \\
\hline Residuo & 102,67 & 11 & 9,33362 & & \\
\hline
\end{tabular}

La ecuación (114) corresponde al modelo de regresión polinómica para describir la relación entre la diferencia entre el percentil 85 de la velocidad en la nariz y el límite de velocidad en la misma $(\Delta V N)$ y la relación $L / L_{0}(R L)$ es:

$$
\Delta V N=28,7454-44,7499^{*} R L+26,9381^{*} R L^{2}
$$

donde:

- $\quad \Delta \mathrm{VN}$ : diferencia entre el percentil 85 de la velocidad en la nariz y el límite de velocidad en el mismo punto $(\mathrm{km} / \mathrm{h})$.

- RL: relación entre la longitud real del carril $(\mathrm{L})$ y la calculada de acuerdo con la Instrucción de Trazado 3.1-IC (1999) $\left(\mathrm{L}_{0}\right)$.

El valor del estadístico R-cuadrado indica que el modelo explica un 58,91\% de la variabilidad de esta diferencia de velocidad.

La relación $L / L_{0}(R L)$ que minimiza la diferencia entre el percentil 85 de la velocidad en la nariz y el límite de velocidad en ella es del $83 \%$ de acuerdo con el modelo de regresión polinómica. 


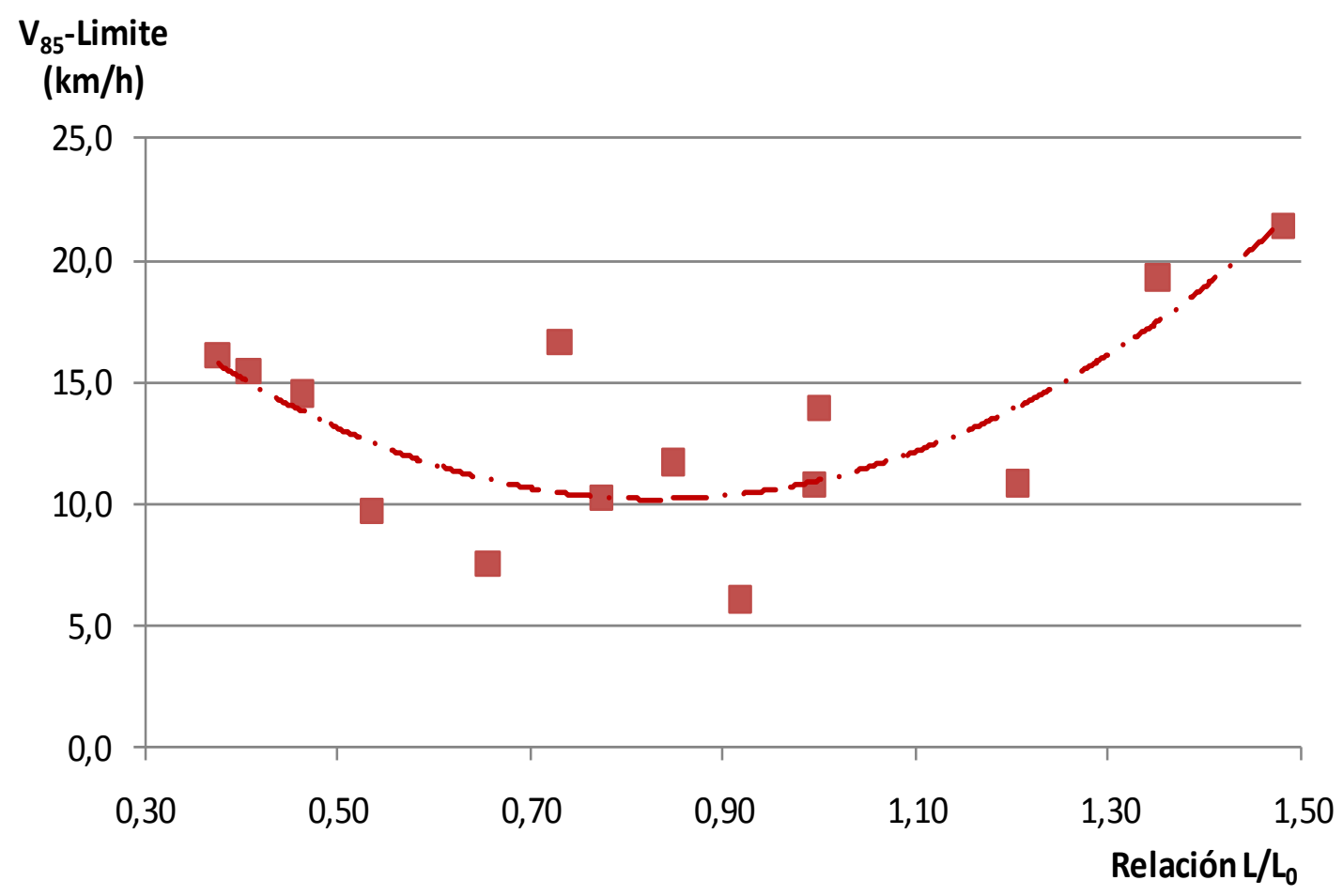

Figura 156: Diferencia entre el percentil 85 de la velocidad en la nariz y el límite de velocidad en ese punto

En la Figura 156 se puede observar cómo la diferencia entre el percentil 85 de la velocidad en la nariz y el límite de velocidad en el mismo punto es menor para valores intermedios de la relación $L / L_{0}$, mientras que para valores extremos está diferencia es mayor.

Como se puede observar en la Figura 156, en todos los carriles de deceleración y las configuraciones evaluadas, se encontró que la velocidad de los vehículos al llegar a la nariz es superior al límite señalizado, lo cual está de acuerdo con la observación hecha por Jouzy (1963) de que muchos vehículos no obedecían la señalización que regulaba la velocidad y alcanzan el ramal de salida con una velocidad mayor a la indicada.

Uno de los factores que puede explicar la variación de la velocidad de los vehículos al llegar a la nariz es la ubicación de la cuña, pues si está a una distancia adecuada, sirve a los conductores como una referencia adicional para la maniobra de frenado. Se aprecia como en carriles de deceleración cortos, la velocidad en la nariz es elevada, aparentemente por tener combinada la maniobra de cambio de carril con el frenado y por iniciar la frenada en la vía principal antes de la cuña; en carriles de deceleración largos, la velocidad de los vehículos al llegar a la nariz también es elevada aparentemente por la posibilidad de acelerar en el carril de deceleración, y por iniciar la frenada sin referencia, pues la cuña se ha dejado atrás. Mientras si se cuenta con una distancia intermedia la velocidad a la que llegan los vehículos a la nariz, es menor que en los casos anteriores, debido a que no se tiene la posibilidad de acelerar y a que se cuenta con la cuña como referencia a una distancia adecuada. 


\subsubsection{Velocidad transversal durante la maniobra de cambio de carril}

Para las maniobras libres seleccionadas se ha analizado la velocidad transversal de los vehículos durante la maniobra de cambio de carril. Se observa en la Figura 157 la distribución de las velocidades transversales medias durante la maniobra de cambio de carril.

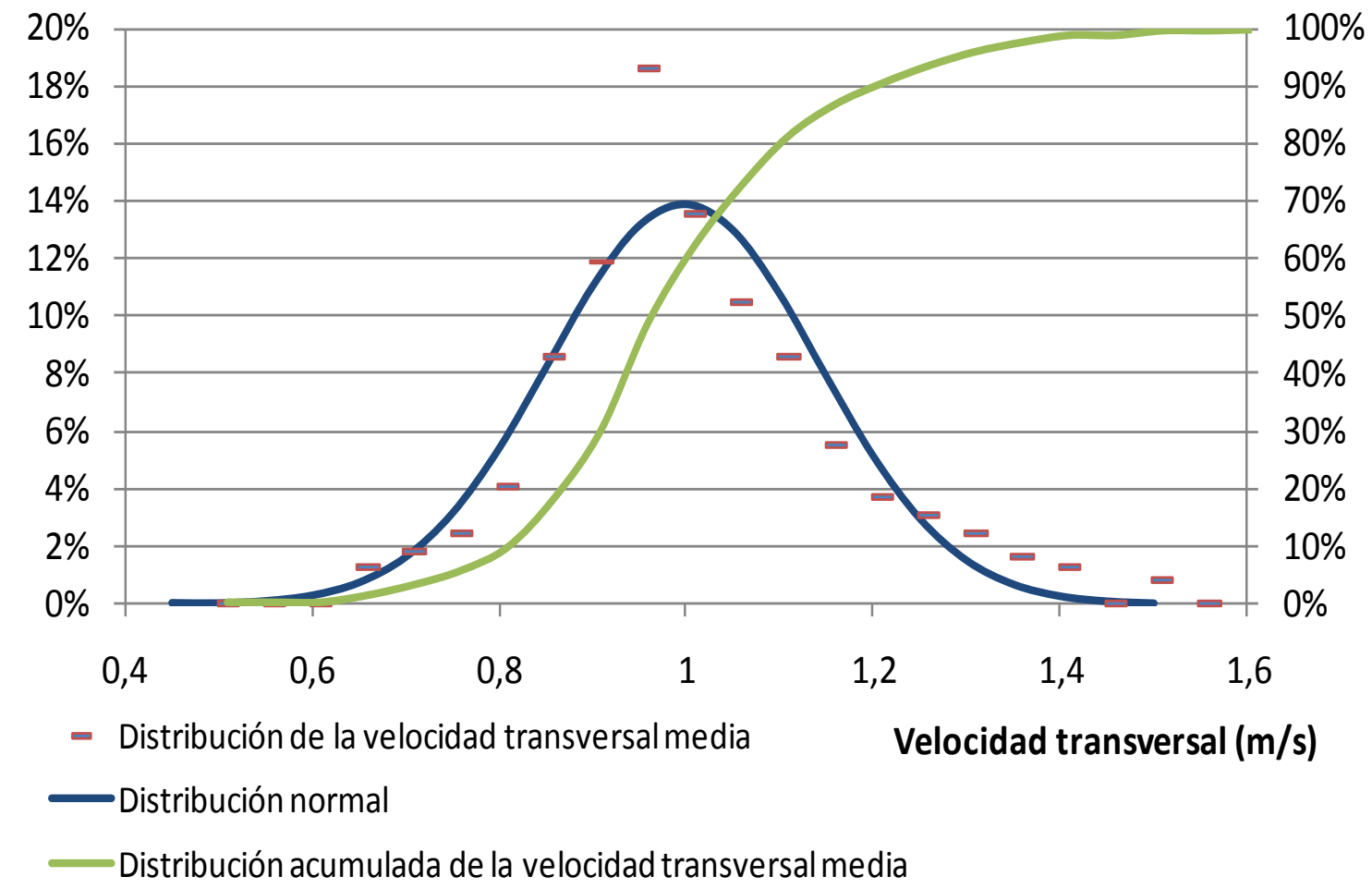

\section{Figura 157: Distribución de la velocidad transversal media en las maniobras de} cambio de carril

Es importante señalar que no se ha encontrado una variación estadísticamente significativa entre los valores de velocidad transversal en función de ninguna de las variables analizadas.

Al tener en cuenta todos los carriles estudiados, se han encontrado que los percentiles 15,50 y 85 de la velocidad transversal media durante la maniobra de cambio de carril tienen un valor de $0,83,0,97$ y $1.14 \mathrm{~m} / \mathrm{s}$, respectivamente.

Se puede observar que los valores de velocidad transversal media son muy cercanos a los encontrados por Rioux (1977), de $1 \mathrm{~m} / \mathrm{s}$, por lo que se ha tomado este valor de velocidad transversal para el cálculo de la duración de la maniobra de cambio de carril.

La duración de la maniobra de cambio de carril está determinada por la anchura del carril. Teniendo en cuenta que la Instrucción de Trazado (1999) establece una anchura de 3,5 m para los carriles de deceleración la duración de la maniobra sería 3,5 s. 


\subsubsection{Aceleraciones y deceleraciones}

En primer lugar, se procedió a evaluar el porcentaje de los vehículos que aceleran en el carril de deceleración, como una medida de la funcionalidad del carril, pues si es demasiado largo, existe la posibilidad de acelerar y posteriormente decelerar para salir.

Tabla 75: Análisis de regresión lineal múltiple para el porcentaje de vehículos que aceleran en el carril de deceleración

\begin{tabular}{|l|c|c|c|c|}
\hline \multicolumn{1}{|c|}{ Parámetro } & Estimación & $\begin{array}{c}\text { Error } \\
\text { Estándar }\end{array}$ & T Estadístico & P-Valor \\
\hline CONSTANTE & $-19,8889$ & 18,1764 & $-1,09421$ & 0,3023 \\
\hline Longitud & 0,131011 & 0,0335253 & 3,90783 & 0,0036 \\
\hline Intensidad & 0,0309834 & 0,01395 & 2,22103 & 0,0535 \\
\hline Carriles VP & $-15,7156$ & 7,32876 & $-2,14437$ & 0,0606 \\
\hline P_Pesados & 1,54016 & 0,453482 & 3,3963 & 0,0079 \\
\hline
\end{tabular}

Tabla 76: Análisis de varianza para el porcentaje de vehículos que aceleran en el carril de deceleración

\begin{tabular}{|l|c|c|c|c|c|}
\hline Fuente & $\begin{array}{c}\text { Suma de } \\
\text { Cuadrados }\end{array}$ & GL & $\begin{array}{c}\text { Cuadrados } \\
\text { Medios }\end{array}$ & F-Ratio & P-Valor \\
\hline Modelo & 2118,44 & 4 & 529,61 & 5,66 & 0,0147 \\
\hline Residuo & 841,463 & 9 & 93,4959 & & \\
\hline
\end{tabular}

En la Tabla 76 se muestran los resultados del ajuste a un modelo de regresión lineal múltiple para describir la relación entre el porcentaje de vehículos que aceleran y 4 variables independientes: longitud del carril de deceleración, intensidad total aguas arriba del carril de deceleración, número de carriles de la vía principal y el porcentaje de vehículos pesados.

La ecuación (115) corresponde al modelo ajustado:

$$
\begin{gathered}
\text { Aceleran }=-19,8889+0,131011 * \mathrm{~L}+0,0309834 * \mathrm{I}-15,7156 * \mathrm{C}+ \\
1,54016 * \mathrm{P}
\end{gathered}
$$

donde:

- $\quad$ L : Longitud del carril de deceleración (m)

- I: Intensidad total (veh/h)

- C: Número de carriles de la vía principal

- P: Porcentaje de vehículos pesados (\%) 
Como se observa en la Tabla 76, el p-valor es inferior a 0,05, por lo que se puede afirmar que existe una relación estadísticamente significativa entre el porcentaje de vehículos que aceleran en el carril de deceleración y las 4 variables independientes mencionadas para un nivel de confianza del 95\%.

El valor del estadístico R-cuadrado indica que el modelo explica un $71,57 \%$ de la variabilidad en el porcentaje de vehículos que aceleran en el carril de deceleración.

\section{Componenete + Residuo para el \% de vehículos que aceleran}

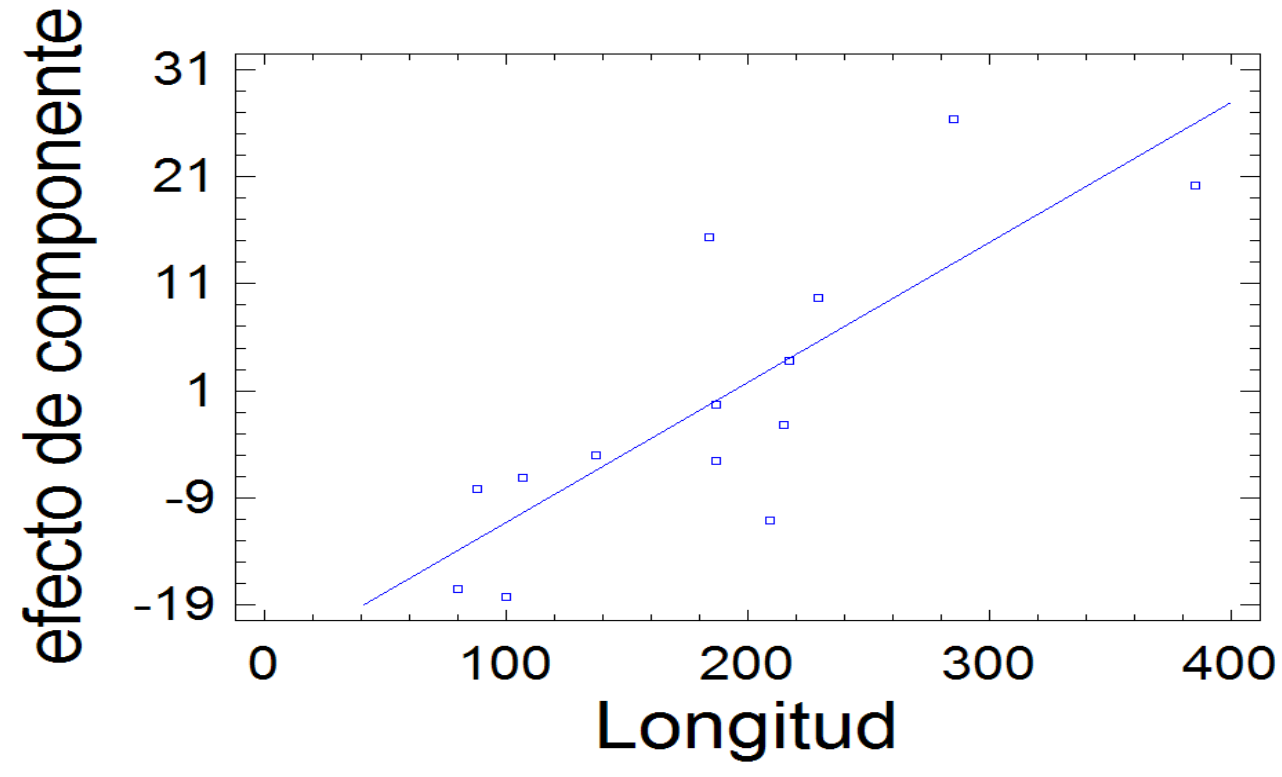

Figura 158: Efecto del componente longitud en la variación del \% de vehículos que aceleran en el carril de deceleración

Como se puede observar en la Figura 158, se puede afirmar que al aumentar la longitud del carril de deceleración, se incrementa el porcentaje de vehículos que aceleran en él lo cual afecta negativamente a su funcionalidad. El efecto del componente longitud sobre el porcentaje de vehículos que aceleran se incrementa con longitudes mayores que $185 \mathrm{~m}$. Asimismo, se puede afirmar que al aumentar el porcentaje de vehículos pesados aumenta el porcentaje de vehículos que aceleran en el carril de deceleración debido principalmente a la diferencia de velocidades entre los coches y los vehículos pesados.

Al tener en cuenta todos los carriles estudiados, se han encontrado que los percentiles 15,50 y 85 de la deceleración por retención del motor tienen un valor de $-0,95,-0,76$ y $-0.54 \mathrm{~m} / \mathrm{s}^{2}$, respectivamente.

El percentil 50 de la tasa de deceleración por retención con el motor de $-0.76 \mathrm{~m} / \mathrm{s}^{2}$ es una valor más alto que el encontrado por Polus et al. (1985), pero más cerca al valor recomendado por la AASHTO. Asimismo, se encontró una duración media de la maniobra subconsciente que varía entre los 5,9 y los 7,4 s, que son valores cercanos al encontrado por de la Iglesia y García (2000) de 6,4 s y superior al de la AASHTO que es de 3,5 s. 


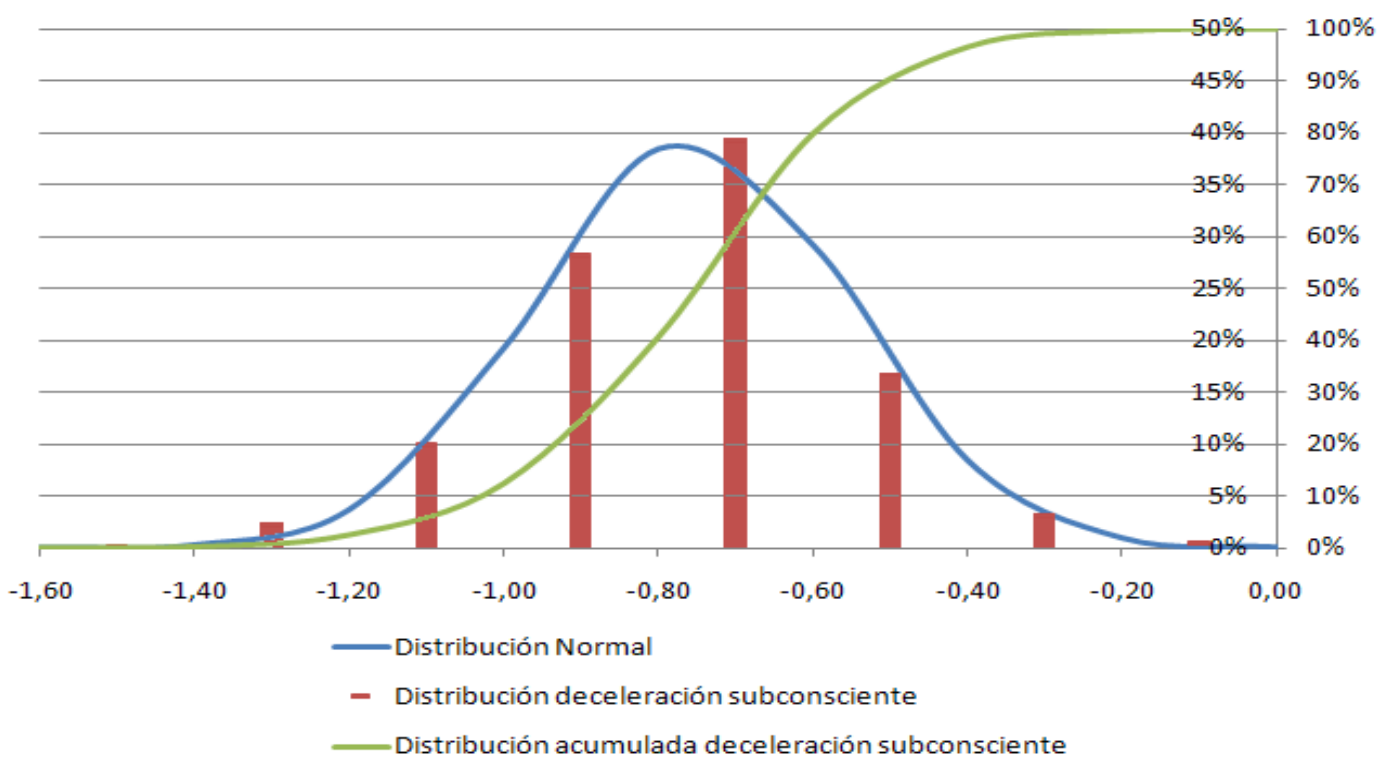

Figura 159: Distribución de frecuencia de tasa de deceleración subconsciente

En cuanto a la deceleración por aplicación de los frenos, se encontró, en las configuraciones experimentales, un valor medio de $-1.74 \mathrm{~m} / \mathrm{s}^{2}$, que al corregirlo por la inclinación de la rasante, equivale a $-1,96 \mathrm{~m} / \mathrm{s}^{2}$, similar a lo obtenido por Colona (1997) y por Canale (1998).

Al tener en cuenta todos los carriles estudiados, se han encontrado que los percentiles 15,50 y 85 de la deceleración tienen un valor de $-1,79,-2,44$ y $-3.30 \mathrm{~m} / \mathrm{s}^{2}$, respectivamente. Estos valores de deceleración son considerados confortables en las maniobras de frenado.

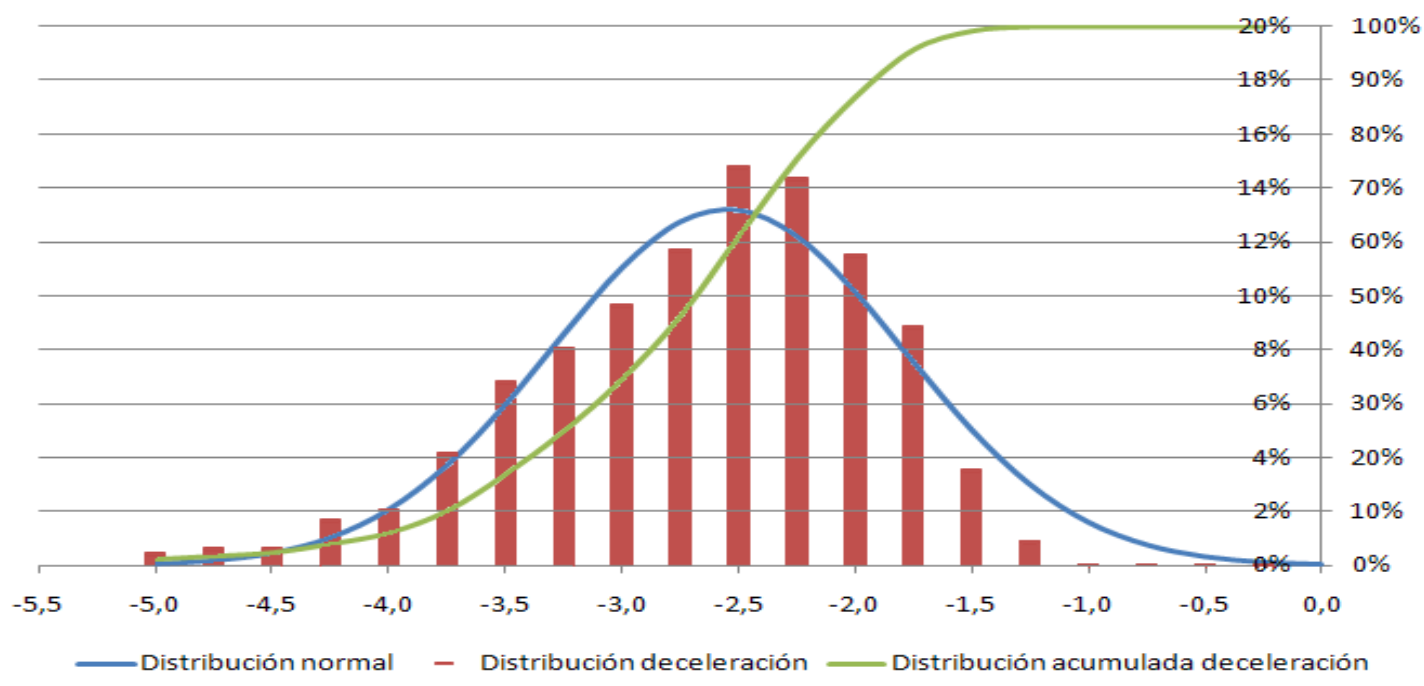

Figura 160: Distribución de frecuencia de tasa de deceleración

Si se tiene en cuenta toda la maniobra de deceleración, como una única maniobra con deceleración uniforme, el valor medio de deceleración resultante varía entre los -1,74 $\mathrm{m} / \mathrm{s}^{2}$ y los $-2,17 \mathrm{~m} / \mathrm{s}^{2}$. Si se corrige este valor por la inclinación de la rasante, el valor medio de deceleración varía entre los $-1,87 \mathrm{~m} / \mathrm{s}^{2}$ y los $-2,17 \mathrm{~m} / \mathrm{s}^{2}$ lo que hace aún más 
estrecho el intervalo de variación de la deceleración y que corresponde a valores muy cercanos al $0,2 \mathrm{~g}\left(-1.96 \mathrm{~m} / \mathrm{s}^{2}\right)$ utilizado en la norma de trazado española y a los -2 $\mathrm{m} / \mathrm{s}^{2}$ utilizados en la norma italiana.

Es importante resaltar que el comportamiento de los conductores no se corresponde con una única deceleración uniforme sino que la maniobra se compone de dos maniobras sucesivas. La primera, una maniobra de cambio de carril, con una deceleración por retención de motor; y la segunda una deceleración de frenado dentro del carril de deceleración.

No se ha encontrado una variación estadísticamente significativa entre los valores de deceleración en función de ninguna de las variables analizadas, lo que nos muestra que los conductores realizan la maniobra de deceleración sin tener en cuenta la longitud del carril, sino dependiendo de su apreciación de la distancia a la salida.

\subsubsection{Trayectorias}

En primer lugar se observa que los conductores prefieren una trayectoria compuesta por una curva y contra-curva en lugar de una trayectoria directa. La trayectoria de la maniobra de cambio de carril coincide con la propuesta por Rioux (1977) siguiendo la función coseno a una velocidad media de $1 \mathrm{~m} / \mathrm{s}$.

Asimismo se ha observado que los conductores inician la maniobra de cambio de carril en un punto que varía, aproximadamente, entre los $17 \mathrm{~m}$ antes del inicio de la cuña hasta los $34 \mathrm{~m}$ después del mismo punto. Estas distancias equivalen a un tiempo de $0,5 \mathrm{~s}$ ates de llegar al punto de inicio de la cuña y $1 \mathrm{~s}$ pasado el mismo punto, respectivamente.

Es importante resaltar que no se ha encontrado una relación estadísticamente significativa entre ninguna de las variables analizadas y la distancia entre el punto en que los conductores inician la maniobra de cambio de carril y el punto de inicio de la cuña.

De igual forma no se ha encontrado una relación estadísticamente significativa entre el tiempo necesario para recorrer esta distancia y ninguna de las variables analizadas.

En cuanto a la longitud de la maniobra de cambio de carril, se ha encontrado que ésta tiene un valor medio equivalente a la distancia recorrida por un vehículo circulando a una velocidad equivalente al límite genérico de la vía durante los 3,5 s de duración de la maniobra de cambio de carril, tomando una velocidad transversal media de $1 \mathrm{~m} / \mathrm{s}$ y una anchura del carril de 3,5 m.

De esto se desprende que la cuña debe tener una longitud mayor a la estipulada en la Instrucción de Trazado 3.1 IC (1999) ya que, en esta norma, la longitud de la cuña equivale a la distancia que recorre un vehículo durante $3 \mathrm{~s}$, en lugar de los 3,5 $\mathrm{s}$ encontrados. 


\subsubsection{Accidentalidad}

Para el caso de la accidentalidad se han tomado: el número medio de accidentes al año con y sin víctimas; el número medio de accidentes al año, con y sin víctimas, por cada 100 millones de vehículos; y el número medio de accidentes al año, con y sin víctimas, por cada 100 millones de vehículos por km.

Con los valores de accidentalidad se ha realizado un análisis de correlación entre estos valores de accidentalidad y las diferentes variables explicativas. Se han ajustado modelos conteniendo todas las combinaciones de variables y se ha determinado cuales de ellas predicen mejor el fenómeno de acuerdo con su valor de R-cuadrado ajustado.

\subsubsection{Número de accidentes totales en la zona de influencia del carril}

Se ha encontrado que las variables que explican mejor la variabilidad de la frecuencia de accidentes en la zona de influencia del carril de deceleración son la longitud del carril de deceleración y la intensidad del tráfico aguas arriba del carril de deceleración.

Tabla 77: Análisis de regresión múltiple para el valor medio del número de accidentes en la zona de influencia del carril de deceleración

\begin{tabular}{|l|c|c|c|c|}
\hline \multicolumn{1}{|c|}{ Parámetro } & Estimación & $\begin{array}{c}\text { Error } \\
\text { Estándar }\end{array}$ & T Estadístico & P-Valor \\
\hline CONSTANTE & 2,19534 & 1,28808 & 1,70436 & 0,1392 \\
\hline Longitud & $-0,0221151$ & 0,00790482 & $-2,79767$ & 0,0313 \\
\hline Longitud $^{2}$ & 0,0000476669 & 0,0000171266 & 2,78321 & 0,0319 \\
\hline Intensidad & 0,0016008 & 0,00061992 & 2,58226 & 0,0416 \\
\hline
\end{tabular}

Tabla 78: Análisis de varianza para el valor medio del número de accidentes en la zona de influencia del carril de deceleración

\begin{tabular}{|l|c|c|c|c|c|}
\hline Fuente & $\begin{array}{c}\text { Suma de } \\
\text { Cuadrados }\end{array}$ & GL & $\begin{array}{c}\text { Cuadrados } \\
\text { Medios }\end{array}$ & F-Ratio & P-Valor \\
\hline Modelo & 5,95762 & 3 & 1,98587 & 9,18 & 0,0117 \\
\hline Residuo & 1,29863 & 6 & 0,216439 & & \\
\hline
\end{tabular}

En la Tabla 77 se muestran los resultados del ajuste a un modelo de regresión múltiple para describir la relación entre el valor medio de número de accidentes al año en la zona de influencia del carril de deceleración y 2 variables independientes: longitud del carril de deceleración y la intensidad aguas arriba del carril de deceleración.

La ecuación (116) corresponde al modelo ajustado:

$$
N A=2,19534-0,0221151 * L+0,0000476669 * L^{2}+0,0016008 * I
$$


donde:

- NA: Valor medio de número de accidentes al año en la zona de influencia del carril de deceleración (número de accidentes).

- L: Longitud del carril de deceleración (m).

- I: Intensidad total aguas arriba del carril de deceleración (veh/h).

Como se observa en la Tabla 78, el p-valor es inferior a 0,05 , por lo que se puede afirmar que existe una relación estadísticamente significativa entre el valor medio de número de accidentes al año en la zona de influencia del carril de deceleración y las 2 variables independientes mencionadas para un nivel de confianza del 95\%.

El valor del estadístico R-cuadrado indica que el modelo explica un $82,10 \%$ de la variabilidad en el valor medio de número de accidentes al año en la zona de influencia del carril de deceleración.

Cómo era de esperarse la intensidad repercute en el número de accidentes debido a la mayor exposición que esto supone, mientras que la longitud tiene un comportamiento con valores que aumentan cuando el carril es demasiado largo o demasiado corto, siendo lo óptimo valores intermedios cercanos a los $232 \mathrm{~m}$.

No se ha encontrado una relación estadísticamente significativa entre el número de accidentes y la relación entre la longitud real del carril $(L)$ y la calculada de acuerdo con la Instrucción de Trazado 3.1-IC (1999) $\left(\mathrm{L}_{0}\right)$ tomando como velocidad inicial el límite genérico de la vía.

\subsubsection{Número de accidentes con víctimas en la zona de influencia del carril}

Se ha encontrado que la variable que mejor explica la variabilidad de la frecuencia de accidentes con víctimas en la zona de influencia del carril de deceleración es la longitud del carril de deceleración.

Tabla 79: Análisis de regresión polinomial para el valor medio del número de accidentes con víctimas en la zona de influencia del carril de deceleración

\begin{tabular}{|l|c|c|c|c|}
\hline \multicolumn{1}{|c|}{ Parámetro } & Estimación & $\begin{array}{c}\text { Error } \\
\text { Estándar }\end{array}$ & T Estadístico & P-Valor \\
\hline CONSTANTE & 3,09019 & 0,350431 & 8,81827 & 0,0000 \\
\hline Longitud & $-0,0231111$ & 0,00347091 & $-6,6585$ & 0,0003 \\
\hline Longitud $^{2}$ & 0,0000491544 & 0,00000754923 & 6,51118 & 0,0003 \\
\hline
\end{tabular}


Tabla 80: Análisis de varianza para el valor medio del número de accidentes con víctimas en la zona de influencia del carril de deceleración

\begin{tabular}{|l|c|c|c|c|c|}
\hline Fuente & $\begin{array}{c}\text { Suma de } \\
\text { Cuadrados }\end{array}$ & GL & $\begin{array}{c}\text { Cuadrados } \\
\text { Medios }\end{array}$ & F-Ratio & P-Valor \\
\hline Modelo & 2,29436 & 2 & 1,14718 & 22,19 & 0,0009 \\
\hline Residuo & 0,361895 & 7 & 0,0516992 & & \\
\hline
\end{tabular}

En la Tabla 79 se muestran los resultados del ajuste a un modelo de regresión polinomial para describir la relación entre el valor medio de número de accidentes con víctimas al año en la zona de influencia del carril de deceleración y la longitud del carril.

La ecuación (117) corresponde al modelo ajustado:

$$
\text { NAV }=3,09019-0,0231111 * L+0,0000491544 * L^{2}
$$

donde:

- NAV: Valor medio de número de accidentes con víctimas al año en la zona de influencia del carril de deceleración (número de accidentes con víctima).

- L: La longitud real del carril (m).

Como se observa en la Tabla 80, el p-valor es inferior a 0,01, por lo que se puede afirmar que existe una relación estadísticamente significativa entre el valor medio de número de accidentes con víctimas al año en la zona de influencia del carril de deceleración y la longitud para un nivel de confianza del $99 \%$.

El valor del estadístico R-cuadrado indica que el modelo explica un $86,36 \%$ de la variabilidad en el valor medio de número de accidentes con víctimas al año en la zona de influencia del carril de deceleración. 


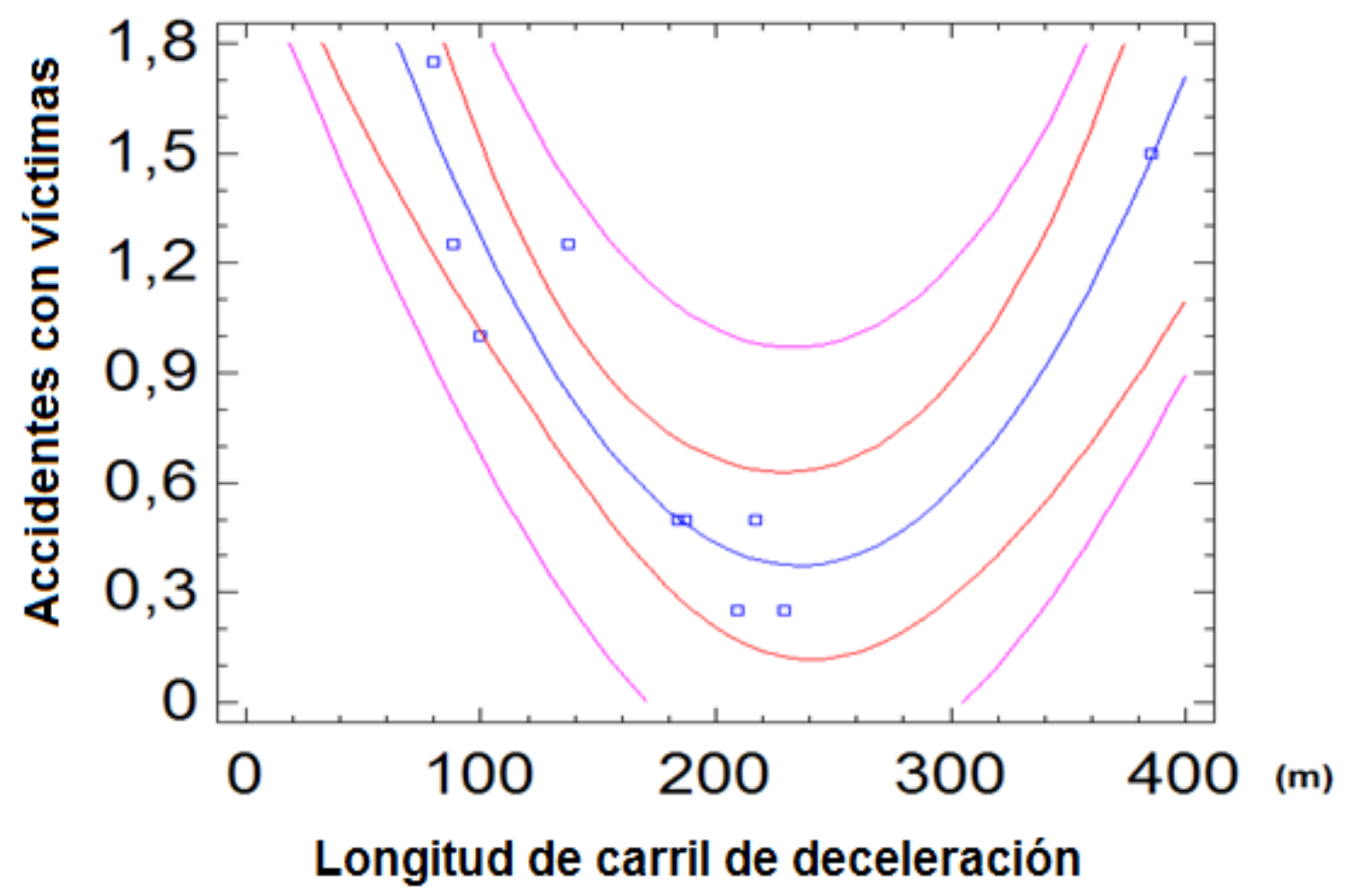

Figura 161: Efecto de la longitud en la variación del número de accidentes con víctimas para diferentes intervalos de confianza

Cómo se observa en la Figura 161, la longitud que minimiza el número de accidentes con víctimas es $235 \mathrm{~m}$.

Aunque la intensidad del tráfico como el porcentaje de vehículos que salen repercute en la accidentalidad por la mayor exposición al riesgo que esto supone, no se encontró una significancia estadística entre la accidentalidad y estas dos variables para un nivel de confianza del $90 \%$.

\subsubsection{Número medio de accidentes totales al año por cada 100 millones de vehículos}

En el análisis del número medio de accidentes al año por cada 100 millones de vehículos se ha encontrado que las variables que explican mejor la variabilidad del número de accidentes en la zona de influencia del carril de deceleración son la longitud del carril de deceleración y la relación entre la longitud real del carril ( $L$ ) y la calculada de acuerdo con la Instrucción de Trazado 3.1-IC (1999) $\left(\mathrm{L}_{0}\right)$ tomando como velocidad inicial el límite genérico de la vía. 
Tabla 81: Análisis de regresión múltiple para el número medio de accidentes totales al año por cada $\mathbf{1 0 0}$ millones de vehículos en la zona de influencia del carril de deceleración

\begin{tabular}{|l|c|c|c|c|}
\hline \multicolumn{1}{|c|}{ Parámetro } & Estimación & $\begin{array}{c}\text { Error } \\
\text { Estándar }\end{array}$ & T Estadístico & P-Valor \\
\hline CONSTANTE & 27,7495 & 7,32598 & 3,78782 & 0,0091 \\
\hline Longitud & $-0,198063$ & 0,0677325 & $-2,92419$ & 0,0265 \\
\hline Longitud $^{2}$ & 0,000344951 & 0,000148998 & 2,31513 & 0,0598 \\
\hline Relación $\mathrm{L}^{\mathrm{L}_{0}}$ & 9,79547 & 4,18072 & 2,34301 & 0,0576 \\
\hline
\end{tabular}

Tabla 82: Análisis de regresión múltiple para el número medio de accidentes totales al año por cada $\mathbf{1 0 0}$ millones de vehículos en la zona de influencia del carril de deceleración

\begin{tabular}{|l|c|c|c|c|c|}
\hline \multicolumn{1}{|c|}{ Fuente } & $\begin{array}{c}\text { Suma de } \\
\text { Cuadrados }\end{array}$ & GL & $\begin{array}{c}\text { Cuadrados } \\
\text { Medios }\end{array}$ & F-Ratio & P-Valor \\
\hline Modelo & 285,995 & 3 & 95,3317 & 4,66 & 0,0521 \\
\hline Residuo & 122,704 & 6 & 20,4506 & & \\
\hline
\end{tabular}

En la Tabla 81 se muestran los resultados del ajuste a un modelo de regresión múltiple para describir la relación entre el número medio de accidentes al año por cada 100 millones de vehículos y 2 variables independientes: longitud del carril de deceleración y la relación entre la longitud real del carril (L) y la calculada de acuerdo con la Instrucción de Trazado 3.1-IC (1999) $\left(\mathrm{L}_{0}\right)$ tomando como velocidad inicial el límite genérico de la vía.

La ecuación (118) corresponde al modelo ajustado:

$$
\text { ATCMV }=27,7495-0,198063 * L+0,000344951 * L^{2}+9,79547^{*} R L
$$

donde:

- ATCMV: Número medio de accidentes al año por cada 100 millones de vehículos en la zona de influencia del carril de deceleración.

- L: Longitud del carril de deceleración (m).

- RL: relación entre la Longitud real del carril $(L)$ y la calculada de acuerdo con la Instrucción de Trazado 3.1-IC (1999) $\left(\mathrm{L}_{0}\right)$.

Como se observa en la Tabla 82 , el p-valor es inferior a 0,1 , por lo que se puede afirmar que existe una relación estadísticamente significativa entre el número medio de accidentes al año por cada 100 millones de vehículos en la zona de influencia del carril de deceleración y las 2 variables independientes mencionadas para un nivel de confianza del $90 \%$. 
El valor del estadístico R-cuadrado indica que el modelo explica un 69,98 \% de la variabilidad en el número medio de accidentes al año por cada 100 millones de vehículos en la zona de influencia del carril de deceleración.

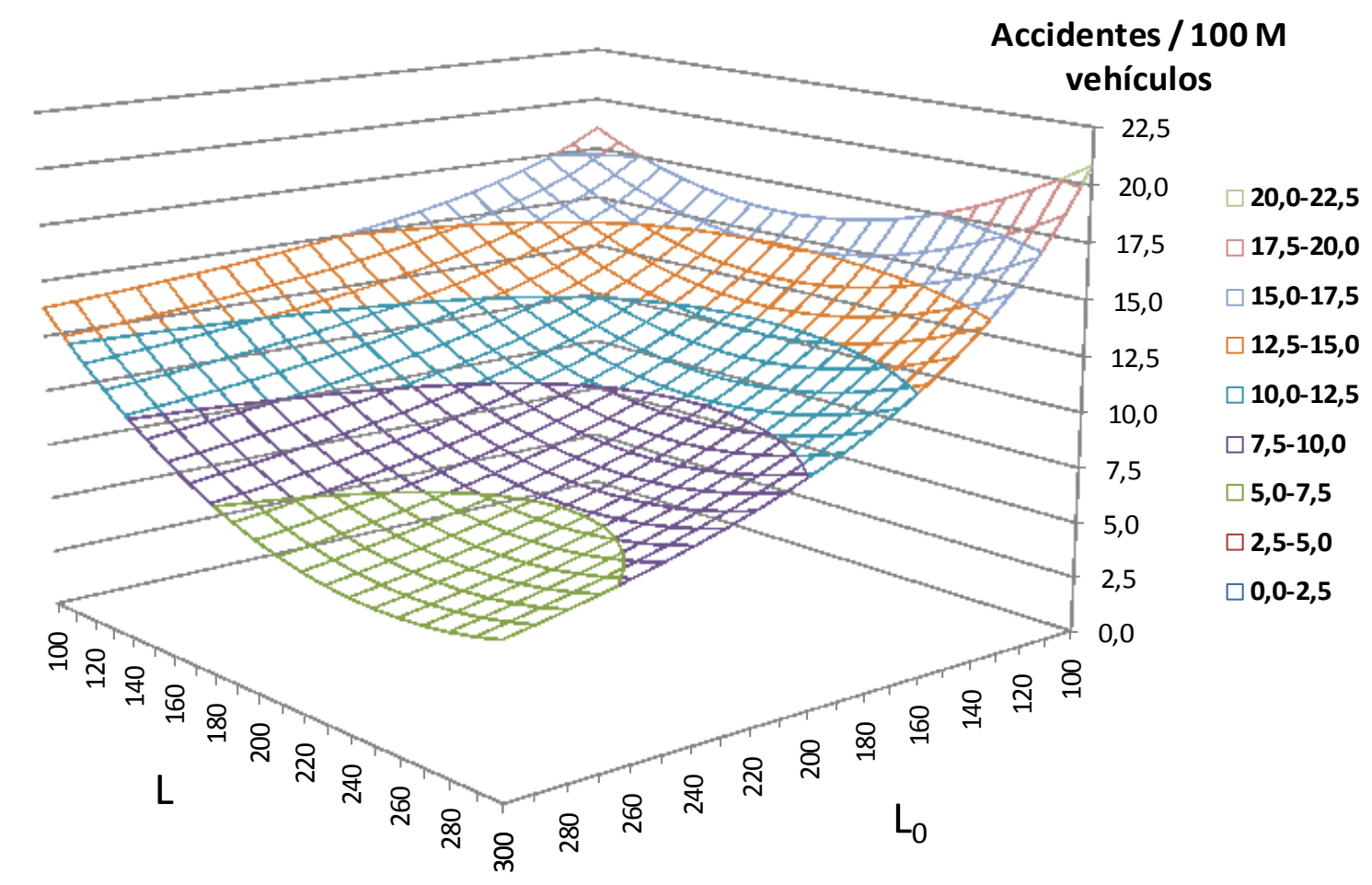

Figura 162: Variación del número de accidentes al año por cada $100 \mathrm{M}$ de vehículos en función de $L$ y de $L_{0}$

Cómo se observa en la Figura 162, la influencia de la longitud en el índice de accidentalidad hace que éste aumente cuando el carril es demasiado largo o demasiado corto, siendo lo óptimo valores intermedios, pero depende de la longitud de diseño $\mathrm{L}_{0}$. Para valores de diseño inferiores a los $240 \mathrm{~m}$ se prefiere longitudes mayores, pero si la longitud de diseño supera los $240 \mathrm{~m}$, se prefieren longitudes menores a la de diseño.

No se ha encontrado una relación estadísticamente significativa entre el número medio de accidentes al año por cada 100 millones de vehículos en la zona de influencia del carril de deceleración y las demás variables explicativas estudiadas.

\subsubsection{Número medio de accidentes con víctimas al año por cada 100 millones de vehículos}

En el análisis del número medio de accidentes con víctimas al año por cada 100 millones de vehículos se ha encontrado que las variables que explican mejor la variabilidad de este número de accidentes con víctimas en la zona de influencia del carril de deceleración por cada 100 millones de vehículos son: la longitud del carril de deceleración y el porcentaje de vehículos que salen. 
Tabla 83: Análisis de regresión múltiple para el número medio de accidentes con víctimas al año por cada $100 \mathrm{M}$ de vehículos

\begin{tabular}{|l|c|c|c|c|}
\hline \multicolumn{1}{|c|}{ Parámetro } & Estimación & $\begin{array}{c}\text { Error } \\
\text { Estándar }\end{array}$ & T Estadístico & P-Valor \\
\hline CONSTANTE & 18,307 & 2,84718 & 6,42988 & 0,0007 \\
\hline Longitud & $-0,150832$ & 0,0238157 & $-6,3333$ & 0,0007 \\
\hline Longitud ${ }^{2}$ & 0,000318314 & 0,0000517563 & 6,15024 & 0,0008 \\
\hline PVS & 0,156674 & 0,0699261 & 2,24057 & 0,0663 \\
\hline
\end{tabular}

Tabla 84: Análisis varianza para el número medio de accidentes con víctimas al año por cada 100 M de vehículos

\begin{tabular}{|l|c|c|c|c|c|}
\hline Fuente & $\begin{array}{c}\text { Suma de } \\
\text { Cuadrados }\end{array}$ & GL & $\begin{array}{c}\text { Cuadrados } \\
\text { Medios }\end{array}$ & F-Ratio & P-Valor \\
\hline Modelo & 116,486 & 3 & 38,8286 & 16,01 & 0,0029 \\
\hline Residuo & 14,5484 & 6 & 2,42473 & & \\
\hline
\end{tabular}

En la Tabla 83 se muestran los resultados del ajuste a un modelo de regresión múltiple para describir la relación entre el número medio de accidentes con víctimas al año por cada 100 millones de vehículos y 2 variables independientes: longitud del carril de deceleración y el porcentaje de vehículos que salen.

La ecuación (119) corresponde al modelo ajustado:

$A V C M V=18,307-0,150832 * L+0,000318314^{*} L^{2}+0,156674 * P V S$ donde:

- AVCMV: Número medio de accidentes con víctimas al año por cada 100 millones de vehículos en la zona de influencia del carril de deceleración.

- $\quad$ L: Longitud del carril de deceleración (m).

- PSV: Porcentaje de vehículos que salen (\%).

Como se observa en la Tabla 84, el p-valor es inferior a 0,01 , por lo que se puede afirmar que existe una relación estadísticamente significativa entre el número medio de accidentes con víctimas al año por cada 100 millones de vehículos y las dos variables independientes mencionadas para un nivel de confianza del $99 \%$.

El valor del estadístico R-cuadrado indica que el modelo explica un 88,90 \% de la variabilidad en el número medio de accidentes con víctimas al año por cada 100 millones de vehículos.

Dada la diferencia entre el $\mathrm{p}$-valor para la longitud y el porcentaje de vehículos que salen se recomienda simplificar el modelo. 
Tabla 85: Análisis de regresión polinomial para el número medio de accidentes con víctimas al año por cada $\mathbf{1 0 0}$ millones de vehículos (simplificado)

\begin{tabular}{|l|c|c|c|c|}
\hline \multicolumn{1}{|c|}{ Parámetro } & Estimación & $\begin{array}{c}\text { Error } \\
\text { Estándar }\end{array}$ & T Estadístico & P-Valor \\
\hline CONSTANTE & 21,7395 & 3,01118 & 7,2196 & 0,0002 \\
\hline Longitud & $-0,154128$ & 0,0298248 & $-5,16776$ & 0,0013 \\
\hline Longitud $^{2}$ & 0,000312918 & 0,000064869 & 4,82384 & 0,0019 \\
\hline
\end{tabular}

Tabla 86: Análisis de varianza para el número medio de accidentes con víctimas al año por cada 100 millones de vehículos (simplificado)

\begin{tabular}{|l|c|c|c|c|c|}
\hline \multicolumn{1}{|c|}{ Fuente } & $\begin{array}{c}\text { Suma de } \\
\text { Cuadrados }\end{array}$ & GL & $\begin{array}{c}\text { Cuadrados } \\
\text { Medios }\end{array}$ & F-Ratio & P-Valor \\
\hline Modelo & 104,313 & 2 & 52,1567 & 13,66 & 0,0038 \\
\hline Residuo & 26,7209 & 7 & 3,81727 & & \\
\hline
\end{tabular}

En la Tabla 85 se muestran los resultados del ajuste a un modelo de regresión polinomial para describir la relación entre el número medio de accidentes con víctimas al año por cada 100 millones de vehículos y la longitud del carril de deceleración.

La ecuación (120) corresponde al modelo ajustado:

$$
\operatorname{AVCMV}=21,7395-0,154128 * L+0,000312918 * L^{2}
$$

donde:

- AVCMV: Número medio de accidentes con víctimas al año por cada 100 millones de vehículos en la zona de influencia del carril de deceleración.

- L: Longitud del carril de deceleración (m).

Como se observa en la Tabla 92, el p-valor es inferior a 0,01, por lo que se puede afirmar que existe una relación estadísticamente significativa entre el número medio de accidentes con víctimas al año por cada 100 millones de vehículos y las longitud del carril de deceleración para un nivel de confianza del 99\%.

El valor del estadístico R-cuadrado indica que el modelo explica un $79,61 \%$ de la variabilidad en el número medio de accidentes con víctimas al año por cada 100 millones de vehículos.

La influencia de la longitud en el número medio de accidentes con víctimas al año por cada 100 millones de vehículos hace que éste aumente cuando el carril es demasiado largo o demasiado corto, siendo lo óptimo valores intermedios. Su valor óptimo está en los $246 \mathrm{~m}$ que es un valor muy cercano al encontrado cómo punto de cambio de tendencia en el índice de accidentalidad y al mínimo encontrado para el número de accidentes con víctima. 


\subsubsection{Número medio de accidentes totales al año por cada 100 millones de vehículos por $\mathrm{km}$}

En el análisis del número medio de accidentes al año por cada 100 millones de vehículos por $\mathrm{km}$ se ha encontrado que las variables que explican mejor la variabilidad del número de accidentes en la zona de influencia del carril de deceleración son la longitud del carril de deceleración y la relación entre la longitud real del carril (L) y la calculada de acuerdo con la Instrucción de Trazado 3.1-IC (1999) $\left(\mathrm{L}_{0}\right)$ tomando como velocidad inicial el límite genérico de la vía.

Tabla 87: Análisis de regresión múltiple para el número medio de accidentes totales al año por cada 100 millones de vehículos $\mathbf{k m}$ en la zona de influencia del carril de deceleración

\begin{tabular}{|l|c|c|c|c|}
\hline \multicolumn{1}{|c|}{ Parámetro } & Estimación & $\begin{array}{c}\text { Error } \\
\text { Estándar }\end{array}$ & T Estadístico & P-Valor \\
\hline CONSTANTE & 15,6491 & 3,62184 & 4,32074 & 0,0035 \\
\hline Longitud & $-0,0438779$ & 0,0191456 & $-2,2918$ & 0,0557 \\
\hline$\left(\text { Relación } \mathrm{L} / \mathrm{L}_{0}\right)^{2}$ & 7,56432 & 2,44185 & 3,09778 & 0,0174 \\
\hline
\end{tabular}

Tabla 88: Análisis de varianza para el número medio de accidentes totales al año por cada $\mathbf{1 0 0}$ millones de vehículos $\mathbf{~ k m}$ en la zona de influencia del carril de deceleración

\begin{tabular}{|l|c|c|c|c|c|}
\hline Fuente & $\begin{array}{c}\text { Suma de } \\
\text { Cuadrados }\end{array}$ & GL & $\begin{array}{c}\text { Cuadrados } \\
\text { Medios }\end{array}$ & F-Ratio & P-Valor \\
\hline Modelo & 249,435 & 2 & 124,717 & 5,48 & 0,0369 \\
\hline Residuo & 159,264 & 7 & 22,752 & & \\
\hline
\end{tabular}

En la Tabla 87 se muestran los resultados del ajuste a un modelo de regresión múltiple para describir la relación entre el número medio de accidentes al año por cada 100 millones de vehículos por $\mathrm{km}$ y dos variables independientes: longitud del carril de deceleración y la relación entre la longitud real del carril $(L)$ y la calculada de acuerdo con la Instrucción de Trazado 3.1-IC (1999) $\left(L_{0}\right)$ tomando como velocidad inicial el límite genérico de la vía.

La ecuación (121) corresponde al modelo ajustado:

$$
I A=15,6491-0,0438779 * L+7,56432 * R L^{2}
$$

donde:

- IA: Índice de accidentalidad - Número medio de accidentes al año por cada 100 millones de vehículos por km en la zona de influencia del carril de deceleración. 
- $\quad$ L: Longitud del carril de deceleración (m).

- RL: relación entre la longitud real del carril (L) y la calculada de acuerdo con la Instrucción de Trazado 3.1-IC (1999) $\left(\mathrm{L}_{0}\right)$.

Como se observa en la Tabla 88, el p-valor es inferior a 0,05 , por lo que se puede afirmar que existe una relación estadísticamente significativa entre el número medio de accidentes al año por cada 100 millones de vehículos por $\mathrm{km}$ en la zona de influencia del carril de deceleración y las dos variables independientes mencionadas para un nivel de confianza del $95 \%$.

El valor del estadístico R-cuadrado indica que el modelo explica un 61,03\% de la variabilidad en el número medio de accidentes al año por cada 100 millones de vehículos por km en la zona de influencia del carril de deceleración.

\subsubsection{6 Índice de peligrosidad - número medio de accidentes con víctimas al año por cada 100 millones de vehículos por $\mathbf{~ k m}$}

En el análisis del índice de peligrosidad definido cómo el número medio de accidentes con víctimas al año por cada 100 millones de vehículos por $\mathrm{km}$ se han encontrado dos grupos de variables que explican la variabilidad del número de accidentes en la zona de influencia del carril de deceleración. El primer grupo corresponde a la longitud del carril de deceleración y el porcentaje de vehículos que salen; el segundo grupo corresponde a relación entre la Longitud real del carril $(L)$ y la calculada de acuerdo con la Instrucción de Trazado 3.1-IC (1999) $\left(\mathrm{L}_{0}\right)$.

Tabla 89: Análisis de regresión múltiple para el índice de peligrosidad

\begin{tabular}{|l|c|c|c|c|}
\hline \multicolumn{1}{|c|}{ Parámetro } & Estimación & $\begin{array}{c}\text { Error } \\
\text { Estándar }\end{array}$ & T Estadístico & P-Valor \\
\hline CONSTANTE & 18,307 & 2,84718 & 6,42988 & 0,0007 \\
\hline Longitud & $-0,150832$ & 0,0238157 & $-6,3333$ & 0,0007 \\
\hline Longitud $^{2}$ & 0,000318314 & 0,0000517563 & 6,15024 & 0,0008 \\
\hline PVS & 0,156674 & 0,0699261 & 2,24057 & 0,0663 \\
\hline
\end{tabular}

Tabla 90: Análisis de varianza para el índice de peligrosidad

\begin{tabular}{|l|c|c|c|c|c|}
\hline Fuente & $\begin{array}{c}\text { Suma de } \\
\text { Cuadrados }\end{array}$ & GL & $\begin{array}{c}\text { Cuadrados } \\
\text { Medios }\end{array}$ & F-Ratio & P-Valor \\
\hline Modelo & 116,486 & 3 & 38,8286 & 16,01 & 0,0029 \\
\hline Residuo & 14,5484 & 6 & 2,42473 & & \\
\hline
\end{tabular}


En la Tabla 89 se muestran los resultados del ajuste a un modelo de regresión múltiple para describir la relación entre el número medio de accidentes con víctimas al año por cada 100 millones de vehículos y 2 variables independientes: longitud del carril de deceleración y el porcentaje de vehículos que salen.

La ecuación (122) corresponde al modelo ajustado:

$$
I P=18,307-0,150832 * L+0,000318314 * L^{2}+0,156674 * P V S
$$

donde:

- IP: Índice de peligrosidad - Número medio de accidentes con víctima al año por cada 100 millones de vehículos por $\mathrm{km}$ en la zona de influencia del carril de deceleración.

- L: Longitud del carril de deceleración (m).

- PSV: Porcentaje de vehículos que salen (\%).

Como se observa en la Tabla 90, el p-valor es inferior a 0,01, por lo que se puede afirmar que existe una relación estadísticamente significativa entre el índice de peligrosidad y las dos variables independientes mencionadas para un nivel de confianza del $99 \%$.

El valor del estadístico R-cuadrado indica que el modelo explica un $88,90 \%$ de la variabilidad en el índice de peligrosidad.

Dada la diferencia entre el p-valor para la longitud y el porcentaje de vehículos que salen se recomienda simplificar el modelo para el índice de peligrosidad.

Tabla 91: Análisis de regresión polinomial para el índice de peligrosidad (simplificado)

\begin{tabular}{|l|c|c|c|c|}
\hline \multicolumn{1}{|c|}{ Parámetro } & Estimación & $\begin{array}{c}\text { Error } \\
\text { Estándar }\end{array}$ & T Estadístico & P-Valor \\
\hline CONSTANTE & 21,7395 & 3,01118 & 7,2196 & 0,0002 \\
\hline Longitud & $-0,154128$ & 0,0298248 & $-5,16776$ & 0,0013 \\
\hline Longitud $^{2}$ & 0,000312918 & 0,000064869 & 4,82384 & 0,0019 \\
\hline
\end{tabular}

Tabla 92: Análisis de varianza para el índice de peligrosidad (simplificado)

\begin{tabular}{|l|c|c|c|c|c|}
\hline Fuente & $\begin{array}{c}\text { Suma de } \\
\text { Cuadrados }\end{array}$ & GL & $\begin{array}{c}\text { Cuadrados } \\
\text { Medios }\end{array}$ & F-Ratio & P-Valor \\
\hline Modelo & 104,313 & 2 & 52,1567 & 13,66 & 0,0038 \\
\hline Residuo & 26,7209 & 7 & 3,81727 & & \\
\hline
\end{tabular}

En la Tabla 91 se muestran los resultados del ajuste a un modelo de regresión polinomial para describir la relación entre el número medio de accidentes con víctimas 
al año por cada 100 millones de vehículos por $\mathrm{km}$ y la longitud del carril de deceleración.

La ecuación (123) corresponde al modelo ajustado:

$$
I P=21,7395-0,154128 * L+0,000312918 * L^{2}
$$

donde:

- IP: Índice de peligrosidad - Número medio de accidentes con víctimas al año por cada 100 millones de vehículos por km en la zona de influencia del carril de deceleración.

- L: Longitud del carril de deceleración (m).

Como se observa en la Tabla 92, el p-valor es inferior a 0,01, por lo que se puede afirmar que existe una relación estadísticamente significativa entre el índice de peligrosidad y la longitud del carril de deceleración para un nivel de confianza del $99 \%$.

El valor del estadístico R-cuadrado indica que el modelo explica un 79,61 \% de la variabilidad en el índice de peligrosidad.

La influencia de la longitud en el índice de peligrosidad hace que éste aumente cuando el carril es demasiado largo o demasiado corto, siendo lo óptimo valores intermedios. Su valor óptimo está en los 246 m.

El otro grupo de variables que explican la variabilidad del índice de peligrosidad es el que corresponde a la relación entre la longitud real del carril $(L)$ y la calculada de acuerdo con la Instrucción de Trazado 3.1-IC (1999) $\left(\mathrm{L}_{0}\right)$ tomando como velocidad inicial el límite genérico de la vía.

Tabla 93: Análisis de regresión polinómica para el índice de peligrosidad y a relación $\mathbf{L} / \mathbf{L}_{\mathbf{0}}(\mathbf{R L})$

\begin{tabular}{|c|c|c|c|c|}
\hline Parámetro & Estimación & $\begin{array}{c}\text { Error } \\
\text { Estándar }\end{array}$ & T Estadístico & P-Valor \\
\hline CONSTANTE & 25,2727 & 4,84409 & 5,21722 & 0,0012 \\
\hline Relación $\mathrm{L}_{\mathrm{L}} \mathrm{L}_{0}$ & $-50,322$ & 11,5137 & $-4,37061$ & 0,0033 \\
\hline$\left(\text { Relación } \mathrm{L} / \mathrm{L}_{0}\right)^{2}$ & 28,1852 & 6,08311 & 4,63336 & 0,0024 \\
\hline
\end{tabular}

Tabla 94: Análisis de varianza para el índice de peligrosidad y a relación $L / L_{0}(R L)$

\begin{tabular}{|l|c|c|c|c|c|}
\hline Fuente & $\begin{array}{c}\text { Suma de } \\
\text { Cuadrados }\end{array}$ & GL & $\begin{array}{c}\text { Cuadrados } \\
\text { Medios }\end{array}$ & F-Ratio & P-Valor \\
\hline Modelo & 100,478 & 2 & 50,2392 & 11,51 & 0,0061 \\
\hline Residuo & 30,5558 & 7 & 4,36512 & & \\
\hline
\end{tabular}


Cómo se observa en la Tabla 94, se ha encontrado una relación polinómica estadísticamente representativa entre el índice de peligrosidad y la relación $L / L_{0}(R L)$ con un nivel de confianza del $99 \%$, ya que el p-valor es inferior a 0,01. La ecuación (124) corresponde del modelo de regresión polinómica para describir esta relación es:

$$
I P=25,2727-50,322 * R L+28,1852 *{ }^{*} L^{2}
$$

donde:

- IP: Índice de peligrosidad - Número medio de accidentes con víctimas al año por cada 100 millones de vehículos por km en la zona de influencia del carril de deceleración.

- RL: relación entre la Longitud real del carril (L) y la calculada de acuerdo con la Instrucción de Trazado 3.1-IC (1999) ( $\left.\mathrm{L}_{0}\right)$.

El valor del estadístico R-cuadrado indica que el modelo explica un $76,68 \%$ de la variabilidad del índice de peligrosidad.

La relación $L / L_{0}(R L)$ que minimiza el índice de peligrosidad es del $89,3 \%$ de acuerdo con el modelo de regresión polinómica.

Como se puede observar en los modelos en carriles de deceleración cortos el índice de peligrosidad es elevado, así como en carriles de deceleración largos. Los carriles de longitud intermedia son los que minimizan el índice de peligrosidad.

\subsubsection{Indicadores de conflictividad}

En primer lugar se presenta la validación del indicador de conflictividad y el análisis de sensibilidad del umbral de TiPCLA, y posteriormente se presenta el análisis de correlación entre los resultados de los indicadores y las diferentes variables explicativas.

\subsubsection{Validación}

La validación de los indicadores de conflictividad de la familia TiPCLA se desarrolló comparando sus resultados con los valores de accidentalidad para diferentes valores de umbral. Con ello no solo se validan los resultados sino que al mismo tiempo se obtiene el valor óptimo de umbral para los indicadores estudiados.

En particular se utilizó el IM_TiPCLA, valor medio de la integral de TiPCLA bajo un valor umbral, y el TM_TiPCLA, valor medio de tiempo bajo el umbral de TiPCLA, para desarrollar dicho análisis, pues son los valores que evalúan el comportamiento de una ubicación específica al integrar todas las maniobras estudiadas.

En primer lugar se analizó la correlación entre cada uno de estos dos indicadores de conflictividad y los datos de accidentalidad.

Se observa en la Figura 163, cómo a partir de un valor umbral de 1,5 segundos, la correlación entre IM_TiPCLA y los indicadores: índice de peligrosidad y accidentes 
anuales con víctimas por cada 100 millones de vehículos y total de accidentes anuales, permanece estable alrededor de $0,40,0,31$ y 0,30 , respectivamente.

Con respecto al número de accidentes con víctimas, permanece estable entre 1,5 y 1,8 s y a partir de 1,9 decrece. Este comportamiento está de acuerdo con la tendencia que tiene el indicador IM_TiPCLA en este intervalo.

Finalmente, el coeficiente de correlación con los indicadores total de accidentes anuales por cada 100 millones de vehículos y total de accidentes anuales por cada 100 millones de vehículos $\mathrm{km}$, crece a medida en que crece el umbral.

La correlación entre los índices estudiados y el indicador IM_TiPCLA para valores de umbral inferiores a 1,4 s es muy baja comparada con los valores de umbral mayores.

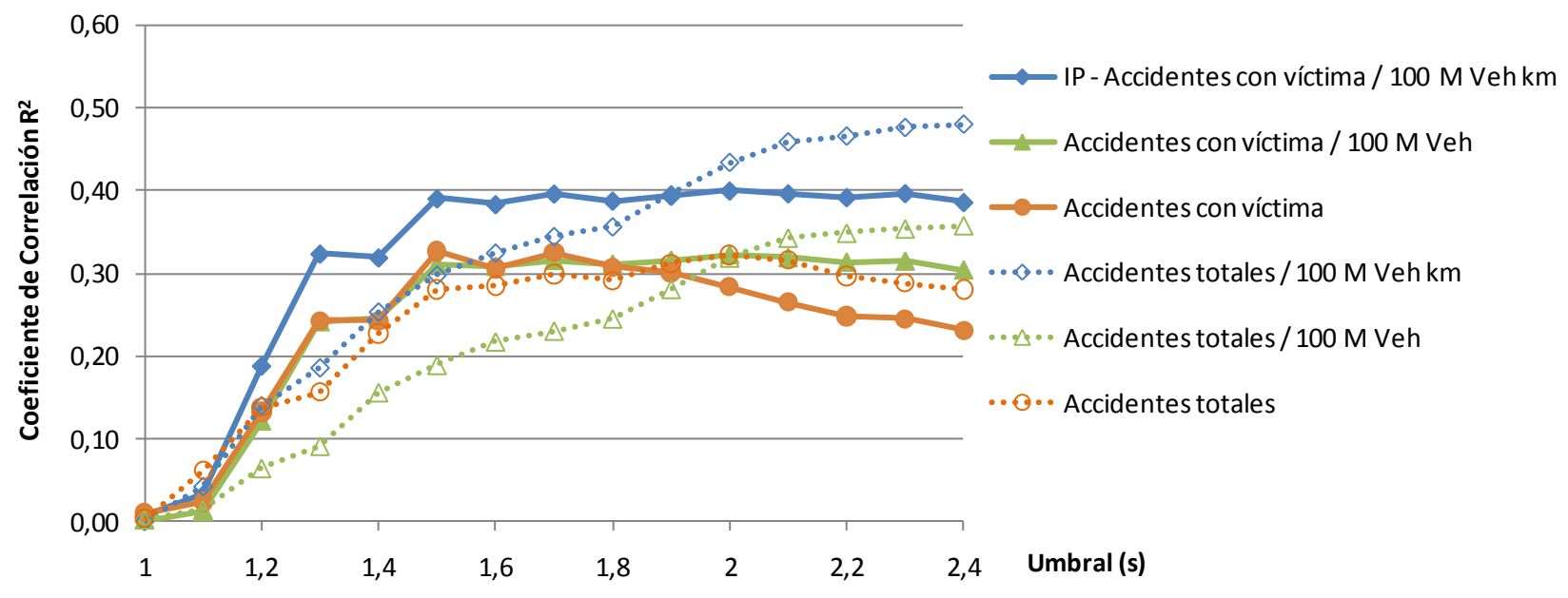

Figura 163: Variación del coeficiente de correlación $\mathbf{R}^{2}$ en función del umbral para IM_TIPCLA

A diferencia de IM_TiPCLA, el comportamiento de la correlación de los indicadores de accidentalidad con TM_TiPCLA no tiene un comportamiento estable tal como se puede observar en la Figura 164. Sin embargo se puede apreciar un comportamiento creciente a partir de un umbral de 1,4 $\mathrm{s}$ hasta un valor de $1,9 \mathrm{~s}$.

Para valores de umbral superiores a 1,9 s, el coeficiente de correlación entre TM_TiPCLA y los índices evaluados decrece rápidamente.

Para valores inferiores a $1,4 \mathrm{~s}$, se observa que el valor del coeficiente de correlación no permanece estable. 


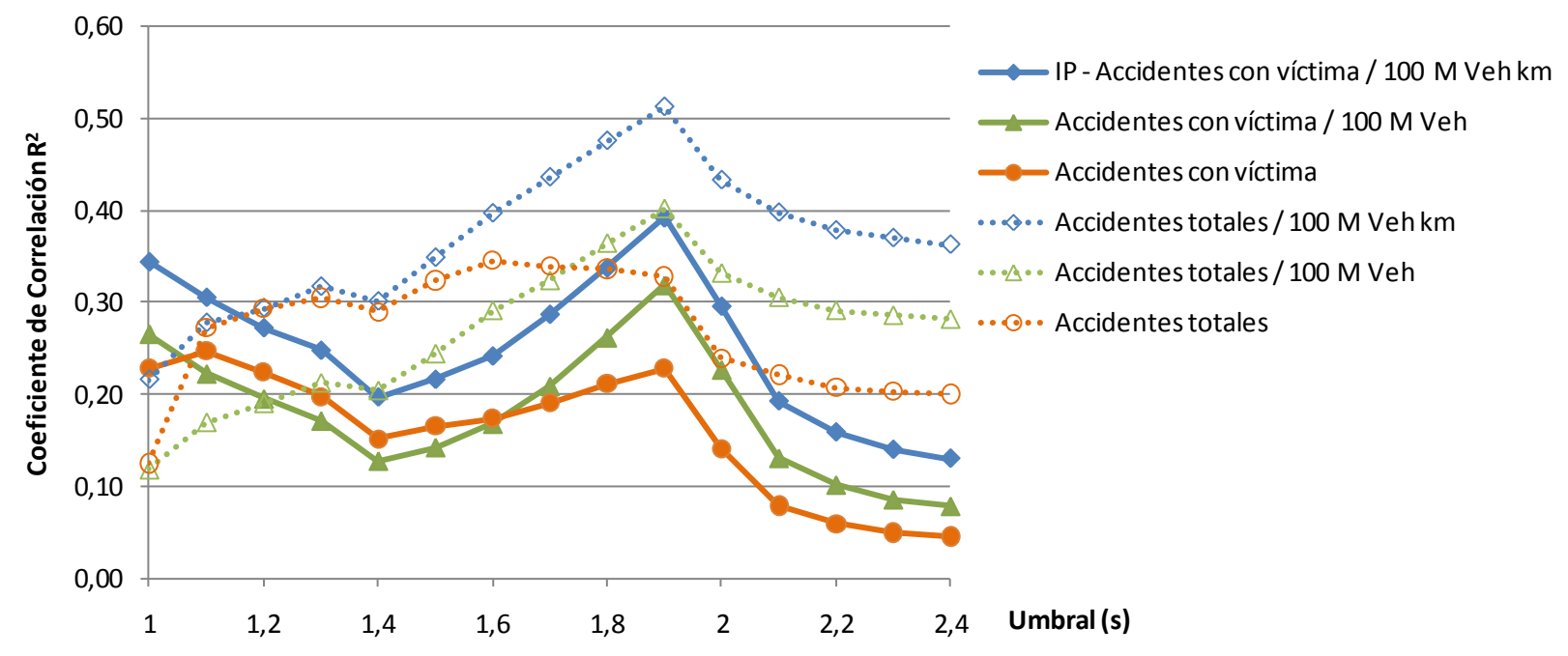

Figura 164: Variación del coeficiente de correlación $\mathbf{R}^{2}$ en función del umbral para TM_TIPCLA

Teniendo en cuenta el comportamiento del coeficiente de correlación en función del umbral para los indicadores IM_TiPCLA y TM_TiPCLA, se puede decir que el valor umbral debe estar en el intervalo $[1,5-1,8] \mathrm{s}$. Este intervalo está contenido en el intervalo de comportamiento uniforme observado para TM_TiPCLA, $[1,4-1,7] \mathrm{s}$, así como el comportamiento de crecimiento lineal para IM_TiPCLA.

De acuerdo con la Figura 163 y la Figura 164, se puede verificar que el indicador que mejor se ajusta a todos los índices analizados es el IM_TiPCLA. Asimismo en el análisis de correlación se observa que este indicador es el que presenta una mejor correlación y una mayor estabilidad con respecto al umbral.

Para la evaluación cuantitativa se utilizará el valor umbral de 1,5 s que además de pertenecer al intervalo de mejor correlación, coincide con el valor medio del intervalos de comportamiento uniforme de los indicadores TiPCLA.

Es importante señalar que aunque la correlación encontrada entre los indicadores TiPCLA y la accidentalidad puede considerarse como una correlación moderada, con valores de $R^{2}$ entre 0,3 y 0,4, de acuerdo con Grayson y Hakker (1987) la validez no solamente debería reducirse al establecimiento de una relación estadística entre accidentes y conflictos, y que Hauer y Garder (1986) argumentan que la validez de las TCT debería ser evaluada comparando los niveles de discrepancia entre las estimaciones de los conflictos y los índices de accidentalidad, sugiriendo que el método que tenga menor discrepancia en los resultados será el método con mayor grado de validez.

\subsubsection{Correlación de IM_TiPCLA}

Con los datos del valor medio de la integral de TiPCLA bajo el valor umbral 1,5 segundos y el valor medio del tiempo bajo ese mismo umbral, de cada carril estudiado se ha realizado el análisis de correlación entre estos indicadores y las diferentes variables explicativas. Se han ajustado modelos conteniendo todas las combinaciones 
de variables y se ha determinado cuales de ellas predicen mejor el fenómeno de acuerdo con su valor de R-cuadrado ajustado.

Se ha encontrado que las variables que explican mejor la variabilidad del indicador IM_TiPCLA son la relación $L / L_{0}(R L)$, el porcentaje de vehículos que salen, el porcentaje de vehículos pesados y el número de carriles de la vía principal.

Para el indicador del valor medio de la integral de TiPCLA se ha encontrado que existe relación estadísticamente significativa entre este indicador y las tres variables explicativas anteriores, para un nivel de confianza del $95 \%$, dado que el p-valor en la Tabla 96 es inferior a 0,05.

Tabla 95: Análisis de regresión lineal múltiple para el valor medio de la integral de TiPCLA $_{1,5}$

\begin{tabular}{|l|c|c|c|c|}
\hline \multicolumn{1}{|c|}{ Parámetro } & Estimación & $\begin{array}{c}\text { Error } \\
\text { Estándar }\end{array}$ & T Estadístico & P-Valor \\
\hline CONSTANTE & 0,132067 & 0,114248 & 1,15597 & 0,2810 \\
\hline Relación L/L $L_{0}$ & $-0,376493$ & 0,156709 & $-2,40249$ & 0,0430 \\
\hline (Relación L/L $)^{2}$ & 0,199241 & 0,0910971 & 2,18712 & 0,0602 \\
\hline PS & 0,00262476 & 0,00154137 & 1,70288 & 0,1270 \\
\hline Carriles VP & 0,0726784 & 0,0270997 & 2,68189 & 0,0278 \\
\hline Pvp & $-0,00434085$ & 0,00134653 & $-3,22373$ & 0,0122 \\
\hline
\end{tabular}

Tabla 96: Análisis de varianza para el valor medio de la integral de TiPCLA,

\begin{tabular}{|l|c|c|c|c|c|}
\hline Fuente & $\begin{array}{c}\text { Suma de } \\
\text { Cuadrados }\end{array}$ & GL & $\begin{array}{c}\text { Cuadrados } \\
\text { Medios }\end{array}$ & F-Ratio & P-Valor \\
\hline Modelo & 0,0335723 & 5 & 0,00671447 & 6,61 & 0,0101 \\
\hline Residuo & 0,00812208 & 8 & 0,00101526 & & \\
\hline
\end{tabular}

En la Tabla 96 se muestran los resultados del ajuste a un modelo de regresión lineal múltiple para describir la relación entre el valor medio de la integral de TiPCLA bajo un valor umbral y cuatro variables independientes: relación $L / L_{0}(R L)$, porcentaje de vehículos que salen ( $P S$, número de carriles de la vía principal y el porcentaje de vehículos pesados. La ecuación (125) corresponde al modelo ajustado:

$$
\begin{gathered}
\mathrm{IM}_{\text {TiPCLA }} \text { Ti, }=0,132067-0,376493 * \mathrm{RL}+0,199241 * \mathrm{RL}^{2}+ \\
0,00262476 * \mathrm{PS}+0,0726784 * \mathrm{C}-0,00434085 * \mathrm{Pvp}
\end{gathered}
$$

donde:

- IM_TiPCLA 1,5 : valor medio de la integral de TiPCLA bajo un umbral de 1,5 s.

- RL: relación entre la longitud real del carril (L) y la calculada de acuerdo con la Instrucción de Trazado 3.1-IC (1999) $\left(L_{0}\right)$. 
- $\quad$ PS: Porcentaje de vehículos que salen (\%).

- C: Número de carriles de la vía principal.

- Pvp: Porcentaje de vehículos pesados aguas arriba del carril de deceleración (\%).

El valor del estadístico R-cuadrado indica que el modelo explica un $80,52 \%$ de la variabilidad del indicador IM_TiPCLA 1,5 .

La influencia de la relación $L / L_{0}$ en IM_TiPCLA $A_{1,5}$ hace que éste aumente cuando el carril es demasiado largo o demasiado corto, siendo lo óptimo valores intermedios. Su valor óptimo está en 0,94.

Al simplificar el modelo se ha encontrado que existe relación estadísticamente significativa entre IM_TiPCLA ${ }_{1,5}$ y la longitud del carril de deceleración, como única variable explicativa, para un nivel de confianza del $90 \%$.

Tabla 97: Análisis de regresión polinomial para IM_TiPCLA ${ }_{1,5}$ en función de la Longitud

\begin{tabular}{|l|c|c|c|c|}
\hline \multicolumn{1}{|c|}{ Parámetro } & Estimación & $\begin{array}{c}\text { Error } \\
\text { Estándar }\end{array}$ & T Estadístico & P-Valor \\
\hline CONSTANTE & 0,317797 & 0,0683113 & 4,65218 & 0,0007 \\
\hline Longitud & $-0,00168897$ & 0,000673843 & $-2,50647$ & 0,0292 \\
\hline Longitud $^{2}$ & 0,00000359169 & 0,0000015076 & 2,38239 & 0,0363 \\
\hline
\end{tabular}

Tabla 98: Análisis de varianza para IM_TiPCLA ${ }_{1,5}$ en función de la Longitud

\begin{tabular}{|l|c|c|c|c|c|}
\hline Fuente & $\begin{array}{c}\text { Suma de } \\
\text { Cuadrados }\end{array}$ & GL & $\begin{array}{c}\text { Cuadrados } \\
\text { Medios }\end{array}$ & F-Ratio & P-Valor \\
\hline Modelo & 0,0152207 & 2 & 0,00761036 & 3,16 & 0,0822 \\
\hline Residuo & 0,0264737 & 11 & 0,0024067 & & \\
\hline
\end{tabular}

En la Tabla 97 se muestran los resultados del ajuste a un modelo de regresión polinomial para describir la relación entre IM_TiPCLA ${ }_{1,5}$ y la longitud del carril de deceleración.

La ecuación (126) corresponde al modelo ajustado:

$$
\text { IM_TiPCLA }{ }_{1,5}=0,317797-0,00168897^{*} \mathrm{~L}+0,00000359169^{*} \mathrm{~L}^{2}
$$

donde:

- IM_TiPCLA $A_{1,5}$ : valor medio de la integral de TiPCLA bajo un umbral de 1,5 s.

- L : Longitud del carril de deceleración (m). 
Como se observa en la Tabla 98, el p-valor es inferior a 0,1 , por lo que se puede afirmar que existe una relación estadísticamente significativa entre el indicador IP_TiPCLA $_{1,5}$ y la longitud del carril de deceleración para un nivel de confianza del $90 \%$.

El valor del estadístico R-cuadrado indica que el modelo explica un $36,51 \%$ de la variabilidad de IM_TiPCLA 1,5 .

La influencia de la longitud en IM_TiPCLA ${ }_{1,5}$ hace que éste aumente cuando el carril es demasiado largo o demasiado corto, siendo lo óptimo valores intermedios. Su valor óptimo está en los $235 \mathrm{~m}$ que es un valor muy cercano al encontrado como punto de cambio de tendencia en el índice de accidentalidad y al mínimo encontrado para el número de accidentes con víctimas.

Si se toma la relación $L / L_{0}(R L)$ como única variable explicativa, se encuentra que existe una relación estadísticamente significativa entre IM_TiPCLA $A_{1,5}$ y dicha relación, para un nivel de confianza del $95 \%$.

Tabla 99: Análisis de regresión polinomial para IM_TiPCLA ${ }_{1,5}$ en función de la relación $L / L_{0}$

\begin{tabular}{|l|c|c|c|c|}
\hline \multicolumn{1}{|c|}{ Parámetro } & Estimación & $\begin{array}{c}\text { Error } \\
\text { Estándar }\end{array}$ & T Estadístico & P-Valor \\
\hline CONSTANTE & 0,3567 & 0,0776065 & 4,59626 & 0,0008 \\
\hline Relación L/ $\mathrm{L}_{0}$ & $-0,572293$ & 0,187917 & $-3,04545$ & 0,0111 \\
\hline$\left(\text { Relación } \mathrm{L} / \mathrm{L}_{0}\right)^{2}$ & 0,336556 & 0,102861 & 3,27196 & 0,0074 \\
\hline
\end{tabular}

Tabla 100: Análisis de varianza para IM_TiPCLA $A_{1,5}$ en función de la relación $L / L_{0}$

\begin{tabular}{|l|c|c|c|c|c|}
\hline Fuente & $\begin{array}{c}\text { Suma de } \\
\text { Cuadrados }\end{array}$ & GL & $\begin{array}{c}\text { Cuadrados } \\
\text { Medios }\end{array}$ & F-Ratio & P-Valor \\
\hline Modelo & 0,021383 & 2 & 0,0106915 & 5,79 & 0,0191 \\
\hline Residuo & 0,0203114 & 11 & 0,00184649 & & \\
\hline
\end{tabular}

En la Tabla 97 se muestran los resultados del ajuste a un modelo de regresión polinomial para describir la relación entre IM_TiPCLA I $_{1,5}$ y la relación entre la longitud real del carril (L) y la calculada de acuerdo con la Instrucción de Trazado 3.1-IC (1999) $\left(L_{0}\right)$.

La ecuación (127) corresponde al modelo ajustado:

$$
I_{-}{ }_{\text {TiPCLA }}, 5=0,3567-0,572293^{*} R L+0,336556^{*} R^{2}
$$

donde:

- IM_TiPCLA 1,5 : valor medio de la integral de TiPCLA bajo un umbral de 1,5 s. 
- RL: relación entre la longitud real del carril (L) y la calculada de acuerdo con la Instrucción de Trazado 3.1-IC (1999) $\left(\mathrm{L}_{0}\right)$.

Como se observa en la Tabla 100 , el p-valor es inferior a 0.05 , por lo que se puede afirmar que existe una relación estadísticamente significativa entre el indicador IP_TiPCLA $A_{1,5}$ y relación entre la Longitud real del carril $(L)$ y la calculada de acuerdo con la Instrucción de Trazado 3.1-IC (1999) ( $\left.\mathrm{L}_{0}\right)$ para un nivel de confianza del 95\%.

El valor del estadístico R-cuadrado indica que el modelo explica un 51,28 \% de la variabilidad de IM_TiPCLA 1,5 .

La influencia de la relación $L / L_{0}$ en IM_TiPCLA $A_{1,5}$ hace que éste aumente cuando el carril es demasiado largo o demasiado corto y disminuyendo con valores intermedios. Su valor óptimo es en 0,85 .

\subsubsection{Correlación de TM_TiPCLA}

Para el indicador del valor medio de tiempo bajo el umbral 1,5 s de TiPCLA se ha encontrado que existe relación estadísticamente significativa entre este indicador y la relación $L / L_{0}(R L)$, el porcentaje de vehículos pesados y el número de carriles de la vía principal, para un nivel de confianza del 99\%, dado que el p-valor en la Tabla 102 es inferior a 0,01 .

Tabla 101: Análisis de regresión lineal múltiple para el valor medio de tiempo bajo el umbral 1,5 s de TiPCLA

\begin{tabular}{|l|c|c|c|c|}
\hline \multicolumn{1}{|c|}{ Parámetro } & Estimación & $\begin{array}{c}\text { Error } \\
\text { Estándar }\end{array}$ & T Estadístico & P-Valor \\
\hline CONSTANTE & 0,37768 & 0,159138 & 2,37328 & 0,0417 \\
\hline Relación L/L 0 & $-0,828562$ & 0,258754 & $-3,20212$ & 0,0108 \\
\hline$(\text { Relación L/Lo })^{2}$ & 0,517346 & 0,14436 & 3,58373 & 0,0059 \\
\hline Carriles VP & 0,137978 & 0,0391762 & 3,52198 & 0,0065 \\
\hline P_Pesados & $-0,00821963$ & 0,00225265 & $-3,64887$ & 0,0053 \\
\hline
\end{tabular}

Tabla 102: Análisis de varianza para el valor medio de tiempo bajo el umbral 1,5 s de TIPCLA

\begin{tabular}{|l|c|c|c|c|c|}
\hline Fuente & $\begin{array}{c}\text { Suma de } \\
\text { Cuadrados }\end{array}$ & GL & $\begin{array}{c}\text { Cuadrados } \\
\text { Medios }\end{array}$ & F-Ratio & P-Valor \\
\hline Modelo & 0,183633 & 4 & 0,0459082 & 14,97 & 0,0005 \\
\hline Residuo & 0,0275943 & 9 & 0,00306603 & & \\
\hline
\end{tabular}


En la Tabla 101 se muestran los resultados del ajuste a un modelo de regresión lineal múltiple para describir la relación entre el valor medio de tiempo bajo el umbral 1,5 $\mathrm{s}$ de TiPCLA y tres variables independientes: relación $L / L_{0}(R L)$, número de carriles de la vía principal y el porcentaje de vehículos pesados.

La ecuación (128) corresponde al modelo ajustado:

$$
\begin{gathered}
\mathrm{TM}_{-} \mathrm{TiPCLA}_{1,5}=0,37768-0,828562^{*} \mathrm{RL}+0,517346^{*} \mathrm{RL}^{2}+0,137978^{*} \mathrm{C}- \\
0,00821963^{*} \mathrm{Pvp}
\end{gathered}
$$

donde:

- TM_TiPCLA 1,5 : valor medio de tiempo bajo el umbral 1,5 s de TiPCLA.

- RL: relación entre la Longitud real del carril (L) y la calculada de acuerdo con la Instrucción de Trazado 3.1-IC (1999) $\left(\mathrm{L}_{0}\right)$

- C: Número de carriles de la vía principal.

- Pvp: Porcentaje de vehículos pesados aguas arriba del carril de deceleración (\%).

El valor del estadístico R-cuadrado indica que el modelo explica un 86,93\% de la variabilidad en el valor medio de la integral de TM_TiPCLA bajo un valor umbral.

Al simplificar el modelo, si se toma la relación $L_{/} L_{0}(R L)$ como única variable explicativa, se encuentra que existe una relación estadísticamente significativa entre IM_TiPCLA 1,5 y dicha relación, para un nivel de confianza del $95 \%$.

Tabla 103: Análisis de regresión polinomial para TM_TiPCLA ${ }_{1,5}$ en función de la relación $L / L_{0}$

\begin{tabular}{|l|c|c|c|c|}
\hline \multicolumn{1}{|c|}{ Parámetro } & Estimación & $\begin{array}{c}\text { Error } \\
\text { Estándar }\end{array}$ & T Estadístico & P-Valor \\
\hline CONSTANTE & 0,741159 & 0,153958 & 4,81403 & 0,0005 \\
\hline Relación $\mathrm{L} / \mathrm{L}_{0}$ & $-1,17544$ & 0,372795 & $-3,15305$ & 0,0092 \\
\hline$\left(\text { Relación } \mathrm{L} / \mathrm{L}_{0}\right)^{2}$ & 0,739015 & 0,204058 & 3,62159 & 0,0040 \\
\hline
\end{tabular}

Tabla 104: Análisis de varianza para TM_TiPCLA $A_{1,5}$ en función de la relación $L / L_{0}$

\begin{tabular}{|l|c|c|c|c|c|}
\hline Fuente & $\begin{array}{c}\text { Suma de } \\
\text { Cuadrados }\end{array}$ & GL & $\begin{array}{c}\text { Cuadrados } \\
\text { Medios }\end{array}$ & F-Ratio & P-Valor \\
\hline Modelo & 0,13129 & 2 & 0,065645 & 9,03 & 0,0048 \\
\hline Residuo & 0,079937 & 11 & 0,007267 & & \\
\hline
\end{tabular}


En la Tabla 103 se muestran los resultados del ajuste a un modelo de regresión polinomial para describir la relación entre TM_TiPCLA TM $_{1,5}$ y la relación entre la longitud real del carril (L) y la calculada de acuerdo con la Instrucción de Trazado 3.1-IC (1999) $\left(L_{0}\right)$.

La ecuación (129) corresponde al modelo ajustado:

$$
\mathrm{TM}_{-} \mathrm{TiPCLA}_{1,5}=0,741159-1,17544{ }^{*} \mathrm{RL}+0,739015^{*} \mathrm{RL}^{2}
$$

donde:

- IM_TiPCLA 1,5 : valor medio de la integral de TiPCLA bajo un umbral de 1,5 s.

- RL: relación entre la Longitud real del carril (L) y la calculada de acuerdo con la Instrucción de Trazado 3.1-IC (1999) $\left(\mathrm{L}_{0}\right)$.

Como se observa en la Tabla 104, el p-valor es inferior a 0,01, por lo que se puede afirmar que existe una relación estadísticamente significativa entre el indicador IP_TiPCLA $_{1,5}$ y relación entre la Longitud real del carril $(L)$ y la calculada de acuerdo con la Instrucción de Trazado 3.1-IC (1999) $\left(L_{0}\right)$ para un nivel de confianza del 99\%.

El valor del estadístico R-cuadrado indica que el modelo explica un $62,16 \%$ de la variabilidad de TM_TiPCLA 1,5 .

La influencia de la relación $L / L_{0}$ en TM_TiPCLA $A_{1,5}$ hace que éste aumente cuando el carril es demasiado largo o demasiado corto y que disminuya en valores intermedios. Su valor óptimo es en 0,80 .

Es importante resaltar que no se ha encontrado una relación estadísticamente significativa entre el indicador TM_TiPCLA y la longitud del carril de deceleración como única variable explicativa, para un nivel de confianza del $90 \%$.

\subsection{COMBINACIÓN DE FACTORES}

En primer lugar es importante destacar que salvo tres factores analizados existe una correlación estadísticamente significativa entre la longitud del carril de deceleración o la longitud relativa del mismo (relación $L_{/} \mathrm{L}_{0}$ ) y los otros 16 factores analizados, lo que en principio confirma que el comportamiento de los conductores que toman un carril de deceleración varía en función de la longitud del carril que es la hipótesis fundamental planteada.

Los factores a los que no se ha encontrado una correlación estadísticamente significativa con la longitud del carril son:

- Porcentaje de salidas tardías.

- Porcentaje de maniobras con adelantamiento interior.

- Porcentaje de maniobras con adelantamiento interior confluyente. 
Los otros 17 factores analizados pueden clasificarse en tres grupos principales: factores que mejoran al aumentar la longitud del carril; factores que mejoran al disminuir la longitud del carril y factores que mejoran con longitudes intermedias.

Dentro de los factores que mejoran al aumentar la longitud del carril se destacan:

- Porcentaje de salidas anticipadas.

- Diferencial de velocidad al abandonar la vía principal.

Los factores que mejoran al disminuir la longitud del carril son:

- Porcentaje de maniobras de reincorporación.

- Porcentaje de maniobras cuyo origen es uno de los carriles rápidos.

- Porcentaje de maniobras con adelantamiento exterior.

- Porcentaje de vehículos que aceleran en el carril de deceleración.

Los factores que mejoran con longitudes intermedias son:

- Porcentaje de salidas en la cuña.

- Porcentaje de salidas en la zona media.

- Velocidad en la nariz.

- Número total de accidentes al año.

- Número de accidentes con víctima al año.

- Número total de accidentes al año por cada 100 millones de vehículos.

- Número total de accidentes al año por cada 100 millones de vehículos por km.

- Número de accidentes con víctima al año por cada 100 millones de vehículos

- Número de accidentes con víctima al año por cada 100 millones de vehículos por km.

- Indicador IM_TiPCLA.

- Indicador TM_TiPCLA.

En primer lugar, es importante destacar que existen correlaciones internas entre los diferentes factores analizados por lo que, en primer lugar, se hace una valoración de los factores analizados indicando cuales son los más importantes y cuales son complementarios. Posteriormente, se presenta el resumen de los resultados obtenidos para cada factor analizado (Tabla 105).

Dentro de los factores relevantes se destacan aquellos relacionados con la seguridad vial, es decir, los factores que tienen en cuenta la accidentalidad y la conflictividad.

En un segundo grupo se destacan los factores relacionados con la funcionalidad del carril como los relacionados con las velocidades y la aceleración.

Finalmente, dentro de los indicadores complementarios se incluyen aquellos relacionados con la distribución porcentual en tipologías de maniobras.

Se destaca que todos los criterios relevantes pertenecen al grupo de factores que mejoran con longitudes intermedias del carril de deceleración. 
Tabla 105: Resumen de valores óptimos para los diferentes factores estudiados

\begin{tabular}{|c|c|c|c|c|}
\hline \multirow{2}{*}{ Factor } & \multirow{2}{*}{ Categoría } & \multirow{2}{*}{ Grupo } & \multicolumn{2}{|c|}{ Valor óptimo } \\
\hline & & & $\mathbf{L}(\mathbf{m})$ & RL (\%) \\
\hline Número total de accidentes al año & $\mathrm{R}$ & I & 232 & \\
\hline Número de accidentes con víctima al año & $\mathrm{R}$ & I & 235 & \\
\hline $\begin{array}{l}\text { Número total de accidentes al año por } \\
\text { cada } 100 \text { millones de vehículos }\end{array}$ & $\mathrm{R}$ & I & $\begin{array}{l}>240 \\
<240\end{array}$ & $\begin{array}{l}<100 \\
>100\end{array}$ \\
\hline $\begin{array}{l}\text { Número total de accidentes al año por } \\
\text { cada } 100 \text { millones de vehículos por km }\end{array}$ & $\mathrm{R}$ & I & & 103 \\
\hline $\begin{array}{l}\text { Número de accidentes con víctima al año } \\
\text { por cada } 100 \text { millones de vehículos }\end{array}$ & $\mathrm{R}$ & I & 246 & \\
\hline $\begin{array}{l}\text { Número de accidentes con víctima al año } \\
\text { por cada } 100 \text { millones de vehículos por } \\
\text { km }\end{array}$ & $\mathrm{R}$ & I & 246 & 89,3 \\
\hline Indicador IM_TiPCLA & $\mathrm{R}$ & $\mathrm{I}$ & 235 & 85 \\
\hline Indicador TM_TiPCLA & $\mathrm{R}$ & I & & 80 \\
\hline Velocidad en la nariz & $\mathrm{F}$ & I & & 83 \\
\hline $\begin{array}{l}\text { Diferencial de velocidad al abandonar la } \\
\text { vía principal }\end{array}$ & $\mathrm{F}$ & $\mathrm{L}$ & & $>84$ \\
\hline $\begin{array}{l}\text { Porcentaje de vehículos que aceleran en } \\
\text { el carril de deceleración }\end{array}$ & $\mathrm{F}$ & C & $<185$ & \\
\hline Porcentaje de salidas anticipadas & $\mathrm{C}$ & $\mathrm{L}$ & & $>84$ \\
\hline $\begin{array}{l}\text { Porcentaje de maniobras de } \\
\text { reincorporación }\end{array}$ & C & $\mathrm{C}$ & $<213$ & \\
\hline $\begin{array}{l}\text { Porcentaje de maniobras cuyo origen es } \\
\text { uno de los carriles rápidos }\end{array}$ & $\mathrm{C}$ & $\mathrm{C}$ & & $<84$ \\
\hline $\begin{array}{l}\text { Porcentaje de maniobras con } \\
\text { adelantamiento exterior }\end{array}$ & $\mathrm{C}$ & C & $<133$ & \\
\hline Porcentaje de salidas en la cuña. & $\mathrm{C}$ & I & & 93,4 \\
\hline Porcentaje de salidas en la zona media & $\mathrm{C}$ & I & & 78,8 \\
\hline
\end{tabular}

Categoría: $\mathrm{R}=$ relevante, $\mathrm{F}=$ Funcional y $\mathrm{C}=$ complementario

Grupo (preferible un carril): $\mathrm{I}=$ intermedio, $\mathrm{C}=$ corto y $\mathrm{L}=$ largo

En la Tabla 105 se puede observar que el valor de longitud óptimo está cercano a los $235 \mathrm{~m}$, mientras para la relación $L_{/} \mathrm{L}_{0}$ el valor óptimo encontrado varía entre 0,79 y 1,03 . 
Se destaca el comportamiento del número medio de accidentes totales al año por cada 100 millones de vehículos, que para longitudes de diseño inferiores a $240 \mathrm{~m}$ se prefiere una relación $L / L_{0}$ mayor que 1 . Para longitudes de diseño más largas, la relación $L / L_{0}$ debe ser menor que 1.

Del análisis se desprende que el nuevo modelo de diseño permita obtener una solución de compromiso que disminuya la afectación a la vía principal y a la vez aumente la funcionalidad y la seguridad. 


\section{MODELO DE DISEÑO DE CARRIL DE DECELERACIÓN PARALELO}

De acuerdo con los resultados y el análisis de los mismos se presenta a continuación una propuesta de modelo de diseño para la longitud de los carriles de deceleración paralelos. En dicho modelo se tiene en cuenta tanto la dinámica de los vehículos cómo el comportamiento de los conductores, de modo que se establezca una solución de compromiso que disminuya la afectación a la vía principal y a la vez aumente la funcionalidad y la seguridad.

En primer lugar, se presenta el modelo de diseño para la longitud de la cuña del carril de deceleración y, en segundo lugar, el modelo de diseño de la longitud del carril de deceleración.

\subsection{LONGITUD DE LA CUÑA PARA CARRILES DE DECELERACIÓN}

En primer lugar, teniendo en cuenta que el percentil 50 de la longitud de las maniobras de salida varía entre el $106 \%$ y el $149 \%$ de la longitud de la cuña, calculada de acuerdo con la Instrucción de Trazado 3.1 IC (1999) pero considerando la el límite de velocidad genérico de la vía, la cuña debe tener una longitud mayor a la estipulada en esta norma.

Este comportamiento se explica debido a que, en la Instrucción de Trazado 3.1 IC (1999), la longitud de la cuña se obtiene calculando la distancia que recorre un vehículo durante $3 \mathrm{~s}$ calculado a la velocidad inicial $V_{\text {dor }}$ que corresponde a la menor entre la velocidad de proyecto $\left(V_{\mathrm{P}}\right)$ y la velocidad máxima señalizada a la altura de la sección característica de $1,5 \mathrm{~m}$, mientras que, de acuerdo con lo observado, la duración de la maniobra de cambio de carril es de 3,5 s.

De acuerdo con ello, para el cálculo de la longitud de la cuña se utiliza la ecuación (130).

$$
L_{c}=3,5 \cdot V_{0}
$$

donde:

- $L_{c}$ : Longitud de la cuña (m).

- $\mathrm{V}_{0}$ : Límite de velocidad genérico de la vía $(\mathrm{m} / \mathrm{s})$.

\subsection{MODELO PARA EL CÁLCULO DE LA LONGITUD DEL CARRIL DE DECELERACIÓN}

En primer lugar, con el fin de facilitar la comprensión del modelo y adaptarlo a los modelos utilizados internacionalmente, se define la longitud del carril de deceleración como la distancia entre el punto de inicio de la cuña y el punto donde la separación 
entre bordes de calzada del carril y la calzada principal, medida perpendicularmente al eje de ésta, sea de 1,00 m, tal como se observa en la Figura 165.

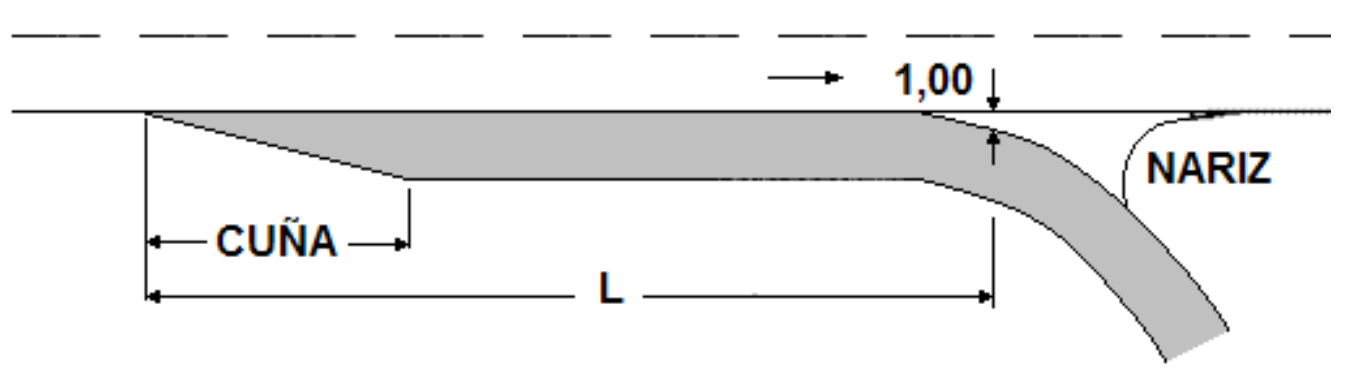

Figura 165: Secciones características del carril de deceleración paralelo

Teniendo en cuenta que la maniobra de deceleración observada está compuesta por dos maniobras sucesivas: la primera, una maniobra de cambio de carril, con una deceleración subconsciente; y la segunda una deceleración de frenado dentro del carril de deceleración, el modelo de diseño para el cálculo de la longitud de los carriles de deceleración paralelos se compone de la suma de dos longitudes correspondientes al cálculo de las longitudes recorridas por los vehículos en cada una de estas maniobras y la distancia entre el inicio de la cuña y el punto de inicio de la maniobra de cambio de carril (ecuación (131)), en lugar de hacer el cálculo como una única maniobra de deceleración con los valores de deceleración medios, como hasta ahora.

$$
L=P_{i c}+L d+L f
$$

donde:

- L: Longitud del carril de deceleración (m).

- $P_{\text {ic: }}$ : Distancia entre el inicio de la cuña y el inicio de la maniobra de cambio de carril (m).

- $L_{d}$ : Longitud de la maniobra de cambio de carril (m).

- $\quad \mathrm{L}_{\mathrm{f}}$ : Longitud de la maniobra de frenado (m).

\subsubsection{Longitud de la maniobra de cambio de carril}

Para el cálculo de la maniobra de cambio de carril es necesario, en primer lugar, tener en cuenta que el análisis ha confirmado que en carriles de deceleración de longitud normal los vehículos reducen su velocidad en aproximadamente un $14 \%$ antes de abandonar la vía principal. 
Por esta razón, para el cálculo de la longitud de la maniobra de cambio de carril, en primer lugar se obtiene la velocidad objetivo después de la deceleración subconsciente, como la mayor entre el $86 \%$ del límite de velocidad genérico de la vía y velocidad específica del elemento del carril de deceleración que contiene la sección característica de $1 \mathrm{~m}$ en la nariz, mediante la aplicación de la ecuación (132).

$$
V_{d d}=\operatorname{Max}\left(0,86 \cdot V_{0}, V_{n}\right)
$$

donde:

- $\mathrm{V}_{\mathrm{dd}}$ : Velocidad después de la deceleración $(\mathrm{m} / \mathrm{s})$.

- $\mathrm{V}_{0}$ : Límite de velocidad genérico de la vía $(\mathrm{m} / \mathrm{s})$.

- $\quad \mathrm{V}_{\mathrm{n}}$ : velocidad específica del elemento del carril de deceleración que contiene la sección característica de $1 \mathrm{~m}$ en la nariz $(\mathrm{m} / \mathrm{s})$.

Por otra parte, se ha observado que la velocidad transversal media coincide con la propuesta por Rioux (1977) de $1 \mathrm{~m} / \mathrm{s}$, con un valor máximo de 1,6 m/s siguiendo la función coseno. La duración de la maniobra de cambio de carril es de 3,5 segundos. Asimismo, se ha encontrado que la deceleración subconsciente tiene una duración que varía entre los 5,9 y los 7,4 segundos y que el cambio de carril se efectúa en la última parte de dicha deceleración. La primera parte de esta deceleración subconsciente se desarrolla en la vía principal.

En consecuencia la longitud de la maniobra de cambio de carril corresponde a la distancia recorrida por el vehículo, durante los últimos 3,5 segundos de deceleración por retención del motor.

Para ello, hay que verificar que la duración de la deceleración para alcanzar la velocidad después de la deceleración subconsciente, $V_{d d}$ (ecuación (133)), sea mayor que los 3,5 segundos de duración que tiene la maniobra de cambio de carril.

$$
t_{d}=\frac{V_{d d}-V_{0}}{d_{s}-i \cdot g}
$$

donde:

- $t_{d}$ : Duración de la deceleración subconsciente (s).

- $V_{d d}$ : Velocidad después de la deceleración (m/s).

- $\mathrm{V}_{0}$ : Límite de velocidad genérico de la vía $(\mathrm{m} / \mathrm{s})$.

- $\mathrm{d}_{\mathrm{s}}$ : tasa de deceleración por retención del motor $\left(\mathrm{m} / \mathrm{s}^{2}\right)$

- $\mathrm{g}$ : aceleración de la gravedad $\left(\mathrm{m} / \mathrm{s}^{2}\right)$

- $\quad$ i: inclinación de la rasante (tanto por uno). 
En caso de que la duración de la deceleración subconsciente sea mayor a 3,5 segundos, para calcular la distancia recorrida por el vehículo durante el cambio de carril se calcula la velocidad al inicio de la maniobra de cambio de carril mediante la aplicación de la ecuación (134).

$$
V_{i c}=V_{d d}-\left(d_{s}-i \cdot g\right) \cdot 3,5
$$

donde:

- $\quad V_{i c}$ : Velocidad al inicio de la maniobra de cambio de carril $(\mathrm{m} / \mathrm{s})$.

- $V_{\mathrm{dd}}$ : Velocidad después de la deceleración (m/s).

- $\mathrm{d}_{\mathrm{s}}$ : tasa de deceleración por retención del motor $\left(\mathrm{m} / \mathrm{s}^{2}\right)$.

- $\mathrm{g}$ : aceleración de la gravedad $\left(\mathrm{m} / \mathrm{s}^{2}\right)$.

- $\quad$ i: inclinación de la rasante (tanto por uno).

En el caso de que la duración de la maniobra de deceleración subconsciente sea menor a la duración de la maniobra de cambio de carril, la primera parte del cambio de carril se calcula a una velocidad igual al límite de velocidad seguida de la deceleración subconsciente.

A partir de los valores calculados anteriormente, la longitud de la maniobra de cambio de carril se calcula con la siguiente ecuación:

$$
L_{d}=\left\{\begin{array}{lr}
\text { si } t_{d} \geq 3,5 & L_{d}=\frac{V_{d d}{ }^{2}-V_{i c}{ }^{2}}{2 \cdot\left(d_{s}-i \cdot g\right)} \\
\text { si } t_{d}<3,5 & L_{d}=\frac{V_{d d}{ }^{2}-V_{0}{ }^{2}}{2 \cdot\left(d_{s}-i \cdot g\right)}+V_{0} \cdot\left(3,5-t_{d}\right)
\end{array}\right.
$$

donde:

- $L_{d}$ : Longitud de la maniobra de cambio de carril (m).

- $\quad t_{d}$ : Duración de la deceleración subconsciente (s).

- $V_{d d}$ : Velocidad después de la deceleración (m/s).

- $\mathrm{V}_{0}$ : Límite de velocidad genérico de la vía $(\mathrm{m} / \mathrm{s})$.

- $\quad \mathrm{V}_{\mathrm{ic}}$ : Velocidad al inicio del cambio de carril $(\mathrm{m} / \mathrm{s})$.

- $\mathrm{d}_{\mathrm{s}}$ : tasa de deceleración por retención del motor $\left(\mathrm{m} / \mathrm{s}^{2}\right)$.

- $\mathrm{g}$ : aceleración de la gravedad $\left(\mathrm{m} / \mathrm{s}^{2}\right)$.

- i: inclinación de la rasante (tanto por uno). 


\subsubsection{Longitud de la maniobra de frenado}

Para calcular la longitud de la maniobra de frenado, con la aplicación de la ecuación (136), es necesario conocer el límite de velocidad en la nariz, la velocidad al inicio del frenado, que es la velocidad después de la deceleración, y la tasa de deceleración frenando.

$$
L_{f}=\frac{V_{n}{ }^{2}-V_{d d}{ }^{2}}{2 \cdot\left(d_{f}-i \cdot g\right)}
$$

donde:

- $\mathrm{L}_{\mathrm{f}}$ : Longitud de la maniobra de frenado $(\mathrm{m})$.

- $V_{d d}$ : Velocidad después de la deceleración $(\mathrm{m} / \mathrm{s})$.

- $\mathrm{V}_{\mathrm{n}}$ : velocidad específica del elemento del carril de deceleración que contiene la sección característica de $1 \mathrm{~m}$ en la nariz $(\mathrm{m} / \mathrm{s})$.

- i: inclinación de la rasante (tanto por uno).

- g: aceleración de la gravedad $\left(\mathrm{m} / \mathrm{s}^{2}\right)$

- $\mathrm{d}_{\mathrm{f}}$ : tasa de deceleración de frenado $\left(\mathrm{m} / \mathrm{s}^{2}\right)$.

\subsubsection{Selección de tasas de deceleración y punto de inicio de la maniobra de cambio de carril}

Para la selección de las tasas de deceleración y el punto de inicio de la maniobra de cambio de carril se ha calculado las longitudes de los carriles de deceleración resultantes de aplicar el modelo para vías de 80,100 y $120 \mathrm{~km} / \mathrm{h}$ y para las diferentes inclinaciones de la rasante, en ramales de salida de diferentes velocidades, utilizando los percentiles 15,50 y 85 de las tasas de deceleración subconsciente y de frenado encontradas experimentalmente.

Se han evaluado cada una de las longitudes calculadas utilizando los modelos de regresión encontrados para el indicador IM_TiPCLA y para el cálculo del índice de peligrosidad. Los resultados se han comparado con los obtenidos para los valores de diseño de la Instrucción de Trazado 3.1-IC (1999).

Para el caso del indicador de conflictividad IM_TiPCLA 1,5 se ha encontrado que, para el punto de inicio de la maniobra de salida en la sección característica en que la cuña tiene una anchura de $1 \mathrm{~m}$ y el percentil 50 de deceleraciones produce el mayor porcentaje de valores que mejoran tal como se observa en la Figura 166. Asimismo, se observa que el percentil 50 de las deceleraciones produce una mejora de cerca de 
$0,006 \mathrm{~s}$ en el valor medio de IM_TiPCLA $A_{1,5}$, que es un valor muy superior al que se obtiene con deceleraciones suaves o con deceleraciones fuertes.

Para cuando el punto de inicio de la maniobra de deceleración coincide con en el punto de inicio de la cuña produce un alto porcentaje de maniobras que mejoran. Sin embargo, el valor medio de indicador empeora. Esto es debido a que produce, para todos los casos, longitudes menores que las de la Instrucción de Trazado 3.1 IC (1999).

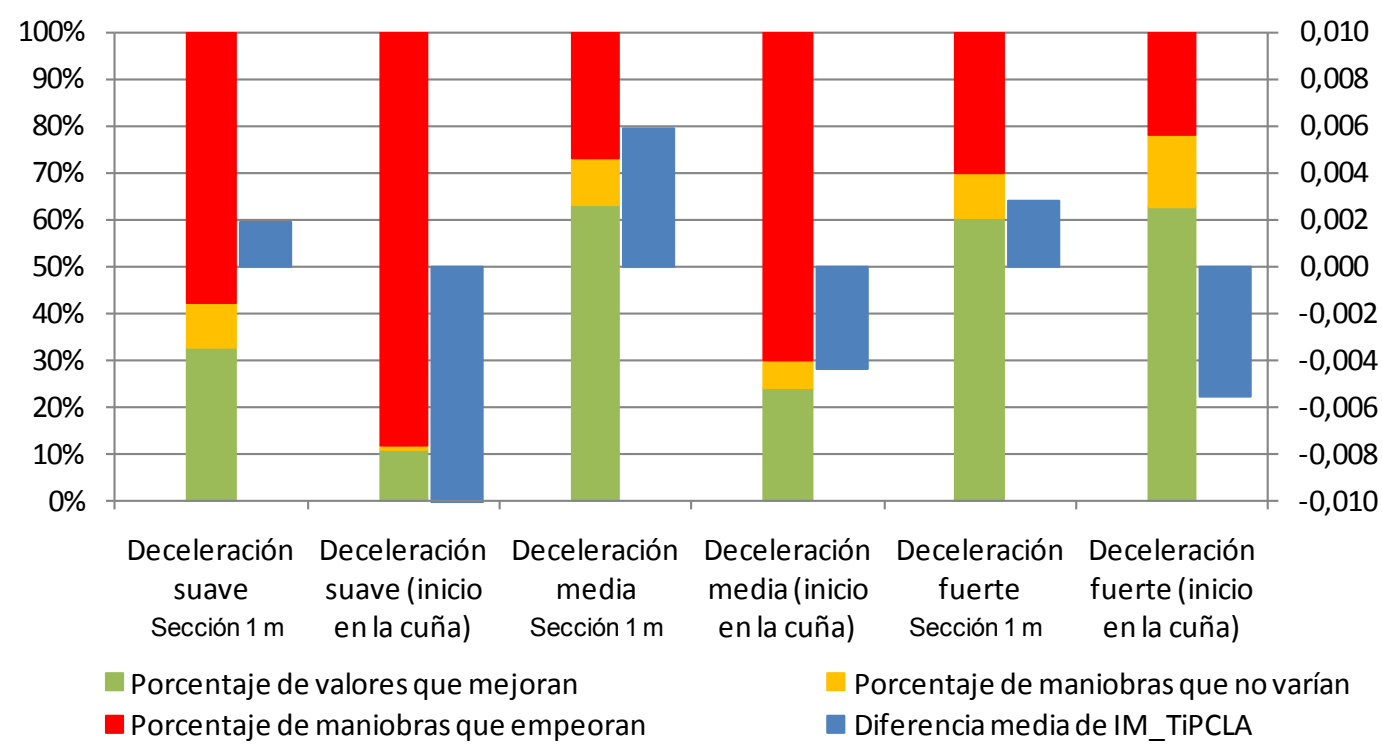

Figura 166: Evaluación del Indicador IM_TiPCLA ${ }_{1,5}$ en función del percentil de deceleración seleccionado

En lo relativo al índice de peligrosidad, al igual que con el indicador de conflictividad IM_TiPCLA 1,5 , se ha encontrado que el percentil 50 de deceleraciones produce el mayor porcentaje de valores que mejoran o no varían tal como se observa en la Figura 167. Asimismo, se observa que el percentil 50 de las deceleraciones produce una mejora media de cerca de 0,5 accidentes con víctima al año por cada 100 millones de vehículos por km, que es un valor muy superior al que se obtiene con deceleraciones suaves o con deceleraciones fuertes. 


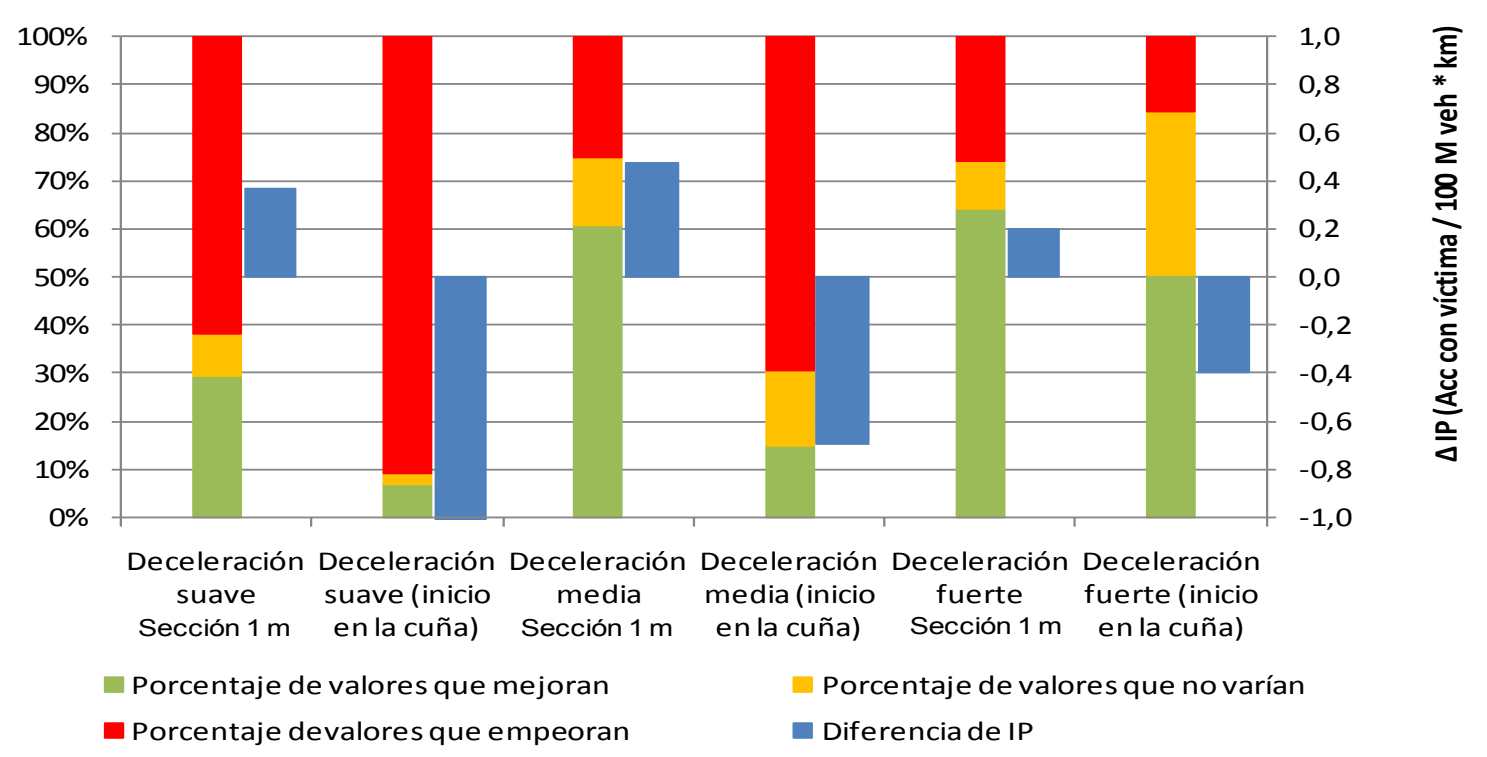

Figura 167: Evaluación del índice de peligrosidad en función del percentil de deceleración seleccionado

De acuerdo con lo anterior, para el modelo de diseño deben utilizarse los valores correspondientes al percentil 50 de la deceleración por retención del motor y por frenado, correspondientes a $-0,76 \mathrm{~m} / \mathrm{s}^{2}$ y $-2,44 \mathrm{~m} / \mathrm{s}^{2}$, respectivamente. Asimismo, el punto de inicio de la maniobra de frenado que debe utilizarse para el cálculo es el punto donde la cuña tiene una anchura de $1 \mathrm{~m}$.

\subsubsection{Límite mínimo para la longitud del carril de deceleración}

En primer lugar hay que tener en cuenta una primera restricción debida a la cuña. El carril de deceleración debe ser lo suficientemente largo para alojar la cuña antes de que inicie su divergencia. Pero esta situación está tenida en cuenta en el cálculo de la maniobra de frenado.

Por otra parte, si el límite de velocidad en la nariz coincide con el límite genérico de velocidad de la vía la distancia de frenado sería cero. En este caso, el carril de deceleración debería tener como mínimo una longitud igual a la distancia recorrida por un vehículo que circula a una velocidad equivalente al límite genérico de velocidad de la vía durante $3,5 \mathrm{~s}$, que es la duración observada de la maniobra de cambio de carril y que coincide con la longitud propuesta para la cuña.

De acuerdo con el modelo planteado, el caso más restrictivo para la longitud del carril de deceleración es cuando el límite de velocidad en la nariz equivale al $86 \%$ del límite genérico de velocidad de la vía, donde la longitud de la maniobra de frenado sería cero y la longitud de la maniobra de cambio de carril sería mínima.

Además, el modelo tiene en cuenta que la maniobra de cambio de carril inicia en la sección en que la cuña tiene una anchura de $1 \mathrm{~m}$. 
Teniendo en cuenta que las consideraciones anteriores están tenidas en cuenta en el modelo de diseño propuesto, no es necesario mantener una longitud mínima del carril de deceleración.

\subsection{LONGITUDES RESULTANTES DE LA APLICACIÓN DEL MODELO}

A continuación, en la Tabla 106, se presentan las longitudes de los carriles de deceleración resultantes de aplicar el modelo para vías de 80,100 y $120 \mathrm{~km} / \mathrm{h}$ y para las diferentes inclinaciones de la rasante, en ramales de salida de diferentes velocidades.

Tabla 106: Longitud de los carriles de deceleración a partir del modelo

\begin{tabular}{|c|c|c|c|c|c|c|c|c|c|c|c|c|c|c|c|}
\hline \multicolumn{16}{|c|}{$\mathrm{V}_{0}=80 \mathrm{~km} / \mathrm{h}$} \\
\hline \multirow{2}{*}{$\begin{array}{c}V_{n} \\
k m / h\end{array}$} & \multicolumn{15}{|c|}{ Inclinación de la rasante \% } \\
\hline & -7 & -6 & -5 & -4 & -3 & -2 & -1 & 0 & 1 & 2 & 3 & 4 & 5 & 6 & 7 \\
\hline 0 & 194 & 189 & 185 & 181 & 177 & 174 & 171 & 169 & 166 & 164 & 162 & 160 & 159 & 157 & 155 \\
\hline 10 & 192 & 187 & 183 & 179 & 175 & 172 & 170 & 167 & 165 & 163 & 161 & 159 & 157 & 156 & 154 \\
\hline 20 & 185 & 181 & 177 & 173 & 170 & 167 & 165 & 162 & 160 & 158 & 157 & 155 & 153 & 152 & 150 \\
\hline 30 & 174 & 170 & 167 & 164 & 161 & 159 & 156 & 155 & 153 & 151 & 150 & 148 & 147 & 145 & 144 \\
\hline 40 & 159 & 156 & 153 & 151 & 148 & 147 & 145 & 143 & 142 & 141 & 140 & 139 & 137 & 136 & 135 \\
\hline 50 & 139 & 137 & 135 & 134 & 132 & 131 & 130 & 129 & 128 & 128 & 127 & 126 & 126 & 125 & 124 \\
\hline 60 & 115 & 114 & 113 & 113 & 112 & 112 & 112 & 112 & 112 & 112 & 111 & 111 & 111 & 111 & 111 \\
\hline
\end{tabular}

\begin{tabular}{|c|c|c|c|c|c|c|c|c|c|c|c|c|c|c|c|}
\hline \multicolumn{16}{|c|}{$V_{0}=100 \mathrm{~km} / \mathrm{h}$} \\
\hline \multirow{2}{*}{$\begin{array}{c}V_{\mathrm{n}} \\
\mathrm{km} / \mathrm{h}\end{array}$} & \multicolumn{15}{|c|}{ Inclinación de la rasante \% } \\
\hline & -7 & -6 & -5 & -4 & -3 & -2 & -1 & 0 & 1 & 2 & 3 & 4 & 5 & 6 & 7 \\
\hline 0 & 275 & 267 & 260 & 253 & 247 & 242 & 238 & 233 & 229 & 226 & 222 & 219 & 217 & 214 & 211 \\
\hline 10 & 273 & 265 & 258 & 251 & 246 & 241 & 236 & 232 & 228 & 224 & 221 & 218 & 215 & 213 & 210 \\
\hline 20 & 266 & 258 & 252 & 246 & 240 & 35 & 231 & 227 & 223 & 220 & 217 & 214 & 211 & 209 & 206 \\
\hline 30 & 255 & 248 & 242 & 236 & 231 & 227 & 223 & 219 & 216 & 213 & 210 & 207 & 205 & 202 & 200 \\
\hline 40 & 240 & 233 & 228 & 223 & 219 & 215 & 211 & 208 & 205 & 202 & 200 & 198 & 195 & 193 & 191 \\
\hline 50 & 220 & 215 & 210 & 206 & 202 & 199 & 196 & 194 & 191 & 189 & 187 & 185 & 184 & 182 & 180 \\
\hline 60 & 196 & 192 & 188 & 185 & 183 & 180 & 178 & 176 & 175 & 173 & 172 & 170 & 169 & 168 & 167 \\
\hline 70 & 167 & 105 & $\perp$ & 10 & 139 & 138 & 1 & 130 & 155 & 154 & 153 & 153 & 152 & 151 & 151 \\
\hline 80 & 134 & 133 & 133 & 133 & 132 & 132 & 132 & 132 & 132 & 132 & 132 & 132 & 132 & 132 & 132 \\
\hline 90 & 275 & 267 & 260 & 253 & 247 & 242 & 238 & 233 & 229 & 226 & 222 & 219 & 217 & 214 & 211 \\
\hline
\end{tabular}




\begin{tabular}{|c|c|c|c|c|c|c|c|c|c|c|c|c|c|}
\hline \multicolumn{14}{|c|}{$V_{0}=120 \mathrm{~km} / \mathrm{h}$} \\
\hline \multirow{2}{*}{$\begin{array}{c}V_{n} \\
\mathrm{~km} / \mathrm{h}\end{array}$} & \multicolumn{13}{|c|}{ Inclinación de la rasante \% } \\
\hline & -6 & -5 & -4 & -3 & -2 & -1 & 0 & 1 & 2 & 3 & 4 & 5 & 6 \\
\hline 0 & 357 & 346 & 337 & 328 & 321 & 313 & 307 & 301 & 296 & 291 & 286 & 282 & 278 \\
\hline 10 & 355 & 344 & 335 & 327 & 319 & 312 & 305 & 300 & 294 & 289 & 285 & 280 & 277 \\
\hline 20 & 349 & 338 & 329 & 321 & 314 & 307 & 301 & 295 & 290 & 285 & 281 & 277 & 273 \\
\hline 30 & 338 & 329 & 320 & 312 & 305 & 299 & 293 & 287 & 282 & 278 & 274 & 270 & 266 \\
\hline 40 & 324 & 315 & 307 & 300 & 293 & 287 & 282 & 277 & 272 & 268 & 264 & 261 & 257 \\
\hline 50 & 305 & 297 & 290 & 283 & 278 & 272 & 267 & 263 & 259 & 255 & 252 & 249 & 246 \\
\hline 60 & 282 & 275 & 269 & 264 & 259 & 254 & 250 & 246 & 243 & 240 & 237 & 234 & 232 \\
\hline 70 & 255 & 249 & 244 & 240 & 236 & 233 & 229 & 227 & 224 & 221 & 219 & 217 & 215 \\
\hline 80 & 223 & 220 & 216 & 213 & 210 & 208 & 206 & 204 & 202 & 200 & 199 & 197 & 196 \\
\hline 90 & 188 & 186 & 184 & 183 & 181 & 180 & 179 & 178 & 177 & 176 & 176 & 175 & 175 \\
\hline 100 & 148 & 148 & 148 & 148 & 148 & 149 & 149 & 149 & 149 & 149 & 150 & 150 & 150 \\
\hline
\end{tabular}

\subsection{EVALUACIÓN DEL MODELO}

En primer lugar se compara la longitud de cada carril de deceleración según el modelo propuesto y la longitud calculada a partir de la Instrucción de Trazado 3.1-IC (1999).

Tabla 107: Longitud de los carriles de deceleración a partir del modelo

\begin{tabular}{|c|c|c|c|c|c|}
\hline Carril & $\begin{array}{c}\text { Longitud } \\
\text { construida } \\
\text { (m) }\end{array}$ & $\begin{array}{c}\text { Longitud } \\
\mathbf{3 . 1 - I C} \\
\text { (m) }\end{array}$ & $\begin{array}{c}\text { Longitud } \\
\text { modelo } \\
\text { propuesto } \\
\text { (m) }\end{array}$ & $\begin{array}{c}\text { Longitud } \\
\text { ajustando } \\
\text { referencias } \\
\text { (m) }\end{array}$ & $\begin{array}{c}\text { Relación de } \\
\text { longitud } \\
\text { (\%) }\end{array}$ \\
\hline A3-351 & 80 & 100 & 99 & 77 & $77 \%$ \\
\hline A7-484 & 217 & 256 & 282 & 239 & $93 \%$ \\
\hline V21-143-1 & 215 & 216 & 250 & 209 & $97 \%$ \\
\hline V21-143-2 & 184 & 238 & 267 & 226 & $95 \%$ \\
\hline V21-51 & 187 & 256 & 282 & 239 & $94 \%$ \\
\hline V21-985 & 209 & 228 & 254 & 211 & $93 \%$ \\
\hline V30-49 & 88 & 216 & 250 & 209 & $97 \%$ \\
\hline V31-68 & 137 & 256 & 282 & 239 & $94 \%$ \\
\hline V31-85 & 100 & 216 & 250 & 209 & $97 \%$ \\
\hline V31-98 & 229 & 190 & 229 & 187 & $98 \%$ \\
\hline CV-35 & 385 & 285 & 293 & 252 & $88 \%$ \\
\hline
\end{tabular}


Como se puede observar en la Tabla 107, para los carriles de deceleración estudiados, el modelo propuesto recomienda ligeramente longitudes inferiores a los propuestos por la Instrucción de Trazado 3.1-IC (1999); sin embargo, al comparar las tablas completas de diseño (Ver Figura 168, Figura 169 y Figura 170), para carriles más cortos, el modelo propuesto recomienda longitudes mayores, debido al que el modelo propuesto incluye en primer lugar una longitud para el cambio de carril, con una tasa de deceleración inferior a la Instrucción de Trazado 3.1-IC (1999).

De igual forma, para carriles más largos, el modelo propuesto recomienda longitudes menores, debido a que la tasa de deceleración por frenado es mayor que la de la norma actual. En términos generales, el modelo propuesto genera longitudes intermedias, que de acuerdo con el análisis, son las longitudes óptimas.
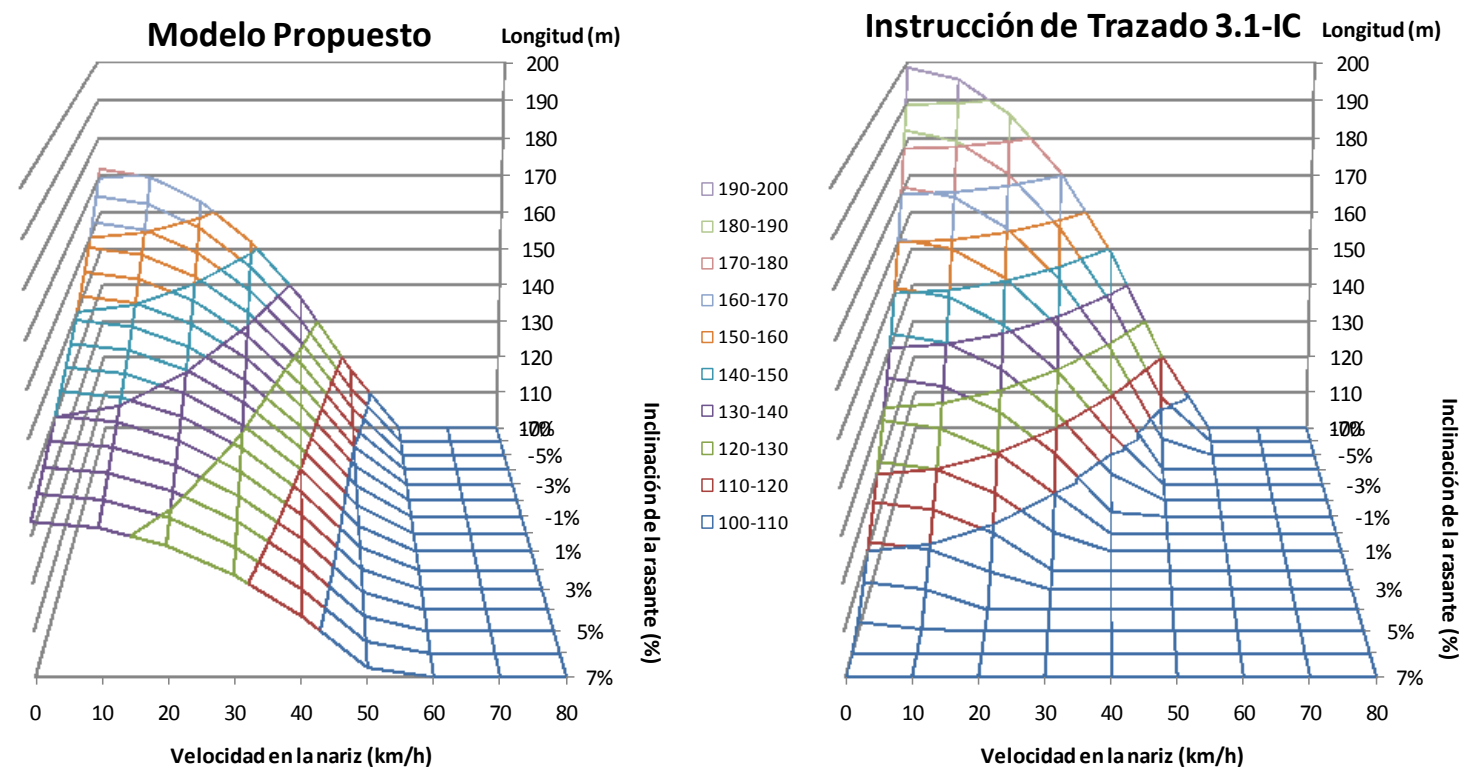

Figura 168: Comparación de longitudes de diseño de los carriles de deceleración para $V_{0}=80 \mathrm{~km} / \mathrm{h}$ (referencia ajustada) 

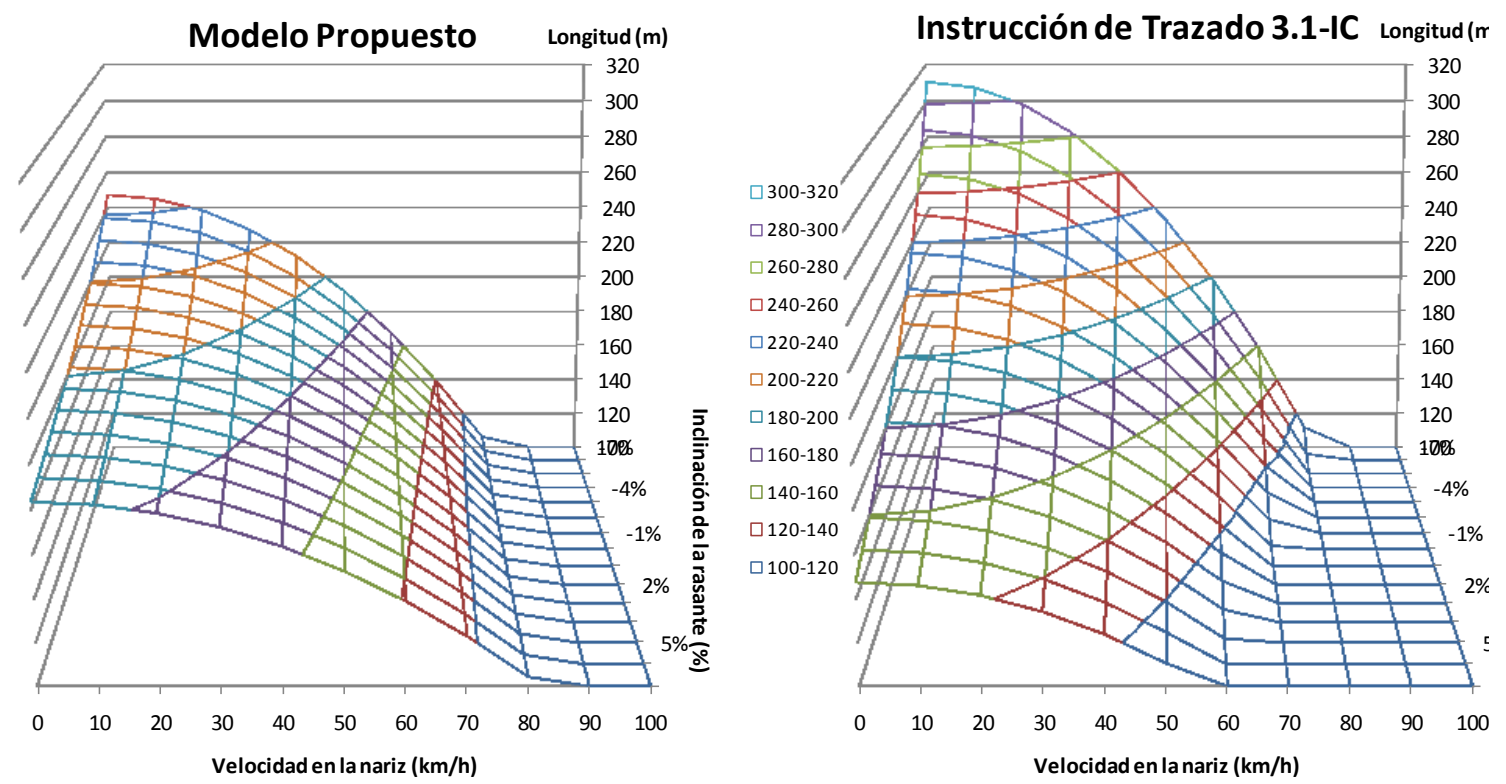

Figura 169: Comparación de longitudes de diseño de los carriles de deceleración para $V_{0}=100 \mathrm{~km} / \mathrm{h}$ (referencia ajustada)
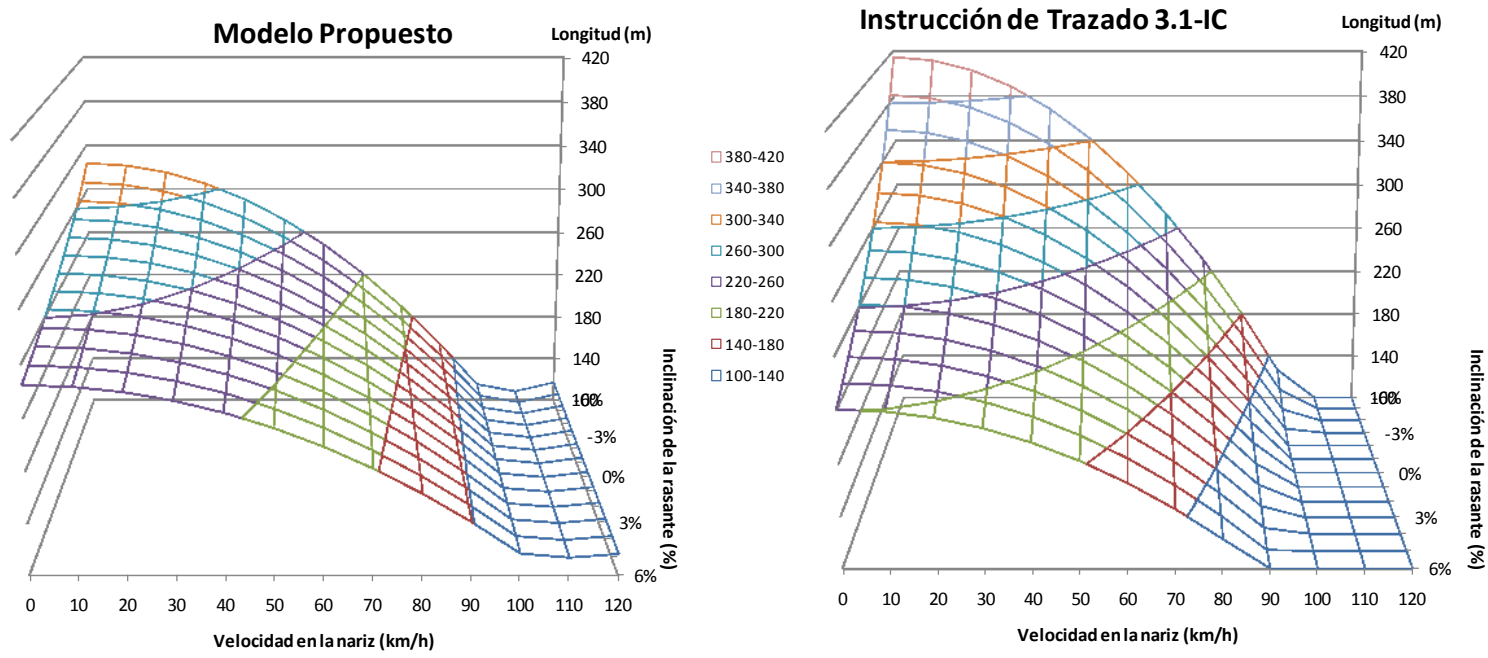

Figura 170: Comparación de longitudes de diseño de los carriles de deceleración para $V_{0}=120 \mathrm{~km} / \mathrm{h}$ (referencia ajustada)

Con el fin de evaluar el modelo de diseño se ha calculado, para cada uno de los carriles de deceleración estudiados, los valores estimados de cada uno de los criterios analizados en el análisis de resultados, utilizando las ecuaciones resultantes de las regresiones realizadas.

Estos valores se han comparado tanto con los valores reales medidos, como con los valores estimados en función de las mismas ecuaciones, pero con la longitud real de los carriles. 


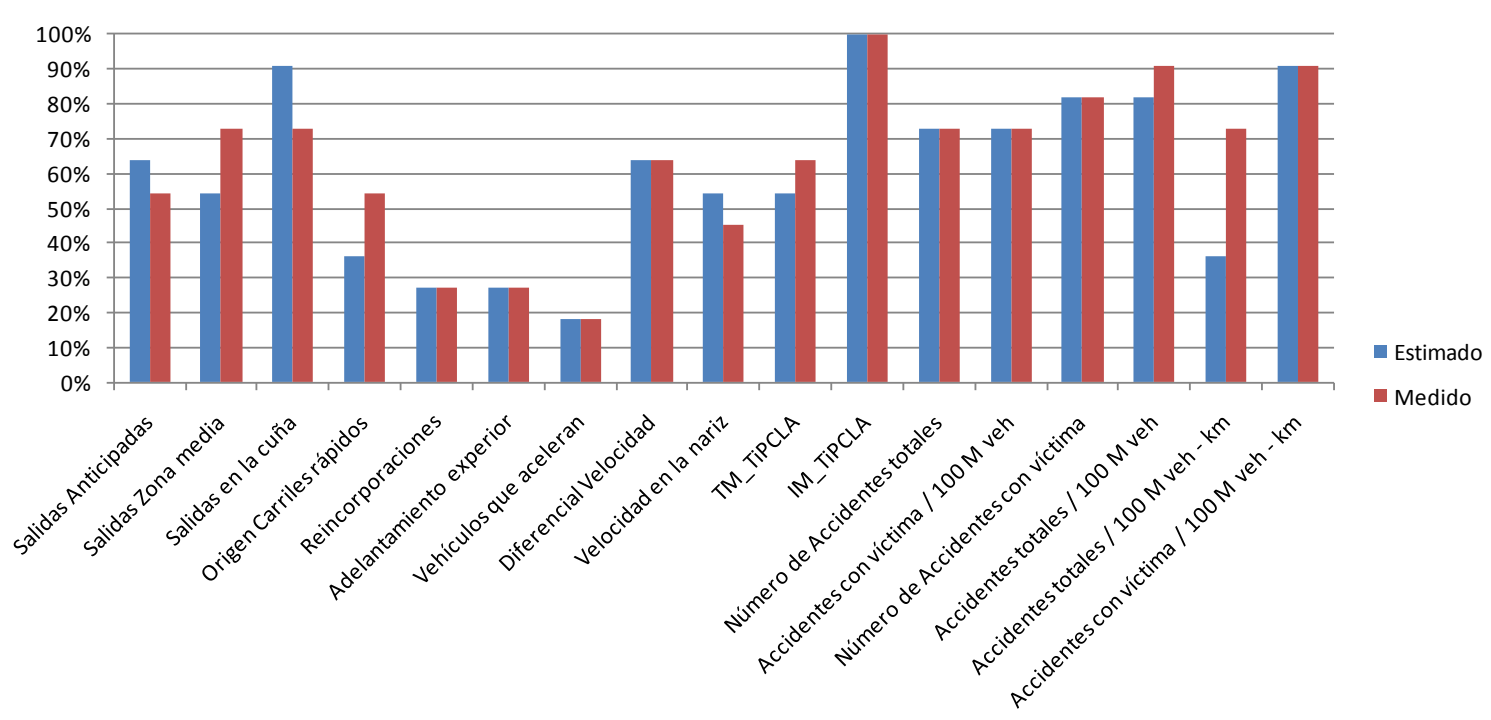

Figura 171: Porcentaje de carriles que mejoran de acuerdo con cada criterio

En la Figura 171 se muestra el porcentaje de carriles que han tenido una mejora en cada uno de los criterios estudiados. Se destaca que para el indicador IM_TiPCLA 1,5 la totalidad de los carriles mejoran con el nuevo modelo de diseño, tanto si se tiene en cuenta los valores estimados como los medidos. Asimismo, para cinco de los seis criterios relacionados con la accidentalidad, y para el porcentaje de vehículos que salen en la cuña, el porcentaje de mejora es superior al 70\%.

Este comportamiento se explica, principalmente, por la variación del comportamiento de la longitud con el nuevo modelo de diseño, pues para carriles muy cortos con el diseño actual, el nuevo modelo de diseño recomienda carriles más largos, mientras que para carriles muy largos, de acuerdo con el modelo actual, el modelo propuesto recomienda carriles más cortos, lo que coincide con el comportamiento de los indicadores de conflictividad, y con los de accidentalidad. 


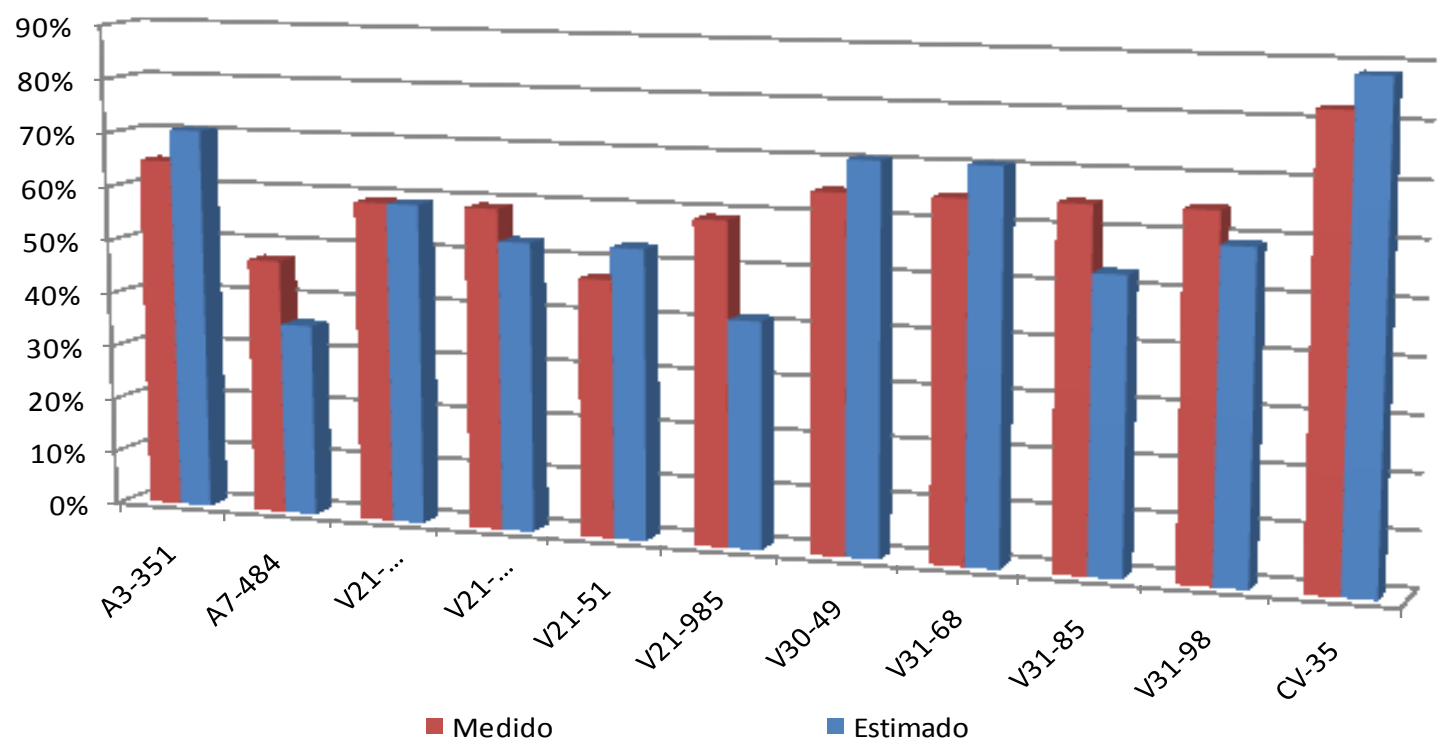

Figura 172: Porcentaje de criterios que mejoran en cada carril estudiado

En la Figura 172 se observa el porcentaje de criterios que mejoran al modificar la longitud de cada carril de deceleración de acuerdo con el modelo de diseño propuesto. Se destaca que el carril que más criterios mejoran es el carril experimental en la CV-35. No se ha ponderado la importancia de los criterios en este cálculo, pero en términos generales se mejoran los relacionados con la accidentalidad y empeoran los relacionados con las maniobras peligrosas, pues en muchos casos la longitud real es inferior a la recomendada por la Instrucción de Trazado 3.1-IC (1999) y por el modelo propuesto. 


\section{DISCUSIÓN}

A continuación se presenta la discusión del modelo de diseño planteado, posteriormente se presentan los comentarios generales respecto a su aplicación y finalmente se hace la discusión relativa a los indicadores de la familia TiPCLA y las herramientas desarrolladas para su cálculo.

\subsection{APLICACIÓN DEL MODELO}

En primer lugar es necesario destacar que el modelo se ha desarrollado a partir de los datos de carriles de deceleración tipo paralelo, por lo que, en principio, el modelo es aplicable a carriles de deceleración de este tipo, aunque podría utilizarse también en carriles de deceleración directos.

En el caso de carriles directos, sería necesario tener en cuenta que las características propias de estos carriles hacen que las consideraciones tenidas en cuenta para el diseño del modelo no sean del todo válidas. Por ejemplo, en los carriles directos la calzada del carril de deceleración diverge rápidamente de la vía principal, separando de la vía principal a los vehículos que salen lo que no permite que se realicen algunas de las maniobras peligrosas encontradas en los carriles paralelos, como los adelantamientos y las reincorporaciones. Sin embargo, esto no impide que algunos vehículos puedan acelerar en estos carriles dando lugar a comportamientos anómalos.

Además, es necesario considerar que para los carriles de deceleración directos los resultados de los indicadores de conflictividad cambiarían debido a que se elimina parte de la interacción lateral con los vehículos que continúan por la vía principal.

Por otra parte, para el desarrollo del modelo se ha tenido en cuenta la evolución de los vehículos ligeros que circulaban a flujo libre sin estar condicionados ni en la vía principal ni en el carril de deceleración permitiendo a los conductores elegir libremente su velocidad y deceleraciones. Para él caso de vehículos condicionados, el modelo es igualmente válido, pues su evolución dependerá del vehículo que le precede, el cual podrá elegir su velocidad y deceleración quedando de esta forma incluido en el modelo.

En el caso de tener una alta intensidad del tráfico se presenta una disminución de velocidad del mismo por lo que las maniobras que ocurren en esta situación quedan del lado de la seguridad dentro del modelo. Sin embargo, es necesario estudiar con mayor detalle lo que sucede en los carriles de alta capacidad, es decir, cuando los ramales tienen más de un carril.

Los vehículos pesados circulan a menor velocidad que los vehículos ligeros, por lo que su comportamiento es menos restrictivo a la hora de calcular las dimensiones del carril de deceleración. Además, el modelo ofrece resultados mayores que el modelo actual cuando su longitud es inferior, lo que favorece a los vehículos pesados.

Cuando el diseño actual da como resultado carriles muy largos, el modelo propuesto da como resultado longitudes inferiores. En este caso los vehículos pesados están tenidos 
en cuenta, en primer lugar, por la diferencia de velocidad a la que circulan que compensa esta disminución $y$, en segundo lugar, porque en cualquier caso la deceleración considerada es una deceleración cómoda $\left(-2,44 \mathrm{~m} / \mathrm{s}^{2}\right)$ que corresponde al percentil 50 de las deceleraciones encontradas.

\subsection{APLICACIÓN DE LOS INDICADORES DE CONFLICTIVIDAD TIPCLA}

De acuerdo con los resultados de la correlación con los indicadores de la familia TiPCLA, en especial el valor medio de la integral de TiPCLA bajo un umbral de 1,5 s (IM_TiPCLA 1,5 ), se puede afirmar que la utilización de este indicador dentro de las Técnicas de Conflictos de Tráfico permite la evaluación de la conflictividad de los carriles de deceleración.

Asimismo, es posible evaluar otras ubicaciones que comparten las tipologías de interacción entre los vehículos, es decir, conflictos laterales al discurrir en paralelo y conflictos longitudinales en maniobras de seguimiento. En particular puede aplicarse en carriles de aceleración, tramos de trenzado y en general tramos de vía en los que los vehículos discurran en paralelo, como bifurcaciones y convergencias de calzadas.

No obstante, aunque estos tramos mencionados presentan el mismo tipo de maniobras, es necesario demostrar la aplicabilidad de los indicadores en estos nuevos sectores mediante un estudio comparativo entre los resultados de la aplicación de los indicadores y los índices de accidentalidad en dichos tramos.

Asimismo, es necesario comentar que los indicadores de la familia TiPCLA no están diseñados para aplicarlos en intersecciones, pues su función es evaluar conflictos de seguimiento y conflictos laterales, pero no los conflictos que se presentan en las intersecciones para las que hay gran cantidad de indicadores aplicables en diferentes casos.

\subsection{APLICACIÓN DE LAS HERRAMIENTAS DESARROLLADAS EN LA INVESTIGACIÓN}

La aplicación informática para la restitución de maniobras a partir de vídeos por perspectiva cónica es una herramienta que permite calcular la posición de diferentes elementos en un vídeo a partir de puntos de referencia y el conocimiento de las medidas reales.

A partir de las posiciones y relacionadas con el tiempo transcurrido en el vídeo permite, utilizando derivadas numéricas, calcular velocidades y aceleraciones con lo que se puede caracterizar la evolución de los elementos que se restituyen.

Su aplicabilidad no se reduce únicamente al seguimiento de vehículos, sino que también es aplicable a peatones y ciclistas, y en general a los diferentes usuarios de las vías. 
Para su aplicación es importante contar con una posición adecuada de la cámara, en la que se pueda apreciar claramente la zona de estudio y preferiblemente en la que la cámara enfoque de manera paralela al eje de la evolución de los elementos que se desean restituir.

La precisión de la restitución depende de varios factores, entre los que se destaca el tamaño de la imagen del vídeo, la posición y la distancia entre la cámara y los elementos que se van a restituir.

El programa tiene la restricción de que los elementos que se desea restituir deben tener su posición en el mismo plano de las referencias.

Para garantizar una adecuada posición de las cámaras, se ha desarrollado en el Grupo de Investigación en Ingeniería de Carreteras de la Universidad Politécnica de Valencia, un Laboratorio Móvil de Tráfico (Figura 173), que permite la ubicación en altura y la grabación simultánea con 6 cámaras digitales de vídeo.

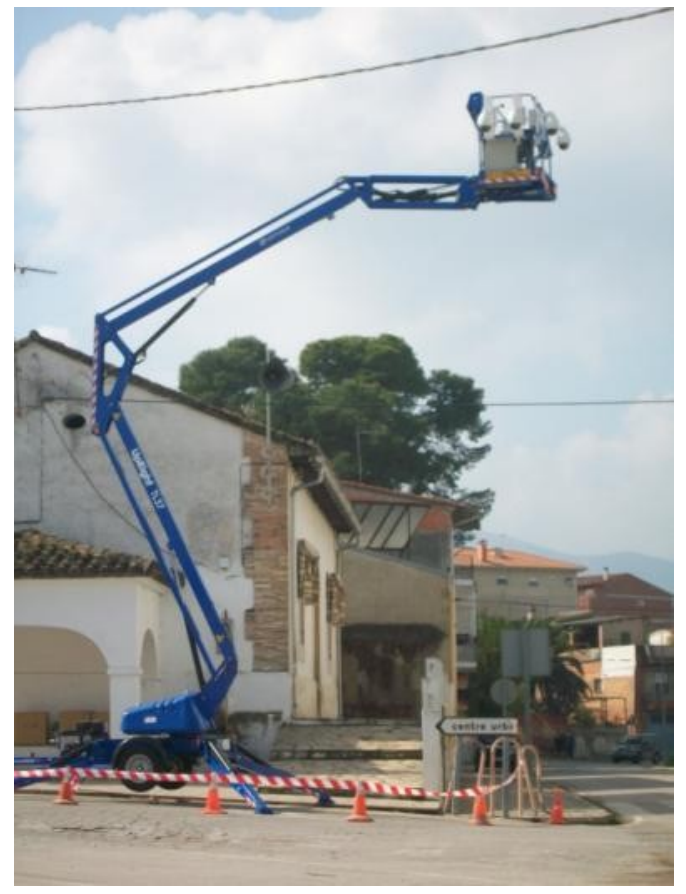

Figura 173: Laboratorio Móvil de Tráfico desarrollado

El laboratorio y la aplicación desarrollados se están utilizando actualmente para realizar evaluaciones de conflictividad peatonal, seguimiento de vehículos en elementos moderadores de tráfico y evaluación de zonas de adelantamientos. 


\section{APLICACIÓNES PRÁCTICAS}

Se presenta a continuación las aplicaciones prácticas tanto del modelo de diseño propuesto para la longitud de los carriles de deceleración, cómo de la familia de indicadores TiPCLA, del programa desarrollado $y$, en general, de los resultados obtenidos durante el desarrollo de esta tesis doctoral.

\subsection{MODELO DE DISEÑO PROPUESTO}

La principal aplicación del modelo de diseño propuesto será la de utilizarlo para el cálculo de la longitud de nuevos carriles de deceleración que se estén proyectando o en carriles de deceleración existentes que se requiera modificar su longitud.

Asimismo, el modelo de diseño es aplicable en aquellos puntos donde se desee intervenir por razones de siniestralidad ya que al ajustar la longitud del carril de deceleración los conductores modifican su comportamiento de modo que se reduzca la frecuencia de maniobras peligrosas, se disminuya la conflictividad en la zona y por consiguiente se obtenga una disminución en la accidentalidad en la zona de influencia del carril de deceleración.

\subsection{MODELOS DE EVALUACIÓN}

En el análisis se han desarrollado modelos de ajuste entre diversas variables explicativas y los distintos factores analizados en la investigación. Estos modelos constituyen funciones que predicen el comportamiento esperado de los conductores en una situación específica. Con ello es posible evaluar y comparar el comportamiento real con el comportamiento esperado de modo que sirva como una herramienta de toma de decisiones para asignar prioridades de intervención en proyectos de mejora de la seguridad vial.

\subsection{INDICADORES DE CONFLICTIVIDAD DE LA FAMILIA TIPCLA}

Los indicadores de conflictividad desarrollados permiten hacer una evaluación rápida y eficaz de la conflictividad en diversos tipos de ubicaciones como en: carriles de aceleración, tramos de trenzado y en general tramos de vía en los que los vehículos discurran en paralelo, como bifurcaciones y convergencias de calzadas, o incluso en las propias calzadas de vías de un solo carril por sentido.

Teniendo en cuenta que las Técnicas de Conflictos de Tráfico sirven como una medida indirecta de la seguridad vial, estos indicadores de la familia TiPCLA permiten ampliar la aplicabilidad de estas técnicas y evaluar la seguridad vial antes de que ocurran los accidentes. Así, pueden ser una herramienta válida para el establecimiento de medidas activas de seguridad vial. 


\subsection{PROGRAMA DE RESTITUCIÓN DE MANIOBRAS}

La aplicación informática para la restitución de maniobras a partir de vídeos permite caracterizar la evolución de los vehículos, peatones y ciclistas en diferentes ámbitos. Con ella se puede conocer la posición de los elementos en cada momento durante el vídeo, su velocidad y su aceleración, tanto longitudinal como transversal con lo que se puede utilizar para estudiar la evolución de los usuarios en una determinada infraestructura.

Su aplicación principal es, por tanto, como apoyo a la actividad investigadora en diferentes etapas de toma y procesamiento de datos.

Dado que la aplicación informática permite conocer las velocidades y aceleraciones de los usuarios, la aplicación puede ser utilizada para hacer peritajes judiciales de accidentes grabados por cámaras de vídeo, por lo que se constituye en una herramienta adicional para el análisis y la reconstrucción de accidentes. El programa es aplicable para hacer aforos direccionales en intersecciones. 


\section{FUTURAS LINEAS DE INVESTIGACIÓN}

A continuación se presentan las líneas de investigación derivadas de esta, no solo en lo relativo a los carriles de deceleración, sino también a las técnicas de conflictos de tráfico y a las técnicas de ITS utilizadas.

En cuanto a los carriles de deceleración es necesario profundizar en el diseño de salidas de alta capacidad, con el fin de definir sus tipologías y evaluar las que presenten mejores prestaciones, tanto por su capacidad, como por la seguridad vial y la funcionalidad.

Asimismo, es necesario evaluar la funcionalidad del nuevo modelo de diseño propuesto para diferentes intensidades de tráfico, haciendo un seguimiento del comportamiento de la conflictividad y de la accidentalidad en carriles diseñados de acuerdo con el modelo propuesto.

En esta investigación se han encontrado reducciones de velocidad en la calzada principal cercanas al $14 \%$, por lo que se plantea la necesidad de estudiar la relación que existe entre la velocidad a la que divergen los conductores y el límite genérico de velocidad de la vía, para lo cual sería necesario evaluar las velocidades en diferentes carriles de deceleración.

Es importante realizar un estudio detallado de los carriles de trenzado, puesto que revisten una mayor conflictividad, para establecer si es necesario restringir su utilización y en qué casos se permitiría, todo ello aplicando el nuevo indicador de conflictividad propuesto.

En el estudio se ha observado distintos tipos de maniobras conflictivas, lo que supone un riesgo para los conductores, por lo que se deberían dirigir las investigaciones hacia tratar de evitarlas. Para ello sería necesario estudiar los efectos que tienen sobre el comportamiento del conductor las distintas marcas viales, señalización vertical o balizamiento. Algunos ejemplos podrían ser:

- Señalización con línea continua que restrinja el cambio de carril en las cercanías de los carriles de cambio de velocidad, para evitar maniobras desde o hacia los carriles rápidos.

- Variar la longitud de la línea continua antes de llegar a la nariz, para estudiar su influencia en el punto de salida de los vehículos y en el comportamiento de los mismos en el carril de deceleración.

- Utilización de marcas viales perpendiculares al flujo en el final del carril de deceleración para influir en la velocidad a la que llegan los vehículos a la nariz.

Debido a la importancia que tiene la cuña en el comportamiento de los conductores, se debería estudiar el comportamiento de los conductores en función de las características de la cuña, como su longitud, desarrollo, forma, anchura, entre otras, con el fin de evaluar la posibilidad de disminuir los efectos sobre la vía principal, acompañado de un estudio en el que se analice la aceleración tangencial que experimentan los vehículos cuando se incorporan a una vía de deceleración ya que es la responsable de la estabilidad transversal del vehículo. 
Se debe estudiar cómo afectan las distintas geometrías de la vía de deceleración y de esta forma poder establecer si los resultados obtenidos son aplicables a vías de deceleración con trazados curvos y a carriles de deceleración directos.

Se debe evaluar la aplicabilidad de la familia de indicadores de conflictividad TiPCLA desarrollada en otros ámbitos de aplicación, como en: carriles de aceleración; calzadas de autovías y autopistas; tramos de trenzado, etc.

Asimismo se debe estudiar la creación de nuevos indicadores de conflictividad para que sean aplicables en lugares en los que estén presentes otros tipos de usuarios de las vías, como tranvías, bicicletas y peatones.

Se debe continuar con el desarrollo del seguimiento en tiempo real de los vehículos para de esta forma poder evaluar la conflictividad en cada momento, y, de esta manera, poder alertar a los usuarios de la ocurrencia de conflictos y de la gravedad de los mismos. Todo ello con el fin de intentar reducir, de manera activa, la accidentalidad, dentro de una gestión dinámica del tráfico.

Con el desarrollo de la aplicación informática se abre un campo importante para el estudio del comportamiento de los conductores en diferentes ámbitos en los que se requiera un seguimiento en detalle de los vehículos como en glorietas, incorporaciones, intersecciones, etc. 


\section{CONCLUSIONES}

Cuando los datos de accidentalidad no se pueden aplicar a toda la red viaria para evaluar su grado de seguridad, ya que en muchos lugares no se cuenta con estos datos o simplemente nunca ha ocurrido un accidente, las Técnicas de Conflictos de Tráfico (Traffic Conflict Techniques, TCT) constituyen la mejor alternativa para evaluar la seguridad vial.

Las Técnicas de Conflictos de Tráfico sacan partido de que las situaciones que revisten cierto grado de peligrosidad suceden con más frecuencia que los accidentes como tal, por lo que es posible determinar, en un tiempo relativamente corto, en qué medida un lugar es potencialmente peligroso mediante un estudio de conflictos.

La aplicación de las Técnicas de Conflictos de Tráfico implica un adelanto en la seguridad del tráfico, pues pueden identificar problemas de seguridad antes de que sucedan los accidentes.

La familia de indicadores de conflictividad TiPCLA desarrollados en esta investigación permite evaluar, no solamente conflictos relacionados con el seguimiento de vehículos sino también los conflictos laterales entre ellos, permitiendo de esta manera aplicar las Técnicas de Conflictos de Tráfico en situaciones donde no hay una zona de conflicto claramente definida. Este es el caso de los carriles de deceleración, los de aceleración, los de trenzado y, en general, en la circulación por los tramos de vía con más de un carril por sentido, no solamente en intersecciones y conexiones.

Es importante resaltar que los indicadores de conflictividad desarrollados amplían el ámbito de aplicación de las Técnicas de Conflictos de Tráfico.

El comportamiento de los indicadores agregados de TiPCLA es estable para un umbral dentro del intervalo $(1,4-1,7)$ s por lo que se recomienda utilizar valores umbrales dentro de este intervalo para realizar el análisis de conflictividad. Específicamente el umbral de mejor ajuste entre los resultados de los indicadores TiPCLA y la accidentalidad en carriles de deceleración es 1,5 s.

El intervalo del umbral $(1,4-1,7) \mathrm{s}$ contiene la mayor parte de maniobras peligrosas que se presentan en la vía y excluye las interacciones entre los vehículos que pueden considerarse normales.

De igual forma con la aplicación informática desarrollada se ha demostrado la facilidad para obtener parámetros de tráfico, como la intensidad y la velocidad, a partir de grabaciones en vídeo.

Se ha desarrollado una herramienta que permite estudiar la evolución de los vehículos, en cuanto a su posición en cada instante, su velocidad, tanto longitudinal como transversal, y su aceleración, que resulta muy útil para el desarrollo de futuras investigaciones.

La ubicación de las cámaras que facilita el procesamiento de los vídeos en una posición elevada, centrada en el carril que se pretende evaluar y enfocado de manera paralela al eje del carril. Teniendo esto en cuenta se ha desarrollado en el Grupo de 
Investigación en Ingeniería de Carreteras, un Laboratorio Móvil de Tráfico que gracias a la utilización de una plataforma elevadora permite ubicar las cámaras en la posición óptima para su posterior procesamiento.

Cuando las técnicas de visión artificial permitan evaluar los indicadores de conflictividad en tiempo real, será posible alertar a los usuarios de la ocurrencia de conflictos y de la gravedad de los mismos y, de esta forma, intentar reducir, de manera activa, la accidentalidad.

Algunas investigaciones anteriores han encontrado una ligera disminución de la accidentalidad al aumentar la longitud del carril de deceleración, pero limitan su longitud basándose en un análisis coste-beneficio. Sin embargo, en esta investigación se ha encontrado que al aumentar dicha longitud se incrementa la ocurrencia de maniobras peligrosas y de la accidentalidad.

Se ha analizado el comportamiento de los conductores en los carriles de deceleración desde diferentes aspectos, tanto de manera cualitativa como de manera cuantitativa, encontrando que los carriles muy cortos son los más peligrosos, seguidos de los carriles demasiado largos y que las longitudes intermedias son las óptimas.

Se ha encontrado también que los conductores deceleran siempre durante la maniobra de cambio de carril, lo cual influye en la vía principal, especialmente en los casos en que el carril es insuficiente, en cuyo caso los conductores inician la maniobra de frenado en la vía principal.

Se ha podido observar que los conductores, en los carriles de deceleración tipo paralelo, prefieren una trayectoria compuesta por curva y contra-curva en lugar de la maniobra directa, independientemente de la longitud del carril.

De los resultados se desprende que, en los carriles estudiados, los percentiles 15,50 y 85 de la deceleración por retención del motor tienen un valor de $-0,95,-0,76$ y $-0,54$ $\mathrm{m} / \mathrm{s}^{2}$, respectivamente, valores que son todos muy cercanos a los encontrados en estudios anteriores.

Asimismo, se han encontrado que los percentiles 15,50 y 85 de la deceleración en la maniobra de frenado tienen un valor de $-1,79,-2,44$ y $-3,30 \mathrm{~m} / \mathrm{s}^{2}$, respectivamente. Estos valores de deceleración son considerados confortables en este tipo de maniobra.

Es importante resaltar que no se ha presentado una variación de los valores de deceleración en función de la longitud del carril, lo que muestra que los conductores realizan la maniobra de deceleración y frenado dependiendo de su apreciación de la distancia a la salida, independientemente de la longitud del carril.

El percentil 50 de deceleración presenta mayores mejoras en el análisis de los modelos de accidentalidad, por lo que para el modelo propuesto de diseño de los carriles de deceleración se utilizan deceleraciones de $-0,76 \mathrm{~m} / \mathrm{s}^{2}$ para la retención del motor $\mathrm{y}$ $2,44 \mathrm{~m} / \mathrm{s}^{2}$ para la maniobra de frenado.

No se ha encontrado una relación estadísticamente significativa entre el porcentaje de maniobras de adelantamiento interior y la longitud del carril de deceleración, tampoco con el porcentaje de maniobras de salidas tardías. 
Al aumentar la longitud del carril se incrementa el porcentaje de reincorporaciones debido a una posible mala interpretación por parte de los conductores del carril de deceleración como un carril adicional, por no apreciar fácilmente la salida y su señalización.

El porcentaje de maniobras cuyo origen es uno de los carriles rápidos se incrementa con la longitud del carril de deceleración. Este tipo de maniobra está relacionada con la maniobra de salida tardía y como ésta, también se ve afectada por la intensidad del tráfico.

Los adelantamientos del tipo exterior se incrementan con la longitud del carril; sin embargo, la frecuencia de los adelantamientos interiores, tanto los confluyentes como los no confluyentes, no se ve afectada por la longitud del carril.

En lo relativo a los indicadores de conflictividad evaluados se puede concluir que los valores más altos, es decir, los de mayor conflictividad, se encuentran en aquellas ubicaciones con menor longitud, debido a que los vehículos deceleran más en la vía principal, aumentando la exposición a un posible conflicto de alcance.

Asimismo, en los carriles más largos se observa un incremento de los indicadores debido a la mayor exposición a conflictos laterales y especialmente debido a la mayor frecuencia de maniobras peligrosas.

El análisis de la accidentalidad ha demostrado que aquellas ubicaciones con menores índices de accidentalidad coinciden con carriles de longitud intermedia y en carriles demasiado cortos o demasiado largos la accidentalidad aumenta.

Los modelos de regresión desarrollados para el análisis de accidentalidad constituyen funciones de desempeño de la accidentalidad ("Safety Performance Functions") que pueden ser aplicados en estudios de seguridad vial.

Se ha encontrado que las variables que explican mejor la variabilidad de los indicadores TiPCLA son: la relación $L / L_{0}(R L)$, el porcentaje de vehículos que salen, el porcentaje de vehículos pesados y el número de carriles de la vía principal.

El análisis conjunto de los diferentes aspectos tenidos en cuenta ha mostrado que la longitud del carril de deceleración que mejor equilibra los efectos sobre la vía principal, tanto en la funcionalidad como en la seguridad, es una longitud que permite encadenar dos maniobras sucesivas. La primera, una maniobra de cambio de carril, con una deceleración por retención de motor; y la segunda una deceleración de frenado dentro del carril de deceleración.

Teniendo en cuenta que la duración de la maniobra de cambio de carril, de acuerdo con las velocidades transversales encontradas, es de 3,5 s, en lugar de los $3 \mathrm{~s}$ considerados actualmente para el cálculo de la longitud de la cuña se propone la ecuación (137) para el cálculo de la longitud de la cuña.

$$
L_{c}=3,5 \cdot V_{0}
$$

donde: 
- $\quad \mathrm{L}_{c}$ : Longitud de la cuña $(\mathrm{m})$.

- $\mathrm{V}_{0}$ : Límite de velocidad genérico de la vía $(\mathrm{m} / \mathrm{s})$.

Con el fin de facilitar la comprensión del modelo y adaptarlo a los modelos utilizados internacionalmente, se propone la longitud del carril de deceleración como la distancia entre el punto de inicio de la cuña y el punto donde la separación entre bordes de calzada del carril y la calzada principal, medida perpendicularmente al eje de ésta, sea de $1,00 \mathrm{~m}$, tal como se observa en la Figura 174

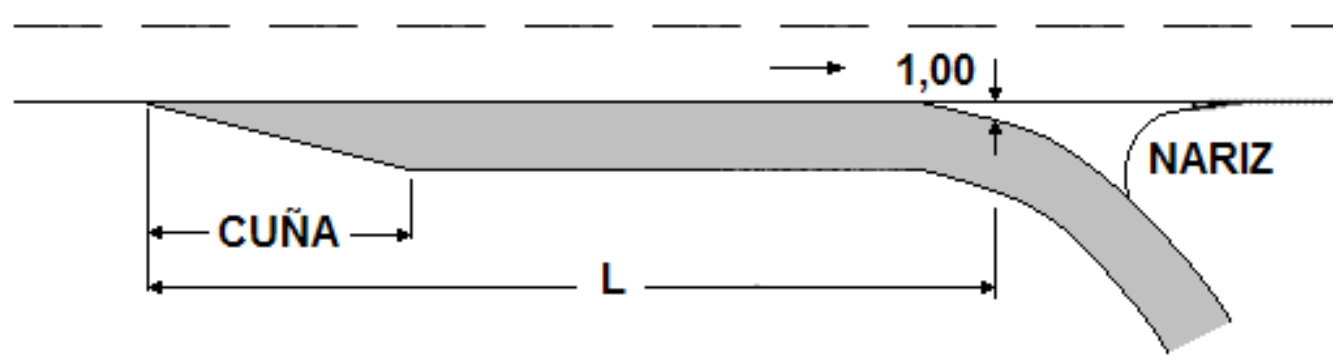

Figura 174: Secciones características del carril de deceleración paralelo

El modelo de diseño desarrollado para el cálculo de la longitud de los carriles de deceleración paralelos se compone de la suma de tres longitudes, (ecuación (138)), correspondientes al cálculo de las longitudes recorridas por los vehículos en cada una de las maniobras mencionadas, en lugar de hacer el cálculo como una única maniobra de deceleración con valores de deceleración medios y la distancia entre el inicio de la maniobra de cambio de carril y el punto de inicio de la cuña.

$$
L=P_{i c}+L d+L f
$$

donde:

- $\quad$ L: Longitud del carril de deceleración (m).

- $\quad P_{\mathrm{ic}}$ : Distancia entre el inicio de la cuña y el inicio de la maniobra de cambio de carril (m).

- $L_{d}$ : Longitud de la maniobra de cambio de carril $(m)$.

- $\quad \mathrm{L}_{\mathrm{f}}$ : Longitud de la maniobra de frenado (m).

Para el cálculo de la longitud de la maniobra de cambio de carril es necesario aplicar sucesivamente las ecuaciones (139), (140), (141), (142) y (143):

$$
P_{i c}=V_{0}
$$




$$
\begin{gathered}
V_{d d}=\operatorname{Max}\left(0,86 \cdot V_{0}, V_{n}\right) \\
t_{d}=\frac{V_{o}-V_{d d}}{0,76+i \cdot g} \\
V_{i c}=V_{d d}+(0,76+i \cdot g) \cdot 3,5 \\
L_{d}=\left\{\begin{array}{r}
L_{d}=\frac{V_{i c}{ }^{2}-V_{d d}{ }^{2}}{2 \cdot(0,76+i \cdot g)} \\
\text { si } t_{d} \geq 3,5
\end{array} t_{d}^{<3,5 \quad L_{d}=\frac{V_{0}{ }^{2}-V_{d d}{ }^{2}}{2 \cdot(0,76+i \cdot g)}+V_{0} \cdot\left(3,5-t_{d}\right)}\right.
\end{gathered}
$$

donde:

- $P_{\mathrm{ic}}$ : Distancia entre el inicio de la cuña y el inicio de la maniobra de cambio de carril (m).

- $\quad t_{d}$ : Duración de la deceleración subconsciente (s).

- $\mathrm{V}_{\mathrm{dd}}$ : Velocidad después de la deceleración (m/s).

- $\mathrm{V}_{0}$ : Límite de velocidad genérico de la vía $(\mathrm{m} / \mathrm{s})$.

- i: inclinación de la rasante (tanto por uno).

- g: aceleración de la gravedad $\left(\mathrm{m} / \mathrm{s}^{2}\right)$

- $\mathrm{V}_{\mathrm{n}}$ : Velocidad específica del elemento del carril de deceleración que contiene la sección característica de $1 \mathrm{~m}$ en la nariz $(\mathrm{m} / \mathrm{s})$.

- $\mathrm{V}_{\mathrm{ic}}$ : Velocidad al inicio de la maniobra de cambio de carril $(\mathrm{m} / \mathrm{s})$.

- $\mathrm{L}_{d}$ : Longitud de la maniobra de cambio de carril (m).

La longitud de la maniobra de frenado se obtiene de la ecuación (144):

$$
L_{d}=\frac{V_{d d}^{2}-V_{n}^{2}}{2 \cdot(2,44+i \cdot g)}
$$

donde:

- $\quad \mathrm{L}_{\mathrm{f}}$ : Longitud de la maniobra de frenado $(\mathrm{m})$.

- $V_{d d}$ : Velocidad después de la deceleración (m/s). 
- $\quad V_{n}$ : Velocidad específica del elemento del carril de deceleración que contiene la sección característica de $1 \mathrm{~m}$ en la nariz $(\mathrm{m} / \mathrm{s})$.

- i: inclinación de la rasante (tanto por uno).

- g: aceleración de la gravedad $\left(\mathrm{m} / \mathrm{s}^{2}\right)$

El caso más restrictivo en la longitud del carril es cuando el límite de velocidad en la nariz equivale al $86 \%$ del límite genérico de velocidad de la vía, donde la longitud de la maniobra de frenado sería cero. No obstante, el modelo propuesto garantiza la longitud mínima para que los vehículos efectúen la maniobra de cambio de carril de manera segura por lo que no se plantea una longitud mínima.

El modelo de diseño desarrollado da como resultado que se debe incrementar la longitud de los carriles más cortos, mientras que la longitud de los carriles más largos debería acortarse.

Valencia, a 18 de mayo de 2010

Fdo. Mario Alfonso Romero Rojas 


\section{REFERENCIAS}

AASHO (1954). "A policy on geometric design on rural highways". American Association of State Highway Officials. Washington D.C.

AASHO (1965). "A policy on geometric design on arterial highways in urban areas". American Association of State Highway Officials. Washington D.C.

AASHO (1965). "A policy on geometric design on rural highways". American Association of State Highway Officials. Washington D.C.

AASHTO (1990). "A policy on geometric design of highways and streets". American Association of State Highway and Transportation Officials. Washington D.C.

AASHTO (1994). "A policy on geometric design of highways and streets". American Association of State Highway and Transportation Officials. Washington D.C.

AASHTO (2001). "A policy on geometric design of highways and streets". American Association of State Highway and Transportation Officials. Washington D.C.

ACKROYD, L.W. (1976). "Vehicle Behaviour during Entering and Leaving Motorways". Symposium on Geometric Road Design Standards; Reports II, pp 127-155.

ACKROYD, L.W.; MADDEN, A.J. (1975). "Vehicle Speeds and Paths at Rural Diamond Roundabout Motorway Interchanges". Traffic Engineering and Control, Vol. 16, May, pp 215-219.

ALBERT, J.,(2002),"Restituciones de Perspectivas Cónicas y Fotografías Mediante Métodos Gráficos" Patrimonio Arquitectónico: Estudios Previos. Departamento de Expresión Gráfica Arquitectónica. Servicio de Publicaciones Universidad Poloitecnica de Valencia, pp 133-143.

AMUNDSEN, F., HYDEN, C., (1977). Proceedings of First Workshop on Traffic Conflicts, Institute of Transport Economics, Oslo, Noruega.

Ahmed K. I., "Modeling Drivers' Acceleration and Lane Changing Behavior", Tesis, Massachusetts Institute of Technology, EEUU, 1999.Auñón J., "Gráficos por Ordenador", Servicio de Publicaciones de UniversidadPolitécnica de Valencia, Valencia, España, 2000.

BAKER, R.F. (1975). "Handbook of Highway Engineering". Van Nostrand Reinhold, Nueva York.

B.O.E. No 21, 24 Enero (1998). "Orden de 16 de Diciembre de 1997 por la que se Regulan los Accesos a las Carreteras del Estado, las Vías de Servicio y la Construcción de Instalaciones de Servicios". Madrid.

BABKOV, V.F. (1985). "Highway Engineering". MIR. Moscú.

BARED J., GIERING, G., WARREN, D. , (1999). "Safety Evaluation of Acceleration and Deceleration Lane Lengths" ITE Journal May 1999, pg 50-54. 
BEAKY, J., (1938). Acceleration and deceleration characteristics of private passenger vehicles. Proceedings of the 18th Highway Research Board Annual Meeting, Washington, D.C., pp.81-89.

BLEYL R.,(1976). "Using Photographs to Map Traffic Accident Scenes: A Mathematical Technique", Journal of Safety Research, 8, National Safety Council and Elsevier Ltd, EEUU. C.N.R. (1983). "Norme sulle Caratteristiche Geometriche e di Traffico delle Intersezioni Stradali Urbane". Bollettino Ufficiale. N.90.

CANALE S., NICOSIA F., LEONARDI S., (1995). "Nuovi Criteri Progettuali per le Curve Stradali". Autostrade n03, pp 60-70.

CANALE S., NICOSIA F., LEONARDI S., (1997). "Inadeguatezza delle corsie di decelerazione proposte dalla Normativa CNR" Atti del convegno SIIV (Società Italiana Infrastrutture Viarie)- Roma 20/21 Febrero 1997. pp 176-204.

CANALE S., TORRISI S., NICOSIA F., LEONARDI S., (1998). "Adeguamento delle Corsie di Uscita Autostradali Mediante Informazioni Ricavate dai Rilievi Sperimentali" Atti del convegno SIIV (Società Italiana Infrastrutture Viarie) - Milan 19/20 Octubre 1998.

CHEN, H., PAN, L., BEHZADI, B y LU, J.(2008)" Impacts of exit Ramp Tipe on the Safety Performance of Freeway Diverge Areas". Actas del Transportation Research Board 2010 Annual Meeting. Washington, enero 2008.

CHEN, H.C., y QUEK, S.T. (1997). Measurement of Traffic Conflicts, Safety Science, Vol. 26, No. 3, pp.169-187

CIRILLO, J.A. (1970). "The relationship of accidents to length of speed-change lanes and weaving areas on interstate highways." Highway Research Record, Report HRR 312 pg. 17-27.

COLONNA P., DELCARMINE P., (1997). "Indicazioni progettuali, desunte da un 'indagine sperimentale, per le corsie di decelerazione in curva" Atti del convegno SIIV (Società Italiana Infrastrutture Viarie) - Roma 20/21 Febbraio 1997, pp 205-227.

COOPER, P.J., (1983). "Experience with Traffic Conflicts in Canada with Emphasis on Post Encroachment Time Techniques. In International Calibration Study of Traffic Conflicts", NATA ASI Series, Vol. F5, Springer-Verlag, Heidelberg, Germany pp.75-96.

COOPER, P.J., (1977). State-of-the-Art Report on Traffic Conflict Research in Canada. In Proceedings: First Workshop on Traffic Conflicts, Oslo, Noruega, pp.22-33

DAVIS G. A., "A Field Study of Gap Acceptance by Left-Turning Drivers", 83rd Annual Meeting of the Transportation Research Board, 2004, Washington D.C., EEUU, 2004.

DE LA IGLESIA, A y GARCÍA, A (2000). "Diseño y funcionalidad de las vías de deceleración" IV Congreso de Ingeniería del Transporte. Valencia, pp 459-466.

DIRECTORAGE GENERAL FOR ENERGI AND TRANSPORT- EUROPIAN COMISSION (2009). EU "Energi and transport in figures, Statistical Pocked Book", Bruselas,pp 173177. 
FAZIO J., MICHAELS R.M. (1989). "Driver Behavior Model of Merging". T.R.R. 1213, pp 4-10.

FAZIO J., MICHAELS R.M. (1990). "Behavioral Model of Freeway Exiting". T.R.R. 1281 pp 16.-27

FHWA (2003) "Surrogate Safety Measures from Traffic Simulation Models", Final Report, Publication No FHWA-RD-03-050, Federal Highway Administration, USA

FITZPATRICK, K., CHRYSLER, S.y BREWER, M. (2010)."Deceleration Lengths for Exit terminals".Actas del Transportation Research Board 2010 Annual Meeting. Washington, enero 2010.

FUKUTOME I., MOSKOWITZ K. (1963). "Traffic Behavior and Off-Ramp Design". HRR 21, pp 17-31.GIL SAURI M. A., "Geometría Aplicada", Editorial Ciencia 3, Valencia, España, 1997.

GULLY, S.M., WHITNEY, D.J., and VANOSDALL, F.E. (1995). "Prediction of Police Officers Traffic Accident Involvement Using Behavioral Observations, Accident Analysis and Prevention", Vol. 27, pp.355-362

GRAYSON, G.B., y HAKKERT, A.S. (1987). Accident Analysis and Conflict Behaviour, In J. Rotherngatter and R.A. de Bruine (Eds.) Road-user and Trafic Safety, pp 27-59. Van Gorcum

GRAYSON, G.B., HYDEN, C., KRAAY, J.H., MUHLRAD, N y OPPE, S. (1984). The Malmö Study. A Calibration of Traffic Conflict Techniques. Institute for Road safety research (SWOV),

HAUER, E. (1979). Methodological Assessment of the Techniques. In Proceedings of the Second Internacional Traffic Conflict Technique Workshop, Paris, Francia, pp.169176.

HAUER, E., y GARDER, P. (1986). Research into the Validity of the Traffic Conflict Technique, Accident Analysis and Prevention, Vol 18., No. 6, pp.471-481

HAYWARD, J., (1972). Near miss determination through use of a scale of danger. Report No. TTSC 7715, Pennsylvania State University, Penn., USA.

HYDEN, C. (1987). The Development of a Method for Traffic Safety Evaluation: The Swedish Traffic Conflicts Technique. Bulletin 70, Dept. of Traffic Planning and Engineering, Lund University, Lund, Suecia

HYDÉN, C. (1996). "Traffic Conflicts Technique: State-of-the-art". In: Topp H.H. (Ed.), (1996). Traffic Safety Work with Video-Processing. University Kaiserslautern. Transportation Department.

HYDEN, C., GARDER, P., y LINDERHOLM, L. (1982). An Updating of the use of Further Development of the Traffic Conflicts technique. In Proceedings of the Third International Workshop on Traffic Conflicts Techniques, Leidschendam, Holanda, pp.42-49 
JANSON B.N., AWAD W., ROBLES J., KONONOV J., PINKERTON B. (1998). "Truck Accidents at Freeway Ramps: Data Analysis and High-Risk Site Identifications". Journal of Transportation and Statistics, Vol. 1, No 1, pp 75-92.

JOUZY N. C., MICHAEL H.L. (1963). "Use and design of Acceleration and Deceleration Lanes in Indiana". HRR no 9, pp 25-51.

KOEPKE F.J. (1993). "Ramp Exit/Entrance Design-Taper versus Paralel and Critical Dimensions". T.R.R. 1385, pp 126-132.

KRAEMER, C., PARDILLO J.M, ROCCI, S, ROMANA M.G., SANCHEZ, V., del VAL, M.A. (2003). "INGENIERIA DE CARRETERAS". Madrid

LIVNEH, M.,POLUS, A., , FACTOR, J. (1988). "Vehicle Behavior on Deceleration Lanes". Journal of Transportation Engineering, Vol. 114, No 6. Noviembre, pp 706-717.

LOUTZENHEISER, D.W.,(1938)"Speed Change Rates of Passenger Vehicles". Memorial del $18^{\circ}$ Highway Research Board Annual Meeting. Washington D.C., pp 90-99

LUNDY R.A. (1967). "The Effect of Ramp Type and Geometry on Accidents". Highway Research Record 163, pp 80-119.

MICHAELS, R. M., and COZAN, L. W. (1963). "Perceptual and field factors causing lateral displacement " Highway Research Record, 25.Washington D.C.

MIGLETZ, D.J., GLAUz, W.D. y BAUER, K.M. (1985) Relationships between Traffic Conflicts and Accidents. Report No: FHWA/RD-84/042. US Department of Transportation, Federal Highway Administration.

MINDERHOUD, M. M., and BOVY, P. H. L., (2001) Extended Time-to-Collision Measures for Road Traffic Safety Assessment, Accident Analysis and Prevention, Vol 33.

MINISTERIO DE FOMENTO (1999). "Norma 3.1-IC Trazado, de la Instrucción de Carreteras". Madrid.

MINISTERIO DE FOMENTO, (1987). Norma 8.3.-IC "Señalización de Obras" Madrid.

MINISTERIO DE OBRAS PÚBLICAS (1964). Norma 3.1-IC. Instrucción de Carreteras:"Trazado". Madrid.

MINISTERIO DE OBRAS PÚBLICAS (1968). "Recomendaciones para el Proyecto de Enlaces". Madrid.

MINISTERIO DE OBRAS PÚBLICAS (1968). "Recomendaciones para el Proyecto de Intersecciones". Madrid.

OPPE, S. (1986). Evaluation of Traffic Conflict Techniques. In Proceeding of the Workshop on Traffic Conflicts and Other Intermediate Measures in Safety Evaluation, Budapest.

OLSON, P., CLIVELAN, D., FANCHER, P., KOSTYNIUK, L.y SCHNEIDER, L.,(1984)"Parameters Affecting Stopping Sieht Distance". National Cooperative Higway Researche Program, Transportation Research Board, National Research Council. Washintong D.C. Report 270 
PARK, B., FITZPATRICK, K. y LORD, D. (2010)."Evaluating the Effects of Freeway Design Elments on Safety". Actas del Transportation Research Board 2010 Annual Meeting. Washington D.C. Enero 2010.

PERKINS, S.R., y HARRIS, J.I. (1967). Criteria for Traffic Conflict Characteristics. Report GMR632, Warren, MI, General Motors Corporation.

PERKINS, S.R., y HARRIS, J.I. (1968). Traffic Conflict Characteristics: Accident potential at intersections. Highway Research Record, Vol. 225, pp. 45-143, Highway Research Board, Washington D.C.

REILLY W., PFEFER R., MICHAELS M., POLUS A., SCHOEN J., (1989). "Speed-Change Lanes User Design Guidelines" NCHRP Report 3-35 Washington, D.C.

RIOUX, T. (1977) "The development of the Texas traffic intersection simulation package". Tesis Doctoral, Universidad de Texas.

ROCCI S. (1988). "Hacia una Norma de Trazado". Carreteras, no 34, mayo-junio, pp 717.

ROCCI, S. (1993). "Libro Blanco sobre Velocidad, Visibilidad y Adelantamientos", Euroconsult S.A. Madrid.

SARHA, M., HASSAN, Y., y EL HALIM, A.,(2006). "Design of Freeway Speed Chance Lanes: Safety- Explicit Approach". Actas del Transportation Research Board 2010 Annual Meeting. Washington D.C. enero 2006.

SVENSSON, A. (1992). Vidareutveckling och Validering av Den Svenska Konflikttekniken (Eng. Further Development and Validation of the Swedish Traffic Conflicts Technique). Dept. of Traffic Planning and Engineering, Lund University, Lund, Suecia

T.R.B. (1997). "Determintion of Stopping Sight Distance", NCHRP Report 400. Washington, D.C. TOPP, H.H. (Ed.), (1998). "Traffic Safety Work with VideoProcessing". University Kaiserslautern. Transportation Department, 1998, Green Series No.43, Kaiserslautern, Alemania.

TWOMEY J.M.; HECKMAN M.L.; HAYWARD J.C.; ZUK R. (1993). "Accidents and Safety Associated with Interchanges". Transportation Research Record 1385, pp 100-105.

UNO, N., IIDA, Y., ITSUBO, S. and YASUHARA, S., 2002. "A Microscopic Analysis of Traffic Conflict Caused by Lane-Changing Vehicle at Weaving Section. Proceedings of The $13^{\text {th }}$ Mini-Euro Conference" Handling Uncertainty in Transportation Analysis of Traffic and Transportation Systems, 143-148.

VAN DER HORST, R., and Kraay, J. (1986). "The Dutch Conflict Observation Technique" - DOCTOR.Proceedings of Workshop - Traffic Conflicts and Other Intermediate Measures in Safety Evaluation, Budapest.

VÁRHELYi, A. (1996). "Dynamic Speed Adaptation Based on Information Technology "A Theoretical Background, Bulletin 142, Dept. of Traffic Planning and Engineering, Lund University, Lund, Suecia. 
VIGUERAS J. F; GARAGORRI J. R.; CRESPO DEL RÍO R., (1992). "La Adherencia Neumático-Pavimento". Carreteras, n059, mayo-junio, pp.6-25.

WÅHLBERG (2000) "The reliability of g-force, and replication of its relation of bus accidents". KFB-rapport 2000:59, Estocolmo, Suecia.

WAKABAYASHI, H. y RENGE, K. (2003). "Traffic Conflict Analysis using Vehicle Tracking System with Digital VCR and New Conflict Indicator under High Speed and Congested Traffic Environment". Proceedings of the $19^{\text {th }}$ Dresden Conference on Traffic and Transportation Sciences, "Mobility and Traffic Management in a Networked World", CDROM (43.1-43.17).

WAKABAYASHI, H. y MURAMATSU, S. (2007). "Traffic Conflict Analysis using a Vehicle Tracking System with Digital VCR: Proposal of PTTC Indicator". $11^{\text {th }}$ World Conference on Transport Research Berkeley, California.

WEI, H., FENG, C., MEYER, E. Y LEE, J. (2005). "Video-Capture-Based Approach to Extract Multiple Vehicular Trajectory Data for Traffic Modeling," Jountal of Transportation Engeneering, Vol. 131, No. 7, pp. 496-505.

WILLIAMS, J. (1981). Validity of the Traffic Conflict Techniques. Accident Analysis and Prevention, Vol. 13, pp.133-145 (programa informático Mathematica ${ }^{\circledR}$, desarrollado por Wolfram Research.)

ZHOU, H., CHEN, H., ZHAO, J. y HSU, P.(2010)" Operational and Safety Performance of Left-Side Off-Ramps at Freeway Diverge Areas". Actas del Transportation Research Board 2010 Annual Meeting. Washington D.C., enero 2010.

ZIMOLONG, B., GSTALTER, H., y ERKE, H. (1980). Traffic Conflicts at Urban Junctions - Reliability and Validity Studies. Institute of Psychology, University of Technology, Brunswick, Alemania. 
ANEXO NO. 1. I NVENTARIO DE MANI OBRAS EN LOS CARRI LES DE DECELERACIÓN 


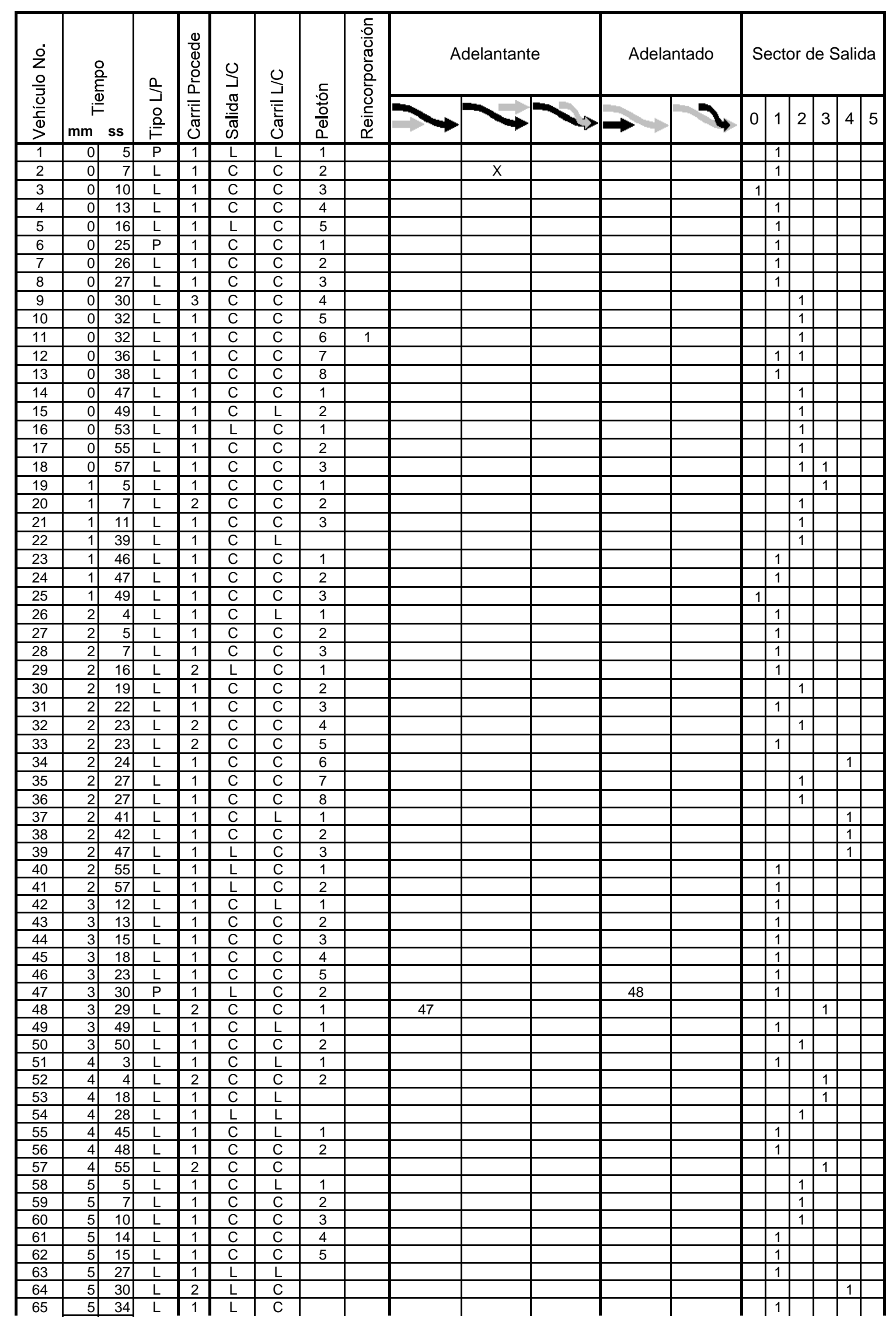




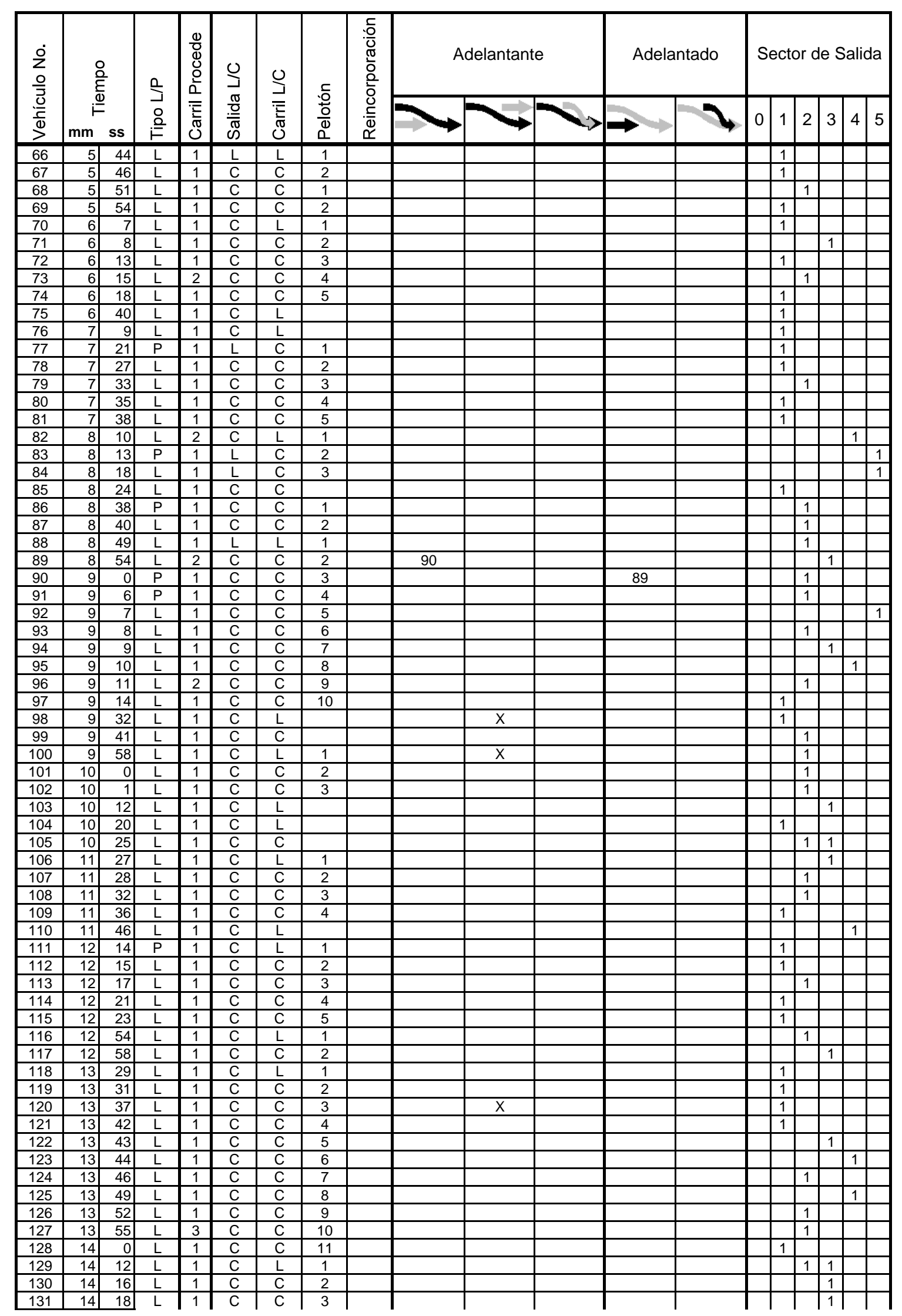




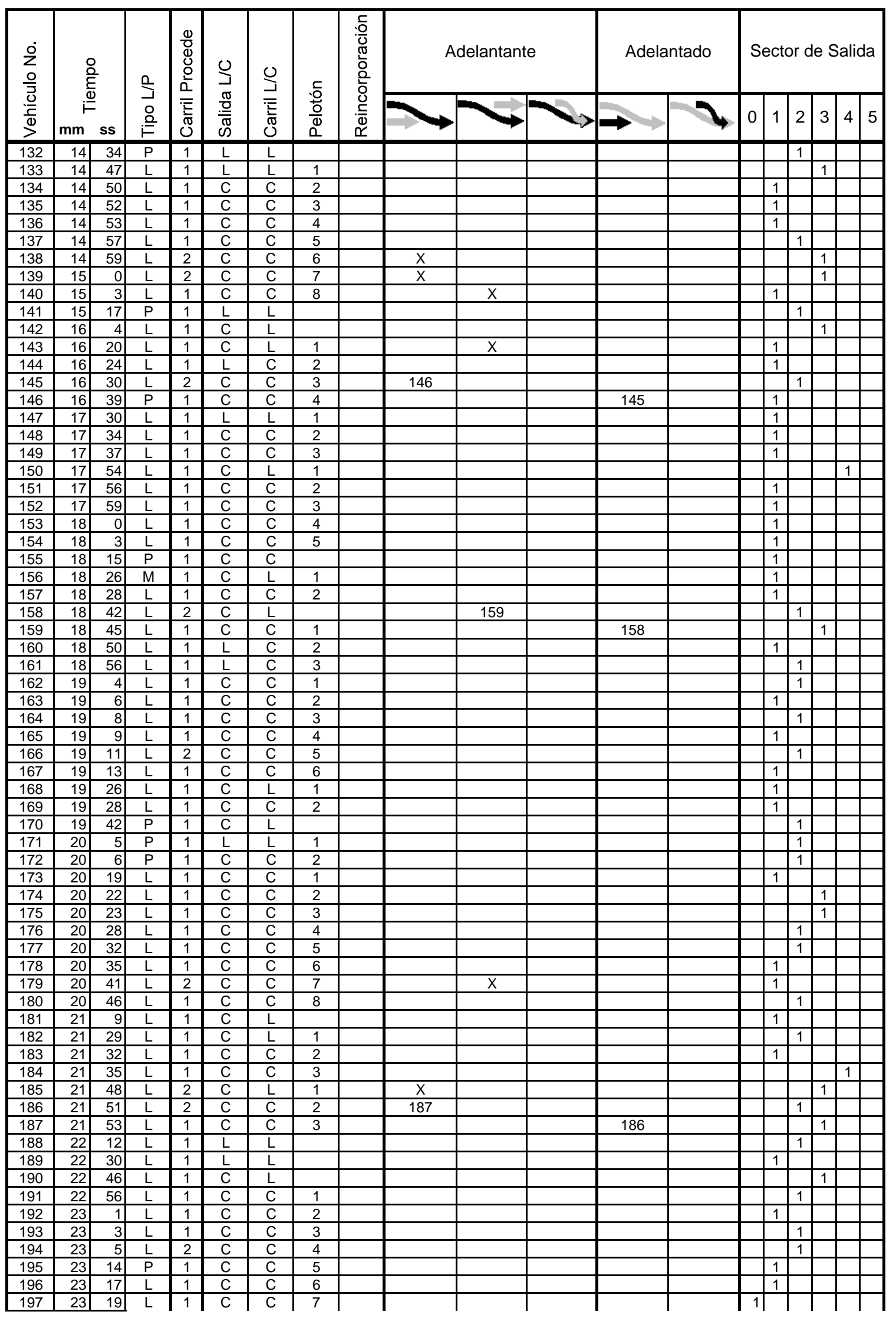




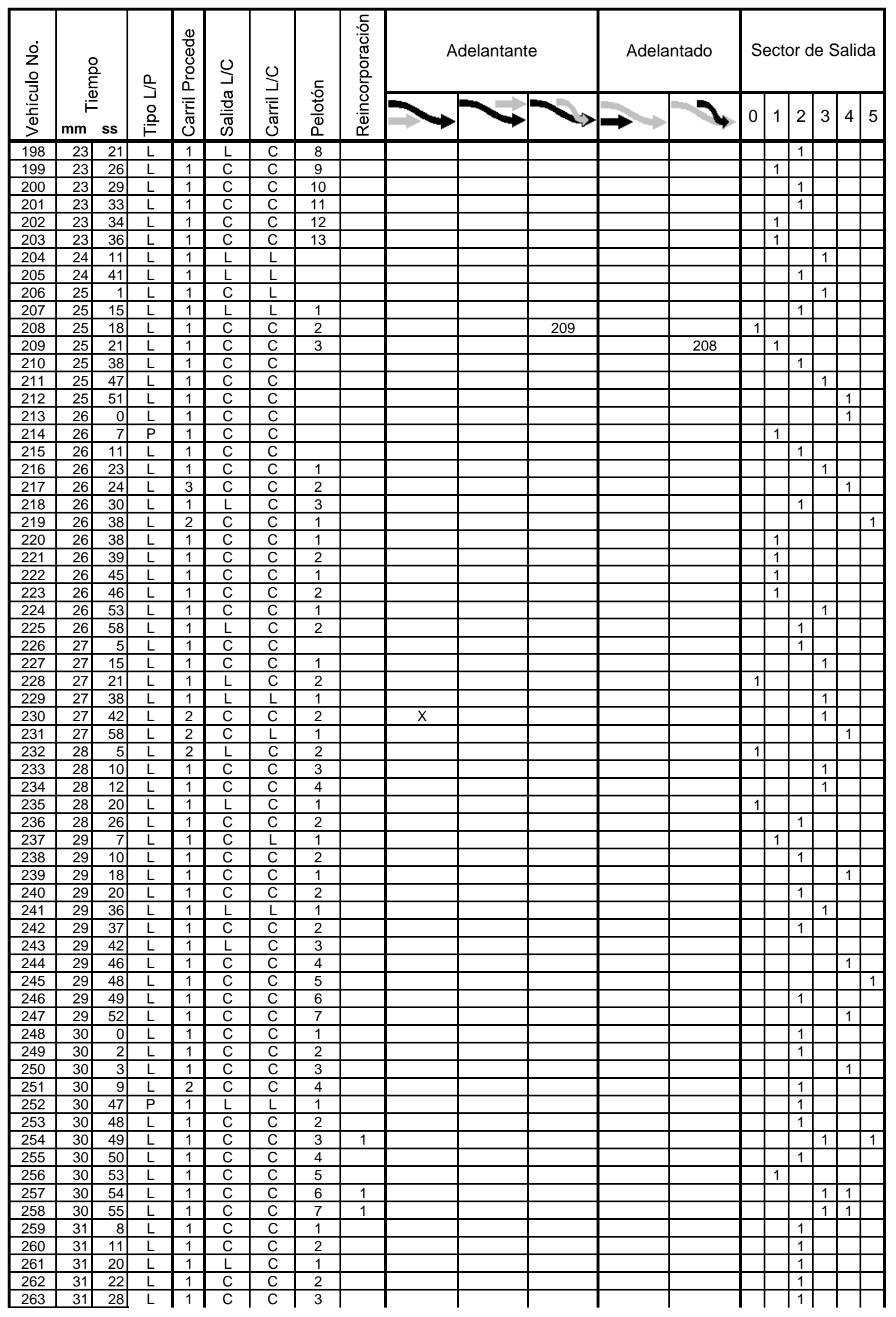




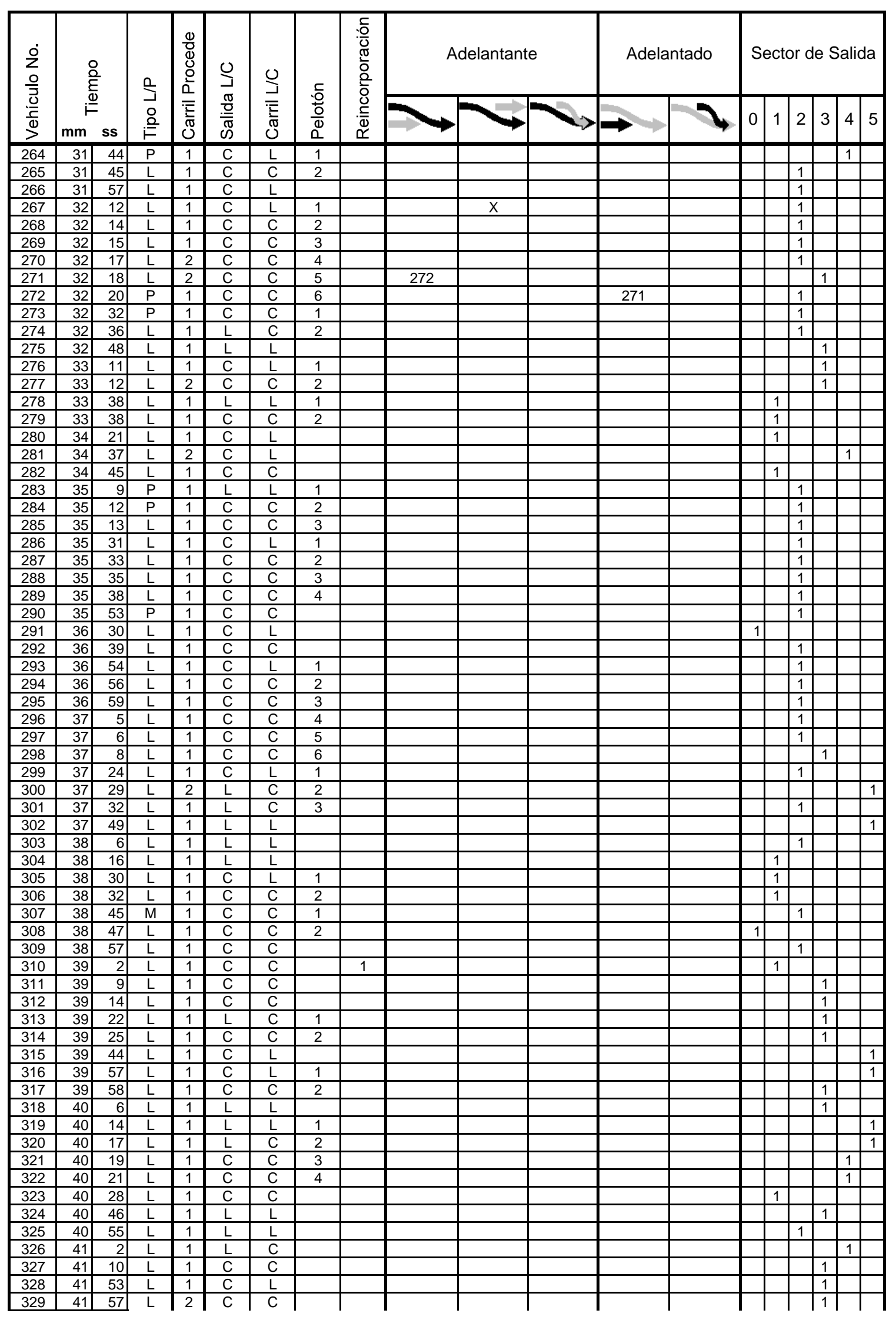




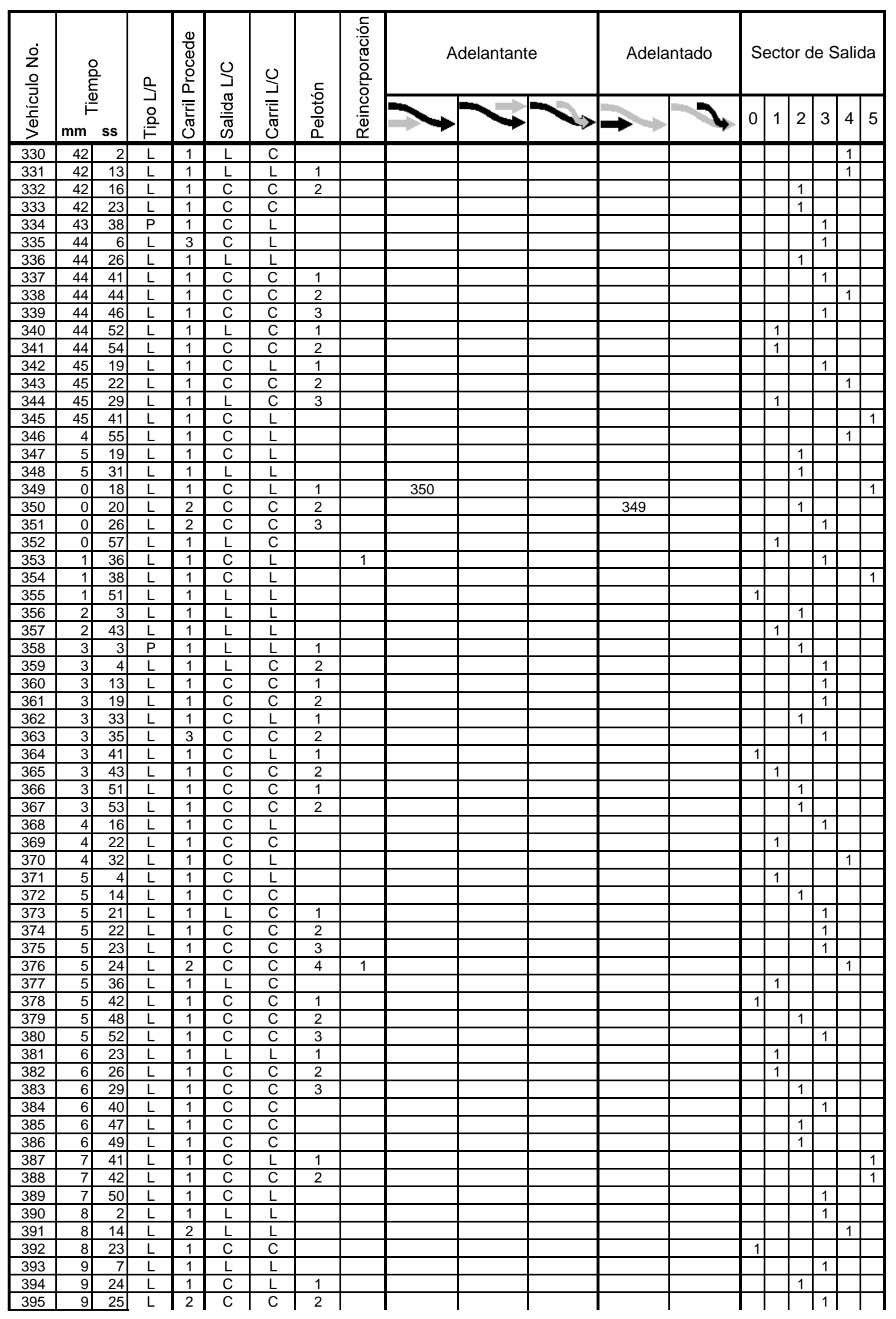




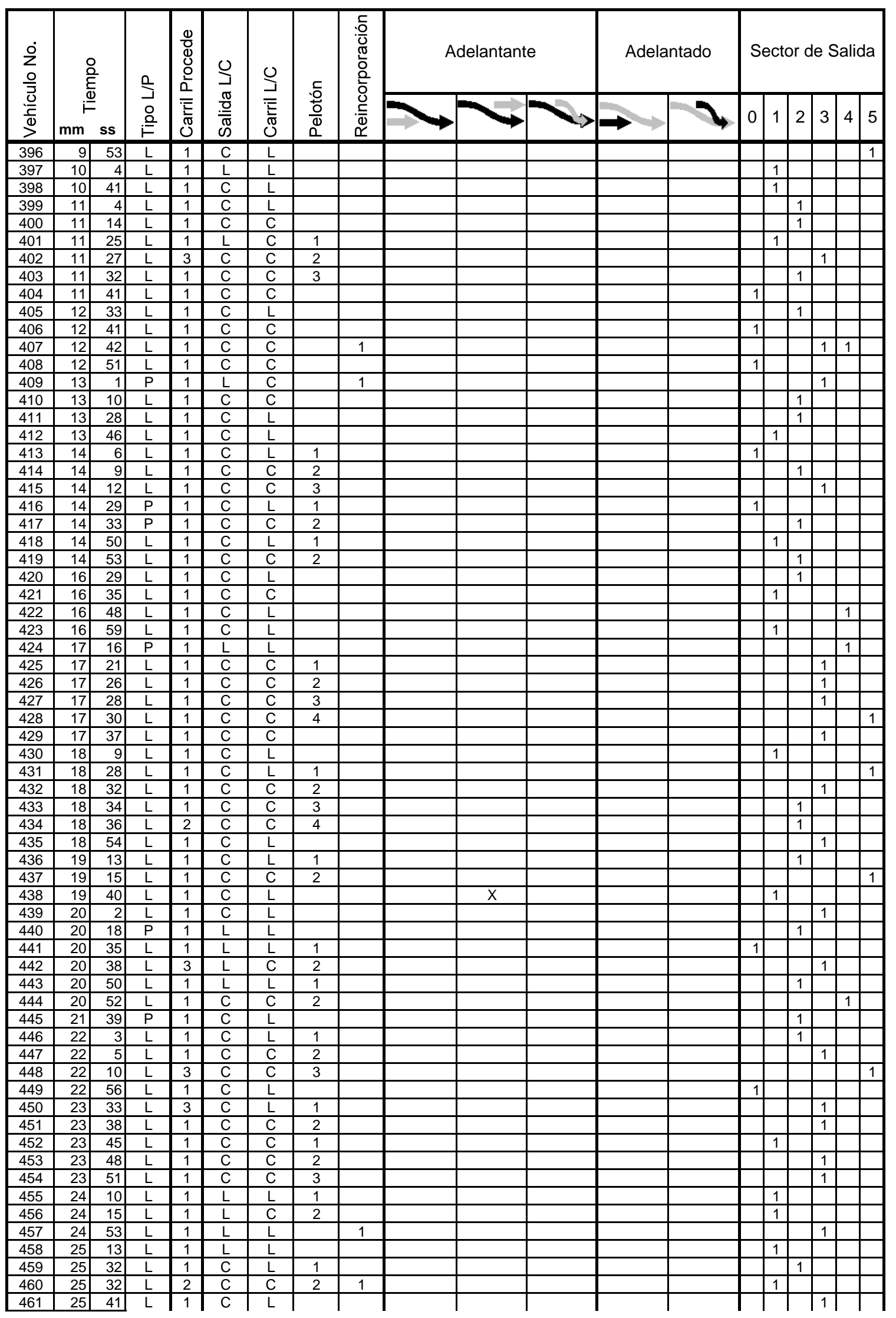




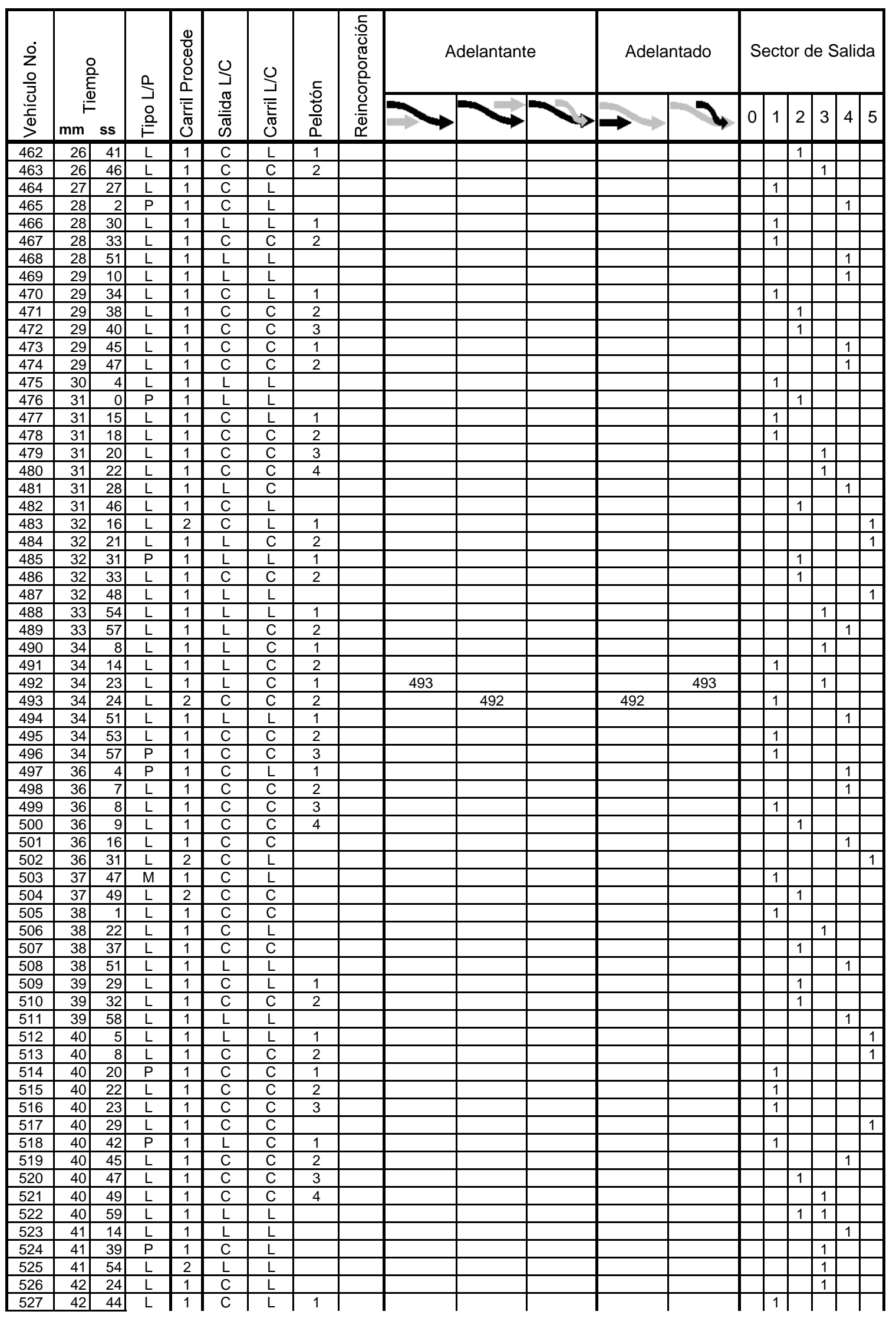




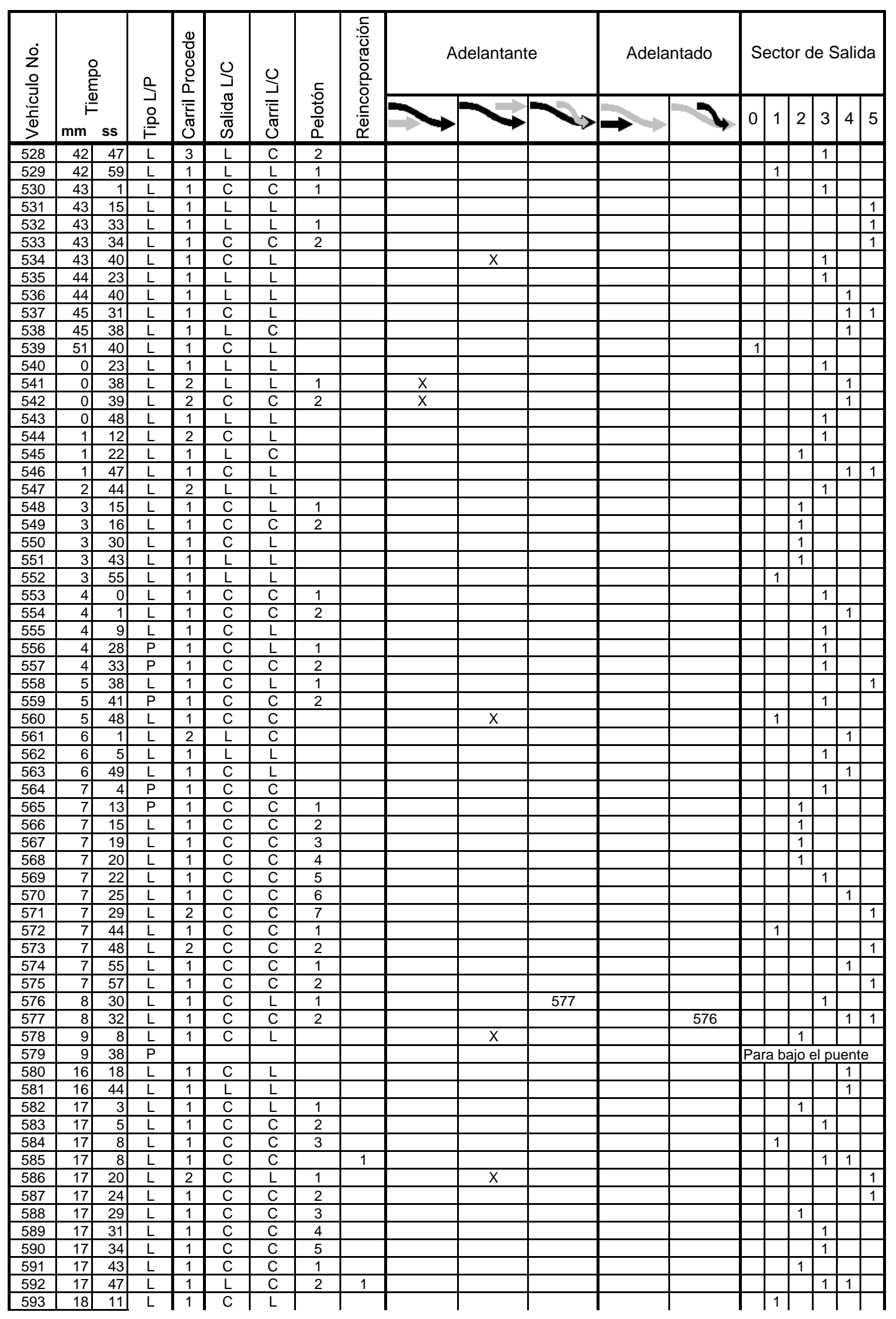




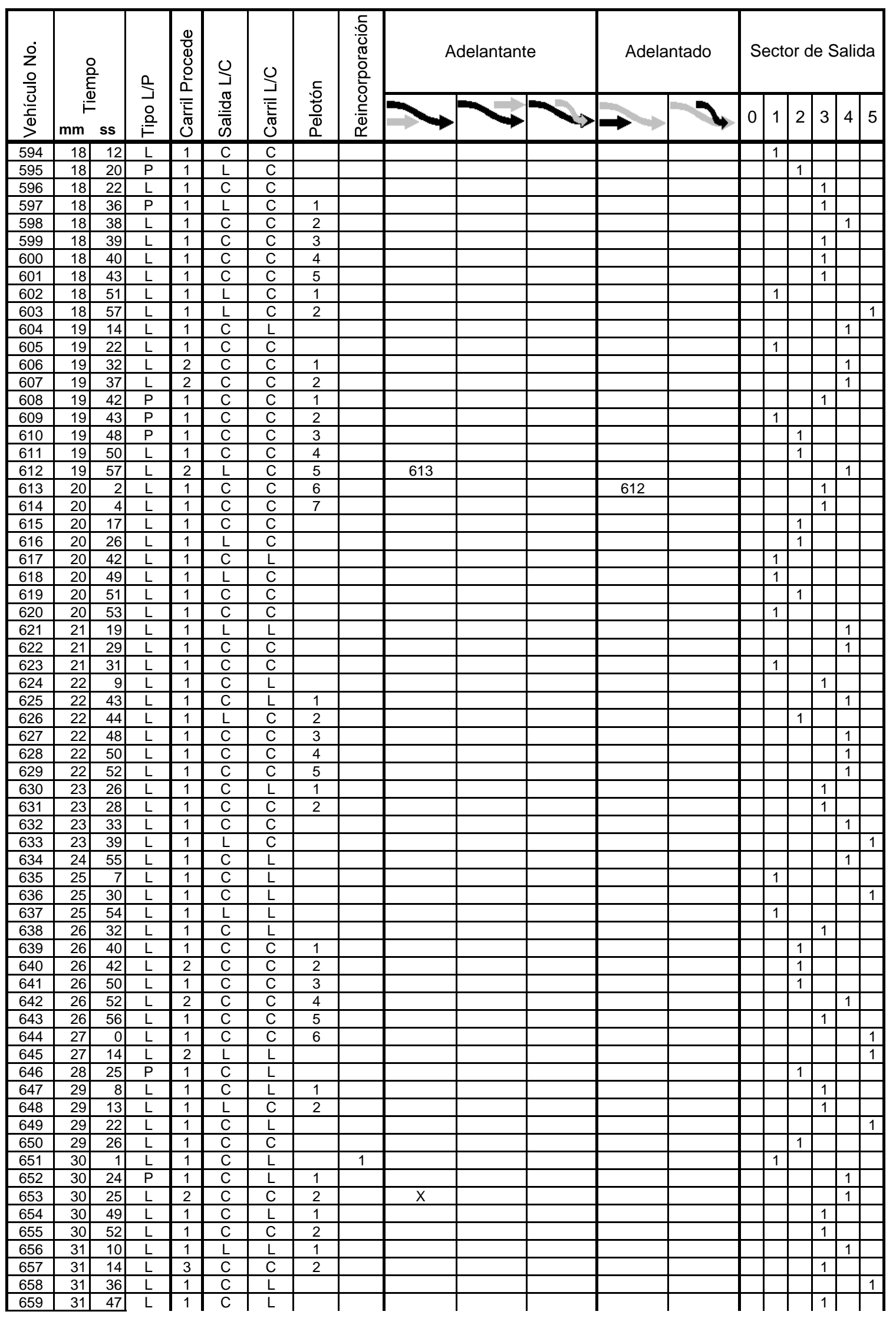




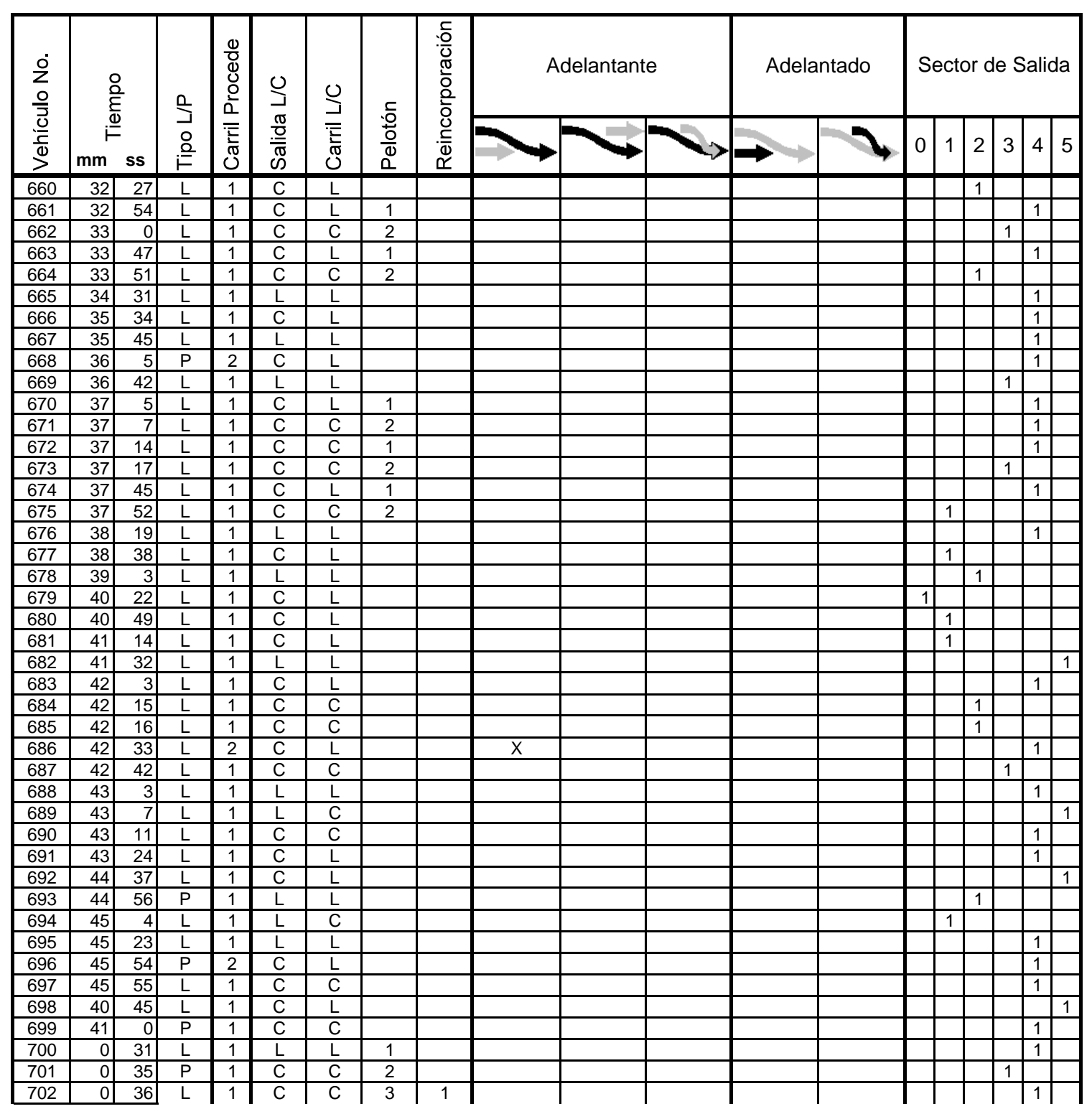




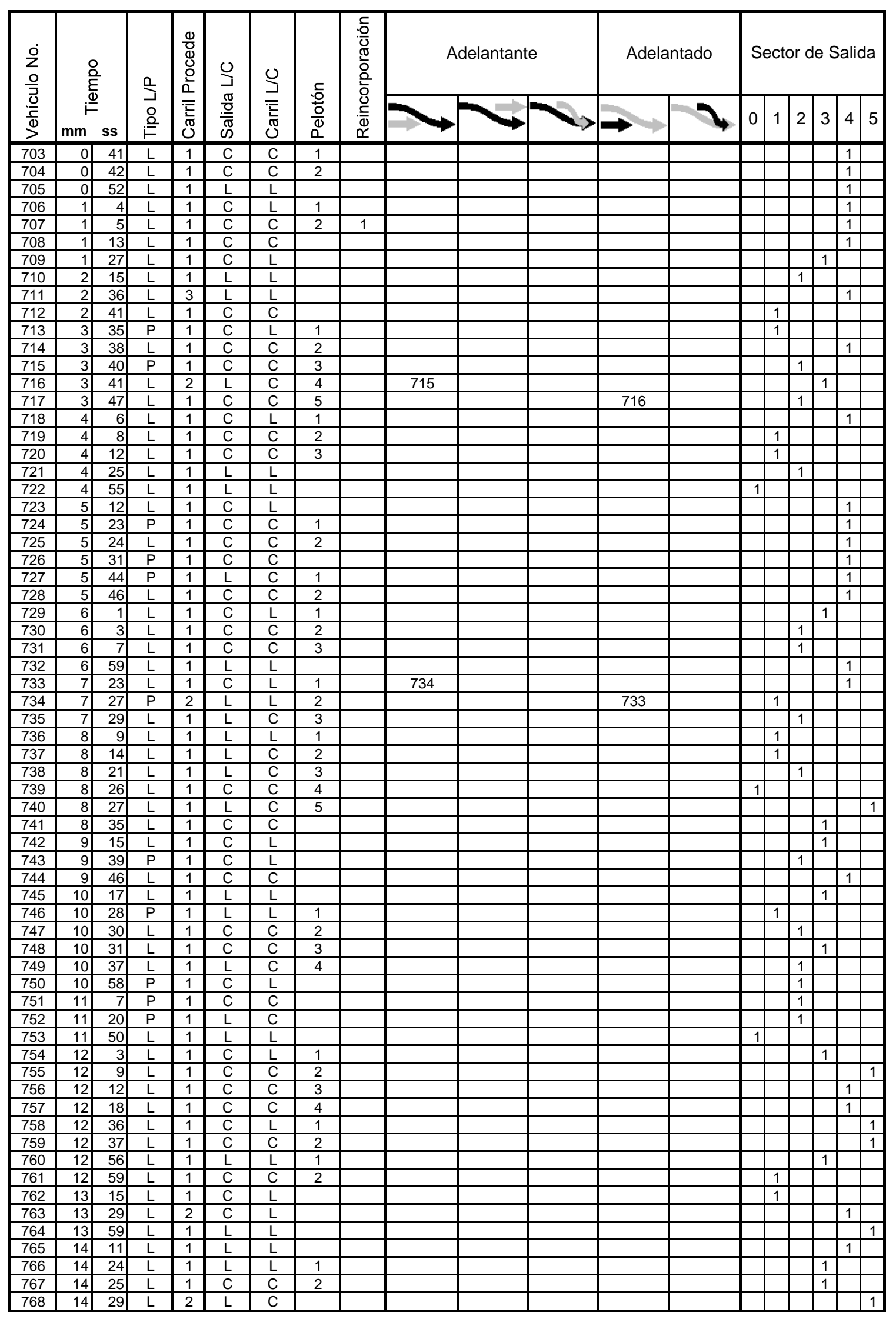




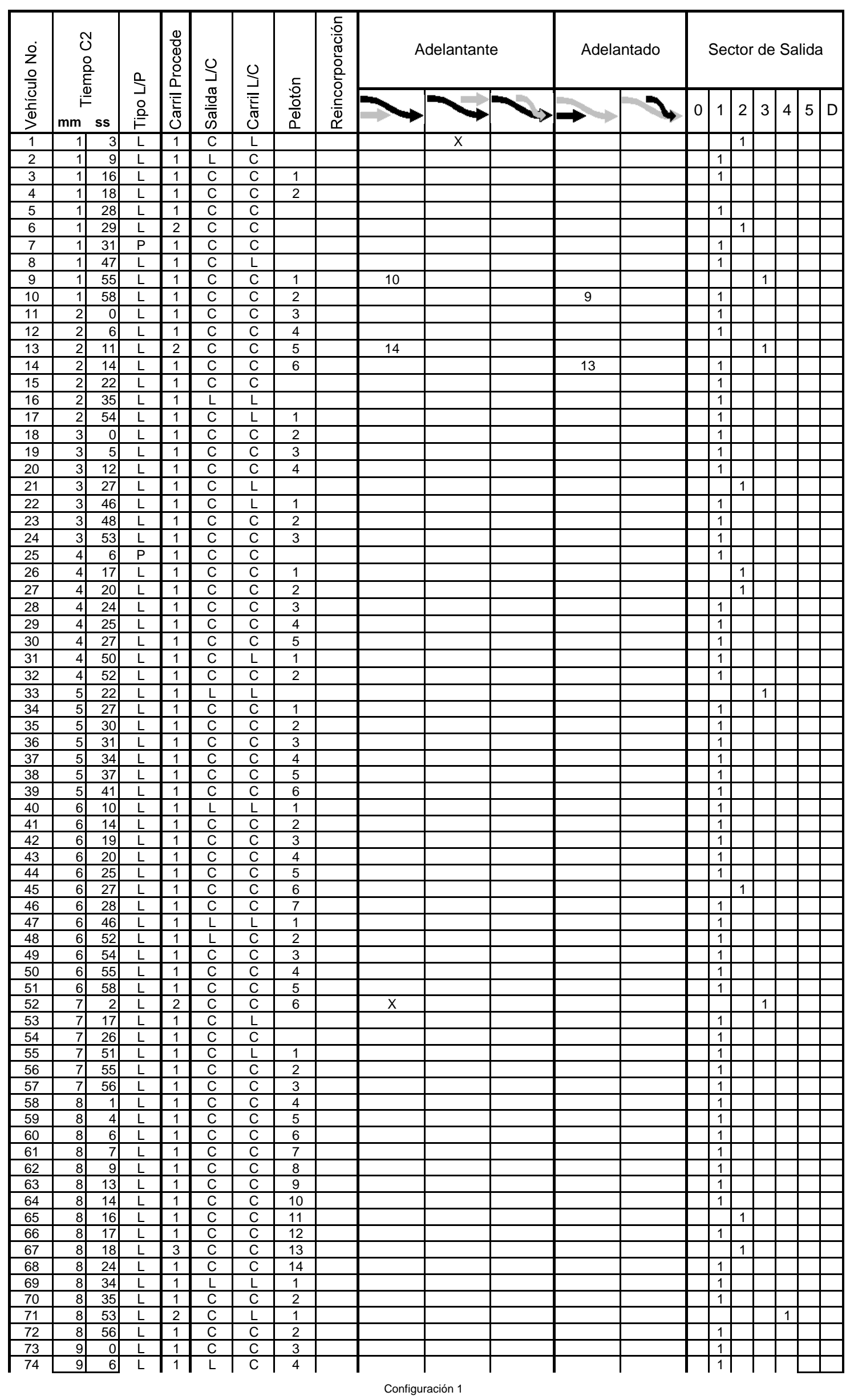




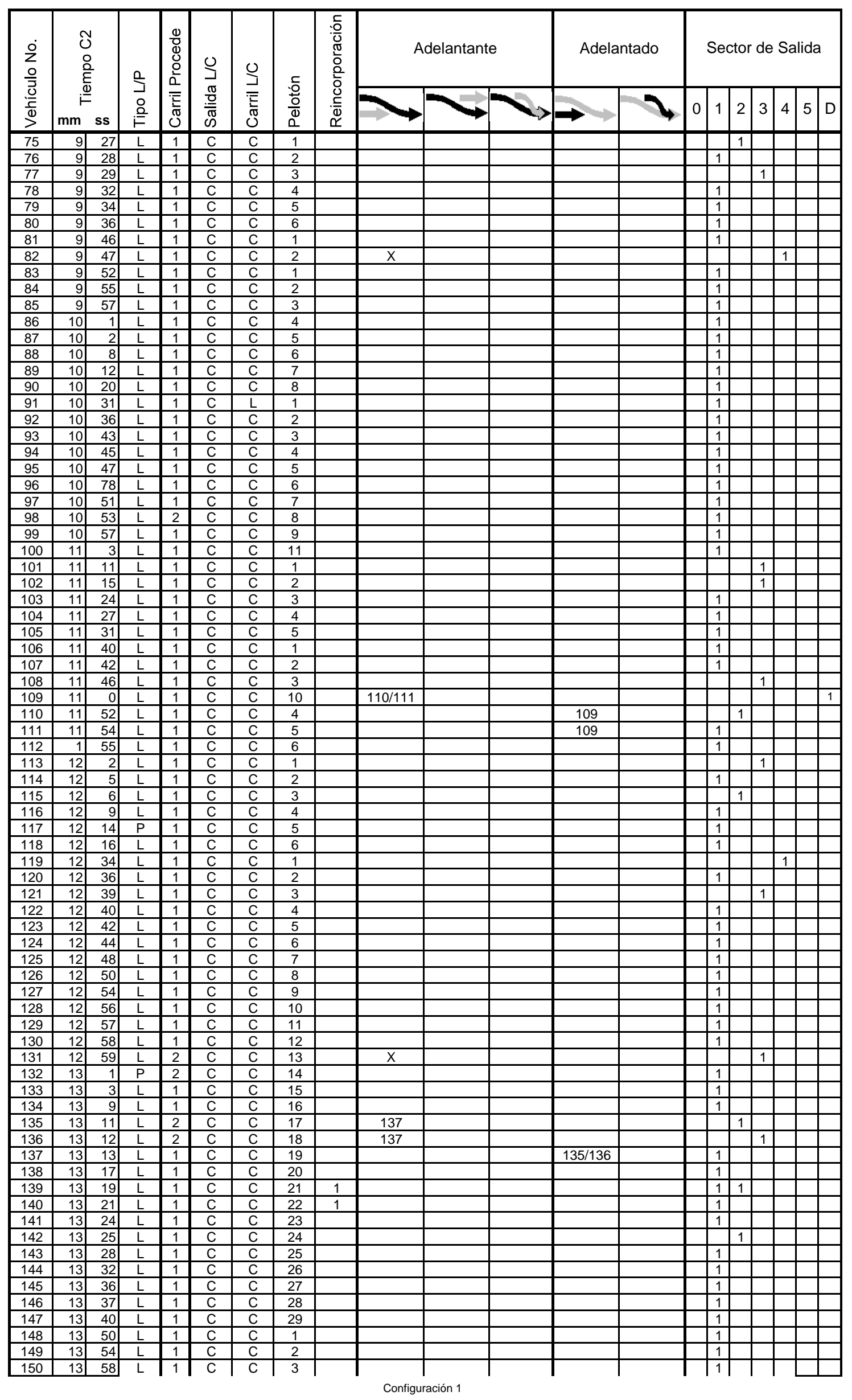




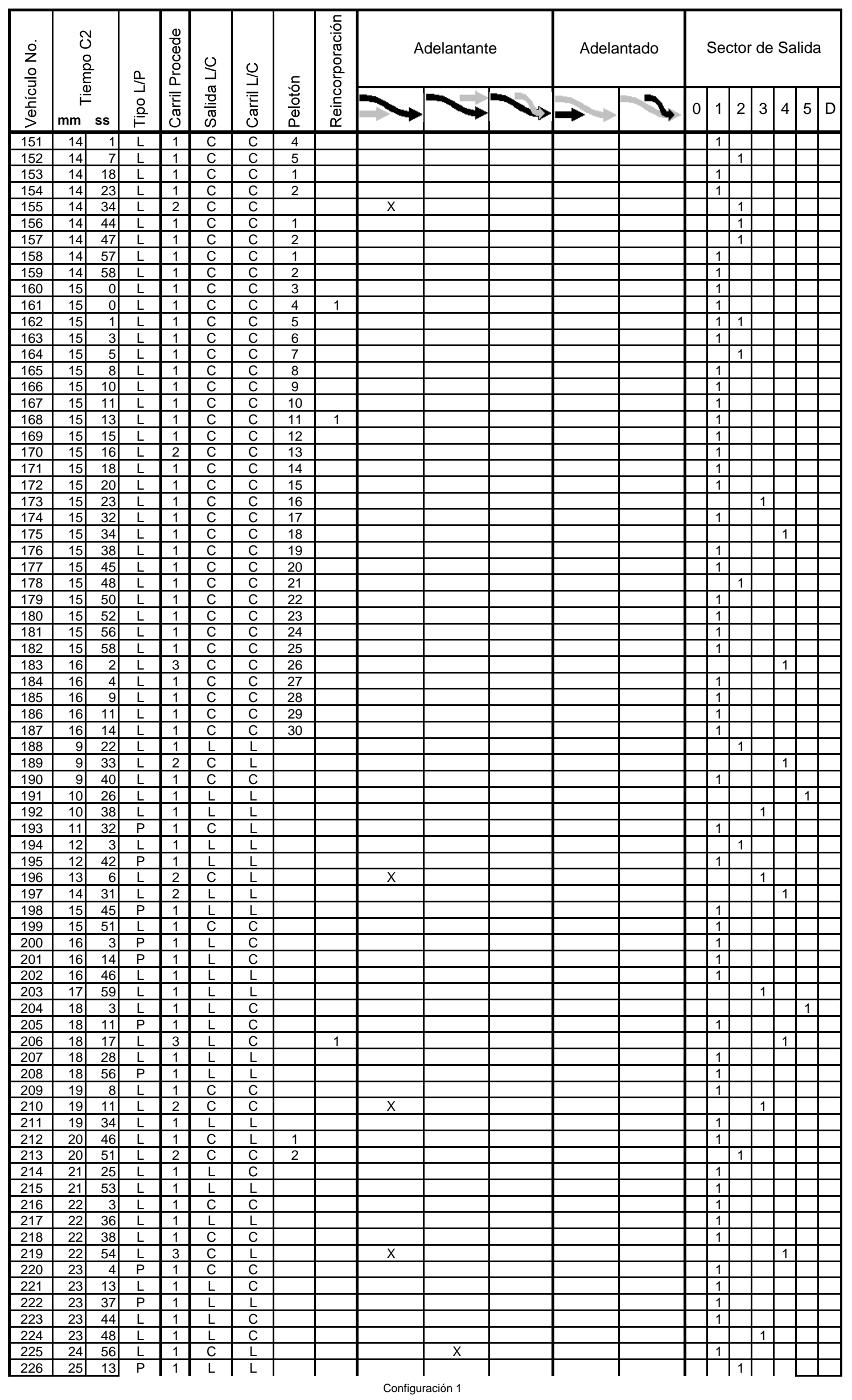




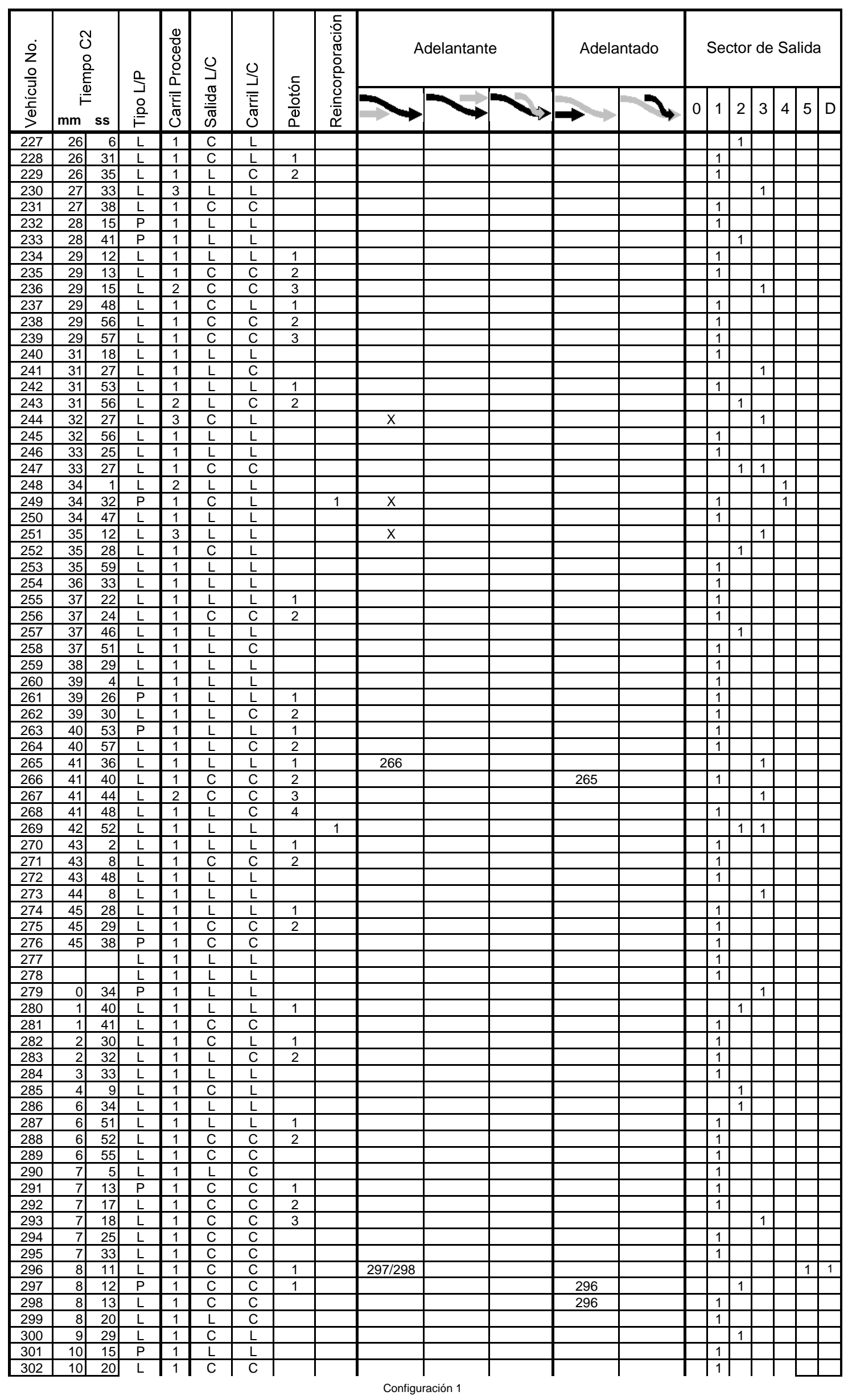




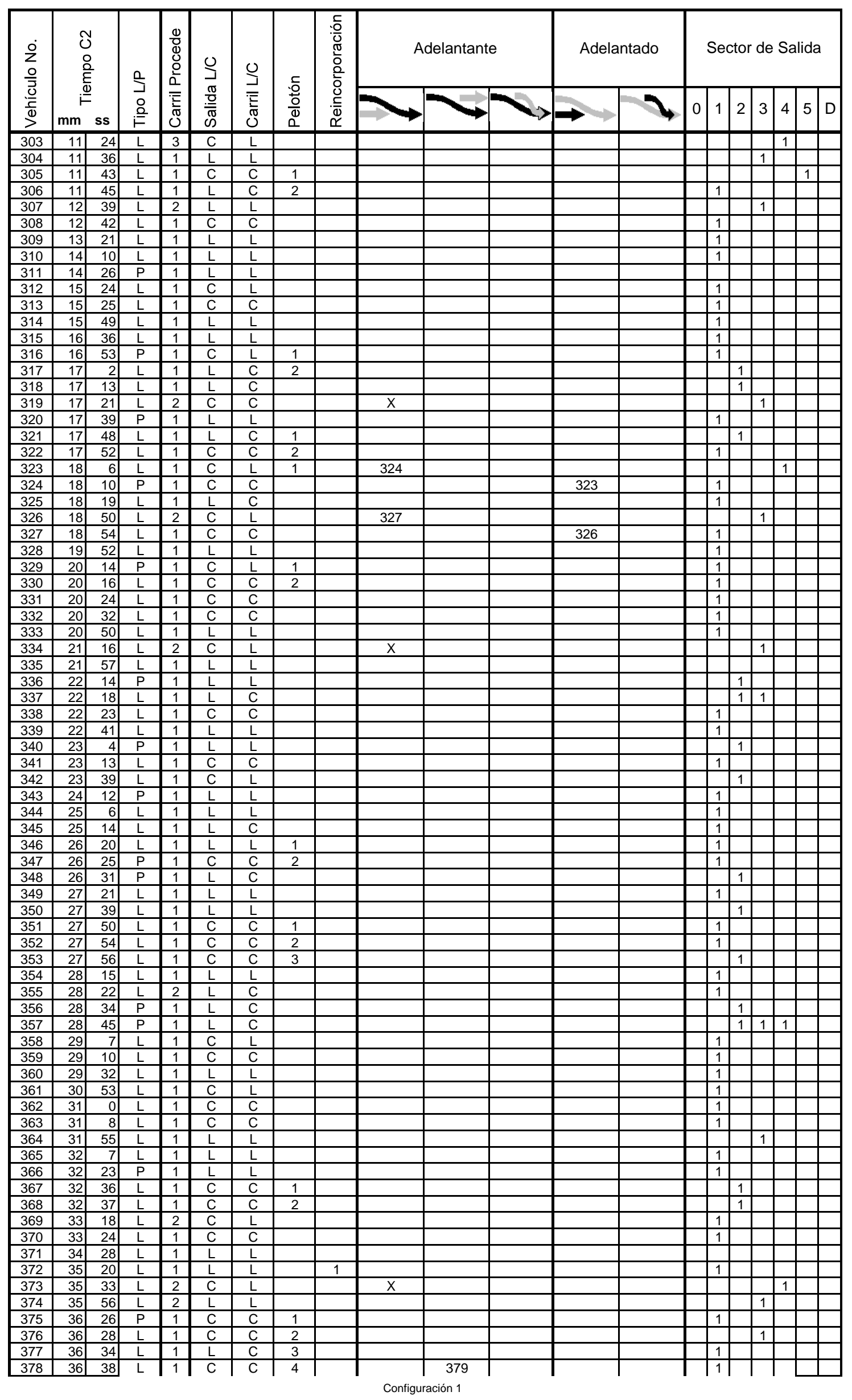




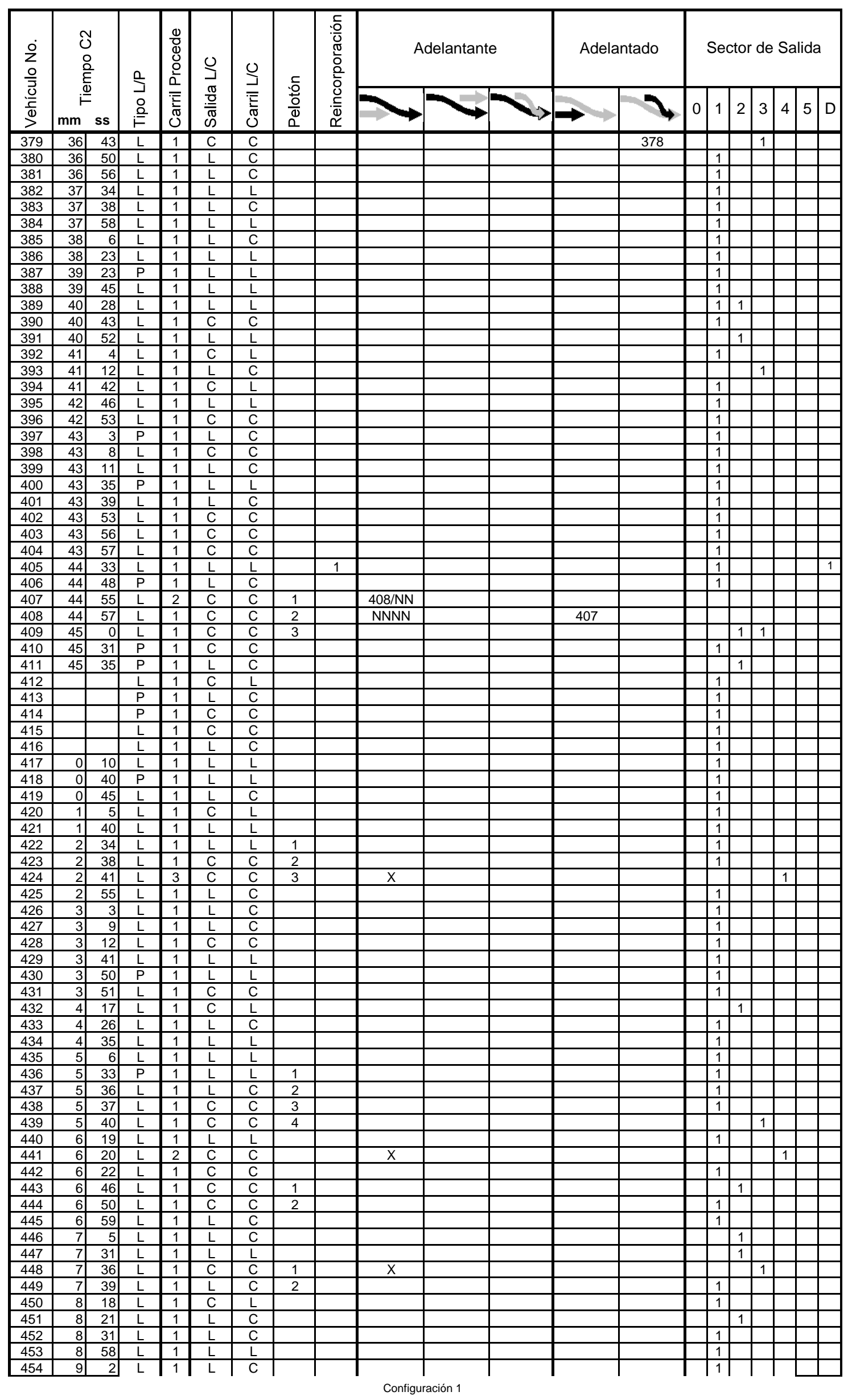




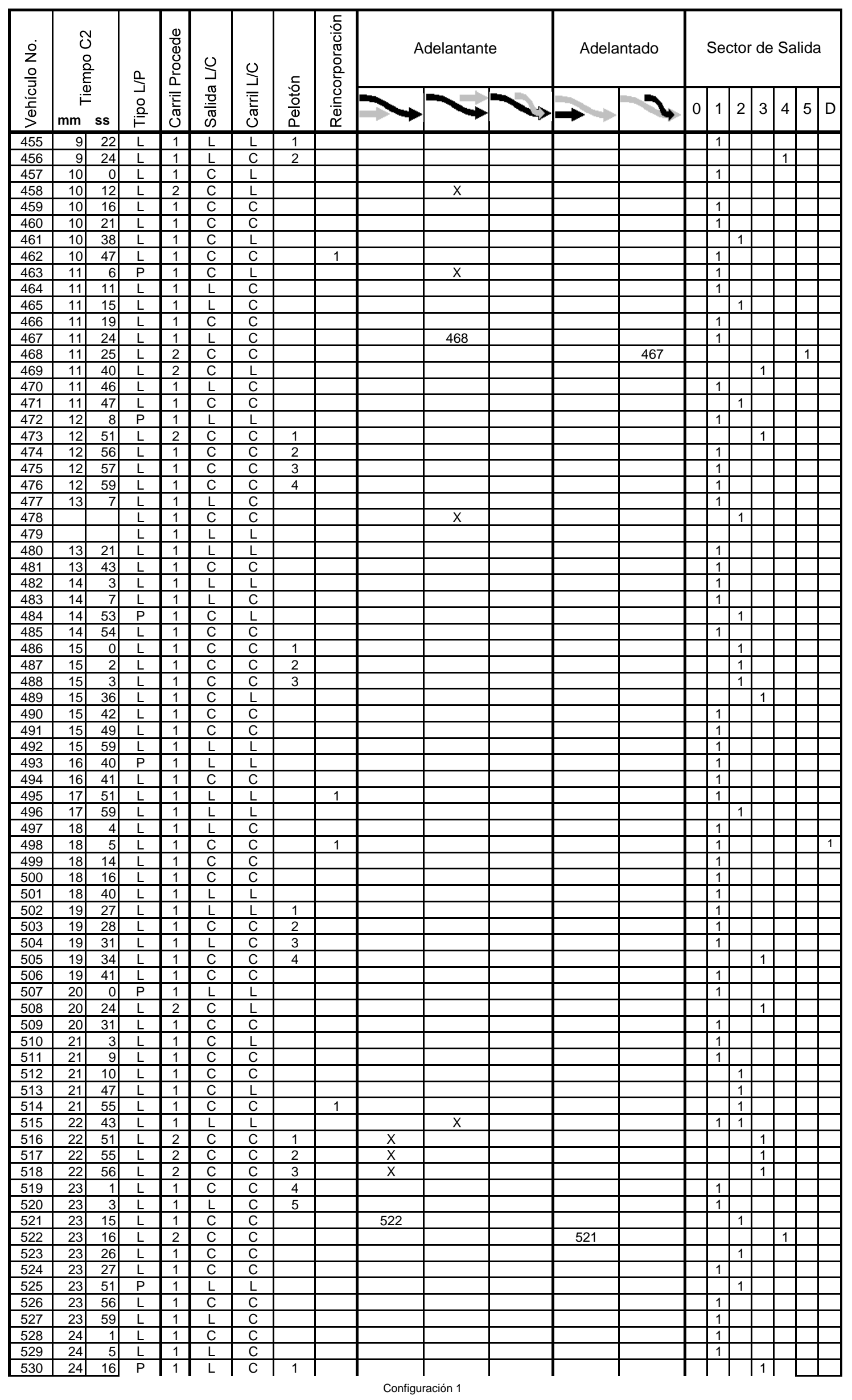




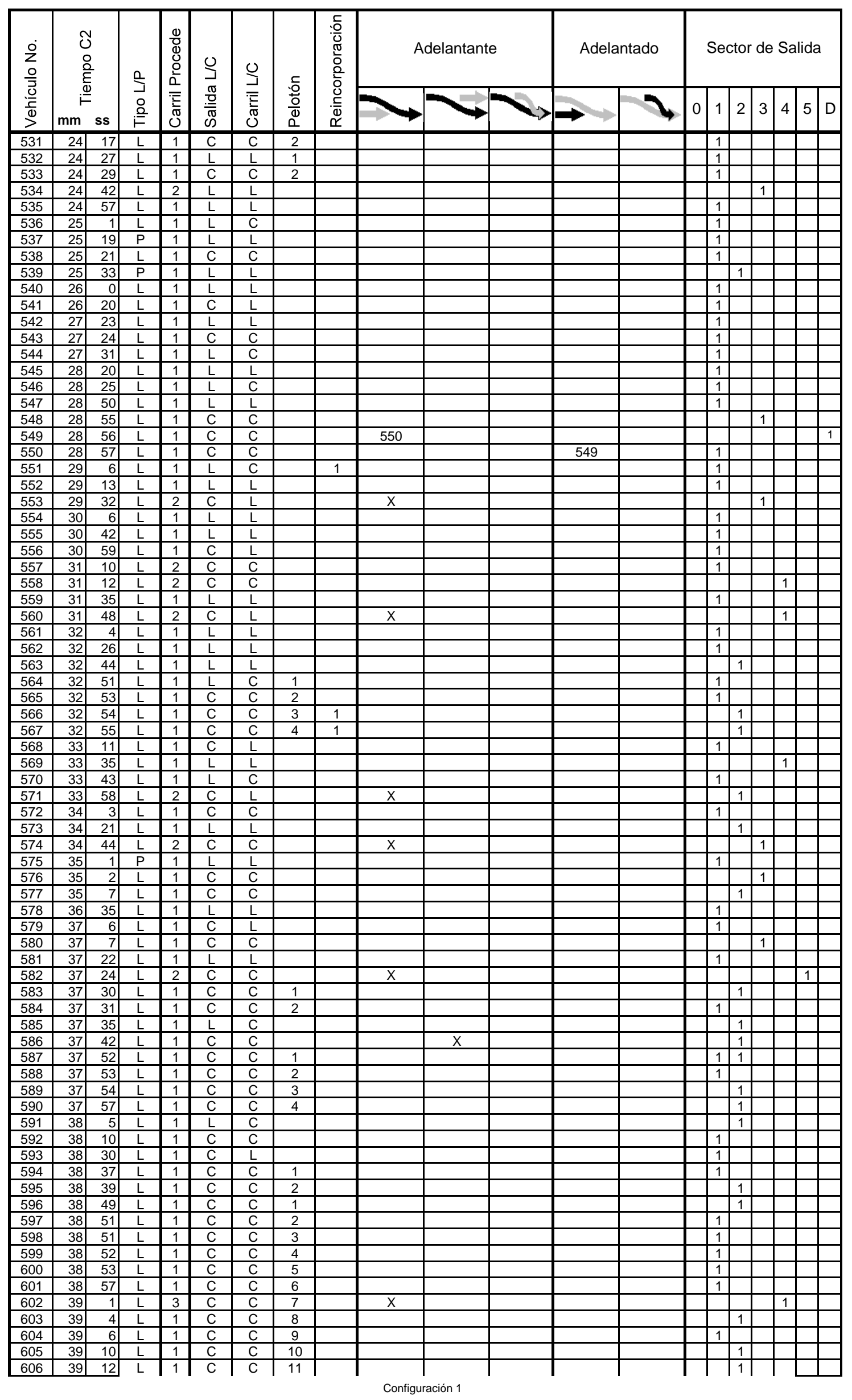




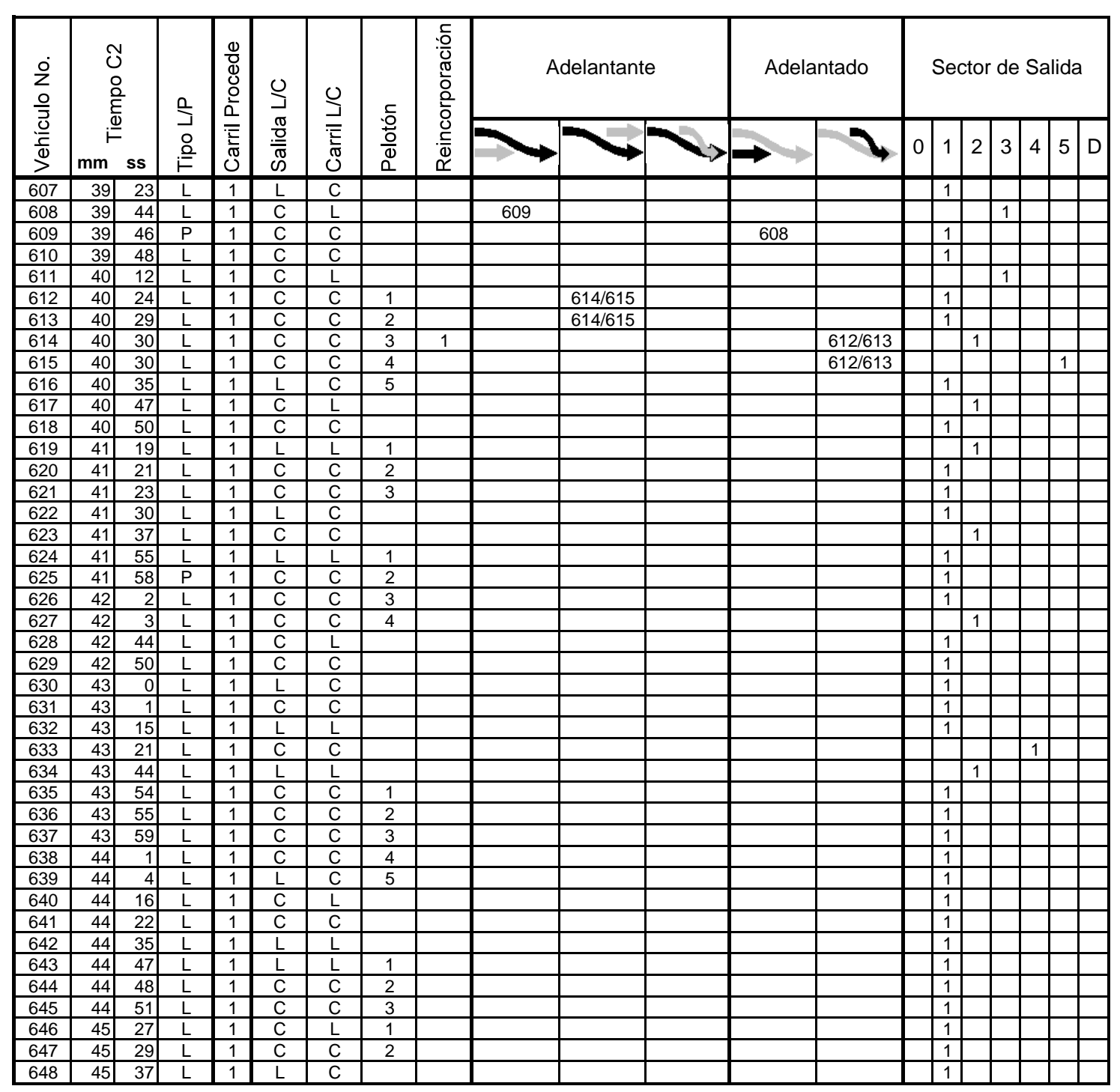




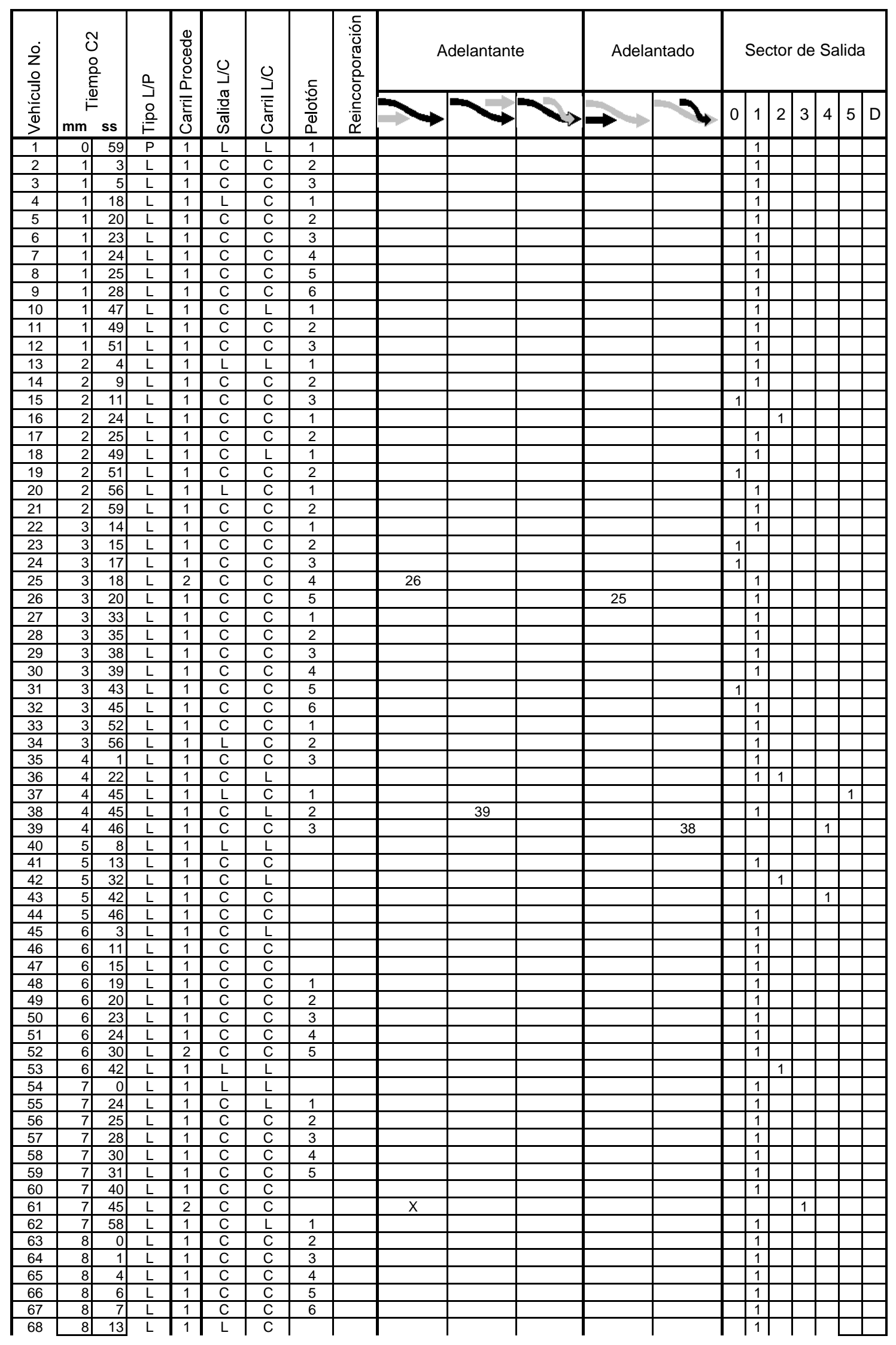




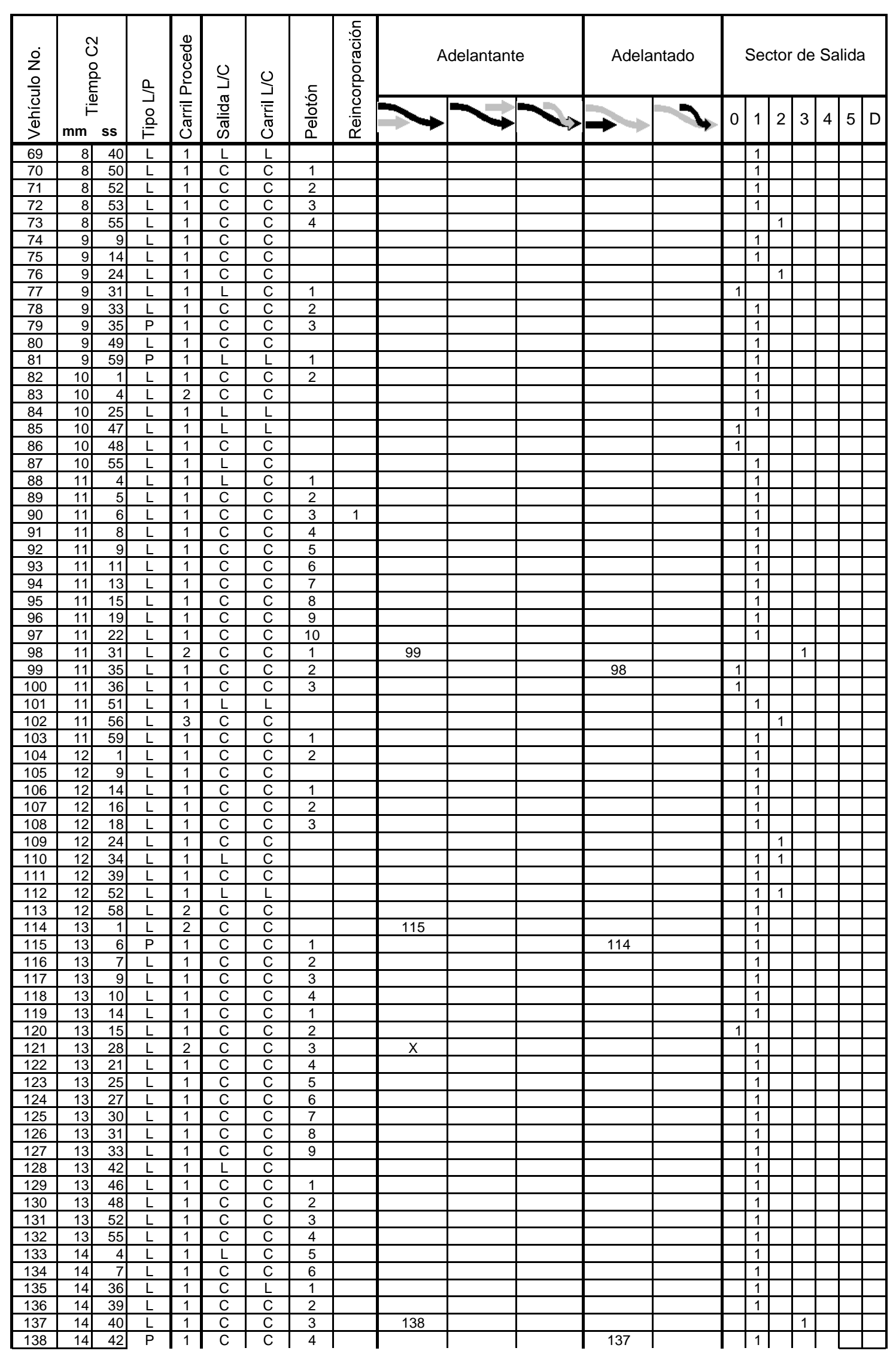




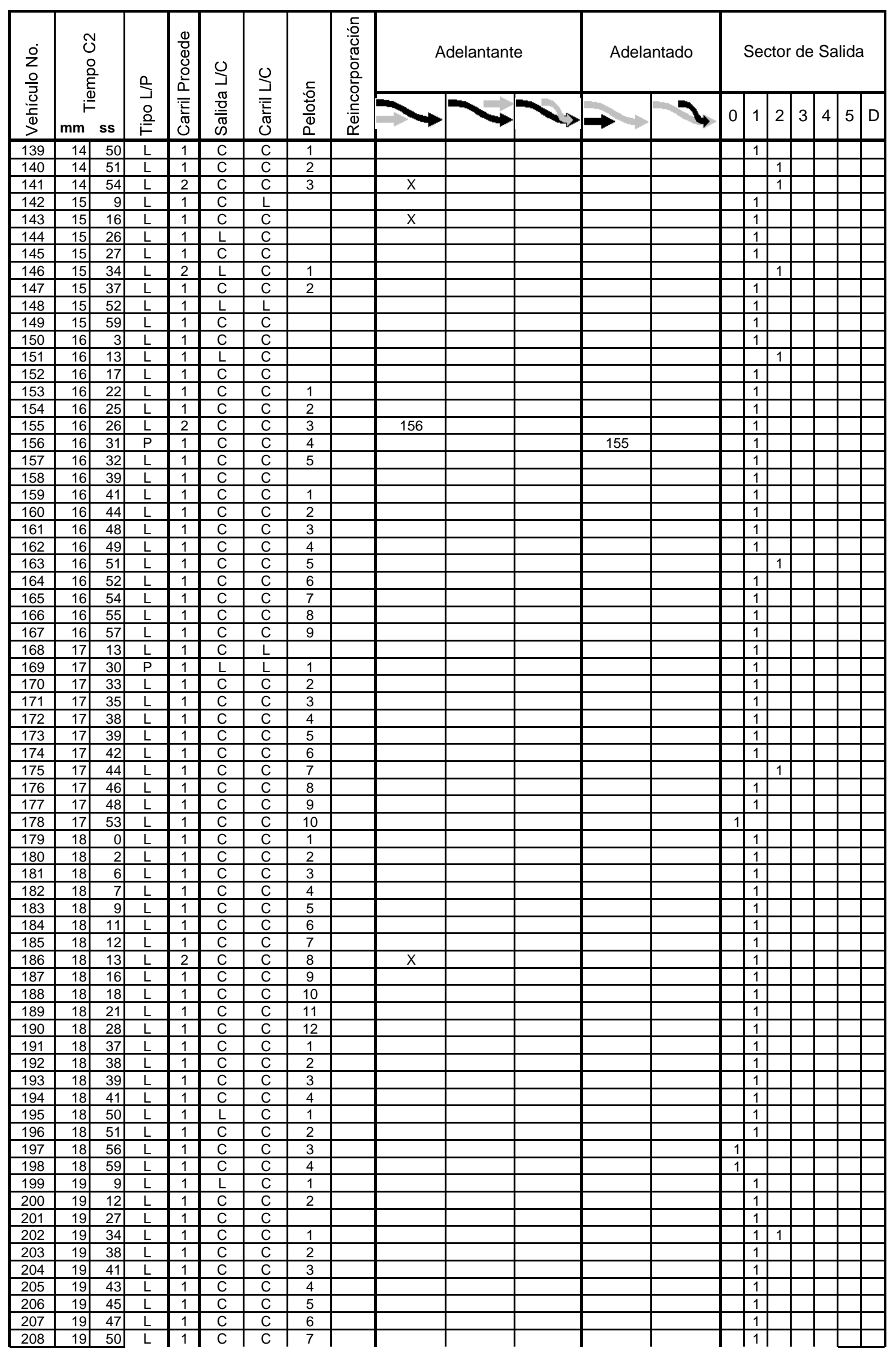




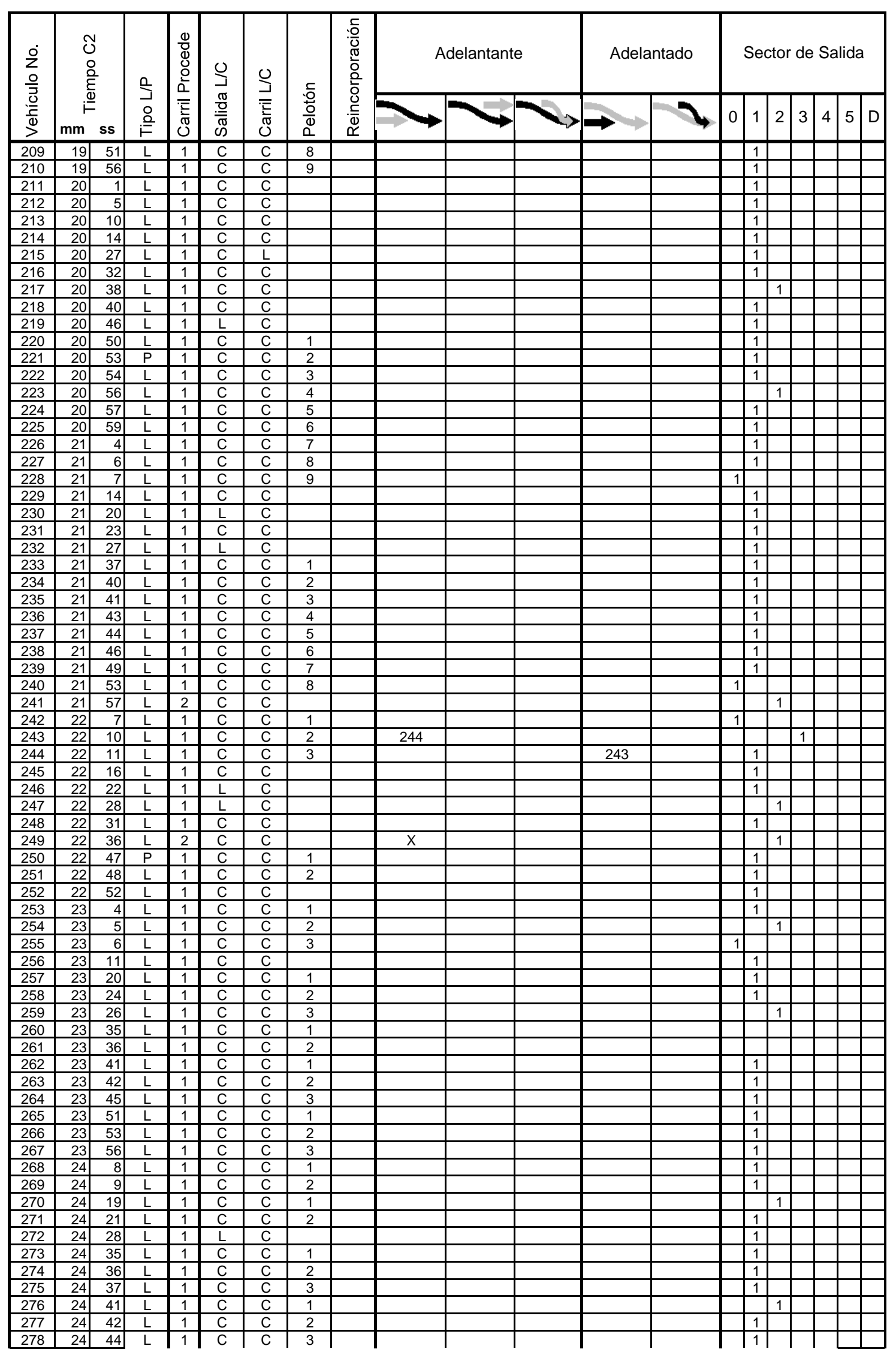




\begin{tabular}{|c|c|c|c|c|c|c|c|c|c|c|c|c|c|c|c|c|c|c|c|}
\hline \multirow{2}{*}{$\begin{array}{l}0 \\
z \\
o \\
\frac{0}{7} \\
\frac{0}{2} \\
\frac{0}{d}\end{array}$} & \multirow{2}{*}{\multicolumn{2}{|c|}{$\begin{array}{l}\text { J } \\
\text { 을 } \\
\text { 듬 } \\
i=\end{array}$}} & \multirow{2}{*}{ 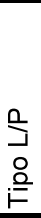 } & Ð & & & & $\begin{array}{l}\text { 등 } \\
: \frac{0}{0} \\
\text { 짐 }\end{array}$ & & Adelantante & Ade & antado & & $\mathrm{Sec}$ & ctor & de & $\mathrm{Sa}$ & lida & \\
\hline & & & & 狊 & $\begin{array}{l}\frac{0}{\overline{0}} \\
\text { 心 } \\
\end{array}$ & 䲶 & $\begin{array}{l}\text { 흠 } \\
0\end{array}$ & 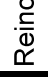 & & & & & 0 & 1 & 2 & 3 & 4 & 5 & D \\
\hline 279 & 24 & 46 & $\mathrm{~L}$ & 1 & $\mathrm{C}$ & $\mathrm{C}$ & 4 & & & & & & & 1 & & & & & \\
\hline 280 & 24 & 47 & $\mathrm{~L}$ & 1 & $\mathrm{C}$ & $\mathrm{C}$ & 5 & & & & & & & 1 & & & & & \\
\hline 281 & 24 & 49 & $\mathrm{~L}$ & 1 & $\mathrm{C}$ & $\mathrm{C}$ & 6 & & & & & & & 1 & & & & & \\
\hline 282 & 24 & 51 & $\mathrm{~L}$ & 1 & $\mathrm{C}$ & $\mathrm{C}$ & 7 & & & & & & & \begin{tabular}{|l|}
1 \\
\end{tabular} & & & & & \\
\hline 283 & 24 & 52 & $\mathrm{~L}$ & 1 & $\mathrm{C}$ & $\mathrm{C}$ & 8 & & & & & & & 1 & & & & & \\
\hline 284 & 24 & 55 & $\mathrm{~L}$ & 1 & $\mathrm{C}$ & $\mathrm{C}$ & 9 & & & & & & & 1 & & & & & \\
\hline 285 & 25 & 3 & $\mathrm{~L}$ & 1 & $\mathrm{C}$ & $\mathrm{C}$ & 1 & & & & & & & 1 & & & & & \\
\hline 286 & 25 & 4 & $\mathrm{~L}$ & 1 & $\mathrm{C}$ & $\mathrm{C}$ & 2 & & & & & & & 1 & & & & & \\
\hline 287 & 25 & 6 & $\mathrm{~L}$ & 1 & $\mathrm{C}$ & $\mathrm{C}$ & 3 & & & & & & & 1 & & & & & \\
\hline 288 & 25 & 8 & $\mathrm{~L}$ & 1 & $\mathrm{C}$ & $\mathrm{C}$ & 4 & & & & & & & \begin{tabular}{|l|}
1 \\
\end{tabular} & & & & & \\
\hline 289 & 25 & 12 & $\mathrm{~L}$ & 1 & $\mathrm{C}$ & $\mathrm{C}$ & 5 & & & & & & & 1 & & & & & \\
\hline 290 & 25 & 16 & $\mathrm{~L}$ & 1 & $\mathrm{C}$ & $\mathrm{C}$ & 6 & & & & & & & 1 & & & & & \\
\hline 291 & 25 & 20 & $\mathrm{~L}$ & 1 & $\mathrm{C}$ & $\mathrm{C}$ & 7 & & & & & & & 1 & & & & & \\
\hline 292 & 25 & 21 & $\mathrm{~L}$ & 1 & C & C & 8 & & & & & & & 1 & & & & & \\
\hline 293 & 25 & 46 & $\mathrm{~L}$ & 1 & $\mathrm{C}$ & $\mathrm{L}$ & 1 & & & & & & & 1 & & & & & \\
\hline 294 & 25 & 48 & $\mathrm{~L}$ & 1 & C & C & 2 & & & & & & & \begin{tabular}{|l|}
1 \\
\end{tabular} & & & & & \\
\hline 295 & 25 & 54 & $\mathrm{~L}$ & 1 & C & C & 3 & & & & & & & \begin{tabular}{|l|}
1 \\
\end{tabular} & & & & & \\
\hline 296 & 25 & 55 & $\mathrm{~L}$ & 1 & $\mathrm{C}$ & C & 4 & & & & & & & \begin{tabular}{|l|}
1 \\
\end{tabular} & & & & & \\
\hline 297 & 26 & 2 & $\mathrm{~L}$ & 1 & $\mathrm{C}$ & $\mathrm{C}$ & 1 & & & & & & & \begin{tabular}{|l|}
1 \\
\end{tabular} & & & & & \\
\hline 298 & 26 & 5 & $\mathrm{~L}$ & 1 & $\mathrm{C}$ & $\mathrm{C}$ & 2 & & & & & & & \begin{tabular}{|l|}
1 \\
\end{tabular} & & & & & \\
\hline 299 & 26 & 12 & $\mathrm{~L}$ & 1 & $\mathrm{C}$ & $\mathrm{C}$ & 1 & & & & & & & \begin{tabular}{|l|}
1 \\
\end{tabular} & & & & & \\
\hline 300 & 26 & 14 & $\mathrm{~L}$ & 1 & $\mathrm{C}$ & $\mathrm{C}$ & 2 & & & & & & & \begin{tabular}{|l|}
1 \\
\end{tabular} & & & & & \\
\hline 301 & 26 & 25 & $L$ & 1 & $\mathrm{~L}$ & $\mathrm{C}$ & 1 & & & & & & & \begin{tabular}{|l|}
1 \\
\end{tabular} & & & & & \\
\hline 302 & 26 & 27 & $L$ & 1 & $\mathrm{C}$ & $\mathrm{C}$ & 2 & & & & & & & \begin{tabular}{|l|}
1 \\
\end{tabular} & & & & & \\
\hline 303 & 26 & 53 & $\mathrm{~L}$ & 2 & $\mathrm{C}$ & $\mathrm{L}$ & & & & & & & & \begin{tabular}{|l|}
1 \\
\end{tabular} & & & & & \\
\hline 304 & 27 & 0 & $\mathrm{P}$ & 1 & $\mathrm{~L}$ & $\mathrm{C}$ & 1 & & & & & & & \begin{tabular}{|l|}
1 \\
\end{tabular} & & & & & \\
\hline 305 & 27 & 2 & $\mathrm{~L}$ & 1 & $\mathrm{C}$ & $\mathrm{C}$ & 2 & & & & & & & \begin{tabular}{|l|}
1 \\
\end{tabular} & & & & & \\
\hline 306 & 27 & 5 & $\mathrm{~L}$ & 1 & $\mathrm{C}$ & $\mathrm{C}$ & 3 & & & & & & & \begin{tabular}{|l|}
1 \\
\end{tabular} & & & & & \\
\hline 307 & 27 & 11 & $\mathrm{~L}$ & 2 & $\mathrm{C}$ & $\mathrm{C}$ & & & & & & & & 1 & & & & & \\
\hline 308 & 27 & 17 & $\mathrm{~L}$ & 1 & $\mathrm{C}$ & $\mathrm{C}$ & 1 & & & & & & & 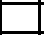 & 1 & & & & \\
\hline 309 & 27 & 19 & $\mathrm{~L}$ & 1 & $\mathrm{C}$ & $\mathrm{C}$ & 2 & & & & & & & 1 & & & & & \\
\hline 310 & 27 & 21 & $\mathrm{~L}$ & 1 & $\mathrm{C}$ & $\mathrm{C}$ & 3 & & & & & & 1 & & & & & & \\
\hline 311 & 27 & 26 & $\mathrm{~L}$ & 1 & $\mathrm{C}$ & $\mathrm{C}$ & 4 & & & & & & & 1 & & & & & \\
\hline 312 & 27 & 34 & $\mathrm{~L}$ & 1 & $\mathrm{C}$ & $\mathrm{C}$ & 1 & & & & & & & 1 & & & & & \\
\hline 313 & 27 & 37 & $\mathrm{~L}$ & 1 & $\mathrm{~L}$ & C & 2 & & & & & & & 1 & & & & & \\
\hline 314 & 27 & 55 & $\mathrm{~L}$ & 1 & $\mathrm{~L}$ & $\mathrm{~L}$ & & & & & & & & 1 & & & & & \\
\hline 315 & 27 & 58 & $\mathrm{~L}$ & 1 & $\mathrm{C}$ & C & & & & & & & & 1 & & & & & \\
\hline 316 & 28 & 0 & $\mathrm{~L}$ & 1 & $\mathrm{C}$ & $\mathrm{C}$ & & & & & & & & 1 & & & & & \\
\hline 317 & 28 & 25 & $\mathrm{~L}$ & 1 & $\mathrm{C}$ & $\mathrm{C}$ & 1 & & & & & & & 1 & & & & & \\
\hline 318 & 28 & 27 & $\mathrm{~L}$ & 1 & $\mathrm{C}$ & $\mathrm{C}$ & 2 & & & & & & & 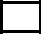 & 1 & & & & \\
\hline 319 & 28 & 29 & $\mathrm{~L}$ & 1 & $\mathrm{C}$ & $\mathrm{C}$ & 3 & & & & & & & 1 & & & & & \\
\hline 320 & 28 & 39 & $\mathrm{~L}$ & 1 & $\mathrm{C}$ & $\mathrm{C}$ & & & & & & & 1 & 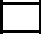 & 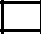 & & & & \\
\hline 321 & 28 & 47 & $\mathrm{~L}$ & 2 & $\mathrm{C}$ & $\mathrm{C}$ & & & $x$ & & & & & 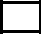 & 1 & & & & \\
\hline 322 & 29 & 3 & $\mathrm{~L}$ & 1 & $\mathrm{~L}$ & $\mathrm{~L}$ & & & & & & & & 1 & & & & & \\
\hline 323 & 29 & 7 & $\mathrm{P}$ & 1 & $\mathrm{C}$ & $\mathrm{C}$ & & & & & & & & 1 & & & & & \\
\hline 324 & 29 & 24 & $\mathrm{~L}$ & 1 & $\mathrm{C}$ & $\mathrm{L}$ & & & & & & & & 1 & & & & & \\
\hline 325 & 29 & 32 & $\mathrm{P}$ & 1 & $\mathrm{C}$ & $\mathrm{C}$ & 1 & & & & & & & 1 & & & & & \\
\hline 326 & 29 & 33 & $\mathrm{~L}$ & 1 & $\mathrm{C}$ & $\mathrm{C}$ & 2 & & & & & & & \begin{tabular}{|l|}
1 \\
\end{tabular} & & & & & \\
\hline 327 & 29 & 34 & $\mathrm{~L}$ & 1 & $\mathrm{C}$ & $\mathrm{C}$ & 3 & & & & & & & 1 & & & & & \\
\hline 328 & 29 & 35 & $\mathrm{~L}$ & 1 & $\mathrm{C}$ & $\mathrm{C}$ & 4 & & & & & & & 1 & & & & & \\
\hline 329 & 29 & 39 & $\mathrm{~L}$ & 1 & $\mathrm{C}$ & $\mathrm{C}$ & & & & & & & & 1 & & & & & \\
\hline 330 & 29 & 54 & $\mathrm{~L}$ & 1 & $\mathrm{~L}$ & $\mathrm{~L}$ & 1 & & & & & & & 1 & & & & & \\
\hline 331 & 29 & 56 & $\mathrm{~L}$ & 1 & $\mathrm{C}$ & $\mathrm{C}$ & 2 & & & & & & & 1 & & & & & \\
\hline 332 & 30 & 5 & $\mathrm{~L}$ & 1 & $\mathrm{C}$ & $\mathrm{L}$ & & & & & & & & 1 & & & & & \\
\hline 333 & 30 & 21 & $\mathrm{~L}$ & 2 & $\mathrm{C}$ & $\mathrm{C}$ & 1 & & & & & & & 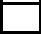 & 1 & & & & \\
\hline 334 & 30 & 23 & $\mathrm{~L}$ & 1 & $\mathrm{C}$ & $\mathrm{C}$ & 2 & & & & & & & 1 & & & & & \\
\hline 335 & 30 & 35 & $\mathrm{P}$ & 1 & $\mathrm{C}$ & $\mathrm{C}$ & 1 & & & & & & & 1 & & & & & \\
\hline 336 & 30 & 37 & $\mathrm{~L}$ & 1 & $\mathrm{C}$ & $\mathrm{C}$ & 2 & & & & & & & 1 & & & & & \\
\hline 337 & 30 & 41 & $\mathrm{~L}$ & 1 & $\mathrm{C}$ & $\mathrm{C}$ & 3 & & & & & & & 1 & & & & & \\
\hline 338 & 30 & 42 & $\mathrm{~L}$ & 1 & $\mathrm{C}$ & $\mathrm{C}$ & 4 & & & & & & & 1 & & & & & \\
\hline 339 & 30 & 44 & $\mathrm{~L}$ & 1 & $\mathrm{C}$ & $\mathrm{C}$ & 5 & & & & & & & 1 & & & & & \\
\hline 340 & 30 & 47 & $\mathrm{~L}$ & 1 & $\mathrm{C}$ & $\mathrm{C}$ & 6 & & & & & & & 1 & & & & & \\
\hline 341 & 30 & 48 & $\mathrm{~L}$ & 1 & $\mathrm{C}$ & $\mathrm{C}$ & 7 & & & & & & & 1 & & & & & \\
\hline 342 & 30 & 50 & $\mathrm{~L}$ & 1 & $\mathrm{C}$ & $\mathrm{C}$ & 8 & & & & & & & 1 & & & & & \\
\hline 343 & 30 & 56 & $\mathrm{P}$ & 2 & $\mathrm{C}$ & $\mathrm{C}$ & 1 & & 344 & & & & & 4 & 1 & & & & \\
\hline 344 & 30 & 57 & $\mathrm{~L}$ & 1 & $\mathrm{C}$ & $\mathrm{C}$ & 2 & & & & 343 & & & 1 & & & & & \\
\hline 345 & 31 & 7 & $\mathrm{~L}$ & 1 & $\mathrm{C}$ & $\mathrm{C}$ & & & & & & & & 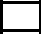 & 1 & & & & \\
\hline 346 & 31 & 12 & $\mathrm{~L}$ & 1 & C & C & 1 & & & & & & & 1 & & & & & \\
\hline 347 & 31 & 13 & $\mathrm{~L}$ & 1 & $\mathrm{C}$ & $\mathrm{C}$ & 2 & & & & & & 1 & & & & & & \\
\hline 348 & 31 & 16 & $\mathrm{~L}$ & 1 & $C$ & $\mathrm{C}$ & 3 & & & & & & & 1 & & & & & \\
\hline
\end{tabular}




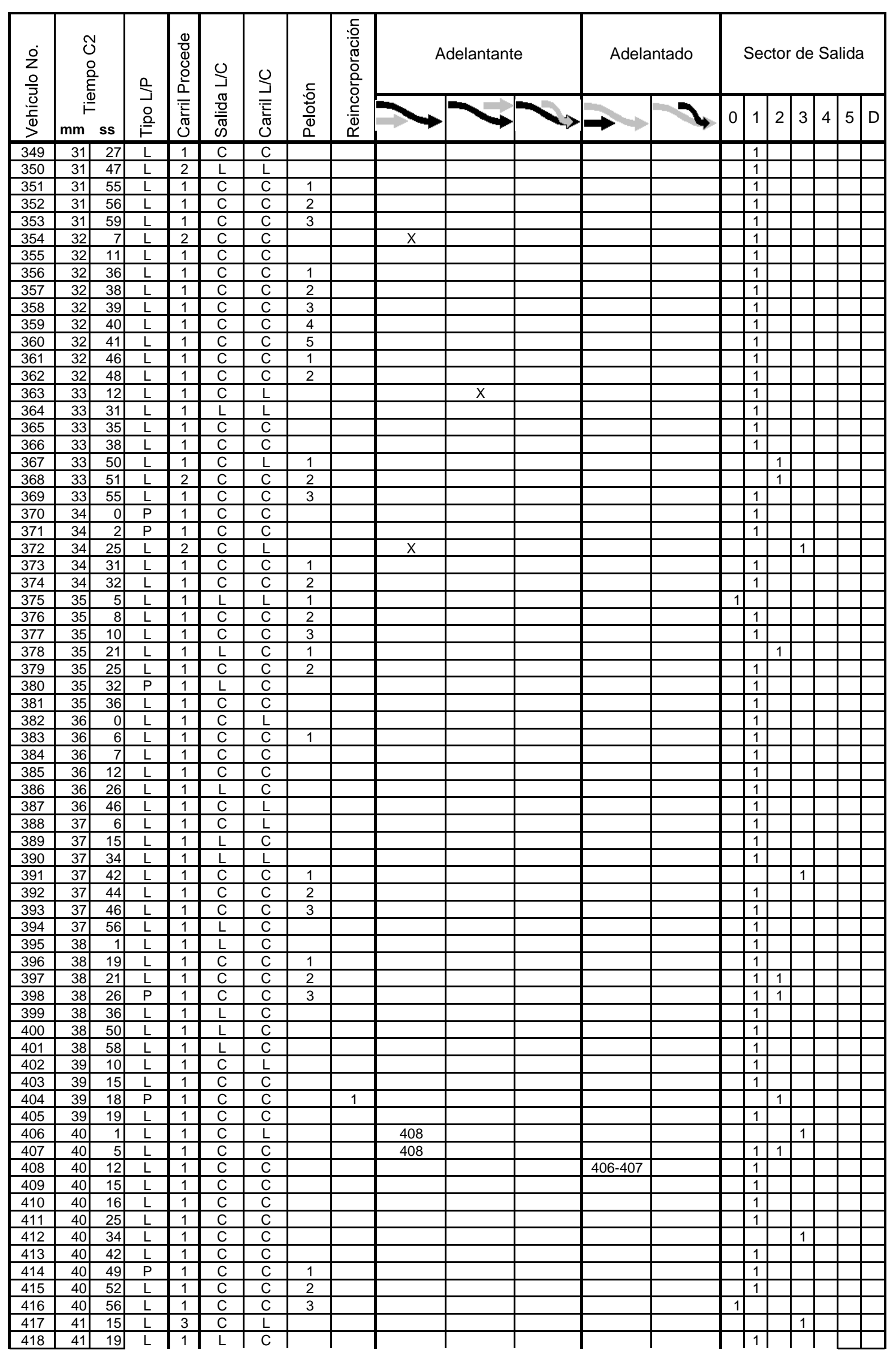




\begin{tabular}{|c|c|c|c|c|c|c|c|c|c|c|c|c|c|c|c|c|c|c|c|}
\hline \multirow{2}{*}{$\begin{array}{l}0 \\
z \\
o \\
\frac{0}{7} \\
\frac{0}{2} \\
\frac{0}{d}\end{array}$} & \multirow{2}{*}{\multicolumn{2}{|c|}{$\begin{array}{l}\text { J } \\
\text { 을 } \\
\text { 듬 } \\
i=\end{array}$}} & \multirow{2}{*}{$\begin{array}{l}\stackrel{0}{\supset} \\
\text { 음 } \\
\stackrel{ }{E}\end{array}$} & Ð & & & & $\begin{array}{l}\text { 등 } \\
\frac{0}{0} \\
\text { 징 }\end{array}$ & & Adelantante & Ade & antado & & $\mathrm{Sec}$ & ctor & de & $\mathrm{Sa}$ & lida & \\
\hline & & & & J & $\begin{array}{l}\frac{0}{\overline{0}} \\
\text { 心 }\end{array}$ & 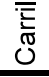 & $\begin{array}{l}\text { 흠 } \\
0 \\
0\end{array}$ & 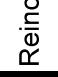 & & & & & 0 & 1 & 2 & 3 & 4 & 5 & D \\
\hline 419 & 41 & 31 & $\mathrm{~L}$ & 1 & $\mathrm{C}$ & $\mathrm{C}$ & & & & & & & & 1 & & & & & \\
\hline 420 & 41 & 38 & $\mathrm{~L}$ & 1 & $\mathrm{C}$ & $\mathrm{C}$ & 1 & & & & & & & 1 & & & & & \\
\hline 421 & 41 & 39 & $\mathrm{~L}$ & 1 & $\mathrm{C}$ & $\mathrm{C}$ & 2 & & & & & & & 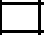 & 1 & & & & \\
\hline 422 & 41 & 44 & $\mathrm{~L}$ & 1 & $\mathrm{C}$ & $\mathrm{C}$ & 3 & & & & & & & 1 & & & & & \\
\hline 423 & 42 & 1 & $\mathrm{~L}$ & 1 & $\mathrm{C}$ & $\mathrm{C}$ & 1 & & & & & & & 1 & & & & & \\
\hline 424 & 42 & 3 & $\mathrm{~L}$ & 1 & $\mathrm{C}$ & $\mathrm{C}$ & 2 & & & & & & & 1 & & & & & \\
\hline 425 & 42 & 14 & $\mathrm{~L}$ & 1 & $\mathrm{C}$ & $\mathrm{C}$ & 1 & & & & & & & 1 & & & & & \\
\hline 426 & 42 & 16 & $\mathrm{~L}$ & 1 & $\mathrm{C}$ & $\mathrm{C}$ & 2 & & & & & & & 1 & & & & & \\
\hline 427 & 42 & 18 & $\mathrm{~L}$ & 1 & $\mathrm{C}$ & $\mathrm{C}$ & 3 & & & & & & & 1 & & & & & \\
\hline 428 & 42 & 24 & $\mathrm{~L}$ & 1 & $\mathrm{C}$ & $\mathrm{C}$ & & & & & & & & 1 & & & & & \\
\hline 429 & 42 & 53 & $\mathrm{~L}$ & 1 & $\mathrm{~L}$ & $\mathrm{~L}$ & 1 & & & & & & & 1 & & & & & \\
\hline 430 & 42 & 55 & $\mathrm{~L}$ & 1 & $\mathrm{C}$ & $\mathrm{C}$ & 2 & & & & & & & 1 & & & & & \\
\hline 431 & 42 & 57 & $\mathrm{~L}$ & 3 & $\mathrm{C}$ & $\mathrm{C}$ & 3 & & $432-X$ & & & & & 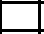 & & 1 & & & \\
\hline 432 & 42 & 58 & $\mathrm{~L}$ & 1 & $\mathrm{C}$ & $\mathrm{C}$ & 4 & & & & 431 & & & 1 & & & & & \\
\hline 433 & 43 & 5 & $\mathrm{~L}$ & 1 & $\mathrm{~L}$ & $\mathrm{C}$ & & & & & & & & 1 & & & & & \\
\hline 434 & 43 & 13 & $\mathrm{~L}$ & 1 & $\mathrm{~L}$ & C & & & & & & & 1 & & & & & & \\
\hline 435 & 43 & 21 & $\mathrm{~L}$ & 1 & C & C & & & & & & & & \begin{tabular}{|l|}
1 \\
\end{tabular} & & & & & \\
\hline 436 & 43 & 24 & $\mathrm{~L}$ & 1 & $\mathrm{C}$ & $\mathrm{C}$ & & & & & & & & 1 & & & & & \\
\hline 437 & 43 & 36 & $\mathrm{~L}$ & 1 & $\mathrm{C}$ & $\mathrm{C}$ & & & & & & & & \begin{tabular}{|l|}
1 \\
\end{tabular} & & & & & \\
\hline 438 & 43 & 40 & $\mathrm{~L}$ & 1 & $\mathrm{C}$ & $\mathrm{C}$ & & & & & & & & \begin{tabular}{|l|}
1 \\
\end{tabular} & & & & & \\
\hline 439 & 44 & 17 & $\mathrm{~L}$ & 1 & $\mathrm{C}$ & $\mathrm{L}$ & 1 & & & & & & & \begin{tabular}{|l|}
1 \\
\end{tabular} & & & & & 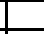 \\
\hline 440 & 44 & 18 & $\mathrm{~L}$ & 1 & $\mathrm{C}$ & $\mathrm{C}$ & 2 & & & & & & & \begin{tabular}{|l|}
1 \\
\end{tabular} & & & & & \\
\hline 441 & 45 & 0 & $\mathrm{~L}$ & 1 & $\mathrm{C}$ & $\mathrm{C}$ & & & & & & & & 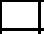 & 1 & & & & \\
\hline 442 & 45 & 4 & $\mathrm{~L}$ & 1 & $\mathrm{C}$ & $\mathrm{C}$ & & & 443 & & & & & 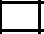 & & & 1 & & \\
\hline 443 & 45 & 5 & $\mathrm{~L}$ & 1 & $\mathrm{C}$ & $\mathrm{C}$ & & & & & 442 & & & \begin{tabular}{|l|}
1 \\
\end{tabular} & & & & & \\
\hline 444 & 45 & 16 & $\mathrm{~L}$ & 1 & $\mathrm{C}$ & $\mathrm{C}$ & & & & & & & & \begin{tabular}{|l|}
1 \\
\end{tabular} & & & & & \\
\hline 445 & 45 & 17 & $\mathrm{~L}$ & 2 & $\mathrm{C}$ & $\mathrm{C}$ & & & & & & & & 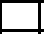 & 1 & & & & \\
\hline 446 & 45 & 33 & $\mathrm{~L}$ & 1 & $\mathrm{~L}$ & $\mathrm{~L}$ & & & & & & & & 1 & & & & & \\
\hline 447 & & & $\mathrm{~L}$ & 1 & $\mathrm{~L}$ & $\mathrm{~L}$ & & & & & & & & 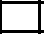 & 1 & & & & \\
\hline 448 & 45 & 40 & $\mathrm{P}$ & 1 & $\mathrm{C}$ & $\mathrm{C}$ & & & & & & & & 1 & & & & & \\
\hline 449 & & & $\mathrm{~L}$ & 1 & $\mathrm{C}$ & C & 1 & & & & & & & 1 & & & & & \\
\hline 450 & & & $\mathrm{~L}$ & 1 & $\mathrm{C}$ & $\mathrm{C}$ & 2 & & & & & & & 1 & & & & & \\
\hline 451 & 0 & 1 & $\mathrm{~L}$ & 1 & $\mathrm{C}$ & $\mathrm{L}$ & 1 & & & & & & & 1 & & & & & \\
\hline 452 & 0 & 1 & $\mathrm{~L}$ & 1 & $\mathrm{C}$ & $\mathrm{C}$ & 2 & & & & & & & 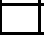 & & & & & 1 \\
\hline 453 & 0 & 6 & $\mathrm{~L}$ & 1 & $\mathrm{C}$ & $\mathrm{L}$ & & & & & & & & 1 & & & & & \\
\hline 454 & 0 & 19 & $\mathrm{~L}$ & 1 & $\mathrm{C}$ & $\mathrm{L}$ & & & & & & & & 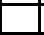 & 1 & & & & \\
\hline 455 & 0 & 27 & $\mathrm{~L}$ & 2 & $\mathrm{C}$ & C & 1 & & $X$ & & & & & 1 & & & & & \\
\hline 456 & 0 & 29 & $\mathrm{~L}$ & 1 & $\mathrm{C}$ & $\mathrm{C}$ & 2 & & & & & & 1 & & & & & & \\
\hline 457 & 1 & 2 & $\mathrm{~L}$ & 1 & $\mathrm{C}$ & $\mathrm{L}$ & 1 & & & & & & & 1 & & & & & \\
\hline 458 & 1 & 3 & $\mathrm{~L}$ & 1 & $\mathrm{C}$ & C & 2 & & & & & & & 1 & & & & & \\
\hline 459 & 1 & 5 & $\mathrm{P}$ & 1 & $\mathrm{C}$ & $\mathrm{C}$ & 3 & & & & & & & 1 & & & & & \\
\hline 460 & 1 & 16 & $\mathrm{P}$ & 1 & $\mathrm{~L}$ & $\mathrm{C}$ & 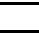 & & & & & & & 1 & & & & & \\
\hline 461 & 1 & 24 & $\mathrm{~L}$ & 1 & $\mathrm{C}$ & $\mathrm{C}$ & & & & & & & & - & 1 & & & & \\
\hline 462 & 1 & 49 & $\mathrm{~L}$ & 1 & $\mathrm{C}$ & $\mathrm{C}$ & 1 & & & & & & & 1 & & & & & \\
\hline 463 & 1 & 50 & $\mathrm{~L}$ & 1 & $\mathrm{C}$ & $\mathrm{C}$ & 2 & & & & & & & 1 & & & & & \\
\hline 464 & 1 & 54 & $\mathrm{~L}$ & 1 & $\mathrm{C}$ & $\mathrm{C}$ & 3 & & & & & & & 1 & & & & & \\
\hline 465 & 1 & 56 & $\mathrm{~L}$ & 1 & $\mathrm{C}$ & $\mathrm{C}$ & 4 & & & & & & & 1 & & & & & \\
\hline 466 & 2 & 1 & $\mathrm{~L}$ & 1 & $\mathrm{C}$ & $\mathrm{C}$ & & & & & & & & 1 & & & & & \\
\hline 467 & 2 & 23 & $\mathrm{~L}$ & 1 & $\mathrm{C}$ & $\mathrm{C}$ & & & & & & & & 1 & & & & & \\
\hline 468 & 2 & 33 & $\mathrm{~L}$ & 2 & $\mathrm{C}$ & $\mathrm{C}$ & & & $X$ & & & & & 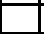 & & 1 & & & \\
\hline 469 & 2 & 39 & $\mathrm{~L}$ & 1 & $\mathrm{C}$ & $\mathrm{C}$ & 1 & & & & & & & 1 & & & & & \\
\hline 470 & 2 & 41 & $\mathrm{~L}$ & 1 & $\mathrm{C}$ & $\mathrm{C}$ & 2 & & & & & & & 1 & & & & & \\
\hline 471 & 2 & 53 & $\mathrm{~L}$ & 1 & $\mathrm{C}$ & $\mathrm{L}$ & & & & & & & & 1 & & & & & \\
\hline 472 & 3 & 7 & $\mathrm{~L}$ & 1 & $\mathrm{C}$ & $\mathrm{C}$ & & & & & & & & 1 & & & & & \\
\hline 473 & 3 & 30 & $\mathrm{~L}$ & 1 & $\mathrm{C}$ & $\mathrm{C}$ & 1 & & & & & & & 1 & & & & & \\
\hline 474 & 3 & 32 & $\mathrm{~L}$ & 1 & $\mathrm{C}$ & $\mathrm{C}$ & 2 & & & & & & & \begin{tabular}{|l|}
1 \\
\end{tabular} & & & & & \\
\hline 475 & 3 & 33 & $\mathrm{~L}$ & 2 & $\mathrm{C}$ & $\mathrm{C}$ & 3 & & 476 & & & & & 1 & & & & & \\
\hline 476 & 3 & 38 & $\mathrm{~L}$ & 1 & $\mathrm{C}$ & $\mathrm{C}$ & 4 & & & & 475 & & & 1 & & & & & \\
\hline 477 & 3 & 43 & $\mathrm{~L}$ & 2 & $\mathrm{C}$ & $\mathrm{C}$ & & & & & & & & & & & & & 1 \\
\hline 478 & 3 & 57 & $\mathrm{~L}$ & 1 & $\mathrm{C}$ & $\mathrm{C}$ & & & & & & & & \begin{tabular}{|l|}
1 \\
\end{tabular} & & & & & \\
\hline 479 & 4 & 13 & $\mathrm{~L}$ & 1 & $\mathrm{~L}$ & $\mathrm{~L}$ & & & & & & & & 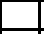 & 1 & & & & \\
\hline 480 & 4 & 33 & $\mathrm{~L}$ & 1 & $\mathrm{~L}$ & $\mathrm{~L}$ & & & & & & & & \begin{tabular}{|l|}
1 \\
\end{tabular} & & & & & \\
\hline 481 & 4 & 41 & $\mathrm{~L}$ & 1 & $\mathrm{~L}$ & $\mathrm{C}$ & & & & & & & & \begin{tabular}{|l|}
1 \\
\end{tabular} & & & & & \\
\hline 482 & 4 & 53 & $\mathrm{~L}$ & 1 & $\mathrm{C}$ & $\mathrm{C}$ & & & & & & & & \begin{tabular}{|l|}
1 \\
\end{tabular} & & & & & \\
\hline 483 & 4 & 57 & $\mathrm{~L}$ & 1 & $\mathrm{~L}$ & $\mathrm{C}$ & 1 & & & & & & & \begin{tabular}{|l|}
1 \\
\end{tabular} & & & & & \\
\hline 484 & 4 & 59 & $\mathrm{~L}$ & 1 & $\mathrm{C}$ & $\mathrm{C}$ & 2 & & & & & & & \begin{tabular}{|l|}
1 \\
\end{tabular} & & & & & \\
\hline 485 & 5 & 10 & $\mathrm{~L}$ & 1 & $\mathrm{C}$ & $\mathrm{C}$ & 1 & & & & & & & 1 & & & & & \\
\hline 486 & 5 & 12 & $\mathrm{~L}$ & 1 & $\mathrm{C}$ & $\mathrm{C}$ & 2 & & & & & & & 1 & & & & & \\
\hline 487 & 5 & 14 & $\mathrm{~L}$ & 1 & $\mathrm{C}$ & $\mathrm{C}$ & 3 & & & & & & & 1 & & & & & \\
\hline 488 & 5 & 22 & $\mathrm{~L}$ & 1 & $\mathrm{~L}$ & $\mathrm{C}$ & & & & & & & & \begin{tabular}{|l|}
1 \\
1
\end{tabular} & & & & & \\
\hline
\end{tabular}




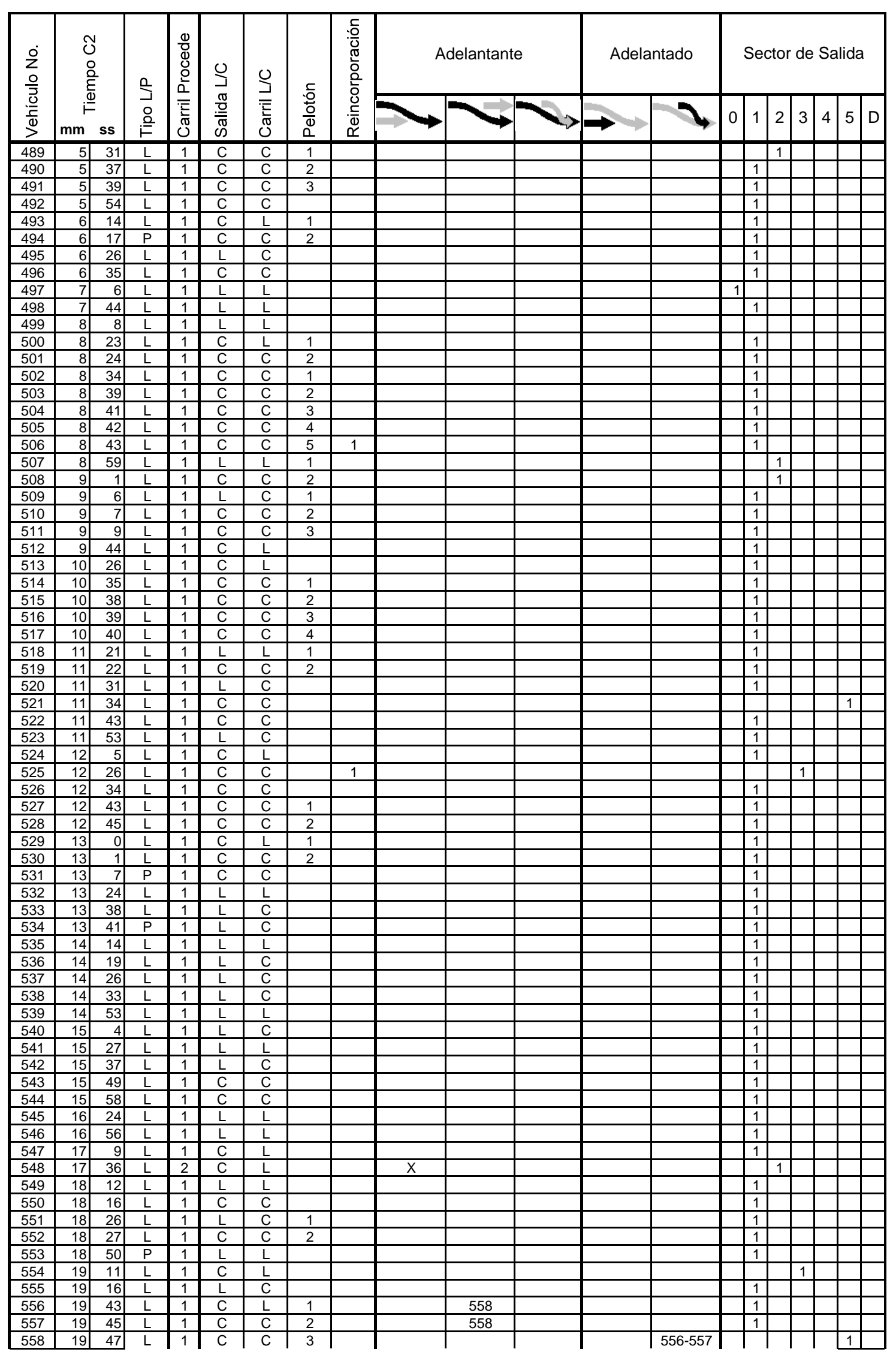




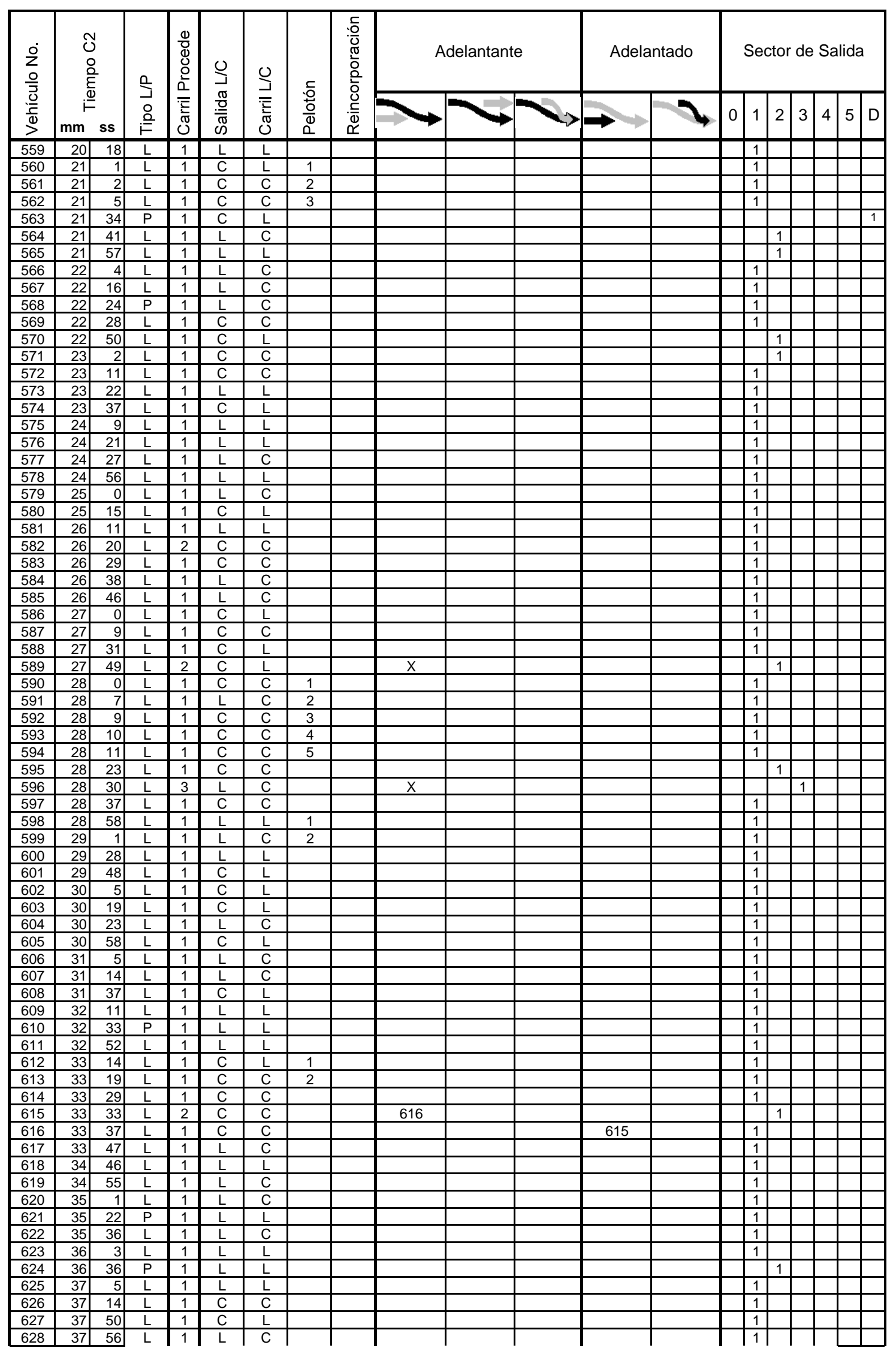




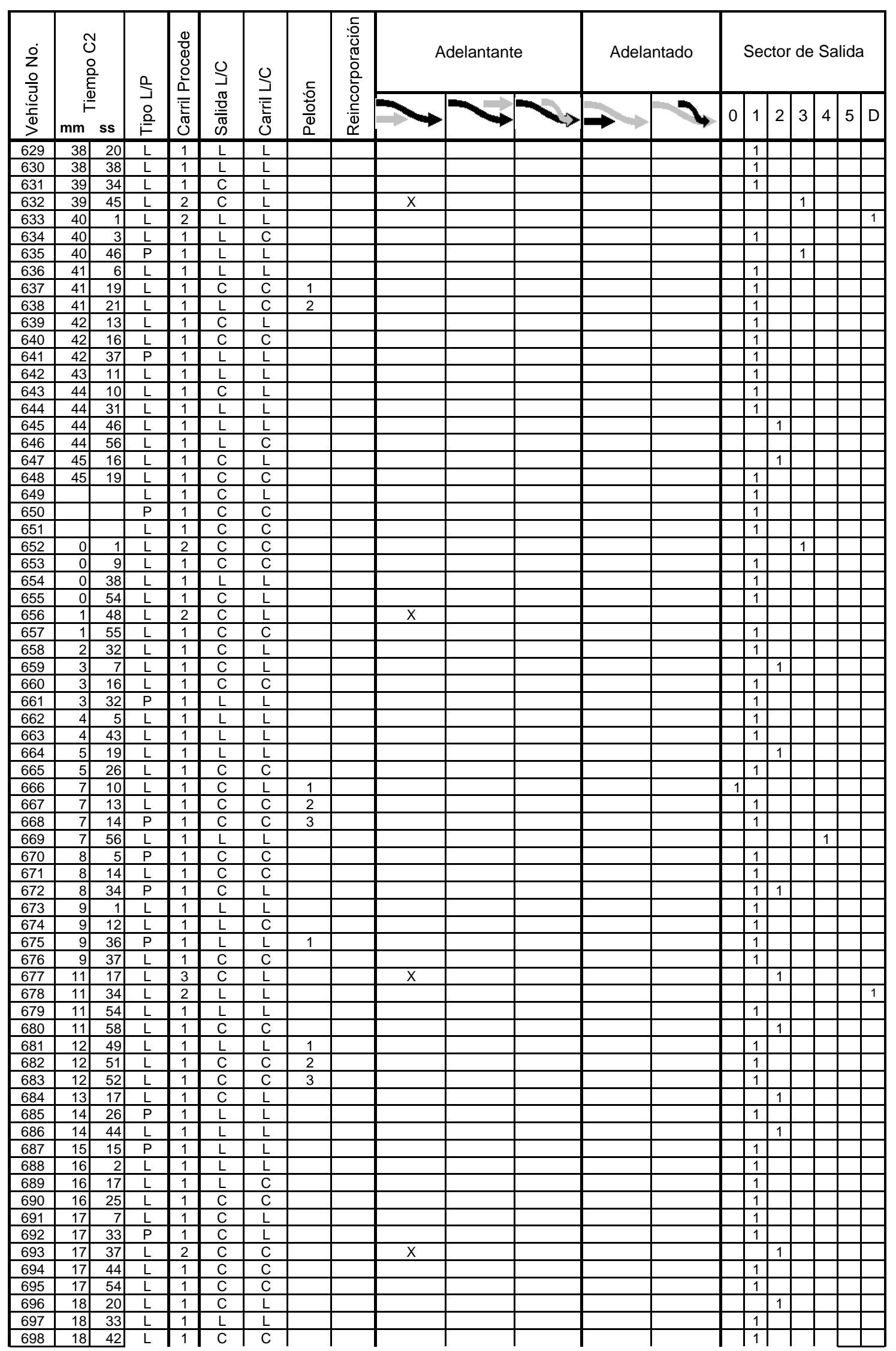




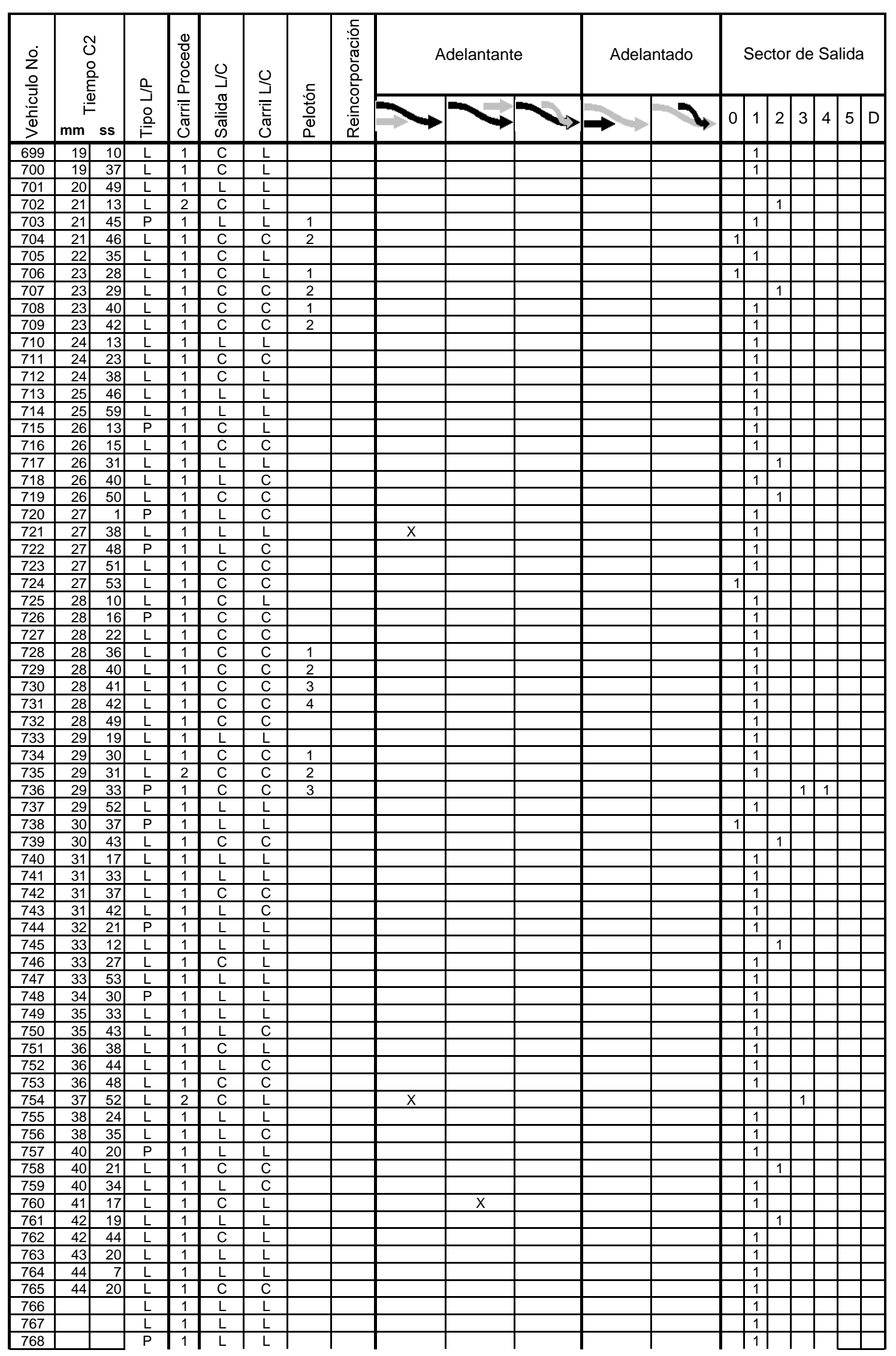




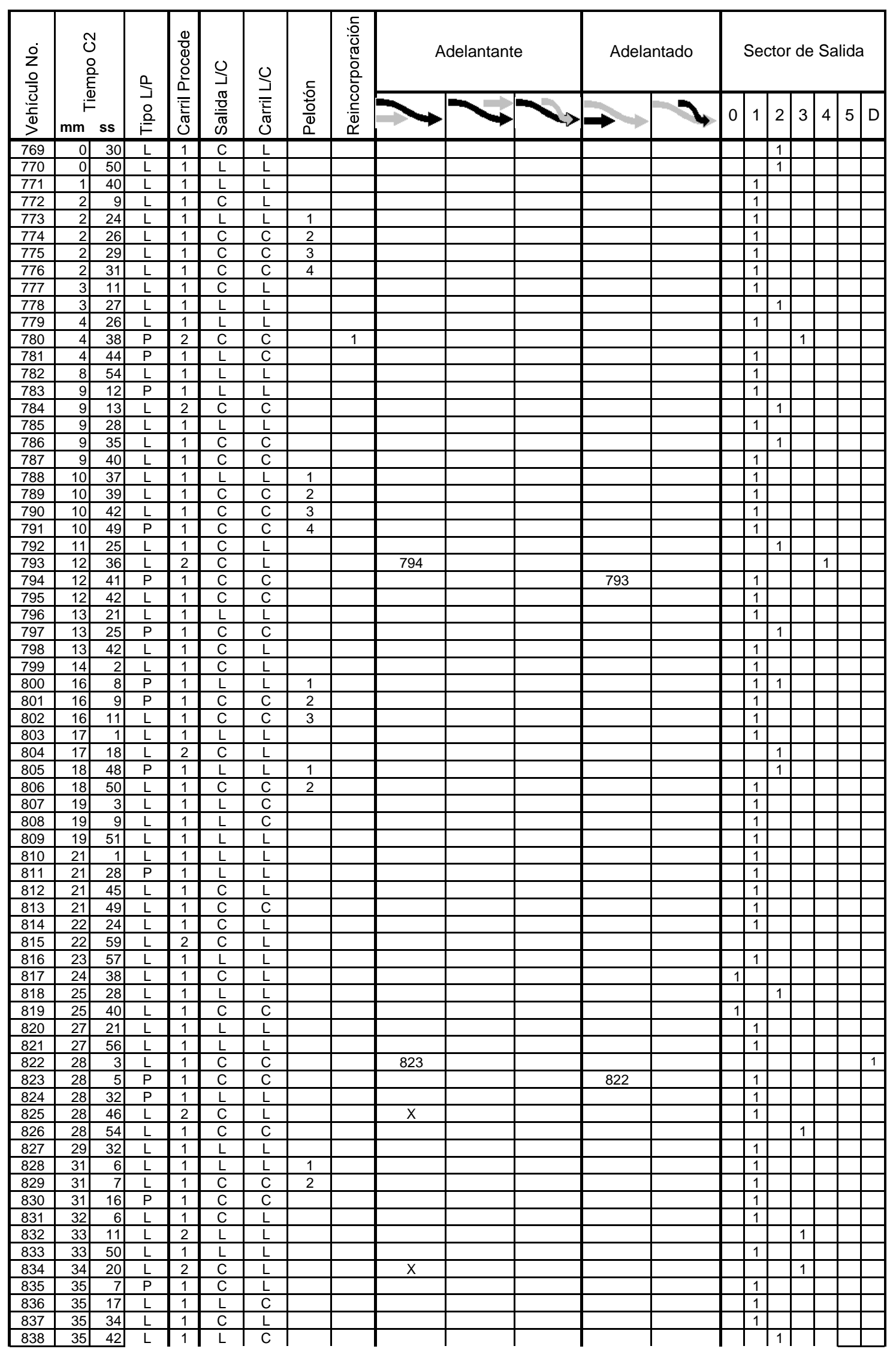




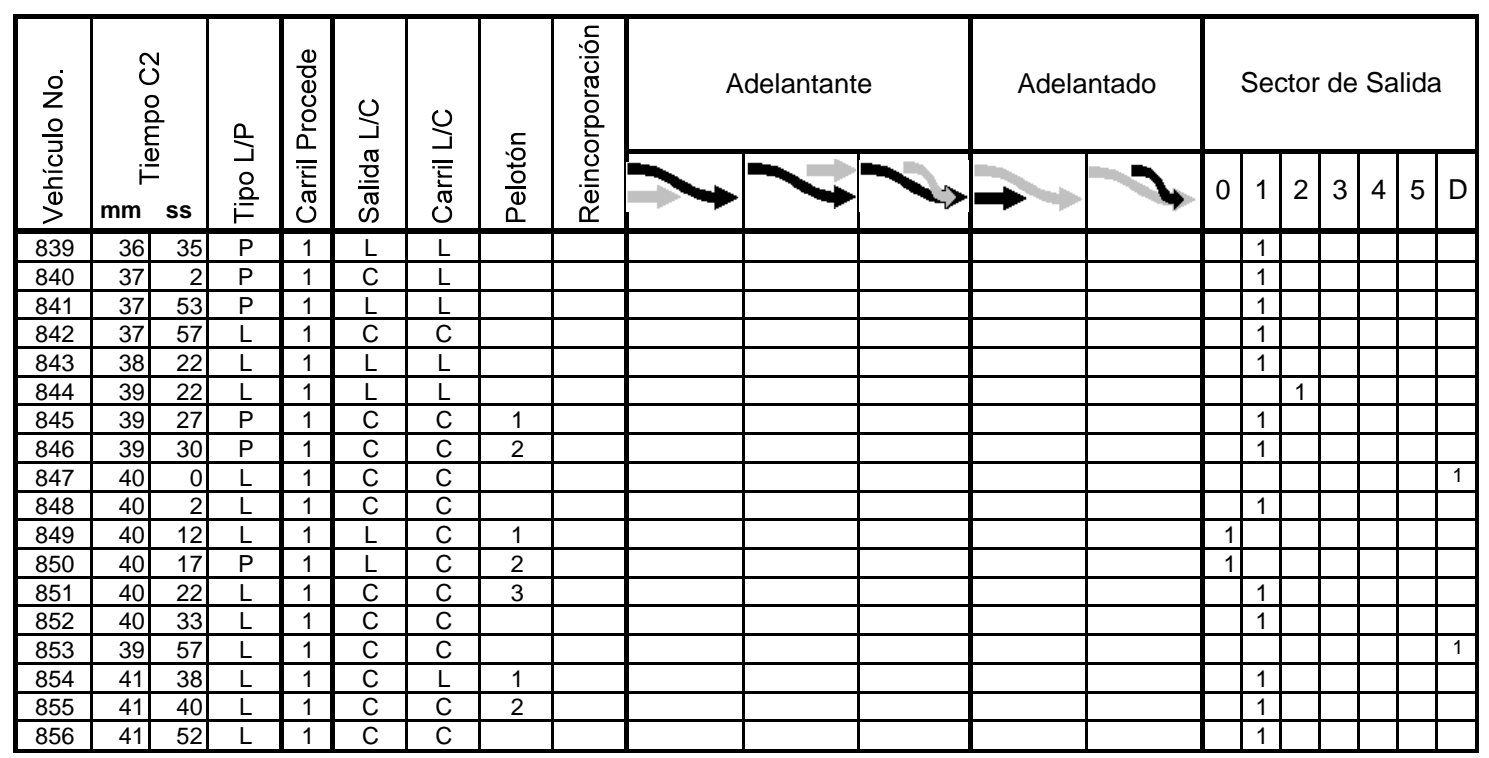




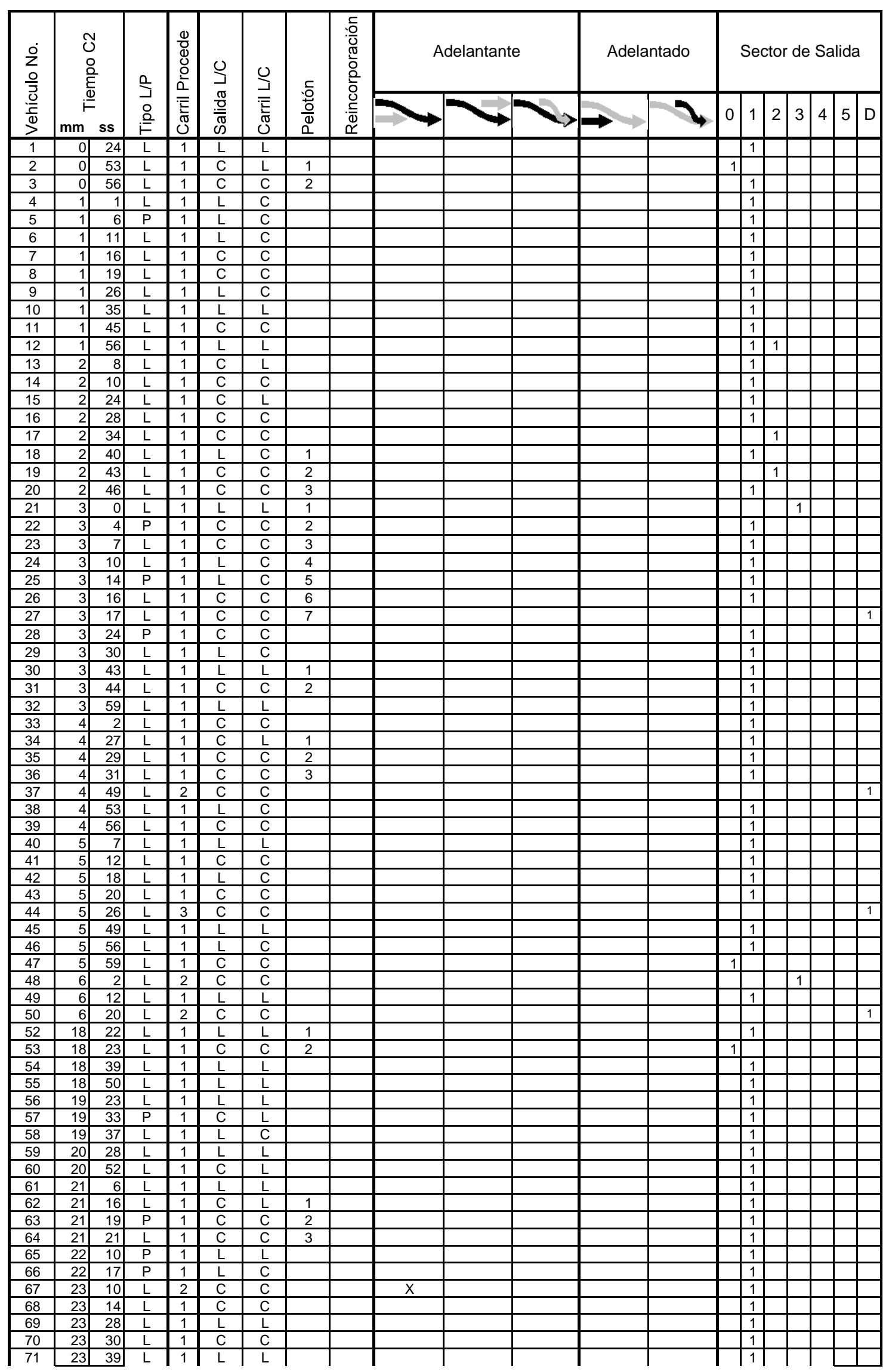




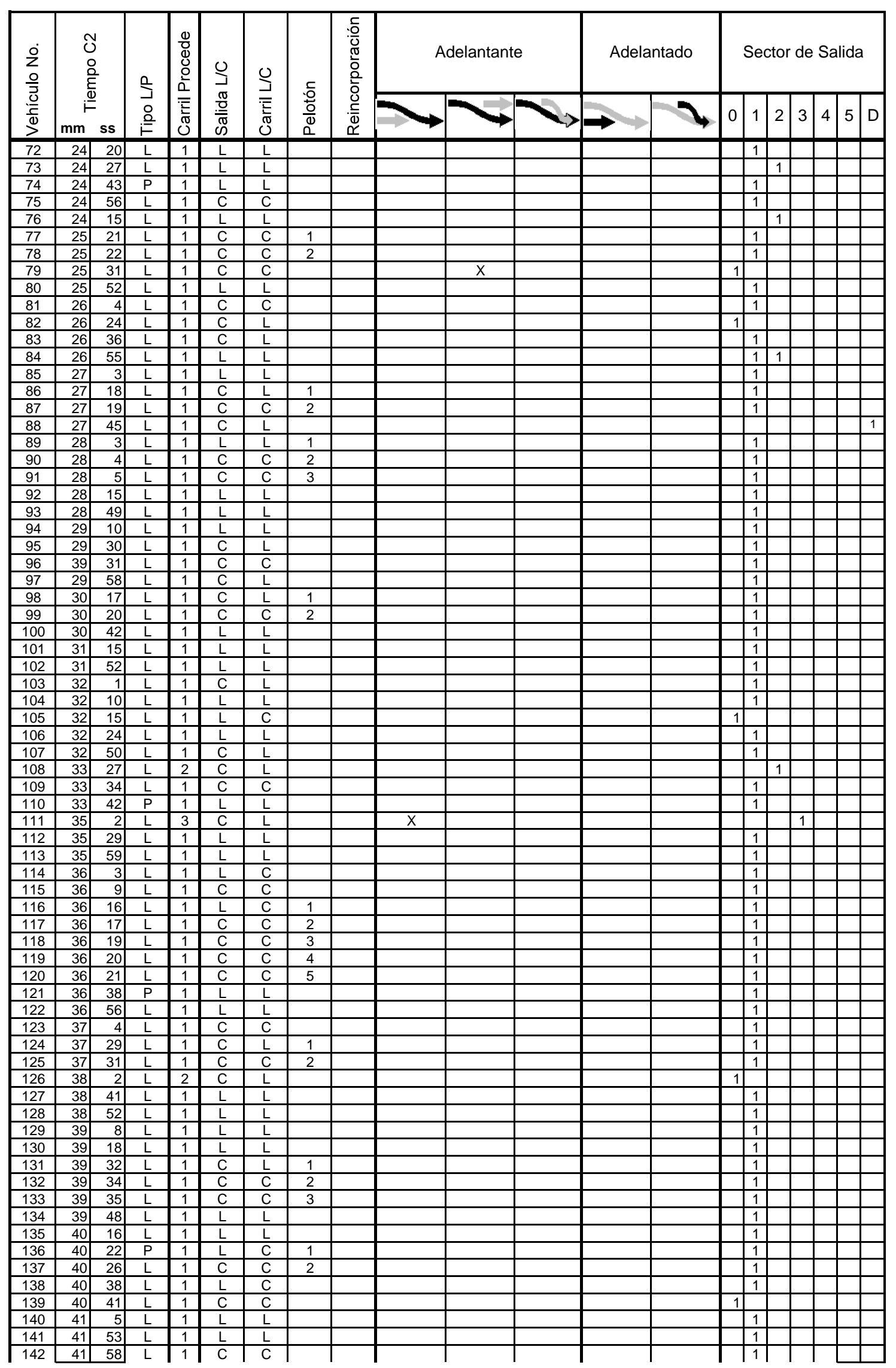




\begin{tabular}{|c|c|c|c|c|c|c|c|c|c|c|c|c|c|c|c|c|c|c|c|}
\hline \multirow{2}{*}{$\begin{array}{l}\text { ㅇ } \\
\text { 을 } \\
\frac{0}{2} \\
\stackrel{0}{0}\end{array}$} & \multirow{2}{*}{\multicolumn{2}{|c|}{$\begin{array}{l}\text { J } \\
\stackrel{\circ}{\circ} \\
\stackrel{E}{\Phi} \\
i=\end{array}$}} & \multirow{2}{*}{ 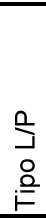 } & O্ & & & & $\begin{array}{l}\text { :음 } \\
\frac{\pi}{0} \\
0\end{array}$ & & Adelantante & Ad & lantado & & $\mathrm{Se}$ & ctor & de & Se & lida & \\
\hline & & & & 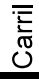 & $\begin{array}{l}\frac{\mathbb{U}}{\bar{O}} \\
\tilde{\mathbb{N}}\end{array}$ & $\begin{array}{l}\bar{\Sigma} \\
\bar{J} \\
\tilde{J}\end{array}$ & $\frac{ \pm}{0}$ & $\begin{array}{l}\stackrel{U}{\Phi} \\
\stackrel{\complement}{\simeq}\end{array}$ & & & & & 0 & 1 & 2 & 3 & 4 & 5 & D \\
\hline 143 & 42 & 8 & L & 1 & $\mathrm{~L}$ & $\mathrm{~L}$ & 1 & & & & & & & 1 & & & & & \\
\hline 144 & 42 & 10 & $\mathrm{~L}$ & 1 & $\mathrm{C}$ & $\mathrm{C}$ & 2 & & & & & & & 1 & & & & & \\
\hline 145 & 42 & 23 & $\mathrm{~L}$ & 1 & $\mathrm{C}$ & $\mathrm{L}$ & & & & & & & 1 & & & & & & \\
\hline 146 & 42 & 55 & $\mathrm{~L}$ & 1 & $\mathrm{~L}$ & $\mathrm{~L}$ & & & & & & & & 1 & & & & & \\
\hline 147 & 43 & 54 & $\mathrm{~L}$ & 1 & $\mathrm{~L}$ & $\mathrm{~L}$ & & & & & & & & 1 & & & & & \\
\hline 148 & 43 & 59 & $\mathrm{~L}$ & 1 & $\mathrm{C}$ & $\mathrm{C}$ & & & & & & & & 1 & & & & & \\
\hline 149 & 44 & 6 & $\mathrm{~L}$ & 1 & $\mathrm{~L}$ & $\mathrm{C}$ & & & & & & & & 1 & & & & & \\
\hline 150 & 44 & 11 & $\mathrm{~L}$ & 1 & $\mathrm{C}$ & $\mathrm{C}$ & & & & & & & 1 & & & & & & \\
\hline 151 & 45 & 46 & $\mathrm{P}$ & 1 & $\mathrm{~L}$ & $\mathrm{~L}$ & & & & & & & & 1 & & & & & \\
\hline 152 & 47 & 37 & $\mathrm{~L}$ & 1 & $\mathrm{~L}$ & $\mathrm{~L}$ & & & & & & & & 1 & & & & & \\
\hline 153 & 47 & 39 & $\mathrm{~L}$ & 1 & $\mathrm{C}$ & $\mathrm{C}$ & & & & & & & & 1 & & & & & \\
\hline 154 & 47 & 48 & $\mathrm{~L}$ & 1 & $\mathrm{~L}$ & $\mathrm{C}$ & & & & & & & 1 & & & & & & \\
\hline 155 & 48 & 39 & $\mathrm{~L}$ & 1 & $\mathrm{~L}$ & $\mathrm{~L}$ & & & & & & & & 1 & & & & & \\
\hline 156 & 49 & 25 & $\mathrm{P}$ & 1 & $\mathrm{~L}$ & $\mathrm{~L}$ & & & & & & & & 1 & & & & & \\
\hline 157 & 49 & 32 & $\mathrm{~L}$ & 1 & $\mathrm{~L}$ & $\mathrm{C}$ & & & & & & & & 1 & & & & & \\
\hline 158 & 49 & 42 & $\mathrm{P}$ & 1 & C & C & 1 & & & & & & & 1 & & & & & \\
\hline 159 & 49 & 44 & $\mathrm{~L}$ & 1 & $\mathrm{C}$ & $\mathrm{C}$ & 2 & & & & & & & 1 & & & & & \\
\hline 160 & 49 & 49 & $\mathrm{~L}$ & 1 & $\mathrm{~L}$ & $\mathrm{C}$ & 3 & & & & & & & 1 & & & & & \\
\hline 161 & 49 & 54 & $\mathrm{~L}$ & 1 & $\mathrm{C}$ & $\mathrm{C}$ & 1 & & & & & & & 1 & & & & & \\
\hline 162 & 49 & 55 & $\mathrm{~L}$ & 1 & $\mathrm{C}$ & $\mathrm{C}$ & 2 & & & & & & & 1 & & & & & \\
\hline 163 & 50 & 43 & $\mathrm{~L}$ & 1 & $\mathrm{C}$ & $\mathrm{L}$ & & & & & & & & 1 & & & & & \\
\hline 164 & 50 & 51 & $\mathrm{~L}$ & 1 & $\mathrm{C}$ & $\mathrm{C}$ & & & & & & & & 1 & & & & & \\
\hline 165 & 51 & 5 & $\mathrm{~L}$ & 1 & $\mathrm{C}$ & $\mathrm{C}$ & & & & & & & & 1 & & & & & \\
\hline 166 & 51 & 6 & $\mathrm{~L}$ & 1 & $\mathrm{C}$ & $\mathrm{C}$ & & & & & & & & - & & & & & \\
\hline 167 & 51 & 28 & $\mathrm{~L}$ & 1 & $\mathrm{~L}$ & $\mathrm{~L}$ & & & & & & & & 1 & & & & & \\
\hline 168 & 51 & 47 & $\mathrm{P}$ & 1 & $\mathrm{~L}$ & $\mathrm{~L}$ & & & & & & & & 1 & & & & & \\
\hline 169 & 51 & 48 & $\mathrm{~L}$ & 1 & $\mathrm{C}$ & $\mathrm{C}$ & & & & & & & & 1 & & & & & \\
\hline 170 & 51 & 49 & $\mathrm{~L}$ & 1 & $\mathrm{C}$ & $\mathrm{C}$ & & & & & & & & 1 & & & & & \\
\hline 171 & 52 & 1 & $\mathrm{~L}$ & 3 & $\mathrm{C}$ & $\mathrm{L}$ & & & $172-X$ & & & & & & & 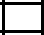 & & & 1 \\
\hline 172 & 52 & 1 & $\mathrm{~L}$ & 1 & $\mathrm{~L}$ & $\mathrm{C}$ & & & & & 171 & & & 1 & & & & & \\
\hline 173 & 52 & 15 & $\mathrm{~L}$ & 2 & $\mathrm{C}$ & $\mathrm{C}$ & & & & & & & & & & 1 & & & \\
\hline 174 & 52 & 37 & $\mathrm{~L}$ & 1 & $\mathrm{~L}$ & $\mathrm{~L}$ & 1 & & & & & & & 1 & & & & & \\
\hline 175 & 52 & 41 & $\mathrm{P}$ & 1 & $\mathrm{C}$ & C & 2 & & & & & & & 1 & & & & & \\
\hline 176 & 52 & 43 & $\mathrm{~L}$ & 1 & $\mathrm{~L}$ & $\mathrm{C}$ & 3 & & & & & & & 1 & & & & & \\
\hline 177 & 52 & 56 & $\mathrm{~L}$ & 11 & $\mathrm{~L}$ & $\mathrm{~L}$ & & & & & & & & 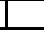 & \begin{tabular}{|l|}
1 \\
\end{tabular} & & & & \\
\hline 178 & 55 & 10 & $\mathrm{~L}$ & 1 & C & $\mathrm{L}$ & & & & & & & & 1 & & & & & \\
\hline 179 & 55 & 41 & $\mathrm{~L}$ & 1 & $\mathrm{C}$ & $\mathrm{L}$ & & & & & & & 1 & & & & & & \\
\hline 180 & 55 & 55 & $\mathrm{~L}$ & 1 & $\mathrm{~L}$ & $\mathrm{~L}$ & 1 & & & & & & & 1 & & & & & \\
\hline 181 & 55 & 57 & $\mathrm{~L}$ & 1 & C & C & 2 & & & & & & & 1 & & & & & \\
\hline 182 & 56 & 3 & $\mathrm{~L}$ & 1 & $\mathrm{~L}$ & $\mathrm{C}$ & & & & & & & & 1 & & & & & \\
\hline 183 & 56 & 27 & $\mathrm{~L}$ & 1 & $\mathrm{~L}$ & $\mathrm{~L}$ & & & & & & & & 1 & & & & & \\
\hline 184 & 56 & 40 & $\mathrm{~L}$ & 1 & $\mathrm{C}$ & $\mathrm{L}$ & & 1 & & & & & & 1 & & & & & \\
\hline 185 & 56 & 50 & $\mathrm{~L}$ & 1 & $\mathrm{~L}$ & $\mathrm{~L}$ & & & & & & & & 1 & & & & & \\
\hline 186 & 57 & 12 & $\mathrm{~L}$ & 1 & $\mathrm{C}$ & $\mathrm{L}$ & & & & & & & & 1 & & & & & \\
\hline 187 & 57 & 15 & $\mathrm{~L}$ & 1 & $\mathrm{C}$ & $\mathrm{C}$ & & & & & & & 1 & & & & & & \\
\hline 188 & 57 & 19 & $\mathrm{~L}$ & 1 & $\mathrm{~L}$ & $\mathrm{C}$ & & & & & & & & 1 & & & & & \\
\hline 189 & 57 & 50 & $\mathrm{~L}$ & 1 & $\mathrm{~L}$ & $\mathrm{~L}$ & & & & & & & & 1 & & & & & \\
\hline 190 & 58 & 2 & $\mathrm{~L}$ & 1 & $\mathrm{~L}$ & $\mathrm{~L}$ & & & & & & & & 1 & & & & & \\
\hline 191 & 58 & 6 & $\mathrm{~L}$ & 1 & $\mathrm{C}$ & $\mathrm{C}$ & & & & & & & & 1 & & & & & \\
\hline 192 & 58 & 18 & $\mathrm{~L}$ & 1 & $\mathrm{~L}$ & $\mathrm{C}$ & & & & & & & & 1 & & & & & \\
\hline 193 & 59 & 29 & $\mathrm{~L}$ & 1 & $\mathrm{~L}$ & $\mathrm{C}$ & & & & & & & & 1 & & & & & \\
\hline 194 & 59 & 25 & $\mathrm{~L}$ & 1 & $\mathrm{~L}$ & $\mathrm{~L}$ & & & & & & & & 1 & & & & & \\
\hline 195 & 59 & 37 & $\mathrm{~L}$ & 1 & $\mathrm{~L}$ & $\mathrm{~L}$ & & & & & & & & 1 & & & & & \\
\hline 196 & 59 & 43 & $\mathrm{~L}$ & 1 & $\mathrm{~L}$ & C & & & & & & & & -1 & 1 & & & & \\
\hline 197 & 59 & 55 & $\mathrm{~L}$ & 1 & $\mathrm{~L}$ & $\mathrm{C}$ & & & & & & & & 1 & & & & & \\
\hline 198 & 60 & 8 & $\mathrm{~L}$ & 1 & $\mathrm{C}$ & $\mathrm{L}$ & & & & & & & 1 & & & & & & \\
\hline 199 & 61 & 7 & $\mathrm{~L}$ & 1 & $\mathrm{~L}$ & $\mathrm{~L}$ & & & & & & & & 1 & & & & & \\
\hline 200 & 61 & 43 & $\mathrm{~L}$ & 1 & $\mathrm{~L}$ & $\mathrm{~L}$ & & & & & & & & 1 & & & & & \\
\hline 201 & 62 & 3 & $\mathrm{~L}$ & 1 & $\mathrm{C}$ & $\mathrm{L}$ & & & & & & & & 1 & & & & & \\
\hline 202 & 62 & 30 & $\mathrm{~L}$ & 1 & $\mathrm{~L}$ & $\mathrm{~L}$ & & & & & & & & 1 & & & & & \\
\hline 203 & 62 & 44 & $\mathrm{~L}$ & 1 & $\mathrm{C}$ & $\mathrm{L}$ & & & & & & & & - & & 1 & & & \\
\hline 204 & 62 & 47 & $\mathrm{~L}$ & 1 & $\mathrm{~L}$ & $\mathrm{C}$ & & & & & & & & 1 & & & & & \\
\hline 205 & 62 & 59 & $\mathrm{~L}$ & 1 & C & $\mathrm{L}$ & & & & & & & & 1 & & & & & \\
\hline 206 & 63 & 50 & $\mathrm{~L}$ & 1 & $\mathrm{~L}$ & $\mathrm{~L}$ & & & & & & & & 1 & & & & & \\
\hline 207 & 64 & 4 & $\mathrm{P}$ & 1 & $\mathrm{~L}$ & $\mathrm{~L}$ & & & & & & & & 1 & & & & & \\
\hline 208 & 64 & 16 & $\mathrm{P}$ & 1 & C & C & & & & & & & 1 & & & & & & \\
\hline 209 & 64 & 44 & $\mathrm{~L}$ & 1 & $\mathrm{C}$ & $\mathrm{L}$ & & & & & & & & 1 & & & & & \\
\hline 210 & 65 & 15 & $\mathrm{~L}$ & 1 & $\mathrm{C}$ & $\mathrm{L}$ & & & & & & & & 1 & & & & & \\
\hline 211 & 65 & 34 & $\mathrm{~L}$ & 2 & $\mathrm{C}$ & $\mathrm{L}$ & & & & & & & & & 1 & & & & \\
\hline 212 & 65 & 41 & $\mathrm{~L}$ & 1 & $\mathrm{C}$ & $\mathrm{C}$ & & & & & & & & 1 & & & & & \\
\hline 213 & 65 & 43 & $\mathrm{~L}$ & 1 & $\mathrm{C}$ & $\mathrm{C}$ & & & & & & & & 1 & & & & & \\
\hline
\end{tabular}




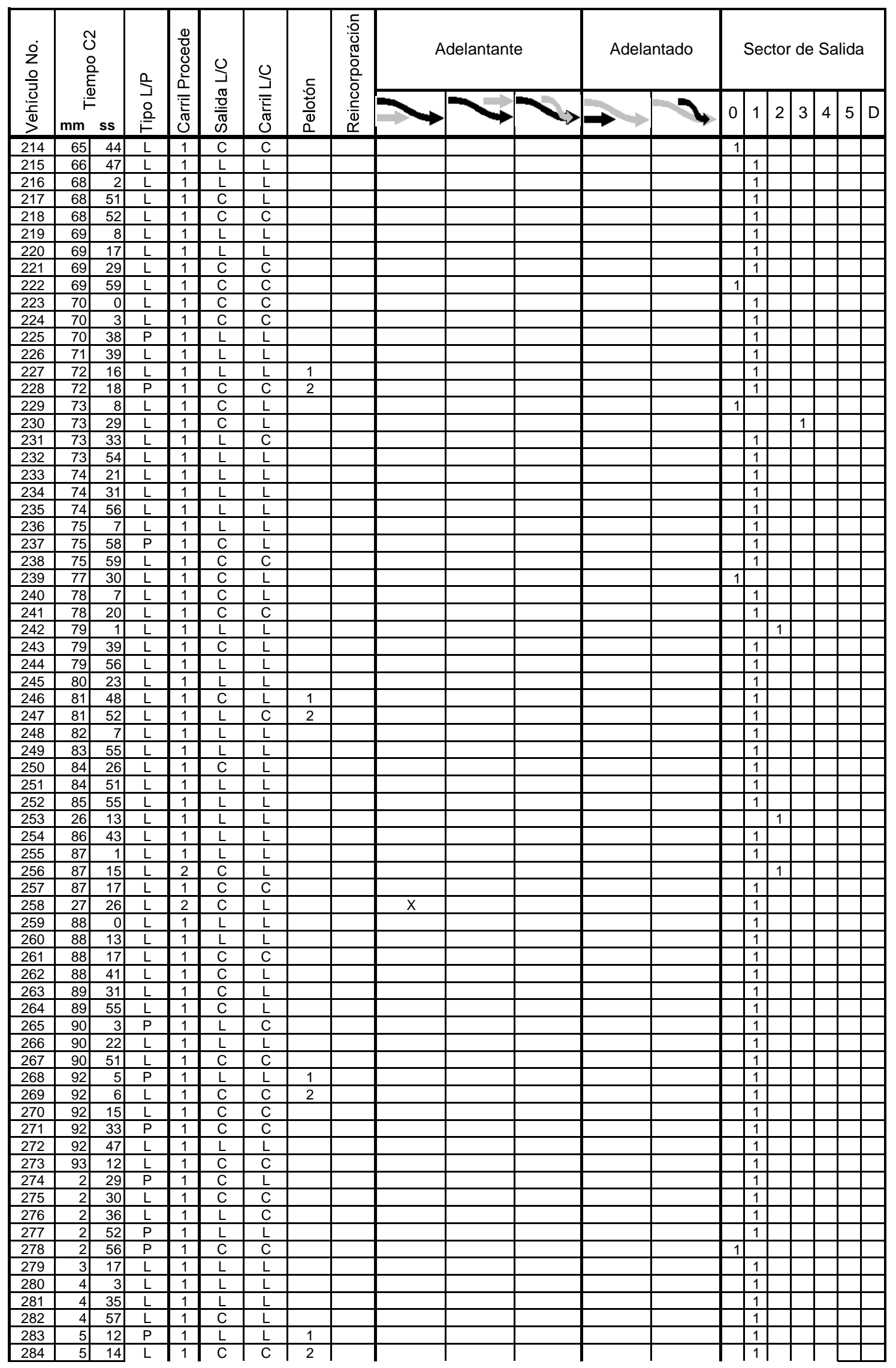




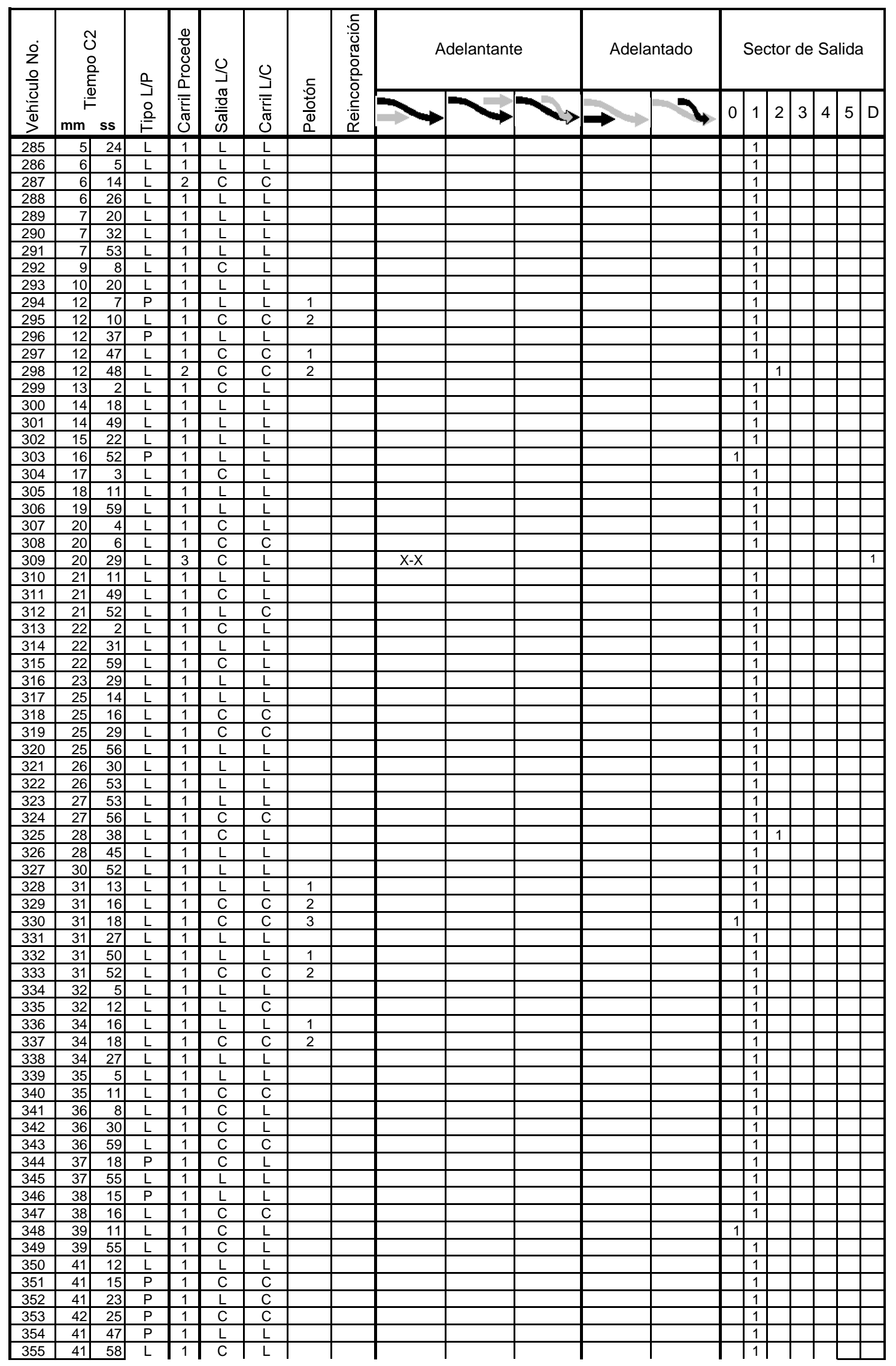




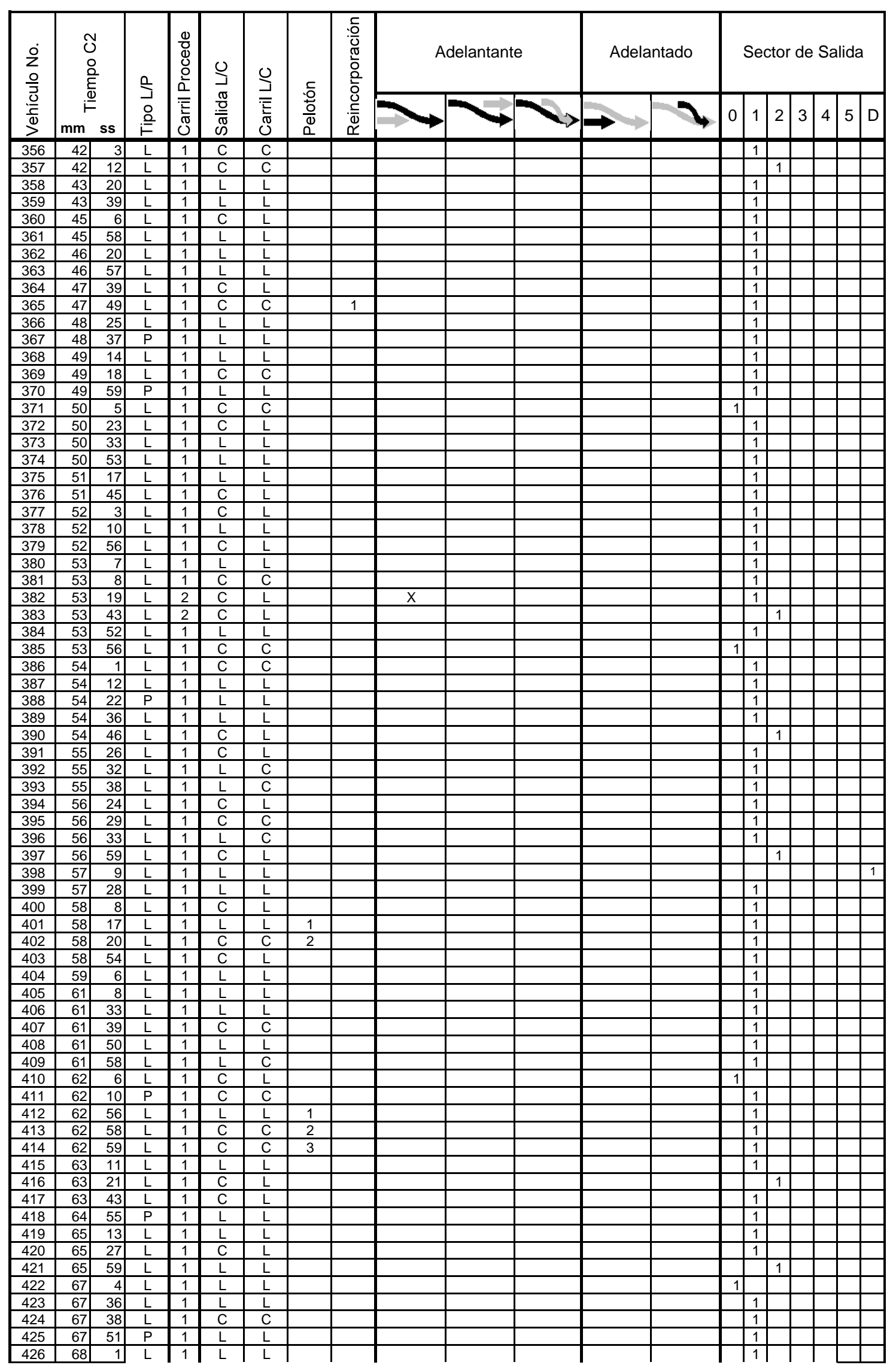




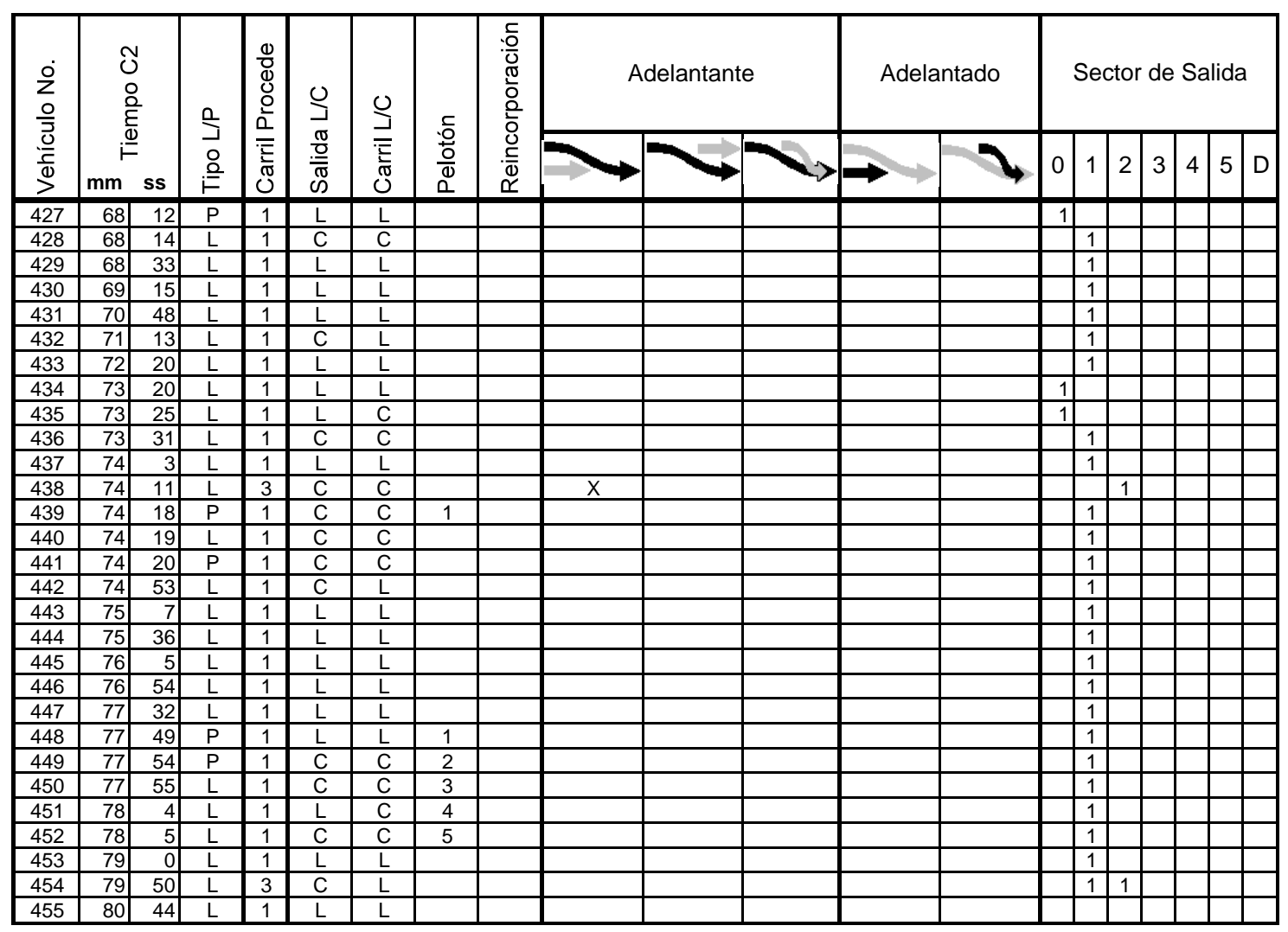




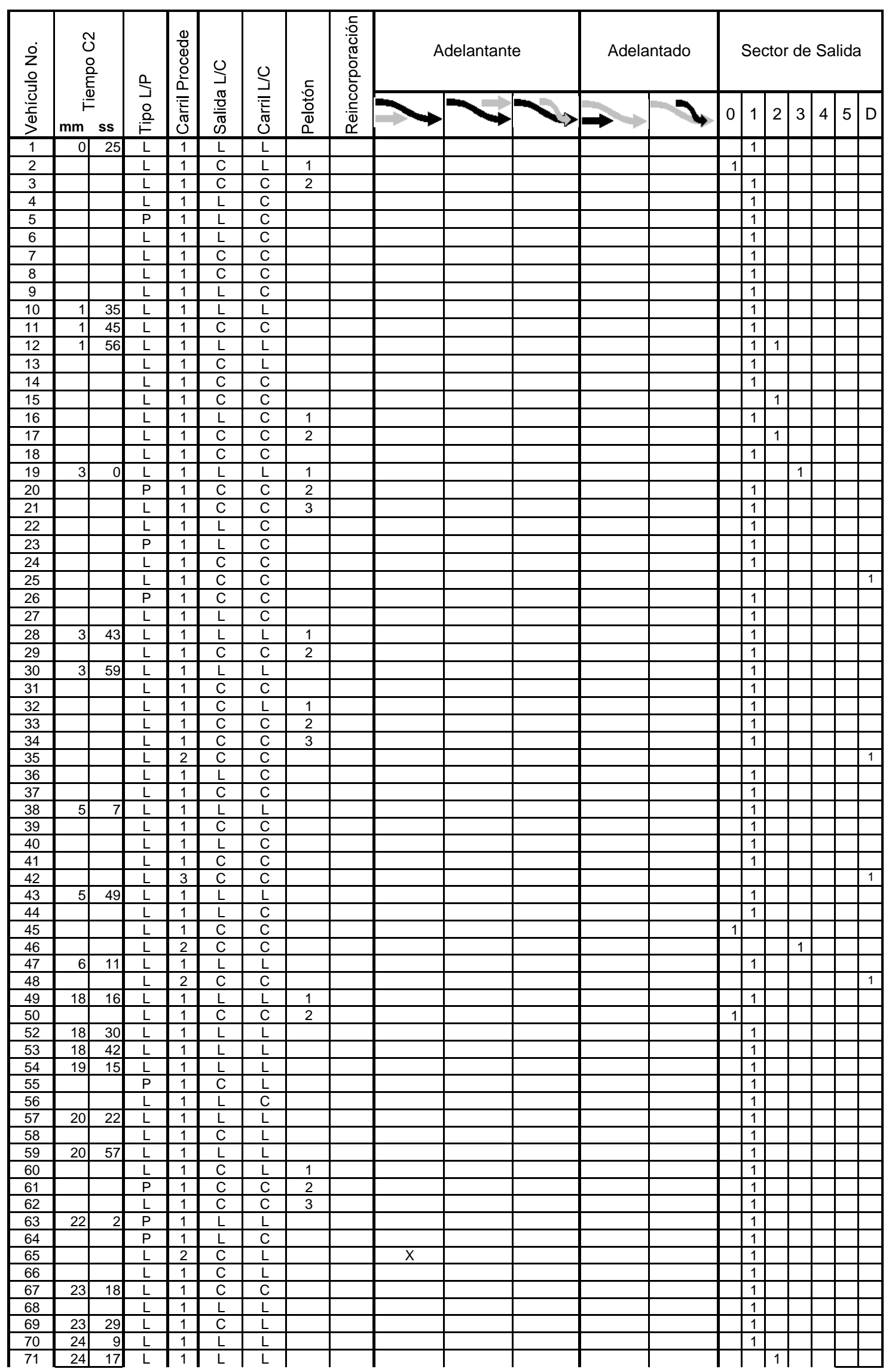




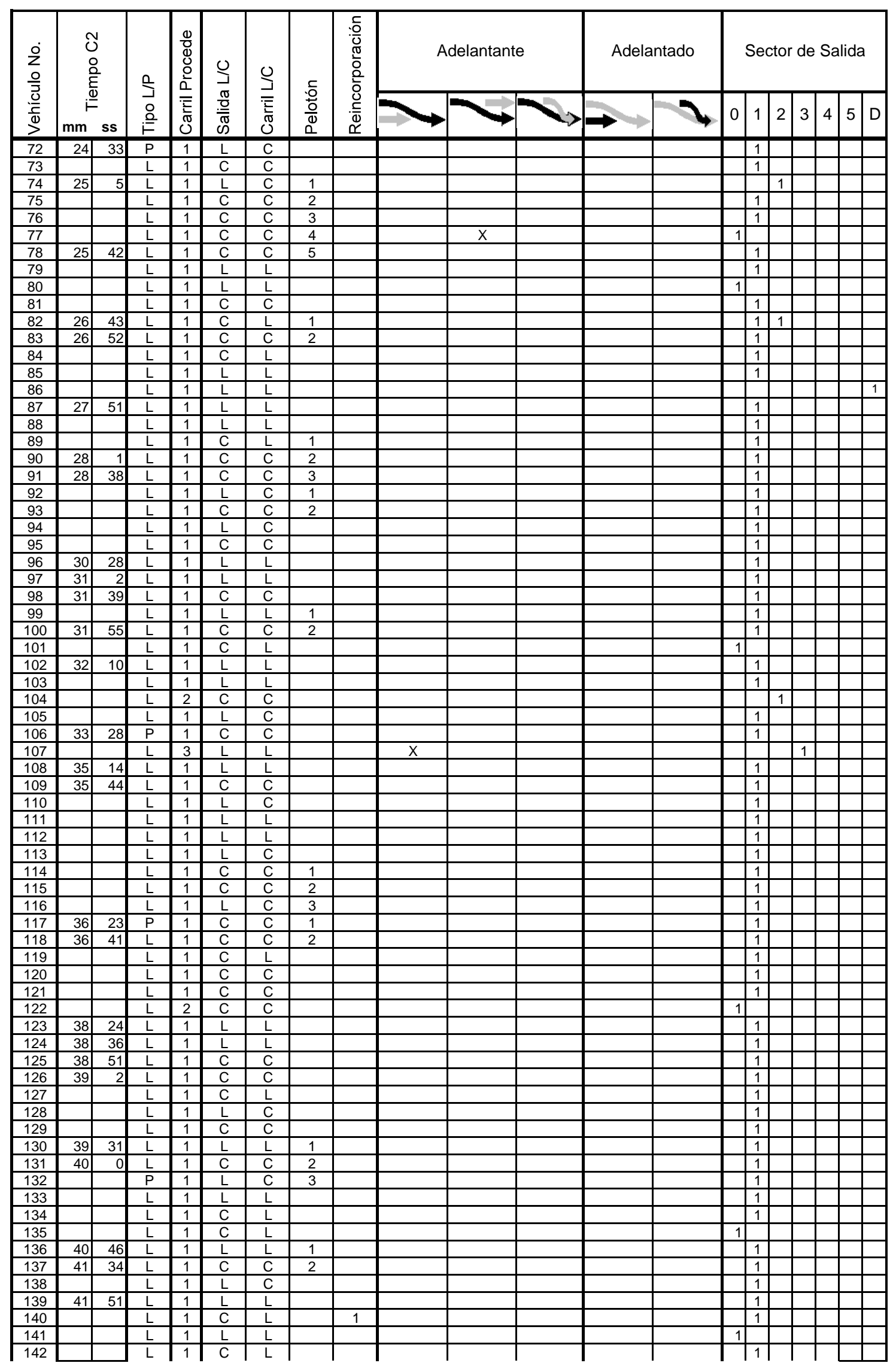




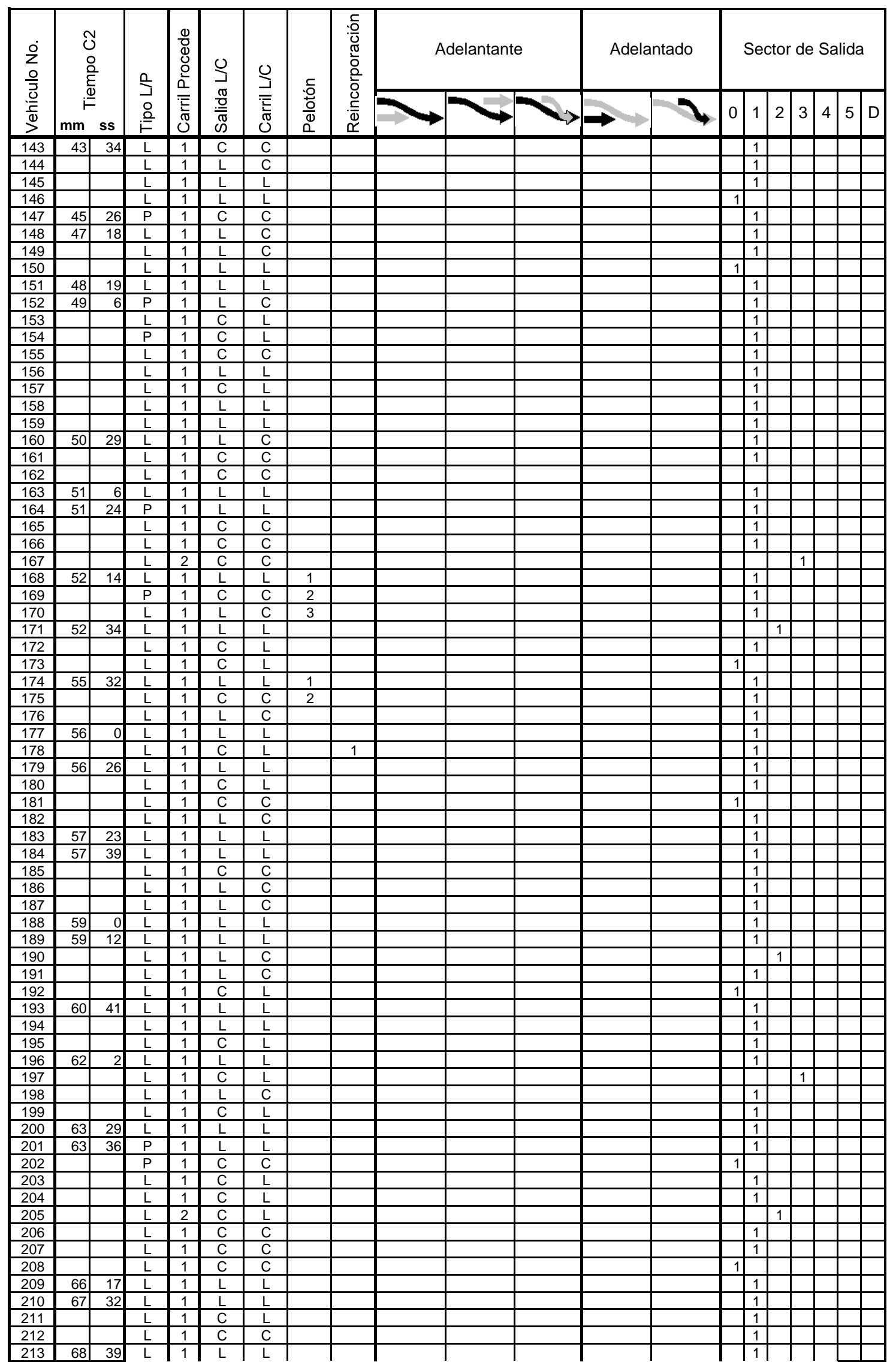




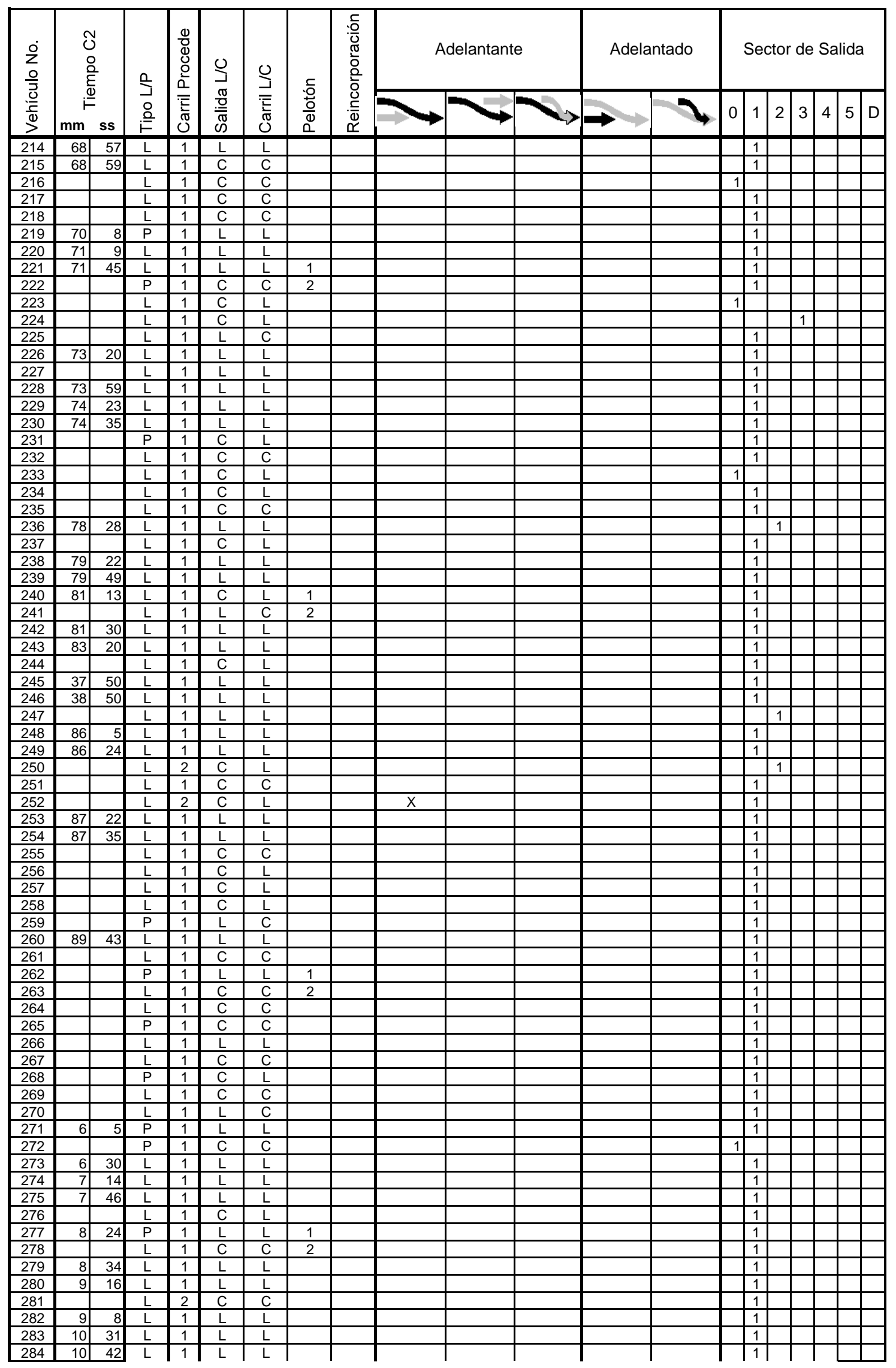




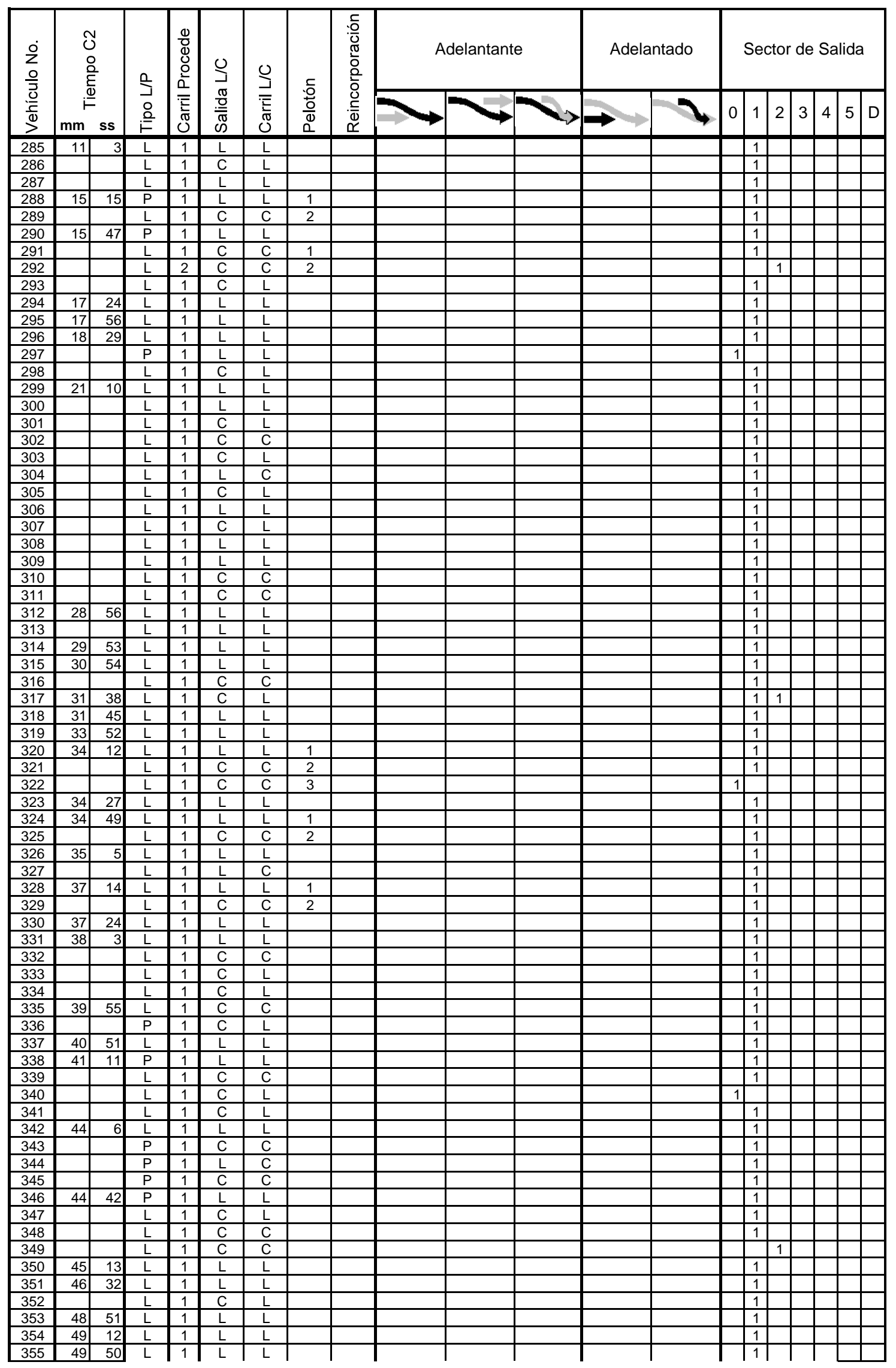




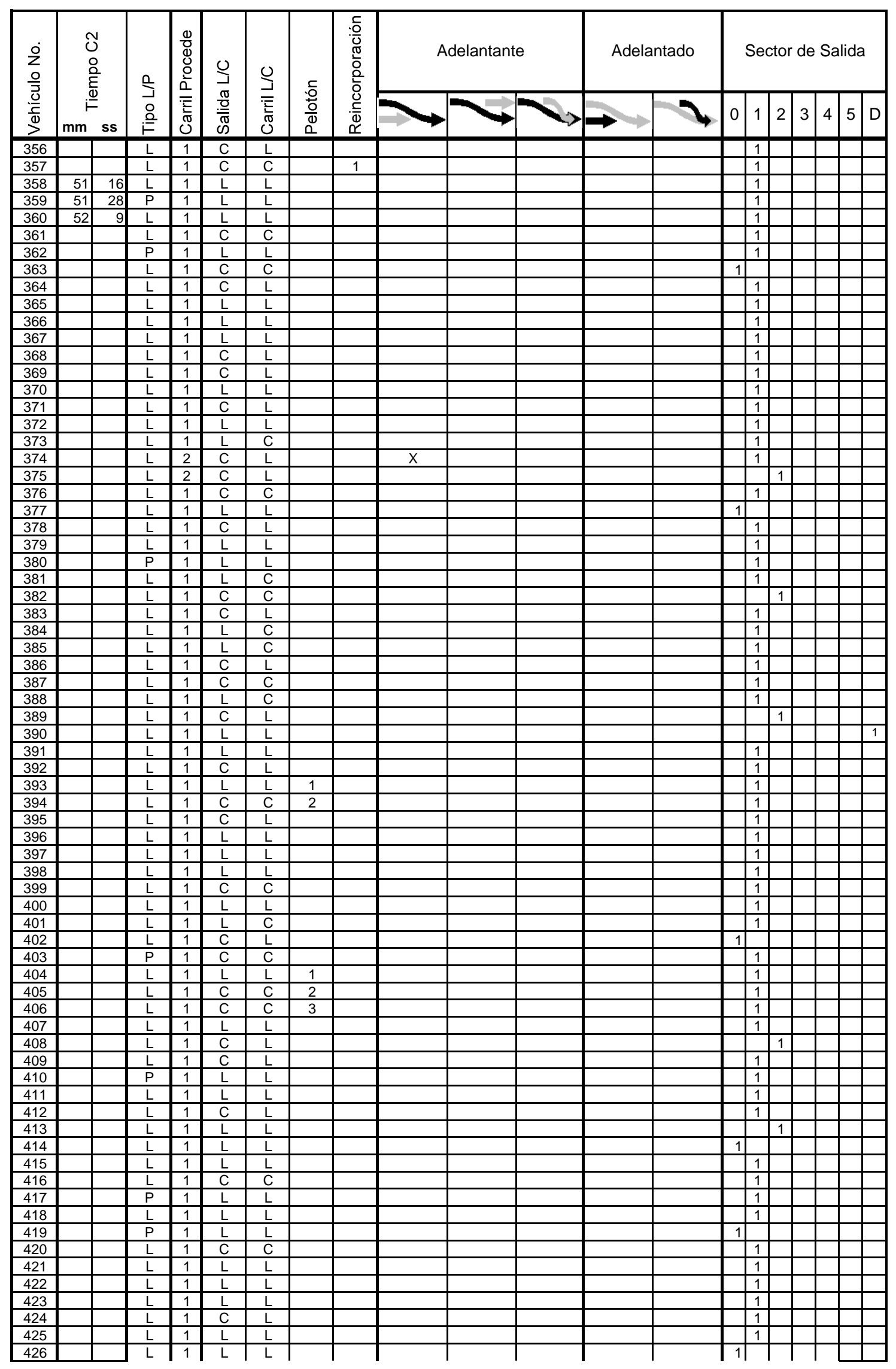




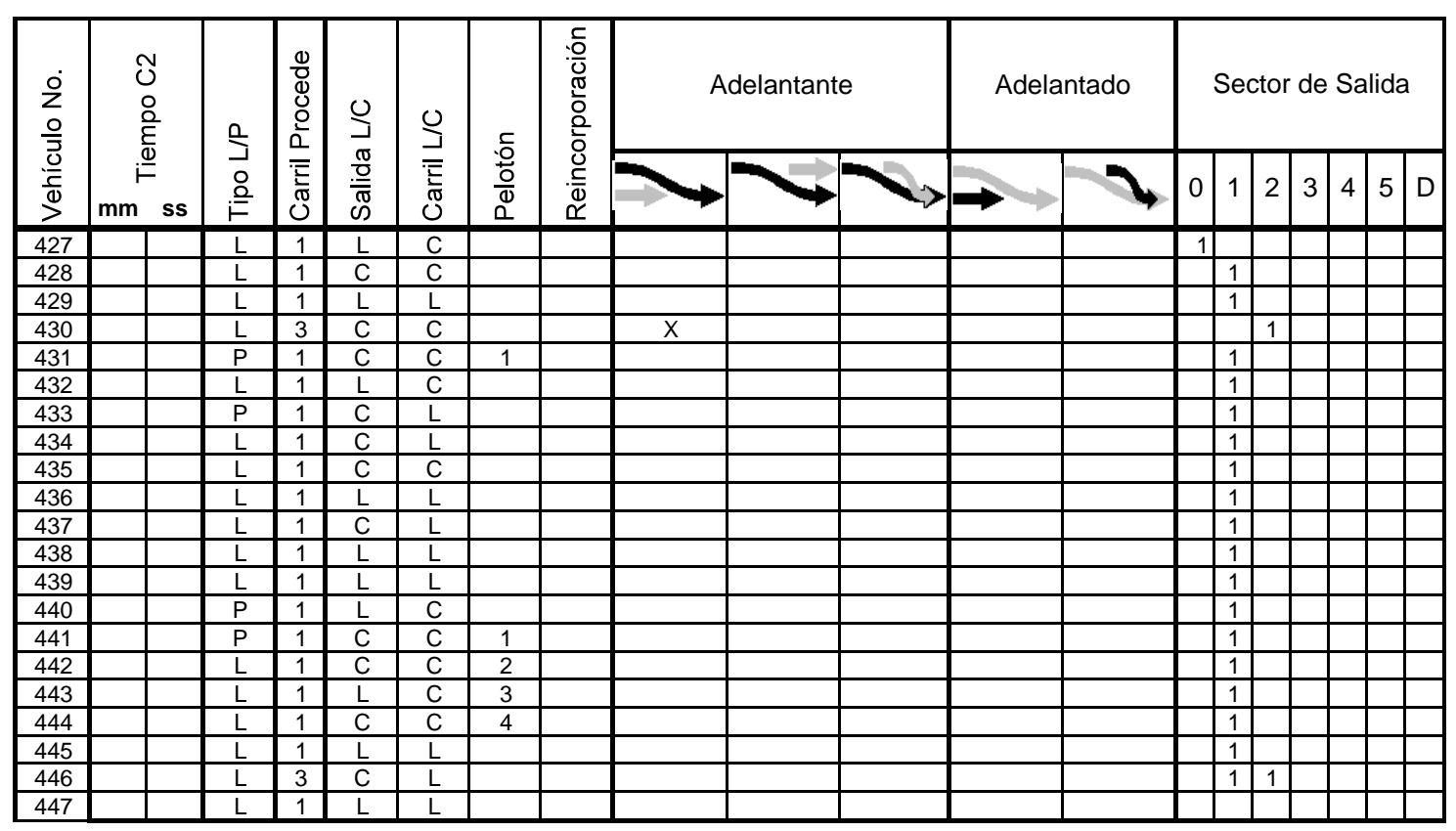




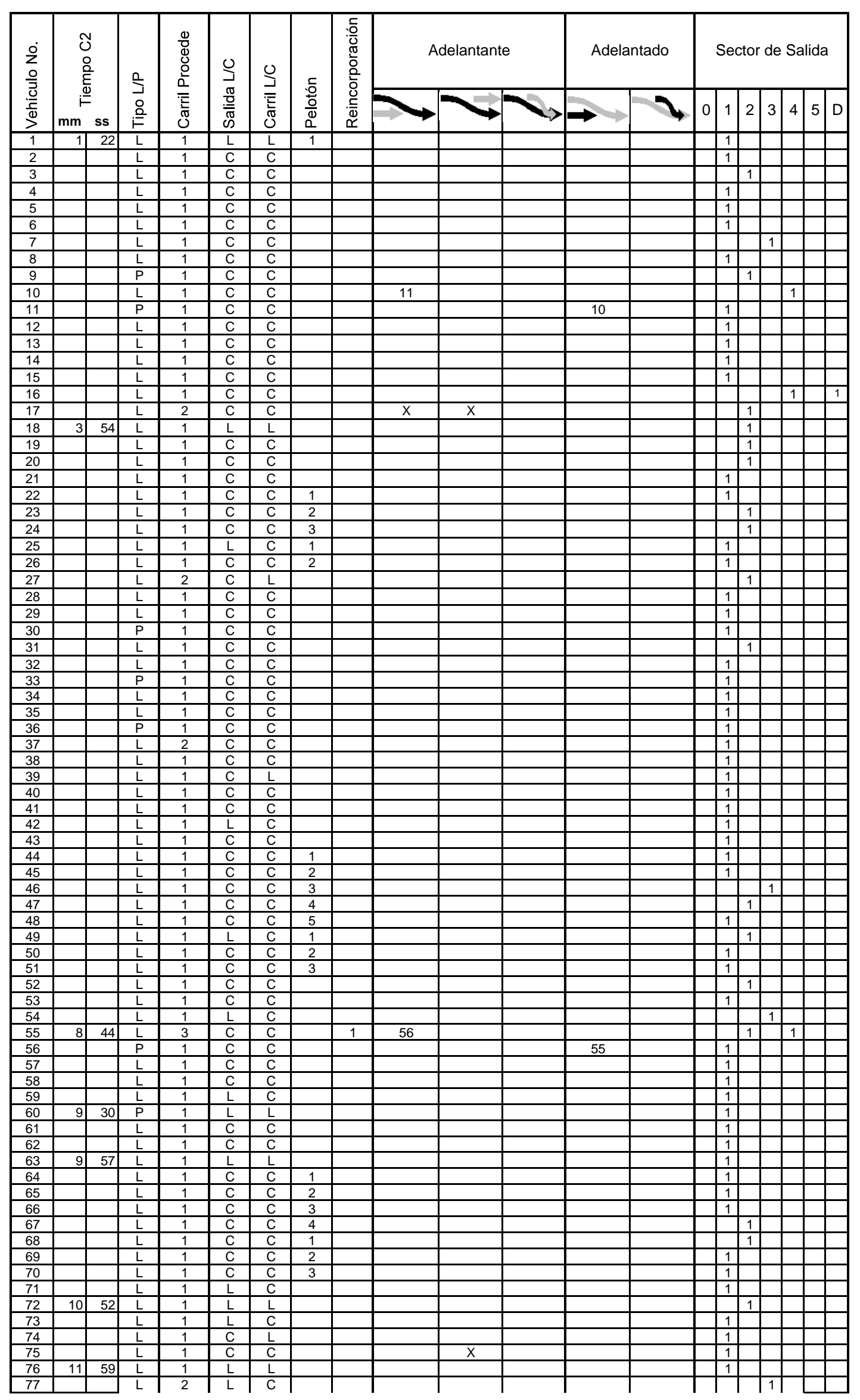




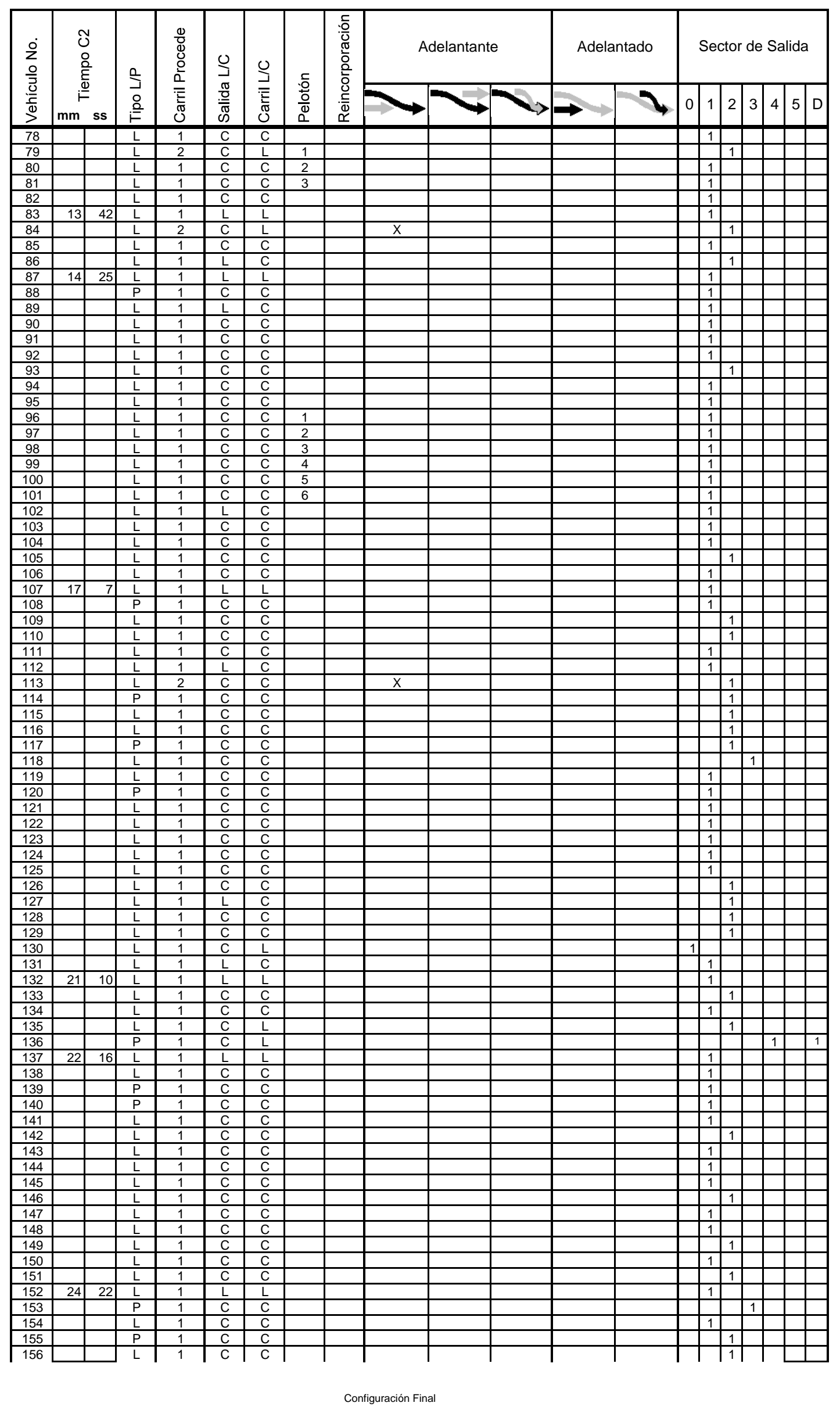




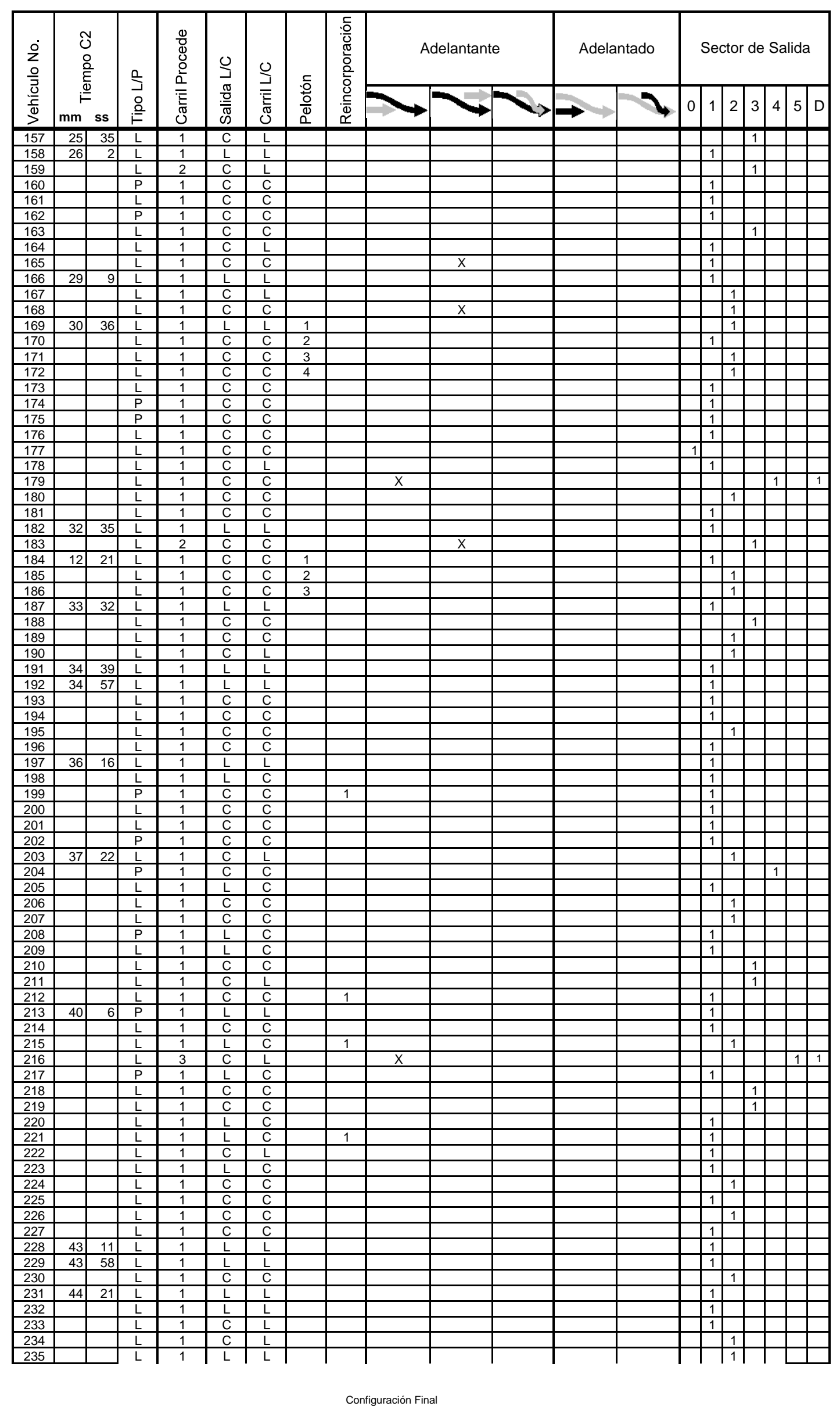




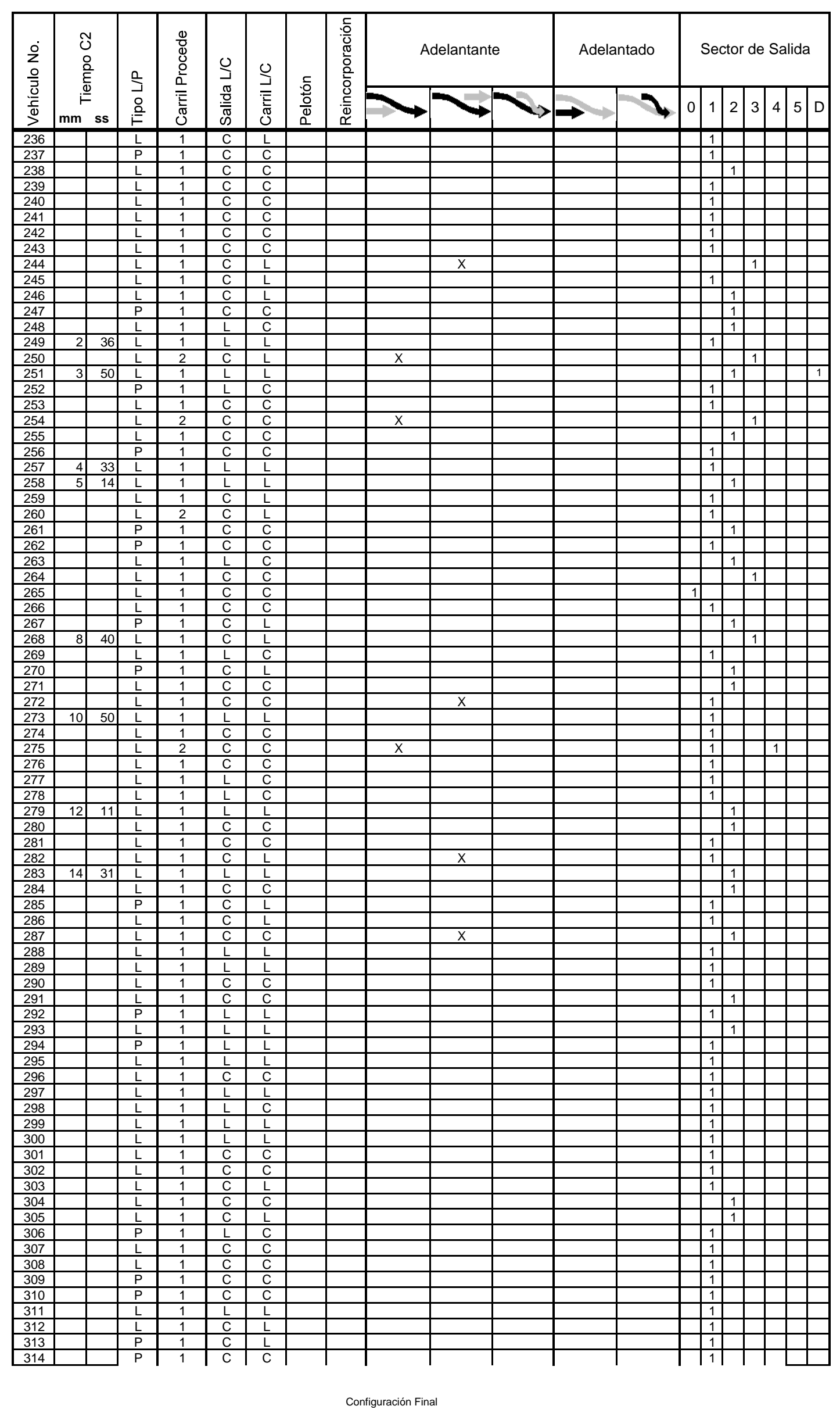




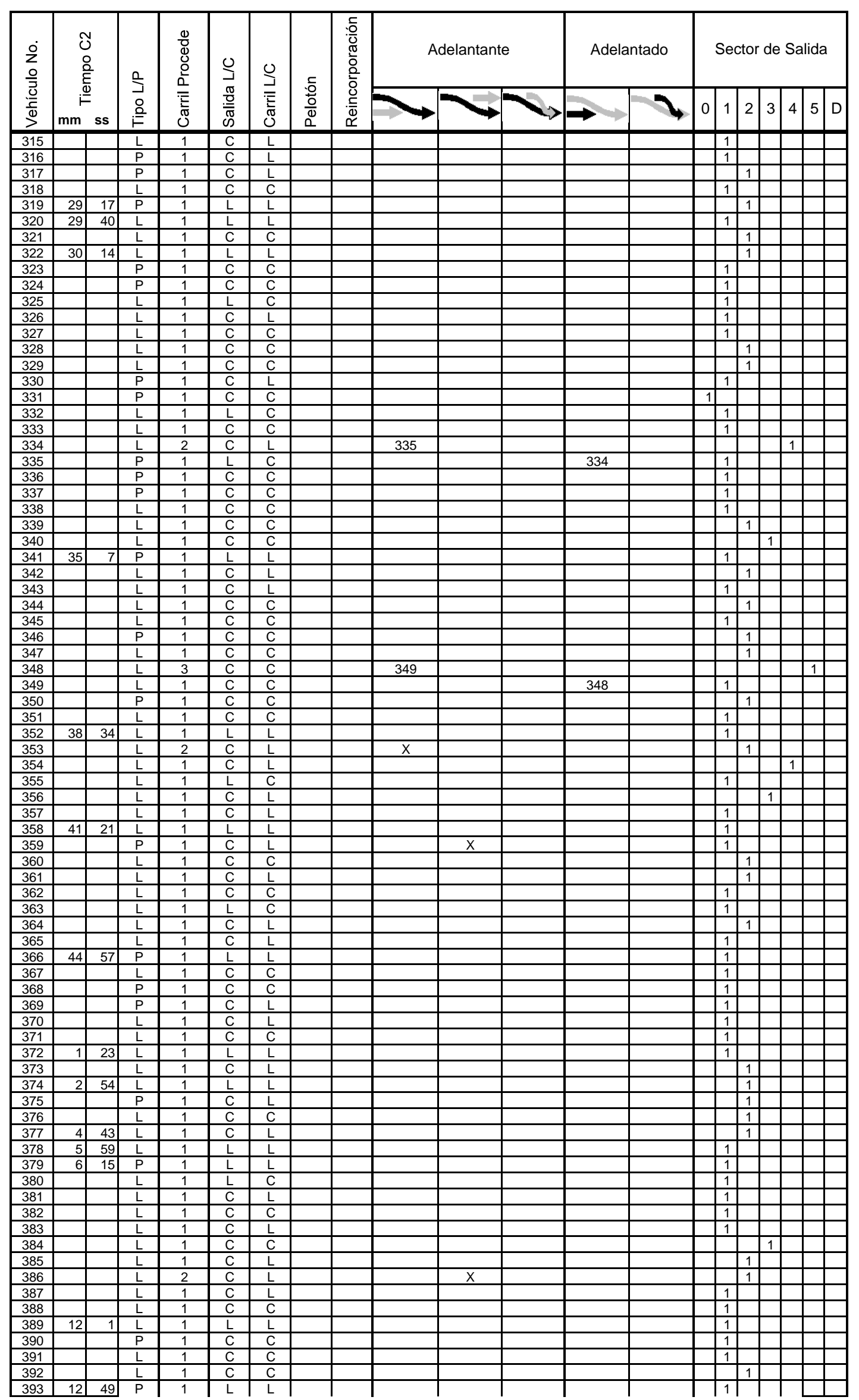




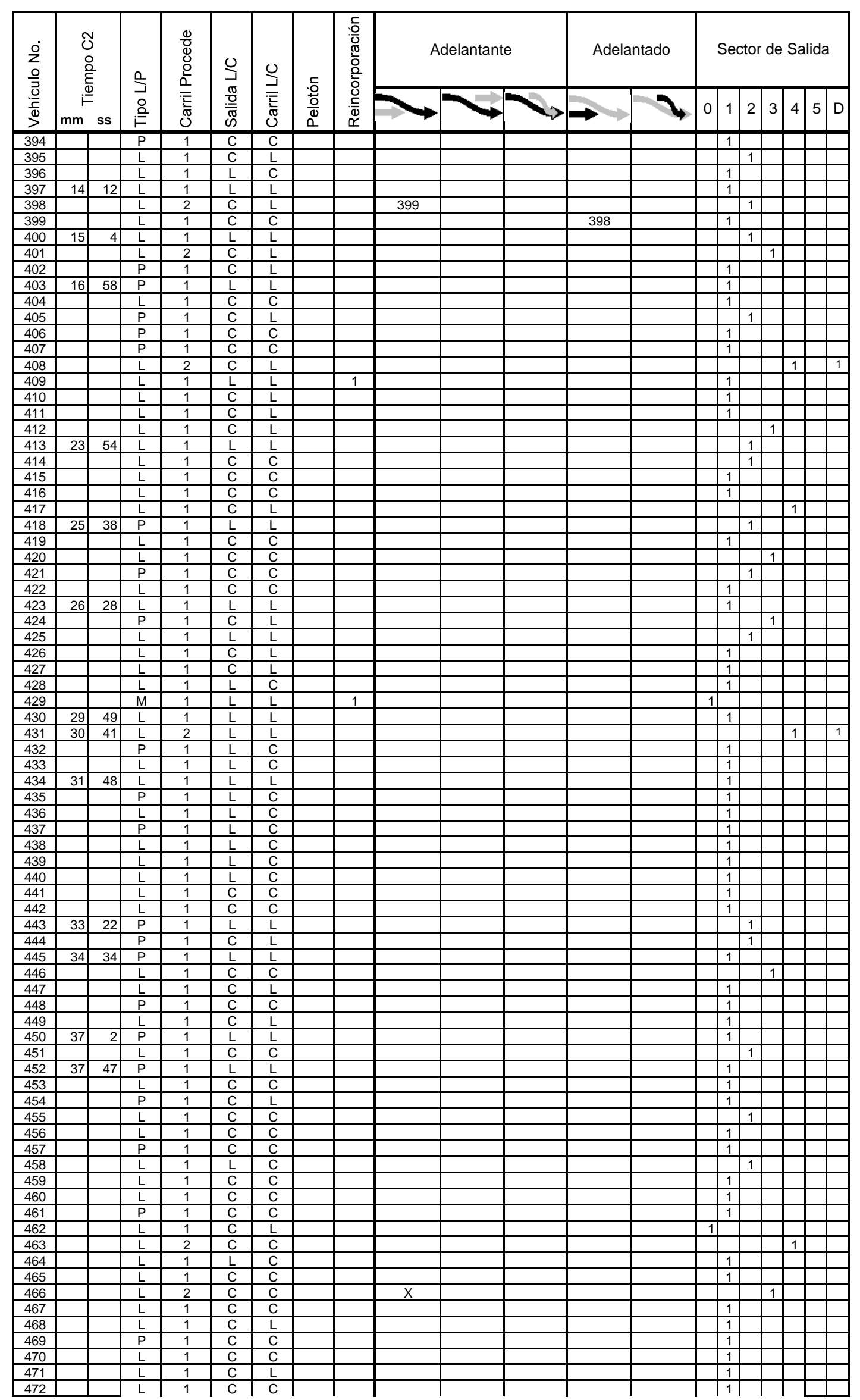




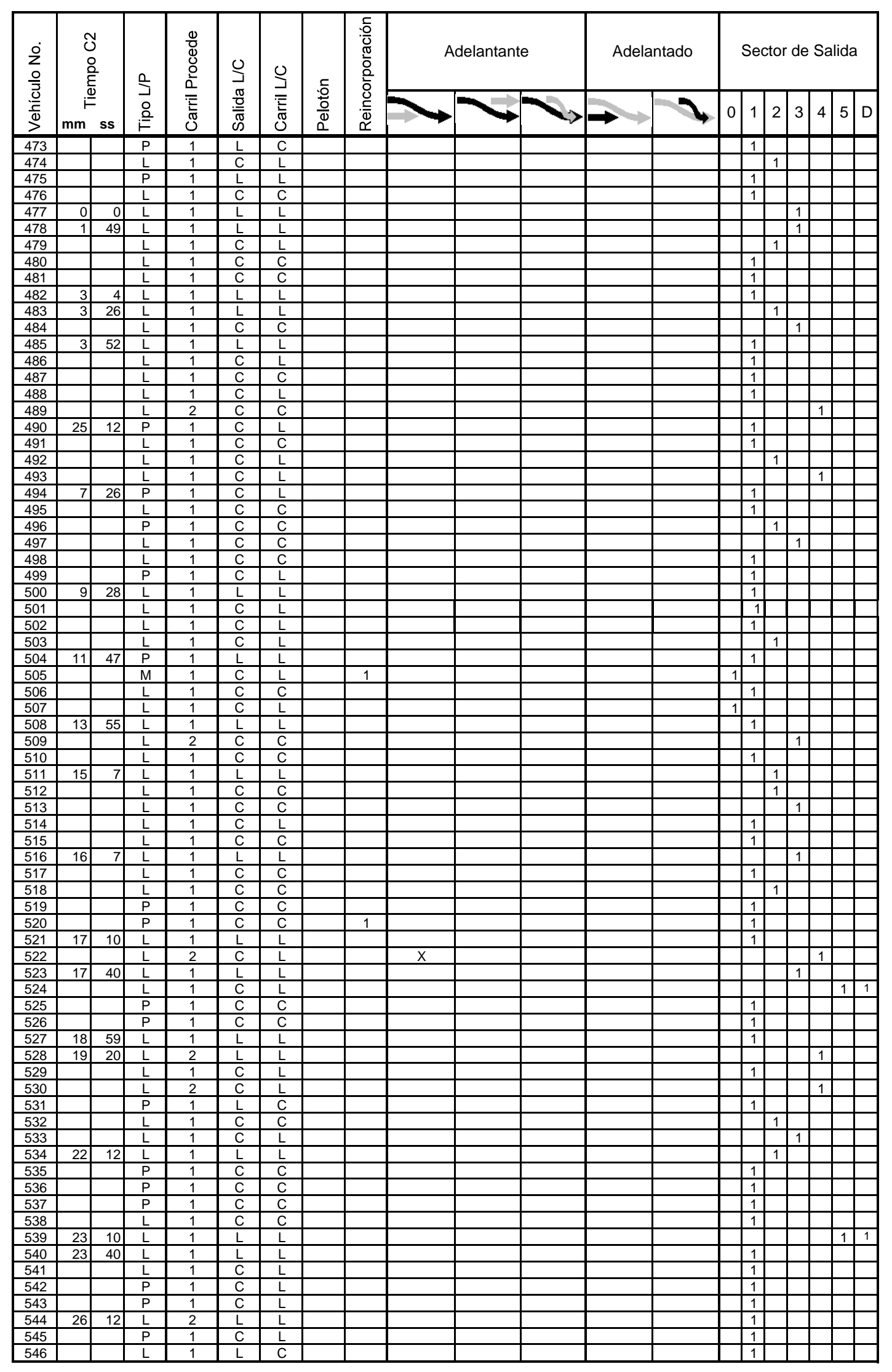




\begin{tabular}{|l|c|c|}
\hline \multicolumn{2}{|c|}{ V31-98 } \\
\hline Maniobras & 358 & \\
\hline Salida anticipada & 0 & $0,0 \%$ \\
\hline Salida en la cuña & 281 & $78,5 \%$ \\
\hline Salida zona media & 62 & $17,3 \%$ \\
\hline Salida tardia & 15 & $4,2 \%$ \\
\hline Origen carriles ràpidos & 39 & $10,9 \%$ \\
\hline Reincorporaciones & 1 & $0,3 \%$ \\
\hline Adelantamiento exterior & 15 & $4,2 \%$ \\
\hline Adelantamiento interior & 20 & $5,6 \%$ \\
\hline Adelantamiento interior confluyente & 3 & $0,8 \%$ \\
\hline
\end{tabular}

\begin{tabular}{|c|c|c|c|c|c|c|}
\hline i & $\begin{array}{l}\frac{\pi}{0} \\
\frac{0}{\pi} \\
\stackrel{\mathscr{D}}{2}\end{array}$ & $\begin{array}{l}\frac{0}{0} \\
\frac{0}{2} \\
\frac{\pi}{0} \\
\frac{c}{0} \\
\frac{0}{2} \\
0\end{array}$ & 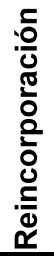 & 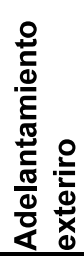 & 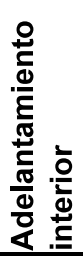 & 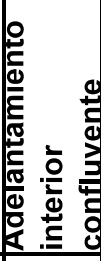 \\
\hline 1 & 1 & & & & & \\
\hline 2 & 1 & & & & & \\
\hline 3 & 1 & & & & $\mathrm{X}$ & \\
\hline 4 & 1 & $X$ & & & & \\
\hline 5 & 1 & & & & & \\
\hline 6 & 2 & & & $\bar{X}$ & & \\
\hline 7 & 1 & & & & & \\
\hline 8 & 1 & & & & & \\
\hline 9 & 1 & & & & & \\
\hline 10 & 1 & & & & & \\
\hline 11 & 1 & & & & & \\
\hline 12 & 2 & $\mathrm{X}$ & & & & \\
\hline 13 & 1 & & & & & \\
\hline 14 & 2 & & & & & \\
\hline 15 & 1 & & & & & \\
\hline 16 & 1 & & & & & \\
\hline 17 & 1 & & & & & \\
\hline 18 & 1 & & & & & \\
\hline 19 & 2 & & & & & \\
\hline 20 & 1 & & & & & \\
\hline 21 & 1 & & & & & \\
\hline 22 & 2 & $\bar{X}$ & & $\bar{X}$ & & \\
\hline 23 & 1 & $X$ & & & & \\
\hline 24 & 2 & & & & & \\
\hline 25 & 1 & & & & & \\
\hline 26 & 1 & $\bar{X}$ & & & & \\
\hline 27 & 1 & & & & & \\
\hline 28 & 1 & & & & & \\
\hline 29 & 1 & & & & & \\
\hline 30 & 1 & & & & & \\
\hline 31 & 1 & & & & & \\
\hline 32 & 1 & & & & & \\
\hline 33 & 1 & & & & & \\
\hline
\end{tabular}

\begin{tabular}{|c|c|c|c|c|c|c|}
\hline i & $\frac{\pi}{\frac{\pi}{0}}$ & \begin{tabular}{l}
$\frac{0}{0}$ \\
\hdashline$\frac{0}{2}$ \\
$\frac{10}{2}$ \\
$\frac{1}{0}$ \\
은 \\
0
\end{tabular} & 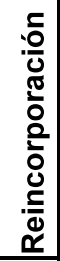 & 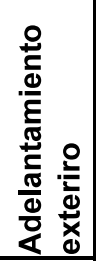 & 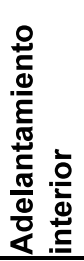 & 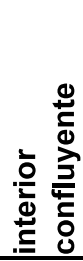 \\
\hline 34 & 1 & & & & & \\
\hline 35 & 1 & & & & & \\
\hline 36 & 1 & & & & & \\
\hline 37 & 1 & & & & & \\
\hline 38 & 1 & & & & & \\
\hline 39 & 1 & & & & & \\
\hline 40 & 1 & & & & & \\
\hline 41 & 2 & & & & & \\
\hline 42 & 1 & & & & & \\
\hline 43 & 2 & $\bar{X}$ & & $\bar{X}$ & & \\
\hline 44 & 1 & & & & & \\
\hline 45 & 1 & & & & & \\
\hline 46 & 1 & & & & & \\
\hline 47 & 2 & & & & & \\
\hline 48 & 1 & & & & & \\
\hline 49 & 1 & & & & & \\
\hline 50 & 1 & & & & & \\
\hline 51 & 1 & & & & & \\
\hline 52 & 3 & $\bar{X}$ & & & & \\
\hline 53 & 1 & & & & & \\
\hline 54 & 3 & $\bar{X}$ & & $\bar{X}$ & & \\
\hline 55 & 2 & & & & & \\
\hline 56 & 1 & & & & & \\
\hline 57 & 1 & & & & & \\
\hline 58 & 1 & & & & & \\
\hline 59 & 1 & & & & & \\
\hline 60 & 1 & & & & & \\
\hline 61 & 2 & & & & & \\
\hline 62 & 1 & & & & & \\
\hline 63 & 1 & & & & & \\
\hline 64 & 1 & & & & & \\
\hline 65 & 1 & $X$ & & $X$ & & \\
\hline 66 & 1 & & & & & \\
\hline
\end{tabular}




\begin{tabular}{|c|c|c|c|c|c|c|}
\hline i & 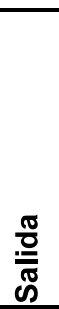 & 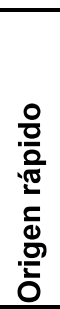 & 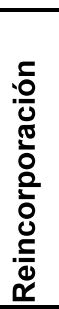 & 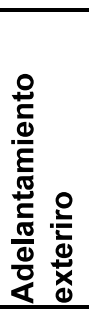 & 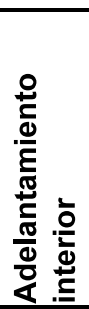 & 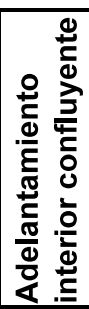 \\
\hline 67 & 1 & & & & & \\
\hline 68 & 1 & & & & $\bar{X}$ & \\
\hline 69 & 1 & & & & & \\
\hline 70 & 2 & & & & $\mathrm{X}$ & \\
\hline 71 & 1 & & & & & \\
\hline 72 & 2 & $\bar{X}$ & & $\bar{X}$ & & \\
\hline 73 & 1 & & & & & \\
\hline 74 & 1 & & & & & \\
\hline 75 & 1 & & & & & \\
\hline 76 & 1 & & & & & \\
\hline 77 & 1 & & & & $\bar{X}$ & \\
\hline 78 & 2 & & & & $X$ & \\
\hline 79 & 1 & & & & & \\
\hline 80 & 1 & & & & & \\
\hline 81 & 2 & & & & & \\
\hline 82 & 1 & & & & & \\
\hline 83 & 3 & $\bar{X}$ & & & & \\
\hline 84 & 2 & & & & & \\
\hline 85 & 1 & & & & & \\
\hline 86 & 1 & & & & & \\
\hline 87 & 1 & $\bar{X}$ & & & & \\
\hline 88 & 1 & & & & & \\
\hline 89 & 1 & & & & & \\
\hline 90 & 1 & & & & $\bar{X}$ & \\
\hline 91 & 2 & $\bar{X}$ & & & & \\
\hline 92 & 1 & & & & & \\
\hline 93 & 2 & $\bar{X}$ & & & & \\
\hline 94 & 1 & & & & & \\
\hline 95 & 1 & & & & & \\
\hline 96 & 1 & & & & & \\
\hline 97 & 1 & & & & & \\
\hline 98 & 1 & & & & & \\
\hline 99 & 2 & & & & & \\
\hline 100 & 1 & & & & & \\
\hline 101 & 1 & & & & $\bar{X}$ & \\
\hline 102 & 1 & & & & & \\
\hline 103 & 1 & $\bar{X}$ & & & & \\
\hline 104 & 1 & $\bar{X}$ & & $\bar{X}$ & & \\
\hline 105 & 1 & & & & & \\
\hline 106 & 1 & & & & & \\
\hline 107 & 1 & & & & & \\
\hline 108 & 1 & & & & $\mathrm{X}$ & \\
\hline 109 & 1 & & & & & \\
\hline 110 & 1 & & & & & \\
\hline 111 & 1 & & & & & \\
\hline 112 & 1 & & & & & \\
\hline 113 & 1 & $\bar{X}$ & & & & \\
\hline
\end{tabular}

\begin{tabular}{|c|c|c|c|c|c|c|}
\hline $\mathbf{z}$ & 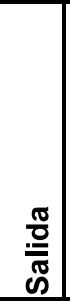 & 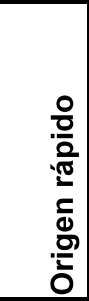 & 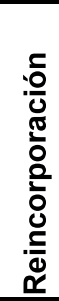 & 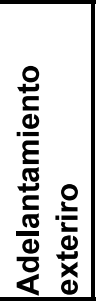 & 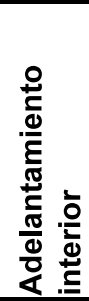 & 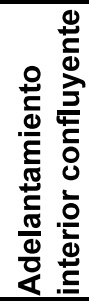 \\
\hline 114 & 1 & & & & & \\
\hline 115 & 1 & & & & & \\
\hline 116 & 1 & & & & & \\
\hline 117 & 1 & & & & & \\
\hline 118 & 1 & & & & & \\
\hline 119 & 2 & & & & & \\
\hline 120 & 2 & & & & & \\
\hline 121 & 1 & & & & & \\
\hline 122 & 2 & & & & & \\
\hline 123 & 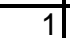 & & & & & \\
\hline 124 & 2 & $\bar{X}$ & & & & $X$ \\
\hline 125 & 1 & & & & & \\
\hline 126 & 1 & & & & & \\
\hline 127 & 2 & & & & & \\
\hline 128 & 1 & & & & & \\
\hline 129 & 1 & & & & & \\
\hline 130 & 1 & & & & & \\
\hline 131 & 2 & & & & & \\
\hline 132 & 1 & & & & & \\
\hline 133 & 1 & & & & & \\
\hline 134 & 1 & & & & & \\
\hline 135 & 1 & & & & & \\
\hline 136 & 2 & & & & & \\
\hline 137 & 1 & & & & & \\
\hline 138 & 1 & & & & & \\
\hline 139 & 3 & $\bar{X}$ & & & & \\
\hline 140 & 3 & $\bar{X}$ & & $\bar{X}$ & & \\
\hline 141 & 3 & $\bar{X}$ & & $\bar{X}$ & & \\
\hline 142 & 1 & & & & & \\
\hline 143 & 1 & & & & & \\
\hline 144 & 1 & & & & & \\
\hline 145 & 1 & & & & & \\
\hline 146 & 1 & & & & & \\
\hline 147 & 1 & & & & & \\
\hline 148 & 1 & & & & & \\
\hline 149 & 1 & & & & & \\
\hline 150 & 1 & & & & & \\
\hline 151 & 1 & & & & & \\
\hline 152 & 3 & & & & $\mathrm{X}$ & \\
\hline 153 & 1 & & & & & \\
\hline 154 & 1 & & & & & \\
\hline 155 & 2 & $\bar{X}$ & & $\bar{X}$ & & \\
\hline 156 & 1 & & & & & \\
\hline 157 & 1 & & & & & \\
\hline 158 & 1 & $\bar{X}$ & & & & \\
\hline 159 & 2 & $\bar{X}$ & & & & \\
\hline 160 & 2 & & & & & \\
\hline
\end{tabular}




\begin{tabular}{|c|c|c|c|c|c|c|}
\hline$\dot{0}$ & ) & $\begin{array}{l}\frac{0}{0} \\
\frac{0}{2} \\
\frac{\pi}{2} \\
\frac{0}{0} \\
\stackrel{0}{0} \\
0\end{array}$ & 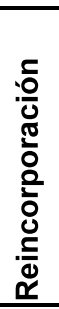 & 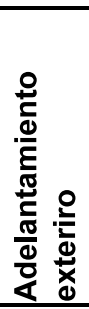 & 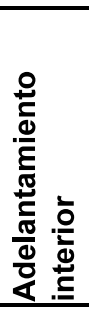 & 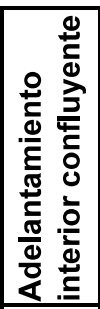 \\
\hline$\overline{161}$ & 1 & & & & & \\
\hline 162 & 1 & & & & & \\
\hline 163 & 1 & & & & & \\
\hline 164 & 1 & $\mathrm{X}$ & & & & \\
\hline 165 & 1 & & & & $\bar{X}$ & \\
\hline 166 & 1 & & & & & \\
\hline 167 & 2 & & & & & \\
\hline 168 & 1 & & & & & \\
\hline 169 & 1 & & & & & \\
\hline 170 & 1 & & & & & \\
\hline 171 & 1 & & & & & \\
\hline 172 & 2 & $X$ & & & & \\
\hline 173 & 2 & & & $\bar{X}$ & & \\
\hline 174 & 2 & & & & & \\
\hline 175 & 2 & & & & & \\
\hline 176 & 1 & & & & & \\
\hline 177 & 2 & $\mathrm{X}$ & & & & \\
\hline 178 & 1 & & & & & \\
\hline 179 & 1 & & & & & \\
\hline 180 & 2 & & & & & \\
\hline 181 & 1 & $X$ & & $\bar{X}$ & & \\
\hline 182 & 2 & & & & & \\
\hline 183 & 1 & & & & & \\
\hline 184 & 1 & & & & & \\
\hline 185 & 1 & & & & & \\
\hline 186 & 1 & & & & & \\
\hline 187 & 1 & & & & & \\
\hline 188 & 1 & & & & & \\
\hline 189 & 2 & & & & & \\
\hline 190 & 1 & & & & & \\
\hline 191 & 1 & & & & & \\
\hline 192 & 1 & & & & & \\
\hline 193 & 1 & $\mathrm{X}$ & & & $\bar{X}$ & \\
\hline 194 & 1 & & & & & \\
\hline 195 & 2 & & & & & \\
\hline 196 & 1 & & & & & \\
\hline 197 & 1 & & & & & \\
\hline 198 & 3 & $X$ & & & & \\
\hline 199 & 2 & & & & & \\
\hline 200 & 2 & & & & & \\
\hline 201 & 1 & & & & & \\
\hline 202 & 1 & & & & & \\
\hline 203 & 2 & & & & & $\bar{X}$ \\
\hline 204 & 1 & & & & & \\
\hline 205 & 2 & & & & & \\
\hline 206 & 2 & $\mathrm{X}$ & & & & \\
\hline 207 & 1 & & & & & \\
\hline
\end{tabular}

\begin{tabular}{|c|c|c|c|c|c|c|}
\hline z & $\begin{array}{l}\frac{\pi}{0} \\
\frac{0}{\pi} \\
\tilde{D}\end{array}$ & $\begin{array}{l}\circ \\
\frac{0}{0} \\
\frac{\pi}{2} \\
\overline{0} \\
\bar{\sigma} \\
\overline{0}\end{array}$ & 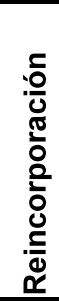 & 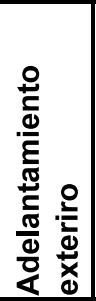 & 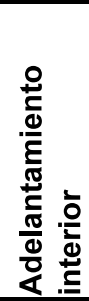 & 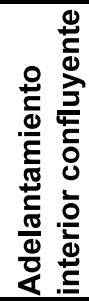 \\
\hline 208 & 1 & & & & & \\
\hline 209 & 1 & & & & & \\
\hline 210 & 2 & & & & & \\
\hline 211 & 1 & & & & & \\
\hline 212 & 1 & & & & & \\
\hline 213 & 1 & & & & & \\
\hline 214 & 2 & & & & & \\
\hline 215 & 1 & & & & & \\
\hline 216 & 1 & & & & & \\
\hline 217 & 1 & & & & & \\
\hline 218 & 1 & & & & & \\
\hline 219 & 1 & & & & & \\
\hline 220 & 1 & & & & $\bar{X}$ & \\
\hline 221 & 1 & & & & & \\
\hline 222 & 1 & & & & . & \\
\hline 223 & 2 & & & & & \\
\hline 224 & 1 & & & & & \\
\hline 225 & 2 & & & & $\bar{X}$ & \\
\hline 226 & 1 & & & & & \\
\hline 227 & 1 & & & & & \\
\hline 228 & 1 & & & & & \\
\hline 229 & 1 & & & & & \\
\hline 230 & 1 & & & & & \\
\hline 231 & 1 & & & & & \\
\hline 232 & 1 & & & & & \\
\hline 233 & 2 & & & & & \\
\hline 234 & 1 & & & & $\bar{X}$ & \\
\hline 235 & 1 & & & & & \\
\hline 236 & 1 & & & & & \\
\hline 237 & 1 & & & $\bar{X}$ & $\bar{X}$ & \\
\hline 238 & 1 & & & & & \\
\hline 239 & 1 & & & & & \\
\hline 240 & 3 & & & & $X$ & \\
\hline 241 & 3 & & & & $\bar{X}$ & \\
\hline 242 & 1 & & & $\bar{X}$ & & \\
\hline 243 & 1 & & & & & \\
\hline 244 & 2 & & & & & \\
\hline 245 & 1 & & & & & \\
\hline 246 & 1 & & & & & \\
\hline 247 & 3 & & & & & \\
\hline 248 & 2 & & & & & \\
\hline 249 & 1 & & & & & \\
\hline 250 & 1 & & & & & \\
\hline 251 & 1 & & & & & \\
\hline 252 & 1 & & & & & \\
\hline 253 & 1 & & & & & \\
\hline 254 & 1 & & & & & \\
\hline
\end{tabular}




\begin{tabular}{|c|c|c|c|c|c|c|}
\hline$\dot{0}$ & ) & $\begin{array}{l}\frac{0}{0} \\
\frac{0}{2} \\
\frac{\pi}{2} \\
\frac{0}{0} \\
\stackrel{0}{0} \\
0\end{array}$ & 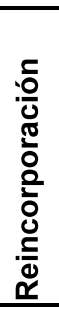 & 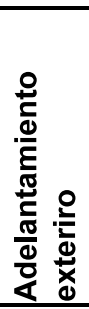 & 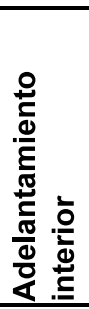 & 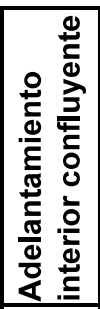 \\
\hline 255 & 3 & & & & & \\
\hline 256 & 2 & & & & & \\
\hline 257 & 1 & & & & & \\
\hline 258 & 1 & & & & & \\
\hline 259 & 1 & & & & & \\
\hline 260 & 1 & & & & & \\
\hline 261 & 1 & & & & & \\
\hline 262 & 1 & & & & & \\
\hline 263 & 1 & & & & & \\
\hline 264 & 1 & & & & & \\
\hline 265 & 1 & & & & & \\
\hline 266 & 1 & & & & & \\
\hline 267 & 1 & & & & & \\
\hline 268 & 1 & & & & & \\
\hline 269 & 1 & & & & & \\
\hline 270 & 1 & & & & & \\
\hline 271 & 1 & & & & $X$ & \\
\hline 272 & 1 & & & & & \\
\hline 273 & 1 & & & & & \\
\hline 274 & 1 & & & & & \\
\hline 275 & 1 & & & & & \\
\hline 276 & 1 & $X$ & & $\bar{X}$ & & \\
\hline 277 & 1 & & & & & \\
\hline 278 & 1 & & & & & \\
\hline 279 & 1 & & & & & \\
\hline 280 & 1 & & & & & \\
\hline 281 & 1 & $X$ & & & & \\
\hline 282 & 1 & & & & & \\
\hline 283 & 3 & & & & & \\
\hline 284 & 1 & & & & & \\
\hline 285 & 1 & $\mathrm{X}$ & & & & \\
\hline 286 & 1 & & & & & \\
\hline 287 & 1 & & & & & \\
\hline 288 & 1 & & & & & \\
\hline 289 & 2 & & & $\bar{X}$ & & \\
\hline 290 & 1 & $X$ & & & & \\
\hline 291 & 2 & & & & & \\
\hline 292 & 1 & & & & & \\
\hline 293 & 1 & & & & & \\
\hline 294 & 1 & & & & & \\
\hline 295 & 1 & & & & & \\
\hline 296 & 1 & $\mathrm{X}$ & & & & \\
\hline 297 & 1 & & & & & \\
\hline 298 & 1 & & & & & \\
\hline 299 & 3 & & & & & \\
\hline 300 & 1 & & $\bar{X}$ & & & \\
\hline 301 & 1 & & & & & \\
\hline
\end{tabular}

\begin{tabular}{|c|c|c|c|c|c|c|}
\hline zo & $\begin{array}{l}\frac{\pi}{0} \\
\frac{0}{5} \\
0\end{array}$ & $\begin{array}{l}\text { 음 } \\
\frac{0}{0} \\
0 \\
0 \\
0 \\
0\end{array}$ & 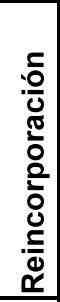 & 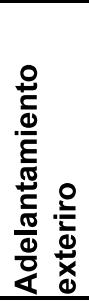 & 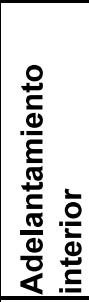 & 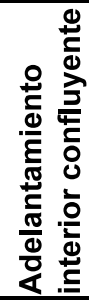 \\
\hline 302 & 2 & & & & & \\
\hline 303 & 1 & & & & & \\
\hline 304 & 1 & & & & & \\
\hline 305 & 1 & & & & & \\
\hline 306 & 1 & & & & & \\
\hline 307 & 1 & & & & & \\
\hline 308 & 1 & & & & & \\
\hline 309 & 1 & & & & & \\
\hline 310 & 1 & & & & & \\
\hline 311 & 1 & & & & & \\
\hline 312 & 1 & & & & & \\
\hline 313 & 3 & & & & & \\
\hline 314 & 1 & & & & & $\mathrm{X}$ \\
\hline 315 & 1 & & & & & \\
\hline 316 & 1 & & & & & \\
\hline 317 & 1 & & & & & \\
\hline 318 & 1 & & & & & \\
\hline 319 & 1 & & & & & \\
\hline 320 & 2 & $\bar{X}$ & & & & \\
\hline 321 & 2 & & & & & \\
\hline 322 & 1 & & & & & \\
\hline 323 & 1 & & & & & \\
\hline 324 & 1 & & & & & \\
\hline 325 & 1 & & & & & \\
\hline 326 & 2 & & & & & \\
\hline 327 & 1 & & & & & \\
\hline 328 & 1 & & & & & \\
\hline 329 & 1 & & & & & \\
\hline 330 & 2 & & & & & \\
\hline 331 & 1 & & & & & \\
\hline 332 & 1 & & & & & \\
\hline 333 & 1 & & & & & \\
\hline 334 & 1 & & & & & \\
\hline 335 & 1 & & & & & \\
\hline 336 & 1 & & & & & \\
\hline 337 & 1 & & & & & \\
\hline 338 & 2 & & & & & \\
\hline 339 & 1 & & & & & \\
\hline 340 & 1 & & & & & \\
\hline 341 & 1 & & & & & \\
\hline 342 & 1 & & & & & \\
\hline 343 & 1 & $\bar{X}$ & & & & \\
\hline 344 & 1 & & & & & \\
\hline 345 & 1 & & & & & \\
\hline 346 & 1 & $\bar{x}$ & & & $X$ & \\
\hline 347 & 1 & & & & & \\
\hline 348 & 1 & & & & & \\
\hline
\end{tabular}




\begin{tabular}{|c|c|c|c|c|c|c|}
\hline$\stackrel{0}{\mathbf{z}}$ & 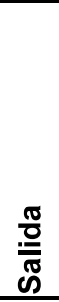 & 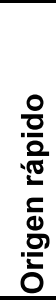 & 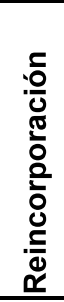 & 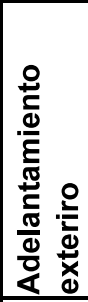 & 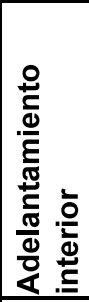 & 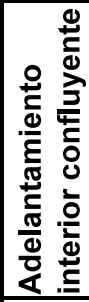 \\
\hline 349 & 1 & & & & & \\
\hline 350 & 2 & $\bar{X}$ & & & & \\
\hline 351 & 1 & & & & & \\
\hline 352 & 1 & & & & & \\
\hline 353 & 2 & & & & & \\
\hline 354 & 1 & & & & & \\
\hline 355 & 1 & & & & & \\
\hline 356 & 1 & & & & & \\
\hline 357 & 1 & & & & & \\
\hline 358 & 1 & & & & & \\
\hline
\end{tabular}




\begin{tabular}{|l|c|c|}
\hline \multicolumn{2}{|c|}{ V31-85 } \\
\hline Maniobras & 431 & \\
\hline Salida anticipada & 0 & $0,0 \%$ \\
\hline Salida en la cuña & 328 & $76,1 \%$ \\
\hline Salida zona media & 76 & $17,6 \%$ \\
\hline Salida tardia & 27 & $6,3 \%$ \\
\hline Origen carriles ràpidos & 48 & $11,1 \%$ \\
\hline Reincorporaciones & 2 & $0,5 \%$ \\
\hline Adelantamiento exterior & 25 & $5,8 \%$ \\
\hline Adelantamiento interior & 22 & $5,1 \%$ \\
\hline Adelantamiento interior confluyente & 6 & $1,4 \%$ \\
\hline
\end{tabular}

\begin{tabular}{|c|c|c|c|c|c|c|}
\hline$\stackrel{0}{2}$ & $\begin{array}{l}\frac{\pi}{0} \\
\frac{0}{\pi} \\
\infty\end{array}$ & 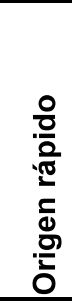 & 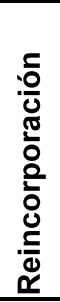 & 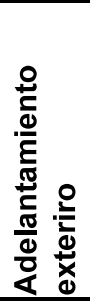 & 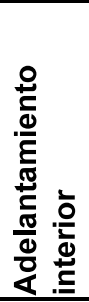 & 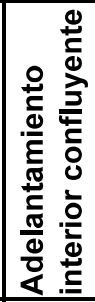 \\
\hline 1 & 1 & & & & & \\
\hline 2 & 1 & $X$ & & & & \\
\hline 3 & 1 & & & & & \\
\hline 4 & 1 & & & & $\mathrm{X}$ & \\
\hline 5 & 3 & & & & & \\
\hline 6 & 1 & $X$ & & & & \\
\hline 7 & 1 & & & & & \\
\hline 8 & 1 & & & & & \\
\hline 9 & 1 & & & & & \\
\hline 10 & 1 & & & & & \\
\hline 11 & 1 & & & & & \\
\hline 12 & 1 & & & & & \\
\hline 13 & 2 & & & & & \\
\hline 14 & 1 & & & & & \\
\hline 15 & 2 & & & & & \\
\hline 16 & 1 & & & & & \\
\hline 17 & 1 & & & & & \\
\hline 18 & 1 & & & & & \\
\hline 19 & 1 & & & & & \\
\hline 20 & 1 & & & & & \\
\hline 21 & 1 & & & & & \\
\hline 22 & 1 & & & & & \\
\hline 23 & 2 & $X$ & & & & \\
\hline 24 & 1 & $X$ & & & & \\
\hline 25 & 1 & & & & & \\
\hline 26 & 1 & & & & & \\
\hline 27 & 1 & & & & & \\
\hline 28 & 1 & & & & & \\
\hline 29 & 1 & & & & & \\
\hline 30 & 1 & & & & & \\
\hline 31 & 1 & & & $X$ & & \\
\hline 32 & 1 & & & & & \\
\hline 33 & 1 & & & & & \\
\hline
\end{tabular}

\begin{tabular}{|c|c|c|c|c|c|c|}
\hline$\dot{0}$ & $\frac{\pi}{\frac{\pi}{0}}$ & $\begin{array}{l}\frac{0}{0} \\
\frac{0}{2} \\
\frac{0}{2} \\
\frac{c}{0} \\
\frac{0}{2} \\
0\end{array}$ & 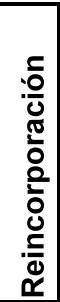 & 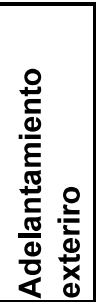 & 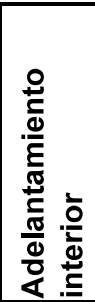 & 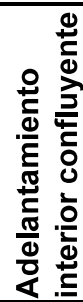 \\
\hline 34 & 1 & & & & & \\
\hline 35 & 1 & & & & & \\
\hline 36 & 1 & & & & & \\
\hline 37 & 1 & & & & & \\
\hline 38 & 1 & & & & & \\
\hline 39 & 1 & & & & & \\
\hline 40 & 1 & & & & & \\
\hline 41 & 1 & & & & & \\
\hline 42 & $1 \times$ & $\bar{X}$ & & & & \\
\hline 43 & 1 & & & & & \\
\hline 44 & 1 & & & & & \\
\hline 45 & 1 & & & & & \\
\hline 46 & 1 & & & & & \\
\hline 47 & 1 & & & & & \\
\hline 48 & 2 & & & & & \\
\hline 49 & 1 & & & & & \\
\hline 50 & 1 & & & & & \\
\hline 51 & 1 & & & & & \\
\hline 52 & 3 & & & & & \\
\hline 53 & 1 & & & & & \\
\hline 54 & 2 & & & & & \\
\hline 55 & 3 & & & & & \\
\hline 56 & 18 & $\mathrm{X}$ & & $X$ & & \\
\hline 57 & 1 & & & & & \\
\hline 58 & 2 & & & & & \\
\hline 59 & 1 & & & & & \\
\hline 60 & 1 & & & & & \\
\hline 61 & 1 & & & & & \\
\hline 62 & 2 & & & & $X$ & \\
\hline 63 & 1 & & & & & \\
\hline 64 & 1 & & & & & \\
\hline 65 & 1 & & & & & \\
\hline 66 & $1 \times$ & $X$ & & $X$ & & \\
\hline
\end{tabular}




\begin{tabular}{|c|c|c|c|c|c|c|}
\hline$\dot{0}$ & $\frac{\mathbb{\pi}}{\frac{\pi}{\overline{0}}}$ & 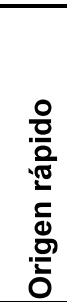 & 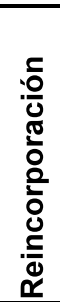 & 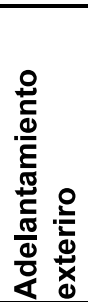 & 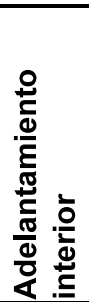 & 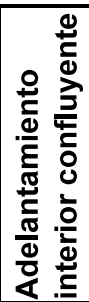 \\
\hline 67 & 2 & & & & & \\
\hline 68 & 2 & & & & & \\
\hline 69 & 1 & & & & & \\
\hline 70 & 1 & & & & & \\
\hline 71 & 2 & & & & $\bar{X}$ & \\
\hline 72 & 1 & & & & & \\
\hline 73 & & $\bar{X}$ & & & & \\
\hline 74 & 3 & & & & & \\
\hline 75 & 1 & & & $\bar{X}$ & & \\
\hline 76 & 1 & & & & & \\
\hline 77 & 1 & & & & & \\
\hline 78 & 1 & & & & $\bar{X}$ & \\
\hline 79 & $\overline{2}$ & & & & $\bar{X}$ & \\
\hline 80 & 1 & & & & & \\
\hline 81 & 1 & & & & & \\
\hline 82 & 2 & & & & & \\
\hline 83 & 1 & & & & & \\
\hline 84 & 3 & & & & & \\
\hline 85 & 2 & $\bar{X}$ & & $\bar{X}$ & & \\
\hline 86 & 1 & & & & & \\
\hline 87 & 1 & & & & & \\
\hline 88 & 1 & & & & & \\
\hline 89 & 1 & & & & & \\
\hline 90 & 1 & & & & & \\
\hline 91 & & $\bar{X}$ & & $\bar{X}$ & & \\
\hline 92 & 3 & & & & & \\
\hline 93 & 1 & $\bar{X}$ & & $\bar{X}$ & & \\
\hline 94 & & $\bar{X}$ & & & & \\
\hline 95 & $\frac{1}{1}$ & & & & & \\
\hline 96 & 1 & & & & & \\
\hline 97 & 1 & & & & & \\
\hline 98 & 1 & & & & & \\
\hline 99 & $\overline{2}$ & & & & & \\
\hline 100 & $\overline{2}$ & & & & & \\
\hline 101 & 1 & & & & & \\
\hline 102 & 1 & & & & & \\
\hline 103 & 1 & & & & & \\
\hline 104 & $\overline{2}$ & & & & & \\
\hline 105 & & $\bar{X}$ & & $\bar{X}$ & & \\
\hline 106 & $\overline{2}$ & & & & & \\
\hline 107 & 1 & & & & & \\
\hline 108 & 1 & & & & & \\
\hline 109 & 1 & & & & & \\
\hline 110 & 1 & & & & & \\
\hline 111 & 1 & & & & & \\
\hline 112 & 1 & & & & & \\
\hline 113 & 1 & & & & & \\
\hline
\end{tabular}

\begin{tabular}{|c|c|c|c|c|c|c|}
\hline $\mathbf{0}$ & 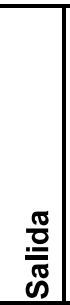 & $\begin{array}{l}\frac{0}{0} \\
\frac{0}{2} \\
\frac{\pi}{2} \\
\frac{\bar{d}}{2} \\
\frac{0}{0}\end{array}$ & 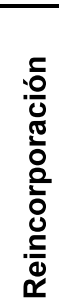 & 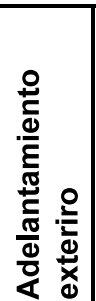 & 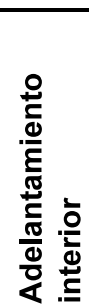 & 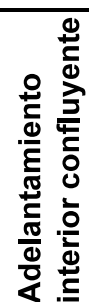 \\
\hline 114 & 1 & & & & $\bar{X}$ & \\
\hline 115 & 1 & $\bar{X}$ & & $\bar{X}$ & & \\
\hline 116 & 1 & & & & & \\
\hline 117 & 1 & & & & & \\
\hline 118 & 1 & & & & & \\
\hline 119 & 1 & & & & & \\
\hline 120 & 2 & & & & & \\
\hline 121 & 1 & & & & & \\
\hline 122 & 1 & & & & & \\
\hline 123 & 2 & & & & & \\
\hline 124 & 1 & & & & & \\
\hline 125 & 2 & & & & & \\
\hline 126 & 1 & & & & & \\
\hline 127 & 2 & & & & & $\bar{X}$ \\
\hline 128 & 1 & & & & & \\
\hline 129 & 2 & & & & & \\
\hline 130 & 1 & & & & & \\
\hline 131 & 1 & & & & & \\
\hline 132 & 1 & & & & & \\
\hline 133 & 2 & & & & & \\
\hline 134 & 1 & & & & & \\
\hline 135 & 1 & & & & & \\
\hline 136 & 1 & & & & & \\
\hline 137 & 1 & & & & & \\
\hline 138 & 1 & & & & & \\
\hline 139 & 1 & & & & & \\
\hline 140 & 1 & & & & & \\
\hline 141 & 3 & & & & & \\
\hline 142 & 2 & & & $\bar{X}$ & & \\
\hline 143 & 1 & & & $X$ & & \\
\hline 144 & 1 & & & & & \\
\hline 145 & 2 & & & & & \\
\hline 146 & 1 & $\bar{X}$ & & & & \\
\hline 147 & 1 & & & & & \\
\hline 148 & 1 & & & & & \\
\hline 149 & 1 & & & & & \\
\hline 150 & 1 & & & & & \\
\hline 151 & 1 & & & & & \\
\hline 152 & 1 & & & & & \\
\hline 153 & 1 & & & & & \\
\hline 154 & 1 & & & & & \\
\hline 155 & 1 & & & & & \\
\hline 156 & 1 & & & & & \\
\hline 157 & 2 & & & & & \\
\hline 158 & 1 & & & & $\bar{X}$ & \\
\hline 159 & 2 & $\bar{X}$ & & & & \\
\hline 160 & 1 & & & & & \\
\hline
\end{tabular}




\begin{tabular}{|c|c|c|c|c|c|c|}
\hline i & 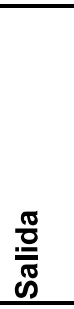 & 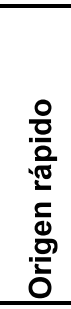 & 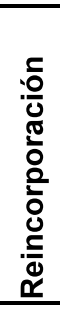 & 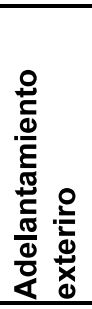 & 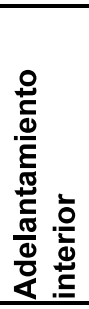 & 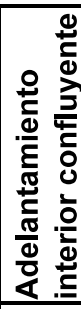 \\
\hline 161 & 3 & $\bar{X}$ & & & & \\
\hline 162 & $\overline{2}$ & & & & & \\
\hline 163 & 1 & & & & & \\
\hline 164 & 2 & & & & & \\
\hline 165 & & $\bar{x}$ & & & & \\
\hline 166 & 1 & & & & & \\
\hline $\begin{array}{ll}167 \\
\end{array}$ & 2 & & & & & \\
\hline 168 & 1 & & & & & \\
\hline 169 & 1 & & & & & \\
\hline 170 & 1 & & & & & \\
\hline \begin{tabular}{l|l|}
171 \\
171
\end{tabular} & 2 & & & & & \\
\hline 172 & 1 & & & & & \\
\hline \begin{tabular}{|c|}
173 \\
\end{tabular} & 1 & & & & & \\
\hline 174 & 1 & & & & & \\
\hline 175 & & $\bar{X}$ & & $\bar{X}$ & & \\
\hline 176 & $\overline{2}$ & & & & & \\
\hline 177 & 2 & & & & & \\
\hline 178 & 1 & & & & & \\
\hline 179 & 1 & & & & & \\
\hline 180 & $\overline{2}$ & & & & & \\
\hline 181 & & $\bar{X}$ & & & & \\
\hline $\begin{array}{ll}182 \\
\end{array}$ & 1 & & & & & \\
\hline 183 & & $\bar{X}$ & & $X$ & & \\
\hline 184 & 1 & & & & & \\
\hline 185 & 2 & & & & & \\
\hline 186 & 2 & & & & & \\
\hline \begin{tabular}{c|}
187 \\
\end{tabular} & 1 & & & & & \\
\hline 188 & 1 & & & & & \\
\hline 189 & 1 & & & & & \\
\hline 190 & $\overline{1}$ & & & & & \\
\hline 191 & $\overline{1}$ & & & & & \\
\hline 192 & 2 & & & & & \\
\hline 193 & 1 & & & & & \\
\hline 194 & $\overline{1}$ & & & & & \\
\hline 195 & 1 & & & & & \\
\hline 196 & & $X$ & & & & \\
\hline 197 & & $\bar{X}$ & & & & \\
\hline 198 & & $\bar{X}$ & & & & \\
\hline 199 & 1 & & & & & \\
\hline 200 & 1 & & & & $\bar{X}$ & \\
\hline 201 & $\overline{1}$ & & & & & \\
\hline 202 & & $X$ & & $X$ & & \\
\hline 203 & $\overline{3}$ & & & & & \\
\hline 204 & $\overline{1}$ & & & & & \\
\hline 205 & 1 & & & & & \\
\hline 206 & $\overline{2}$ & & & & & \\
\hline 207 & 1 & & & & & \\
\hline
\end{tabular}

\begin{tabular}{|c|c|c|c|c|c|c|}
\hline z & $\begin{array}{l}\frac{\pi}{0} \\
\frac{0}{\pi} \\
\tilde{D}\end{array}$ & 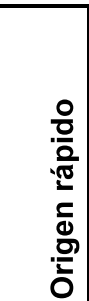 & 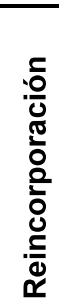 & 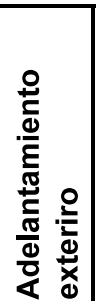 & 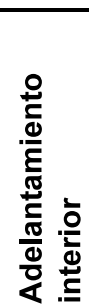 & 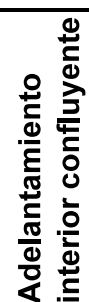 \\
\hline 208 & 1 & & & & & $\bar{x}$ \\
\hline 209 & 2 & & & & & \\
\hline 210 & 1 & $\bar{X}$ & & & & \\
\hline 211 & 1 & & & & & \\
\hline 212 & 1 & $\bar{X}$ & & & & \\
\hline 213 & 1 & & & & & \\
\hline 214 & 2 & & & & & \\
\hline 215 & 1 & & & & & \\
\hline 216 & 1 & & & & & \\
\hline 217 & 1 & & & & & \\
\hline 218 & 1 & & & & & \\
\hline 219 & 1 & & & & & \\
\hline 220 & 1 & & & & & \\
\hline 221 & 1 & & & & & \\
\hline 222 & 3 & & & & & \\
\hline 223 & 1 & & & & & \\
\hline 224 & 1 & & & & & \\
\hline 225 & 1 & & & & & \\
\hline 226 & 1 & & & & & \\
\hline 227 & 1 & & & & $\bar{X}$ & \\
\hline 228 & 1 & & & & & \\
\hline 229 & 1 & & & & & \\
\hline 230 & 2 & & & & $\mathrm{X}$ & \\
\hline 231 & 1 & & & & & \\
\hline 232 & 1 & & & & & \\
\hline 233 & 1 & & & & & \\
\hline 234 & 1 & & & & & \\
\hline 235 & 1 & & & & & \\
\hline 236 & 1 & & & & & \\
\hline 237 & 1 & & & & & \\
\hline 238 & 2 & & & & & \\
\hline 239 & 1 & $\bar{X}$ & & & & \\
\hline 240 & 1 & & & & & \\
\hline 241 & 1 & & & & & \\
\hline 242 & 2 & $\bar{X}$ & & & & \\
\hline 243 & 1 & & & $\bar{X}$ & & \\
\hline 244 & 2 & & & & & \\
\hline 245 & 3 & $\bar{X}$ & & $\bar{X}$ & $\bar{X}$ & \\
\hline 246 & 2 & & & & & \\
\hline 247 & 1 & & & & & \\
\hline 248 & 1 & & & & & \\
\hline 249 & 1 & & & & $X$ & $\bar{X}$ \\
\hline 250 & 2 & & & & & \\
\hline 251 & 3 & $\bar{X}$ & & & & \\
\hline 252 & 2 & & & & & \\
\hline 253 & 1 & & & & & \\
\hline 254 & 1 & & & & & \\
\hline
\end{tabular}




\begin{tabular}{|c|c|c|c|c|c|c|}
\hline i & 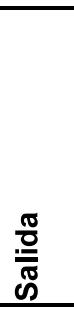 & 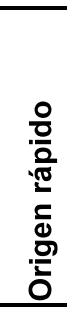 & 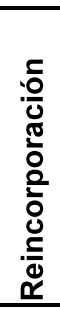 & 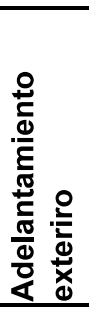 & 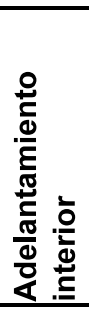 & 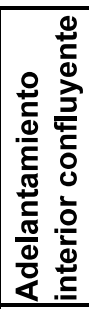 \\
\hline 255 & 1 & & & & & \\
\hline 256 & $\overline{1}$ & & & & & \\
\hline 257 & $\overline{3}$ & & & & & \\
\hline 258 & 1 & & & & & \\
\hline 259 & 1 & & & & & \\
\hline 260 & 1 & & & & & \\
\hline 261 & 1 & & & & & \\
\hline 262 & 1 & & & & & \\
\hline 263 & 1 & & & & & \\
\hline 264 & 1 & & & & & \\
\hline 265 & 1 & & & & & \\
\hline 266 & 1 & & & & & \\
\hline 267 & $\overline{1}$ & & & & & \\
\hline 268 & 1 & & & & & \\
\hline 269 & 1 & & & & & \\
\hline 270 & 1 & & & & & \\
\hline 271 & 1 & & & & & \\
\hline 272 & 1 & & & & & \\
\hline 273 & 1 & & & & & \\
\hline 274 & $\overline{1}$ & & & & $\bar{X}$ & \\
\hline 275 & 1 & & & & & \\
\hline 276 & 1 & & & & & \\
\hline 277 & $\overline{2}$ & & & & & \\
\hline 278 & $\overline{1}$ & & & & & \\
\hline 279 & 1 & & & & & \\
\hline 280 & 1 & & & & & \\
\hline 281 & $\overline{3}$ & & & & & \\
\hline 282 & 1 & & & & & \\
\hline 283 & 2 & & & & & \\
\hline 284 & $\overline{2}$ & & & & & \\
\hline 285 & & $\bar{X}$ & & & & \\
\hline 286 & 1 & & & & & \\
\hline 287 & 1 & & & & & \\
\hline 288 & & $\bar{X}$ & & $X$ & & \\
\hline 289 & 3 & & & & & \\
\hline 290 & & $\bar{X}$ & & & & \\
\hline 291 & $\overline{1}$ & & & & & \\
\hline 292 & $\overline{2}$ & $\bar{X}$ & & & & \\
\hline 293 & 1 & & & $X$ & & \\
\hline 294 & 1 & & & & & \\
\hline 295 & $\overline{3}$ & & & & & \\
\hline 296 & 1 & & & & & \\
\hline 297 & 1 & & & & & \\
\hline 298 & $\overline{1}$ & & & & & \\
\hline 299 & 1 & & & & & \\
\hline 300 & 1 & & & & & \\
\hline 301 & 1 & & & & & \\
\hline
\end{tabular}

\begin{tabular}{|c|c|c|c|c|c|c|}
\hline i & $\begin{array}{l}\frac{\pi}{0} \\
\frac{0}{\pi} \\
\stackrel{5}{0}\end{array}$ & 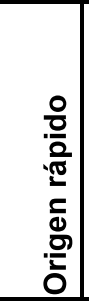 & 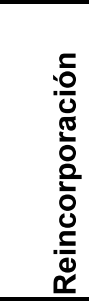 & 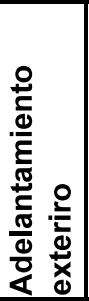 & 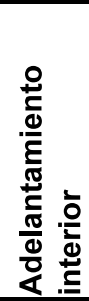 & 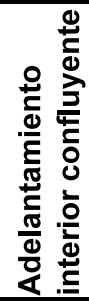 \\
\hline 302 & 3 & & & & & \\
\hline 303 & 1 & & $\bar{X}$ & & & \\
\hline 304 & 1 & & & & & \\
\hline 305 & 2 & & & & & \\
\hline 306 & 1 & & & & & \\
\hline 307 & 1 & & & & & \\
\hline 308 & 1 & & & & & \\
\hline 309 & 1 & & & & & \\
\hline 310 & 1 & & & & & \\
\hline 311 & 1 & & & & & \\
\hline 312 & 1 & & & & & \\
\hline 313 & 2 & & & & & \\
\hline 314 & 1 & & & & & \\
\hline 315 & 3 & & & & & $\bar{X}$ \\
\hline 316 & 1 & & & & & \\
\hline 317 & 2 & & & & & \\
\hline 318 & 1 & & & & & \\
\hline 319 & 1 & & & & & \\
\hline 320 & 1 & & & & & \\
\hline 321 & 2 & $\bar{x}$ & & & & \\
\hline 322 & 1 & & & & & \\
\hline 323 & 1 & & & & & \\
\hline 324 & 1 & & & & & \\
\hline 325 & 1 & & & & & \\
\hline 326 & 2 & & & & & \\
\hline 327 & 1 & & & & & \\
\hline 328 & 1 & & & & & \\
\hline 329 & 1 & & & & & \\
\hline 330 & 1 & & & & & \\
\hline 331 & 2 & & & & & \\
\hline 332 & 1 & & & & & \\
\hline 333 & 1 & & & & & \\
\hline 334 & 1 & & & & & \\
\hline 335 & 1 & & & & & \\
\hline 336 & 1 & & & & & \\
\hline 337 & 1 & & & & & \\
\hline 338 & 2 & & & & & \\
\hline 339 & 1 & & & & & \\
\hline 340 & 1 & & & & & \\
\hline 341 & 1 & & & & & \\
\hline 342 & 1 & & & & & \\
\hline 343 & 1 & & & & & \\
\hline 344 & 1 & & & & & \\
\hline 345 & 1 & & & & & \\
\hline 346 & 1 & & & & & \\
\hline 347 & 1 & & & & $\bar{X}$ & \\
\hline 348 & 1 & & & & $\bar{X}$ & \\
\hline
\end{tabular}




\begin{tabular}{|c|c|c|c|c|c|c|}
\hline i & 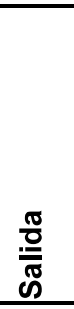 & 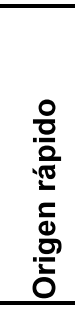 & 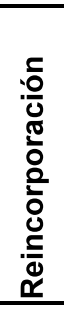 & 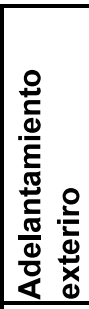 & 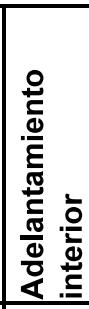 & 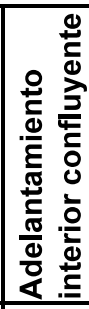 \\
\hline 349 & 1 & & & & & \\
\hline 350 & 2 & $\bar{X}$ & & & & \\
\hline 351 & 1 & & & $X$ & & \\
\hline 352 & 1 & & & & & \\
\hline 353 & 2 & & & & & \\
\hline 354 & 1 & . & & & & \\
\hline 355 & 1 & & & & & \\
\hline 356 & 1 & & & & & \\
\hline 357 & $\overline{1}$ & . & & & & \\
\hline 358 & 1 & & & & & \\
\hline 359 & 1 & . & & & & \\
\hline 360 & 3 & & & & & \\
\hline 361 & 1 & $X$ & & $X$ & & \\
\hline 362 & 1 & & & & . & \\
\hline 363 & 2 & & & & & \\
\hline 364 & 1 & 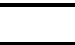 & $\bar{X}$ & & & \\
\hline 365 & 1 & 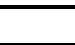 & & & & \\
\hline 366 & 1 & 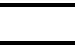 & & & & \\
\hline 367 & 1 & 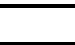 & & & 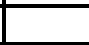 & \\
\hline 368 & $\overline{1}$ & & & & & \\
\hline 369 & 1 & $\bar{X}$ & & $X$ & & \\
\hline 370 & 1 & & & & & \\
\hline 371 & 1 & & & & & \\
\hline 372 & $\overline{2}$ & & & & $X$ & \\
\hline 373 & 1 & & & & & \\
\hline 374 & 3 & & & & $X$ & \\
\hline 375 & 2 & & & & & \\
\hline 376 & 1 & & & & & \\
\hline 377 & 1 & & & & & \\
\hline 378 & $\overline{1}$ & & & & & \\
\hline 379 & 1 & & & & & \\
\hline 380 & 1 & & & & & \\
\hline 381 & 2 & $\bar{X}$ & & & & \\
\hline 382 & 2 & & & & & \\
\hline 383 & 1 & & & & & \\
\hline 384 & 1 & & & & & \\
\hline 385 & $\overline{3}$ & $\bar{X}$ & & $X$ & & \\
\hline 386 & 3 & $\bar{X}$ & & & & \\
\hline 387 & $\overline{1}$ & & & & & \\
\hline 388 & 1 & & & & $X$ & \\
\hline 389 & $\overline{1}$ & & & & & \\
\hline 390 & 1 & & & & & \\
\hline 391 & 1 & & & & & \\
\hline 392 & $\overline{1}$ & & & & & \\
\hline 393 & 1 & & & & $X$ & \\
\hline 394 & $\overline{3}$ & & & & & $X$ \\
\hline 395 & 1 & & & & & \\
\hline
\end{tabular}

\begin{tabular}{|c|c|c|c|c|c|c|}
\hline$\stackrel{0}{z}$ & $\begin{aligned} \frac{\pi}{5} \\
\text { s) }\end{aligned}$ & 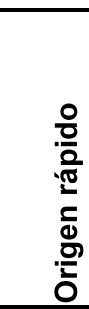 & 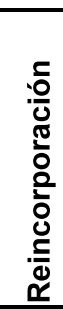 & 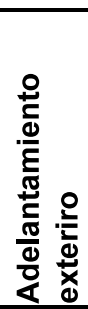 & 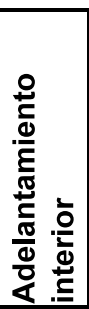 & 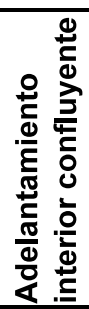 \\
\hline 396 & 1 & & & & & \\
\hline 397 & 1 & & & & & \\
\hline 398 & 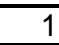 & & & & & \\
\hline 399 & 1 & $\bar{X}$ & & $\bar{X}$ & & \\
\hline 400 & 1 & & & & & \\
\hline 401 & 1 & & & & & \\
\hline 402 & 2 & & & & & \\
\hline 403 & 1 & $\bar{X}$ & & & & \\
\hline 404 & 1 & & & & & \\
\hline 405 & 1 & & & & & \\
\hline 406 & 2 & & & & & \\
\hline 407 & 3 & & & $\bar{X}$ & & $\bar{X}$ \\
\hline 408 & 1 & & & & & \\
\hline 409 & 1 & & & & & \\
\hline 410 & 1 & & & & & \\
\hline 411 & 1 & & & & & \\
\hline 412 & 1 & & & & & \\
\hline 413 & 2 & & & & & \\
\hline 414 & 3 & & & & & \\
\hline 415 & 2 & & & & & \\
\hline 416 & 1 & & & & & \\
\hline 417 & 1 & & & & $\bar{X}$ & \\
\hline 418 & 1 & & & & $\bar{X}$ & \\
\hline 419 & 1 & & & & $\bar{X}$ & \\
\hline 420 & 1 & & & & & \\
\hline 421 & 1 & & & & & \\
\hline 422 & 1 & & & & & \\
\hline 423 & 1 & & & & & \\
\hline 424 & 1 & & & & & \\
\hline 425 & 1 & & & & & \\
\hline 426 & $\overline{2}$ & $\bar{X}$ & & & & \\
\hline 427 & 1 & & & & & \\
\hline 428 & 2 & $X$ & & & & \\
\hline 429 & 1 & & & & & \\
\hline 430 & 1 & & & & & \\
\hline 431 & 1 & & & & & \\
\hline
\end{tabular}




\begin{tabular}{|l|c|c|}
\hline \multicolumn{2}{|c|}{ V31-68 } \\
\hline Maniobras & 473 & \\
\hline Salida anticipada & 5 & $1,1 \%$ \\
\hline Salida en la cuña & 442 & $93,4 \%$ \\
\hline Salida zona media & 24 & $5,1 \%$ \\
\hline Salida tardia & 2 & $0,4 \%$ \\
\hline Origen carriles ràpidos & 1 & $0,2 \%$ \\
\hline Reincorporaciones & 0 & $0,0 \%$ \\
\hline Adelantamiento exterior & 0 & $0,0 \%$ \\
\hline Adelantamiento interior & 6 & $1,3 \%$ \\
\hline Adelantamiento interior confluyente & 0 & $0,0 \%$ \\
\hline
\end{tabular}

\begin{tabular}{|c|c|c|c|c|c|c|}
\hline$\stackrel{0}{z}^{\circ}$ & $\frac{\frac{\pi}{0}}{\bar{D}}$ & $\begin{array}{l}\text { 음 } \\
\text { 문 } \\
\text { 임 } \\
\text { 은 }\end{array}$ & 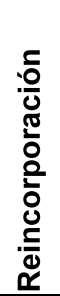 & 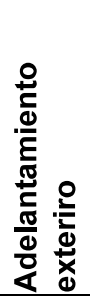 & 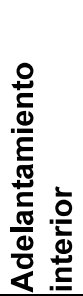 & 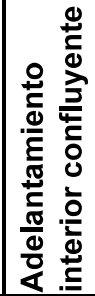 \\
\hline 1 & 2 & & & & & \\
\hline 2 & 1 & & & & & \\
\hline 3 & 1 & & & & & \\
\hline 4 & 3 & & & & & \\
\hline 5 & 1 & & & & & \\
\hline 6 & 1 & & & & & \\
\hline 7 & 1 & & & & & \\
\hline 8 & 3 & & & & & \\
\hline 9 & 1 & $\mathrm{X}$ & & & & \\
\hline 10 & 1 & & & & & \\
\hline 11 & 1 & & & & & \\
\hline 12 & 1 & & & & & \\
\hline 13 & 0 & & & & & \\
\hline 14 & 1 & & & & & \\
\hline 15 & 1 & & & & & \\
\hline 16 & 1 & & & & & \\
\hline 17 & 2 & & & & & \\
\hline 18 & 1 & & & & & \\
\hline 19 & 2 & & & & & \\
\hline 20 & 1 & & & & & \\
\hline 21 & 1 & & & & & \\
\hline 22 & 1 & & & & & \\
\hline 23 & 2 & & & & & \\
\hline 24 & 1 & & & & & \\
\hline 25 & 1 & & & & & \\
\hline 26 & 1 & & & & & \\
\hline 27 & 1 & & & & & \\
\hline 28 & 1 & & & & & \\
\hline 29 & 1 & & & & & \\
\hline 30 & 1 & & & & & \\
\hline 31 & 1 & & & & & \\
\hline 32 & 1 & & & & & \\
\hline 33 & 1 & & & & & \\
\hline
\end{tabular}

\begin{tabular}{|c|c|c|c|c|c|c|}
\hline í & $\frac{\frac{\pi}{0}}{\frac{0}{\pi}}$ & $\begin{array}{l}\text { 음 } \\
\frac{0}{0} \\
\frac{5}{0} \\
\frac{0}{0}\end{array}$ & 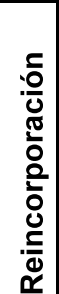 & 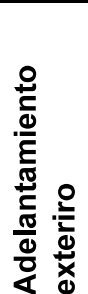 & 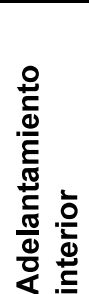 & 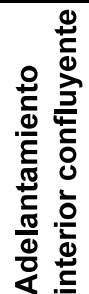 \\
\hline 34 & 1 & & & & & \\
\hline 35 & 1 & & & & & \\
\hline 36 & 1 & & & & & \\
\hline 37 & 1 & & & & & \\
\hline 38 & 1 & & & & & \\
\hline 39 & 1 & & & & & \\
\hline 40 & 1 & & & & & \\
\hline 4 & 1 & & & & & \\
\hline 42 & 2 & & & & & \\
\hline 43 & 1 & & & & & \\
\hline 44 & 1 & & & & & \\
\hline 45 & 2 & & & & & \\
\hline 46 & 1 & & & & & \\
\hline 47 & 1 & & & & & \\
\hline 4 & 1 & & & & & \\
\hline 49 & 1 & & & & & \\
\hline 50 & 1 & & & & & \\
\hline 51 & 1 & & & & & \\
\hline 52 & 1 & & & & & \\
\hline 5 & 1 & & & & & \\
\hline 54 & 2 & & & & & \\
\hline 55 & 1 & & & & & \\
\hline 56 & $\overline{1}$ & & & & & \\
\hline 57 & 1 & & & & & \\
\hline 5 & $\overline{1}$ & & & & & \\
\hline 59 & 1 & & & & & \\
\hline 60 & 1 & & & & & \\
\hline 61 & 1 & & & & & \\
\hline 62 & 1 & & & & & \\
\hline 63 & 1 & & & & & \\
\hline 64 & 1 & & & & & \\
\hline 65 & 1 & & & & & \\
\hline 66 & 1 & & & & & \\
\hline
\end{tabular}




\begin{tabular}{|c|c|c|c|c|c|c|}
\hline$\dot{0}$ & $\frac{\mathbb{\pi}}{\frac{\pi}{\overline{0}}}$ & 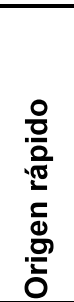 & 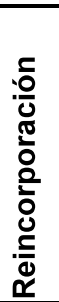 & 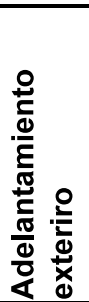 & 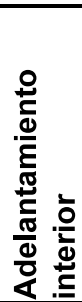 & 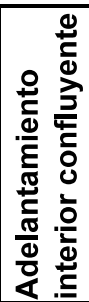 \\
\hline 67 & 1 & & & & & \\
\hline 68 & 1 & & & & & \\
\hline 69 & 1 & & & & & \\
\hline 70 & 1 & & & & & \\
\hline 71 & 1 & & & & & \\
\hline 72 & 1 & & & & & \\
\hline 73 & 1 & & & & & \\
\hline 74 & 1 & & & & & \\
\hline 75 & 1 & & & & & \\
\hline 76 & 1 & & & & $\bar{X}$ & \\
\hline 77 & 1 & & & & & \\
\hline 78 & 1 & & & & & \\
\hline 79 & 1 & & & & & \\
\hline 80 & 1 & & & & & \\
\hline 81 & 1 & & & & & \\
\hline 82 & 2 & & & & & \\
\hline 83 & 1 & & & & & \\
\hline 84 & 1 & & & & & \\
\hline 85 & 1 & & & & & \\
\hline 86 & $\overline{2}$ & & & & & \\
\hline 87 & 1 & & & & & \\
\hline 88 & 1 & & & & & \\
\hline 89 & 1 & & & & & \\
\hline 90 & 1 & & & & & \\
\hline 91 & 1 & & & & & \\
\hline 92 & 1 & & & & & \\
\hline 93 & 1 & & & & & \\
\hline 94 & 1 & & & & & \\
\hline 95 & 1 & & & & & \\
\hline 96 & 1 & & & & & \\
\hline 97 & 1 & & & & & \\
\hline 98 & 1 & & & & & \\
\hline 99 & 1 & & & & & \\
\hline 100 & 1 & & & & & \\
\hline 101 & 1 & & & & & \\
\hline 102 & 1 & & & & & \\
\hline 103 & 1 & & & & & \\
\hline 104 & 1 & & & & & \\
\hline 105 & 1 & & & & & \\
\hline 106 & 1 & & & & & \\
\hline 107 & 1 & & & & & \\
\hline 108 & 1 & & & & & \\
\hline 109 & 1 & & & & $\bar{X}$ & \\
\hline 110 & 1 & & & & & \\
\hline 111 & 1 & & & & & \\
\hline 112 & $\overline{2}$ & & & & & \\
\hline 113 & 1 & & & & & \\
\hline
\end{tabular}

\begin{tabular}{|c|c|c|c|c|c|c|}
\hline $\mathbf{z}$ & : & 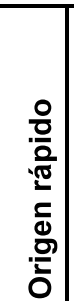 & 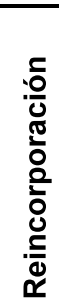 & 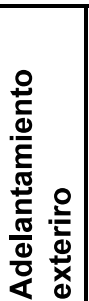 & 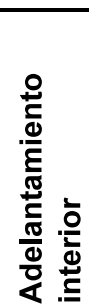 & 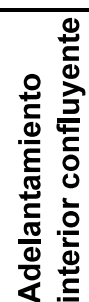 \\
\hline 114 & 1 & & & & & \\
\hline 115 & $\overline{0}$ & & & & & \\
\hline 116 & 1 & & & & & \\
\hline 117 & 1 & & & & & \\
\hline 118 & 1 & & & & & \\
\hline 119 & 1 & & & & & \\
\hline 120 & 1 & & & & & \\
\hline 121 & 1 & & & & & \\
\hline 122 & 1 & & & & & \\
\hline 123 & 1 & & & & & \\
\hline 124 & 1 & & & & & \\
\hline 125 & 1 & & & & & \\
\hline 126 & 1 & & & & & \\
\hline 127 & 1 & & & & & \\
\hline 128 & 1 & & & & & \\
\hline 129 & 1 & & & & & \\
\hline 130 & 1 & & & & & \\
\hline 131 & 1 & & & & & \\
\hline 132 & 1 & & & & & \\
\hline 133 & 1 & & & & & \\
\hline 134 & 1 & & & & & \\
\hline 135 & 1 & & & & & \\
\hline 136 & 1 & & & & & \\
\hline 137 & 1 & & & & & \\
\hline 138 & 1 & & & & & \\
\hline 139 & 1 & & & & & \\
\hline 140 & 1 & & & & & \\
\hline 141 & 1 & & & & & \\
\hline 142 & 1 & & & & & \\
\hline 143 & 1 & & & & & \\
\hline 144 & 1 & & & & & \\
\hline 145 & 1 & & & & & \\
\hline 146 & 1 & & & & & \\
\hline 147 & 1 & & & & & \\
\hline 148 & 1 & & & & & \\
\hline 149 & 1 & & & & & \\
\hline 150 & 1 & & & & & \\
\hline 151 & 1 & & & & & \\
\hline 152 & 1 & & & & & \\
\hline 153 & 1 & & & & & \\
\hline 154 & 1 & & & & & \\
\hline 155 & 1 & & & & & \\
\hline 156 & 1 & & & & & \\
\hline 157 & 1 & & & & & \\
\hline 158 & 1 & & & & & \\
\hline 159 & 1 & & & & & \\
\hline 160 & 2 & & & & & \\
\hline
\end{tabular}




\begin{tabular}{|c|c|c|c|c|c|c|}
\hline i & 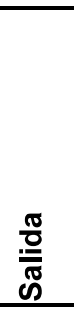 & 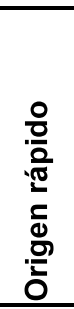 & 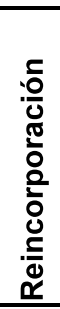 & 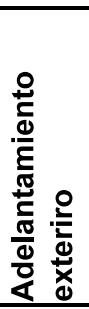 & 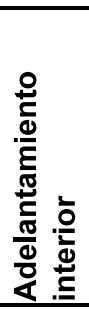 & 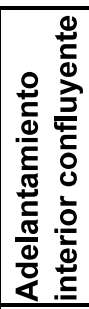 \\
\hline 161 & 1 & & & & & \\
\hline 162 & $\overline{1}$ & & & & & \\
\hline 163 & 1 & & & & & \\
\hline 164 & 1 & & & & & \\
\hline 165 & 1 & & & & & \\
\hline 166 & 1 & & & & & \\
\hline 167 & 1 & & & & & \\
\hline 168 & 1 & & & & & \\
\hline 169 & $\overline{1}$ & & & & & \\
\hline 170 & 1 & & & & & \\
\hline 171 & 1 & & & & & \\
\hline 172 & 1 & & & & & \\
\hline 173 & $\overline{1}$ & & & & & \\
\hline 174 & 1 & & & & & \\
\hline 175 & 1 & & & & & \\
\hline 176 & $\overline{1}$ & & & & & \\
\hline 177 & 1 & & & & & \\
\hline 178 & 1 & & & & & \\
\hline 179 & 1 & & & & & \\
\hline 180 & $\overline{1}$ & & & & & \\
\hline 181 & 1 & & & & & \\
\hline 182 & 1 & & & & & \\
\hline 183 & 1 & & & & & \\
\hline 184 & 1 & & & & & \\
\hline 185 & 1 & & & & & \\
\hline 186 & 1 & & & & & \\
\hline 187 & $\overline{1}$ & & & & & \\
\hline 188 & 1 & & & & & \\
\hline 189 & 1 & & & & & \\
\hline 190 & $\overline{1}$ & & & & $\bar{X}$ & \\
\hline 191 & $\overline{1}$ & & & & & \\
\hline 192 & 1 & & & & & \\
\hline 193 & 1 & & & & & \\
\hline 194 & $\overline{1}$ & & & & & \\
\hline 195 & 2 & & & & & \\
\hline 196 & 1 & & & & & \\
\hline 197 & $\overline{1}$ & & & & & \\
\hline 198 & $\overline{1}$ & & & & & \\
\hline 199 & 2 & & & & & \\
\hline 200 & 1 & & & & & \\
\hline 201 & 1 & & & & & \\
\hline 202 & 1 & & & & & \\
\hline 203 & 1 & & & & & \\
\hline 204 & $\overline{1}$ & & & & & \\
\hline 205 & 1 & & & & & \\
\hline 206 & 1 & & & & & \\
\hline 207 & 1 & & & & & \\
\hline
\end{tabular}

\begin{tabular}{|c|c|c|c|c|c|c|}
\hline 之o & 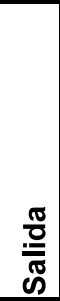 & 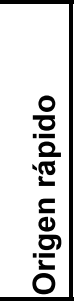 & 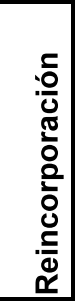 & 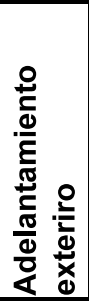 & 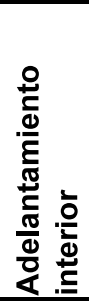 & 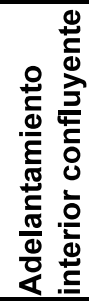 \\
\hline 208 & 1 & & & & & \\
\hline 209 & 1 & & & & & \\
\hline 210 & 1 & & & & & \\
\hline 211 & 1 & & & & & \\
\hline 212 & 1 & & & & & \\
\hline 213 & 1 & & & & & \\
\hline 214 & 1 & & & & & \\
\hline 215 & 1 & & & & & \\
\hline 216 & 1 & & & & & \\
\hline 217 & 1 & & & & & \\
\hline 218 & 2 & & & & & \\
\hline 219 & 1 & & & & & \\
\hline 220 & 1 & & & & & \\
\hline 221 & 1 & & & & & \\
\hline 222 & 1 & & & & & \\
\hline 223 & 1 & & & & & \\
\hline 224 & 1 & & & & & \\
\hline 225 & 2 & & & & & \\
\hline 226 & 1 & & & & & \\
\hline 227 & 1 & & & & & \\
\hline 228 & 1 & & & & & \\
\hline 229 & 1 & & & & & \\
\hline 230 & 1 & & & & & \\
\hline 231 & 1 & & & & & \\
\hline 232 & 1 & & & & & \\
\hline 233 & 1 & & & & & \\
\hline 234 & 1 & & & & & \\
\hline 235 & 1 & & & & & \\
\hline 236 & 2 & & & & & \\
\hline 237 & 1 & & & & & \\
\hline 238 & 1 & & & & & \\
\hline 239 & 1 & & & & & \\
\hline 240 & 1 & & & & & \\
\hline 241 & 1 & & & & & \\
\hline 242 & 1 & & & & & \\
\hline 243 & 1 & & & & & \\
\hline 244 & 1 & & & & & \\
\hline 245 & 1 & & & & & \\
\hline 246 & 1 & & & & & \\
\hline 247 & 1 & & & & & \\
\hline 248 & 1 & & & & & \\
\hline 249 & 1 & & & & & \\
\hline 250 & 1 & & & & & \\
\hline 251 & 1 & & & & & \\
\hline 252 & 1 & & & & & \\
\hline 253 & 1 & & & & & \\
\hline 254 & 1 & & & & & \\
\hline
\end{tabular}




\begin{tabular}{|c|c|c|c|c|c|c|}
\hline o & 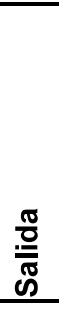 & 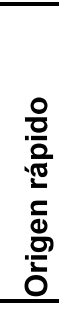 & 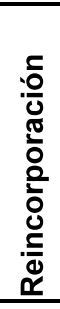 & 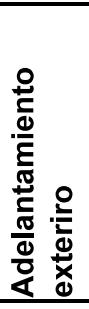 & 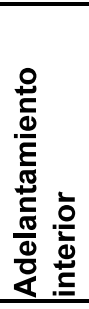 & 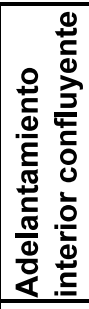 \\
\hline 255 & 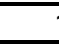 & & & & & \\
\hline 256 & 7 & & & & & \\
\hline 257 & 7 & & & & & \\
\hline 258 & 7 & & & & & \\
\hline 259 & 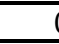 & & & & & \\
\hline 260 & 3 & & & & & \\
\hline 261 & 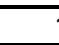 & & & & & \\
\hline 262 & 7 & & & & & \\
\hline 263 & 7 & & & & & \\
\hline 264 & 7 & & & & & \\
\hline 265 & 7 & & & & & \\
\hline 266 & 7 & & & & & \\
\hline 267 & . & & & & & \\
\hline 268 & 7 & & & & & \\
\hline 269 & 7 & & & & & \\
\hline 270 & 7 & & & & & \\
\hline 271 & . & & & & & \\
\hline 272 & 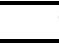 & & & & & \\
\hline 273 & 7 & & & & & \\
\hline 274 & 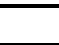 & & & & & \\
\hline 275 & & & & & & \\
\hline 276 & 7 & & & & & \\
\hline 277 & 7 & & & & & \\
\hline 278 & 7 & & & & & \\
\hline 279 & 7 & & & & & \\
\hline 280 & 7 & & & & & \\
\hline 281 & . & & & & & \\
\hline 282 & 7 & & & & & \\
\hline 283 & 7 & & & & & \\
\hline 284 & 8 & & & & & \\
\hline 285 & 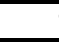 & & & & & \\
\hline 286 & 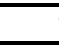 & & & & & \\
\hline 287 & 7 & & & & & \\
\hline 288 & 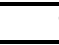 & & & & & \\
\hline 289 & . & & & & & \\
\hline 290 & 7 & & & & & \\
\hline 291 & 7 & & & & & \\
\hline 292 & . & & & & & \\
\hline 293 & 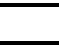 & & & & & \\
\hline 294 & & & & & & \\
\hline 295 & . & & & & & \\
\hline 296 & . & & & & & \\
\hline 297 & & & & & & \\
\hline 298 & 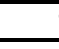 & & & & & \\
\hline 299 & 7 & & & & & \\
\hline 300 & 7 & & & & & \\
\hline 301 & . & & & & & \\
\hline
\end{tabular}

\begin{tabular}{|c|c|c|c|c|c|c|}
\hline z & 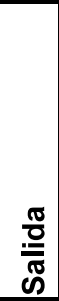 & $\begin{array}{l}\circ \\
\frac{0}{0} \\
\frac{\pi}{2} \\
\overline{0} \\
\bar{\sigma} \\
\overline{0}\end{array}$ & 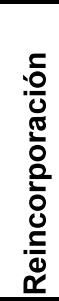 & 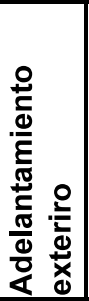 & 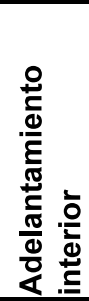 & 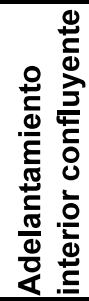 \\
\hline 302 & 1 & & & & & \\
\hline 303 & 1 & & & & & \\
\hline 304 & 1 & & & & & \\
\hline 305 & 1 & & & & & \\
\hline 306 & 1 & & & & & \\
\hline 307 & 1 & & & & & \\
\hline 308 & 1 & & & & & \\
\hline 309 & 1 & & & & & \\
\hline 310 & 1 & & & & & \\
\hline 311 & 1 & & & & & \\
\hline 312 & 1 & & & & & \\
\hline 313 & 1 & & & & & \\
\hline 314 & 1 & & & & & \\
\hline 315 & 1 & & & & & \\
\hline 316 & 1 & & & & & \\
\hline 317 & 1 & & & & & \\
\hline 318 & 1 & & & & & \\
\hline 319 & 1 & & & & & \\
\hline 320 & 1 & & & & & \\
\hline 321 & 1 & & & & & \\
\hline 322 & 1 & & & & & \\
\hline 323 & 1 & & & & & \\
\hline 324 & 1 & & & & & \\
\hline 325 & 1 & & & & & \\
\hline 326 & 1 & & & & $X$ & \\
\hline 327 & 1 & & & & & \\
\hline 328 & 1 & & & & & \\
\hline 329 & 1 & & & & & \\
\hline 330 & 1 & & & & & \\
\hline 331 & 1 & & & & & \\
\hline 332 & 1 & & & & & \\
\hline 333 & 1 & & & & & \\
\hline 334 & 1 & & & & & \\
\hline 335 & 1 & & & & & \\
\hline 336 & 1 & & & & & \\
\hline 337 & 1 & & & & & \\
\hline 338 & 1 & & & & & \\
\hline 339 & 1 & & & & & \\
\hline 340 & 2 & & & & & \\
\hline 341 & 1 & & & & & \\
\hline 342 & 1 & & & & & \\
\hline 343 & 1 & & & & & \\
\hline 344 & 1 & & & & & \\
\hline 345 & 1 & & & & & \\
\hline 346 & 1 & & & & & \\
\hline 347 & 1 & & & & & \\
\hline 348 & 1 & & & & & \\
\hline
\end{tabular}




\begin{tabular}{|c|c|c|c|c|c|c|}
\hline ż & 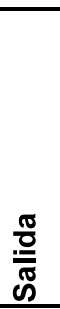 & 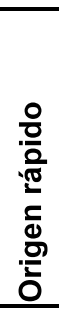 & 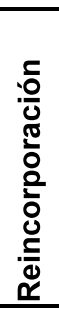 & 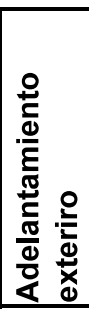 & 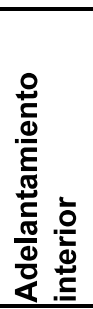 & 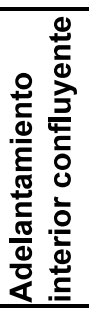 \\
\hline 349 & 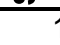 & & & & & \\
\hline 350 & & & & & & \\
\hline 351 & 1 & & & & & \\
\hline 352 & 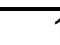 & & & & & \\
\hline 353 & & & & & & \\
\hline 354 & & & & & & \\
\hline 355 & & & & & & \\
\hline 356 & & & & & & \\
\hline 357 & 7 & & & & & \\
\hline 358 & 7 & & & & & \\
\hline 359 & 2 & & & & & \\
\hline 360 & 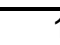 & & & & & \\
\hline 361 & & & & & & \\
\hline 362 & 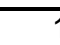 & & & & & \\
\hline 363 & 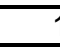 & & & & & \\
\hline 364 & 7 & & & & & \\
\hline 365 & 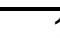 & & & & & \\
\hline 366 & & & & & & \\
\hline 367 & 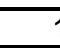 & & & & & \\
\hline 368 & 7 & & & & & \\
\hline 369 & 7 & & & & & \\
\hline 370 & 7 & & & & & \\
\hline 371 & 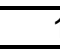 & & & & & \\
\hline 372 & & & & & & \\
\hline 373 & 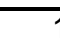 & & & & & \\
\hline 374 & & & & & & \\
\hline 375 & 7 & & & & & \\
\hline 376 & 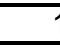 & & & & & \\
\hline 377 & 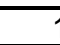 & & & & & \\
\hline 378 & 7 & & & & & \\
\hline 379 & & & & & & \\
\hline 380 & 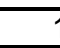 & & & & & \\
\hline 381 & 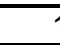 & & & & & \\
\hline 382 & & & & & & \\
\hline 383 & 7 & & & & & \\
\hline 384 & 7 & & & & & \\
\hline 385 & & & & & & \\
\hline 386 & 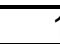 & & & & & \\
\hline 387 & 7 & & & & & \\
\hline 388 & 7 & & & & & \\
\hline 389 & 7 & & & & & \\
\hline 390 & 7 & & & & & \\
\hline 391 & 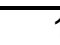 & & & & & \\
\hline 392 & 7 & & & & $X$ & \\
\hline 393 & & & & & & \\
\hline 394 & 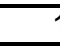 & & & & & \\
\hline 395 & 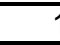 & & & & & \\
\hline
\end{tabular}

\begin{tabular}{|c|c|c|c|c|c|c|}
\hline $\mathbf{0}$ & 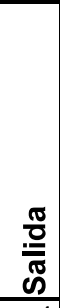 & 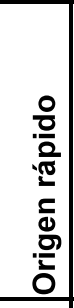 & 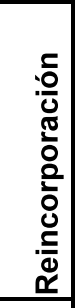 & 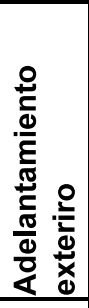 & 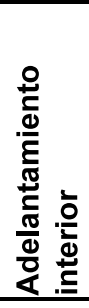 & 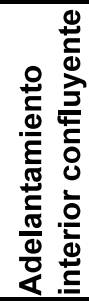 \\
\hline 396 & 1 & & & & & \\
\hline 397 & 1 & & & & & \\
\hline 398 & 1 & & & & & \\
\hline 399 & 1 & & & & & \\
\hline 400 & 1 & & & & & \\
\hline 401 & 1 & & & & & \\
\hline 402 & 1 & & & & & \\
\hline 403 & 2 & & & & & \\
\hline 404 & 1 & & & & & \\
\hline 405 & 1 & & & & & \\
\hline 406 & 1 & & & & & \\
\hline 407 & 1 & & & & & \\
\hline 408 & 2 & & & & & \\
\hline 409 & 1 & & & & & \\
\hline 410 & 1 & & & & & \\
\hline 411 & 1 & & & & & \\
\hline 412 & 1 & & & & & \\
\hline 413 & 1 & & & & & \\
\hline 414 & 1 & & & & & \\
\hline 415 & 1 & & & & & \\
\hline 416 & 1 & & & & & \\
\hline 417 & 1 & & & & & \\
\hline 418 & 1 & & & & & \\
\hline 419 & 1 & & & & & \\
\hline 420 & 1 & & & & & \\
\hline 421 & 1 & & & & & \\
\hline 422 & 1 & & & & & \\
\hline 423 & 1 & & & & & \\
\hline 424 & 1 & & & & & \\
\hline 425 & 1 & & & & & \\
\hline 426 & 1 & & & & & \\
\hline 427 & 1 & & & & & \\
\hline 428 & 1 & & & & & \\
\hline 429 & 1 & & & & & \\
\hline 430 & 1 & & & & & \\
\hline 431 & 1 & & & & & \\
\hline 432 & 1 & & & & & \\
\hline 433 & 1 & & & & & \\
\hline 434 & 1 & & & & & \\
\hline 435 & 1 & & & & & \\
\hline 436 & 1 & & & & & \\
\hline 437 & 1 & & & & & \\
\hline 438 & 1 & & & & & \\
\hline 439 & 1 & & & & & \\
\hline 440 & 1 & & & & & \\
\hline 441 & 1 & & & & & \\
\hline 442 & 1 & & & & $x$ & \\
\hline
\end{tabular}




\begin{tabular}{|c|c|c|c|c|c|c|}
\hline ż & $\begin{array}{l}\frac{\pi}{0} \\
\frac{0}{\pi} \\
\stackrel{0}{n}\end{array}$ & 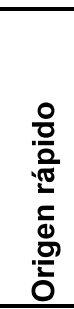 & 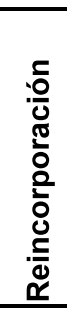 & 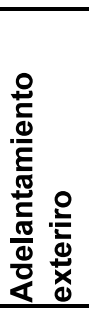 & 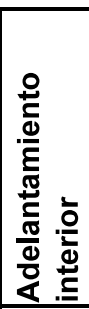 & 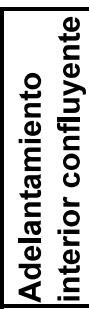 \\
\hline 443 & 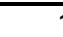 & & & & & \\
\hline 444 & 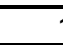 & & & & & \\
\hline 445 & & & & & & \\
\hline 446 & & & & & & \\
\hline 447 & 8 & & & & & \\
\hline 448 & & & & & & \\
\hline 449 & 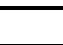 & & & & & \\
\hline 450 & & & & & & \\
\hline 451 & & & & & & \\
\hline 452 & & & & & & \\
\hline 453 & & & & & & \\
\hline 454 & & & & & & \\
\hline 455 & & & & & & \\
\hline 456 & & & & & & \\
\hline 457 & & & & & & \\
\hline 458 & & & & & & \\
\hline 459 & & & & & & \\
\hline 460 & & & & & & \\
\hline 461 & & & & & & \\
\hline 462 & & & & & & \\
\hline 463 & & & & & & \\
\hline 464 & & & & & & \\
\hline 465 & & & & & & \\
\hline 466 & & & & & & \\
\hline 467 & & & & & & \\
\hline 468 & & & & & & \\
\hline 469 & & & & & & \\
\hline 470 & & & & & & \\
\hline 471 & & & & & & \\
\hline 472 & & & & & & \\
\hline 473 & & & & & & \\
\hline
\end{tabular}




\begin{tabular}{|l|c|c|}
\hline \multicolumn{2}{|c|}{ V30-49 } \\
\hline Maniobras & 328 & \\
\hline Salida anticipada & 8 & $2,4 \%$ \\
\hline Salida en la cuña & 281 & $85,7 \%$ \\
\hline Salida zona media & 36 & $11,0 \%$ \\
\hline Salida tardia & 3 & $0,9 \%$ \\
\hline Origen carriles ràpidos & 6 & $1,8 \%$ \\
\hline Reincorporaciones & 1 & $0,3 \%$ \\
\hline Adelantamiento exterior & 0 & $0,0 \%$ \\
\hline Adelantamiento interior & 3 & $0,9 \%$ \\
\hline Adelantamiento interior confluyente & 0 & $0,0 \%$ \\
\hline
\end{tabular}

\begin{tabular}{|c|c|c|c|c|c|c|}
\hline$\stackrel{0}{2}$ & $\begin{array}{l}\frac{\pi}{0} \\
\frac{0}{\pi} \\
\infty\end{array}$ & $\begin{array}{l}\text { 음 } \\
\text { 문 } \\
\text { 인 } \\
\text { 은 }\end{array}$ & 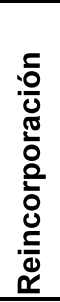 & 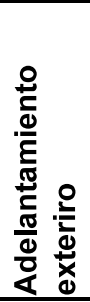 & 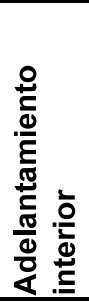 & 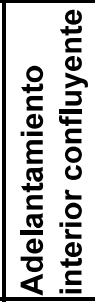 \\
\hline 1 & 1 & & & & & \\
\hline 2 & 1 & & & & & \\
\hline 3 & 1 & & & & & \\
\hline 4 & 1 & & & & & \\
\hline 5 & 1 & & & & & \\
\hline 6 & 1 & & & & & \\
\hline 7 & 1 & & & & & \\
\hline 8 & 1 & & & & & \\
\hline 9 & 1 & & & & & \\
\hline 10 & 1 & & & & $X$ & \\
\hline 11 & 3 & & & & & \\
\hline 12 & 1 & & & & & \\
\hline 13 & 1 & & & & & \\
\hline 14 & 1 & & & & & \\
\hline 15 & 1 & & & & & \\
\hline 16 & 1 & & & & & \\
\hline 17 & 1 & & & & & \\
\hline 18 & 1 & $\bar{X}$ & & & & \\
\hline 19 & 1 & & & & & \\
\hline 20 & 1 & & & & & \\
\hline 21 & 1 & & & & & \\
\hline 22 & 1 & & & & & \\
\hline 23 & 1 & & & & & \\
\hline 24 & 1 & & & & & \\
\hline 25 & 1 & & & & & \\
\hline 26 & 2 & & & & & \\
\hline 27 & 2 & & & & & \\
\hline 28 & 1 & & & & & \\
\hline 29 & 0 & & & & & \\
\hline 30 & 1 & & & & & \\
\hline 31 & 1 & & & & & \\
\hline 32 & 1 & & & & & \\
\hline 33 & 1 & & & & & \\
\hline
\end{tabular}

\begin{tabular}{|c|c|c|c|c|c|c|}
\hline$\dot{0}$ & $\begin{array}{l}\frac{\pi}{0} \\
\frac{0}{\pi} \\
\text { ஸे }\end{array}$ & 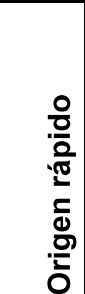 & 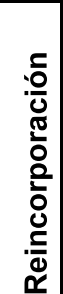 & 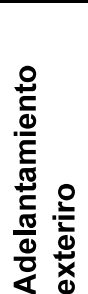 & 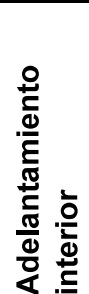 & 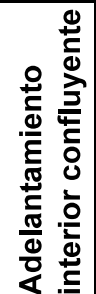 \\
\hline 34 & 1 & & & & & \\
\hline 35 & 1 & & & & & \\
\hline 36 & 1 & & & & & \\
\hline 37 & 1 & & & & & \\
\hline 38 & 1 & & & & & \\
\hline 39 & 1 & & & & & \\
\hline 40 & 0 & & & & & \\
\hline 41 & 1 & & & & & \\
\hline 42 & 3 & & & & & \\
\hline 43 & 2 & & & & & \\
\hline 44 & 1 & & & & & \\
\hline 45 & 1 & & & & & \\
\hline 46 & & $\bar{X}$ & & & & \\
\hline 47 & 1 & & & & & \\
\hline 48 & 2 & & & & & \\
\hline 49 & 1 & & & & & \\
\hline 50 & 0 & & & & & \\
\hline 51 & 1 & & & & & \\
\hline 52 & 1 & & & & & \\
\hline 53 & 2 & & & & & \\
\hline 54 & 1 & & & & & \\
\hline 55 & 1 & & & & & \\
\hline 56 & 0 & & & & & \\
\hline 57 & 1 & & & & & \\
\hline 58 & 2 & & & & & \\
\hline 59 & 1 & & & & & \\
\hline 60 & 2 & & & & & \\
\hline 61 & 2 & & & & & \\
\hline 62 & 1 & & & & & \\
\hline 63 & 1 & & & & & \\
\hline 64 & 1 & & & & & \\
\hline 65 & 1 & & & & & \\
\hline 66 & 0 & & & & & \\
\hline
\end{tabular}




\begin{tabular}{|c|c|c|c|c|c|c|}
\hline$\dot{0}$ & $\frac{\mathbb{\pi}}{\frac{\pi}{\overline{0}}}$ & 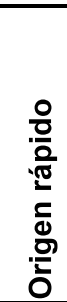 & 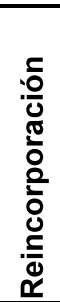 & 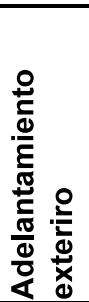 & 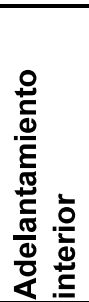 & 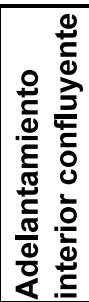 \\
\hline 67 & 1 & & & & & \\
\hline 68 & 2 & & & & & \\
\hline 69 & 1 & & & & & \\
\hline 70 & 1 & & & & & \\
\hline 71 & 1 & & & & & \\
\hline 72 & 1 & & & & & \\
\hline 73 & 1 & & & & & \\
\hline 74 & 2 & & & & & \\
\hline 75 & 1 & & & & & \\
\hline 76 & 2 & & & & & \\
\hline 77 & $\frac{2}{2}$ & & & & & \\
\hline 78 & 1 & & & & & \\
\hline 79 & 1 & & & & & \\
\hline 80 & 0 & & & & & \\
\hline 81 & 1 & & & & & \\
\hline 82 & & $\bar{X}$ & & & & \\
\hline 83 & 3 & & & & & \\
\hline 84 & 2 & & & & & \\
\hline 85 & 1 & & & & & \\
\hline 86 & 1 & & & & & \\
\hline 87 & 1 & & & & & \\
\hline 88 & 1 & & & & & \\
\hline 89 & 1 & & & & & \\
\hline 90 & 1 & $\bar{X}$ & & & & \\
\hline 91 & 1 & & & & & \\
\hline 92 & 2 & & & & & \\
\hline 93 & 1 & & & & & \\
\hline 94 & 2 & & & & & \\
\hline 95 & $\frac{1}{2}$ & & & & & \\
\hline 96 & 1 & & & & & \\
\hline 97 & 1 & & & & & \\
\hline 98 & 1 & & & & & \\
\hline 99 & 1 & & & & & \\
\hline 100 & 1 & & & & & \\
\hline 101 & 1 & & & & & \\
\hline 102 & 1 & & & & & \\
\hline 103 & 1 & & & & & \\
\hline 104 & 1 & & & & & \\
\hline 105 & 1 & & & & & \\
\hline 106 & 1 & & & & & \\
\hline 107 & 1 & & & & & \\
\hline 108 & 1 & & & & & \\
\hline 109 & 1 & & & & & \\
\hline 110 & $\frac{1}{1}$ & & & & & \\
\hline 111 & 1 & & & & & \\
\hline 112 & 1 & & & & & \\
\hline 113 & 1 & & & & & \\
\hline
\end{tabular}

\begin{tabular}{|c|c|c|c|c|c|c|}
\hline $\mathbf{z}$ & 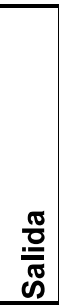 & 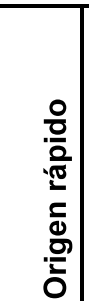 & 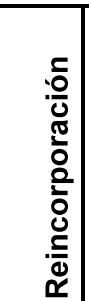 & 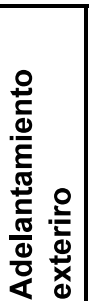 & 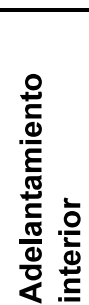 & 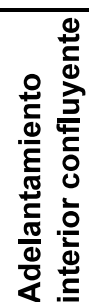 \\
\hline 114 & 1 & & & & & \\
\hline 115 & 1 & & & & & \\
\hline 116 & 1 & & & & & \\
\hline 117 & 1 & & & & & \\
\hline 118 & 1 & & & & & \\
\hline 119 & 1 & & & & & \\
\hline 120 & 1 & & & & & \\
\hline 121 & 1 & & & & & \\
\hline 122 & 1 & & & & & \\
\hline 123 & 1 & & & & & \\
\hline 124 & 2 & & & & & \\
\hline 125 & 1 & & & & & \\
\hline 126 & 1 & & & & & \\
\hline 127 & 1 & & & & & \\
\hline 128 & 1 & & & & & \\
\hline 129 & 1 & & & & & \\
\hline 130 & 1 & & & & & \\
\hline 131 & 1 & & & & & \\
\hline 132 & 1 & & & & & \\
\hline 133 & 1 & & & & & \\
\hline 134 & 1 & & & & & \\
\hline 135 & 0 & & & & & \\
\hline 136 & 1 & & & & & \\
\hline 137 & 1 & & & & & \\
\hline 138 & 1 & & & & & \\
\hline 139 & 1 & & & & & \\
\hline 140 & 1 & & & & & \\
\hline 141 & 1 & & & & & \\
\hline 142 & 2 & & & & & \\
\hline 143 & 1 & $\bar{x}$ & & & & \\
\hline 144 & 1 & & & & & \\
\hline 145 & 1 & & & & & \\
\hline 146 & 1 & & & & & \\
\hline 147 & 1 & & & & & \\
\hline 148 & 1 & & & & & \\
\hline 149 & 1 & & & & & \\
\hline 150 & 1 & & $\bar{X}$ & & & \\
\hline 151 & 1 & & & & & \\
\hline 152 & 1 & & & & & \\
\hline 153 & 1 & & & & & \\
\hline 154 & 1 & & & & & \\
\hline 155 & 1 & & & & & \\
\hline 156 & 1 & & & & & \\
\hline 157 & 1 & & & & & \\
\hline 158 & 1 & & & & & \\
\hline 159 & 1 & & & & & \\
\hline 160 & 1 & & & & & \\
\hline
\end{tabular}




\begin{tabular}{|c|c|c|c|c|c|c|}
\hline i & 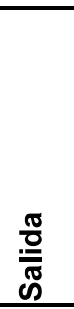 & $\begin{array}{l}\stackrel{\circ}{\circ} \\
\frac{0}{2} \\
\frac{\pi}{2} \\
\bar{d} \\
\stackrel{\circ}{5} \\
0\end{array}$ & 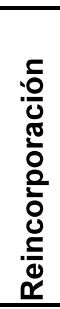 & 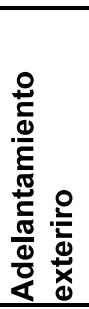 & 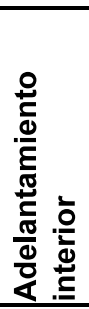 & 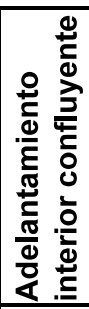 \\
\hline 161 & 1 & & & & & \\
\hline 162 & $\overline{1}$ & & & & & \\
\hline 163 & 1 & & & & & \\
\hline 164 & 1 & & & & & \\
\hline 165 & 1 & & & & & \\
\hline 166 & 1 & & & & & \\
\hline 167 & 1 & & & & & \\
\hline 168 & $\underline{2}$ & & & & & \\
\hline 169 & $\overline{1}$ & & & & & \\
\hline 170 & 1 & & & & & \\
\hline 171 & 1 & & & & & \\
\hline 172 & 1 & & & & & \\
\hline 173 & $\overline{1}$ & & & & & \\
\hline 174 & 1 & & & & & \\
\hline 175 & 1 & & & & & \\
\hline 176 & $\overline{1}$ & & & & & \\
\hline 177 & 1 & & & & & \\
\hline 178 & 1 & & & & & \\
\hline 179 & 1 & & & & & \\
\hline 180 & 1 & & & & $\bar{X}$ & \\
\hline 181 & $\overline{2}$ & & & & $\bar{X}$ & \\
\hline 182 & 1 & & & & & \\
\hline 183 & 1 & & & & & \\
\hline 184 & 2 & & & & & \\
\hline 185 & 1 & & & & & \\
\hline 186 & 1 & & & & & \\
\hline 187 & $\overline{1}$ & & & & & \\
\hline 188 & 1 & & & & & \\
\hline 189 & 2 & & & & & \\
\hline 190 & $\overline{1}$ & & & & & \\
\hline 191 & $\overline{1}$ & & & & & \\
\hline 192 & 1 & & & & & \\
\hline 193 & 1 & & & & & \\
\hline 194 & $\overline{1}$ & & & & & \\
\hline 195 & 1 & & & & & \\
\hline 196 & 1 & & & & & \\
\hline 197 & $\overline{1}$ & & & & & \\
\hline 198 & $\overline{1}$ & & & & & \\
\hline 199 & 1 & & & & & \\
\hline 200 & 1 & & & & & \\
\hline 201 & 1 & & & & & \\
\hline 202 & 1 & & & & & \\
\hline 203 & 1 & & & & & \\
\hline 204 & $\overline{1}$ & & & & & \\
\hline 205 & 1 & & & & & \\
\hline 206 & 1 & & & & & \\
\hline 207 & 1 & & & & & \\
\hline
\end{tabular}

\begin{tabular}{|c|c|c|c|c|c|c|}
\hline 之o & 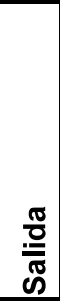 & 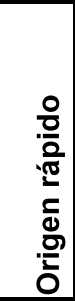 & 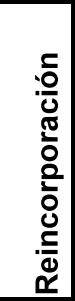 & 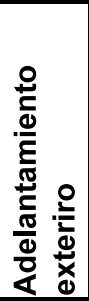 & 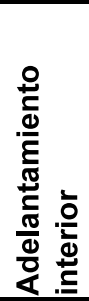 & 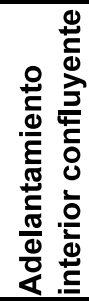 \\
\hline 208 & 1 & & & & & \\
\hline 209 & 1 & & & & & \\
\hline 210 & 1 & & & & & \\
\hline 211 & 1 & & & & & \\
\hline 212 & 1 & & & & & \\
\hline 213 & 1 & & & & & \\
\hline 214 & 1 & & & & & \\
\hline 215 & 1 & & & & & \\
\hline 216 & 1 & & & & & \\
\hline 217 & 1 & & & & & \\
\hline 218 & 2 & & & & & \\
\hline 219 & 1 & & & & & \\
\hline 220 & 1 & & & & & \\
\hline 221 & 1 & & & & & \\
\hline 222 & 1 & & & & & \\
\hline 223 & 1 & & & & & \\
\hline 224 & 1 & & & & & \\
\hline 225 & 1 & & & & & \\
\hline 226 & 1 & & & & & \\
\hline 227 & 1 & & & & & \\
\hline 228 & 1 & & & & & \\
\hline 229 & 1 & & & & & \\
\hline 230 & 1 & & & & & \\
\hline 231 & 2 & & & & & \\
\hline 232 & 1 & & & & & \\
\hline 233 & 1 & & & & & \\
\hline 234 & 1 & & & & & \\
\hline 235 & 1 & & & & & \\
\hline 236 & 1 & & & & & \\
\hline 237 & 2 & & & & & \\
\hline 238 & 1 & & & & & \\
\hline 239 & 1 & & & & & \\
\hline 240 & 1 & & & & & \\
\hline 241 & 1 & & & & & \\
\hline 242 & 1 & & & & & \\
\hline 243 & 1 & & & & & \\
\hline 244 & 1 & & & & & \\
\hline 245 & 1 & & & & & \\
\hline 246 & 1 & & & & & \\
\hline 247 & 1 & & & & & \\
\hline 248 & 1 & & & & & \\
\hline 249 & 1 & & & & & \\
\hline 250 & 1 & & & & & \\
\hline 251 & 1 & & & & & \\
\hline 252 & 1 & & & & & \\
\hline 253 & 1 & & & & & \\
\hline 254 & 1 & & & & & \\
\hline
\end{tabular}




\begin{tabular}{|c|c|c|c|c|c|c|}
\hline i & $\begin{array}{l}\frac{\pi}{0} \\
\frac{\pi}{\pi} \\
\end{array}$ & 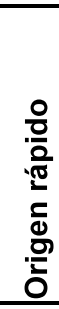 & 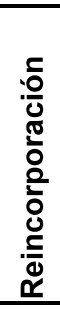 & 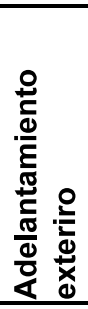 & 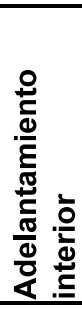 & 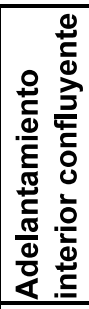 \\
\hline 255 & 1 & & & & & \\
\hline 256 & $a_{1}$ & & & & & \\
\hline 257 & 7 & & & & & \\
\hline 258 & 2 & & & & & \\
\hline 259 & 1 & & & & & \\
\hline 260 & 1 & & & & & \\
\hline 261 & 1 & & & & & \\
\hline 262 & 2 & & & & & \\
\hline 263 & 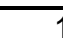 & & & & & \\
\hline 264 & 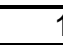 & & & & & \\
\hline 265 & $\underline{2}$ & & & & & \\
\hline 266 & 7 & & & & & \\
\hline 267 & 1 & & & & & \\
\hline 268 & 2 & & & & & \\
\hline 269 & 2 & & & & & \\
\hline 270 & 7 & & & & & \\
\hline 271 & 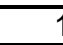 & & & & & \\
\hline 272 & 1 & & & & & \\
\hline 273 & 7 & & & & & \\
\hline 274 & c & & & & & \\
\hline 275 & 7 & & & & & \\
\hline 276 & 7 & & & & & \\
\hline 277 & 7 & & & & & \\
\hline 278 & 7 & & & & & \\
\hline 279 & 7 & & & & & \\
\hline 280 & 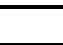 & & & & & \\
\hline 281 & 7 & & & & & \\
\hline 282 & 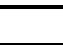 & & & & & \\
\hline 283 & 7 & & & & & \\
\hline 284 & 7 & & & & & \\
\hline 285 & & & & & & \\
\hline 286 & 8 & & & & & \\
\hline 287 & 7 & & & & & \\
\hline 288 & 7 & & & & & \\
\hline 289 & 7 & & & & & \\
\hline 290 & 7 & & & & & \\
\hline 291 & 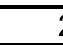 & & & & & \\
\hline 292 & 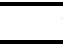 & & & & & \\
\hline 293 & 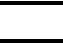 & & & & & \\
\hline 294 & 7 & & & & & \\
\hline 295 & . & & & & & \\
\hline 296 & 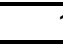 & & & & & \\
\hline 297 & 7 & & & & & \\
\hline 298 & . & & & & & \\
\hline 299 & 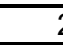 & & & & & \\
\hline 300 & 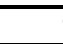 & & & & & \\
\hline 301 & & & & & & \\
\hline
\end{tabular}

\begin{tabular}{|c|c|c|c|c|c|c|}
\hline $\mathbf{z}$ & $\begin{array}{l}\frac{\pi}{0} \\
\frac{0}{\pi} \\
\stackrel{5}{5}\end{array}$ & 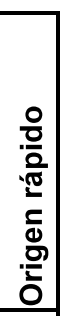 & 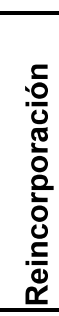 & 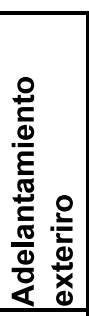 & 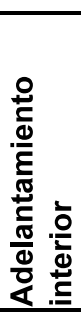 & 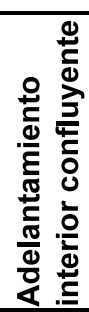 \\
\hline 302 & 1 & & & & & \\
\hline 303 & 1 & & & & & \\
\hline 304 & 1 & & & & & \\
\hline 305 & 1 & & & & & \\
\hline 306 & 1 & & & & & \\
\hline 307 & 1 & & & & & \\
\hline 308 & 1 & & & & & \\
\hline 309 & 1 & & & & & \\
\hline 310 & 1 & & & & & \\
\hline 311 & 1 & & & & & \\
\hline 312 & 1 & & & & & \\
\hline 313 & 1 & & & & & \\
\hline 314 & 1 & & & & & \\
\hline 315 & 2 & & & & & \\
\hline 316 & 1 & & & & & \\
\hline 317 & 1 & & & & & \\
\hline 318 & 1 & & & & & \\
\hline 319 & 1 & & & & & \\
\hline 320 & 1 & & & & & \\
\hline 321 & 1 & & & & & \\
\hline 322 & 1 & & & & & \\
\hline 323 & 1 & & & & & \\
\hline 324 & 1 & & & & & \\
\hline 325 & 1 & & & & & \\
\hline 326 & 1 & & & & & \\
\hline 327 & 1 & & & & & \\
\hline 328 & 1 & & & & & \\
\hline
\end{tabular}




\begin{tabular}{|l|c|c|}
\hline \multicolumn{2}{|c|}{ V21-895 } \\
\hline Maniobras & 239 & \\
\hline Salida anticipada & 5 & $2,1 \%$ \\
\hline Salida en la cuña & 205 & $85,8 \%$ \\
\hline Salida zona media & 27 & $11,3 \%$ \\
\hline Salida tardia & 2 & $0,8 \%$ \\
\hline Origen carriles ràpidos & 2 & $0,8 \%$ \\
\hline Reincorporaciones & 0 & $0,0 \%$ \\
\hline Adelantamiento exterior & 0 & $0,0 \%$ \\
\hline Adelantamiento interior & 11 & $4,6 \%$ \\
\hline Adelantamiento interior confluyente & 0 & $0,0 \%$ \\
\hline
\end{tabular}

\begin{tabular}{|c|c|c|c|c|c|c|}
\hline$\stackrel{0}{2}$ & $\begin{array}{l}\frac{\pi}{0} \\
\frac{0}{\pi} \\
\infty\end{array}$ & $\begin{array}{l}\text { 음 } \\
\text { 은 } \\
\text { 엉 } \\
\text { 은 }\end{array}$ & 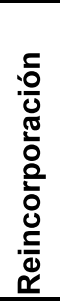 & 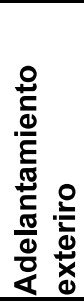 & 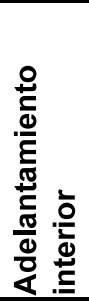 & 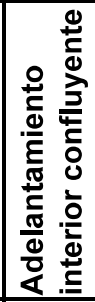 \\
\hline 1 & 1 & & & & & \\
\hline 2 & 1 & & & & & \\
\hline 3 & 1 & & & & & \\
\hline 4 & 1 & & & & & \\
\hline 5 & 1 & & & & & \\
\hline 6 & 1 & & & & & \\
\hline 7 & 1 & & & & & \\
\hline 8 & 1 & & & & & \\
\hline 9 & 1 & & & & & \\
\hline 10 & 1 & & & & & \\
\hline 11 & 1 & & & & & \\
\hline 12 & 1 & & & & & \\
\hline 13 & 1 & & & & & \\
\hline 14 & 1 & & & & & \\
\hline 15 & 1 & & & & & \\
\hline 16 & 1 & & & & & \\
\hline 17 & 1 & & & & & \\
\hline 18 & 1 & & & & & \\
\hline 19 & 1 & & & & & \\
\hline 20 & 1 & & & & & \\
\hline 21 & 1 & & & & & \\
\hline 22 & 1 & & & & & \\
\hline 23 & 1 & & & & & \\
\hline 24 & 1 & & & & & \\
\hline 25 & 1 & & & & & \\
\hline 26 & 1 & & & & & \\
\hline 27 & 1 & & & & $X$ & \\
\hline 28 & 1 & & & & & \\
\hline 29 & 1 & & & & $\bar{X}$ & \\
\hline 30 & 1 & & & & & \\
\hline 31 & 1 & & & & & \\
\hline 32 & 1 & & & & & \\
\hline 33 & 1 & & & & & \\
\hline
\end{tabular}

\begin{tabular}{|c|c|c|c|c|c|c|}
\hline i & $\frac{\frac{\pi}{0}}{\frac{0}{\pi}}$ & $\begin{array}{l}\circ \\
\frac{0}{0} \\
\frac{0}{0} \\
\frac{2}{0} \\
\frac{0}{2} \\
\frac{0}{2}\end{array}$ & 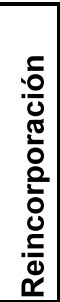 & 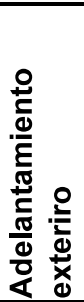 & 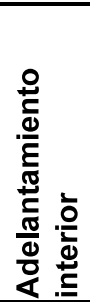 & 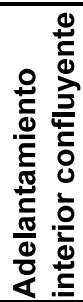 \\
\hline 34 & 1 & & & & & \\
\hline 35 & 1 & & & & & \\
\hline 36 & 1 & & & & & \\
\hline 37 & 1 & & & & & \\
\hline 38 & 1 & & & & & \\
\hline 39 & 1 & & & & & \\
\hline 40 & 1 & & & & & \\
\hline 41 & 1 & & & & & \\
\hline 42 & 1 & & & & & \\
\hline 43 & 1 & & & & & \\
\hline 44 & 1 & & & & & \\
\hline 45 & 2 & & & & & \\
\hline 46 & 1 & & & & & \\
\hline 47 & 1 & & & & & \\
\hline 48 & 1 & & & & & \\
\hline 49 & 2 & & & & & \\
\hline 50 & 1 & & & & & \\
\hline 51 & 1 & & & & & \\
\hline 52 & 1 & & & & & \\
\hline 53 & 0 & & & & & \\
\hline 54 & 1 & & & & & \\
\hline 55 & 1 & & & & & \\
\hline 56 & 3 & & & & & \\
\hline 57 & 1 & & & & & \\
\hline 58 & 1 & & & & & \\
\hline 59 & 1 & & & & & \\
\hline 60 & 1 & & & & & \\
\hline 61 & 1 & & & & & \\
\hline 62 & 1 & & & & $\bar{X}$ & \\
\hline 63 & 1 & & & & & \\
\hline 64 & 2 & & & & & \\
\hline 65 & 1 & & & & & \\
\hline 66 & 1 & & & & $\bar{X}$ & \\
\hline
\end{tabular}




\begin{tabular}{|c|c|c|c|c|c|c|}
\hline$\dot{0}$ & $\frac{\mathbb{\pi}}{\frac{\pi}{\overline{0}}}$ & 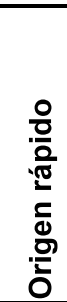 & 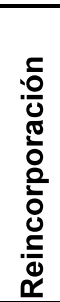 & 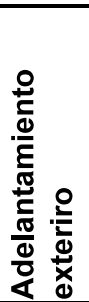 & 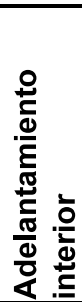 & 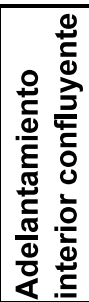 \\
\hline 67 & 1 & & & & & \\
\hline 68 & 2 & & & & & \\
\hline 69 & 1 & & & & & \\
\hline 70 & 1 & & & & & \\
\hline 71 & & $\bar{x}$ & & & & \\
\hline 72 & 2 & & & & & \\
\hline 73 & $\overline{2}$ & & & & & \\
\hline 74 & 1 & & & & $\bar{X}$ & \\
\hline 75 & $\overline{2}$ & & & & & \\
\hline 76 & 1 & & & & & \\
\hline 77 & 1 & & & & & \\
\hline 78 & 1 & & & & & \\
\hline 79 & 1 & & & & & \\
\hline 80 & 1 & & & & & \\
\hline 81 & 1 & & & & & \\
\hline 82 & 1 & & & & & \\
\hline 83 & 1 & & & & & \\
\hline 84 & 1 & & & & & \\
\hline 85 & 1 & & & & & \\
\hline 86 & 1 & & & & & \\
\hline 87 & 1 & & & & & \\
\hline 88 & 1 & & & & & \\
\hline 89 & 1 & & & & & \\
\hline 90 & 1 & & & & & \\
\hline 91 & 1 & & & & & \\
\hline 92 & 2 & & & & & \\
\hline 93 & 1 & & & & $\bar{X}$ & \\
\hline 94 & 1 & & & & & \\
\hline 95 & 2 & & & & & \\
\hline 96 & 2 & & & & & \\
\hline 97 & 1 & & & & & \\
\hline 98 & 1 & & & & & \\
\hline 99 & 1 & & & & & \\
\hline 100 & 1 & & & & & \\
\hline 101 & 1 & & & & & \\
\hline 102 & 1 & & & & & \\
\hline 103 & 1 & & & & & \\
\hline 104 & $\overline{2}$ & & & & & \\
\hline 105 & 1 & & & & & \\
\hline 106 & $\overline{2}$ & & & & & \\
\hline 107 & 1 & & & & & \\
\hline 108 & 1 & & & & & \\
\hline 109 & 2 & & & & & \\
\hline 110 & $\frac{2}{1}$ & & & & & \\
\hline 111 & 1 & & & & & \\
\hline 112 & 1 & & & & & \\
\hline 113 & 1 & & & & & \\
\hline
\end{tabular}

\begin{tabular}{|c|c|c|c|c|c|c|}
\hline $\mathbf{z}$ & 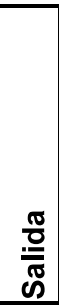 & 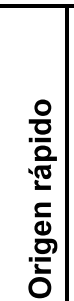 & 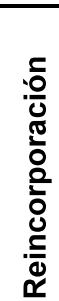 & 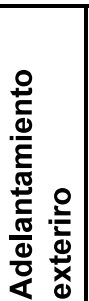 & 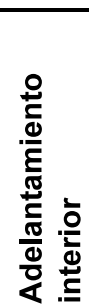 & 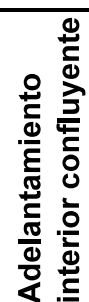 \\
\hline 114 & 1 & & & & & \\
\hline 115 & 1 & & & & & \\
\hline 116 & 1 & & & & & \\
\hline 117 & 1 & & & & & \\
\hline 118 & 1 & & & & & \\
\hline 119 & 0 & & & & & \\
\hline 120 & 1 & & & & & \\
\hline 121 & 1 & & & & & \\
\hline 122 & 1 & & & & & \\
\hline 123 & 1 & & & & & \\
\hline 124 & 1 & & & & & \\
\hline 125 & 1 & & & & & \\
\hline 126 & 1 & & & & & \\
\hline 127 & 0 & & & & & \\
\hline 128 & 1 & & & & & \\
\hline 129 & 1 & & & & $\bar{X}$ & \\
\hline 130 & 1 & & & & & \\
\hline 131 & 1 & & & & & \\
\hline 132 & 1 & & & & & \\
\hline 133 & 1 & & & & & \\
\hline 134 & 1 & & & & & \\
\hline 135 & 1 & & & & & \\
\hline 136 & 1 & & & & & \\
\hline 137 & 1 & & & & & \\
\hline 138 & 2 & & & & & \\
\hline 139 & 2 & & & & & \\
\hline 140 & 1 & & & & & \\
\hline 141 & 1 & & & & & \\
\hline 142 & 1 & & & & & \\
\hline 143 & 1 & & & & & \\
\hline 144 & 2 & & & & & \\
\hline 145 & 1 & & & & & \\
\hline 146 & 1 & & & & & \\
\hline 147 & 2 & & & & & \\
\hline 148 & 1 & & & & & \\
\hline 149 & 1 & & & & & \\
\hline 150 & 1 & & & & & \\
\hline 151 & 1 & & & & & \\
\hline 152 & 1 & & & & & \\
\hline 153 & 1 & & & & & \\
\hline 154 & 2 & & & & & \\
\hline 155 & 1 & & & & & \\
\hline 156 & 1 & & & & & \\
\hline 157 & 1 & & & & & \\
\hline 158 & 0 & & & & & \\
\hline 159 & 1 & & & & & \\
\hline 160 & 1 & & & & & \\
\hline
\end{tabular}




\begin{tabular}{|c|c|c|c|c|c|c|}
\hline i & 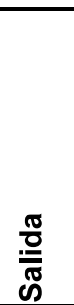 & 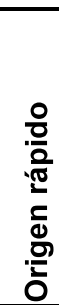 & 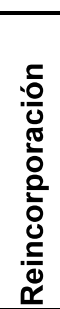 & 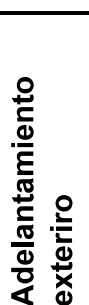 & 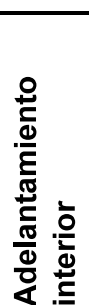 & 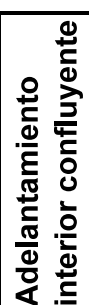 \\
\hline 161 & 1 & & & & & \\
\hline 162 & 1 & & & & & \\
\hline 163 & 2 & & & & & \\
\hline 164 & 1 & & & & & \\
\hline 165 & 1 & & & & & \\
\hline 166 & 1 & & & & & \\
\hline 167 & 1 & & & & & \\
\hline 168 & 1 & & & & $\bar{X}$ & \\
\hline 169 & $\overline{1}$ & & & & & \\
\hline 170 & 1 & & & & & \\
\hline 171 & 1 & & & & & \\
\hline 172 & 1 & & & & & \\
\hline 173 & $\overline{2}$ & & & & & \\
\hline 174 & 1 & & & & & \\
\hline 175 & 1 & & & & & \\
\hline 176 & 2 & & & & & \\
\hline 177 & 1 & & & & & \\
\hline 178 & 1 & & & & & \\
\hline 179 & 1 & & & & & \\
\hline 180 & $\overline{1}$ & & & & & \\
\hline 181 & 1 & & & & & \\
\hline 182 & 1 & & & & & \\
\hline 183 & 1 & & & & & \\
\hline 184 & 1 & & & & & \\
\hline 185 & 1 & & & & & \\
\hline 186 & 1 & & & & & \\
\hline 187 & 1 & & & & & \\
\hline 188 & 1 & & & & & \\
\hline 189 & 1 & & & & & \\
\hline 190 & 2 & & & & & \\
\hline 191 & $\overline{2}$ & & & & & \\
\hline 192 & 1 & & & & & \\
\hline 193 & 3 & & & & & \\
\hline 194 & 1 & & & & & \\
\hline 195 & 1 & & & & & \\
\hline 196 & 1 & & & & & \\
\hline 197 & 1 & & & & & \\
\hline 198 & $\overline{1}$ & & & & & \\
\hline 199 & 1 & & & & & \\
\hline 200 & 1 & & & & & \\
\hline 201 & $\overline{1}$ & & & & & \\
\hline 202 & 1 & & & & & \\
\hline 203 & 1 & & & & & \\
\hline 204 & 1 & & & & & \\
\hline 205 & 1 & & & & $\bar{X}$ & \\
\hline 206 & 1 & & & & & \\
\hline 207 & 1 & & & & & \\
\hline
\end{tabular}

\begin{tabular}{|c|c|c|c|c|c|c|}
\hline i & $\begin{array}{l}\frac{\pi}{0} \\
\overline{0} \\
0\end{array}$ & 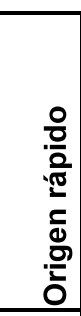 & 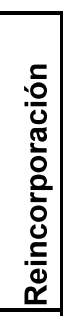 & 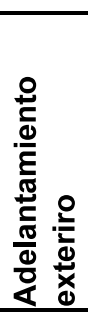 & 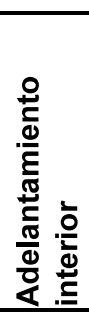 & 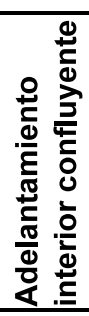 \\
\hline 208 & 1 & & & & & \\
\hline 209 & 1 & & & & & \\
\hline 210 & 1 & & & & $\bar{X}$ & \\
\hline 211 & 1 & & & & & \\
\hline 212 & 0 & & & & & \\
\hline 213 & 1 & & & & & \\
\hline 214 & 1 & & & & & \\
\hline 215 & 1 & & & & & \\
\hline 216 & 1 & & & & & \\
\hline 217 & & $\bar{X}$ & & & & \\
\hline 218 & 1 & & & & & \\
\hline 219 & 1 & & & & & \\
\hline 220 & 1 & & & & & \\
\hline 221 & 1 & & & & & \\
\hline 222 & 2 & & & & & \\
\hline 223 & 1 & & & & & \\
\hline 224 & 1 & & & & & \\
\hline 225 & 2 & & & & & \\
\hline 226 & 1 & & & & & \\
\hline 227 & 2 & & & & & \\
\hline 228 & 1 & & & & & \\
\hline 229 & 1 & & & & & \\
\hline 230 & 1 & & & & & \\
\hline 231 & 1 & & & & $\bar{X}$ & \\
\hline 232 & 1 & & & & & \\
\hline 233 & 1 & & & & & \\
\hline 234 & 1 & & & & & \\
\hline 235 & 1 & & & & & \\
\hline 236 & 2 & & & & & \\
\hline 237 & 1 & & & & & \\
\hline 238 & 1 & & & & & \\
\hline 239 & 1 & & & & & \\
\hline
\end{tabular}




\begin{tabular}{|l|c|c|}
\hline \multicolumn{2}{|c|}{ V21-51 } \\
\hline Maniobras & 196 & \\
\hline Salida anticipada & 8 & $4,1 \%$ \\
\hline Salida en la cuña & 161 & $82,1 \%$ \\
\hline Salida zona media & 24 & $12,2 \%$ \\
\hline Salida tardia & 3 & $1,5 \%$ \\
\hline Origen carriles ràpidos & 2 & $1,0 \%$ \\
\hline Reincorporaciones & 2 & $1,0 \%$ \\
\hline Adelantamiento exterior & 1 & $0,5 \%$ \\
\hline Adelantamiento interior & 4 & $2,0 \%$ \\
\hline Adelantamiento interior confluyente & 0 & $0,0 \%$ \\
\hline
\end{tabular}

\begin{tabular}{|c|c|c|c|c|c|c|}
\hline$\stackrel{0}{2}$ & $\begin{array}{l}\frac{\pi}{0} \\
\frac{0}{\pi} \\
\infty\end{array}$ & $\begin{array}{l}\text { 음 } \\
\text { 문 } \\
\text { 인 } \\
\text { 은 }\end{array}$ & 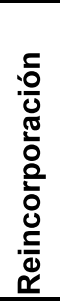 & 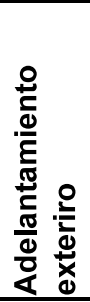 & 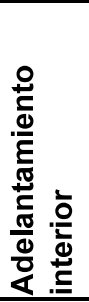 & 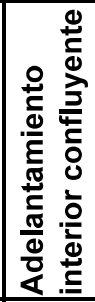 \\
\hline 1 & 1 & & & & & \\
\hline 2 & 1 & & & & & \\
\hline 3 & 1 & & & & & \\
\hline 4 & 1 & & & & & \\
\hline 5 & 1 & & & & & \\
\hline 6 & 1 & & & & & \\
\hline 7 & 0 & & & & & \\
\hline 8 & 1 & & & & & \\
\hline 9 & 1 & & & & & \\
\hline 10 & 0 & & & & & \\
\hline 11 & 1 & & & & & \\
\hline 12 & 1 & & & & & \\
\hline 13 & 2 & & & & & \\
\hline 14 & 1 & & & & & \\
\hline 15 & 1 & & & & & \\
\hline 16 & 1 & & & & & \\
\hline 17 & 1 & & & & & \\
\hline 18 & 2 & & & & & \\
\hline 19 & 2 & $X$ & & & & \\
\hline 20 & 1 & & & & & \\
\hline 21 & 1 & & & & & \\
\hline 22 & 0 & & & & & \\
\hline 23 & 1 & & & & & \\
\hline 24 & 1 & & & & $\mathrm{X}$ & \\
\hline 25 & 1 & & & & & \\
\hline 26 & 1 & & & & & \\
\hline 27 & 1 & & & & & \\
\hline 28 & 1 & & & & & \\
\hline 29 & 1 & & & & & \\
\hline 30 & 1 & & & & & \\
\hline 31 & 1 & & & & & \\
\hline 32 & 1 & & & & & \\
\hline 33 & 1 & & & & & \\
\hline
\end{tabular}

\begin{tabular}{|c|c|c|c|c|c|c|}
\hline zo & 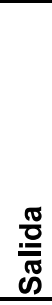 & $\begin{array}{l}\text { 음 } \\
\frac{0}{\sigma} \\
\frac{\sigma}{0} \\
.0 \\
0\end{array}$ & 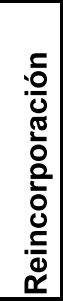 & 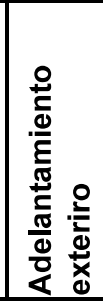 & 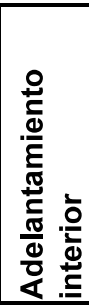 & 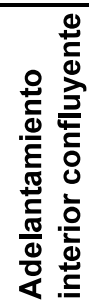 \\
\hline 34 & 1 & & & & & \\
\hline 35 & 1 & & & & & \\
\hline 36 & 2 & & & & & \\
\hline 37 & 2 & & & & & \\
\hline 38 & 1 & & & & & \\
\hline 39 & 1 & & & & & \\
\hline 40 & 1 & & & & & \\
\hline 41 & 2 & & & & & \\
\hline 42 & 1 & & & & & \\
\hline 43 & 1 & & & & & \\
\hline 44 & 2 & & & & & \\
\hline 45 & 1 & & & & & \\
\hline 46 & 1 & & & & & \\
\hline 47 & 1 & & & & & \\
\hline 48 & 1 & & & & & \\
\hline 49 & 3 & & & & & \\
\hline 50 & 1 & & & & & \\
\hline 51 & 1 & & & & & \\
\hline 52 & 1 & & & & & \\
\hline 53 & 1 & & & & & \\
\hline 54 & 1 & & & & & \\
\hline 55 & 1 & & & & & \\
\hline 56 & 1 & & & & & \\
\hline 57 & 1 & & & & & \\
\hline 58 & 2 & & & & & \\
\hline 59 & $\overline{2}$ & & & & & \\
\hline 60 & 1 & & & & & \\
\hline 61 & $\overline{1}$ & & & & & \\
\hline 62 & & $\mathrm{X}$ & & $\mathrm{X}$ & & \\
\hline 63 & 2 & & & & & \\
\hline 64 & 1 & & & & & \\
\hline 65 & 1 & & & & & \\
\hline 66 & & & & & & \\
\hline
\end{tabular}




\begin{tabular}{|c|c|c|c|c|c|c|}
\hline$\dot{0}$ & $\frac{\mathbb{\pi}}{\frac{\pi}{\overline{0}}}$ & 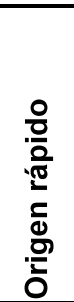 & 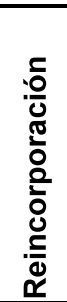 & 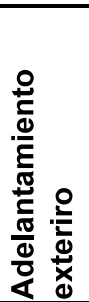 & 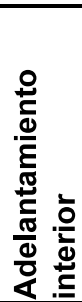 & 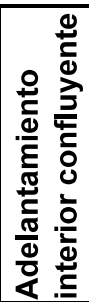 \\
\hline 67 & 1 & & & & & \\
\hline 68 & 1 & & & & & \\
\hline 69 & 1 & & & & & \\
\hline 70 & 1 & & & & & \\
\hline 71 & 1 & & & & $\bar{X}$ & \\
\hline 72 & 2 & & & & & \\
\hline 73 & 1 & & & & & \\
\hline 74 & 1 & & & & & \\
\hline 75 & 1 & & & & & \\
\hline 76 & 1 & & & & & \\
\hline 77 & 1 & & & & & \\
\hline 78 & 1 & & & & & \\
\hline 79 & 1 & & & & & \\
\hline 80 & 1 & & & & & \\
\hline 81 & 1 & & & & & \\
\hline 82 & 1 & & & & & \\
\hline 83 & 0 & & & & & \\
\hline 84 & 2 & & & & & \\
\hline 85 & 1 & & $\bar{X}$ & & & \\
\hline 86 & 1 & & & & & \\
\hline 87 & 1 & & & & & \\
\hline 88 & 1 & & & & & \\
\hline 89 & 1 & & & & & \\
\hline 90 & 1 & & & & & \\
\hline 91 & 1 & & & & & \\
\hline 92 & 1 & & & & & \\
\hline 93 & $\overline{2}$ & & & & & \\
\hline 94 & 1 & & & & & \\
\hline 95 & 1 & & & & & \\
\hline 96 & 1 & & & & & \\
\hline 97 & 1 & & & & & \\
\hline 98 & 1 & & & & & \\
\hline 99 & 1 & & & & & \\
\hline 100 & 1 & & & & & \\
\hline 101 & 1 & & & & & \\
\hline 102 & 1 & & & & & \\
\hline 103 & 1 & & & & & \\
\hline 104 & 1 & & & & & \\
\hline 105 & 2 & & & & & \\
\hline 106 & $\overline{0}$ & & & & & \\
\hline 107 & 1 & & & & & \\
\hline 108 & 1 & & & & & \\
\hline 109 & 1 & & & & & \\
\hline 110 & $\frac{1}{1}$ & & & & & \\
\hline 111 & 1 & & & & & \\
\hline 112 & 1 & & & & & \\
\hline 113 & 1 & & & & & \\
\hline
\end{tabular}

\begin{tabular}{|c|c|c|c|c|c|c|}
\hline $\mathbf{z}$ & 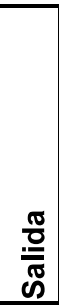 & 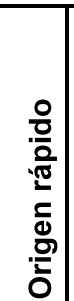 & 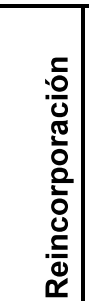 & 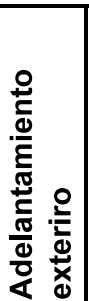 & 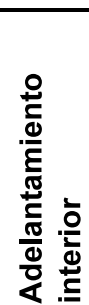 & 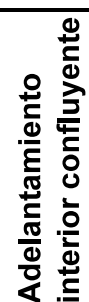 \\
\hline 114 & 1 & & & & & \\
\hline 115 & 1 & & & & & \\
\hline 116 & 2 & & & & & \\
\hline 117 & 2 & & $\bar{X}$ & & & \\
\hline 118 & 1 & & & & & \\
\hline 119 & 1 & & & & & \\
\hline 120 & 2 & & & & & \\
\hline 121 & 1 & & & & & \\
\hline 122 & 1 & & & & & \\
\hline 123 & 2 & & & & & \\
\hline 124 & 1 & & & & & \\
\hline 125 & 1 & & & & & \\
\hline 126 & 1 & & & & & \\
\hline 127 & 2 & & & & & \\
\hline 128 & 1 & & & & & \\
\hline 129 & 2 & & & & & \\
\hline 130 & 1 & & & & & \\
\hline 131 & 1 & & & & & \\
\hline 132 & 0 & & & & & \\
\hline 133 & 1 & & & & & \\
\hline 134 & 1 & & & & & \\
\hline 135 & 1 & & & & & \\
\hline 136 & 1 & & & & & \\
\hline 137 & 1 & & & & & \\
\hline 138 & 1 & & & & & \\
\hline 139 & 1 & & & & & \\
\hline 140 & 1 & & & & & \\
\hline 141 & 1 & & & & & \\
\hline 142 & 1 & & & & & \\
\hline 143 & 1 & & & & & \\
\hline 144 & 1 & & & & & \\
\hline 145 & 1 & & & & & \\
\hline 146 & 2 & & & & & \\
\hline 147 & 1 & & & & & \\
\hline 148 & 1 & & & & & \\
\hline 149 & 1 & & & & & \\
\hline 150 & 1 & & & & & \\
\hline 151 & 1 & & & & & \\
\hline 152 & 1 & & & & & \\
\hline 153 & 1 & & & & $\mathrm{X}$ & \\
\hline 154 & 1 & & & & & \\
\hline 155 & 1 & & & & & \\
\hline 156 & 1 & & & & & \\
\hline 157 & 0 & & & & & \\
\hline 158 & 1 & & & & & \\
\hline 159 & 1 & & & & & \\
\hline 160 & 1 & & & & & \\
\hline
\end{tabular}




\begin{tabular}{|c|c|c|c|c|c|c|}
\hline í & 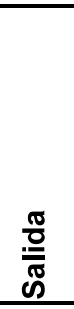 & 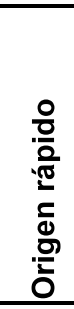 & 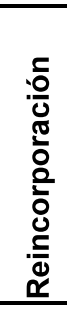 & 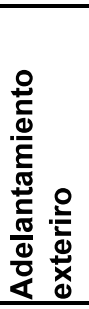 & 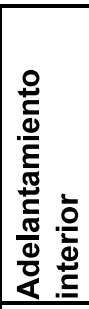 & 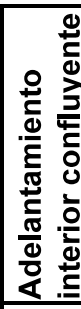 \\
\hline 161 & 1 & & & & & \\
\hline 162 & 1 & & & & & \\
\hline 163 & 1 & & & & & \\
\hline 164 & 1 & & & & & \\
\hline 165 & 1 & & & & & \\
\hline 166 & 1 & & & & & \\
\hline 167 & 1 & & & & & \\
\hline 168 & $\overline{0}$ & & & & & \\
\hline 169 & 1 & & & & & \\
\hline 170 & $\overline{1}$ & & & & & \\
\hline 171 & $\overline{3}$ & & & & & \\
\hline 172 & $\overline{2}$ & & & & & \\
\hline 173 & 1 & & & & & \\
\hline 174 & 1 & & & & & \\
\hline 175 & 2 & & & & & \\
\hline 176 & $\overline{3}$ & & & & & \\
\hline 177 & $\overline{1}$ & & & & & \\
\hline 178 & 1 & & & & & \\
\hline 179 & 1 & & & & & \\
\hline 180 & 1 & & & & & \\
\hline 181 & $\overline{1}$ & & & & & \\
\hline 182 & 2 & & & & & \\
\hline 183 & 1 & & & & & \\
\hline 184 & 1 & & & & & \\
\hline 185 & 1 & & & & & \\
\hline 186 & 1 & & & & & \\
\hline 187 & $\overline{1}$ & & & & & \\
\hline 188 & 1 & & & & & \\
\hline 189 & 1 & & & & & \\
\hline 190 & $\overline{1}$ & & & & & \\
\hline 191 & 1 & & & & & \\
\hline 192 & 1 & & & & & \\
\hline 193 & 1 & & & & & \\
\hline 194 & 1 & & & & & \\
\hline 195 & & & & & & \\
\hline 196 & $\overline{1}$ & & & & $X$ & \\
\hline
\end{tabular}




\begin{tabular}{|l|c|c|}
\hline \multicolumn{2}{|c|}{ V21-143-1 } \\
\hline Maniobras & 340 & \\
\hline Salida anticipada & 5 & $1,5 \%$ \\
\hline Salida en la cuña & 295 & $86,8 \%$ \\
\hline Salida zona media & 38 & $11,2 \%$ \\
\hline Salida tardia & 2 & $0,6 \%$ \\
\hline Origen carriles ràpidos & 3 & $0,9 \%$ \\
\hline Reincorporaciones & 1 & $0,3 \%$ \\
\hline Adelantamiento exterior & 2 & $0,6 \%$ \\
\hline Adelantamiento interior & 5 & $1,5 \%$ \\
\hline Adelantamiento interior confluyente & 0 & $0,0 \%$ \\
\hline
\end{tabular}

\begin{tabular}{|c|c|c|c|c|c|c|}
\hline i & $\begin{array}{l}\frac{\pi}{0} \\
\frac{}{\pi} \\
\text { ஸे }\end{array}$ & $\begin{array}{l}\text { 음 } \\
\text { 몬 } \\
\text { 인 } \\
\text { 은 }\end{array}$ & 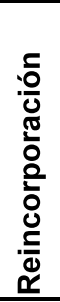 & 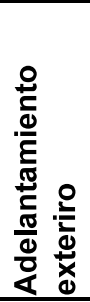 & 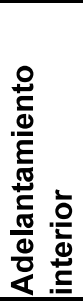 & 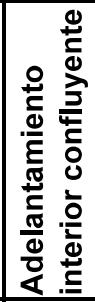 \\
\hline 1 & 1 & & & & & \\
\hline 2 & 1 & & & & & \\
\hline 3 & 1 & & & & & \\
\hline 4 & 2 & & & & & \\
\hline 5 & 2 & & & & & \\
\hline 6 & 1 & & & & & \\
\hline 7 & 1 & & & & & \\
\hline 8 & 3 & & & & & \\
\hline 9 & 1 & $X$ & & & & \\
\hline 10 & 1 & & & & & \\
\hline 11 & 1 & & & & & \\
\hline 12 & 1 & & & & & \\
\hline 13 & 1 & & & & & \\
\hline 14 & 2 & & & & & \\
\hline 15 & 1 & & & & & \\
\hline 16 & 1 & & & & & \\
\hline 17 & 1 & & & & & \\
\hline 18 & 1 & & & & & \\
\hline 19 & 1 & & & & & \\
\hline 20 & 1 & & & & & \\
\hline 21 & 1 & & & & & \\
\hline 22 & 1 & & & & & \\
\hline 23 & 1 & & & & & \\
\hline 24 & 1 & & & & & \\
\hline 25 & 1 & & & & & \\
\hline 26 & 1 & & & & & \\
\hline 27 & 1 & & & & & \\
\hline 28 & 1 & & & & & \\
\hline 29 & 1 & & & & & \\
\hline 30 & 1 & & & & & \\
\hline 31 & $\overline{1}$ & & & & & \\
\hline 32 & 2 & & & & & \\
\hline 33 & 1 & & & & & \\
\hline
\end{tabular}

\begin{tabular}{|c|c|c|c|c|c|c|}
\hline i & $\begin{array}{l}\frac{\pi}{0} \\
\frac{0}{\pi} \\
\stackrel{5}{~}\end{array}$ & 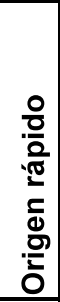 & 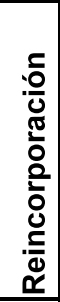 & 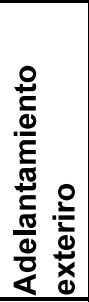 & 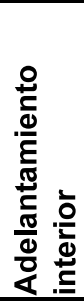 & 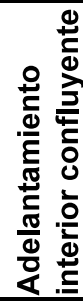 \\
\hline 34 & 0 & & & & & \\
\hline 35 & 2 & & & & & \\
\hline 36 & 1 & & & & & \\
\hline 37 & 2 & & & & & \\
\hline 38 & 1 & & & & & \\
\hline 39 & 1 & & & & & \\
\hline 40 & 1 & & & & & \\
\hline 41 & 1 & & & & & \\
\hline 42 & 1 & & & & & \\
\hline 43 & 1 & & & & & \\
\hline 44 & 1 & & & & & \\
\hline 45 & 1 & & & & & \\
\hline 46 & 1 & & & & & \\
\hline 47 & 1 & & & & & \\
\hline 48 & 1 & & & & & \\
\hline 49 & 2 & & & & & \\
\hline 50 & 1 & & & & & \\
\hline 51 & 1 & & & & & \\
\hline 52 & 1 & & & & & \\
\hline 53 & 1 & & & & & \\
\hline 54 & 1 & & & & & \\
\hline 55 & 1 & & & & & \\
\hline 56 & 1 & & & & & \\
\hline 57 & 1 & & & & & \\
\hline 58 & 1 & & & & & \\
\hline 59 & 1 & & & & & \\
\hline 60 & 1 & & & & & \\
\hline 61 & 2 & & & & & \\
\hline 62 & 1 & & & & & \\
\hline 63 & 2 & & & & & \\
\hline 64 & 1 & & & & & \\
\hline 65 & 1 & & & & & \\
\hline 66 & 1 & & & & & \\
\hline
\end{tabular}




\begin{tabular}{|c|c|c|c|c|c|c|}
\hline$\dot{0}$ & $\frac{\pi}{\frac{\pi}{\pi}}$ & 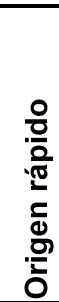 & 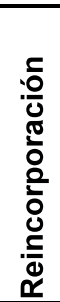 & 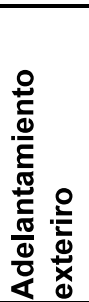 & 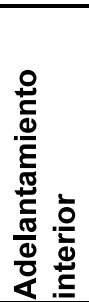 & 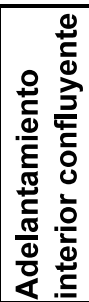 \\
\hline 67 & 1 & & & & & \\
\hline 68 & 1 & & & & & \\
\hline 69 & 1 & & & & & \\
\hline 70 & 1 & & & & & \\
\hline 71 & 1 & & & & & \\
\hline 72 & 1 & & & & & \\
\hline 73 & 1 & & & & & \\
\hline 74 & 1 & & & & & \\
\hline 75 & 1 & & & & & \\
\hline 76 & 1 & & & & & \\
\hline 77 & 1 & & & & & \\
\hline 78 & 1 & & & & & \\
\hline 79 & $\overline{2}$ & & & & & \\
\hline 80 & 1 & & & & & \\
\hline 81 & 1 & & & & & \\
\hline 82 & 1 & & & & & \\
\hline 83 & 2 & & & & & \\
\hline 84 & 1 & & & & & \\
\hline 85 & 1 & & & & & \\
\hline 86 & 1 & & & & & \\
\hline 87 & 1 & & & & & \\
\hline 88 & 1 & & & & & \\
\hline 89 & 1 & & & & & \\
\hline 90 & 1 & & & & & \\
\hline 91 & 1 & & & & & \\
\hline 92 & 1 & & & & & \\
\hline 93 & 1 & & & & & \\
\hline 94 & 1 & & & & & \\
\hline 95 & 1 & & & & & \\
\hline 96 & 1 & & & & & \\
\hline 97 & 1 & & & & & \\
\hline 98 & 1 & & & & & \\
\hline 99 & 1 & & & & & \\
\hline 100 & 1 & & & & & \\
\hline 101 & 1 & & & & & \\
\hline 102 & 1 & & & & & \\
\hline 103 & 1 & & & & & \\
\hline 104 & 1 & & & & & \\
\hline 105 & 1 & & & & & \\
\hline 106 & 1 & & & & & \\
\hline 107 & 1 & & & & & \\
\hline 108 & 1 & & & & & \\
\hline 109 & 1 & & & & & \\
\hline 110 & $\frac{1}{1}$ & & & & & \\
\hline 111 & 1 & & & & & \\
\hline 112 & 1 & & & & & \\
\hline 113 & 1 & & & & & \\
\hline
\end{tabular}

\begin{tabular}{|c|c|c|c|c|c|c|}
\hline $\mathbf{z}$ & 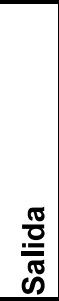 & $\begin{array}{l}\circ \\
\frac{0}{0} \\
\frac{\pi}{2} \\
\overline{0} \\
\bar{\sigma} \\
\overline{0}\end{array}$ & 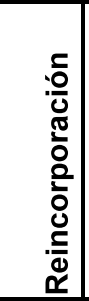 & 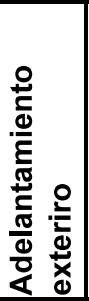 & 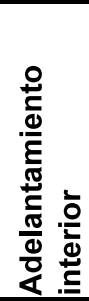 & 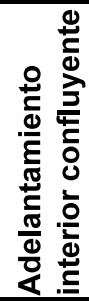 \\
\hline 114 & 1 & & & & & \\
\hline 115 & 1 & & & & & \\
\hline 116 & 1 & & & & & \\
\hline 117 & 1 & & & & & \\
\hline 118 & 1 & & & & $\mathrm{X}$ & \\
\hline 119 & 1 & & & & & \\
\hline 120 & 1 & & & & & \\
\hline 121 & 1 & & & & & \\
\hline 122 & 1 & & & & $\bar{X}$ & \\
\hline 123 & 1 & & & & & \\
\hline 124 & 1 & & & & & \\
\hline 125 & 1 & & & & & \\
\hline 126 & 1 & & & & & \\
\hline 127 & 1 & & & & & \\
\hline 128 & 1 & & & & & \\
\hline 129 & 1 & & & & & \\
\hline 130 & 1 & & & & & \\
\hline 131 & 1 & & & & & \\
\hline 132 & 1 & & & & & \\
\hline 133 & 1 & & & & & \\
\hline 134 & 1 & & & & & \\
\hline 135 & 1 & & & & & \\
\hline 136 & 1 & & & & & \\
\hline 137 & 1 & & & & & \\
\hline 138 & 1 & & & & & \\
\hline 139 & 1 & & & & & \\
\hline 140 & 1 & & & & & \\
\hline 141 & 1 & & & & & \\
\hline 142 & 1 & & & & & \\
\hline 143 & 1 & & & & & \\
\hline 144 & 1 & & & & & \\
\hline 145 & 1 & & & & & \\
\hline 146 & 1 & & & & & \\
\hline 147 & 1 & & & & & \\
\hline 148 & 2 & & & & $\bar{X}$ & \\
\hline 149 & 1 & & & & & \\
\hline 150 & 1 & & & & & \\
\hline 151 & 1 & & & & & \\
\hline 152 & 1 & & & & & \\
\hline 153 & 1 & & & & & \\
\hline 154 & 1 & & & & & \\
\hline 155 & 1 & & & & & \\
\hline 156 & 2 & & & & & \\
\hline 157 & 1 & & & & & \\
\hline 158 & 1 & & $\bar{x}$ & & & \\
\hline 159 & 1 & & & & & \\
\hline 160 & 1 & & & & & \\
\hline
\end{tabular}




\begin{tabular}{|c|c|c|c|c|c|c|}
\hline i & 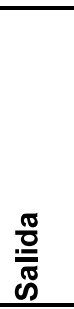 & 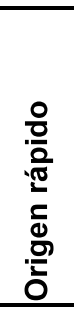 & 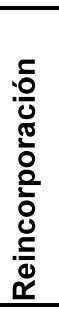 & 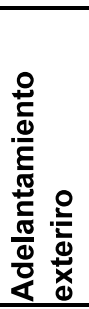 & 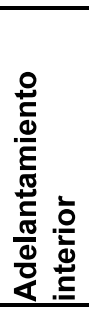 & 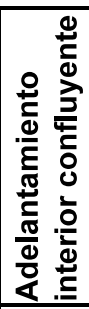 \\
\hline 161 & 1 & & & & & \\
\hline 162 & 1 & & & & & \\
\hline 163 & 1 & & & & & \\
\hline 164 & 1 & & & & & \\
\hline 165 & 1 & & & & & \\
\hline 166 & 1 & & & & & \\
\hline 167 & 1 & & & & & \\
\hline 168 & 1 & & & & & \\
\hline 169 & 1 & & & & & \\
\hline 170 & 1 & & & & & \\
\hline 171 & 1 & & & & & \\
\hline 172 & 2 & & & & & \\
\hline 173 & $\overline{1}$ & & & & & \\
\hline 174 & 1 & & & & & \\
\hline 175 & 1 & & & & & \\
\hline 176 & 1 & & & & & \\
\hline 177 & 1 & & & & & \\
\hline 178 & 2 & & & & & \\
\hline 179 & 1 & & & & & \\
\hline 180 & 1 & & & & & \\
\hline 181 & 1 & & & & & \\
\hline 182 & 2 & & & & & \\
\hline 183 & 1 & & & & & \\
\hline 184 & 1 & & & & & \\
\hline 185 & 1 & & & & & \\
\hline 186 & $\underline{2}$ & & & & & \\
\hline 187 & 1 & & & & & \\
\hline 188 & 1 & & & & & \\
\hline 189 & 1 & & & & & \\
\hline 190 & 1 & & & & & \\
\hline 191 & $\overline{1}$ & & & & & \\
\hline 192 & 1 & & & & & \\
\hline 193 & $\underline{2}$ & & & & & \\
\hline 194 & 1 & & & & & \\
\hline 195 & 1 & & & & & \\
\hline 196 & 1 & & & & & \\
\hline 197 & $\overline{1}$ & & & & & \\
\hline 198 & $\overline{1}$ & & & & & \\
\hline 199 & 1 & & & & & \\
\hline 200 & 2 & & & & & \\
\hline 201 & 1 & & & & & \\
\hline 202 & 1 & & & & & \\
\hline 203 & 1 & & & & & \\
\hline 204 & $\overline{1}$ & & & & & \\
\hline 205 & 1 & & & & & \\
\hline 206 & 1 & & & & & \\
\hline 207 & $\underline{0}$ & & & & & \\
\hline
\end{tabular}

\begin{tabular}{|c|c|c|c|c|c|c|}
\hline 之o & 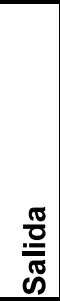 & 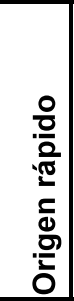 & 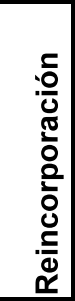 & 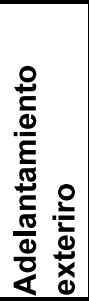 & 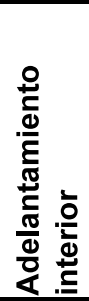 & 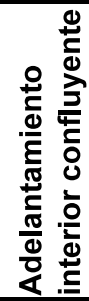 \\
\hline 208 & 1 & & & & & \\
\hline 209 & 1 & & & & & \\
\hline 210 & 1 & & & & & \\
\hline 211 & 1 & & & & & \\
\hline 212 & 1 & & & & & \\
\hline 213 & 1 & & & & & \\
\hline 214 & 1 & & & & & \\
\hline 215 & 2 & & & & & \\
\hline 216 & 1 & & & & & \\
\hline 217 & 1 & & & & & \\
\hline 218 & 1 & & & & & \\
\hline 219 & 1 & & & & & \\
\hline 220 & 2 & & & & & \\
\hline 221 & 2 & & & & & \\
\hline 222 & 1 & & & & & \\
\hline 223 & 1 & & & & & \\
\hline 224 & 1 & & & & & \\
\hline 225 & 2 & & & & & \\
\hline 226 & 0 & & & & & \\
\hline 227 & 1 & & & & & \\
\hline 228 & 1 & & & & & \\
\hline 229 & 2 & & & & & \\
\hline 230 & 1 & & & & & \\
\hline 231 & 1 & & & & & \\
\hline 232 & 1 & & & & & \\
\hline 233 & 0 & & & & & \\
\hline 234 & 2 & & & & & \\
\hline 235 & 1 & & & & & \\
\hline 236 & 1 & & & & & \\
\hline 237 & 1 & & & & & \\
\hline 238 & 1 & & & & & \\
\hline 239 & 2 & & & & & \\
\hline 240 & 1 & & & & & \\
\hline 241 & 1 & & & & & \\
\hline 242 & 1 & & & & & \\
\hline 243 & 2 & & & & & \\
\hline 244 & 1 & & & & & \\
\hline 245 & 1 & & & & & \\
\hline 246 & 2 & & & & & \\
\hline 247 & 1 & & & & & \\
\hline 248 & 1 & & & & & \\
\hline 249 & 1 & & & & & \\
\hline 250 & 1 & & & & & \\
\hline 251 & 1 & & & & & \\
\hline 252 & 1 & & & & & \\
\hline 253 & 1 & & & & & \\
\hline 254 & 1 & & & & & \\
\hline
\end{tabular}




\begin{tabular}{|c|c|c|c|c|c|c|}
\hline i & 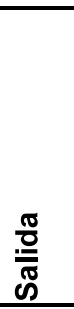 & 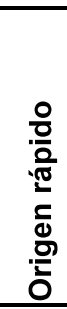 & 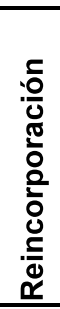 & 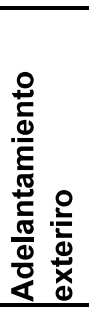 & 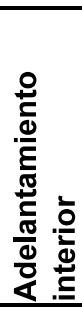 & 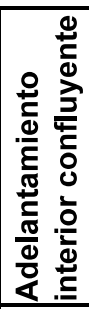 \\
\hline 255 & 1 & & & & & \\
\hline 256 & & $\bar{X}$ & & $\bar{X}$ & & \\
\hline 257 & $\overline{1}$ & & & & & \\
\hline 258 & 1 & & & & & \\
\hline 259 & 1 & & & & & \\
\hline 260 & 1 & & & & & \\
\hline 261 & 1 & & & & $\bar{X}$ & \\
\hline 262 & $\underline{0}$ & & & & & \\
\hline 263 & $\overline{1}$ & & & & & \\
\hline 264 & 1 & & & & & \\
\hline 265 & 1 & & & & & \\
\hline 266 & 1 & & & & & \\
\hline 267 & $\overline{2}$ & & & & & \\
\hline 268 & 1 & & & & & \\
\hline 269 & 1 & & & & & \\
\hline 270 & 1 & & & & & \\
\hline 271 & 1 & & & & & \\
\hline 272 & 1 & & & & & \\
\hline 273 & 1 & & & & & \\
\hline 274 & $\overline{1}$ & & & & & \\
\hline 275 & 1 & & & & & \\
\hline 276 & 1 & & & & & \\
\hline 277 & 1 & & & & & \\
\hline 278 & $\overline{1}$ & & & & & \\
\hline 279 & 1 & & & & & \\
\hline 280 & 1 & & & & & \\
\hline 281 & 1 & & & & & \\
\hline 282 & 1 & & & & & \\
\hline 283 & 2 & & & & & \\
\hline 284 & 1 & & & & & \\
\hline 285 & $\overline{1}$ & & & & & \\
\hline 286 & 1 & & & & & \\
\hline 287 & 1 & & & & & \\
\hline 288 & 1 & & & & & \\
\hline 289 & 1 & & & & & \\
\hline 290 & 1 & & & & & \\
\hline 291 & $\overline{1}$ & & & & & \\
\hline 292 & $\overline{1}$ & & & & & \\
\hline 293 & 1 & & & & & \\
\hline 294 & 1 & & & & & \\
\hline 295 & 1 & & & & & \\
\hline 296 & 1 & & & & & \\
\hline 297 & 1 & & & & & \\
\hline 298 & $\overline{1}$ & & & & & \\
\hline 299 & 1 & & & & & \\
\hline 300 & 1 & & & & & \\
\hline 301 & 1 & & & & & \\
\hline
\end{tabular}

\begin{tabular}{|c|c|c|c|c|c|c|}
\hline z & 吾 & 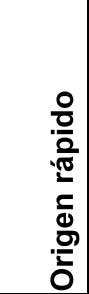 & 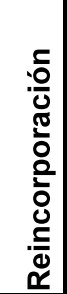 & 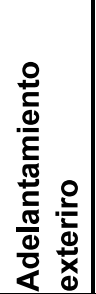 & 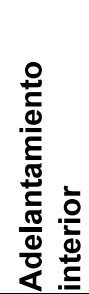 & 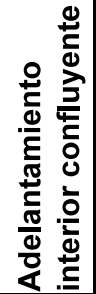 \\
\hline 302 & 1 & & & & & \\
\hline 303 & 1 & & & & & \\
\hline 304 & 1 & & & & & \\
\hline 305 & 1 & & & & & \\
\hline 306 & 2 & & & & & \\
\hline 307 & 1 & & & & & \\
\hline 308 & 1 & & & & & \\
\hline 309 & 1 & & & & & \\
\hline 310 & 1 & & & & & \\
\hline 311 & 1 & & & & & \\
\hline 312 & 2 & & & & & \\
\hline 313 & 1 & & & & & \\
\hline 314 & 1 & & & & & \\
\hline 315 & 1 & & & & & \\
\hline 316 & 1 & & & & & \\
\hline 317 & 1 & & & & & \\
\hline 318 & 1 & & & & & \\
\hline 319 & 1 & & & & & \\
\hline 320 & 2 & & & & & \\
\hline 321 & 1 & & & & & \\
\hline 322 & 1 & & & & & \\
\hline 323 & 1 & & & & & \\
\hline 324 & 2 & & & & & \\
\hline 325 & 1 & & & & & \\
\hline 326 & 1 & & & & & \\
\hline 327 & 2 & & & & & \\
\hline 328 & 1 & & & & & \\
\hline 329 & 1 & $\bar{x}$ & & $\bar{x}$ & & \\
\hline 330 & 1 & & & & & \\
\hline 331 & 2 & & & & & \\
\hline 332 & 1 & & & & & \\
\hline 333 & 1 & & & & & \\
\hline 334 & 2 & & & & & \\
\hline 335 & 2 & & & & & \\
\hline 336 & 1 & & & & & \\
\hline 337 & 1 & & & & $X$ & \\
\hline 338 & $\overline{1}$ & & & & & \\
\hline 339 & 1 & & & & & \\
\hline 340 & 1 & & & & & \\
\hline
\end{tabular}




\begin{tabular}{|l|c|c|}
\hline \multicolumn{2}{|c|}{ V21-143-2 } \\
\hline Maniobras & 406 & \\
\hline Salida anticipada & 9 & $2,2 \%$ \\
\hline Salida en la cuña & 375 & $92,4 \%$ \\
\hline Salida zona media & 19 & $4,7 \%$ \\
\hline Salida tardia & 3 & $0,7 \%$ \\
\hline Origen carriles ràpidos & 6 & $1,5 \%$ \\
\hline Reincorporaciones & 1 & $0,2 \%$ \\
\hline Adelantamiento exterior & 1 & $0,2 \%$ \\
\hline Adelantamiento interior & 21 & $5,2 \%$ \\
\hline Adelantamiento interior confluyente & 0 & $0,0 \%$ \\
\hline
\end{tabular}

\begin{tabular}{|c|c|c|c|c|c|c|}
\hline i & $\begin{array}{l}\frac{\pi}{0} \\
\frac{0}{\pi} \\
\infty\end{array}$ & $\begin{array}{l}\text { 웅 } \\
\text { 몬 } \\
\text { 엉 } \\
\text { 은 }\end{array}$ & 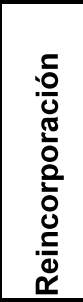 & 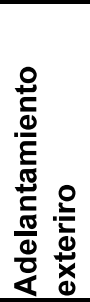 & 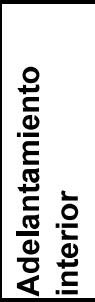 & 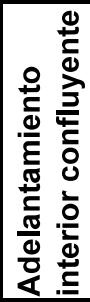 \\
\hline 1 & 1 & & & & & \\
\hline 2 & 1 & & & & & \\
\hline 3 & 1 & & & & & \\
\hline 4 & 1 & & & & & \\
\hline 5 & 1 & & & & & \\
\hline 6 & 1 & & & & & \\
\hline 7 & 0 & & & & & \\
\hline 8 & 1 & & & & & \\
\hline 9 & 1 & & & & & \\
\hline 10 & 0 & & & & & \\
\hline 11 & 0 & & & & & \\
\hline 12 & 1 & & $X$ & & & \\
\hline 13 & 1 & & & & & \\
\hline 14 & 1 & & & & & \\
\hline 15 & 1 & & & & & \\
\hline 16 & 1 & & & & & \\
\hline 17 & 1 & & & & & \\
\hline 18 & 1 & & & & & \\
\hline 19 & 1 & & & & & \\
\hline 20 & 1 & & & & & \\
\hline 21 & 1 & & & & & \\
\hline 22 & 1 & & & & & \\
\hline 23 & 1 & & & & $X$ & \\
\hline 24 & 1 & & & & & \\
\hline 25 & 1 & & & & & \\
\hline 26 & 1 & & & & & \\
\hline 27 & 1 & & & & & \\
\hline 28 & 1 & & & & & \\
\hline 29 & 1 & & & & & \\
\hline 30 & 2 & & & & & \\
\hline 31 & 1 & $X$ & & & & \\
\hline 32 & 1 & & & & & \\
\hline 33 & 1 & & & & & \\
\hline
\end{tabular}

\begin{tabular}{|c|c|c|c|c|c|c|}
\hline$\dot{0}$ & $\frac{\text { 음 }}{\frac{0}{\pi}}$ & 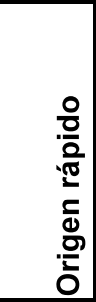 & 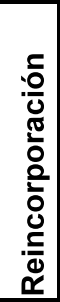 & 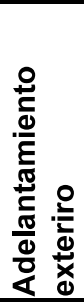 & 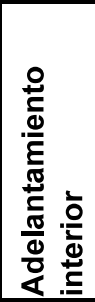 & 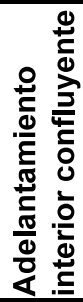 \\
\hline 34 & 1 & & & & & \\
\hline 35 & 1 & & & & & \\
\hline 36 & 2 & $X$ & & & & \\
\hline 37 & 1 & & & & & \\
\hline 38 & 1 & & & & & \\
\hline 39 & 1 & & & & & \\
\hline 40 & 1 & & & & & \\
\hline 41 & 1 & & & & & \\
\hline 42 & 1 & & & & & \\
\hline 43 & 1 & & & & & \\
\hline 44 & 1 & & & & & \\
\hline 45 & 1 & & & & & \\
\hline 46 & 1 & & & & & \\
\hline 47 & 1 & & & & & \\
\hline 48 & 1 & & & & $X$ & \\
\hline 49 & 1 & & & & & \\
\hline 50 & 1 & & & & & \\
\hline 51 & 1 & & & & & \\
\hline 52 & 1 & & & & $X$ & \\
\hline 53 & 1 & & & & & \\
\hline 54 & 2 & & & & & \\
\hline 55 & 1 & & & & & \\
\hline 56 & 1 & & & & & \\
\hline 57 & 2 & & & & & \\
\hline 58 & 1 & & & & & \\
\hline 59 & 0 & & & & & \\
\hline 60 & 1 & & & & & \\
\hline 61 & 1 & & & & & \\
\hline 62 & 1 & & & & & \\
\hline 63 & 1 & & & & & \\
\hline 64 & 1 & & & & & \\
\hline 65 & 1 & & & & & \\
\hline 66 & 1 & & & & & \\
\hline
\end{tabular}




\begin{tabular}{|c|c|c|c|c|c|c|}
\hline$\dot{0}$ & $\frac{\mathbb{\pi}}{\frac{\pi}{\overline{0}}}$ & 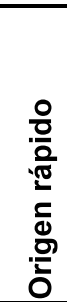 & 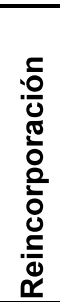 & 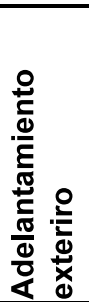 & 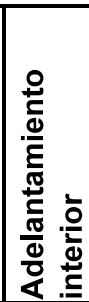 & 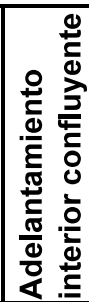 \\
\hline 67 & 1 & & & & $x$ & \\
\hline 68 & 1 & & & & & \\
\hline 69 & 1 & & & & & \\
\hline 70 & 1 & & & & & \\
\hline 71 & 1 & & & & & \\
\hline 72 & 1 & & & & & \\
\hline 73 & 1 & & & & & \\
\hline 74 & 1 & & & & & \\
\hline 75 & 1 & & & & & \\
\hline 76 & & $\bar{X}$ & & & & \\
\hline 77 & 1 & & & & & \\
\hline 78 & 1 & & & & & \\
\hline 79 & 1 & & & & & \\
\hline 80 & 1 & & & & $X$ & \\
\hline 81 & 1 & & & & & \\
\hline 82 & 1 & & & & . & \\
\hline 83 & 1 & & & & & \\
\hline 84 & 1 & & & & & \\
\hline 85 & 1 & & & & $x$ & \\
\hline 86 & 1 & & & & & \\
\hline 87 & 1 & & & & & \\
\hline 88 & 1 & & & & & \\
\hline 89 & 1 & & & & & \\
\hline 90 & 1 & & & & & \\
\hline 91 & 1 & & & & & \\
\hline 92 & 1 & & & & & \\
\hline 93 & $\overline{2}$ & & & & & \\
\hline 94 & 1 & & & & & \\
\hline 95 & 1 & & & & & \\
\hline 96 & 1 & & & & & \\
\hline 97 & 1 & & & & & \\
\hline 98 & 2 & & & & & \\
\hline 99 & 1 & & & & & \\
\hline 100 & 1 & & & & & \\
\hline 101 & 1 & & & & & \\
\hline 102 & 1 & & & & & \\
\hline 103 & 1 & & & & & \\
\hline 104 & 1 & & & & & \\
\hline 105 & 1 & & & & & \\
\hline 106 & $\overline{2}$ & & & & & \\
\hline 107 & 0 & $\bar{X}$ & & & & \\
\hline 108 & 1 & & & & & \\
\hline 109 & 1 & & & & & \\
\hline 110 & $\frac{1}{1}$ & & & & & \\
\hline 111 & 2 & & & & & \\
\hline 112 & 1 & & & & & \\
\hline 113 & 1 & & & & $X$ & \\
\hline
\end{tabular}

\begin{tabular}{|c|c|c|c|c|c|c|}
\hline $\mathbf{z}$ & 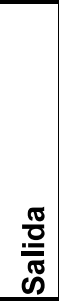 & $\begin{array}{l}\circ \\
\frac{0}{0} \\
\frac{\pi}{2} \\
\overline{0} \\
\bar{\sigma} \\
\overline{0}\end{array}$ & 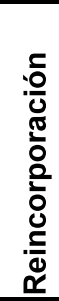 & 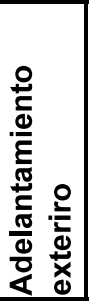 & 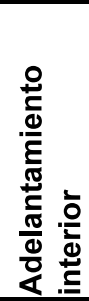 & 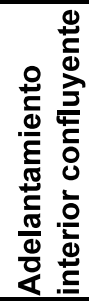 \\
\hline 114 & 1 & & & & & \\
\hline 115 & 1 & & & & $\bar{X}$ & \\
\hline 116 & 1 & & & & & \\
\hline 117 & 1 & & & & & \\
\hline 118 & 1 & & & & & \\
\hline 119 & 1 & & & & & \\
\hline 120 & 1 & & & & & \\
\hline 121 & 1 & & & & $\mathrm{X}$ & \\
\hline 122 & 1 & & & & & \\
\hline 123 & 1 & & & & & \\
\hline 124 & 1 & & & & & \\
\hline 125 & 1 & & & & & \\
\hline 126 & 1 & & & & & \\
\hline 127 & 1 & & & & & \\
\hline 128 & 1 & & & & & \\
\hline 129 & 1 & & & & & \\
\hline 130 & 1 & & & & & \\
\hline 131 & 1 & & & & & \\
\hline 132 & 1 & & & & & \\
\hline 133 & 1 & & & & & \\
\hline 134 & 1 & & & & & \\
\hline 135 & 0 & & & & & \\
\hline 136 & 1 & & & & & \\
\hline 137 & 1 & & & & & \\
\hline 138 & 1 & & & & & \\
\hline 139 & 1 & & & & & \\
\hline 140 & 1 & & & & & \\
\hline 141 & 2 & & & & & \\
\hline 142 & 1 & & & & & \\
\hline 143 & 1 & & & & & \\
\hline 144 & 1 & & & & & \\
\hline 145 & 1 & & & & $\bar{X}$ & \\
\hline 146 & 1 & & & & & \\
\hline 147 & 0 & & & & & \\
\hline 148 & 1 & & & & & \\
\hline 149 & 0 & & & & & \\
\hline 150 & 1 & & & & & \\
\hline 151 & 1 & & & & & \\
\hline 152 & 1 & & & & & \\
\hline 153 & 1 & & & & & \\
\hline 154 & 1 & & & & & \\
\hline 155 & 1 & & & & & \\
\hline 156 & 1 & & & & & \\
\hline 157 & 1 & & & & & \\
\hline 158 & 1 & & & & & \\
\hline 159 & 1 & & & & & \\
\hline 160 & 1 & & & & & \\
\hline
\end{tabular}




\begin{tabular}{|c|c|c|c|c|c|c|}
\hline i & 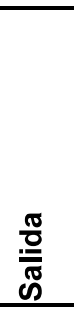 & 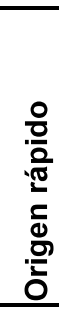 & 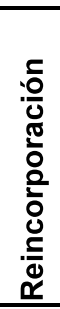 & 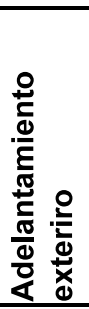 & 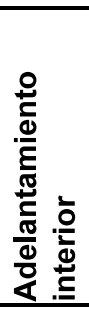 & 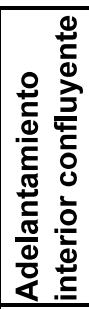 \\
\hline 161 & 1 & & & & & \\
\hline 162 & $\overline{1}$ & & & & $\bar{X}$ & \\
\hline 163 & 1 & & & & & \\
\hline 164 & 1 & & & & & \\
\hline 165 & 1 & & & & & \\
\hline 166 & 1 & & & & & \\
\hline 167 & 1 & & & & & \\
\hline 168 & 1 & & & & & \\
\hline 169 & $\overline{1}$ & & & & & \\
\hline 170 & 1 & & & & $\bar{X}$ & \\
\hline 171 & 1 & & & & & \\
\hline 172 & 1 & & & & & \\
\hline 173 & $\overline{1}$ & & & & & \\
\hline 174 & 1 & & & & & \\
\hline 175 & 1 & & & & & \\
\hline 176 & $\overline{1}$ & & & & & \\
\hline 177 & 1 & & & & $\bar{X}$ & \\
\hline 178 & 1 & & & & & \\
\hline 179 & 1 & & & & & \\
\hline 180 & $\overline{1}$ & & & & & \\
\hline 181 & 1 & & & & & \\
\hline 182 & 1 & & & & & \\
\hline 183 & 1 & & & & & \\
\hline 184 & 1 & & & & & \\
\hline 185 & 1 & & & & & \\
\hline 186 & 1 & & & & & \\
\hline 187 & $\overline{1}$ & & & & & \\
\hline 188 & 1 & & & & & \\
\hline 189 & 1 & & & & & \\
\hline 190 & $\overline{1}$ & & & & & \\
\hline 191 & $\overline{1}$ & & & & & \\
\hline 192 & 1 & & & & & \\
\hline 193 & 1 & & & & & \\
\hline 194 & $\overline{1}$ & & & & & \\
\hline 195 & 1 & & & & & \\
\hline 196 & 1 & & & & & \\
\hline 197 & $\overline{1}$ & & & & & \\
\hline 198 & $\overline{1}$ & & & & & \\
\hline 199 & 1 & & & & & \\
\hline 200 & 1 & & & & $\bar{X}$ & \\
\hline 201 & 1 & & & & & \\
\hline 202 & 1 & & & & & \\
\hline 203 & 1 & & & & & \\
\hline 204 & $\overline{1}$ & & & & & \\
\hline 205 & 1 & & & & & \\
\hline 206 & 1 & & & & & \\
\hline 207 & 1 & & & & & \\
\hline
\end{tabular}

\begin{tabular}{|c|c|c|c|c|c|c|}
\hline 之o & 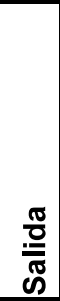 & 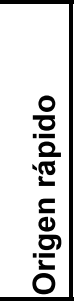 & 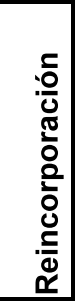 & 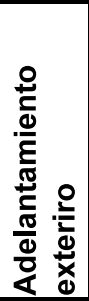 & 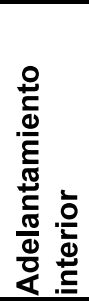 & 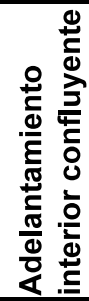 \\
\hline 208 & 1 & & & & & \\
\hline 209 & 1 & & & & & \\
\hline 210 & 1 & & & & & \\
\hline 211 & 2 & & & & & \\
\hline 212 & 1 & & & & & \\
\hline 213 & 1 & & & & & \\
\hline 214 & 1 & & & & & \\
\hline 215 & 1 & & & & & \\
\hline 216 & 1 & & & & & \\
\hline 217 & 1 & & & & & \\
\hline 218 & 1 & & & & & \\
\hline 219 & 1 & & & & & \\
\hline 220 & 2 & & & & & \\
\hline 221 & 1 & & & & & \\
\hline 222 & 1 & & & & & \\
\hline 223 & 2 & & & & & \\
\hline 224 & 1 & & & & & \\
\hline 225 & 1 & & & & & \\
\hline 226 & 1 & & & & & \\
\hline 227 & 1 & & & & & \\
\hline 228 & 1 & & & & & \\
\hline 229 & 1 & & & & & \\
\hline 230 & 1 & & & & & \\
\hline 231 & 1 & & & & & \\
\hline 232 & 1 & & & & & \\
\hline 233 & 1 & & & & & \\
\hline 234 & 2 & & & & & \\
\hline 235 & 1 & & & & & \\
\hline 236 & 1 & & & & & \\
\hline 237 & 1 & & & & & \\
\hline 238 & 1 & & & & & \\
\hline 239 & 1 & & & & & \\
\hline 240 & 1 & & & & $\bar{X}$ & \\
\hline 241 & 1 & & & & & \\
\hline 242 & 1 & & & & & \\
\hline 243 & 1 & & & & & \\
\hline 244 & 1 & & & & & \\
\hline 245 & 1 & & & & & \\
\hline 246 & 1 & & & & & \\
\hline 247 & 1 & & & & & \\
\hline 248 & 2 & & & & & \\
\hline 249 & 1 & & & & & \\
\hline 250 & 1 & & & & & \\
\hline 251 & 1 & & & & & \\
\hline 252 & 2 & & & & & \\
\hline 253 & 1 & & & & & \\
\hline 254 & 1 & & & & & \\
\hline
\end{tabular}




\begin{tabular}{|c|c|c|c|c|c|c|}
\hline$\dot{0}$ & 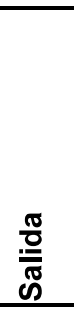 & 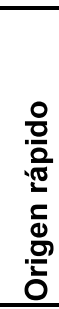 & 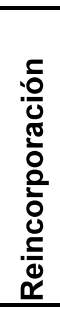 & 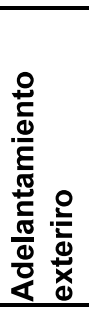 & 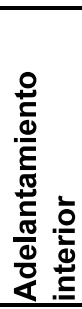 & 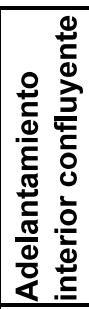 \\
\hline 255 & 1 & & & & & \\
\hline 256 & $\overline{1}$ & & & & & \\
\hline 257 & $\overline{1}$ & & & & & \\
\hline 258 & 2 & & & & & \\
\hline 259 & 1 & & & & & \\
\hline 260 & 1 & & & & & \\
\hline 261 & 1 & & & & & \\
\hline 262 & 1 & & & & & \\
\hline 263 & $\overline{1}$ & & & & & \\
\hline 264 & 1 & & & & & \\
\hline 265 & 1 & & & & & \\
\hline 266 & 1 & & & & & \\
\hline 267 & $\overline{1}$ & & & & & \\
\hline 268 & 2 & & & & & \\
\hline 269 & 1 & & & & & \\
\hline 270 & 1 & & & & & \\
\hline 271 & 1 & & & & & \\
\hline 272 & 1 & & & & & \\
\hline 273 & 1 & & & & & \\
\hline 274 & $\overline{1}$ & & & & & \\
\hline 275 & 1 & & & & & \\
\hline 276 & 1 & & & & & \\
\hline 277 & 1 & & & & & \\
\hline 278 & 1 & & & & & \\
\hline 279 & 1 & & & & & \\
\hline 280 & 1 & & & & & \\
\hline 281 & $\overline{1}$ & & & & & \\
\hline 282 & 1 & & & & & \\
\hline 283 & 1 & & & & & \\
\hline 284 & $\overline{1}$ & & & & & \\
\hline 285 & $\overline{1}$ & & & & & \\
\hline 286 & 1 & & & & & \\
\hline 287 & 1 & & & & & \\
\hline 288 & $\overline{1}$ & & & & & \\
\hline 289 & 1 & & & & & \\
\hline 290 & 1 & & & & & \\
\hline 291 & $\overline{1}$ & & & & & \\
\hline 292 & $\overline{1}$ & & & & & \\
\hline 293 & 1 & & & & & \\
\hline 294 & 1 & & & & & \\
\hline 295 & 1 & & & & & \\
\hline 296 & 1 & & & & & \\
\hline 297 & 1 & & & & & \\
\hline 298 & $\overline{1}$ & & & & $\bar{X}$ & \\
\hline 299 & 1 & & & & & \\
\hline 300 & 1 & & & & & \\
\hline 301 & 1 & & & & & \\
\hline
\end{tabular}

\begin{tabular}{|c|c|c|c|c|c|c|}
\hline z & $\begin{array}{l}\stackrel{\pi}{0} \\
\frac{0}{\bar{\pi}} \\
\stackrel{5}{n}\end{array}$ & 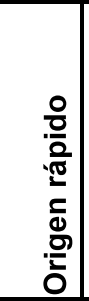 & 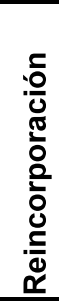 & 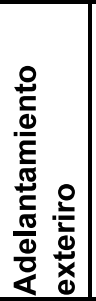 & 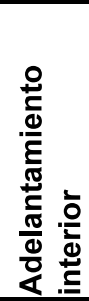 & 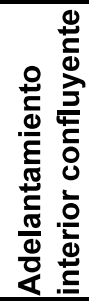 \\
\hline 302 & 1 & & & & & \\
\hline 303 & 1 & & & & & \\
\hline 304 & 3 & & & & & \\
\hline 305 & 1 & & & & & \\
\hline 306 & 1 & & & & & \\
\hline 307 & 1 & & & & & \\
\hline 308 & 1 & & & & $\bar{X}$ & \\
\hline 309 & 1 & & & & $X$ & \\
\hline 310 & 1 & & & & & \\
\hline 311 & 1 & & & & & \\
\hline 312 & 1 & & & & & \\
\hline 313 & 1 & & & & & \\
\hline 314 & 1 & & & & & \\
\hline 315 & 1 & & & & & \\
\hline 316 & 1 & & & & & \\
\hline 317 & 1 & & & & & \\
\hline 318 & 1 & & & & & \\
\hline 319 & 1 & & & & & \\
\hline 320 & 1 & & & & & \\
\hline 321 & 1 & & & & & \\
\hline 322 & 1 & & & & & \\
\hline 323 & 1 & & & & & \\
\hline 324 & 1 & & & & & \\
\hline 325 & 1 & & & & & \\
\hline 326 & 1 & & & & & \\
\hline 327 & 1 & & & & & \\
\hline 328 & 1 & & & & & \\
\hline 329 & 1 & & & & & \\
\hline 330 & 1 & & & & & \\
\hline 331 & 3 & & & & & \\
\hline 332 & 1 & & & $\bar{X}$ & & \\
\hline 333 & 1 & & & & & \\
\hline 334 & 1 & X & & & & \\
\hline 335 & 1 & & & & & \\
\hline 336 & 1 & & & & & \\
\hline 337 & 1 & & & & & \\
\hline 338 & 1 & & & & & \\
\hline 339 & 1 & & & & & \\
\hline 340 & 1 & & & & & \\
\hline 341 & 1 & & & & & \\
\hline 342 & 1 & & & & & \\
\hline 343 & 1 & & & & & \\
\hline 344 & 1 & & & & & \\
\hline 345 & 1 & & & & & \\
\hline 346 & 1 & & & & & \\
\hline 347 & 1 & & & & & \\
\hline 348 & 1 & & & & & \\
\hline
\end{tabular}




\begin{tabular}{|c|c|c|c|c|c|c|}
\hline i & 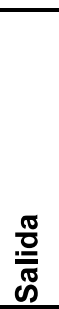 & 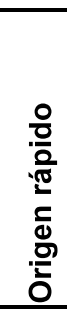 & 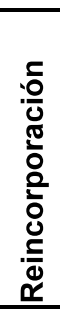 & 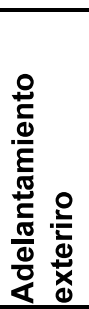 & 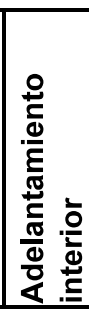 & 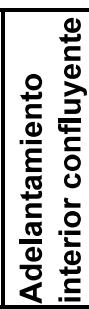 \\
\hline 349 & 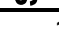 & & & & & \\
\hline 350 & 7 & & & & & \\
\hline 351 & 7 & & & & & \\
\hline 352 & 7 & & & & & \\
\hline 353 & 7 & & & & & \\
\hline 354 & 7 & & & & & \\
\hline 355 & 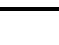 & & & & & \\
\hline 356 & 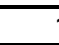 & & & & & \\
\hline 357 & 7 & & & & & \\
\hline 358 & 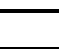 & & & & & \\
\hline 359 & 7 & & & & $X$ & \\
\hline 360 & 7 & & & & & \\
\hline 361 & 7 & & & & & \\
\hline 362 & 7 & & & & & \\
\hline 363 & 7 & & & & & \\
\hline 364 & 7 & & & & & \\
\hline 365 & 7 & & & & & \\
\hline 366 & 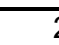 & & & & & \\
\hline 367 & 3 & & & & & \\
\hline 368 & 7 & & & & & \\
\hline 369 & 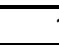 & & & & & \\
\hline 370 & 7 & & & & & \\
\hline 371 & 7 & & & & & \\
\hline 372 & 7 & & & & & \\
\hline 373 & 7 & & & & & \\
\hline 374 & 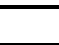 & & & & & \\
\hline 375 & 7 & & & & & \\
\hline 376 & 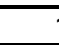 & & & & & \\
\hline 377 & 7 & & & & & \\
\hline 378 & 7 & & & & & \\
\hline 379 & 7 & & & & & \\
\hline 380 & . & & & & & \\
\hline 381 & 7 & & & & & \\
\hline 382 & 7 & & & & & \\
\hline 383 & . & & & & & \\
\hline 384 & . & & & & & \\
\hline 385 & . & & & & & \\
\hline 386 & 7 & & & & & \\
\hline 387 & . & & & & & \\
\hline 388 & & $\bar{X}$ & & & & \\
\hline 389 & . & & & & & \\
\hline 390 & 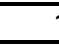 & & & & & \\
\hline 391 & . & & & & & \\
\hline 392 & . & & & & 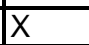 & \\
\hline 393 & . & & & & & \\
\hline 394 & . & & & & & \\
\hline 395 & 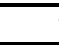 & & & & & \\
\hline
\end{tabular}

\begin{tabular}{|c|c|c|c|c|c|c|}
\hline zo & $\begin{array}{l}\frac{\pi}{0} \\
\frac{0}{\sqrt{5}} \\
\end{array}$ & 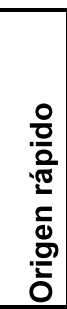 & 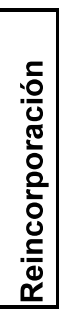 & 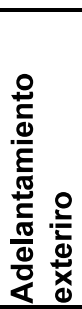 & 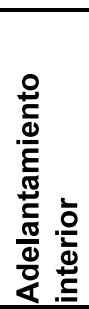 & 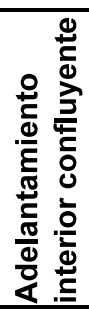 \\
\hline 396 & 1 & & & & $\bar{X}$ & \\
\hline 397 & 1 & & & & & \\
\hline 398 & $\overline{1}$ & & & & & \\
\hline 399 & 1 & & & & & \\
\hline 400 & 1 & & & & & \\
\hline 401 & $\overline{1}$ & & & & & \\
\hline 402 & 1 & & & & & \\
\hline 403 & $\overline{1}$ & & & & & \\
\hline 404 & $\overline{1}$ & & & & & \\
\hline 405 & 1 & & & & & \\
\hline 406 & $\overline{0}$ & & & & & \\
\hline
\end{tabular}




\begin{tabular}{|l|c|c|}
\hline \multicolumn{2}{|c|}{ A7-494 } \\
\hline Maniobras & 252 & \\
\hline Salida anticipada & 3 & $1,2 \%$ \\
\hline Salida en la cuña & 229 & $90,9 \%$ \\
\hline Salida zona media & 19 & $7,5 \%$ \\
\hline Salida tardia & 1 & $0,4 \%$ \\
\hline Origen carriles ràpidos & 12 & $4,8 \%$ \\
\hline Reincorporaciones & 2 & $0,8 \%$ \\
\hline Adelantamiento exterior & 6 & $2,4 \%$ \\
\hline Adelantamiento interior & 7 & $2,8 \%$ \\
\hline Adelantamiento interior confluyente & 0 & $0,0 \%$ \\
\hline
\end{tabular}

\begin{tabular}{|c|c|c|c|c|c|c|}
\hline$\stackrel{0}{2}$ & $\begin{array}{l}\frac{\pi}{0} \\
\frac{0}{\pi} \\
\infty\end{array}$ & 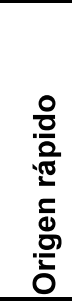 & 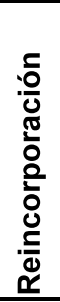 & 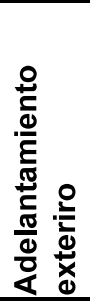 & 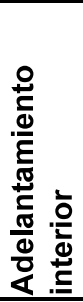 & 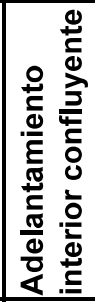 \\
\hline 1 & 1 & & & & & \\
\hline 2 & 1 & & & & & \\
\hline 3 & 1 & & & & & \\
\hline 4 & 1 & & & & & \\
\hline 5 & 1 & & & & & \\
\hline 6 & 1 & & & & & \\
\hline 7 & 1 & & & & & \\
\hline 8 & 1 & & & & & \\
\hline 9 & 1 & & & & & \\
\hline 10 & 1 & & & & & \\
\hline 11 & 2 & & & & & \\
\hline 12 & 1 & $X$ & & & & \\
\hline 13 & 1 & & & & & \\
\hline 14 & 1 & & & & & \\
\hline 15 & 1 & & & & & \\
\hline 16 & 1 & & & & & \\
\hline 17 & 1 & $\bar{X}$ & & & & \\
\hline 18 & 1 & & & & & \\
\hline 19 & 1 & & & & & \\
\hline 20 & 1 & & & & & \\
\hline 21 & 1 & & & & & \\
\hline 22 & 1 & & & & & \\
\hline 23 & 1 & & & & & \\
\hline 24 & 2 & & & & & \\
\hline 25 & 1 & $\mathrm{X}$ & & & & \\
\hline 26 & 1 & & & & & \\
\hline 27 & 1 & & & & & \\
\hline 28 & 1 & & & & & \\
\hline 29 & 1 & & & & & \\
\hline 30 & 1 & & & & & \\
\hline 31 & 1 & & & & & \\
\hline 32 & 1 & & & & & \\
\hline 33 & 0 & & & & & \\
\hline
\end{tabular}

\begin{tabular}{|c|c|c|c|c|c|c|}
\hline$\dot{0}$ & $\frac{\text { 음 }}{\frac{0}{\pi}}$ & \begin{tabular}{l} 
음 \\
\hdashline$\frac{0}{0}$ \\
$\frac{c}{0}$ \\
$\frac{0}{2}$ \\
0
\end{tabular} & 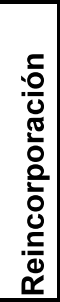 & 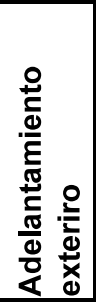 & 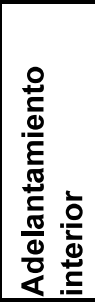 & 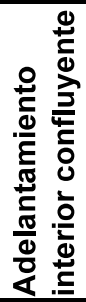 \\
\hline 34 & 1 & & & & & \\
\hline 35 & 1 & & & $X$ & & \\
\hline 36 & 3 & & & & & \\
\hline 37 & 1 & $\bar{X}$ & & & & \\
\hline 38 & 1 & & & & & \\
\hline 39 & 1 & & & & & \\
\hline 40 & 1 & & & & & \\
\hline 41 & 1 & & & & & \\
\hline 42 & 1 & & & & & \\
\hline 43 & 1 & & & & & \\
\hline 44 & 2 & & & & & \\
\hline 45 & 1 & $X$ & & & & \\
\hline 46 & 2 & & & & & \\
\hline 47 & 1 & & & & & \\
\hline 48 & 1 & & & & & \\
\hline 49 & 1 & & & & & \\
\hline 50 & 1 & & & & & \\
\hline 51 & 1 & & & & & \\
\hline 52 & 1 & & & & & \\
\hline 53 & 1 & & & & & \\
\hline 54 & 1 & & & & & \\
\hline 55 & 1 & & & & & \\
\hline 56 & 1 & & & $X$ & & \\
\hline 57 & 1 & & & & & \\
\hline 58 & 1 & & & & & \\
\hline 59 & 1 & & & & & \\
\hline 60 & 1 & & & & & \\
\hline 61 & 1 & & & & & \\
\hline 62 & 1 & & & $X$ & $X$ & \\
\hline 63 & 1 & & & & & \\
\hline 64 & 1 & & & & & \\
\hline 65 & 1 & & & & & \\
\hline 66 & 1 & & & & & \\
\hline
\end{tabular}




\begin{tabular}{|c|c|c|c|c|c|c|}
\hline io & 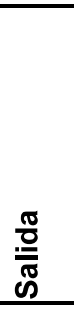 & 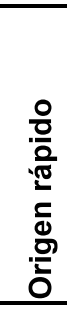 & 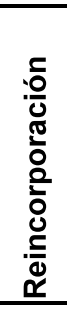 & 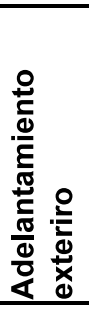 & 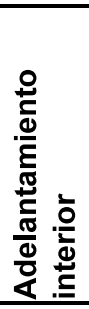 & 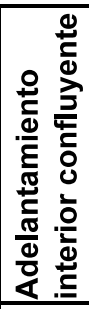 \\
\hline 67 & 1 & & & & & \\
\hline 68 & 1 & & & & & \\
\hline 69 & 1 & & & & & \\
\hline 70 & 1 & & & & & \\
\hline 71 & 1 & & & & & \\
\hline 72 & 1 & & & & & \\
\hline 73 & & $\bar{X}$ & & & & \\
\hline 74 & 1 & & & & & \\
\hline 75 & 1 & & & & & \\
\hline 76 & 1 & & & & & \\
\hline 77 & 2 & & & & & \\
\hline 78 & 1 & & & & & \\
\hline 79 & 1 & & & & & \\
\hline 80 & 1 & & & & & \\
\hline 81 & 1 & & & & & \\
\hline 82 & 1 & & & & & \\
\hline 83 & 1 & & & & $\bar{X}$ & \\
\hline 84 & 1 & & $\bar{X}$ & & & \\
\hline 85 & 1 & & & & & \\
\hline 86 & 1 & & & & & \\
\hline 87 & 1 & & & & & \\
\hline 88 & 1 & & & & & \\
\hline 89 & 1 & & & & & \\
\hline 90 & 1 & & & & & \\
\hline 91 & 1 & & & & & \\
\hline 92 & 1 & & & & & \\
\hline 93 & 1 & & & & & \\
\hline 94 & 1 & & & & & \\
\hline 95 & 1 & & & & & \\
\hline 96 & 1 & & & & & \\
\hline 97 & 1 & & & & & \\
\hline 98 & 1 & & & & & \\
\hline 99 & 1 & & & & & \\
\hline 100 & 1 & & & & & \\
\hline 101 & 1 & & & & & \\
\hline 102 & 1 & & & & & \\
\hline 103 & 1 & & & & & \\
\hline 104 & 1 & & & & & \\
\hline 105 & & $\bar{X}$ & & & & \\
\hline 106 & & $\bar{X}$ & & & & \\
\hline 107 & 1 & & & & & \\
\hline 108 & & $\bar{X}$ & & & & \\
\hline 109 & 1 & & & & & \\
\hline 110 & $\frac{1}{1}$ & & & & & \\
\hline 111 & 2 & & & & & \\
\hline 112 & 1 & & & & & \\
\hline 113 & 1 & & & & & \\
\hline
\end{tabular}

\begin{tabular}{|c|c|c|c|c|c|c|}
\hline $\mathbf{z}$ & 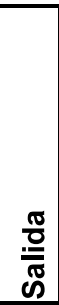 & $\begin{array}{l}\text { 음 } \\
\frac{0}{0} \\
\frac{0}{0} \\
0 \\
0\end{array}$ & 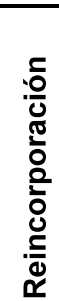 & 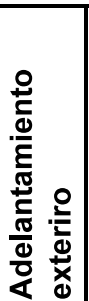 & 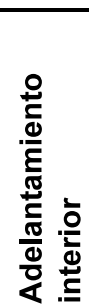 & 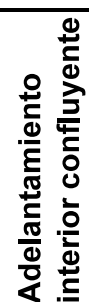 \\
\hline 114 & 1 & & & & & \\
\hline 115 & 2 & & & & & \\
\hline 116 & 1 & & & & & \\
\hline 117 & 1 & & & & & \\
\hline 118 & 1 & & & & & \\
\hline 119 & 1 & & & & & \\
\hline 120 & 1 & & & & & \\
\hline 121 & 1 & & & & & \\
\hline 122 & 1 & & & & & \\
\hline 123 & 1 & & & & & \\
\hline 124 & 2 & & & & & \\
\hline 125 & 1 & & & & & \\
\hline 126 & 1 & & & & & \\
\hline 127 & 1 & & & & & \\
\hline 128 & 1 & & & & & \\
\hline 129 & 1 & & & & & \\
\hline 130 & 1 & & & & $\mathrm{X}$ & \\
\hline 131 & 1 & & & & & \\
\hline 132 & 1 & & & & & \\
\hline 133 & 1 & & & & & \\
\hline 134 & 1 & & & & & \\
\hline 135 & 1 & & & & $X$ & \\
\hline 136 & 1 & & & & & \\
\hline 137 & 1 & & & & & \\
\hline 138 & 0 & & & & & \\
\hline 139 & 1 & & & & & \\
\hline 140 & 1 & & & & & \\
\hline 141 & 1 & & & & & \\
\hline 142 & 1 & & & & & \\
\hline 143 & 1 & & & & & \\
\hline 144 & 1 & & & & & \\
\hline 145 & 1 & & & & & \\
\hline 146 & 1 & & & & & \\
\hline 147 & 1 & & & & & \\
\hline 148 & 1 & $\bar{X}$ & & & & \\
\hline 149 & 2 & & & & & \\
\hline 150 & 1 & & & & & \\
\hline 151 & 1 & & & & & \\
\hline 152 & 2 & & & & $\mathrm{X}$ & \\
\hline 153 & 1 & $\bar{X}$ & & & & \\
\hline 154 & 1 & & & & & \\
\hline 155 & 1 & & & & & \\
\hline 156 & 0 & & & & & \\
\hline 157 & 1 & & & & & \\
\hline 158 & 2 & & & & & \\
\hline 159 & 1 & & & & & \\
\hline 160 & 1 & & & & & \\
\hline
\end{tabular}




\begin{tabular}{|c|c|c|c|c|c|c|}
\hline í & 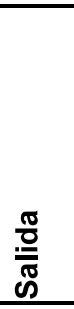 & 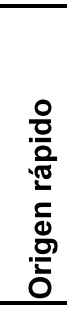 & 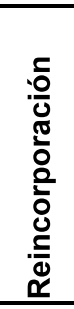 & 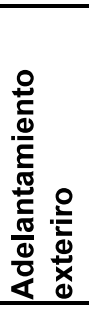 & 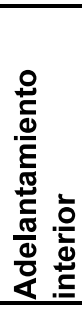 & 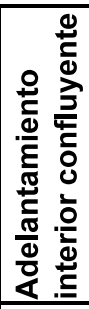 \\
\hline 161 & 1 & & & & & \\
\hline 162 & 1 & & & & & \\
\hline 163 & 1 & & & & & \\
\hline 164 & 1 & & & & & \\
\hline 165 & 1 & & & & & \\
\hline 166 & 1 & & & & & \\
\hline 167 & 1 & & & & & \\
\hline 168 & 1 & & & & & \\
\hline 169 & 1 & & & & & \\
\hline 170 & 1 & & & & & \\
\hline 171 & 1 & & & & & \\
\hline 172 & 1 & & & & & \\
\hline 173 & 1 & & & & & \\
\hline 174 & 1 & & & & & \\
\hline 175 & 1 & & & & & \\
\hline 176 & $\overline{1}$ & & & & $\bar{X}$ & \\
\hline 177 & 1 & & & & & \\
\hline 178 & 1 & & $\bar{X}$ & & & \\
\hline 179 & 1 & & & & & \\
\hline 180 & 1 & & & & & \\
\hline 181 & $\overline{1}$ & & & & $\bar{X}$ & \\
\hline 182 & 1 & & & & & \\
\hline 183 & 1 & & & & & \\
\hline 184 & 1 & & & & & \\
\hline 185 & 1 & & & & & \\
\hline 186 & 1 & & & & & \\
\hline 187 & 1 & & & & & \\
\hline 188 & 2 & & & & & \\
\hline 189 & 1 & & & $X$ & & \\
\hline 190 & $\overline{1}$ & & & & & \\
\hline 191 & $\overline{1}$ & & & & & \\
\hline 192 & 1 & & & & & \\
\hline 193 & $\overline{2}$ & & & & & \\
\hline 194 & $\underline{2}$ & & & & & \\
\hline 195 & 1 & & & & & \\
\hline 196 & 1 & & & & & \\
\hline 197 & 1 & & & & & \\
\hline 198 & $\overline{1}$ & & & & & \\
\hline 199 & 1 & & & & & \\
\hline 200 & 1 & & & & & \\
\hline 201 & $\overline{1}$ & & & & & \\
\hline 202 & 2 & & & & & \\
\hline 203 & & $\bar{X}$ & & $X$ & & \\
\hline 204 & $\overline{1}$ & & & & & \\
\hline 205 & 1 & & & & & \\
\hline 206 & 1 & & & & & \\
\hline 207 & 1 & & & & & \\
\hline
\end{tabular}

\begin{tabular}{|c|c|c|c|c|c|c|}
\hline$\dot{\dot{z}}$ & $\begin{array}{l}\frac{\pi}{0} \\
\frac{0}{\pi} \\
0\end{array}$ & 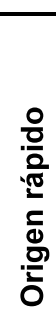 & 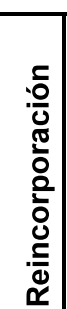 & 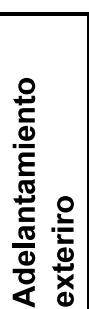 & 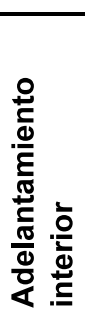 & 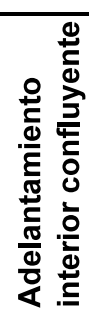 \\
\hline 208 & 1 & & & & & \\
\hline 209 & 1 & & & & & \\
\hline 210 & 1 & & & & & \\
\hline 211 & 1 & & & & & \\
\hline 212 & 1 & & & & & \\
\hline 213 & 1 & & & & & \\
\hline 214 & 1 & & & & & \\
\hline 215 & 1 & & & & & \\
\hline 216 & 2 & & & & & \\
\hline 217 & 1 & & & & & \\
\hline 218 & 1 & & & & & \\
\hline 219 & 1 & & & & & \\
\hline 220 & 1 & & & & & \\
\hline 221 & 1 & & & & & \\
\hline 222 & 1 & & & & & \\
\hline 223 & 1 & & & & & \\
\hline 224 & 1 & & & & & \\
\hline 225 & 1 & & & & & \\
\hline 226 & 1 & & & & & \\
\hline 227 & 1 & & & & & \\
\hline 228 & 2 & & & & & \\
\hline 229 & 2 & & & & & \\
\hline 230 & 2 & & & & & \\
\hline 231 & 1 & & & & & \\
\hline 232 & 1 & & & & & \\
\hline 233 & 1 & & & & & \\
\hline 234 & 1 & & & & & \\
\hline 235 & 1 & & & & & \\
\hline 236 & 1 & & & & & \\
\hline 237 & 1 & & & & & \\
\hline 238 & 1 & & & & & \\
\hline 239 & 1 & & & & & \\
\hline 240 & 1 & & & & & \\
\hline 241 & 1 & & & & & \\
\hline 242 & 1 & & & & & \\
\hline 243 & 1 & & & & & \\
\hline 244 & 1 & & & & & \\
\hline 245 & 1 & & & & & \\
\hline 246 & 1 & & & & & \\
\hline 247 & 1 & & & & & \\
\hline 248 & 1 & & & & & \\
\hline 249 & 1 & & & & & \\
\hline 250 & 1 & & & & & \\
\hline 251 & 1 & & & & & \\
\hline 252 & 1 & & & & & \\
\hline
\end{tabular}




\begin{tabular}{|l|c|c|}
\hline \multicolumn{2}{|c|}{ A3-351 } \\
\hline Maniobras & 523 & \\
\hline Salida anticipada & 0 & $0,0 \%$ \\
\hline Salida en la cuña & 432 & $82,6 \%$ \\
\hline Salida zona media & 73 & $14,0 \%$ \\
\hline Salida tardia & 18 & $3,4 \%$ \\
\hline Origen carriles ràpidos & 3 & $0,6 \%$ \\
\hline Reincorporaciones & 1 & $0,2 \%$ \\
\hline Adelantamiento exterior & 0 & $0,0 \%$ \\
\hline Adelantamiento interior & 0 & $0,0 \%$ \\
\hline Adelantamiento interior confluyente & 0 & $0,0 \%$ \\
\hline
\end{tabular}

\begin{tabular}{|c|c|c|c|c|c|c|}
\hline i & $\begin{array}{l}\frac{\pi}{0} \\
\frac{}{\pi} \\
\text { ஸे }\end{array}$ & $\begin{array}{l}\text { 음 } \\
\text { 문 } \\
\text { 엉 } \\
\text { 은 }\end{array}$ & 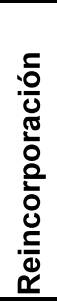 & 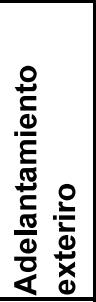 & 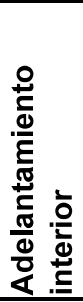 & 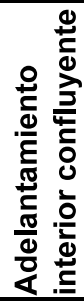 \\
\hline 1 & 1 & & & & & \\
\hline 2 & 1 & & & & & \\
\hline 3 & 1 & & & & & \\
\hline 4 & $\overline{1}$ & & & & & \\
\hline 5 & 2 & & & & & \\
\hline 6 & 1 & & & & & \\
\hline 7 & 2 & & & & & \\
\hline 8 & 2 & & & & & \\
\hline 9 & 1 & & & & & \\
\hline 10 & 1 & & & & & \\
\hline 11 & 1 & & & & & \\
\hline 12 & 1 & & & & & \\
\hline 13 & 1 & & & & & \\
\hline 14 & 1 & & & & & \\
\hline 15 & 2 & & & & & \\
\hline 16 & 1 & & & & & \\
\hline 17 & 3 & & & & & \\
\hline 18 & 3 & & & & & \\
\hline 19 & 1 & & & & & \\
\hline 20 & 1 & & & & & \\
\hline 21 & 2 & & & & & \\
\hline 22 & 3 & & & & & \\
\hline 23 & 2 & & & & & \\
\hline 24 & 1 & & & & & \\
\hline 25 & 1 & & & & & \\
\hline 26 & 1 & & & & & \\
\hline 27 & 1 & & & & & \\
\hline 28 & 3 & & & & & \\
\hline 29 & 2 & & & & & \\
\hline 30 & 2 & & & & & \\
\hline 31 & $\underline{2}$ & & & & & \\
\hline 32 & 1 & & & & & \\
\hline 33 & 1 & & & & & \\
\hline
\end{tabular}

\begin{tabular}{|c|c|c|c|c|c|c|}
\hline í & $\frac{\frac{\pi}{0}}{\frac{0}{\pi}}$ & $\begin{array}{l}\text { 음 } \\
\frac{0}{0} \\
\frac{5}{0} \\
\frac{0}{0}\end{array}$ & 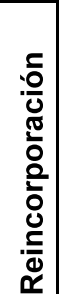 & 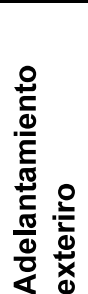 & 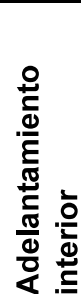 & 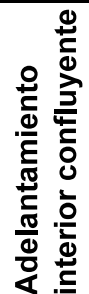 \\
\hline 34 & 1 & & & & & \\
\hline 35 & 1 & & & & & \\
\hline 36 & 3 & & & & & \\
\hline 37 & 3 & & & & & \\
\hline 38 & 2 & & & & & \\
\hline 39 & 1 & & & & & \\
\hline 40 & 1 & & & & & \\
\hline 4 & 3 & & & & & \\
\hline 42 & 3 & & & & & \\
\hline 43 & 1 & & & & & \\
\hline 4 & 1 & & & & & \\
\hline 45 & 1 & & & & & \\
\hline 46 & 2 & & & & & \\
\hline 47 & 1 & & & & & \\
\hline 48 & 1 & & & & & \\
\hline 49 & 1 & & & & & \\
\hline 50 & 1 & & & & & \\
\hline 51 & 1 & & & & & \\
\hline 52 & 1 & & & & & \\
\hline 53 & 2 & & & & & \\
\hline 54 & 1 & & & & & \\
\hline 55 & 1 & & & & & \\
\hline 56 & 2 & & & & & \\
\hline 57 & 1 & & & & & \\
\hline 5 & 1 & & & & & \\
\hline 59 & 1 & & & & & \\
\hline 60 & 1 & & & & & \\
\hline 61 & 1 & & & & & \\
\hline 62 & 1 & & & & & \\
\hline 63 & 1 & & & & & \\
\hline 64 & 1 & & & & & \\
\hline 65 & 1 & & & & & \\
\hline 66 & 1 & & & & & \\
\hline
\end{tabular}




\begin{tabular}{|c|c|c|c|c|c|c|}
\hline$\dot{0}$ & $\frac{\mathbb{\pi}}{\frac{\pi}{\overline{0}}}$ & 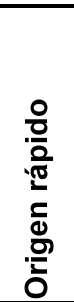 & 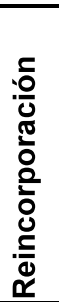 & 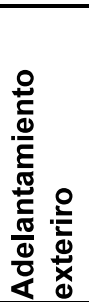 & 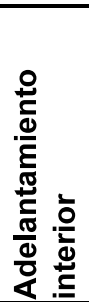 & 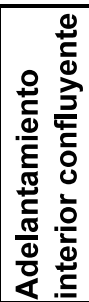 \\
\hline 67 & 1 & & & & & \\
\hline 68 & 2 & & & & & \\
\hline 69 & 3 & & & & & \\
\hline 70 & 1 & & & & & \\
\hline 71 & 1 & & & & & \\
\hline 72 & 2 & & & & & \\
\hline 73 & $\overline{3}$ & & & & & \\
\hline 74 & 2 & & & & & \\
\hline 75 & 1 & & & & & \\
\hline 76 & 1 & & & & & \\
\hline 77 & 1 & & & & & \\
\hline 78 & 1 & & & & & \\
\hline 79 & 1 & & & & & \\
\hline 80 & 1 & & & & & \\
\hline 81 & 1 & & & & & \\
\hline 82 & 1 & & & & & \\
\hline 83 & 1 & & & & & \\
\hline 84 & 1 & & & & & \\
\hline 85 & 1 & & & & & \\
\hline 86 & 1 & & & & & \\
\hline 87 & 1 & & & & & \\
\hline 88 & 1 & & & & & \\
\hline 89 & 1 & & & & & \\
\hline 90 & 1 & & & & & \\
\hline 91 & 3 & & & & & \\
\hline 92 & 1 & & & & & \\
\hline 93 & $\overline{2}$ & & & & & \\
\hline 94 & 1 & & & & & \\
\hline 95 & 1 & & & & & \\
\hline 96 & 2 & & & & & \\
\hline 97 & 1 & & & & & \\
\hline 98 & 1 & & & & & \\
\hline 99 & 1 & & & & & \\
\hline 100 & 1 & & & & & \\
\hline 101 & 1 & & & & & \\
\hline 102 & 1 & & & & & \\
\hline 103 & 1 & & & & & \\
\hline 104 & 1 & & & & & \\
\hline 105 & 1 & & & & & \\
\hline 106 & 1 & & & & & \\
\hline 107 & 1 & & & & & \\
\hline 108 & 2 & & & & & \\
\hline 109 & 1 & & & & & \\
\hline 110 & $\frac{1}{1}$ & & & & & \\
\hline 111 & 1 & & & & & \\
\hline 112 & 1 & & & & & \\
\hline 113 & 1 & & & & & \\
\hline
\end{tabular}

\begin{tabular}{|c|c|c|c|c|c|c|}
\hline $\mathbf{z}$ & 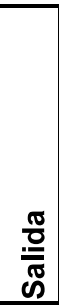 & 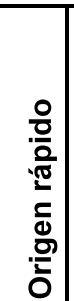 & 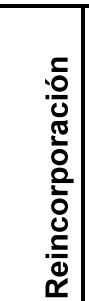 & 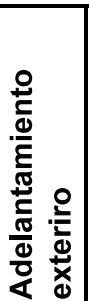 & 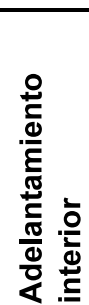 & 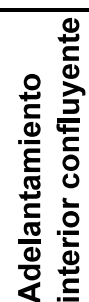 \\
\hline 114 & 1 & & & & & \\
\hline 115 & 1 & & & & & \\
\hline 116 & 1 & & & & & \\
\hline 117 & 1 & & & & & \\
\hline 118 & 1 & & & & & \\
\hline 119 & 1 & & & & & \\
\hline 120 & 1 & & & & & \\
\hline 121 & 1 & & & & & \\
\hline 122 & 1 & & $\bar{x}$ & & & \\
\hline 123 & 3 & & & & & \\
\hline 124 & 1 & & & & & \\
\hline 125 & 1 & & & & & \\
\hline 126 & 1 & & & & & \\
\hline 127 & 1 & & & & & \\
\hline 128 & 1 & & & & & \\
\hline 129 & 1 & & & & & \\
\hline 130 & 1 & & & & & \\
\hline 131 & 1 & & & & & \\
\hline 132 & 1 & & & & & \\
\hline 133 & 1 & & & & & \\
\hline 134 & 1 & & & & & \\
\hline 135 & 1 & & & & & \\
\hline 136 & 1 & & & & & \\
\hline 137 & 1 & & & & & \\
\hline 138 & 1 & & & & & \\
\hline 139 & 1 & & & & & \\
\hline 140 & 1 & & & & & \\
\hline 141 & 1 & & & & & \\
\hline 142 & 1 & & & & & \\
\hline 143 & 1 & & & & & \\
\hline 144 & 1 & & & & & \\
\hline 145 & 1 & & & & & \\
\hline 146 & 1 & & & & & \\
\hline 147 & 1 & & & & & \\
\hline 148 & 1 & & & & & \\
\hline 149 & 3 & & & & & \\
\hline 150 & 2 & & & & & \\
\hline 151 & 1 & & & & & \\
\hline 152 & 1 & & & & & \\
\hline 153 & 2 & & & & & \\
\hline 154 & 1 & & & & & \\
\hline 155 & 1 & & & & & \\
\hline 156 & 1 & & & & & \\
\hline 157 & 1 & & & & & \\
\hline 158 & 1 & & & & & \\
\hline 159 & 1 & & & & & \\
\hline 160 & 1 & & & & & \\
\hline
\end{tabular}




\begin{tabular}{|c|c|c|c|c|c|c|}
\hline i & 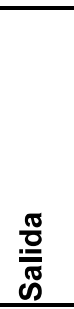 & $\begin{array}{l}\stackrel{\circ}{\circ} \\
\frac{0}{2} \\
\frac{\pi}{2} \\
\bar{d} \\
\stackrel{\circ}{5} \\
0\end{array}$ & 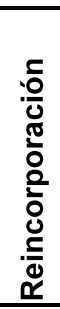 & 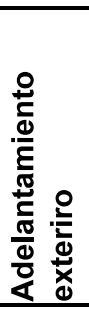 & 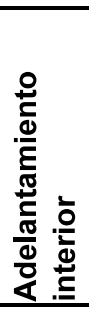 & 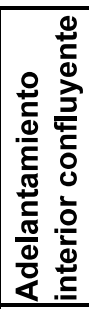 \\
\hline 161 & 1 & & & & & \\
\hline 162 & $\overline{1}$ & & & & & \\
\hline 163 & 1 & & & & & \\
\hline 164 & 2 & & & & & \\
\hline 165 & 1 & & & & & \\
\hline 166 & 1 & & & & & \\
\hline 167 & 1 & & & & & \\
\hline 168 & 1 & & & & & \\
\hline 169 & $\overline{1}$ & & & & & \\
\hline 170 & 1 & & & & & \\
\hline 171 & 1 & & & & & \\
\hline 172 & 1 & & & & & \\
\hline 173 & $\overline{1}$ & & & & & \\
\hline 174 & 1 & & & & & \\
\hline 175 & 1 & & & & & \\
\hline 176 & $\overline{2}$ & & & & & \\
\hline 177 & 1 & & & & & \\
\hline 178 & 1 & & & & & \\
\hline 179 & 1 & & & & & \\
\hline 180 & $\overline{1}$ & & & & & \\
\hline 181 & 1 & & & & & \\
\hline 182 & 1 & & & & & \\
\hline 183 & 2 & & & & & \\
\hline 184 & 2 & & & & & \\
\hline 185 & 1 & & & & & \\
\hline 186 & $\overline{2}$ & & & & & \\
\hline 187 & $\overline{1}$ & & & & & \\
\hline 188 & 1 & & & & & \\
\hline 189 & 1 & & & & & \\
\hline 190 & $\overline{1}$ & & & & & \\
\hline 191 & $\overline{1}$ & & & & & \\
\hline 192 & 1 & & & & & \\
\hline 193 & 1 & & & & & \\
\hline 194 & $\overline{2}$ & & & & & \\
\hline 195 & 1 & & & & & \\
\hline 196 & 1 & & & & & \\
\hline 197 & $\overline{1}$ & & & & & \\
\hline 198 & $\overline{2}$ & & & & & \\
\hline 199 & 1 & & & & & \\
\hline 200 & 1 & & & & & \\
\hline 201 & 1 & & & & & \\
\hline 202 & 1 & & & & & \\
\hline 203 & 1 & & & & & \\
\hline 204 & $\overline{2}$ & & & & & \\
\hline 205 & 1 & & & & & \\
\hline 206 & $\overline{3}$ & & & & & \\
\hline 207 & 1 & & & & & \\
\hline
\end{tabular}

\begin{tabular}{|c|c|c|c|c|c|c|}
\hline 之o & 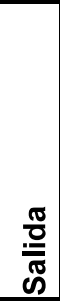 & $\begin{array}{l}\frac{0}{0} \\
\frac{0}{2} \\
\frac{\pi}{2} \\
\frac{d}{\Phi} \\
\stackrel{0}{2} \\
0\end{array}$ & 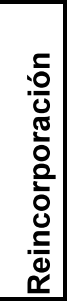 & 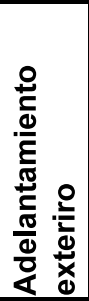 & 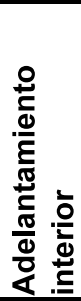 & 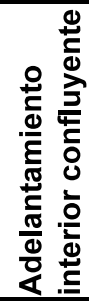 \\
\hline 208 & 2 & & & & & \\
\hline 209 & 1 & & & & & \\
\hline 210 & 1 & & & & & \\
\hline 211 & 1 & & & & & \\
\hline 212 & 1 & & & & & \\
\hline 213 & 1 & & & & & \\
\hline 214 & 2 & & & & & \\
\hline 215 & 1 & & & & & \\
\hline 216 & 2 & & & & & \\
\hline 217 & 1 & & & & & \\
\hline 218 & 1 & & & & & \\
\hline 219 & 1 & & & & & \\
\hline 220 & 1 & & & & & \\
\hline 221 & 3 & & & & & \\
\hline 222 & 1 & $\bar{X}$ & & & & \\
\hline 223 & 2 & & & & & \\
\hline 224 & 2 & & & & & \\
\hline 225 & 2 & & & & & \\
\hline 226 & 1 & & & & & \\
\hline 227 & 1 & & & & & \\
\hline 228 & 1 & & & & & \\
\hline 229 & 1 & & & & & \\
\hline 230 & 1 & & & & & \\
\hline 231 & 1 & & & & & \\
\hline 232 & 1 & & & & & \\
\hline 233 & 2 & & & & & \\
\hline 234 & 1 & & & & & \\
\hline 235 & 1 & & & & & \\
\hline 236 & 1 & & & & & \\
\hline 237 & 1 & & & & & \\
\hline 238 & 1 & & & & & \\
\hline 239 & 1 & $\bar{X}$ & & & & \\
\hline 240 & 1 & & & & & \\
\hline 241 & 1 & & & & & \\
\hline 242 & 1 & & & & & \\
\hline 243 & 1 & & & & & \\
\hline 244 & 1 & & & & & \\
\hline 245 & 1 & & & & & \\
\hline 246 & 1 & & & & & \\
\hline 247 & 1 & & & & & \\
\hline 248 & 1 & & & & & \\
\hline 249 & 1 & & & & & \\
\hline 250 & 1 & & & & & \\
\hline 251 & 2 & & & & & \\
\hline 252 & 1 & & & & & \\
\hline 253 & 2 & & & & & \\
\hline 254 & 1 & & & & & \\
\hline
\end{tabular}




\begin{tabular}{|c|c|c|c|c|c|c|}
\hline io & 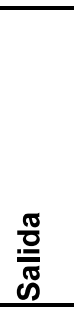 & 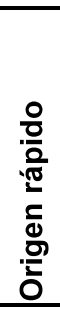 & 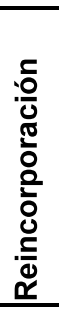 & 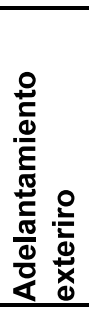 & 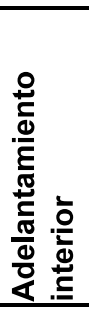 & 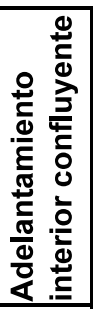 \\
\hline 255 & 1 & & & & & \\
\hline 256 & 1 & & & & & \\
\hline 257 & 1 & & & & & \\
\hline 258 & 1 & & & & & \\
\hline 259 & 1 & & & & & \\
\hline 260 & 2 & & & & & \\
\hline 261 & 2 & & & & & \\
\hline 262 & 1 & & & & & \\
\hline 263 & 2 & & & & & \\
\hline 264 & 1 & & & & & \\
\hline 265 & 1 & & & & & \\
\hline 266 & 1 & & & & & \\
\hline 267 & $\overline{1}$ & & & & & \\
\hline 268 & 2 & & & & & \\
\hline 269 & 2 & & & & & \\
\hline 270 & $\overline{2}$ & & & & & \\
\hline 271 & 1 & & & & & \\
\hline 272 & 2 & & & & & \\
\hline 273 & 1 & & & & & \\
\hline 274 & $\overline{1}$ & & & & & \\
\hline 275 & 1 & & & & & \\
\hline 276 & 1 & & & & & \\
\hline 277 & 1 & & & & & \\
\hline 278 & 1 & & & & & \\
\hline 279 & 1 & & & & & \\
\hline 280 & 1 & & & & & \\
\hline 281 & 1 & & & & & \\
\hline 282 & 1 & & & & & \\
\hline 283 & 1 & & & & & \\
\hline 284 & $\overline{1}$ & & & & & \\
\hline 285 & $\overline{1}$ & & & & & \\
\hline 286 & 1 & & & & & \\
\hline 287 & 1 & & & & & \\
\hline 288 & 1 & & & & & \\
\hline 289 & 1 & & & & & \\
\hline 290 & 1 & & & & & \\
\hline 291 & $\overline{1}$ & & & & & \\
\hline 292 & $\overline{3}$ & & & & & \\
\hline 293 & 1 & & & & & \\
\hline 294 & 1 & & & & & \\
\hline 295 & 1 & & & & & \\
\hline 296 & 1 & & & & & \\
\hline 297 & 1 & & & & & \\
\hline 298 & $\overline{2}$ & & & & & \\
\hline 299 & $\frac{2}{2}$ & & & & & \\
\hline 300 & 1 & & & & & \\
\hline 301 & 1 & & & & & \\
\hline
\end{tabular}

\begin{tabular}{|c|c|c|c|c|c|c|}
\hline z & 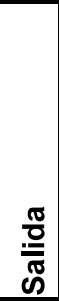 & $\begin{array}{l}\circ \\
\frac{0}{0} \\
\frac{\pi}{2} \\
\overline{0} \\
\bar{\sigma} \\
\overline{0}\end{array}$ & 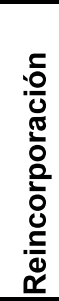 & 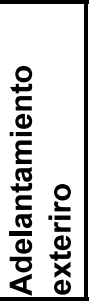 & 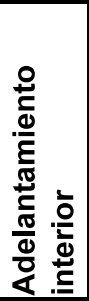 & 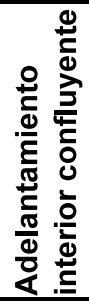 \\
\hline 302 & 1 & & & & & \\
\hline 303 & 1 & & & & & \\
\hline 304 & 1 & & & & & \\
\hline 305 & 1 & & & & & \\
\hline 306 & 1 & & & & & \\
\hline 307 & 1 & & & & & \\
\hline 308 & 1 & & & & & \\
\hline 309 & 1 & & & & & \\
\hline 310 & 1 & & & & & \\
\hline 311 & 1 & & & & & \\
\hline 312 & 1 & & & & & \\
\hline 313 & 3 & & & & & \\
\hline 314 & 1 & & & & & \\
\hline 315 & 1 & & & & & \\
\hline 316 & 1 & & & & & \\
\hline 317 & 1 & & & & & \\
\hline 318 & 2 & & & & & \\
\hline 319 & 1 & & & & & \\
\hline 320 & 2 & & & & & \\
\hline 321 & 2 & & & & & \\
\hline 322 & 1 & & & & & \\
\hline 323 & 1 & & & & & \\
\hline 324 & 1 & & & & & \\
\hline 325 & 1 & & & & & \\
\hline 326 & 2 & & & & & \\
\hline 327 & 1 & & & & & \\
\hline 328 & 1 & & & & & \\
\hline 329 & 1 & & & & & \\
\hline 330 & 1 & & & & & \\
\hline 331 & 1 & & & & & \\
\hline 332 & 1 & & & & & \\
\hline 333 & 2 & & & & & \\
\hline 334 & 1 & & & & & \\
\hline 335 & 1 & & & & & \\
\hline 336 & 1 & & & & & \\
\hline 337 & 1 & & & & & \\
\hline 338 & 1 & & & & & \\
\hline 339 & 1 & & & & & \\
\hline 340 & 1 & & & & & \\
\hline 341 & 1 & & & & & \\
\hline 342 & 1 & & & & & \\
\hline 343 & 1 & & & & & \\
\hline 344 & 1 & & & & & \\
\hline 345 & 1 & & & & & \\
\hline 346 & 1 & & & & & \\
\hline 347 & 1 & & & & & \\
\hline 348 & 2 & & & & & \\
\hline
\end{tabular}




\begin{tabular}{|c|c|c|c|c|c|c|}
\hline ì & $\begin{array}{l}\frac{\pi}{0} \\
\frac{0}{\pi} \\
0\end{array}$ & 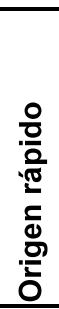 & 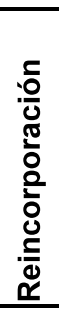 & 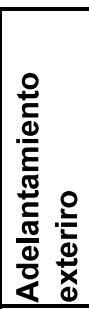 & 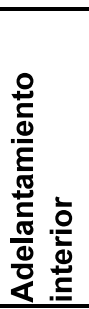 & 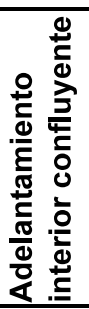 \\
\hline 349 & 1 & & & & & \\
\hline 350 & 1 & & & & & \\
\hline 351 & 1 & & & & & \\
\hline 352 & 1 & & & & & \\
\hline 353 & 1 & & & & & \\
\hline 354 & 1 & & & & & \\
\hline 355 & 1 & & & & & \\
\hline 356 & 1 & & & & & \\
\hline 357 & $\overline{1}$ & & & & & \\
\hline 358 & 1 & & & & & \\
\hline 359 & 1 & & & & & \\
\hline 360 & 2 & & & & & \\
\hline 361 & $\overline{1}$ & & & & & \\
\hline 362 & 1 & & & & & \\
\hline 363 & 1 & & & & & \\
\hline 364 & $\overline{2}$ & & & & & \\
\hline 365 & 1 & & & & & \\
\hline 366 & 1 & & & & & \\
\hline 367 & 1 & & & & & \\
\hline 368 & $\overline{1}$ & & & & & \\
\hline 369 & 1 & & & & & \\
\hline 370 & 2 & & & & & \\
\hline 371 & 1 & & & & & \\
\hline 372 & $\overline{1}$ & & & & & \\
\hline 373 & 1 & & & & & \\
\hline 374 & 1 & & & & & \\
\hline 375 & $\overline{2}$ & & & & & \\
\hline 376 & 1 & & & & & \\
\hline 377 & 1 & & & & & \\
\hline 378 & $\overline{1}$ & & & & & \\
\hline 379 & $\overline{1}$ & & & & & \\
\hline 380 & 2 & & & & & \\
\hline 381 & 1 & & & & & \\
\hline 382 & $\overline{1}$ & & & & & \\
\hline 383 & $\overline{1}$ & & & & & \\
\hline 384 & 1 & & & & & \\
\hline 385 & $\overline{1}$ & & & & & \\
\hline 386 & $\overline{1}$ & & & & & \\
\hline 387 & 1 & & & & & \\
\hline 388 & 1 & & & & & \\
\hline 389 & $\overline{1}$ & & & & & \\
\hline 390 & 1 & & & & & \\
\hline 391 & 1 & & & & & \\
\hline 392 & 1 & & & & & \\
\hline 393 & 1 & & & & & \\
\hline 394 & 1 & & & & & \\
\hline 395 & 1 & & & & & \\
\hline
\end{tabular}

\begin{tabular}{|c|c|c|c|c|c|c|}
\hline $\mathbf{0}$ & 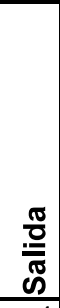 & 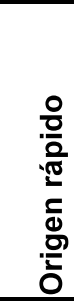 & 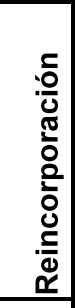 & 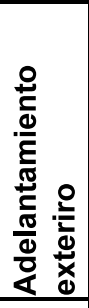 & 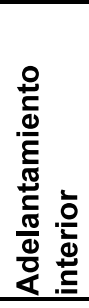 & 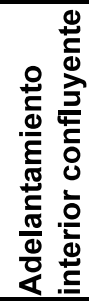 \\
\hline 396 & 1 & & & & & \\
\hline 397 & 1 & & & & & \\
\hline 398 & 2 & & & & & \\
\hline 399 & 1 & & & & & \\
\hline 400 & 1 & & & & & \\
\hline 401 & 1 & & & & & \\
\hline 402 & 1 & & & & & \\
\hline 403 & 1 & & & & & \\
\hline 404 & 1 & & & & & \\
\hline 405 & 1 & & & & & \\
\hline 406 & 1 & & & & & \\
\hline 407 & 1 & & & & & \\
\hline 408 & 1 & & & & & \\
\hline 409 & 1 & & & & & \\
\hline 410 & 1 & & & & & \\
\hline 411 & 1 & & & & & \\
\hline 412 & 1 & & & & & \\
\hline 413 & 1 & & & & & \\
\hline 414 & 1 & & & & & \\
\hline 415 & 1 & & & & & \\
\hline 416 & 1 & & & & & \\
\hline 417 & 1 & & & & & \\
\hline 418 & 1 & & & & & \\
\hline 419 & 1 & & & & & \\
\hline 420 & 1 & & & & & \\
\hline 421 & 1 & & & & & \\
\hline 422 & 1 & & & & & \\
\hline 423 & 2 & & & & & \\
\hline 424 & 1 & & & & & \\
\hline 425 & 1 & & & & & \\
\hline 426 & 2 & & & & & \\
\hline 427 & 1 & & & & & \\
\hline 428 & 1 & & & & & \\
\hline 429 & 1 & & & & & \\
\hline 430 & 1 & & & & & \\
\hline 431 & 1 & & & & & \\
\hline 432 & 1 & & & & & \\
\hline 433 & 1 & & & & & \\
\hline 434 & 1 & & & & & \\
\hline 435 & 2 & & & & & \\
\hline 436 & 1 & & & & & \\
\hline 437 & 1 & 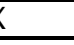 & & & & \\
\hline 438 & 1 & & & & & \\
\hline 439 & 1 & & & & & \\
\hline 440 & 1 & & & & & \\
\hline 441 & 1 & & & & & \\
\hline 442 & 1 & & & & & \\
\hline
\end{tabular}




\begin{tabular}{|c|c|c|c|c|c|c|}
\hline i & 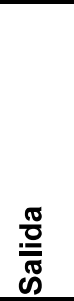 & 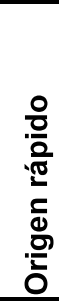 & 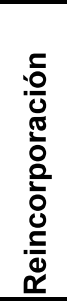 & 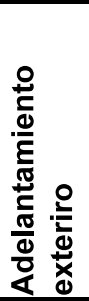 & 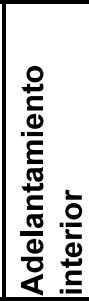 & 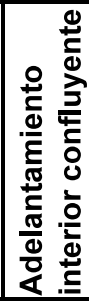 \\
\hline 443 & 2 & & & & & \\
\hline 444 & 1 & & & & & \\
\hline 445 & 1 & & & & & \\
\hline 446 & 1 & & & & & \\
\hline 447 & 1 & & & & & \\
\hline 448 & 1 & & & & & \\
\hline 449 & 1 & & & & & \\
\hline 450 & 1 & & & & & \\
\hline 451 & 1 & & & & & \\
\hline 452 & 1 & & & & & \\
\hline 453 & 2 & & & & & \\
\hline 454 & 1 & & & & & \\
\hline 455 & 1 & & & & & \\
\hline 456 & 1 & & & & & \\
\hline 457 & 1 & & & & & \\
\hline 458 & 1 & & & & & \\
\hline 459 & 1 & & & & & \\
\hline 460 & 1 & & & & & \\
\hline 461 & 1 & & & & & \\
\hline 462 & $\overline{1}$ & & & & & \\
\hline 463 & 7 & & & & & \\
\hline 464 & 1 & & & & & \\
\hline 465 & 1 & & & & & \\
\hline 466 & 1 & & & & & \\
\hline 467 & 1 & & & & & \\
\hline 468 & 1 & & & & & \\
\hline 469 & 1 & & & & & \\
\hline 470 & 1 & & & & & \\
\hline 471 & 1 & & & & & \\
\hline 472 & $\overline{1}$ & & & & & \\
\hline 473 & 1 & & & & & \\
\hline 474 & 2 & & & & & \\
\hline 475 & 2 & & & & & \\
\hline 476 & 1 & & & & & \\
\hline 477 & $\overline{2}$ & & & & & \\
\hline 478 & 1 & & & & & \\
\hline 479 & $\overline{1}$ & & & & & \\
\hline 480 & $\overline{1}$ & & & & & \\
\hline 481 & 1 & & & & & \\
\hline 482 & 1 & & & & & \\
\hline 483 & $\overline{1}$ & & & & & \\
\hline 484 & 1 & & & & & \\
\hline 485 & 1 & & & & & \\
\hline 486 & $\overline{1}$ & & & & & \\
\hline 487 & 3 & & & & & \\
\hline 488 & 1 & & & & & \\
\hline 489 & $\overline{1}$ & & & & & \\
\hline
\end{tabular}

\begin{tabular}{|c|c|c|c|c|c|c|}
\hline zo & 吾 & 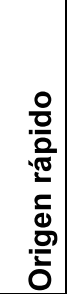 & 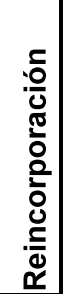 & 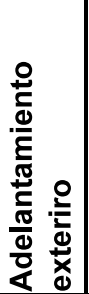 & 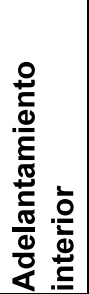 & 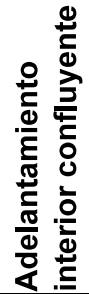 \\
\hline $4 \overline{90}$ & 1 & & & & & \\
\hline 491 & 2 & & & & & \\
\hline 492 & 1 & & & & & \\
\hline 493 & 1 & & & & & \\
\hline 494 & 1 & & & & & \\
\hline 495 & 1 & & & & & \\
\hline 496 & 1 & & & & & \\
\hline 497 & 1 & & & & & \\
\hline 498 & 1 & & & & & \\
\hline 499 & 2 & & & & & \\
\hline 500 & 1 & & & & & \\
\hline 501 & 1 & & & & & \\
\hline 502 & 2 & & & & & \\
\hline 503 & 2 & & & & & \\
\hline 504 & 1 & & & & & \\
\hline 505 & 1 & & & & & \\
\hline 506 & 1 & & & & & \\
\hline 507 & 1 & & & & & \\
\hline 508 & 1 & & & & & \\
\hline 509 & 1 & & & & & \\
\hline 510 & 1 & & & & & \\
\hline 511 & 1 & & & & & \\
\hline 512 & 1 & & & & & \\
\hline 513 & 1 & & & & & \\
\hline 514 & 1 & & & & & \\
\hline 515 & 1 & & & & & \\
\hline 516 & 1 & & & & & \\
\hline 517 & 1 & & & & & \\
\hline 518 & 1 & & & & & \\
\hline 519 & 2 & & & & & \\
\hline 520 & 2 & & & & & \\
\hline 521 & 1 & & & & & \\
\hline 522 & 1 & & & & & \\
\hline 523 & 1 & & & & & \\
\hline
\end{tabular}


ANEXO No 2. CARACTERISTICAS DE LOS CARRILES DE DECELERACIÓN 


\begin{tabular}{|l|c|}
\hline Carril & Conf 1 \\
\hline Longitud & 385 \\
\hline Salen & 8,2 \\
\hline Carriles VP & 3 \\
\hline P Pesados & 12 \\
\hline
\end{tabular}

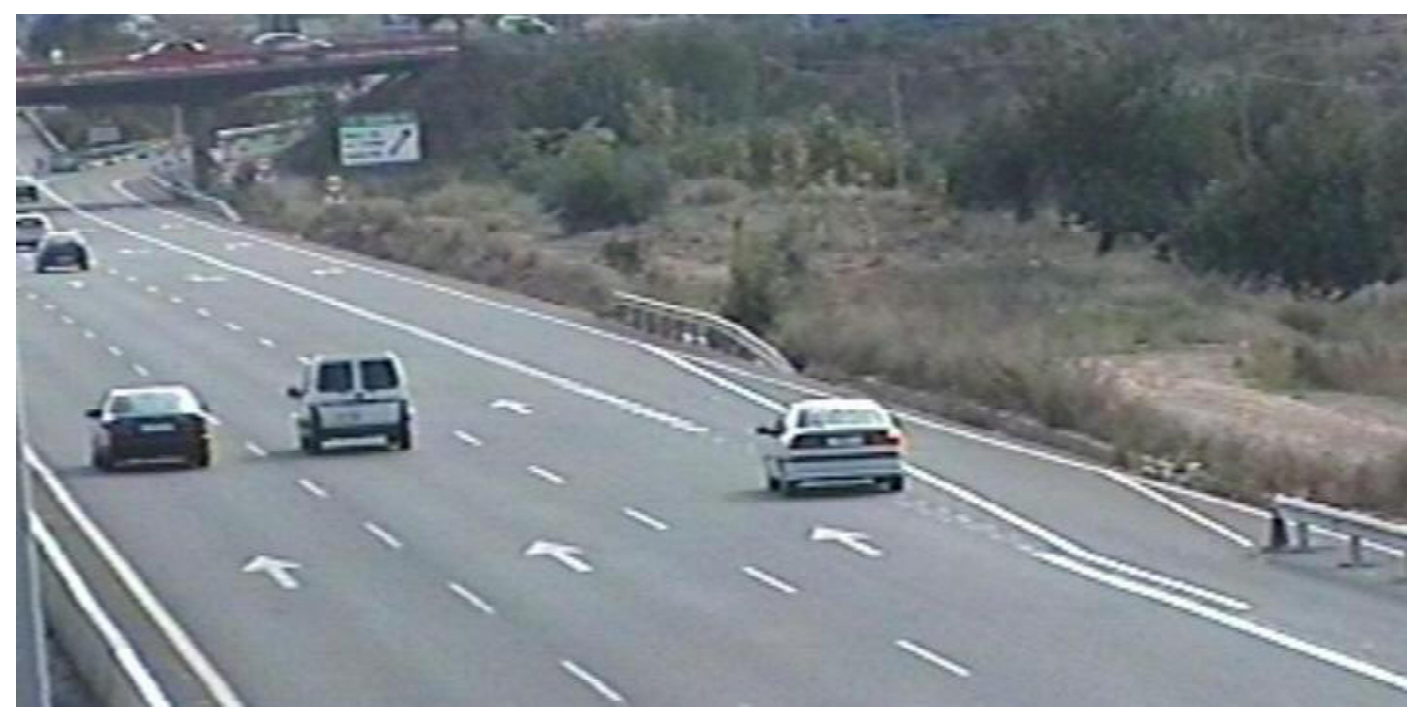




\begin{tabular}{|l|c|}
\hline Carril & Conf 2 \\
\hline Longitud & 285 \\
\hline Salen & 8,3 \\
\hline Carriles VP & 3 \\
\hline P Pesados & 12 \\
\hline
\end{tabular}

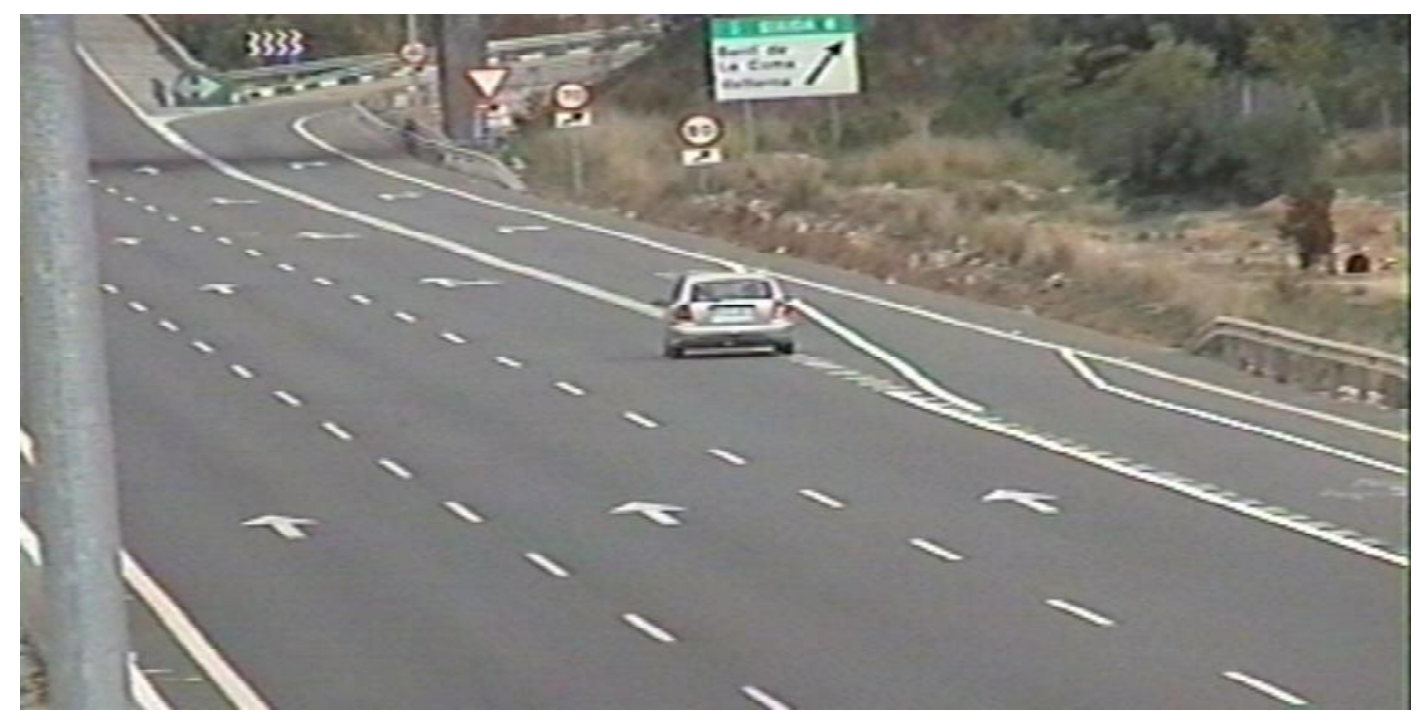




\begin{tabular}{|l|c|}
\hline Carril & Conf 3 \\
\hline Longitud & 187 \\
\hline Salen & 8,2 \\
\hline Carriles VP & 3 \\
\hline P Pesados & 12 \\
\hline
\end{tabular}

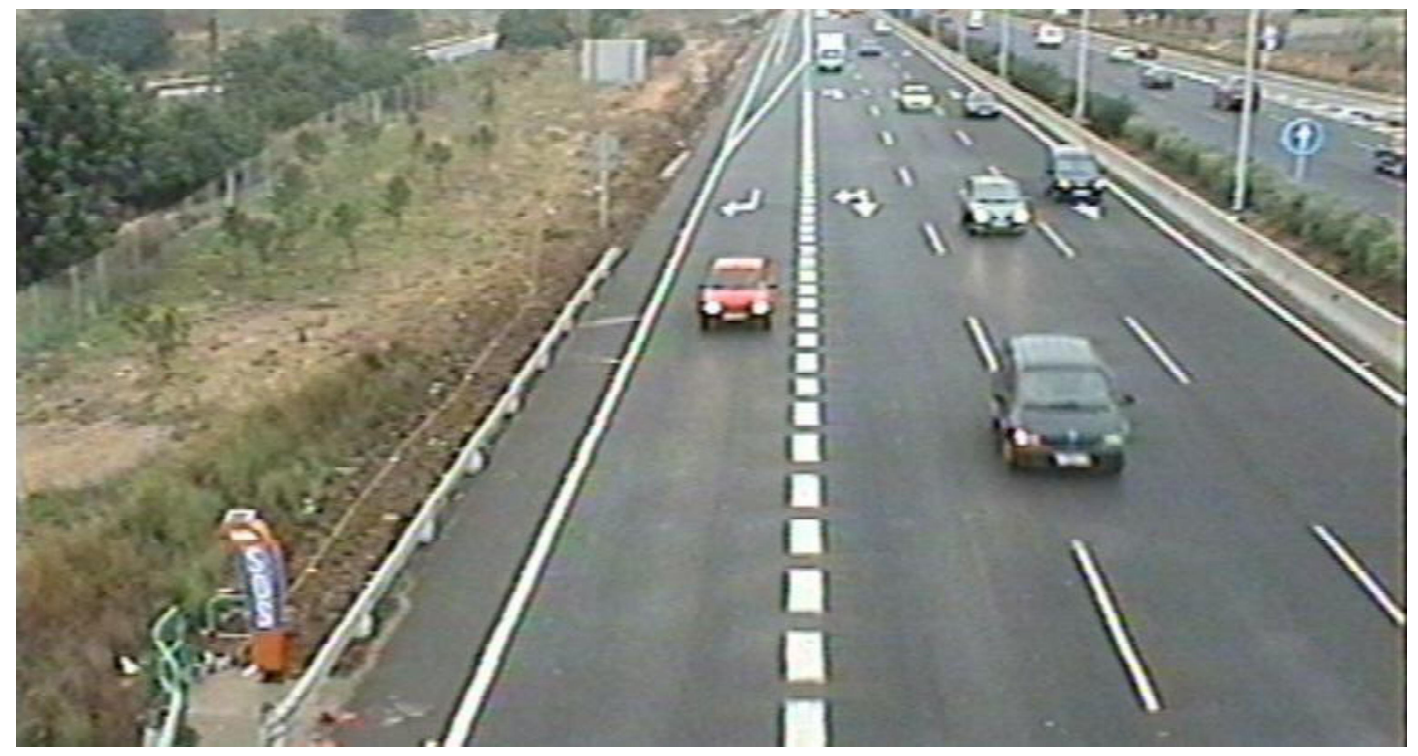




\begin{tabular}{|l|c|}
\hline Carril & Conf 4 \\
\hline Longitud & 107 \\
\hline Salen & 8,0 \\
\hline Carriles VP & 3 \\
\hline P Pesados & 12 \\
\hline
\end{tabular}

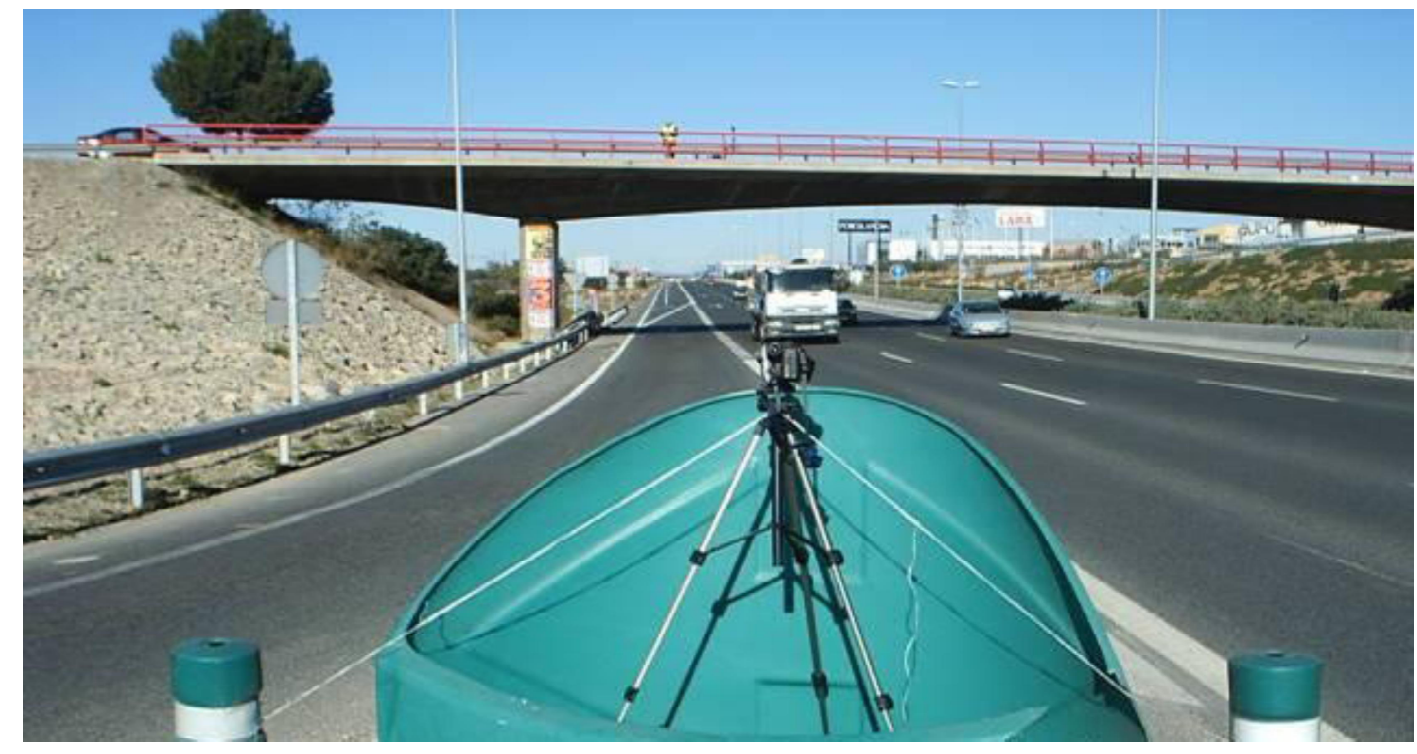




\begin{tabular}{|l|c|}
\hline Carril & A3-351 \\
\hline Longitud & 80 \\
\hline Salen & 34,5 \\
\hline Carriles VP & 3 \\
\hline P Pesados & 11 \\
\hline
\end{tabular}
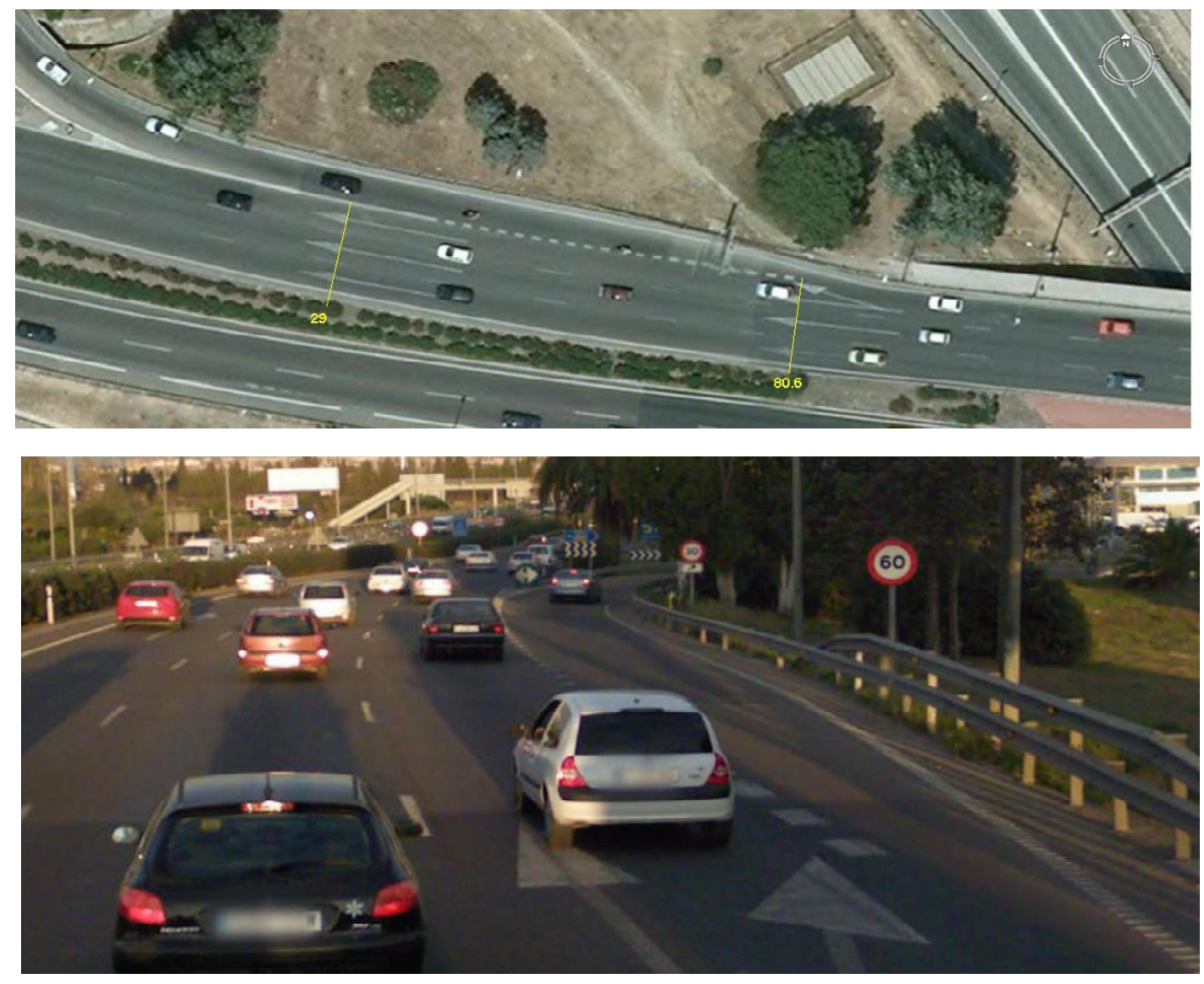


\begin{tabular}{|l|c|}
\hline Carril & A7-484 \\
\hline Longitud & 217 \\
\hline Salen & 18,6 \\
\hline Carriles VP & 3 \\
\hline P Pesados & 37 \\
\hline
\end{tabular}
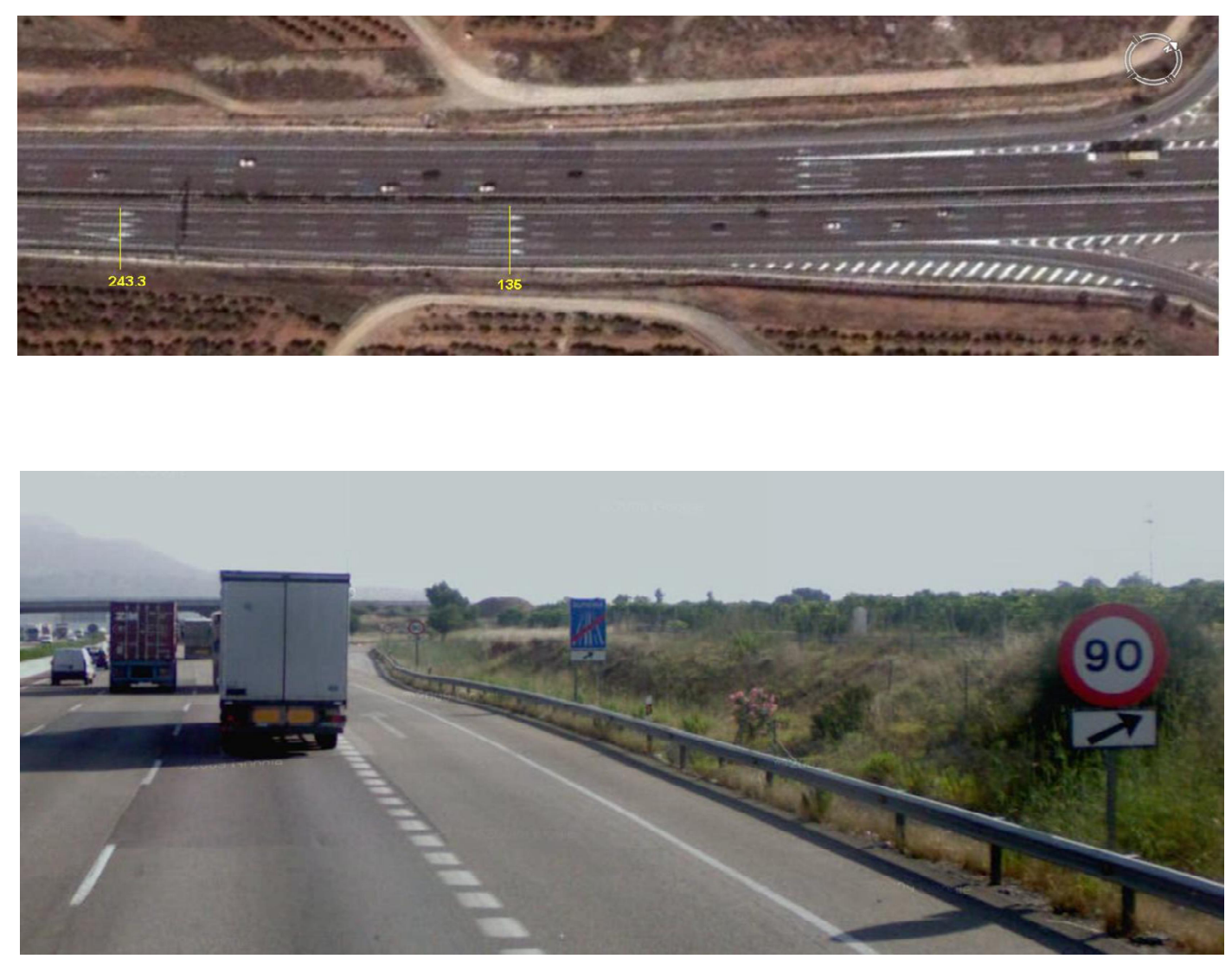


\begin{tabular}{|l|c|}
\hline Carril & V21-51 \\
\hline Longitud & 187 \\
\hline Salen & 16,0 \\
\hline Carriles VP & 2 \\
\hline P Pesados & 11 \\
\hline
\end{tabular}
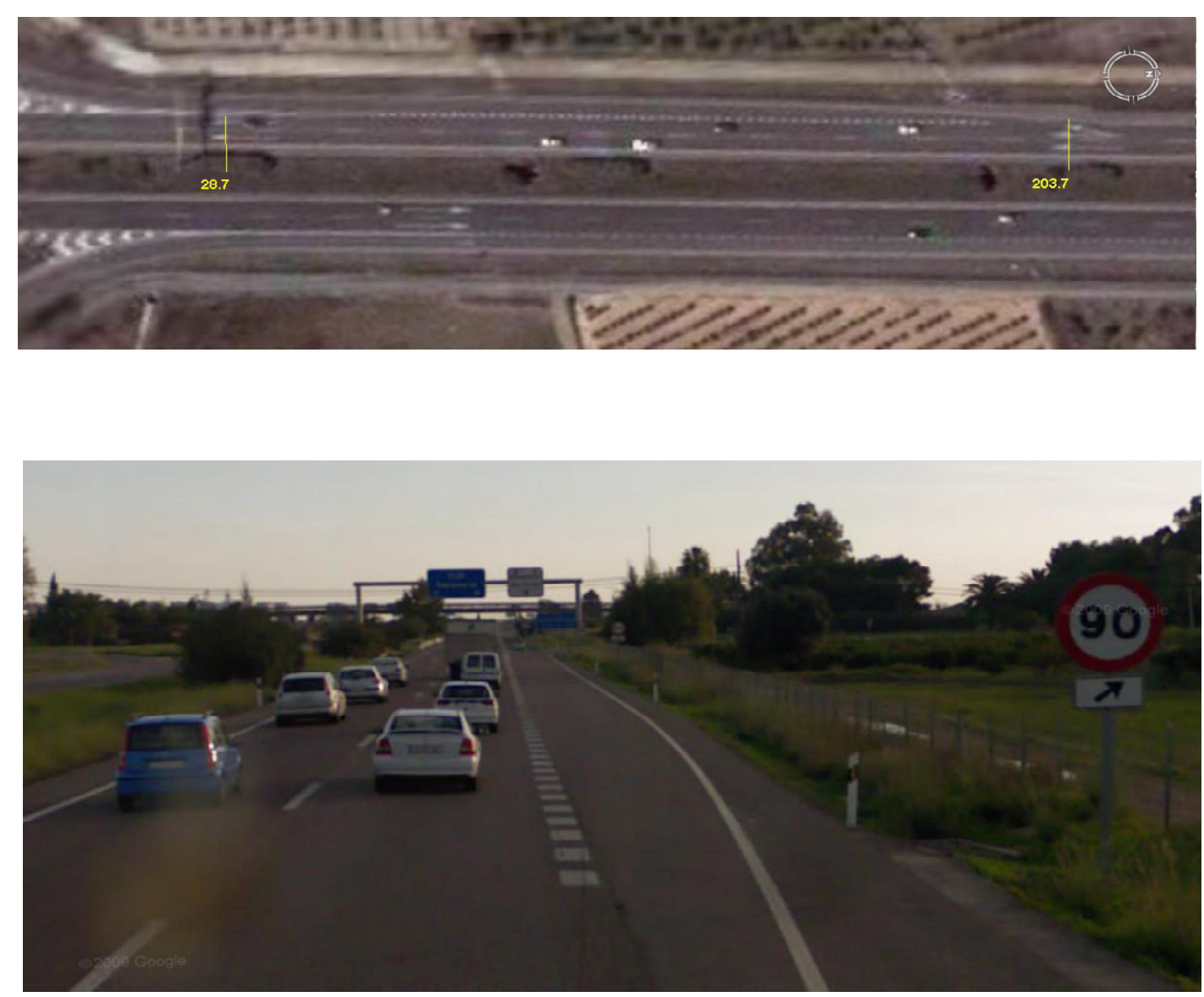


\begin{tabular}{|l|c|}
\hline Carril & V21-985 \\
\hline Longitud & 209 \\
\hline Salen & 15,3 \\
\hline Carriles VP & 2 \\
\hline P Pesados & 7 \\
\hline
\end{tabular}
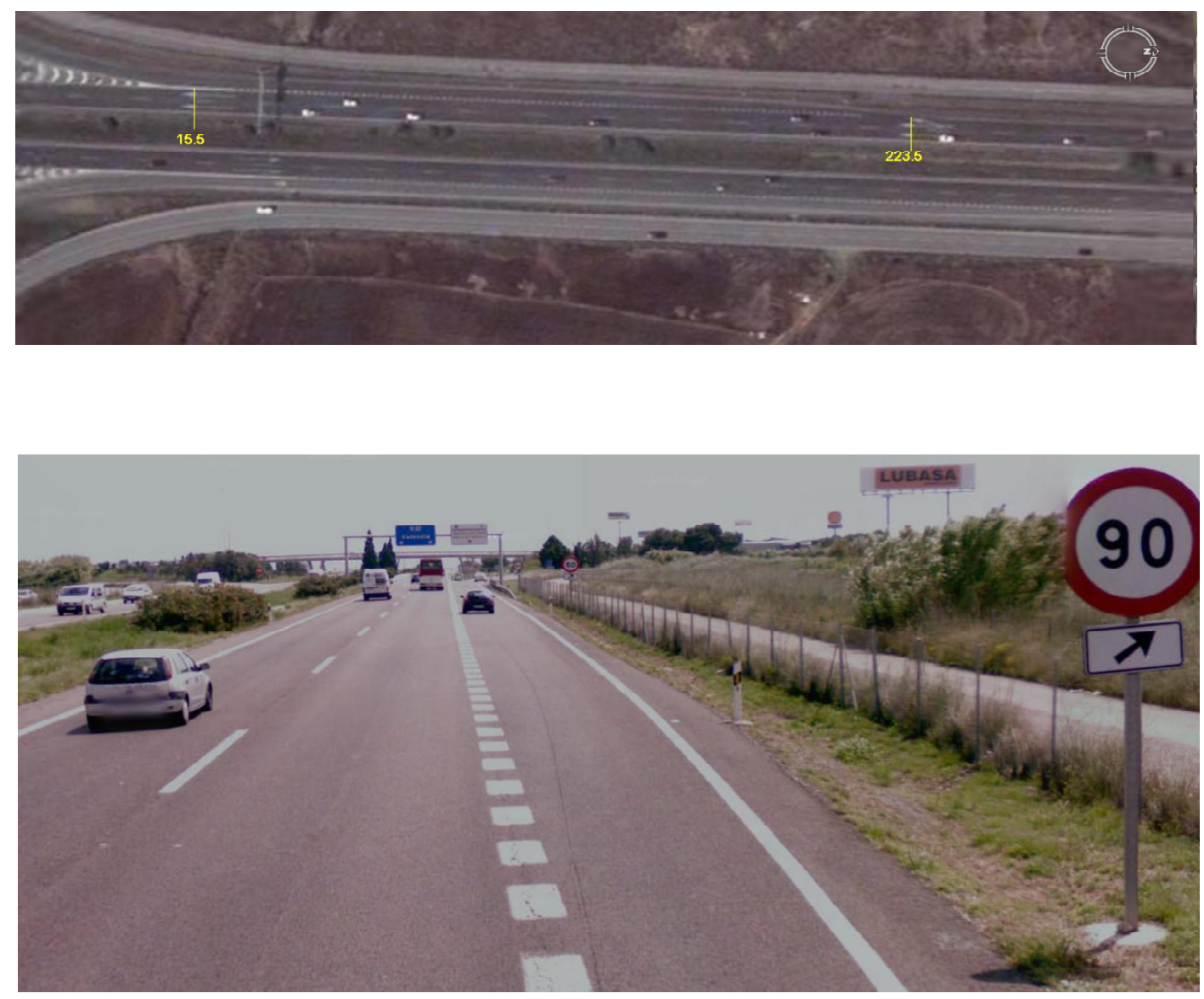


\begin{tabular}{|l|c|}
\hline Carril & V21-143-d \\
\hline Longitud & 184 \\
\hline Salen & 25,4 \\
\hline Carriles VP & 2 \\
\hline P Pesados & 4 \\
\hline
\end{tabular}
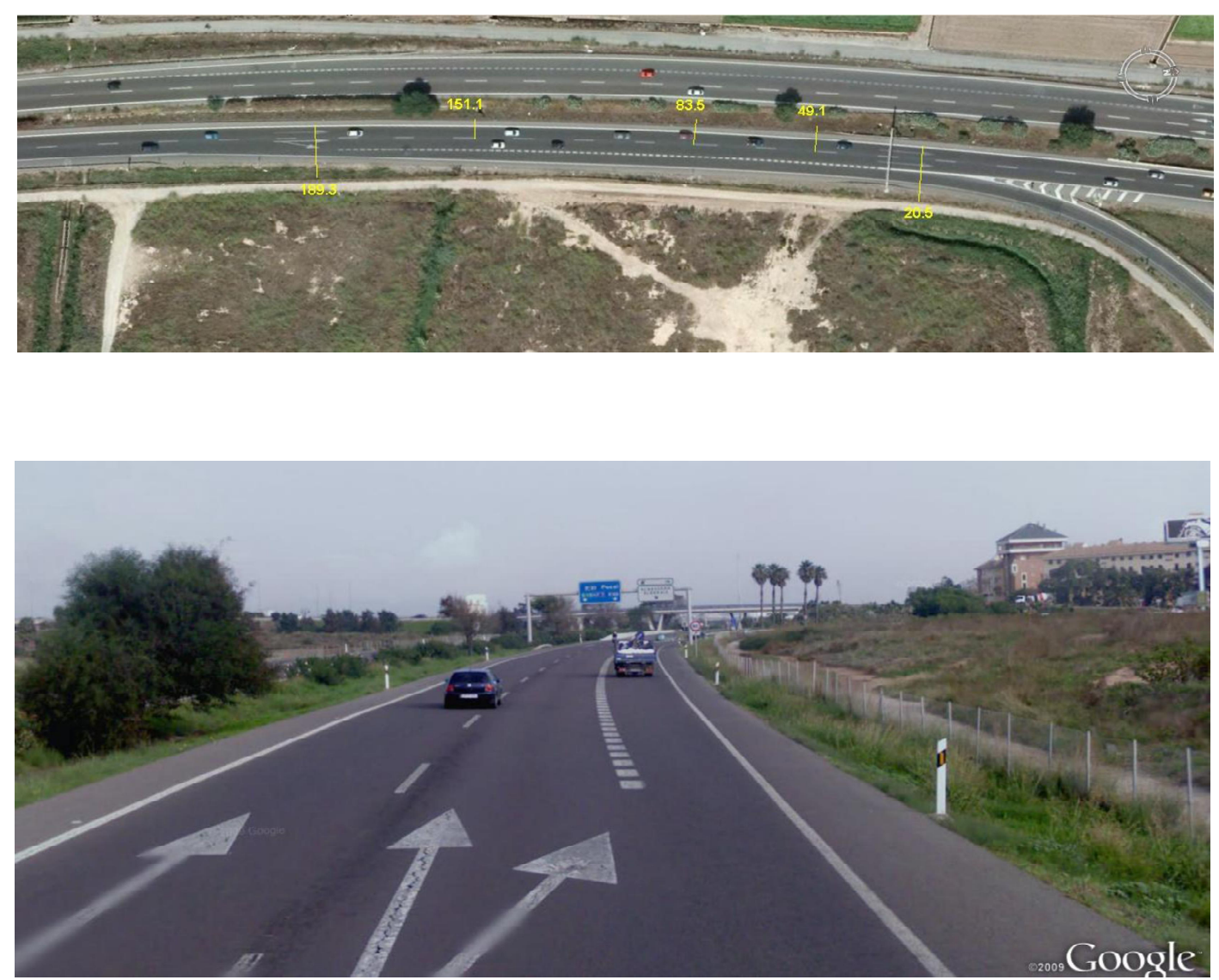


\begin{tabular}{|l|c|}
\hline Carril & V21-143-C \\
\hline Longitud & 215 \\
\hline Salen & 16,2 \\
\hline Carriles VP & 2 \\
\hline P Pesados & 5 \\
\hline
\end{tabular}
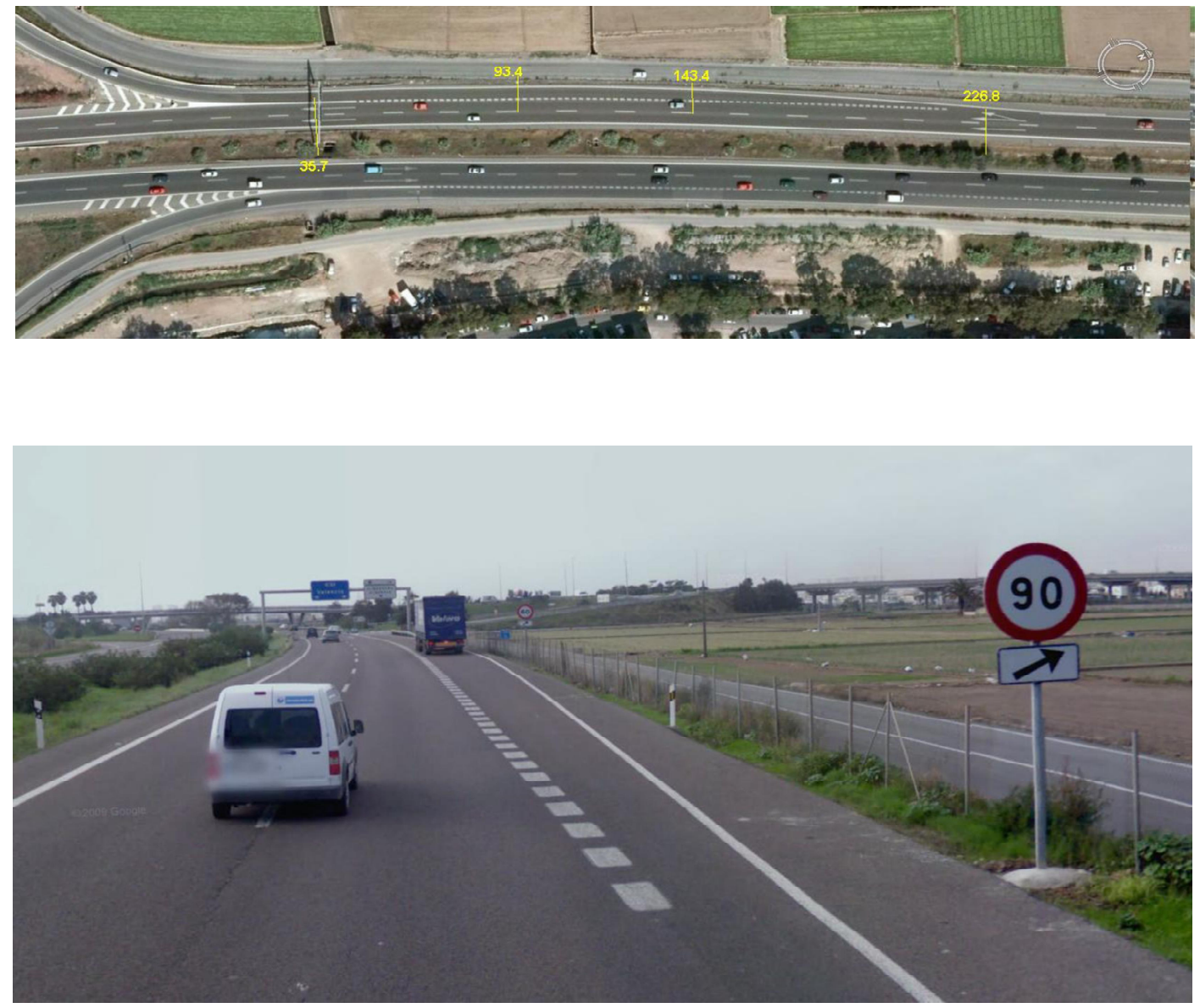


\begin{tabular}{|l|c|}
\hline Carril & V30-49 \\
\hline Longitud & 88 \\
\hline Salen & 16,0 \\
\hline Carriles VP & 2 \\
\hline P Pesados & 17 \\
\hline
\end{tabular}
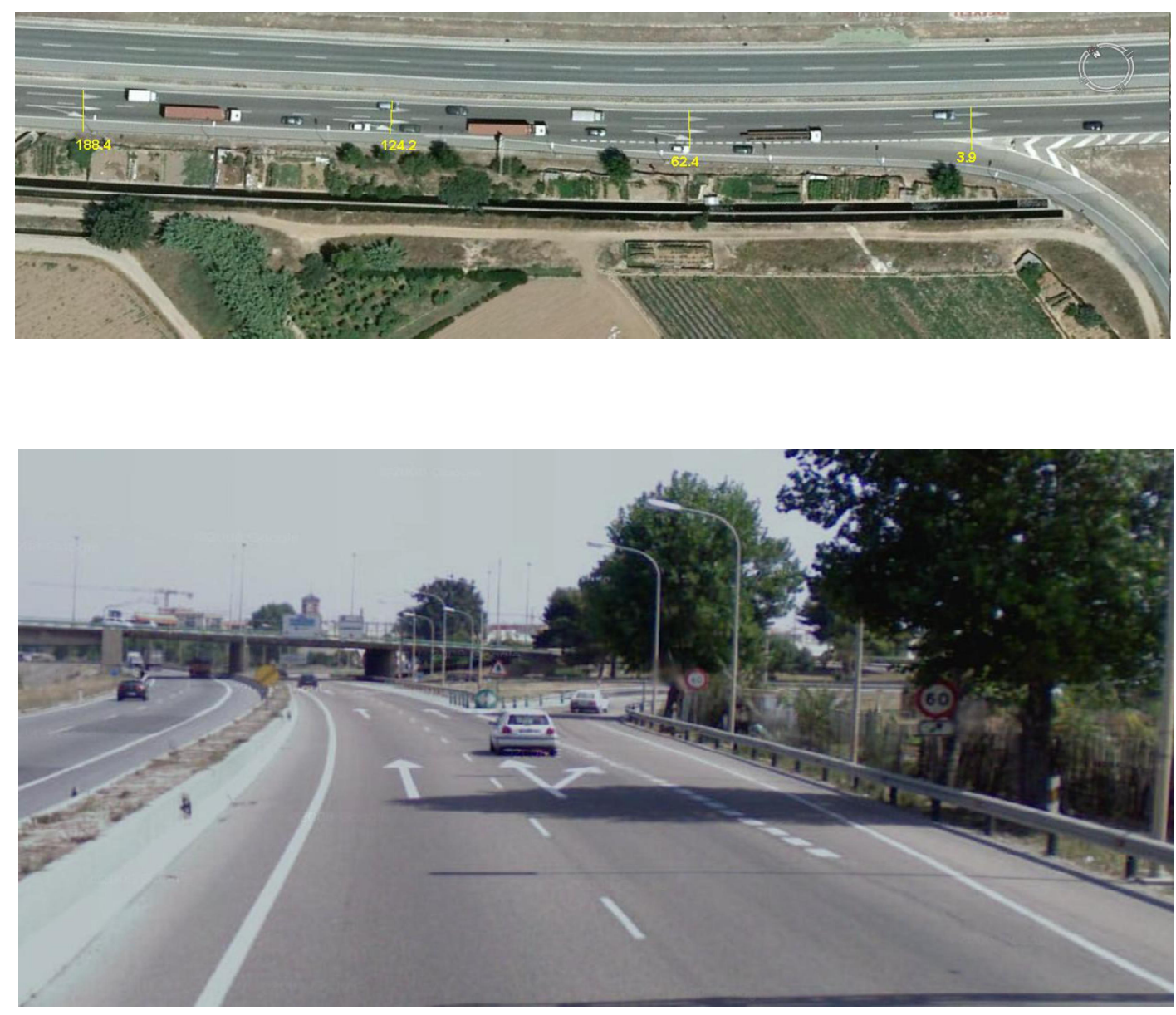


\begin{tabular}{|l|c|}
\hline Carril & V31-68 \\
\hline Longitud & 137 \\
\hline Salen & 13,1 \\
\hline Carriles VP & 3 \\
\hline P Pesados & 13 \\
\hline
\end{tabular}
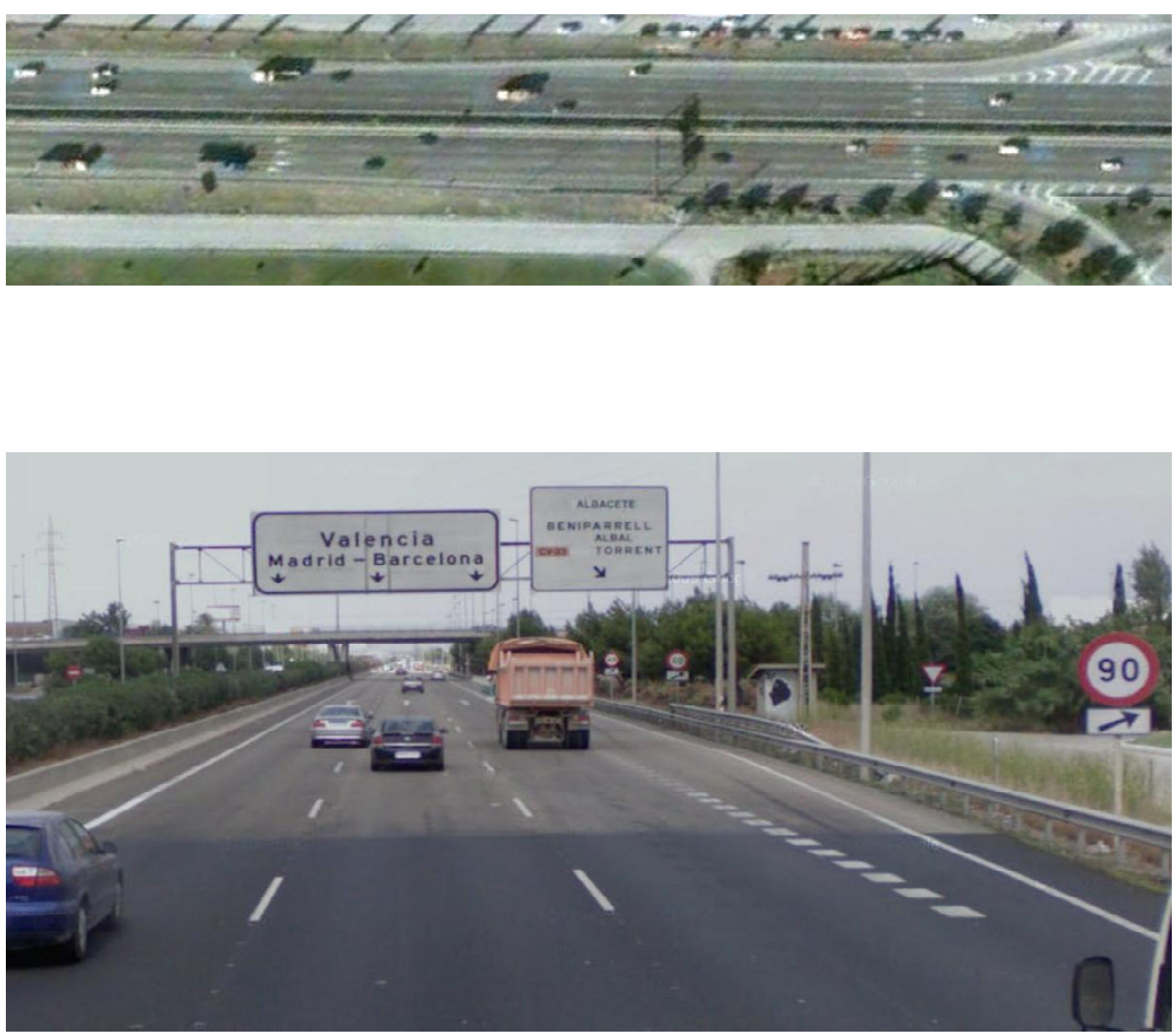


\begin{tabular}{|l|c|}
\hline Carril & V31-85 \\
\hline Longitud & 100 \\
\hline Salen & 7,1 \\
\hline Carriles VP & 3 \\
\hline P Pesados & 17 \\
\hline
\end{tabular}
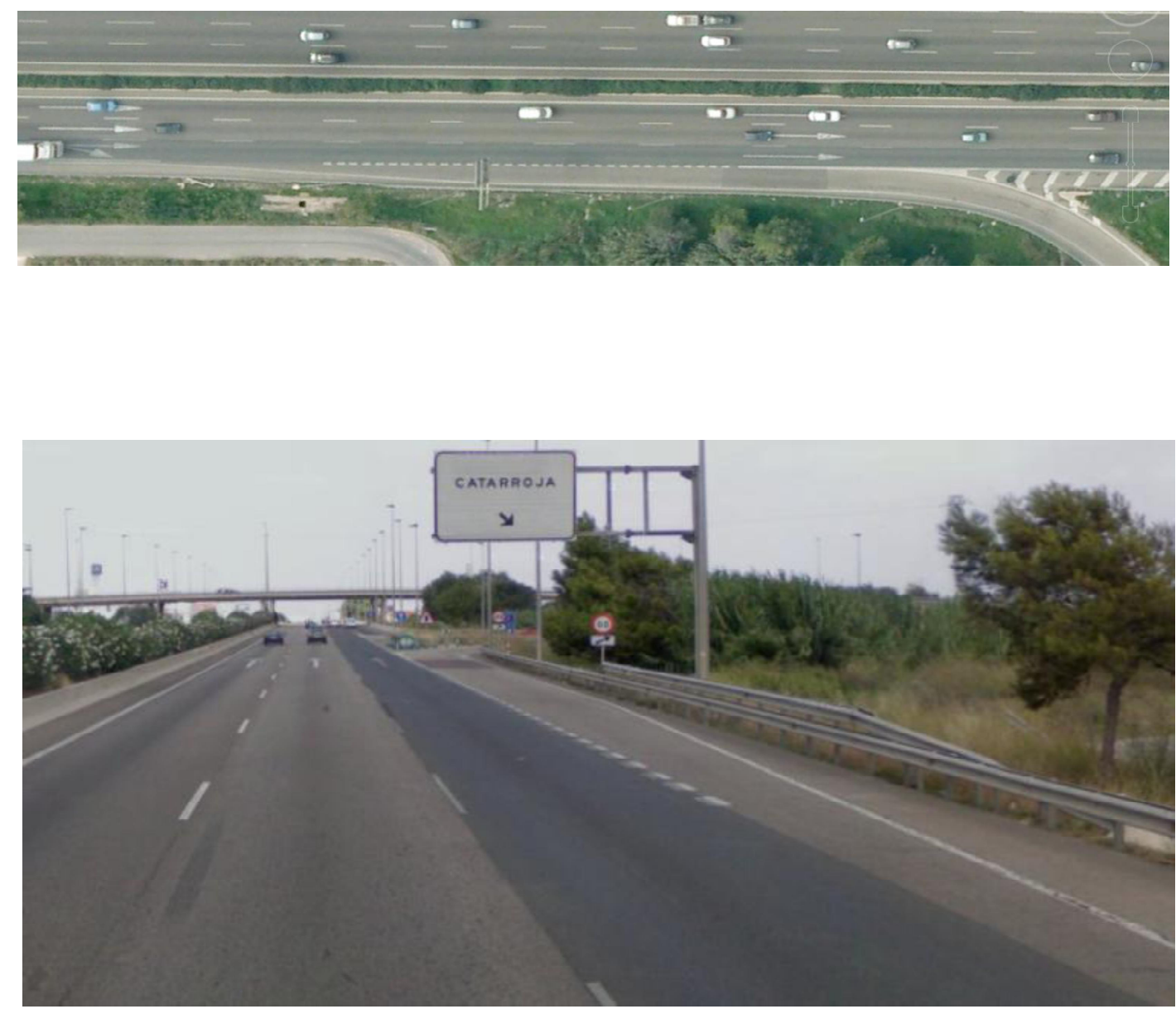


\begin{tabular}{|l|c|}
\hline Carril & V31-98 \\
\hline Longitud & 229 \\
\hline Salen & 12,7 \\
\hline Carriles VP & 3 \\
\hline P Pesados & 18 \\
\hline
\end{tabular}
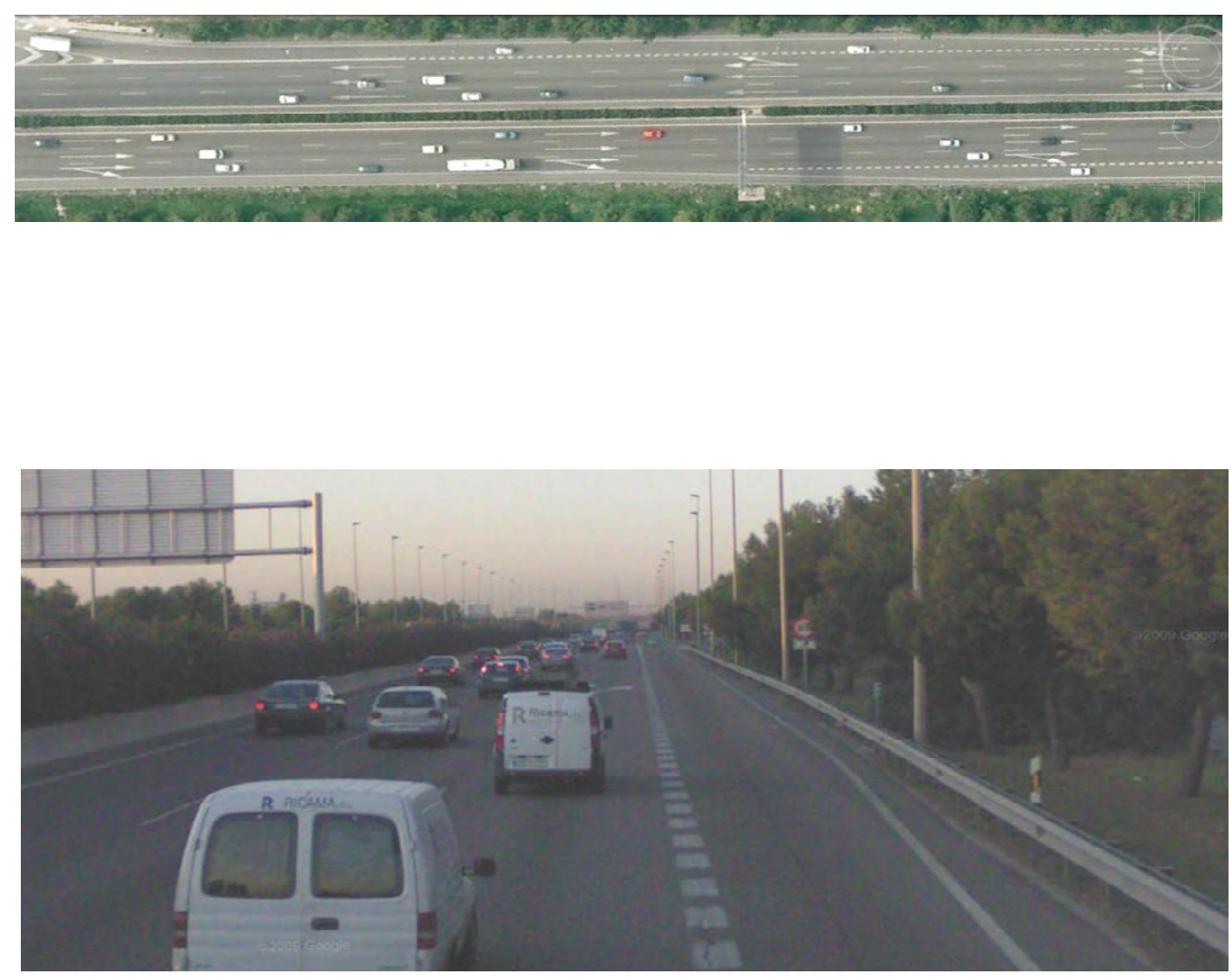

ANEXO No. 3. CODIGO FUENTE DE LA APLICACIÓN DESARROLLADOA 


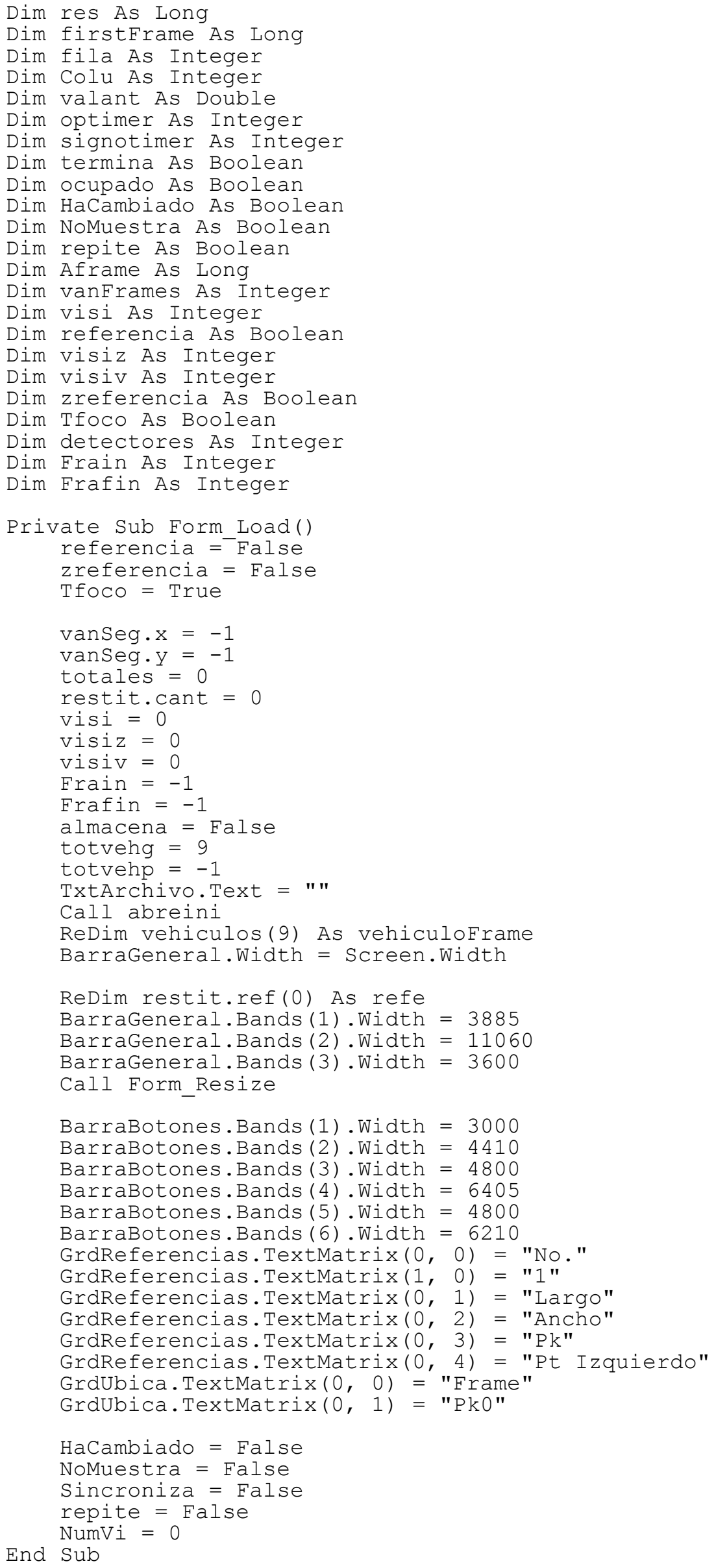

End Sub 
Private Sub Form Resize ()

BarraBotones.-Bands (1). Width $=3000$

BarraBotones.Bands (2). Width $=4410$

BarraBotones.Bands ( 3$)$. Width $=4800$

BarraBotones.Bands (4). Width $=6405$

BarraBotones.Bands (5). Width $=4800$

BarraBotones.Bands (6). Width $=6210$

For $i=1$ To 6

Next i

BarraBotones.Bands (i). MinHeight $=390$

End Sub

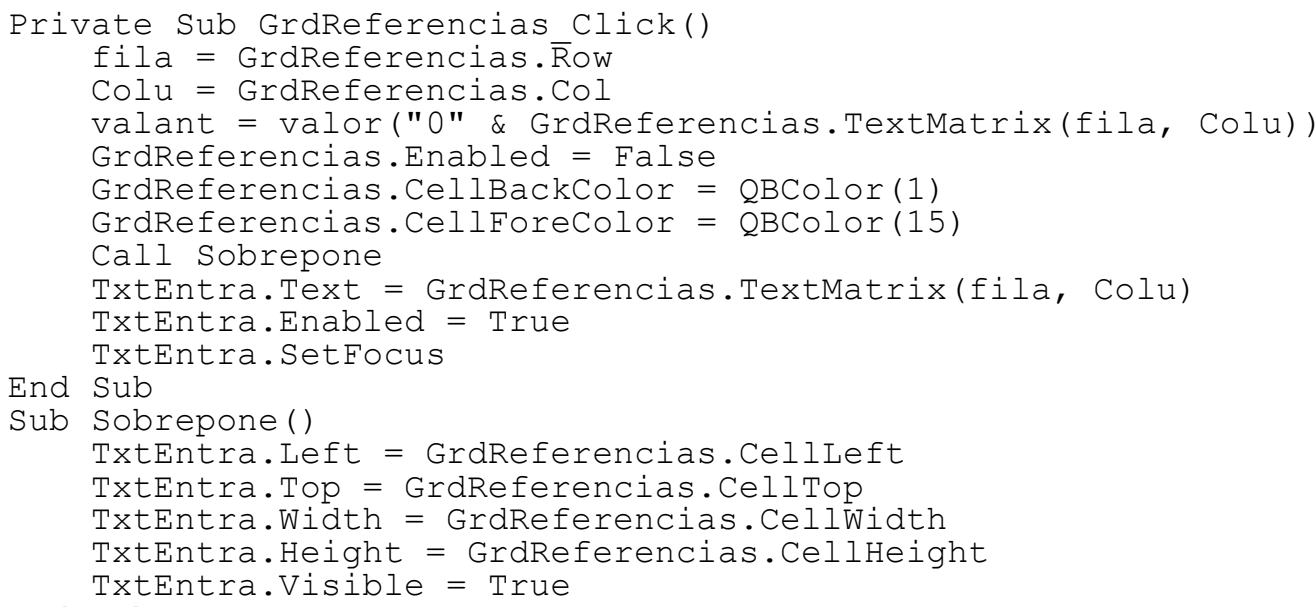

Case 8 'Seguir 


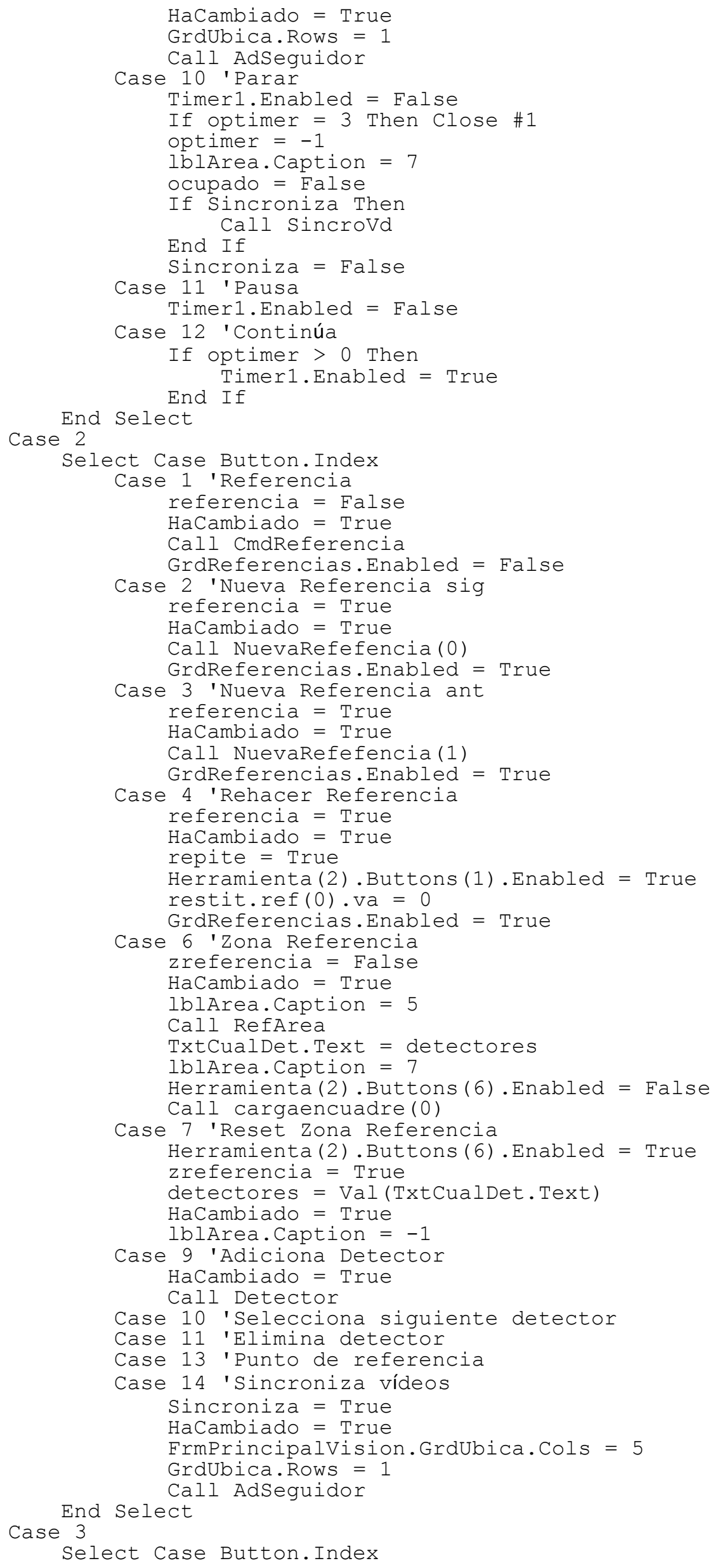


$\operatorname{Chr} \$(9)$

Case 1 'Copia el contenido al clipboard

Clipboard.Clear

$\mathrm{msg}=" n$

For $i=1$ To GrdUbica.Rows - 1

For $j=0$ To GrdUbica.Cols - 1

$\mathrm{msg}=\mathrm{msg} \& \operatorname{GrdUbica}$. TextMatrix $(i, j) \&$

$\operatorname{Chr} \$(9)$

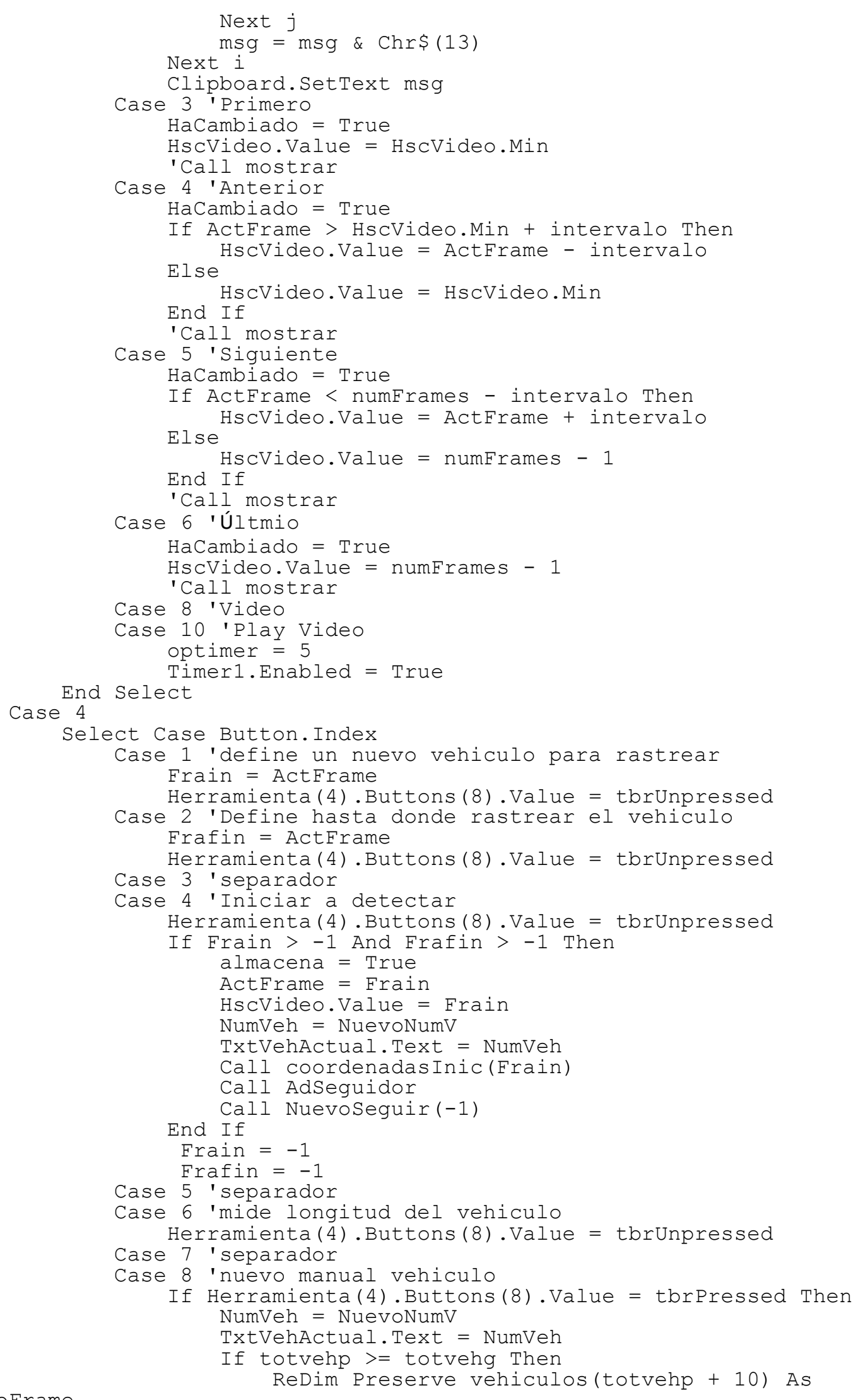

vehiculoFrame 


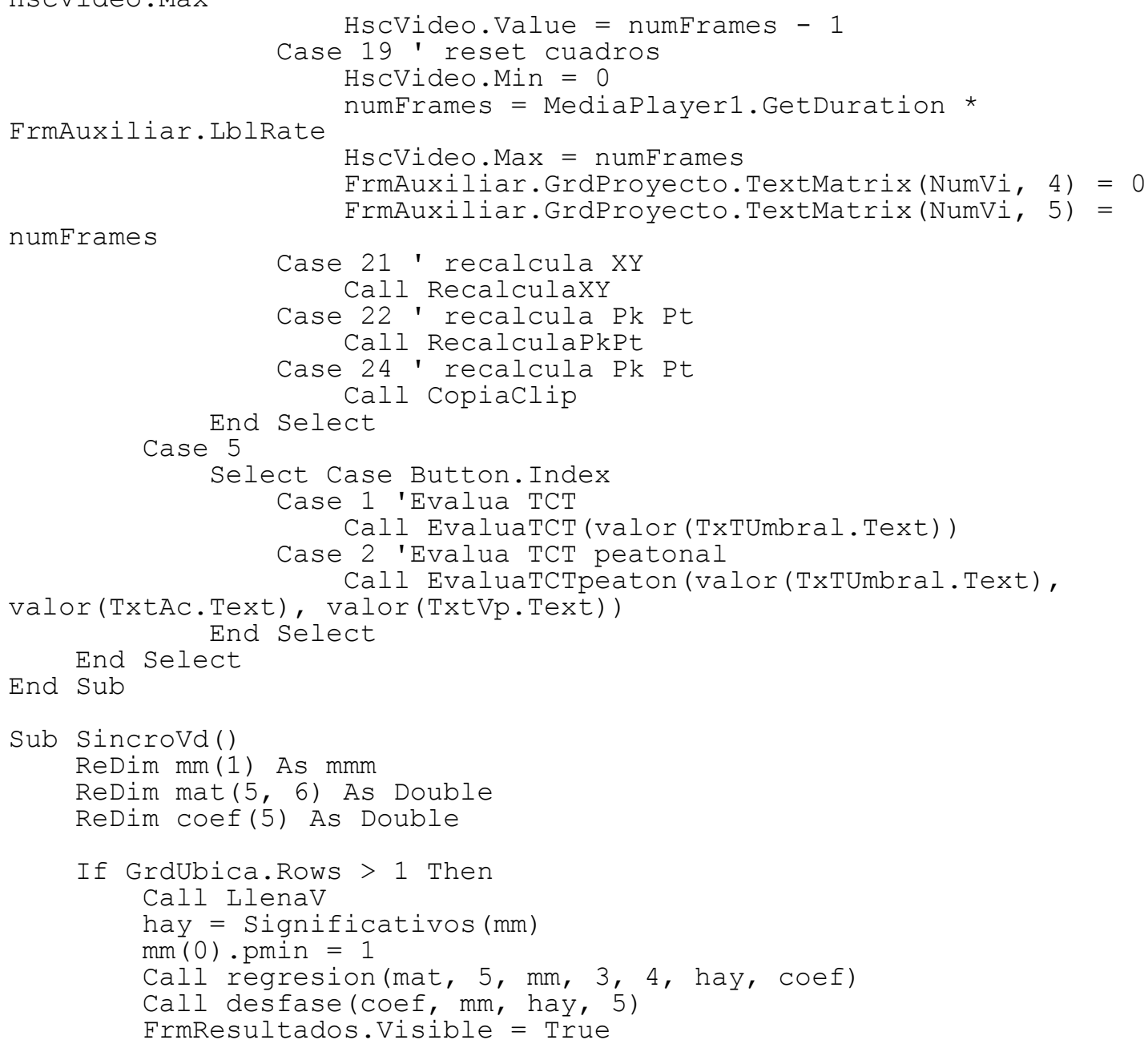




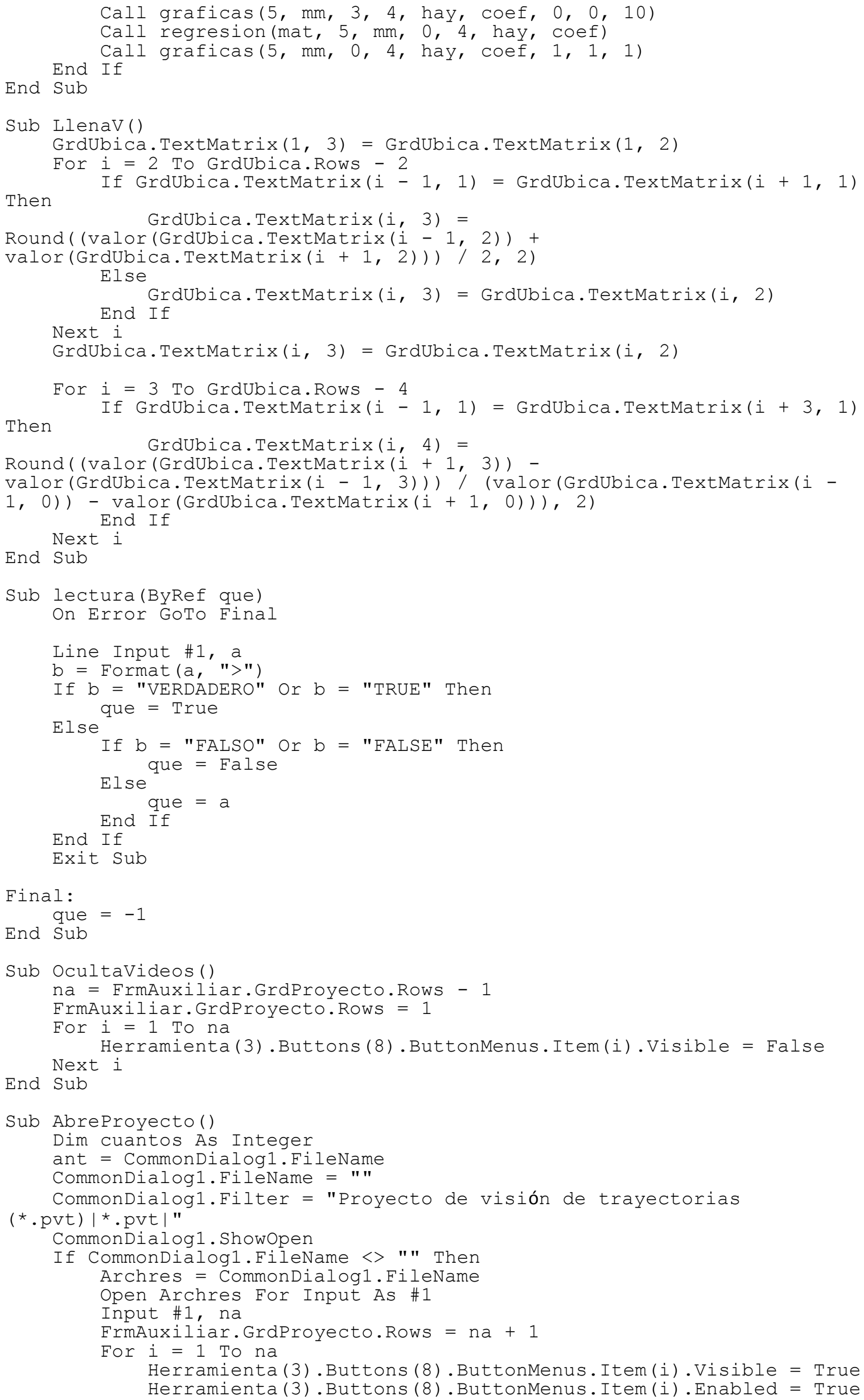




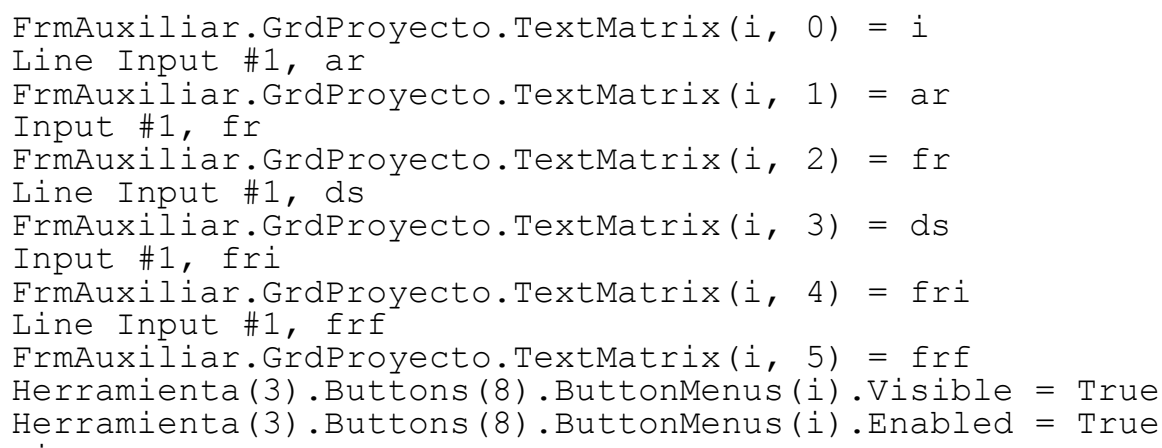

End Sub

Sub abrevid (archavi)

Archres = Left\$(archavi, Len(archavi) - 3) \& "rvt"

archa $=$ Left\$ (Archres, Len (Archres) - 4)

FrmPrincipalVision.Caption = "Restitución de maniobras : " \& Archres Call Abrir (1, archavi)

On Error GoTO 10

restit.ref $(0) \cdot \operatorname{lr}(0) \cdot \mathrm{p} \cdot \mathrm{x}=100$

restit.ref $(0) \cdot \operatorname{lr}(0) \cdot \mathrm{p} \cdot \mathrm{y}=200$

restit.ref $(0) \cdot \operatorname{lr}(0) \cdot q \cdot x=110$

restit.ref $(0) \cdot \operatorname{lr}(0) \cdot q \cdot y=100$

restit.ref (0). $\operatorname{lr}(1) \cdot \mathrm{p} \cdot \mathrm{x}=190$

restit.ref $(0) \cdot \operatorname{lr}(1) \cdot \mathrm{p} \cdot \mathrm{y}=200$

restit.ref(0). $\operatorname{lr}(1) \cdot q \cdot x=200$

restit.ref(0). $\operatorname{lr}(1) \cdot \mathrm{q} \cdot \mathrm{y}=100$

restit.ref $(0) \cdot \operatorname{lr}(2) \cdot \mathrm{p} \cdot \mathrm{x}=90$

restit.ref $(0) \cdot \operatorname{lr}(2) \cdot \mathrm{p} \cdot \mathrm{y}=109$

restit.ref $(0) \cdot \operatorname{lr}(2) \cdot q \cdot x=210$

restit.ref (0). $\operatorname{lr}(2) \cdot q \cdot y=110$

restit.ref $(0) \cdot \operatorname{lr}(3) \cdot p \cdot x=90$

restit.ref $(0) \cdot \operatorname{lr}(3) \cdot \mathrm{p} \cdot \mathrm{y}=190$

restit.ref(0). $\operatorname{lr}(3) \cdot \mathrm{q} \cdot \mathrm{x}=210$

restit.ref(0). Ir (3) $\cdot q \cdot y=191$

Call CmdReferencia

detecto $(0) \cdot \operatorname{area}(0) \cdot x=100$

detecto $(0) \cdot \operatorname{area}(0) \cdot y=200$

detecto $(0) \cdot \operatorname{area}(1) \cdot x=100$

detecto $(0) \cdot \operatorname{area}(1) \cdot y=100$

detecto $(0) \cdot \operatorname{area}(2) \cdot x=200$

detecto $(0) \cdot \operatorname{area}(2) \cdot y=200$

detecto(0).area(3).x $=200$

detecto $(0) \cdot \operatorname{area}(3) \cdot y=100$

detecto $(0) \cdot \operatorname{area}(4) \cdot x=150$ 


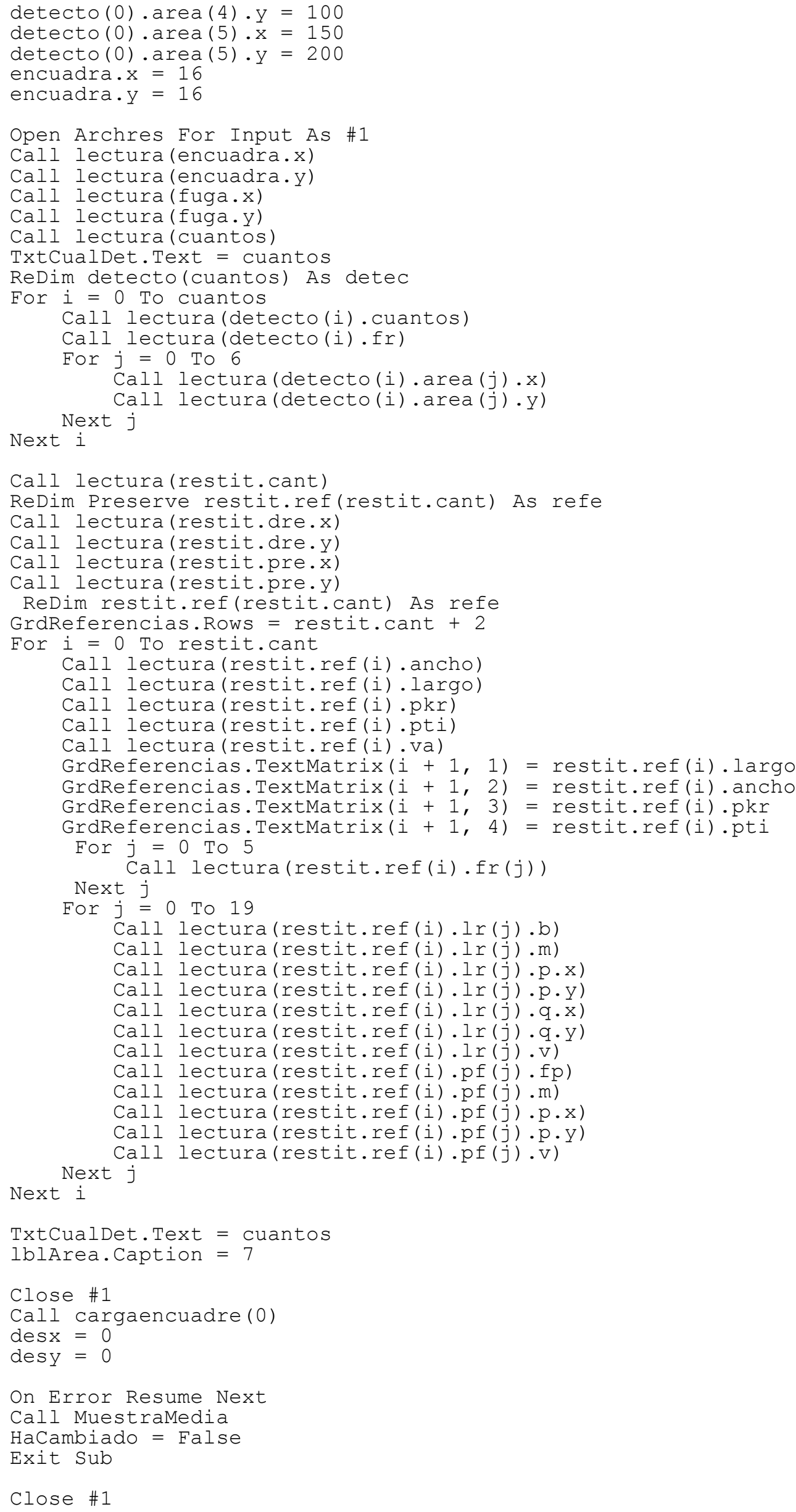

Close \#1 
lblArea.Caption $=" 0 "$

End Sub

Sub GuardaProyecto()

ant $=$ CommonDialog1.FileName

If HaCambiado Then Call GuardaVid

CommonDialog1.FileName = " "

CommonDialog1. Filter = "Proyecto de visión de trayectorias

(*.pvt) |*.pvt |"

CommonDialog1. ShowSave

If CommonDialog1.FileName $<>$ "" Then

Archres = CommonDialog1.FileName

Open Archres For Output As \#1

na $=$ FrmAuxiliar.GrdProyecto.Rows - 1

Print \#1, na

For $i=1$ To na

Print \#1, FrmAuxiliar.GrdProyecto.TextMatrix(i, 1)

Print \#1, FrmAuxiliar.GrdProyecto.TextMatrix(i, 2)

Print \#1, FrmAuxiliar.GrdProyecto.TextMatrix(i, 3)

Print \#1, FrmAuxiliar.GrdProyecto.TextMatrix(i, 4)

Next i

Print \#1, FrmAuxiliar.GrdProyecto.TextMatrix(i, 5)

End If

End Sub

Close \#1

Sub GuardaVid()

Dim cuantos As Integer

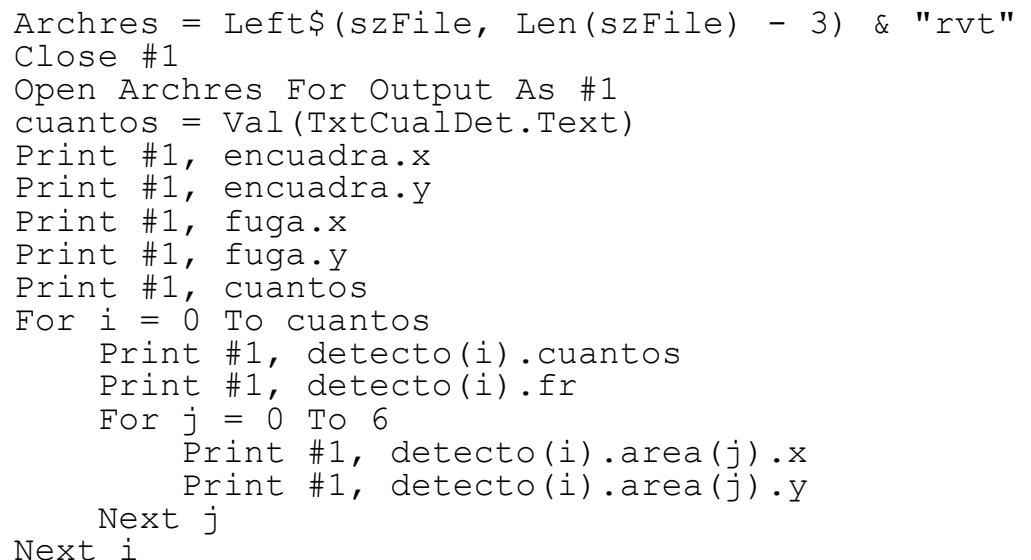

Next i

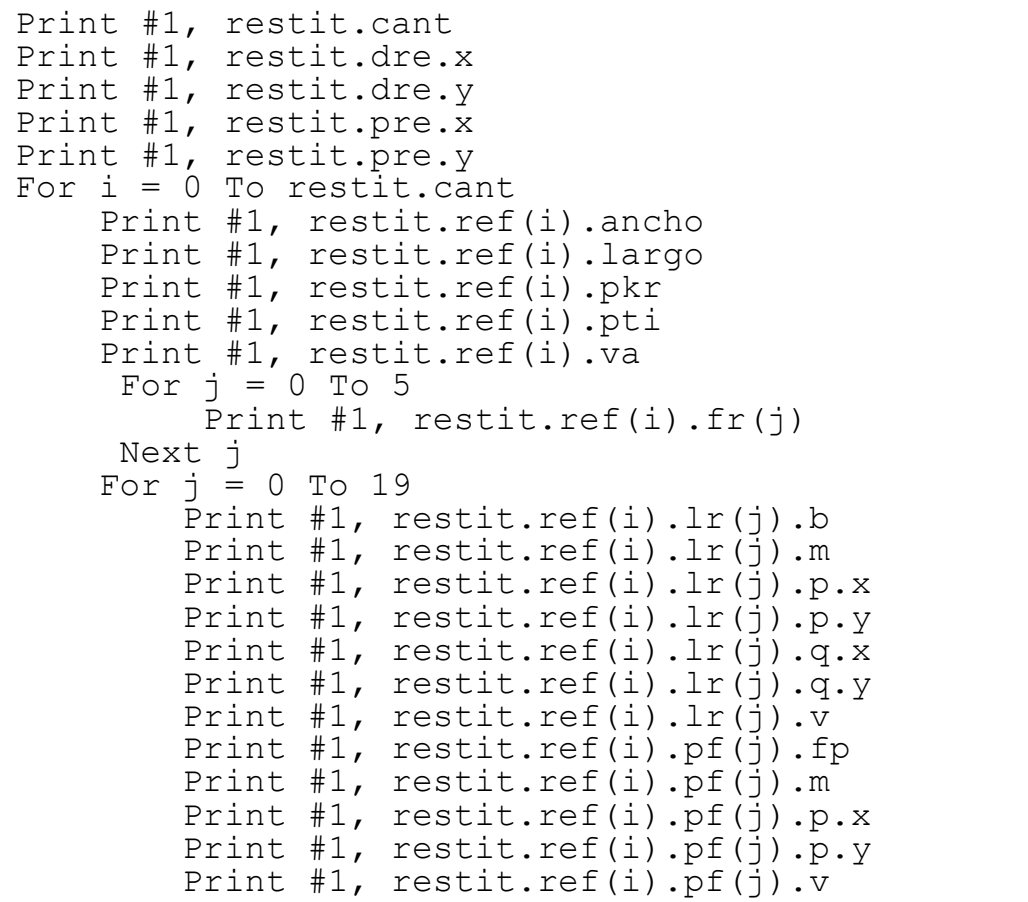




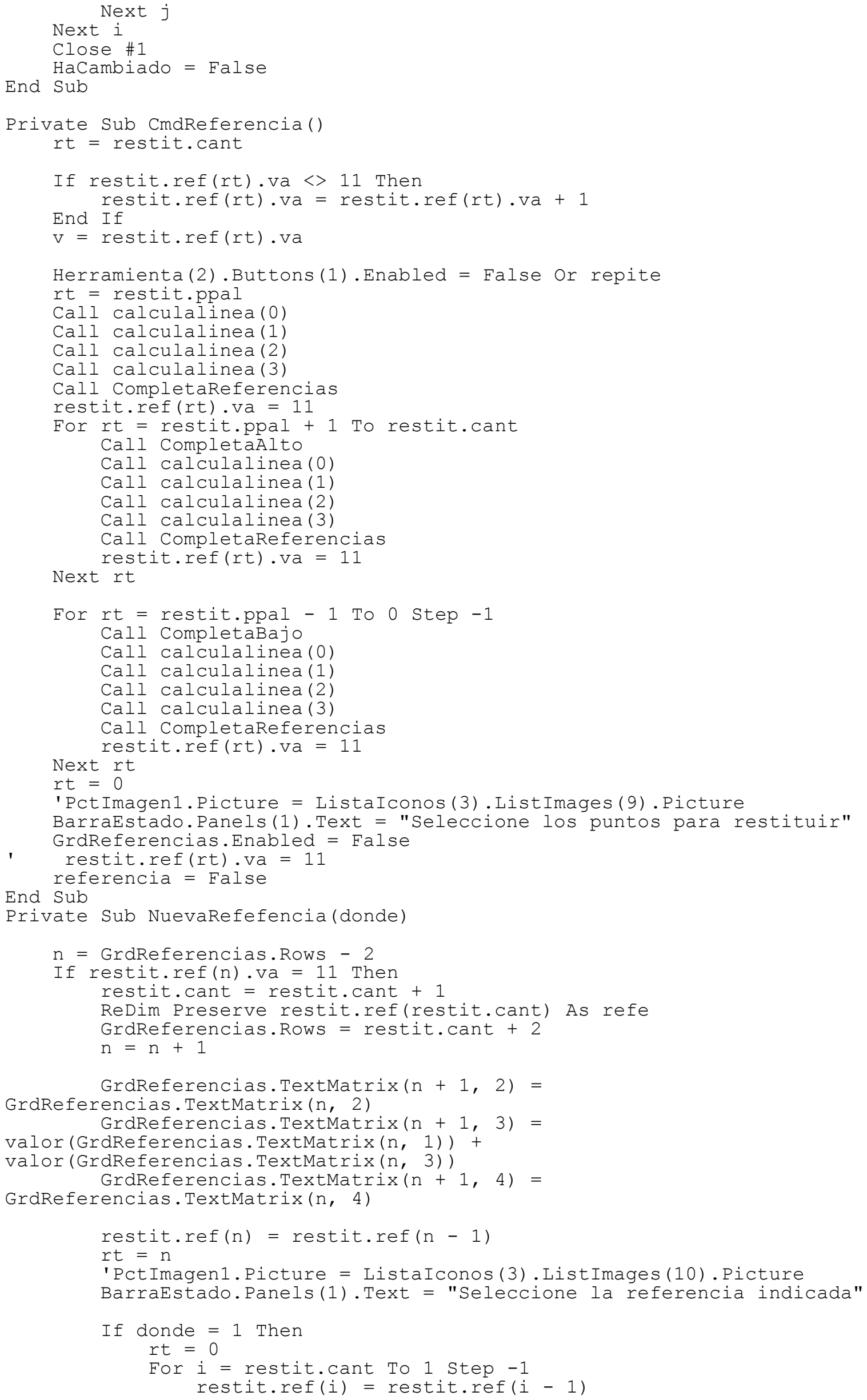




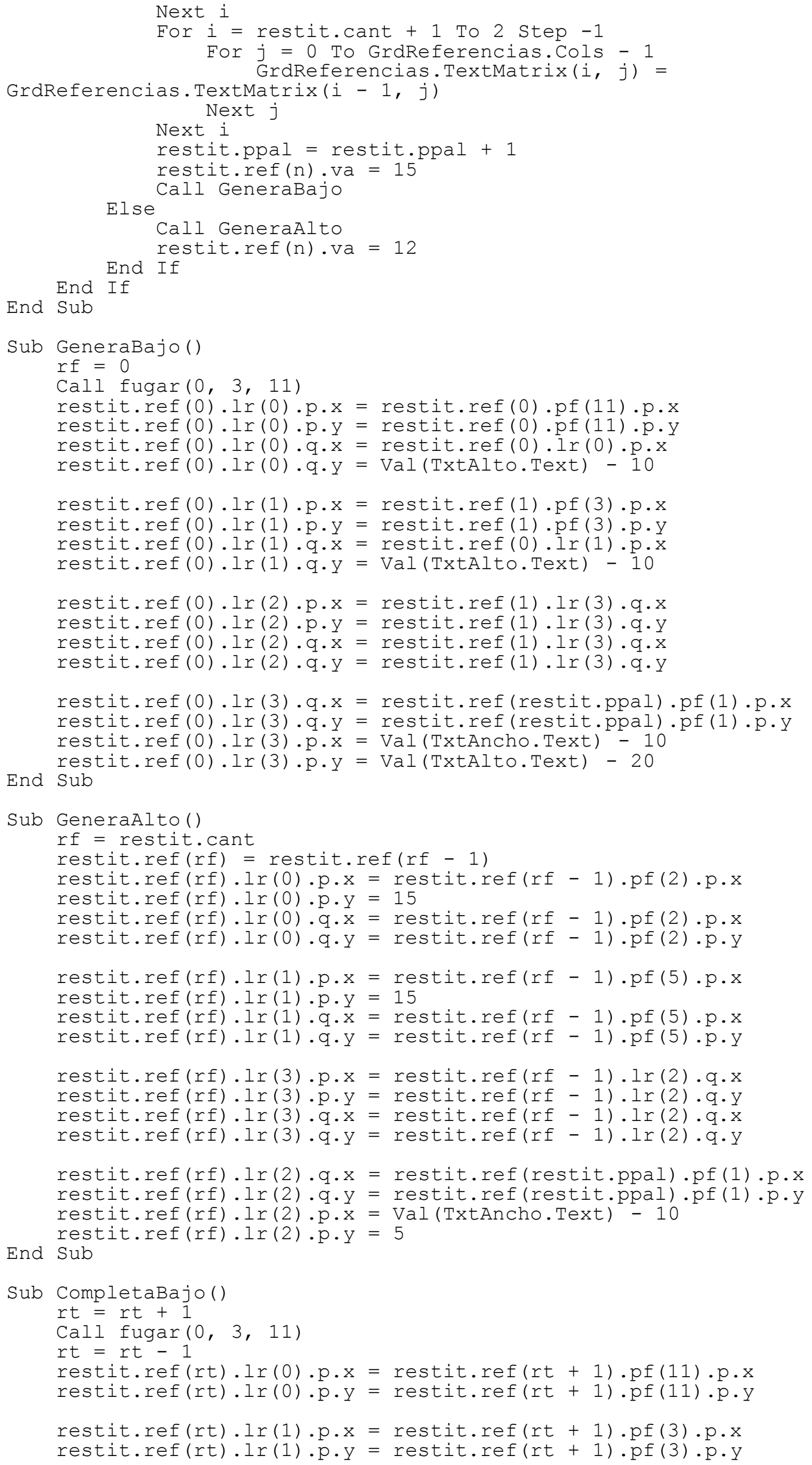

Sub GeneraAlto()

rf $=$ restit.cant

restit.ref $(r f)=$ restit.ref $(r f-1)$

restit.ref(rf). Ir (0).p.x = restit.ref(rf - 1).pf(2).p.x restit.ref $(r f) \cdot \operatorname{lr}(0) \cdot p \cdot y=15$ 


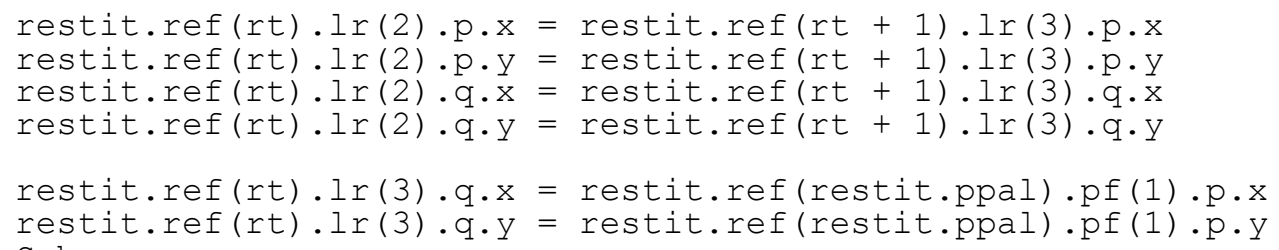


End If

Call mostrarVeh (ActFrame)

LblFrame. Caption = ActFrame

End Sub

terminado = True

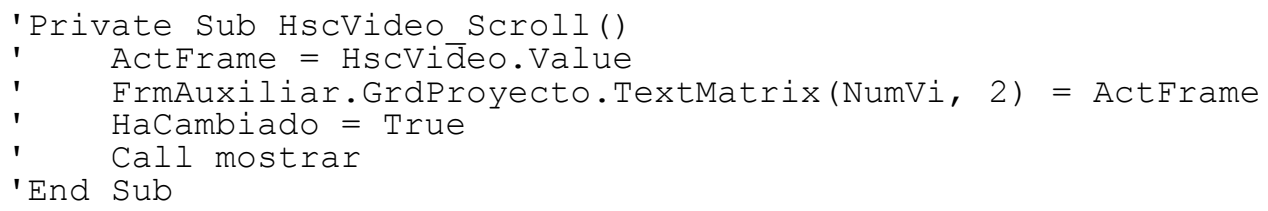

Sub PintaRef()

visi $=($ visi +1$) \operatorname{Mod} 2$

hacer $=$ True

If Not referencia Then

If $\mathrm{visi}=0$ Then

Else

hacer $=$ False

End If

hacer $=$ False

End If

visi $=0$

If hacer Then

PctPrincipal. DrawMode $=7$

PctPrincipal. DrawWidth $=1$

For $i=0$ To restit. cant

PctPrincipal.Line (restit.ref(i). Ir (0).p.x + desx,

restit.ref(i).lr(0).p.y + desy)-(restit.ref(i).lr(0).q.x + desx, restit.ref(i).lr(0).q.y + desy), QBColor(2) PctPrincipal.Line (restit.ref(i).lr(1).p.x + desx,

restit.ref(i).lr(1).p.y + desy)-(restit.ref(i).lr(1).q.x + desx, restit.ref(i).lr(1).q.y + desy), QBColor(2) If $i=$ restit.ppal Then PctPrincipal.Line (restit.ref(i). Ir(2).p.x + desx,

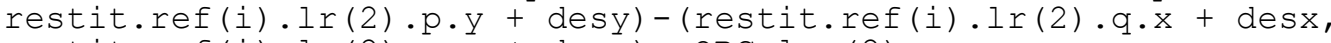
restit.ref(i).lr(2).q.y + desy), QBColor(2)

PctPrincipal.Line (restit.ref(i).lr(3).p.x + desx,

restit.ref(i). Ir (3) $\cdot \mathrm{p} \cdot \mathrm{y}+\mathrm{desy})-(\operatorname{restit} \cdot r e f(i) \cdot \operatorname{lr}(3) \cdot \mathrm{q} \cdot \mathrm{x}+\mathrm{des}$,

restit.ref(i).lr(3).q.y + desy), QBColor(2)

For $j=0$ To 3

Call PintaMarca(restit.ref(i). lr (j).p.x,

restit.ref(i). Ir (j) $\cdot p \cdot y)$

Call PintaMarca(restit.ref(i).lr(j).q.x,

restit.ref (i) $\cdot \operatorname{lr}(j) \cdot q \cdot y)$

Else Next j

If $i<$ restit.ppal Then

PctPrincipal.Line (restit.ref(i).lr(3).p.x + desx,

restit.ref(i).lr(3).p.y + desy)-(restit.ref(i).lr(3).q.x + desx,

restit.ref(i).lr(3).q.y + desy), oBColor(2)

restit.ref(i). $\operatorname{lr}(0) \cdot q \cdot y)$

Call PintaMarca(restit.ref(i). Ir (0).q.x,

restit.ref (i). $\operatorname{lr}(1) \cdot q \cdot y)$

Call PintaMarca(restit.ref(i). Ir(1).q.x,

restit.ref(i).lr(3) $\cdot \mathrm{p} \cdot \mathrm{y})$

Call PintaMarca(restit.ref(i). Ir(3) .p.x,

Else

PctPrincipal.Line (restit.ref(i).lr(2).p.x + desx,

restit.ref(i).lr(2).p.y + desy)-(restit.ref(i).lr(2).q.x + desx,

restit.ref(i).lr(2).q.y + desy), QBColor(2)

restit.ref(i). Ir (0) $\cdot \mathrm{p} \cdot \mathrm{y})$

Call PintaMarca(restit.ref(i). lr(0).p.x,

restit.ref(i).1

$(1) \cdot \mathrm{p} \cdot \mathrm{y})$

PintaMarca (restit.ref (i). Ir (1) .p.x,

restit.ref $(i$

Call PintaMarca(restit.ref(i). lr(2) .p.x,

Next i

$(2) \cdot p \cdot y)$

End If

End If

PctPrincipal.DrawMode $=13$

End Sub 
Sub PintaVehs ()

visiv $=($ visiv +1$)$ Mod 2

hacer $=$ True

If referencia or zreferencia Then

If visiv $=0$ Then

Else

hacer = False

hacer $=$ False

visiv $=0$

End If

End If

If hacer Then

Call MuestraVeh

End Sub

PctPrincipal.DrawMode $=13$

Sub PintaRefz()

visiz $=($ visiz +1$)$ Mod 2

hacer $=$ True

If Not zreferencia Then

If visiz $=0$ Then

Else

hacer $=$ False

hacer $=$ False

visiz $=0$

End If

End If

If hacer Then

PctPrincipal. DrawMode $=7$

PctPrincipal.DrawWidth $=1$

Call PintaMarca (encuadra.x + 16 + desx, encuadra.y + 16 + desy)

PctPrincipal.Line (detecto(0).area(0).x + desx,

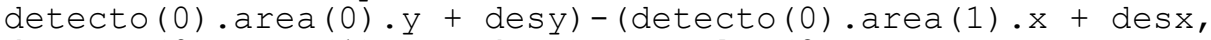

detecto(0). area(1).y + desy), QBColor (2)

PctPrincipal.Line (detecto(0).area(2).x + desx,

detecto (0) $\cdot \operatorname{area}(2) \cdot y+\operatorname{desy})-(\operatorname{detecto}(0) \cdot \operatorname{area}(3) \cdot x+\operatorname{des} x$,

detecto(0) $\cdot$ area (3) $\cdot y+$ desy), QBColor (2)

Call Pintamarca (detecto $(0)$. area $(0) \cdot x$, detecto(0). area $(0) \cdot y)$

Call PintaMarca (detecto(0).area(1).x, detecto(0).area(1).y)

Call PintaMarca (detecto(0). area (2).x, detecto(0). area (2).y)

Call PintaMarca (detecto (0). area (3).x, detecto(0). area (3).y)

Call PintaMarca (detecto(0).area(4).x, detecto(0).area(4).y)

Call PintaMarca (detecto(0). area (5).x, detecto(0).area (5).y)

PctPrincipal.Line (1, detecto(0).area(4).y + desy)-(768,

detecto(0).area (4).y + desy), QBColor (2)

PctPrincipal.Line (1, detecto(0).area(5).y + desy)-(768,

detecto(0).area (5).y + desy), QBColor (2)

End If

PctPrincipal.DrawMode $=13$

End Sub

Private Sub Abrir (ya, nom)

If ya $=1$ Then

szFile $=$ nom

Call AbrirDatos (Left (nom, Len(nom) - 4)

MediaPlayerl.FileName $=$ nom

'get media information

TxtAncho.Text = MediaPlayer1.GetWidth

TxtAlto. Text = MediaPlayer1.GetHeight

Call Inicializa

FrmAuxiliar.LblRate. Caption = MediaPlayer1.GetBitRate / 32 /

TxtAncho.Text / TxtAlto.Text

If Val (FrmAuxiliar.LblRate.Caption) $<1$ Then

End If

FrmAuxiliar.LblRate.Caption $=5$

numFrames = MediaPlayer1.GetDuration * FrmAuxiliar.LblRate

TxtIntervalo.Text = FrmAuxiliar.LblRate / 5 


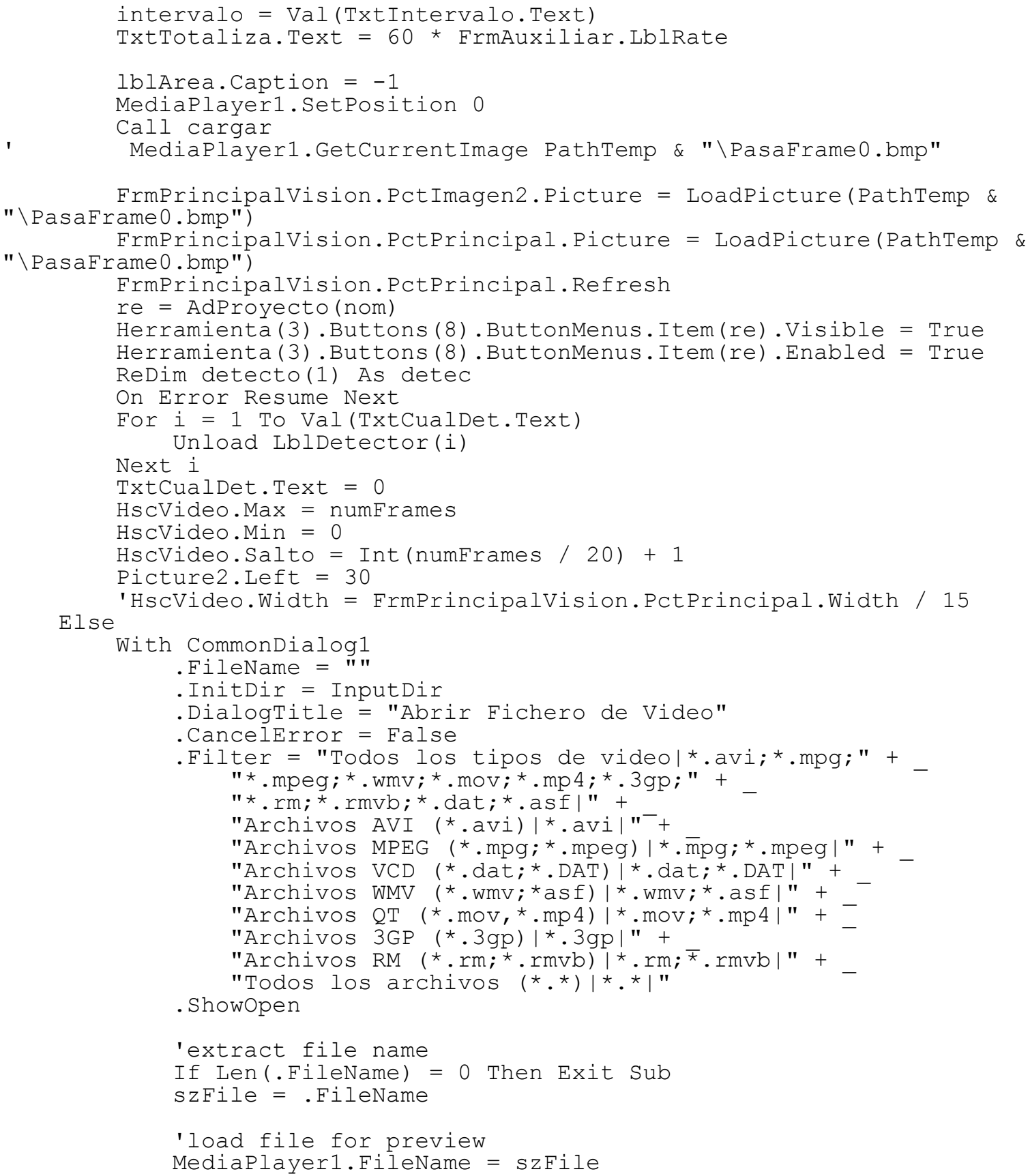

End With 
Private Sub BordeDer()

MediaPlayer1.GetCurrentImage PathTemp \& "\PasaFrame0.bmp"

Call leeimagen(PathTemp \& "\PasaFrame0.bmp", 0)

FrmPrincipalVision.PctImagen1.Picture = LoadPicture(PathTemp \&

"\PasaFrame0.bmp")

Call Borde $(0,2$, Val (TxtBorde.Text))

Call guardal (PathTemp \& "\PasaFrame2.bmp", 2)

FrmPrincipalVision.PctPrincipal.Picture = LoadPicture (PathTemp \&

"\PasaFrame2.bmp")

End Sub

Private Sub BordeM()

MediaPlayer1.GetCurrentImage PathTemp \& "\PasaFrame1.bmp"

Call leeimagen(PathTemp \& "\PasaFrame0.bmp", 1)

FrmPrincipalVision.PctImagen1.Picture = LoadPicture(PathTemp \&

"\PasaFrame0.bmp")

Call Borde (0, 2, Val (TxtBorde.Text))

Call guardal (PathTemp \& "\PasaFrame2.bmp", 2)

FrmPrincipalVision.PctPrincipal.Picture = LoadPicture(PathTemp \&

"\PasaFrame2.bmp")

archmedia $=$ Left\$(szFile, Len(szFile) - 3) \& "bmp"

Call leeimagen (archmedia, 0)

Call $\operatorname{BordeD}(0,1,2$, Val'(TxtBorde. Text))

Call guarda1 (PathTemp \& "\PasaFrame2.bmp", 2)

FrmPrincipalVision.PctPrincipal.Picture = LoadPicture (PathTemp \&

"\PasaFrame2.bmp")

End Sub

Private Sub Bordes()

MediaPlayer1.GetCurrentImage PathTemp \& "\PasaFrame0.bmp"

Call leeimagen (PathTemp \& "\PasaFrame0.bmp", 0)

FrmPrincipalVision.PctImagen1.Picture = LoadPicture(PathTemp \&

"\PasaFrame0.bmp")

Call Borderesta $(0,2)$

Call guarda1 (PathTemp \& "\PasaFrame2.bmp", 2)

FrmPrincipalVision.PctPrincipal.Picture = LoadPicture (PathTemp \&

"\PasaFrame2.bmp")

End Sub

Private Sub BordesDif()

MediaPlayer1.GetCurrentImage PathTemp \& "\PasaFrame0.bmp"

Call leeimagen (PathTemp \& "\PasaFrame0.bmp", 0)

FrmPrincipalVision.PctImagen1.Picture = LoadPicture(PathTemp \&

"\PasaFrame0.bmp")

Call Resta

Call guarda1 (PathTemp \& "\PasaFrame2.bmp", 2)

FrmPrincipalVision.PctPrincipal.Picture = LoadPicture (PathTemp \&

"\PasaFrame2.bmp")

MediaPlayer1.GetCurrentImage PathTemp \& "\PasaFrame0.bmp"

Call leeimagen (PathTemp \& "\PasaFrame0.bmp", 0)

FrmPrincipalVision.PctImagen1.Picture = LoadPicture (PathTemp \&

"\Pasaframe0.bmp")

Call Borderesta $(0,2)$

Call dib.guardar (PathTemp \& "\PasaFrame2.bmp", 2)

FrmPrincipalVision.PctPrincipal.Picture = LoadPicture (PathTemp \&

"\PasaFrame2.bmp")

End Sub

Private Sub Cerrar()

PctPrincipal.Picture = LoadPicture ()

PctImagen1.Picture = LoadPicture ()

PctImagen2. Picture = LoadPicture ()

Call CerrarDatos

End Sub 


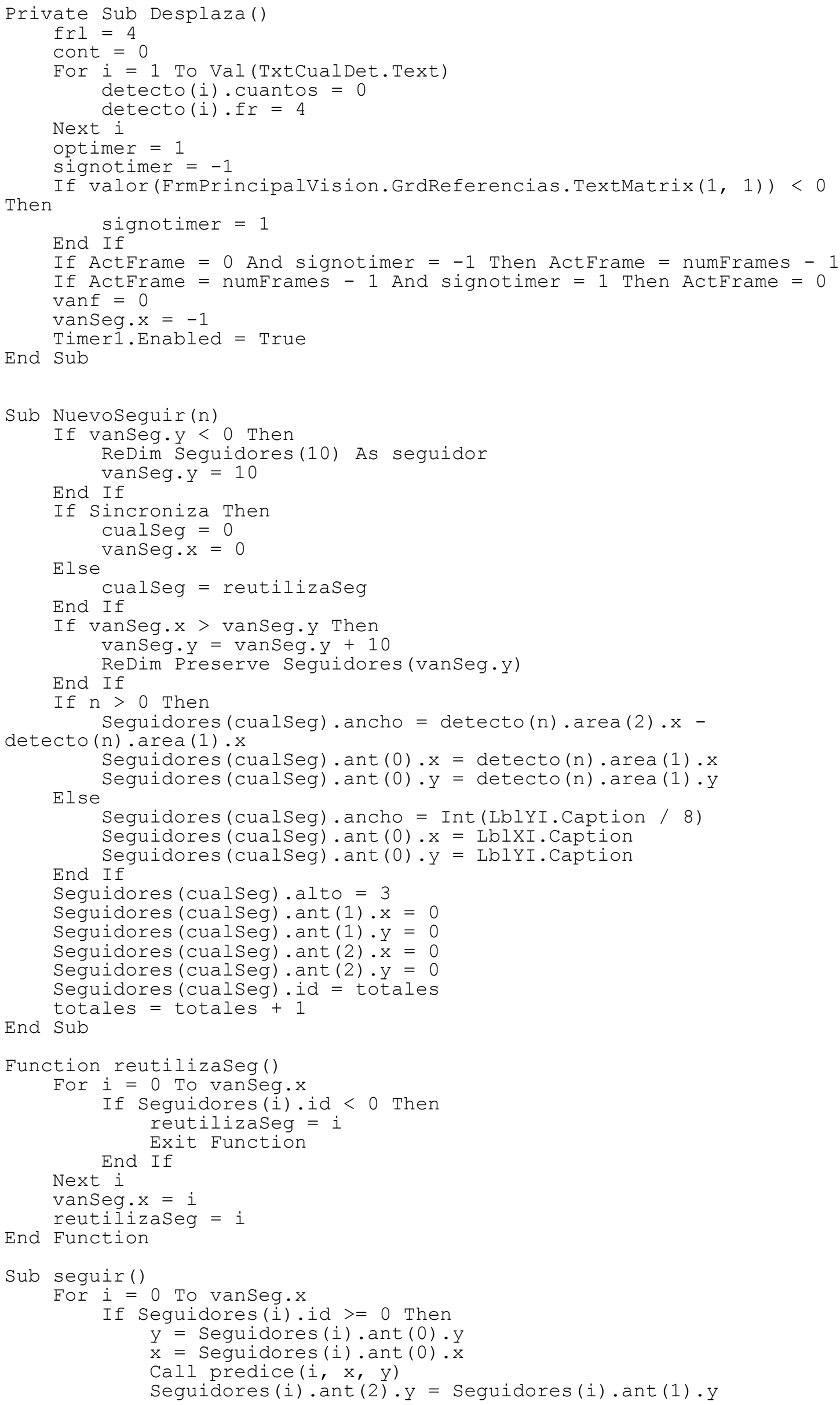




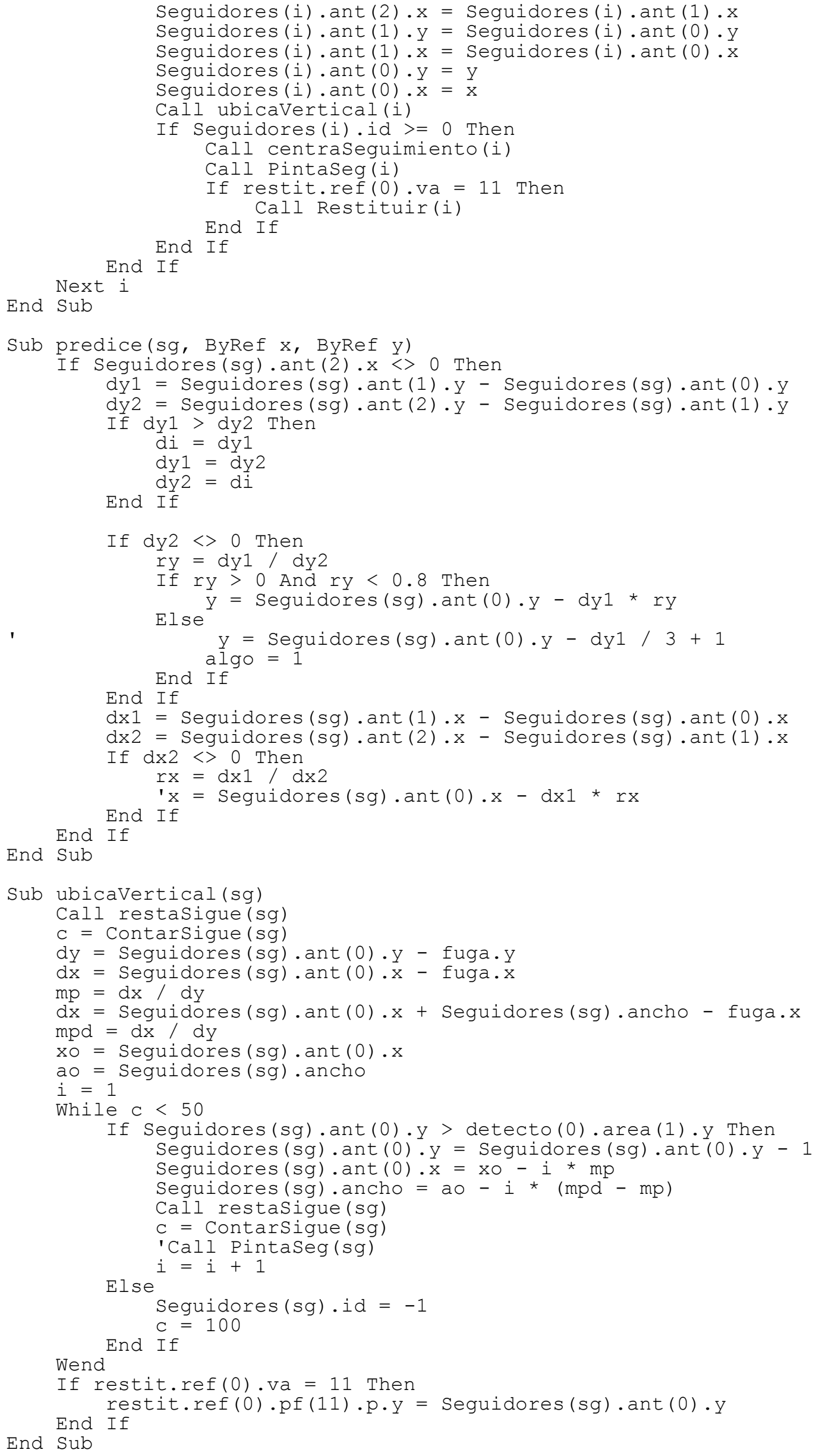


Sub centraseguimiento(i)

$\mathrm{xi}=$ Seguidores(i).ant(0).x - Seguidores(i).ancho

$\mathrm{xf}=$ Seguidores(i).ant (0).x + Seguidores(i).ancho $* 2$

' For $i i=5$ To 8

' Call punto(Seguidores(i).ancho * 2, ii, 6)

'Next ii

Call punto(Seguidores(i).ancho, ii, 6)

If $x i<=1$ Then $x i=1$

If $x f>=$ imagenes(2). ancho Then $x f=$ imagenes (2). ancho -1

$\mathrm{C}=4$

$\mathrm{xwi}=0$

$x x=$ Seguidores(i).ant (0).x + Int (Seguidores(i).ancho / 2)

While $x x<x f$ And $c>1$

$\mathrm{C}=$ lineasVS $(\mathrm{xx}, \mathrm{i})$

$\mathrm{xwi}=\mathrm{xwi}+1$

Wend

$x x=x x+1$

$\mathrm{C}=4$

$x=$ Seguidores(i).ant (0) $x+$ Int (Seguidores(i).ancho / 2)

$\mathrm{x}=\mathrm{xx}-1$

$\mathrm{XWf}=0$

While $x>=x i$ And $c>1$

$\mathrm{c}=$ lineasVS $(\mathrm{x}, \mathrm{i})$

$\mathrm{x}=\mathrm{x}-1$

Wend

$\mathrm{xWf}=\mathrm{xwf}+1$

If $x<5$ Then $x=5$

Seguidores(i). ant $(0) \cdot x=(x+x x-$ Seguidores(i).ancho) / 2

'For ii $=5$ To 8

' Call punto(xwi + Seguidores(i). ancho * 1.5, ii, 8)

Call punto(Seguidores(i). ancho * 1.5 - xwf, ii, 8)

'Next ii

If restit.ref(0).va $=11$ Then

End If

restit.ref $(0) \cdot \operatorname{pf}(11) \cdot p \cdot x=(x+x x) / 2$

End Sub

Private Sub Detectar()

frl $=4$

cont $=0$

For $i=1$ To Val (TxtCual Det. Text)

detecto(i). cuantos $=0$

detecto(i).fr $=4$

Next i

CommonDialog1.FileName = " "

CommonDialog1. Filter = "Fichero de Texto para resultados

(*.txt)|*.txt|"

CommonDialog1. Show Save

If CommonDialog1. FileName = " " Then

Exit Sub

End If

Close \#1

Open CommonDialog1. FileName For Output As \#1

Print \#1, "Deteccion de Vehículos"

Print \#1, szFile

Print \#1, "Frame Inicial :", ActFrame

Print \#1, "Datos consolidados cada (minutos) :",

Int(valor(TxtTotaliza.Text) / 6 / valor(FrmAuxiliar.LblRate)) / 10

Print \#1, "Frame", "Valores detectores"

Aframe = ActFrame

optimer $=3$

End Sub

Timer1.Enabled = True

Private Sub Detector()

lblArea.Caption $=0$

$\mathrm{n}=\mathrm{Val}$ (TxtCualDet. Text) +1

TxtCualDet. Text $=n$ 


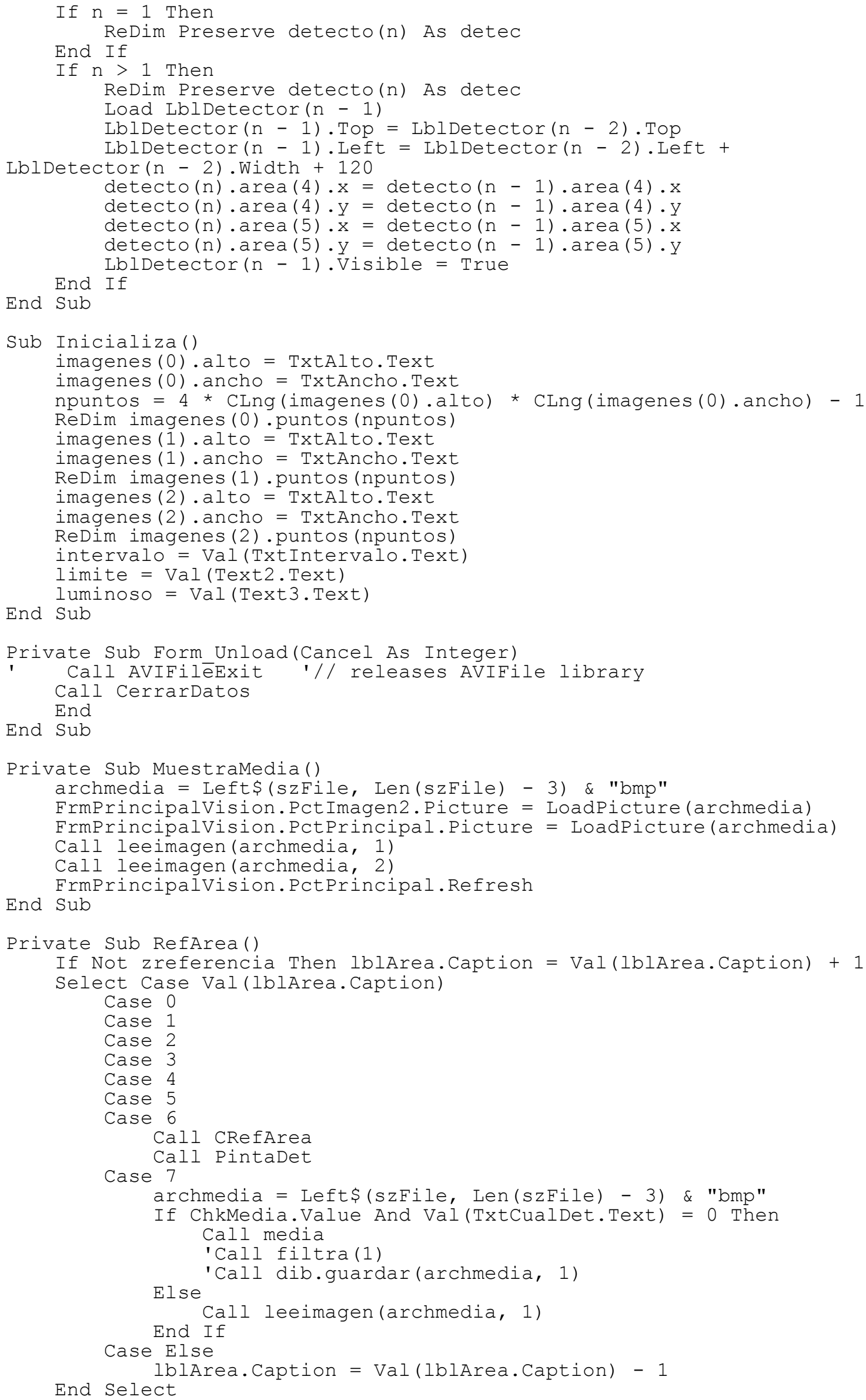


Sub CRefArea()

nde $=\operatorname{Val}($ TxtCualDet. Text $)$

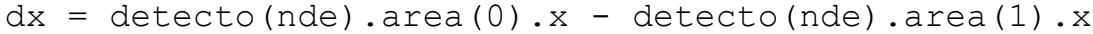

If $\mathrm{dx}<>0$ Then

$d y=$ detecto (nde) $\cdot$ area (0) $\cdot y$ - detecto (nde) $\cdot$ area (1) $y$

$\mathrm{mi}=\mathrm{dy} / \mathrm{dx}$

If $\mathrm{mi}<>0$ Then

detecto (nde) . area (0) $\cdot \mathrm{x}=\operatorname{detecto}($ nde) . area $(0) \cdot \mathrm{x}+$

(detecto (nde).area(5).y - detecto(nde).area(0).y) / mi

detecto(nde) . area (1) $\cdot \mathrm{x}=\operatorname{detecto}($ nde) $)$ area (1) $\cdot \mathrm{x}+$

(detecto(nde).area(4).y - detecto(nde).area(1).y) / mi

Else

detecto (nde). area $(0) \cdot x=$ detecto (nde). area $(0) \cdot x$ End If

detecto(nde). area (1) $\cdot x=$ detecto(nde). area(1).x

End If

detecto (nde) $\cdot \operatorname{area}(0) \cdot y=\operatorname{detecto}($ nde) $\cdot \operatorname{area}(5) \cdot y$

detecto (nde). area (1) $\cdot y=$ detecto (nde). area (4).y

$d x=$ detecto (nde). area (3).x - detecto(nde). area (2).x

If $d x<>0$ Then

$d y=\operatorname{detecto}($ nde) $\cdot \operatorname{area}(3) \cdot y-\operatorname{detecto}($ nde) $\cdot \operatorname{area}(2) \cdot y$

md $=d y / d x$

If md $<>0$ Then

detecto(nde) area (3) $\cdot x=$ detecto(nde). area (3) $\cdot x+$

(detecto (nde). area (5).y - detecto (nde). area(3).y) / md detecto(nde) . area (2) $\cdot x=\operatorname{detecto(nde)} \cdot \operatorname{area}(2) \cdot x+$

(detecto(nde) .area (4).y - detecto(nde).area(2).y) / mo

Else

detecto(nde). area (3) $\cdot x=$ detecto(nde). area (3).$x$ End If

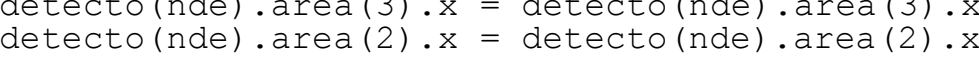

End If

detecto(nde).area (3) $y=$ detecto (nde). area (5) $\cdot y$

detecto (nde) . area (2) $\cdot y=$ detecto (nde) $\cdot$ area (4) $\cdot y$

If nde $=0$ Then

If $\mathrm{mi}-\mathrm{md}<>0$ Then

$\mathrm{dx}=\mathrm{md} \star(\operatorname{detecto}(0) \cdot \operatorname{area}(2) \cdot \mathrm{x}-\operatorname{detecto}(0) \cdot \operatorname{area}(1) \cdot \mathrm{x}) /$

$(\mathrm{mi}-\mathrm{md})$

End If

fuga. $x=\operatorname{detecto}(0) \cdot \operatorname{area}(1) \cdot x-d x$

fuga.y $=\operatorname{detecto}(0) \cdot \operatorname{area}(1) \cdot y-m i * d x$

End Sub

Private Sub RestaSolo()

MediaPlayer1.GetCurrentImage PathTemp \& "\PasaFrame0.bmp"

Call leeimagen (PathTemp \& "\PasaFrame0.bmp", 0)

FrmPrincipalVision.PctImagen1.Picture = LoadPicture(PathTemp \&

"\PasaFrame0.bmp")

Call encuadrar (0)

Call soloresta

Call guarda1 (PathTemp \& "\PasaFrame2.bmp", 2)

FrmPrincipalVision.PctPrincipal.Picture = LoadPicture(PathTemp \&

"\PasaFrame2.bmp")

End Sub

Sub PintaMarca $(x, y)$

PctPrincipal.Line $(\mathrm{x}-2+\operatorname{des} x, \mathrm{y}-2+\operatorname{desy})-(\mathrm{x}+2+\operatorname{des} x, \mathrm{y}+2$

+ desy), QBColor (2), B

PctPrincipal.Line $(x-4+\operatorname{des} x, y+\operatorname{desy})-(x-1+\operatorname{desx}, y+\operatorname{desy})$, QBColor (2)

PctPrincipal.Line $(x+1+\operatorname{desx}, y+\operatorname{desy})-(x+4+\operatorname{desx}, y+\operatorname{desy})$, oBColor (2)

PctPrincipal.Line $(x+\operatorname{des} x, y-4+\operatorname{des} y)-(x+\operatorname{des} x, y-1+\operatorname{desy})$, QBColor (2)

PctPrincipal.Line $(x+\operatorname{des} x, y+1+\operatorname{desy})-(x+\operatorname{des} x, y+4+\operatorname{desy})$, QBColor (2)

End Sub 


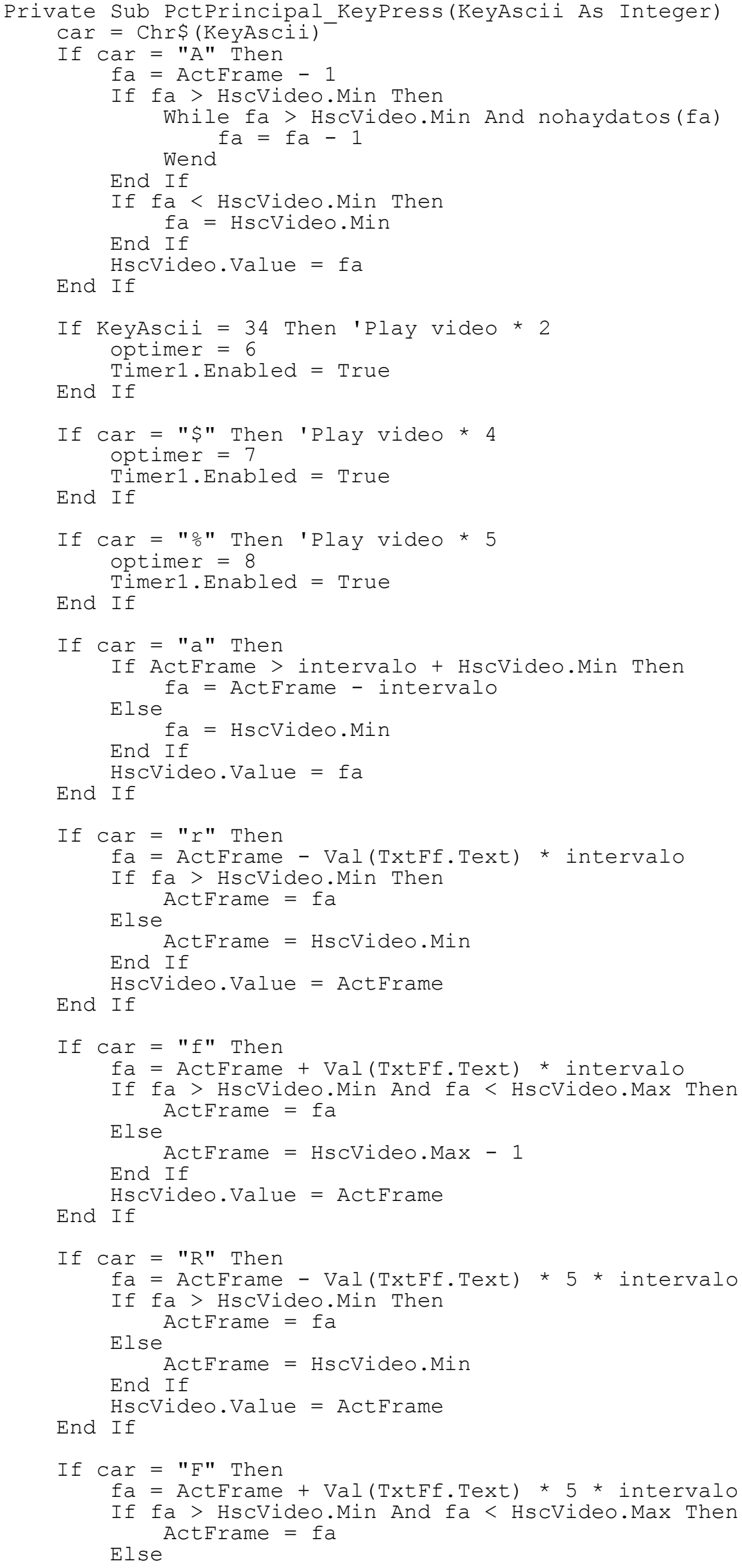




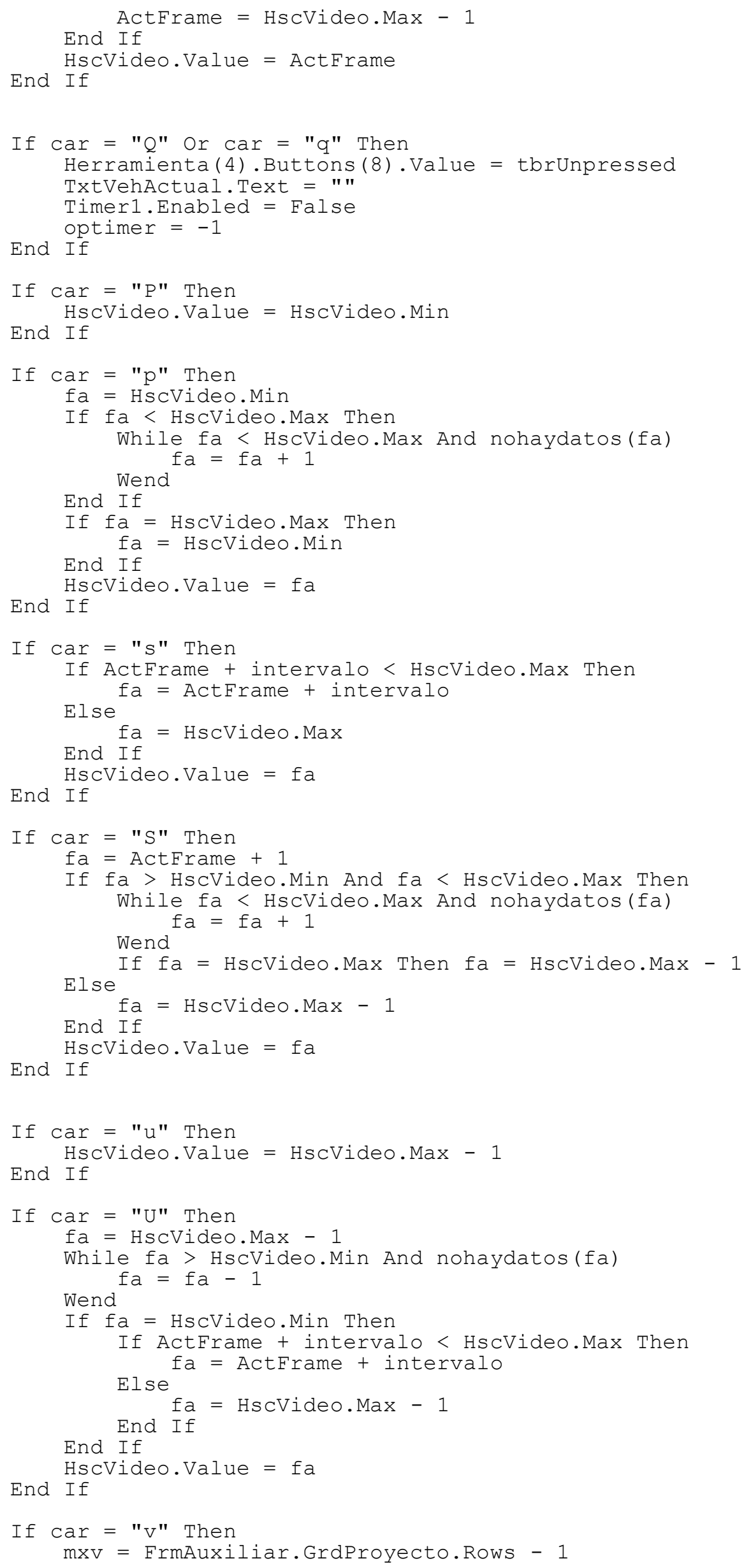




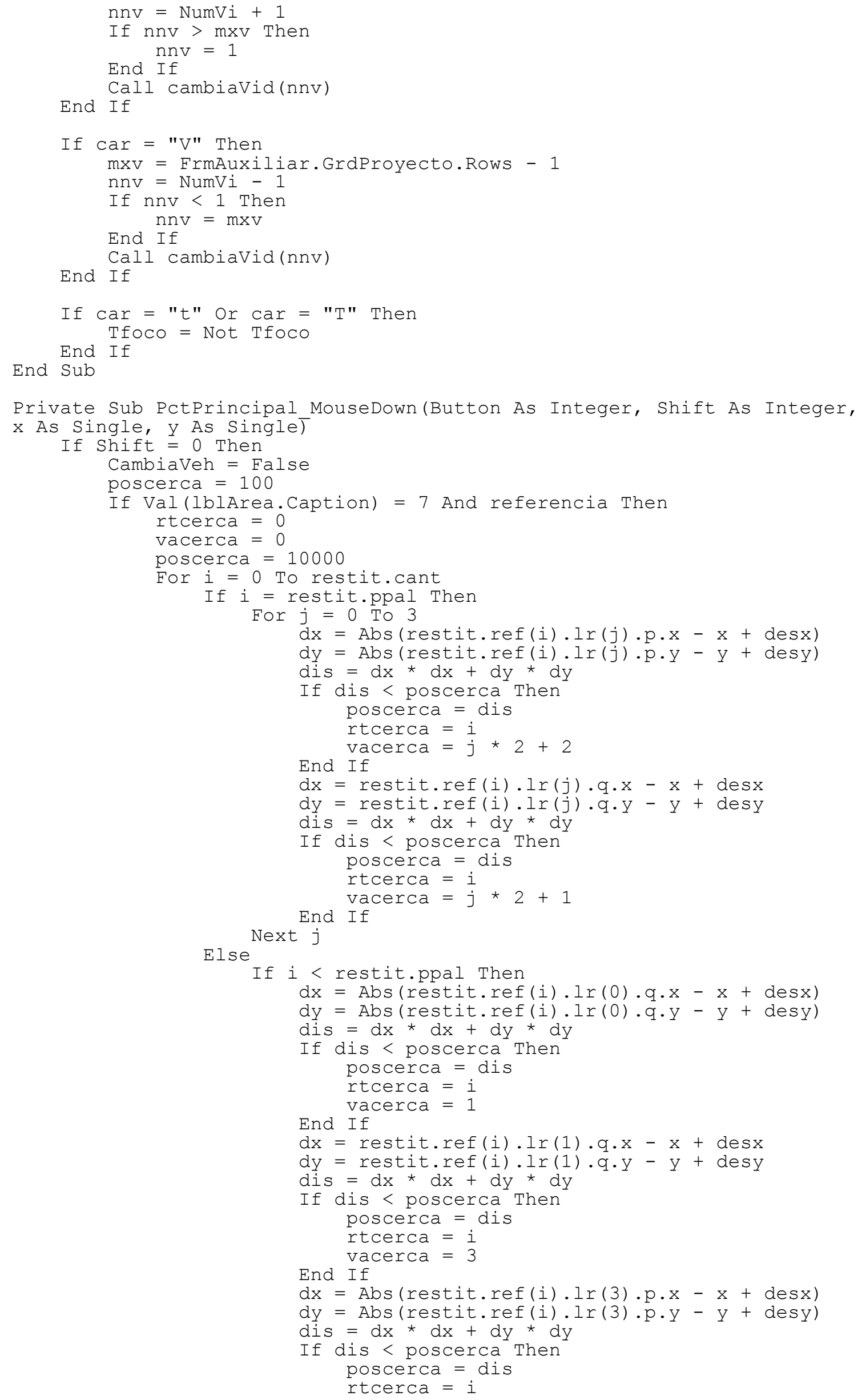




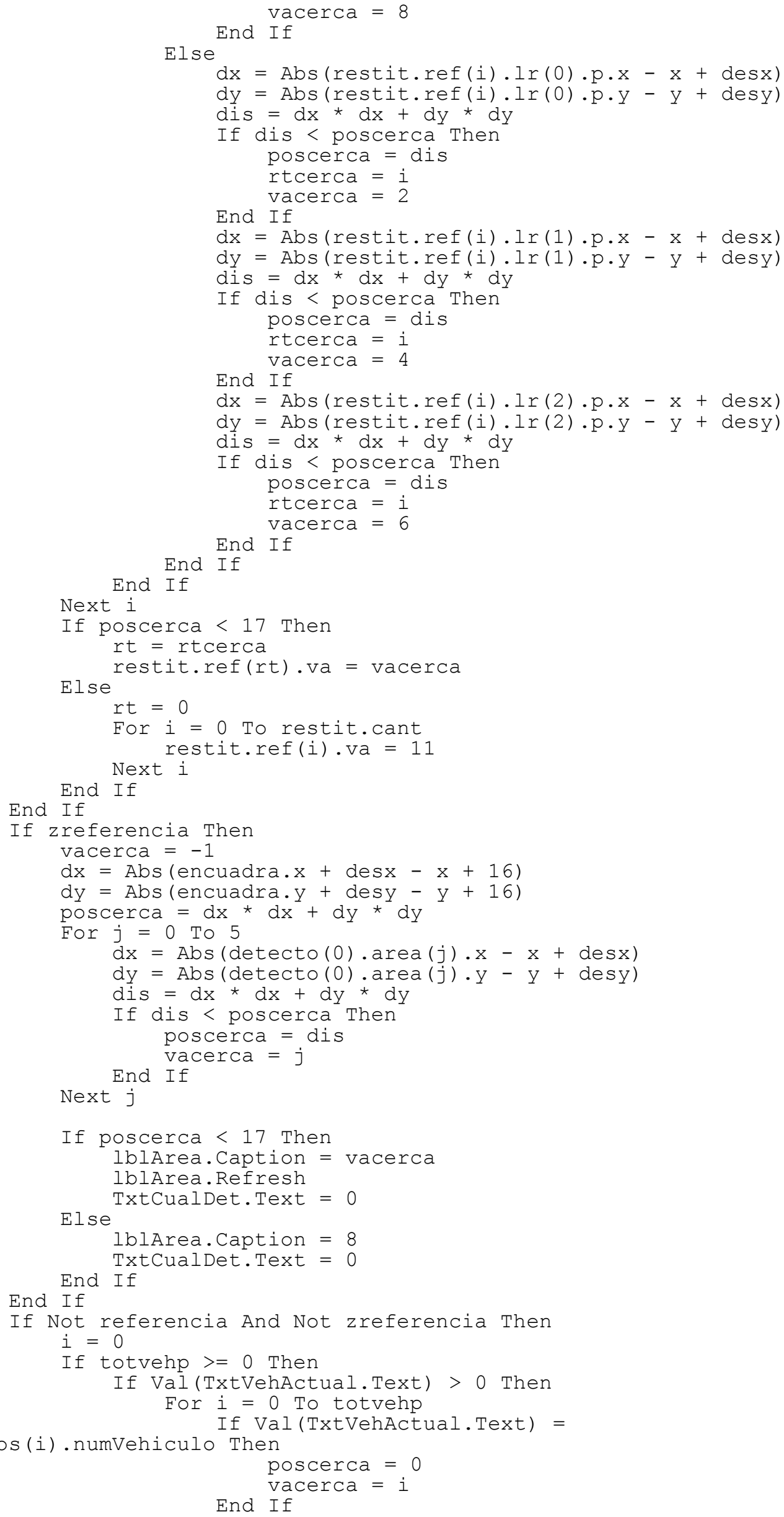




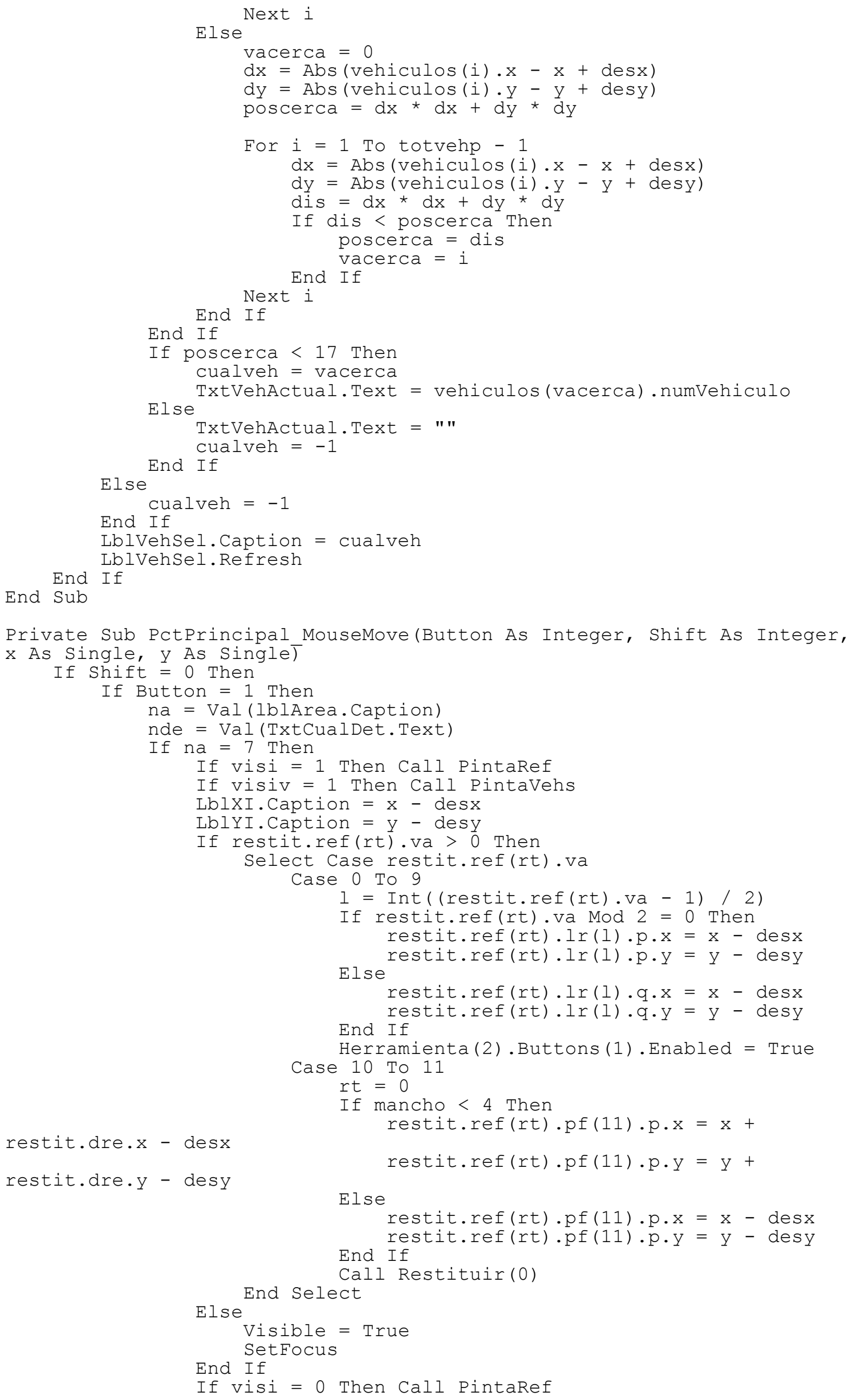




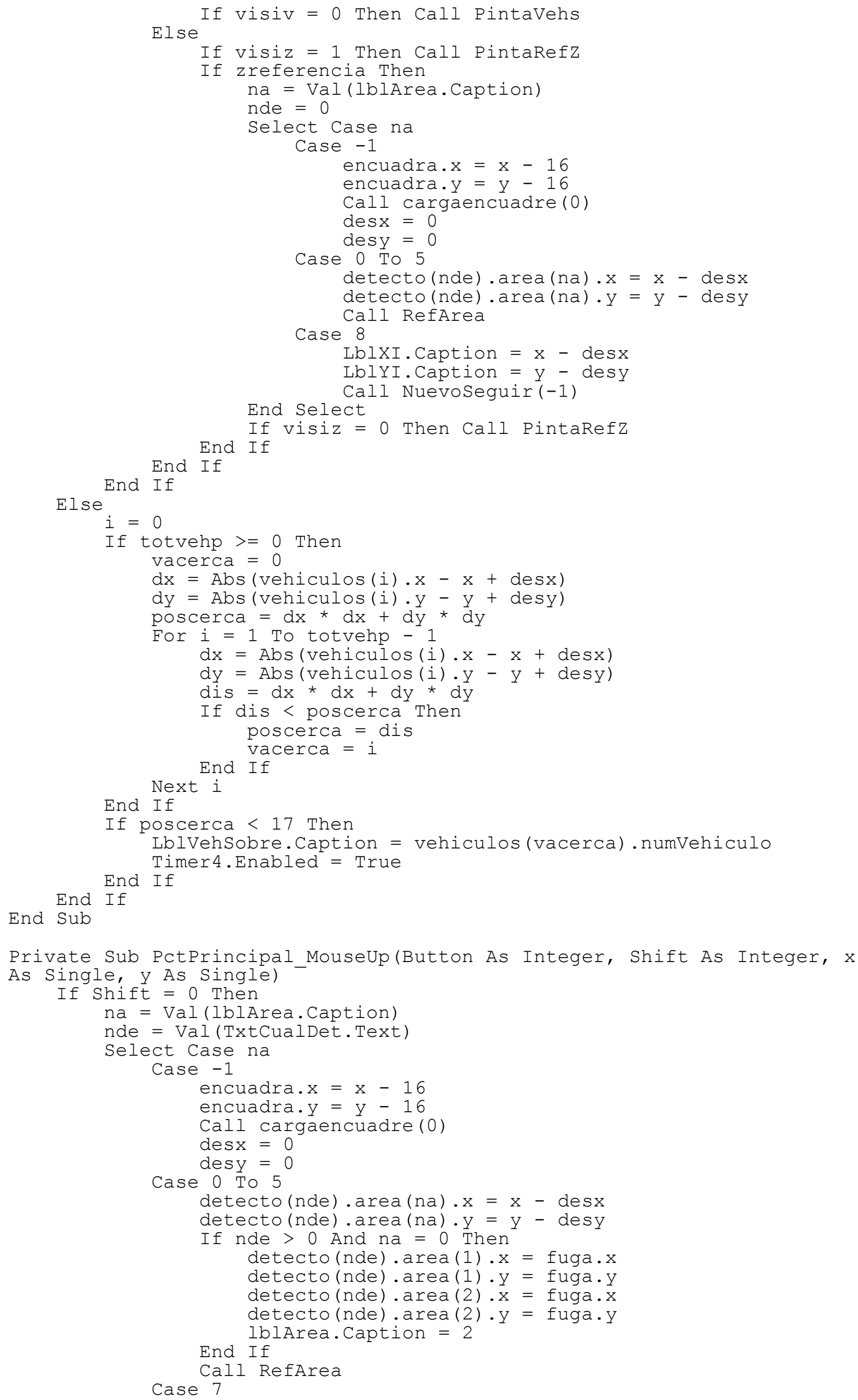




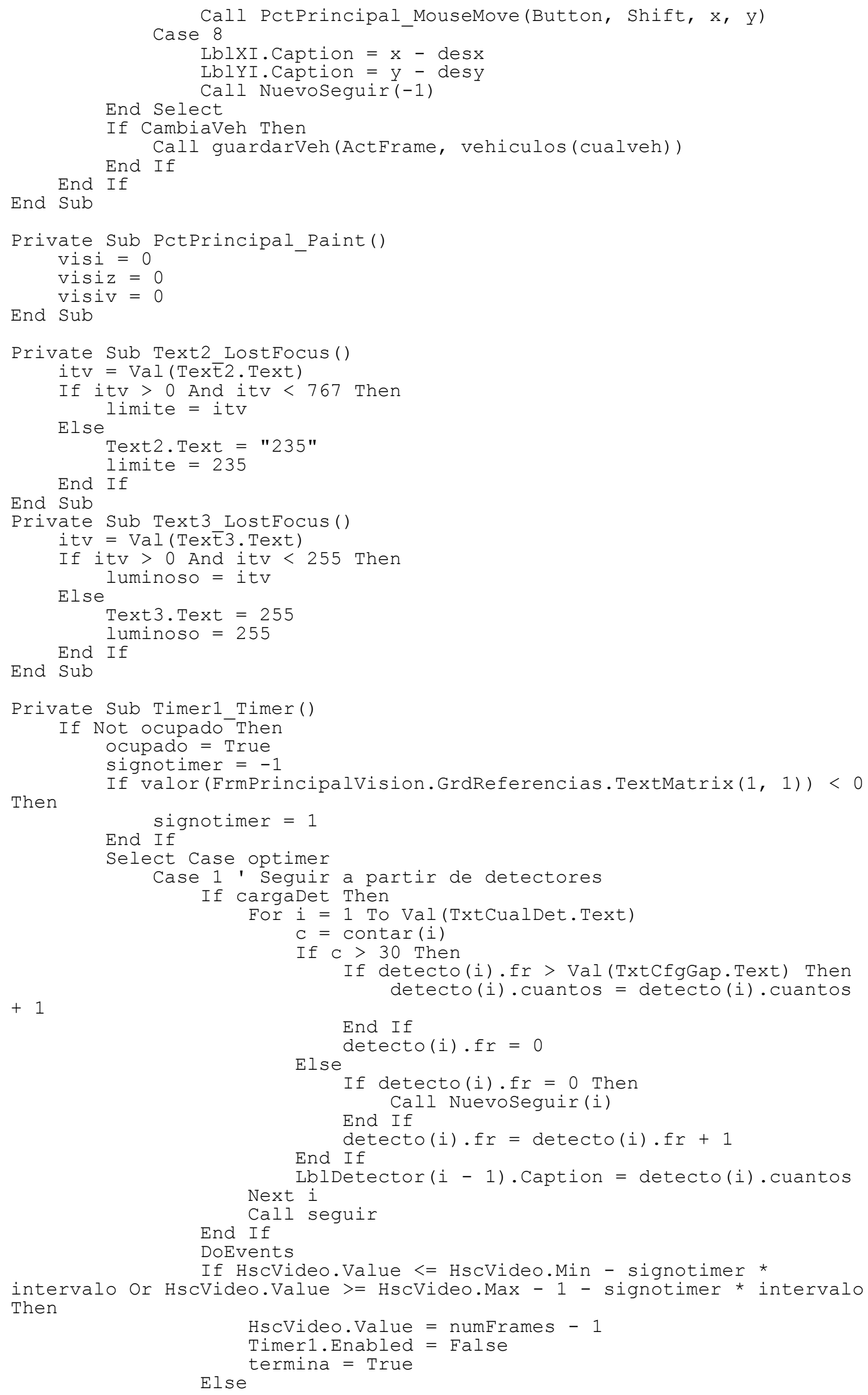




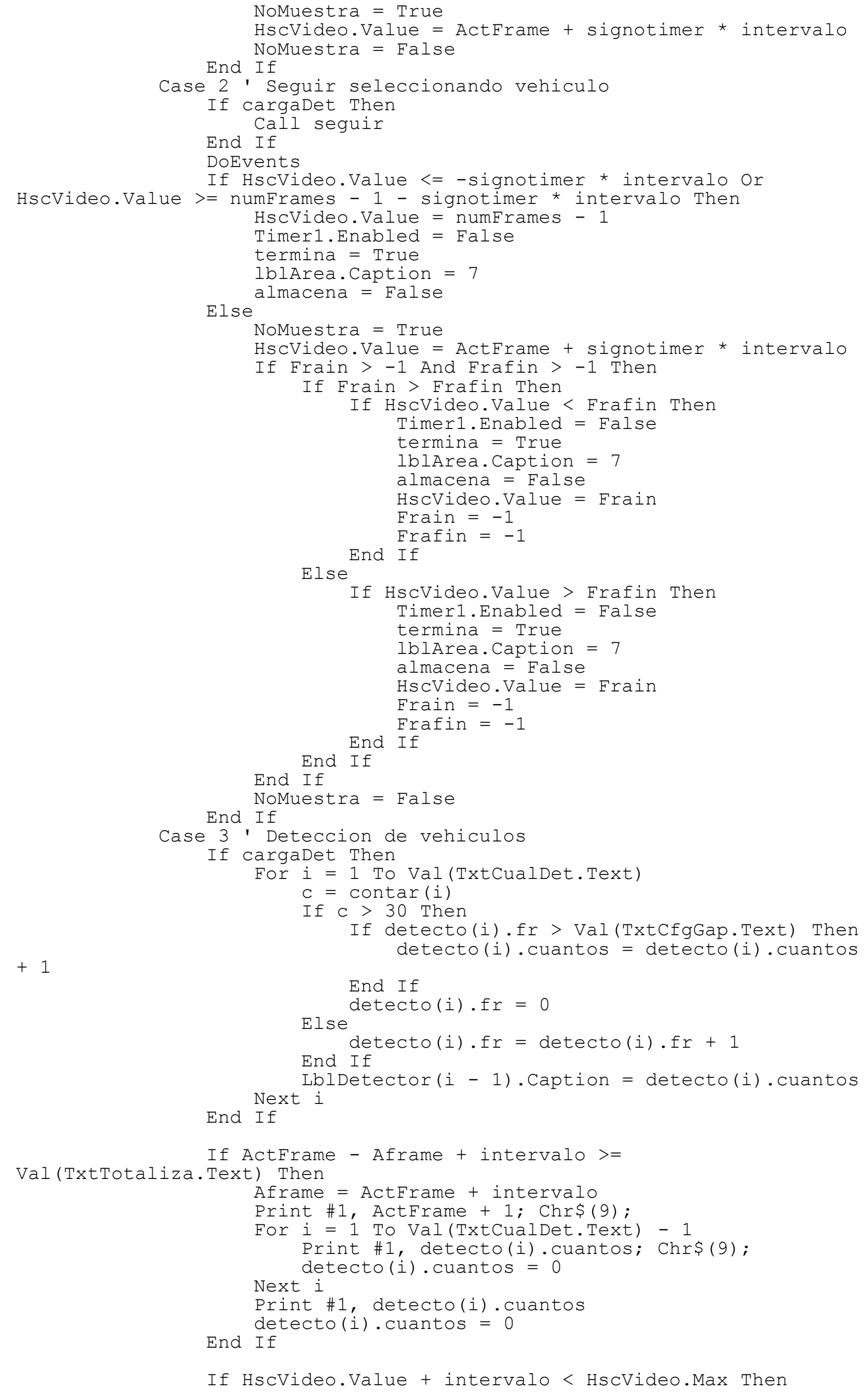




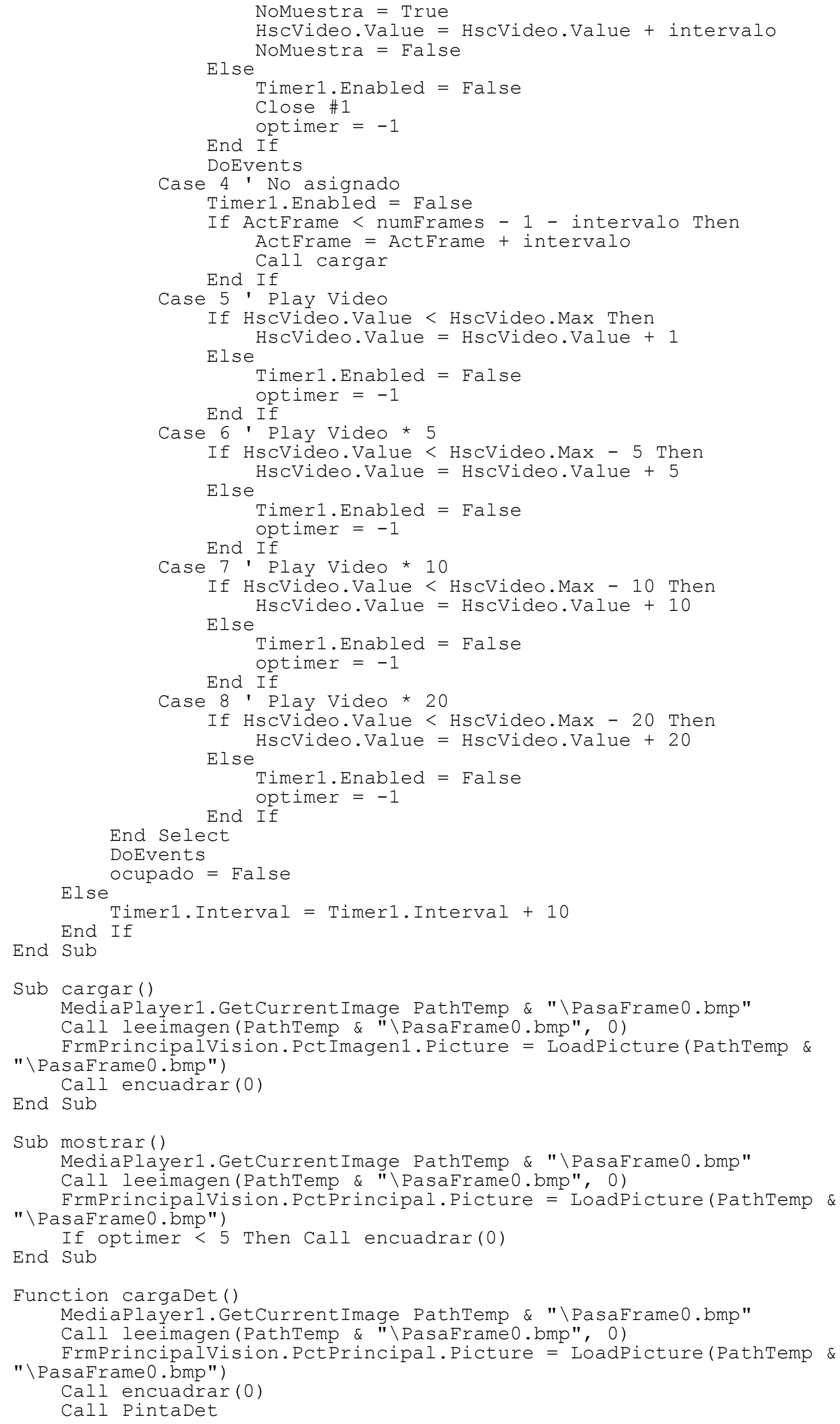


Call restaDet

cargaDet $=$ True

End Function

Sub PintaDet ()

For $i=1$ To Val (TxtCualDet. Text)

$\mathrm{CO}=12$

If detecto(i).fr $=0$ Then $c o=10$

FrmPrincipalVision. PctPrincipal. Line (detecto(i).area (0). $x+$

desx, detecto(i).area(0).y + desy)-(detecto(i).area(1).x + desx,

detecto(i).area(1).y + desy), QBColor(co)

FrmPrincipalVision.PctPrincipal. Line (detecto(i).area(1).x +

desx, detecto(i).area(1).y + desy)-(detecto(i).area(2).x + desx,

detecto(i).area(2).y + desy), QBColor(co)

FrmPrincipalVision.PctPrincipal. Line (detecto(i).area(2).x +

desx, detecto(i).area(2).y + desy)-(detecto(i).area(3).x + desx,

detecto(i).area(3).y + desy), QBColor(co)

FrmPrincipalvision.PctPrincipal.Line (detecto(i).area(3).x +

desx, detecto(i).area(3).y + desy)-(detecto(i).area(0).x + desx,

detecto(i).area $(0) \cdot y+$ desy), eBColor (co)

Next i

End Sub

Sub PintaSeg(i)

$\mathrm{CO}=15$

FrmPrincipalVision.PctPrincipal.Line (Seguidores(i).ant(0).x + desx, Seguidores(i).ant (0).y + desy)-(Seguidores(i).ant (0).x +

Seguidores(i). ancho + desx, Seguidores(i).ant(0).y + desy), QBColor(co)

FrmPrincipalVision. PctPrincipal. Line (Seguidores(i).ant(0).x +

Seguidores(i). ancho + desx, Seguidores(i).ant(0).y + desy)-

(Seguidores(i).ant(0).x + Seguidores(i).ancho + desx,

Seguidores(i).ant(0).y + Seguidores(i).alto + desy), QBColor(co)

FrmPrincipalVision. PctPrincipal. Line (Seguidores(i).ant(0).x + desx, Seguidores(i).ant(0).y + desy + Seguidores(i).alto) -

(Seguidores (i).ant (0).x + Seguidores(i).ancho + desx,

Seguidores(i).ant(0).y + Seguidores(i).alto + desy), QBColor(co)

FrmPrincipalVision. PctPrincipal.Line (Seguidores(i).ant(0).x + desx,

Seguidores (i).ant (0).y + desy) - (Seguidores(i).ant (0).x + desx,

Seguidores(i).ant(0).y + Seguidores(i).alto + desy), QBColor(co) $\mathrm{CO}=7$

If Seguidores(i).ant(1).x<>0 Then

FrmPrincipalVision.PctPrincipal.Line (Seguidores(i).ant(1).x,

Seguidores (i).ant(1).y)-(Seguidores(i). ant(1).x + Seguidores(i).ancho, Seguidores(i).ant (1).y), QBColor(co)

FrmPrincipalVision. PctPrincipal.Line (Seguidores(i).ant(1).x +

Seguidores(i). ancho, Seguidores(i).ant(1).y)-(Seguidores (i). ant (1).x +

Seguidores(i).ancho, Seguidores(i).ant(1).y + Seguidores(i).alto),

QBColor ( $\mathrm{CO})$

FrmPrincipalVision.PctPrincipal.Line (Seguidores(i).ant(1).x,

Seguidores (i) . ant(1).y + Seguidores(i).alto)-(Seguidores(i).ant(1). $x+$

Seguidores(i).ancho, Seguidores(i).ant(1).y + Seguidores(i).alto),

QBColor (CO)

FrmPrincipalVision.PctPrincipal.Line (Seguidores(i).ant(1).x, Seguidores (i). ant(1).y)-(Seguidores(i).ant(0).x, Seguidores(i).ant(1).y + Seguidores(i).alto), QBColor(co)

End If

If Seguidores(i).ant(2).x $<>0$ Then

FrmPrincipalVision. PctPrincipal. Line (Seguidores(i).ant (2).x,

Seguidores(i). ant(2).y) - (Seguidores(i).ant(2).x + Seguidores(i).ancho, Seguidores(i).ant (2).y), QBColor (co)

FrmPrincipalVision.PctPrincipal.Line (Seguidores (i).ant(2).x +

Seguidores(i). ancho, Seguidores(i). ant(2).y)-(Seguidores(i). ant(2).x +

Seguidores(i).ancho, Seguidores(i).ant(2).y + Seguidores(i).alto), QBColor (CO)

FrmPrincipalVision.PctPrincipal.Line (Seguidores(i).ant(2).x,

Seguidores(i) . ant(2).y + Seguidores(i).alto)-(Seguidores(i).ant(2). $x+$

Seguidores(i) . ancho, Seguidores(i).ant(2).y + Seguidores(i).alto),

QBColor ( $\mathrm{CO})$

FrmPrincipalVision.PctPrincipal.Line (Seguidores(i).ant(2).x, Seguidores(i).ant(2).y)-(Seguidores(i).ant(2).x, Seguidores(i).ant(2).y + Seguidores(i).alto), QBColor(co)

End Sub End If 


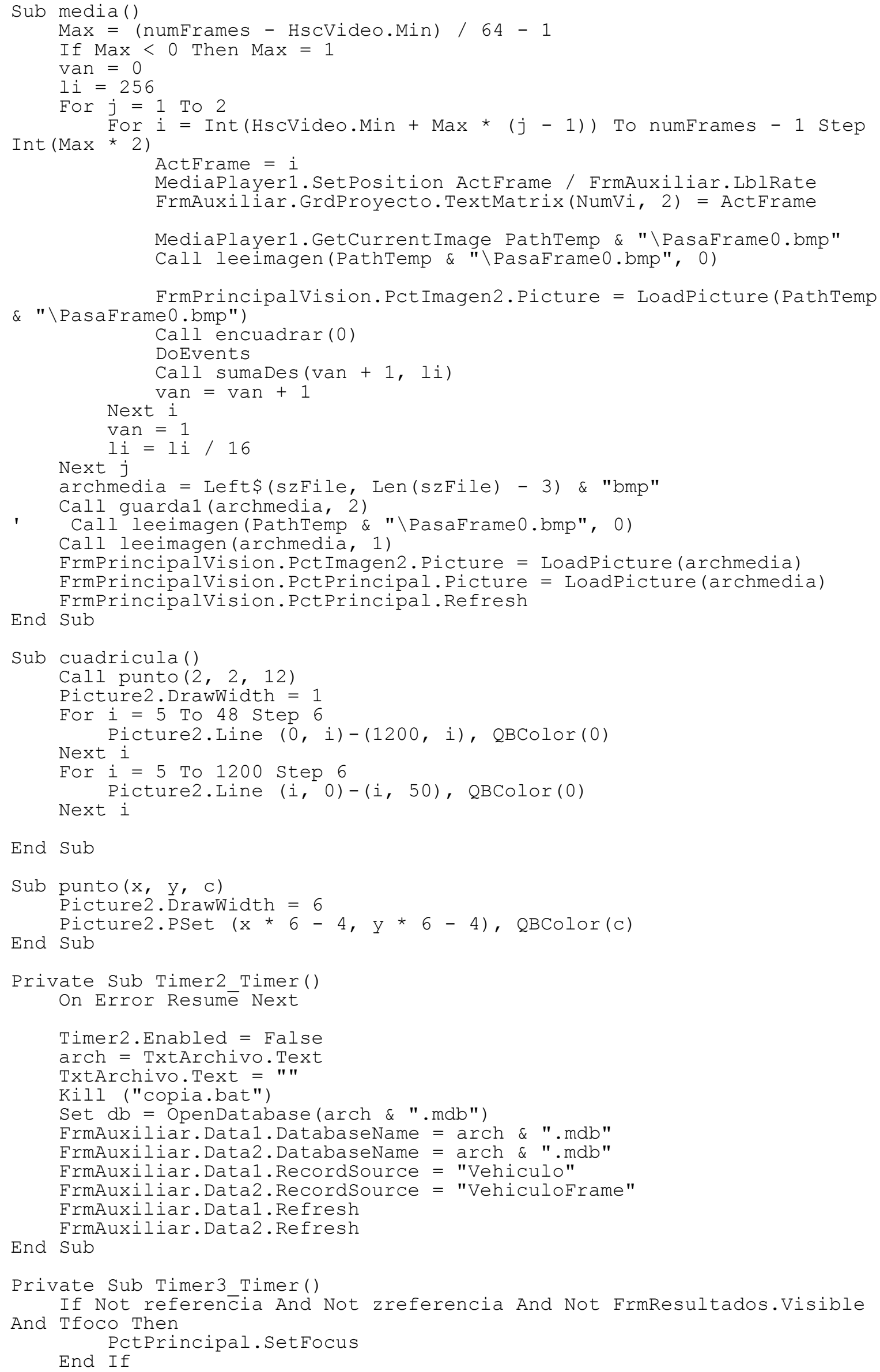

End Sub

Sub punto $(\mathrm{x}, \mathrm{y}, \mathrm{c})$ 


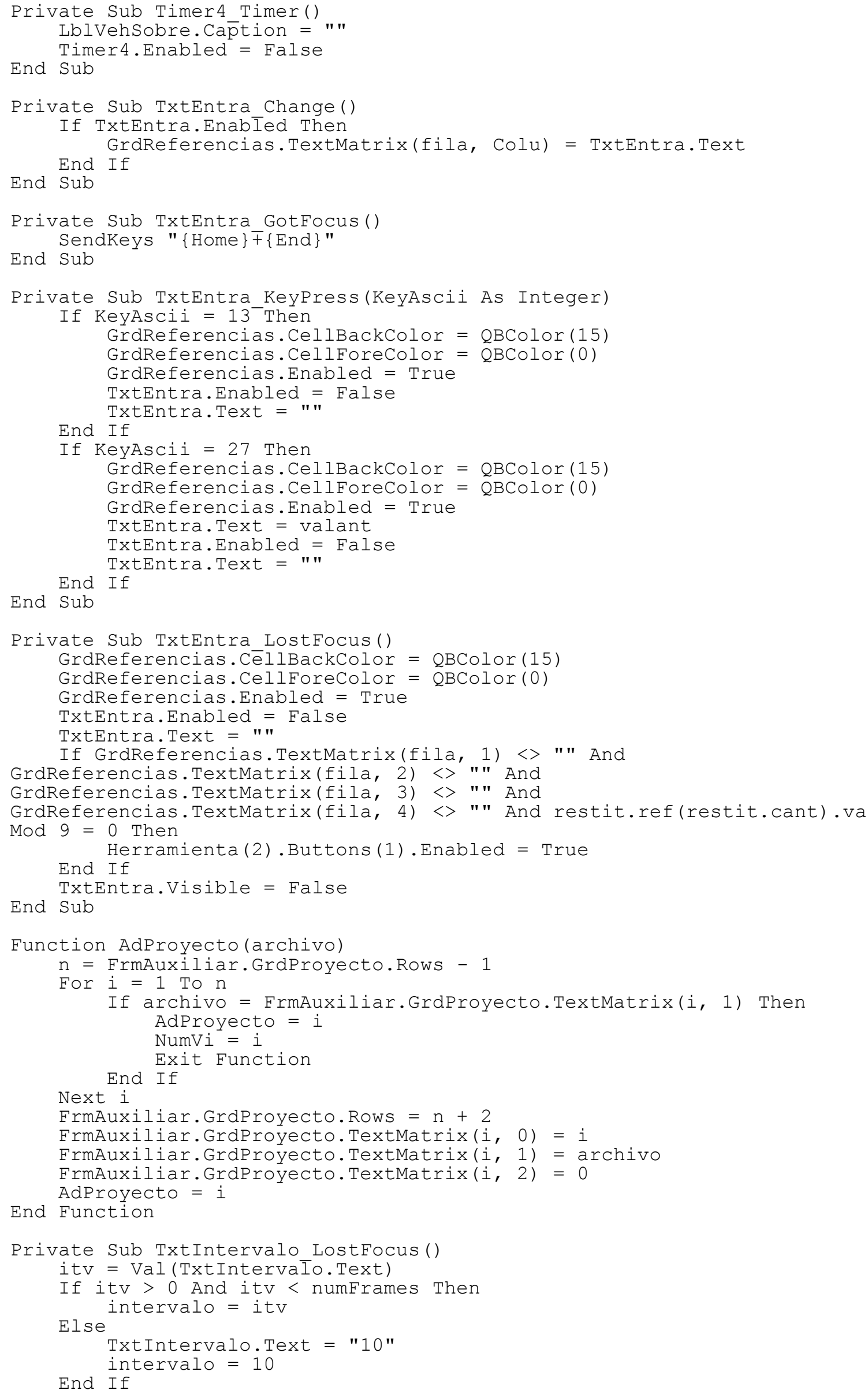




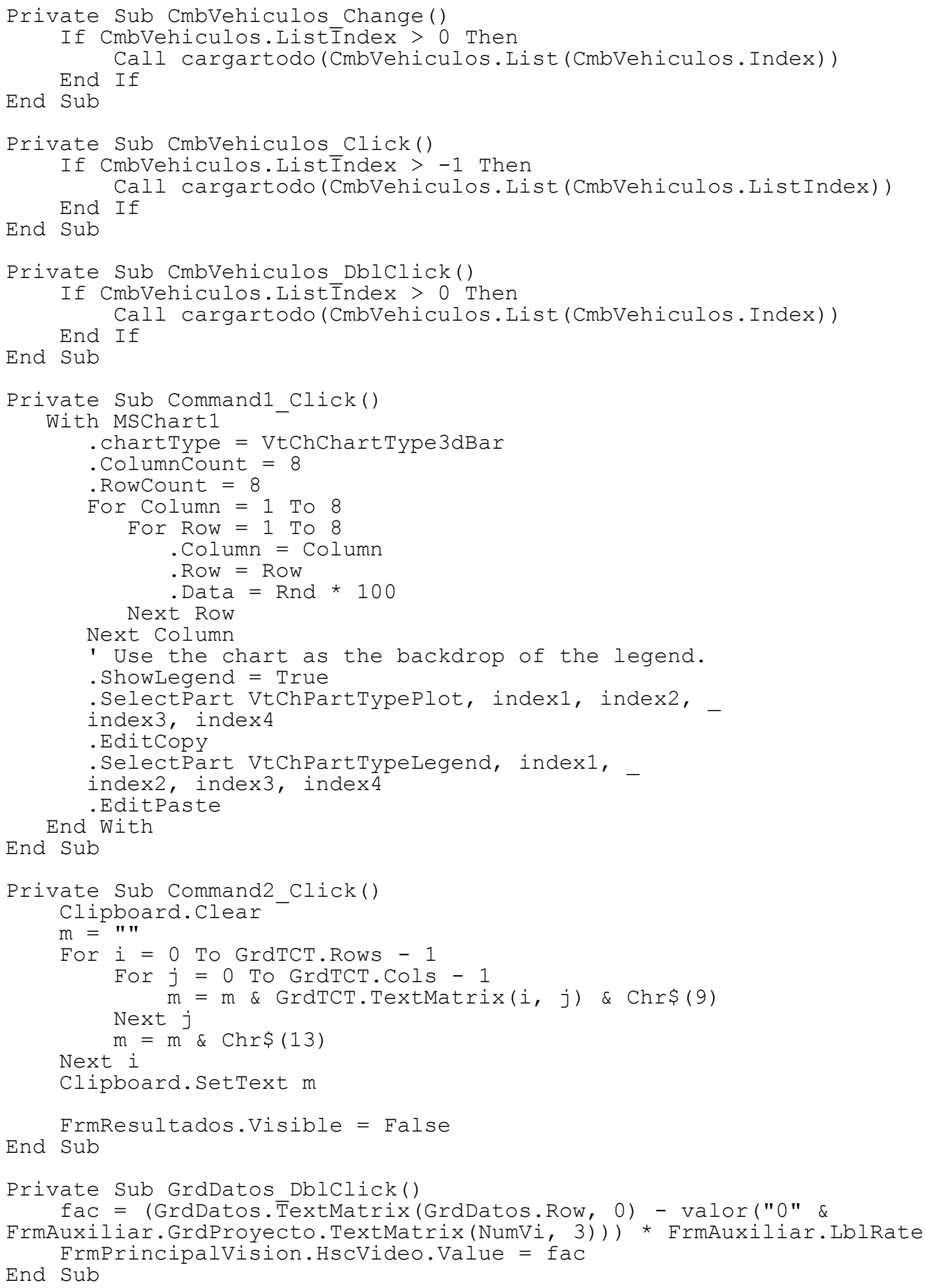




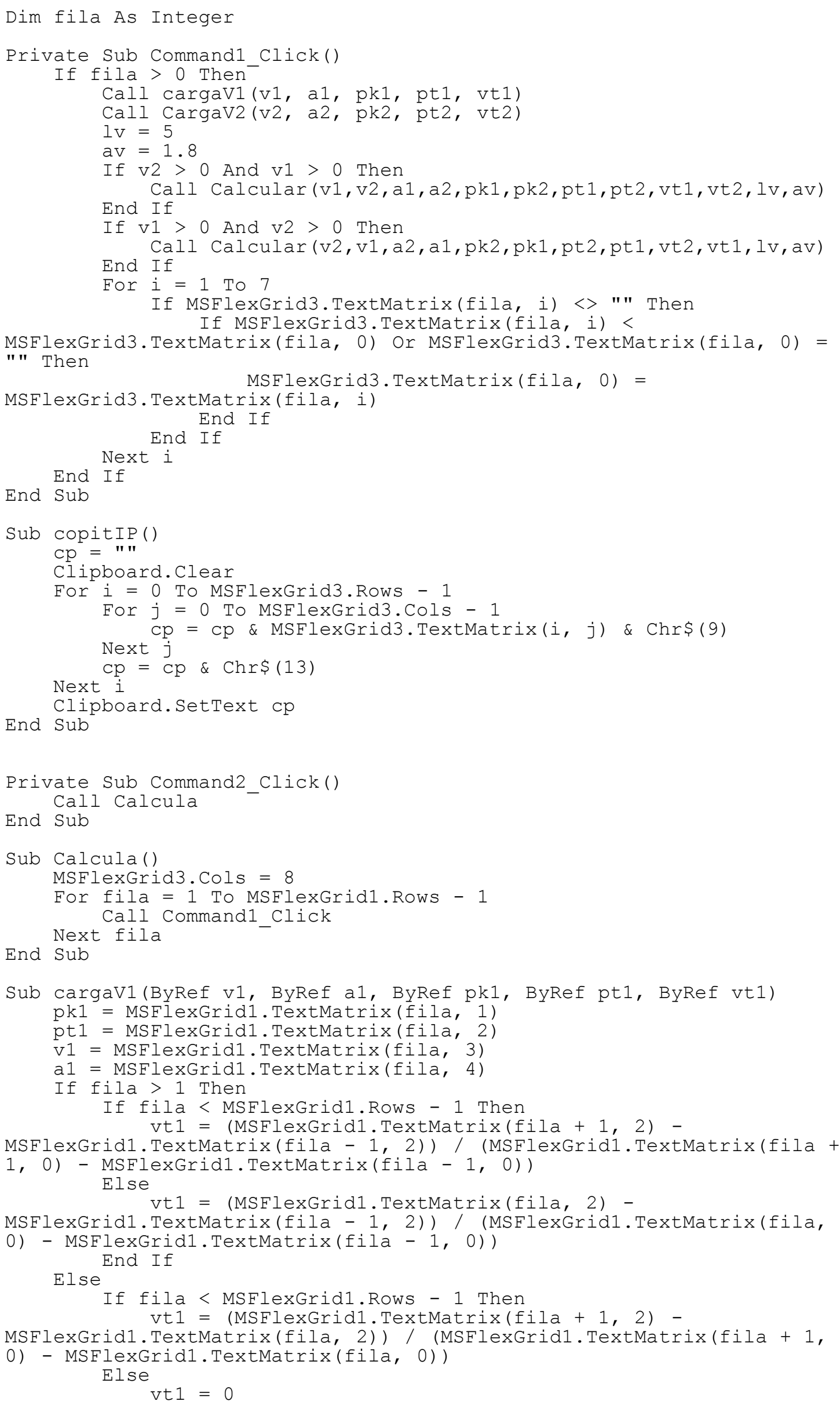

End Sub

Sub copitip()

$\mathrm{cp}=" "$

Clipboard.Clear

For $i=0$ To MSFlexGrid3. Rows - 1

For $j=0$ To MSFlexGrid3.Cols - 1

Clipboard. SetText cp

End Sub

Private Sub Command2_Click()

Call Calcula

End Sub

Sub Calcula()

MSFlexGrid3. Cols $=8$

For fila $=1$ To MSFlexGridl. Rows - 1

Next fila

End Sub

Sub cargav1 (ByRef v1, ByRef a1, ByRef pk1, ByRef pt1, ByRef vt1)

pk1 = MSFlexGrid1.TextMatrix(fila, 1)

pt1 = MSFlexGrid1. TextMatrix(fila, 2)

$\mathrm{v1}=$ MSFlexGrid1.TextMatrix(fila, 3)

al = MSFlexGridl. TextMatrix (fila, 4)

If fila $>1$ Then

If fila < MSFlexGridl.Rows - 1 Then vt1 = (MSFlexGrid1.TextMatrix(fila $+1,2) \quad$

MSFlexGrid1. TextMatrix(fila - 1, 2)) / (MSFlexGridl.TextMatrix(fila + 1 , 0) - MSFlexGrid1. TextMatrix(fila - 1, 0))

Else

vt1 = (MSFlexGrid1.TextMatrix(fila, 2) -

MSFlexGridl. TextMatrix(fila - 1, 2)) / (MSFlexGridl.TextMatrix(fila,

0) - MSFlexGrid1.TextMatrix(fila - 1, 0)) End If

Else

If fila < MSFlexGridl. Rows - 1 Then

vt1 = (MSFlexGrid1.TextMatrix(fila $+1,2)-$

MSFlexGridl. TextMatrix(fila, 2)) / (MSFlexGridl. TextMatrix(fila +1,

0) - MSFlexGridl.TextMatrix(fila, 0))

Else

$\mathrm{vt1}=0$ 
End If

" 0 . \#\#\#")

FrmTiPCLA.MSFlexGrid1.TextMatrix(fila, 5) = Format(vt1,

End If

End Sub

Sub Cargav2 (ByRef v2, ByRef a2, ByRef pk2, ByRef pt2, ByRef vt2)

ti = MSFlexGridl.TextMatrix(fila, 0)

For $\mathrm{f} 2=1$ To MSFlexGrid2. Rows - 1

If MSFlexGrid2.TextMatrix (f2, 0$)=$ ti Then

pk2 = MSFlexGrid2.TextMatrix $(f 2,1)$

pt2 = MSFlexGrid2. TextMatrix (f2, 2)

$\mathrm{v} 2=$ MSFlexGrid2. TextMatrix $(\mathrm{f} 2,3)$

$\mathrm{a} 2=$ MSFlexGrid2. TextMatrix (f2, 4)

vt2 = MSFlexGrid2.TextMatrix(f2, 5)

If $\mathrm{f} 2>1$ Then

If $\mathrm{f} 2<$ MSFlexGrid2.Rows - 1 Then

vt2 = (MSFlexGrid2.TextMatrix (f2 + 1, 2) -

MSFlexGrid2.TextMatrix(f2 - 1, 2)) / (MSFlexGrid2.TextMatrix(f2 + 1 , 0) - MSFlexGrid2.TextMatrix(f2 - 1, 0))

Else vt2 = (MSFlexGrid2. TextMatrix $(f 2,2)$ -

MSFlexGrid2.TextMatrix(f2 - 1, 2)) / (MSFlexGrid2.TextMatrix(f2, 0) MSFlexGrid2.TextMatrix(f2 - 1, 0))

Else End If

If $\mathrm{f} 2<$ MSFlexGrid2. Rows - 1 Then

vt2 = (MSFlexGrid2. TextMatrix(f2 + 1, 2) -

MSFlexGrid2.TextMatrix (f2, 2)) / (MSFlexGrid2.TextMatrix (f2 + 1, 0) MSFlexGrid2.TextMatrix (f2, 0$)$ )

Else

End If

vt2 $=0$

End If

" 0 . \#\#\#")

FrmTiPCLA.MSFlexGrid2.TextMatrix(f2, 5) = Format(vt2,

Fnd If

Exit Sub

Next f2

$\mathrm{v} 2=0$

$\mathrm{a} 2=0$

$\mathrm{pk} 2=0$

pt2 $=0$

$\mathrm{vt} 2=0$

End Sub

Sub Calcular(v1, v2, a1, a2, pk1, pk2, pt1, pt2, vt1, vt2, lv, av) $\mathrm{C}=0$

$\mathrm{mi}=$ evalua $(\mathrm{v} 1, \mathrm{v} 2, \mathrm{vt} 1, \mathrm{vt} 2, \mathrm{pk} 1, \mathrm{pk} 2, \mathrm{pt} 1, \mathrm{pt} 2,-20 / 3.6,0,0,0,1 \mathrm{v}, \mathrm{av})$

If $\mathrm{mi}<100$ Then MSFlexGrid3. TextMatrix(fila, 1) = mi

$\mathrm{mn}=$ evalua(v1, v2, vt1, vt2, pk1, pk2, pt1, pt2, $-10 / 3.6,0,1$,

$0, \quad l v, a v)$

If $\mathrm{mn}<\mathrm{mi}$ Then

$\mathrm{mi}=\mathrm{mn}$

$\mathrm{C}=1$

End If

If $m n<100$ And (mn < MSFlexGrid3. TextMatrix(fila, 2) Or

MSFlexGrid3. TextMatrix(fila, 2) = "") Then

End If

MSFlexGrid3. TextMatrix(fila, 2) = mn

$\mathrm{mn}=$ evalua $(\mathrm{v} 1, \mathrm{v} 2, \mathrm{vt1}, \mathrm{vt2}, \mathrm{pk} 1, \mathrm{pk} 2, \mathrm{pt1}, \mathrm{pt} 2,-10 / 3.6,0,-$

$1,0,1 \mathrm{v}, \mathrm{av})$

If $\mathrm{mn}<\mathrm{mi}$ Then

$\mathrm{mi}=\mathrm{mn}$

$c=2$

End If

If $m n<100$ And (mn < MSFlexGrid3. TextMatrix(fila, 3) Or

MSFlexGrid3.TextMatrix(fila, 3) = "") Then

End If

MSFlexGrid3. TextMatrix(fila, 3) $=\mathrm{mn}$

$\mathrm{mn}=$ evalua (v1, v2, vt1, vt2, pk1, pk2, pt1, pt2, $-10 / 10.8,0$,

$1.5,0,1 \mathrm{v}, \mathrm{av}$ 


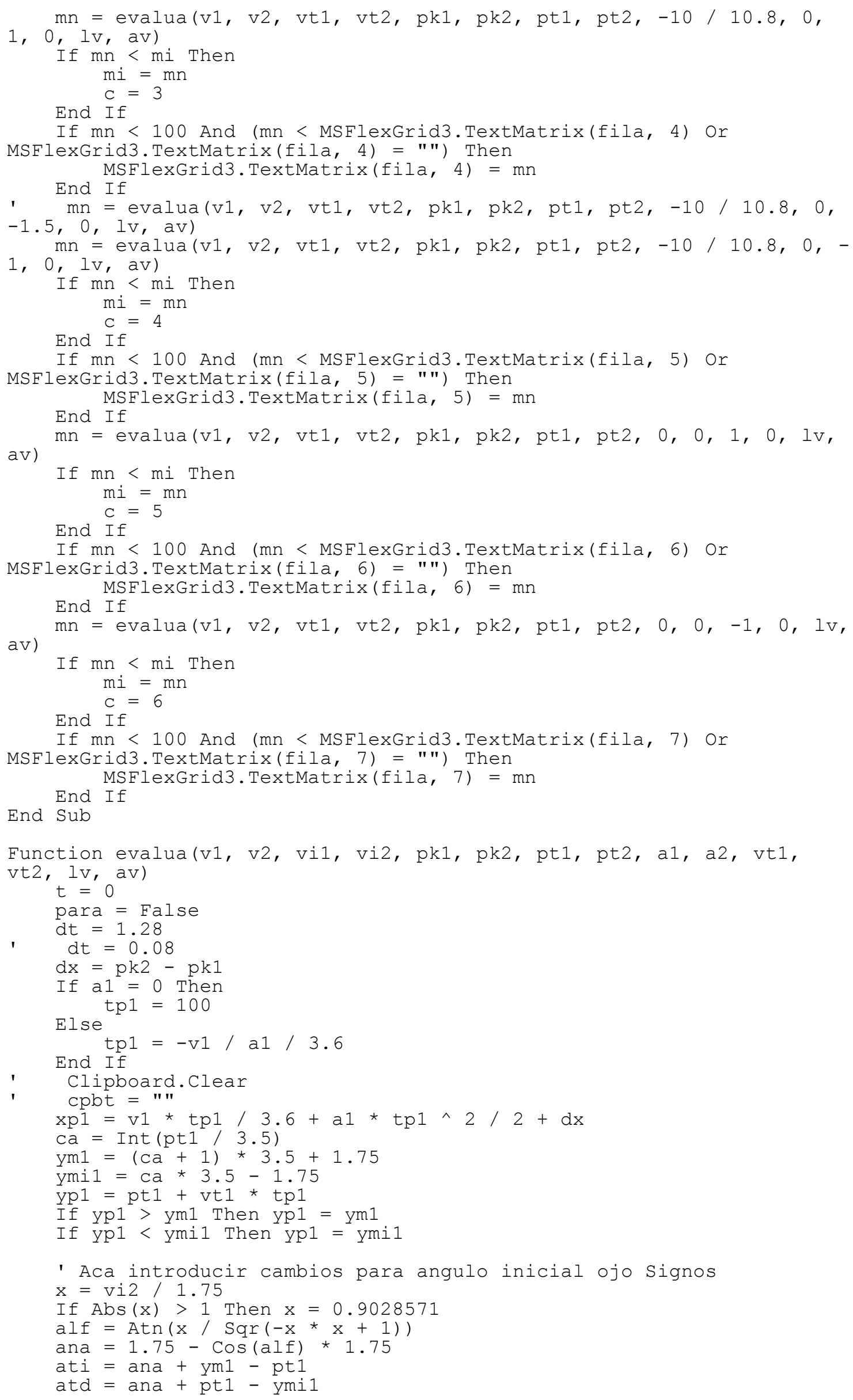




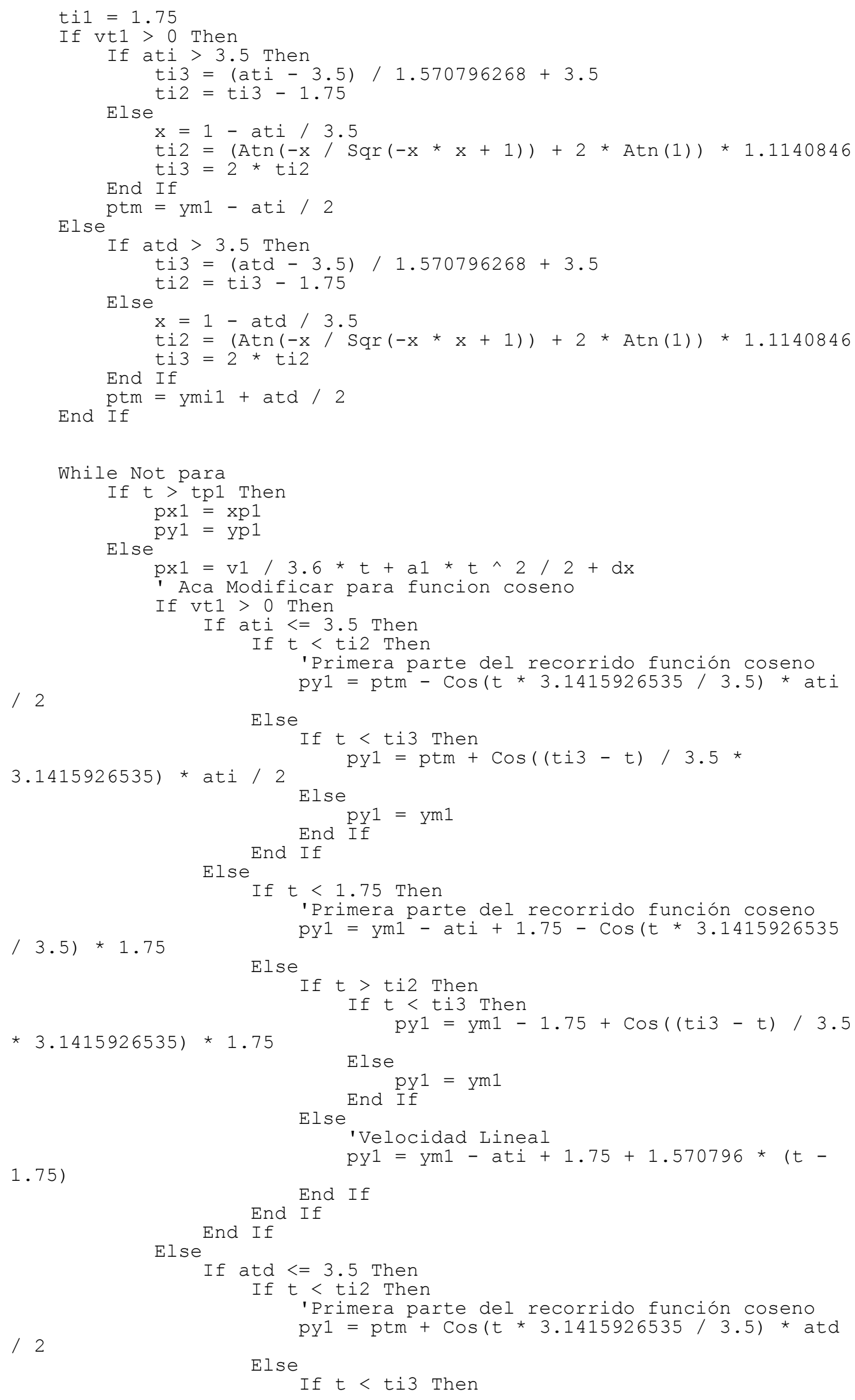




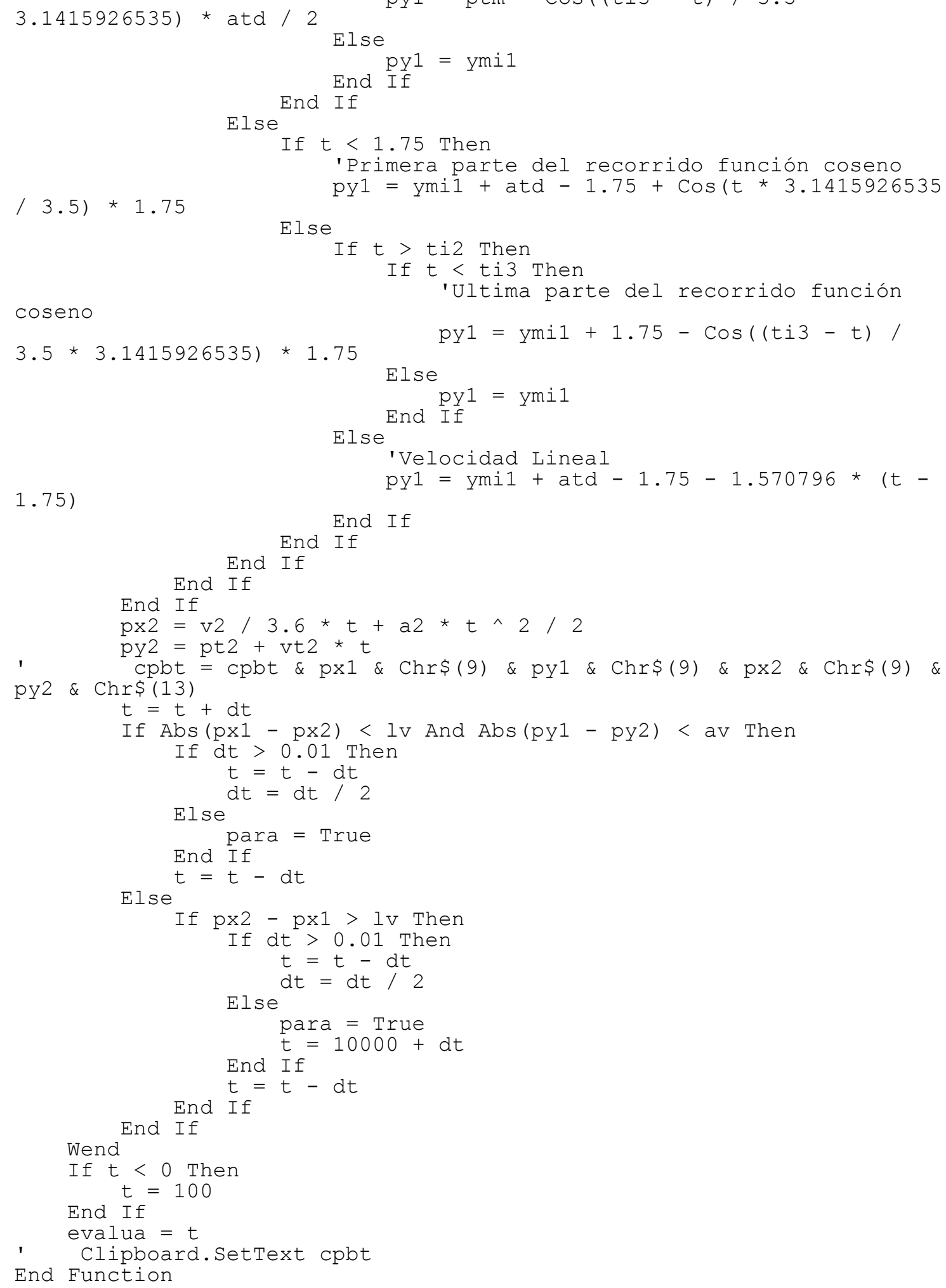

$1.75)$

'Velocidad Lineal 


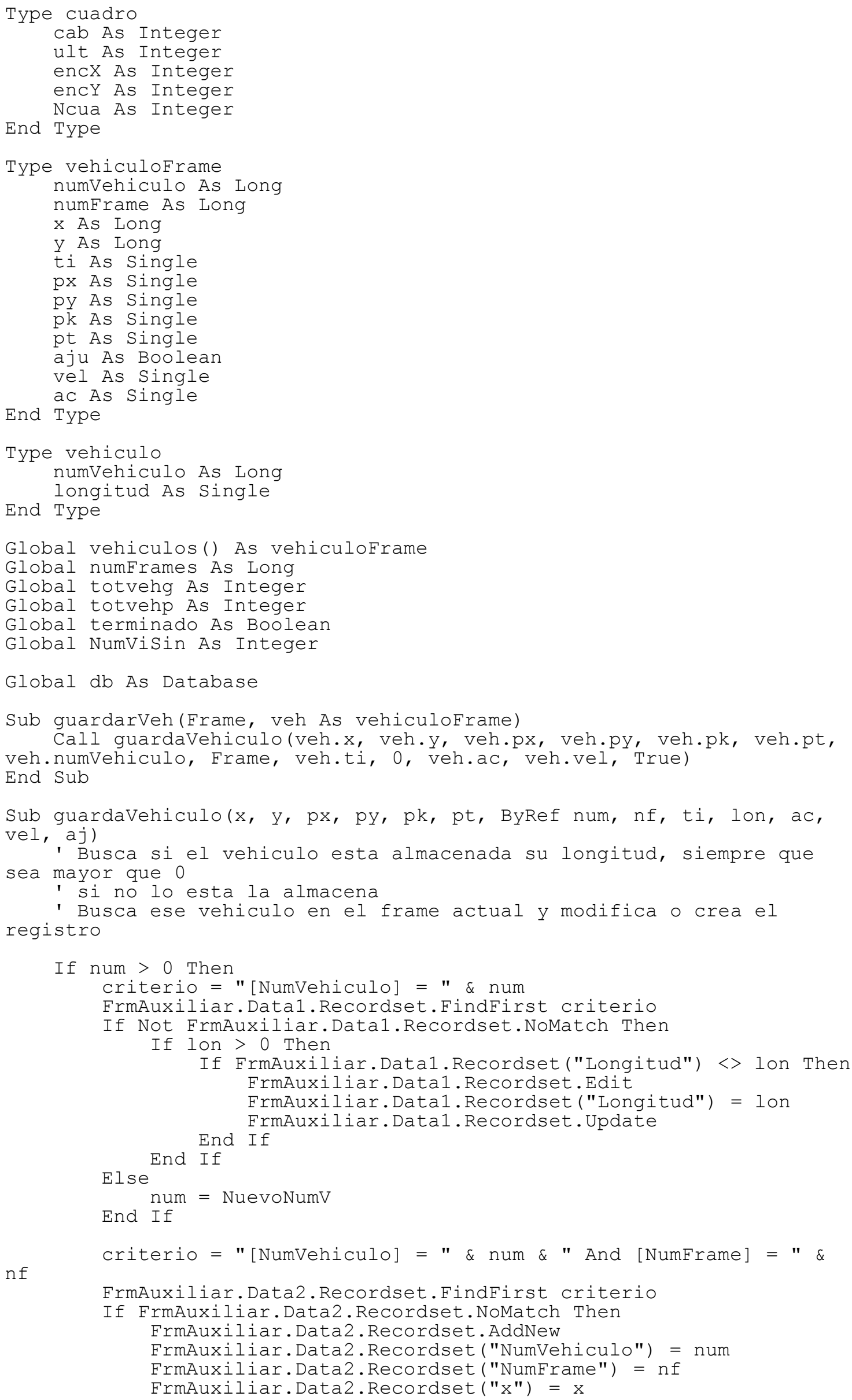

Global vehiculos() As vehiculoframe

Global numFrames As Long

Global totvehg As Integer

Global totvehp As Integer

Global terminado As Boolean

Global NumViSin As Integer

Global db As Database

Sub guardarVeh (Frame, veh As vehiculoframe)

Call guardaVehiculo(veh.x, veh.y, veh.px, veh.py, veh.pk, veh.pt, veh.numVehiculo, Frame, veh.ti, 0, veh.ac, veh.vel, True) End Sub 


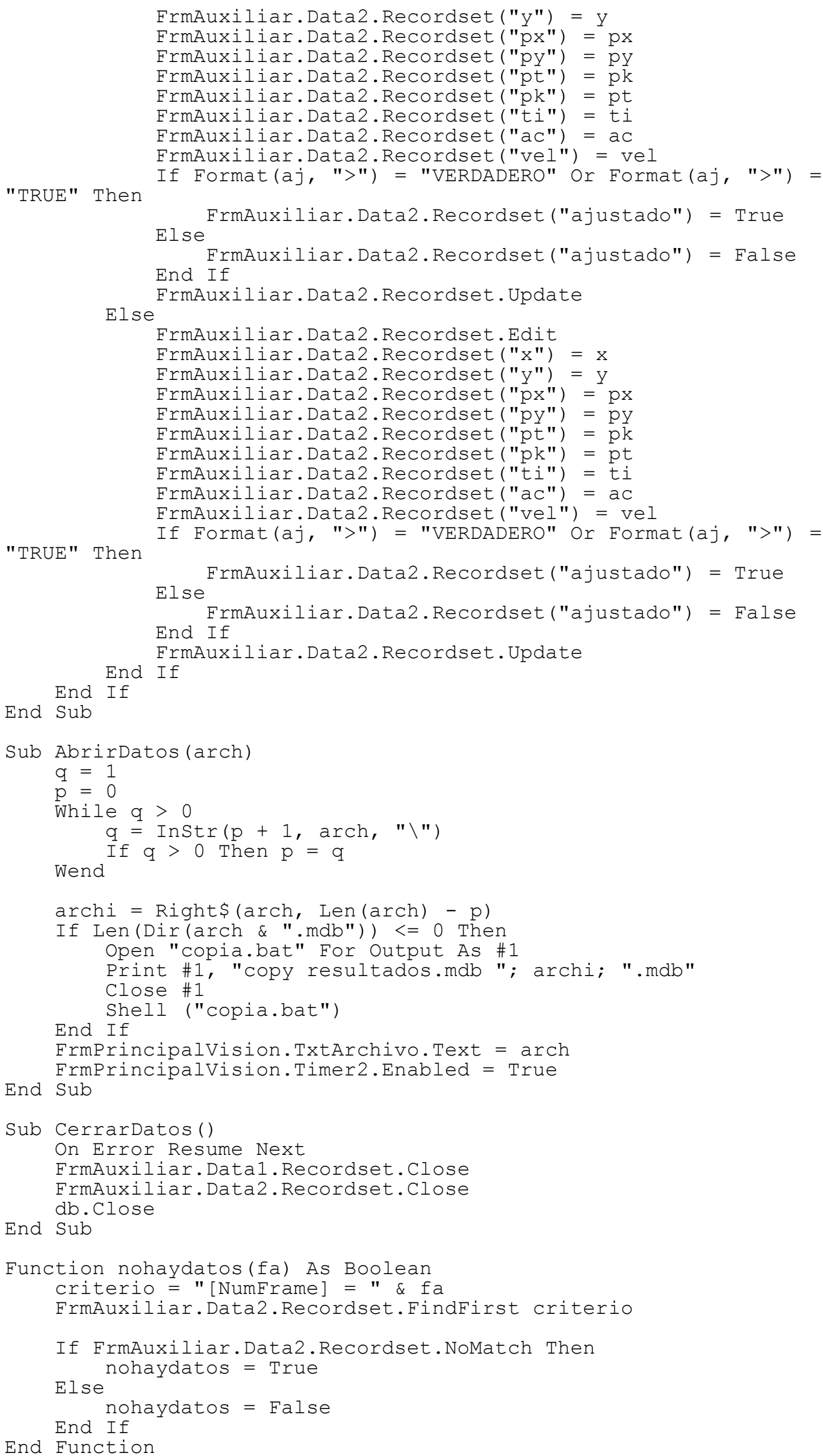

End Sub

Sub AbrirDatos (arch)

$q=1$

$\mathrm{p}=0$

While $\mathrm{q}>0$

$q=\operatorname{InStr}(p+1, \operatorname{arch}, " \backslash ")$

Wend

If $q>0$ Then $p=q$

archi = Right\$(arch, Len (arch) - p)

If Len(Dir(arch \& ".mdb")) $<=0$ Then

Open "copia.bat" For Output As \#1

Print \#1, "copy resultados.mdb "; archi; ".mdb"

Close \#1

End If

Shell ("copia.bat")

FrmPrincipalVision.TxtArchivo.Text = arch

End Sub

FrmPrincipalVision.Timer2. Enabled = True

Sub CerrarDatos()

On Error Resume Next

FrmAuxiliar.Datal.Recordset.Close

FrmAuxiliar.Data2. Recordset. Close

End Sub

db. Close

Function nohaydatos(fa) As Boolean

criterio = "[NumFrame] = " \& fa

FrmAuxiliar.Data2.Recordset.FindFirst criterio

If FrmAuxiliar.Data2.Recordset.NoMatch Then

Else nohaydatos = True

End If

End Function 
cargartodo (NumVeh)

- Busca un vehiculo y carga todas sus posiciones

' en un Grid

Dim vetl As vehiculoFrame

criterio = "[NumVehiculo] $=" \&$ NumVeh

FrmAuxiliar.Data2.Recordset.FindFirst criterio

$\mathrm{f}=0$

FrmResultados.GrdDatos.Rows $=2$

While Not FrmAuxiliar.Data2.Recordset. NoMatch $\mathrm{f}=\mathrm{f}+\mathrm{I}$

vetl.numVehiculo = FrmAuxiliar.Data2.Recordset ("NumVehiculo")

vetl. $\mathrm{x}=$ FrmAuxiliar.Data2.Recordset $(" \mathrm{x} ")$

vetl.y = FrmAuxiliar.Data2.Recordset ("y")

vetl.px = FrmAuxiliar.Data2. Recordset ("px")

vetl.py = FrmAuxiliar.Data2.Recordset ("py")

vetl.pk = FrmAuxiliar.Data2.Recordset ("pt")

vetl.pt = FrmAuxiliar.Data2.Recordset("pk")

vetl.ti = FrmAuxiliar.Data2.Recordset("ti")

vetl.ac = FrmAuxiliar.Data2.Recordset("ac")

vetl.vel = FrmAuxiliar.Data2.Recordset ("vel")

vetl.aju = FrmAuxiliar.Data2.Recordset ("ajustado")

Call llenaGrid(vetl, f,

FrmAuxiliar.Data2.Recordset ("NumFrame"), 1) Wend

FrmAuxiliar.Data2.Recordset.FindNext criterio

End Sub

Sub CargaTodoAjustado (NumVeh, donde)

' Busca un vehiculo y carga todas sus posiciones

' en un Grid

Dim vetl As vehiculoframe

criterio = "[NumVehiculo] $=" \&$ NumVeh

FrmAuxiliar.Data2.Recordset.FindFirst criterio

$\mathrm{f}=0$

FrmResultados.GrdDatos.Rows $=2$

While Not FrmAuxiliar.Data2.Recordset. NoMatch

If FrmAuxiliar.Data2.Recordset("ajustado") or donde > 1 Then $\mathrm{f}=\mathrm{f}+\mathrm{I}$

vetl.numVehiculo =

FrmAuxiliar.Data2.Recordset ("NumVehiculo")

vetl.x = FrmAuxiliar.Data2.Recordset ("x")

vetl.y = FrmAuxiliar.Data2.Recordset ("y")

vetl.px = FrmAuxiliar.Data2.Recordset ("px")

vet $1 . \mathrm{py}=$ FrmAuxiliar.Data2.Recordset ("py")

vetl.pk = FrmAuxiliar.Data2.Recordset ("pt")

vetl.pt $=$ FrmAuxiliar.Data2.Recordset ("pk")

vetl.ti = FrmAuxiliar.Data2.Recordset ("ti")

vetl.ac = FrmAuxiliar.Data2.Recordset ("ac")

vetl.vel = FrmAuxiliar.Data2.Recordset ("vel")

vetl.aju = FrmAuxiliar.Data2.Recordset("ajustado")

Call lienaGrid(vetl, f,

FrmAuxiliar.Data2.Recordset("numFrame"), donde)

End If

Wend

FrmAuxiliar.Data2.Recordset.FindNext criterio

FrmResultados. GrdDatos. Col =0

End Sub

FrmResultados.GrdDatos.Sort $=3$

Sub llenaGrid(veh As vehiculoFrame, f, fra, donde)

If donde $=1$ Then

If FrmResultados.GrdDatos.Rows $<=$ f Then

End If

FrmResultados.GrdDatos.Rows $=f+1$

FrmResultados.GrdDatos.TextMatrix(f, 0) = fra

FrmAuxiliar.LblRate + valor("0" \&

FrmAuxiliar.GrdProyecto.TextMatrix (NumVi, 3))

FrmResultados.GrdDatos.TextMatrix(f, 1) = fra

FrmResultados.GrdDatos.TextMatrix $(f, 2)=$ veh.numVehiculo

FrmResultados.GrdDatos.TextMatrix $(\mathrm{f}, 3)=$ veh.x 


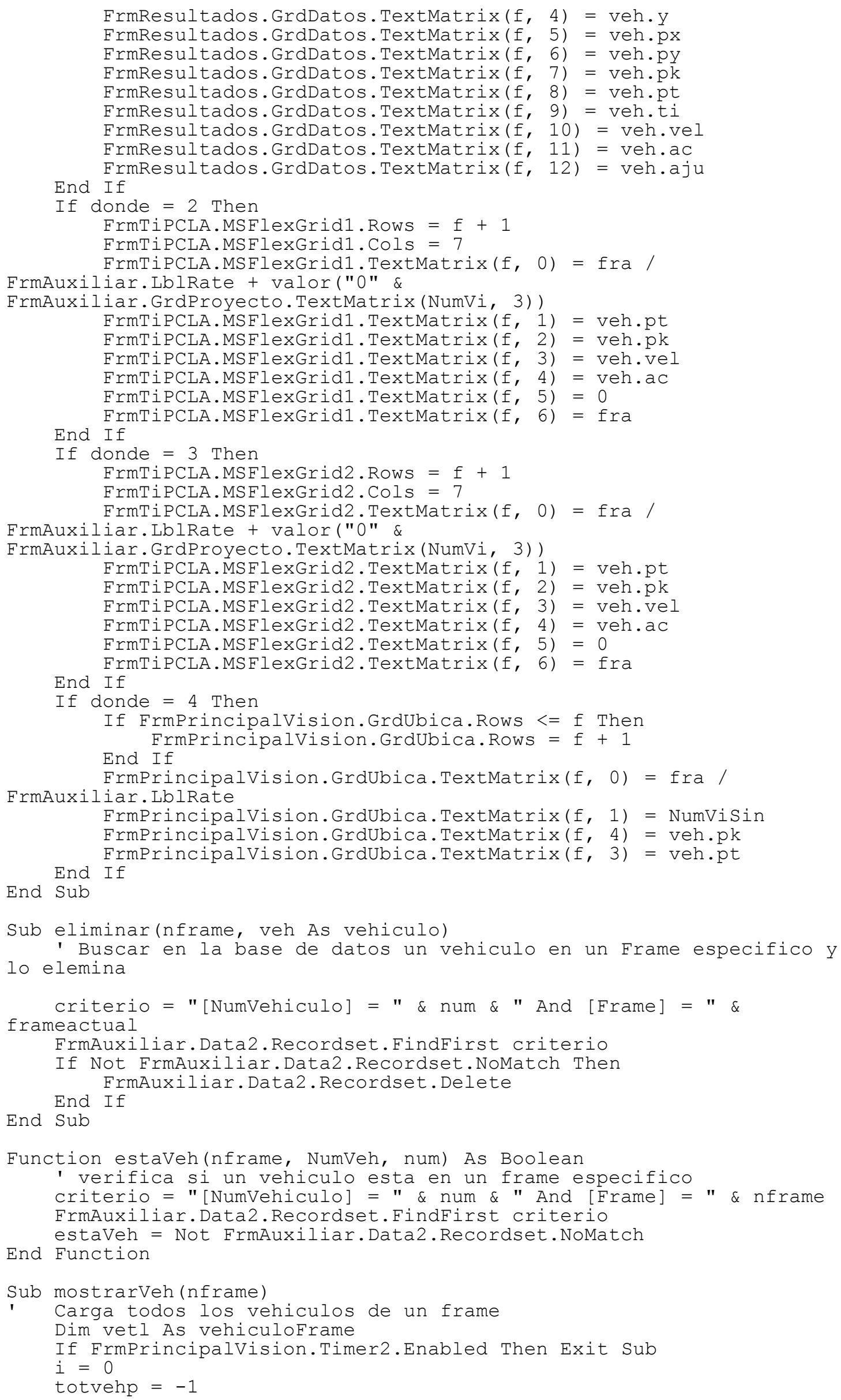


criterio = "[numFrame] = " \& nframe

FrmAuxiliar.Data2.Recordset.FindFirst criterio

While Not FrmAuxiliar.Data2.Recordset. NoMatch

vetl.numVehiculo = FrmAuxiliar.Data2.Recordset ("NumVehiculo")

vetl. $\mathrm{x}=$ FrmAuxiliar.Data2.Recordset ("x")

vetl.y = FrmAuxiliar.Data2.Recordset ("y")

vetl.px = FrmAuxiliar.Data2.Recordset ("px")

vetl.py = FrmAuxiliar.Data2.Recordset ("py")

vetl.pk = FrmAuxiliar.Data2.Recordset ("pt")

vetl.pt $=$ FrmAuxiliar.Data2.Recordset ("pk")

vetl.ti = FrmAuxiliar.Data2.Recordset("ti")

vetl.ac = FrmAuxiliar.Data2.Recordset("ac")

vetl.vel = FrmAuxiliar.Data2.Recordset ("vel")

vetl.aju = FrmAuxiliar.Data2.Recordset ("ajustado")

vetl.numFrame = FrmAuxiliar.Data2.Recordset ("NumFrame")

If $i>$ totvehg Then

ReDim vehiculos $(i+10)$ As vehiculoframe

End If

totvehg $=i+10$

vehiculos $(i)=\operatorname{vet} l$

$i=i+1$

totvehp $=i$

Wend

FrmAuxiliar.Data2.Recordset. FindNext criterio

If Val (FrmPrincipalVision.TxtVehActual. Text) > 0 Then

$\mathrm{ya}=0$

For $i=0$ To totvehp -1

If Val (FrmPrincipalVision.TxtVehActual.Text) =

vehiculos(i). numvehiculo Then

Next i

End If

$$
\begin{aligned}
& \text { ya }=1 \\
& \text { Exit For }
\end{aligned}
$$

If $\mathrm{ya}=0$ Then

FrmPrincipalVision.TxtVehActual. Text = NumVeh

If totvehp $>=$ totvehg Then

ReDim Preserve vehiculos (totvehp + 10) As

vehiculoframe

End If

totvehg $=$ totvehp +10

totvehp $=$ totvehp +1

vehiculos (totvehp) $\cdot$ ac $=0$

vehiculos (totvehp). $a j u=$ False

vehiculos (totvehp). numFrame = ActFrame

vehiculos (totvehp). numVehiculo = NumVeh

vehiculos (totvehp) $\cdot$ pk $=0$

vehiculos (totvehp).pt $=0$

vehiculos (totvehp). $\mathrm{x}=0$

vehiculos (totvehp) $\cdot y=0$

vehiculos (totvehp) $\cdot \mathrm{px}=0$

vehiculos (totvehp) $\cdot$ py $=0$

vehiculos (totvehp). ti $=0$

vehiculos (totvehp). vel = 0

End If

End If

Call MuestraVeh

If optimer $=-3$ Then

Call ReubicaPkPt

End If

terminado = True

End Sub

Sub RecalculaXY1()

Carga todos los vehiculos y recalcula su posicion

Dim vetl As vehiculoframe

criterio = "[Ajustado] = TRUE"

FrmAuxiliar.Data2.Recordset.FindFirst criterio

While Not FrmAuxiliar.Data2. Recordset. NoMatch

vetl.numVehiculo = FrmAuxiliar.Data2.Recordset ("NumVehiculo")

vetl.x = FrmAuxiliar.Data2.Recordset ("x")

vetl.y = FrmAuxiliar.Data2.Recordset ("y")

vetl.px = FrmAuxiliar.Data2. Recordset ("px")

vetl.py $=$ FrmAuxiliar.Data2.Recordset("py") 
vetl.pk = FrmAuxiliar.Data2.Recordset ("pt")

vetl.pt $=$ FrmAuxiliar.Data2.Recordset ("pk")

vetl.ti = FrmAuxiliar.Data2.Recordset("ti")

vetl.ac = FrmAuxiliar.Data2.Recordset ("ac")

vetl.vel = FrmAuxiliar.Data2.Recordset ("vel")

vetl.aju = FrmAuxiliar.Data2.Recordset("ajustado")

vetl.numFrame = FrmAuxiliar.Data2.Recordset ("NumFrame")

Call trazaretro(vetl.py, vetl.px, vetl.x, vetl.y)

FrmAuxiliar.Data2.Recordset. Edit

FrmAuxiliar.Data2.Recordset $(" \mathrm{x} ")$ = vetl.x

FrmAuxiliar.Data2.Recordset("y") = vetl.y

FrmAuxiliar.Data2. Recordset. Update Wend

FrmAuxiliar. Data2. Recordset.FindNext criterio

End Sub

Sub RecalculaXY ()

Carga todos los vehiculos y recalcula su posicion

Dim vetl As vehiculoframe

FrmAuxiliar.Data2.Recordset.MoveFirst

While Not FrmAuxiliar.Data2.Recordset.EOF

vetl.numVehiculo = FrmAuxiliar.Data2.Recordset ("NumVehiculo")

vetl. $\mathrm{x}=$ FrmAuxiliar.Data2.Recordset ("x")

vetl.y = FrmAuxiliar.Data2.Recordset ("y")

vetl.px = FrmAuxiliar.Data2. Recordset ("px")

vetl.py = FrmAuxiliar.Data2.Recordset ("py")

vetl.pk = FrmAuxiliar.Data2.Recordset ("pt")

vetl.pt $=$ FrmAuxiliar.Data2.Recordset ("pk")

vetl.ti = FrmAuxiliar.Data2.Recordset ("ti")

vetl.ac = FrmAuxiliar.Data2.Recordset ("ac")

vetl.vel = FrmAuxiliar.Data2.Recordset ("vel")

vetl.aju = FrmAuxiliar.Data2.Recordset ("ajustado")

vet1.numFrame = FrmAuxiliar.Data2.Recordset ("NumFrame")

If vetl.aju Then Else

Call trazaretro(vetl.py, vetl.px, vetl.x, vetl.y)

End If

Call trazaretro(vetl.pt, vetl.pk, vetl.x, vetl.y)

FrmAuxiliar.Data2.Recordset.Edit

FrmAuxiliar.Data2. Recordset ("x") = vetl.x

FrmAuxiliar.Data2. Recordset("y") = vetl.y

FrmAuxiliar.Data2. Recordset. Update

Wend

FrmAuxiliar. Data2. Recordset. MoveNext

End Sub

Sub RecalculapkPt ()

FrmPrincipalVision.HscVideo.Value =

FrmPrincipalVision.HscVideo.Max

For $i=$ FrmPrincipalVision.HscVideo.Min To

FrmprincipalVision. HscVideo.Max

criterio = "[Ajustado] = TRUE And [NumFrame] = " \& $i$

FrmAuxiliar. Data2.Recordset.FindFirst criterio

If Not FrmAuxiliar.Data2.Recordset. NoMatch Then

terminado $=$ False

optimer $=-3$

FrmPrincipalVision.HscVideo.Value = i

While Not terminado

Wend

DoEvents

Next i

End If

End Sub

Sub ReubicaPkPt ()

For $i=0$ To totvehp

If vehiculos(i).aju Then

cualveh $=i$

restit.ref(rt).pf(11).p.x = vehiculos(cualveh). $\mathrm{x}$ - desx restit.ref(rt).pf(11).p.y = vehiculos (cualveh).y - desy Call Restituir(0)

vehiculos(i))

Call guardarVeh(FrmPrincipalVision.HscVideo.Value, 
End If

Next i

terminado $=$ True

End Sub

Function NuevoNumV() As Integer

FrmAuxiliar.Data1.Recordset.AddNew

FrmAuxiliar.Data1. Recordset("Longitud") =0

NuevoNumV = Int(FrmAuxiliar.Data1.Recordset("NumVehiculo"))

FrmAuxiliar.Data1.Recordset. Update

End Function

Sub MuestraVeh ()

FrmPrincipalVision. PctPrincipal. DrawMode $=7$

FrmPrincipalVision. PctPrincipal. DrawWidth = 1

For $i=0$ To totvehp - 1

vehiculos (i) . y

Call FrmprincipalVision. PintaMarca(vehiculos(i).x,

Next i

End Sub

FrmPrincipalVision.PctPrincipal.DrawMode $=13$

Function SaleVeh (num)

criterio $="[$ NumVehiculo $]=" \&$ num

FrmAuxiliar.Data2.Recordset.FindLast criterio

SaleVeh = False

If Not FrmAuxiliar.Data2.Recordset. NoMatch Then

End If SaleVeh = (FrmAuxiliar.Data2.Recordset ("pt") < 0$)$

End Function

Sub EvaluaTCTpeaton(tr, ac, vp)

FrmResultados.GrdTCT.Rows = 1

FrmAuxiliar.Data1.Recordset.MoveFirst

$\mathrm{nf}=1$

archexp = Left\$(szFile, Len(szFile) - 3) \& "pri"

Open archexp For Output As \#7

While Not FrmAuxiliar.Datal.Recordset.EOF

num = FrmAuxiliar.Datal.Recordset ("NumVehiculo")

Call Pri(num, tr, ac, vp, nf)

Print \#7, num

For $i=1$ To FrmResultados.GrdDatos.Rows - 1

For $j=0$ To FrmResultados.GrdDatos.Cols - 1

Print \#7, FrmResultados.GrdDatos.TextMatrix(i,j);

$\operatorname{Chr} \$(9)$

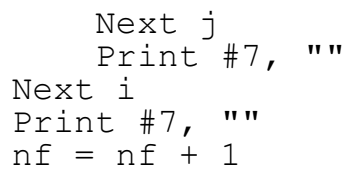

End Sub

Sub EvaluaTCT (umbral)

FrmResultados.GrdTCT.Rows $=1$

FrmAuxiliar.Data1. Recordset. MoveFirst

While Not FrmAuxiliar.Datal. Recordset.EOF

num = FrmAuxiliar.Datal.Recordset("NumVehiculo")

If SaleVeh (num) Then

$$
\text { Call TiPCLA (num, umbral) }
$$

End If

FrmAuxiliar.Datal.Recordset.MoveNext 


\section{Wend}

tt $=\operatorname{valor}($ FrmResultados.LblTu) - valor (FrmResultados.LblTp)

For $i=1$ To FrmResultados.GrdTCT.Rows - 1 FrmResultados.GrdTCT.TextMatrix $(i, 6)=$

valor (FrmResultados.GrdTCT.TextMatrix(i, 1)) / tt * 3600 FrmResultados.GrdTCT.TextMatrix $(i, 7)=$

valor (FrmResultados.GrdTCT.TextMatrix(i, 2)) / tt *3600 FrmResultados.GrdTCT.TextMatrix $(i, 8)=$

valor (FrmResultados.GrdTCT.TextMatrix(i, 4)) / tt * 3600 FrmResultados.GrdTCT.TextMatrix (i, 9) =

valor (FrmResultados.GrdTCT.TextMatrix(i, 5)) / tt * 3600

Next i

For $i=1$ To FrmResultados.GrdTCT.Rows - 1

For $j=1$ To FrmResultados.GrdTCT.Cols - 1

FrmResultados.GrdTCT.TextMatrix $(i, j)=$

Format (valor (FrmResultados.GrdTCT.TextMatrix (i, j)), "0.\#\#\#\#") Next $j$

Next i

FrmResultados.Visible = True

FrmResultados.GrdDatos.Visible = False

End Sub

FrmResultados.GrdTCT.Visible = True

Sub Pri (num, tr, ac, vp, f)

FrmResultados.GrdTCT.Rows = FrmResultados.GrdTCT.Rows +1

FrmResultados.GrdDatos.Rows $=1$

FrmResultados. GrdDatos.Cols $=18$

Call cargartodo (num)

Call Calculapri(num, tr, ac, vp, f)

'Call exportapri

End Sub

Sub CalculaPri(num, tr, ac, vp, nf)

spri $=0$

st $=0$

maxpri $=0$

For $f=1$ To FrmResultados.GrdDatos.Rows - 1

$\mathrm{tp}=\operatorname{valor}($ FrmResultados.GrdDatos.TextMatrix $(\mathrm{f}, 8))$ / vp

FrmResultados.GrdDatos.TextMatrix $(\mathrm{f}, 13)=t p$

vel = valor(FrmResultados.GrdDatos.TextMatrix (f, 10)) / 3.6

If vel $>0$ Then

tfv $=$ tr + vel / $2 / \mathrm{ac}$

FrmResultados.GrdDatos.TextMatrix (f, 14) = tfv

$\mathrm{pk}=\operatorname{valor}($ FrmResultados.GrdDatos.TextMatrix (f, 7))

$\mathrm{tcv}=\mathrm{Abs}(\mathrm{pk})$ / vel

FrmResultados.GrdDatos.TextMatrix(f, 15) = tcv

If $\mathrm{f}=1$ Then

$d t=$ Abs (valor (FrmResultados.GrdDatos.TextMatrix (f,

9)) - valor(FrmResultados.GrdDatos.TextMatrix (f + 1, 9))) Else

$d t=$ Abs (valor (FrmResultados.GrdDatos.TextMatrix $(f$,

9)) - valor(FrmResultados.GrdDatos.TextMatrix(f - 1, 9)))

End If

If $t p<t c v$ And $t c v<t f v$ Then

If vel $2>2$ * ac * (Abs (pk) - tr * vel) Then

$\operatorname{vimp}=(\operatorname{vel} \wedge 2-2 \star \mathrm{ac} \star(\operatorname{Abs}(\mathrm{pk})-\operatorname{tr} \star \mathrm{vel})) \wedge$

0.5

vpri $=$ vimp $\wedge 2 *(t f v-t c v)$

FrmResultados.GrdDatos.TextMatrix $(f, 16)=$ vimp

FrmResultados.GrdDatos.TextMatrix $(f, 17)=$ vpri

' FrmResultados.GrdDatos.TextMatrix $(f, 18)=$ vpri *

$d t$

If vpri > maxpri Then maxpri = vpri

spri $=$ spri + vpri

End If

$s t=s t+d t$

End If

Next $\mathrm{f}$

End If

FrmResultados.GrdTCT.TextMatrix (nf, 0) = num

FrmResultados.GrdTCT. TextMatrix (nf, 1) = spri

FrmResultados.GrdTCT.TextMatrix $(n f, 2)=$ maxpri 
FrmResultados.GrdTCT.TextMatrix (nf, 3) = st

End Sub

Sub TiPCLA (num, umbral)

FrmTiPCLA.Lstotr.Clear

FrmTiPCLA.MSFlexGrid1.Rows $=1$

FrmTiPCLA.MSFlexGrid2. Rows $=1$

FrmTiPCLA.MSFlexGrid3. Rows $=1$

Call CargatiPCLA (num, pfr, ufr, 2)

FrmTiPCLA.MSFlexGrid3.Rows = FrmTiPCLA.MSFlexGrid1.Rows

Call Llenalistaotr(pfr, ufr, num)

If num $=61$ Then

End If

num $=$ num

For $i=0$ To FrmTiPCLA.Lstotr.ListCount - 1

Call CargaTiPCLA (FrmTiPCLA.Lstotr.List(i), pfr, ufr, 3)

Call FrmTiPCLA.Calcula

Call FrmTiPCLA. copitip

Next i

Aca colocar la copia por vehiculo para hacer la grafica

If FrmTiPCLA.Lstotr.ListCount $>0$ Then

$t \mathrm{p}=\operatorname{valor}($ FrmTiPCLA.MSFlexGrid1.TextMatrix $(1,0))$

tu $=$

valor(FrmTiPCLA.MSFlexGrid1.TextMatrix(FrmTiPCLA.MSFlexGrid1.Rows - 1, 0))

Then If FrmResultados.LblTp = "" Or valor(FrmResultados.LblTp) > tp End If

ErmResultados.LblTp $=$ tp

If FrmResultados.LblTu = " " Or valor(FrmResultados.LblTu) < tu

Then

End If

FrmResultados.LblTu $=$ tu

$i=1$

FrmResultados.GrdTCT.Rows $=(3-$ umbral $) * 10+1$

For $u=$ umbral To 3 Step 0.1

FrmResultados.GrdTCT.TextMatrix $(i, 0)=u$ FrmResultados.GrdTCT.TextMatrix $(i, 1)=$

valor (FrmResultados.GrdTCT.TextMatrix(i, 1)) + integralTiPCLA (u, tbu) FrmResultados.GrdTCT.TextMatrix (i, 2) =

valor (FrmResultados.GrdTCT.TextMatrix(i, 2)) + tbu FrmResultados.GrdTCT.TextMatrix $(i, 3)=$

valor (FrmResultados.GrdTCT.TextMatrix(i, 3)) + 1 FrmResultados.GrdTCT.TextMatrix (i, 4) =

valor (FrmResultados.GrdTCT.TextMatrix(i, 1)) /

valor (FrmResultados.GrdTCT.TextMatrix (i, 3)) FrmResultados.GrdTCT.TextMatrix $(i, 5)=$

valor (FrmResultados.GrdTCT. TextMatrix (i, 2))

valor (FrmResultados.GrdTCT.TextMatrix(i, 3)) $i=i+1$

End If

End Sub

Next u

Sub CargatipCLA (num, ByRef pfr, ByRef ufr, donde)

Call CargaTodoAjustado (num, donde)

If donde $=2$ Then

FrmTiPCLA.MSFlexGrid1. Col $=0$

FrmTiPCLA.MSFlexGrid1. Sort $=3$

pfr = FrmTiPCLA.MSFlexGrid1.TextMatrix $(1,6)$ ufr $=$

FrmTiPCLA.MSFlexGrid1.TextMatrix (FrmTiPCLA.MSFlexGrid1.Rows - 1, 6)

End If

If donde $=3$ Then

FrmTiPCLA.MSFlexGrid2. Col = 0

End If

FrmTiPCLA.MSFlexGrid2. Sort $=3$

End Sub

Sub LlenaListaotr(pfr, ufr, num)

FrmTiPCLA. Lstotr.Clear 


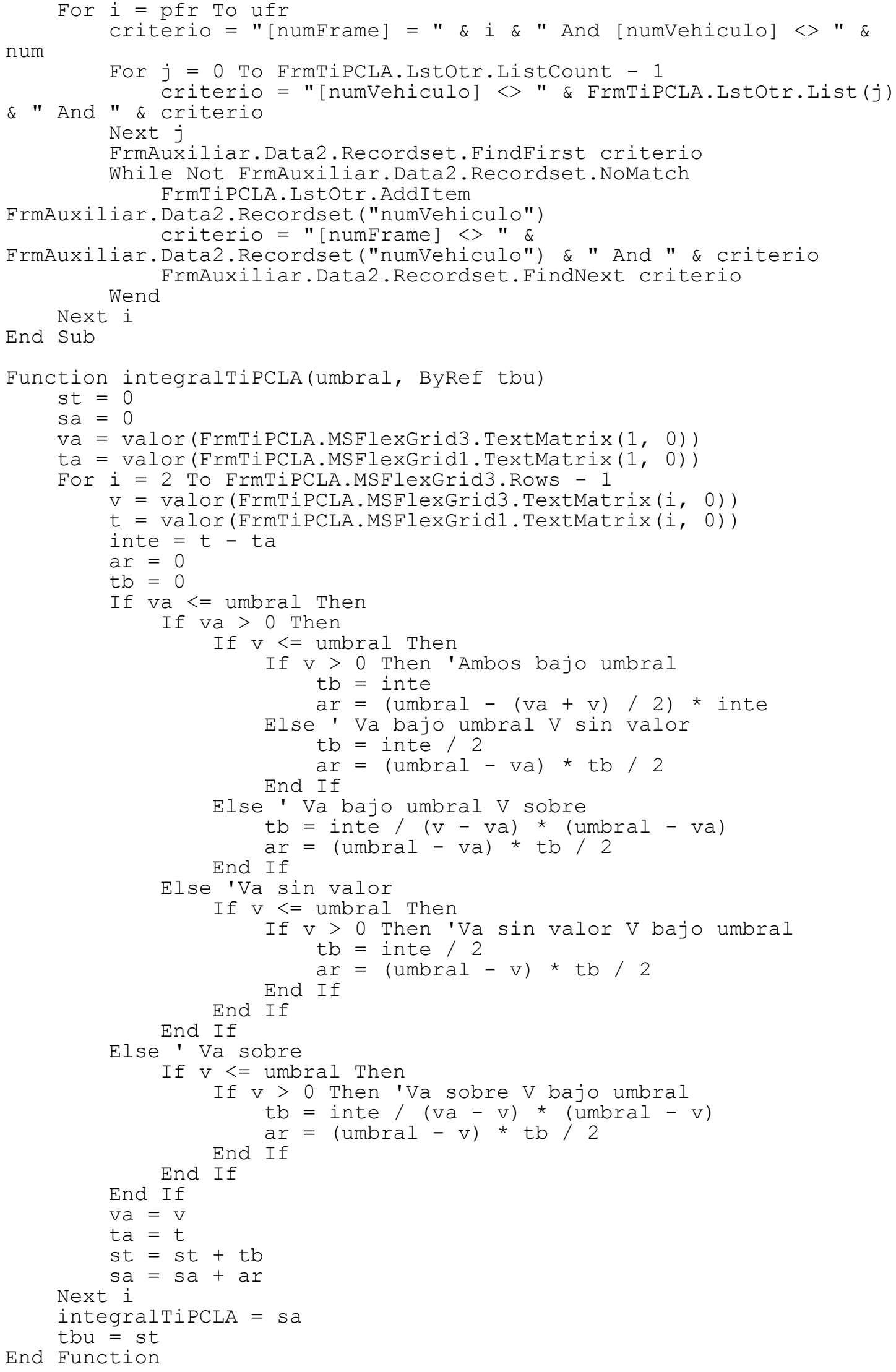




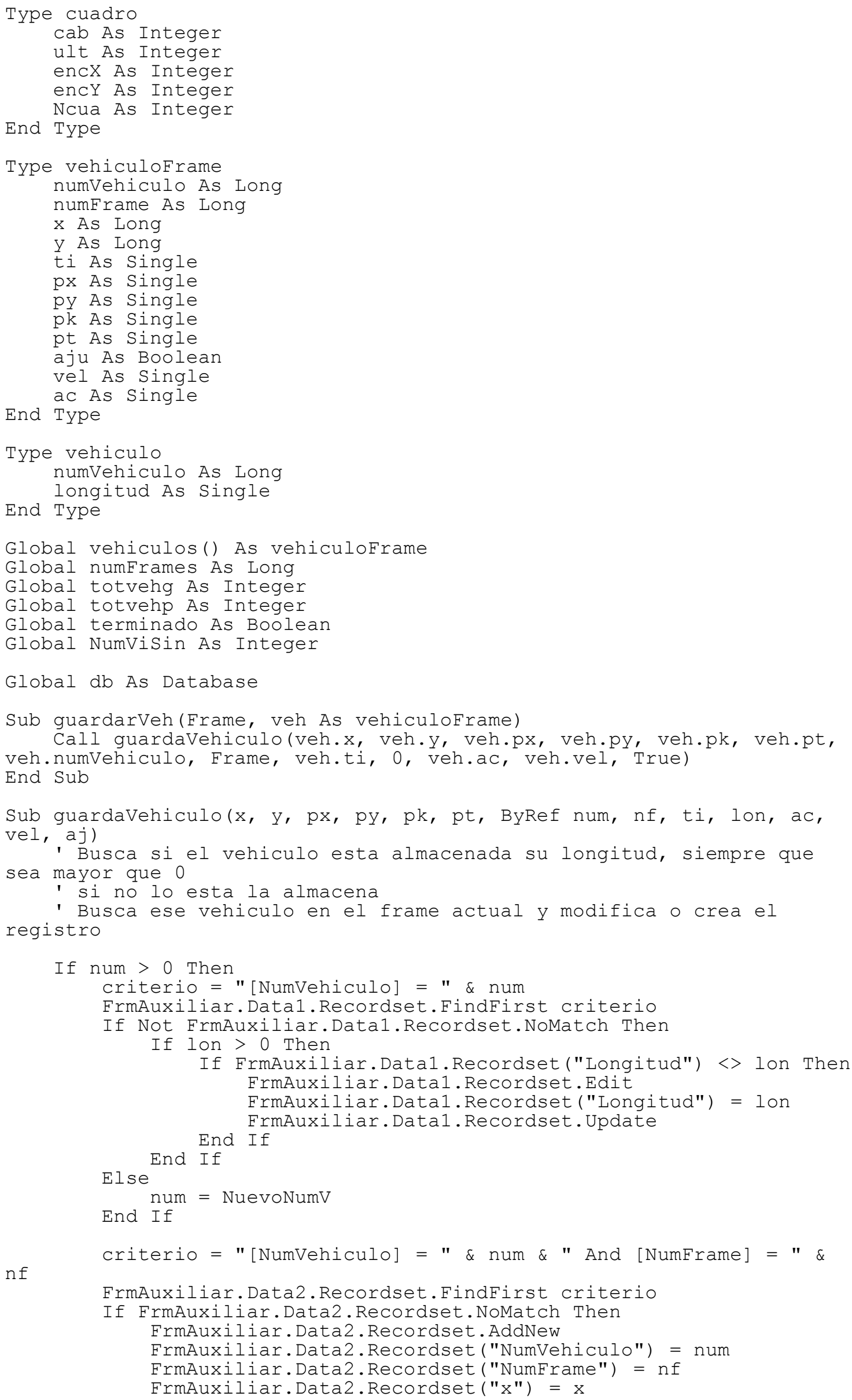

Global vehiculos() As vehiculoframe

Global numFrames As Long

Global totvehg As Integer

Global totvehp As Integer

Global terminado As Boolean

Global NumViSin As Integer

Global db As Database

Sub guardarVeh (Frame, veh As vehiculoframe)

Call guardaVehiculo(veh.x, veh.y, veh.px, veh.py, veh.pk, veh.pt, veh.numVehiculo, Frame, veh.ti, 0, veh.ac, veh.vel, True) End Sub 


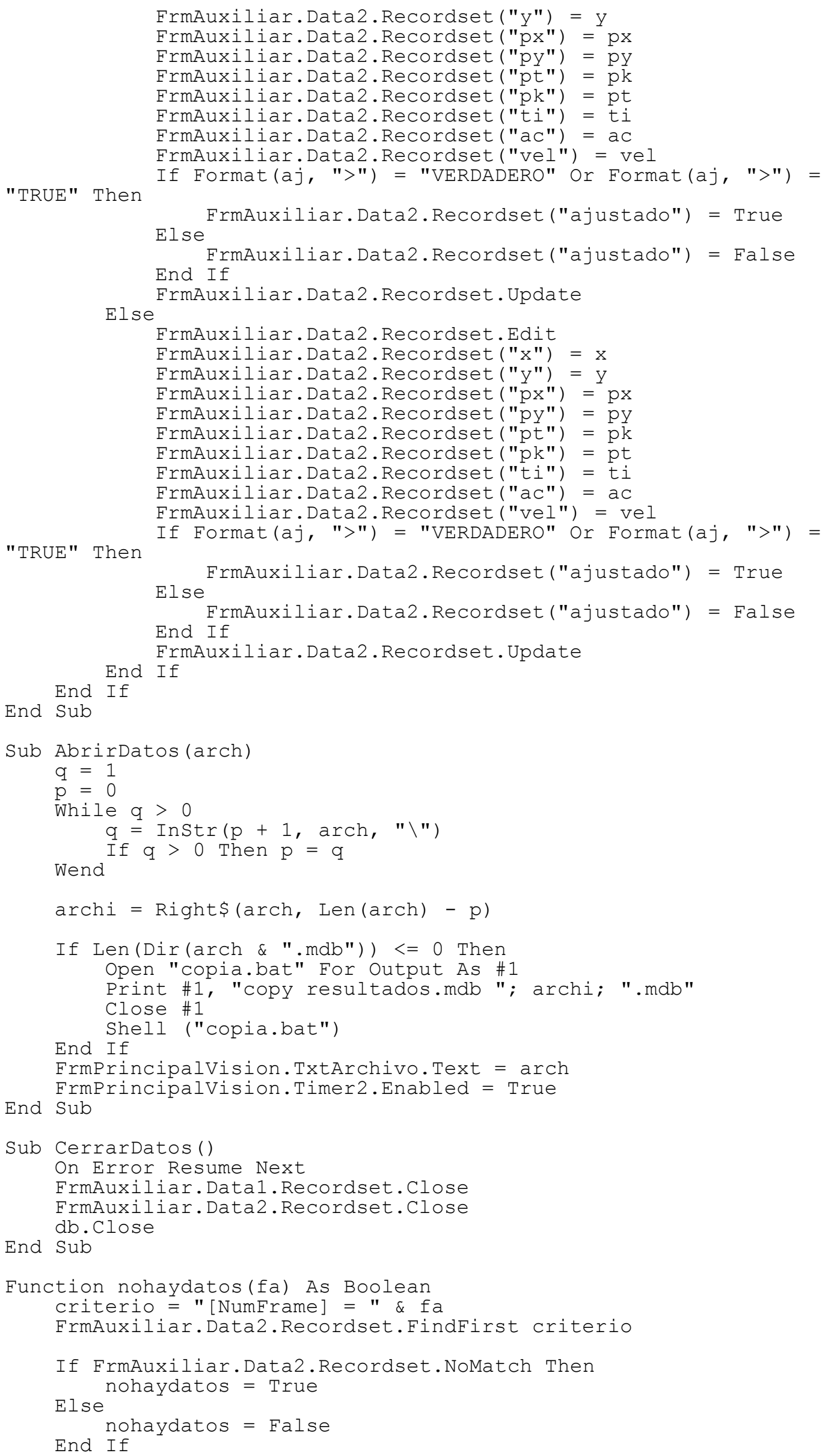

End Sub

Sub AbrirDatos (arch)

$q=1$

$\mathrm{p}=0$

While $\mathrm{q}>0$

Sub CerrarDatos()

On Error Resume Next

FrmAuxiliar.Data1.Recordset.Close

FrmAuxiliar.Data2.Recordset. Close

End Sub

$\mathrm{db} . \mathrm{Close}$

Function nohaydatos(fa) As Boolean

criterio = "[NumFrame] = " \& fa

FrmAuxiliar.Data2.Recordset.FindFirst criterio

If FrmAuxiliar.Data2.Recordset.NoMatch Then

Else nohaydatos $=$ True

End If

nohaydatos $=$ False 
End Function

Sub cargartodo (NumVeh)

' Busca un vehiculo y carga todas sus posiciones

en un Grid

Dim vetl As vehiculoFrame

criterio $="[$ NumVehiculo $]=" \&$ NumVeh

FrmAuxiliar.Data2.Recordset.FindFirst criterio

$\mathrm{f}=0$

FrmResultados. GrdDatos. Rows $=2$

While Not FrmAuxiliar.Data2.Recordset. NoMatch

$\mathrm{f}=\mathrm{f}+\mathrm{I}$

vetl.numVehiculo = FrmAuxiliar.Data2.Recordset ("NumVehiculo")

vetl.x = FrmAuxiliar.Data2.Recordset (" $\mathrm{x} "$ ")

vetl.y = FrmAuxiliar.Data2.Recordset ("y")

vet1.px = FrmAuxiliar.Data2.Recordset("px")

vetl.py = FrmAuxiliar.Data2.Recordset("py")

vetl.pk = FrmAuxiliar.Data2.Recordset ("pt")

vetl.pt $=$ FrmAuxiliar.Data2. Recordset ("pk")

vetl.ti = FrmAuxiliar.Data2.Recordset("ti")

vetl.ac = FrmAuxiliar.Data2.Recordset("ac")

vetl.vel = FrmAuxiliar.Data2.Recordset("vel")

vetl.aju = FrmAuxiliar.Data2.Recordset("ajustado")

Call llenaGrid(vetl, f,

FrmAuxiliar.Data2.Recordset ("NumFrame"), 1) Wend

FrmAuxiliar.Data2.Recordset.FindNext criterio

End Sub

Sub CargaTodoAjustado (NumVeh, donde)

- Busca un vehiculo y carga todas sus posiciones

' en un Grid

Dim vetl As vehiculoFrame

criterio = "[NumVehiculo] $=" \&$ NumVeh

FrmAuxiliar.Data2.Recordset.FindFirst criterio

$\mathrm{f}=0$

FrmResultados.GrdDatos.Rows $=2$

While Not FrmAuxiliar.Data2.Recordset. NoMatch

If FrmAuxiliar.Data2. Recordset ("ajustado") or donde > 1 Then $\mathrm{f}=\mathrm{f}+\mathrm{I}$

vetl.numVehiculo =

FrmAuxiliar.Data2.Recordset ("NumVehiculo")

vetl.x = FrmAuxiliar.Data2.Recordset ("x")

vetl.y = FrmAuxiliar.Data2.Recordset ("y")

vetl.px = FrmAuxiliar.Data2.Recordset ("px")

vet1.py = FrmAuxiliar.Data2.Recordset ("py")

vet $1 . \mathrm{pk}=$ FrmAuxiliar.Data2.Recordset ("pt")

vetl.pt = FrmAuxiliar.Data2.Recordset ("pk")

vetl.ti = FrmAuxiliar.Data2.Recordset("ti")

vetl.ac = FrmAuxiliar.Data2.Recordset ("ac")

vetl.vel = FrmAuxiliar.Data2.Recordset ("vel")

vetl.aju = FrmAuxiliar.Data2.Recordset ("ajustado")

Call llenaGrid(vetl, f,

FrmAuxiliar.Data2.Recordset("numFrame"), donde)

End If

Wend

FrmAuxiliar.Data2.Recordset.FindNext criterio

End Sub

FrmResultados.GrdDatos.Col $=0$

FrmResultados. GrdDatos. Sort $=3$

Sub llenaGrid(veh As vehiculoFrame, f, fra, donde)

If donde $=1$ Then

If FrmResultados. GrdDatos. Rows $<=$ f Then

FrmResultados.GrdDatos.Rows $=\mathrm{f}+1$

End If 


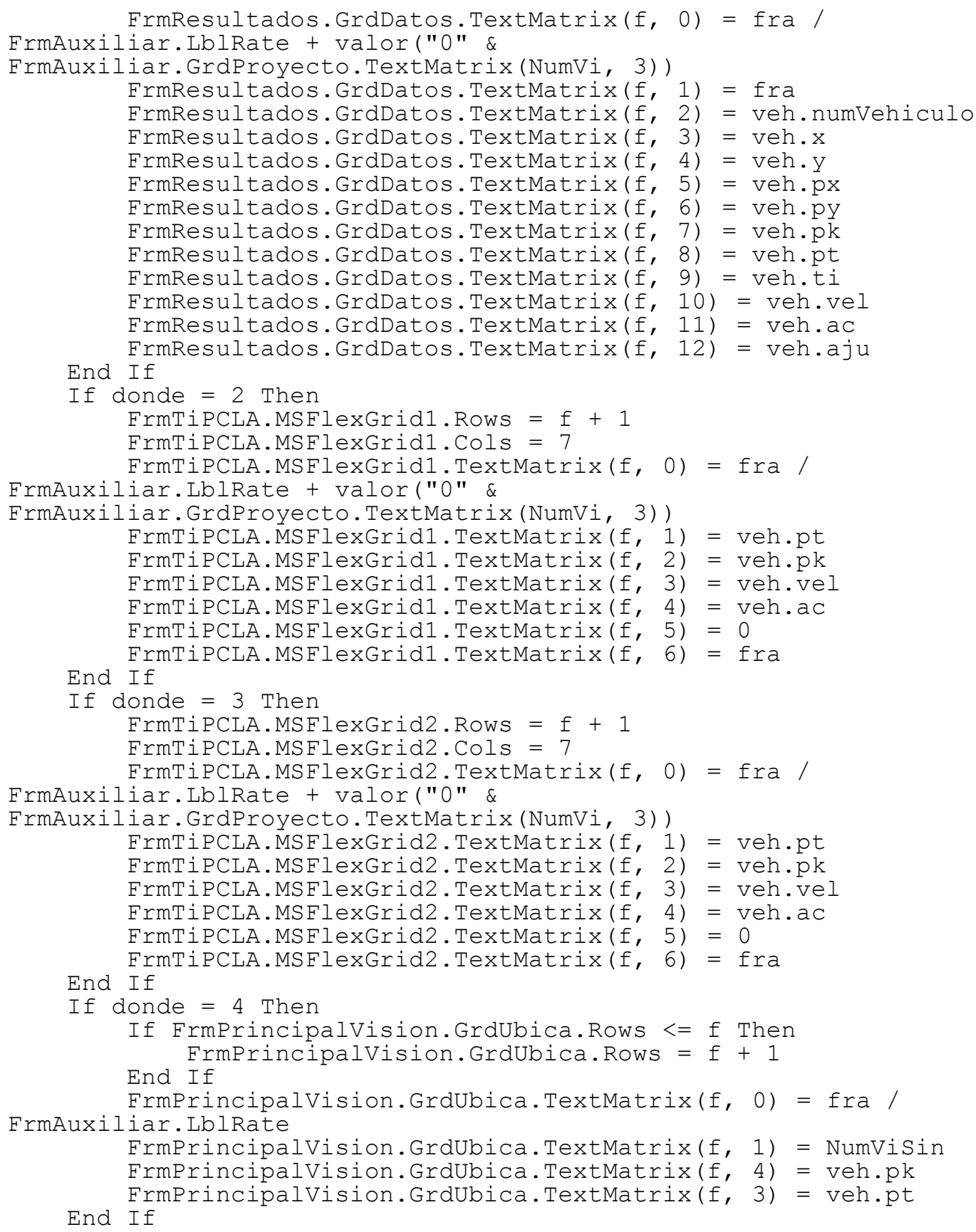


End Function

Sub mostrarVeh (nframe)

' Carga todos los vehiculos de un frame Dim vetl As vehiculoFrame

If FrmPrincipalVision.Timer2.Enabled Then Exit Sub

$i=0$

totvehp $=-1$

criterio = "[numFrame] = " \& nframe

FrmAuxiliar.Data2.Recordset.FindFirst criterio

While Not FrmAuxiliar.Data2.Recordset. NoMatch vetl.numVehiculo = FrmAuxiliar.Data2.Recordset ("NumVehiculo")

vetl.x = FrmAuxiliar.Data2.Recordset (" $\mathrm{x} ")$

vetl.y = FrmAuxiliar.Data2.Recordset ("y")

vetl.px = FrmAuxiliar.Data2.Recordset("px")

vetl.py = FrmAuxiliar.Data2.Recordset ("py")

vetl.pk = FrmAuxiliar.Data2.Recordset ("pt")

vetl.pt = FrmAuxiliar.Data2.Recordset ("pk")

vetl.ti = FrmAuxiliar.Data2.Recordset ("ti")

vetl.ac = FrmAuxiliar.Data2.Recordset("ac")

vetl.vel = FrmAuxiliar.Data2.Recordset ("vel")

vetl.aju = FrmAuxiliar.Data2.Recordset ("ajustado")

vetl.numFrame = FrmAuxiliar.Data2.Recordset ("NumFrame")

' FrmResultados. CmbVehiculos.AddItem vetl.numVehiculo

'FrmResultados.LblNFrame.Caption = nframe

If $i$ > totvehg Then

ReDim vehiculos $(i+10)$ As vehiculoframe

End If

totvehg $=i+10$

vehiculos $(i)=$ vetl

$i=i+1$

totvehp $=i$

Wend

FrmAuxiliar. Data2.Recordset.FindNext criterio

If Val (FrmPrincipalVision.TxtVehActual.Text) > 0 Then

$\mathrm{ya}=0$

For $i=0$ To totvehp -1

If Val (FrmPrincipalVision.TxtVehActual. Text) =

vehiculos(i).numVehiculo Then

$\mathrm{ya}=1$

Exit For

End If

Next $i$

If ya $=0$ Then

FrmPrincipalVision.TxtVehActual. Text $=$ NumVeh

If totvehp $>=$ totvehg Then

ReDim Preserve vehiculos (totvehp + 10) As

vehiculoframe

End If

totvehg $=$ totvehp +10

totvehp = totvehp +1

vehiculos (totvehp) $\cdot$ ac $=0$

vehiculos (totvehp). $a j u=$ False

vehiculos (totvehp). numFrame = ActFrame

vehiculos (totvehp). numVehiculo = NumVeh

vehiculos (totvehp).pk = 0

vehiculos (totvehp) $\cdot$ pt $=0$

vehiculos (totvehp) $\cdot x=0$

vehiculos (totvehp) $\cdot y=0$

vehiculos (totvehp) $\cdot \mathrm{px}=0$

vehiculos (totvehp) $\cdot$ py $=0$

vehiculos (totvehp). ti $=0$

vehiculos (totvehp) $\cdot$ vel $=0$

End If

End If

Call MuestraVeh

If optimer $=-3$ Then

Call ReubicaPkPt

terminado $=$ True 
End If

End Sub

Sub RecalculaXY1()

' Carga todos los vehiculos y recalcula su posicion

Dim vetl As vehiculoFrame

criterio = "[Ajustado] = TRUE"

FrmAuxiliar.Data2.Recordset.FindFirst criterio

While Not FrmAuxiliar.Data2.Recordset.NoMatch

vetl.numVehiculo = FrmAuxiliar.Data2.Recordset ("NumVehiculo")

vetl.x = FrmAuxiliar.Data2.Recordset ("x")

vetl.y = FrmAuxiliar.Data2.Recordset ("y")

vetl.px = FrmAuxiliar.Data2. Recordset ("px")

vetl.py = FrmAuxiliar.Data2.Recordset("py")

vetl.pk = FrmAuxiliar.Data2.Recordset ("pt")

vetl.pt $=$ FrmAuxiliar.Data2.Recordset ("pk")

vetl.ti = FrmAuxiliar.Data2.Recordset("ti")

vetl.ac = FrmAuxiliar.Data2.Recordset("ac")

vetl.vel = FrmAuxiliar.Data2.Recordset("vel")

vetl.aju = FrmAuxiliar.Data2.Recordset ("ajustado")

vetl.numFrame = FrmAuxiliar.Data2.Recordset ("NumFrame")

Call trazaretro(vetl.py, vetl.px, vetl.x, vetl.y)

'Call CopiaClip

FrmAuxiliar.Data2.Recordset.Edit

FrmAuxiliar.Data2.Recordset $(" \mathrm{x} ")=\operatorname{vet} \cdot \mathrm{x}$

FrmAuxiliar.Data2.Recordset ("y") = vetl.y

FrmAuxiliar. Data2.Recordset. Update

Wend

FrmAuxiliar.Data2.Recordset.FindNext criterio

End Sub

Sub RecalculaXY ()

Carga todos los vehiculos y recalcula su posicion

Dim vetl As vehiculoFrame

FrmAuxiliar.Data2.Recordset.MoveFirst

While Not FrmAuxiliar.Data2.Recordset.EOF

vetl.numVehiculo = FrmAuxiliar.Data2.Recordset ("NumVehiculo")

vetl. $\mathrm{x}=$ FrmAuxiliar.Data2.Recordset (" $\mathrm{x} "$ )

vetl.y = FrmAuxiliar.Data2.Recordset ("y")

vetl.px = FrmAuxiliar.Data2.Recordset ("px")

vetl.py = FrmAuxiliar.Data2.Recordset ("py")

vetl.pk = FrmAuxiliar.Data2.Recordset ("pt")

vetl.pt = FrmAuxiliar.Data2.Recordset ("pk")

vetl.ti = FrmAuxiliar.Data2.Recordset ("ti")

vetl.ac = FrmAuxiliar.Data2.Recordset ("ac")

vetl.vel = FrmAuxiliar.Data2.Recordset ("vel")

vetl.aju = FrmAuxiliar.Data2.Recordset ("ajustado")

vetl.numFrame = FrmAuxiliar.Data2.Recordset ("NumFrame")

If vetl.aju Then Else

Call trazaretro(vetl.py, vetl.px, vetl.x, vetl.y)

End If

'Call Copiaclip

FrmAuxiliar. Data2. Recordset. Edit

FrmAuxiliar.Data2. Recordset $(" \mathrm{x} ")$ = vetl.x

FrmAuxiliar.Data2.Recordset("y") = vetl.y

FrmAuxiliar. Data2.Recordset. Update

Wend

FrmAuxiliar.Data2.Recordset.MoveNext

End Sub

Sub RecalculapkPt()

FrmPrincipalVision.HscVideo.Value =

FrmPrincipalVision. HscVideo.Max 
For $i=$ FrmPrincipalVision.HscVideo.Min To

FrmPrincipalVision.HscVideo.Max

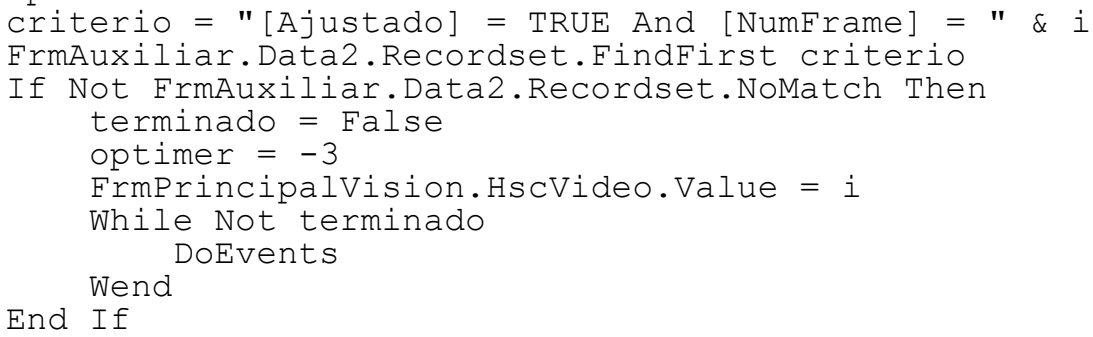

Function NuevoNumV() As Integer

FrmAuxiliar.Data1.Recordset.AddNew

FrmAuxiliar.Data1.Recordset("Longitud") = 0

NuevoNumV = Int(FrmAuxiliar.Datal.Recordset("NumVehiculo"))

FrmAuxiliar.Data1.Recordset. Update

End Function

Sub MuestraVeh ()

FrmPrincipalVision.PctPrincipal. DrawMode $=7$

FrmPrincipalVision. PctPrincipal. DrawWidth $=1$

For $i=0$ To totvehp -1

Call FrmPrincipalVision. PintaMarca (vehiculos(i).x,

$\operatorname{vehiculos}(i) \cdot y)$

Next i

FrmPrincipalVision.PctPrincipal. DrawMode $=13$

End Sub

Function SaleVeh (num)

criterio $="[$ NumVehiculo $]=" \&$ num

FrmAuxiliar.Data2.Recordset.FindLast criterio SaleVeh = False

If Not FrmAuxiliar. Data2.Recordset. NoMatch Then End If SaleVeh $=($ FrmAuxiliar.Data2.Recordset $($ pt") < $)$

End Function

Sub EvaluaTCTpeaton(tr, ac, vp)

FrmResultados.GrdTCT.Rows $=1$

FrmAuxiliar.Data1.Recordset.MoveFirst

$\mathrm{nf}=1$

archexp = Left\$(szFile, Len(szFile) - 3) \& "pri" Open archexp For Output As \#7

While Not FrmAuxiliar.Datal.Recordset.EOF num = FrmAuxiliar.Datal.Recordset ("NumVehiculo")

Call Pri (num, tr, ac, vp, nf)

Print \#7, num

For $i=1$ To FrmResultados.GrdDatos. Rows - 1 For $j=0$ To FrmResultados.GrdDatos.Cols - 1 
$\operatorname{Chr} \$(9) ;$

Print \#7, FrmResultados.GrdDatos.TextMatrix(i, j);

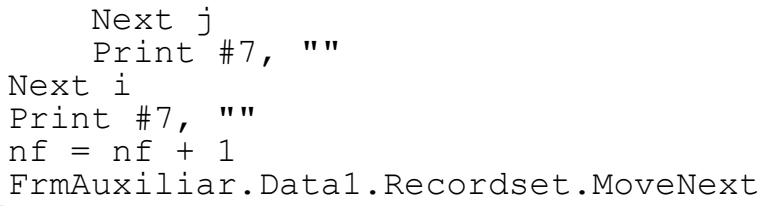

Wend

For $i=1$ To FrmResultados.GrdTCT.Rows - 1

Print \#7, " "

For $j=0$ To 3 Next j

rint \#7, FrmResultados.GrdTCT.TextMatrix(i, j) ; Chr\$(9);

Next i

Close \#7

End Sub

Sub EvaluaTCT (umbral)

FrmResultados.GrdTCT.Rows $=1$

FrmAuxiliar.Data1.Recordset.MoveFirst

While Not FrmAuxiliar.Datal.Recordset.EOF

num = FrmAuxiliar.Data1.Recordset ("NumVehiculo")

If SaleVeh (num) Then

Call TiPCLA (num, umbral)

End If

Wend

FrmAuxiliar. Data1. Recordset. MoveNext

tt $=\operatorname{valor}($ FrmResultados.LblTu) - valor(FrmResultados.LblTp)

For $i=1$ To FrmResultados.GrdTCT.Rows - 1 FrmResultados.GrdTCT.TextMatrix(i, 6) =

valor (FrmResultados.GrdTCT.TextMatrix(i, 1)) / tt * 3600 FrmResultados.GrdTCT.TextMatrix $(i, 7)=$

valor (FrmResultados.GrdTCT.TextMatrix(i, 2)) / tt * 3600 FrmResultados.GrdTCT.TextMatrix $(i, 8)=$

valor (FrmResultados.GrdTCT.TextMatrix(i, 4)) / tt * 3600 FrmResultados.GrdTCT.TextMatrix (i, 9) =

valor (FrmResultados.GrdTCT.TextMatrix(i, 5)) / tt * 3600

Next i

For $i=1$ To FrmResultados.GrdTCT.Rows - 1

For $j=1$ To FrmResultados.GrdTCT.Cols - 1

FrmResultados.GrdTCT.TextMatrix $(i, j)=$

Format (valor(FrmResultados.GrdTCT.TextMatrix $(i, j)$ ), "0.\#\#\#\#") Next $j$

Next i

FrmResultados.Visible = True

FrmResultados.GrdDatos.Visible = False

End Sub

FrmResultados.GrdTCT.Visible = True

Sub Pri (num, tr, ac, vp, f)

FrmResultados.GrdTCT.Rows = FrmResultados.GrdTCT.Rows +1

FrmResultados.GrdDatos.Rows $=1$

FrmResultados.GrdDatos.Cols $=18$

Call cargartodo (num)

Call Calculapri(num, tr, ac, vp, f)

End Sub

Call exportapri

Sub Calculapri(num, tr, ac, vp, nf)

spri $=0$

st $=0$

maxpri $=0$

For $f=1$ To FrmResultados.GrdDatos.Rows - 1

$\mathrm{tp}=\operatorname{valor}($ FrmResultados.GrdDatos.TextMatrix $(\mathrm{f}, 8))$ / vp 
FrmResultados.GrdDatos.TextMatrix (f, 13) = tp

vel = valor(FrmResultados.GrdDatos.TextMatrix $(f, 10))$ / 3.6

If vel $>0$ Then

tfv $=$ tr + vel / $2 / \mathrm{ac}$

FrmResultados.GrdDatos.TextMatrix (f, 14) = tfv

pk = valor(FrmResultados.GrdDatos.TextMatrix (f, 7))

$\mathrm{tcv}=\mathrm{Abs}(\mathrm{pk}) / \mathrm{vel}$

FrmResultados.GrdDatos.TextMatrix (f, 15) = tcv

If $\mathrm{f}=1$ Then

$d t=$ Abs (valor (FrmResultados.GrdDatos.TextMatrix (f,

9)) - valor(FrmResultados.GrdDatos.TextMatrix (f + 1, 9)))

Else

$d t=$ Abs (valor (FrmResultados.GrdDatos.TextMatrix $(f$,

9)) - valor(FrmResultados.GrdDatos.TextMatrix(f - 1, 9)))

End If

If $t p<t c v$ And $t c v<t f v$ Then

If vel ^ $2>2$ *ac * (Abs (pk) - tr * vel) Then

$\operatorname{vimp}=(\operatorname{vel} \wedge 2-2 \star \mathrm{ac} \star(\mathrm{Abs}(\mathrm{pk})-\mathrm{tr} \star \mathrm{vel})) \wedge$

0.5

vpri $=\operatorname{vimp} \wedge 2 \star(t f v-t c v)$

FrmResultados.GrdDatos.TextMatrix $(f, 16)=$ vimp

FrmResultados.GrdDatos.TextMatrix $(f, 17)=$ vpri

' FrmResultados.GrdDatos.TextMatrix (f, 18) = vpri *

$d t$

If vpri > maxpri Then maxpri = vpri

End If

spri = spri + vpri

End If

$s t=s t+d t$

Next $f$

End If

FrmResultados.GrdTCT.TextMatrix (nf, 0) = num

FrmResultados.GrdTCT.TextMatrix $(n f, 1)=$ spri

FrmResultados.GrdTCT.TextMatrix (nf, 2) = maxpri

End Sub

FrmResultados.GrdTCT.TextMatrix (nf, 3) = st

Sub TiPCLA (num, umbral)

FrmTiPCLA.Lstotr.Clear

FrmTiPCLA.MSFlexGrid1.Rows $=1$

FrmTiPCLA.MSFlexGrid2. Rows $=1$

FrmTiPCLA.MSFlexGrid3.Rows $=1$

Call CargatiPCLA (num, pfr, ufr, 2)

FrmTiPCLA.MSFlexGrid3.Rows = FrmTiPCLA.MSFlexGrid1.Rows

Call LlenaListaotr(pfr, ufr, num)

If num $=61$ Then

End If

num $=$ num

For $i=0$ To FrmTiPCLA.Lstotr.ListCount - 1

Call CargaTiPCLA(FrmTiPCLA.Lstotr.List(i), pfr, ufr, 3)

Call FrmTiPCLA.Calcula

Call FrmTiPCLA. copitip

Next i

- Aca colocar la copia por vehiculo para hacer la grafica

If FrmTiPCLA.Lstotr.ListCount $>0$ Then

$t p=\operatorname{valor}($ FrmTiPCLA.MSFlexGridl.TextMatrix $(1,0))$

tu $=$

valor(FrmTiPCLA.MSFlexGrid1. TextMatrix (FrmTiPCLA.MSFlexGrid1.Rows - 1, 0))

Then

If FrmResultados.LblTp = "" Or valor(FrmResultados.LblTp) > tp End If

FrmResultados.LblTp = tp

If FrmResultados.LblTu = " " Or valor(FrmResultados.LblTu) < tu End If

FrmResultados.LblTu = tu

$i=1$ 


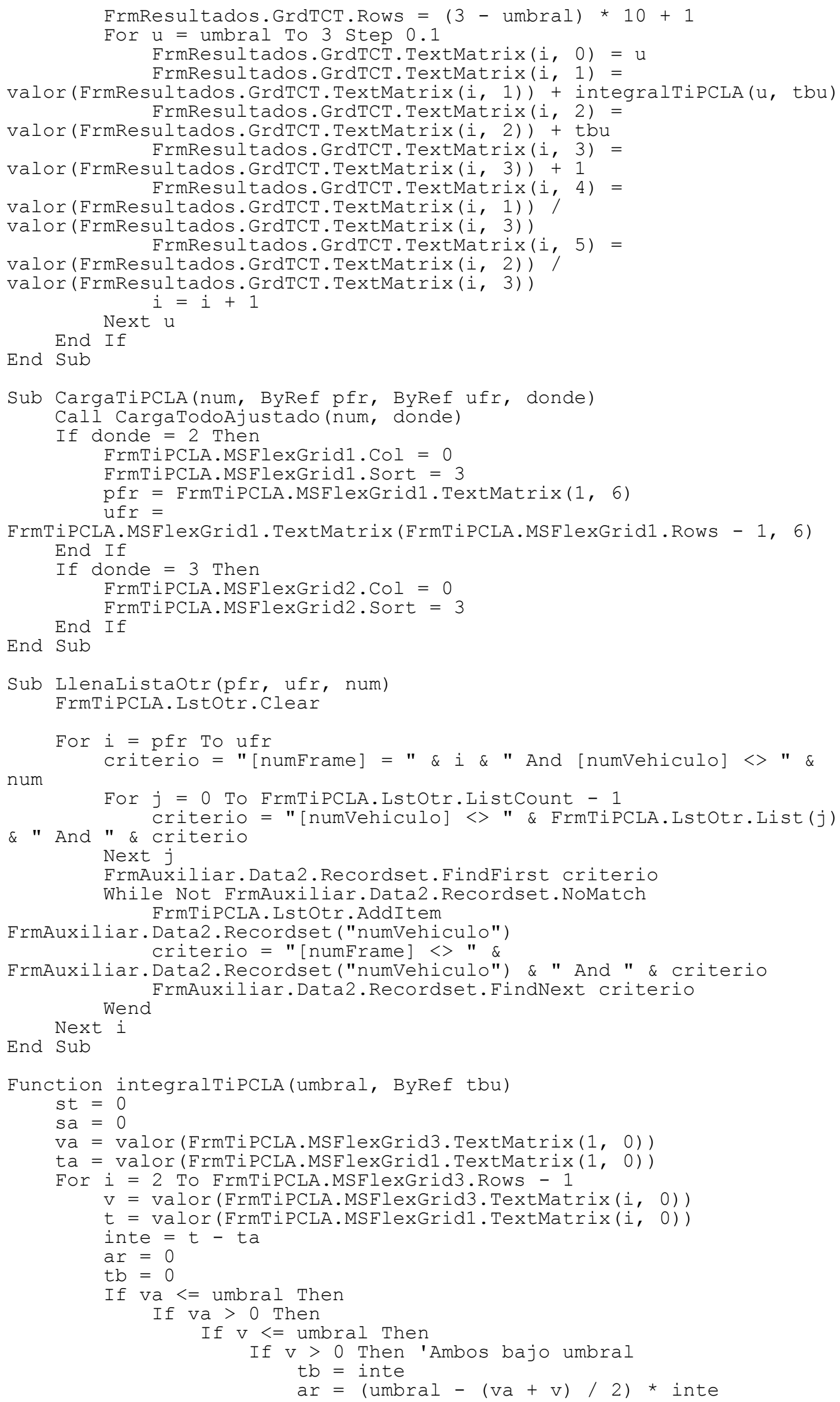




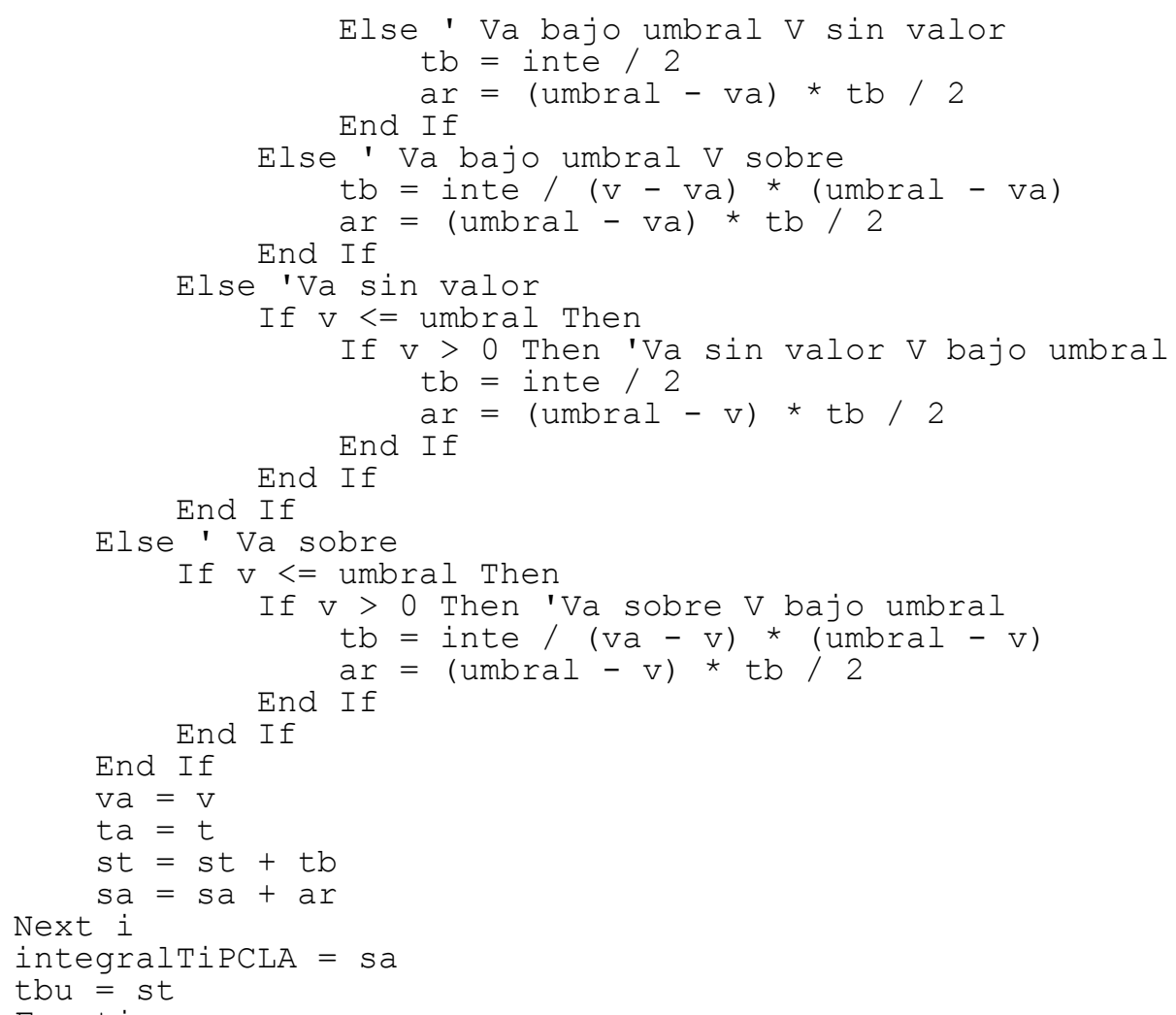


Sub Recalculasplines()

Call trazador (1)

While FrmResultados.GrdDatos.Rows $>2$

num $=$ num +1

Wend

Call trazador(num)

End Sub

Sub trazador (num)

Call CargaTodoAjustado (num, 1)

'Call CalculaVelinterpoal

$\mathrm{n}$ = FrmResultados.GrdDatos.Rows - 1

\begin{tabular}{|c|c|c|c|}
\hline ReDim & $a(n)$ & As & Double \\
\hline ReDim & $b(n)$ & As & Double \\
\hline ReDim & $C(n)$ & As & Double \\
\hline ReDim & $d(n)$ & As & Double \\
\hline ReDim & $x(n)$ & As & Double \\
\hline ReDim & $y(n)$ & As & Double \\
\hline ReDim & $\mathrm{h}(\mathrm{n})$ & As & Double \\
\hline ReDim & $m(n)$ & As & Doubl \\
\hline im & $Z(n)$ & As & ble \\
\hline & $1(n)$ & As & ul \\
\hline & & & \\
\hline
\end{tabular}

If $\mathrm{n}>1$ Then

' trae los datos

$\mathrm{x}(0)=$ FrmResultados.GrdDatos.TextMatrix $(1,1)$

$\mathrm{y}(0)=$ FrmResultados.GrdDatos.TextMatrix $(1,5)$

For $j=1$ To $n-2$

$\mathrm{x}(\mathrm{j})=$ FrmResultados.GrdDatos.TextMatrix $(j+1,1)$

$\mathrm{dx} 1=\mathrm{x}(j)-\mathrm{x}(j-1)$

$\mathrm{dx} 2=$ FrmResultados.GrdDatos.TextMatrix $(j+2,1)-x(j)$

$\mathrm{y}(j)=($ (valor (FrmResultados.GrdDatos.TextMatrix $(j, 5))+$

(valor (FrmResultados.GrdDatos.TextMatrix $(j+2,5)$ ) -

valor (FrmResultados.GrdDatos.TextMatrix $\left.(j, 5)))^{\prime} /(d x 1+d x 2) * d x 1\right)+$ valor (FrmResultados.GrdDatos.TextMatrix $(j+1,5))$ * 2) / 3

Next j

$x(j)=$ FrmResultados.GrdDatos.TextMatrix $(j+1,1)$

$y(j)=$ FrmResultados.GrdDatos.TextMatrix $(j+1,5)$

For $j=0$ To $n-1$

$h(j)=x(j+1)-x(j)$

Next j

$a(j)=y(j)$

$\mathrm{a}(\mathrm{n})=\mathrm{y}(\mathrm{n})$

For $j=1$ To $n-1$ $\mathrm{al}(j)=3 *(\mathrm{a}(j+1) * \mathrm{~h}(j-1)-\mathrm{a}(j) \star(\mathrm{h}(j)+\mathrm{h}(j-$

1) $)+a(j-1) * h(j)) /(h(j-1) * h(j))$

Next $j$

$l(0)=1$

$m(0)=0$

$Z(0)=0$

$l(n)=1$

$\mathrm{Z}(\mathrm{n})=0$

$\mathrm{C}(\mathrm{n})=0$

For $j=1$ To $n-1$

$l(j)=2 \star(h(j)+h(j-1))-h(j-1) * m(j-1)$

$m(j)=h(j) / l(j)$

Next j

$Z(j)=(a l(j)-h(j-1) * Z(j-1)) / l(j)$

For $j=n-1$ To 0 Step -1

$c(j)=z(j)-m(j) \star c(j+1)$

$c(j)) / 3$

$\mathrm{b}(j)=(\mathrm{a}(j+1)-\mathrm{a}(j)) / \mathrm{h}(j)-\mathrm{h}(j) *(\mathrm{c}(j+1)+2 *$

Next $j$ 


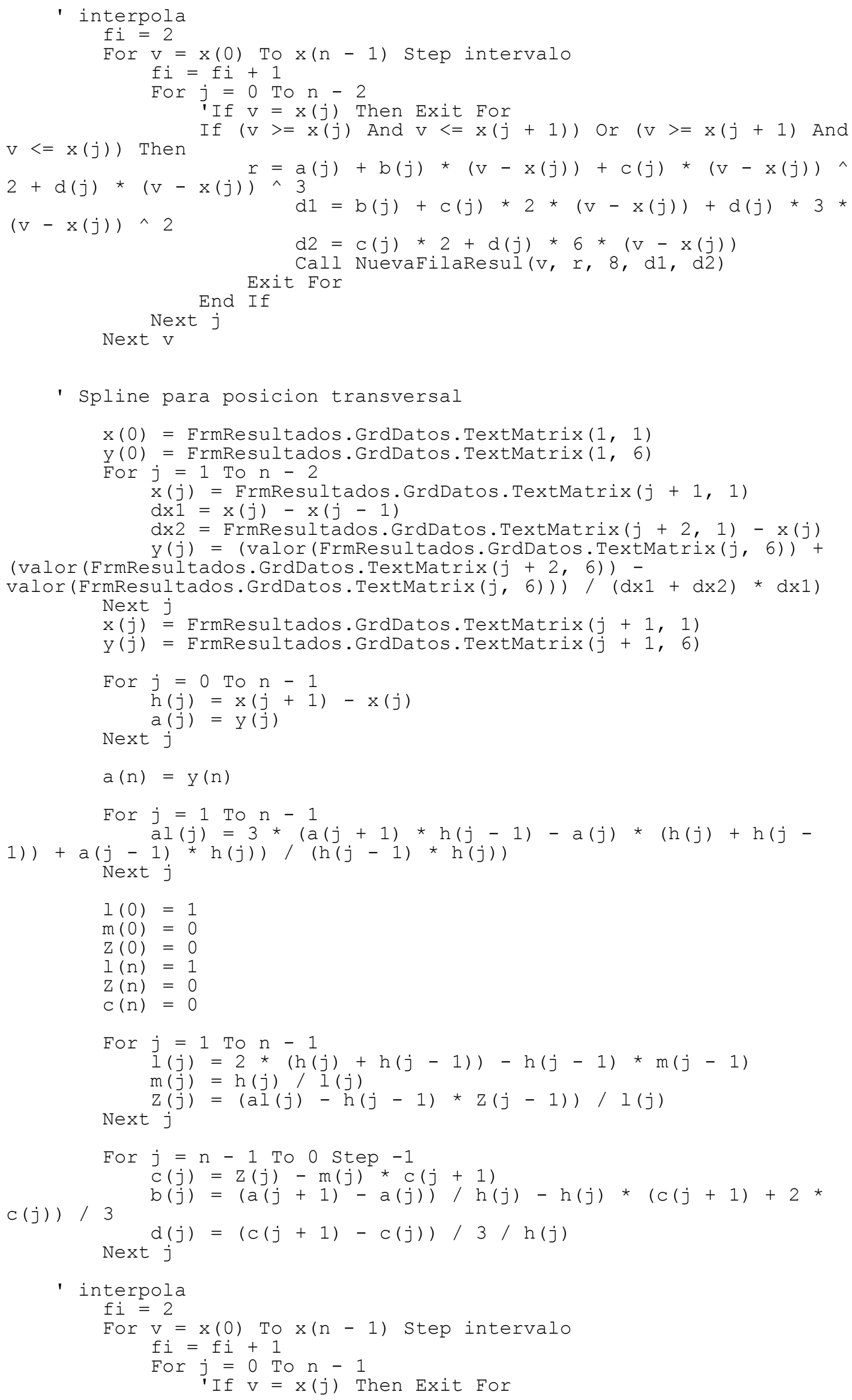




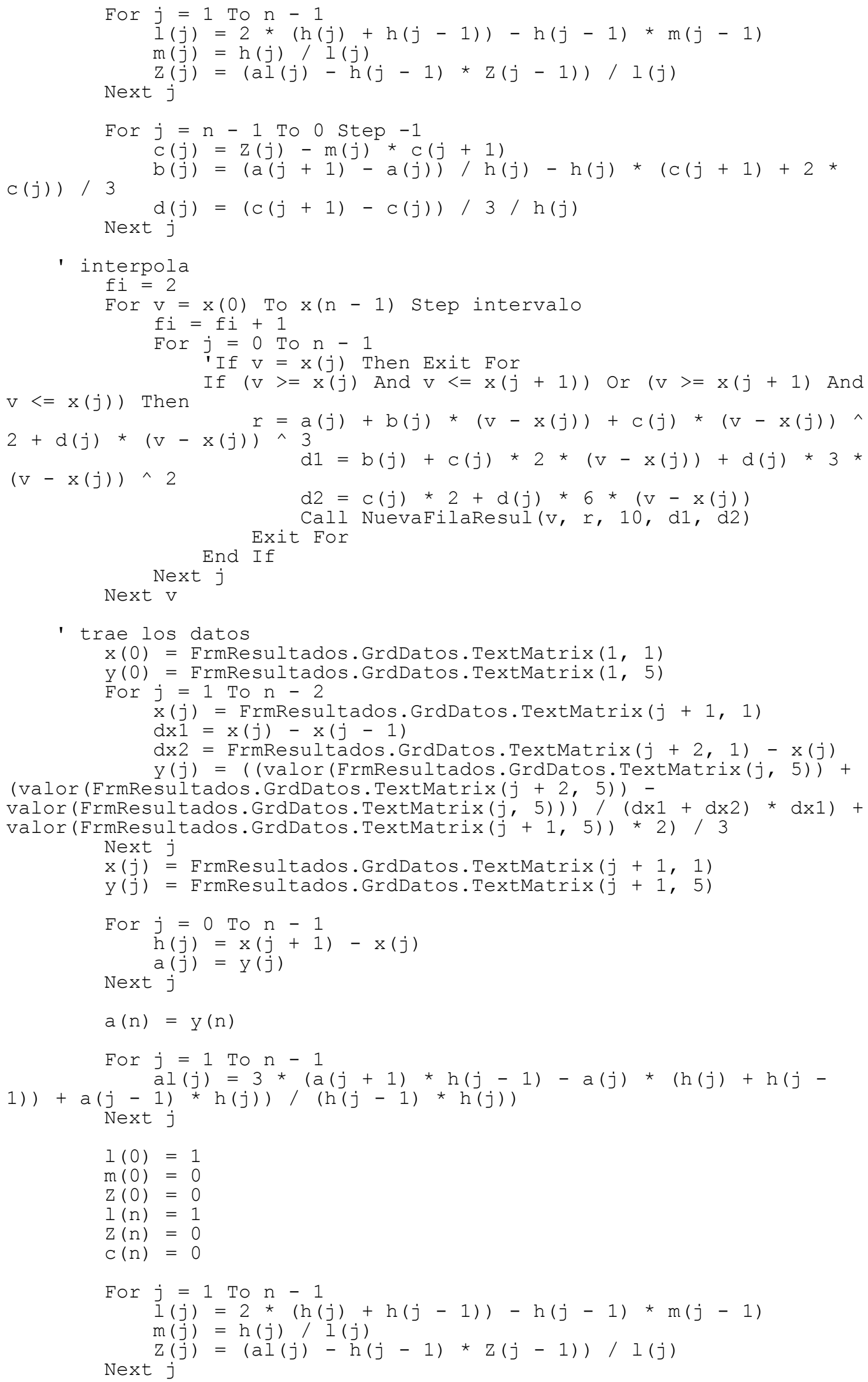




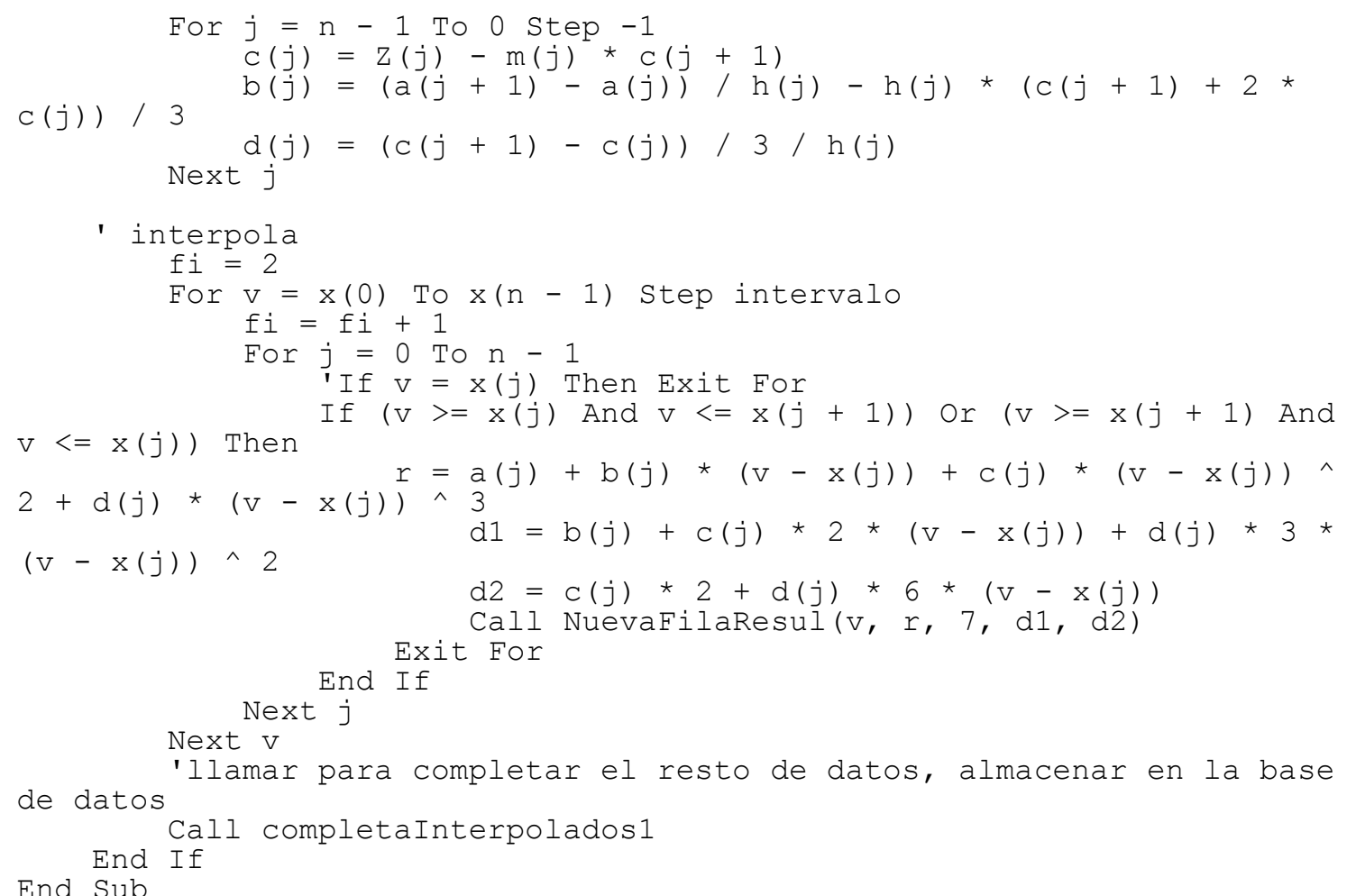

Sub CalculaVelif()

$i=$ FrmResultados.GrdDatos.Rows - 1

If $i>1$ Then

delpx = FrmResultados.GrdDatos.TextMatrix (1, 7) -

FrmResultados.GrdDatos.TextMatrix (2, 5)

delpy = FrmResultados.GrdDatos.TextMatrix $(1,8)$ -

FrmResultados.GrdDatos.TextMatrix $(2,6)$

tie = Abs (FrmResultados.GrdDatos.TextMatrix $(1,0)$ -

FrmResultados.GrdDatos. TextMatrix $(2,0)$ )

dist $=(\operatorname{delpx} \wedge 2+\operatorname{delpy} \wedge 2) \wedge 0.5$

vel $=$ Round (dist / tie $\star 3.6,2$ )

If valor(FrmResultados.GrdDatos.TextMatrix $(1,10)$ ) = " "Then

FrmResultados.GrdDatos.TextMatrix $(1,10)=$ vel

FrmResultados.GrdDatos.TextMatrix $(1,10)=$ vel

For $i=2$ To FrmResultados.GrdDatos.Rows - 2

delpx = FrmResultados.GrdDatos.TextMatrix (i - 1, 7) -

FrmResultados.GrdDatos.TextMatrix (i, 5) delpy = FrmResultados.GrdDatos.TextMatrix $(i-1,8)$ -

FrmResultados.GrdDatos.TextMatrix (i, 6) tie = Abs (FrmResultados.GrdDatos.TextMatrix (i - 1, 0) -

FrmResultados.GrdDatos.TextMatrix (i, 0))

dist $=(\operatorname{delpx} \wedge 2+\operatorname{delpy} \wedge 2) \wedge 0.5$

vel $=$ Round (dist / tie $\star 3.6,2)$

If valor(FrmResultados.GrdDatos.TextMatrix(i, 10)) = 0

Then FrmResultados.GrdDatos.TextMatrix (i, 10) = vel Next $i$ FrmResultados.GrdDatos.TextMatrix $(i, 10)=$ vel

delpx = FrmResultados.GrdDatos.TextMatrix (i - 1, 7) -

FrmResultados.GrdDatos. TextMatrix (i, 5)

delpy = FrmResultados.GrdDatos.TextMatrix (i - 1, 8) -

FrmResultados.GrdDatos.TextMatrix (i, 6)

tie = Abs (FrmResultados.GrdDatos. TextMatrix (i - 1, 0) -

FrmResultados.GrdDatos. TextMatrix ( $i, 0)$ )

dist $=(\operatorname{delpx} \wedge 2+\operatorname{delpy} \wedge 2) \wedge 0.5$

vel $=$ Round(dist / tie $\star 3.6,2$ )

If valor(FrmResultados.GrdDatos.TextMatrix (i, 10)) = 0 Then

FrmResultados.GrdDatos.TextMatrix (i, 10) = vel

End If

FrmResultados.GrdDatos.TextMatrix $(i, 10)=$ vel 
End Sub

Sub NuevaFilaResul ( $v, r, c o, d 1, d 2$ )

For $i=1$ To FrmResultados.GrdDatos.Rows - 1

If valor(FrmResultados.GrdDatos.TextMatrix (i, 1)) = V Then FrmResultados.GrdDatos.TextMatrix $(i, \mathrm{co})=$ Round $(r, 2)$ If $\mathrm{CO}=7$ Then

pt $=$ valor (FrmResultados.GrdDatos.TextMatrix (i, 7))

$\mathrm{pk}=\operatorname{valor}($ FrmResultados.GrdDatos.TextMatrix $(i, 8))$

Call trazaretro (pk, pt, $\mathrm{x}, \mathrm{y})$

FrmResultados.GrdDatos.TextMatrix $(i, 3)=\operatorname{Round}(x, 2)$

FrmResultados.GrdDatos.TextMatrix (i, 4) $=\operatorname{Round}(y, 2)$ Else

'FrmResultados.GrdDatos.TextMatrix $(i, 9)=d 1$

' FrmResultados.GrdDatos. TextMatrix $(i, 10)=d 2$

'FrmResultados.GrdDatos.TextMatrix $(i, 7)=\mathrm{d} 1$

End If

FrmResultados.GrdDatos.TextMatrix $(i, 8)=d 2$

End If

Next i

$\mathrm{f}=\mathrm{i}$

FrmResultados.GrdDatos.Rows $=\mathrm{f}+1$

FrmResultados.GrdDatos.TextMatrix(f, 0) = V / FrmAuxiliar.LblRate

+ valor("0" \& FrmAuxiliar.GrdProyecto.TextMatrix (NumVi, 3))

FrmResultados.GrdDatos.TextMatrix $(\mathrm{f}, 1)=\mathrm{V}$

FrmResultados.GrdDatos.TextMatrix $(f, 2)=$

FrmResultados.GrdDatos. TextMatrix (f - 1, 2)

FrmResultados.GrdDatos.TextMatrix $(f, 3)=" "$

FrmResultados.GrdDatos.TextMatrix (f, 4) = ""

'FrmResultados.GrdDatos. TextMatrix $(f, 7)=d 1$

'FrmResultados.GrdDatos.TextMatrix $(f, 8)=d 2$

FrmResultados.GrdDatos.TextMatrix $(f, 9)="$ "

FrmResultados.GrdDatos.TextMatrix $(f, 10)=" 1$

FrmResultados.GrdDatos.TextMatrix $(f, 11)="$ "

FrmResultados.GrdDatos.TextMatrix $(f, 12)=$ False

FrmResultados.GrdDatos.TextMatrix $(\mathrm{f}, \mathrm{co})=\operatorname{Round}(\boldsymbol{r}, 2)$

End Sub

Sub completaInterpolados()

FrmResultados.GrdDatos.Col $=0$

FrmResultados. GrdDatos. Sort $=3$

Call CalculaVel

Call CalculaAc

For $\mathrm{f}=1$ To FrmResultados.GrdDatos.Rows - 1

$\mathrm{nf}=$ valor (FrmResultados.GrdDatos.TextMatrix (f, 1) FrmResultados.GrdDatos.TextMatrix $(\mathrm{f}, 0)=\mathrm{nf} /$

FrmAuxiliar.LblRate + valor("0" \&

FrmAuxiliar.GrdProyecto.TextMatrix (NumVi, 3))

num = valor (FrmResultados.GrdDatos.TextMatrix $(\mathrm{f}, 2))$

$\mathrm{x}$ = valor(FrmResultados.GrdDatos.TextMatrix (f, 3))

$y=\operatorname{valor}($ FrmResultados.GrdDatos.TextMatrix $(f, 4))$

$\mathrm{px}=\operatorname{valor}($ FrmResultados.GrdDatos.TextMatrix(f, 5))

py $=\operatorname{valor}($ FrmResultados.GrdDatos.TextMatrix (f, 6))

$\mathrm{pt}=\operatorname{valor}($ FrmResultados.GrdDatos.TextMatrix (f, 7))

$\mathrm{pk}=\operatorname{valor}($ FrmResultados.GrdDatos.TextMatrix (f, 8))

$\mathrm{ti}=\operatorname{valor}($ FrmResultados.GrdDatos.TextMatrix $(\mathrm{f}, 0))$

vel = valor (FrmResultados.GrdDatos.TextMatrix (f, 10))

$\mathrm{ac}_{\mathrm{c}}=\operatorname{valor}($ FrmResultados.GrdDatos.TextMatrix $(\mathrm{f}, 11))$

aj = FrmResultados.GrdDatos.TextMatrix (f, 12)

vet $=$ valor (ErmResultados.GrdDatos.TextMatrix $(\mathrm{f}, 13))$

ac, vel, aj)

Call guardaVehiculo(x, y, px, py, pk, pt, num, nf, ti, lon,

Next $f$

End Sub

Sub CalculaVel() 


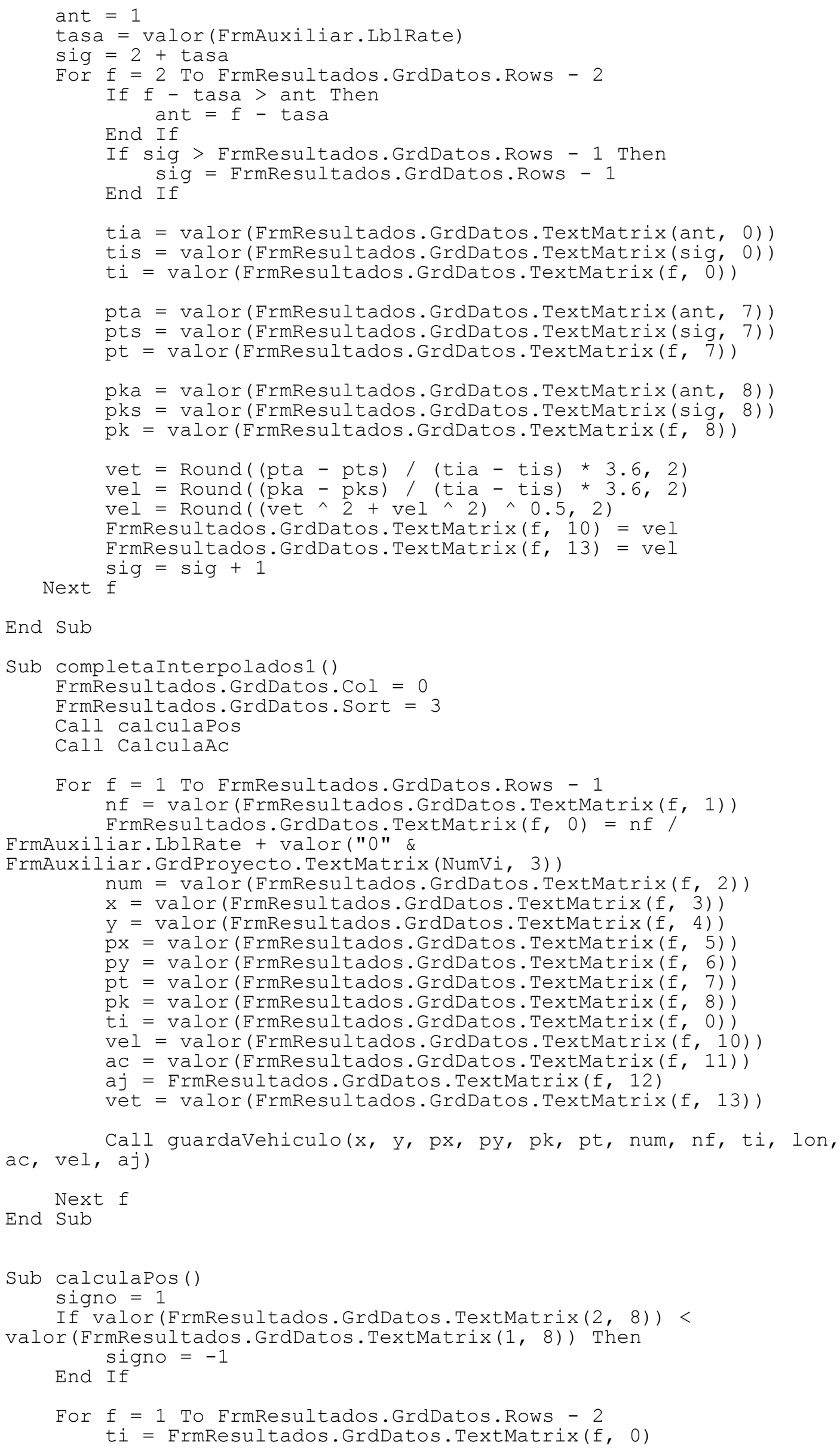


deltapk = valor(FrmResultados.GrdDatos.TextMatrix(f, 8)) valor (FrmResultados.GrdDatos.TextMatrix(f, 6))

deltat = valor(FrmResultados.GrdDatos.TextMatrix (f, 0)) -

valor (FrmResultados.GrdDatos.TextMatrix(1, 0))

Wend

deltav = deltapk/ deltat *3.6

End Sub

Sub CalculaAc()

ant $=2$

tasa = valor (FrmAuxiliar.LblRate)

sig $=2+$ tasa

For $f=3$ To FrmResultados. GrdDatos. Rows - 3

If $f$ - tasa > ant Then

End If

ant $=\mathrm{f}-$ tasa

If sig > FrmResultados.GrdDatos.Rows - 2 Then

End If sig $=$ FrmResultados.GrdDatos.Rows - 2

tia = valor (FrmResultados.GrdDatos.TextMatrix (ant, 0))

tis = valor(FrmResultados.GrdDatos.TextMatrix (sig, 0))

$t i=\operatorname{valor}($ FrmResultados.GrdDatos.TextMatrix (f, 0))

vela $=\operatorname{valor}($ FrmResultados.GrdDatos.TextMatrix (ant, 10))

vels = valor (FrmResultados.GrdDatos.TextMatrix (sig, 10))

vel = valor (FrmResultados.GrdDatos.TextMatrix (f, 10))

Next

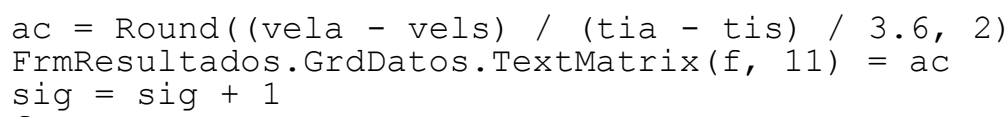

End Sub 


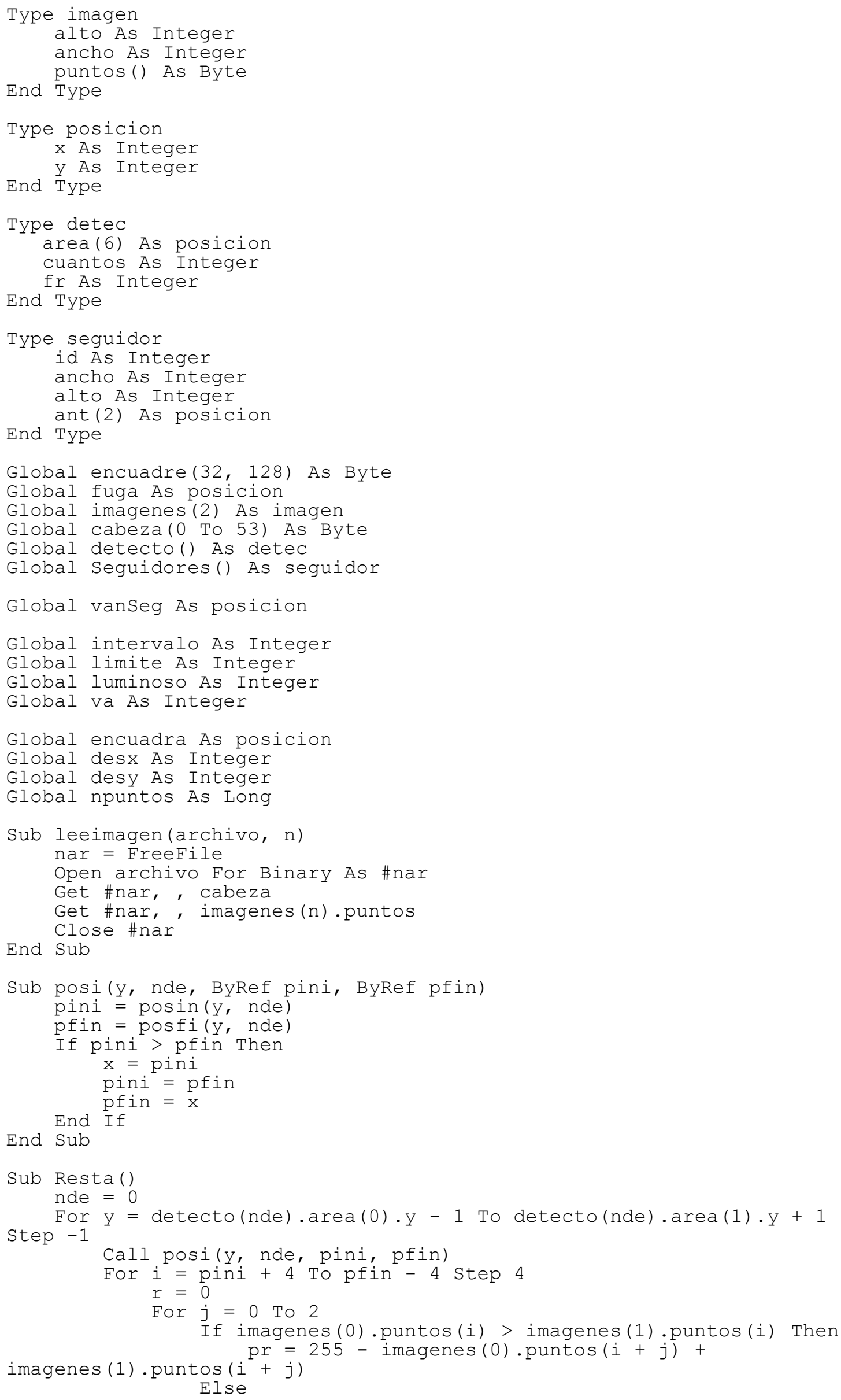

End Sub

Sub Resta () 


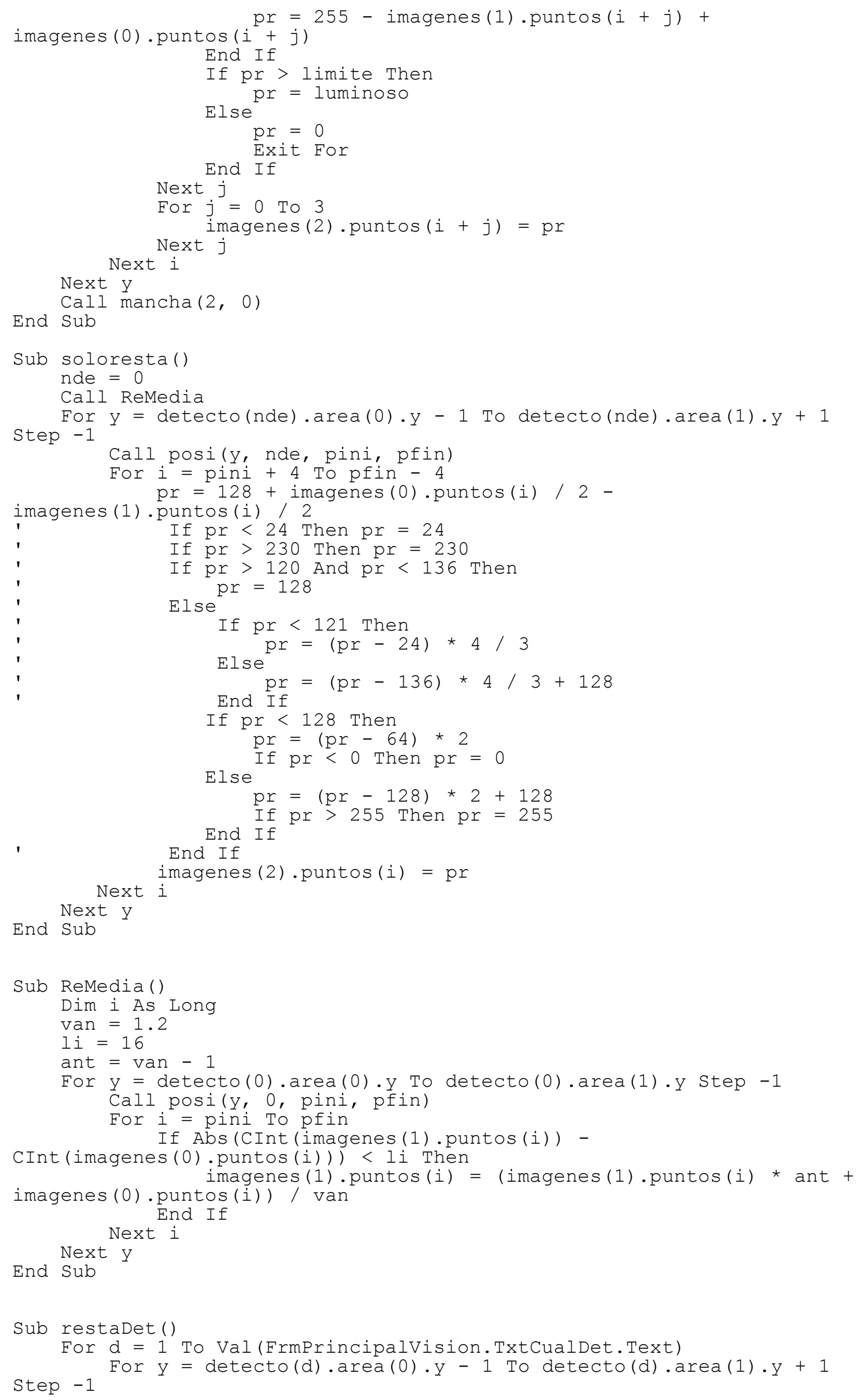




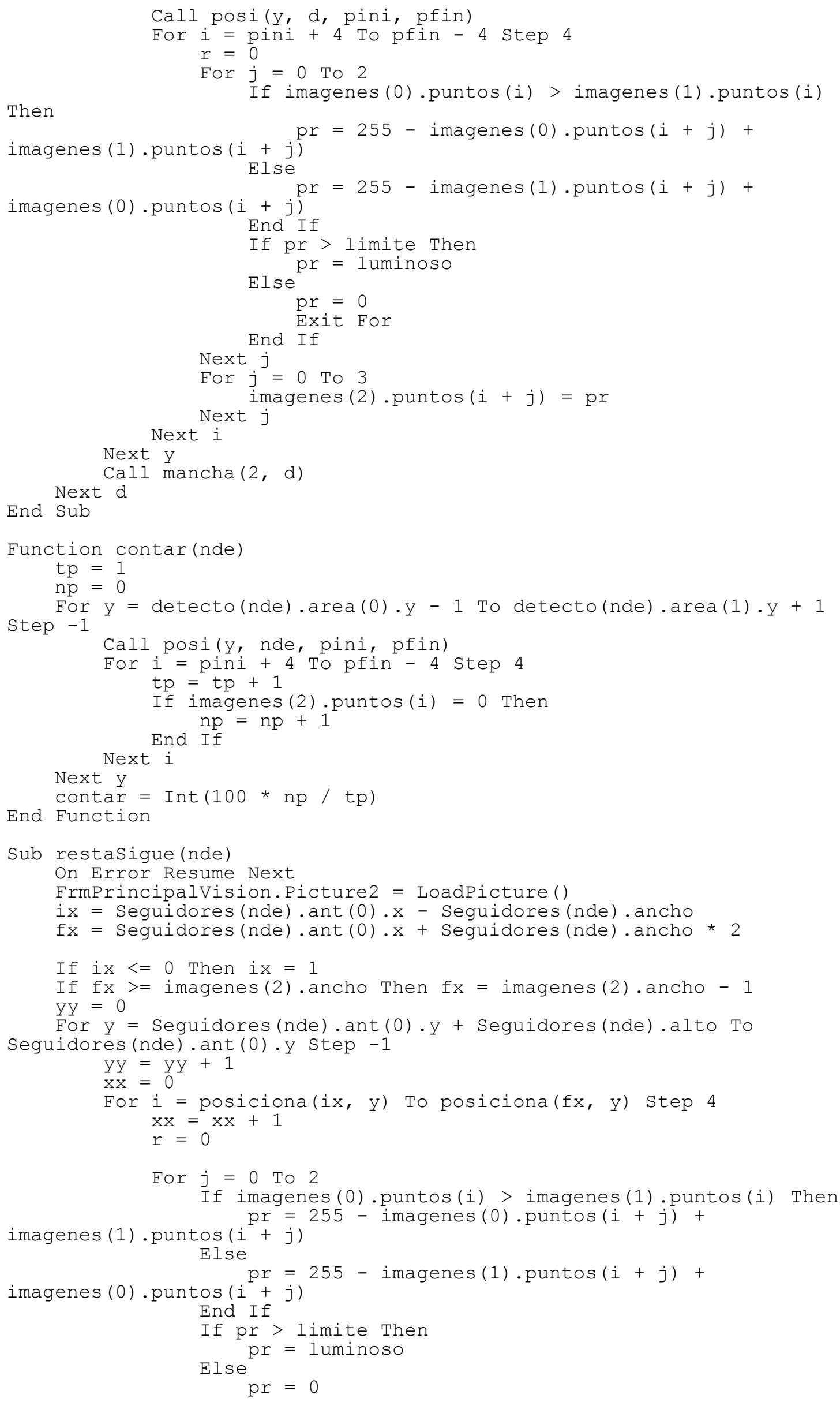




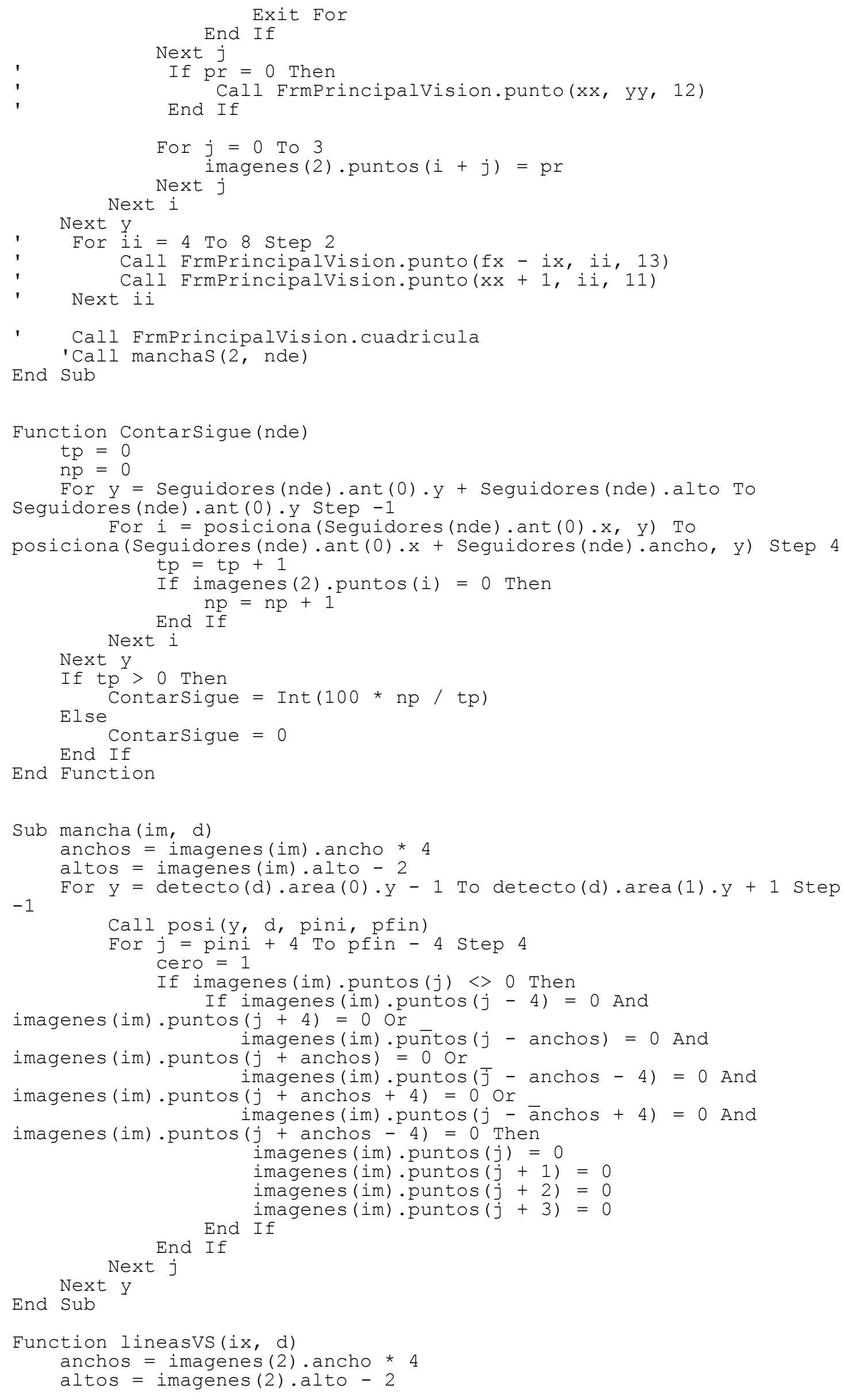


$\mathrm{C}=0$

For $y=$ Seguidores $(d) \cdot \operatorname{ant}(0) \cdot y-1+$ Seguidores $(d)$. alto To

Seguidores $(d)$. ant $(0) \cdot y$ step -1

$j=$ posiciona(ix, y)

If imagenes $(2) \cdot \operatorname{puntos}(j)=0$ Then

End If

$\mathrm{C}=\mathrm{C}+\mathrm{I}$

Next y

lineasvs $=\mathrm{C}$

End Function

Sub manchas (im, d)

anchos = imagenes $($ im) . ancho $\star 4$

altos = imagenes (im).alto - 2

$i x=$ Seguidores (nde). ant (0).x - Seguidores (nde). ancho +1

$f_{x}=$ Seguidores (nde) $\cdot$ ant $(0) \cdot x+2 \star$ Seguidores (nde) $\cdot$ ancho -1

If $i x<=0$ Then ix $=1$

If $f x>=$ imagenes(2). ancho Then $f_{x}=$ imagenes(2). ancho -1

For $y=$ Seguidores $(d) \cdot \operatorname{ant}(0) \cdot y-1+$ Seguidores $(d) \cdot$ alto To Seguidores (d).ant (0) . y step -1

For $j=$ posiciona $(i x, y)+4$ To posiciona $(f x, y)-4$ step 4 cero $=1$

If imagenes (im).puntos $(j)<>0$ Then

If imagenes $(i m) \cdot p u n t o s(j-4)=0$ And

imagenes $(i m) \cdot \operatorname{puntos}(j+4)=0$ Or

imagenes $(i m) \cdot \operatorname{pu} n t o s(j-$ anchos $)=0$ And

imagenes $(i m) \cdot \operatorname{puntos}(j+$ anchos $)=0$ or

imagenes (im) puntos $\bar{j}$ - anchos - 4) = 0 And

imagenes $(i m)$. puntos $(j+$ anchos +4$)=0$ Or

imagenes $(i m) \cdot \operatorname{puntos}\left(j-{ }^{-}\right.$anchos +4$)=0$ And

imagenes $(i m)$. puntos $(j+$ anchos - 4) = 0 Then

imagenes $(i \mathrm{~m}) \cdot \operatorname{puntos}(j)=0$

imagenes $(i m) \cdot \operatorname{puntos}(j+1)=0$

imagenes $(i m) \cdot \operatorname{puntos}(j+2)=0$

Find If

imagenes $(i m) \cdot \operatorname{puntos}(j+3)=0$

Next $y$

End Sub

Sub Borde(im, imr, lim)

anchos = imagenes (im). ancho * 4

altos $=$ imagenes $($ im) .alto -2

nde $=0$

Dim pos As Long

For $y=\operatorname{detecto}($ nde) $\cdot \operatorname{area}(0) \cdot y-1$ To detecto (nde) $\cdot$ area $(1) \cdot y+1$ Step -1

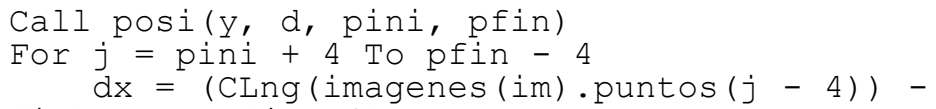

imagenes $(i m) \cdot \operatorname{puntos}(j+4)+$ imagenes (im).puntos (j-anchos - 4) -

imagenes $(i m) \cdot \operatorname{puntos}(j-$ anchos +4$)+$ imagenes $(\mathrm{im}) \cdot \operatorname{puntos}\left(j^{-}+\operatorname{anchos}-4\right)-$

imagenes $(i \mathrm{~m}) \cdot \operatorname{puntos}(j+$ anchos +4$)+$

5) + imagenes $(i m) \cdot \operatorname{puntos}\left(j^{-}-3\right)$ - imagenes $(i m) \cdot \operatorname{puntos}(j+$ imagenes (im) . puntos $(j-$ anchos +5$)+$ imagenes $(\mathrm{im}) \cdot \operatorname{puntos}\left(\mathrm{j}^{-}+\operatorname{anchos}-3\right)$ imagenes $(i m) \cdot \operatorname{puntos}(j+$ anchos +5$)+$

6) +

imagenes $(\mathrm{im}) \cdot \operatorname{puntos}\left(j^{-}-2\right)$ - imagenes(im).puntos $(j+$

imagenes (im) puntos $(j$
imagenes $(i m)$. puntos $(j-$ anchos +6$)+$

imagenes $(i m) \cdot p u n t o s\left(j^{-}+\operatorname{anchos}-2\right)-$

imagenes $(i m) \cdot \operatorname{puntos}(j+\operatorname{anchos}+6)) / 9$ 
$d y=($ CLng $($ imagenes $(i m) \cdot \operatorname{puntos}(j-\operatorname{anchos}-4))-$

imagenes $(i m) \cdot p u n t o s(j+$ anchos -4$)+$ imagenes $(\mathrm{im})$. puntos $\left(j^{-}-\operatorname{anchos}-3\right)$ -

imagenes $(i m) \cdot \operatorname{puntos}(j+$ anchos -3$)+$ imagenes $(\mathrm{im}) \cdot \operatorname{puntos}\left(j^{-}-\operatorname{anchos}-2\right)-$

imagenes $(i m) \cdot p u n t o s(j+$ anchos -2$)+$ imagenes $(\mathrm{im}) \cdot \operatorname{puntos}\left(j^{-}-\operatorname{anchos}+4\right)-$

imagenes $(i m) \cdot p u n t o s(j+$ anchos +4$)+$ imagenes $(\mathrm{im}) \cdot \operatorname{puntos}\left(\mathrm{j}^{-}-\operatorname{anchos}+2\right)$ -

imagenes $(i m) \cdot p u n t o s(j+$ anchos +2$)+$ imagenes $(\mathrm{im}) \cdot \operatorname{puntos}\left(\mathrm{j}^{-}-\operatorname{anchos}+1\right)$ imagenes $(i m) \cdot \operatorname{puntos}(j+$ anchos +1$)+$ imagenes (im) . puntos $\left(j^{-}-\right.$anchos) -

imagenes (im).puntos $(j+$ anchos $)+$ imagenes $(i m) \cdot p u n t \bar{o} s(j-a n c h o s+4)-$

imagenes (im) . puntos $(j+$ anchos +4$)+$ imagenes $(i m) \cdot p u n t o s\left(j^{-}-\right.$anchos +5$)$ imagenes $(i m) \cdot p u n t o s(j+$ anchos +5$)+$ imagenes $(\mathrm{im}) \cdot$ puntos $\left(j^{-}-\operatorname{anchos}+6\right)$ imagenes $(i m) \cdot \operatorname{puntos}(j+\operatorname{anchos}+6)) / 9$ $\operatorname{der}=(\mathrm{dx} \wedge 2+d y \wedge 2) \wedge 0.5$

If der > lim Then

imagenes $(i m r) \cdot \operatorname{puntos}(j)=0$

imagenes $(i m r) \cdot$ puntos $(j+1)=0$

imagenes $(i m r) \cdot \operatorname{puntos}(j+2)=0$

Else

imagenes $(i m r) \cdot p u n t o s(j+3)=0$

imagenes $(i m r) \cdot \operatorname{puntos}(j)=$ imagenes $(i m) \cdot \operatorname{puntos}(j)$

imagenes $(i m r) \cdot p u n t o s(j+1)=$ imagenes $(i m) \cdot \operatorname{puntos}(j+$

1)

2) imagenes $(i m r) \cdot \operatorname{puntos}(j+2)=$ imagenes $(i m) \cdot \operatorname{puntos}(j+$

imagenes $(i m r) \cdot p u n t o s(j)=$ luminoso

imagenes $(i m r) \cdot p u n t o s(j+1)=1$ uminoso

imagenes (imr).puntos $(j+2)=1$ uminoso

imagenes (imr) p puntos $(j)=255-$ der

imagenes $(i m r) \cdot p u n t o s(j+1)=255$ - der

imagenes $(i m r) \cdot p u n t o s(j+2)=255$ - der End If

imagenes $(i m r) \cdot \operatorname{puntos}(j+3)=255$ - der

Next j

Next y

End Sub

Sub Borded (im, im2, imr, lim)

anchos = imagenes $(\mathrm{im})$. ancho * 4

altos $=$ imagenes $($ im) .alto -2

$i m a=i m$

nde $=0$

For $y=$ detecto(nde) $\cdot \operatorname{area}(0) \cdot y-1$ To detecto (nde). area (1) $y+1$ Step -1

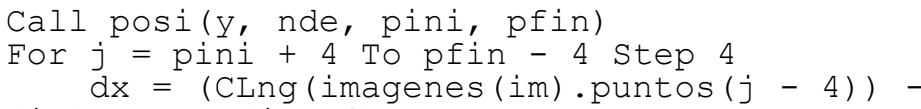

imagenes $(i m) \cdot \operatorname{puntos}(j+4)+$ imagenes(im).puntos (j - anchos - 4) -

imagenes $(i m) \cdot p u n t o s(j-$ anchos +4$)+$ imagenes (im).puntos $\left(j^{-}+\right.$anchos - 4) -

imagenes $(i m) \cdot p u n t o s(j+$ anchos +4$)+$

5) + imagenes $(i m) \cdot \operatorname{puntos}\left(j^{-}-3\right)$ - imagenes (im) p puntos $(j+$ imagenes $(i m) \cdot$ puntos $(j-$ anchos +5$)+$ imagenes $(\mathrm{im}) \cdot \operatorname{puntos}\left(\mathrm{j}^{-}+\operatorname{anchos}-3\right)$ imagenes $(i m) \cdot p u n t o s(j+$ anchos +5$)+$

6) + imagenes $(i m) \cdot p u n t o s\left(j^{-}-2\right)$ - imagenes (im) p puntos $(j+$

imagenes (im) puntos $(j$
imagenes (im) p puntos $(j-$ anchos +6$)+$ imagenes $(\mathrm{im}) \cdot \operatorname{puntos}\left(\mathrm{j}^{-}+\right.$anchos - 2) imagenes $(i m) \cdot p u n t o s(j+\operatorname{anchos}+6)) / 9$ 
$d y=($ CLng $($ imagenes $(i m) \cdot \operatorname{puntos}(j-\operatorname{anchos}-4))-$

imagenes $(i m)$.puntos $(j+$ anchos -4$)+$ imagenes $(\mathrm{im})$. puntos $\left(j^{-}-\operatorname{anchos}-3\right)$ imagenes $(i m) \cdot p u n t o s(j+$ anchos -3$)+$ imagenes (im).puntos $\left(j^{-}-\right.$anchos - 2) imagenes $(i m) \cdot p u n t o s(j+$ anchos -2$)+$ imagenes $(\mathrm{im})$. puntos $\left(j^{-}-\operatorname{anchos}+4\right)-$

imagenes $(i m) \cdot p u n t o s(j+$ anchos +4$)+$ imagenes $(\mathrm{im}) \cdot$ puntos $\left(j^{-}-\operatorname{anchos}+2\right)$ -

imagenes $(i m) \cdot p u n t o s(j+$ anchos +2$)+$ imagenes $(\mathrm{im}) \cdot \operatorname{puntos}\left(\mathrm{j}^{-}-\operatorname{anchos}+1\right)$ imagenes (im).puntos $(j+$ anchos +1$)+$ imagenes (im) p puntos ( $j^{-}-$anchos) imagenes (im).puntos $(j+$ anchos $)+$ imagenes (im).puntōs $(j-$ anchos + 4) imagenes (im) puntos $(j+$ anchos +4$)+$ imagenes $(i m) \cdot p u n t o s\left(j^{-}-\right.$anchos +5$)$ imagenes (im) puntos (j+anchos +5$)+$ imagenes $(\mathrm{im}) \cdot$ puntos $\left(j^{-}-\right.$anchos +6$)$ imagenes $(i m) \cdot \operatorname{puntos}(j+\operatorname{anchos}+6)) / 9$ $\operatorname{der}=(d x \wedge 2+d y \wedge 2) \wedge 0.5$

If der > lim Then

imagenes $(i m r) \cdot \operatorname{puntos}(j)=0$

imagenes $(i m r)$. puntos $(j+1)=0$

imagenes $(i m r) \cdot p u n t o s(j+2)=0$ Else

imagenes $(i m r) \cdot p u n t o s(j+3)=0$

imagenes $(i m r) \cdot \operatorname{puntos}(j)=$ luminoso

imagenes $(i m r)$. puntos $(j+1)=1$ uminoso

imagenes $(i m r) \cdot p u n t o s(j+2)=$ luminoso End If

imagenes $(i m r) \cdot$ puntos $(j+3)=$ luminoso

Next $y$ Next j

ima $=$ im2

For $y=$ detecto(nde). area(0).y - 1 To detecto (nde).area (1) $y+1$ Step -1

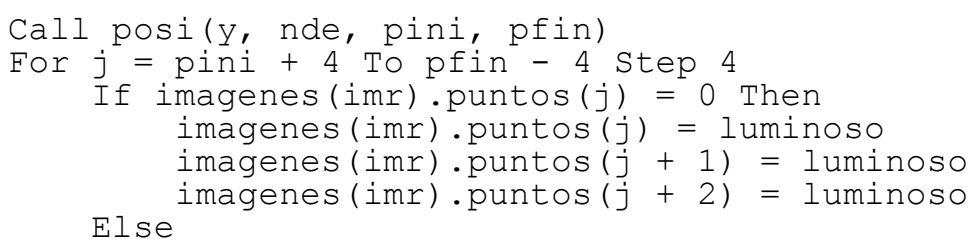




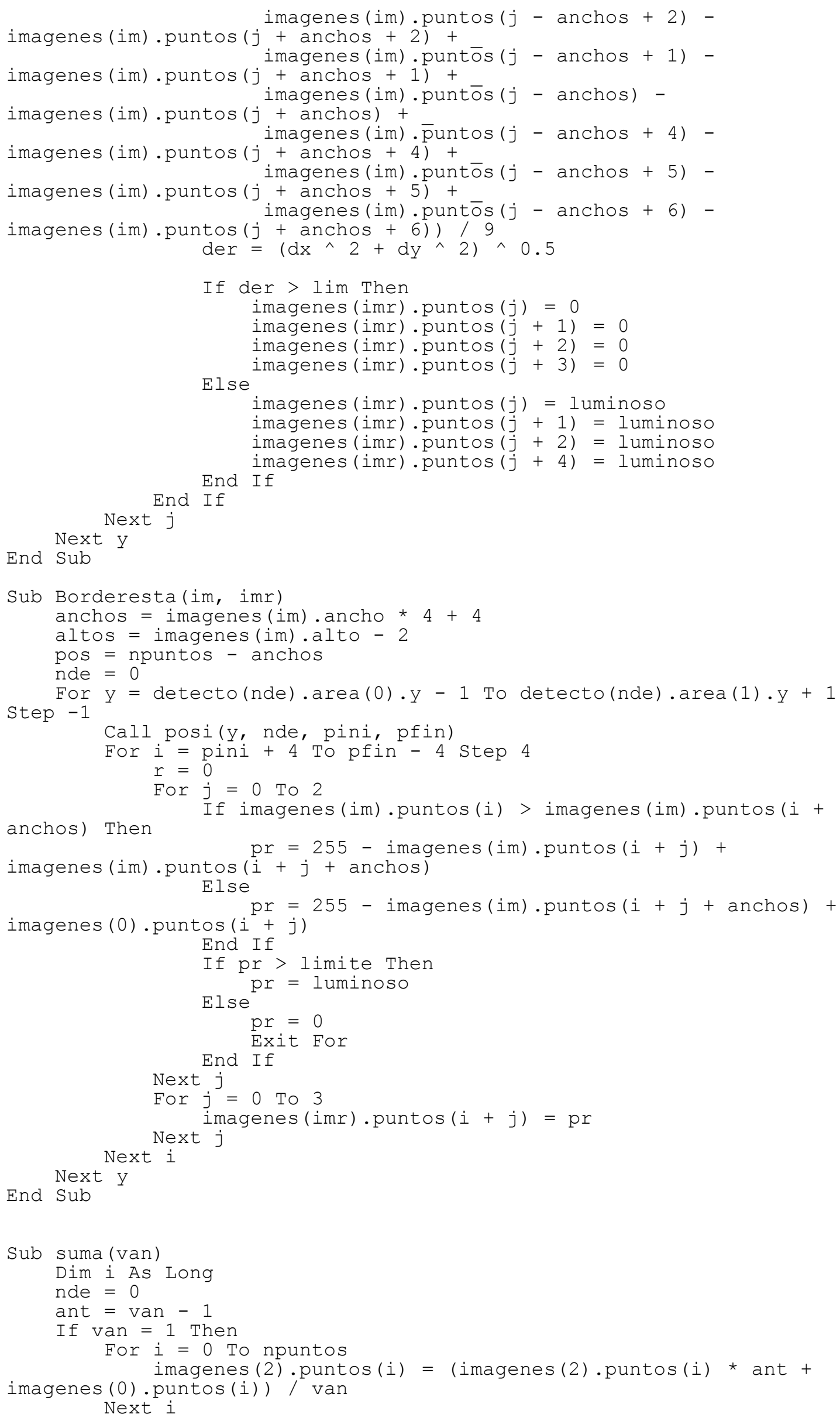




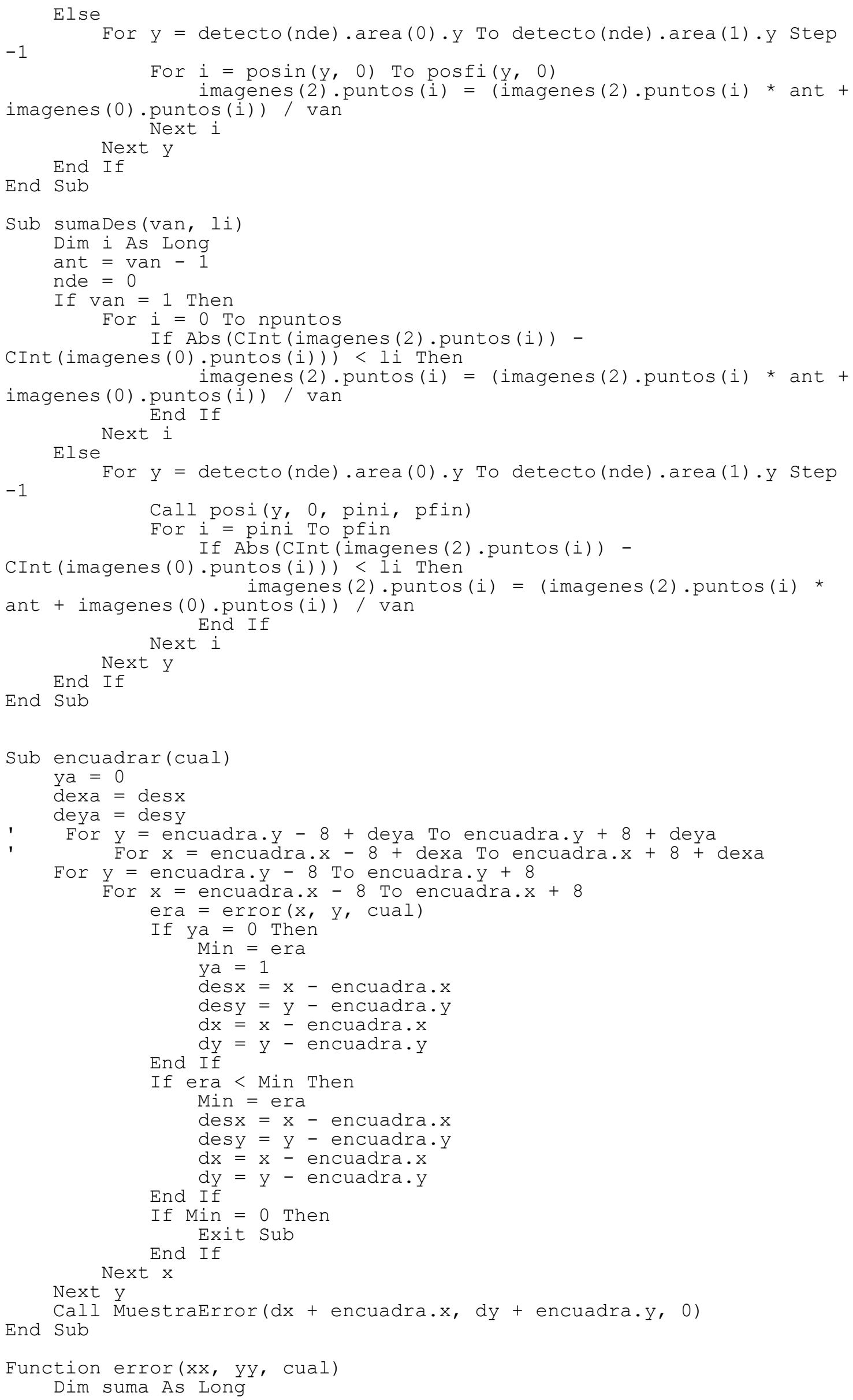




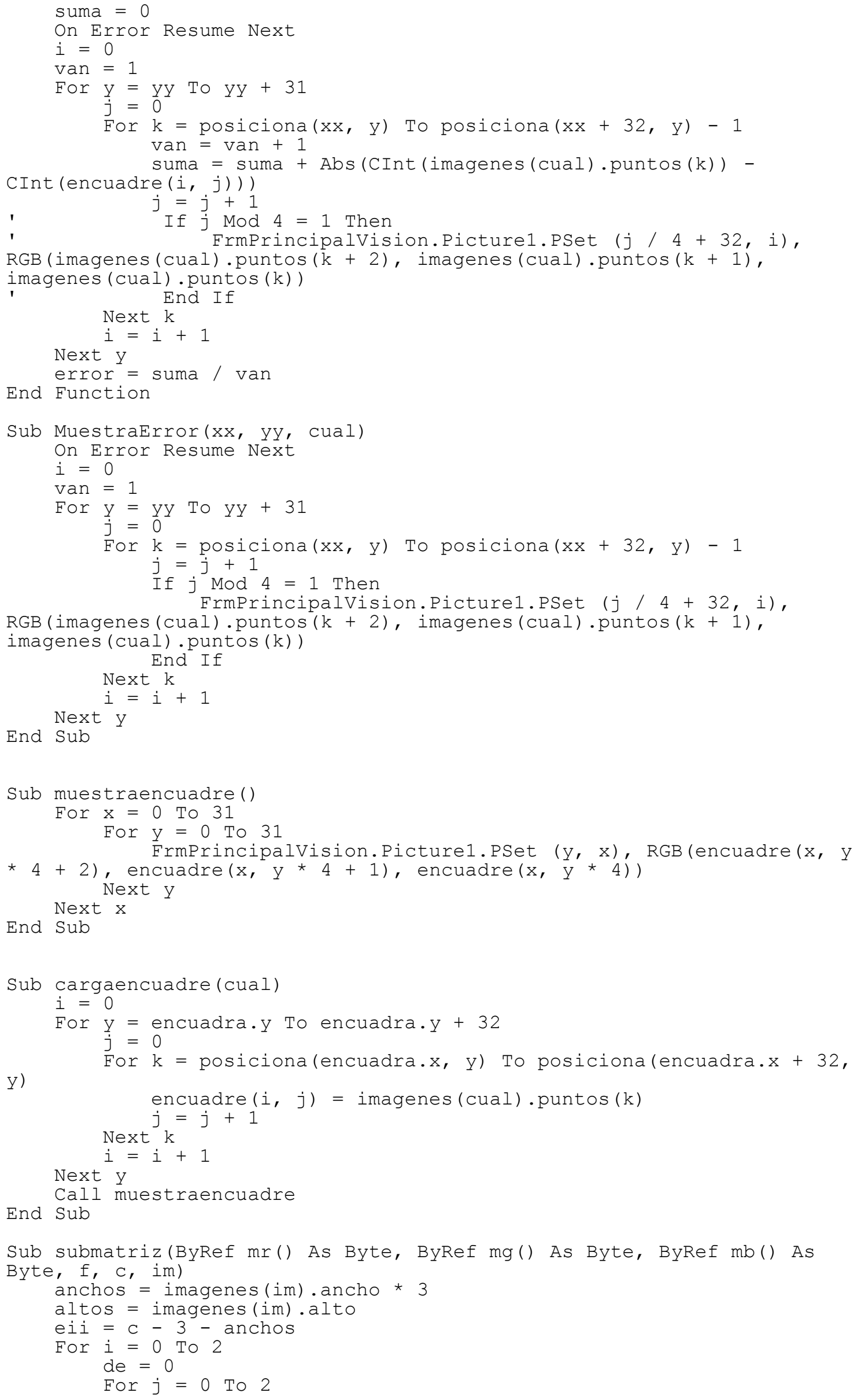




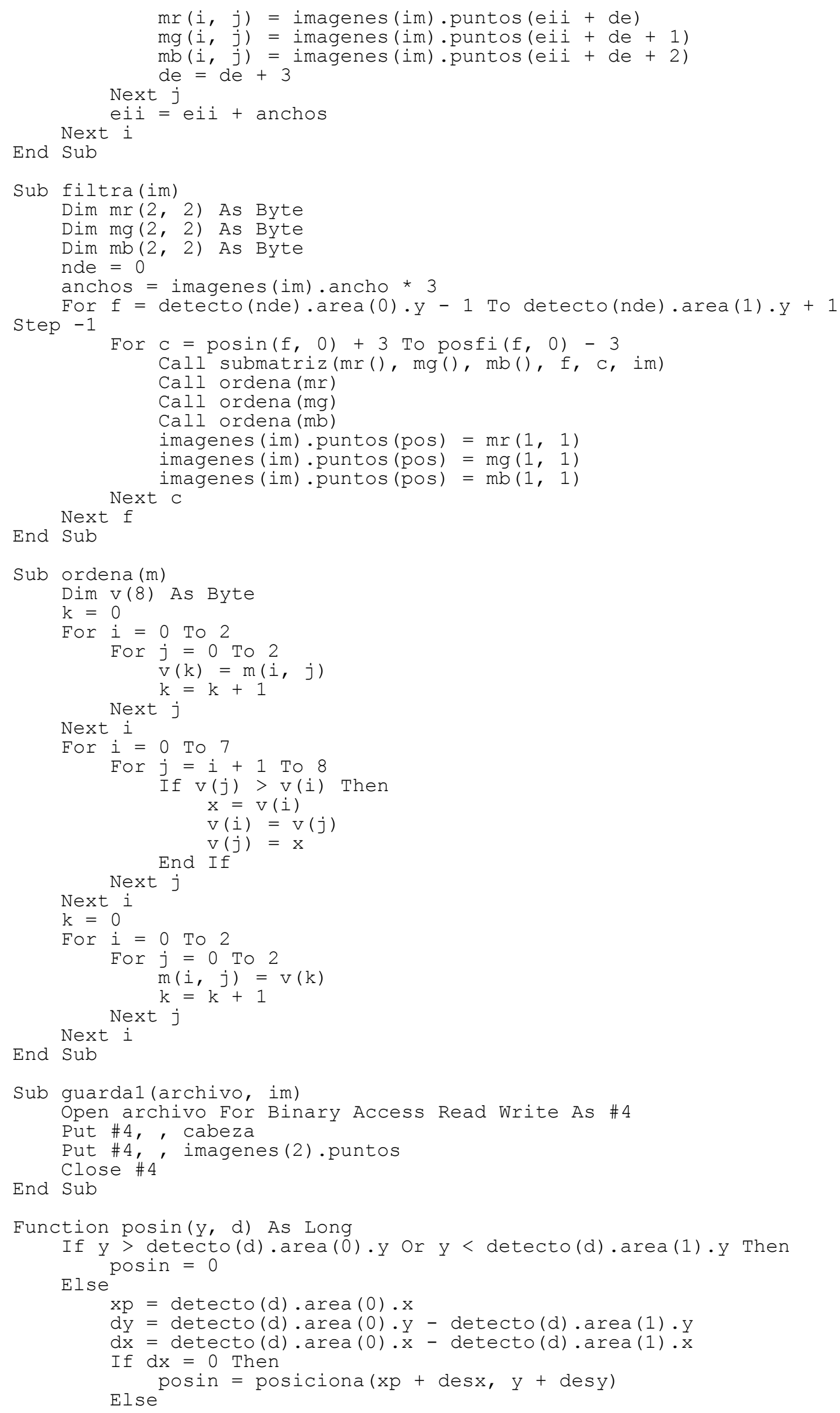


End If

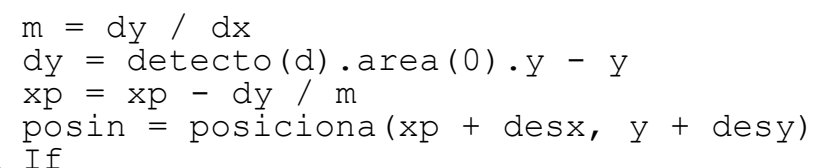

End Function

Function posfi(y, d)

If $y>$ detecto (d).area (3) $y$ or $y<$ detecto(d).area (2) y Then posfi $=0$

End Function

Function posiciona(x, y) As Long

Dim mait As Long

$\mathrm{xp}=\mathrm{x}$

If $x<0$ Then $x p=0$

If $\mathrm{x}>$ imagenes(2). ancho Then $\mathrm{xp}=$ imagenes(2). ancho

posiciona $=($ imagenes (2). alto - y) * imagenes (2). ancho $\star 4+4$ *

Int $(\mathrm{xp}+0.5)$

If posiciona $<0$ Then posiciona $=0$

mait = CLng (imagenes (2).alto) * CLng(imagenes (2).ancho) * 4

If posiciona $>=$ mait Then posiciona = mait - 1

End Function 
ANEXO No. 4. DATOS DE ACCIDENTALIDAD 
Cómputo de muertos realizado a $24 \mathrm{~h}$.

\begin{tabular}{|c|c|c|c|c|}
\hline No. & CARRETERA & $\mathrm{Km} / 10$ & SENTIDO & TIPO DE ACCIDENTE \\
\hline 1 & A-3 & 351,3 & A & SALIDA DE LA VÍA POR LA DERECHA CON COLISIÓN (CHOQUE CON MURO Ó EDIFICIO) \\
\hline 2 & A-3 & 351,4 & $\mathrm{D}$ & COLISIÓN DE VEHÍCULOS EN MARCHA (MÚLTIPLE O EN CARAVANA) \\
\hline 3 & A-3 & 351,5 & A & SALIDA DE LA VÍA POR LA DERECHA CON COLISIÓN (OTRO TIPO DE CHOQUE) \\
\hline 4 & A-3 & 351,5 & A & COLISIÓN DE VEHÍCULOS EN MARCHA (FRONTOLATERAL) \\
\hline 5 & A-3 & 351,5 & A & COLISIÓN DE VEHÍCULOS EN MARCHA (LATERAL) \\
\hline 6 & $\mathrm{~A}-3$ & 351,6 & $\mathrm{D}$ & COLISIÓN DE VEHÍCULOS EN MARCHA (FRONTOLATERAL) \\
\hline 7 & $\mathrm{~A}-3$ & 351,6 & $\mathrm{D}$ & COLISIÓN DE VEHÍCULOS EN MARCHA (ALCANCE) \\
\hline 8 & A-7 & 484,3 & $\mathrm{D}$ & SALIDA DE LA VÍA POR LA IZQUIERDA CON COLISIÓN (OTRO TIPO DE CHOQUE) \\
\hline 9 & A-7 & 484,3 & $\bar{A}$ & SALIDA DE LA VÍA POR LA DERECHA SIN COLISIÓN (CON VUELCO) \\
\hline 10 & A-7 & 484,5 & A & COLISIÓN DE VEHÍCULOS EN MARCHA (ALCANCE) \\
\hline 11 & $\mathrm{~A}-3$ & 351,3 & $\mathrm{D}$ & Otro tipo de accidente \\
\hline 12 & A-3 & 351,3 & $\mathrm{D}$ & Salida de la vía por la derecha con colisión (Otro tipo de choque) \\
\hline 13 & $A-3$ & 351,3 & $\mathrm{D}$ & Salida de la vía por la izquierda con colisión (Otro tipo de choque) \\
\hline 14 & $\mathrm{~A}-3$ & 351,3 & $\mathrm{D}$ & Vuelco en la calzada \\
\hline 15 & A-3 & 351,3 & $\mathrm{D}$ & Atropello a animales sueltos \\
\hline 16 & A-3 & 351,3 & $\mathrm{D}$ & Colisión de vehículos en marcha (Alcance) \\
\hline 17 & A-3 & 351,4 & A & Otro tipo de accidente \\
\hline 18 & A-3 & 351,4 & $\mathrm{D}$ & Salida de la vía por la derecha con colisión (Choque con muro o edifício) \\
\hline 19 & A-3 & 351,4 & $\mathrm{D}$ & Colisión de vehículos en marcha (Lateral) \\
\hline 20 & A-3 & 351,5 & $\mathrm{D}$ & Colisión de vehículos en marcha (Lateral) \\
\hline 21 & A-3 & 351,5 & A & Colisión de vehículos en marcha (Múltiple o en caravana) \\
\hline 22 & A-3 & 351,5 & A & Colisión de vehículos en marcha (Lateral) \\
\hline 23 & A-3 & 351,5 & A & Salida de la vía por la derecha con colisión (Otro tipo de choque) \\
\hline 24 & A-3 & 351,5 & A & Colisión de vehículos en marcha (Múltiple o en caravana) \\
\hline 25 & $A-3$ & 351,5 & $\mathrm{D}$ & Colisión de vehículos en marcha (Alcance) \\
\hline 26 & A-3 & 351,5 & A & Colisión de vehículos en marcha (Alcance) \\
\hline 27 & A-3 & 351,5 & A & Salida de la vía por la izquierda con colisión (Otro tipo de choque) \\
\hline 28 & A-3 & 351,5 & A & Colisión de vehículos en marcha (Alcance) \\
\hline 29 & $\mathrm{~A}-3$ & 351,5 & $\mathrm{D}$ & Colisión de vehículos en marcha (Alcance) \\
\hline
\end{tabular}


Cómputo de muertos realizado a $24 \mathrm{~h}$.

\begin{tabular}{|c|c|c|c|c|c|c|c|c|c|c|c|}
\hline No. & CARRETERA & $\mathrm{Km} / 10$ & SENTIDO & 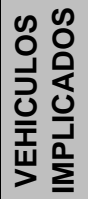 & HORA & FECHA & 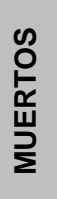 & 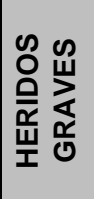 & 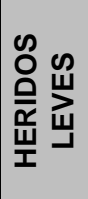 & SUPERFICIE & $\begin{array}{c}\text { FACTORES } \\
\text { ATMOSFERICOS }\end{array}$ \\
\hline 1 & $A-3$ & 351,3 & $A$ & 1 & 4 & 2003517 & 0 & 1 & 2 & MOJADA & LLOVIZNANDO \\
\hline 2 & $A-3$ & 351,4 & $\mathrm{D}$ & 3 & 21 & 2003609 & 0 & 0 & 1 & SECA Y LIMPIA & BUEN TIEMPO \\
\hline 3 & $A-3$ & 351,5 & $A$ & 1 & 4 & 2005416 & 2 & 0 & 0 & SECA Y LIMPIA & BUEN TIEMPO \\
\hline 4 & $A-3$ & 351,5 & $A$ & 2 & 21 & 2004922 & 0 & 0 & 1 & SECA Y LIMPIA & BUEN TIEMPO \\
\hline 5 & $A-3$ & 351,5 & $A$ & 3 & 18 & 20051109 & 0 & 0 & 2 & MOJADA & LLOVIZNANDO \\
\hline 6 & $A-3$ & 351,6 & $\mathrm{D}$ & 2 & 14 & \begin{tabular}{|l|}
2005118 \\
\end{tabular} & 0 & 0 & 1 & SECA Y LIMPIA & BUEN TIEMPO \\
\hline 7 & $A-3$ & 351,6 & $\mathrm{D}$ & 3 & 20 & 2003214 & 0 & 0 & 1 & SECA Y LIMPIA & BUEN TIEMPO \\
\hline 8 & $A-7$ & 484,3 & $\mathrm{D}$ & 1 & 2 & 2005618 & 0 & 0 & 2 & SECA Y LIMPIA & BUEN TIEMPO \\
\hline 9 & $A-7$ & 484,3 & $\mathrm{~A}$ & 1 & 0 & 20051128 & 0 & 2 & 1 & SECA Y LIMPIA & BUEN TIEMPO \\
\hline 10 & $A-7$ & 484,5 & $A$ & 2 & 22 & \begin{tabular}{|l|}
2004622 \\
\end{tabular} & 0 & 0 & 2 & SECA Y LIMPIA & BUEN TIEMPO \\
\hline 11 & $A-3$ & 351,3 & $\mathrm{D}$ & 3 & 15 & \begin{tabular}{|l|}
20060721 \\
\end{tabular} & 0 & 0 & 0 & SECA Y LIMPIA & BUEN TIEMPO \\
\hline 12 & $A-3$ & 351,3 & $\mathrm{D}$ & 1 & 9 & 20060806 & 0 & 0 & 0 & SECA Y LIMPIA & BUEN TIEMPO \\
\hline 13 & $A-3$ & 351,3 & $\mathrm{D}$ & 1 & 17 & \begin{tabular}{|l|}
20060930 \\
\end{tabular} & 0 & 2 & 0 & SECA Y LIMPIA & BUEN TIEMPO \\
\hline 14 & $A-3$ & 351,3 & $\mathrm{D}$ & 1 & 12 & \begin{tabular}{|l|}
20060406 \\
\end{tabular} & 0 & 0 & 0 & SECA Y LIMPIA & BUEN TIEMPO \\
\hline 15 & $A-3$ & 351,3 & $\mathrm{D}$ & 1 & 12 & 20060205 & 0 & 0 & 1 & SECA Y LIMPIA & BUEN TIEMPO \\
\hline 16 & $A-3$ & 351,3 & $\mathrm{D}$ & 3 & 21 & \begin{tabular}{|l|}
20061219 \\
\end{tabular} & 0 & 0 & 1 & MOJADA & BUEN TIEMPO \\
\hline 17 & $A-3$ & 351,4 & $\mathrm{~A}$ & 1 & 10 & \begin{tabular}{|l|}
20061030 \\
\end{tabular} & 0 & 1 & 2 & SECA Y LIMPIA & BUEN TIEMPO \\
\hline 18 & $A-3$ & 351,4 & $\mathrm{D}$ & 1 & 6 & \begin{tabular}{|l|}
20070205 \\
\end{tabular} & 0 & 0 & 0 & SECA Y LIMPIA & BUEN TIEMPO \\
\hline 19 & $A-3$ & 351,4 & $\mathrm{D}$ & 2 & 23 & 20060205 & 0 & 0 & 0 & SECA Y LIMPIA & BUEN TIEMPO \\
\hline 20 & $A-3$ & 351,5 & $\mathrm{D}$ & 2 & 9 & \begin{tabular}{|l|}
20071122 \\
\end{tabular} & 0 & 0 & 0 & SECA Y LIMPIA & BUEN TIEMPO \\
\hline 21 & $A-3$ & 351,5 & $A$ & 3 & 23 & \begin{tabular}{|l|}
20071103 \\
\end{tabular} & 0 & 0 & 4 & SECA Y LIMPIA & BUEN TIEMPO \\
\hline 22 & $A-3$ & 351,5 & $A$ & 2 & 20 & \begin{tabular}{|l|}
20061031 \\
\end{tabular} & 0 & 0 & 0 & SECA Y LIMPIA & BUEN TIEMPO \\
\hline 23 & $A-3$ & 351,5 & $A$ & 3 & 19 & \begin{tabular}{|l|}
20060603 \\
\end{tabular} & 0 & 0 & 0 & SECA Y LIMPIA & BUEN TIEMPO \\
\hline 24 & $A-3$ & 351,5 & $A$ & 6 & 8 & \begin{tabular}{|l|}
20060418 \\
\end{tabular} & 0 & 0 & 0 & SECA Y LIMPIA & BUEN TIEMPO \\
\hline 25 & $A-3$ & 351,5 & $\mathrm{D}$ & 2 & 21 & \begin{tabular}{|l|}
20060415 \\
\end{tabular} & 0 & 0 & 1 & SECA Y LIMPIA & BUEN TIEMPO \\
\hline 26 & A-3 & 351,5 & $A$ & 2 & 0 & \begin{tabular}{|l|}
20070211 \\
\end{tabular} & 0 & 0 & 0 & SECA Y LIMPIA & BUEN TIEMPO \\
\hline 27 & $A-3$ & 351,5 & $A$ & 3 & 22 & \begin{tabular}{|l|}
20070210 \\
\end{tabular} & 1 & 1 & 1 & SECA Y LIMPIA & BUEN TIEMPO \\
\hline 28 & $A-3$ & 351,5 & $A$ & 2 & 10 & \begin{tabular}{|l|}
20060922 \\
\end{tabular} & 0 & 0 & 0 & SECA Y LIMPIA & BUEN TIEMPO \\
\hline 29 & $A-3$ & 351,5 & $\mathrm{D}$ & 2 & 18 & \begin{tabular}{|l|}
20070322 \\
\end{tabular} & 0 & 0 & 0 & SECA Y LIMPIA & BUEN TIEMPO \\
\hline
\end{tabular}


Cómputo de muertos realizado a $24 \mathrm{~h}$.

\begin{tabular}{|c|c|c|c|c|c|c|c|c|c|c|}
\hline No. & CARRETERA & $\mathrm{Km} / 10$ & SENTIDO & VISIBILIDAD & LUMINOSIDAD & 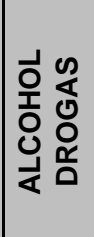 & $\begin{array}{l}\frac{\varangle}{\widetilde{\alpha}} \\
\stackrel{\Psi}{\gtrless}\end{array}$ & 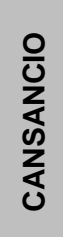 & 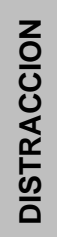 & 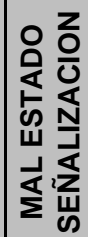 \\
\hline 1 & $A-3$ & 351,3 & $\mathrm{~A}$ & CONFIGURACION DEL TERRENO & NOCHE: ILUMINACIÓN SUFICIENTE & & & & & \\
\hline 2 & $A-3$ & 351,4 & $\mathrm{D}$ & SIN RESTRICCIÓN & CRESPÚSCULO & $\mathrm{S}$ & & & $\mathrm{S}$ & \\
\hline 3 & $\mathrm{~A}-3$ & 351,5 & $\mathrm{~A}$ & SIN RESTRICCIÓN & NOCHE: ILUMINACIÓN SUFICIENTE & & & & & \\
\hline 4 & $\mathrm{~A}-3$ & 351,5 & A & SIN RESTRICCIÓN & NOCHE: ILUMINACIÓN SUFICIENTE & & & & & \\
\hline 5 & $A-3$ & 351,5 & $\bar{A}$ & SIN RESTRICCIÓN & PLENO DÍA & $\mathrm{S}$ & & & $\mathrm{S}$ & \\
\hline 6 & $A-3$ & 351,6 & $\mathrm{D}$ & SIN RESTRICCIÓN & PLENO DÍA & & & & & \\
\hline 7 & $\mathrm{~A}-3$ & 351,6 & $\mathrm{D}$ & SIN RESTRICCIÓN & NOCHE: ILUMINACIÓN SUFICIENTE & & & & & \\
\hline 8 & A-7 & 484,3 & $\mathrm{D}$ & SIN RESTRICCIÓN & NOCHE: SIN ILUMINACIÓN & & & & & \\
\hline 9 & $\mathrm{~A}-7$ & 484,3 & $\mathrm{~A}$ & SIN RESTRICCIÓN & NOCHE: SIN ILUMINACIÓN & & & & $\mathrm{S}$ & \\
\hline 10 & A-7 & 484,5 & $\mathrm{~A}$ & SIN RESTRICCIÓN & NOCHE: ILUMINACIÓN INSUFICIENTE & & & & $\mathrm{S}$ & \\
\hline 11 & $A-3$ & 351,3 & $\mathrm{D}$ & SIN RESTRICCIÓN & PLENO DÍA & & & & & \\
\hline 12 & $A-3$ & 351,3 & $\mathrm{D}$ & SIN RESTRICCIÓN & PLENO DÍA & $\mathrm{S}$ & & & $\mathrm{S}$ & \\
\hline 13 & $A-3$ & 351,3 & $\mathrm{D}$ & SIN RESTRICCIÓN & PLENO DÍA & & & & & \\
\hline 14 & $\mathrm{~A}-3$ & 351,3 & $\mathrm{D}$ & SIN RESTRICCIÓN & PLENO DÍA & & $\mathrm{S}$ & & & \\
\hline 15 & $A-3$ & 351,3 & $\mathrm{D}$ & SIN RESTRICCIÓN & PLENO DÍA & & & & & \\
\hline 16 & $A-3$ & 351,3 & $\mathrm{D}$ & SIN RESTRICCIÓN & NOCHE: ILUMINACIÓN SUFICIENTE & & & & $\mathrm{S}$ & \\
\hline 17 & $A-3$ & 351,4 & $\bar{A}$ & SIN RESTRICCIÓN & PLENO DÍA & & & & & \\
\hline 18 & $A-3$ & 351,4 & $\mathrm{D}$ & SIN RESTRICCIÓN & NOCHE: ILUMINACIÓN SUFICIENTE & & & $\mathrm{S}$ & & \\
\hline 19 & $A-3$ & 351,4 & $\mathrm{D}$ & SIN RESTRICCIÓN & NOCHE: ILUMINACIÓN SUFICIENTE & $\mathrm{S}$ & & & & \\
\hline 20 & $A-3$ & 351,5 & $\mathrm{D}$ & SIN RESTRICCIÓN & PLENO DÍA & & & & & \\
\hline 21 & $A-3$ & 351,5 & A & SIN RESTRICCIÓN & NOCHE: ILUMINACIÓN SUFICIENTE & & & & $\mathrm{S}$ & \\
\hline 22 & $A-3$ & 351,5 & A & SIN RESTRICCIÓN & NOCHE: ILUMINACIÓN SUFICIENTE & & & & $\mathrm{S}$ & \\
\hline 23 & $A-3$ & 351,5 & A & SIN RESTRICCIÓN & PLENO DÍA & & & & $\mathrm{S}$ & \\
\hline 24 & $A-3$ & 351,5 & A & SIN RESTRICCIÓN & PLENO DÍA & & & & $\mathrm{S}$ & \\
\hline 25 & $A-3$ & 351,5 & $\mathrm{D}$ & SIN RESTRICCIÓN & NOCHE: ILUMINACIÓN SUFICIENTE & & & & & \\
\hline 26 & $A-3$ & 351,5 & A & SIN RESTRICCIÓN & NOCHE: ILUMINACIÓN SUFICIENTE & & & & $\mathrm{S}$ & \\
\hline 27 & $A-3$ & 351,5 & A & SIN RESTRICCIÓN & NOCHE: ILUMINACIÓN SUFICIENTE & & & & $\mathrm{S}$ & \\
\hline 28 & $A-3$ & 351,5 & A & SIN RESTRICCIÓN & PLENO DÍA & & & & & \\
\hline 29 & $\mathrm{~A}-3$ & 351,5 & $\mathrm{D}$ & SIN RESTRICCIÓN & PLENO DÍA & & & & $\mathrm{S}$ & \\
\hline
\end{tabular}


Cómputo de muertos realizado a $24 \mathrm{~h}$.

\begin{tabular}{|c|c|c|c|c|c|c|c|c|c|c|c|c|}
\hline No. & CARRETERA & $\mathrm{Km} / 10$ & SENTIDO & 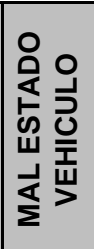 & 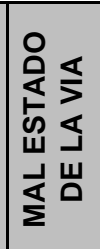 & 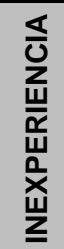 & 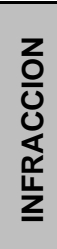 & 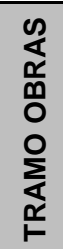 & $\begin{array}{l}\text { ஜ } \\
\text { ㅁ } \\
\text { ○ }\end{array}$ & $\begin{array}{l}z \\
0 \\
z \\
0 \\
0 \\
z \\
\text { n }\end{array}$ & 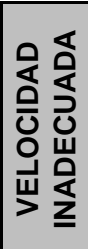 & 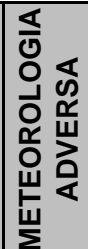 \\
\hline 1 & $A-3$ & 351,3 & $A$ & & & & & & & & $S$ & \\
\hline 2 & $A-3$ & 351,4 & $\mathrm{D}$ & & & & & & & & & \\
\hline 3 & $A-3$ & 351,5 & $A$ & & & & & & $\mathrm{~S}$ & & & \\
\hline 4 & $A-3$ & 351,5 & $A$ & & & & $\mathrm{~S}$ & & & & & \\
\hline 5 & $A-3$ & 351,5 & $A$ & & & & $\mathrm{~S}$ & & & & & \\
\hline 6 & $A-3$ & 351,6 & $\mathrm{D}$ & & & & & & & & $S$ & \\
\hline 7 & $A-3$ & 351,6 & $\mathrm{D}$ & & & & & & & $\mathrm{S}$ & & \\
\hline 8 & A-7 & 484,3 & $\mathrm{D}$ & & & & & & & & $S$ & \\
\hline 9 & $A-7$ & 484,3 & $\mathrm{~A}$ & & & & & & & & & \\
\hline \begin{tabular}{|l|}
10 \\
\end{tabular} & $A-7$ & 484,5 & $A$ & & & & & & & & & \\
\hline \begin{tabular}{|l|}
11 \\
\end{tabular} & $A-3$ & 351,3 & $\mathrm{D}$ & & & & $\mathrm{S}$ & & & & & \\
\hline \begin{tabular}{|l|}
12 \\
\end{tabular} & $A-3$ & 351,3 & $\mathrm{D}$ & & & & & & & & & \\
\hline \begin{tabular}{|l|}
13 \\
\end{tabular} & $A-3$ & 351,3 & $\mathrm{D}$ & & & & & & & & $S$ & \\
\hline \begin{tabular}{|l|}
14 \\
\end{tabular} & $A-3$ & 351,3 & $\mathrm{D}$ & $S$ & & & & & & & & \\
\hline \begin{tabular}{|l|}
15 \\
\end{tabular} & $A-3$ & 351,3 & $\mathrm{D}$ & & & & & & $\mathrm{N}$ & & & \\
\hline \begin{tabular}{|l|}
16 \\
\end{tabular} & $A-3$ & 351,3 & $\mathrm{D}$ & & & & & & & & & \\
\hline \begin{tabular}{|l|}
17 \\
\end{tabular} & $A-3$ & 351,4 & $A$ & & & & & & & & $S$ & \\
\hline \begin{tabular}{|l|}
18 \\
\end{tabular} & $A-3$ & 351,4 & $\mathrm{D}$ & & & & & & & & & \\
\hline \begin{tabular}{|l|}
19 \\
\end{tabular} & $A-3$ & 351,4 & $\mathrm{D}$ & & & & & & & & & \\
\hline \begin{tabular}{|l|}
20 \\
\end{tabular} & $A-3$ & 351,5 & $\mathrm{D}$ & & & & & & & $S$ & & \\
\hline \begin{tabular}{|l|}
21 \\
\end{tabular} & $A-3$ & 351,5 & $A$ & & & & & & & & & \\
\hline \begin{tabular}{|l|}
22 \\
\end{tabular} & $A-3$ & 351,5 & $A$ & & & & & & & & & \\
\hline \begin{tabular}{|l|}
23 \\
\end{tabular} & $A-3$ & 351,5 & $A$ & & & & & & & & & \\
\hline \begin{tabular}{|l|}
24 \\
\end{tabular} & $A-3$ & 351,5 & $A$ & & & & & & & & & \\
\hline \begin{tabular}{|l|}
25 \\
\end{tabular} & $A-3$ & 351,5 & $\mathrm{D}$ & & & & $\mathrm{S}$ & & & & & \\
\hline \begin{tabular}{|l|}
26 \\
26
\end{tabular} & $A-3$ & 351,5 & $A$ & & & & & & & & & \\
\hline \begin{tabular}{|l|}
27 \\
\end{tabular} & $A-3$ & 351,5 & $A$ & & & & $\mathrm{~S}$ & & & & & \\
\hline \begin{tabular}{|l|}
28 \\
\end{tabular} & $A-3$ & 351,5 & $A$ & & & & $\mathrm{~S}$ & & & & & \\
\hline \begin{tabular}{|l|}
29 \\
\end{tabular} & $A-3$ & 351,5 & $\mathrm{D}$ & & & & & & & & & \\
\hline
\end{tabular}


Cómputo de muertos realizado a $24 \mathrm{~h}$.

\begin{tabular}{|c|c|c|c|c|}
\hline No. & CARRETERA & $\mathrm{Km} / 10$ & SENTIDO & TIPO DE ACCIDENTE \\
\hline 30 & $A-3$ & 351,6 & $\bar{A}$ & Colisión de vehículos en marcha (Alcance) \\
\hline 31 & $A-3$ & 351,6 & A & Colisión de vehículos en marcha (Alcance) \\
\hline 32 & $A-3$ & 351,6 & A & Colisión de vehículos en marcha (Alcance) \\
\hline 33 & $A-3$ & 351,6 & $\bar{A}$ & Colisión de vehículos en marcha (Lateral) \\
\hline 34 & $A-3$ & 351,6 & $\bar{A}$ & Colisión de vehículos en marcha (Alcance) \\
\hline 35 & $A-3$ & 351,6 & A & Colisión de vehículos en marcha (Alcance) \\
\hline 36 & $A-3$ & 351,7 & $\mathrm{D}$ & Otro tipo de accidente \\
\hline 37 & $A-3$ & 351,7 & $\bar{A}$ & Colisión de vehículos en marcha (Alcance) \\
\hline 38 & $A-3$ & 351,8 & A & Colisión de vehículos en marcha (Alcance) \\
\hline 39 & $A-3$ & 351,8 & A & Colisión de vehículos en marcha (Múltiple o en caravana) \\
\hline 40 & $A-3$ & 351,8 & $\mathrm{D}$ & Atropello a peatón aislado o en grupo \\
\hline 41 & A-7 & 484,3 & $\bar{A}$ & Colisión de vehículos en marcha (Frontolateral) \\
\hline 42 & A-7 & 484,3 & A & Colisión de vehículo con obstáculo en calzada (Otro objeto o material) \\
\hline 43 & A-7 & 484,4 & $\mathrm{D}$ & Colisión de vehículos en marcha (Alcance) \\
\hline 44 & A-7 & 484,5 & A & Salida de la vía por la izquierda con colisión (Choque con muro o edifício) \\
\hline 45 & A-7 & 484,6 & A & Colisión de vehículos en marcha (Múltiple o en caravana) \\
\hline 46 & A-7 & 485,0 & A & Colisión de vehículos en marcha (Alcance) \\
\hline 47 & A-7 & 485,0 & $\mathrm{D}$ & Colisión de vehículo con obstáculo en calzada (Vehículo estacionado o averiado) \\
\hline 48 & V-21 & 0,9 & $\mathrm{D}$ & COLISIÓN DE VEHÍCULOS EN MARCHA (ALCANCE) \\
\hline 49 & V-21 & 4,9 & A & PEATÓN AISLADO O EN GRUPO \\
\hline 50 & V-21 & 4,9 & $\mathrm{D}$ & SALIDA DE LA VÍA POR LA DERECHA CON COLISIÓN (CHOQUE CON CUNETA O BORDILLO) \\
\hline 51 & V-30 & 4,9 & $\mathrm{D}$ & COLISIÓN DE VEHÍCULOS EN MARCHA (LATERAL) \\
\hline 52 & V-31 & 0,8 & $\mathrm{D}$ & COLISIÓN DE VEHÍCULOS EN MARCHA (FRONTOLATERAL) \\
\hline 53 & V-31 & 1,0 & A & COLISIÓN DE VEHÍCULOS EN MARCHA (MÚLTIPLE O EN CARAVANA) \\
\hline 54 & V-31 & 6,3 & A & SALIDA DE LA VÍA POR LA IZQUIERDA SIN COLISIÓN (EN LLANO) \\
\hline \begin{tabular}{|l|l|l}
55 & 1 \\
\end{tabular} & V-31 & 6,7 & $\mathrm{D}$ & COLISIÓN DE VEHÍCULOS EN MARCHA (MÚLTIPLE O EN CARAVANA) \\
\hline 56 & V-31 & 6,8 & A & COLISIÓN DE VEHÍCULO CON OBSTÁCULO EN CALZADA (OTRO OBJETO O MATERIAL) \\
\hline
\end{tabular}


Cómputo de muertos realizado a $24 \mathrm{~h}$.

\begin{tabular}{|c|c|c|c|c|c|c|c|c|c|c|c|}
\hline No. & CARRETERA & $\mathrm{Km} / \mathbf{1 0}$ & SENTIDO & 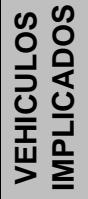 & HORA & FECHA & 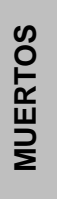 & 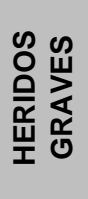 & 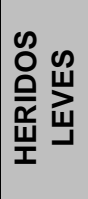 & SUPERFICIE & $\begin{array}{c}\text { FACTORES } \\
\text { ATMOSFERICOS }\end{array}$ \\
\hline 30 & $A-3$ & 351,6 & $\bar{A}$ & 2 & 15 & 20060303 & 0 & 0 & 0 & SECA Y LIMPIA & BUEN TIEMPO \\
\hline 31 & A-3 & 351,6 & $\mathrm{~A}$ & 2 & 8 & 20070214 & 0 & 0 & 2 & SECA Y LIMPIA & BUEN TIEMPO \\
\hline 32 & $A-3$ & 351,6 & $\bar{A}$ & 2 & 8 & 20070214 & 0 & 0 & 1 & SECA Y LIMPIA & BUEN TIEMPO \\
\hline 33 & A-3 & 351,6 & $\bar{A}$ & 3 & 9 & 20070310 & 0 & 0 & 0 & SECA Y LIMPIA & BUEN TIEMPO \\
\hline 34 & A-3 & 351,6 & $\mathrm{~A}$ & 2 & 19 & 20070628 & 0 & 0 & 1 & SECA Y LIMPIA & BUEN TIEMPO \\
\hline 35 & A-3 & 351,6 & A & 2 & 18 & 20070621 & 0 & 1 & 0 & SECA Y LIMPIA & BUEN TIEMPO \\
\hline 36 & A-3 & 351,7 & $\mathrm{D}$ & 3 & 20 & 20070214 & 0 & 3 & 0 & SECA Y LIMPIA & BUEN TIEMPO \\
\hline 37 & A-3 & 351,7 & A & 2 & 16 & 20060128 & 0 & 0 & 1 & SECA Y LIMPIA & BUEN TIEMPO \\
\hline 38 & A-3 & 351,8 & $\mathrm{~A}$ & 2 & 9 & 20070604 & 0 & 0 & 0 & SECA Y LIMPIA & BUEN TIEMPO \\
\hline 39 & $A-3$ & 351,8 & A & 5 & 19 & 20060802 & 0 & 0 & 2 & SECA Y LIMPIA & BUEN TIEMPO \\
\hline 40 & A-3 & 351,8 & $\mathrm{D}$ & 1 & 13 & 20061019 & 0 & 1 & 0 & SECA Y LIMPIA & BUEN TIEMPO \\
\hline 41 & $A-7$ & 484,3 & A & 2 & 0 & 20071105 & 0 & 0 & 2 & SECA Y LIMPIA & BUEN TIEMPO \\
\hline 42 & $A-7$ & 484,3 & $\mathrm{~A}$ & 7 & 7 & 20061127 & 0 & 0 & 0 & SECA Y LIMPIA & BUEN TIEMPO \\
\hline 43 & $A-7$ & 484,4 & $\mathrm{D}$ & 2 & 16 & 20070902 & 0 & 0 & 1 & SECA Y LIMPIA & BUEN TIEMPO \\
\hline 44 & $A-7$ & 484,5 & A & 1 & 11 & 20070727 & 0 & 0 & 0 & SECA Y LIMPIA & BUEN TIEMPO \\
\hline 45 & $A-7$ & 484,6 & $\mathrm{~A}$ & 8 & 7 & 20070222 & 0 & 1 & 3 & SECA Y LIMPIA & BUEN TIEMPO \\
\hline 46 & $A-7$ & 485,0 & $\mathrm{~A}$ & 2 & 11 & 20060217 & 0 & 0 & 2 & SECA Y LIMPIA & BUEN TIEMPO \\
\hline 47 & $A-7$ & 485,0 & $\mathrm{D}$ & 2 & 18 & 20060726 & 0 & 0 & 0 & SECA Y LIMPIA & BUEN TIEMPO \\
\hline 48 & $\mathrm{~V}-21$ & 0,9 & $\mathrm{D}$ & 2 & 0 & 2005210 & 0 & 2 & 0 & SECA Y LIMPIA & BUEN TIEMPO \\
\hline 49 & $\mathrm{~V}-21$ & 4,9 & $\mathrm{~A}$ & 1 & 2 & 2005612 & 1 & 0 & 2 & SECA Y LIMPIA & BUEN TIEMPO \\
\hline 50 & $\mathrm{~V}-21$ & 4,9 & $\mathrm{D}$ & 1 & 5 & 2004808 & 0 & 1 & 0 & SECA Y LIMPIA & BUEN TIEMPO \\
\hline 51 & V-30 & 4,9 & $\mathrm{D}$ & 2 & 11 & 2004525 & 0 & 0 & 2 & SECA Y LIMPIA & BUEN TIEMPO \\
\hline 52 & V-31 & 0,8 & $\bar{D}$ & 2 & 7 & 2005611 & 0 & 1 & 0 & SECA Y LIMPIA & BUEN TIEMPO \\
\hline 53 & V-31 & 1,0 & $\mathrm{~A}$ & 4 & 10 & 2004628 & 0 & 0 & 3 & SECA Y LIMPIA & BUEN TIEMPO \\
\hline 54 & V-31 & 6,3 & $A$ & 2 & 22 & 2004922 & 0 & 0 & 1 & SECA Y LIMPIA & BUEN TIEMPO \\
\hline 55 & V-31 & 6,7 & $\mathrm{D}$ & 4 & 7 & 2004908 & 0 & 1 & 1 & SECA Y LIMPIA & BUEN TIEMPO \\
\hline 56 & V-31 & 6,8 & A & 1 & 13 & 2004724 & 0 & 0 & 1 & OTRO TIPO & BUEN TIEMPO \\
\hline
\end{tabular}


Cómputo de muertos realizado a $24 \mathrm{~h}$.

\begin{tabular}{|c|c|c|c|c|c|c|c|c|c|c|}
\hline No. & CARRETERA & $\mathrm{Km} / 10$ & SENTIDO & VISIBILIDAD & LUMINOSIDAD & 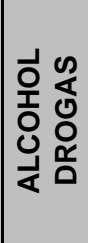 & 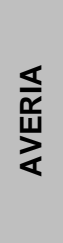 & 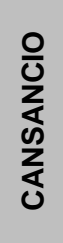 & 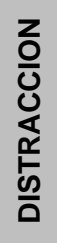 & 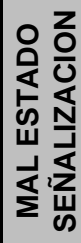 \\
\hline 30 & $A-3$ & 351,6 & $\mathrm{~A}$ & SIN RESTRICCIÓN & PLENO DÍA & & & & & \\
\hline 31 & A-3 & 351,6 & A & SIN RESTRICCIÓN & CREPÚSCULO & & & & & \\
\hline 32 & A-3 & 351,6 & A & SIN RESTRICCIÓN & PLENO DÍA & & & & $\mathrm{S}$ & \\
\hline 33 & A-3 & 351,6 & A & SIN RESTRICCIÓN & PLENO DÍA & & & & & \\
\hline 34 & A-3 & 351,6 & A & SIN RESTRICCIÓN & PLENO DÍA & & & & & \\
\hline 35 & A-3 & 351,6 & A & SIN RESTRICCIÓN & PLENO DÍA & & & & & \\
\hline 36 & A-3 & 351,7 & $\mathrm{D}$ & SIN RESTRICCIÓN & NOCHE: ILUMINACIÓN SUFICIENTE & & & & $\mathrm{S}$ & \\
\hline 37 & A-3 & 351,7 & A & SIN RESTRICCIÓN & PLENO DÍA & & & & $\mathrm{S}$ & \\
\hline 38 & A-3 & 351,8 & A & SIN RESTRICCIÓN & PLENO DÍA & & & & $\mathrm{S}$ & \\
\hline 39 & A-3 & 351,8 & A & SIN RESTRICCIÓN & PLENO DÍA & & & & $\mathrm{S}$ & \\
\hline 40 & A-3 & 351,8 & $\mathrm{D}$ & SIN RESTRICCIÓN & PLENO DÍA & & & & & \\
\hline 41 & A-7 & 484,3 & A & SIN RESTRICCIÓN & NOCHE: ILUMINACIÓN INSUFICIENTE & & & & $\mathrm{S}$ & \\
\hline 42 & A-7 & 484,3 & A & SIN RESTRICCIÓN & NOCHE: SIN ILUMINACIÓN & & & & & \\
\hline 43 & A-7 & 484,4 & $\mathrm{D}$ & SIN RESTRICCIÓN & PLENO DÍA & & & & & \\
\hline 44 & A-7 & 484,5 & A & SIN RESTRICCIÓN & PLENO DÍA & & & & S & \\
\hline 45 & A-7 & 484,6 & A & SIN RESTRICCIÓN & CREPÚSCULO & & & & & \\
\hline 46 & A-7 & 485,0 & A & SIN RESTRICCIÓN & PLENO DÍA & & & & $\mathrm{S}$ & \\
\hline 47 & A-7 & 485,0 & $\mathrm{D}$ & SIN RESTRICCIÓN & PLENO DÍA & & & & & \\
\hline 48 & $\mathrm{~V}-21$ & 0,9 & $\mathrm{D}$ & SIN RESTRICCIÓN & NOCHE: ILUMINACIÓN INSUFICIENTE & & & & $\mathrm{S}$ & \\
\hline 49 & $\mathrm{~V}-21$ & 4,9 & A & SIN RESTRICCIÓN & NOCHE: SIN ILUMINACIÓN & & & & & \\
\hline 50 & $\mathrm{~V}-21$ & 4,9 & $\mathrm{D}$ & SIN RESTRICCIÓN & NOCHE: SIN ILUMINACIÓN & $\mathrm{S}$ & & & $\mathrm{S}$ & \\
\hline 51 & $\mathrm{~V}-30$ & 4,9 & $\mathrm{D}$ & SIN RESTRICCIÓN & PLENO DÍA & & & & & \\
\hline 52 & $\mathrm{~V}-31$ & 0,8 & $\mathrm{D}$ & SIN RESTRICCIÓN & PLENO DÍA & & & & & \\
\hline 53 & $\mathrm{~V}-31$ & 1,0 & A & SIN RESTRICCIÓN & PLENO DÍA & & & & & \\
\hline 54 & $\mathrm{~V}-31$ & 6,3 & A & SIN RESTRICCIÓN & NOCHE: ILUMINACIÓN SUFICIENTE & $\mathrm{S}$ & & & $\mathrm{S}$ & \\
\hline 55 & V-31 & 6,7 & $\mathrm{D}$ & SIN RESTRICCIÓN & CRESPÚSCULO & & & & $\mathrm{S}$ & \\
\hline 56 & V-31 & 6,8 & A & CONFIGURACION DEL TERRENO & PLENO DÍA & & & & & \\
\hline
\end{tabular}


Cómputo de muertos realizado a $24 \mathrm{~h}$

\begin{tabular}{|c|c|c|c|c|c|c|c|c|c|c|c|c|}
\hline No. & CARRETERA & $\mathrm{Km} / 10$ & SENTIDO & 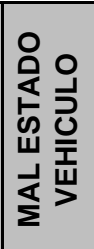 & 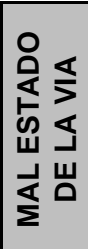 & 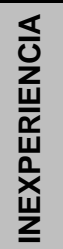 & 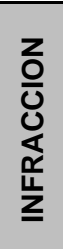 & 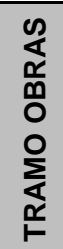 & 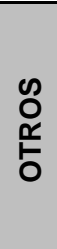 & $\begin{array}{l}z \\
o \\
z \\
0 \\
0 \\
z \\
\text { क }\end{array}$ & 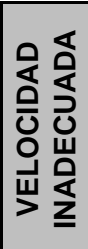 & 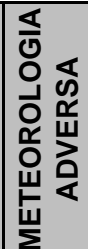 \\
\hline 30 & $A-3$ & 351,6 & $\bar{A}$ & & & & $\mathrm{~S}$ & & & & & \\
\hline 31 & A-3 & 351,6 & A & & & & $\mathrm{S}$ & & & & & \\
\hline 32 & $A-3$ & 351,6 & $\mathrm{~A}$ & & & & & & & & & \\
\hline 33 & A-3 & 351,6 & $A$ & & & & & & & $S$ & & \\
\hline 34 & A-3 & 351,6 & $\mathrm{~A}$ & & & & & & & $\mathrm{~S}$ & & \\
\hline 35 & A-3 & 351,6 & $\mathrm{~A}$ & & & & $S$ & & & & & \\
\hline 36 & $\mathrm{~A}-3$ & 351,7 & $\mathrm{D}$ & & & & & & & & & \\
\hline 37 & A-3 & 351,7 & $\mathrm{~A}$ & & & & & & & & & \\
\hline 38 & A-3 & 351,8 & $\mathrm{~A}$ & & & & & & & & & \\
\hline 39 & A-3 & 351,8 & $\mathrm{~A}$ & & & & & & & & & \\
\hline 40 & $\mathrm{~A}-3$ & 351,8 & $\mathrm{D}$ & & & & & & $\mathrm{S}$ & & & \\
\hline 41 & A-7 & 484,3 & $\mathrm{~A}$ & & & & & & & & & \\
\hline 42 & A-7 & 484,3 & $\mathrm{~A}$ & & & & & & $\mathrm{~S}$ & & & \\
\hline 43 & A-7 & 484,4 & $\mathrm{D}$ & & & & & & & $\mathrm{S}$ & & \\
\hline 44 & A-7 & 484,5 & $\mathrm{~A}$ & & & & & & & & & \\
\hline 45 & A-7 & 484,6 & $\mathrm{~A}$ & & & & $\mathrm{~S}$ & & & & & \\
\hline 46 & A-7 & 485,0 & $\mathrm{~A}$ & & & & & & & & & \\
\hline 47 & A-7 & 485,0 & $\mathrm{D}$ & & & & & & & $S$ & & \\
\hline 48 & $\mathrm{~V}-21$ & 0,9 & $\mathrm{D}$ & & & & & & & & & \\
\hline 49 & $\mathrm{~V}-21$ & 4,9 & $\mathrm{~A}$ & & & & $S$ & & & & & \\
\hline 50 & $\mathrm{~V}-21$ & 4,9 & $\mathrm{D}$ & & & $\mathrm{S}$ & & & & & & \\
\hline 51 & $\mathrm{~V}-30$ & 4,9 & $\mathrm{D}$ & & & & $\mathrm{S}$ & & & & & \\
\hline 52 & $\mathrm{~V}-31$ & 0,8 & $\mathrm{D}$ & & & $\mathrm{S}$ & $\mathrm{S}$ & & & & & \\
\hline 53 & $\mathrm{~V}-31$ & 1,0 & $\mathrm{~A}$ & & & & $S$ & & & & $\mathrm{~S}$ & \\
\hline 54 & $\mathrm{~V}-31$ & 6,3 & $\mathrm{~A}$ & & & & & & & & & \\
\hline 55 & $\mathrm{~V}-31$ & 6,7 & $\mathrm{D}$ & & & & & & & & & \\
\hline 56 & V-31 & 6,8 & $A$ & & & & $\mathrm{~S}$ & & & & & \\
\hline
\end{tabular}


Cómputo de muertos realizado a $24 \mathrm{~h}$.

\begin{tabular}{|c|c|c|c|c|}
\hline No. & CARRETERA & $\mathrm{Km} / 10$ & SENTIDO & TIPO DE ACCIDENTE \\
\hline 57 & $\mathrm{~V}-21$ & 4,7 & A & Salida de la vía por la derecha sin colisión (Con vuelco) \\
\hline 58 & $\mathrm{~V}-21$ & 5,0 & A & Colisión de vehículos en marcha (Alcance) \\
\hline 59 & $\mathrm{~V}-21$ & 5,0 & $\mathrm{D}$ & Colisión de vehículos en marcha (Lateral) \\
\hline 60 & $\mathrm{~V}-21$ & 5,0 & $\mathrm{D}$ & Salida de la vía por la derecha con colisión (Otro tipo de choque) \\
\hline 61 & V-21 & 5,0 & $\mathrm{D}$ & Salida de la vía por la izquierda sin colisión (Con vuelco) \\
\hline 62 & $\mathrm{~V}-21$ & 5,1 & $\mathrm{D}$ & Colisión de vehículos en marcha (Lateral) \\
\hline \begin{tabular}{|c|c|}
63 \\
\end{tabular} & $\mathrm{~V}-21$ & 8,9 & $A$ & Colisión de vehículos en marcha (Múltiple o en caravana) \\
\hline \begin{tabular}{|l|l|}
64 \\
64
\end{tabular} & $\mathrm{~V}-21$ & 9,0 & $A$ & Colisión de vehículos en marcha (Alcance) \\
\hline 65 & $\mathrm{~V}-21$ & 9,0 & A & Colisión de vehículos en marcha (Múltiple o en caravana) \\
\hline 66 & $\mathrm{~V}-21$ & 9,0 & A & Salida de la vía por la derecha con colisión (Otro tipo de choque) \\
\hline \begin{tabular}{|l|}
67 \\
\end{tabular} & V-21 & 9,0 & $\mathrm{D}$ & Salida de la vía por la izquierda sin colisión (Con vuelco) \\
\hline \begin{tabular}{|l|l|l}
68 & 0 \\
\end{tabular} & V-21 & 9,0 & $\mathrm{D}$ & Salida de la vía por la izquierda sin colisión (Con vuelco) \\
\hline \begin{tabular}{|l|}
69 \\
\end{tabular} & V-21 & 9,0 & $\mathrm{D}$ & Colisión de vehículos en marcha (Frontal) \\
\hline \begin{tabular}{|l|l|l}
70 \\
\end{tabular} & V-21 & 9,0 & A & Colisión de vehículos en marcha (Múltiple o en caravana) \\
\hline \begin{tabular}{|l|l|l}
71 \\
\end{tabular} & V-21 & 9,0 & A & Colisión de vehículos en marcha (Múltiple o en caravana) \\
\hline \begin{tabular}{|l|l|l}
72 & 1 \\
\end{tabular} & V-21 & 9,0 & A & Colisión de vehículos en marcha (Alcance) \\
\hline \begin{tabular}{|l|l|l}
73 & 1 \\
\end{tabular} & V-21 & 13,7 & A & Colisión de vehículos en marcha (Alcance) \\
\hline \begin{tabular}{|l|l|l}
74 & 1 \\
\end{tabular} & V-21 & 13,7 & A & Colisión de vehículos en marcha (Alcance) \\
\hline \begin{tabular}{|l|l|l}
75 \\
\end{tabular} & V-21 & 13,9 & A & Salida de la vía por la derecha con colisión (Otro tipo de choque) \\
\hline 76 & V-21 & 14,0 & A & Colisión de vehículo con obstáculo en calzada (Otro objeto o material) \\
\hline 77 & V-21 & 14,0 & $\mathrm{D}$ & Salida de la vía por la derecha con colisión (Otro tipo de choque) \\
\hline 78 & V-21 & 14,0 & A & Salida de la vía por la derecha sin colisión (Con vuelco) \\
\hline 79 & V-21 & 14,0 & A & Colisión de vehículos en marcha (Alcance) \\
\hline 80 & V-21 & 14,0 & $\mathrm{D}$ & Salida de la vía por la derecha sin colisión (Con vuelco) \\
\hline 81 & V-21 & 14,1 & A & Colisión de vehículos en marcha (Múltiple o en caravana) \\
\hline 82 & V-21 & 14,2 & A & Otro tipo de accidente \\
\hline 83 & $\mathrm{~V}-21$ & 14,4 & A & Salida de la vía por la izquierda sin colisión (Con vuelco) \\
\hline 84 & $\mathrm{~V}-21$ & 14,4 & $\mathrm{~A}$ & Colisión de vehículos en marcha (Alcance) \\
\hline
\end{tabular}


Cómputo de muertos realizado a $24 \mathrm{~h}$.

\begin{tabular}{|c|c|c|c|c|c|c|c|c|c|c|c|}
\hline No. & CARRETERA & $\mathrm{Km} / \mathbf{1 0}$ & SENTIDO & 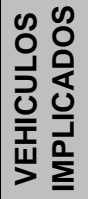 & HORA & FECHA & 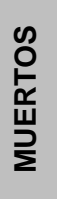 & 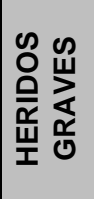 & 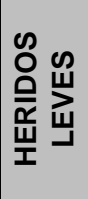 & SUPERFICIE & $\begin{array}{c}\text { FACTORES } \\
\text { ATMOSFERICOS }\end{array}$ \\
\hline 57 & $\bar{V}-21$ & 4,7 & $A$ & 1 & 12 & \begin{tabular}{|l|}
20060724 \\
\end{tabular} & 0 & 1 & 0 & SECA Y LIMPIA & BUEN TIEMPO \\
\hline 58 & V-21 & 5,0 & $A$ & 2 & 6 & 20061216 & 0 & 3 & 3 & SECA Y LIMPIA & BUEN TIEMPO \\
\hline 59 & $\mathrm{~V}-21$ & 5,0 & $\mathrm{D}$ & 2 & 10 & \begin{tabular}{|l|}
20060817 \\
\end{tabular} & 0 & 0 & 0 & SECA Y LIMPIA & BUEN TIEMPO \\
\hline 60 & $\mathrm{~V}-21$ & 5,0 & $\mathrm{D}$ & 1 & 9 & 20060318 & 0 & 0 & 1 & MOJADA & LLOVIZNANDO \\
\hline 61 & $\mathrm{~V}-21$ & 5,0 & $\mathrm{D}$ & 1 & 7 & 20070908 & 0 & 0 & 0 & SECA Y LIMPIA & BUEN TIEMPO \\
\hline 62 & $\mathrm{~V}-21$ & 5,1 & $\mathrm{D}$ & 2 & 8 & 20070324 & 0 & 0 & 1 & SECA Y LIMPIA & BUEN TIEMPO \\
\hline 63 & $\mathrm{~V}-21$ & 8,9 & $A$ & 3 & 19 & 20060103 & 0 & 0 & 0 & SECA Y LIMPIA & BUEN TIEMPO \\
\hline 64 & $\mathrm{~V}-21$ & 9,0 & $A$ & 5 & 18 & 20060830 & 0 & 0 & 0 & SECA Y LIMPIA & BUEN TIEMPO \\
\hline 65 & $\mathrm{~V}-21$ & 9,0 & $A$ & 3 & 19 & 20061112 & 0 & 0 & 2 & SECA Y LIMPIA & BUEN TIEMPO \\
\hline 66 & $\mathrm{~V}-21$ & 9,0 & $A$ & 1 & 16 & 20070815 & 0 & 0 & 0 & SECA Y LIMPIA & BUEN TIEMPO \\
\hline 67 & $\mathrm{~V}-21$ & 9,0 & $\mathrm{D}$ & 2 & 6 & 20061016 & 0 & 0 & 1 & SECA Y LIMPIA & BUEN TIEMPO \\
\hline 68 & $\mathrm{~V}-21$ & 9,0 & $\mathrm{D}$ & 1 & 14 & 20061226 & 0 & 0 & 1 & SECA Y LIMPIA & BUEN TIEMPO \\
\hline 69 & $\mathrm{~V}-21$ & 9,0 & $\mathrm{D}$ & 2 & 10 & 20070309 & 0 & 0 & 2 & SECA Y LIMPIA & BUEN TIEMPO \\
\hline 70 & $\mathrm{~V}-21$ & 9,0 & $A$ & 4 & 20 & 20061214 & 0 & 0 & 0 & SECA Y LIMPIA & BUEN TIEMPO \\
\hline 71 & $\mathrm{~V}-21$ & 9,0 & $A$ & 3 & 19 & 20060625 & 0 & 1 & 3 & SECA Y LIMPIA & BUEN TIEMPO \\
\hline 72 & $\mathrm{~V}-21$ & 9,0 & $A$ & 3 & 18 & \begin{tabular}{|l|}
20071228 \\
\end{tabular} & 0 & 0 & 0 & SECA Y LIMPIA & BUEN TIEMPO \\
\hline 73 & $\mathrm{~V}-21$ & 13,7 & $A$ & 1 & 6 & 20070304 & 0 & 0 & 0 & SECA Y LIMPIA & BUEN TIEMPO \\
\hline 74 & $\mathrm{~V}-21$ & 13,7 & $A$ & 3 & 14 & 20070703 & 0 & 0 & 1 & SECA Y LIMPIA & BUEN TIEMPO \\
\hline 75 & $\mathrm{~V}-21$ & 13,9 & $A$ & 1 & 5 & 20071215 & 0 & 0 & 0 & SECA Y LIMPIA & BUEN TIEMPO \\
\hline 76 & $\mathrm{~V}-21$ & 14,0 & $A$ & 1 & 14 & \begin{tabular}{|l|}
20070107 \\
\end{tabular} & 0 & 0 & 0 & SECA Y LIMPIA & BUEN TIEMPO \\
\hline 77 & $\mathrm{~V}-21$ & 14,0 & $\mathrm{D}$ & 1 & 17 & 20070324 & 0 & 0 & 1 & SECA Y LIMPIA & BUEN TIEMPO \\
\hline 78 & $\mathrm{~V}-21$ & 14,0 & $A$ & 2 & 18 & 20070903 & 0 & 0 & 1 & SECA Y LIMPIA & BUEN TIEMPO \\
\hline 79 & $\mathrm{~V}-21$ & 14,0 & $A$ & 2 & 19 & \begin{tabular}{|l|}
20060227 \\
\end{tabular} & 0 & 0 & 0 & SECA Y LIMPIA & BUEN TIEMPO \\
\hline 80 & $\mathrm{~V}-21$ & 14,0 & $\mathrm{D}$ & 1 & 23 & 20060818 & 0 & 0 & 0 & SECA Y LIMPIA & BUEN TIEMPO \\
\hline 81 & $\mathrm{~V}-21$ & 14,1 & $A$ & 3 & 18 & 20061115 & 0 & 0 & 0 & SECA Y LIMPIA & BUEN TIEMPO \\
\hline 82 & $\mathrm{~V}-21$ & 14,2 & $A$ & 6 & 8 & 20070612 & 0 & 0 & 1 & SECA Y LIMPIA & BUEN TIEMPO \\
\hline 83 & $\mathrm{~V}-21$ & 14,4 & $A$ & 1 & 13 & 20071031 & 0 & 0 & 1 & SECA Y LIMPIA & BUEN TIEMPO \\
\hline 84 & $\mathrm{~V}-21$ & 14,4 & $A$ & 2 & 12 & 20060421 & 0 & 0 & 1 & SECA Y LIMPIA & BUEN TIEMPO \\
\hline
\end{tabular}


Cómputo de muertos realizado a $24 \mathrm{~h}$.

\begin{tabular}{|c|c|c|c|c|c|c|c|c|c|c|}
\hline No. & CARRETERA & $\mathrm{Km} / 10$ & SENTIDO & VISIBILIDAD & LUMINOSIDAD & 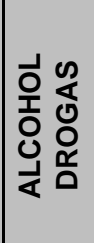 & 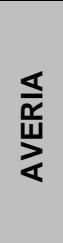 & $\begin{array}{l}\frac{0}{0} \\
\frac{1}{4} \\
\text { 心 } \\
\frac{1}{0}\end{array}$ & 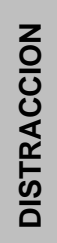 & 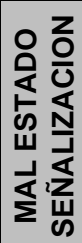 \\
\hline 57 & $\mathrm{~V}-21$ & 4,7 & $\bar{A}$ & SIN RESTRICCIÓN & PLENO DÍA & & & & $\mathrm{N}$ & \\
\hline 58 & V-21 & 5,0 & A & SIN RESTRICCIÓN & NOCHE: SIN ILUMINACIÓN & & & & $\mathrm{S}$ & \\
\hline 59 & $\mathrm{~V}-21$ & 5,0 & $\bar{D}$ & SIN RESTRICCIÓN & PLENO DÍA & & & & $\mathrm{S}$ & \\
\hline 60 & $\mathrm{~V}-21$ & 5,0 & $\mathrm{D}$ & SIN RESTRICCIÓN & PLENO DÍA & & & & & \\
\hline 61 & V-21 & 5,0 & $\mathrm{D}$ & SIN RESTRICCIÓN & PLENO DÍA & $\bar{N}$ & $\mathrm{~N}$ & $\mathrm{~N}$ & $\mathrm{~S}$ & $\bar{N}$ \\
\hline 62 & $\mathrm{~V}-21$ & 5,1 & $\mathrm{D}$ & SIN RESTRICCIÓN & PLENO DÍA & & & & & \\
\hline 63 & V-21 & 8,9 & $A$ & SIN RESTRICCIÓN & NOCHE: SIN ILUMINACIÓN & & & & $\mathrm{S}$ & \\
\hline 64 & $\mathrm{~V}-21$ & 9,0 & A & SIN RESTRICCIÓN & PLENO DÍA & & & & & \\
\hline 65 & $\mathrm{~V}-21$ & 9,0 & $\bar{A}$ & SIN RESTRICCIÓN & NOCHE: SIN ILUMINACIÓN & & & & $\mathrm{S}$ & \\
\hline 66 & $\mathrm{~V}-21$ & 9,0 & A & SIN RESTRICCIÓN & PLENO DÍA & & & & & \\
\hline 67 & V-21 & 9,0 & $\mathrm{D}$ & SIN RESTRICCIÓN & NOCHE: ILUMINACIÓN INSUFICIENTE & & & & $\mathrm{S}$ & \\
\hline 68 & $\mathrm{~V}-21$ & 9,0 & $\mathrm{D}$ & SIN RESTRICCIÓN & PLENO DÍA & & & & & \\
\hline 69 & $\mathrm{~V}-21$ & 9,0 & $\mathrm{D}$ & SIN RESTRICCIÓN & PLENO DÍA & $\mathrm{N}$ & $\mathrm{N}$ & $\mathrm{N}$ & $\mathrm{N}$ & $\mathrm{N}$ \\
\hline 70 & $\mathrm{~V}-21$ & 9,0 & $\bar{A}$ & SIN RESTRICCIÓN & CREPÚSCULO & & & & & \\
\hline 71 & $\mathrm{~V}-21$ & 9,0 & A & SIN RESTRICCIÓN & PLENO DÍA & $\mathrm{S}$ & & & $\mathrm{S}$ & \\
\hline 72 & $\mathrm{~V}-21$ & 9,0 & $\bar{A}$ & SIN RESTRICCIÓN & NOCHE: SIN ILUMINACIÓN & & & & $\mathrm{S}$ & \\
\hline 73 & V-21 & 13,7 & $\bar{A}$ & SIN RESTRICCIÓN & NOCHE: ILUMINACIÓN INSUFICIENTE & & & & & \\
\hline 74 & $\mathrm{~V}-21$ & 13,7 & A & SIN RESTRICCIÓN & PLENO DÍA & & & & $\mathrm{S}$ & \\
\hline 75 & V-21 & 13,9 & A & SIN RESTRICCIÓN & NOCHE: SIN ILUMINACIÓN & & & & & \\
\hline 76 & V-21 & 14,0 & $\bar{A}$ & SIN RESTRICCIÓN & PLENO DÍA & $\mathrm{N}$ & $\mathrm{N}$ & $\mathrm{N}$ & $\mathrm{N}$ & $\mathrm{N}$ \\
\hline 77 & $\mathrm{~V}-21$ & 14,0 & $\mathrm{D}$ & SIN RESTRICCIÓN & PLENO DÍA & & & & & \\
\hline 78 & $\mathrm{~V}-21$ & 14,0 & A & SIN RESTRICCIÓN & PLENO DÍA & & & & & \\
\hline 79 & V-21 & 14,0 & $\bar{A}$ & SIN RESTRICCIÓN & NOCHE: ILUMINACIÓN INSUFICIENTE & & & & $\mathrm{S}$ & \\
\hline 80 & $\mathrm{~V}-21$ & 14,0 & $\mathrm{D}$ & SIN RESTRICCIÓN & NOCHE: SIN ILUMINACIÓN & & & & $\mathrm{S}$ & \\
\hline 81 & V-21 & 14,1 & $\bar{A}$ & SIN RESTRICCIÓN & NOCHE: SIN ILUMINACIÓN & & & & $\mathrm{S}$ & \\
\hline 82 & $\mathrm{~V}-21$ & 14,2 & A & SIN RESTRICCIÓN & PLENO DÍA & & & & $\mathrm{S}$ & \\
\hline 83 & $\mathrm{~V}-21$ & 14,4 & $\mathrm{~A}$ & SIN RESTRICCIÓN & PLENO DÍA & & & & $\mathrm{S}$ & \\
\hline 84 & $\mathrm{~V}-21$ & 14,4 & $\mathrm{~A}$ & SIN RESTRICCIÓN & PLENO DÍA & & & & $\mathrm{S}$ & \\
\hline
\end{tabular}


Cómputo de muertos realizado a $24 \mathrm{~h}$

\begin{tabular}{|c|c|c|c|c|c|c|c|c|c|c|c|c|}
\hline No. & CARRETERA & $\mathrm{Km} / 10$ & SENTIDO & 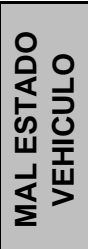 & 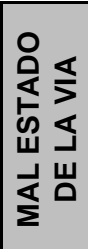 & 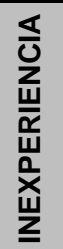 & 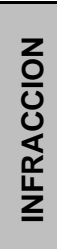 & 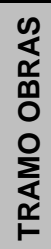 & 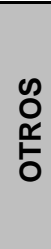 & $\begin{array}{l}z \\
\text { on } \\
z \\
0 \\
\text { o } \\
\text { s }\end{array}$ & 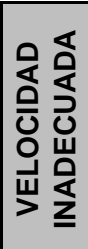 & 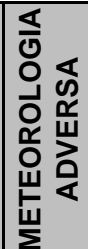 \\
\hline 57 & $\mathrm{~V}-21$ & 4,7 & $\bar{A}$ & & & & & & $\mathrm{~S}$ & & & \\
\hline 58 & $V-21$ & 5,0 & A & & & & & & & & & \\
\hline 59 & $\mathrm{~V}-21$ & 5,0 & $\mathrm{D}$ & & & & & & & & & \\
\hline 60 & $\mathrm{~V}-21$ & 5,0 & $\mathrm{D}$ & & & & & & & & $S$ & \\
\hline 61 & $\mathrm{~V}-21$ & 5,0 & $\mathrm{D}$ & $\mathrm{N}$ & $\mathrm{N}$ & $\mathrm{S}$ & $\mathrm{S}$ & $\mathrm{N}$ & $S$ & & $S$ & $\mathrm{~N}$ \\
\hline 62 & $\mathrm{~V}-21$ & 5,1 & $\mathrm{D}$ & & & & & & & $\mathrm{S}$ & & \\
\hline 63 & $\mathrm{~V}-21$ & 8,9 & $\mathrm{~A}$ & & & & $\mathrm{~S}$ & & & & & \\
\hline 64 & $\mathrm{~V}-21$ & 9,0 & $\mathrm{~A}$ & & & $\mathrm{~S}$ & & & & & & \\
\hline 65 & $\mathrm{~V}-21$ & 9,0 & $\mathrm{~A}$ & & & & & & & & & \\
\hline 66 & $\mathrm{~V}-21$ & 9,0 & $\mathrm{~A}$ & & & & & & & $\mathrm{~S}$ & & \\
\hline 67 & $\mathrm{~V}-21$ & 9,0 & $\mathrm{D}$ & & & & $\mathrm{S}$ & & $S$ & & & \\
\hline 68 & $\mathrm{~V}-21$ & 9,0 & $\mathrm{D}$ & & & & & & & $S$ & & \\
\hline 69 & $\mathrm{~V}-21$ & 9,0 & $\mathrm{D}$ & $\mathrm{N}$ & $\mathrm{N}$ & $\mathrm{N}$ & $\mathrm{S}$ & $\mathrm{N}$ & $\mathrm{N}$ & & $\mathrm{N}$ & $\mathrm{N}$ \\
\hline 70 & $\mathrm{~V}-21$ & 9,0 & $\mathrm{~A}$ & & & & & & & $\mathrm{~S}$ & & \\
\hline 71 & $\mathrm{~V}-21$ & 9,0 & $\mathrm{~A}$ & & & & $\mathrm{~S}$ & & & & & \\
\hline 72 & $\mathrm{~V}-21$ & 9,0 & $\mathrm{~A}$ & & & & & & & & & \\
\hline 73 & $\mathrm{~V}-21$ & 13,7 & $\mathrm{~A}$ & & & & & & & $\mathrm{~S}$ & & \\
\hline 74 & $\mathrm{~V}-21$ & 13,7 & $\mathrm{~A}$ & & & & & & & & & \\
\hline 75 & $\mathrm{~V}-21$ & 13,9 & $\mathrm{~A}$ & & & & & & & $\mathrm{~S}$ & & \\
\hline 76 & $\mathrm{~V}-21$ & 14,0 & $\mathrm{~A}$ & $\mathrm{~N}$ & $S$ & $\mathrm{~N}$ & $\mathrm{~N}$ & $\mathrm{~N}$ & $\mathrm{~N}$ & & $\mathrm{~N}$ & $\mathrm{~N}$ \\
\hline 77 & $\mathrm{~V}-21$ & 14,0 & $\mathrm{D}$ & & & & & & & & $S$ & \\
\hline 78 & $\mathrm{~V}-21$ & 14,0 & $A$ & & & & & & & $\mathrm{~S}$ & & \\
\hline \begin{tabular}{|l|}
79 \\
\end{tabular} & $\mathrm{~V}-21$ & 14,0 & $\mathrm{~A}$ & & & & & & & & & \\
\hline \begin{tabular}{|l|}
80 \\
\end{tabular} & $\mathrm{~V}-21$ & 14,0 & $D$ & & & & & & & & & \\
\hline \begin{tabular}{|l|}
81 \\
\end{tabular} & $\mathrm{~V}-21$ & 14,1 & $\mathrm{~A}$ & & & & & & & & & \\
\hline \begin{tabular}{|l|}
82 \\
\end{tabular} & $\mathrm{~V}-21$ & 14,2 & $A$ & & & & $S$ & & & & & \\
\hline \begin{tabular}{|l|}
83 \\
\end{tabular} & $\mathrm{~V}-21$ & 14,4 & A & & & & & & & & & \\
\hline \begin{tabular}{|l|}
84 \\
\end{tabular} & $\mathrm{~V}-21$ & 14,4 & $\mathrm{~A}$ & & & & & & & & & \\
\hline
\end{tabular}


Cómputo de muertos realizado a $24 \mathrm{~h}$.

\begin{tabular}{|c|c|c|c|c|}
\hline No. & CARRETERA & $\mathrm{Km} / 10$ & SENTIDO & TIPO DE ACCIDENTE \\
\hline 85 & $\mathrm{~V}-21$ & 14,5 & $\mathrm{~A}$ & Colisión de vehículos en marcha (Múltiple o en caravana) \\
\hline \begin{tabular}{|l|l|l}
86 \\
\end{tabular} & V-21 & 14,5 & $\mathrm{D}$ & Salida de la vía por la derecha con colisión (Choque con cuneta o bordillo) \\
\hline \begin{tabular}{|l|l|l}
87 & 1 \\
\end{tabular} & V-21 & 14,5 & A & Colisión de vehículos en marcha (Alcance) \\
\hline \begin{tabular}{|l|l|l}
88 \\
\end{tabular} & $\mathrm{~V}-21$ & 14,5 & A & Colisión de vehículos en marcha (Alcance) \\
\hline \begin{tabular}{|l|l|l}
89 & 1 \\
\end{tabular} & V-21 & 14,6 & A & Colisión de vehículos en marcha (Alcance) \\
\hline 90 & V-21 & 14,7 & $\mathrm{D}$ & Salida de la vía por la izquierda sin colisión (Con vuelco) \\
\hline \begin{tabular}{|l|l|l}
91 \\
\end{tabular} & V-30 & 4,8 & $\mathrm{~N}$ & Colisión de vehículos en marcha (Múltiple o en caravana) \\
\hline \begin{tabular}{|l|l|l}
92 \\
\end{tabular} & V-30 & 4,8 & $\mathrm{D}$ & Salida de la vía por la izquierda con colisión (Otro tipo de choque) \\
\hline \begin{tabular}{|l|l|l}
93 & \\
\end{tabular} & V-30 & 4,8 & $\overline{\mathrm{N}}$ & Colisión de vehículos en marcha (Alcance) \\
\hline \begin{tabular}{|l|l|l}
94 \\
\end{tabular} & V-30 & 4,8 & $\mathrm{~N}$ & Colisión de vehículos en marcha (Alcance) \\
\hline \begin{tabular}{|l|l|}
95 \\
\end{tabular} & V-30 & 4,9 & $\mathrm{D}$ & Colisión de vehículos en marcha (Alcance) \\
\hline \begin{tabular}{|l|l|l}
96 \\
\end{tabular} & V-30 & 5,0 & A & Colisión de vehículos en marcha (Alcance) \\
\hline \begin{tabular}{|l|}
97 \\
\end{tabular} & V-30 & 5,0 & $\mathrm{D}$ & Colisión de vehículos en marcha (Alcance) \\
\hline \begin{tabular}{|l|l|}
98 \\
\end{tabular} & V-30 & 5,0 & A & Colisión de vehículos en marcha (Lateral) \\
\hline \begin{tabular}{|l|}
99 \\
\end{tabular} & V-30 & 5,0 & $\bar{A}$ & Colisión de vehículos en marcha (Lateral) \\
\hline 100 & $\mathrm{~V}-30$ & 5,0 & A & Otro tipo de accidente \\
\hline 101 & V-30 & 5,0 & $\mathrm{D}$ & Salida de la vía por la izquierda con colisión (Choque con cuneta o bordillo) \\
\hline 102 & V-30 & 5,1 & $\mathrm{D}$ & Salida de la vía por la izquierda con colisión (Choque con árbol o poste) \\
\hline 103 & V-30 & 5,2 & D & Salida de la vía por la izquierda con colisión (Otro tipo de choque) \\
\hline 104 & V-30 & 5,2 & $\mathrm{D}$ & Salida de la vía por la izquierda con colisión (Choque con muro o edifício) \\
\hline 105 & V-30 & 5,2 & A & Salida de la vía por la derecha con colisión (Choque con árbol o poste) \\
\hline 106 & V-30 & 5,3 & $\mathrm{~N}$ & Salida de la vía por la derecha sin colisión (En llano) \\
\hline 107 & V-30 & 5,4 & $\mathrm{D}$ & Colisión de vehículos en marcha (Lateral) \\
\hline 108 & V-31 & 6,4 & A & Colisión de vehículos en marcha (Alcance) \\
\hline 109 & V-31 & 6,5 & $\mathrm{D}$ & Colisión de vehículos en marcha (Alcance) \\
\hline 110 & V-31 & 6,5 & $\mathrm{D}$ & Colisión de vehículos en marcha (Lateral) \\
\hline 111 & V-31 & 6,5 & A & Colisión de vehículos en marcha (Múltiple o en caravana) \\
\hline 112 & V-31 & 6,5 & $\mathrm{D}$ & Colisión de vehículos en marcha (Frontolateral) \\
\hline
\end{tabular}


Cómputo de muertos realizado a $24 \mathrm{~h}$.

\begin{tabular}{|c|c|c|c|c|c|c|c|c|c|c|c|}
\hline No. & CARRETERA & $\mathrm{Km} / \mathbf{1 0}$ & SENTIDO & 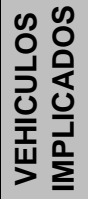 & HORA & FECHA & 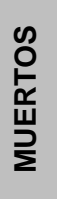 & 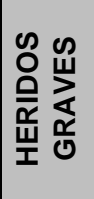 & 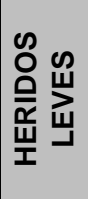 & SUPERFICIE & $\begin{array}{c}\text { FACTORES } \\
\text { ATMOSFERICOS }\end{array}$ \\
\hline 85 & $\bar{V}-21$ & 14,5 & $\bar{A}$ & 4 & 17 & \begin{tabular}{|l|}
20061027 \\
\end{tabular} & 0 & 0 & 0 & SECA Y LIMPIA & BUEN TIEMPO \\
\hline 86 & V-21 & 14,5 & $\mathrm{D}$ & 1 & 2 & 20060207 & 0 & 0 & 0 & SECA Y LIMPIA & BUEN TIEMPO \\
\hline 87 & V-21 & 14,5 & $A$ & 2 & 20 & \begin{tabular}{|l|}
20071212 \\
\end{tabular} & 0 & 0 & 3 & SECA Y LIMPIA & BUEN TIEMPO \\
\hline 88 & $\mathrm{~V}-21$ & 14,5 & $A$ & 2 & 20 & 20070622 & 0 & 0 & 5 & SECA Y LIMPIA & BUEN TIEMPO \\
\hline 89 & $\mathrm{~V}-21$ & 14,6 & $A$ & 2 & 7 & 20071004 & 0 & 0 & 1 & SECA Y LIMPIA & BUEN TIEMPO \\
\hline 90 & $\mathrm{~V}-21$ & 14,7 & $\mathrm{D}$ & 1 & 6 & 20060604 & 0 & 0 & 2 & SECA Y LIMPIA & BUEN TIEMPO \\
\hline 91 & V-30 & 4,8 & $\mathrm{~N}$ & 4 & 14 & 20060414 & 0 & 1 & 0 & SECA Y LIMPIA & BUEN TIEMPO \\
\hline 92 & V-30 & 4,8 & $\mathrm{D}$ & 2 & 22 & 20060110 & 0 & 0 & 0 & MOJADA & LLOVIZNANDO \\
\hline 93 & V-30 & 4,8 & $\mathrm{~N}$ & 2 & 7 & \begin{tabular}{|l|}
20070113 \\
\end{tabular} & 0 & 2 & 1 & SECA Y LIMPIA & BUEN TIEMPO \\
\hline 94 & V-30 & 4,8 & $\mathrm{~N}$ & 2 & 20 & 20061115 & 0 & 0 & 1 & SECA Y LIMPIA & BUEN TIEMPO \\
\hline 95 & V-30 & 4,9 & $\mathrm{D}$ & 2 & 18 & 20071105 & 0 & 0 & 3 & SECA Y LIMPIA & BUEN TIEMPO \\
\hline 96 & V-30 & 5,0 & $A$ & 2 & 21 & 20070109 & 0 & 0 & 1 & SECA Y LIMPIA & BUEN TIEMPO \\
\hline 97 & V-30 & 5,0 & $\mathrm{D}$ & 2 & 15 & 20061010 & 0 & 0 & 0 & SECA Y LIMPIA & BUEN TIEMPO \\
\hline 98 & V-30 & 5,0 & $A$ & 2 & 19 & 20070222 & 0 & 0 & 0 & SECA Y LIMPIA & BUEN TIEMPO \\
\hline 99 & V-30 & 5,0 & $A$ & 2 & 14 & \begin{tabular}{|l|}
20060727 \\
\end{tabular} & 0 & 0 & 1 & SECA Y LIMPIA & BUEN TIEMPO \\
\hline 100 & V-30 & 5,0 & $A$ & 1 & 17 & 20070221 & 0 & 0 & 1 & SECA Y LIMPIA & BUEN TIEMPO \\
\hline 101 & V-30 & 5,0 & $\mathrm{D}$ & 1 & 21 & 20060130 & 0 & 0 & 1 & MOJADA & BUEN TIEMPO \\
\hline 102 & V-30 & 5,1 & $\mathrm{D}$ & 1 & 12 & 20061104 & 0 & 0 & 1 & MOJADA & LLOVIZNANDO \\
\hline 103 & V-30 & 5,2 & $\mathrm{D}$ & 1 & 15 & 20070412 & 0 & 1 & 0 & SECA Y LIMPIA & BUEN TIEMPO \\
\hline 104 & V-30 & 5,2 & $\mathrm{D}$ & 1 & 13 & 20070816 & 0 & 0 & 0 & SECA Y LIMPIA & BUEN TIEMPO \\
\hline 105 & V-30 & 5,2 & $A$ & 1 & 6 & 20060604 & 2 & 0 & 0 & SECA Y LIMPIA & BUEN TIEMPO \\
\hline 106 & V-30 & 5,3 & $\mathrm{~N}$ & 1 & 21 & 20060902 & 0 & 0 & 1 & SECA Y LIMPIA & BUEN TIEMPO \\
\hline 107 & V-30 & 5,4 & $\mathrm{D}$ & 2 & 10 & \begin{tabular}{|l|}
20060517 \\
\end{tabular} & 0 & 0 & 0 & SECA Y LIMPIA & BUEN TIEMPO \\
\hline 108 & V-31 & 6,4 & $A$ & 2 & 18 & 20061114 & 0 & 0 & 0 & SECA Y LIMPIA & BUEN TIEMPO \\
\hline 109 & V-31 & 6,5 & $\mathrm{D}$ & 3 & 7 & 20061016 & 0 & 0 & 0 & SECA Y LIMPIA & BUEN TIEMPO \\
\hline 110 & V-31 & 6,5 & $\mathrm{D}$ & 3 & 15 & 20060107 & 0 & 0 & 0 & MOJADA & LLOVIZNANDO \\
\hline 111 & V-31 & 6,5 & $A$ & 3 & 10 & 20070521 & 0 & 0 & 4 & SECA Y LIMPIA & BUEN TIEMPO \\
\hline 112 & V-31 & 6,5 & $\mathrm{D}$ & 2 & 12 & \begin{tabular}{|l|}
20061107 \\
\end{tabular} & 0 & 0 & 0 & MOJADA & LLOVIZNANDO \\
\hline
\end{tabular}


Cómputo de muertos realizado a $24 \mathrm{~h}$.

\begin{tabular}{|c|c|c|c|c|c|c|c|c|c|c|}
\hline No. & CARRETERA & $\mathrm{Km} / 10$ & SENTIDO & VISIBILIDAD & LUMINOSIDAD & 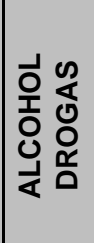 & $\begin{array}{l}\overleftarrow{\widetilde{r}} \\
\stackrel{\amalg}{\gtrless}\end{array}$ & 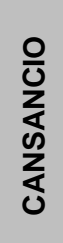 & 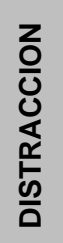 & 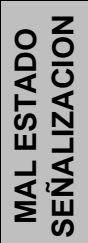 \\
\hline 85 & $\mathrm{~V}-21$ & 14,5 & $\bar{A}$ & SIN RESTRICCIÓN & PLENO DÍA & & & & $\mathrm{S}$ & \\
\hline 86 & $\mathrm{~V}-21$ & 14,5 & $\mathrm{D}$ & SIN RESTRICCIÓN & NOCHE: SIN ILUMINACIÓN & $\mathrm{S}$ & & & & \\
\hline 87 & $\mathrm{~V}-21$ & 14,5 & A & SIN RESTRICCIÓN & NOCHE: ILUMINACIÓN INSUFICIENTE & & & & $\mathrm{S}$ & \\
\hline 88 & V-21 & 14,5 & $\bar{A}$ & SIN RESTRICCIÓN & PLENO DÍA & & & & & \\
\hline 89 & V-21 & 14,6 & $\bar{A}$ & SIN RESTRICCIÓN & NOCHE: ILUMINACIÓN INSUFICIENTE & & & & $\mathrm{S}$ & \\
\hline 90 & $\mathrm{~V}-21$ & 14,7 & $\mathrm{D}$ & SIN RESTRICCIÓN & NOCHE: SIN ILUMINACIÓN & $\mathrm{S}$ & & & $\mathrm{S}$ & \\
\hline 91 & $\mathrm{~V}-30$ & 4,8 & $\mathrm{~N}$ & SIN RESTRICCIÓN & PLENO DÍA & & & & $S$ & \\
\hline 92 & V-30 & 4,8 & $\mathrm{D}$ & SIN RESTRICCIÓN & NOCHE: ILUMINACIÓN SUFICIENTE & & & & $\mathrm{S}$ & \\
\hline 93 & V-30 & 4,8 & $\mathrm{~N}$ & SIN RESTRICCIÓN & NOCHE: ILUMINACIÓN SUFICIENTE & & & & & \\
\hline 94 & V-30 & 4,8 & $\mathrm{~N}$ & SIN RESTRICCIÓN & NOCHE: SIN ILUMINACIÓN & & & & $\mathrm{S}$ & \\
\hline 95 & V-30 & 4,9 & $\mathrm{D}$ & SIN RESTRICCIÓN & NOCHE: ILUMINACIÓN SUFICIENTE & & & & & \\
\hline 96 & V-30 & 5,0 & $\bar{A}$ & SIN RESTRICCIÓN & PLENO DÍA & & & & $\mathrm{S}$ & \\
\hline 97 & V-30 & 5,0 & $\mathrm{D}$ & SIN RESTRICCIÓN & PLENO DÍA & & & & & \\
\hline 98 & V-30 & 5,0 & A & SIN RESTRICCIÓN & NOCHE: SIN ILUMINACIÓN & & & & & \\
\hline 99 & V-30 & 5,0 & A & SIN RESTRICCIÓN & PLENO DÍA & & & & $\mathrm{S}$ & \\
\hline 100 & V-30 & 5,0 & $\bar{A}$ & SIN RESTRICCIÓN & PLENO DÍA & & & & & \\
\hline 101 & V-30 & 5,0 & $\mathrm{D}$ & SIN RESTRICCIÓN & NOCHE: SIN ILUMINACIÓN & & & & $\mathrm{N}$ & \\
\hline 102 & V-30 & 5,1 & $\mathrm{D}$ & SIN RESTRICCIÓN & PLENO DÍA & & & & $\mathrm{S}$ & \\
\hline 103 & V-30 & 5,2 & $\mathrm{D}$ & SIN RESTRICCIÓN & PLENO DÍA & & $\mathrm{S}$ & & & \\
\hline 104 & V-30 & 5,2 & $\mathrm{D}$ & SIN RESTRICCIÓN & PLENO DÍA & & & & & \\
\hline 105 & V-30 & 5,2 & $\bar{A}$ & SIN RESTRICCIÓN & NOCHE: ILUMINACIÓN SUFICIENTE & & & & & \\
\hline 106 & V-30 & 5,3 & $\mathrm{~N}$ & SIN RESTRICCIÓN & NOCHE: SIN ILUMINACIÓN & & $\mathrm{S}$ & & & \\
\hline 107 & V-30 & 5,4 & $\mathrm{D}$ & SIN RESTRICCIÓN & PLENO DÍA & & & & $\mathrm{S}$ & \\
\hline 108 & V-31 & 6,4 & $\bar{A}$ & SIN RESTRICCIÓN & NOCHE: ILUMINACIÓN SUFICIENTE & & & & $\mathrm{S}$ & \\
\hline 109 & V-31 & 6,5 & $\mathrm{D}$ & SIN RESTRICCIÓN & CREPÚSCULO & & & & $\mathrm{S}$ & \\
\hline 110 & V-31 & 6,5 & $\mathrm{D}$ & SIN RESTRICCIÓN & PLENO DÍA & & & & & \\
\hline 111 & V-31 & 6,5 & $\mathrm{~A}$ & SIN RESTRICCIÓN & PLENO DÍA & $\mathrm{N}$ & $\mathrm{N}$ & $\mathrm{N}$ & $\mathrm{S}$ & $\mathrm{N}$ \\
\hline \begin{tabular}{|l|l|}
112 \\
\end{tabular} & V-31 & 6,5 & $\mathrm{D}$ & SIN RESTRICCIÓN & PLENO DÍA & & & & & \\
\hline
\end{tabular}


Cómputo de muertos realizado a $24 \mathrm{~h}$

\begin{tabular}{|c|c|c|c|c|c|c|c|c|c|c|c|c|}
\hline No. & CARRETERA & $\mathrm{Km} / 10$ & SENTIDO & 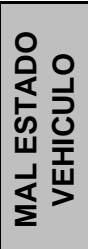 & 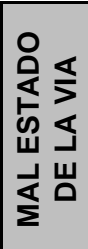 & 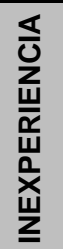 & 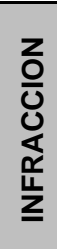 & 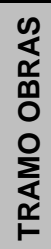 & 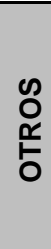 & $\begin{array}{l}z \\
\text { o } \\
z \\
0 \\
0 \\
z \\
\text { 心 }\end{array}$ & 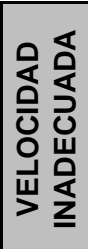 & 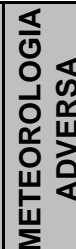 \\
\hline 85 & $\mathrm{~V}-21$ & 14,5 & $\bar{A}$ & & & & $\mathrm{~S}$ & & & & & \\
\hline \begin{tabular}{|l|}
86 \\
\end{tabular} & $V-21$ & 14,5 & $\mathrm{D}$ & & & & $\mathrm{S}$ & & & & & \\
\hline \begin{tabular}{|l|}
87 \\
\end{tabular} & $\mathrm{~V}-21$ & 14,5 & $A$ & & & & & & & & & \\
\hline \begin{tabular}{|l|}
88 \\
\end{tabular} & $\mathrm{~V}-21$ & 14,5 & $A$ & & & & & & & & $S$ & \\
\hline \begin{tabular}{|l|}
89 \\
\end{tabular} & $\mathrm{~V}-21$ & 14,6 & $\mathrm{~A}$ & & & & & & & & & \\
\hline 90 & $\mathrm{~V}-21$ & 14,7 & $\mathrm{D}$ & & & & & & & & & \\
\hline \begin{tabular}{|l|}
91 \\
\end{tabular} & $\mathrm{~V}-30$ & 4,8 & $\mathrm{~N}$ & & & & & & & & $S$ & \\
\hline \begin{tabular}{|l|}
92 \\
\end{tabular} & $\mathrm{~V}-30$ & 4,8 & $\mathrm{D}$ & & & & & & & & & \\
\hline \begin{tabular}{|l|}
93 \\
\end{tabular} & $\mathrm{~V}-30$ & 4,8 & $\mathrm{~N}$ & & & & $\mathrm{~S}$ & & & & & \\
\hline \begin{tabular}{|l|}
94 \\
\end{tabular} & $\mathrm{~V}-30$ & 4,8 & $\mathrm{~N}$ & & & & & & & & & \\
\hline \begin{tabular}{|l|}
95 \\
\end{tabular} & $\mathrm{~V}-30$ & 4,9 & $\mathrm{D}$ & & & & & & & $\mathrm{S}$ & & \\
\hline \begin{tabular}{|l|}
96 \\
\end{tabular} & $\mathrm{~V}-30$ & 5,0 & $\mathrm{~A}$ & & & & & & & & & \\
\hline \begin{tabular}{|l|}
97 \\
\end{tabular} & $\mathrm{~V}-30$ & 5,0 & $\mathrm{D}$ & & & & & & & $\mathrm{S}$ & & \\
\hline \begin{tabular}{|l|}
98 \\
\end{tabular} & $\mathrm{~V}-30$ & 5,0 & $\mathrm{~A}$ & & & & $\mathrm{~S}$ & $\mathrm{~S}$ & & & $\mathrm{~S}$ & \\
\hline \begin{tabular}{|l|}
99 \\
\end{tabular} & $\mathrm{~V}-30$ & 5,0 & $\mathrm{~A}$ & & & & & & & & & \\
\hline 100 & V-30 & 5,0 & $A$ & & & & $\mathrm{~S}$ & & & & & \\
\hline 101 & $\mathrm{~V}-30$ & 5,0 & $\mathrm{D}$ & & & & & & & & $\mathrm{S}$ & \\
\hline 102 & $\mathrm{~V}-30$ & 5,1 & $\mathrm{D}$ & & & & & & & & $\mathrm{S}$ & \\
\hline 103 & $\mathrm{~V}-30$ & 5,2 & $\mathrm{D}$ & & & & & & & & & \\
\hline 104 & V-30 & 5,2 & $\mathrm{D}$ & & & & & & & $S$ & & \\
\hline 105 & $\mathrm{~V}-30$ & 5,2 & $\mathrm{~A}$ & & & & & & & & $S$ & \\
\hline 106 & $\mathrm{~V}-30$ & 5,3 & $\mathrm{~N}$ & & & & & & & & & \\
\hline \begin{tabular}{|l|}
107 \\
\end{tabular} & V-30 & 5,4 & $\mathrm{D}$ & & & $\mathrm{S}$ & & & & & & \\
\hline 108 & $\mathrm{~V}-31$ & 6,4 & $\mathrm{~A}$ & & & & & & & & & \\
\hline 109 & $\mathrm{~V}-31$ & 6,5 & $\mathrm{D}$ & & & & & & & & & \\
\hline 110 & $\mathrm{~V}-31$ & 6,5 & $\mathrm{D}$ & & & & $S$ & & & & & \\
\hline 111 & $\mathrm{~V}-31$ & 6,5 & $\mathrm{~A}$ & $\mathrm{~N}$ & $\mathrm{~N}$ & $\mathrm{~N}$ & $\mathrm{~N}$ & $\mathrm{~N}$ & $\mathrm{~N}$ & & $\mathrm{~S}$ & $\mathrm{~N}$ \\
\hline \begin{tabular}{|l|l}
112 \\
\end{tabular} & V-31 & 6,5 & $D$ & & & & $S$ & & & & $S$ & \\
\hline
\end{tabular}


Cómputo de muertos realizado a $24 \mathrm{~h}$.

\begin{tabular}{|c|c|c|c|c|}
\hline No. & CARRETERA & $\mathrm{Km} / 10$ & SENTIDO & TIPO DE ACCIDENTE \\
\hline 113 & V-31 & 6,5 & $\mathrm{D}$ & Salida de la vía por la derecha con colisión (Otro tipo de choque) \\
\hline 114 & V-31 & 6,5 & $\mathrm{D}$ & Colisión de vehículos en marcha (Lateral) \\
\hline 115 & V-31 & 6,6 & $\mathrm{D}$ & Salida de la vía por la izquierda con colisión (Otro tipo de choque) \\
\hline 116 & V-31 & 6,7 & A & Salida de la vía por la derecha con colisión (Choque con muro o edifício) \\
\hline 117 & V-31 & 6,7 & $\mathrm{D}$ & Colisión de vehículos en marcha (Lateral) \\
\hline 118 & V-31 & 6,8 & $\bar{A}$ & Colisión de vehículos en marcha (Alcance) \\
\hline 119 & V-31 & 6,8 & $\mathrm{D}$ & Colisión de vehículos en marcha (Alcance) \\
\hline 120 & V-31 & 6,8 & $\mathrm{~S}$ & Salida de la vía por la izquierda sin colisión (Con vuelco) \\
\hline 121 & V-31 & 6,8 & $\mathrm{D}$ & Salida de la vía por la izquierda con colisión (Otro tipo de choque) \\
\hline \begin{tabular}{|l|l|l}
122 \\
\end{tabular} & V-31 & 6,8 & $\bar{A}$ & Salida de la vía por la izquierda con colisión (Choque con muro o edifício) \\
\hline 123 & V-31 & 6,8 & A & Colisión de vehículo con obstáculo en calzada (Otro objeto o material) \\
\hline 124 & V-31 & 6,8 & $\mathrm{D}$ & Colisión de vehículos en marcha (Alcance) \\
\hline 125 & V-31 & 6,8 & $\bar{A}$ & Colisión de vehículos en marcha (Alcance) \\
\hline 126 & V-31 & 6,9 & A & Salida de la vía por la izquierda sin colisión (Con vuelco) \\
\hline \begin{tabular}{|l|l|l}
127 \\
\end{tabular} & V-31 & 7,9 & $\mathrm{D}$ & Colisión de vehículos en marcha (Lateral) \\
\hline 128 & V-31 & 8,0 & $\bar{A}$ & Colisión de vehículos en marcha (Alcance) \\
\hline \begin{tabular}{|l|l|l}
129 \\
\end{tabular} & V-31 & 8,0 & $\bar{A}$ & Colisión de vehículos en marcha (Alcance) \\
\hline 130 & V-31 & 8,0 & $\mathrm{D}$ & Colisión de vehículos en marcha (Alcance) \\
\hline 131 & V-31 & 8,0 & $\mathrm{D}$ & Colisión de vehículos en marcha (Alcance) \\
\hline \begin{tabular}{|l|l|l}
132 \\
\end{tabular} & V-31 & 8,0 & $\mathrm{D}$ & Salida de la vía por la izquierda con colisión (Choque con muro o edifício) \\
\hline 133 & V-31 & 8,0 & $\mathrm{D}$ & Colisión de vehículos en marcha (Alcance) \\
\hline 134 & V-31 & 8,0 & $\bar{A}$ & Otro tipo de accidente \\
\hline \begin{tabular}{|c|}
135 \\
\end{tabular} & V-31 & 8,1 & $\bar{A}$ & Colisión de vehículos en marcha (Múltiple o en caravana) \\
\hline 136 & V-31 & 8,2 & $\bar{D}$ & Otro tipo de accidente \\
\hline 137 & V-31 & 8,2 & $\bar{A}$ & Colisión de vehículos en marcha (Alcance) \\
\hline 138 & V-31 & 8,2 & A & Otro tipo de accidente \\
\hline 139 & V-31 & 8,2 & $\bar{D}$ & Colisión de vehículos en marcha (Alcance) \\
\hline 140 & V-31 & 8,3 & $\bar{D}$ & Atropello a animales sueltos \\
\hline
\end{tabular}


Cómputo de muertos realizado a $24 \mathrm{~h}$.

\begin{tabular}{|c|c|c|c|c|c|c|c|c|c|c|c|}
\hline No. & CARRETERA & $\mathrm{Km} / \mathbf{1 0}$ & SENTIDO & 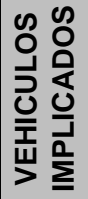 & HORA & FECHA & 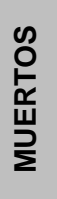 & 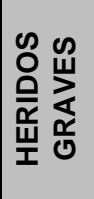 & 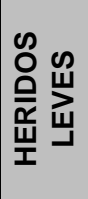 & SUPERFICIE & $\begin{array}{c}\text { FACTORES } \\
\text { ATMOSFERICOS }\end{array}$ \\
\hline 113 & $\mathrm{~V}-31$ & 6,5 & $\mathrm{D}$ & 2 & 4 & \begin{tabular}{|l|}
20060629 \\
\end{tabular} & 0 & 0 & 1 & SECA Y LIMPIA & BUEN TIEMPO \\
\hline 114 & V-31 & 6,5 & $\mathrm{D}$ & 3 & 15 & 20060107 & 0 & 0 & 0 & MOJADA & LLOVIZNANDO \\
\hline 115 & V-31 & 6,6 & $\mathrm{D}$ & 1 & 3 & \begin{tabular}{|l|}
20060512 \\
\end{tabular} & 0 & 0 & 0 & SECA Y LIMPIA & BUEN TIEMPO \\
\hline 116 & V-31 & 6,7 & $A$ & 1 & 8 & 20060326 & 0 & 0 & 0 & SECA Y LIMPIA & BUEN TIEMPO \\
\hline 117 & V-31 & 6,7 & $\mathrm{D}$ & 2 & 10 & 20071130 & 0 & 0 & 0 & SECA Y LIMPIA & BUEN TIEMPO \\
\hline 118 & V-31 & 6,8 & $A$ & 5 & 20 & 20070711 & 0 & 0 & 3 & SECA Y LIMPIA & BUEN TIEMPO \\
\hline 119 & V-31 & 6,8 & $\mathrm{D}$ & 3 & 9 & 20071105 & 0 & 0 & 0 & SECA Y LIMPIA & BUEN TIEMPO \\
\hline 120 & V-31 & 6,8 & $S$ & 1 & 7 & 20060430 & 0 & 1 & 1 & SECA Y LIMPIA & BUEN TIEMPO \\
\hline 121 & V-31 & 6,8 & $\mathrm{D}$ & 1 & 5 & 20060205 & 0 & 0 & 0 & SECA Y LIMPIA & BUEN TIEMPO \\
\hline 122 & V-31 & 6,8 & $A$ & 1 & 8 & 20070526 & 0 & 0 & 1 & SECA Y LIMPIA & BUEN TIEMPO \\
\hline 123 & V-31 & 6,8 & $A$ & 1 & 21 & 20070901 & 0 & 0 & 0 & SECA Y LIMPIA & BUEN TIEMPO \\
\hline 124 & V-31 & 6,8 & $\mathrm{D}$ & 2 & 21 & 20060324 & 0 & 0 & 2 & SECA Y LIMPIA & BUEN TIEMPO \\
\hline 125 & V-31 & 6,8 & $A$ & 2 & 18 & 20070112 & 0 & 0 & 0 & SECA Y LIMPIA & BUEN TIEMPO \\
\hline 126 & V-31 & 6,9 & $A$ & 1 & 11 & 20060912 & 0 & 0 & 2 & SECA Y LIMPIA & BUEN TIEMPO \\
\hline 127 & V-31 & 7,9 & $\mathrm{D}$ & 2 & 10 & 20061103 & 0 & 0 & 0 & MOJADA & LLOVIZNANDO \\
\hline 128 & V-31 & 8,0 & $A$ & 2 & 6 & 20061126 & 0 & 0 & 1 & SECA Y LIMPIA & BUEN TIEMPO \\
\hline 129 & V-31 & 8,0 & $A$ & 2 & 8 & 20070515 & 0 & 0 & 0 & SECA Y LIMPIA & BUEN TIEMPO \\
\hline 130 & V-31 & 8,0 & $\mathrm{D}$ & 2 & 13 & 20070615 & 0 & 0 & 3 & SECA Y LIMPIA & BUEN TIEMPO \\
\hline 131 & V-31 & 8,0 & $\mathrm{D}$ & 2 & 2 & 20060228 & 0 & 0 & 3 & SECA Y LIMPIA & BUEN TIEMPO \\
\hline 132 & V-31 & 8,0 & $\mathrm{D}$ & 2 & 20 & 20060224 & 0 & 0 & 0 & SECA Y LIMPIA & BUEN TIEMPO \\
\hline 133 & V-31 & 8,0 & $\mathrm{D}$ & 2 & 1 & 20061023 & 0 & 0 & 2 & SECA Y LIMPIA & BUEN TIEMPO \\
\hline 134 & V-31 & 8,0 & $A$ & 1 & 22 & 20071014 & 0 & 0 & 0 & SECA Y LIMPIA & BUEN TIEMPO \\
\hline 135 & V-31 & 8,1 & $A$ & 3 & 14 & 20060529 & 0 & 0 & 2 & SECA Y LIMPIA & BUEN TIEMPO \\
\hline 136 & V-31 & 8,2 & $\mathrm{D}$ & 1 & 22 & 20060314 & 0 & 0 & 0 & OTRO TIPO & BUEN TIEMPO \\
\hline 137 & V-31 & 8,2 & $A$ & 2 & 6 & 20060316 & 0 & 0 & 1 & SECA Y LIMPIA & BUEN TIEMPO \\
\hline 138 & V-31 & 8,2 & $A$ & 1 & 20 & 20060601 & 0 & 0 & 0 & SECA Y LIMPIA & BUEN TIEMPO \\
\hline 139 & V-31 & 8,2 & $\mathrm{D}$ & 3 & 7 & 20061230 & 0 & 0 & 6 & SECA Y LIMPIA & BUEN TIEMPO \\
\hline 140 & V-31 & 8,3 & $\mathrm{D}$ & 1 & 12 & 20070719 & 0 & 0 & 0 & SECA Y LIMPIA & BUEN TIEMPO \\
\hline
\end{tabular}


Cómputo de muertos realizado a $24 \mathrm{~h}$.

\begin{tabular}{|c|c|c|c|c|c|c|c|c|c|c|}
\hline No. & CARRETERA & $\mathrm{Km} / 10$ & SENTIDO & VISIBILIDAD & LUMINOSIDAD & 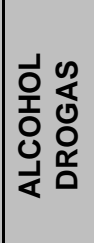 & 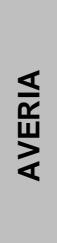 & 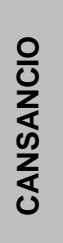 & 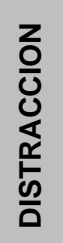 & 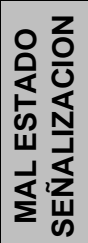 \\
\hline 113 & V-31 & 6,5 & $\mathrm{D}$ & SIN RESTRICCIÓN & NOCHE: ILUMINACIÓN SUFICIENTE & $\mathrm{S}$ & & & & \\
\hline 114 & V-31 & 6,5 & $\mathrm{D}$ & SIN RESTRICCIÓN & PLENO DÍA & & & & & \\
\hline 115 & V-31 & 6,6 & $\mathrm{D}$ & SIN RESTRICCIÓN & NOCHE: ILUMINACIÓN SUFICIENTE & & & & $\mathrm{S}$ & \\
\hline 116 & V-31 & 6,7 & $\bar{A}$ & SIN RESTRICCIÓN & PLENO DÍA & $\mathrm{S}$ & & & & \\
\hline 117 & V-31 & 6,7 & $\mathrm{D}$ & SIN RESTRICCIÓN & PLENO DÍA & & & & & \\
\hline 118 & V-31 & 6,8 & A & SIN RESTRICCIÓN & PLENO DÍA & $\mathrm{N}$ & $\mathrm{N}$ & $\mathrm{N}$ & $\mathrm{S}$ & $\mathrm{N}$ \\
\hline 119 & V-31 & 6,8 & $\mathrm{D}$ & SIN RESTRICCIÓN & PLENO DÍA & & & & $\mathrm{S}$ & \\
\hline 120 & V-31 & 6,8 & $S$ & SIN RESTRICCIÓN & PLENO DÍA & & & & $\mathrm{S}$ & \\
\hline 121 & V-31 & 6,8 & $\mathrm{D}$ & SIN RESTRICCIÓN & NOCHE: ILUMINACIÓN INSUFICIENTE & & & & $\mathrm{S}$ & \\
\hline 122 & V-31 & 6,8 & A & SIN RESTRICCIÓN & PLENO DÍA & $\mathrm{S}$ & & & $\mathrm{S}$ & \\
\hline 123 & V-31 & 6,8 & A & SIN RESTRICCIÓN & NOCHE: ILUMINACIÓN INSUFICIENTE & & & & & \\
\hline 124 & V-31 & 6,8 & $\mathrm{D}$ & SIN RESTRICCIÓN & NOCHE: ILUMINACIÓN SUFICIENTE & & & & $\mathrm{S}$ & \\
\hline 125 & V-31 & 6,8 & $\bar{A}$ & SIN RESTRICCIÓN & NOCHE: ILUMINACIÓN SUFICIENTE & & & & & \\
\hline 126 & V-31 & 6,9 & A & SIN RESTRICCIÓN & PLENO DÍA & & & & & \\
\hline 127 & V-31 & 7,9 & $\mathrm{D}$ & SIN RESTRICCIÓN & PLENO DÍA & & & & $\mathrm{S}$ & \\
\hline 128 & V-31 & 8,0 & $\bar{A}$ & SIN RESTRICCIÓN & CREPÚSCULO & $\mathrm{S}$ & & & $\mathrm{S}$ & \\
\hline 129 & V-31 & 8,0 & $\bar{A}$ & SIN RESTRICCIÓN & PLENO DÍA & & & & $\mathrm{S}$ & \\
\hline 130 & V-31 & 8,0 & $\mathrm{D}$ & SIN RESTRICCIÓN & PLENO DÍA & & & & $\mathrm{S}$ & \\
\hline 131 & V-31 & 8,0 & $\mathrm{D}$ & SIN RESTRICCIÓN & NOCHE: ILUMINACIÓN SUFICIENTE & & & $\mathrm{S}$ & $\mathrm{S}$ & \\
\hline 132 & V-31 & 8,0 & $\mathrm{D}$ & SIN RESTRICCIÓN & NOCHE: ILUMINACIÓN SUFICIENTE & & & & $\mathrm{S}$ & \\
\hline 133 & V-31 & 8,0 & $\mathrm{D}$ & SIN RESTRICCIÓN & NOCHE: ILUMINACIÓN SUFICIENTE & $\mathrm{S}$ & & & $\mathrm{S}$ & \\
\hline 134 & V-31 & 8,0 & A & SIN RESTRICCIÓN & NOCHE: ILUMINACIÓN SUFICIENTE & & & & & \\
\hline 135 & V-31 & 8,1 & $\bar{A}$ & SIN RESTRICCIÓN & PLENO DÍA & & & & & \\
\hline 136 & V-31 & 8,2 & $\mathrm{D}$ & SIN RESTRICCIÓN & NOCHE: ILUMINACIÓN SUFICIENTE & & & & & \\
\hline 137 & V-31 & 8,2 & $\bar{A}$ & SIN RESTRICCIÓN & NOCHE: ILUMINACIÓN SUFICIENTE & & & & $\mathrm{S}$ & \\
\hline 138 & V-31 & 8,2 & A & SIN RESTRICCIÓN & PLENO DÍA & & & & $\mathrm{S}$ & \\
\hline 139 & V-31 & 8,2 & $\mathrm{D}$ & SIN RESTRICCIÓN & NOCHE: ILUMINACIÓN SUFICIENTE & & & & $\mathrm{S}$ & \\
\hline 140 & V-31 & 8,3 & $\mathrm{D}$ & OTRA_CAUSA & PLENO DÍA & & & & & \\
\hline
\end{tabular}


Cómputo de muertos realizado a $24 \mathrm{~h}$.

\begin{tabular}{|c|c|c|c|c|c|c|c|c|c|c|c|c|}
\hline No. & CARRETERA & $\mathrm{Km} / 10$ & SENTIDO & 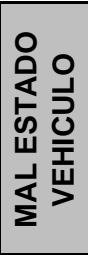 & 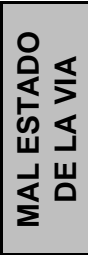 & 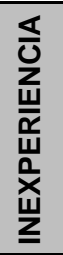 & 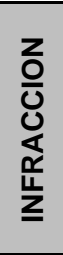 & 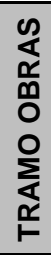 & 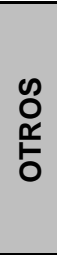 & $\begin{array}{l}z \\
\text { o } \\
z \\
0 \\
0 \\
z \\
\text { क }\end{array}$ & 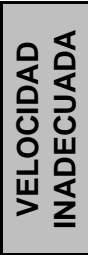 & 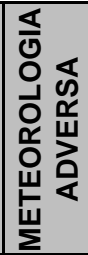 \\
\hline 113 & $\mathrm{~V}-31$ & 6,5 & $\mathrm{D}$ & & & & & & & & & \\
\hline 1114 & V-31 & 6,5 & $\mathrm{D}$ & & & & $S$ & & & & & \\
\hline 115 & $\mathrm{~V}-31$ & 6,6 & $\mathrm{D}$ & & & & & & & & & \\
\hline 116 & $\mathrm{~V}-31$ & 6,7 & $\mathrm{~A}$ & & & & $\mathrm{~S}$ & & & & & \\
\hline 117 & $\mathrm{~V}-31$ & 6,7 & $\mathrm{D}$ & & & & $\mathrm{S}$ & & & & & \\
\hline 118 & $\mathrm{~V}-31$ & 6,8 & $\mathrm{~A}$ & $\mathrm{~N}$ & $\mathrm{~N}$ & $\mathrm{~N}$ & $\mathrm{~S}$ & $\mathrm{~N}$ & $\mathrm{~N}$ & & $\mathrm{~N}$ & $\mathrm{~N}$ \\
\hline 119 & $\mathrm{~V}-31$ & 6,8 & $\mathrm{D}$ & & & & & & & & & \\
\hline 120 & $\mathrm{~V}-31$ & 6,8 & $\mathrm{~S}$ & & & & & & & & $\mathrm{~S}$ & \\
\hline 121 & $\mathrm{~V}-31$ & 6,8 & $\mathrm{D}$ & & & & & & & & $\mathrm{S}$ & \\
\hline 122 & $\mathrm{~V}-31$ & 6,8 & $\mathrm{~A}$ & & & & & & & & & \\
\hline 123 & $\mathrm{~V}-31$ & 6,8 & $\mathrm{~A}$ & & & & & & $\mathrm{~S}$ & & & \\
\hline 124 & $\mathrm{~V}-31$ & 6,8 & $\mathrm{D}$ & & & & & & & & & \\
\hline 125 & $\mathrm{~V}-31$ & 6,8 & $\mathrm{~A}$ & & & & $\mathrm{~S}$ & & & & & \\
\hline 126 & $\mathrm{~V}-31$ & 6,9 & $\mathrm{~A}$ & & & & $\mathrm{~S}$ & & & & $\mathrm{~S}$ & \\
\hline 127 & $\mathrm{~V}-31$ & 7,9 & $\mathrm{D}$ & & & & & & & & & \\
\hline 128 & $\mathrm{~V}-31$ & 8,0 & $\mathrm{~A}$ & & & & & & & & & \\
\hline 129 & $\mathrm{~V}-31$ & 8,0 & $\mathrm{~A}$ & & & & & & & & & \\
\hline 130 & $\mathrm{~V}-31$ & 8,0 & $\mathrm{D}$ & & & & & & & & & \\
\hline 131 & V-31 & 8,0 & $\mathrm{D}$ & & & & & & & & & \\
\hline 132 & $\mathrm{~V}-31$ & 8,0 & $\mathrm{D}$ & & & & & & $S$ & & & \\
\hline 133 & V-31 & 8,0 & $\mathrm{D}$ & & & & $S$ & & & & & \\
\hline 134 & V-31 & 8,0 & $A$ & & & & & & & $S$ & & \\
\hline 135 & $\mathrm{~V}-31$ & 8,1 & $A$ & & & & $S$ & & & & & \\
\hline 136 & $\mathrm{~V}-31$ & 8,2 & $\mathrm{D}$ & & $\mathrm{S}$ & & & & $S$ & & & \\
\hline 137 & $\mathrm{~V}-31$ & 8,2 & $A$ & & & & $S$ & & & & $S$ & \\
\hline 138 & $\mathrm{~V}-31$ & 8,2 & $\mathrm{~A}$ & & & & & & & & & \\
\hline 139 & $\mathrm{~V}-31$ & 8,2 & $\mathrm{D}$ & & & & & & & & & \\
\hline 140 & $\mathrm{~V}-31$ & 8,3 & $D$ & & & & & & & $S$ & & \\
\hline
\end{tabular}


Cómputo de muertos realizado a $24 \mathrm{~h}$.

\begin{tabular}{|c|c|c|c|c|}
\hline No. & CARRETERA & $\mathrm{Km} / 10$ & SENTIDO & TIPO DE ACCIDENTE \\
\hline 141 & $\mathrm{~V}-31$ & 8,3 & A & Salida de la vía por la izquierda sin colisión (Otra) \\
\hline 142 & V-31 & 8,5 & $\mathrm{D}$ & Colisión de vehículo con obstáculo en calzada (Otro objeto o material) \\
\hline 143 & V-31 & 8,5 & A & Salida de la vía por la izquierda con colisión (Choque con muro o edifício) \\
\hline 144 & V-31 & 8,5 & $\mathrm{~N}$ & Colisión de vehículos en marcha (Alcance) \\
\hline 145 & V-31 & 8,5 & $\mathrm{~S}$ & Colisión de vehículos en marcha (Frontal) \\
\hline 146 & V-31 & 8,5 & $\mathrm{~N}$ & Colisión de vehículos en marcha (Múltiple o en caravana) \\
\hline 147 & V-31 & 8,5 & $\mathrm{D}$ & Colisión de vehículos en marcha (Múltiple o en caravana) \\
\hline 148 & V-31 & 8,5 & $\mathrm{D}$ & Colisión de vehículo con obstáculo en calzada (Otro objeto o material) \\
\hline 149 & V-31 & 10,0 & $\mathrm{D}$ & Colisión de vehículos en marcha (Lateral) \\
\hline 150 & V-31 & 10,0 & A & Colisión de vehículos en marcha (Lateral) \\
\hline 151 & $\mathrm{~V}-31$ & 10,0 & A & Colisión de vehículos en marcha (Lateral) \\
\hline 152 & $\mathrm{~V}-31$ & 10,0 & A & Colisión de vehículos en marcha (Alcance) \\
\hline 153 & V-31 & 10,0 & $\bar{A}$ & Colisión de vehículos en marcha (Alcance) \\
\hline 154 & V-31 & 10,0 & A & Colisión de vehículos en marcha (Múltiple o en caravana) \\
\hline 155 & $\mathrm{~V}-31$ & 10,1 & $\mathrm{D}$ & Colisión de vehículos en marcha (Frontolateral) \\
\hline 156 & V-31 & 10,1 & $\mathrm{D}$ & Colisión de vehículos en marcha (Lateral) \\
\hline 157 & V-31 & 10,1 & $\mathrm{D}$ & Colisión de vehículos en marcha (Lateral) \\
\hline 158 & V-31 & 10,1 & $\mathrm{~N}$ & Colisión de vehículos en marcha (Lateral) \\
\hline 159 & V-31 & 10,2 & A & Colisión de vehículos en marcha (Frontolateral) \\
\hline 160 & V-31 & 10,2 & $\mathrm{D}$ & Colisión de vehículos en marcha (Alcance) \\
\hline 161 & V-31 & 10,2 & $\bar{A}$ & Salida de la vía por la izquierda con colisión (Choque con muro o edifício) \\
\hline 162 & V-31 & 10,3 & A & Colisión de vehículos en marcha (Frontolateral) \\
\hline 163 & V-31 & 10,3 & $\bar{A}$ & Salida de la vía por la derecha con colisión (Choque con muro o edifício) \\
\hline 164 & V-31 & 10,4 & $\mathrm{D}$ & Salida de la vía por la izquierda con colisión (Choque con muro o edifício) \\
\hline 165 & V-31 & 10,4 & A & Colisión de vehículos en marcha (Múltiple o en caravana) \\
\hline 166 & V-31 & 10,5 & A & Colisión de vehículos en marcha (Alcance) \\
\hline 167 & V-31 & 10,5 & $\mathrm{D}$ & Colisión de vehículos en marcha (Lateral) \\
\hline 168 & V-31 & 10,5 & $\mathrm{~A}$ & Colisión de vehículos en marcha (Alcance) \\
\hline
\end{tabular}


Cómputo de muertos realizado a $24 \mathrm{~h}$.

\begin{tabular}{|c|c|c|c|c|c|c|c|c|c|c|c|}
\hline No. & CARRETERA & $\mathrm{Km} / \mathbf{1 0}$ & SENTIDO & 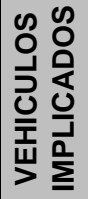 & HORA & FECHA & 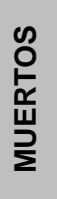 & 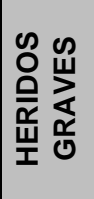 & 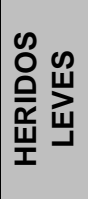 & SUPERFICIE & $\begin{array}{c}\text { FACTORES } \\
\text { ATMOSFERICOS }\end{array}$ \\
\hline 141 & $\overline{V-31}$ & 8,3 & $A$ & 1 & 12 & \begin{tabular}{|l|}
20070828 \\
\end{tabular} & 0 & 0 & 1 & SECA Y LIMPIA & BUEN TIEMPO \\
\hline 142 & V-31 & 8,5 & $\mathrm{D}$ & 1 & 20 & 20060317 & 0 & 0 & 1 & SECA Y LIMPIA & BUEN TIEMPO \\
\hline 143 & V-31 & 8,5 & $A$ & 1 & 15 & 20061018 & 0 & 0 & 0 & SECA Y LIMPIA & BUEN TIEMPO \\
\hline 144 & V-31 & 8,5 & $\mathrm{~N}$ & 2 & 8 & 20070515 & 0 & 0 & 0 & SECA Y LIMPIA & BUEN TIEMPO \\
\hline 145 & V-31 & 8,5 & $\mathrm{~S}$ & 2 & 16 & 20070623 & 0 & 0 & 2 & SECA Y LIMPIA & BUEN TIEMPO \\
\hline 146 & V-31 & 8,5 & $\mathrm{~N}$ & 4 & 12 & \begin{tabular}{|l|}
20070129 \\
\end{tabular} & 0 & 0 & 1 & SECA Y LIMPIA & BUEN TIEMPO \\
\hline 147 & V-31 & 8,5 & $\mathrm{D}$ & 3 & 8 & 20070706 & 0 & 0 & 1 & SECA Y LIMPIA & BUEN TIEMPO \\
\hline 148 & V-31 & 8,5 & $\mathrm{D}$ & 2 & 18 & \begin{tabular}{|l|}
20061227 \\
\end{tabular} & 0 & 0 & 1 & SECA Y LIMPIA & BUEN TIEMPO \\
\hline 149 & V-31 & 10,0 & $\mathrm{D}$ & 2 & 14 & \begin{tabular}{|l|}
20070823 \\
\end{tabular} & 0 & 0 & 0 & SECA Y LIMPIA & BUEN TIEMPO \\
\hline 150 & V-31 & 10,0 & $A$ & 2 & 15 & 20070510 & 0 & 0 & 1 & SECA Y LIMPIA & BUEN TIEMPO \\
\hline 151 & V-31 & 10,0 & $A$ & 2 & 14 & 20060207 & 0 & 0 & 0 & SECA Y LIMPIA & BUEN TIEMPO \\
\hline 152 & V-31 & 10,0 & $A$ & 2 & 17 & 20070920 & 0 & 0 & 0 & SECA Y LIMPIA & BUEN TIEMPO \\
\hline 153 & V-31 & 10,0 & $A$ & 2 & 17 & 20060403 & 0 & 0 & 1 & SECA Y LIMPIA & BUEN TIEMPO \\
\hline 154 & V-31 & 10,0 & $A$ & 3 & 19 & 20060126 & 0 & 0 & 0 & SECA Y LIMPIA & BUEN TIEMPO \\
\hline 155 & V-31 & 10,1 & $\mathrm{D}$ & 2 & 15 & 20070913 & 0 & 0 & 0 & SECA Y LIMPIA & BUEN TIEMPO \\
\hline 156 & V-31 & 10,1 & $\mathrm{D}$ & 2 & 21 & 20071123 & 0 & 0 & 0 & SECA Y LIMPIA & BUEN TIEMPO \\
\hline 157 & V-31 & 10,1 & $\mathrm{D}$ & 3 & 14 & 20060519 & 0 & 0 & 2 & SECA Y LIMPIA & BUEN TIEMPO \\
\hline 158 & V-31 & 10,1 & $\mathrm{~N}$ & 2 & 3 & 20071104 & 0 & 0 & 0 & SECA Y LIMPIA & BUEN TIEMPO \\
\hline 159 & V-31 & 10,2 & $A$ & 2 & 8 & 20060426 & 0 & 0 & 0 & SECA Y LIMPIA & BUEN TIEMPO \\
\hline 160 & V-31 & 10,2 & $\mathrm{D}$ & 2 & 19 & 20070801 & 0 & 0 & 0 & SECA Y LIMPIA & BUEN TIEMPO \\
\hline 161 & V-31 & 10,2 & $A$ & 1 & 23 & 20070227 & 0 & 0 & 1 & SECA Y LIMPIA & BUEN TIEMPO \\
\hline 162 & V-31 & 10,3 & $\mathrm{~A}$ & 2 & 16 & 20060504 & 0 & 0 & 1 & SECA Y LIMPIA & BUEN TIEMPO \\
\hline 163 & V-31 & 10,3 & $A$ & 1 & 8 & 20070708 & 0 & 0 & 1 & SECA Y LIMPIA & BUEN TIEMPO \\
\hline 164 & $\mathrm{~V}-31$ & 10,4 & $\mathrm{D}$ & 1 & 0 & 20060831 & 0 & 0 & 0 & MOJADA & LLUVIA FUERTE \\
\hline 165 & V-31 & 10,4 & $\mathrm{~A}$ & 3 & 12 & 20071113 & 0 & 0 & 1 & SECA Y LIMPIA & BUEN TIEMPO \\
\hline 166 & V-31 & 10,5 & $A$ & 2 & 23 & 20070723 & 0 & 0 & 0 & SECA Y LIMPIA & BUEN TIEMPO \\
\hline 167 & V-31 & 10,5 & $\mathrm{D}$ & 2 & 19 & 20060704 & 0 & 0 & 0 & SECA Y LIMPIA & BUEN TIEMPO \\
\hline 168 & V-31 & 10,5 & $A$ & 2 & 20 & 20070806 & 0 & 0 & 0 & SECA Y LIMPIA & BUEN TIEMPO \\
\hline
\end{tabular}


Cómputo de muertos realizado a $24 \mathrm{~h}$.

\begin{tabular}{|c|c|c|c|c|c|c|c|c|c|c|}
\hline No. & CARRETERA & $\mathrm{Km} / 10$ & SENTIDO & VISIBILIDAD & LUMINOSIDAD & 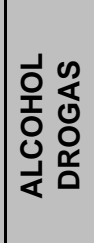 & 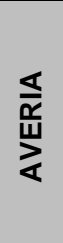 & 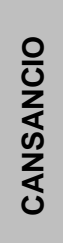 & 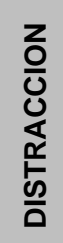 & 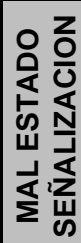 \\
\hline \begin{tabular}{|l|l}
141 \\
\end{tabular} & $\mathrm{~V}-31$ & 8,3 & $\mathrm{~A}$ & SIN RESTRICCIÓN & |PLENO DÍA & & & & $\mathrm{S}$ & \\
\hline \begin{tabular}{|c|}
$142 \cdot r \cdot r \cdot r$ \\
\end{tabular} & $\mathrm{~V}-31$ & 8,5 & $\mathrm{D}$ & SIN RESTRICCIÓN & NOCHE: ILUMINACIÓN SUFICIENTE & & & & & \\
\hline \begin{tabular}{|c|}
143 \\
\end{tabular} & $\mathrm{~V}-31$ & 8,5 & $\mathrm{~A}$ & SIN RESTRICCIÓN & PLENO DÍA & & & & & \\
\hline 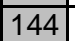 & V-31 & 8,5 & $\mathrm{~N}$ & SIN RESTRICCIÓN & PLENO DÍA & & & & $\mathrm{S}$ & \\
\hline \begin{tabular}{|l|l|}
145 \\
\end{tabular} & $\mathrm{~V}-31$ & 8,5 & $\mathrm{~S}$ & SIN RESTRICCIÓN & PLENO DÍA & & & & $\mathrm{S}$ & \\
\hline 146 & $\mathrm{~V}-31$ & 8,5 & $\mathrm{~N}$ & SIN RESTRICCIÓN & PLENO DÍA & & & & & \\
\hline \begin{tabular}{|l|l|}
147 \\
\end{tabular} & $\mathrm{~V}-31$ & 8,5 & $\mathrm{D}$ & SIN RESTRICCIÓN & PLENO DÍA & & & & $\mathrm{S}$ & \\
\hline \begin{tabular}{|l|l|}
148 \\
\end{tabular} & $\mathrm{~V}-31$ & 8,5 & $\mathrm{D}$ & SIN RESTRICCIÓN & NOCHE: ILUMINACIÓN SUFICIENTE & & $\mathrm{S}$ & & & \\
\hline 149 & $\mathrm{~V}-31$ & 10,0 & $\mathrm{D}$ & SIN RESTRICCIÓN & PLENO DÍA & & & & & \\
\hline \begin{tabular}{|l|l|}
150 \\
\end{tabular} & $\mathrm{~V}-31$ & 10,0 & A & SIN RESTRICCIÓN & PLENO DÍA & & & & $\mathrm{S}$ & \\
\hline 151 & $\mathrm{~V}-31$ & 10,0 & A & SIN RESTRICCIÓN & PLENO DÍA & & & & $\mathrm{S}$ & \\
\hline \begin{tabular}{|l|l|}
152 \\
\end{tabular} & $\mathrm{~V}-31$ & 10,0 & A & SIN RESTRICCIÓN & PLENO DÍA & & & & & \\
\hline 153 & $\mathrm{~V}-31$ & 10,0 & A & SIN RESTRICCIÓN & PLENO DÍA & & & & $\mathrm{S}$ & \\
\hline 154 & $\mathrm{~V}-31$ & 10,0 & A & SIN RESTRICCIÓN & NOCHE: ILUMINACIÓN SUFICIENTE & & & & & \\
\hline \begin{tabular}{|l|l|}
155 \\
\end{tabular} & $\mathrm{~V}-31$ & 10,1 & $\mathrm{D}$ & SIN RESTRICCIÓN & PLENO DÍA & $\bar{N}$ & & & & \\
\hline 156 & $\mathrm{~V}-31$ & 10,1 & $\mathrm{D}$ & SIN RESTRICCIÓN & NOCHE: ILUMINACIÓN SUFICIENTE & & & & $\mathrm{S}$ & \\
\hline 157 & V-31 & 10,1 & $\mathrm{D}$ & SIN RESTRICCIÓN & PLENO DÍA & & & & & \\
\hline \begin{tabular}{|l|l|}
158 \\
\end{tabular} & $\mathrm{~V}-31$ & 10,1 & $\mathrm{~N}$ & SIN RESTRICCIÓN & NOCHE: ILUMINACIÓN SUFICIENTE & & & & & \\
\hline 159 & $\mathrm{~V}-31$ & 10,2 & A & SIN RESTRICCIÓN & PLENO DÍA & & & & $\mathrm{S}$ & \\
\hline 160 & V-31 & 10,2 & $\mathrm{D}$ & SIN RESTRICCIÓN & PLENO DÍA & & & & & \\
\hline 161 & $\mathrm{~V}-31$ & 10,2 & A & SIN RESTRICCIÓN & NOCHE: ILUMINACIÓN SUFICIENTE & $\mathrm{N}$ & $\mathrm{N}$ & $\mathrm{N}$ & $\mathrm{S}$ & $\mathrm{N}$ \\
\hline 162 & $\mathrm{~V}-31$ & 10,3 & A & SIN RESTRICCIÓN & PLENO DÍA & & & & & \\
\hline 163 & V-31 & 10,3 & A & SIN RESTRICCIÓN & PLENO DÍA & & & $\mathrm{S}$ & & \\
\hline 164 & $\mathrm{~V}-31$ & 10,4 & $\mathrm{D}$ & FACTORES ATMOSFÉRICOS & NOCHE: ILUMINACIÓN SUFICIENTE & & & & & \\
\hline 165 & V-31 & 10,4 & A & SIN RESTRICCIÓN & PLENO DÍA & & & & & \\
\hline 166 & $\mathrm{~V}-31$ & 10,5 & A & SIN RESTRICCIÓN & NOCHE: ILUMINACIÓN SUFICIENTE & & & & & \\
\hline 167 & $\mathrm{~V}-31$ & 10,5 & $\mathrm{D}$ & SIN RESTRICCIÓN & PLENO DÍA & & & & & \\
\hline 168 & V-31 & 10,5 & A & SIN RESTRICCIÓN & PLENO DÍA & & & & $\mathrm{S}$ & \\
\hline
\end{tabular}


Cómputo de muertos realizado a $24 \mathrm{~h}$.

\begin{tabular}{|c|c|c|c|c|c|c|c|c|c|c|c|c|}
\hline No. & CARRETERA & $\mathrm{Km} / 10$ & SENTIDO & 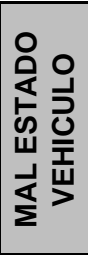 & 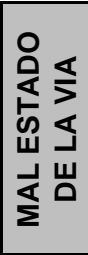 & 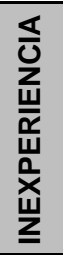 & 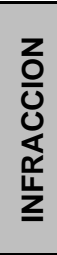 & 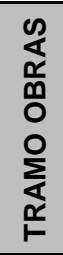 & 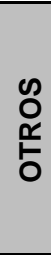 & $\begin{array}{l}z \\
\text { o } \\
z \\
0 \\
0 \\
z \\
\text { 心 }\end{array}$ & 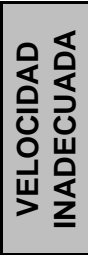 & 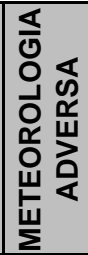 \\
\hline 141 & $\mathrm{~V}-31$ & 8,3 & $\bar{A}$ & & & & & & & & & \\
\hline 142 & V-31 & 8,5 & $\mathrm{D}$ & & $S$ & & & & & & & \\
\hline 143 & $\mathrm{~V}-31$ & 8,5 & $\mathrm{~A}$ & & & & & & $S$ & & & \\
\hline 144 & V-31 & 8,5 & $\mathrm{~N}$ & & & & & & & & & \\
\hline 145 & $\mathrm{~V}-31$ & 8,5 & $\mathrm{~S}$ & & & & $\mathrm{~S}$ & & & & & \\
\hline 146 & $\mathrm{~V}-31$ & 8,5 & $\mathrm{~N}$ & & & & & & & $\mathrm{~S}$ & & \\
\hline 147 & $\mathrm{~V}-31$ & 8,5 & $\mathrm{D}$ & & & & $\mathrm{S}$ & & & & & \\
\hline 148 & $\mathrm{~V}-31$ & 8,5 & $\mathrm{D}$ & & & & & & & & & \\
\hline 149 & $\mathrm{~V}-31$ & 10,0 & $\mathrm{D}$ & & & & $\mathrm{S}$ & & & & & \\
\hline 150 & $\mathrm{~V}-31$ & 10,0 & $\mathrm{~A}$ & & & & & & & & & \\
\hline 151 & $\mathrm{~V}-31$ & 10,0 & $\mathrm{~A}$ & & & & $\mathrm{~S}$ & & & & & \\
\hline 152 & $\mathrm{~V}-31$ & 10,0 & $\mathrm{~A}$ & & & & & & $S$ & & & \\
\hline 153 & $\mathrm{~V}-31$ & 10,0 & $\mathrm{~A}$ & & & & $\mathrm{~S}$ & & & & & \\
\hline 154 & $\mathrm{~V}-31$ & 10,0 & $\mathrm{~A}$ & & & & $\mathrm{~S}$ & & & & & \\
\hline 155 & $\mathrm{~V}-31$ & 10,1 & $\mathrm{D}$ & & & & $\mathrm{S}$ & & & & & \\
\hline 156 & $\mathrm{~V}-31$ & 10,1 & $\mathrm{D}$ & & & & & & & & & \\
\hline 157 & $\mathrm{~V}-31$ & 10,1 & $\mathrm{D}$ & & & & $\mathrm{S}$ & & & & & \\
\hline 158 & $\mathrm{~V}-31$ & 10,1 & $\mathrm{~N}$ & & & & & & $\mathrm{~S}$ & & & \\
\hline 159 & V-31 & 10,2 & $A$ & & & & & & & & & \\
\hline 160 & $\mathrm{~V}-31$ & 10,2 & $\mathrm{D}$ & & & & & & & $S$ & & \\
\hline 161 & $\mathrm{~V}-31$ & 10,2 & $\mathrm{~A}$ & $\mathrm{~N}$ & $\mathrm{~N}$ & $\mathrm{~N}$ & $\mathrm{~N}$ & $\mathrm{~N}$ & & & $S$ & $\mathrm{~N}$ \\
\hline 162 & $\mathrm{~V}-31$ & 10,3 & $\mathrm{~A}$ & & & $S$ & & & & & & \\
\hline 163 & $\mathrm{~V}-31$ & 10,3 & $A$ & & & $S$ & & & & & & \\
\hline 164 & $\mathrm{~V}-31$ & 10,4 & $\mathrm{D}$ & & & & & & & $\mathrm{S}$ & & \\
\hline 165 & $\mathrm{~V}-31$ & 10,4 & $\mathrm{~A}$ & & & & $S$ & & & & & \\
\hline 166 & $\mathrm{~V}-31$ & 10,5 & A & & & & & & & $S$ & & \\
\hline 167 & $\mathrm{~V}-31$ & 10,5 & $\mathrm{D}$ & & & & $\mathrm{S}$ & & & & & \\
\hline 168 & $\mathrm{~V}-31$ & 10,5 & $A$ & & & & $\mathrm{~S}$ & & & & $\mathrm{~S}$ & \\
\hline
\end{tabular}


Cómputo de muertos realizado a $24 \mathrm{~h}$.

\begin{tabular}{|c|c|c|c|c|}
\hline No. & CARRETERA & $\mathrm{Km} / \mathbf{1 0}$ & SENTIDO & TIPO DE ACCIDENTE \\
\hline 169 & $\mathrm{~V}-31$ & 10,5 & $\mathrm{D}$ & Salida de la vía por la izquierda sin colisión (Con vuelco) \\
\hline 170 & V-31 & 10,5 & A & Colisión de vehículos en marcha (Alcance) \\
\hline 171 & V-31 & 10,5 & A & Salida de la vía por la izquierda con colisión (Otro tipo de choque) \\
\hline 172 & V-31 & 10,5 & A & Colisión de vehículos en marcha (Múltiple o en caravana) \\
\hline 173 & V-31 & 10,5 & A & Colisión de vehículos en marcha (Múltiple o en caravana) \\
\hline 174 & V-31 & 10,6 & A & Colisión de vehículos en marcha (Lateral) \\
\hline 175 & V-31 & 10,6 & A & Salida de la vía por la derecha con colisión (Choque con muro o edifício) \\
\hline 176 & CV-35 & 7 & A & Colisión de vehículos en marcha (Múltiple o en caravana) \\
\hline 177 & CV-35 & 7 & $\mathrm{~S}$ & Colisión de vehículos en marcha (Frontal) \\
\hline 178 & CV-35 & 7 & $\mathrm{D}$ & Salida de la vía por la derecha con colisión (Otro tipo de choque) \\
\hline 179 & CV-35 & 7 & $\mathrm{D}$ & Salida de la vía por la derecha con colisión (Choque con cuneta o bordillo) \\
\hline 180 & CV-35 & 7 & $\mathrm{D}$ & Salida de la vía por la izquierda con colisión (Choque con árbol o poste) \\
\hline 181 & CV-35 & 7 & $\mathrm{D}$ & Colisión de vehículos en marcha (Múltiple o en caravana) \\
\hline 182 & CV-35 & 7 & $\mathrm{D}$ & Colisión de vehículos en marcha (Lateral) \\
\hline 183 & CV-35 & 7,10 & $\mathrm{D}$ & Vuelco en la calzada \\
\hline 184 & CV-35 & 7,20 & $\mathrm{D}$ & Salida de la vía por la derecha sin colisión (Con vuelco) \\
\hline 185 & CV-35 & 7,50 & $\bar{A}$ & Colisión de vehículos en marcha (Múltiple o en caravana) \\
\hline 186 & CV-35 & 7,50 & $\bar{A}$ & Colisión de vehículos en marcha (Alcance) \\
\hline 187 & CV-35 & 7,50 & A & Otro tipo de accidente \\
\hline 188 & CV-35 & 7,50 & A & Otro tipo de accidente \\
\hline 189 & CV-35 & 7,50 & A & Salida de la vía por la derecha con colisión (Choque con muro o edifício) \\
\hline 190 & CV-35 & 7,50 & $\mathrm{D}$ & Salida de la vía por la izquierda con colisión (Choque con árbol o poste) \\
\hline 191 & CV-35 & 7,80 & A & Colisión de vehículos en marcha (Alcance) \\
\hline 192 & CV-35 & 7,80 & $\mathrm{D}$ & Salida de la vía por la izquierda con colisión (Otro tipo de choque) \\
\hline 193 & CV-35 & 7,90 & A & Colisión de vehículos en marcha (Alcance) \\
\hline 194 & CV-35 & 8 & $\mathrm{D}$ & Colisión de vehículos en marcha (Múltiple o en caravana) \\
\hline 195 & CV-35 & 8 & A & Colisión de vehículos en marcha (Múltiple o en caravana) \\
\hline 196 & CV-35 & 8 & A & Colisión de vehículos en marcha (Múltiple o en caravana) \\
\hline 197 & CV-35 & 8 & A & Atropello a animales sueltos \\
\hline 198 & CV-35 & 8 & A & Colisión de vehículos en marcha (Alcance) \\
\hline 199 & CV-35 & 8 & A & Colisión de vehículos en marcha (Alcance) \\
\hline
\end{tabular}


Cómputo de muertos realizado a $24 \mathrm{~h}$.

\begin{tabular}{|c|c|c|c|c|c|c|c|c|c|c|c|}
\hline No. & CARRETERA & $\mathrm{Km} / 10$ & SENTIDO & 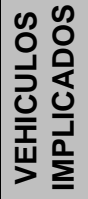 & HORA & FECHA & 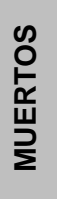 & 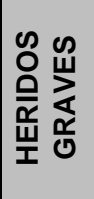 & 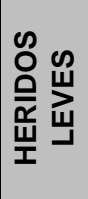 & SUPERFICIE & $\begin{array}{c}\text { FACTORES } \\
\text { ATMOSFERICOS }\end{array}$ \\
\hline 169 & $\mathrm{~V}-31$ & 10,5 & $\mathrm{D}$ & 1 & 5 & \begin{tabular}{|l|}
20070317 \\
\end{tabular} & 0 & 0 & 0 & SECA Y LIMPIA & BUEN TIEMPO \\
\hline 170 & V-31 & 10,5 & $\mathrm{~A}$ & 2 & 7 & 20061130 & 0 & 0 & 1 & SECA Y LIMPIA & BUEN TIEMPO \\
\hline 171 & V-31 & 10,5 & $\mathrm{~A}$ & 1 & 3 & 20060511 & 0 & 0 & 1 & SECA Y LIMPIA & BUEN TIEMPO \\
\hline 172 & V-31 & 10,5 & $A$ & 3 & 20 & 20070928 & 0 & 0 & 0 & SECA Y LIMPIA & BUEN TIEMPO \\
\hline 173 & V-31 & 10,5 & $A$ & 3 & 20 & 20060308 & 0 & 0 & 0 & SECA Y LIMPIA & BUEN TIEMPO \\
\hline 174 & V-31 & 10,6 & $\mathrm{~A}$ & 2 & 10 & 20060510 & 0 & 0 & 0 & SECA Y LIMPIA & BUEN TIEMPO \\
\hline 175 & V-31 & 10,6 & $A$ & 1 & 5 & 20060916 & 0 & 0 & 0 & SECA Y LIMPIA & BUEN TIEMPO \\
\hline 176 & CV-35 & 7 & $A$ & 5 & 20 & 20060208 & 0 & 0 & 1 & SECA Y LIMPIA & BUEN TIEMPO \\
\hline 177 & CV-35 & 7 & $\mathrm{~S}$ & 2 & 18 & \begin{tabular}{|l|}
20070907 \\
\end{tabular} & 0 & 0 & 1 & SECA Y LIMPIA & BUEN TIEMPO \\
\hline 178 & CV-35 & 7 & $\mathrm{D}$ & 1 & 08 & 20071202 & 0 & 0 & 0 & SECA Y LIMPIA & BUEN TIEMPO \\
\hline 179 & CV-35 & 7 & $\mathrm{D}$ & 1 & 19 & 20070512 & 0 & 0 & 0 & SECA Y LIMPIA & BUEN TIEMPO \\
\hline 180 & CV-35 & 7 & $\bar{D}$ & 1 & 19 & 20071102 & 0 & 0 & 1 & SECA Y LIMPIA & BUEN TIEMPO \\
\hline 181 & CV-35 & 7 & $\mathrm{D}$ & 10 & 17 & 20060110 & 0 & 0 & 6 & MOJADA & LLUVIA FUERTE \\
\hline 182 & CV-35 & 7 & $\mathrm{D}$ & 2 & 22 & 20071220 & 0 & 0 & 1 & MOJADA & BUEN TIEMPO \\
\hline 183 & CV-35 & 7,10 & $\bar{D}$ & 1 & 18 & 20070620 & 0 & 1 & 0 & SECA Y LIMPIA & BUEN TIEMPO \\
\hline 184 & CV-35 & 7,20 & $\mathrm{D}$ & 1 & 15 & 20070502 & 0 & 0 & 0 & SECA Y LIMPIA & BUEN TIEMPO \\
\hline 185 & CV-35 & 7,50 & $A$ & 3 & 08 & 20071115 & 0 & 0 & 0 & SECA Y LIMPIA & BUEN TIEMPO \\
\hline 186 & CV-35 & 7,50 & $\mathrm{~A}$ & 2 & 09 & 20060308 & 0 & 0 & 0 & SECA Y LIMPIA & BUEN TIEMPO \\
\hline 187 & CV-35 & 7,50 & $A$ & 3 & 12 & 20070723 & 0 & 0 & 1 & SECA Y LIMPIA & BUEN TIEMPO \\
\hline 188 & CV-35 & 7,50 & $A$ & 1 & 10 & 20060309 & 0 & 0 & 0 & SECA Y LIMPIA & BUEN TIEMPO \\
\hline 189 & CV-35 & 7,50 & $\mathrm{~A}$ & 1 & 11 & 20060903 & 0 & 1 & 0 & SECA Y LIMPIA & BUEN TIEMPO \\
\hline 190 & CV-35 & 7,50 & $\mathrm{D}$ & 1 & 06 & 20060513 & 0 & 0 & 3 & SECA Y LIMPIA & BUEN TIEMPO \\
\hline 191 & CV-35 & 7,80 & $\mathrm{~A}$ & 2 & 08 & \begin{tabular}{|l|}
20060503 \\
\end{tabular} & 0 & 0 & 0 & MOJADA & LLUVIA FUERTE \\
\hline 192 & CV-35 & 7,80 & $\mathrm{D}$ & 2 & 20 & \begin{tabular}{|l|}
20071219 \\
\end{tabular} & 0 & 0 & 0 & MOJADA & LLUVIA FUERTE \\
\hline 193 & CV-35 & 7,90 & $\mathrm{~A}$ & 2 & 09 & \begin{tabular}{|l|}
20071023 \\
\end{tabular} & 0 & 0 & 0 & MOJADA & LLOVIZNANDO \\
\hline 194 & CV-35 & 8 & $\mathrm{D}$ & 4 & 14 & 20061202 & 0 & 0 & 1 & SECA Y LIMPIA & BUEN TIEMPO \\
\hline 195 & CV-35 & 8 & $\mathrm{~A}$ & 3 & 20 & \begin{tabular}{|l|}
20060905 \\
\end{tabular} & 0 & 0 & 1 & SECA Y LIMPIA & BUEN TIEMPO \\
\hline 196 & CV-35 & 8 & A & 3 & 15 & \begin{tabular}{|l|}
20070706 \\
\end{tabular} & 0 & 0 & 2 & SECA Y LIMPIA & BUEN TIEMPO \\
\hline 197 & CV-35 & 8 & $\mathrm{~A}$ & 1 & 22 & \begin{tabular}{|l|}
20071227 \\
\end{tabular} & 0 & 0 & 0 & SECA Y LIMPIA & BUEN TIEMPO \\
\hline 198 & CV-35 & 8 & $\bar{A}$ & 2 & 08 & 20060601 & 0 & 0 & 0 & MOJADA & LLOVIZNANDO \\
\hline 199 & CV-35 & 8 & $A$ & 2 & 19 & 20070731 & 0 & 0 & 2 & SECA Y LIMPIA & BUEN TIEMPO \\
\hline
\end{tabular}


Cómputo de muertos realizado a $24 \mathrm{~h}$.

\begin{tabular}{|c|c|c|c|c|c|c|c|c|c|c|}
\hline No. & CARRETERA & $\mathrm{Km} / 10$ & SENTIDO & VISIBILIDAD & LUMINOSIDAD & 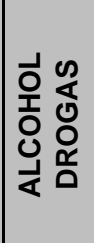 & $\begin{array}{l}\frac{\varangle}{\widetilde{\alpha}} \\
\stackrel{\Psi}{\gtrless}\end{array}$ & 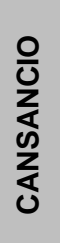 & 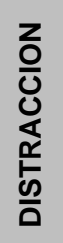 & 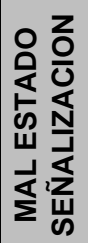 \\
\hline 169 & V-31 & 10,5 & $\mathrm{D}$ & SIN RESTRICCIÓN & NOCHE: ILUMINACIÓN SUFICIENTE & $\mathrm{S}$ & & & $\mathrm{S}$ & \\
\hline 170 & $\mathrm{~V}-31$ & 10,5 & A & SIN RESTRICCIÓN & PLENO DÍA & & & & $\mathrm{S}$ & \\
\hline 171 & $\mathrm{~V}-31$ & 10,5 & $\mathrm{~A}$ & SIN RESTRICCIÓN & NOCHE: ILUMINACIÓN SUFICIENTE & & & & & \\
\hline 172 & V-31 & 10,5 & A & SIN RESTRICCIÓN & CREPÚSCULO & & & & $\mathrm{S}$ & \\
\hline 173 & V-31 & 10,5 & $\bar{A}$ & SIN RESTRICCIÓN & NOCHE: ILUMINACIÓN INSUFICIENTE & $\mathrm{S}$ & & & $\mathrm{S}$ & \\
\hline 174 & V-31 & 10,6 & $\mathrm{~A}$ & SIN RESTRICCIÓN & PLENO DÍA & & & & $\mathrm{S}$ & \\
\hline 175 & V-31 & 10,6 & $\mathrm{~A}$ & SIN RESTRICCIÓN & NOCHE: SIN ILUMINACIÓN & $\mathrm{S}$ & & & $\mathrm{S}$ & \\
\hline 176 & CV-35 & 7 & $\bar{A}$ & SIN RESTRICCIÓN & NOCHE: ILUMINACIÓN INSUFICIENTE & & & & $\mathrm{S}$ & \\
\hline 177 & CV-35 & 7 & $S$ & SIN RESTRICCIÓN & PLENO DÍA & & & & & \\
\hline 178 & CV-35 & 7 & $\mathrm{D}$ & SIN RESTRICCIÓN & PLENO DÍA & $\mathrm{S}$ & & & & \\
\hline 179 & CV-35 & 7 & $\mathrm{D}$ & SIN RESTRICCIÓN & PLENO DÍA & $\mathrm{N}$ & $\mathrm{N}$ & $\mathrm{N}$ & $\mathrm{N}$ & $\mathrm{N}$ \\
\hline 180 & CV-35 & 7 & $\mathrm{D}$ & SIN RESTRICCIÓN & NOCHE: ILUMINACIÓN SUFICIENTE & & & & $\mathrm{S}$ & \\
\hline 181 & CV-35 & 7 & $\mathrm{D}$ & FACTORES ATMOSFÉRICOS & PLENO DÍA & & & & & \\
\hline 182 & CV-35 & 7 & $\mathrm{D}$ & SIN RESTRICCIÓN & NOCHE: SIN ILUMINACIÓN & & & & & \\
\hline 183 & CV-35 & 7,10 & $\mathrm{D}$ & SIN RESTRICCIÓN & PLENO DÍA & & $\mathrm{S}$ & & & \\
\hline 184 & CV-35 & 7,20 & $\mathrm{D}$ & SIN RESTRICCIÓN & PLENO DÍA & & & & & \\
\hline 185 & CV-35 & 7,50 & $\bar{A}$ & SIN RESTRICCIÓN & PLENO DÍA & & & & $\mathrm{S}$ & \\
\hline 186 & CV-35 & 7,50 & $\bar{A}$ & SIN RESTRICCIÓN & PLENO DÍA & & & & & \\
\hline 187 & CV-35 & 7,50 & A & SIN RESTRICCIÓN & PLENO DÍA & & & & & \\
\hline 188 & CV-35 & 7,50 & $\bar{A}$ & SIN RESTRICCIÓN & PLENO DÍA & & & & & \\
\hline 189 & CV-35 & 7,50 & $\bar{A}$ & SIN RESTRICCIÓN & PLENO DÍA & & & & $\mathrm{S}$ & \\
\hline 190 & CV-35 & 7,50 & $\mathrm{D}$ & SIN RESTRICCIÓN & NOCHE: ILUMINACIÓN SUFICIENTE & & & & & \\
\hline 191 & CV-35 & 7,80 & A & SIN RESTRICCIÓN & PLENO DÍA & & & & $\mathrm{S}$ & \\
\hline \begin{tabular}{|l|}
192 \\
\end{tabular} & CV-35 & 7,80 & $\mathrm{D}$ & FACTORES ATMOSFÉRICOS & NOCHE: ILUMINACIÓN SUFICIENTE & & & & & \\
\hline \begin{tabular}{|l|l|}
193 \\
\end{tabular} & CV-35 & 7,90 & $\bar{A}$ & SIN RESTRICCIÓN & PLENO DÍA & $\bar{N}$ & $\mathrm{~N}$ & $\mathrm{~N}$ & $\mathrm{~S}$ & $\overline{\mathrm{N}}$ \\
\hline 194 & CV-35 & 8 & $\mathrm{D}$ & SIN RESTRICCIÓN & PLENO DÍA & & & & $\mathrm{S}$ & \\
\hline 195 & CV-35 & 8 & A & SIN RESTRICCIÓN & NOCHE: ILUMINACIÓN SUFICIENTE & & & & $\mathrm{S}$ & \\
\hline 196 & CV-35 & 8 & A & SIN RESTRICCIÓN & PLENO DÍA & & & & & \\
\hline 197 & CV-35 & 8 & A & SIN RESTRICCIÓN & NOCHE: ILUMINACIÓN SUFICIENTE & & & & & \\
\hline \begin{tabular}{|l|}
198 \\
\end{tabular} & CV-35 & 8 & $\mathrm{~A}$ & SIN RESTRICCIÓN & PLENO DÍA & & & & $\mathrm{S}$ & \\
\hline \begin{tabular}{|l|}
199 \\
\end{tabular} & CV-35 & 8 & $\mathrm{~A}$ & SIN RESTRICCIÓN & PLENO DÍA & & & & $\mathrm{N}$ & \\
\hline
\end{tabular}


Cómputo de muertos realizado a $24 \mathrm{~h}$.

\begin{tabular}{|c|c|c|c|c|c|c|c|c|c|c|c|c|}
\hline No. & CARRETERA & $\mathrm{Km} / 10$ & SENTIDO & 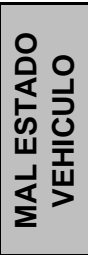 & 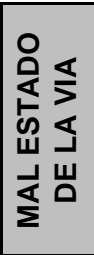 & 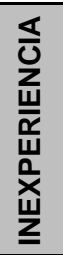 & 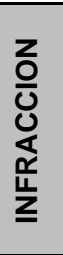 & 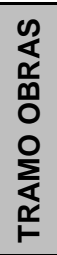 & 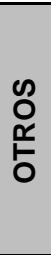 & $\begin{array}{l}z \\
\text { o } \\
z \\
0 \\
z \\
\text { 心 }\end{array}$ & 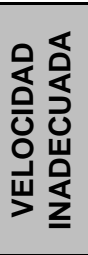 & 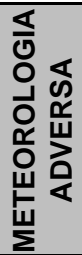 \\
\hline 169 & $\mathrm{~V}-31$ & 10,5 & $\mathrm{D}$ & & & & & & & & $\bar{S}$ & \\
\hline 170 & V-31 & 10,5 & A & & & & & & & & & \\
\hline 171 & V-31 & 10,5 & $\bar{A}$ & & & & $\mathrm{~S}$ & & & & $\mathrm{~S}$ & \\
\hline 172 & V-31 & 10,5 & $\bar{A}$ & & & & & & & & & \\
\hline 173 & $\mathrm{~V}-31$ & 10,5 & $\mathrm{~A}$ & & & & & & & & & \\
\hline 174 & V-31 & 10,6 & $\mathrm{~A}$ & & & & & & & & & \\
\hline 175 & V-31 & 10,6 & $\mathrm{~A}$ & & & & & & & & & \\
\hline 176 & CV-35 & 7 & $\mathrm{~A}$ & & & & & & & & & \\
\hline 177 & CV-35 & 7 & $\mathrm{~S}$ & & & & & & & & $\mathrm{~S}$ & \\
\hline 178 & CV-35 & 7 & $\mathrm{D}$ & & & & $S$ & & & & & \\
\hline 179 & CV-35 & 7 & $\mathrm{D}$ & $\mathrm{N}$ & $\mathrm{N}$ & $\mathrm{N}$ & $\mathrm{N}$ & $\mathrm{N}$ & $\mathrm{S}$ & & $\mathrm{N}$ & $\mathrm{N}$ \\
\hline 180 & CV-35 & 7 & $\bar{D}$ & & & & & & & & & \\
\hline 181 & CV-35 & 7 & $\mathrm{D}$ & & & & $S$ & & & & & \\
\hline 182 & CV-35 & 7 & $\mathrm{D}$ & & & & $S$ & & & & & \\
\hline 183 & CV-35 & 7,10 & $\mathrm{D}$ & & & & & & & & & \\
\hline 184 & CV-35 & 7,20 & $\mathrm{D}$ & & & & & & & $\mathrm{S}$ & & \\
\hline 185 & CV-35 & 7,50 & $\mathrm{~A}$ & & & & & & & & & \\
\hline 186 & CV-35 & 7,50 & $\mathrm{~A}$ & & & & $S$ & & & & & \\
\hline 187 & CV-35 & 7,50 & A & & & & & & $\mathrm{S}$ & & & \\
\hline 188 & CV-35 & 7,50 & $A$ & & & & $S$ & & & & & \\
\hline 189 & CV-35 & 7,50 & $\mathrm{~A}$ & & & & & & & & $\mathrm{~S}$ & \\
\hline 190 & CV-35 & 7,50 & $\mathrm{D}$ & & & & & & $\mathrm{S}$ & & & \\
\hline 191 & CV-35 & 7,80 & $\bar{A}$ & & & & $S$ & & & & & \\
\hline 192 & CV-35 & 7,80 & $\mathrm{D}$ & & & $\mathrm{S}$ & & & & & & \\
\hline 193 & CV-35 & 7,90 & $\bar{A}$ & $\mathrm{~N}$ & $\bar{N}$ & $\mathrm{~N}$ & $\mathrm{~N}$ & $\mathrm{~N}$ & & & $\mathrm{~N}$ & $\bar{N}$ \\
\hline 194 & CV-35 & 8 & $\mathrm{D}$ & & & & & & & & & \\
\hline 195 & CV-35 & 8 & $\bar{A}$ & & & & & & & & & \\
\hline 196 & CV-35 & 8 & $\bar{A}$ & & & & & & & $\mathrm{~S}$ & & \\
\hline 197 & CV-35 & 8 & $\bar{A}$ & & & & & & $\mathrm{~S}$ & & & \\
\hline 198 & CV-35 & 8 & $\bar{A}$ & & & & & & & & & \\
\hline 199 & CV-35 & 8 & $\bar{A}$ & & & & $\mathrm{~S}$ & & & & & \\
\hline
\end{tabular}



ANEXO No. 5. RESULTADOS DE LA APLICACIÓN DE LOS INDICADORES TIPCLA PARA LOS CARRILES DE DECELERACIÓN ESTUDIADOS 


\section{Configuración 1}

$\Sigma$ I_TiPCLA $\Sigma$ T_TiPCLA

\begin{tabular}{crrrrr} 
Umbral & (s2) & \multicolumn{1}{c}{ (s) } & (s2/veh) & (s/veh) & R_TiPCLA (s) \\
1 & 1,3561 & 12,5455 & 0,0140 & 0,1293 & 0,8919 \\
1,1 & 3,5482 & 29,1828 & 0,0366 & 0,3009 & 0,9784 \\
1,2 & 6,8195 & 37,3120 & 0,0703 & 0,3847 & 1,0172 \\
1,3 & 10,9571 & 43,2865 & 0,1130 & 0,4463 & 1,0469 \\
1,4 & 15,1310 & 46,7265 & 0,1560 & 0,4817 & 1,0762 \\
1,5 & 19,8771 & 49,4207 & 0,2049 & 0,5095 & 1,0978 \\
1,6 & 24,2964 & 50,5149 & 0,2505 & 0,5208 & 1,1190 \\
1,7 & 30,0098 & 56,5834 & 0,3094 & 0,5833 & 1,1696 \\
1,8 & 35,3987 & 66,0470 & 0,3649 & 0,6809 & 1,2640 \\
1,9 & 42,7280 & 85,4237 & 0,4405 & 0,8807 & 1,3998 \\
2 & 52,0289 & 127,1926 & 0,5364 & 1,3113 & 1,5909 \\
2,1 & 66,2901 & 159,0190 & 0,6834 & 1,6394 & 1,6831 \\
2,2 & 82,8097 & 174,6236 & 0,8537 & 1,8002 & 1,7258 \\
2,3 & 100,4045 & 183,6380 & 1,0351 & 1,8932 & 1,7532 \\
2,4 & 116,4892 & 183,7701 & 1,2009 & 1,8945 & 1,7661 \\
2,5 & 134,5506 & 185,7819 & 1,3871 & 1,9153 & 1,7758 \\
2,6 & 150,1029 & 186,1299 & 1,5475 & 1,9189 & 1,7936 \\
2,7 & 165,9217 & 190,0310 & 1,7105 & 1,9591 & 1,8269
\end{tabular}

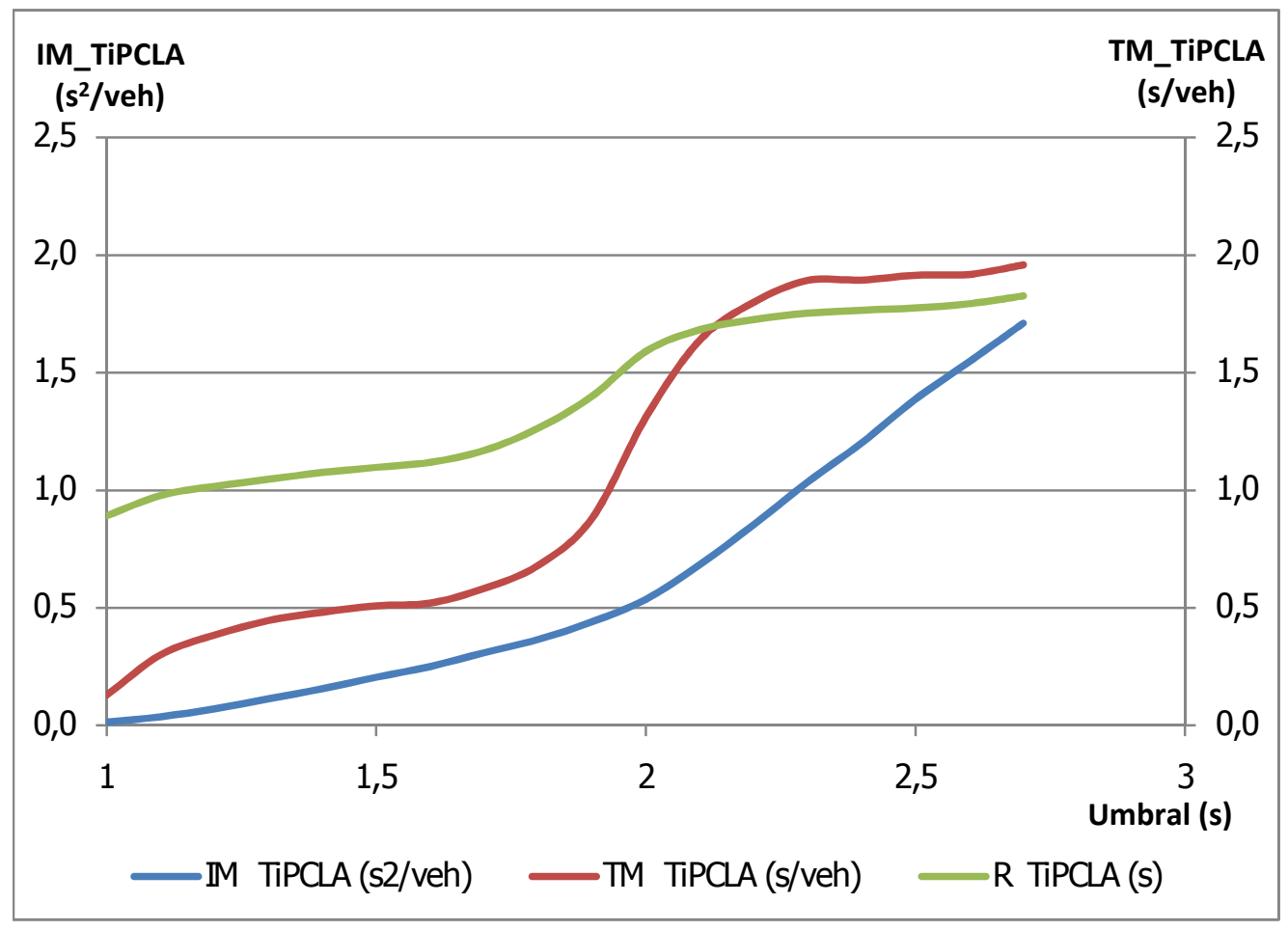




\section{Configuración 2}

$\begin{array}{crrrrr}\text { Umbral } & \begin{array}{r}\boldsymbol{\Sigma} \text { I_TiPCLA } \\ \text { (s2) }\end{array} & \begin{array}{c}\boldsymbol{\Sigma} \text { T_TiPCLA } \\ \text { (s) }\end{array} & \begin{array}{c}\text { IM_TiPCLA } \\ \text { (s2/veh) }\end{array} & \begin{array}{r}\text { TM_TiPCLA } \\ \text { (s/veh) }\end{array} & \text { R_TiPCLA (s) } \\ 1 & 1,2854 & 7,9562 & 0,0121 & 0,0751 & 0,8384 \\ 1,1 & 3,9135 & 23,2669 & 0,0369 & 0,2195 & 0,9318 \\ 1,2 & 6,1273 & 28,9482 & 0,0578 & 0,2731 & 0,9883 \\ 1,3 & 8,6504 & 32,1806 & 0,0816 & 0,3036 & 1,0312 \\ 1,4 & 11,2840 & 35,1594 & 0,1065 & 0,3317 & 1,0791 \\ 1,5 & 13,9390 & 36,0184 & 0,1315 & 0,3398 & 1,1130 \\ 1,6 & 17,0895 & 37,3075 & 0,1612 & 0,3520 & 1,1419 \\ 1,7 & 19,7018 & 39,8889 & 0,1859 & 0,3763 & 1,2061 \\ 1,8 & 22,6530 & 45,4330 & 0,2137 & 0,4286 & 1,3014 \\ 1,9 & 27,3424 & 58,2940 & 0,2579 & 0,5499 & 1,4310 \\ 2 & 33,8484 & 83,9420 & 0,3193 & 0,7919 & 1,5968 \\ 2,1 & 41,3789 & 102,3416 & 0,3904 & 0,9655 & 1,6957 \\ 2,2 & 47,9807 & 108,1525 & 0,4526 & 1,0203 & 1,7564 \\ 2,3 & 55,2125 & 112,5871 & 0,5209 & 1,0621 & 1,8096 \\ 2,4 & 62,4230 & 112,8750 & 0,5889 & 1,0649 & 1,8470 \\ 2,5 & 71,3370 & 114,2788 & 0,6730 & 1,0781 & 1,8758 \\ 2,6 & 78,7815 & 113,9566 & 0,7432 & 1,0751 & 1,9087 \\ 2,7 & 87,6604 & 116,7840 & 0,8270 & 1,1017 & 1,9494 \\ 2,8 & 97,3811 & 120,5866 & 0,9187 & 1,1376 & 1,9924 \\ 2,9 & 107,4279 & 126,2354 & 1,0135 & 1,1909 & 2,0490\end{array}$

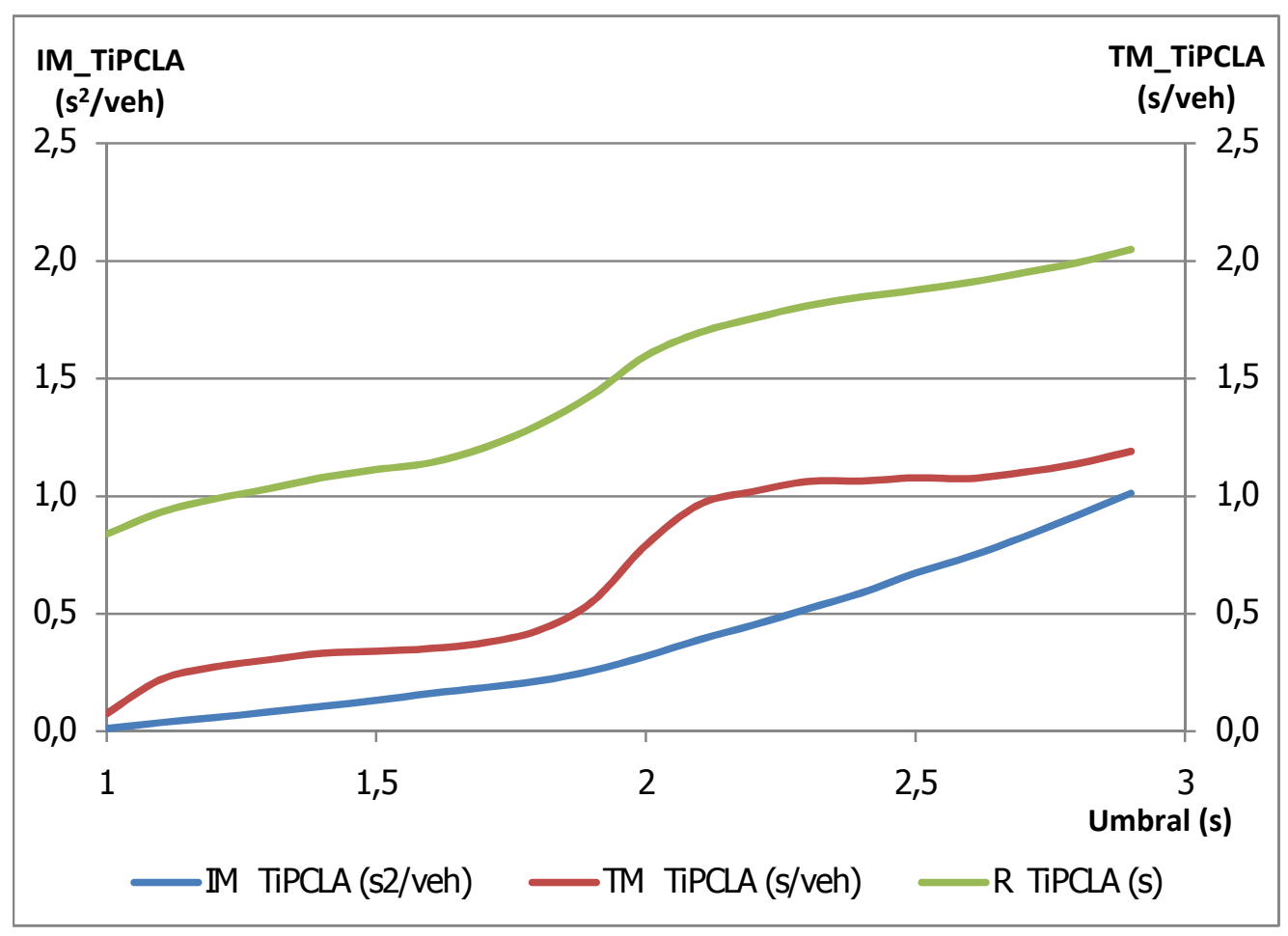




\section{Configuración 3}

$\begin{array}{crrrrr}\text { Umbral } & \begin{array}{c}\boldsymbol{\Sigma} \text { I_TiPCLA } \\ \text { (s2) }\end{array} & \begin{array}{c}\boldsymbol{\Sigma} \text { T_TiPCLA } \\ \text { (s) }\end{array} & \begin{array}{c}\text { IM_TiPCLA } \\ \text { (s2/veh) }\end{array} & \begin{array}{r}\text { TM_TiPCLA } \\ \text { (s/veh) }\end{array} & \text { R_TiPCLA (s) } \\ 1 & 1,2553 & 6,8769 & 0,0113 & 0,0620 & 0,8175 \\ 1,1 & 4,1960 & 23,4692 & 0,0378 & 0,2114 & 0,9212 \\ 1,2 & 6,3171 & 29,5820 & 0,0569 & 0,2665 & 0,9865 \\ 1,3 & 8,7381 & 33,1424 & 0,0787 & 0,2986 & 1,0363 \\ 1,4 & 11,3351 & 36,6076 & 0,1021 & 0,3298 & 1,0904 \\ 1,5 & 13,8192 & 37,5282 & 0,1245 & 0,3381 & 1,1318 \\ 1,6 & 17,2403 & 39,6006 & 0,1553 & 0,3568 & 1,1646 \\ 1,7 & 19,2455 & 41,2804 & 0,1734 & 0,3719 & 1,2338 \\ 1,8 & 22,3827 & 47,3191 & 0,2016 & 0,4263 & 1,3270 \\ 1,9 & 27,1370 & 60,7570 & 0,2445 & 0,5474 & 1,4534 \\ 2 & 34,6307 & 90,0065 & 0,3120 & 0,8109 & 1,6152 \\ 2,1 & 41,4878 & 111,6794 & 0,3738 & 1,0061 & 1,7285 \\ 2,2 & 48,7585 & 121,5205 & 0,4393 & 1,0948 & 1,7988 \\ 2,3 & 55,8436 & 127,3035 & 0,5031 & 1,1469 & 1,8613 \\ 2,4 & 63,1762 & 127,7384 & 0,5692 & 1,1508 & 1,9054 \\ 2,5 & 72,6187 & 129,5123 & 0,6542 & 1,1668 & 1,9393 \\ 2,6 & 81,9884 & 131,7745 & 0,7386 & 1,1872 & 1,9778 \\ 2,7 & 89,7328 & 132,8274 & 0,8084 & 1,1966 & 2,0244 \\ 2,8 & 100,2682 & 137,7714 & 0,9033 & 1,2412 & 2,0722 \\ 2,9 & 108,9445 & 142,1905 & 0,9815 & 1,2810 & 2,1338\end{array}$

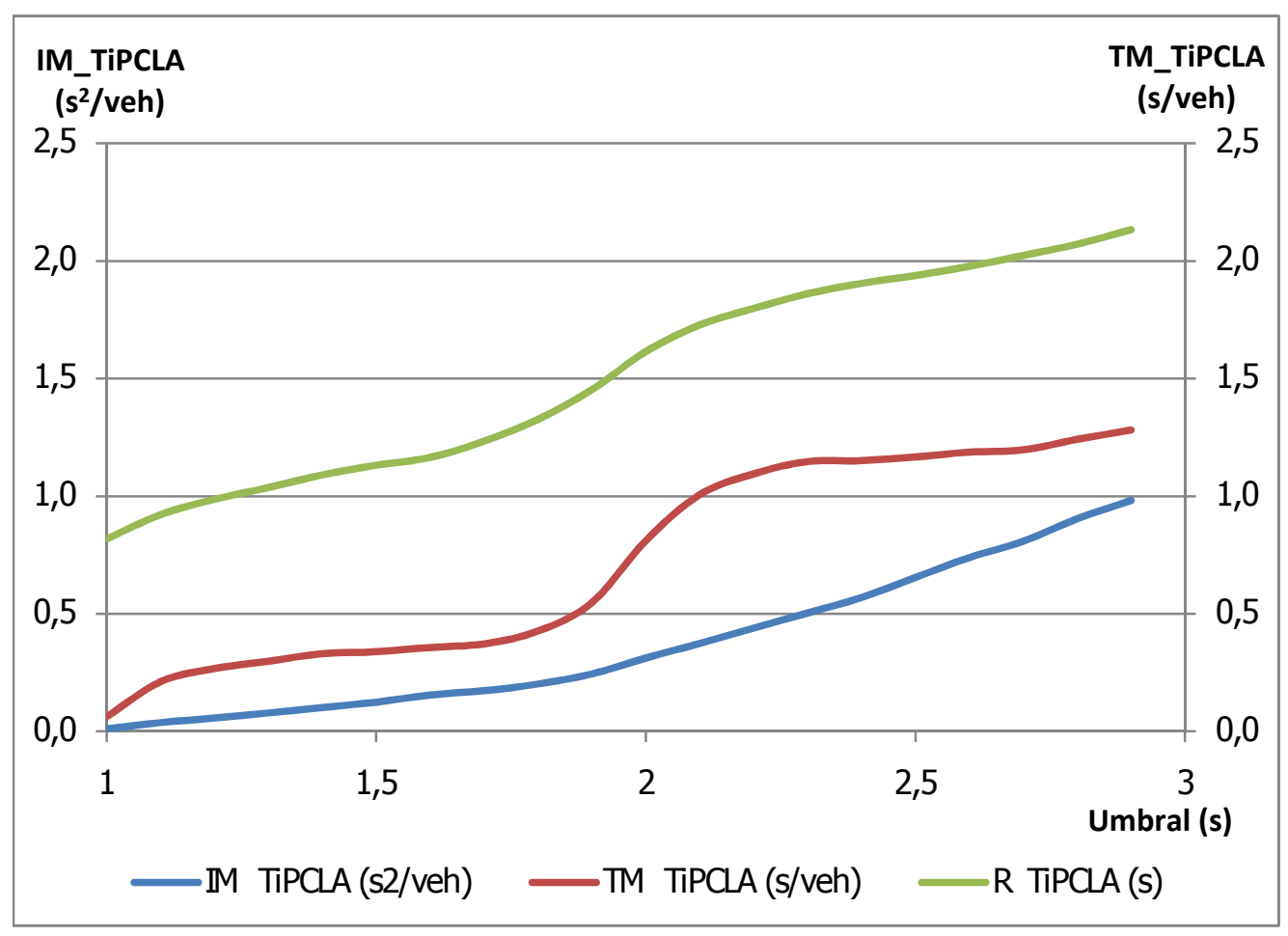




\section{Configuración 4}

$\Sigma$ I_TiPCLA $\Sigma$ T_TiPCLA

\begin{tabular}{crrrrr} 
Umbral & (s2) & \multicolumn{1}{l}{ (s) } & (s2/veh) & (s/veh) & R_TiPCLA (s) \\
1 & 1,4476 & 17,3716 & 0,0151 & 0,1810 & 0,9167 \\
1,1 & 4,3561 & 33,1078 & 0,0454 & 0,3449 & 0,9684 \\
1,2 & 8,3784 & 40,5424 & 0,0873 & 0,4223 & 0,9933 \\
1,3 & 13,0201 & 45,1998 & 0,1356 & 0,4708 & 1,0119 \\
1,4 & 17,8631 & 48,1541 & 0,1861 & 0,5016 & 1,0290 \\
1,5 & 23,1786 & 50,4233 & 0,2414 & 0,5252 & 1,0403 \\
1,6 & 28,9067 & 53,0066 & 0,3011 & 0,5522 & 1,0547 \\
1,7 & 34,1266 & 56,6654 & 0,3555 & 0,5903 & 1,0978 \\
1,8 & 40,6158 & 66,2009 & 0,4231 & 0,6896 & 1,1865 \\
1,9 & 48,4963 & 83,8697 & 0,5052 & 0,8736 & 1,3218 \\
2 & 58,9528 & 130,3541 & 0,6141 & 1,3579 & 1,5477 \\
2,1 & 72,0844 & 156,4780 & 0,7509 & 1,6300 & 1,6393 \\
2,2 & 88,3213 & 170,6288 & 0,9200 & 1,7774 & 1,6824 \\
2,3 & 105,6671 & 179,2167 & 1,1007 & 1,8668 & 1,7104 \\
2,4 & 121,1824 & 179,2868 & 1,2623 & 1,8676 & 1,7241 \\
2,5 & 139,0360 & 181,4432 & 1,4483 & 1,8900 & 1,7337 \\
2,6 & 157,1408 & 185,0380 & 1,6369 & 1,9275 & 1,7508 \\
2,7 & 172,2445 & 188,0213 & 1,7942 & 1,9586 & 1,7839
\end{tabular}

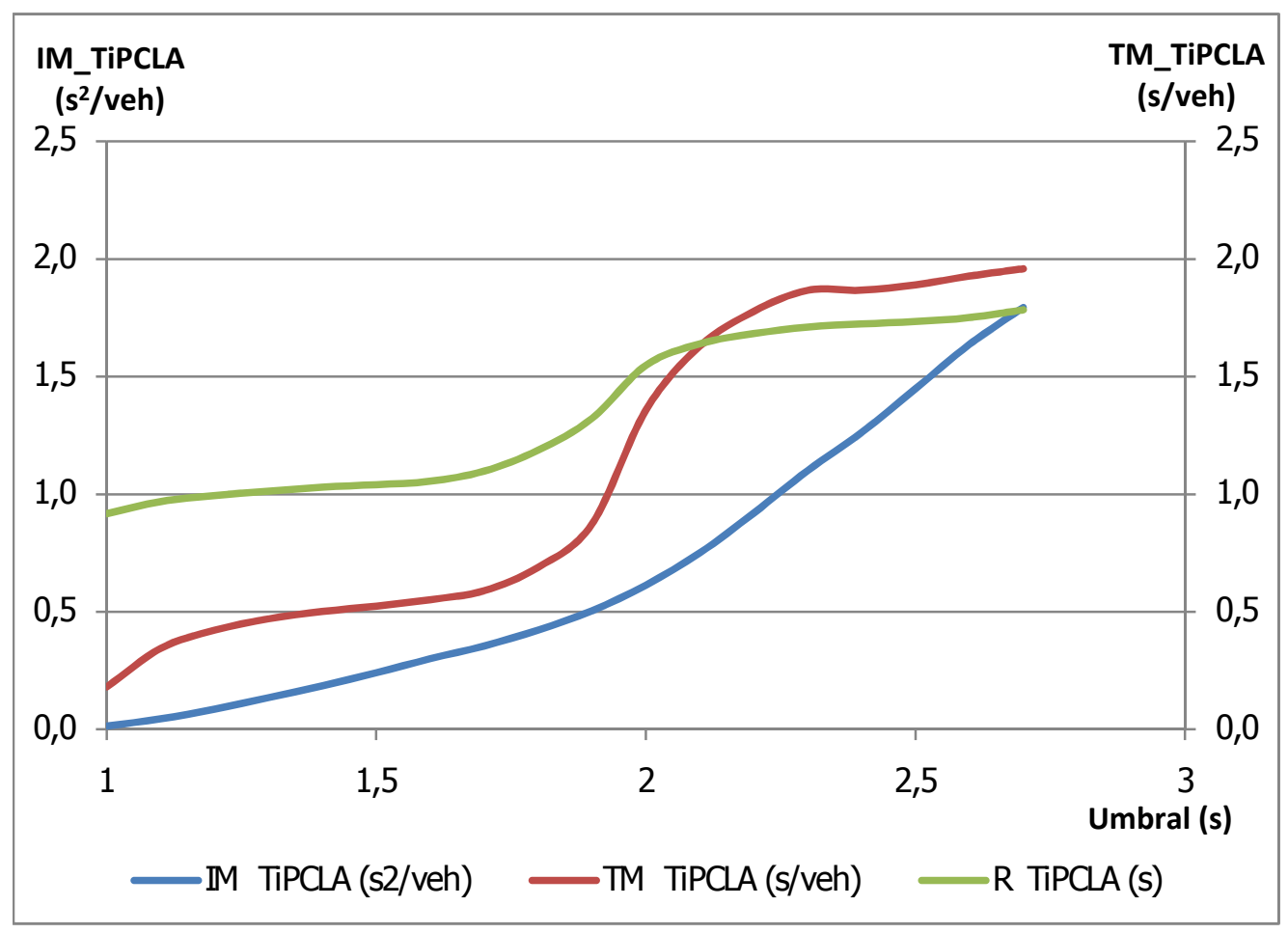


$\Sigma$ I_TiPCLA $\Sigma$ T_TiPCLA

\begin{tabular}{crrrrr} 
Umbral & \multicolumn{1}{c}{ (s2) } & \multicolumn{1}{c}{ (s) } & (s2/veh) & (s/veh) & R_TiPCLA (s) \\
1 & 1,7001 & 26,1722 & 0,0160 & 0,2469 & 0,9350 \\
1,1 & 5,1965 & 43,2887 & 0,0490 & 0,4084 & 0,9800 \\
1,2 & 9,9771 & 52,3983 & 0,0941 & 0,4943 & 1,0096 \\
1,3 & 15,4315 & 57,7142 & 0,1456 & 0,5445 & 1,0326 \\
1,4 & 21,3009 & 61,0272 & 0,2010 & 0,5757 & 1,0510 \\
1,5 & 27,4872 & 64,6567 & 0,2593 & 0,6100 & 1,0749 \\
1,6 & 35,4299 & 73,2883 & 0,3342 & 0,6914 & 1,1166 \\
1,7 & 42,2294 & 89,4383 & 0,3984 & 0,8438 & 1,2278 \\
1,8 & 52,3976 & 119,1860 & 0,4943 & 1,1244 & 1,3604 \\
1,9 & 66,9138 & 191,2018 & 0,6313 & 1,8038 & 1,5500 \\
2 & 89,5755 & 256,5671 & 0,8451 & 2,4204 & 1,6509 \\
2,1 & 116,6938 & 290,5367 & 1,1009 & 2,7409 & 1,6984 \\
2,2 & 146,4530 & 309,7849 & 1,3816 & 2,9225 & 1,7272 \\
2,3 & 177,5107 & 317,6458 & 1,6746 & 2,9967 & 1,7412 \\
2,4 & 209,0673 & 321,0953 & 1,9723 & 3,0292 & 1,7489 \\
2,5 & 240,9466 & 325,6711 & 2,2731 & 3,0724 & 1,7602 \\
2,6 & 273,3652 & 332,1736 & 2,5789 & 3,1337 & 1,7770 \\
2,7 & 306,5817 & 342,3758 & 2,8923 & 3,2300 & 1,8045 \\
2,8 & 341,0177 & 356,9045 & 3,2171 & 3,3670 & 1,8445
\end{tabular}

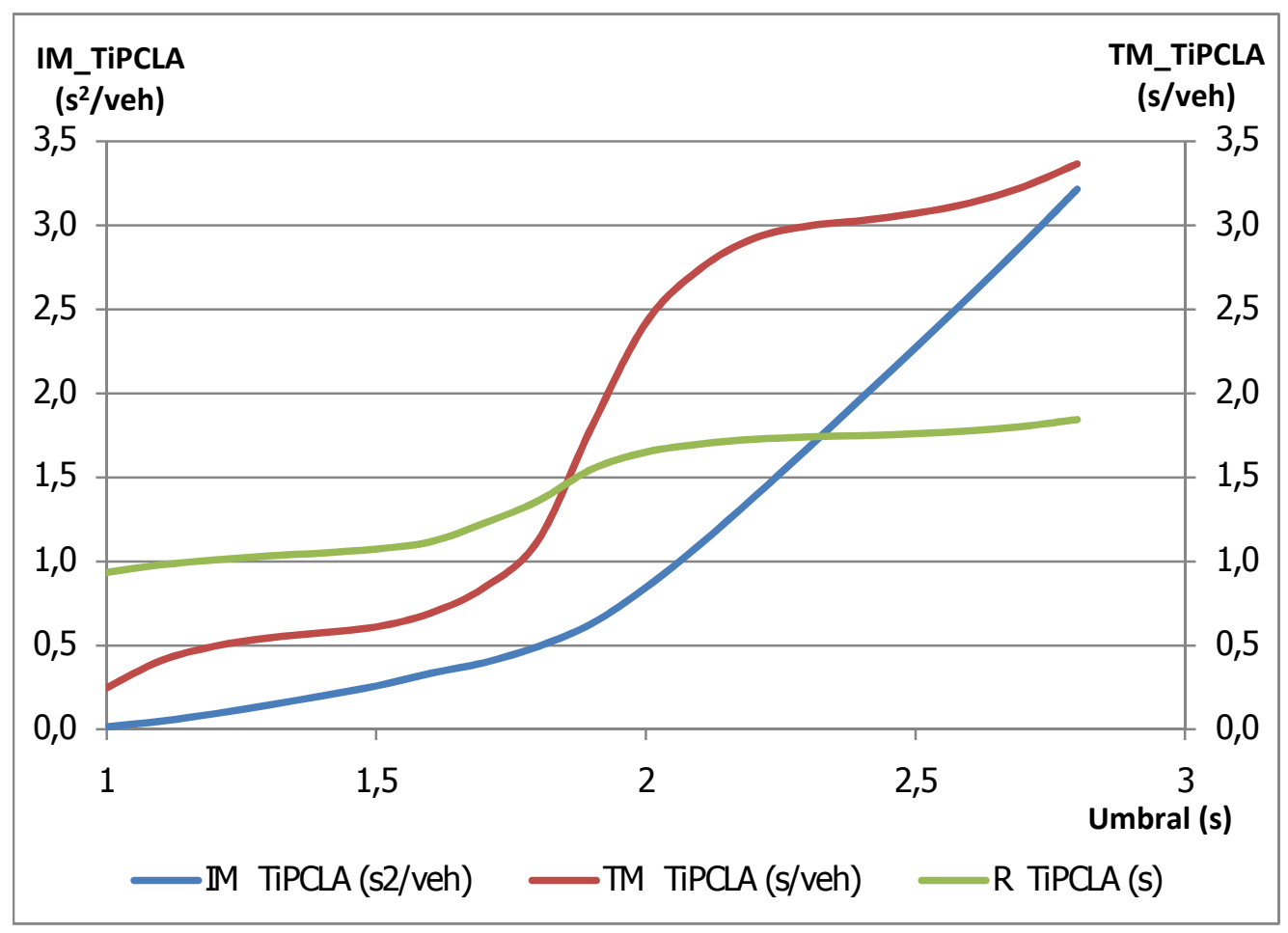


$\Sigma$ I_TiPCLA $\Sigma$ T_TiPCLA

$\begin{array}{crrrrr}\text { Umbral } & \text { (s2) } & \text { (s) } & \text { (s2/veh) } & \text { (s/veh) } & \text { R_TiPCLA (s) } \\ 1 & 0,0000 & 0,2119 & 0,0000 & 0,0024 & 1,0000 \\ 1,1 & 0,5830 & 11,1934 & 0,0066 & 0,1258 & 1,0479 \\ 1,2 & 1,9593 & 15,3122 & 0,0220 & 0,1720 & 1,0720 \\ 1,3 & 3,4983 & 15,7816 & 0,0393 & 0,1773 & 1,0783 \\ 1,4 & 5,0658 & 15,9600 & 0,0569 & 0,1793 & 1,0826 \\ 1,5 & 6,6443 & 16,0353 & 0,0747 & 0,1802 & 1,0856 \\ 1,6 & 8,2348 & 16,3008 & 0,0925 & 0,1832 & 1,0948 \\ 1,7 & 9,8786 & 16,9816 & 0,1110 & 0,1908 & 1,1183 \\ 1,8 & 11,6048 & 18,2066 & 0,1304 & 0,2046 & 1,1626 \\ 1,9 & 13,5447 & 21,5162 & 0,1522 & 0,2418 & 1,2705 \\ 2 & 16,0213 & 30,7688 & 0,1800 & 0,3457 & 1,4793 \\ 2,1 & 19,3620 & 36,7663 & 0,2176 & 0,4131 & 1,5734 \\ 2,2 & 23,2157 & 40,7109 & 0,2609 & 0,4574 & 1,6297 \\ 2,3 & 27,3658 & 42,9397 & 0,3075 & 0,4825 & 1,6627 \\ 2,4 & 31,6950 & 44,3582 & 0,3561 & 0,4984 & 1,6855 \\ 2,5 & 36,1207 & 44,9461 & 0,4059 & 0,5050 & 1,6964 \\ 2,6 & 40,5988 & 45,4765 & 0,4562 & 0,5110 & 1,7073 \\ 2,7 & 45,1387 & 46,5269 & 0,5072 & 0,5228 & 1,7298 \\ 2,8 & 49,9068 & 50,1875 & 0,5608 & 0,5639 & 1,8056 \\ 2,9 & 55,2137 & 57,2849 & 0,6204 & 0,6437 & 1,9362\end{array}$

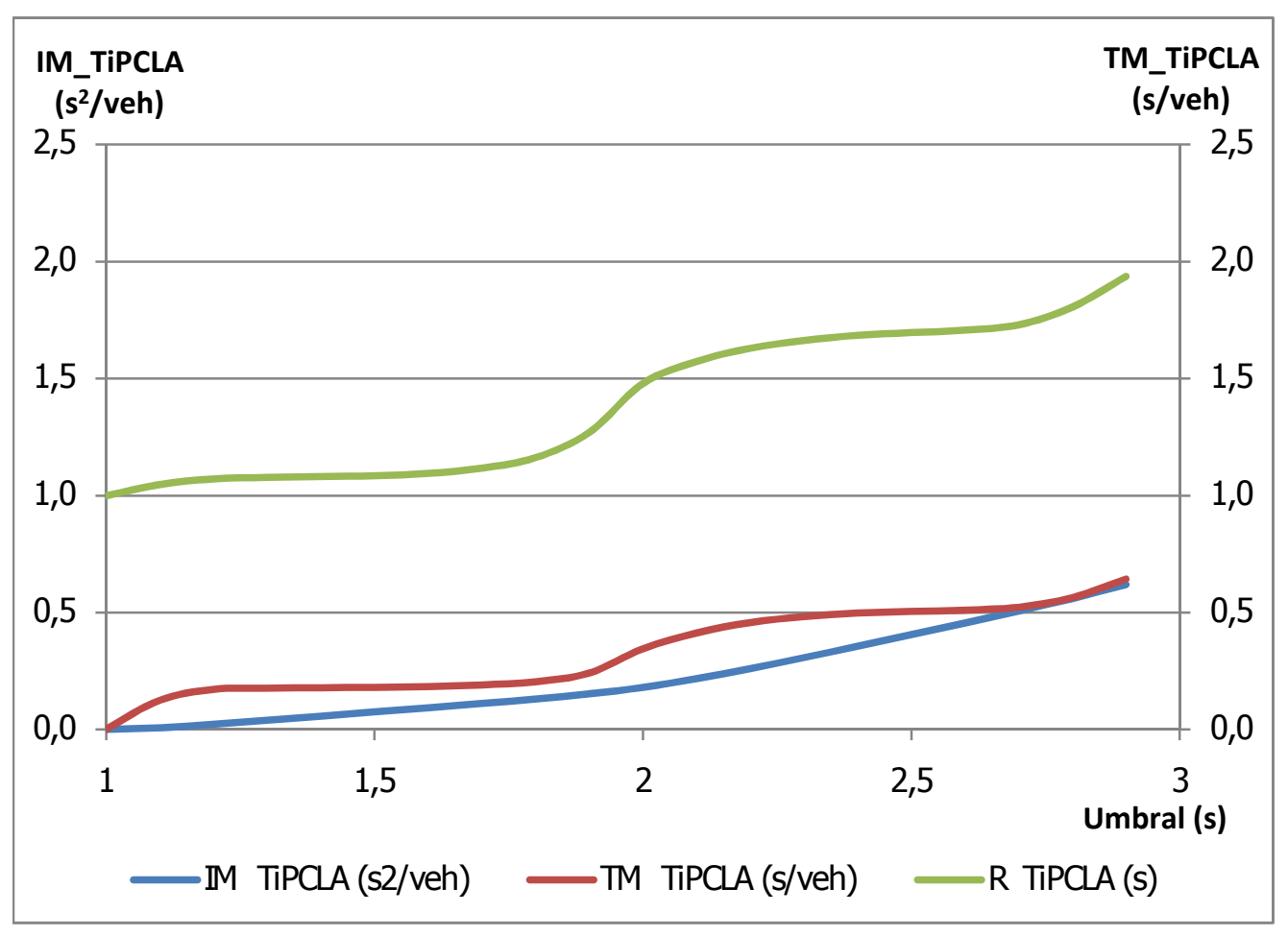




$\begin{array}{crrrrr}\text { Umbral } & \begin{array}{r}\boldsymbol{\Sigma} \text { I_TiPCLA } \\ \text { (s2) }\end{array} & \begin{array}{c}\boldsymbol{\Sigma} \text { T_TiPCLA } \\ \text { (s) }\end{array} & \begin{array}{c}\text { IM_TiPCLA } \\ \text { (s2/veh) }\end{array} & \begin{array}{c}\text { TM_TiPCLA } \\ \text { (s/veh) }\end{array} & \text { R_TiPCLA (s) } \\ 1 & 0,4089 & 6,2000 & 0,0044 & 0,0667 & 0,9341 \\ 1,1 & 1,2464 & 12,1663 & 0,0134 & 0,1308 & 0,9976 \\ 1,2 & 4,2328 & 15,8550 & 0,0455 & 0,1705 & 0,9330 \\ 1,3 & 7,2296 & 18,0116 & 0,0777 & 0,1937 & 0,8986 \\ 1,4 & 9,7943 & 19,1518 & 0,1053 & 0,2059 & 0,8886 \\ 1,5 & 12,3750 & 19,7610 & 0,1331 & 0,2125 & 0,8738 \\ 1,6 & 14,9896 & 20,7198 & 0,1612 & 0,2228 & 0,8766 \\ 1,7 & 15,7779 & 24,0142 & 0,1697 & 0,2582 & 1,0430 \\ 1,8 & 18,2756 & 29,6307 & 0,1965 & 0,3186 & 1,1832 \\ 1,9 & 20,4610 & 42,5785 & 0,2200 & 0,4578 & 1,4195 \\ 2 & 26,7017 & 83,7307 & 0,2871 & 0,9003 & 1,6811 \\ 2,1 & 34,0098 & 108,9985 & 0,3657 & 1,1720 & 1,7880 \\ 2,2 & 45,4621 & 120,8699 & 0,4888 & 1,2997 & 1,8239 \\ 2,3 & 57,6554 & 124,5568 & 0,6200 & 1,3393 & 1,8371 \\ 2,4 & 70,0687 & 126,2236 & 0,7534 & 1,3572 & 1,8449 \\ 2,5 & 82,6314 & 127,9466 & 0,8885 & 1,3758 & 1,8542 \\ 2,6 & 95,4037 & 131,3808 & 1,0258 & 1,4127 & 1,8738 \\ 2,7 & 108,6119 & 137,6360 & 1,1679 & 1,4800 & 1,9109 \\ 2,8 & 122,5346 & 145,6470 & 1,3176 & 1,5661 & 1,9587 \\ 2,9 & 137,4862 & 158,8629 & 1,4783 & 1,7082 & 2,0346\end{array}$

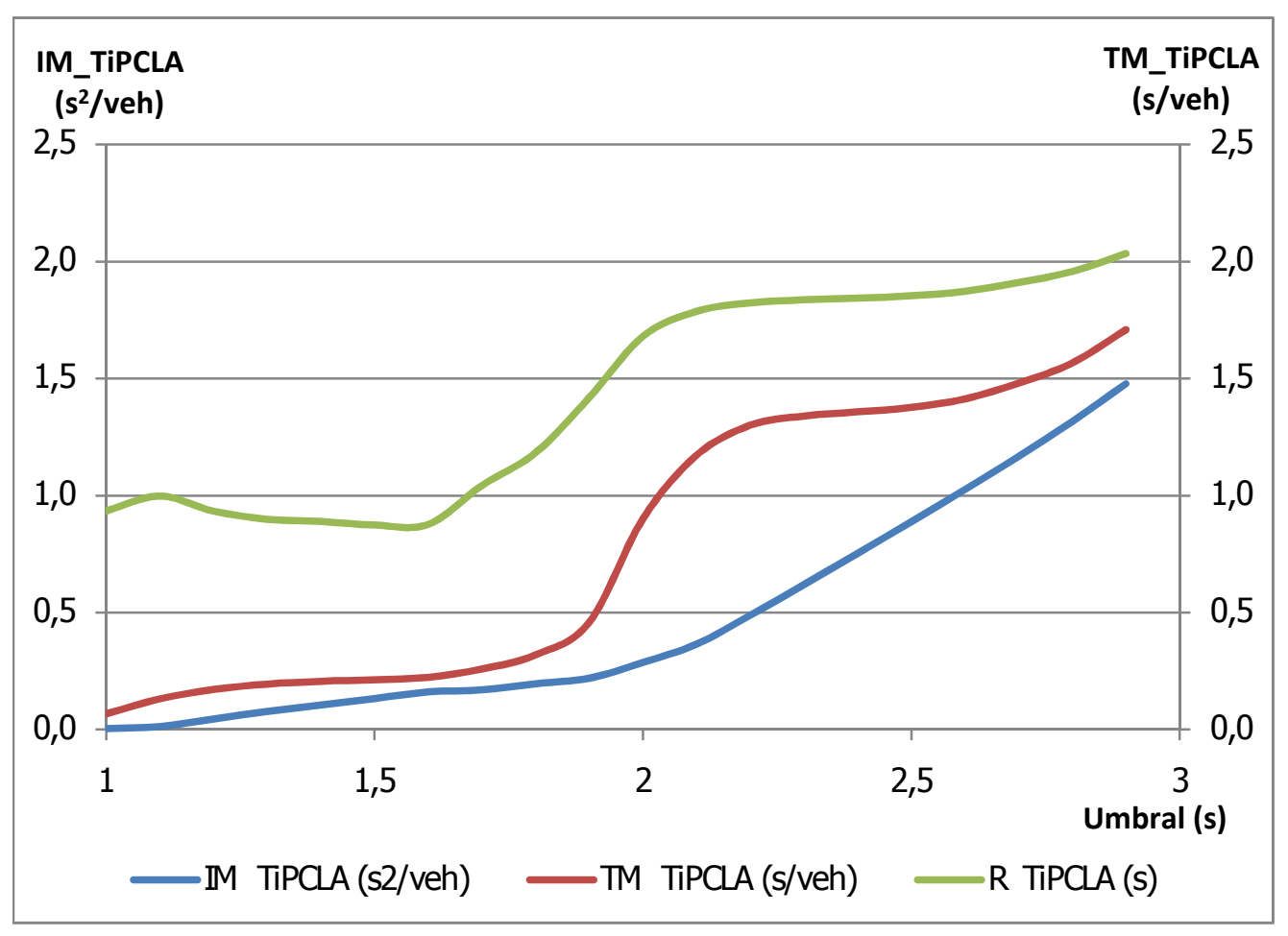


$\Sigma$ I_TiPCLA $\Sigma$ T_TiPCLA

$\begin{array}{crrrrr}\text { Umbral } & \text { (s2) } & \text { (s) } & \text { (s2/veh) } & \text { (s/veh) } & \text { R_TiPCLA (s) } \\ 1 & 1,6116 & 12,7911 & 0,0158 & 0,1254 & 0,8740 \\ 1,1 & 3,7285 & 26,8227 & 0,0366 & 0,2630 & 0,9610 \\ 1,2 & 6,6332 & 32,1678 & 0,0650 & 0,3154 & 0,9938 \\ 1,3 & 10,2378 & 34,9493 & 0,1004 & 0,3426 & 1,0071 \\ 1,4 & 13,1563 & 36,9324 & 0,1290 & 0,3621 & 1,0438 \\ 1,5 & 16,8286 & 37,7520 & 0,1650 & 0,3701 & 1,0542 \\ 1,6 & 20,9277 & 39,4984 & 0,2052 & 0,3872 & 1,0702 \\ 1,7 & 24,9462 & 43,0709 & 0,2446 & 0,4223 & 1,1208 \\ 1,8 & 29,5572 & 51,4809 & 0,2898 & 0,5047 & 1,2259 \\ 1,9 & 35,2874 & 65,9156 & 0,3460 & 0,6462 & 1,3647 \\ 2 & 42,9683 & 93,3117 & 0,4213 & 0,9148 & 1,5395 \\ 2,1 & 52,6369 & 100,4884 & 0,5160 & 0,9852 & 1,5762 \\ 2,2 & 62,7355 & 103,3759 & 0,6151 & 1,0135 & 1,5931 \\ 2,3 & 73,0554 & 104,9936 & 0,7162 & 1,0293 & 1,6042 \\ 2,4 & 83,4954 & 105,8809 & 0,8186 & 1,0380 & 1,6114 \\ 2,5 & 94,0125 & 106,5790 & 0,9217 & 1,0449 & 1,6179 \\ 2,6 & 104,5981 & 107,2783 & 1,0255 & 1,0517 & 1,6250 \\ 2,7 & 115,2661 & 108,2894 & 1,1301 & 1,0617 & 1,6356 \\ 2,8 & 126,0548 & 109,7057 & 1,2358 & 1,0755 & 1,6510 \\ 2,9 & 137,0102 & 111,6828 & 1,3432 & 1,0949 & 1,6732\end{array}$

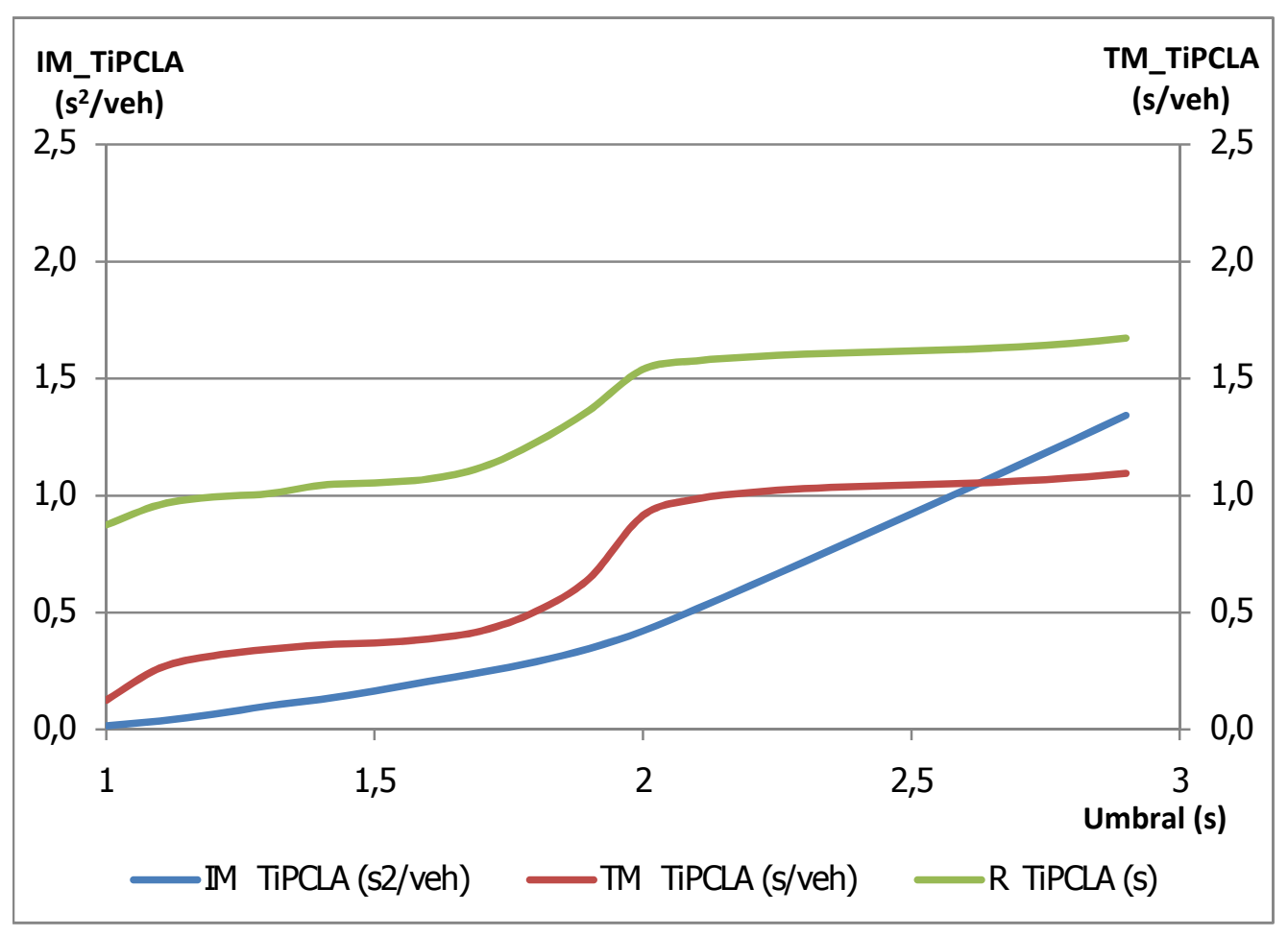


$\Sigma$ I_TiPCLA $\Sigma$ T_TiPCLA

$\begin{array}{crrrrr}\text { Umbral } & \text { (s2) } & \text { (s) } & \text { (s2/veh) } & \text { (s/veh) } & \text { R_TiPCLA (s) } \\ 1 & 0,2090 & 4,4000 & 0,0021 & 0,0444 & 0,9525 \\ 1,1 & 1,2359 & 14,9287 & 0,0125 & 0,1508 & 1,0172 \\ 1,2 & 2,9937 & 19,8726 & 0,0302 & 0,2007 & 1,0494 \\ 1,3 & 5,1579 & 22,1205 & 0,0521 & 0,2234 & 1,0668 \\ 1,4 & 8,0696 & 22,8371 & 0,0815 & 0,2307 & 1,0466 \\ 1,5 & 11,6309 & 24,7638 & 0,1175 & 0,2501 & 1,0303 \\ 1,6 & 14,1944 & 26,7383 & 0,1434 & 0,2701 & 1,0691 \\ 1,7 & 16,3708 & 28,9273 & 0,1654 & 0,2922 & 1,1341 \\ 1,8 & 19,0201 & 35,5801 & 0,1921 & 0,3594 & 1,2654 \\ 1,9 & 22,5973 & 47,9292 & 0,2283 & 0,4841 & 1,4285 \\ 2 & 28,0880 & 64,5304 & 0,2837 & 0,6518 & 1,5647 \\ 2,1 & 34,7160 & 69,2439 & 0,3507 & 0,6994 & 1,5986 \\ 2,2 & 41,7384 & 72,8569 & 0,4216 & 0,7359 & 1,6271 \\ 2,3 & 49,0919 & 75,4611 & 0,4959 & 0,7622 & 1,6494 \\ 2,4 & 56,6231 & 76,6128 & 0,5720 & 0,7739 & 1,6609 \\ 2,5 & 64,2274 & 77,1700 & 0,6488 & 0,7795 & 1,6677 \\ 2,6 & 71,9065 & 78,2370 & 0,7263 & 0,7903 & 1,6809 \\ 2,7 & 79,7731 & 80,8731 & 0,8058 & 0,8169 & 1,7136 \\ 2,8 & 87,8746 & 83,6726 & 0,8876 & 0,8452 & 1,7498 \\ 2,9 & 96,3237 & 87,6766 & 0,9730 & 0,8856 & 1,8014\end{array}$

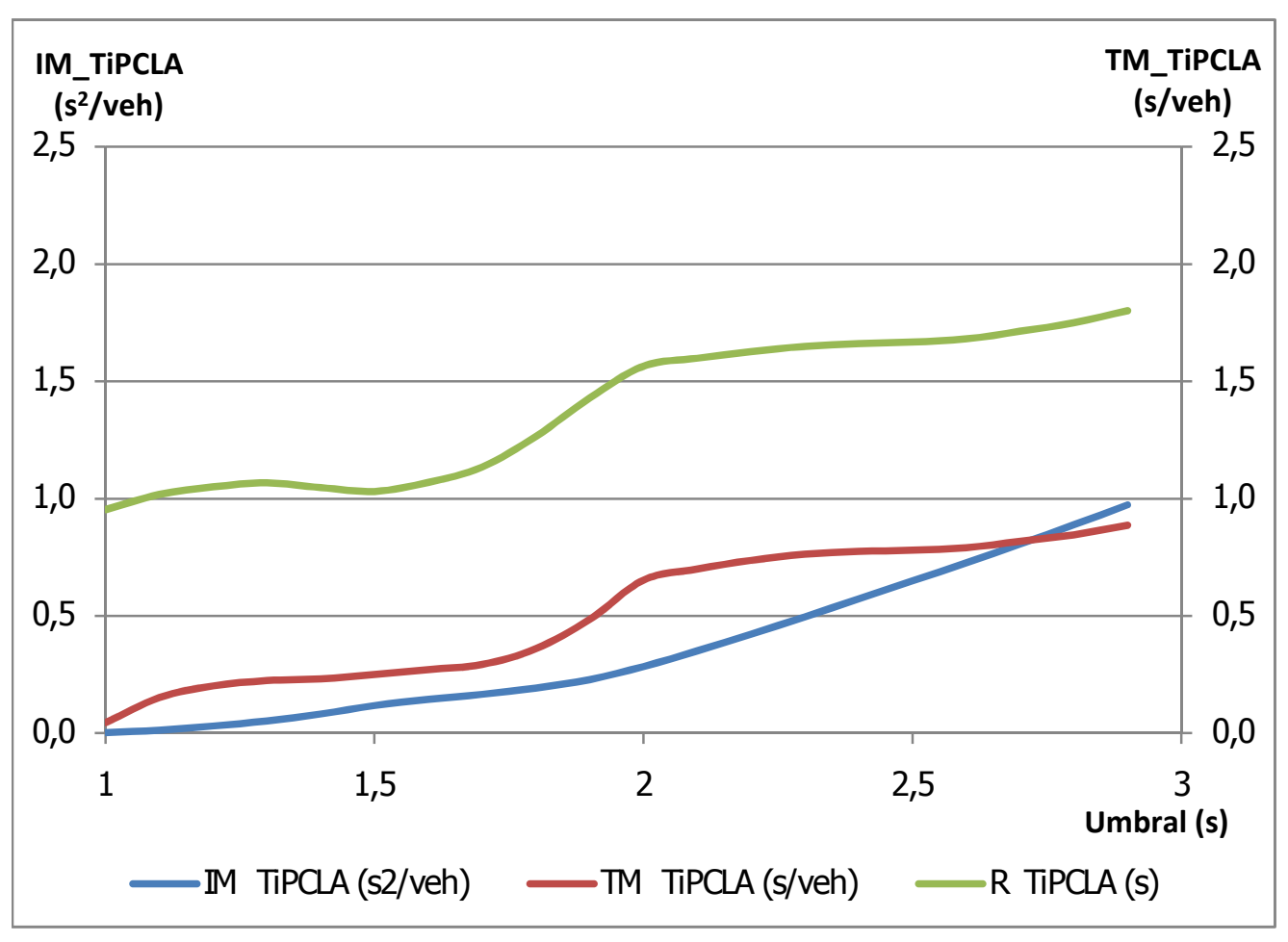




$\begin{array}{crrrrr}\text { Umbral } & \begin{array}{r}\boldsymbol{\Sigma} \text { I_TiPCLA } \\ \text { (s2) }\end{array} & \begin{array}{c}\boldsymbol{\Sigma} \text { T_TiPCLA } \\ \text { (s) }\end{array} & \begin{array}{r}\text { IM_TiPCLA } \\ \text { (s2/veh) }\end{array} & \begin{array}{r}\text { TM_TiPCLA } \\ \text { (s/veh) }\end{array} & \text { R_TiPCLA (s) } \\ 1 & 0,0038 & 2,6400 & 0,0000 & 0,0300 & 0,9986 \\ 1,1 & 0,6189 & 9,8167 & 0,0070 & 0,1116 & 1,0370 \\ 1,2 & 1,8612 & 15,2562 & 0,0212 & 0,1734 & 1,0780 \\ 1,3 & 3,2772 & 19,4677 & 0,0372 & 0,2212 & 1,1317 \\ 1,4 & 5,6851 & 22,1018 & 0,0646 & 0,2512 & 1,1428 \\ 1,5 & 8,0739 & 25,1034 & 0,0917 & 0,2853 & 1,1784 \\ 1,6 & 10,6607 & 27,0996 & 0,1211 & 0,3080 & 1,2066 \\ 1,7 & 13,4847 & 30,3019 & 0,1532 & 0,3443 & 1,2550 \\ 1,8 & 16,7135 & 35,6939 & 0,1899 & 0,4056 & 1,3318 \\ 1,9 & 20,7568 & 47,1953 & 0,2359 & 0,5363 & 1,4602 \\ 2 & 26,5086 & 79,2317 & 0,3012 & 0,9004 & 1,6654 \\ 2,1 & 36,5316 & 119,3378 & 0,4151 & 1,3561 & 1,7939 \\ 2,2 & 49,3869 & 139,7073 & 0,5612 & 1,5876 & 1,8465 \\ 2,3 & 63,8284 & 151,9441 & 0,7253 & 1,7266 & 1,8799 \\ 2,4 & 79,0827 & 156,5373 & 0,8987 & 1,7788 & 1,8948 \\ 2,5 & 94,6678 & 159,2825 & 1,0758 & 1,8100 & 1,9057 \\ 2,6 & 110,6032 & 164,7296 & 1,2569 & 1,8719 & 1,9286 \\ 2,7 & 127,3231 & 175,0030 & 1,4469 & 1,9887 & 1,9725 \\ 2,8 & 145,5017 & 194,4466 & 1,6534 & 2,2096 & 2,0517 \\ 2,9 & 166,0726 & 223,4632 & 1,8872 & 2,5394 & 2,1568\end{array}$

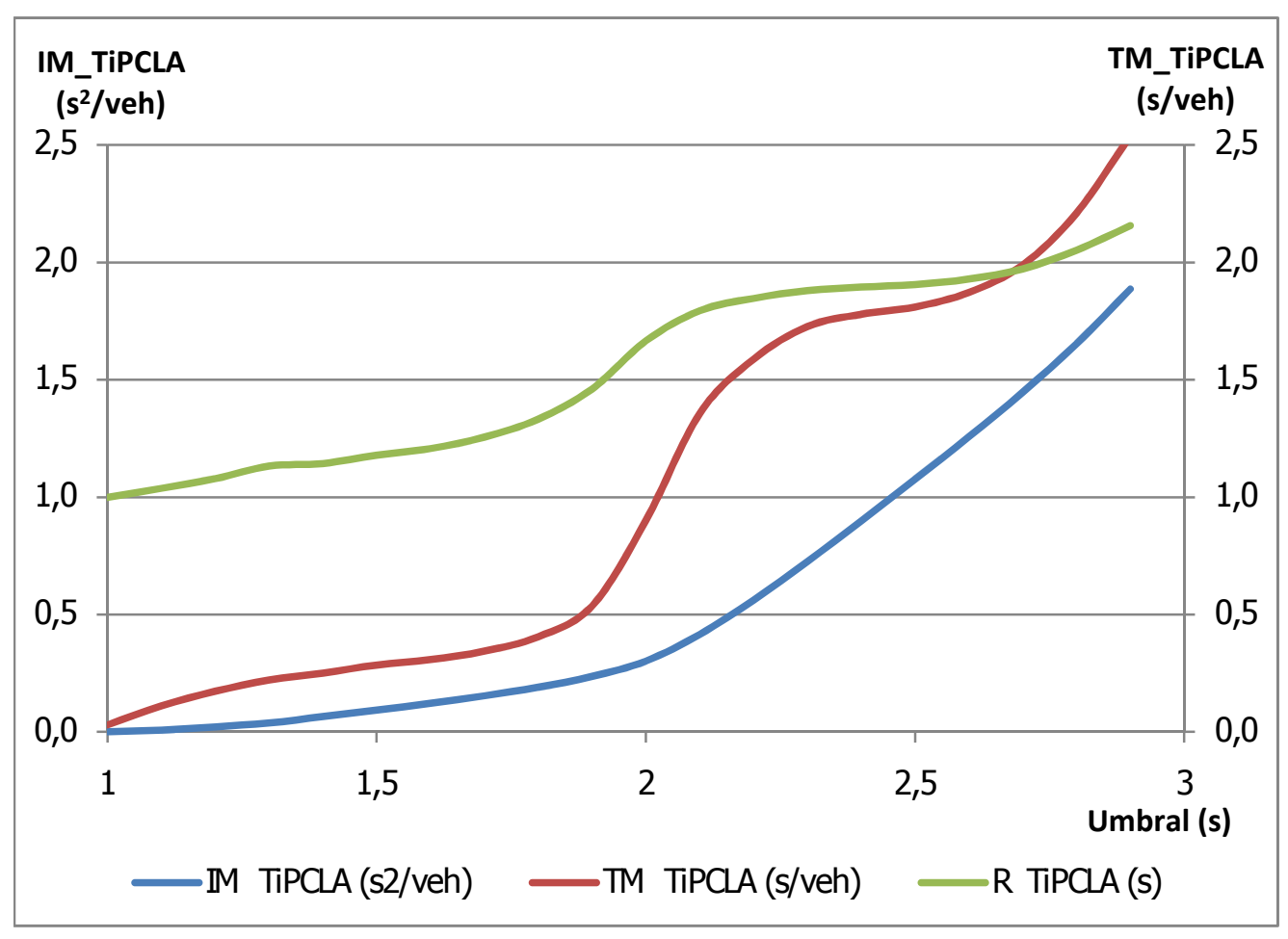


$\Sigma$ I_TiPCLA $\Sigma$ T_TiPCLA

\begin{tabular}{crrrrr} 
Umbral & \multicolumn{1}{c}{ (s2) } & \multicolumn{1}{c}{ (s) } & (s2/veh) & (s/veh) & R_TiPCLA (s) \\
1 & 0,8834 & 13,1052 & 0,0076 & 0,1120 & 0,9326 \\
1,1 & 2,5044 & 18,9043 & 0,0214 & 0,1616 & 0,9675 \\
1,2 & 4,9117 & 23,0736 & 0,0420 & 0,1972 & 0,9871 \\
1,3 & 6,4079 & 25,1468 & 0,0548 & 0,2149 & 1,0452 \\
1,4 & 9,6174 & 26,3022 & 0,0822 & 0,2248 & 1,0343 \\
1,5 & 12,2212 & 27,5506 & 0,1045 & 0,2355 & 1,0564 \\
1,6 & 15,3703 & 28,9990 & 0,1314 & 0,2479 & 1,0700 \\
1,7 & 18,6972 & 30,0620 & 0,1598 & 0,2569 & 1,0780 \\
1,8 & 20,5750 & 34,7355 & 0,1759 & 0,2969 & 1,2077 \\
1,9 & 24,7338 & 60,8423 & 0,2114 & 0,5200 & 1,4935 \\
2 & 31,4116 & 74,9362 & 0,2685 & 0,6405 & 1,5808 \\
2,1 & 39,2049 & 83,7117 & 0,3351 & 0,7155 & 1,6317 \\
2,2 & 47,7676 & 90,7575 & 0,4083 & 0,7757 & 1,6737 \\
2,3 & 56,9035 & 95,1590 & 0,4864 & 0,8133 & 1,7020 \\
2,4 & 66,4197 & 98,5608 & 0,5677 & 0,8424 & 1,7261 \\
2,5 & 76,2407 & 101,4881 & 0,6516 & 0,8674 & 1,7488 \\
2,6 & 86,4080 & 105,7271 & 0,7385 & 0,9037 & 1,7827 \\
2,7 & 97,1562 & 113,5181 & 0,8304 & 0,9702 & 1,8441 \\
2,8 & 109,0329 & 129,0177 & 0,9319 & 1,1027 & 1,9549
\end{tabular}

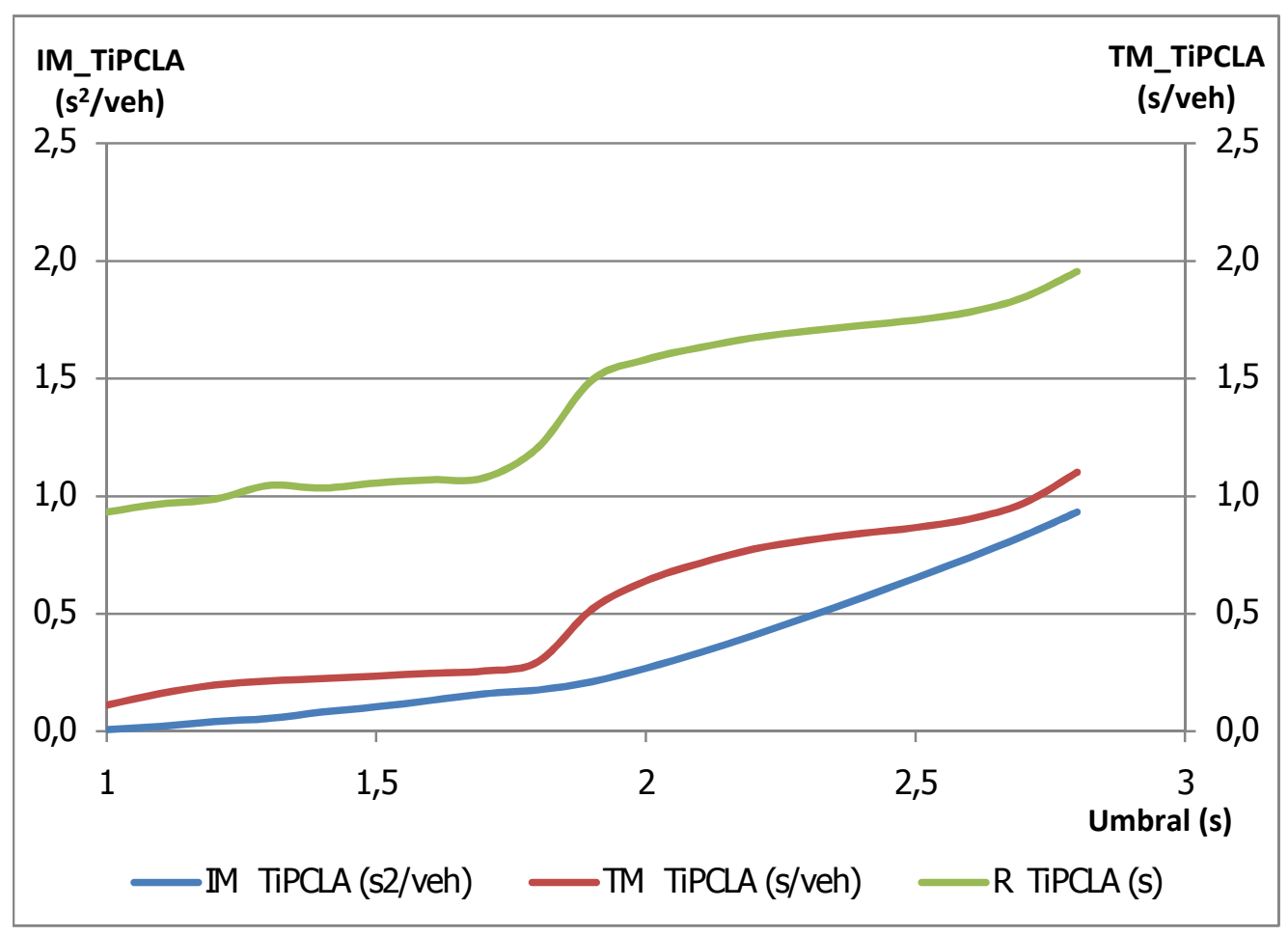


$\Sigma$ I_TiPCLA $\Sigma$ T_TiPCLA

\begin{tabular}{crrrrr} 
Umbral & \multicolumn{1}{c}{ (s2) } & \multicolumn{1}{c}{ (s) } & (s2/veh) & (s/veh) & R_TiPCLA (s) \\
1 & 1,2144 & 23,3538 & 0,0132 & 0,2538 & 0,9480 \\
1,1 & 4,8950 & 31,9770 & 0,0532 & 0,3476 & 0,9469 \\
1,2 & 8,9756 & 35,2959 & 0,0976 & 0,3837 & 0,9457 \\
1,3 & 14,2248 & 37,2032 & 0,1546 & 0,4044 & 0,9176 \\
1,4 & 19,3723 & 38,0405 & 0,2106 & 0,4135 & 0,8907 \\
1,5 & 24,3118 & 38,5020 & 0,2643 & 0,4185 & 0,8686 \\
1,6 & 29,4868 & 39,7038 & 0,3205 & 0,4316 & 0,8573 \\
1,7 & 34,8905 & 41,9470 & 0,3792 & 0,4559 & 0,8682 \\
1,8 & 40,7181 & 46,2362 & 0,4426 & 0,5026 & 0,9193 \\
1,9 & 47,3402 & 54,0262 & 0,5146 & 0,5872 & 1,0238 \\
2 & 55,3512 & 92,5894 & 0,6016 & 1,0064 & 1,4022 \\
2,1 & 65,2511 & 104,4961 & 0,7093 & 1,1358 & 1,4756 \\
2,2 & 75,9844 & 110,8061 & 0,8259 & 1,2044 & 1,5143 \\
2,3 & 87,2380 & 115,1030 & 0,9482 & 1,2511 & 1,5421 \\
2,4 & 98,8242 & 117,5301 & 1,0742 & 1,2775 & 1,5592 \\
2,5 & 110,5857 & 118,6948 & 1,2020 & 1,2902 & 1,5683 \\
2,6 & 122,4592 & 120,1547 & 1,3311 & 1,3060 & 1,5808 \\
2,7 & 134,5673 & 123,6477 & 1,4627 & 1,3440 & 1,6117 \\
2,8 & 147,1491 & 129,6995 & 1,5994 & 1,4098 & 1,6655
\end{tabular}

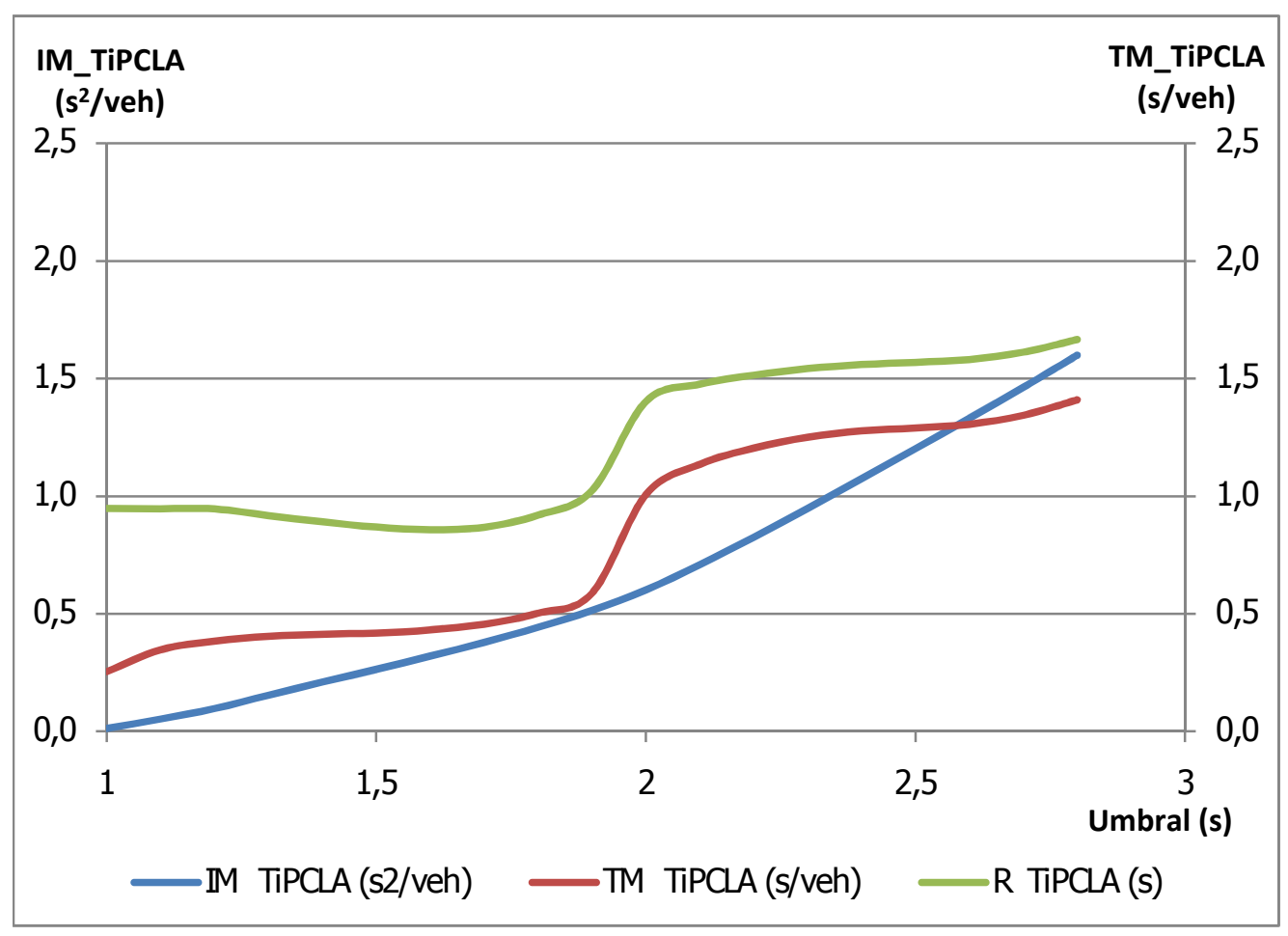


$\Sigma$ I_TiPCLA $\Sigma$ T_TiPCLA

\begin{tabular}{crrrrr} 
Umbral & \multicolumn{1}{c}{ (s2) } & \multicolumn{1}{c}{ (s) } & (s2/veh) & (s/veh) & R_TiPCLA (s) \\
1 & 5,8438 & 18,7500 & 0,0584 & 0,1875 & 0,6883 \\
1,1 & 6,3132 & 20,8063 & 0,0631 & 0,2081 & 0,7966 \\
1,2 & 6,8153 & 23,7075 & 0,0682 & 0,2371 & 0,9125 \\
1,3 & 8,0125 & 25,2144 & 0,0801 & 0,2521 & 0,9822 \\
1,4 & 8,5251 & 27,2186 & 0,0853 & 0,2722 & 1,0868 \\
1,5 & 14,0775 & 30,4481 & 0,1408 & 0,3045 & 1,0377 \\
1,6 & 14,7153 & 32,8725 & 0,1472 & 0,3287 & 1,1524 \\
1,7 & 15,6483 & 33,2430 & 0,1565 & 0,3324 & 1,2293 \\
1,8 & 16,8732 & 34,5386 & 0,1687 & 0,3454 & 1,3115 \\
1,9 & 18,6402 & 36,9891 & 0,1864 & 0,3699 & 1,3961 \\
2 & 23,2536 & 69,0060 & 0,2325 & 0,6901 & 1,6630 \\
2,1 & 25,8876 & 115,4781 & 0,2589 & 1,1548 & 1,8758 \\
2,2 & 31,3681 & 138,1756 & 0,3137 & 1,3818 & 1,9730 \\
2,3 & 45,4556 & 151,8781 & 0,4546 & 1,5188 & 2,0007 \\
2,4 & 60,7525 & 161,6731 & 0,6075 & 1,6167 & 2,0242 \\
2,5 & 76,7631 & 166,6169 & 0,7676 & 1,6662 & 2,0393 \\
2,6 & 93,2000 & 171,7531 & 0,9320 & 1,7175 & 2,0574 \\
2,7 & 110,3644 & 182,8613 & 1,1036 & 1,8286 & 2,0965 \\
2,8 & 128,9350 & 199,0238 & 1,2894 & 1,9902 & 2,1522
\end{tabular}

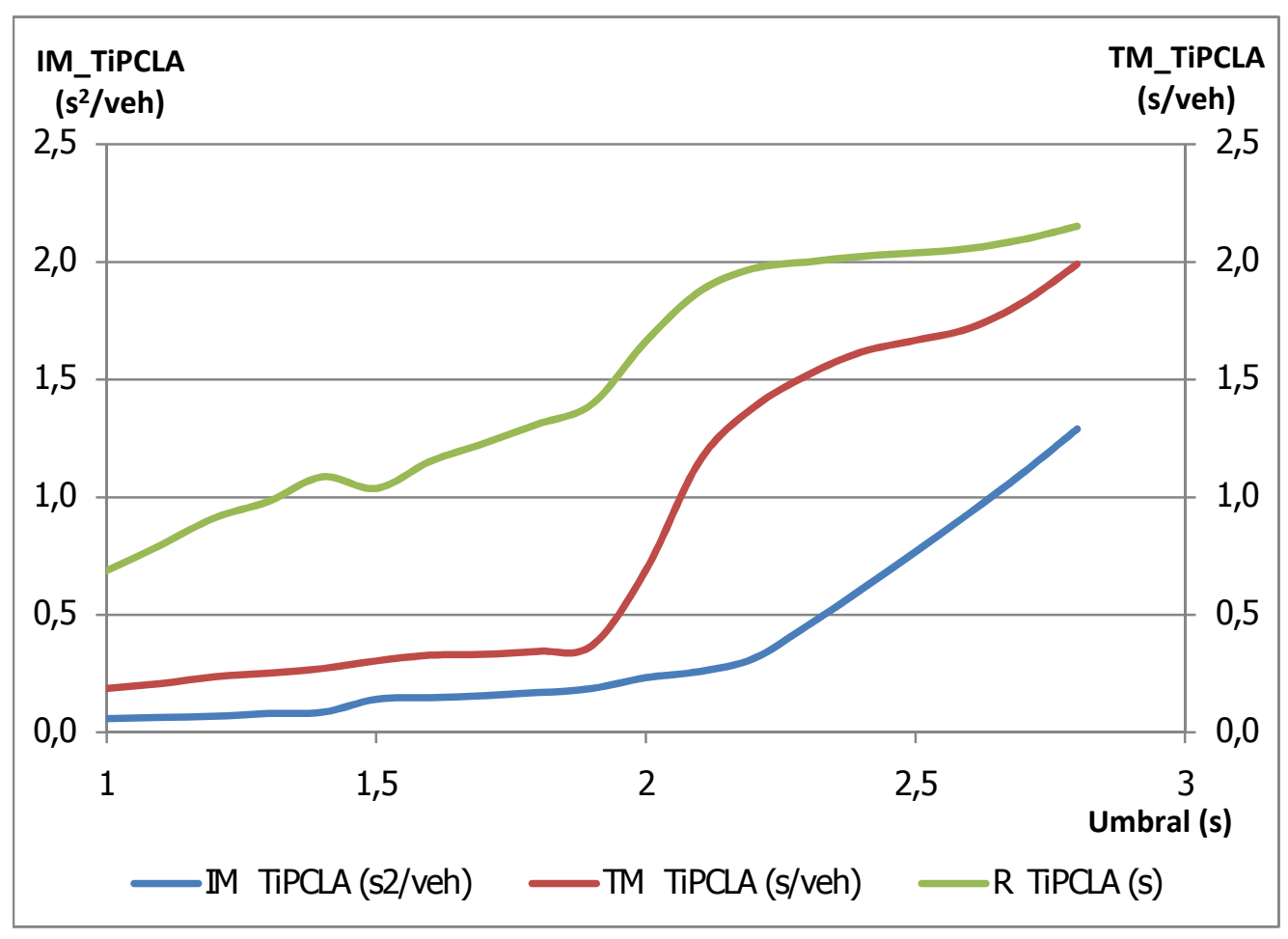


$\Sigma$ I_TiPCLA $\Sigma$ T_TiPCLA

\begin{tabular}{crrrrr} 
Umbral & \multicolumn{1}{c}{ (s2) } & \multicolumn{1}{c}{ (s) } & (s2/veh) & (s/veh) & R_TiPCLA (s) \\
1 & 1,1610 & 1,8743 & 0,0108 & 0,0174 & 0,3806 \\
1,1 & 5,1856 & 25,4494 & 0,0480 & 0,2356 & 0,8962 \\
1,2 & 6,9742 & 33,9358 & 0,0646 & 0,3142 & 0,9945 \\
1,3 & 7,2137 & 39,2541 & 0,0668 & 0,3635 & 1,1162 \\
1,4 & 12,0633 & 45,2498 & 0,1117 & 0,4190 & 1,1334 \\
1,5 & 13,8136 & 46,5113 & 0,1279 & 0,4307 & 1,2030 \\
1,6 & 17,3093 & 49,4629 & 0,1603 & 0,4580 & 1,2501 \\
1,7 & 18,4091 & 51,3014 & 0,1705 & 0,4750 & 1,3412 \\
1,8 & 20,7935 & 56,4181 & 0,1925 & 0,5224 & 1,4314 \\
1,9 & 25,8306 & 72,6497 & 0,2392 & 0,6727 & 1,5445 \\
2 & 35,2993 & 112,5338 & 0,3268 & 1,0420 & 1,6863 \\
2,1 & 42,9468 & 162,2503 & 0,3977 & 1,5023 & 1,8353 \\
2,2 & 49,4839 & 183,3030 & 0,4582 & 1,6973 & 1,9300 \\
2,3 & 55,3115 & 195,7640 & 0,5121 & 1,8126 & 2,0175 \\
2,4 & 64,7379 & 202,1485 & 0,5994 & 1,8717 & 2,0798 \\
2,5 & 76,6352 & 205,8299 & 0,7096 & 1,9058 & 2,1277 \\
2,6 & 88,2715 & 210,7409 & 0,8173 & 1,9513 & 2,1811 \\
2,7 & 100,3338 & 219,0839 & 0,9290 & 2,0286 & 2,2420 \\
2,8 & 115,2206 & 230,1980 & 1,0669 & 2,1315 & 2,2995
\end{tabular}

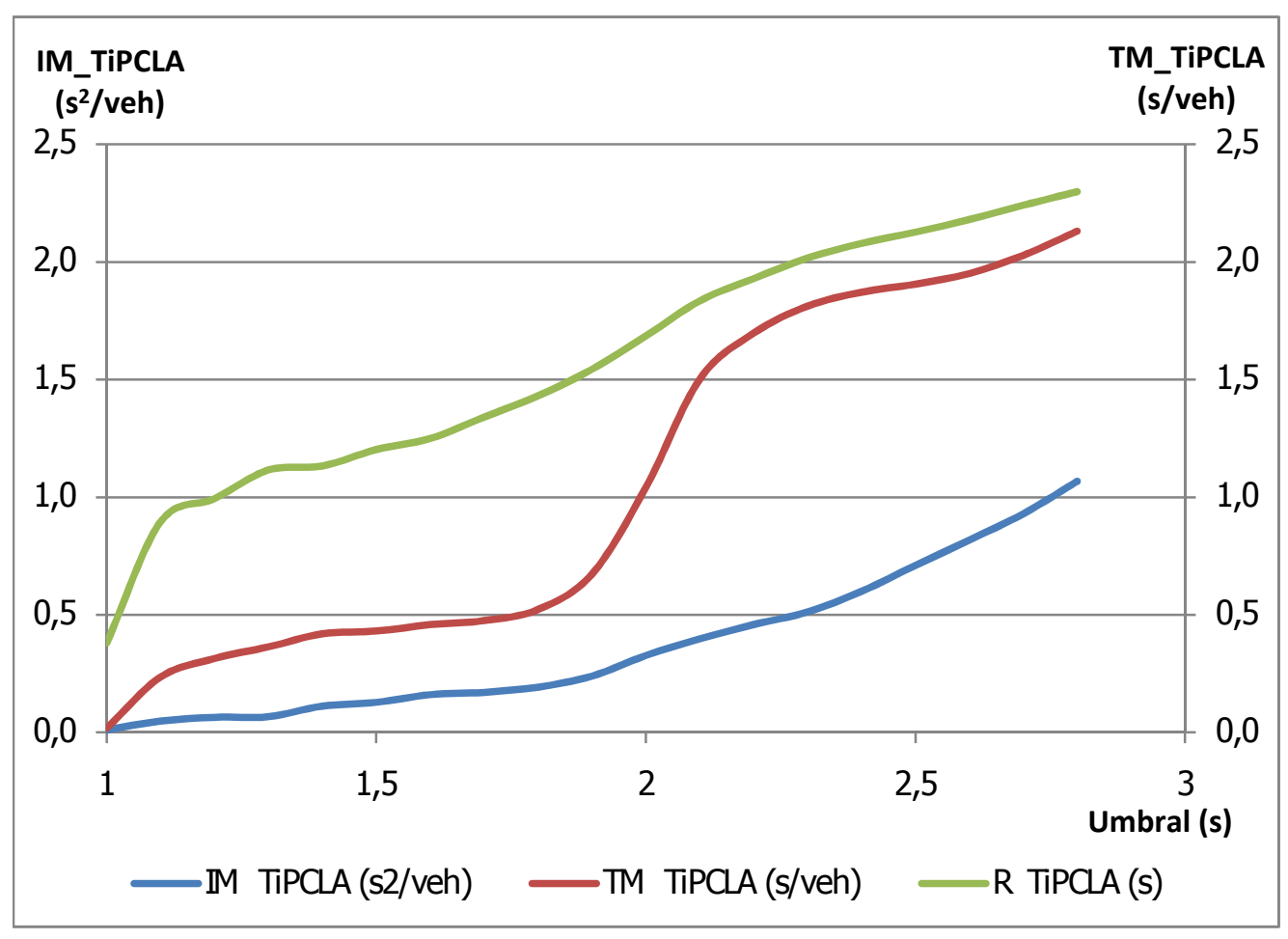



ANEXO No. 6. PUBLICACIONES PROPIAS Y SUS REFERENCIAS 
A continuación se relacionan las publicaciones propias relacionadas con los diferentes aspectos de la investigación desarrollada y las publicaciones que las referencian.

\section{PUBLICACIONES PROPIAS}

[1]. ROMERO, M. y GARCÍA, A. (2004): "Seguimiento Experimental de la Evolución de los Vehículos en un Carril de Deceleración de Longitud Variable". VI CONGRESO DE INGENIERÍA DEL TRANSPORTE. Zaragoza Junio 2004.

[2]. GARCÍA, A. y ROMERO, M. (2004): "Influencia de la Longitud del Carril de Deceleración en la Evolución de los Vehículos". I CONGRESO NACIONAL DE SEGURIDAD VIAL. Logroño Noviembre de 2004.

[3]. GARCÍA, A., BELLA, F., CAVALIERE, A. y ROMERO, M. (2005): "L'Influenza della Linghezza della Corsia di Decelerazione sul Comportamento dell'utente: gli Esiti di una Indagine Sperimentale". STRADE \& AUTOSTRADE. Mayo - junio 2005. pp. 181188.

[4]. GARCIA, A. y ROMERO, M: (2005): "Tracking Vehicle Behavior in a Deceleration Lane with Different Lengths". 3rd INTERNATIONAL SYMPOSIUM ON HIGHWAY GEOMETRIC DESIGN. Chicago, Junio 2005.

[5]. GARCIA, A. y ROMERO, M: (2005): "Operational and Safety Effects of the Deceleration Lane Length". $3^{\text {rd }}$ INTERNATIONAL SIIV CONGRESS. Bari, Italia. Septiembre 2005

[6]. GARCIA, A. y ROMERO, M: (2006): "Influencia de la longitud del carril de deceleración en la funcionalidad y seguridad". CARRETERAS. REVISTA TÉCNICA DE LA ASOCIACIÓN ESPAÑOLA DE LA CARRETERA Número 145, pp. 6-16. Marzo - abril 2006.

[7]. GARCIA, A. y ROMERO, M: (2006): "Experimental Observation of Vehicle Evolution on a Deceleration Lane With Different Lengths". TRANSPORTATION RESEARCH BOARD. 85 ${ }^{\text {th }}$ Annual Meeting. Washington, enero 2006.

[8]. ROMERO, M. y GARCÍA, A. (2006): "Estudio de la Conflictividad en Maniobras de Salida a través de Carriles de Deceleración", VII CONGRESO DE INGENIERÍA DEL TRANSPORTE. Ciudad Real, Junio 2006.

[9]. BELLA, F., GARCÍA, A., SOLVES, F y ROMERO, M. (2007): "Driving Simulator Validation for Deceleration Lane Design". TRANSPORTATION RESEARCH BOARD. $86^{\text {th }}$ Annual Meeting. Washington, enero 2007.

[10]. BELLA, F., GARCÍA, A., SOLVES, F y ROMERO, M. (2007): "Validación de un simulador de conducción para el diseño de carriles de deceleración". RUTAS TÉCNICA. Septiembre - octubre 2007.

[11]. GARCIA, A. y ROMERO, M: (2007): Discussion of "3D Calculation of Stopping-Sight Distance from GPS Data" by Girish Nehate y Malgorzata Rys. JOURNAL OF TRANSPORTATION ENGINEERING. Vol. 133, No. 11, Noviembre 2007, pp. 645-646,

[12]. ROMERO, M y GARCIA, A: (2007): "Aplicación de técnicas de conflictos de tráfico mediante el seguimiento de vehículos por visión artificial". VII CONGRESO ESPAÑOL SOBRE SISTEMAS INTELIGENTES DE TRANSPORTE. Valencia. Septiembre 2007.

[13]. ROMERO, M, GARCIA, A, PEREZ, A, y CAMACHO, F. (2008): "TiPCLA, un nuevo indicador de conflictividad aplicable en tramos de trenzado", VIII CONGRESO DE INGENIERÍA DEL TRANSPORTE. La Coruña, Julio 2008. 
[14]. GARCIA, A. y ROMERO, M. (2009): Discussion of "Video-Capture-Based Approach to Extract Multiple Vehicular Trajectory Data for Traffic Modeling" by Heng Wei, P.E. Chuen Feng, Eric Meyer, P.E. and Joe Lee. JOURNAL OF TRANSPORTATION ENGINEERING. Volume 135, Issue 3, marzo 2009, pp. 149-150.

[15]. ROMERO, M. y GARCIA, A. (2010): "Deceleration lane length evaluation based on a new conflict indicator", $4^{\text {th }}$ International Symposium on Highway Geometric Design, Valencia, junio 2010. (aceptado y pendiente de presenter).

\section{REFERENCIAS A LAS PUBLICACIONES}

- BELLA, F (2008). "Driving simulator for speed research on two-lane rural roads", Accident Analysis \& Prevention. Volume 40, Issue 3, Mayo 2008, Pages 1078-1087. [9]

- BELLA, F (2009). "Can Driving Simulators Contribute to Solving Critical Issues in Geometric Design?", Transportation Research Record Número 2138. Washignton. pp 120-126 [9]

- CHEN, H., PAN, L., BEHZADI, B y LU, J.(2008)" Impacts of exit Ramp Tipe on the Safety Performance of Freeway Diverge Areas". Actas del Transportation Research Board 2010 Annual Meeting. Washington, enero 2008.

- CHEN, H. (2008) "Safety Evaluation of Freeway Exit Ramps", Tesina de Máster en Ingeniería Civil. University of South Florida, marzo 2008. [7]

- CHEN, H, LIUN,P, LC, J Y BEHZADID, B. (2009) "Evaluating the safety impacts of the number and arrangement of lanes on freeway exit ramps" Accident Analysis \& Prevention Volume 41, Issue 3, mayo 2009, pp 543-551. [7]

- EL-BASHA, R.H.S. HASSAN, Y. y SAYED, T.A (2007) "Modeling Freeway Diverging Behavior on Deceleration Lanes" Transportation Research Record. Número 2012, pp 30-37. [4]

- FITZPATRICK, K, ZIMMERMAN, K, BLIGH, R, CHRYSLER, S y BLASCHKE, B (2007) "Criteria for High Design Speed Facilities". FHWA, Report 0-5544-1. [7]

- $\quad$ FITZPATRICK, K., CHRYSLER, S. y BREWER, M. (2010)."Deceleration Lengths for Exit terminals". Actas del Transportation Research Board 2010 Annual Meeting. Washington, enero 2010. [7]

- HAMDAR, S y MAHMASSANI, H. (2009) "Duration-Based Investigation of Driver Behavior Differences Across Freeway Lanes". Journal Transportation Research Record: Journal of the Transportation Research Board. Issue Volume 2124 / 2009. pp 89-102. [4]

- WANG, Z, CHEN, H y LIUN, J (2009). "Exploring Impacts of Factors Contributing to Injury Severity at Freeway Diverge Areas". Transportation Research Record: Journal of the Transportation Research Board. Volume 2102 / 2009. pp 43-52. [7]

- ZHOU, H.,CHEN, H., ZHAO, J. y HSU, P.(2010)" Operational and Safety Performance of Left-Side Off-Ramps at Freeway Diverge Areas". Actas del Transportation Research Board 2010 Annual Meeting. Washington, enero 2010. [7] 